PREMIO TESI DI DOTTORATO

$-72-$ 


\section{PREMIO TESI DI DOTTORATO}

Commissione giudicatrice, anno 2017

Vincenzo Varano, Presidente della Commissione

Tito Arecchi, Area Scientifica

Aldo Bompani, Area delle Scienze Sociali

Mario Caciagli, Area delle Scienze Sociali

Franco Cambi, Area Umanistica

Paolo Felli Area Tecnologica

Siro Ferrone, Area Umanistica

Roberto Genesio, Area Tecnologica

Flavio Moroni, Area Biomedica

Adolfo Pazzagli, Area Biomedica

Giuliano Pinto, Area Umanistica

Vincenzo Schettino, Area Scientifica

Luca Uzielli, Area Tecnologica

Graziella Vescovini, Area Umanistica 
María Teresa Egea Molines

\title{
Etnobotánica en el Alto Valle del Reno (Toscana y Emilia-Romaña, Italia)
}

\author{
Etnobotanica nell'Alta Valle del Reno \\ (Toscana ed Emilia-Romagna, Italia)
}


Etnobotánica en el Alto Valle del Reno (Toscana y

Emilia-Romaña, Italia) $=$ etnobotanica nell'Alta Valle

del Reno (Toscana ed Emilia-Romagna, Italia) / María

Teresa Egea Molines. - Firenze : Firenze University

Press, 2018.

(Premio Tesi di Dottorato ; 72)

http://digital.casalini.it/9788864537870

ISBN 978-88-6453-786-3 (print)

ISBN 978-88-6453-787-0 (online)

Progetto grafico di Alberto Pizarro Fernández, Pagina Maestra snc

Certificazione scientifica delle Opere

Tutti i volumi pubblicati sono soggetti ad un processo di referaggio esterno di cui sono responsabili il Consiglio editoriale della FUP e i Consigli scientifici delle singole collane. Le opere pubblicate nel catalogo della FUP sono valutate e approvate dal Consiglio editoriale della casa editrice. Per una descrizione più analitica del processo di referaggio si rimanda ai documenti ufficiali pubblicati sul catalogo on-line della casa editrice (www.fupress.com).

Consiglio editoriale Firenze University Press

A. Dolfi (Presidente), M. Boddi, A. Bucelli, R. Casalbuoni, M. Garzaniti, M.C. Grisolia, P. Guarnieri, R. Lanfredini, A. Lenzi, P. Lo Nostro, G. Mari, A. Mariani, P.M. Mariano, S. Marinai, R. Minuti, P. Nanni, G. Nigro, A. Perulli, M.C. Torricelli.

La presente opera è rilasciata nei termini della licenza Creative Commons Attribution 4.0 International (CC BY 4.0: http://creativecommons.org/licenses/by/4.0/)

This book is printed on acid-free paper

CC 2018 Firenze University Press

Università degli Studi di Firenze

Firenze University Press

via Cittadella, 7, 50144 Firenze, Italy

www.fupress.com

Printed in Italy 
A Alma y a Romeo 

Contenido - Índice

Sommario $\quad 13$

$\begin{array}{ll}\text { Lista de Tablas } & 15\end{array}$

$\begin{array}{ll}\text { Lista de Figuras } & 17\end{array}$

$\begin{array}{lr}\text { Lista de abreviaturas } & 19\end{array}$

PARTE 1 InTRODUCCIÓN

\section{Capítulo 1}

Presentación $\quad 23$

1. Justificación 23

2. Breve historia y evolución de la Etnobotánica 24

3. Marco legislativo 26

4. Marco teórico 27

\section{Capítulo 2}

Antecedentes $\quad 31$

\section{Capítulo 3}

El Medio Físico $\quad 35$

1. Localización y caracterización del territorio estudiado 35

2. Sistema fluvial 39

3. Geología 41

4. Climatología 42

5. Flora y vegetación $\quad 45$

5.1. Los bosques $\quad 45$

5.2. Vegetación y flora arbustiva 46

5.3. Vegetación y flora herbácea $\quad 47$

6. Áreas protegidas $\quad 48$ 
Etnobotánica en el Alto Valle del Reno (Toscana y Emilia-Romaña, Italia)

\section{Capítulo 4}

El Medio Humano

1. Historia $\quad 59$

2. Lengua 60

3. Distribución y evolución de la población 61

$\begin{array}{ll}\text { 3.1. Evolución demográfica } & 61 \\ 3.2 . \text { Tigración }\end{array}$

$\begin{array}{ll}\text { 3.2. Migración } & 62\end{array}$

4. La economía tradicional y su evolución 63

$\begin{array}{ll}\text { 4.1. El bosque y sus productos } & 63\end{array}$

4.2. El castañar $\quad 65$

4.3. Agricultura: cultivos arbóreos, viticultura, fruticultura, cultivos de
herbáceos, forrajeras

4.4. Evolución del uso del suelo y del paisaje $\quad 67$

$\begin{array}{ll}\text { 4.5. Artesanía } & 68\end{array}$

4.6. Economía actual $\quad 69$

Parte 2. Objetivos

Parte 3. Metodología

\section{Capítulo 1}

$\begin{array}{ll}\text { Fase de exploración } & 79\end{array}$

1. Delimitación del área de estudio e investigación bibliográfica 79

2. Estrategias metodológicas adaptadas $\quad 80$

\section{Capítulo 2}

El trabajo de campo $\quad 83$

1. Recolección de datos etnobotánicos $\quad 83$

2. Selección de los informantes $\quad 85$

3. Las entrevistas 86

4. Observación participante 89

5. Testimonios 91

6. Los nombres vernaculares 92

7. Identificación botánica 93

\section{Capítulo 3}

Investigación bibliográfica $\quad 97$

1. Selección de los datos bibliográficos 97

\section{Capítulo 4}

Clasificación y procesado de la información 103

1. Gestión de datos con la hoja de cálculo 103

2. Categorización y clasificación de la información 104

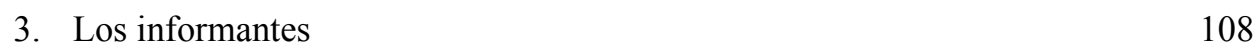


4. Trascripción de los datos bibliográficos 114

5. Catálogo etnobotánico 116

6. Análisis de los datos etnobotánicos 116

Parte 4 Resultados

\section{Capítulo 1}

Catálogo etnobotánico

1. ADOXACEAE (incluye CAPRIFOLIACAE p.p.) 125

2. AMARANTHACEAE (incluye CHENOPODIACEAE) 133

3. AMARYLLIDACEAE (incluye LILIACEAE p.p.) 136

4. APIACEAE (= UMBELLIFERAE) 144

5. AQUIFOLIACEAE 153

6. ARACEAE 155

7. ARALIACEAE 156

8. ASPARAGACEAE (incluye LILIACEAE p.p.) 157

9. ASPLENIACEAE 160

10. BALSAMINACEAE 161

11. BETULACEAE (incluye CORYLACEAE) 162

12. BORAGINACEAE 168

13. BRASSICACEAE (= CRUCIFERAE) 171

14. BUXACEAE 176

15. CAMPANULACEAE 181

16. CANNABACEAE 182

17. CAPRIFOLIACEAE (incluye DIPSACACEAE, VALERIANACEAE) 185

18. CARYOPHYLLACEAE 189

19. CELASTRACEAE 195

20. COMPOSITAE (=ASTERACEAE) 196

21. CORNACEAE 237

22. CRASSULACEAE 240

23. CUCURBITACEAE 245

24. CUPRESSACEAE 248

25. CYPERACEAE 252

26. DENNSTAEDTIACEAE (incluye HYPOLEPIDACEAE) 253

27. DRYOPTERIDACEAE (incluye ASPIDIACEAE) 255

28. ELAEAGNACEAE 256

29. EQUISETACEAE 257

30. ERICACEAE 259

31. EUPHORBIACEAE 267

32. FAGACEAE 269 
Etnobotánica en el Alto Valle del Reno (Toscana y Emilia-Romaña, Italia)

33. GENTIANACEAE

34. GERANIACEAE

35. GROSSULARIACEAE (incluye SAXIFRAGACEAE p.p.) 303

36. HYPERICACEAE (incluye GUTTIFERAE) 305

37. IRIDACEAE

38. JUGLANDACEAE 308

39. JUNCACEAE 314

40. LAMIACEAE (= LABIATAE) 315

41. LAURACEAE 333

42. LEGUMINOSAE 337

43. LILIACEAE 358

44. LINACEAE $\quad 359$

45. LORANTHACEAE 361

46. LYTHRACEAE (incluye PUNICACEAE) 362

47. MALVACEAE (incluye TILIACEAE p.p.) 363

48. MORACEAE 370

49. MYRTACEAE 372

50. OLEACEAE $\quad 374$

51. ORCHIDACEAE 384

52. PAPAVERACEAE 385

53. PHYTOLACCACEAE 388

54. PINACEAE 388

55. PIPERACEAE 392

56. PLANTAGINACEAE (incluye SCROPHULARIACEAE p.p.) 393

57. POACEAE (= GRAMINACEAE) 399

58. POLYGONACEAE 419

59. POLYPODIACEAE 424

60. PORTULACACEAE 425

61. PRIMULACEAE 426

62. RANUNCULACEAE 428

63. RHAMNACEAE 438

64. ROSACEAE 438

65. RUBIACEAE 498

66. RUTACEAE 498

67. SALICACEAE 502

68. SANTALACEAE (incluye LORANTHACEAE p.p.) 515

69. SAPINDACEAE (incluye ACERACEAE, HIPPOCASTANACEAE) 516

70. SCROPHULARIACEAE 519

71. SOLANACEAE 521 
72. THEACEAE 528

73. THYMELAEACEAE

74. ULMACEAE 529

75. URTICACEAE 531

76. VERBENACEAE 542

77. VIOLACEAE

78. VITACEAE 546

79. XANTHORRHOEACEAE 553

PARTe 5 Discusión

\section{Capítulo 1}

Informantes $\quad 557$

1. Características de los informantes 557

2. Distribución del conocimiento entre los informantes 558

\section{Capítulo 2}

Etnoflora

1. Familias 563

2. Especies botánicas 566

3. Sectores y Categorías de uso $\quad 569$

4. Nombres vernaculares $\quad 573$

5. Análisis ecológico 595

5.1. Biotipos $\quad 595$

5.2. Corología 596

5.3. Ambientes y hábitat $\quad 596$

5.4. Abundancia y estado de conservación 597

\section{Capítulo 3}

$\begin{array}{ll}\text { Usos tradicionales por sectores } & 617\end{array}$

1. Alimentarios 617

1.1. Sistema alimentario tradicional 617

$\begin{array}{ll}\text { 1.2. Partes usadas } & 620\end{array}$

1.3. Familias botánicas con usos alimentarios $\quad 620$

1.4. Especies alimentarias más citadas, más populares, más versátiles $\quad 624$

1.5. Categorías alimentarias más importantes $\quad 627$

1.6. Mezcla de plantas alimentarias 631

1.7. Alimentos funcionales o especies nutracéuticas 633

1.8. Contraste regional en las categorías alimentarias $\quad 639$

1.9. Usos novedosos alimentarios respecto a la bibliografía local 640

2. Medicinales 641

2.1. Sistema de salud tradicional 641

2.2. Familias botánicas con usos medicinales 643

2.3. Especies medicinales más citadas, más populares, más versatiles $\quad 645$ 
2.4. Categorías medicinales más importantes

647

2.5. Nosología popular (de campo y bibliográfica) clasificada por categorías 652

2.6. Mezcla de plantas

2.7. Partes usadas, formas de preparación y de administración

662

2.8. Contraste e influencia regional en el conocimiento etnofarmacobotánico 663

2.9. Usos novedosos medicinales respecto a la bibliografía local 664

3. Mágico-Medicinales 665

4. Veterinarios 666

5. Domésticos 668

$\begin{array}{ll}\text { 6. Agropastoral } & 670\end{array}$

$\begin{array}{ll}\text { 7. Artesanal } & 672\end{array}$

8. Mágico-ritual-supersticioso 673

9. Lúdico-voluptuoso $\quad 674$

$\begin{array}{ll}\text { 10. Religioso } & 676\end{array}$

11. Caza y pesca 676

12. Efecto nocivo $\quad 677$

Capítulo 4

Vigencia y grado de conocimiento de los usos 695

Capítulo 5

Contraste bibliográfico: datos novedosos e influencia regional en el AVR. 701

Parte 6 Conclusiones - Conclusioni

Capítulo 1

Conclusiones

Capítulo 2

Conclusioni

Parte 7 Bibliografía 


\section{Sommario}

El Alto Valle del Reno (Alta Valle del Reno, AVR) es una tierra de frontera entre Toscana y Emilia-Romaña marcada por el río Reno, por los intensos bosques y por una identidad propia caracterizada por la montaña, el agua y la frontera. El patrimonio natural y cultural basado en los conocimientos etnobotánicos del AVR han sido estudiados, documentados, y analizados a través de entrevistas semiestructuradas a 113 informantes, oriundos de los 6 municipios que recorre el Reno en su tramo inicial de montaña entre Toscana y Emilia-Romaña.

La información se presenta en un catálogo etnoflorístico sobre las especies cultivadas y silvestres conocidas por la comunidad. Con el fin de resaltar la especificidad cultural y las características biológicas del AVR, han sido analizadas y estudiadas en profundidad las especies silvestres y cultivadas, solo si éstas últimas son utilizadas para fines diferentes para los cuales son cultivadas de forma común. Han sido recogidas 281 especies, 814 nombres vernaculares, 1165 usos y 3667 citas. La mayoría de las especies útiles se recolectan en ambientes antropizados o en bosques. Las especies con más importancia relativa son Urtica dioica L., Taraxacum campylodes G.E.Haglund (s.1.), Malva sylvestris L., Castanea sativa Mill. y Clematis vitalba L.

Resaltan las especies con usos alimentarios y medicinales. En la alimentación tradicional se utilizan 142 especies, y destacan su empleo en los licores, las ensaladas, la verdura cocida y las golosinas y masticatorias. Las prácticas sobre los alimentos funcionales o medicinales son muy importantes en la cultura local. La categoría etnotaxonómica, etnogastronómica y nutracéutica de los "radicchi" tiene una gran relevancia. En la medicina familiar o tradicional se han recogido 142 especies y 1455 citas, en las que resaltan las especies panaceas Malva sylvestris L. y Matricaria chamomilla L. Las patologías más tratadas con las especies locales son las afecciones dermatológicas, los problemas respiratorios y los problemas digestivos.

El grado de novedad de la investigación respecto a la bibliografía local es del $88,20 \%$ en la fitonímia y del $91,33 \%$ en los usos, debido entre otros factores, a los escasos estudios previos realizados en la zona sobre Etnobotánica, a pesar de lo mucho que ha sido estudiada la cultura y la historia del Alto Valle del Reno.

La sabiduría popular relacionada con las plantas se ha mostrado mayor en la parte emiliana respecto a la parte toscana en varios aspectos, y la cultura popular del AVR se ha mostrado más influenciada por la cultura emiliana que por la cultura toscana. 



\section{Lista de Tablas}

Tab. 1. Características y población del área de estudio.......................................36

Tab. 2. Datos termopluviométricos relativos a la estación de Pracchia (Pi).......43

Tab. 3. Datos termopluviométricos relativos a la estación Acquerino (PI)........43

Tab. 4. Datos termopluviométricos relativos a la estación de Suviana (BO).....44

Tab. 5. Evolución de la cobertura del suelo.........................................................68

Tab. 6. Cronograma del Trabajo de Campo en el AVR (2009-2015)..................84

Tab. 7. Clasificaciones empleadas en la ecología de las especies. ......................105

Tab. 8, Sectores y categorías de uso. ...............................................................106

Tab. 9. Categorías de las partes de las plantas usadas y transformados.............107

Tab. 10. Clasificaciones para las formas de preparación y de administración. 108

Tab. 11. Descripción de los 113 informantes entrevistados. .............................109

Tab. 12. Abreviaturas de la referencias bibliográficas seleccionadas................115

Tab. 13. Resumen estadístico de la información registrada................................559

Tab. 14. Las 20 familias botánicas más importantes. ......................................564

Tab. 15. Número de especies usadas de las 6 familias más importantes. ..........566

Tab. 16. Las 20 especies botánicas más importantes.......................................567

Tab. 17. Sectores de aplicación de los usos etnobotánicos.................................570

Tab. 18. Categorías de uso por orden de importancia........................................572

Tab. 19. Categorización y criterios de formación de los nombres vernaculares.

Tab. 20. Especies que presentan un mayor número de nombres vernaculares. 581

Tab. 21. Nombres vernaculares recogidos en el AVR....................................582

Tab. 22. Evolución territorial del dialecto del AVR ..........................................593

Tab. 23. Especies en proceso de disminución o desaparición. ............................599

Tab. 24. Especies útiles en la etnobotánica del AVR que están protegidas......609

Tab. 25. Familias botánicas utilizadas con fines alimentarios...........................623

Tab. 26. Las familias de plantas en las tradiciones fitoalimúrgicas italianas. ..625

Tab. 27. Distribución del conocimiento fitoalimúrgico entre los informantes. 627

Tab. 28. Importancia de las categorías alimentarias en función del sexo.........627

Tab. 29. Especies alimentarias en la tradición del AVR....................................629

Tab. 30. Usos alimentarios clasificados por categorías. ....................................631

Tab. 31. Especies más empleadas en las mezclas. ............................................635

Tab. 32. Categorías alimentarias en las que más mezclas de plantas se utilizan. Las más citadas.

Tab. 33. Categorías medicinales para las que se utilizan plantas alimentarias. 637

Tab. 34. Distribución del conocimiento del uso de los alimentos medicinales.641 
Etnobotánica en el Alto Valle del Reno (Toscana y Emilia-Romaña, Italia)

Tab. 35. Categorías alimentarias según el orden de importancia regional.........643

Tab. 36. Familias botánicas utilizadas con fines medicinales..............................647

Tab. 37. Especies medicinales en la tradición del AVR. ...................................650

Tab. 38. Categorías medicinales y su reparto en familias botánicas..................652

Tab. 39. Distribución de los usos medicinales...................................................65

Tab. 40. Comparación de la nosología popular del AVR (dialecto)...................657

Tab. 41. Especies más frecuentes en mezclas medicinales.................................665

Tab. 42. Categorías medicinales en las que más mezclas de plantas se utilizan.

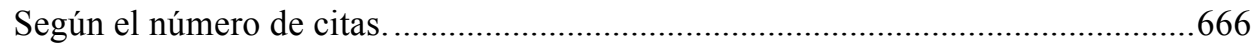

Tab. 43. Categorías medicinales según la importancia regional en el AVR.....668

Tab. 44. Categoría mágico/medicinales en el AVR..........................................671

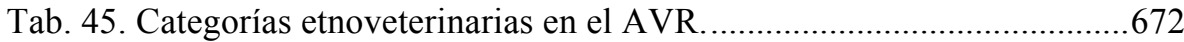

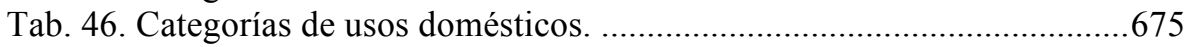

Tab. 47. Categorías de usos agropastorales en el AVR. ...................................676

Tab. 48. Categorías de usos artesanales en el AVR.........................................677

Tab. 49. Categorías de uso mágico/ritual/supersticioso en el AVR...................679

Tab. 50. Categorías de uso lúdico/voluptuoso en el AVR.................................680

Tab. 51. Vigencia de los usos etnobotánicos en el AVR..................................699

Tab. 52. Grado del conocimiento de los usos etnobotánicos en el AVR ...........702

Tab. 53. Características del conocimiento etnobotánico en la bibliografía local. .706

Tab. 54. Usos etnobotánicos bibliográficos locales no confirmados.................709

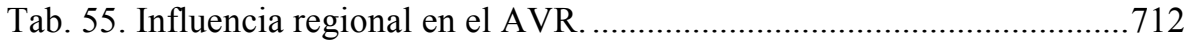




\section{Lista de Figuras}

Fig. 1 Localización del área de estudio...........................................................50

Fig. 2. Carta geológica del Apenino Norte (parte emiliana) desde Abetone (Pistoia) hasta Castiglione dei Pepoli (Bolonia)......................................................51

Fig. 3. Balance hídrico y fórmula climática según Thornthwaite relativas a la estación Pracchia (PI) extraído de Foggi et al., 2007..............................................52

Fig. 4. Balance hídrico y fórmula climática según Thornthwaite relativas a la estación de Acquerino (PI), extraído de Foggi et al., 2007. .....................................53

Fig. 5. Climograma según Walter y Lieth relativo a la estación Suviana (BO)..54

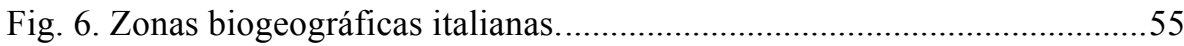

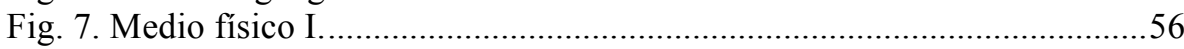

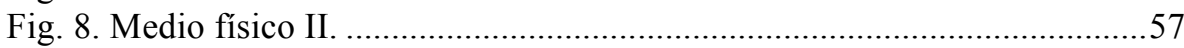

Fig. 9. Límites del Parco dei laghi di Suviana e Brasimone ................................58

Fig. 10. Localización de la Línea Spezia-Rímini...............................................70

Fig. 11. Evolución demográfica en los municipios del Alto Valle del Reno......71

Fig. 14. Metodología y Trabajo de campo I......................................................99

Fig. 15. Metodología. Trabajo de campo II. …………..................................... 100

Fig. 16. Metodología. Trabajo de campo III.......................................................101

Fig. 17. Área y localidades estudiadas............................................................... 119

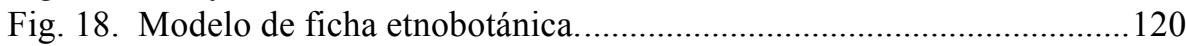

Fig. 19. Mapa de número de informantes por municipio...................................561

Fig. 20. Distribución del conocimiento etnobotánico en el AVR.....................561

Fig. 21. Mapa del número de especies usadas por municipio.............................612

Fig. 22. Mapa del número de citas por municipio. ..........................................612

Fig. 23. Importancia relativa de los diferentes sectores de los usos

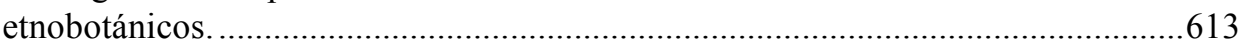

Fig. 24. Tipos biológicos de la etnoflora del AVR ..........................................613

Fig. 25. Tipos biológicos de la flora de Le Valli della Limentra Orientale e Limentrella, y su distribución porcentual (Venturi, 2006). .614

Fig. 26. Tipos biológicos de la flora de Toscana, distribución porcentual. Datos: (Pignatti, 1994). .614

Fig. 27. Tipos biológicos de la flora de Emilia-Romaña, distribución porcentual. Datos: (Pignatti, 1994). .615

Fig. 28. Tipos biológicos de la flora de Italia, distribución porcentual. Datos: (Pignatti, 1994). 615

Fig. 29. Espectro corológico de la etnoflora del AVR 616 
Etnobotánica en el Alto Valle del Reno (Toscana y Emilia-Romaña, Italia)

Fig. 30. Ambientes de recolección de plantas de interés en el AVR. 616

Fig. 31. Distribución de las especies silvestres y cultivadas en la etnoflora.....617

Fig. 32. Frecuencia de la etnoflora en el AVR. Especies silvestres, cultivadas e importadas (ausentes).

617

Fig. 33. Partes de las plantas más utilizadas en el AVR. Según el número de citas. 683

Fig. 34. Sector etnobotánico alimentario I 684

Fig. 35. Sector etnobotánico alimentario II 685

Fig. 36. Mapa del número de especies alimentarias por municipio..................686

Fig. 37. Mapa del número de citas alimentarias por municipio. 687

Fig. 39. Sector medicinal y veterinario. 688

Fig. 40. Partes más utilizadas para fines medicinales. Según el número de citas.

Fig. 41. Formas de preparación de los remedios con plantas. 689

Fig. 42. Formas de administración de los remedios tradicionales con plantas. 690

Fig. 43. Mapa del número de especies medicinales por municipio. 690

Fig. 44. Mapa del número de citas medicinales por municipio. 691

Fig. 45. Sector doméstico. 692

Fig. 46. Sector agropastoral. 693

Fig. 47. Sector Artesanal 694

Fig. 48. Sector Artesanal II 695

Fig. 49. Sector Mágico-ritual-supersticioso 696

Fig. 50. Lúdico-voluptuoso. 697

Fig. 51. Sector religioso abandonado 698 


\section{Lista de abreviaturas}

$\begin{array}{ll}\text { AVR } & \text { Alto Valle del Reno } \\ \text { AVRB } & \text { Alto Valle del Reno, la parte boloñesa } \\ \text { AVRT } & \text { Alto Valle del Reno, la parte toscana } \\ \text { BURER } & \text { Bollettino Ufficiale Regione Emilia-Romagna } \\ \text { BURT } & \text { Bollettino Ufficiale Regione Toscana } \\ \text { cfr. } & \text { Confronta (Identificación probable por no disponer de muestra } \\ \text { testigo) } & \\ \text { CV } & \text { Índice de Valor cultural } \\ \text { ERT } & \text { Emilia-Romagna Turismo } \\ \text { GURI } & \text { Gazzetta Ufficiale della Repubblica Italiana } \\ \text { ICGM } & \text { Istituto comprensorio di Grizzana Morandi } \\ \text { LIC } & \text { Lugar de Interés Comunitaria } \\ \text { p.p. } & \text { pro parte (solo en parte) } \\ \text { PTP } & \text { Piano Territoriale del Parco } \\ \text { RFC } & \text { Índice de Frecuencia Relativa de las citas } \\ \text { RI } & \text { Índice de Importancia relativa } \\ \text { s.d. } & \text { sine die (sin fecha) } \\ \text { s.l. } & \text { sensu lato (en sentido amplio) } \\ \text { SIC } & \text { Sitios de Importancia Comunitarios } \\ \text { sp.pl. } & \text { species plurimi (varias especies) } \\ \text { UV } & \text { Índice de Valor de uso } \\ \text { UVactual } & \text { Índice de Valor de uso de los usos actuales } \\ \text { UVdirecto } & \text { Índice de Valor de uso de los usos directos } \\ \text { UVindirecto } & \text { Índice de Valor de uso de los usos indirectos } \\ \text { UVpasado } & \text { Índice de Valor de uso de los usos pasados } \\ \text { VPSRU } & \text { Varianti a Piano Strutturale e Regolamento Urbanistico }\end{array}$



Parte 1 Introducción 



\section{Capítulo 1}

\section{Presentación}

\section{Justificación}

El Alto Valle del Reno (Alta Valle del Reno) constituye un área de particular interés por su posición fronteriza entre las regiones italianas Toscana y Emilia-Romaña. El río Reno nace en Toscana, en el Monte delle Piastre (Pistoia, Toscana), recorre la frontera regional entre Toscana y Emilia-Romaña, y desemboca en la llanura de Bolonia (Emilia-Romaña). El uso de sus aguas ha influenciado la economía de sus tierras haciendo de Bolonia la primera ciudad industrial de Europa (ERT, 2012). Situado en los Apeninos Tosco-Emilianos, ésta zona de montaña constituye un área crucial que ha separado siempre el Norte del Sur en aspectos históricos, lingüísticos, ambientales y culturales. Desde el punto de vista biogeográfico, el Alto Valle del Reno ocupa una posición extremadamente importante a nivel Europeo, ya que se sitúa justo en la línea que separa la región Centroeuropea de la Mediterránea (Adamovic, 1933; Pignatti et al., 2001). Aunque constituya un lugar de tránsito y de frontera, el Alto Valle del Reno también representa un lugar de encuentro que alberga una identidad única por sí misma, en la cual existe una cultura en común (Alto Reno Toscano II, 2016) y un sistema dialectal denominado "Galo-Toscano". Se trata de un dialecto de frontera que se encuentra en la barrera dialectal más importante de Italia llamada la "línea Spezia-Rímini" (Guccini, 1998), la cual según muchos autores separa la lenguas románicas (Signorini, 2003), así como el sistema lingüístico del norte de Italia del sistema lingüístico toscano (Alto Reno Toscano II, 2016).

Este contexto tan particular ha generado una riqueza cultural extraordinaria y una gran diversidad biológica que ha llevado al reconocimiento internacional a través de varios Sitios de Importancia Comunitaria (SIC) otorgados por la Comunidad Europea y Red Natura 2000 (92/43/CEE), además de varias áreas protegidas a nivel regional como Parco dei laghi di Suviana e Brasimone y la Riserva Naturale Biogenetica di Acquerino. El relativo aislamiento geográfico e histórico que ha sufrido el Valle ha creado una estrecha relación entre sus habitantes y su entorno natural, creando así un profundo conocimiento tradicional sobre los usos de las plantas locales de las cuales han dependido durante mucho tiempo su supervivencia y bienestar.

Las tierras de frontera son lugares que albergan una gran riqueza en diferentes aspectos: riqueza biológica, ya que a menudo la biodiversidad es generalmente 
mayor en los espacios de fronteras respecto a otros lugares (los espacios "residuales", indicados por Clément (2005) en "fragmentos de paisajes", constituyen "refugios para la diversidad", de los cuales los ecólogos han indicado su importancia), riqueza espacial en cuanto son territorios generalmente caracterizados por usos y funciones diferentes, y riqueza relacional, en cuanto son lugares en los que se manifiestan contraposiciones, yuxtaposiciones y contradicciones (Zanini, 1997). El Alto Valle del Reno constituye una tierra de frontera con una gran riqueza cultural y biológica, que la hacen extremadamente interesante desde el punto de vista de las interacciones entre la población humana y el reino vegetal.

El conocimiento etnobotánico es un acervo cultural que engloba los usos, prácticas, costumbres, representaciones y creencias relacionadas con las plantas, que surgen de la observación y de la experiencia con el medio natural. Las prácticas y conocimientos tradicionales han ido adaptándose a las características ambientales y sociales del territorio y han sido transmitidas de generación en generación dentro de una comunidad, a través de la comunicación oral. El patrimonio etnobotánico forma parte de la memoria colectiva del grupo social y puede representar una herramienta de agregación y de identidad cultural de la comunidad. Las comunidades tradicionales utilizan los recursos biológicos para un sinfín de propósitos cotidianos. A lo largo de las generaciones, las comunidades han protegido e incrementado la diversidad biológica de la cual dependía su supervivencia y bienestar, por esto se consideran los custodios y entendedores de la diversidad biológica que les rodea.

En los últimos años, el gran éxodo rural que han sufrido las comunidades tradicionales, la migración hacia otros lugares buscando mejores condiciones de vida, el proceso de aculturación y la desaparición de la última generación poseedora de los conocimientos tradicionales resaltan la urgente necesidad de registrar, documentar y recuperar la sabiduría tradicional relacionada con las plantas antes de que desaparezcan del todo, como pasa en otras culturas (Biscotti y Pieroni, 2015; Nebel et al., 2006; Pieroni, 1999; Pieroni, 2000; Pieroni et al., 2004; Carvalho, 2005).

La presente investigación tiene como fin el estudio etnobotánico en el Alto Valle del Reno, y se propone documentar, conservar y valorizar el patrimonio natural y cultural que constituyen los conocimientos tradicionales relacionados con las plantas.

\section{Breve historia y evolución de la Etnobotánica}

El hombre ha utilizado siempre las plantas que le rodeaban para alimentarse, para vestirse, para la construcción de casas o cobijos, para hacer herramientas y desde muy pronto incluso para la medicina. Ya en el I siglo d.C., se documentaban los usos medicinales de las plantas por Dioscórides, en De Materia Medica (Pieroni, et al. 2013).

Las primeras ciencias que estudian las interacciones entre las sociedades humanas y las poblaciones vegetales (alimentación, vestido, combustible, medicina) son la Botánica Aplicada, utilizado por primera vez por Augusto Píramo de Candolle a comienzos del siglo XIX, la cual se definía como el estudio de las 


\section{María Teresa Egea Molines}

relaciones existentes entre los vegetales y la especie humana (comprendiendo la Botánica Agrícola, la Botánica Médica, la Botánica Económica e Industrial, la Botánica Histórica, etc.). En cambio, la Botánica Económica es una parte del "estudio de las plantas al servicio del hombre" y representa un punto de contacto entre la Antropología y el estudio de las plantas de interés industrial (Rivera y Obón, 1998).

El concepto de Etnobotánica fue utilizado por primera vez por el profesor John Harshberger en Estados Unidos en el 1895, quien la definió como "el uso de las plantas por los pueblos aborígenes" (Harshberger, 1895). Este concepto de la Etnobotánica forma parte de una visión imperialista de la época que se interesaba por el uso de las plantas por parte de los indígenas desde una perspectiva económica para poder ser valorizados comercialmente en los países desarrollados (Brousse, 2011). La Etnobotánica fue evolucionando como disciplina interdisciplinaria, intensificando el enfoque etnográfico y la importancia de la interpretación del uso de las plantas (Haudricourt y Hédin, 1943). Al comenzar a integrarse como una disciplina de investigación, el objeto de estudio se fue ampliando a la totalidad de las relaciones del hombre con las plantas, incluyendo la forma de percibir y categorizar el mundo vegetal, los aspectos simbólicos y las creencias por parte de la comunidad en estudio, considerando los conocimientos transmitidos de forma generacional. Ya en el 1916, Robbins y otros autores interpretaban ésta disciplina de forma más completa: "La Etnobotánica no trata sólo de un catálogo de plantas útiles, sino de la percepción del medio natural a través de las costumbres y rituales" (Robinns et al., 1916). Entonces el término de Etnobotánica se fue expandiendo no sólo al uso de las plantas por los pueblos aborígenes sino al estudio de las relaciones entre los vegetales y las sociedades humanas (Hurrel, 1987).

Desde entonces la Etnobotánica se ha divulgado y especializado, haciéndose cada vez más rigurosa e intensificando su carácter interdisciplinar, adoptando técnicas y aplicaciones desde las perspectivas de la botánica, la farmacología, la medicina, la veterinaria, la agronomía, la silvicultura, la ecología, la lingüística, la ecología, la antropología, la historia y la sociología (Heywood, 2014).

En los últimos veinte años la Etnobotánica ha sufrido una profunda transformación, reconociendo la necesidad de análisis críticos adecuadamente diseñados y buscando la validación científica de los datos recolectados a través del estudio cualitativo y cuantitativo de los datos recogidos, los estudios comparativos intraculturales e interculturales, y los contrastes temporales a partir de fuentes bibliográficas históricas (Heywood, 2014; Pieroni et al., 2013). El contexto en el que los estudios etnobotánicos se llevan a cabo también ha cambiado radicalmente, por ejemplo, intensificando la colaboración con ONGs en programas internacionales de cooperación y desarrollo y promoviendo la cooperación académica inter-europea (Pieroni, et al. 2013). En particular, se reconoce cada vez más la importancia de la investigación etnobotánica en la mejora de la alimentación, la nutrición, y la salud de la humanidad. La conservación de los conocimientos ecológicos tradicionales relacionados con las plantas estudiadas y la conservación de los cultivos infrautilizados y marginados se han vuelto prácticas indispensables en los proyectos de conservación de los recursos fitogenéticos y en proyectos de gestión de los recursos naturales (Heywood, 2014). Actualmente los estudios etnobotánicos se 
encuentran en fase de progreso por todo el mundo, resaltando la función ética, social y ambiental que debe tener la Etnobotánica, lo cual ha sido proclamado por distintos Convenios Internacionales.

\section{Marco legislativo}

Las amenazas a la biodiversidad de las plantas como resultado de la pérdida y degradación de los hábitats, la erosión del patrimonio cultural tradicional, la desigualdad de oportunidades, la malnutrición y la sobreexplotación de los recursos naturales han creado un marco legislativo y normativo internacional, nacional y regional con el fin de salvaguardar el patrimonio natural y cultural que constituyen los conocimientos tradicionales relacionados con las plantas en todos sus aspectos y aplicaciones, con respeto hacia los pueblos y hacia su ambiente (Heywood, 2014).

A nivel internacional, resalta el Convenio de Diversidad Biológica de las Naciones Unidas (artículo 8j en CBD, 1992), y el Protocolo de Nagoya sobre Acceso a Recursos Genéticos y Distribución de Beneficios (ABS, 2016) establece la necesidad de que los gobiernos respeten, preserven, mantengan y promuevan una mayor aplicación de los conocimientos tradicionales con la aprobación y la participación de las comunidades indígenas y locales pertinentes, así como una justa repartición de los beneficios que derivan del uso de tales conocimientos, ratificada por parte de Italia con la ley 14 febrero 1994, n. 124 (MATTM, 1994). El Convenio sobre la Salvaguardia del Patrimonio Cultural Inmaterial de la UNESCO (UNESCO, 2007) promueve la investigación y la valorización de los conocimientos tradicionales relacionados con la naturaleza, considerándolos por primera vez parte del patrimonio inmaterial cultural. El Tratado Internacional sobre los Recursos Fitogenéticos para la Alimentación y la Agricultura de la Resolución 3/2001 (FAO, 2001) incluye la protección de los conocimientos tradicionales y el derecho a participar equitativamente en la distribución de los beneficios y en la adopción de decisiones nacionales relativas a los recursos fitogenéticos. La Organización Mundial de la Salud (OMS, 2013) anima a los estados miembros a integrar la medicina tradicional en los sistemas nacionales de salud en la "Estrategia sobre medicina tradicional para los próximos diez años 2014-2023”.

A nivel nacional italiano, el ministro del gobierno italiano ha instituido el decreto n. 17070 del 19 noviembre 2012 (MPAAF, 2012) relativo a la creación del Observatorio nacional del paisaje rural, de las prácticas agrícolas y los conocimientos tradicionales.

A nivel regional también existen leyes que promueven la documentación y la conservación de los conocimientos tradicionales. En la región Toscana, la ley regional n. 44 (GURI, 2009) sostiene la divulgación y la conservación de los conocimientos tradicionales relacionados con la biodiversidad y con los productos de cadena corta. Y en la región Emilia-Romaña, a través de la ley regional 29 enero 2008, n.1 (BURER, 2008) se reconoce en el artículo 3 el patrimonio de los conocimientos tradicionales como fundamentales para la conservación de la diversidad biológica, promoviendo una mayor aplicación con el consenso de los detentores del conocimiento y favoreciendo una justa repartición de los beneficios 
derivados del uso de esos conocimientos, en acorde con el Convenio de Diversidad Biológica (CBD, 1992).

En cambio, a nivel local, en el Alto Valle del Reno resalta el Plan Territorial emitido por el Parque Regional Parco dei laghi di Suviana e Brasimone, el cual prevé una serie de normativas de gestión de los recursos fitogenéticos con el objetivo de conservar y preservar la diversidad biológica (NAPTT, 2005) según unos criterios científicos que no contemplan las prácticas tradicionales de gestión de los hábitat locales. Las políticas de conservación locales tienden normalmente a la "no intervención" y no consideran las prácticas que durante generaciones han gestionado y protegido el ambiente dando lugar a la biodiversidad que se encuentra actualmente. Las normativas del Parque Regional prohíben en numerosas ocasiones la gestión y el uso tradicional de los hábitats por parte de los habitantes, lo cual ha puesto en conflicto la relación entre la institución responsable de la protección del ambiente y la población local que se considera la propia protectora de su ambiente. Ambos sujetos pretenden realizar el mismo objetivo con modalidades a veces opuestas y contradictorias correspondientes al conocimiento formal y "ético" (gestores del ambiente del Parque Regional) y al conocimiento tradicional y "émico" (gestión tradicional por parte de la población local).

Por esto también, urge un estudio profundo sobre la validación científica del conocimiento y de las prácticas tradicionales que resalte sus potencialidades ambientales y económicas. Con el presente estudio se pretende contribuir a mejorar la relación, a veces conflictiva, entre los gestores institucionales y políticos de los recursos naturales locales y los nativos, a través de la valorización científica del conocimiento tradicional. De hecho, el Parque Regional Parco dei laghi di Suviana e Brasimone ha apoyado la parte de ésta investigación que se ha centrado en el área del Parque, lo cual representa un primer paso hacia la valorización de los conocimientos y las prácticas tradicionales por parte de los entes locales.

\section{Marco teórico}

Actualmente en el mundo globalizado donde vivimos, a menudo las culturas vernáculas se ven contaminadas por la cultura dominante de la sociedad de consumo y sus conocimientos y prácticas tradicionales sufren una gran erosión. La comunidad científica internacional no se pone de acuerdo sobre ciertos matices en la definición exacta de la Etnobotánica. Considerando la contaminación irremediable de la globalización, su flujo acelerado de bienes, informaciones, especies y culturas así como la generalización de la forma de vida del bienestar hacen que a veces la relación tradicional y vernacular entre el hombre y las plantas sea difícilmente identificable o al menos discutible.

Con el fin de hacer de la Etnobotánica una herramienta fundamental para la conservación del patrimonio cultural inmaterial, para la conservación de la diversidad biológica y cultural, así como para la gestión sostenible de los recursos naturales, es necesario ser más estrictos en la definición genérica dada por diferentes autores "el estudio de las interacciones entre los vegetales y los seres humanos" (Hurrel, 1987). 
En la presente investigación Etnobotánica adoptamos la siguiente definición: La Etnobotánica es el uso tradicional de las plantas silvestres o cultivadas, sólo si son utilizadas para un uso diferente para el cual son cultivadas de forma común (por ejemplo la aplicación de láminas de patata para el dolor de dientes y no como alimento), una visión adoptada por diferentes autores italianos (Camangi et al., 2007; Signorini et al., 2008; Signorini et al., 2013). Además los usos etnobotánicos de las plantas no contemplan los usos industriales y comerciales de las plantas, porque los usos tradicionales de las plantas no suelen ser masivos. La Etnobotánica en este estudio no contemplará el uso común de las plantas cultivadas que han sido mejoradas genéticamente, introducidas por los imperativos de mercado y agronómicos, por lo que se han vuelto comunes a la mayoría de pueblos por un proceso comercial y no tradicional (como son las plantas compradas en las cooperativas agrícolas locales y cultivadas como las forrajeras o las variedades mejoradas de frutales). La relación tradicional del hombre con las plantas y el uso de éstas implica un cuidado, una observación, su protección, reproducción y conservación a través de las generaciones con el fin de poder seguir utilizándolas a largo plazo. Por esto, los conocimiento tradicionales de las plantas y su uso sostenible han sido reconocidos como herramientas fundamentales para la conservación de los recursos fitogenéticos y de la biodiversidad (CBD, 1992). Como usos tradicionales se entienden los usos que forman parte integral de una cultura durante más de una generación, adoptando la definición de "tradicional" que utilizan otros autores (Nebel et al., 2006; Ogoye-Ndegwa y Aagaard-Hansen, 2003; Pardode-Santayana et al., 2010). El conocimiento tradicional relacionado con el medio natural donde se da es de carácter subjetivo, informal, empírico, holístico y variable. Los conocimientos tradicionales de las plantas son aquellos que nacen de la experiencia dentro de la comunidad y se comunican a través de la lengua vernacular, con lo cual, los usos de las plantas aprendidos a partir del conocimiento formal (médicos, farmacéuticos, expertos en general, o libros), o bien a través de la televisión, del comercio o de otras culturas no son considerados como etnobotánicos, al no ser que se hayan integrado en la comunidad durante más de una generación, según la definición anterior. Según ésta delimitación de la amplia definición de la Etnobotánica, podremos caracterizar la identidad cultural de la comunidad en estudio y sus particularidades valorizando los usos tradicionales de las plantas y la gestión tradicional de sus hábitats, con el fin de que puedan ser recogidas informaciones útiles para la conservación del patrimonio cultural y de la diversidad biológica.

El significado de Etnobotánica cobra sentido sólo cuando realmente se ve revertido en sus numerosos beneficios sociales, culturales, económicos, ambientales en la propia comunidad (CBD, 1992; Nicolas, s.d.). La investigación Etnobotánica aporta informaciones de gran valor ambiental y económico, al ser integradas y aceptadas en la comunidad, experimentadas y seleccionadas en el tiempo y a través de las cuales, se crea un ecosistema estable y maduro, de gran diversidad biológica, en equilibrio con los habitantes. Adaptar entonces las informaciones etnobotánicas a las exigencias socio-culturales, económicas y ambientales actuales puede dar lugar a numerosas aplicaciones de gran interés en la actualidad: como en la conservación de la biodiversidad y de su patrimonio cultural indisociable, la denominada "diversidad 


\section{María Teresa Egea Molines}

biocultural" (Maffi, 2001), en el desarrollo de bioeconomías (Georgescu-Roegen, 2003), en la gestión de los recursos naturales con un enfoque participativo y "émico", en el desarrollo de un eco-turismo sostenible, así como pueden ser fuente de inspiración en el campo de la farmacología y herboristería a nivel local. En el ámbito del aprovechamiento agroforestal sostenible, las informaciones etnobotánicas dan la posibilidad de diversificar la agricultura y la economía local a través de productos tradicionales a base de plantas, a menudo con un gran valor añadido ambiental (al ser especies infrautilizadas) y cultural (al ser tradicionales). La economía local se puede ver beneficiada con productos de cadena corta, sostenibles, integrados culturalmente, de alta calidad y con importantes efectos nutricionales, nutracéuticos y medicinales.

Los conocimientos etnobotánicos constituyen un sistema complejo que para ser valorizados y conservados será fundamental adoptar una visión holística e interdisciplinar del ecosistema que constituyen el hombre y su ambiente. Para conservar las especies botánicas es necesario conservar sus respectivos hábitats en un sistema donde todos los elementos están interconectados. A su vez, para conservar los hábitats, es necesario conservar y promover los modos de vida que los crean y los modos de gestión de los hábitats antropizados; que al fin y al cabo equivale a conservar y promover el conjunto de conocimientos tradicionales relacionados. La Etnobotánica es una ciencia cuyo objetivo es validar científicamente el conocimiento tradicional y rural, para poder conservarlo a través de la proyección en los múltiples sectores de la vida relacionada con la naturaleza que se han desarrollado en la actualidad. En este proceso complejo es importante mantener una coherencia y ética en acorde con la cosmovisión y la índole tradicional. La valorización de los conocimientos tradicionales relacionados con las plantas debe estimular una reconversión ecológica de nuestras sociedades que prometa en definitiva una mejor calidad de vida: una gestión más eficiente y limitada de los recursos naturales, una producción y un consumo menor y de mayor calidad, una alimentación más sana, más tiempo libre y más convivencia (Latouche, 2008). 



\title{
Capítulo 2
}

\author{
Antecedentes
}

En las últimas décadas, la mayoría de los estudios etnobotánicos italianos se han llevado a cabo en el centro y sur de Italia (Camangi et al., 2002; Camangi et al., 2007; Guarino et al., 2008; Guarrera y Lucia, 2007; Idolo et al., 2010; Lentini y Venza, 2007; Leonti et al., 2009; Motti et al., 2009; Nebel y Heinrich, 2009; Pieroni, 1999; Raimondo y Lentini, 1990; Savo et al., 2011). En cambio, existen algunas lagunas en la parte Norte del país (Vitalini et al., 2013). La región Toscana (Italia Central) ha sido profundamente estudiada por un gran número de investigadores, y es sin duda una de las regiones más estudiadas de toda Italia. En la revisión bibliográfica sobre la Etnobotánica de Italia, Guarrera (2006) recoge 40 estudios etnobotánicos en Toscana. Por otra parte, el Centro Etnobotánico de la Toscana (CET, 2015) y Camangi et al. (2007) citan respectivamente 67 y 98 estudios etnobotánicos realizados en Toscana.

En cambio, las investigaciones etnobotánicas en Emilia-Romaña (Nororiente de Italia) son extremadamente escasas. En la revisión de Guarrera (2006), se citan solamente dos publicaciones en Emilia-Romaña (Borghi y Zagnoni, 1990; Fossati et al., 1999), ambas sobre las plantas usadas en la medicina tradicional. Además en Emilia-Romaña, existen otras dos publicaciones sobre la etnomedicina de las provincias de Bolonia (Ungarelli, 1921) y de Parma (Castelli, 1992). Recientemente Sansanelli y Tassoni (2014) han publicado un estudio sobre los conocimientos tradicionales de las plantas alimenticias en los alrededores de la ciudad de Bolonia, zona que incluye una pequeña parte del Alto Valle del Reno. Desde el punto de visto agronómico, es importante citar el trabajo de Guidi (2013) sobre el estudio de las variedades antiguas de frutales y vides en Emilia-Romaña.

El Alto Valle del Reno es una zona ampliamente estudiada y documentada desde el punto de vista ambiental, histórico y cultural. El Gruppo di studi Alta valle del Reno edita numerosas publicaciones sobre una gran variedad de temas relacionados con la cultura y el territorio del Alto Valle del Reno. La Società Pistoiese di storia patria, el Ecomuseo della Montagna Pistoiese, el "B.A.M." (Biblioteca, archivo histórico y museo del Alto Reno), el Parque Regional Parco dei laghi di Suviana e Brasimone, la Comunità montana dell'alta e media valle del Reno y las asociaciones culturales locales llamadas las pro-loco albergan y generan un relevante número de libros, estudios e investigaciones sobre todos los ámbitos culturales y ambientales del Alto Valle del Reno. 


\section{Etnobotánica en el Alto Valle del Reno (Toscana y Emilia-Romaña, Italia)}

Desde el punto de vista histórico resalta el profesor, escritor y presidente del Gruppo di studi Alta valle del Reno Renzo Zagnoni, quien ha aportado más de un centenar de publicaciones entre libros, artículos de diferente índole y actas de jornadas de estudios sobre la cultura, la historia medieval, eclesiástica y contemporánea del Alto Valle del Reno. Muchos de los trabajos de Zagnoni (1977, 1981, 1982, 1986, 1990, 1991, 1992, 1993, 1997a, 1997b, 1998, 2001a, 2001b, 2001c, 2003, 2004, 2005, 2006, 2008a, 2008b, 2009, 2013) destacan por su interés directo o indirecto con la Etnobotánica. Igualmente el investigador etnográfico Gian Paolo Borghi, se ha dedicado al estudio etnohistórico y etnoantropológico del Alto Valle del Reno aportando una gran variedad de estudios folklóricos e históricos de gran valor científico (Borghi, 1989a, 1989b, 1991, 1997, 2000, 2002, 2004; Borghi y Zagnogni, 1983; Borghi y Zagnoni, 1990; Borghi et al., 2002; Zagnoni et al., 1996; Zagnoni y Borghi, 2010).

A nivel etnográfico también existe una gran cantidad de estudios y publicaciones que documentan las características folklóricas y tradicionales de los pueblos del Alto Valle del Reno. Diversos autores locales, como Stefano Appoggi en Baigno (Appoggi, 2010; Appoggi y Bacchi, 2008; Appoggi y Pritoni, s.d.) y Renzo Nerattini en Badi (Nerattini, s.d.; Nerattini, 1980; Nerattini y Boldri, 2003; Nerattini et al., 2006; Nerattini et al., 2009; Nerattini et al., 2010) han aportado un gran material etnográfico sobre temas relacionados con las tradiciones y la historia local y oral.

La vasta bibliografía realizada por la población local en colaboración con las asociaciones culturales (pro-loco) y los propios municipios, denota un pueblo orgulloso de su cultura, su historia y sus raíces. La revista semestral Nuèter noialtri - storia, tradizione e ambiente dell'alta valle del reno bolognese e pistoiese editada por el Gruppo di studi Alta Valle del Reno, muestra como la gente local (más o menos instruida), escritores y personas emblemáticas del territorio investigan y documentan todo lo relacionado con sus tradiciones, su historia y el ambiente del Alto Valle del Reno, plasmándolo en pequeños artículos publicados semestralmente.

El municipio de Sambuca Pistoiese (parte toscana del Alto Valle del Reno, objeto de estudio de esta investigación), es un municipio que cuenta con una literatura muy amplia sobre la historia, cultura y ambiente, editada por el propio municipio en colaboración con autores locales y con la población local (Foschi et al., 1991; Hug, 1993; Balletti, 2001a; Balletti y Gioffredi, 1997; Boldri, 1991; Breschi y Pozzi, 1997; Gioffredi, s.d.; Guccini, 1989; Mattei, s.d.; Mucci, s.d.; Pucci, 2007). El margen derecho y boloñés del área de estudio del Alto Valle del Reno, es decir Castel di Casio, Camugnano y Castiglione dei Pepoli también cuentan con importantes aportaciones de autores locales que documentan la historia y las tradiciones locales (Comelli, 1917; Fioni et al., 1993; Guidotti, 1985).

Las peculiaridades lingüísticas han sido profundamente estudiadas en la zona en diferentes trabajos de investigación (Bernardi, 1940-1941; Filipponio, 2007a, 2007b; Pellegrini, 1992), numerosos diccionarios de los dialectos locales (Appoggi, 2010; Beneforti, 1998; Bonzi, 2000; Guccini, 1998; Malagoli, 1930; Montemagni, 1984) así como recopilaciones lingüísticas inéditas (Poli, c. 2014) o publicadas en la web de las asociaciones locales (Lustrola, 2015), y en la revista semestral de Nuèter 
noialtri - storia, tradizione e ambiente dell'alta valle del reno bolognese e pistoiese en forma de pequeños artículos.

Los grandes estudios toponomásticos publicados en el valle, aportan una importante información no sólo a nivel de la toponimia del territorio, sino también sobre el dialecto, la historia y la fitotoponímia local (Balletti, 2001b; Rauty, 1993). Además, la arquitectura tradicional del Alto Valle del Reno ha sido rigurosamente documentada y estudiada por el arquitecto inglés Bill Homes en sus numerosas publicaciones de gran valor cultural y científico (Homes, s.d.; Homes, 1996, 1999, 2006, 2011, 2014; Homes et al., 2002; Homes et al., 2005; Homes et al., 2008; Homes y Balletti, 1997; Homes y Zagnoni, 2008).

Desde el punto de vista ambiental, resaltan autores locales como Piero Balletti con sus numerosas contribuciones florísticas en los estudios arriba mencionados y en la revista Nuèter noialtri - storia, tradizione e ambiente dell'alta valle del reno bolognese e pistoiese (Balletti, 1979, 1980a, 1980b, 1981a, 1981b); Giorgio Sirgi, quien aportó importantes testimonios sobre la evolución ambiental del territorio del Alto Valle del Reno (Sirgi, 1991, 1998, 2004, 2007) así como Eugenio Ciuti y su contribución sobre la evolución agrícola en Sambuca Pistoiese (Ciuti, 1993, 1997). Existen varios estudios científicos sobre la vegetación y la flora de zonas vecinas del Alto Valle del Reno (Arrigoni et al., 2002; Arrigoni et al., 2005; Dondini y Vergari, 2009; Speranza et al., 2001). El Parque Regional también ha aportado importantes estudios a nivel ambiental del territorio. Resaltan las investigaciones científicas (Bolognesi, 2003; Elmi, 1999; Mattioli, 1999; Pinzauti, s.d.; Scavarelli, 1999; Sirotti, 1999; Sirotti, 2004; Sirotti, 2005; Speranza et al., 2003) realizadas para el marco cognitivo del Piano Territoriale del Parco (PTP, 2008) en el que se definen las características y especificidades ambientales, naturales, históricas y paisajísticas del territorio. El Parque también ha apoyado diferentes proyectos de investigación ambientales (Ponzetta et al., 2007; Ponzetta et al., 2009), y entre otros, la parte de la presente investigación etnobotánica que se realizó en el área protegida (Bruschi et al., 2012).

Antiguamente, el difícil acceso al Alto Valle del Reno, contribuyó a hacer de éste, un territorio desconocido por la mayor parte de los botánicos (Venturi, 2006). Actualmente tanto el área de estudio como el total del área del Alto Valle del Reno no disponen de una flora completa, pero han sido realizados estudios florísticos parciales, en zonas localizadas y limitadas.

Los estudios florísticos en el Alto Valle del Reno se remontan a la segunda mitad del siglo XIX con los importantes trabajos de Bertoloni (1867) y Lorenzini (1910) sobre el estudio de las plantas cultivadas y silvestres de Porretta Terme y sus alrededores. Igualmente cabe mencionar el estudio florístico de Bèguinot y Gabelli (1915) en la flora fluvial del río Reno, realizado prevalentemente en el Alto Valle del Reno. Estos estudios florísticos del siglo pasado, tienen un interés desde un punto de vista de la evolución de la flora y del conocimiento del área en estudio. En cambio, la parte pistoyesa no ha sido estudiada hasta hace poco a nivel de la flora y la vegetación. Los únicos datos disponibles son los trabajos fin de carrera no publicados de Porciatti (1959) y Gioffredi (1959-1960), a los cuales se les suma un muestreo de la vegetación efectuado por Balletti y Gioffredi (1997), y más recientemente el estudio sobre la flora vascular de Venturi (2006) dedicada a la parte 
del valle de la Limentrella y el valle de la Limentra Orientale, situado en parte en el municipio Sambuca Pistoiese (parte pistoyesa del Alto Valle del Reno) y por último, el estudio ambiental realizado por las autoridades competentes del Ayuntamiento de Sambuca Pistoiese (VPSRU, 2013).

Al no existir una flora del territorio completa del Alto Valle del Reno, en el presente estudio han sido tomados como referencias florísticas los estudios de Sirotti (1999) en el área del Parque Regional Parco dei laghi di Suviana e Brasimone y de Venturi (2006) en los valles de las Limentra Orientale y Limentrella.

Sin embargo, casi no existen estudios científicos etnobotánicos en el Alto Valle del Reno. En la provincia de Pistoia, se ha realizado una investigación etnobotánica y farmacéutica (Uncini Manganelli y Tomei, 1998) limitada sólo a las plantas medicinales de un área de la Montaña Pistoyesa situada en las proximidades del área del Alto Valle del Reno. El farmacéutico de Porretta Terme (Lorenzini, 1910) aportó algunas noticias sobre los usos medicinales de las plantas de Porretta Terme, pero no distinguía sobre los usos tradicionales locales y las informaciones formales y extraídas de la literatura científica. Aunque sea de escaso valor científico, también cabe mencionar el trabajo realizado por los alumnos del instituto de Grizzana Morandi, situado en el Alto Valle del Reno sobre los usos familiares y tradicionales de las plantas locales en la alimentación (ICGM, 2003). Ungarelli (1921) aportó en su trabajo sobre las plantas medicinales de la Emilia-Romaña muy pocas informaciones relativas al Alto Valle del Reno. Así como son muy escasas las noticias sobre la medicina popular publicadas en Borghi y Zagnoni (1990).

Por todo lo anteriormente expuesto, es necesario y urgente realizar una investigación etnobotánica que estudie la identidad cultural tan peculiar que alberga el Alto Valle del Reno como un unicum en un territorio de frontera entre dos regiones de gran importancia en Italia. El Alto Valle del Reno es una zona que aunque haya sido profundamente estudiada por el gran interés que supone desde el punto de vista biogeográfico, ambiental, lingüístico, cultural e histórico, carece de una investigación que valide científicamente (y sobre todo botánicamente) las tradiciones relacionadas con las plantas. Es necesario realizar un estudio que ponga de manifiesto las relaciones entre el ambiente natural y las tradiciones relacionadas con las plantas, entre la biodiversidad y la diversidad cultural, entre las fronteras lingüísticas y las fronteras biogeográficas.

El aislamiento histórico, la abundancia de recursos naturales y la peculiaridad cultural han hecho que el acervo etnobotánico del Alto Valle del Reno sea particularmente interesante por investigar y por recuperar antes de que desaparezca con la última generación poseedora y con el proceso de aculturación. 


\section{Capítulo 3}

\section{El Medio Físico}

\section{Localización y caracterización del territorio estudiado}

El Reno (en céltico, "agua que fluye") es el sexto río más importante de Italia por su longitud $(212 \mathrm{~km})$ y su cuenca hidrográfica $\left(5040 \mathrm{~km}^{2}\right.$ totales y $2540 \mathrm{~km}^{2}$ en la cuenca montañosa). El río nace en Toscana y después de atravesar las provincias de Pistoia, Prato, Firenze (Toscana), Bologna, Modena, Ferrara y Ravenna (EmiliaRomaña) desemboca en el mar Adriático. El Reno ha constituido siempre un insustituible enlace entre el Norte y el Centro de Italia. Su valle ha sido un lugar de comunicaciones e intercambios entre la llanura Padana y la cuenca del Arno, aunque su parte montañosa fuera inaccesible hasta la mitad del siglo XIX.

La cuenca montañosa del Reno se denomina Alta Valle del Reno y corresponde a su tramo inicial. Se encuentra en la cadena montañosa del Appennino ToscoEmiliano, justo en la frontera regional entre la provincia toscana de Pistoia y la provincia emiliana de Bolonia. En su tramo de montaña, el río, junto al flujo de sus primeros afluentes por el margen izquierdo y derecho, conforman unos valles estrechos e intensamente boscosos así como numerosas dorsales que bajan paralelas entre ellas y transversales respecto al eje principal apenínico en dirección Noreste, abriéndose poco a poco hacia la llanura boloñesa.

El Reno nace precisamente en la provincia de Pistoia a $745 \mathrm{~m} \mathrm{s.} \mathrm{n.} \mathrm{m.,} \mathrm{donde} \mathrm{los}$ dos afluentes del río, el Reno di Prunetta (con manantial entre Poggi Piaggette y Castello, en el municipio de Piteglio, Pistoia) y el Reno di Campolungo, se unen en la localidad Le Piastre (Pistoia). En su tramo montañoso, desde Pracchia (Pistoia) hasta Ponte alla Venturina (Granaglione), el río marca con su curso, la frontera entre Emilia-Romaña y Toscana, y atraviesa una salvaje y boscosa garganta de más de $14 \mathrm{~km}$.

El territorio del Alto Valle del Reno comprende en la parte toscana los municipios de San Marcello Pistoiese, Piteglio, Pistoia y Sambuca Pistoiese (provincia de Pistoia). Y en la parte emiliana, los municipios de Castel d'Aiano, Gaggio Montano, Lizzano in Belvedere, Granaglione, Porretta Terme (en el márgen izquierdo del río), Camugnano, Grizzana Morandi, Castel di Casio, Castiglione dei Pepoli (en el márgen derecho del Reno) (provincia de Bolonia).

La amplitud del territorio total del Alto Valle del Reno ha llevado a delimitar un área de estudio de forma que sea abordable para la presente investigación y representativa del territorio total, procurando estudiar ambos márgenes izquierdo y 


\section{Etnobotánica en el Alto Valle del Reno (Toscana y Emilia-Romaña, Italia)}

derecho del río, tanto la parte toscana como emiliana, y tanto las zonas altas de frondosos bosques como las zonas más bajas que también caracterizan el valle. Por tanto se ha limitado al municipio de Sambuca Pistoiese (parte toscana del AVR), el Parque Regional dei laghi di Suviana e Brasimone y sus alrededores, el cual se localiza por completo en el municipio de Camugnano y en parte en el municipio de Castel di Casio y Castiglione dei Pepoli (parte boloñesa del AVR) y los municipios boloñeses del margen izquierdo del valle, Porretta Terme y Granaglione (Fig. 1)

Administrativamente, cada región (Toscana, Emilia-Romaña) está constituida por provincias (en el Alto Valle del Reno, Pistoia y Bolonia respectivamente), formadas por municipios (con propio ayuntamiento), que a su vez están formados por localidades o comarcas (frazioni), en los cuales se hayan pequeñas aldeas (località).

El área de estudio se extiende en $362 \mathrm{~km}^{2}$ aproximadamente y se encuentra entre los límites de los municipios tomados en consideración. En la parte Sur y Norte, el límite está marcado principalmente por las llanuras de Pistoia y de Bolonia respectivamente. En la parte Sudeste, desde el Acquerino hasta Le Fabbriche, el límite está marcado por el Limentra Orientale (que desemboca en la cuenca de Suviana). Hacia el Este, el límite coincide con la cordillera apenínica del Monte delle Scalette, Monte delle Lamacce, Monte della Scoperta, Monte Gatta y Monte Baducco, que corresponden a los límites de la parte sur de los municipios de Camugnano y Castiglione dei Pepoli, colindantes con la Región Toscana. En la parte norte, el límite lo marcan las fronteras municipales de la parte norte de los municipios de Castiglione dei Pepoli, Camugnano, Castel di Casio y Porretta Terme. Los límites de la parte oeste del área recaen sobre la frontera regional que separan los municipios de Granaglione (Bolonia) con Pistoia (Toscana).

Las altitudes varían desde el punto más alto del Monte Orsigna (1555 m s. n. m.), situado justo entre las provincias de Pistoia (la vertiente sur pertenece a Pistoia) y la provincia de Bolonia (la vertiente norte pertenece a Granaglione y Porretta Terme) hasta el punto más bajo situado en Camugnano (271 m s. n. m.) (Tab. 1).

Tab. 1. Características y población del área de estudio.

${ }^{1}$ dato proporcionado por el Ayuntamiento (21-11-2015); ${ }^{2}$ dato Istat (31-12-2014) (Wikipedia, 2015c); ${ }^{3}$ dato proporcionado por Ayuntamiento de Castiglione dei Pepoli (2111-2015); ${ }^{4}$ dato Istat (31-12-2014) (Wikipedia, 2015d); ${ }^{5}$ (Wikipedia, 2015e); ${ }^{6}$ (Wikipedia, 2015f). Istat: Istituto nazionale di statistica.

\begin{tabular}{|c|c|c|c|c|c|c|}
\hline $\begin{array}{l}\text { Municipios del } \\
\text { área de estudio } \\
\text { (Provincia, } \\
\text { Región) }\end{array}$ & $\mathrm{KM}^{2}$ & $\begin{array}{l}\text { Densidad } \\
\mathrm{hab} / \mathrm{km}^{2}\end{array}$ & $\begin{array}{l}\text { Población } \\
\text { (núm. de } \\
\text { habitantes) }\end{array}$ & $\begin{array}{l}\text { Altitud } \\
\text { máxima } \\
\text { m s. n. } \\
\text { m. }\end{array}$ & $\begin{array}{l}\text { Altitud } \\
\text { mínima } \\
\text { m s. n. } \\
\text { m. }\end{array}$ & $\begin{array}{l}\text { Localidades de } \\
\text { los municipios } \\
\text { ("frazioni") }\end{array}$ \\
\hline $\begin{array}{l}\text { Camugnano } \\
\text { (Bolonia, } \\
\text { Emilia- }\end{array}$ & 96,61 & 19,54 & $1888^{1}$ & 1283 & 271 & $\begin{array}{l}\text { Guzzano, } \\
\text { Carpineta, } \\
\text { Stagno, Mogne, }\end{array}$ \\
\hline
\end{tabular}


María Teresa Egea Molines

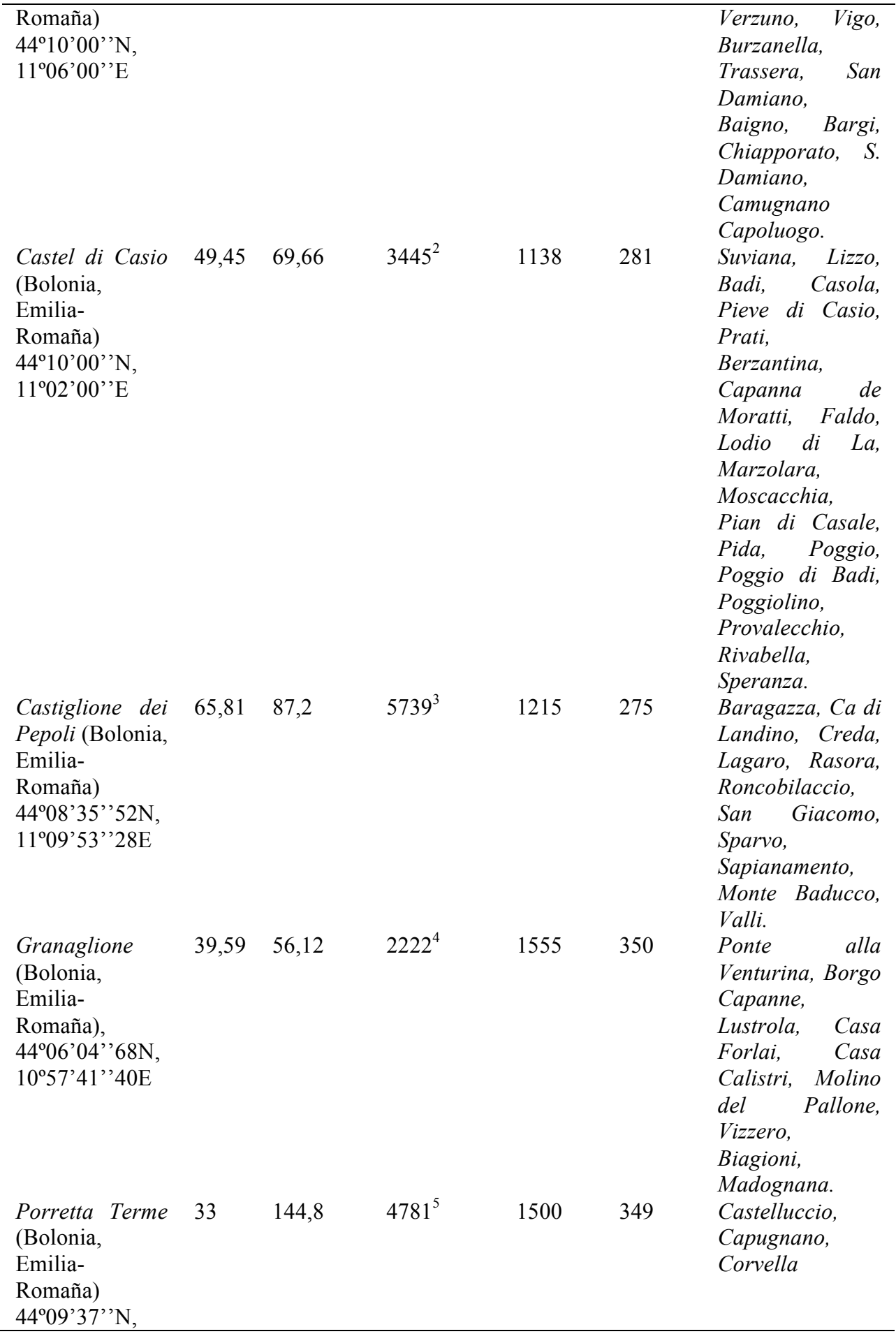


Etnobotánica en el Alto Valle del Reno (Toscana y Emilia-Romaña, Italia)

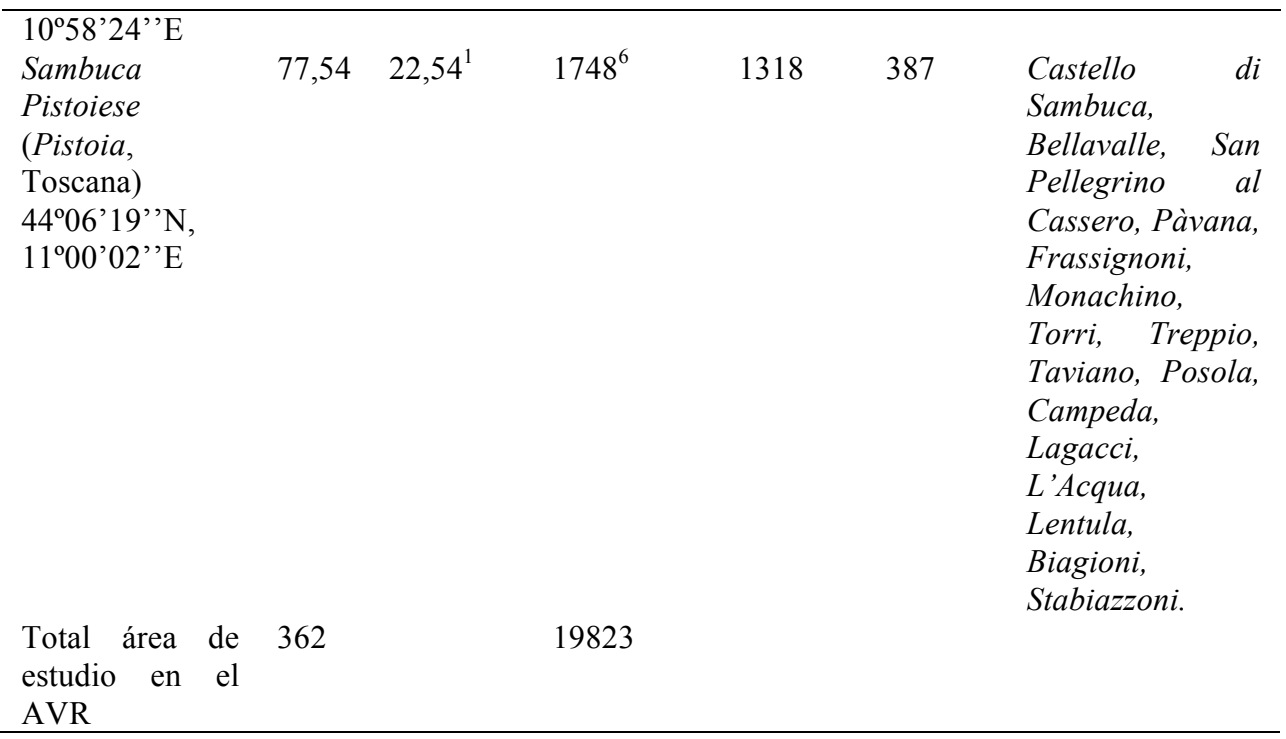

El área de estudio está compuesta por dos paisajes geomorfológicos principales: la cordillera de los Apeninos constituida por una litología arenoso-margosa (formación de piedra arenisca del Monte Cervarola) y la zona de piedemonte caracterizada por una litología arcilloso-margosa (formación de Porretta Terme y Brasimone) (Beghelli, 1999) (Imagen 2.6).

La primera se caracteriza por una cadena montañosa situada en la parte sureste (M. Calvi, M. della Scoperta, M. Casciaio) de aspecto rugoso, con pendientes pronunciadas y numerosas paredes verticales a menudo generadas por fallas (con altitudes máximas entre 1100 y 1300 m s. n. m.). Los valles principales del área de estudio están profundamente marcados por los ríos Randaragna, Reno, Limentra di Sambuca, Limentrella, Limentra Orientale, Brasimone y otros arroyos. Los valles se presentan estrechos, oscuros, encajados y simétricos en general, con tendencia a ser perpendiculares al eje de los Apeninos. Estos valles casi paralelos están cubiertos casi en su totalidad (90\% del territorio según VPSRU, 2013) de bosques densos y frondosos que presentan un aspecto salvaje e incontaminado. La barrera natural y biogeográfica que conforman, abarca principalmente los municipios de Granaglione, Sambuca Pistoiese y la parte sur de Camugnano. A partir de la localidad de Pàvana (margen derecho del Limentra di Sambuca, en Sambuca Pistoiese) y del límite norte del Parco dei laghi di Suviana e Brasimone, es decir, Badi (Castel di Casio), Bargi y Baigno (Camugnano) el paisaje empieza a cambiar dando lugar a una zona de colinas orientadas hacia el noroeste que tienden hacia la llanura boloñesa. Este otro tipo de paisaje más soleado y habitado, presenta una morfología más dulce, ligeramente ondulada (con cotas entre 600 y $800 \mathrm{~m} \mathrm{s.} \mathrm{n.} \mathrm{m),}$ con colinas poco marcadas (Beghelli, 1999) en el que, en un mosaico paisajístico, se alternan campos cultivados, pastos, matorrales y bosques, con terrazas fluviales, barrancos y acantilados rocosos marcados por el retículo hidrológico (que 
corresponde a la zona de Porretta Terme, Castel di Casio, Castiglione dei Pepoli, Camugnano) (Imagen 2.5).

\section{Sistema fluvial}

En el Alto Valle del Reno, las aguas son reconocidas como un elemento que ha caracterizado $\mathrm{y}$ ha marcado profundamente la cultura material del territorio (Ronchetti, s.d.). En estas tierras localizadas entre Bolonia y Pistoia, existe un fuerte vínculo con las aguas representadas por el río Reno y sus numerosos afluentes, ríos, cursos de aguas menores que marcan la geografía del territorio. El sistema fluvial ha proporcionado alimento y fuerza motriz para los numerosos molinos, batanes, herrerías, aserraderos, fábricas que caracterizan la zona, además de haber sido la fuente principal para la irrigación agrícola. El uso de las aguas del Reno ha influenciado profundamente la economía de la montaña e incluso hicieron de Bolonia, la primera ciudad industrial de Europa (ERT, 2012).

La zona se caracteriza por numerosos manantiales, acequias, canales, arroyos y lagos artificiales cuyas aguas se utilizan para diferentes fines. Antiguamente permitieron que numerosas aldeas de montaña aisladas fueran habitadas por las personas y sus animales. Los ríos y sus arroyos o torrentes eran utilizados para los numerosos molinos de agua de los cuales dependía la alimentación de la población local y parte de la economía familiar, así como para el transporte de la madera, para su comercio desde la montaña hasta la llanura (Guidotti, 1985). Actualmente las aguas del Reno se destinan para uso civil (suministro de agua local), para el riego, para la energía hidroeléctrica, para su uso deportivo y para el baño recreativo e incluso terapéutico. A principios del siglo $\mathrm{XX}$, se realizaron cuatro presas creando un complejo de 4 lagos artificiales interconectados para satisfacer la energía eléctrica del valle del Reno: Lago di Suviana, Bacino di Brasimone, Bacino di Pàvana y el Lago di Santa María (o Lago San Damiano) (PTP, 2008). Los lagos han modificado drásticamente la economía general del territorio, no sólo por el sector hidroeléctrico y el centro de investigación nuclear que albergan, sino por ser un recurso turístico y deportivo importante. Cabe mencionar las aguas termales de Porretta Terme que nacen en el estrecho valle del Rio Maggiore, un afluente del Reno (Terme Alte), y en el márgen izquierdo del Reno (Acqua Basse), las cuales han hecho de Porretta Terme un centro importante de bienestar y de salud (ERT, 2012).

El sistema fluvial de la cuenca del Alto Valle del Reno, está formado por los numerosos afluentes y torrentes que recibe el Reno en su tramo de montaña. De oeste a este, el retículo hidrográfico conforma la cuenca hidrográfica del río Randaragna, la cuenca principal del Reno, el Valle del Limentra y Limentrella, y el Valle del Brasimone (Fig. 7, Imagen 1.1).

En el margen izquierdo del Reno, y del área de estudio, se haya la cuenca hidrográfica del río Randaragna (Fig. 7, Imagen 1.4. y Imagen 1.5.), uno de los más importantes afluentes del Reno que conforma un valle perteneciente en su totalidad al municipio de Granaglione. La vega del Randaragna se presenta como un lugar incontaminado cubierto en su totalidad por bosque. 
El municipio de Sambuca Pistoiese se caracteriza por 3 crestas de montañas con tendencia SW-NE (algunas sobre los mil metros de altitud) cursados por cuatro ríos (de oeste a este) (Foggi et al., 2007) : el Reno, que marca la frontera regional entre Sambuca y Granaglione (Fig. 8, Imagen 2.4), el Limentra di Sambuca o Limentra Occidentale, que da lugar a la cuenca de Pàvana) y desemboca en el Reno en Ponte alla Venturina; el Limentrella, afluente del Limentra Orientale (Balletti y Gioffredi, 1997). En el límite este, el Limentra Orientale (Venturi, 2006) o Limentra di Treppio (como consta en la Carta degli itinerari Sambuca Pistoiese, Anónimo (s.d.)), el cual desemboca en el Lago de Suviana, marca la frontera del municipio toscano de Sambuca Pistoiese e irá a confluir a la derecha del río Reno, en la localidad de Riola (Vergato). Estos 4 ríos que constituyen la circunscripción RenoTre Limentre (Foggi et al., 2007) han formado valles profundos con un fondo muy estrecho, erosionables y ocupados casi en su totalidad por el cauce del río. Es importante resaltar la influencia biogeográfica y cultural que tienen los ríos en el Alto Valle del Reno, ejemplificándolo con el caso del Limentra di Sambuca, el cual crea una distinción clara a nivel vegetativo, climático y cultural entre el márgen izquierdo y el margen derecho del río. En la parte izquierda, crece mayoritariamente el castaño, el clima y la geomorfología son más duros y los habitantes son denominados popularmente como "merlacquai" (puede que sea por una referencia a la humedad de la zona por sus numerosos riachuelos y fosas, Guccini, 1998), los cuales eran de carácter más civilizado. En cambio en la parte derecha, la denominada "dla da l'acqua" (en la otra parte del agua), la geomorfología y la exposición al sol daban lugar a numerosos cultivos, maquias, y especies como Quecus cerris L. así como abundantes arbustos espinosos (Prunus spinosa L., Elaeagnus rhamnoides (L.) A.Nelson, Rubus spp., Rosa canina L. (s.1.)), por esto los habitantes eran denominados "spinaióli" (de espinas) y se caracterizaban por ser más salvajes.

La presa de Suviana se encuentra sobre el río Limentra di Treppio, forma el lago de Suviana (470 msnm) y alimenta la central hidroeléctrica situada en la parte inferior de la presa, que a su vez utiliza las aguas del embalse de Pàvana con la cual se comunican a través de grandes conductos (PTP, 2008) (Fig. 2.1).

El torrente Brasimone nace en la cresta que marca la frontera regional y resulta casi en su totalidad dentro del área protegida del "Parco dei laghi di Suviana e Brasimone". En la localidad de Le Scalere, se encuentra la represa que forma el Lago de Brasimone ( $845 \mathrm{~m}$ s. n. m.) al servicio del sistema hidroeléctrico RenoLimentra (Fig. 1.1), siendo comunicada con la "Presa de Suviana" a través de tuberías aprovechando el desnivel entre los dos lagos (aproximadamente de $375 \mathrm{~m}$ ). Después, el torrente Brasimone baja hacia el valle que se va ensanchando, y en Castiglione dei Pepoli, justo en el punto donde se une con el Rio Le Mogne, el torrente vuelve a ser cerrado por la presa de Santa Maria dando lugar al homónimo Lago di Santa Maria (o Lago di San Damiano), el cual alimenta a la correspondiente central hidroeléctrica. Seguidamente en Lagaro (Castiglione dei Pepoli), el Brasimone desemboca en el torrente Setta, otro afluente del río Reno (PTP, 2008). 


\section{Geología}

La génesis de la configuración geológica del territorio se da en la tectogénesis con convergencia africana (Burdigaliano) que ha conllevado a la apertura del Mediterráneo oriental y la colisión del bloque de Cerdeña y Córcega contra las unidades del antiguo margen africano. En este periodo se depositó el flysch de la Unidad Cervarola-Falterona, que representa el relleno de la primera zanja de la cadena apenínica (Oligoceno superior-Mioceno inferior).

El relleno se realizó en dirección NW-SE, tratándose de materiales de proveniencia alpina. El levantamiento de la cadena apenínica deformó fuertemente los depósitos provocando el plegamiento de los estratos y la intensa fracturación observables en los afloramientos. Las deformaciones principales se atribuyen al Tortoniense y durante ésta fase diastrófica se conformaron las unidades alóctonas. La fase distensiva que sucedió en el Plioceno medio confirió al Apenino Central los rasgos actuales (Elmi, 1999).

El territorio del área de estudio está compuesto por varios ámbitos geológicos y geomorfológicos en los que predominan las areniscas de Monte Cervarola o también denominadas Unidad del Dominio Toscano (Unidad Cervarola-Falterona) y la sucesión de la Unidad del Dominio Liguria (Formación Ponte della Venturina y Complejo caótico heterogéneo), en los que se encuentran también islotes de la Formación Porretta Terme (Oligoceno Superior- Mioceno inferior). En éstos terrenos se sobreponen geométricamente formaciones mucho más recientes, esencialmente detríticas o de deposición fluvial reciente (Elmi, 1999).

Las areniscas de la subunidad Monte Cervarola (Oligoceno Superior - Mioceno inferior) se encuentran en gran parte del territorio de Sambuca Pistoiese, Granaglione, y en la parte Sur del Parque Regional (Fig. 2, n.3). Se trata de areniscas turbiditícas cuarzosas feldespáticas de grano fino, en capas finas, con intervalos frecuentes de margas limolíticas y limolitas, raras intercalaciones de turbiditas de grano grueso e intercalaciones de margas grises, arcillas de varios colores y limos (Venturi, 2006) (Fig. 2.3).

La Formación Ponte della Venturina (Cretáceo-Eoceno) se extiende desde la parte norte de Granaglione (Ponte della Venturina), pasando por Pàvana de Sambuca Pistoiese, los alrededores del Lago de Suviana (Fig. 2, n.4). Se trata prevalentemente de litotipos arcillitas arcillas margosas de color gris oscuro hasta negro, con frecuentes venas blanquecinas de calcita y capas de 20 a $60 \mathrm{~cm}$ de calizas micríticas y/o margosas a menudo silíceas, de color gris oscuro.

La Formación Porretta Terme (Oligoceno Superior-Mioceno inferior) se encuentra en forma de terrones flotantes parautóctonos (denominadas así porque se ha sedimentado in situ sobre las arcillitas margosas de la primera capa gravitacional Formación Ponte della Venturina durante su sedimentación). Se trata de margas limosas en escamas, calizas margosas de color oscuro y areniscas cuarzofeldespáticas con matriz micácea. Estas tres facies sobrepuestas afloran en las franjas del Parque alineados en dirección NW-SE.

La morfología cambia completamente a partir del Norte de Pàvana debido a las argilitas del Sistema caótico heterogéneo, fácilmente erosionable, que forman relieves redondeados, laderas con débiles pendientes y valles con fondos anchos, en 
el que el cauce fluvial cambia a menudo su curso con formaciones continuas de terrazas, constituyendo el típico paisaje "emiliano"( Fig. 1.2), determinado por una fuerte erosión areal, que se contrapone al paisaje más áspero y duro de la zona pistoyesa, donde predomina la erosión linear de los cursos de agua (Fig. 2.2). El Sistema caótico heterogéneo (Cretáceo-Eoceno) cubre toda la parte Norte del área de estudio (desde Pàvana hasta el Norte), (excepto una los islotes que se dan en Castel di Casio en la que se encuentra la Formación de Monghidoro y en el islote de Camugnano con la Formación de Camugnano). Se trata de una unidad en la que se alternan de manera irregular, arcilla y arcillas fisionables grises y verdes, a veces se pueden observar capas intercaladas de calcareníticas y calcilutitas de espesor muy variable. En las argilitas se pueden encontrar capas únicas o grupos de finas turbiditas areniscas-pelíticas con granos de medianos a muy finos. El aspecto es caótico, con bloques calcáreos completamente aislados, cataclásticos y dispersos irregularmente en la pelita muy deformada (Elmi, 1999).

En el área de estudio los terrenos más evolucionados y profundos se encuentran en los hayedos con elevada cobertura y pendiente moderada. Generalmente éstos terrenos se caracterizan por una textura arenosa, con lo cual tienen un buen drenaje, una buena compenetración de la sustancia orgánica con la fracción mineral, una reacción débilmente ácida y un cúmulo de elementos limosos arcillosos en los horizontes inferiores (Venturi, 2006). En cambio, en los terrenos degradados en los que los horizontes superiores presentan fenómenos erosivos, prevalece la roca madre en cuanto a las características de estructura y textura de los horizontes: se dan en bosques de monte bajo escasos sobre terrenos de acusada pendiente, en las áreas donde se dieron en el pasado un intenso pastoreo y en correspondencia a los afloramientos rocosos (Venturi, 2006). La acción antrópica ha modificado la estructura clímax el suelo considerablemente, determinando los procesos de degradación pedológica que se dan actualmente. Los principales factores de degradación pueden ser desde la gestión que incluye la tala de ciclo corto, que ha reducido la densidad de los tocones y la consecuente disminución de la cobertura forestal, provocando procesos de erosión superficial del terreno, hasta el pastoreo o el laboreo del suelo (Susmel, 1964).

\section{Climatología}

El clima del área de estudio es prevalentemente de tipo apenínico, con inviernos muy fríos y una presencia constante de precipitaciones nevosas cada año, y veranos calientes. La climatología de la zona cuenta con 4 estaciones bien diferenciadas, muy características del clima continental. A pesar de que las características térmicas se acentúen en verano y en invierno, las estaciones intermedias se reducen en breves periodos de transición entre la situación invernal y la estiva. La influencia reducida del mar hace más amplias las oscilaciones térmicas.

Para la descripción climatológica, los datos termopluviométricos tomados en consideración corresponden a las estaciones de Pracchia (Pistoia, muy cerca de 


\section{María Teresa Egea Molines}

Granaglione), de Acquerino (Sambuca Pistoiese, en el Valle del Limentra de Treppio), (Foggi et al. 2007) y de la estación de Suviana (Parco dei laghi di Suviana e Brasimone) cuyos datos han sido extraídos de la página web de la región EmiliaRomaña (ARPA, 2012). Se presentan los valores medios mensuales de temperaturas y precipitaciones observados en el periodo 1956-1985 para las estaciones de Pracchia y Acquerino, y en el periodo 1961-1990 para la estación de Suviana.

Los datos climáticos relativos a la estación de Pracchia y Acquerino se muestran en la Tab. 2 y Fig. 3, y Tab. 3 y Fig. 4 respectivamente. A partir de los valores PE (potencial de evapotranspiración) y el índice CE (concentración de verano del PE) de la fórmula climática, según la clasificación Thornthwaite (1948) y Thornthwaite y Mather (1957), se deduce que el tipo de clima corresponde al primer mesotérmico ( $\mathrm{B}^{\prime} 1$ ) con tendencia a la suboceanicidad (b'4) en el caso de Pracchia y a una mayor continentalidad (b'3) en el Acquerino (Foggi et al., 2007). Los valores de Im (índice de humedad global) e Ia (índice de aridez) indican respectivamente un tipo climático perhúmedo (o hiperhúmedo según las escuela geobotánica española) (A2) y una deficiencia hídrica de verano (r) muy pequeña (Foggi et al., 2007). En las figuras 3 y 4, se encuentran los gráficos relativos al balance hídrico, en las ordenadas aparecen los valores medios de las precipitaciones en $\mathrm{mm}$, del surplus hídrico $\mathrm{S}$ (en negro) y del déficit hídrico $\mathrm{D}$ (blanco con puntos negros) y de la recarga (en tramado); ésta última representa la fase de reconstitución de las reservas hídricas del suelo. En las estaciones examinadas, el déficit hídrico se observa en los meses de Julio y Agosto, mientras la recarga en el mes de septiembre.

Tab. 2. Datos termopluviométricos relativos a la estación de Pracchia (Pi).

Alt. 627 m, Lat. $44^{\circ}$ N. Códigos: GEN: Enero; FEB: Febrero; MAR: Marzo; APR: Abril; MAG: Mayo; GIU: Junio; LUG: Julio; AGO: Agosto; SET: Septiembre; OTT: Octubre; NOV: Noviembre; DIC: Diciembre. $\mathrm{T}^{\circ} \mathrm{C}$ : Temperatura media, P: Precipitaciones. ANNO: año.

\begin{tabular}{llllllllllllll}
\hline & GEN & FEB & MAR & APR & MAG & GIU & LUG & AGO & SET & OTT & NOV & DIC & ANNO \\
$\mathrm{T}^{\circ} \mathrm{C}$ & 1,8 & 2,6 & 4,9 & 8,0 & 12,0 & 15,3 & 17,9 & 17,6 & 14,7 & 10,4 & 5,8 & 2,7 & 9,5 \\
$\mathrm{P}$ & 208 & 218 & 187 & 170 & 116 & 91 & 58 & 84 & 148 & 210 & 258 & 237 & 1985 \\
\hline
\end{tabular}

Tab. 3. Datos termopluviométricos relativos a la estación Acquerino (PI).

Alt. 890 m, Lat. $44^{\circ}$ N. Códigos: GEN: Enero; FEB: Febrero; MAR: Marzo; APR: Abril; MAG: Mayo; GIU: Junio; LUG: Julio; AGO: Agosto; SET: Septiembre; OTT: Octubre; NOV: Noviembre; DIC: Diciembre. $\mathrm{T}^{\circ} \mathrm{C}$ : Temperatura media, P: Precipitaciones, ANNO: año.

\begin{tabular}{|c|c|c|c|c|c|c|c|c|c|c|c|c|c|}
\hline & GEN & FEB & MAR & APR & MAG & GIU & LUG & AGO & SET & OTT & $\mathrm{NOV}$ & DIC & ANNO \\
\hline $\mathrm{T}^{\circ} \mathrm{C}$ & 1,1 & 1,6 & 3,9 & 7,0 & 11,0 & 14,6 & 17,5 & 17,3 & 14,4 & 10,1 & 5,5 & 2,3 & 8,0 \\
\hline $\mathrm{P}$ & 232 & 229 & 201 & 172 & 133 & 98 & 62 & 91 & 147 & 219 & 257 & 247 & 2088 \\
\hline
\end{tabular}


Etnobotánica en el Alto Valle del Reno (Toscana y Emilia-Romaña, Italia)

En cuanto a los datos termopluviométricos de la estación de Suviana (Tab. 4), en provincia de Bolonia, vemos como de diciembre a marzo, las temperaturas medias están por debajo de $10^{\circ} \mathrm{C}$, de abril a junio, las temperaturas medias están entre los $10^{\circ} \mathrm{C}$ y $19^{\circ} \mathrm{C}$, y en julio y agosto llegan a 21 grados, bajando de nuevo de septiembre a noviembre, en el que la temperatura media disminuye suavemente desde 17 grados a 8 grados para afrontar de nuevo el duro invierno. La temperatura máxima absoluta es de $38,6^{\circ}$ y la temperatura mínima absoluta es de $-13.4^{\circ}$. El promedio de la precipitación anual es de $1289.6 \mathrm{~mm}$. El mes más lluvioso es noviembre, con 177,9 Mm de precipitación media y el mes más seco es julio, con un promedio de 54,3 $\mathrm{mm}$.

Según el climograma Walter y Lieth (Fig. 5), resulta que en el área no se da un periodo de aridez estiva, ya que la curva de las precipitaciones no se cruza con la curva de la temperatura, manteniéndose siempre por encima de ésta.

Tab. 4. Datos termopluviométricos relativos a la estación de Suviana (BO).

Alt. 500 m, Lat. 44'13' N. Códigos: GEN: Enero; FEB: Febrero; MAR: Marzo; APR: Abril; MAG: Mayo; GIU: Junio; LUG: Julio; AGO: Agosto; SET: Septiembre; OTT: Octubre; NOV: Noviembre; DIC: Diciembre.

\begin{tabular}{cccccccccccccc}
\hline & GEN & FEB & MAR & APR & MAG & GIU & LUG & AGO & SET & OTT & NOV & DIC & ANNO \\
$\mathbf{T}^{\circ} \mathbf{C}$ & 3,0 & 4,3 & 6,9 & 10,6 & 14,6 & 18,1 & 21,2 & 21,0 & 17,9 & 13,4 & 7,9 & 4,3 & 11,93 \\
& & & & & & & & & & & & & \\
$\mathbf{P}$ & 124,4 & 106,3 & 119,8 & 111,8 & 85,2 & 78,9 & 54,3 & 72,9 & 100,1 & 127,2 & 177,9 & 130,8 & 1289,6 \\
& & & & & & & & & & & & & \\
\hline
\end{tabular}

Las temperaturas en la zona de estudio pueden ser condicionadas por factores relacionados con el movimiento de las masas de aire a gran escala, por la presencia de las dos cuencas, por la presencia de la cordillera de los Apeninos, por los factores locales morfológicos, tales como los valles estrechos o la exposición de las vertientes. 


\section{Flora y vegetación}

Desde el punto de vista biogeográfico, el Alto Valle del Reno ocupa una posición extremadamente importante a nivel nacional y europeo, ya que se sitúa justo en la zona de transición entre la región centroeuropea y la región mediterránea (Adamovic, 1933; Pignatti et al., 2001), y esto hace que en el territorio exista una flora rica y variada (Fig. 6).

\subsection{Los bosques}

Según la clasificación fitoclimática del sistema Pavari (1916) y De Phillipis (1937) las fitocenosis forestales del área de estudio se encuentran por completo en el área de Castanetum y Fagetum (Balletti, 2001a)

Los bosques constituyen el $85 \%$ de la cubierta vegetal en el Parco dei laghi di Suviana e Brasimone y $90 \%$ en Granaglione y Sambuca Pistoiese (Balletti y Gioffredi, 1997; PTP, 2008; VPSRU, 2013) (Imagen 1.4; 1.5). Entre estas prevalecen los bosques de hayas (Fagus sylvatica L.), que representa el $30 \%$ de los bosques de la zona de estudio. Se distinguen dos tipologías principales de bosques en función de la altitud, la geología y el clima. Los bosques de la franja colinarsubmontana o piedemonte (aproximadamente hasta 800 y $900 \mathrm{~m}$ s. n. m.), pertenecientes a la zona fitoclimática del Castanetum, son bosques mixtos y caducifolios, se caracterizan principalmente por robledales mixtos y castañares de sustitución. El bosque de robles está constituido principalmente por dos especies caducifolias que crecen hasta los 600 m s. n. m.: Quercus pubescens Willd., típica de ambientes secos y calientes, y Quercus cerris L., el cual prefiere suelos más arcillosos (como la parte Noreste de Sambuca Pistoiese, la denominada "dla da l'acqua"). Desde los 500 hasta los 900 m s. n. m., en función de la exposición y en los suelos ácidos y no arcillosos, predomina el bosque de castaños de origen antropogénico que se caracteriza por un alto grado de artificialidad, aunque por el abandono generalizado de ésta práctica, se encuentran alternados con castañares asilvestrados (Imagen 1.3). Actualmente los castañares constituyen bosques donde el castaño se encuentra espontáneamente mezclado con Fagus sylvatica L., en suelos profundos y ácidos, en lugares con moderada pendiente y orientados hacia el norte. Y en suelos más finos y rocosos prevalecen Ostrya carpinifolia Scop. y Fraxinus ornus L., cultivados a menudo para la producción de carbón o madera. Entre las especies menos frecuentes se encuentran Sorbus torminalis (L.) Crantz, Acer opalus Mill., Acer campestre L., Carpinus betulus L., Laburnum anagyroides Medik. y sólo en los lugares más frescos Fagus sylvatica L. (Balletti, 1997).

En la zona son frecuentes las formaciones mixtas de bosques y arbustos en las orillas de los arroyos y de los humedales, compuestas por Salix alba L., Salix eleagnos Scop., Salix apennina A.K.Skvortsov, Salix purpurea L., Salix triandra L., Populus nigra L., Alnus glutinosa (L.) Gaertn., acompañados por la presencia de especies no estrictamente ribereñas, como Acer pseudoplatanus L., Fraxinus ornus L. y a veces Fagus sylvatica L. (Imagen 2.7). 
En cambio, en la franja montañosa (a partir de los 900 m s. n. m.) perteneciente a la zona fitoclimática Fagetum, la vegetación dominante es Fagus sylvatica L., que a veces se alterna con plantaciones antrópicas de coníferas como Abies alba Mill., Picea abies (L.) H.Karst., Pinus nigra J.F.Arnold o Pseudotsuga menziesii (Mirb.) Franco. En esta zona de la montaña, los suelos son de piedra arenisca y los bosques son seminaturales para la producción de madera o carbón (práctica caída en desuso en la actualidad). El haya tiende a formar bosques puros donde se encuentra como única especie arbórea, pero esporádicamente puede formar bosques mixtos con otros especies latifolias típicas de la franja montañosa como Acer pseudoplatanus L., Laburnum anagyroides Medik., Sorbus aucuparia L., Picea abies (L.) H.Karst., Prunus avium (L.) L. y Salix caprea L. El haya se encuentra además en altitudes inferiores, en ciertas zonas de las vaguadas estrechas de los ríos, donde se da un estancamiento de área fría y húmeda, que determina unas condiciones climáticas aptas para el haya que crece junto al Alnus glutinosa (L.) Gaertn. y al Salix alba L. entorno a los $600 \mathrm{~m} \mathrm{s.} \mathrm{n.} \mathrm{m.}$

\subsection{Vegetación y flora arbustiva}

En el Parque Regional "Parco dei laghi di Suviana e Brasimone", las comunidades vegetales arbustivas presentan la mayor diversidad con 185 especies que representan aproximadamente el $30 \%$ de todas las especies estudiadas en el Parque (Sirotti, 1999). Esta riqueza florística notable está relacionada con el hecho de que estas formaciones corresponden a las fases de la reconstitución del bosque a partir de los pastos y los cultivos abandonados; por lo tanto, comprenden tanto especies de praderas como elementos preforestales. Entre éstas, se encuentran muchas especies de arbustos típicos del sotobosque del piedemonte y de las reforestaciones tales como el Crataegus monogyna Jacq., Crataegus rhipidophylla Gand., Cornus mas L., Cornus sanguinea L., Lonicera caprifolium L., Lonicera xylosteum L. y otras como Euonymus latifolius (L.) Mill., Daphne laureola L., Hippocrepis emerus (L.) Lassen.

Los arbustos pueden presentarse como comunidades vegetales densas y extensas, o como formaciones lineales dominadas por Prunus spinosa L. y acompañado por Pyrus pyraster (L.) Burgsd., Crataegus sp. y Cornus mas L.

En los castañares de fruto, eran típicas la formaciones de Vaccinium myrtillus L. y Rubus idaeus L. aunque actualmente por el abandono de los cultivos, el aumento de densidad de estos bosques y la proliferación de los ungulados en el territorio, este tipo de especies son muy raras en estado silvestre.

Las comunidades de recolonización también pueden estar formadas por grupos de los acidófilos Pteridium aquilinum (L.) Kuhn (Ponzetta et al., 2007) en suelos de piedra arenisca, originados por la tala de los bosques de hayas o por el abandono de pastizales muy explotados por el hombre. El helecho puede estar acompañado por arbustos más o menos acidófilos como Cytisus scoparius (L.) Link, Rubus idaeus L. y otros.

La siguiente formación evolutiva está representada por arbustos y pastos de arbustos acidófilos de Cytisus scoparius (L.) Link a veces mezclados con los ya mencionados Pyrus pyraster (L.) Burgsd. y Prunus avium (L.) L. (PTP, 2008). 


\subsection{Vegetación y flora herbácea}

Se diferencian distintos tipos de comunidades herbáceas en función de la corología y de la gestión antrópica. Se encuentran agrupaciones discontinuas sobre laderas rocosas, constituidas por especies herbáceas perennes y pequeños arbustos como Helichrysum italicum (Roth) G.Don, Thymus longicaulis C.Pesl, Sesleria insularis Sommier, Astragalus hypoglottis L., Lotus corniculatus L., Vulpia brevis Boiss. \& Kotschy, Knautia purpurea (Vill.) Bordás, Sanguisorba minor Scop., Sempervivum tectorum L., Silene vulgaris (Moench) Garcke, Teucrium montanum L., Galium lucidum All., Amelanchier ovalis Medik. En el territorio del "Parco dei laghi di Suviana e Brasimone", en este tipo de praderas se han registrado 79 especies, lo que representa el $12,5 \%$ de la flora de las comunidades de plantas herbáceas del Parque (Sirotti, 1999). La vegetación de las praderas húmedas en las orillas de los lagos sobre suelo de granulometría fina está constituida por especies como Agrostis stolonifera L., Carex hirta L., Juncus inflexus L., Rumex obtusifolius L. En el Parque las comunidades de plantas herbáceas antropogénicas dedicadas a los cultivos muestran una importante riqueza florística, respecto a la reducida extensión del territorio que ocupan (Sirotti, 1999).

En el sotobosque del castañar se encuentran especies acidófilas, como Calluna vulgaris (L.) Hull, Fragaria vesca L. y Geranium nodosum L.

En los campos y pastos soleados (como en la denominada zona "dla da l'acqua" con suelos arcillosos) son muy comunes diferentes tipos de orquídeas como Epipactis helleborine (L.) Crantz, Neottia nidus-avis (L.) Rich., Limodorum abortivum (L.) Sw. En los claros de bosque se encuentran también Cephalantera longifolia (L.) Fritsch, Cephalantera rubra (L.) Rich., Dactylorhiza maculata (L.) Soó, Orchis mascula (L.) L., Orchis provincialis (Balb. ex Lam. \& DC.), Anacamptis pyramidalis (L.) Rich., Dactylorhiza sambucina (L.) Soó, Anacamptis morio (L.) R.M.Bateman, Pridgeon \& M.W.Chase. (Balletti y Gioffredi, 1997).

Los prados permanentes cortados o pastoreados comprenden muchas especies, entre las cuales prevalecen, en función de las características micro ambientales y de las prácticas culturales, Arrhenatherum elatius (L.) P.Beauv. ex J.Presl \& C.Presl., Bromus erectus Huds., Dactylis glomerata L., Onobrychis viciifolia Scop., Trisetum flavescens (L.) P.Beauv., junto con una variedad de especies mesófilas como Trifolium sp.pl., Plantago lanceolata L., Leontodon hispidus L., Rumex acetosa L. y otras especies meso-xerófilos como Sanguisorba minor Scop., Ranunculus bulbosus L., Campanula sp.pl., Salvia pratensis L., así como especies sinantrópicas como Convolvulus arvensis L., Bunium bulbocastanum L., Agropyron repens (L.) P.Beauv. En el "Parco dei laghi di Suviana e Brasimone", se detectaron en este tipo de praderas 158 especies, que representan el 25\% de la flora total del Parque (Sirotti, 1999).

Las praderas secundarias meso-xerófila, más o menos arbustivas, muestran una prevalencia de gramíneas como Bromus erectus Huds. y Brachypodium pinnatum (L.) P.Beauv., que pueden ir acompañadas de Dactylis glomerata L., Sanguisorba minor Scop., Hypericum perforatum L., Lotus corniculatus L., Phleum pratense L., Trifolium ochroleucum Huds., Hippocrepis comosa L., Thymus longicaulis C.Presl, Knautia purpurea (Vill) Borbás, entre otras especies. En el territorio del Parque, en 
estos pastizales se han registrado 164 especies, es decir, el $26 \%$ de la flora total, (Sirotti, 1999). Muchas de éstas praderas anteriormente cultivadas o pastoreadas, han sido abandonadas y colonizadas en diversos grados por arbustos como Rosa canina L., Rubus ulmifolius Schott, Prunus spinosa L., Cytisus scoparius (L.) Link, Crataegus sp. pl. y Juniperus communis L., creando fases dinámicas diversas hacia la formación de las fitocenosis arbustivas citadas anteriormente. Igualmente en el Parque, las formaciones herbáceas cultivadas (alfalfa, heno, cereales) abarcan una gran riqueza florística respecto al territorio que ocupan (13-14\% de la flora total de Parque Regional, con una cobertura del 1\% de la totalidad del territorio (Sirotti, 1999).

Los cultivos de forrajes periódicamente cortados con prevalencia de Medicago sativa L. y Lolium multiflorum Lam. albergan especies como Convolvulus arvensis L., Helminthotheca echioides (L.) Holub., Elymus repens (L.) Gould. características de las zonas antropizadas, prestándose a la inclusión espontánea (durante el año siguiente de la siembra) de las especies perennes de prados como Dactylis glomerata L., Crepis vesicaria L., Rumex acetosa L. y otros. Los campos de cultivo de cereales invernales (cebada o trigo) trabajados anualmente se caracterizan por una buena diversidad florística y la presencia de terófitos comensales como Cyanus segetum Hill., Ranunculus arvensis L., Legousia speculum-veneris (L.) Durande ex Vill. o Papaver rhoeas L. Aunque estas especies son cada vez más raras a causa de las técnicas modernas agronómicas como la selección de las semillas, el laboreo profundo, los herbicidas químicos, el uso de variedades seleccionadas con una elevada uniformidad genética.

\section{6. Áreas protegidas}

Este particular contexto ambiental hace que el Alto Valle del Reno albergue una extraordinaria y rica diversidad biológica conservada y tutelada por diferentes áreas protegidas y Sitios de Importancia Comunitarios (SIC o LIC).

En el territorio estudiado del Alto Valle del Reno, se encuentran el "Parco dei laghi di Suviana e Brasimone" (o "Parco dei laghi") que cubre una superficie de 3300 hectáreas, incluidas en los municipios de Camugnano, Castel di Casio y Castiglione dei Pepoli (BO) (Fig. 7). Fue instituido con la L.R. 14 Abril 1995 n.38 y más de la mitad del territorio del Parque (1900 hectáreas) está reconocida como Sitio de Importancia Comunitaria (SIC IT 4050020) por su gran valor naturalístico y el elevado grado de biodiversidad.

En la parte Toscana, la creación de la Reserva Natural Biogenética de Acquerino (242 ha) y de la Reserva Natural Acquerino-Cantagallo (Arrigoni et al., 2002) en la parte este de Sambuca Pistoiese también ha reconocido el valor naturalístico del área. Igualmente merecen ser mencionados los Sitios de Importancia Comunitarios (SIC) otorgados por la Comunidad Europea y Red Natura 2000 (92/43/CEE) en el área de estudio como "Tre Limentre-Reno" (IT 5130009), "Monte Vigese" (IT4050013) y el "Monte Gennaio" (IT5130006).

En el resto del territorio del Alto Valle del Reno también se hayan otras importantes áreas protegidas como el "Parco Regionale Corno alle Scale", "Parco 
Monte Sole", "Parco Provinciale di Montovolo" confinantes con el área de estudio, que demuestran la riqueza biológica y ambiental del territorio en cuestión.

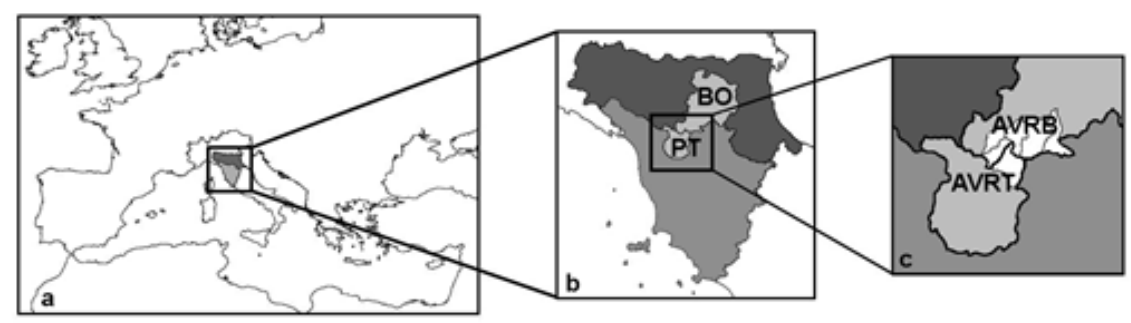

Fig. 1 Localización del área de estudio.

a) Localización de Toscana (gris) y Emilia-Romaña (gris oscuro) en Europa; b) PT: provincia de Pistoia (Toscana); BO: provincia de Bolonia (Emilia-Romaña); c) en blanco: los seis municipios del área de estudio; AVRT: Alto Valle del Reno, parte toscana; AVRB: Alto Valle del Reno, parte emiliana. 
Etnobotánica en el Alto Valle del Reno (Toscana y Emilia-Romaña, Italia)

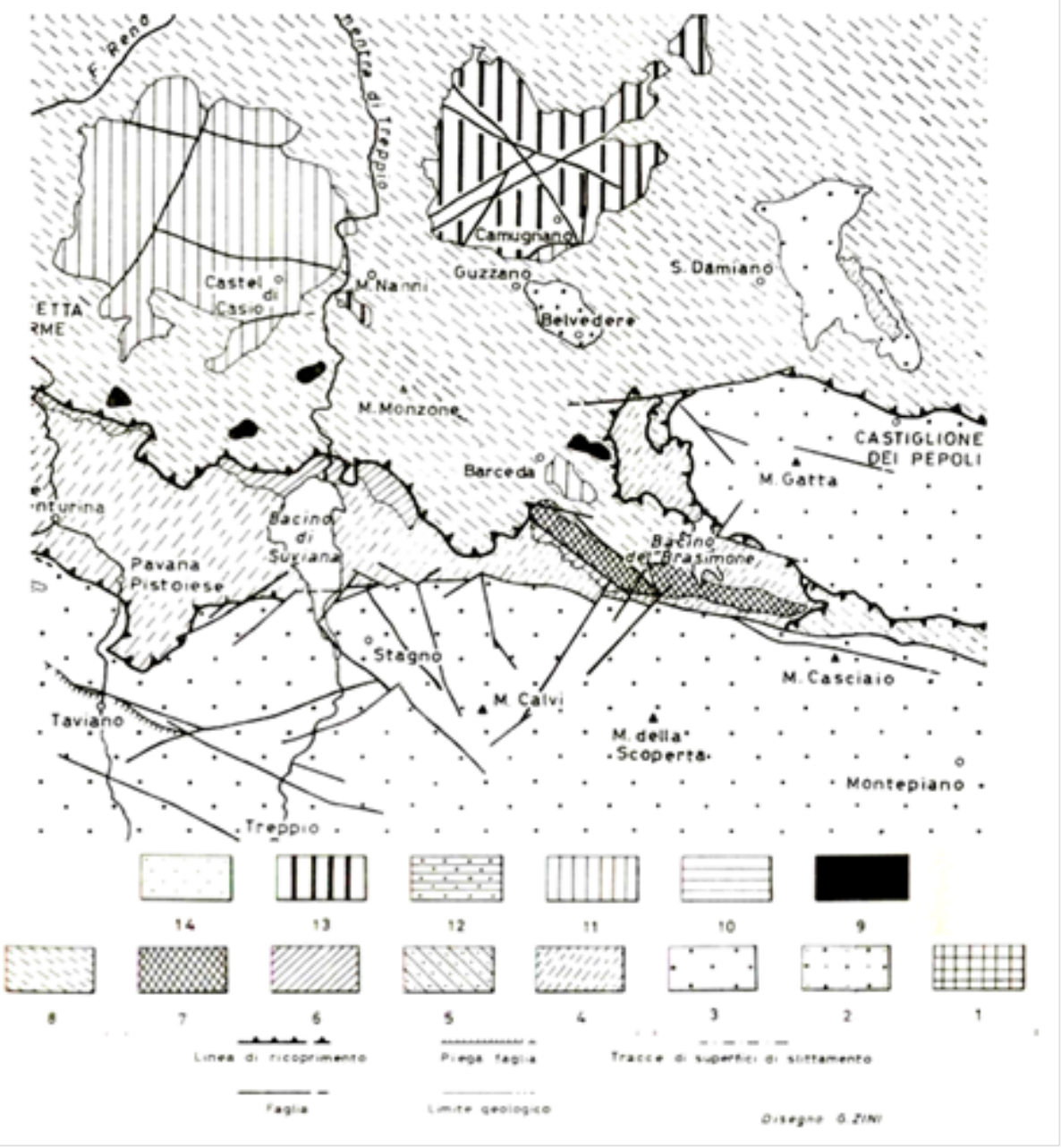

Fig. 2. Carta geológica del Apenino Norte (parte emiliana) desde Abetone (Pistoia) hasta Castiglione dei Pepoli (Bolonia).

Detalle, (PTP, 2008). 3: Formación Monte Cervarola; 4: Formación Ponte della Venturina; 6: Formación Porretta Terme; 8: Complejo caótico heterogéneo; Formación de Monghidoro (islote de Castel di Casio y Barceda del Cretácico superior-Paleoceno); Formación de Camugnano (islote de Camugnano y de Mulino Nanni del Cretácico superiorEoceno). 


\section{María Teresa Egea Molines}

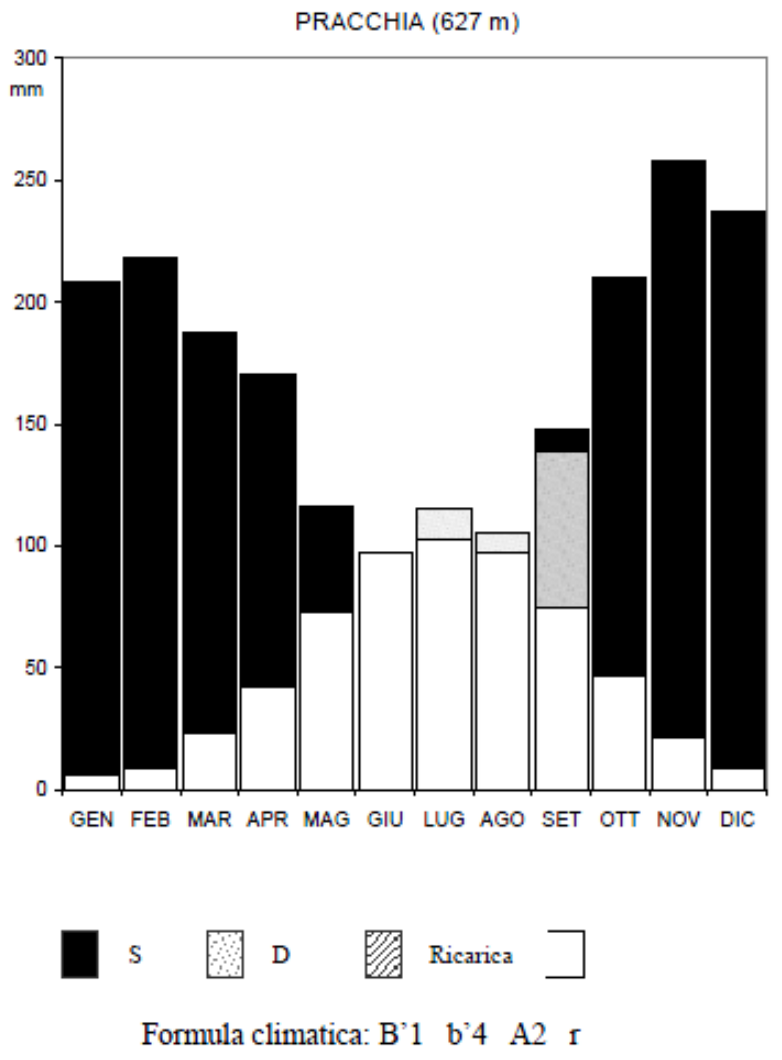

Fig. 3. Balance hídrico y fórmula climática según Thornthwaite relativas a la estación Pracchia (PI) extraído de Foggi et al., 2007.

Códigos: GEN: Enero; FEB: Febrero; MAR: Marzo; APR: Abril; MAG: Mayo; GIU: Junio; LUG: Julio; AGO: Agosto; SET: Septiembre; OTT: Octubre; NOV: Noviembre; DIC: Diciembre. Formula climática: Fórmula climática. 
Etnobotánica en el Alto Valle del Reno (Toscana y Emilia-Romaña, Italia)

ACQUERINO $(890 \mathrm{~m})$

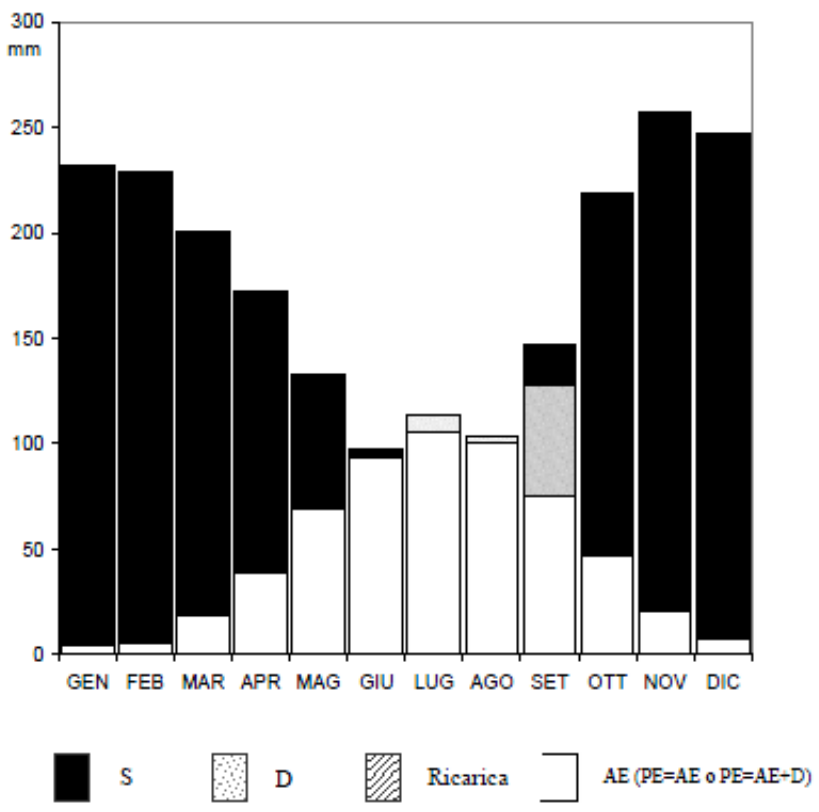

Formula climatica: B'1 b'3 A2 r

Fig. 4. Balance hídrico y fórmula climática según Thornthwaite relativas a la estación de Acquerino (PI), extraído de Foggi et al., 2007.

Códigos: GEN: Enero; FEB: Febrero; MAR: Marzo; APR: Abril; MAG: Mayo; GIU: Junio; LUG: Julio; AGO: Agosto; SET: Septiembre; OTT: Octubre; NOV: Noviembre; DIC: Diciembre. Formula climática: Formula climática. 


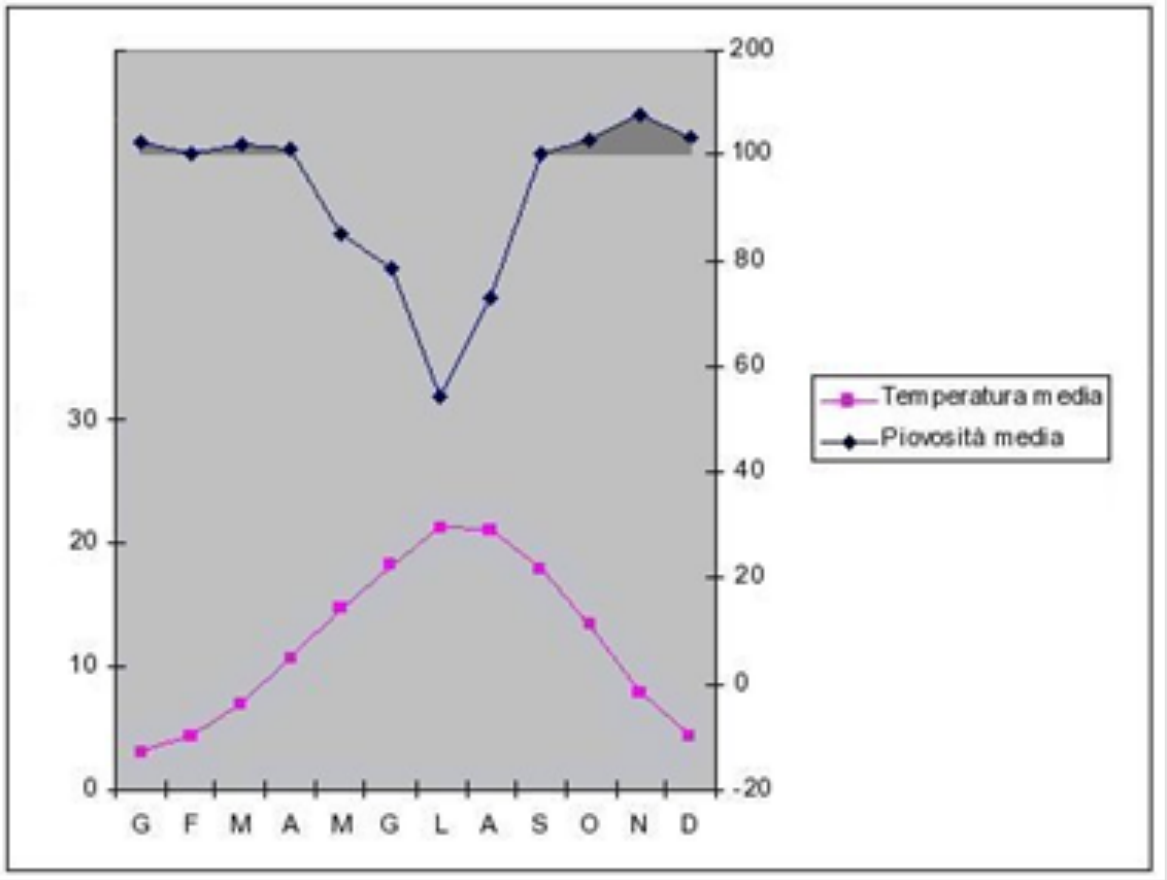

Fig. 5. Climograma según Walter y Lieth relativo a la estación Suviana (BO).

Datos extraídos de ARPA (2012). Temperatura media: Temperatura media; Piovosità media: Pluviosidad media, Códigos: GEN: Enero; FEB: Febrero; MAR: Marzo; APR: Abril; MAG: Mayo; GIU: Junio; LUG: Julio; AGO: Agosto; SET: Septiembre; OTT: Octubre; NOV: Noviembre; DIC: Diciembre. 


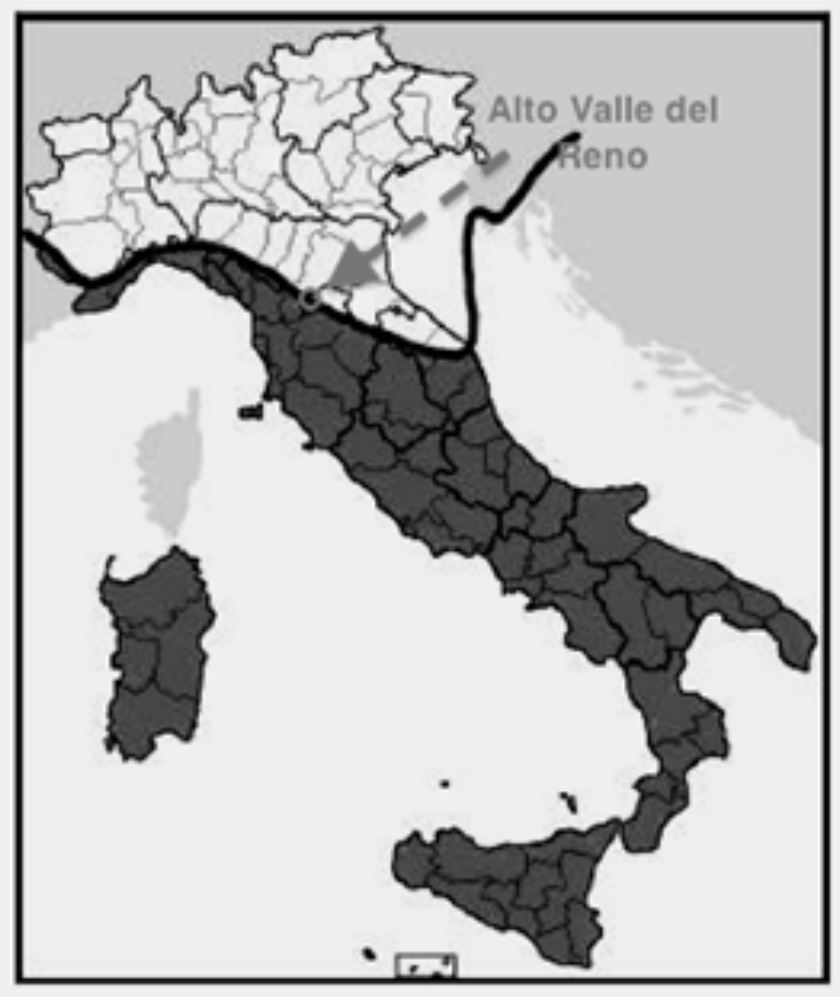

Fig. 6. Zonas biogeográficas italianas.

(Arriba la centroeuropea y abajo la mediterránea) y el límite biogeográfico situado sobre el Alto Valle del Reno (extraído de Pignatti et al., 2001) 
María Teresa Egea Molines

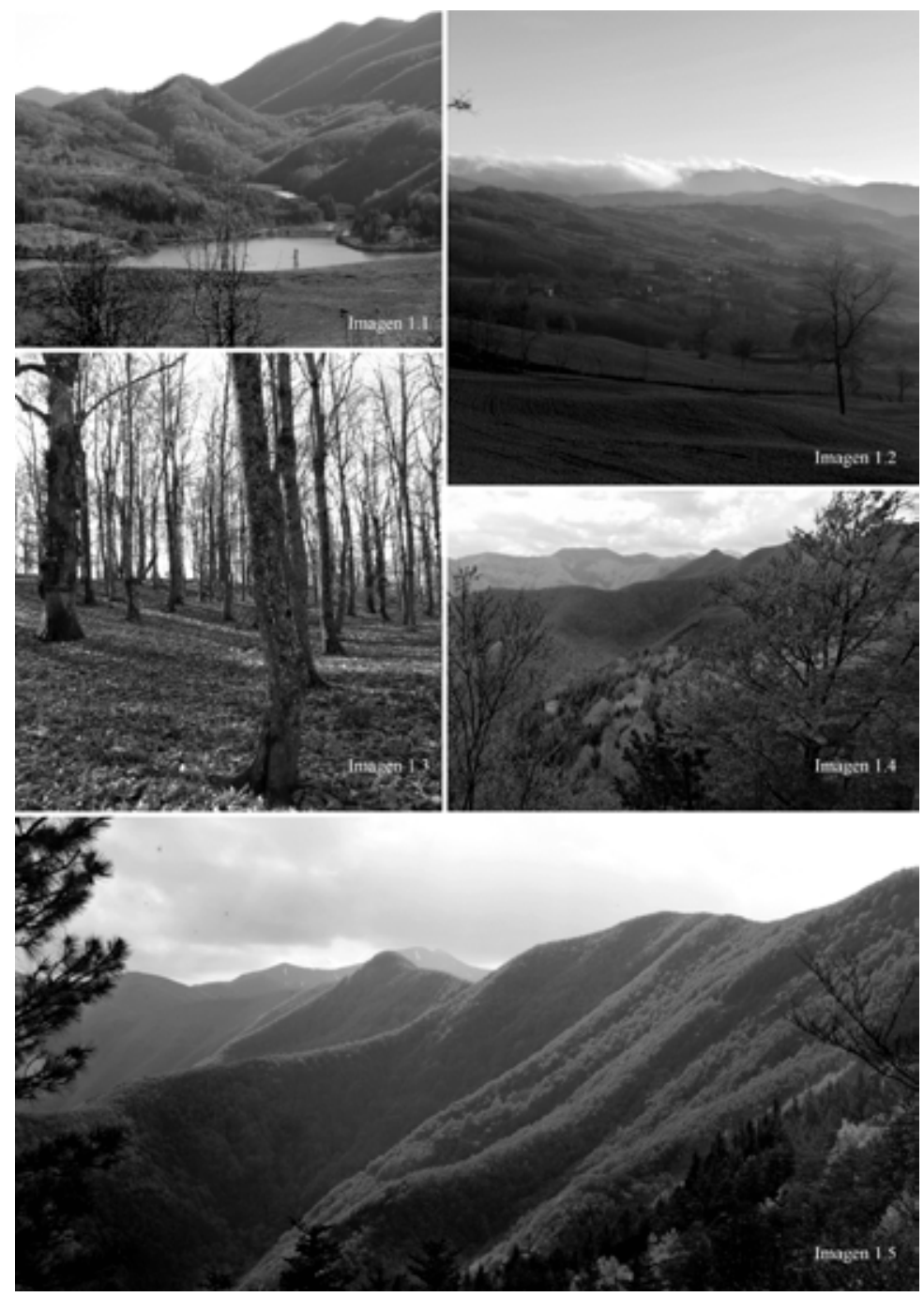

Fig. 7. Medio físico I.

Imagen 1.1. Lago del Brasimone (BO) y entorno vegetal, Imagen 1.2. Paisaje del Parco dei laghi di Suviana e Brasimone (BO), Imagen 1.3. Castañar del Poranceto (BO), Imagen 1.4. Valle del Randaragna, Valle del Reno, Valle Limentre (de más cerca a más lejos) y diferentes formaciones boscosas, Imagen 1.5. Valle del Randaragna (afluente del Reno, Granaglione (BO)). Fotos de Teresa Egea. 
Etnobotánica en el Alto Valle del Reno (Toscana y Emilia-Romaña, Italia)
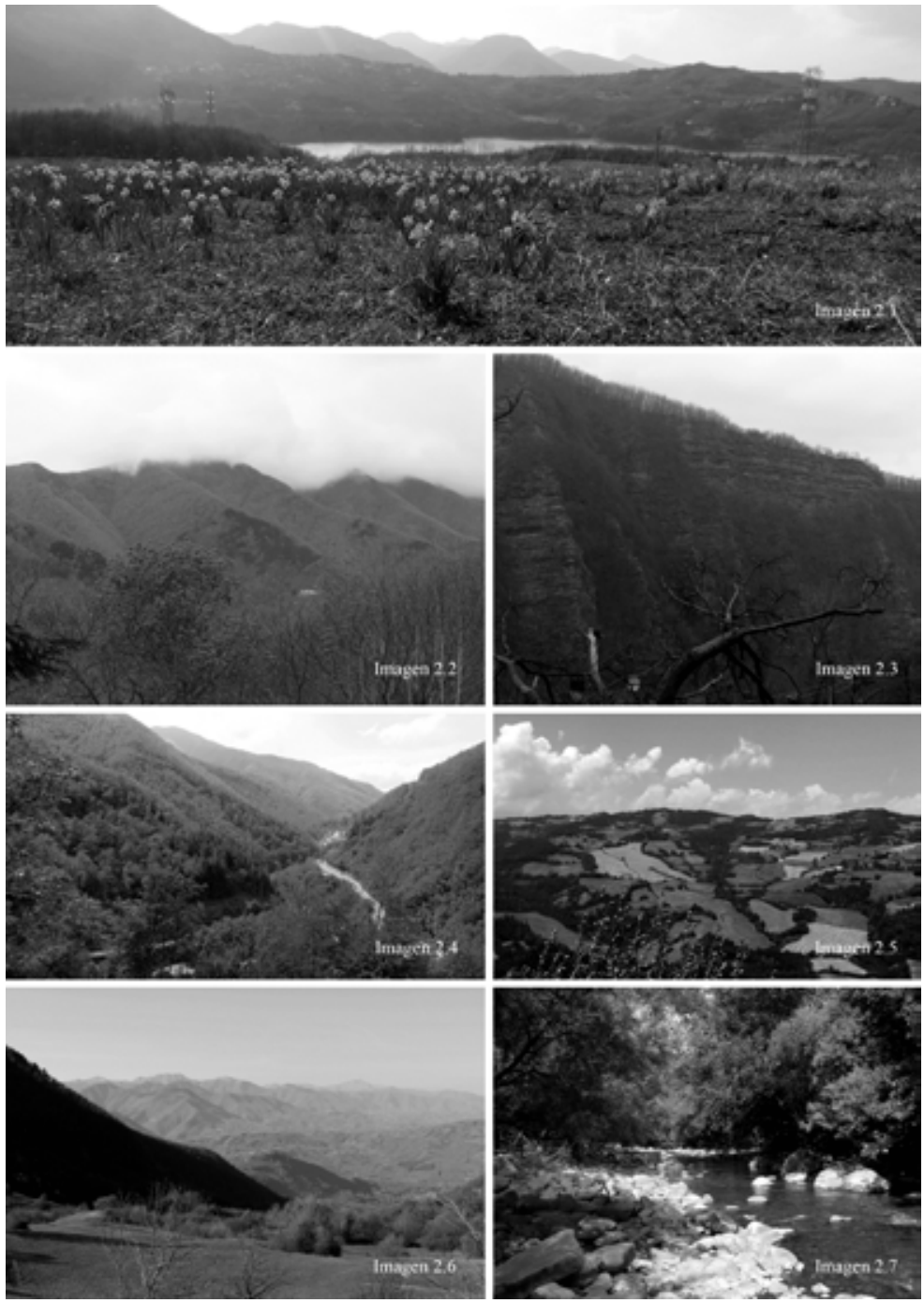

Fig. 8. Medio físico II.

Imagen 2.1. Lago de Suviana (BO) y entorno vegetal. Imagen 2.2. Aspecto paisajístico del territorio en Granaglione (BO) y las diferentes formaciones boscosas. Imagen 2.3. Paredes del Cinghi delle Mogne (BO), estratificaciones de areniscas turbiditícas. Imagen 2.4. Alto Valle del Reno, río Reno, Via Porrettana, Ferrovía Porrettana, Biagioni (Sambuca Pistoiese) recorren de la frontera regional entre Toscana y Bolonia. Imagen 2.5. Mosaico de hábitats antropizados de Camugnano (BO). Imagen 2.6. Diferentes geomorfologías del área de estudio en el AVR (PI, BO). Imagen 2.7. Vegetación fluvial en el torrente de Limentra di Treppio en Le Fabbriche, Camugnano (BO). Fotos de Teresa Egea. 
María Teresa Egea Molines

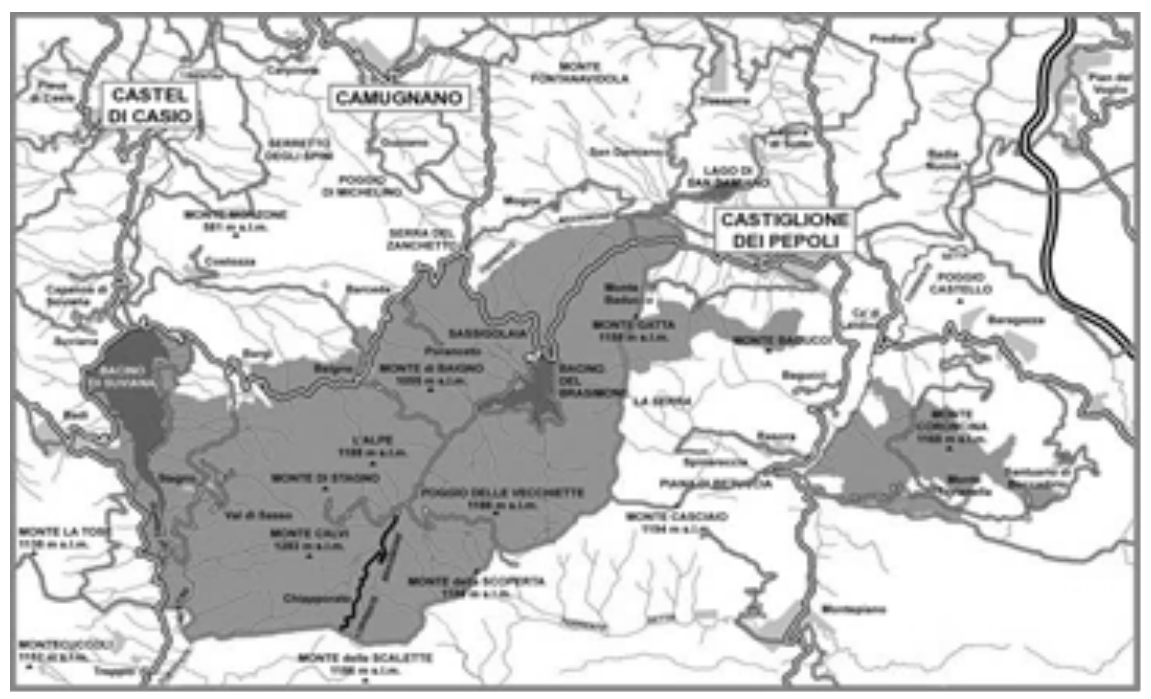

Fig. 9. Límites del Parco dei laghi di Suviana e Brasimone 



\title{
Capítulo 4
}

\author{
EI Medio Humano
}

\section{Historia}

Por su posición geográfica estratégica, el Alto Valle del Reno, ha sido siempre una tierra de intercambios, de guerras, conflictos y de difícil paso. Desde el punto de vista histórico, también ha constituido una tierra de frontera entre diferentes imperios. Fue habitado desde la Edad del Bronce como testimonian el depósito de catorce hachas y algunas estatuillas votivas encontradas en Burzanella o el hacha encontrada en Baigno. Desde entonces fue una tierra de fronteras, siendo dividida primero por los pueblos celtas en la parte Norte y por los etruscos en la parte Sur. Entre el VI y el VII siglo fue la línea fronteriza que separaba la Tuscia de los Longobardos y el Exarcado de Ravenna de los Bizantinos. Con la instauración del régimen feudal, el Alto Valle del Reno se encontró de nuevo justo en la frontera entre diferentes gobiernos, los de las estirpes de origen toscano, la ciudad de Bolonia, la ciudad de Pistoia, el Granducato di Toscana y el Estado de la Iglesia. Esto hizo que las comunidades de montaña tuvieran que asistir a constantes luchas por la dominación de las tierras de montaña y de sus comunidades de frontera, así como a menudo iban cambiando de gobierno en función de quién ganaba dichas luchas.

Durante la Segunda Guerra Mundial, también fue un punto crucial por donde pasaba la Línea Gótica, del movimiento de Resistencia apenínico italiano, un frente de más de 300 kilómetros que dividió Italia desde el Tirreno hasta el Adriático, y que bloqueó el avance de los tropas aliadas durante 8 meses.

El aislamiento geográfico, los bosques frondosos, los valles oscuros y las condiciones históricas a veces inestables hicieron del Alto Valle del Reno un refugio ideal desde la Edad Media de ladrones y fugitivos que ocuparon pueblos enteros como Vizzero (Granaglione).

Todos estos acontecimientos, junto al aislamiento del territorio, forjaron a las gentes de éstas montañas un carácter áspero, duro, orgulloso, desconfiado y pendenciero por una vida difícil de siglos de aislamiento económico y cultural (Camugnano, 2015) y a menudo de hambre y duro trabajo, que todavía se reconoce en la actualidad como el carácter "montanaro".

Desde los tiempos de los etruscos, el Alto Valle del Reno, ha tenido un rol decisivo como vía privilegiada de comunicaciones entre Emilia-Romaña y Toscana. 
En la Edad Media, la Via Francigena (Via Francesca della Sambuca, en su variante por Sambuca Pistoiese), antiguo camino de peregrinación que comunicaba Canterbury con Roma, atravesaba el Alto Valle del Reno, recogiendo miles de fieles por su recorrido. Creado durante el dominio longobardo en el siglo VI, el camino de peregrinación empezó a ser una importante vía de comunicación para comerciantes y viajeros, transformándose así en una vía de conexión importantísima entre el Norte y el Sur de Europa. De hecho, en el siglo XVIII, el simple camino de herraduras que pasaba por el fondo del Valle del Reno ya era una de las vías transapenínicas más recorridas. Con la industrialización, las exigencias infraestructurales cambiaron y el Gobierno Pontificio del Papa Gregorio XVI construyó la carretera estatal 64 denominada Porrettana en 1846 que pasa a través de la frontera regional entre Toscana y Emilia. En el 1864, se construyó la primera línea del ferrocarril transapenínica de la época, paralela a la Porrettana, que determinó una mejoría en la economía local (Ciuti, 1997) (Imagen 2.4). Ambas vías de comunicación han asegurado durante más de un siglo las comunicaciones entre Bolonia y Toscana.

Fue durante el siglo XIX cuando estos valles solitarios comenzaron a liberarse de siglos de aislamiento. Las escuelas, oficinas de correos, las carreteras y los periódicos no existían hasta finales del siglo XIX. En el 1884 se abrió la primera carretera en Castiglione dei Pepoli y en el 1903 se creó la carretera que comunicaba Camugnano a la carretera nacional Porrettana y al ferrocarril Bolonia-Pistoia y se activó el servicio telefónico.

Las condiciones de pobreza extrema se prolongaron hasta que, con la unificación de Italia, los valles altos fueron distribuidos en los municipios actuales con sus respectivos pueblos. Más tarde, en el siglo $\mathrm{XX}$, el territorio y sus características socio-económicas se caracterizaron por la creación de grandes obras públicas como los diques de Suviana y Brasimone (Imagen 2.1 y 1.1), las respectivas centrales hidroeléctricas, el centro de investigación de energía alternativa ENEA, entre otras obras que han proporcionaron puestos de trabajo a la población local, mejorando así las condiciones de vida del territorio.

\section{Lengua}

Aunque el Alto Valle del Reno sea un lugar de separación y división desde el punto de vista administrativo, geográfico, biogeográfico e histórico, al mismo tiempo también representa una tierra de encuentro que alberga una identidad única por sí misma, en la que existe un sistema dialectal denominado el Galo-toscano. Los municipios de Sambuca Pistoiese, Granaglione, Castel di Casio, Camugnano y Castiglione dei Pepoli están situados a lo largo de una línea ideal denominada "la línea La Spezia-Rímini” (Guccini, 1998), la cual tiene una importancia excepcional para la estructura lingüística de Italia, ya que representa el límite más pronunciado en el sistema dialectal de Italia donde terminan los fenómenos "galo-itálicos" (Lepschy, 2001; Guccini, 1998). Según varios investigadores "la línea La SpeziaRímini" separa al mismo tiempo dos bloques lingüísticos que se oponen entre sí: las lenguas romances Occidentales (Francia, España, Portugal) y las lenguas romances Orientales (Italia, Rumanía), y la lengua o sistema dialectal del Alto Reno 


\section{María Teresa Egea Molines}

constituyen una lengua de transición entre las dos familias neolatinas (Fig. 10). En definitiva, el sistema dialectal del Alto Valle del Reno no es ni un dialecto emiliano, ni un dialecto toscano, sino la unión de dos formas lingüísticas que crean un sistema lingüístico a parte denominado el galo-toscano.

\section{Distribución y evolución de la población}

\subsection{Evolución demográfica}

Desde el siglo XI hasta principios del siglo XX, la población local fue aumentando progresivamente (Ciuti, 1997; Zagnoni y Borghi, 2010) hasta llegar al máximo número de habitantes sobre todo desde la primera hasta la segunda Guerra Mundial, periodo en el que las condiciones no eran favorables para la emigración. La densidad demográfica alcanza su máximo en 1911 en Sambuca Pistoiese y en 1931 en los municipios del margen derecho boloñés, es decir en Castiglione dei Pepoli, Castel di Casio y Camugnano. Destaca Castiglione dei Pepoli por haber tenido desde 1861 un aumento muy importante de habitantes llegando a 10.538 habitantes en el 1931 y presentando el mayor número de habitantes del área de estudio. Seguidamente la población sufrió una fuerte disminución hasta los años 70 , debido sobre todo a la demanda obligatoria de hombres para la armada italiana para luchar en la Segunda Guerra Mundial en un primer momento, y a la emigración en busca de trabajo posteriormente (Sirgi, 2007). Los municipios más afectados por la disminución de la población fueron Castiglione dei Pepoli que desde 1951 al 2011 sufrió una disminución del 70\% de la población y Sambuca Pistoiese, en el que desde 1911 al 2001 la población no ha dejado de disminuir durante casi un siglo hasta un $77 \%$. En las últimas décadas con la mejora de las vías de comunicación y el aumento general de la calidad de vida, la tendencia demográfica se invirtió, produciéndose un aumento moderado de la población en todo el territorio, exceptuando el caso de Castiglione dei Pepoli (aunque la tasa de disminución de la población es muy baja en la actualidad).

Cabe destacar como Granaglione y Porretta Terme, los municipios boloñeses del margen izquierdo del Reno, presentan una tendencia diferente del resto de municipios. En Granaglione la población permaneció más o menos estable hasta 1921, y desde entonces sufrió igualmente una lenta disminución de la población. La población de Porretta Terme tuvo un crecimiento demográfico más prolongado y estable, y la emigración no afectó tanto ya que la población empezó a disminuir a partir del 1951 de forma moderada. Esta evolución demográfica diferente se debía a las mejores condiciones económicas que existían en el municipio gracias a las pequeñas industrias textiles; al centro terapéutico y balneario termal Terme di Porretta, (que durante el siglo XIX fue el lugar de moda de la alta sociedad como destino recreativo además de terapéutico) así como a las mejores comunicaciones que existía en la zona ya en aquella fecha. De hecho, el municipio de Castel di Casio, que se encuentra en las inmediaciones de la pequeña ciudad de Porretta 
Etnobotánica en el Alto Valle del Reno (Toscana y Emilia-Romaña, Italia)

Terme, el cual también está bien conectado con la carretera y las líneas de ferrocarril, vio aumentar su población en un 10,7\% entre 1991 y 2001 (Fig. 11).

En la actualidad, los municipios más importantes en cuanto a densidad demográfica son Porretta Terme (144,8 hab. / km²) y Castiglione dei Pepoli $(87,2$ $\mathrm{hab} / \mathrm{km}^{2}$ ), como se puede apreciar en la Tab. 1, los cuales corresponden a los municipios más urbanizados.

\subsection{Migración}

Desde el siglo XIX la pobreza y el aumento de la población llevaron a muchos habitantes de la montaña a emigrar, gracias a los oficios tradicionales que estos habían aprendido en el territorio relacionados con la artesanía y con la silvicultura, como los carboneros y leñadores, los tejedores de cestas, los cinceladores, los cuales que llegaron hasta el Alto Egipto (Sirgi, 2007). En el 1860, hubo una gran emigración hacia Estados Unidos, Canadá y diferentes estados europeos. La primera guerra mundial bloqueó este proceso migratorio, que se retomó a su fin, de nuevo prevalentemente hacia Estados Unidos, Francia, Alemania y otros estados europeos (Sirgi, 2007). Fueron importantes las emigraciones temporales de los leñadores y carboneros hacia la Maremma (sur de Toscana), Córcega y Cerdeña y el fenómeno de la trashumancia hacia la Maremma (Borghi, 2004). Durante la segunda guerra mundial, la emigración disminuyó aunque se caracterizó más bien por la demanda de hombres para luchar en la guerra, o trabajar en sus fábricas y sus campos, para suministrar productos a la guerra. El proceso migratorio se intensificó sobre el 19461947, cuando los soldados y prisioneros de guerra regresaron a la montaña y tuvieron que emigrar en busca de trabajo y mejores condiciones de vida. Entonces, la migración se caracterizó por los mineros que fueron a Bélgica y Francia, los artesanos de cestería, de cualquier edad y sexo, para la producción de cestas de flores, y el cultivo de flores en la ribera ítalo-francesa (desde Génova a Niza), los obreros en las fábricas de Suiza, Francia, América del Sur y otros lugares (Nerattini et al., 2006). Y el 80\% de las familias aparceras fueron a trabajar en fincas agrícolas más productivas de la llanura boloñesa, o en el sector de la construcción en las ciudades cercanas como Bolonia, Prato, Florencia, Pistoia. Finalmente durante los años 50' y 60' hubo un gran éxodo rural, las mujeres emigraban a las ciudades cercanas para trabajar como empleadas domésticas ("le domestiche"), como obreras o artesanas. En cambio, los hombres eran solicitados en todas las infraestructuras públicas que surgían en toda Italia y en el extranjero (diques y centrales hidroeléctricas, autovías, caminos, fábricas, etc.) (Sirgi, 2007).

Actualmente, el Alto Valle del Reno presenta unas características y recursos naturales muy atractivos para diferentes tipos de población, que al contrario que los habitantes oriundos, han inmigrado desde otras partes del mundo y residen temporalmente o definitivamente en estos valles.

Cabe resaltar la inmigración hacia el Alto Valle del Reno por parte de la población de origen marroquí y también de Rumanía. Los municipios con más extranjeros residentes son Porretta Terme con un 6,15\% de habitantes marroquíes y 


\section{María Teresa Egea Molines}

1,46\% de habitantes de Rumanía y Granaglione con 5,56\% de residentes marroquíes y $1,19 \%$ de Rumanía.

En Sambuca Pistoiese, existe un interesante fenómeno de repoblación del territorio por parte de personas de todo el mundo que desde el 1980 crearon una ecoaldea denominada "Il Popolo Elfico della Valle dei Burroni" (Chelucci, 1997; Spada, 2010) en la cual habitan (según uno de los fundadores y residentes de la ecoaldea) 230 habitantes, de los cuales 70 son residentes en Sambuca Pistoiese (4\% de los residentes totales). Durante más de 30 años de ocupación han nacido 170 niños de los cuales 70 todavía residen en el territorio. A través del proyecto realizado entre la asociación de la ecoaldea y la Communità Montana Appennino Pistoiese, este grupo de personas de diferentes nacionalidades han reocupado antiguas aldeas y fincas aisladas y abandonadas por el gran éxodo rural, en las que han retomado la actividad agrícola, forestal y de silvicultura que se practicaba tradicionalmente, implementando técnicas de agricultura y ganadería ecológica, y reconstruyendo antiguos edificios rurales y ruinas a través de la bioarquitectura. Este particular fenómeno aporta además centenares de visitantes curiosos y turistas, con un impacto positivo en la zona.

El territorio ofrece una rica y varia oferta turística además de un clima y vegetación muy atractivos para los residentes en la zonas urbanas, lo cual hace que la población se multiplique en los meses de verano, haciendo que muchas localidades que están completamente vacías durante el año se repueblen considerablemente durante los meses de verano por personas originarias del territorio que vuelven a su tierra natal, familiar a veranear, así como numerosos turistas que van a disfrutar del buen clima veraniego de la montaña.

\section{La economía tradicional y su evolución}

La economía tradicional se basaba en el trinomio del sector primario: agricultura, pastoreo y forestal, siendo integrada por modestas actividades artesanales y por los escasos ingresos de la emigración temporal. Las actividades agrícolas y forestales, ocupaban a todos los miembros de la familia con tareas diferentes en función del sexo y de la edad (Gioffredi, 1997). La caza también ha sido una fuente importante de alimentación. Aunque los recursos naturales fueran abundantes, la tierra no era accesible a todos, siendo la aparcería la forma de cultivo más difundida en el territorio hasta los años 1960 (Sirgi, 2007).

\subsection{El bosque y sus productos}

El bosque, que ha cubierto siempre la gran parte del territorio, representaba el pilar de la economía del valle. Cuando la densidad demográfica fue creciendo, los habitantes cultivaban cualquier tipo de terreno, buscaban continuamente nuevos campos y pastos para los animales, los castañares eran muy valorados y cuidados, así como el bosque era claro con tendencia a la reducción.

Los habitantes del Alto Valle del Reno han utilizado desde siempre la madera del bosque como principal recurso para la construcción, la arquitectura tradicional y 
para la combustión, usada para calentar las casas, para cocinar, para forjar el hierro, para la construcción de muebles, para la producción del carbón y para muchos usos más. La madera y el carbón se comercializaban con la llanura Boloñesa. Ya a finales del siglo XIV, el comercio de leña para combustión y construcción se comercializaba con Bolonia gracias al trasporte por deslizamiento por las aguas de los Limentre llegando hasta Bolonia a través del Reno (Guidotti, 1985). Aproximadamente en el siglo XIX, se difundió la producción del carbón en el Alto Valle del Reno, ya que se podía comercializar mejor y en lugares más distantes por su bajo peso, además de ser mejor para la combustión doméstica. Los carboneros y leñadores del Apenino Tosco-Emiliano eran reconocidos como los mejores, abundantes y muy pobres, por esto eran solicitados por los comerciantes de leña de toda Italia (Sirgi, 2007). Los leñadores y carboneros, adultos y niños, dejaban las familias en noviembre, después de la siembra del trigo (quienes disponían de tierra) y de la recogida de las castañas, para emigrar durante todo el invierno y hasta la primavera, hacia zonas de bosques intensos y deshabitados como Cerdeña, Sur de Toscana, Abruzos, Calabria, Trentino, Córcega, Francia y Túnez, para realizar el duro trabajo de leñador o carbonero (Gioffredi, 1997; Sirgi, 1991; Sirgi, 2007).

Durante el invierno, las mujeres se ocupaban de los niños, las casas, los animales y los campos. Los productos del sotobosque han representado siempre una fuente alimenticia y de integración de la renta familiar, que a menudo se reservaba para los niños y las mujeres, ya que era un trabajo menos duro y los productos se vendían fácilmente a diferentes comerciantes de Pistoia y Bolonia.

También cabe mencionar la actividad de los viveros forestales y la reforestación que caracterizó el Alto Valle del Reno a partir de finales del siglo XIX. El consorcio creado entre el Estado y la Provincia "para la reforestación y consolidación del territorio de montaña" y la Sociedad Pro Montibus et Sylvis promovieron numerosas actividades de silvicultura que dieron lugar a la creación de viveros forestales (en Porretta Terme y Castiglione dei Pepoli sobre todo), y a puestos de trabajo, aunque de bajo coste, con los que se repoblaron antiguos cultivos y pastos, terrenos degradados, deforestados o con tendencia a deslizamientos con especies de origen alpino como Pinus nigra J.F.Arnold, Abies alba Mill., Picea abies (L.) H.Karst. Pseudotsuga menziesii (Mirb.) Franco, Taxus baccata L., Pinus mugo Turra (Balletti y Gioffredi, 1997; VPSRU, 2013). La finalidad de estas reforestaciones artificiales que marcaron el paisaje del Alto Valle del Reno era la de hacer una rápida producción de materia maderable, una regulación hidrogeológica previniendo la inestabilidad y el deslizamiento de los terrenos, y una valorización paisajística. Pero con el abandono de las actividades de silvicultura, estas plantaciones artificiales son cada vez menos estables y expuestas a problemas sanitarios (Cavazza, 2005). Actualmente el corte del bosque de monte bajo se realiza solamente en los bosques que se sitúan bien comunicados con caminos forestales, donde la intervención convenga económicamente (según la pendiente de los bosques, la calidad y la abundancia de la madera) (Cavazza, 2003). 


\subsection{El castañar}

El castañar de fruto representó durante siglos el principal alimento del Alto Valle del Reno y el cultivo forestal más importante. Aunque su producción era muy laboriosa, dificultosa y dura, el cultivo de la castaña (llamada popularmente "pan di legno") alimentó a toda la población incluso en las épocas de hambruna y miseria. Los métodos tradicionales de cultivo y de aprovechamiento del castaño en el Apenino Tosco-Emiliano han sido profundamente estudiados en la literatura local (Balletti y Gioffredi, 1997; Borghi, 1989a; Borghi, 1989b; Bufalari et al., s.d.; GSAVR, 1989; Mucci, s.d.; Roda, 1989; Sirgi 2007; Zagnoni, 1997b). En un estudio del 1935 de la Inspección Provincial de Agricultura de Pistoia en el que consideraba todas las actividades agrícolas, forrajeras, forestales e incluso el aprovechamiento del sotobosque, afirmaba que los bosques y castañares contribuían en la producción neta vendible agrícola y forestal de la montaña pistoyesa en un $60 \%$ del total (Ciuti, 1993). Los castañares eran trabajados con extremo cuidado, por lo que los habitantes siempre dicen "los castañares parecían jardines", lo cual denotaba el valor que la gente de montaña atribuía al castañar y a los cultivos forestales (Ciuti, 1997). Casi toda la producción de las castañas era destinada a ser secadas y transformadas en harina, base fundamental de la alimentación y una fuente importante de ingresos. En 1935 la superficie de Sambuca Pistoiese dedicada al cultivo del castañar de fruto era de un $63,3 \%$ de la superficie boscosa del municipio. La superficie boscosa se componía de castañar de monte bajo (para madera, 0,42\%), bosques mixtos de monte bajo (para madera, 18,8\%), castañares de monte alto (para fruto 63,3\%), bosques mixtos de monte alto (para madera, $13 \%$ ) y bosques variados $(4,6 \%)$ (Ciuti, 1993).

En los años 30, en el municipio de Sambuca Pistoiese, según Ciuti (1993) los castañares de fruto más importantes se distribuían en el municipio, en función de las características del territorio y eran principalmente de las variedades "Neratino Sambucano", "Molano", "Pastinese", "Neratino delle Scalette Pego", "Carpinese" o "Carrarese".

A partir de la segunda guerra mundial, los cambios en las exigencias de vida de la población y la crisis del sector primario, conllevó a un gran éxodo de la población que provocó el abandono de numerosas superficies cultivadas en el territorio y a la invasión del bosque silvestre en los castañares y cultivos forestales. La variación más importante del territorio lo sufrieron los castañares, pasando de 2572 ha en 1838 hasta 970 ha en el 1990. En cambio en el mismo periodo, la superficie boscosa aumento de 2454 a 5430 ha (Ciuti, 1993). Este declive del castañar ha sido debido a diferentes motivos como la emigración, los nuevos parásitos del castaño (" $m a l$ dell'inchiostro", "cancro") y la disminución del interés por la castaña en la alimentación.

\subsection{Agricultura: cultivos arbóreos, viticultura, fruticultura, cultivos de herbáceos, forrajeras}

Según testimonios locales, los habitantes que tenían acceso a la tierra satisfacían las necesidades básicas de la familia y no sufrían la miseria. El aprovechamiento de los 
recursos naturales a través de los oficios y conocimientos tradicionales de las plantas hacía que las familias numerosas pudieran vivir con dignidad. Los suelos más fértiles eran destinados al cultivo de cereales y heno para el ganado, y se encontraban a menudo lejos de los centros de población, que en cambio se construían en lugares a menudo boscosos y escarpados, con un potencial agrícola limitado.

Los cultivos de frutales eran muy importantes a nivel familiar, aunque existían numerosas variedades locales de frutas, se introdujeron variedades mejoradas de manzanas, perales, ciruelas y cerezas. Como en el caso de la manzana la "Renetta del Canadà", "Rosa Mantovana", "Francesca Starking", "Commercio", "Delicious". En 1932-1939 se plantaron 37000 plantas de frutales en Sambuca Pistoiese (Ciuti, 1993).

Los cultivos herbáceos también eran muy importante en la economía y alimentación familiar. Existían antiguas variedades de montaña resistentes a las condiciones ambientales pero con un rendimiento menor. El trigo se sembraba para obtener la harina de trigo (variedad local "Andriolo"), para obtener paja para la realización de sombreros (variedades como "l'Abetone", "Terminillo", "Mottin") y para la alimentación animal. Como en el caso de los frutales, a principios de los años 30 se introdujeron nuevas variedades mejoradas con un rendimiento mucho mayor ("Virgilio", "Rieti11", “Catria”, "Mont. Calme”, "Todaro210", "Mentana", "Roma") que sustituyeron las antiguas variedades.

El centeno se cultivaba gracias a su resistencia al frío y a la nieve, y a su crecimiento en tierras pobres. Solo en Sambuca Pistoiese se registró en 1929 un cultivo de 34 ha de centeno. Este cereal se cultivaba para hacer pan mezclado con trigo, por su paja muy apreciada (con la cual se hacían cubiertas, sombreros, embalaje), para venderla a los viveros de Pistoia, y como alimento forrajero. También se introdujeron variedades mejoradas como "Segale 500", "Todaro", "Petkuser", "Otterbacher", "Segale Ottavi", "Edelhorf”.

La cebada se cultivaba igualmente por sus pocas exigencias, y se utilizaba en el valle para realizar un sucedáneo del café. Como en el caso del trigo, existían las cebadas "Vernini" (que se sembraban en otoño) y los "Marzuoli" (que se sembraban en primavera).

El Alto Valle del Reno es un territorio ideal para el cultivo de patata. En 1958 incluso se constituyó el "Consorzio Produttori Patate da seme dell'Appennino Pistoiese". El cultivo empezó en el territorio en 1817 (Ciuti, 1993) con la variedad "Americana Bianca" la cual fue degradándose y siendo sustituida por otras variedades mejoradas ("Majestic", "Bohms", "Esterlingen", "Imperator", "Pepo", etc.). El maíz también era un cultivo bastante difundido.

El cultivo de la vid tiene tradiciones muy antiguas en el territorio, era muy valorado por los hombres y tenía un función alimentaria, nutracéutica, cultural y social muy importante, los testimonios aseguran que el vino era la única diversión de la montaña. En 1929, la superficie cultivada de vid en Sambuca Pistoiese era de 10 hectáreas, aunque en los últimos datos estadísticos del 1990 consta que la superficie se ha reducido a solo 2 hectáreas. Las variedades cultivadas en Sambuca Pistoiese eran "Sangiovese", "Albana", "Trebbiano", una variedad local denominada "Negratina", de la cual se obtenía un vino de baja graduación alcohólica. Cerca de 
las casas y en los huertos se cultivaban híbridos de vides llamados "l'Isabella" o "Uva Fragola", importados de América, aunque éstos también están desapareciendo (Ciuti, 1993).

Al igual que las otras especies, el cultivo de forrajes se ha ido reduciendo considerablemente por el abandono de los terrenos y la consecuente disminución del patrimonio zootécnico. En Sambuca Pistoiese, la superficie de prados, prados-pastos y pastos permanentes pasó de 1881 hectáreas en el 1838, a 375 hectáreas en 1929, a 202 hectáreas en 1982, llegando a solo 183 hectáreas en el 1990 (Ciuti, 1993). Los prados eran cultivados de alfalfa, diferentes variedades de trébol, otras leguminosas y brasicáceas forrajeras. Cada familia tenía un huerto cerca de las casas donde cultivaban especies y variedades adaptas a las condiciones climáticas, principalmente patatas, judías, maíz, coles, ensaladas, calabacines, calabazas, tomates, achicorias, acelgas, pero también moras domésticas, frambuesas, grosellas, uva espina y otro tipo de frutales como cerezas, cerezas "amarene", ciruelas, albaricoques.

\subsection{Evolución del uso del suelo y del paisaje}

A partir de 1960, la economía del territorio se ha transformado radicalmente debido a la emigración de la población, al abandono de las tierras cultivadas, al cambio de las condiciones de vida y a la mejora de las vías de comunicación, provocando así una consecuente modificación del paisaje, apreciable en la Tab. 5 del Parque Regional Parco dei laghi di Suviana e Brasimone. El abandono del corte y del aprovechamiento del bosque de monte bajo, el abandono de los cultivos de los castañares, de los prados, de los campos y el abandono de los pastos, con la consecuente colonización de la vegetación silvestre, arbustiva y arbórea, ha conllevado a un importante cambio en el territorio rural apenínico, cuyo paisaje era caracterizado por un mosaico formado por bosques, desmontes y cultivos con una gran función en la biodiversidad (Cavazza, 2003). Las laderas empinadas y esculpidas por terrazas cultivadas que caracterizaba el territorio y los caminos de montaña que conectaban cada caserío y cada campo, se han convertido en lugares impenetrables por la invasión de la vegetación y por constantes derrumbamientos causados por el abandono de las tierras y por las condiciones climáticas duras.

A través de la lectura diacrónica del uso del suelo de los años 1944, 1954 y 2003 (Tab. 5) y 1944, 1954 y 1999, se nota un progresivo abandono de los cultivos y un correspondiente aumento de la naturalidad con un dinamismo constante de la vegetación hacia el bosque (PTP, 2008). Los territorios boscosos y los ambientes seminaturales pasan del $62,34 \%$ en el 1944 al $82,34 \%$ en el 2003 y al contrario, los territorios agrícolas que constituyen el $32,94 \%$ en el 1944 y han disminuido considerablemente hasta el 10,03\% en el 2003 (PTP, 2008). 
Etnobotánica en el Alto Valle del Reno (Toscana y Emilia-Romaña, Italia)

Tab. 5. Evolución de la cobertura del suelo.

En el Parco dei laghi di Suviana e Brasimone Años 1944, 1954 y 2003. Extraído del Quadro Conoscitivo del Piano Territoriale del Parco dei laghi di Suviana e Brasimone (PTP, 2008).

\begin{tabular}{lllllll}
\hline Cobertura del suelo & 1944 & & 1954 & & 2003 & \\
& Hectáreas & $\%$ & Hectáreas & $\%$ & Hectáreas & $\%$ \\
$\begin{array}{l}\text { Territorios boscosos } \\
\text { ambientes seminaturales }\end{array}$ & $2.075,6$ & 62,34 & $2.395,4$ & 71,94 & $2.738,69$ & 82,24 \\
Territorios agrícolas & $1.095,8$ & 32,91 & 767,5 & 23,06 & 333,77 & 10,02 \\
$\begin{array}{l}\text { Ambientes de las aguas } \\
\begin{array}{l}\text { Territorios modificados } \\
\text { artificialmente }\end{array}\end{array}$ & $\begin{array}{l}\text { No } \\
\text { disponibles }\end{array}$ & - & $\begin{array}{l}\text { No } \\
\text { disponibles }\end{array}$ & - & 56,77 & 1,70 \\
\hline
\end{tabular}

\subsection{Artesanía}

El aprovechamiento de los recursos naturales para una gran variedad de finalidades durante siglos creó en el Alto Valle del Reno numerosos oficios y artesanos, gracias a los cuales gran parte de la población encontró trabajo en el extranjero para mejorar sus condiciones de vida.

Desde finales del siglo XVI, la transformación y elaboración de la fibra textil a partir del cáñamo y la cría de gusanos de seda a base de hojas de moreras era una actividad económica muy difundida en la zona, sobre todo por las mujeres (Guccini y Guccini, 2008). El cáñamo sobre todo proporcionó una fuente de ingresos importante para la población del siglo XVIII y representó la primera industrialización de Porretta Terme, dando la oportunidad a la población local de abandonar las sacrificadas actividades agrícolas tradicionales con contratos de aparcería. Pero durante finales del siglo XIX, con la llegada de los nuevos materiales, la gran producción de cáñamo cesó en la zona (Daghini, 2005; Vezzali y Martelli, 2006).

La producción de cestas a partir de Salix sp. y otras especies era una práctica tradicional realizada por todas las familias del Alto Valle del Reno para el uso doméstico y como integración de la renta familiar. Estos conocimientos hicieron que muchas personas sobre todo de Castel di Casio y de Sambuca Pistoiese emigraran a la ribera ítalo-francesa para la realización de cestas in situ, e incluso para abrir sus propias empresas de cestería en Niza y otros lugares cercanos (Nerattini et al., 2006). Así otros muchos oficios tradicionales como el del carpintero, el cantero, los herreros ambulantes (llamados "magnano") también eran una parte importante de la 
economía local (Gioffredi, 1997) y ayudaron a la población a encontrar trabajo en el exterior, exportando sus cualidades artesanales.

\subsection{Economía actual}

En la actualidad el territorio conserva una fuerte caracterización rural, el porcentaje de unidades locales pertenecientes al sector de la agricultura $(23,5 \%)$ es casi el doble que el de la provincia $(12,4 \%)(\mathrm{PTP}, 2008)$. Camugnano, en particular, recoge en la agricultura más del $40 \%$ de sus activos. Castiglione dei Pepoli tiene el mayor número de unidades de producción en el comercio $(29,4 \%)$ y el municipio de Castel di Casio destaca por el sector de la construcción donde casi el 30\% de la población ocupada encuentra trabajo.

Dentro del territorio del Parque Regional se encuentran 10 empresas agrícolas, gestionadas en su mayoría por personas mayores con pocas perspectivas de futuro con la excepción de una en la que se da un relevo generacional. Dos empresas se dedican también a la actividad agroturística (La Succhiata y La Azienda Elmi), pero la mayoría realizan actividades mixtas, en las que predomina el prado estable sin prevención de rotaciones de los cultivos. La mitad de estas empresas se dedican a la ganadería de bovinos y solo una de ovinos. Todas ellas incluyen cultivos de forrajes y cereales, algunas de ellas se dedican en parte a la silvicultura en monte bajo.

Los embalses construidos en el siglo XX en las cuencas de Suviana, Brasimone, Pàvana, San Damiano y las grandes infraestructuras de explotación hidroeléctrica e investigación de propiedad ENEL y ENEA han creado una gran actividad económica a nivel local, creando 150 puestos de trabajo en el Centro ENEA situado en Brasimone y además un gran atractivo turístico que ha sabido explotar el sector de la hostelería y del agroturismo de la zona. 
Etnobotánica en el Alto Valle del Reno (Toscana y Emilia-Romaña, Italia)

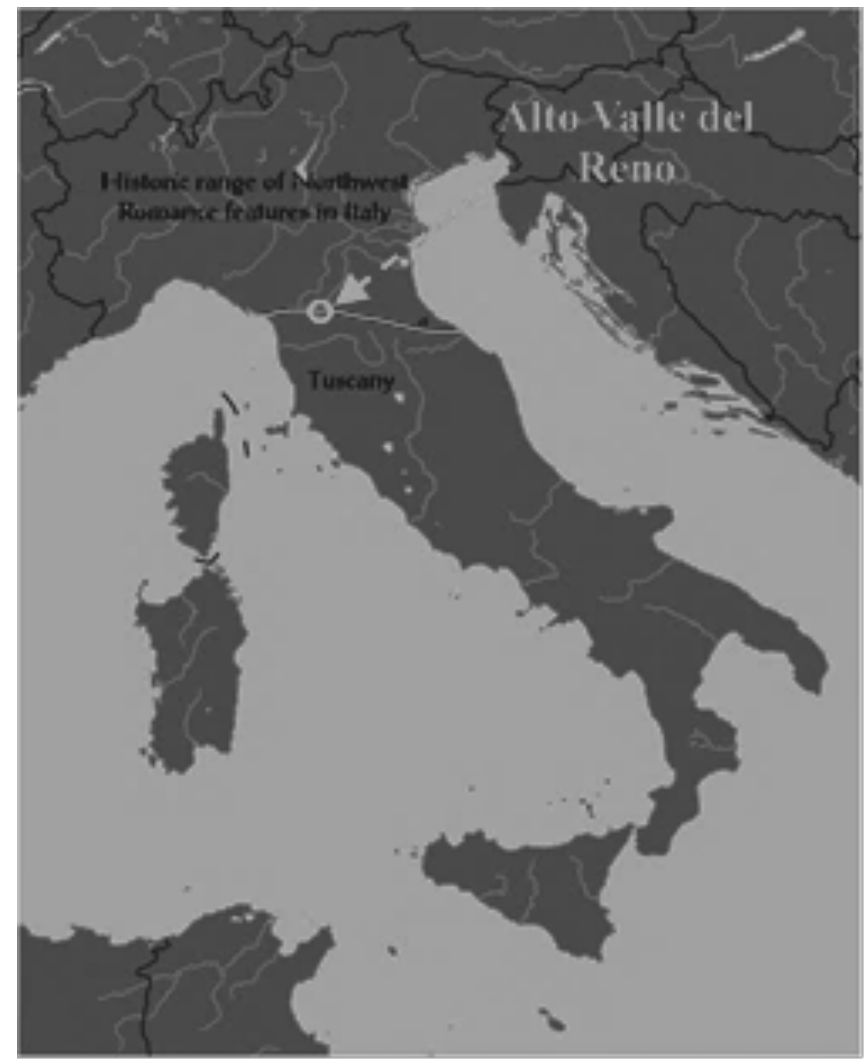

Fig. 10. Localización de la Línea Spezia-Rímini.

La Línea Spezia-Rimini cruza a través del Alto Valle del Reno (Italia), extraído de Línea Spezia-Rímini (2015) 


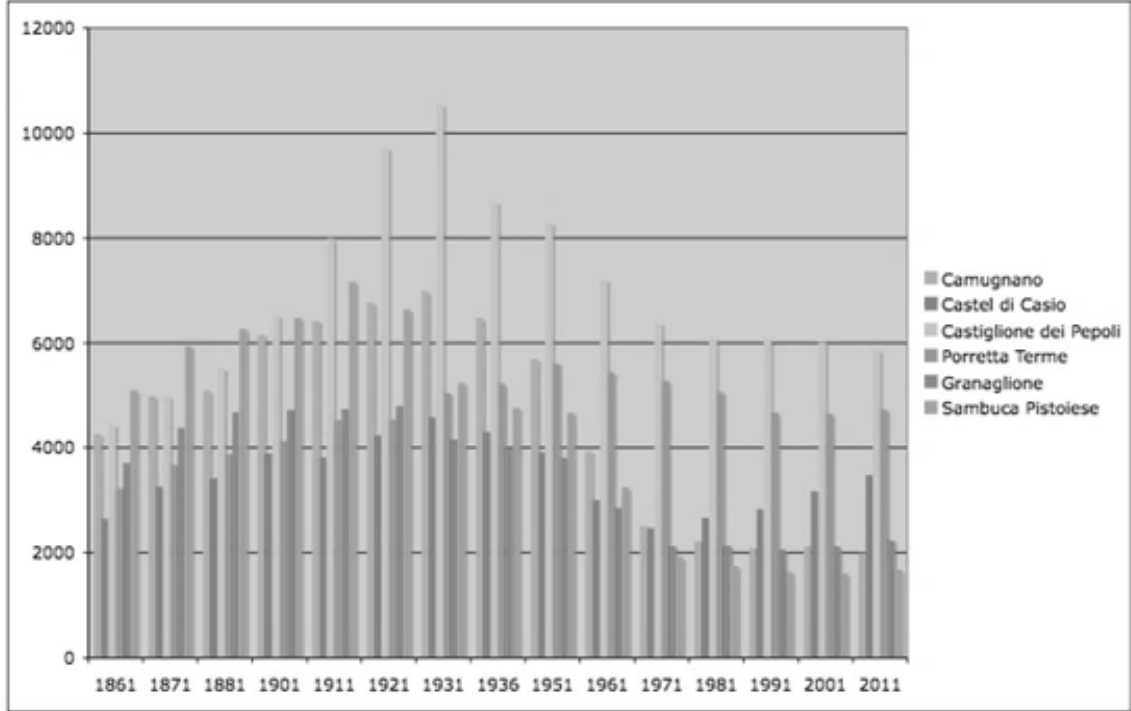

Fig. 11. Evolución demográfica en los municipios del Alto Valle del Reno.

Período desde 1861 hasta 2011. Datos Istat (Istituto nazionale statistica), (Wikipedia, 2015c; Wikipedia, 2015b; Wikipedia, 2015a; Wikipedia, 2015d; Wikipedia, 2015e; Wikipedia, 2015f) 

Parte 2. Objetivos 
El objetivo general de la investigación es el de documentar los conocimientos tradicionales relacionados con las plantas silvestres, y cultivadas en el Alto Valle del Reno solo si son empleadas para usos diferentes para los cuales son cultivadas de forma común, de forma que puedan ser elaborados, analizados e interpretados para su comprensión crítica, y valorizados en los ámbitos de la conservación de la biodiversidad y del desarrollo rural.

Considerando los recursos económicos, humanos, logísticos y temporales a disposición para la realización de la tesis doctoral, la compleja relación entre la comunidad en estudio y las plantas, la investigación se ha centrado sobre todo en las plantas silvestres aunque se han tenido en cuenta los usos de las plantas cultivadas distintos a los habituales para los que se cultivan.

Durante la investigación, y aun no siendo el objetivo principal, han salido a la luz diversos datos sobre los usos comunes de las plantas cultivadas, los cuales son usos generalizados y frecuentes al resto de las regiones italianas e incluso europeas, que están ampliamente documentados y por tanto no han sido objeto de la tesis.

Sin embargo, con la finalidad de registrar todos los datos resultantes del trabajo de campo (según el enfoque antropológico) y evitar la pérdida de información que pueda ser utilizada en futuras investigaciones más específicas, las informaciones recogidas que no fueron el objeto de estudio han sido igualmente registradas en una primera fase de los resultados. Estos datos no forman parte del objetivo específico de la tesis, por tanto no serán considerados en los análisis cuantitativos de la investigación, ya que los informantes no han sido entrevistados con esa finalidad ni de la misma manera.

En este sentido, los objetivos específicos de la investigación son:

1. Elaborar un catálogo etnobotánico cualitativo de la etnoflora del Alto Valle del Reno que recoja la información sobre el conocimiento, el uso, el manejo y la gestión de las plantas silvestres de la zona de estudio a partir de entrevistas semiestructuradas a la población local y a partir de una revisión bibliográfica de la literatura local.

2. Documentar los usos y el manejo de las especies, describiendo las técnicas, los recetarios y los procesamientos en cada caso.

3. Recopilar la etnotaxonomía local de las plantas relacionándola con la taxonomía científica.

4. Registrar las informaciones etnobotánicas documentadas en la literatura local sobre las especies útiles recogidas durante el trabajo de campo, adoptando el mismo método de clasificación de datos, para poder ser comparados.

5. Identificar botánicamente las especies utilizadas por la comunidad, recoger el material testigo de estas especies y conservar los pliegos testigos en el Herbario FIAF de la Universidad de Florencia una vez etiquetados correctamente. Si no es posible la recolección de las especies citadas, estudiar la identidad posible de éstas confrontando con la flora local y los usos tradicionales de las plantas en la bibliografía. 
6. Realizar un análisis cuantitativo sobre el conocimiento tradicional de las plantas silvestres y de las plantas cultivadas, sólo si son utilizadas para un uso diferente para el cual son cultivadas de forma común, concretamente:

- Analizar la distribución de los conocimientos tradicionales en la cultura-población en estudio.

- Identificar y analizar las especies más importantes en la cultura local.

- Analizar el conocimiento tradicional de las plantas por tipologías de uso (sectores y categorías de uso)

- Analizar cómo se articula el sistema nomenclatural de las plantas en el conocimiento tradicional

- Definir y analizar la ecología de las especies utilizadas así como el nivel de antropización de las especies útiles y la percepción ambiental que tiene la comunidad de ellas como condición de recurso.

- Estudiar los diferentes sectores de usos tradicionales de las plantas y sus características culturales y biológicas.

- Estudiar la fitoalimurgia local y los alimentos funcionales como prácticas de salud comunitarias.

- Estudiar la etnofarmacología local a través del estudio de la nosología popular, conocer el perfil epidemiológico del AVR, las plantas empleadas como remedio, su forma de preparación y administración.

- Valorar la vigencia de los usos tradicionales y el grado del conocimiento de los usos.

- Evidenciar los datos novedosos de la investigación etnobotánica respecto a los datos etnobotánicos bibliográficos registrados.

- Confrontar los conocimientos etnobotánicos recogidos en la parte toscana del Alta Valle del Reno con aquellos recogidos en la parte emiliana, así como la influencia de la cultura toscana y emiliana en los conocimientos tradicionales del AVR. 

Parte 3. Metodología 
Etnobotánica en el Alto Valle del Reno (Toscana y Emilia-Romaña, Italia)

El trabajo de investigación se ha llevado a cabo desde el año 2009 hasta el 2015 y ha sido realizado en diferentes fases: la fase de exploración, la fase de trabajo de campo, la investigación bibliográfica, la clasificación y procesado de la información, la elaboración de los resultados en un catálogo etnobotánico, el análisis y discusión de los resultados obtenidos y por último, la redacción de la memoria de la tesis doctoral. 


\section{Capítulo 1}

\section{Fase de exploración}

\section{Delimitación del área de estudio e investigación bibliográfica}

Una vez tomada la decisión de estudiar el área del Alto Valle del Reno por su interés cultural, geográfico y ambiental, se realizó una investigación bibliográfica previa para verificar si existían trabajos publicados de etnobotánica en la zona. Al comprobar que el área de estudio elegida carecía de estudios etnobotánicos se procedió a la delimitación de la zona, fase muy importante en este tipo de estudios, tratándose de una investigación territorial.

La zona fue elegida por su gran interés a nivel ambiental, histórico y cultural además de por ser de gran interés personal para la investigadora. Fue viviendo en la zona de estudio, en estrecho contacto con la naturaleza incontaminada del AVR, que la investigadora empezó a apasionarse por la historia y la sabiduría de los habitantes que habían vivido durante generaciones en el lugar. La implicación personal es el motor esencial para poder llevar a cabo el trabajo de campo, sobre todo cuando la investigadora pertenece a una cultura distinta de la del estudio, como en este caso. El área de la investigación fue delimitada según fue avanzando la investigación, a medida que el conocimiento sobre la cultura, la historia y el ambiente local fue profundizándose. La delimitación del área de estudio se realizó con el fin de muestrear todas la zonas representativas y características del Alto Valle del Reno, es decir la parte emiliana y toscana del Alto Valle del Reno; la parte izquierda y derecha del Valle; la parte protegida por el Parque Regional así como la parte no protegida.

Los municipios del Alto Valle del Reno que finalmente decidimos muestrear, fueron elegidos por lo siguiente:

- Que mantuvieran entre sí una cierta homogeneidad histórica, cultural y geográfica,

- Que fueran a su vez representativas de la identidad cultural que alberga el Alto Valle del Reno,

- Que el área total por estudiar fuera abordable con los recursos humanos y económicos de los cuales disponíamos.

En primer lugar, se realizó un exhaustivo estudio bibliográfico sobre el Alto Valle del Reno y sus diferentes aspectos: ambiente natural, historia pasada y reciente, tradiciones, dialecto, aspectos socio-económicos, etnográficos y demográficos (Camarda y Guarrera, 2005). Cualquier tipo de fuente bibliográfica ha 
sido útil para conocer la cultura del lugar y entender la idiosincrasia de la población. Los documentos recogidos han sido posteriormente seleccionados y objeto de la investigación etnobotánica bibliográfica.

En el territorio, primero se tomó contacto con las autoridades y los entes locales, (como asociaciones culturales, ayuntamientos, asesores de la cultura, bibliotecas, el Parque Regional) para presentar el proyecto de investigación y sus objetivos, y eventualmente para poder encontrar informantes claves o intermediarios. Igualmente contactamos con personas de un alto nivel cultural así como autores de la literatura local, artistas autóctonos o profesores locales, los cuales fueron de gran ayuda para entender ciertos comportamientos y costumbres locales, así como para la búsqueda de informantes.

En una investigación etnobotánica, es muy importante prepararse para la observación. La lectura de varias obras de ciencias sociales y antropológicas ha sido de gran utilidad para tomar distancia con el propio sistema cultural y para usar aptitudes personales para gestionar las entrevistas, como la obra de Levi-Strauss (1955).

La inserción social en la zona de estudio es crucial para poder llevar a cabo el trabajo de campo con éxito. El haber residido durante el primer año de la investigación en una de las aldeas más aisladas de la zona, en estrecha relación con la naturaleza, ha ayudado mucho a la investigadora a entender la cosmovisión de la cultura local así como a ser aceptada por la comunidad. En los años sucesivos, se han realizado largas estancias en las comunidades durante la recogida de la información alternándolas con un periodo de distanciamiento que permitía transcribir los datos con objetividad, tomar distancia y reflexionar sobre el método seguido y los resultados obtenidos. Estos periodos eran muy útiles para no saturar ni a la población local ni a la propia investigadora. Por otra parte, permanecer largos periodos en la comunidad ha permitido observar en detalle y anotar, participar en la rutina cotidiana y en las costumbres locales (como comprar en las tiendas y acudir a los bares, etc.), asistir a los eventos y a las festividades. De este modo, se ha podido familiarizar con la organización social y ganarse la entrada del escenario de estudio antes de abordar la investigación.

En ésta primera fase de exploración, ha sido fundamental analizar los estudios o aportaciones etnobotánicas de la zona y de zonas colindantes, para aprender los nombres vernaculares de las plantas y sus usos tradicionales registrados en la literatura, y así poder realizar las entrevistas de forma más eficaz utilizando el dialecto local en la medida de lo posible. Igualmente, hemos debido procurarnos todos los elementos necesarios para el reconocimiento de las plantas como los estudios florísticos de la zona (Foggi, et al., 2007; Sirotti, 1999; Venturi, 2006).

\section{Estrategias metodológicas adaptadas}

El método de trabajo ha sido seleccionado en función de nuestros principales objetivos y se ha modificado en función de las características culturales del área de estudio. La toma de datos es la fase más importante y delicada de la investigación. En una investigación etnobotánica, la población por muestrear está formada por 


\section{María Teresa Egea Molines}

individuos sociales, emocionales y condicionados por su propia cultura. Por lo tanto, las estrategias y las aptitudes que se utilizarán se basarán en métodos antropológicos y sociales, que irán adaptándose a las características sociales, culturales, geográficas de la zona en estudio. Por esto es importante estudiar previamente la cultura que vamos a entrevistar, para poder prepararse y contextualizar los encuentros. Tratándose de seres vivos y a menudo imprevisibles (sobre todo los más ancianos), los métodos de investigación no pueden ser rígidos sino que deben adaptarse a las circunstancias, a las personas y a las condiciones subjetivas que se darán en el momento del encuentro con las personas por entrevistar. Sin tener una regla preestablecida, se han ido adoptando diferentes estrategias y comportamientos según el tipo de persona que se debía entrevistar (si es hombre o mujer, cariñosa o fría, confiada o desconfiada, etc...) y según las circunstancias que se daban en el momento de la entrevista (dependiendo si estábamos solos o acompañados, si es en la casa personal o en un lugar público, si el informante dispone de tiempo o bien no, si había un intermediario o no, etc...). El comportamiento y la personalidad del entrevistador es esencial para poder obtener la información deseada, ya que se pretende entrar en la esfera personal, íntima y emocional de las personas. En líneas generales, se ha hecho referencia a uno de los códigos éticos reconocidos internacionalmente (ISE, 2006). En un trabajo de campo etnobotánico, el mejor enfoque metodológico es el de integrar diferentes técnicas de recolección de datos según las circunstancias aleatorias que se den. Pero el método principal utilizado se basa principalmente en hablar con las personas, observar lo que hacen, participar en sus actividades (Martin, 1995; Alexiades, 1996) y analizar los documentos locales. 



\section{Capítulo 2}

\section{El trabajo de campo}

\section{Recolección de datos etnobotánicos}

La toma de datos ha sido realizada desde Mayo 2009 hasta Mayo 2015. Esta fase de la investigación ha sido efectuada en primer lugar a través del trabajo de campo, basado en las entrevistas y en la recolección de testimonios (Láminas 4, 5 y 6), y un segundo lugar a través de la investigación bibliográfica, con el objetivo de poder confrontar los datos de campo con los datos recogidos anteriormente en la literatura local.

El cronograma del trabajo de campo (Tab. 6) muestra las fases diferentes de la recolección de datos a través de entrevistas, observación participante, conversaciones con la población local, inserción social en la comunidad y en la cultura local. Como se puede apreciar durante los meses de verano, cuando el tiempo lo permite, han sido realizados los periodos más intensos y fijos en la comunidad, adoptando la forma de vida local y realizando observación participante, viviendo en estrecho contacto con el medio natural del territorio intentando mantener una coherencia con la vida tradicional que se quiere estudiar, para poder entenderla, conocerla e interpretarla. Sin embargo en los meses de otoño y primavera, el tiempo no permite en todo momento realizar el trabajo de campo, por lo cual se realizaban estancias intermedias que pudieran dar lugar a nuevos encuentros así como a programar salidas de campo y nuevas entrevistas. Y en los meses de invierno el trabajo de campo ha sido más escaso debido a las intensas nevadas y a la mala circulación en el territorio. Aún así siempre se ha procurado realizar entrevistas puntuales o salidas de campo durante esos periodos para vivir todos los ciclos de la naturaleza y de la vida relacionada con ésta, así como poder localizar las muestras de las pocas especies que florecen en este periodo. 
Etnobotánica en el Alto Valle del Reno (Toscana y Emilia-Romaña, Italia)

Tab. 6. Cronograma del Trabajo de Campo en el AVR (2009-2015).

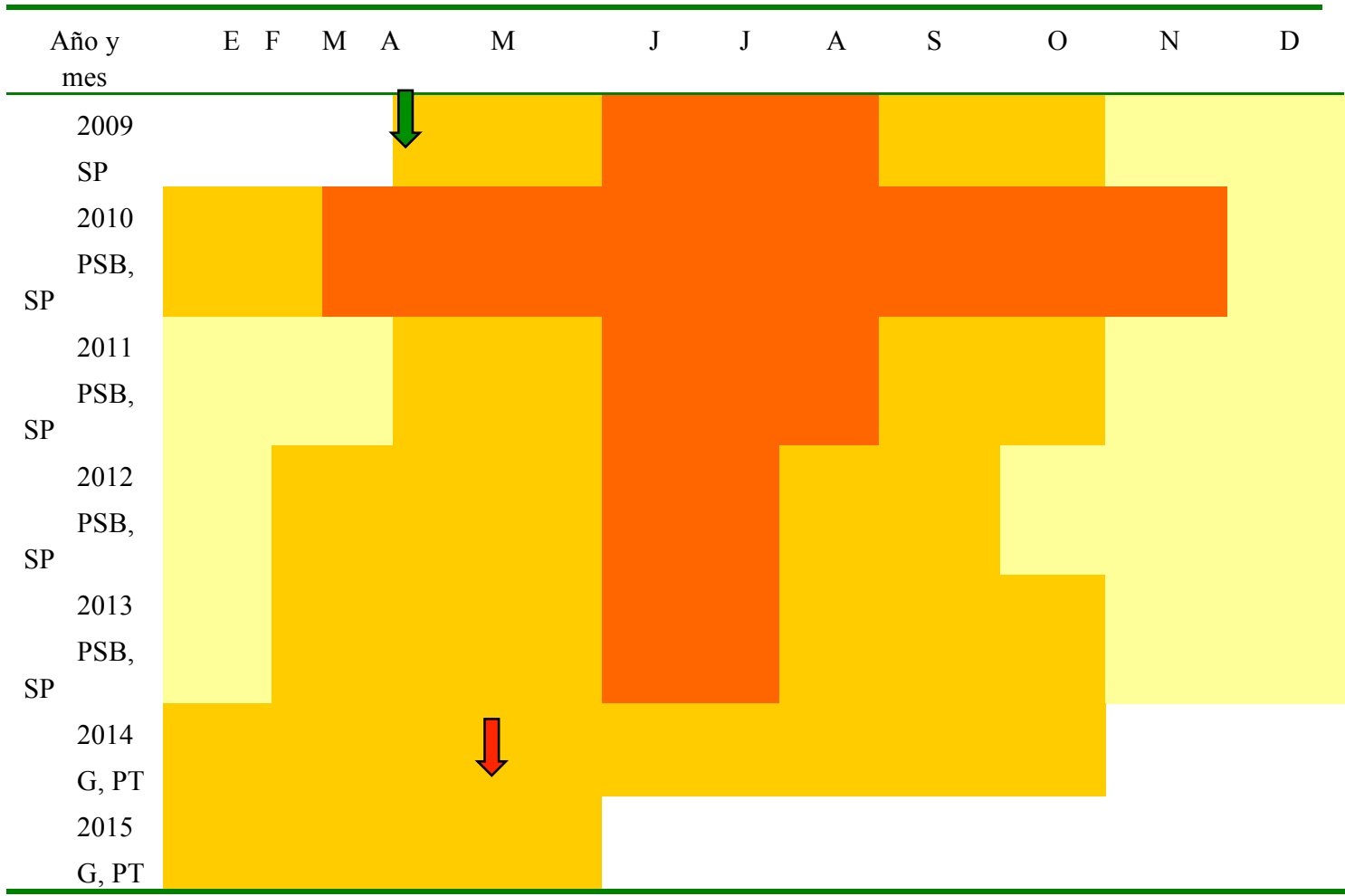

Municipios estudiados y visitados: Sambuca Pistoiese (SP), Parco dei laghi di Suviana e Brasimone (PSB) (Camugnano, Castel di Casio, Castiglione dei Pepoli), Granaglione (G) y Porretta Terme (PT).

$\square$ Periodo de inmersión e integración en la comunidad en estudio, viviendo en localidades aisladas a $800 \mathrm{~m}$ s. n. m, adoptando una forma de vida en estrecho contacto con la naturaleza usando las plantas locales para los fines cotidianos, al igual que la vida tradicional que se pretende estudiar, y adoptando la cotidianidad social de la comunidad. Periodo en los que se ha conocido a los intermediarios, y se realizado observación participativa.

$\square$ Periodos en los que se combinan periodos intensos dentro de la comunidad de 5 o 7 días, tiempo suficiente para poder profundizar la relación con ciertos informantes, prever actividades, visitas, y salidas al campo a buscar las plantas, así como poder ir al bar tranquilamente y vivir el día a día del lugar. Pero es necesario combinar estos periodos, con periodos de toma de distancia por parte de la investigadora y descanso mental y físico para los intermediarios que han acompañado a la investigadora, para evitar saturar y sobrecargar a los informantes y a la comunidad en sí.

Salidas esporádicas para realizar entrevistas ya concordadas previamente o a buscar especies útiles exclusivamente por el tiempo de floración correspondiente.

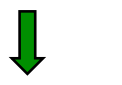

Primera entrevista en Monacchino, acompañada por una persona respetada y estimada por el informante.

$\llbracket$ Última entrevista en Porretta Terme. 


\section{Selección de los informantes}

Los informantes locales se definen como personas pertenecientes a la comunidad de estudio que poseen los conocimientos etnobotánicos y están dispuestos a compartirlos (Signorini et al., 2013).

La selección de los informantes ha sido realizada en base a determinados criterios y procurando, en la medida de lo posible, que la muestra sea representativa. El método más utilizado es el de bola de nieve o "snow-ball sampling" (Bernard, 1988), que consiste en localizar a algunos individuos, los cuales conducen a otros, y estos a otros, y así hasta conseguir una muestra suficiente.

Debido a la historia reciente de la población en estudio, marcada por una gran emigración y por el proceso de aculturación, no existe un perfil común de informante. Los informantes han sido seleccionados en función de su propio sentido de pertenencia a la cultura estudiada, lo cual puede ser debido al haber nacido y vivido su infancia en el lugar, al haber residido mucho tiempo en la zona en estrecho contacto con la naturaleza y las tradiciones, o al tipo de trabajo realizado en el lugar.

Al inicio hemos contactado con personas autóctonas que tuvieran un alto nivel cultural y que estuvieran relacionadas en algún aspecto con la etnobotánica (como el presidente del Parque Regional, autores de libros locales, investigadores locales de botánica o historia, miembros del "Gruppo Studi Alta Valle del Reno", maestros, etc.) para explicarles los objetivos del proyecto de investigación. Generalmente estos primeros contactos mostraron interés por el estudio y me acompañaron a entrevistar a conocidos y familiares que tuvieran un perfil adecuado, haciendo de intermediarios.

La fuerte emigración y el importante proceso de aculturación que ha sufrido la población ha provocado una ruptura en la transmisión de los conocimientos tradicionales, muchas personas entrevistadas no han aprendido las prácticas que realizaban sus antecesores. Se acordaban que utilizaban plantas para diferentes usos pero nunca aprendieron qué plantas, por qué y cómo, a causa de la ruptura cultural. Por esto ha sido muy difícil encontrar personas que todavía recordasen o practicasen los usos tradicionales de las plantas en el Alto Valle del Reno, y consecuentemente ha sido fundamental seleccionar con conciencia los métodos para la selección de informantes, con el fin de realizar entrevistas dentro de lo posible eficaces.

El mejor método ha resultado ser a través de intermediarios, que normalmente son a su vez informantes que han entendido los objetivos de la investigación y pueden ayudar a encontrar nuevos informantes (Imágenes 4.1, 4.5, 5.1, 5.3, 6.6). El intermediario tiene un gran rol en el momento de la primera entrevista con otros informantes, ya que normalmente acompaña al investigador para entrevistar a amigos suyos o familiares, con lo cual se crea enseguida una ambiente familiar y de confianza durante la entrevista.

Por otro lado el intermediario permite que las entrevistas se realicen en dialecto local, lo cual estimula los recuerdos sobre los usos tradicionales de las plantas e intensifica la familiaridad y confianza entre los locutores. El intermediario ha sido una Fig. crucial durante el trabajo de campo, y equivale a lo que otros autores denominan "key informants" o informantes clave, definidos por ser observadores, reflexivos sobre la comunidad de estudio, grandes conocedores sobre la cultura, son 
capaces de compartir sus conocimientos y están dispuestos a hacerlo (Tongco, 2007), añadiendo que además ellos mismos están interesados en conocer más sobre su cultura y las plantas locales.

A lo largo de la investigación ha habido 4 intermediarios clave que me han acompañado a visitar diferentes informantes y han hecho de guías en la cultura a estudiar. En éstos casos, se ha seguido la costumbre local para las visitas, es decir a veces se realizaban con previo aviso y con cita, y en algún caso se hizo de forma espontánea, yendo a buscarlos en sus lugares habituales sin avisar, por lo que la entrevistas se han realizado en distintos lugares como en el bar, en el huerto, en la plaza del pueblo (Imagen 6.3), en las casas (Imagen 6.5, Imagen 4.2), en el bosque, en los campos, etc... Pero considerando el carácter y la idiosincrasia de las gentes de la comunidad de estudio, el método aleatorio y casual no ha resultado ser un método adecuado.

La historia, la geografía y el aislamiento del Alto Valle del Reno han forjado un carácter desconfiado e introvertido (Camugnano, 2015), reconocido por los propios miembros de la comunidad. El difícil carácter "montanaro" (montaraz) fue advertido por los primeros contactos de los entes y autoridades locales, así como por la bibliografía de la zona. Obviamente estas características han limitado mucho la posibilidad de encontrar informantes disponibles y han dificultado la realización de entrevistas eficaces. Esto lo demuestra por ejemplo que en numerosas ocasiones los informantes no han querido dar su nombre ni datos personales.

Sin embargo, a través de las entrevistas semicasuales se han obtenido buenos resultados. El método "semicasual" es aquel que resulta de la observación participante. Participando en la vida cotidiana de la comunidad, hemos provocado intencionadamente la entrevista con informantes, yendo a comer a sus bares o restaurantes, comprando en sus tiendas, etc. Otra manera semicasual de seleccionar informantes ha sido durante entrevistas con otros informantes en lugares públicos, en las que a menudo se han acercado amigos y familiares para curiosear pudiendo establecer con ellos una entrevista de forma semicasual y nuevas entrevistas individuales posteriormente.

\section{Las entrevistas}

Las entrevistas han sido dirigidas con diferentes métodos según el carácter del informante (hablador y dicharachero o bien tímido y poco hablador), la acogida de la investigadora por parte del informante (si se lo esperaba o no, si tiene tiempo o no: las mujeres normalmente están muy ocupadas y enseguida deben preparar la comida y atender a las tareas familiares) y según la actitud del informante hacia la investigación (si cree que los conocimientos tradicionales no tienen importancia, incluso se avergüenzan de hablar de éstos porque las relacionan con la pobreza, o al contrario si les interesan las plantas y les recuerdan periodos felices de su vida).

Por lo general, las entrevistas fueron desarrolladas en la medida de lo posible en dialecto local y de forma semiestructurada, es decir como conversaciones generales, más o menos libres, en las que se formulaban preguntas específicas sin un orden preestablecido, dirigiendo el tema de conversación hacia los usos de las plantas, teniendo en mente un esquema de entrevista de referencia. 


\section{María Teresa Egea Molines}

Los encuentros empezaban siempre explicando al informante los objetivos de nuestra investigación, explicándole que las informaciones serían recogidas de forma anónima y servirían para estudios sin ánimo de lucro. Las entrevistas se realizaron acorde con las líneas generales seguidas normalmente en los estudios etnobotánicos (ISE, 2006) pidiendo previamente a la entrevista el consentimiento por parte de los informantes de coger apuntes durante la conversación. El método de grabar las entrevistas no es adecuado en este grupo cultural, ya que las personas se avergüenzan e incluso desconfían, por esto no ha sido utilizado.

En la mayoría de los casos, las entrevistas se han repetido varias veces a cada informante hasta que se ha notado que el informante repite siempre las mismas plantas. Entonces, se ha considerado que hemos recogido una parte representativa de su conocimiento tradicional. En algunos casos, la poca disponibilidad de los informantes (por carácter o por desconfianza), las malas condiciones de salud o la edad muy avanzada de los informantes no han permitido repetir las entrevistas y profundizar los datos. Sin embargo en otros casos, las entrevistas se han repetido tantas veces y el nivel de empatía era tal que la relación entre la investigadora y el informante se ha transformado en amistad, por lo que ya no se realizaban entrevistas etnobotánica, sino observación participante.

Empezar las entrevistas con preguntas directas sobre los usos de las plantas ha demostrado ser bastante contraproducente, ya que el informante suele pensar que pretendemos o nos esperamos noticias complejas y formales, con lo cual les bloquea el miedo de poder decepcionarnos. Las preguntas fueron formuladas con elementos que trasladara la memoria del informante a su mundo más familiar y tradicional, como “¿su madre qué hacía cuando los hijos tenían dolor de barriga?”, “¿a qué jugaban los niños?”, “qqué se hacía en las fiestas de primavera?”, “Cuando su madre iba a recolectar las plantas en el campo para comer, qué plantas recolectaba?". Se trata de preguntas claves que desencadenan conversaciones temáticas y recuerdos.

Cuando a veces el contexto no era idóneo para una conversación fluida y distendida, se ha recurrido a realizar preguntas sobre plantas directamente usando el nombre vernacular. Se ha comprobado que utilizar el dialecto local para mantener la entrevista estimula la memoria y hace que el informante sea más confiado y receptivo. En las entrevistas es fundamental tener mucha paciencia y capacidad para escuchar a las personas desde la alteridad, interpretando ciertas reacciones y respuestas, y creando empatía con personas ancianas y de cultura ajena. El estudio bibliográfico y el conversar no sólo sobre las plantas sino sobre la cultura e historia en general con la población local ayuda a poder tener alteridad con el informante y contextualizar respuestas. Por ejemplo la asociación de los usos tradicionales de las plantas a épocas duras de hambrunas y miseria y el recuerdo de épocas de carestía (Nerattini,s.d.; Sirgi, 1991) hace que las personas se avergüencen e incluso se sientan mal al recordar tiempos duros, y esto ha hecho que muchas personas consideradas por la comunidad posibles informantes claves (por sus conocimientos sobre los usos tradicionales), se hayan negado a ser entrevistados incluso siendo solicitados por sus familiares y amigos más cercanos. También ha provocado que ciertas entrevistas no fueran efectivas, ya que los entrevistados tenían una actitud muy negativa respecto a todas las preguntas, respondiendo solamente que "antaño se 
moría de hambre", "se moría por cualquier enfermedad", "no se curaba nada" y "las afecciones y el dolor se aguantaban". Por lo previamente expuesto, durante la presente investigación han sido entrevistadas muchas personas que no han sido considerados como informantes por no proporcionar informaciones etnobotánicas.

Las entrevistas han sido realizadas en diferentes modalidades: individuales (Fig. 16, Imagen 6.1), con un intermediario (Fig. 14, Imagen 4.1) y entrevistas de grupo (Fig. 14, Imágenes 4.2, 6.3, 6.6). Cada tipo de entrevistas tiene sus ventajas y desventajas, según el carácter del informante. Por ejemplo, a veces la presencia del marido puede inhibir a la mujer o bien si hay una persona que menosprecia y no quiere hablar de los usos tradicionales por asociarlos a la pobreza, también puede inhibir a la otra persona. Las entrevistas individuales pueden crear vergüenza si no hay confianza entre el informante y el entrevistador, y las entrevistas de grupo pueden ser muy positivas para estimular los recuerdos pero negativas a la hora de registrar el conocimiento que realmente posee cada uno de los informantes. Por esto, cuando se ha podido, se ha adaptado el tipo de entrevista al carácter y personalidad del informante, para poder hacer entrevistas lo más eficaces posibles.

Durante las entrevistas, siempre se ha de considerar si los usos mencionados han sido aprendidos en la comunidad de estudio, asegurándonos de que no hayan sido asimilados de fuentes externas (como la televisión, libros, personas de otros lugares o bien durante sus estancias en otras zonas o incluso inventadas). Si el informante no lo especificaba, se ha solido preguntar: ¿de quién lo ha aprendido?, ¿dónde lo ha aprendido? A menudo los informantes suelen mencionar noticias contaminadas por fuentes externas por diferentes motivos:

- Por satisfacer al entrevistador y poder quedar bien

- Por haber vivido durante parte de su vida en otros lugares o tener amigos y familiares de otras zonas, entonces hay una contaminación cultural y natural

- Por el uso de libros, televisión y fuentes externas a la propia cultura (Signorini et al., 2013).

A la hora de desarrollar la entrevista, cabe considerar en todo momento ciertos aspectos inherentes a la cultura en estudio. Al igual que en otro tipo de culturas, ciertas prácticas tradicionales que se transmiten de generación en generación son secretas (desde prácticas mágico-medicinales a recetas de licores), y se pueden dar situaciones en las que la cultura pretende una reciprocidad, es decir para realizar las entrevistas es necesario dar algo a cambio (Edwards et al., 2005). Por ejemplo, cuando el eventual informante posee una tienda, un restaurante o un bar, ha sido de gran utilidad, comprar o consumir algo en su actividad antes de empezar la entrevista, de ésta forma el informante se muestra automáticamente más disponible y receptivo.

Al final o durante las entrevistas siempre se ha procurado invitar a los informantes a dar un paseo por alrededor de la casa o incluso a ir a buscar las plantas mencionadas, según la disponibilidad del informante. Esta parte de las entrevistas es fundamental para validar la información recogida. El informante debería indicar y recolectar las especies citadas, con el fin de ser identificadas posteriormente en la siguiente fase de laboratorio. El duro clima del Alto Valle del Reno, con 6 meses de nieve, y precipitaciones muy frecuentes durante todo el año (ver climatología), ha hecho que el tiempo disponible tanto para realizar las entrevistas como la recogida 


\section{María Teresa Egea Molines}

de las plantas fuera muy limitado. El duro clima hace que las personas se cierren dentro de las casas y condiciona su predisposición hacia lo nuevo, lo desconocido. Incluso en épocas de verano, las personas no suelen estar fuera de sus casas en tertulias. Cuando la recolección de las plantas por parte de los informantes no era posible también se han recurrido a enseñar pliegos o muestras de plantas e incluso fotos, para verificar la identidad de las plantas nombradas por los informantes.

Las informaciones han sido recogidas desde una perspectiva émica, registrando cada dato como es percibido y como es expresado por el informante, con su terminología propia. Se ha observado que los informantes empiezan a hablar de las plantas con su nombre dialectal, desde el momento en el que empiezan a coger confianza y cuando hablan sin pensar, sin compostura. Al contrario tienden a nombrar las plantas con su nombre italiano al principio de la entrevista o en la primera entrevista. Por esto es importante, cuando lo permiten, repetir las entrevistas a cada informante tantas veces cuanto sea posible, ya que la primera entrevista normalmente sirve para que la investigadora y el informante se conozcan y este último entienda los objetivos de la entrevista, y a partir de la segunda entrevista, éstas suelen ser más eficaces, se solicita previamente el paseo o la muestra de plantas testigos y se completan las informaciones recogidas en la precedente entrevista.

Por el proceso de aculturación que sufre la montaña y la ruptura generacional, la edad media de las personas que todavía conservan esos conocimientos es muy alta: $41,6 \%$ de los informantes es mayor de 80 años y $33 \%$ de los informantes tiene entre 61 y 80 años (apartado 1.4 .3 e Fig. 15, Imagen 5.5). De una entrevista a otra, muchos informantes han sufrido desmejoramientos físicos y mentales muy acentuados, y muchos otros han fallecido. Por esto, las entrevistas por segunda o tercera vez así como la recogida de muestras etnobotánicas con la presencia del informante ha sido posible sólo en pocas ocasiones, ya que muchas personas no podían moverse, no estaban lo bastante lúcidos para recordar los usos tradicionales, ni para reconocer las plantas a partir de muestras secas, de fotografías. Hemos asistido así a la desaparición abismal que sufren el patrimonio cultural y natural en el Alto Valle del Reno, y a la dificultad que conlleva conservarlos y recuperarlos con el rigor científico que exigimos.

\section{Observación participante}

El método malinowskiano de la observación participante (Malinowski, 1975) ha sido una estrategia muy importante en un territorio donde encontrar nuevos informantes que todavía recuerden o practiquen los usos tradicionales de las plantas ha sido una difícil labor, como se ha explicado anteriormente. Este método ha permitido:

- Llegar hasta informantes difíciles (carácter más cerrado, desconfiado o tímidos),

- Obtener otro tipo de información distinto del que se tome a través de las entrevistas, como si el uso es practicado personalmente por el informante o bien si lo ha visto hacer u oído decir; si es un uso actual que todavía practica 
o bien si es un uso pasado; la forma y lugar de recolección, y otros detalles sobre el uso y manejo de la planta,

- Crear un ambiente más informal, íntimo y amistoso en el que el informante se abre realmente al entrevistador y comparte con él los conocimientos transmitidos por sus familiares, que equivale a confiarle recuerdos íntimos de su vida personal,

- Que el investigador se ponga al mismo nivel que el informante, creando empatía con éste y demostrando que el investigador admira y valora sus conocimientos y su cultura, rompiendo muros y prejuicios por parte del informante,

- Estimular la memoria y los recuerdos.

La observación participante consiste en hacer del objetivo de la investigación, un interés personal, siempre manteniendo un sentido de la objetividad a través de la distancia. Esto implica por ejemplo, no tener nunca prisa y dedicar todo el tiempo necesario para poder establecer ése tipo de relación con los informantes que permita, de forma natural, compartir recuerdos y prácticas familiares.

Este método etnográfico se caracteriza por acciones tales como tener "una actitud abierta, libre de juicios, estar interesado en aprender más acerca de los otros, ser consciente de la propensión a sentir un choque cultural y cometer errores, la mayoría de los cuales pueden ser superados, ser un observador cuidadoso y un buen escucha, y ser abierto a las cosas inesperadas de lo que se está aprendiendo" (De Walt y DeWalt, 1998; Kawulich, 2005).

Siempre se ha mostrado la predisposición a participar y colaborar en las tareas domésticas, agrícolas y forestales que el informante pudiera hacer, aunque no siempre ha sido posible por la falta de disponibilidad de muchos informantes.

En ocasiones, he colaborado o asistido a ritos mágico-medicinales (Imagen 6.2) o apotropaicos y en trabajos como el de cortar leña, cuidar el huerto, preparar licores y pastas a base de plantas o recolectar partes de plantas para trabajos artesanales. También se ha compartido comidas entre amigos y tertulias en las que se tomaban licores y comidas a base de plantas así como se ha participado en las fiestas locales y eventos sociales (Imagen 4.3, 5.4). Este método antropológico, permite sobre todo entender la importancia cultural de ciertas prácticas tradicionales y facilita una mejor interpretación de los datos en diferentes aspectos.

En la investigación participante, se admite que los conocimientos tradicionales son fundamentalmente válidos y verdaderos en el contexto geográfico y cultural en los que se dan (Hersch, 1987).

\section{Testimonios}

La recolección de testimonios es fundamental para validar la información recogida durante las entrevistas. Los testimonios están constituidos por las plantas testigos que proporcionan una entidad botánica al nombre vernacular, pero también pueden ser plantas secas, semillas, productos transformados que testimonien el uso tradicional realizado a partir de la planta, etc. Durante el desarrollo del trabajo de 


\section{María Teresa Egea Molines}

campo siempre se ha procurado que los informantes enseñaran a la entrevistadora las plantas citadas de forma que fuera posible recolectarla e identificarla posteriormente en el laboratorio. El rigor científico exige que las plantas sean recolectadas por el informante en su lugar habitual de recolecta y con la presencia de flor y fruto para su correcta identificación (Imágenes 4.1, 4.4, 4.6, 5.1, 5.3, 5.6, 6.4). Esto ha sido una difícil labor en el Alto Valle del Reno por los siguientes motivos:

- Inmovilidad o mal estado de salud del informante

- Poca disponibilidad del informante hacia la investigación

- Periodo de la entrevista diferente del periodo de floración o de crecimiento de la planta

- El cambio del uso del suelo y de los ecosistemas ha hecho que en varias ocasiones hemos ido a las zonas habituales donde los informantes solían recolectar las plantas, pero los hábitats se han transformado totalmente haciendo imposible el crecimiento de las plantas en cuestión.

- Según los informantes, la proliferación excesiva de los ungulados introducidos en los últimos 50 años ha provocado la desaparición de muchas plantas de su zona habitual de recolección.

Por ejemplo, en el caso de Gentiana lutea L. (cfr.), numerosas veces el informante acompañó a la investigadora al lugar donde él solía recolectar la raíz de la planta que usaba como depuradora, pero la vegetación silvestre había invadido el lugar de recolección cambiando por completo el hábitat donde crecía la supuesta planta. Según la descripción de la planta del informante, los usos otorgados y otros indicios botánicos se decidió relacionarla con Gentiana lutea L. (cfr.), asegurados por la información recogida durante la investigación bibliográfica: Balletti (1980a), afirmaba que "ésta especie ha desaparecido completamente en el territorio, ya que el último ejemplar fue encontrado hace 50 años, desde entonces naturalistas y apasionados la buscan inútilmente en nuestro montes y valles".

En los casos en los que la recolección de la planta por el informante no era posible, se ha recurrido a enseñarles muestras frescas previamente recolectadas de las posibles plantas, y si esto tampoco era posible (por el periodo de la entrevista) se han utilizados todas las herramientas posibles: como pliegos de herbario, fotografías, libros o dibujos de las plantas. En cualquier estudio etnobotánico, la identificación de las plantas no se puede hacer nunca en base a su nombre vernacular, aunque tengamos una muestra del mismo nombre vernacular y parezca obvio, ya que los nombres vernaculares de las plantas cambian incluso dentro de un mismo núcleo familiar y en muchos casos un nombre vernacular puede referirse a distintas especies. Por esto hay que procurar siempre que el informante proporcione una planta que corresponda al nombre vernacular que utiliza y el uso concreto que describe. En cambio, la comprobación de la identificación botánica puede ser eventualmente descuidada sólo en los casos de las plantas cultivadas y utilizadas en etnobotánica, como la cebolla, el ajo, la patata (Signorini et al., 2013), así como las plantas exóticas para las cuales se adoptan las especies más utilizadas generalmente.

Las muestras recogidas han sido posteriormente, identificadas, secadas, montadas, etiquetadas en el laboratorio y conservadas según la normativa del Herbario FIAF (Erbario dei Laboratori di Botanica Agraria e Forestale di Firenze) de la Università degli studi di Firenze. 
Los pliegos de herbario constituyen los especímenes testigo (voucher specimens) de las informaciones obtenidas (Imagen 5.2). Los pliegos equivalen a las muestras proporcionadas por los informantes a las cuales les han otorgado un nombre vernacular, un uso tradicional, y han sido identificadas botánicamente. Los pliegos pueden diferenciarse por haber sido proporcionados y reconocidos por diferentes informantes con nombres vernaculares diferentes o iguales, aunque constituyan la misma especie botánica.

La fotografía también ha sido de gran utilidad para la identificación de las plantas, para testimoniar los usos y los productos derivados de cada una. Una vasta colección de fotos (más de 2000 fotos) ilustra las especies botánicas con usos etnobotánicos, documentan el manejo y la gestión de la planta durante las prácticas mencionadas, así como los hábitats y los paisajes donde crecen las plantas útiles. En definitiva la fotografía ilustra la relación que tienen las personas de la comunidad de estudio con el mundo vegetal que le rodea.

Numerosos objetos estudiados a partir de plantas han sido conservados a nivel privado, así como semillas y plantas secas proporcionadas por los informantes.

\section{Los nombres vernaculares}

Los nombres vernaculares forman parte de una etnotaxonomía o folk-taxonomy (Berlin, 1973) en la que las especies se definen y clasifican atendiendo a sus características morfológicas u organolépticas, el ambiente en el que crecen, el uso que se hace tradicionalmente y puede cambiar de individuo a individuo. Por ejemplo, el informante GGI decía "antes llamábamos a las plantas por el uso que se hacía de ellas, como por ejemplo "erba per al brugiado" (hierba para quemaduras), pero en el pueblo la llamaban "lingua di bue". La unidad sistemática elemental en la que se basa la etnotaxonomía ha sido definida por Berlin (1973) como folk generic y por Atran (1998) como generic species. En ésta investigación utilizaremos el concepto de etnospecie, parecido a los términos anteriores y propuesto por Signorini et al. (2008), que se define como la unidad sistemática émica elemental diferenciada por los informantes.

En botánica sistemática, en cambio, las especies se definen y se organizan en categorías superiores (géneros, familias...) atendiendo a características morfológicas, biosistemáticas, corológicas y moleculares, y son considerados como productos de su historia evolutiva (filogénesis) (Signorini et al., 2013).

En un estudio etnobotánico, la identificación botánica consiste en asignar un nombre científico, perteneciente a la sistemática botánica científica, a un nombre vernacular, perteneciente a la etnotaxonomía local. Esta labor que se basa en trasladar un conocimiento émico al conocimiento ético no es siempre automática. Se pueden dar casos en los que una etnospecie se refiera a un grupo de especies botánicas muy afines entre ellas y difícilmente distinguibles a partir de las características morfológicas, lo que Berlin (1973) ha denominado under differentiation. Como es el caso de la cicerbita, nombre vernacular utilizado para denominar Sonchus oleraceus L. s.s. como Sonchus asper L. como una unidad 
única. También es el caso de las numerosas agamoespeciès del grupo de Taraxacum officinale percibidas todas como una única identidad por los informantes.

Por el contrario se puede dar el caso opuesto que Berlin (1973) denominó over differentiation, es decir, cuando una única especie botánica constituye diferentes etnospecies porque están asociadas a fases de desarrollo vegetativo diferentes, a partes diferentes de las plantas o a subespecies distintas. Éste es el caso de Salix alba L. que es denominado "salgòn" cuando el árbol no se poda y se deja crecer hasta alcanzar los 30 metros y en cambio se le llama "salcio" cuando es podado todos los años. El informante está convencido de que se trata de dos plantas diferentes que no tienen nada que ver una con la otra.

Conscientes de que el estudio de los nombres populares de las plantas necesita unos métodos más bien alejados del ámbito de las ciencias naturales (Vallès, 1996) y son merecedores de investigaciones específicas, durante el trabajo de campo, la transcripción fonética de los nombres ha sido realizada con la ayuda de los numerosos diccionarios locales y siguiendo el alfabeto normal (o estándar) de la lengua italiana, conservando su variantes de género y número, tal y como han sido revelados por el informante. En el método utilizado para la transcripción de los nombres vernaculares se ha elegido distinguir tanto el género como el número para evitar pérdida de información y para transcribir tal y como percibe el informante la especie (en plural o bien en singular), por ejemplo "scopicci" es utilizado para denominar Erica arborea L. en cambio "scopiccio" se utiliza para denominar Calluna vulgaris (L.) Hull, y "farfanello" es utilizado para designar Petasites hybridus (L.) G.Gaertn., B.Mey. \& Scherb. en cambio "farfanella" designa Tussilago farfara L. Aunque esto haya modificado y dilatado el número de nombres vernaculares recogidos, hemos preferido esto a la pérdida de información valiosa que pueda ser utilizada en futuros estudios lingüísticos.

Sin embargo durante la investigación bibliográfica, los nombres populares han sido recogidos tal y como han sido escritos en la fuente bibliográfica.

\section{Identificación botánica}

La identificación botánica de las plantas recolectadas o indicadas por los informantes a las cuales les han asignado un nombre vernacular y un uso tradicional ha sido realizada posteriormente en el laboratorio del Herbario FIAF de la Universidad de Florencia bajo la dirección de la ex-responsable del Herbario y especialista en Botánica Sistemática, Prof. M. Adele Signorini.

Considerando los objetivos de la investigación y con la finalidad de poder confrontar los datos obtenidos con otras investigaciones precedentes del grupo de investigación con el que se ha colaborado en este proyecto, se ha elegido la Flora d'Italia (Pignatti,1982), ya que es la flora analítica más reciente, para poder estudiar todas las características referidas a la especie: identificación botánica, la nomenclatura y sistemática, la corología, el biotipo, el hábitat y el ambiente de la planta en Italia.

Sin embargo con la finalidad de que los datos puedan ser confrontables con cualquier investigación internacional, se ha procedido a actualizar tanto el nombre 
de las especies como de las familias siguiendo The Plant List (TPL, 2015) y APG III (2009). En los casos en los que en la base de datos de The Plant List no estaban resueltos, se ha consultado y aceptado todo los que eran legítimos en Tropicos (Tropicos, 2015). Para plantas cultivadas se ha utilizado la base de datos USDA (2015).

A la hora de realizar la identificación botánica, pueden darse los siguientes casos, para los cuales se explican los diferentes métodos que han sido adoptados:

- La muestra de la etnospecie está a disposición y ésta es identificada con una especie botánica: en este caso ha sido utilizada la nomenclatura botánica citada anteriormente.

- La especie mencionada por el informante ha sido identificada en el lugar de la entrevista durante el trabajo de campo, se trata de especies de fácil identificación y muy comunes (como ciertas cultivadas como Rosmarinus officinalis L. o Salvia officinalis L.) para las cuales normalmente no se proporciona un número de exsciccata).

- La muestra de la etnospecie está a disposición pero no coincide con la especie botánica: cuando la etnospecie se refiere a un varias especies muy afines entre si y difíciles de distinguir a partir de sus características morfológicas se ha recurrido al concepto de especie botánica sensu lato (“s.l."). En cambio cuando la etnospecie se refiere a un número de especies no especificado pertenecientes a un género para el mismo uso, aunque incluya diferentes especies distintas entre ellas, estas han sido denominadas con el término "sp. pl.". Es el caso de Trifolium sp. pl. para el cual ningún informante ha referido ninguna especificidad o distinción entre varias especies.

- La muestra de las plantas citadas no está disponible por los motivos enumerados anteriormente (ver 3.2.3. Testimonios): en este caso cuando hemos podido llegar a una identificación probable de la etnospecie siguiendo con rigor todas las informaciones émicas y éticas que pudiéramos tener a disposición que se detallan a continuación, hemos recurrido a la terminología "cfr.":

- En función de la descripción detallada por parte del informante de la planta así como del hábitat en el que crece y de su uso tradicional.

- Controlar si otro informante de la misma comunidad o de una comunidad afín haya citado el mismo nombre vernacular indicando a su vez una muestra vegetal, entonces por analogía y verificando que las informaciones de la planta (uso tradicional, ambiente y periodo de crecimiento, etc.) coincidan con la especie botánica transcrita.

- Comprobar que las especies candidatas crezcan en la zona de estudio en las floras locales de referencia, averiguar si en la bibliografía local existen informaciones sobre el uso, el lugar de crecimiento de las eventuales especies. 
- Por último, confrontar nuestras previsiones con el Herbario Central de Florencia y con los botánicos especialistas de la zona.

- Han sido recogidos un total de 238 pliegos que han sido depositados en el herbario FIAF y que corresponden con aproximadamente 201 especies de las 281 especies citadas, algunos pliegos son de la misma especie. En los casos en los que no ha sido posible recolectar una muestra y tampoco disponíamos de las informaciones necesarias para poder realizar una identificación válida, las plantas y los datos relativos han sido excluidas de las fases sucesivas de la investigación. 



\section{Capítulo 3}

\section{Investigación bibliográfica}

\section{Selección de los datos bibliográficos}

La investigación bibliográfica sobre los datos relacionados con los usos tradicionales de las plantas en el Alto Valle del Reno y sus zonas próximas ha sido realizada a través de una profunda revisión bibliográfica, buscando libros, revistas, y cualquier tipo de documento que contuviera información sobre la historia, la cultura, el ambiente del lugar. Estas fuentes han sido encontradas en las bibliotecas locales, en los centros turísticos (agroturismos, restaurantes, refugios), en los ayuntamientos y hasta en las propias casas. Existe una gran variedad de literatura local que aporta contribuciones merecedoras de ser organizadas y analizadas con el fin de complementar y comparar nuestros datos etnobotánicos de campo. A partir de la exhaustiva revisión bibliográfica han sido identificados numerosos usos tradicionales, sobre las plantas, registrados en la literatura. Sin embargo se ha puesto de manifiesto la gran laguna botánica que existe en la literatura en cuanto a la validez o a la carencia total de las identificaciones botánicas de los nombres vernaculares de las plantas citadas. El trabajo de campo y la correspondiente trascripción de datos ha sido de gran ayuda para poder asignar con mayor validez y seguridad la adscripción botánica a las numerosas informaciones sobre nombres vernaculares de planta ( sin identificación botánica asociada).

Las informaciones sobre los usos tradicionales de las plantas registradas en la bibliografía local han sido seleccionadas según las siguientes características:

- Que pertenezcan a la cultura tradicional del Alto Valle del Reno, es decir, que sean datos obtenidos a través de entrevistas a personas locales, o bien explícitamente calificadas como "tradicionales" (por ejemplo, "en la medicina popular", "en el campo o en montaña se usa").

- Que se refirieran a noticias relativas al Alto Valle del Reno.

- Que los datos estuvieran asignados a una especie botánica.

- Que fueran relativas a las especies relevadas por nuestra investigación de campo (debido a la poca fiabilidad de las identificaciones botánicas).

Se ha realizado una revisión exhaustiva de las referencias bibliográficas, registrando y clasificando las informaciones etnobotánicas. Mayoritariamente las referencias bibliográficas han sido diccionarios sobre el dialecto local (Appoggi, 2010; Beneforti, 1998; Guccini, 1998) y publicaciones de la revista etnográfica "Nuèter noialtri - storia, tradizione e ambiente dell'Alta Valle del Reno bolognese e 
pistoiese" realizadas por el "Gruppo di studi dell'Alta Valle del Reno" (Balletti, 1980a; Balletti, 1980b; Bernardi y Zagnoni, 1978; Bernardi y Zagnoni, 1979; Bernardi y Zagnoni, 1981; Bonzi, 2000; Borghi et al., 1990; Borri, 1977; Bracchi, 2003; Canuto, 1978; Corradi, 2014; Guccini, 1978; Guccini, 1981; Poli, c. 2014; Sabattini, 1975), libros sobre la historia local (Sirgi, 1991). También han sido registradas noticias a partir de un estudio local de la vegetación (Bertoloni, 1867), un estudio realizado por el instituto local de Grizzana Morandi basado en entrevistas hechas por los estudiantes a sus familiares sobre el uso tradicional de las plantas locales (ICGM, 2003), un recetario tradicional realizado por las personas locales en la Asociación cultural ("Proloco") de una de las comunidades (Badi, 2015), el libro de Ungarelli sobre los conocimientos tradicionales de las plantas en la provincia de Bolonia, en la cual incluye el Alto Valle del Reno (Ungarelli, 1921), la única investigación etnobotánica que existe en la provincia de Bolonia que coincide en una pequeña zona con el Alto Valle del Reno (Sansanelli y Tassoni, 2014), y por último, una investigación etnofarmacológica realizada en la provincia de Pistoia en la parte del Alto Valle del Reno (Uncini Manganelli y Tomei, 1998).

Las informaciones bibliográficas han sido seleccionadas de forma que puedan ser confrontables y comparables con nuestros datos etnobotánicos. Por esto se ha adoptado la misma metodología del trabajo de campo, es decir han sido registradas de forma prioritaria las informaciones sobre los usos tradicionales de las plantas que fueran silvestres o cultivadas (sólo si son utilizadas para un uso distinto de aquel para el cual es de forma general cultivada). Los usos industriales o pertenecientes al conocimiento formal (médicos, farmacéuticos, etc.) aunque sean locales no han sido registrados. El problema del análisis y contraste bibliográfico se basa en la gran laguna que existe en la literatura local sobre la identificación botánica correcta de las plantas con nombres comunes o vernaculares y a menudo, las noticias etnobotánicas encontradas en la bibliografía proporcionan datos parciales e incompletos (falta la parte de la planta usada, el modo de preparación y administración, etc.). En la mayoría de los casos se trata de plantas cuyos nombres vernaculares se refieren a una sola especie reconocidas por toda la comunidad (como "vitalba" se refiere a la Clematis vitalba L.). Los estudios de Ungarelli (1921) y Sansanelli y Tassoni (2014) han sido tomados en consideración porque aunque sus áreas de estudio no se limiten al Alto Valle del Reno, sí que incluyen parte de éste y además engloban la parte boloñesa que lleva el Valle hasta la llanura de Bolonia. E igualmente el estudio de Uncini Manganelli y Tomei (1998) abarca la zona del Alto Valle del Reno de la parte pistoiese que no se ha abordado en este estudio y otra parte colindante del área de Pistoia. Nos parece de suma importancia tomar en consideración estos estudios para poder evaluar, a través del contraste bibliográfico, la influencia cultural que predomina en el Alto Valle del Reno, una zona entre Pistoia (Toscana) y Bolonia (Emilia-Romaña). 
María Teresa Egea Molines
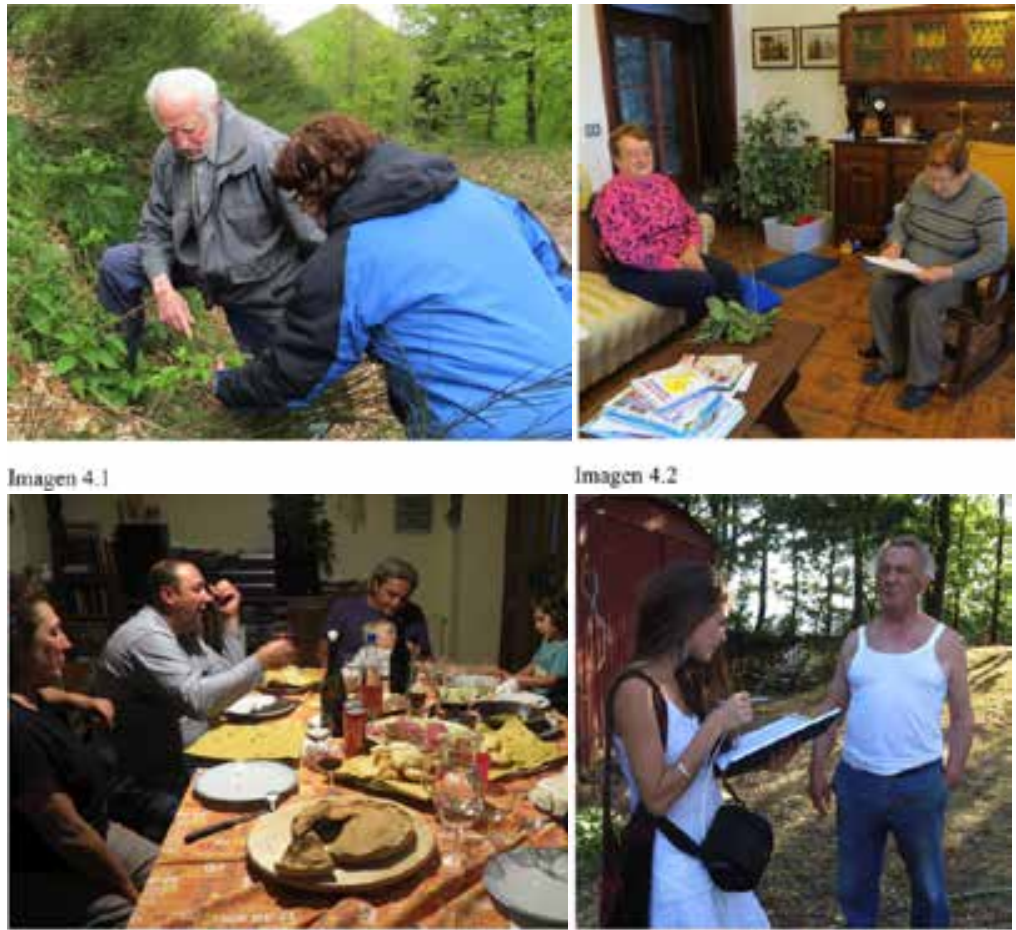

Imagen 4.2

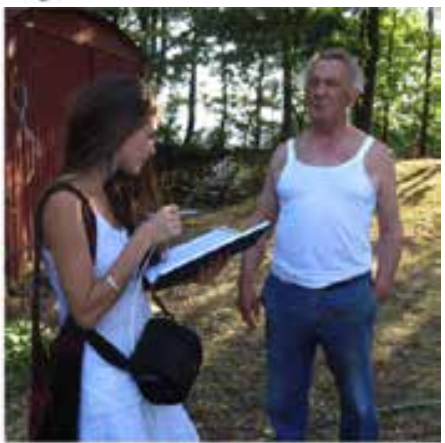

lmagen 43

Imagen 4.4
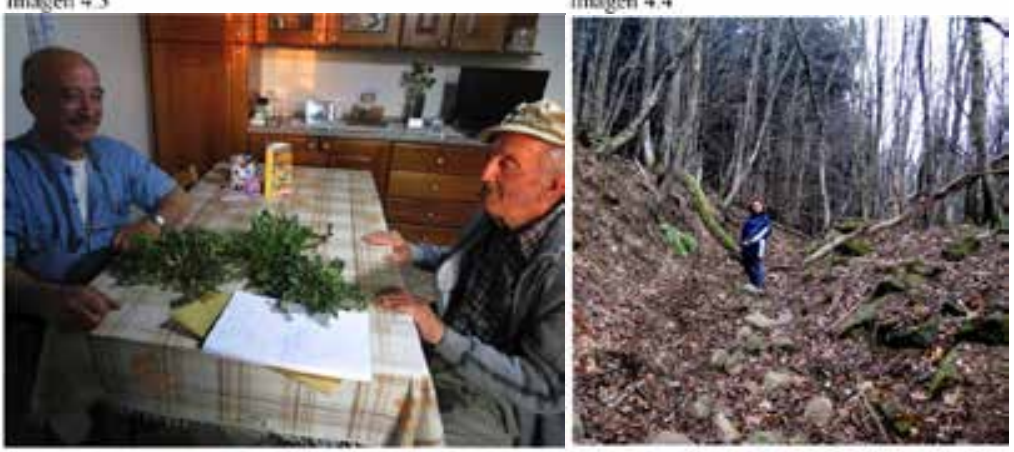

Imagen 4.5

Imagen 4.6

Fig. 12. Metodología y Trabajo de campo I.

Imagen 4.1. Entrevista con un intermediario en Monte Cavallo (Granaglione, Bologna). Imagen 4.2. Entrevistas de grupo en casas particulares (Castel di Casio). Imagen 4.3. Observación participante, participación en la vida social de la comunidad (Le Roncacce). Imagen 4.4. Recolección de especies de interés etnobotánico indicadas por el informante (Baigno). Imagen 4.5. Entrevistas con un intermediario (Baigno). Imagen 4.6. Búsqueda de especies útiles con la informante en hábitats completamente cambiados (Roncacce). Fotos de Teresa Egea. 
Etnobotánica en el Alto Valle del Reno (Toscana y Emilia-Romaña, Italia)
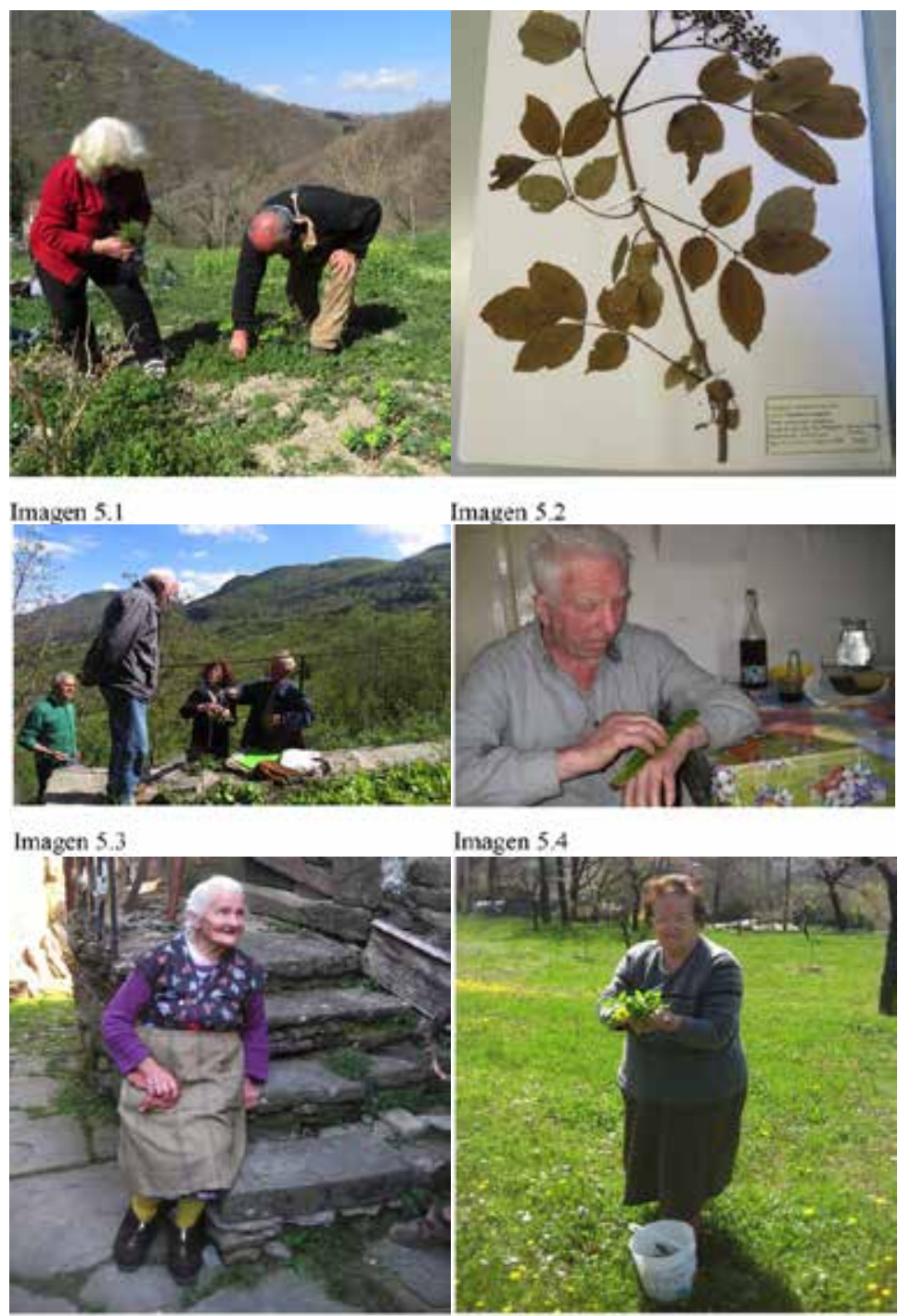

Imagen 5.5

Imagen 5.6

Fig. 13. Metodología. Trabajo de campo II.

Imagen 5.1. Recolección de especies útiles en el huerto de una informante con el intermediario (Le Fabbriche, Camugnano). Imagen 5.2. Pliegos testigos conservados en el herbario FIAF de la Universidad de Florencia. Imagen 5.3. Entrevista de grupo con intermediario y muestra de las especies útiles por parte de los informantes alrededor de su casa (Castelluccio, Porretta Terme). Imagen 5.4. Entrevista en casa de un informante y muestra del modo de aplicación de una especie medicinal (Ronco di Serra, Sambuca Pistoiese). Imagen 5.5. entrevista a una informante en Chiapporato (Camugnano, BO). Imagen 5.6. Recolección de "radicchi" con la informante en Castel di Casio (BO). Fotos de Teresa Egea. 
María Teresa Egea Molines
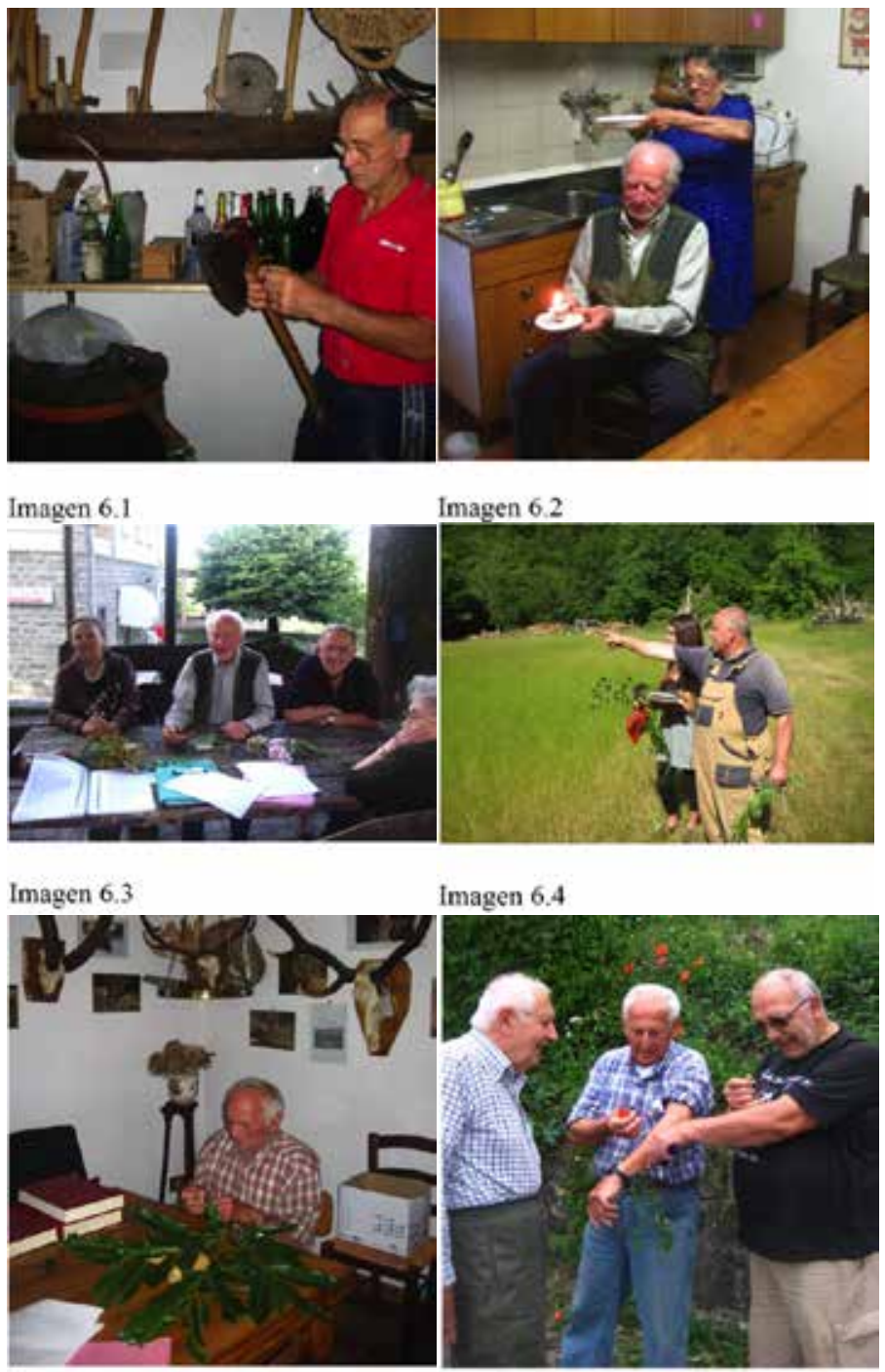

Imagen 6.5

Imagen 6.6

Fig. 14. Metodología. Trabajo de campo III.

Imagen 6.1. Entrevista individual (Lentula). Imagen. 6.2. Realización de un rito mágicoritual-supersticioso (San Pellegrino al Cassero). Imagen 6.3. Entrevista de grupo en la plaza del pueblo de Pàvana (PT). Imagen 6.4. Observación participante, entrevista mientras el informante trabaja en el sector agroforestal (Le Fabbriche). Imagen 6.5. Entrevista con intermediario y realización de un instrumento musical a base de corteza de Castanea sativa Mill. (Corniolo). Imagen 6.6. Entrevista de grupo con intermediario y muestra de los juegos colectivos de antaño (Pàvana). Fotos de Teresa Egea. 



\section{Capítulo 4}

\section{Clasificación y procesado de la información}

\section{Gestión de datos con la hoja de cálculo}

Los datos etnobotánicos recogidos durante el trabajo de campo han sido transcritos en una base de datos constituido por una hoja de cálculo Microsoft Excel 2003. Este tipo de base de datos ha sido elegido (respecto a una base de datos relacional, por ejemplo) puesto que permite una inserción de datos simple, rápida y fácilmente actualizable y también permite utilizar el mismo instrumento tanto para la clasificación como para las elaboraciones numéricas. Con este sistema, los datos han podido ser transcritos en italiano (para mantener una mayor fidelidad con los datos etnográficos) y una vez trabajados, se ha procedido a la traducción de una parte de la Tab. de datos al español de forma rápida y sencilla. Los términos cuya traducción en español no aparecen en la Real Academia Española han sido escritos en italiano entre comillas. La forma de explicación del uso tradicional según el informante ha sido mantenida en italiano (en cursiva) para evitar la pérdida de información vernacular, cultural, dialectal y en definitiva para transcribir la cosmovisión de la cultura en estudio tal y como ha sido transmitida. Según la metodología propuesta por Signorini et al. (2009), la base de datos consiste en una Tab. denominada "Tab. analítica de las especies y de los usos". Cada fila corresponde a una cita, que se define como un dato elemental que corresponde a un único uso referido por un solo informante sobre una única especie, y las columnas corresponden a los atributos (informaciones) referidos por el informante sobre el uso de cada especie, por tanto los atributos están reflejados en las siguientes columnas:

- Nombre vernacular de la planta (según el informante).

- Nombre científico (atribuido por los investigadores).

- Familia botánica (atribuido por los investigadores).

- Número de exsiccata (si hay un pliego).

- Nombre del informante que cita el uso de la planta.

- Código identificador del informante (para mantener el anonimato).

- Parte de la planta utilizada para aquel uso.

- Tipología general de uso (sector de uso).

- Tipología detallada de uso (categorías de uso).

- Breve descripción del modo de uso de la planta (según el informante, indicando la parte de la planta utilizada).

- Eventuales mezclas con otras plantas. 
- Ambiente de crecimiento según el informante.

- Uso actual o pasado (con los códigos 1 = uso actual, es decir que el informante lo práctica en la actualidad, 2 = uso pasado, es decir que el informante lo practicaba en el pasado).

- Uso personal o indirecto (con los códigos 1= lo practica o practicaba personalmente, $2=10$ ha visto hacer a alguien de la familia o de la comunidad, o le han hablado de tal uso, es un conocimiento indirecto).

- La difusión pasada y actual según el informante de la planta $(3=$ la especie era o es abundante en el territorio según el informante, $0=$ la planta no existía en el territorio o ha desaparecido en la actualidad).

- Si la planta es silvestre, cultivada o ambas dos, según el informante.

- Notas (eventuales noticias relacionadas a la cita, como periodos de recolecta, proverbios, descripción de la planta según el informante, otro tipo de conocimiento tradicional del uso, o notas sobre particularidades botánicas o florísticas).

- Zona de uso (Sambuca Pistoiese, Parco dei Laghi di Suviana e Brasimone, Granaglione o Porretta Terme).

Sólo para los usos medicinales se registran también los datos relativos a:

- Indicaciones terapéuticas.

- Nosología popular (clasificación y denominación vernacular de las enfermedades).

- Forma de preparación de la droga.

- Forma de administración del remedio.

Han sido consideradas como diferentes citas, aquellas que se diferencian entre ellas por lo menos por uno de los siguientes datos: la especie botánica, el informante, la categoría de uso. Las citas que se diferencian en los aspectos secundarios, como las partes de las plantas, el modo de preparación o la forma de administración han sido incluidas como una única cita. Cada cita coincide con una única fila en la Tab. analítica.

El número de usos ha sido obtenido considerando como usos diferentes para cada especie aquellos cuyas categorías de uso se diferencian. De ésta manera, las citas relativas a una misma especie sobre la misma categoría de uso, citadas por diferentes informantes son consideradas como un único uso (Signorini et al., 2009).

\section{Categorización y clasificación de la información}

Para poder analizar los conocimientos etnobotánicos tanto cuantitativamente como cualitativamente, es necesario estandarizar los datos obtenidos durante el trabajo de campo. La transcripción de las informaciones desde el lenguaje popular a un lenguaje formal se ha realizado con el máximo de objetividad posible para poder en una fase posterior, elaborar, analizar e interpretar los resultados. Pero para documentar la percepción, la cosmovisión y la idiosincrasia intrínsecas en cada uso tradicional registrado, el modo de preparación ha sido trascrito según las 


\section{María Teresa Egea Molines}

explicaciones populares de los informantes, si ningún tipo de filtro, interpretación o categorización. Por otra parte, la clasificación de los datos también es importante porque determina los resultados etnobotánicos y la posibilidad de confrontarlos con otros estudios etnobotánicos. Considerando que no existe una clasificación acordada o estándar, merece la pena explicar ciertos criterios distintivos de los sectores y las categorías seleccionadas para poder eventualmente adaptar los resultados para futuros estudios comparativos.

La ecología de las especies ha sido descrita según las caracterizaciones de Pignatti (1982) con algunas adaptaciones o precisiones necesarias. Las distintas clasificaciones utilizadas para las formas biológicas, los corotipos, la abundancia, la biología, y el ambiente de las especies se exponen en la Tab. 7.

Tab. 7. Clasificaciones empleadas en la ecología de las especies.

En función de los corotipos, biotipos, abundancia, biología (según Pignatti, 1982) así como los ambientes de crecimiento.

\begin{tabular}{|c|c|c|}
\hline & Tipos & Categorías \\
\hline pos & Coroti & $\begin{array}{l}\text { Europeas - Cultivadas - Eurimediterránea - Amplia distribución - Nórdicas } \\
\text { - Estenomediterránea - Montañosas - Atlánticas - Exóticas - Mediterráneas } \\
\text { montañosas - Atlánticas y Mediterráneas }\end{array}$ \\
\hline os & Biotip & $\begin{array}{l}\text { Caméfito - Fanerófito - Geófito - Hemicriptófito - Nanofanerófito - } \\
\text { Terófito }\end{array}$ \\
\hline anci & Abund & Cultivada o ausente - Rara - Común - Bastante Común - Muy Común \\
\hline ía & Biolog & Silvestre - Silvestre y Cultivada - Cultivada - Ausente \\
\hline ntes & Ambie & $\begin{array}{l}\text { Rocas y acantilados - hayedos y bosques mixtos de hayas y abetos - zonas } \\
\text { húmedas y riparias - Bosques mixtos caducifolios y de monte bajo - Encinares } \\
\text { y otros siempreverdes mediterráneos - orla, desmontes, márgenes - prados, } \\
\text { pastos - arbustos, matorrales, brezales - maquias, garrigas - Castañares puros } \\
\text { (de fruto o de monte bajo) - reforestaciones de coníferas - caminos, baldíos, } \\
\text { muros, setos - cultivos, invasoras, jardines - áreas marginales, ambientes } \\
\text { ruderales, calles, en las casas - plantas adquiridas en las tiendas }\end{array}$ \\
\hline
\end{tabular}

Las tipologías generales de usos, llamadas sectores son 12 (ver Tab. 8), y a su vez se subdividen en tipologías detalladas, llamadas categorías (Tab. 8). En el sector medicinal (Tab. 8), las categorías corresponden a las indicaciones terapéuticas, las cuales se refieren al órgano o aparato que está afectado, criterio adoptado igualmente con algunas variantes en otras investigaciones en Italia realizadas por Ballero y Poli (1997), Bruni et al. (1997), Camangi et al., (2004), Tammaro (1976). Las categorías han sido también adaptadas a las características de la etnofarmacología local y sobre todo a la epidemiología local.

En cambio en el sector veterinario, las categorías corresponden al tipo de animal que se cura, por la dificultad que implica clasificar las enfermedades de animales con nombres vernaculares y la interpretación de la enfermedad según el informante. La nosología etnoveterinaria es muy general y se basa sobre comportamientos 
anómalos de los animales sin un diagnóstico preciso, como el "male rosso" que era diagnosticado por la población en base a que el cerdo no comía y se quedaba inmóvil en su establo, o bien el malestar o debilidad de las ovejas ("quando stavano male") o el hinchazón de las vacas que les llevaba a la muerte. Por tanto, al no ser evidente el origen de las afecciones veterinarias tratadas con plantas, los usos son clasificados según el animal que es tratado.

\section{Tab. 8, Sectores y categorías de uso.}

Sectores de usos (tipologías generales o de primer nivel) y categorías de uso (tipologías detalladas o de segundo nivel). (1) Solo cuando la planta es considerablemente transformada y dura en el tiempo, al contrario se trata de usos domésticos o agro-pastorales. (2) Usos relacionados con las actividades de la casa, incluidos los cosméticos, tintóreos y ornamentales) (3) Juegos, pasatiempos, bromas, cigarrillos. (4) Si prevalece el aspecto mágico-propiciatorio y apotropaico, o bien si constituye un rito, es decir, una práctica que se realiza siempre en el mismo momento y por el mismo motivo por toda la comunidad. (5) Sólo si prevalece el uso religioso, -ante el uso propiciatorio-apotropaico). (6) Incluidos los usos mágico-veterinarios.

Sectores de usos

Agro-pastoral

Alimentario

Artesanal (1)

Caza y pesca

Doméstico (2)
Categorías de usos

alimentación animal (incluidos forrajeros) - antiparasitario (para animales) - apicultura - avicultura - construcción agrícola (cabañas, etc...) - cría de cerdos y productos porcinos - cría de ganado bovino - cría de ovejas - cuerdas y ataduras - cultivos de gusano de seda (solo aparece en el catálogo etnobotánico, por ser un uso común de plantas cultivadas) - herramientas y objetos agrícolas - horticultura - otro agropastoral - portainjertos productos lácteos - repelentes y trampas - vallas y delimitaciones - viticultura y enología

aromatizante - arroces y "risotto" - bebida - conserva de frutas (fruta cocida, conservada en tarro, en alcohol) - dulces y golosinas - empanadas - encurtidos y conserva en aceite (en vinagre o en aceite) - ensalada - fritura - fruta fresca - fruta seca - gachas o polentas - golosinas y masticatorias (pasatiempos campestres) - licor - mermelada - otro alimentario - pan y similares - pasta y "gnocchi" - relleno de ravioli - sopas de verduras y potaje ("zuppe di verdure e minestre") - sucedáneos del café - tortilla - verdura cocida - verdura cruda

cestería - fibra textil - instrumentos y utensilios para la artesanía - muebles - objetos domésticos - objetos personales y calzado - otro artesanal - tejer sillas

caza de pájaros - ictiotóxico - otro caza y pesca

ambientador - chimenea y horno - cuidado personal y cosmética - detergente - detergente/tintorial (al mismo tiempo que lavan intensifican el color) - integración de la renta familiar (plantas que recolectaban y se vendían para aumentar el nivel de ingresos, o se intercambiaban para incrementar los recursos) jardín - objetos doméstico y escobas - ornamental - otro doméstico - repelentes o trampas domésticas - ropa de cama y 
Efecto nocivo

Lúdico/voluptuoso (3)

Mágico/medicinal cioso (4)

Mágico/ritual/supersti

Medicinal

Religioso (5)

Veterinario (6) muebles - tinta o utensilios para escribir - tintorial

efecto perjudicial (efecto negativo, por evitar por alguna razón) - tóxicas y venenosas

alimentos/juguetes - decoraciones y disfraces de niños fumable - instrumentos musicales - juego colectivo y bromas juguetes - muñecas - otro lúdico - pasatiempos contra el miedo y los traumas - otro mágico/medicinal preventivo de enfermedades - vermífugo - verrugas adivinatorio - efecto negativo - otro mágico/ritual/supersticioso - propiciatorio - protector - rituales de Mayo - rituales navideños

afecciones oro-faríngeas y de la cavidad oral enfermedades del oído - afecciones cutáneas y tejidos subcutáneos - afecciones oftalmológicas - afecciones típicas infantiles - otro medicinal - patologías del aparato circulatorio patologías del aparato digestivo - patologías del aparato urinario - trastornos musculo-esqueléticos - Afecciones ginecológicas, complicaciones obstétricas, del post-parto y del puerperio afecciones del metabolismo - patologías del sistema nervioso fiebre - dolor de cabeza - afecciones del aparato respiratorio parásitos externos - para provocar enfermedad - estado general otro religioso - alfombras florales - ornamento para altares e iglesias - ornamento para cementerios (solo en el catálogo etnobotánico) - procesiones - rogativas

- otro veterinario - ganado bovino - conejos - equinos ovejas y cabras - aves de corral - cerdos - todos los animales

Las partes usadas de las plantas también han sido clasificadas en 18 grupos homogéneos (ver Tab. 9) que incluyen algunos transformados sencillos como harina/salvado o aceite, para los remedios tradicionales siempre y cuando no sea concebido por los informantes como un vector medicinal (en cuyo caso sería en el caso del aceite un oleato, es decir una preparación galénica de otra especie). Para facilitar la comprensión y la interpretación de los resultados, y acorde con la metodología adoptada (Signorini et al., 2009), las partes de las plantas han sido acumuladas si para un uso particular (una misma categoría de uso de una especie) se utilizan dos partes diferentes. Es decir que han sido consideradas como diferentes, el uso de varias partes de la planta en una sola preparación.

Tab. 9. Categorías de las partes de las plantas usadas y transformados

\begin{tabular}{|c|c|}
\hline $\begin{array}{l}\text { Grandes } \\
\text { tipos }\end{array}$ & Categorías \\
\hline $\begin{array}{l}\text { Partes de } \\
\text { la planta }\end{array}$ & $\begin{array}{l}\text { brotes - corteza - flores/inflorescencias y sus partes, sumidades floridas - } \\
\text { frutos/infrutescencias/falsos frutos - hojas - órganos subterráneos } \\
\text { (raíces/bulbos/rizomas) - otras partes - parte aérea (toda) - planta entera/viva - } \\
\text { semillas - tallos herbáceos/escapos - tallos leñosos/ramas/ramitas/vástagos }\end{array}$ \\
\hline
\end{tabular}


Etnobotánica en el Alto Valle del Reno (Toscana y Emilia-Romaña, Italia)

Transform aceite - agalla - harina/salvado - látex o savia - madera - resina -
ados, exudados
y extractos

Han sido reconocidas 15 formas de preparación y 15 formas de administración para el sector medicinal (Tab. 10).

Tab. 10. Clasificaciones para las formas de preparación y de administración.

Clasificaciones para las formas de preparación y las formas de administración de los preparados medicinales a base de plantas

\begin{tabular}{|c|c|}
\hline $\begin{array}{l}\text { Grandes } \\
\text { tipos }\end{array}$ & Categorías \\
\hline $\begin{array}{c}\text { Formas } \\
\text { de preparación }\end{array}$ & $\begin{array}{l}\text { al natural - ceniza - cocción - decocción - emplasto cocido - emplasto crudo } \\
\text { - extracto líquido - infusión - jarabe - macerado en aceite (oleato) - macerado en } \\
\text { agua (hidrolito) - macerado en alcohol (alcoholito)/vino(enolito) - no } \\
\text { especificado - otra preparación - pomada }\end{array}$ \\
\hline $\begin{array}{l}\text { Formas } \\
\text { de } \\
\text { administración }\end{array}$ & $\begin{array}{l}\text { aplicación directa incluido la cataplasma - baños de asientos - baños o } \\
\text { lavados - colutorios - como alimento - compresas - enemas - lavados vaginales - } \\
\text { masajes - no especificado - oral - otra administración - pediluvio - supositorio - } \\
\text { vahos e inhalaciones }\end{array}$ \\
\hline
\end{tabular}

\section{Los informantes}

Análogamente a la "Tab. analítica de las especies y de los usos" mencionada anteriormente se ha realizado otra Tab. analítica (a partir de una hoja de cálculo Microsoft Excel 2003) denominada "Tab. analítica de los informantes". En ésta tabla, cada fila corresponde a un informante y cada columna contiene los diferentes atributos de los informantes: sexo, edad (en la última entrevista realizada), localidad y municipio de nacimiento, localidad y municipio de residencia, nivel de escolarización, sector laboral al cual se dedica, si está jubilado o no y eventuales notas útiles para la investigación de campo, como el número de teléfono, fechas de las entrevistas, el intermediario utilizado durante las entrevistas, cuantos años ha vivido fuera, etc. Cada informante ha sido identificado con un código que se utilizará en el capítulo de los resultados.

En la Tab. 11 se resumen los datos más importantes de los 113 informantes entrevistados. 


\section{María Teresa Egea Molines}

Tab. 11. Descripción de los 113 informantes entrevistados.

Códigos de los sectores laborales: 1, Agrícola-forestal; 2, Artesanía; 3, Comercio; 4, Doméstico o Amas de casa; 5, Empleado; 6, Enseñanza; 7, Obrero; 8, Otro (músico, escritor o político); 9, Restauración-Hostelería.

\begin{tabular}{|c|c|c|c|c|c|c|c|}
\hline Código & S & E & "Frazioni" & Municipio & & Nivel & Códi \\
\hline informantes & exo & dad & $\begin{array}{l}\text { località)-Localidades de } \\
\text { referencia }\end{array}$ & de referencia & & lucación & $\begin{array}{l}\text { go sector } \\
\text { laboral }\end{array}$ \\
\hline AMA & M & 72 & Mogne & no Camugna & & Primaria & 1 \\
\hline AN3 & M & 77 & $\begin{array}{l}\text { Castiglione dei } \\
\text { Pepoli }\end{array}$ & $\begin{array}{l}\text { Castiglion } \\
\text { e dei Pepoli }\end{array}$ & & Primaria & 4 \\
\hline AP1 & $\mathrm{H}$ & 81 & Prati & $\begin{array}{l}\text { Castel di } \\
\text { Casio }\end{array}$ & $\mathrm{a}$ & Secundari & 1 \\
\hline AP2 & $\mathrm{H}$ & 84 & Porretta Terme & $\begin{array}{l}\text { Porretta } \\
\text { Terme }\end{array}$ & & Primaria & 5 \\
\hline BAD & $\mathrm{H}$ & 72 & Barceda & no Camugna & & Primaria & 2 \\
\hline BAN & M & 92 & Stagno & no Camugna & & Primaria & 1,5 \\
\hline BAR & M & 77 & Case Roncacce & no Camugna & & Primaria & 4 \\
\hline BAT & M & 89 & Stagno & no Camugna & & Primaria & 4 \\
\hline BAZ & M & 67 & Stagno & no Camugna & $\mathrm{a}$ & Secundari & 5 \\
\hline BBA & M & 92 & $\begin{array}{l}\text { San Pellegrino al } \\
\text { Cassero }\end{array}$ & $\begin{array}{l}\text { Sambuca } \\
\text { Pistoiese }\end{array}$ & $\mathrm{a}$ & Secundari & 5 \\
\hline BBI & M & 65 & Barceda & Camugna & & Secundari & 9,4 \\
\hline BDI & $\mathrm{H}$ & 90 & Barceda & no Camugna & $\mathrm{a}$ & Primaria & 5,2 \\
\hline BEL & M & 97 & $\begin{array}{l}\text { Castiglione } \\
\text { Pepoli }\end{array}$ & $\begin{array}{l}\text { Castiglion } \\
\text { e dei Pepoli }\end{array}$ & & Primaria & 1 \\
\hline BFE & M & 89 & Treppio & $\begin{array}{l}\text { Sambuca } \\
\text { Pistoiese }\end{array}$ & to & Bachillera & 4 \\
\hline BGI & $\mathrm{H}$ & 63 & $\begin{array}{l}\text { Treppio-Casa } \\
\text { Giomi }\end{array}$ & $\begin{array}{l}\text { Sambuca } \\
\text { Pistoiese }\end{array}$ & & Primaria & 1 \\
\hline $\mathrm{BIO}$ & $\mathrm{M}$ & 85 & Stagno & $\begin{array}{l}\text { Camugna } \\
\text { no }\end{array}$ & & Primaria & 1,5 \\
\hline BLI & M & 78 & Torri & $\begin{array}{l}\text { Sambuca } \\
\text { Pistoiese }\end{array}$ & & Primaria & 5 \\
\hline BMA & $\mathrm{H}$ & 56 & Baigno & no Camugna & $\mathrm{a}$ & Secundari & 1 \\
\hline BOR & M & 76 & $\begin{array}{l}\text { Stagno-Le } \\
\text { Fabbriche }\end{array}$ & $\begin{array}{l}\text { Camugna } \\
\text { no }\end{array}$ & & Primaria & 1 \\
\hline BPA & $\mathrm{H}$ & 74 & Pàvana & $\begin{array}{l}\text { Sambuca } \\
\text { Pistoiese }\end{array}$ & $\mathrm{a}$ & Secundari & 5 \\
\hline BPI & $\mathrm{H}$ & 94 & Taviano & Sambuca & & Primaria & 5 \\
\hline
\end{tabular}


Etnobotánica en el Alto Valle del Reno (Toscana y Emilia-Romaña, Italia)

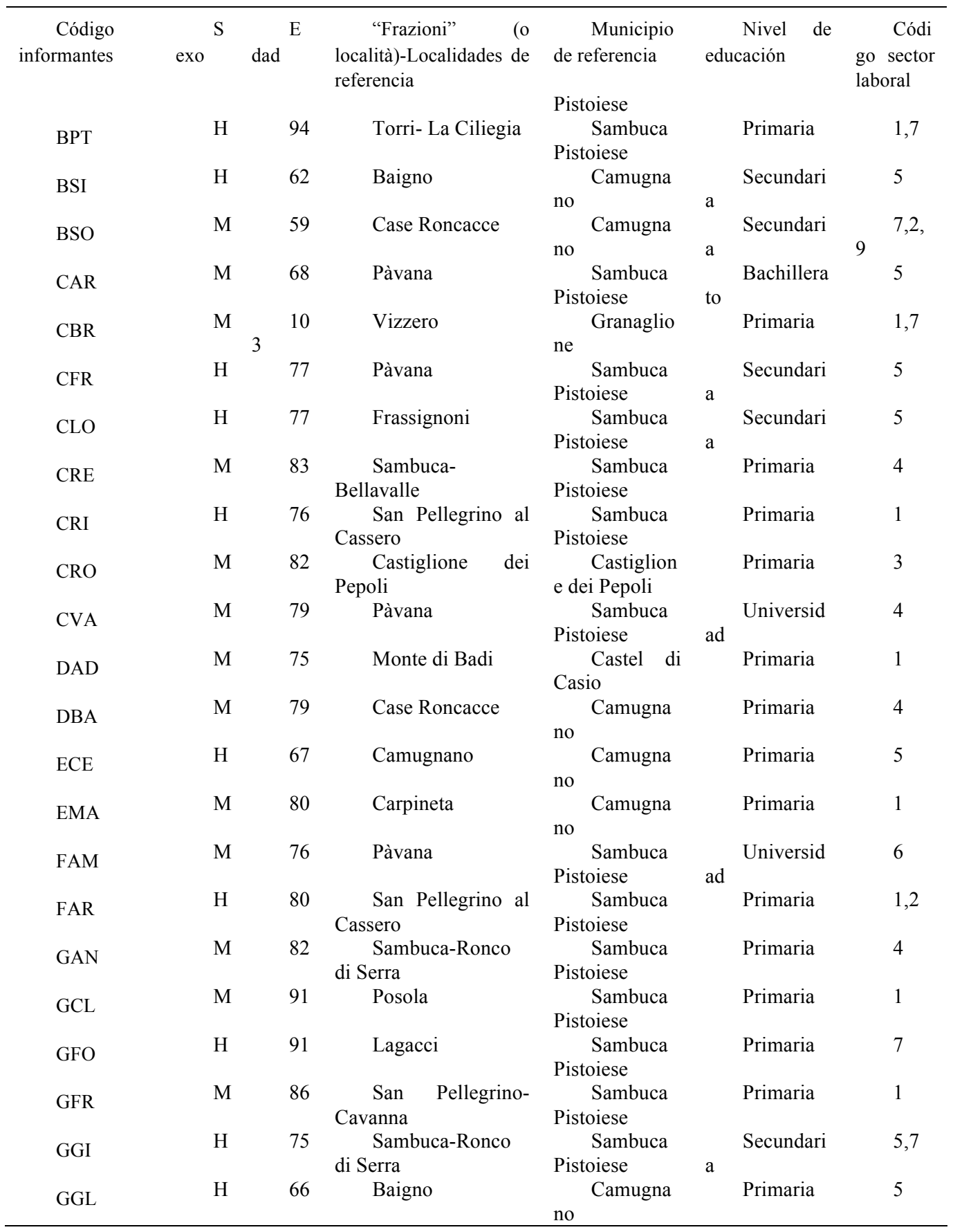


María Teresa Egea Molines

\begin{tabular}{|c|c|c|c|c|c|c|c|}
\hline Código & S & $\mathrm{E}$ & "Frazioni" & Municipio & & Nivel & Códi \\
\hline informantes & exo & dad & $\begin{array}{l}\text { località)-Localidades de } \\
\text { referencia }\end{array}$ & de referencia & educ & cación & $\begin{array}{l}\text { go sector } \\
\text { laboral }\end{array}$ \\
\hline GLA & M & 70 & $\begin{array}{c}\text { San Pellegrino- } \\
\text { Cavanna }\end{array}$ & $\begin{array}{l}\text { Sambuca } \\
\text { Pistoiese }\end{array}$ & $\mathrm{a}$ & Secundari & 9 \\
\hline GPU & M & 99 & $\begin{array}{r}\text { Stagno- } \\
\text { Chiapporato }\end{array}$ & no ${ }^{\text {Camugna }}$ & & Primaria & 1 \\
\hline GRI & M & 95 & $\begin{array}{l}\text { San Pellegrino al } \\
\text { Cassero }\end{array}$ & $\begin{array}{l}\text { Sambuca } \\
\text { Pistoiese }\end{array}$ & & Primaria & 1 \\
\hline GUF & $\mathrm{H}$ & 75 & Pàvana & $\begin{array}{l}\text { Sambuca } \\
\text { Pistoiese }\end{array}$ & $\mathrm{ad}$ & Universid & 8 \\
\hline GZE & M & 91 & $\begin{array}{r}\text { Stagno- } \\
\text { Chiapporato }\end{array}$ & no ${ }^{\text {Camugna }}$ & & Primaria & 1,5 \\
\hline IMA & M & 79 & Stabiazzoni & $\begin{array}{l}\text { Sambuca } \\
\text { Pistoiese }\end{array}$ & & Primaria & 1 \\
\hline IRE & $\mathrm{H}$ & 80 & Torri & $\begin{array}{l}\text { Sambuca } \\
\text { Pistoiese }\end{array}$ & & Primaria & 5 \\
\hline LGI & M & 75 & Stagno & no Camugna & & Primaria & 4,2 \\
\hline LLU & $\mathrm{H}$ & 86 & Barceda & no $\quad$ Camugna & & Primaria & 1,5 \\
\hline LRE & M & 73 & Porretta Terme & $\begin{array}{l}\text { Porretta } \\
\text { Terme }\end{array}$ & $\mathrm{a}$ & Secundari & 3,9 \\
\hline LST & M & 43 & Vizzero & ne & & Secundari & 9,4 \\
\hline MCL & M & 94 & Pàvana & $\begin{array}{l}\text { Sambuca } \\
\text { Pistoiese }\end{array}$ & & Primaria & 4 \\
\hline MDA & M & 61 & Docciola & $\begin{array}{l}\text { Sambuca } \\
\text { Pistoiese }\end{array}$ & $\mathrm{a}$ & Secundari & 5 \\
\hline MGE & $\mathrm{H}$ & 75 & Vizzero & ne & to & Bachillera & 5 \\
\hline MGI & $\mathrm{H}$ & 87 & Stagno & no Camugna & to & Bachillera & 6 \\
\hline MGO & $\mathrm{H}$ & 88 & Torri-Torraccia & $\begin{array}{l}\text { Sambuca } \\
\text { Pistoiese }\end{array}$ & & Primaria & 1,2 \\
\hline MIO & M & 83 & Barceda & no Camugna & & Primaria & 4 \\
\hline MME & M & 79 & Campaldaio & $\begin{array}{l}\text { Sambuca } \\
\text { Pistoiese }\end{array}$ & & Primaria & 1,4 \\
\hline MMR & M & 51 & Stagno & $\begin{array}{l}\text { Camugna } \\
\text { no }\end{array}$ & $\mathrm{a}$ & Secundari & 5 \\
\hline MOR & M & 77 & Stagno & no $\quad$ Camugna & & Primaria & 5 \\
\hline MRI & $\mathrm{H}$ & 69 & $\begin{array}{l}\text { Stagno-Le } \\
\text { Fabbriche }\end{array}$ & no Camugna & $\mathrm{ad}$ & Universid & 1,3 \\
\hline MSA & $\mathrm{H}$ & 79 & Bargi & no Camugna & & Primaria & 3 \\
\hline MSI & M & 94 & Bargi & no Camugna & & Primaria & 4 \\
\hline MSR & M & 89 & Bivio & Castel di & & Secundari & 2 \\
\hline
\end{tabular}


Etnobotánica en el Alto Valle del Reno (Toscana y Emilia-Romaña, Italia)

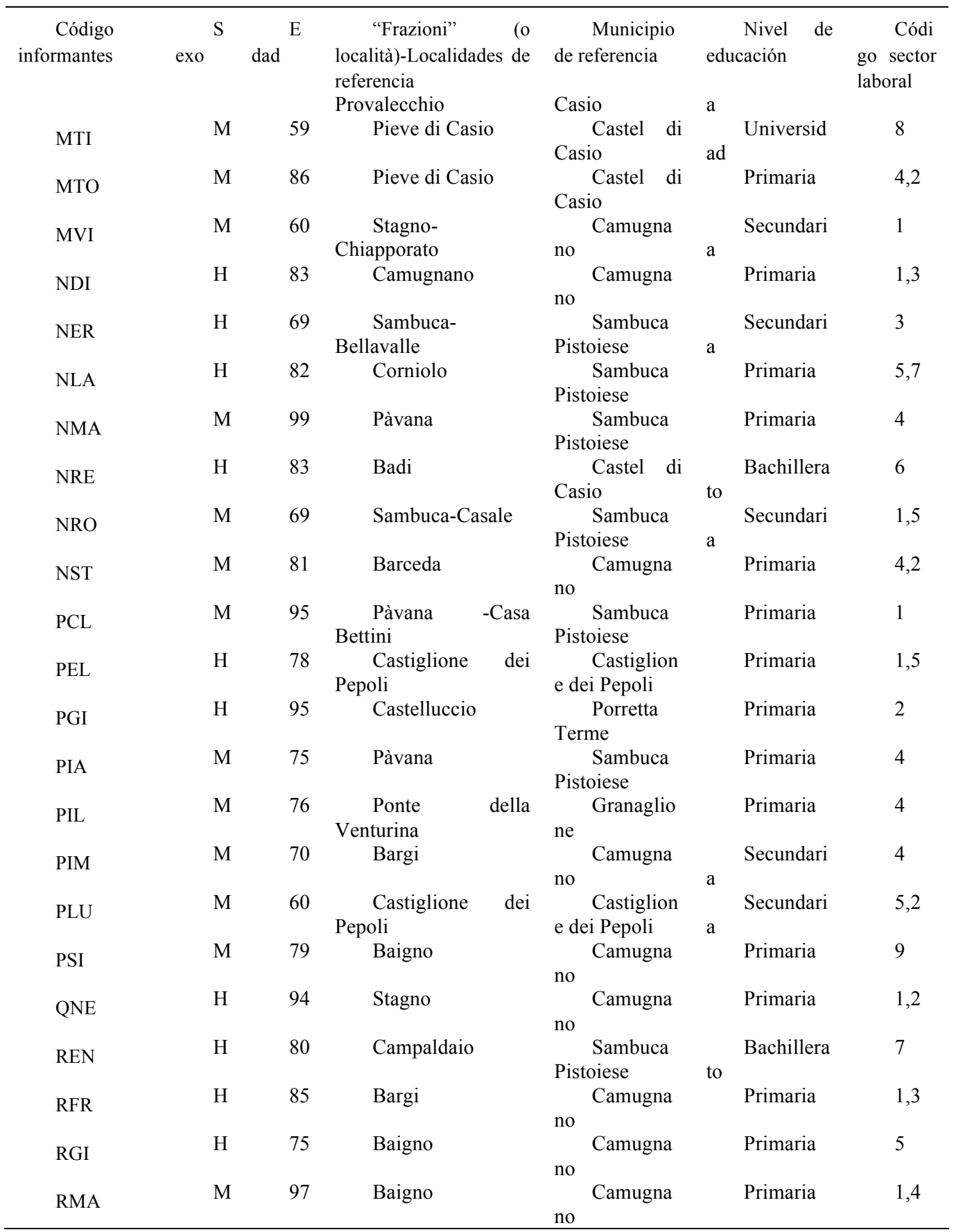


María Teresa Egea Molines

\begin{tabular}{|c|c|c|c|c|c|c|c|}
\hline Código & S & $\mathrm{E}$ & "Frazioni" & Municipio & & Nivel & Códi \\
\hline informantes & exo & dad & $\begin{array}{l}\text { località)-Localidades de } \\
\text { referencia }\end{array}$ & de referencia & & ucación & $\begin{array}{l}\text { go sector } \\
\text { laboral }\end{array}$ \\
\hline RNI & M & 72 & $\begin{array}{r}\text { Ponte della } \\
\text { Venturina }\end{array}$ & ne ${ }^{\text {Granaglio }}$ & & Primaria & 7 \\
\hline RRE & $\mathrm{H}$ & 85 & Baigno & no Camugna & & Primaria & 1,5 \\
\hline $\mathrm{SCO}$ & M & 77 & Pàvana & $\begin{array}{l}\text { Sambuca } \\
\text { Pistoiese }\end{array}$ & & Primaria & 4 \\
\hline SLU & $\mathrm{H}$ & 91 & Il Giardino & $\begin{array}{l}\text { Sambuca } \\
\text { Pistoiese }\end{array}$ & & Primaria & 1,2 \\
\hline SOT & $\mathrm{H}$ & 74 & Torri-Lentula & $\begin{array}{l}\text { Sambuca } \\
\text { Pistoiese }\end{array}$ & & Primaria & 1,2 \\
\hline TAD & M & 79 & Torri-Lentula & $\begin{array}{l}\text { Sambuca } \\
\text { Pistoiese }\end{array}$ & & Primaria & 9,1 \\
\hline TAT & M & 48 & Monte Baducco & $\begin{array}{l}\text { Castiglion } \\
\text { e dei Pepoli }\end{array}$ & $\mathrm{a}$ & Secundari & 5,9 \\
\hline TGA & M & 87 & Monachino & $\begin{array}{l}\text { Sambuca } \\
\text { Pistoiese }\end{array}$ & to & Bachillera & 6 \\
\hline TGO & $\mathrm{H}$ & 89 & Monachino & $\begin{array}{l}\text { Sambuca } \\
\text { Pistoiese }\end{array}$ & ad & Universid & 5 \\
\hline TIV & $\mathrm{H}$ & 66 & Corniolo & $\begin{array}{l}\text { Sambuca } \\
\text { Pistoiese }\end{array}$ & $\mathrm{a}$ & Secundari & 5 \\
\hline TOA & M & 86 & Treppio & $\begin{array}{l}\text { Sambuca } \\
\text { Pistoiese }\end{array}$ & & Primaria & 1 \\
\hline TRU & $\mathrm{H}$ & 64 & $\begin{array}{l}\text { S.Pellegrino-Casa } \\
\text { Pasquinetti }\end{array}$ & $\begin{array}{l}\text { Sambuca } \\
\text { Pistoiese }\end{array}$ & $\mathrm{a}$ & Secundari & 7 \\
\hline TSI & M & 81 & Torri- La Ciliegia & $\begin{array}{l}\text { Sambuca } \\
\text { Pistoiese }\end{array}$ & & Primaria & 1,3 \\
\hline TUL & M & 73 & $\begin{array}{l}\text { San Pellegrino al } \\
\text { Cassero }\end{array}$ & $\begin{array}{l}\text { Sambuca } \\
\text { Pistoiese }\end{array}$ & & Primaria & 4,2 \\
\hline UMI & M & 82 & Treppio & $\begin{array}{l}\text { Sambuca } \\
\text { Pistoiese }\end{array}$ & & Primaria & 1 \\
\hline VAL & M & 70 & $\begin{array}{l}\text { Castiglione dei } \\
\text { Pepoli }\end{array}$ & $\begin{array}{l}\text { Castiglion } \\
\text { e dei Pepoli }\end{array}$ & $\mathrm{ad}$ & Universid & 8 \\
\hline VFR & M & 66 & Docciola & $\begin{array}{l}\text { Sambuca } \\
\text { Pistoiese }\end{array}$ & & Primaria & 5 \\
\hline VMA & $\mathrm{H}$ & 74 & Madognana & ne ${ }^{\text {Granaglio }}$ & to & Bachillera & 5 \\
\hline VMR & M & 62 & Case Boni & ne ${ }^{\text {Granaglio }}$ & to & Bachillera & 3,9 \\
\hline VMU & $\mathrm{H}$ & 75 & Case Boni & ne & to & Bachillera & 5 \\
\hline VSI & $\mathrm{H}$ & 64 & Baigno & $\begin{array}{l}\text { Camugna } \\
\text { no }\end{array}$ & $\mathrm{a}$ & Secundari & 5 \\
\hline ZAN & $\mathrm{H}$ & 83 & Porretta Terme & $\begin{array}{l}\text { Porretta } \\
\text { Terme }\end{array}$ & & Primaria & 1,2 \\
\hline
\end{tabular}


Entre los informantes 56 son originarios de los municipios pertenecientes a la parte boloñesa (Bolonia, Emilia-Romaña) del Alto Valle del Reno: Camugnano, Castel di Casio, Castiglione dei Pepoli, Granaglione, Porretta Terme; 45 informantes han nacido en la parte pistoyesa (Pistoia, Toscana) del Alto Valle del Reno, 5 han nacido en otros lugares de Italia pero han pasado la mayor parte de su vida como residentes del Alto Valle del Reno, y 7 informantes nacieron en otras zonas del Alto Valle del Reno aunque externas al área de estudio de la investigación y residen dentro de ésta. Del total de 113 informantes, 13 informantes han nacido en la parte izquierda del Valle del Reno y el resto en la parte derecha del Valle. Observando las localidades de nacimiento y las localidades de residencia, se denota un gran flujo migratorio en el Alto Valle del Reno como a las afueras de éste. Con el fin de analizar la distribución del conocimiento etnobotánico a nivel territorial en el capítulo de la discusión, se ha seleccionado entre la localidad y el municipio de nacimiento y de residencia, "la localidad y el municipio de referencia" que corresponde a aquel que sea más representativo de cada informante, y donde mayoritariamente el informante haya aprendido y practicado los conocimientos etnobotánicos en cuestión. Por lo que resulta que han sido entrevistados 64 informantes en la parte boloñesa del AVR y 49 en la parte pistoyesa distribuidos como se puede apreciar en la Fig. 17.

\section{Trascripción de los datos bibliográficos}

Con el fin de poder comparar y completar los datos de campo con los datos bibliográficos, se ha utilizado el mismo modelo de Tab. que la "Tab. analítica de las especies" denominada "Tab. analítica bibliográfica”. Al igual que en la "Tab. analítica de las especies", las columnas corresponden a los atributos (informaciones) referidos por la referencia bibliográfica (en lugar de por el informante) sobre el uso de cada especie. Sin embargo, por la falta de información, en la Tab. bibliográfica se omiten los datos relativos al número de exsiccata, ambiente de crecimiento según el informante, si el uso es actual o pasado, si es personal o indirecto, la difusión actual o pasada según el informante, si la planta es silvestre, cultivada o ambas dos, según el informante y la zona de uso. Las filas corresponden a una cita, que se define como un dato elemental que corresponde a un único uso referido por una sola referencia bibliográfica sobre una única especie. En este caso, un uso puede equivaler también a un solo atributo de la planta como puede ser solo al nombre vernacular. Por otra parte, el nombre del informante es sustituido por el código de la referencia bibliográfica y se añade el número de la página donde se encuentra dicha información. A ésta Tab. analítica se le relaciona otra Tab. análoga a la "Tab. analítica de los informantes" denominada "Tab. de las referencias", la cual ha sido resumida en la Tab. 12, en la que se encuentran los códigos de referencia y las referencias bibliográficas correspondientes. La identificación botánica del nombre vernacular para el cual ha sido registrado el uso tradicional, ha sido recogido tal y como aparece en la referencia bibliográfica, siempre y cuando fuera una identificación probable. En los casos en los que no se diera la relación de una 


\section{María Teresa Egea Molines}

especie botánica al nombre vernacular, la identificación botánica ha sido realizada en base a nuestros datos estudiados en profundidad, por analogía.

Acorde con los objetivos de la tesis doctoral, las noticias relativas a los usos de las plantas cultivadas que equivalen a los usos para los cuales éstas son cultivadas de forma común, aunque no era el objetivo principal de la investigación bibliográfica, también han sido registradas siempre que fueran usos locales. Las noticias relacionadas con los usos industriales (madera, licorería industrial, fibra textil industrial), con la medicina convencional o con el conocimiento formal (médicos, expertos) no han sido recogidas, ya que no han sido considerados como objeto de ésta investigación.

Tab. 12. Abreviaturas de la referencias bibliográficas seleccionadas

\begin{tabular}{ll}
\hline Abreviaturas & Autor y año de publicación \\
APPO10 & Appoggi 2010 \\
BADI15 & Badi 2015 \\
BAL48 & Balletti 1998 \\
BAL801 & Balletti 1980a \\
BAL802 & Balletti 1980b \\
BAL97 & Balletti y Gioffredi 1997 \\
BENE96 & Beneforti 1998 \\
BER78 & Bernardi y Zagnoni 1978 \\
BER79 & Bernardi y Zagnoni 1979 \\
BER81 & Bernardi y Zagnoni 1981 \\
BERT67 & Bertoloni 1867 \\
BONZI00 & Bonzi 2000 \\
BORR77 & Borri 1977 \\
CANU78 & Canuto 1978 \\
CORR14 & Corradi 2014 \\
GRIZ03 & ICGM 2003 \\
GUC78 & Guccini 1978 \\
GUC80 & Guccini 1980 \\
GUC81 & Guccini 1981 \\
GUC82 & Guccini 1982 \\
GUC98 & Guccini 1998 \\
MANG98 & Uncini Manganelli y Tomei 1998 \\
MATT & Mattei s.d. \\
MUCC01 & Mucci s.d. \\
ROLI14 & Poli 2014 \\
\hline & \\
\hline
\end{tabular}


Etnobotánica en el Alto Valle del Reno (Toscana y Emilia-Romaña, Italia)

\begin{tabular}{ll}
\hline Abreviaturas & Autor y año de publicación \\
SABA75 & Sabattini 1975 \\
SANS14 & Sansanelli y Tassoni 2014 \\
SIRGI91 & Sirgi 1991 \\
UNGA21 & Ungarelli 1921 \\
ZAGN90 & Borghi y Zagnoni 1990 \\
\hline
\end{tabular}

\section{Catálogo etnobotánico}

La presentación de los datos se ha realizado en forma de un catálogo etnobotánico en el que se ordenan por orden alfabético de las familias botánicas y por orden alfabético de las especies botánicas según TPL (2015). Las fichas etnobotánicas de cada especies se organizan de la manera que se explica en la Figura. 18.

\section{Análisis de los datos etnobotánicos}

En un primer momento, han sido efectuadas ciertas estadísticas de base con el objetivo de calcular las medias y la desviación estándar para cada uno de las variables asociadas a la riqueza del conocimiento (número total de especies citadas, número de usos diversos citados, número de sectores de uso citados y número de categorías de uso citados) respecto a las características demográficas (provincia de residencia), culturales (nivel de educación) así como respecto al sexo y a la edad de los informantes. En un segundo momento, con la finalidad de evidenciar la existencia de relaciones entre las características en cuestión de los informantes y la riqueza de los conocimientos poseídos por cada uno de ellos, se ha procedido a efectuar una regresión múltiple según el enfoque GLM (Modelo Lineal General) usando como variables dependientes: 1. La provincia a la que pertenece; 2 . El sexo; 3. La clase de edad; 4. El nivel de educación (Tab. 13).

La importancia local de cada especie y de los usos ha sido evaluada y comparada a través del cálculo de los siguientes índices:

- Frecuencia Relativa de las Citas (RFC), es decir el número de informantes que cita un determinado uso de una especie (también denominada frecuencia de cita FC) dividido por el número total de informantes $(\mathrm{N})$.

$$
\mathrm{RFC}=\mathrm{FC} / \mathrm{N} \quad(0<\mathrm{RFC}<1)
$$

- Índice de valor de uso (UV), con el fin de evaluar la importancia relativa de cada especie con usos etnobotánicos, ha sido utilizado el índice de valor de uso (UV) propuesto por Rossato et al. (1999). Este índice demuestra la importancia relativa de las plantas conocidas a nivel local y ha sido calculado siguiendo la fórmula mencionada también por Tardío y Pardo-de-Santayana 
(2008), donde U(i) es el número de diferentes usos mencionados por cada informante para una cierta especie (i) y $\mathrm{N}$ es el número total de informantes:

$$
U V(i)=\sum_{j=1}^{N} U(i)_{j} / N
$$

Las plantas mencionadas con más frecuencia tienen un mayor valor de uso que las menos mencionadas.

Han sido calculados diferentes tipos de UV: valor de uso total (UVtotal), basado en las citas de cada uso de las especies registradas durante las entrevistas; valor de uso actual (UVactual), basado solamente en las citas de cada especie proporcionadas por los informantes para los usos que son practicados actualmente; valor de uso pasado (UVpasado), basado en las citas de las plantas proporcionadas por los informantes como usos pasados, que ya no se suelen practicar. También ha sido evaluada la experiencia de los usos a través del cálculo del valor de uso experiencia directa (UVdirecto), basado en las citas de los usos que son practicados directamente y personalmente por los informantes, y por último el valor de uso experiencia indirecta (UVindirecto), basado en usos que los informantes han visto hacer a otros, o bien oído decir a otras personas de la comunidad o de la familia, pero que no son practicados por ellos mismos.

- Índice de importancia relativa (RI), propuesto por Tardío y Pardo De Santayana (2008), el cual considera tanto la versatilidad de las especies, es decir, su diversidad de usos, como la extensión de estos usos medida por la cantidad de personas que los conocen (denominada a veces frecuencia de cita FC). Tienen mayor valor las especies conocidas por más personas y con distintos usos. Se calcula a partir de la frecuencia de citación relativa de cada especie, de su número relativo de usos, y de su número relativo de subcategorías o de aplicaciones.

$$
\text { RIs }=(\operatorname{RFCs}(\max )+\operatorname{RNUs}(\max )) / 2
$$

Donde RFCs(max) es la frecuencia relativa de citación sobre el máximo, el cual es obtenido dividiendo FCs, por el máximo valor de todas las especies en la investigación $(\mathrm{RFCs}(\max )=\mathrm{FCs} / \max (\mathrm{FC}))$, y RNUs(max) es el número relativo de categorías de usos (en ésta investigación "sectores") sobre el máximo, obtenido dividiendo el número de usos de las especies (NUs $\left.=\sum U R u\right)$ por el máximo valor de todas las especies de la investigación $(\mathrm{RNUs}(\max )=\mathrm{NUs} / \max (\mathrm{NU}))$.

- Índice de valor cultural $\left(\mathrm{CV}_{\mathrm{e}}\right)$ de una etnoespecie, propuesto por ReyesGarcía et al. (2006):

$\mathrm{CV}_{\mathrm{e}}=\mathrm{Uc}_{\mathrm{e}} * \mathrm{Ic}_{\mathrm{e}} * \sum \mathrm{IUc}_{\mathrm{e}}$

Donde $\mathrm{CV}_{\mathrm{e}}$ es el valor cultural de una etnoespecie $e . \mathrm{Uc}_{\mathrm{e}}$ es el número total de usos reportados para las etnoespecies $e$, dividido por los potenciales usos de una etnoespecie considerada en el estudio (por ejemplo los 12 sectores 
Etnobotánica en el Alto Valle del Reno (Toscana y Emilia-Romaña, Italia)

considerados en la investigación). Ic $\mathrm{c}_{\mathrm{e}}$ es el número de participantes quienes citan las etnoespecies e como útiles, dividido por el número total de personas participantes en la investigación (113). IUc $\mathrm{c}_{\mathrm{e}}$ expresa el número de personas quienes han mencionado cada uso para la etnoespecie $e$, dividido por el número total de participantes (113). 


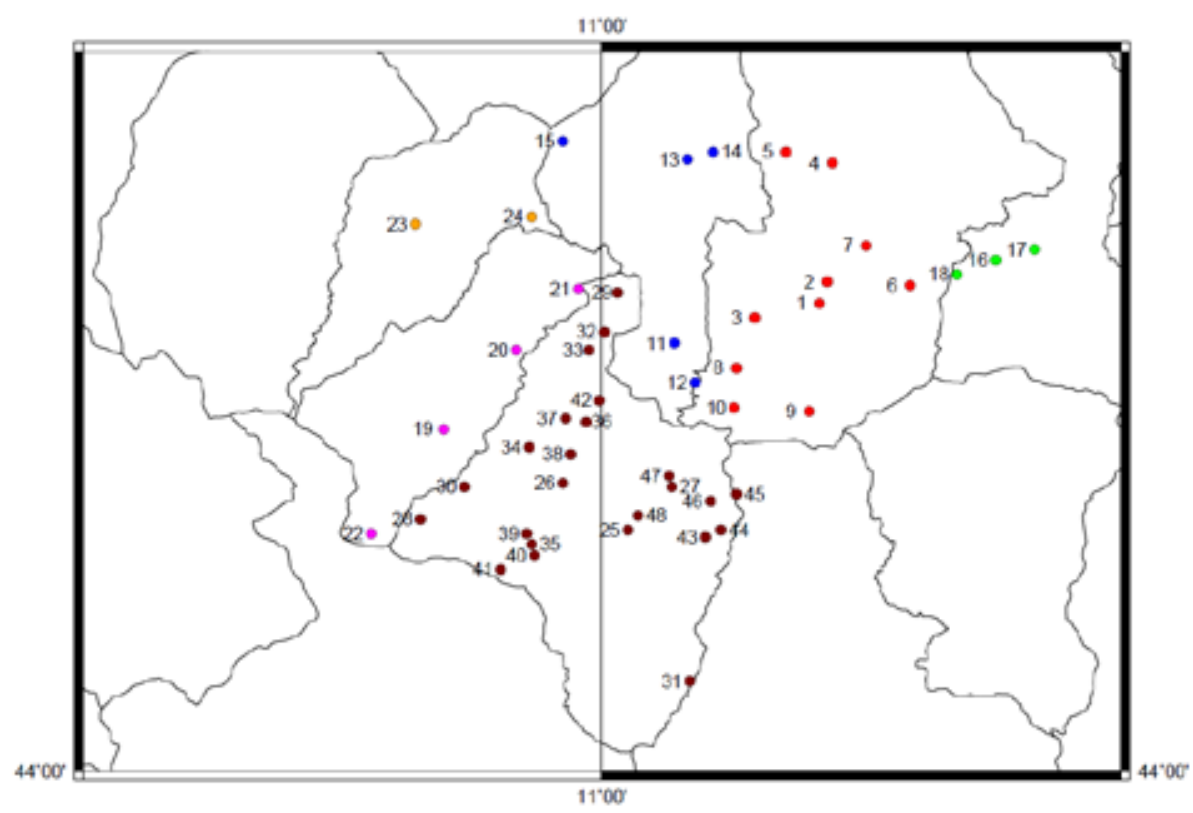

Fig. 15. Área y localidades estudiadas.

Códigos de colores: Rojo $=$ Camugnano, Azul $=$ Castel di Casio, Verde $=$ Castiglione dei Pepoli, Magenta $=$ Granaglione, Naranja $=$ Porreta Terme, Marrón= Sambuca Pistoiese. 
Etnobotánica en el Alto Valle del Reno (Toscana y Emilia-Romaña, Italia)

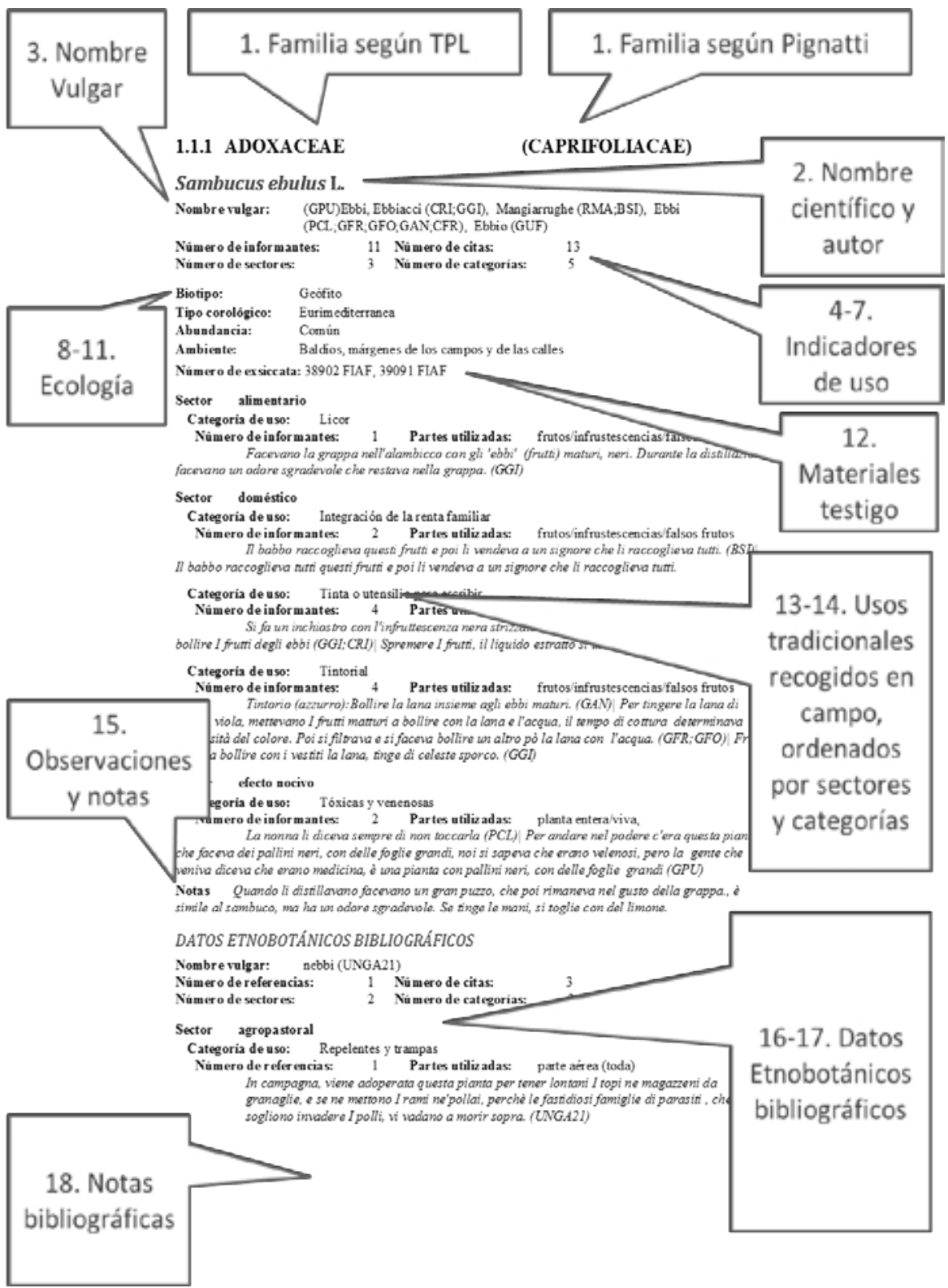

Fig. 16. Modelo de ficha etnobotánica.

Explicación de los códigos: DATOS DE LA ESPECIE - 1. Familia según TPL (2015) (entre paréntesis se indica el nombre de la familia según aparece en la obra de Pignatti (1982) y que ahora han sido incluidas en otras familias- 2. Nombre científico y Autor Siguiendo TPL (2015) y con los sinónimos que aparecen en Pignatti (1982), ordenados por orden alfabético - 3. Nombre vulgar: nombre referido por los informantes y entre paréntesis el código de los informantes que la 


\section{María Teresa Egea Molines}

citan - INDICADORES DE USO -4. Número de informantes. - 5. Número de citas. 6. Número de sectores. - 7. Número de categoría. - ECOLOGÍA - 8. Biotipo: la forma biológica según el sistema de Raunkiaer, siendo variable en el territorio Italiano, hemos seguido las adaptaciones que realiza Pignatti (1982) categorizando las especies en 7 grandes grupos: Fanerófitos (incluye los Nanofanerófitos), Caméfitos, Hemicriptófitos, Geófitos, Hidrófitos, Terófitos, Helófitos. 9. Tipo corológico: la distribución actual según Pignatti (1982), con pequeñas adaptaciones, clasificados en 11 grandes grupos corológicos: Endémicas, Estenomediterráneas, Eurimediterráneas, Mediterráneas-montanas, Europeas, Atlánticas, Orofitas, Nórdicas, Amplia distribución, Cultivadas, Exóticas. 10. Abundancia: indica la distribución de la planta en la zona según Pignatti (1982) siguiendo los siguientes códigos: Cultivada o ausente - Rara- Común Bastante Común - Muy Común. 11. Ambiente: ambiente de crecimiento de la planta según Pignatti (1982). MATERIAL TESTIGO - 12. Número de exsiccata: número de exsiccata del Herbario FIAF de la Universidad de Florencia (Italia) si existe, en el caso en el que la especie haya sido reconocida durante el trabajo de campo o mediantes otros métodos, esta información no ha sido reportada. USOS TRADICIONALES RECOGIDOS EN CAMPO. 13. Sector (por orden alfabético). 14. Categoría de uso (por orden alfabético): Número de informantes y Partes utilizadas. Descripción del uso: se resumen todos los usos citados tal y como han sido expresados por los informantes, en italiano y dialecto local. (CODIGO INFORMANTE). OBSERVACIONES Y NOTAS - 15. Notas: proverbios, datos sobre la gestión de las plantas, el periodo de recolección, el lugar donde lo recolecta el informante, sobre la percepción de la difusión según los informantes. DATOS ETNOBOTÁNICOS BIBLIOGRÁFICOS. 16. Nombre vulgar: nombre vernacular citado por la referencia bibliográfica (códigos de la referencia bibliográfica por orden alfabético). 17. Sector y Categoría de uso, Partes utilizadas y Descripción del uso: se resumen todos los usos citados por los informantes según sus explicaciones. (CODIGO). NOTAS RECOGIDAS DE LA BIBLIOGRAFÍA - 18. Notas bibliográficas: comentarios, proverbios, datos sobre la gestión de las plantas, el periodo de recolección, el lugar donde lo recolecta el informante, informaciones suplementarias por parte del informante o bien respecto a la flora local. 

Parte 4 Resultados 



\section{Capítulo 1}

\section{Catálogo etnobotánico}

\section{ADOXACEAE (incluye CAPRIFOLIACAE p.p.)}

\section{Sambucus ebulus L.}

Nombre vulgar: Ebbi, Ebbiacci (CRI, GGI), Mangiarrughe (RMA, BSI), Ebbi, (PCL, GFR, GFO, GAN, CFR), Ebbio (GUF).

Número de informantes: 11 Número de citas: 13.

Número de sectores: 3 Número de categorías: 5 .

Biotipo: Geófito.

Tipo corológico: Eurimediterránea.

Abundancia: Común.

Ambiente: Baldíos, márgenes de los campos y de las calles.

Número de exsiccata: 38902 FIAF, 39091 FIAF.

Sector alimentario

Categoría de uso: Licor.

Número de informantes: 1 Partes utilizadas: frutos/infrutescencias/falsos frutos.

Facevano la grappa nell'alambicco con gli 'ebbi' (frutti) maturi, neri. Durante la distillazione facevano un odore sgradevole che restava nella grappa. (GGI).

Sector doméstico

Categoría de uso: Integración de la renta familiar.

Número de informantes: 2 Partes utilizadas: frutos/infrutescencias/falsos frutos.

Il babbo raccoglieva questi frutti e poi li vendeva a un signore che li raccoglieva tutti. $(B S I) \mid$ Il babbo raccoglieva tutti questi frutti e poi li vendeva a un signore che li raccoglieva tutti..

Categoría de uso: Tinta o utensilio para escribir.

Número de informantes: 4 Partes utilizadas: frutos/infrutescencias/falsos frutos.

Si fa un inchiostro con l'infruttescenza nera strizzata. (CFR) $\mid$ Per fare l'inchiostro si fanno bollire I frutti degli ebbi (GGI, CRI)| Spremere I frutti, il liquido estratto si usa come inchiostro (GUF).

Categoría de uso: Tintorial.

Número de informantes: 4 Partes utilizadas: frutos/infrutescencias/falsos frutos.

Tintorio (azzurro):Bollire la lana insieme agli ebbi maturi. (GAN)| Per tingere la lana di colore viola, mettevano I frutti matturi a bollire con la lana e l'acqua, il tempo di cottura determinava l'intensità del colore. Poi si filtrava e si faceva bollire un altro pò 
la lana con l'acqua. (GFR, GFO)| Frutti messi a bollire con i vestiti la lana, tinge di celeste sporco. (GGI).

Sector efecto nocivo

Categoría de uso: Tóxicas y venenosas.

Número de informantes: 2 Partes utilizadas: planta entera/viva,.

La nonna li diceva sempre di non toccarla (PCL)| Per andare nel podere c'era questa pianta che faceva dei pallini neri, con delle foglie grandi, noi si sapeva che erano velenosi, pero la gente che veniva diceva che erano medicina, è una pianta con pallini neri, con delle foglie grandi $(G P U)$.

Notas Quando li distillavano facevano un gran puzzo, che poi rimaneva nel gusto della grappa., è simile al sambuco, ma ha un odore sgradevole. Se tinge le mani, si toglie con del limone.

DATOS ETNOBOTÁNICOS BIBLIOGRÁFICOS

Nombre vulgar: nebbi (UNGA21).

Número de referencias: 1 Número de citas: 3 .

Número de sectores: 2 Número de categorías: 3 .

Sector agropastoral

Categoría de uso: Repelentes y trampas.

Número de referencias: 1 Partes utilizadas: parte aérea (toda).

In campagna, viene adoperata questa pianta per tener lontani I topi ne magazzeni da granaglie, e se ne mettono I rami ne'pollai, perchè le fastidiosi famiglie di parasiti, che sogliono invadere I polli, vi vadano a morir sopra. (UNGA21).

Categoría de uso: Viticultura y enología.

Número de referencias: 1 Partes utilizadas: frutos/infrutescencias/falsos frutos.

Le bacche come quelle del sambuco nero per la colorazione del vino, però sono velenose..

(UNGA21).

Sector medicinal

Categoría de uso: Fiebre.

Número de referencias: 1 Partes utilizadas: flores/inflorescencias y sus partes.

Nella medicina popolare I fiori sono adoperati per uso interno come emolliente e sudorifero.

(UNGA21).

\section{Sambucus nigra L.}

Nombre vulgar: Sambuco (MMR, LGI, GPU, VMU, GLA, VMR, TIV, REN, MGO, GRI, CRE, TAT, PIM, GUF, CVA, BPA, EMA, GFR, GFO, NDI, BAR, PCL, NMA, GGI, FAM, DAD, BLI, TUL, TAD, NLA, AN3, BSO, MGE, LST, BPT, CFR, MRI).

Número de informantes: 37 Número de citas: 69 .

Número de sectores: 7 Número de categorías: 24 .

Biotipo: Fanerófito.

Tipo corológico: Europeas.

Abundancia: Común.

Ambiente: Bosques húmedos, aclarados, de monte bajo, setos.

Número de exsiccata: 38900 FIAF, 38908 FIAF.

Sector agropastoral 
Categoría de uso: Herramientas y objetos agrícolas.

Número de informantes: 1 Partes utilizadas: tallos leñosos/ramas/ramitas/vástagos.

Per fare i manici degli attrezzi. E' un ottimo legno perché è un legno leggero, elastico, resistente alla flessione, fa delle 'messe' (cacciate) dritte. Va tagliato a primavera quando non hanno foglie e fatto asciugare 2 o 3 mesi. (MRI).

Sector alimentario

Categoría de uso: Bebida.

Número de informantes: 1 Partes utilizadas: flores/inflorescencias y sus partes.

Fiori messi a macerare nell' acqua per un paio di giorni. E' dissetante. (CFR).

Categoría de uso: Conserva de frutas.

Número de informantes: 3 Partes utilizadas: frutos/infrutescencias/falsos frutos.

Raccolte, schiacciate, messe a bollire con poco zucchero,si fanno fermentare, poi il liquido viene riscaldato e filtrato (BPT)| Lo sciroppo di sambuco è una bevanda dissetante, può essere diluito nell'acqua d'estate oppure bevuto anche da solo, oppure messo anche sul dolce. Ricetta dello sciroppo di Sambuco: raccogliere la frutta matura, metterla in un secchio o un tino, chiuderlo con un canovaccio perché prenda il meno area possibile. Lasciare riposare 4 o 5 giorni, (deve formarsi una sorta di muffa sopra).Poi strizzarli con le mani per estrarre il succo e togliere $i$ frutti senza succo. Dipende da quanto ne viene fuori. Per un tino piccolo o un secchio ne va messo $1 \mathrm{~kg} o$ $800 \mathrm{gr}$. di zucchero. Fare bollire il succo con lo zucchero 10 o 15 minuti, poi si imbarattola calda, si chiude e si mette alla rovescia. Vengono 5 o 6 bottiglie. Più si invecchia più buono diventa. (LST) $\mid$ Si faceva lo sciroppo del Sambuco: prendere I frutti maturi, metterli a macerare e fermentare, pestarli e passarli al passaverdura. Poi si allunga con l'acqua e si beve come bevanda, pero fa bene per la pressione alta (MGE).

Categoría de uso: Dulces y golosinas.

Número de informantes: 2 Partes utilizadas: flores/inflorescencias y sus partes.

Fritelle dolci di fiori di Sambuco: lavare il fiore, fare la pastella con farina, acqua e zucchero, immergere il fiore nella pastella e friggere. Poi spagere un pò di zucchero sopra. (BSO)| Lo sciroppo di sambuco è una bevanda dissetante, può essere diluito nell'acqua d'estate oppure bevuto anche da solo, oppure messo anche sul dolce. Ricetta dello sciroppo di Sambuco: raccogliere la frutta matura, metterla in un secchio o un tino, chiuderlo con un canovaccio perché prenda il meno area possibile. Lasciare riposare 4 o 5 giorni, (deve formarsi una sorta di muffa sopra).Poi strizzarli con le mani per estrarre il succo e togliere i frutti senza succo. Dipende da quanto ne viene fuori. Per un tino piccolo o un secchio ne va messo $1 \mathrm{~kg}$ o $800 \mathrm{gr}$. di zucchero. Fare bollire il succo con lo zucchero 10 o 15 minuti, poi si imbarattola calda, si chiude e si mette alla rovescia. Vengono 5 o 6 bottiglie. Più si invecchia più buono diventa. (LST).

Categoría de uso: Fritura.

Número de informantes: 3 Partes utilizadas: flores/inflorescencias y sus partes.

Con I fiori del Sambuco e la pastella si fanno I fiori fritti. (AN3)| Fiori imbevuti nella pastella.

e fritti (NLA)| Bagnati nella pastella e fritti (TAD).

Categoría de uso: Licor.

Número de informantes: 1 Partes utilizadas: frutos/infrutescencias/falsos frutos.

Come bevanda, si fa macerare nell'alcol per un mese. (TUL).

Categoría de uso: Mermelada.

Número de informantes: 9 Partes utilizadas: frutos/infrutescencias/falsos frutos. 
Con I frutti del Sambuco si fanno le marmellate, con lo zucchero e I frutti e si fanno bollire. (AN3)| non specificato (CFR, BLI) | Frutti maturi raccolti, messi a bollire con un po di zucchero e poi settacciati con il passaverdura, per toglierli i semi, e imbarattolati per conservarli (DAD) $\mid$ Fanno bollire i frutti ben maturi (neri) con lo zucchero e lo inbarattolano (FAM) $\mid$ Mettere a bollire i frutti con l' acqua, poi aggiungere lo zucchero $(G G I) \mid$ Facevano la marmellata con i frutti di sambuco ed era lassativa. (MRI)| Fare bollire I frutti, e poi passarle al setaccio e aggiungere zucchero alla fine bollendo un altro po. (NLA)| Si facevano bollire $i$ frutti con lo zucchero e si conservavano in barattoli (NMA).

Sector artesanal

Categoría de uso: Instrumentos y utensilios para la artesanía.

Número de informantes: 1 Partes utilizadas: tallos leñosos/ramas/ramitas/vástagos.

Strumenti per fare maglia:" A faturi" è un atrezzo per apogiare I ferri di cucire (PCL).

Sector doméstico

Categoría de uso: Cuidado personal y cosmética.

Número de informantes: 1 Partes utilizadas: frutos/infrutescencias/falsos frutos.

Si prendevano i frutti, si schiacciavano e si mettevano direttamente sulle unghie, usando il succo come smalto. (BAR).

Categoría de uso: Objetos domésticos y escobas.

Número de informantes: 1 Partes utilizadas: tallos leñosos/ramas/ramitas/vástagos.

Nella conca per fare il buccato, c' è un bucco nella parte inferiore dove si metteva una cannella di Sambuco senza l'anima, e da dove usciva il ranno. (NMA).

Categoría de uso: Otro doméstico.

Número de informantes: 1 Partes utilizadas: tallos leñosos/ramas/ramitas/vástagos.

Mettere un ramo bucato di sambuco nella sorgente per prendere l'acqua meglio (NDI).

Categoría de uso: Tinta o utensilio para escribir.

Número de informantes: 1 Partes utilizadas: frutos/infrutescencias/falsos frutos.

Inchiostro:Frutti bolliti, passati per un straccio insieme ad un po' di 'calligine' (fuliggine) (NLA).

Categoría de uso: Tintorial.

Número de informantes: 2 Partes utilizadas: flores/inflorescencias y sus partes.

Tintorio:Bollire insieme ai vestiti per tingerli di colore viola $(G F O) \mid$ Bollire I frutti insieme alla lana per tingerla di viola (GFR).

Sector lúdico/voluptuoso

Categoría de uso: Decoraciones y disfraces de niños.

Número de informantes: 1 Partes utilizadas: frutos/infrutescencias/falsos frutos.

Si prendevano I frutti maturi, si schiacciavano e ci si tingeva la faccia per gioco, quando si era bambini. (EMA).

Categoría de uso: Fumable.

Número de informantes: 1 Partes utilizadas: tallos leñosos/ramas/ramitas/vástagos.

Con un ramo secco si fumava perché era poroso. (BPA).

Categoría de uso: Juego colectivo y bromas.

Número de informantes: 7 Partes utilizadas: tallos leñosos/ramas/ramitas/vástagos.

Per fare gli 'schiopetti', sorta di cerbottane. Si taglia una bacchetta di sambuco giovane in tacche orizzontali e si toglie l' "anima" (midollo). Poi si fanno delle palline di stoppa di canapa, si metteno dentro allo 'schiopetto' una da ogni lato, in modo tale che una pallina schizzi via quando si inserisce dall'altra parte parti una bacchetta a fare da 
stantuffo. (NLA, CVA, BPA)| Per fare $i$ "chiocaballe". Si taglia una bacchetta di sambuco giovane in tacche orizzontali e si toglie l' "anima" (midollo). Poi si fanno delle palline di stoppa di canapa, si metteno dentro allo 'schiopetto' una da ogni lato, in modo tale che una pallina schizzi via quando si inserisce dall'altra parte parti una bacchetta a fare da stantuffo. (GUF)| Per fare gli 'schioppetti' (cerbottane): Prendere un ramo dritto di sambuco e con un altro paletto svuotare la parte interna del sambuco, poi con un pezzo di carta masticata si metteva nella parte esterna e dall'altra parte si soffiava. (MRI) $\mid$ Si facevano gli 'schioppetti' (cerbottane) con un ramo di sambuco che è già bucato e un pezzo di stoffa. (PIM)| Si facevano gli 'schiccetti': si prendeva un ramo di sambuco, con un paletto piccolo si toglieva la parte interna che è spugnosa, e con lo stesso palo si riempiva il rametto di sambuco di acqua tirando in su e poi si schizzava l'acqua addosso ad altri ragazzi (TAT).

Sector medicinal

Categoría de uso: Afecciones cutáneas y tejidos subcutáneos.

Número de informantes: 7 Partes utilizadas: tallos leñosos/ramas/ramitas/vástagos.

A primavera-estate, fare un taglio ad un ramo di Sambuco ed estrarre "l'anima" nel Sambuco, applicarla sopra le ferite per disinfettarle. (BLI) $\mid$ Applicare direttamente delle foglie di Sambuco sulle bruciature. (CRE)| Mettere le foglie di sambuco pulite direttamente sul bruciato (GRI)| Fare degli impacchi di foglie di sambuco, se secche, messe a mollo previamente, sulla ferita. (MGO)| Applicare direttamente le foglie scaldate sulla bruciatura e fasciare. (REN) $\mid$ Mettere varie foglie di Sambuco sulla ferita infetta durante una notte, e la mattina dopo le foglie hanno tirato fuori tutto il pus. $(T I V) \mid$ Prendere le foglie di Sambuco, pestarle con il coltello e applicarle sopra, per tirare fuori il pus da spine. (VMR).

Categoría de uso: Afecciones del aparato respiratorio.

Número de informantes: 6 Partes utilizadas: frutos/infrutescencias/falsos frutos.

Decotto delle infruttescenze di Sambuco dolcificato con miele. (BLI) $\mid$ Fare bollire l'acqua, scioglere il miele, spengere, e mettere in infusion I fiori di sambuco per 15 o 30 min. Poi bere contro I problemi di raffreddore, tosse, mal di gola (BSO)| I fiori raccolti si mettevano ad essiccare, poi messi in acqua bollente. (DAD)| Fare I fumenti con la radice di regolizia, I fiori di sambuco, il rosmarino e la salvia. (GLA)| Cuocere i frutti maturi per un po' con poca acqua ed aggiungere un po' di miele (NLA)| Mettere nell'acqua bollente I 'cemolini' (germogli pieni di resina) dei pini, insieme alle foglie del Sambuco e alle foglie di Malva. Lasciare un pò a riposo e aggiungere del miele. (VMR).

Categoría de uso: Afecciones oro-faríngeas y de la cavidad oral.

Número de informantes: 6 Partes utilizadas: flores/inflorescencias y sus partes.

Infiammazione della bocca: fare bollire le foglie e I fiori di sambuco e fare sciacqui. Mal di denti: mettere le foglie fresche sulla parte infiammata (si appiccicavano alla guancia) e legare con un fazzoletto. (CRE) $\mid$ I fiorI raccolti si mettevano ad essiccare, poi venivano messi in acqua bollente. (DAD) I fiori raccolti si mettevano ad essiccare, poi venivano messi in acqua bollente. (DAD)| Mal di denti: prendevano il ramettino, gratugiavano la corteccia e insieme alle foglie crude si mettevano sopra sulla guancia legati con un fazzoletto. (GFR)| Mettere la foglia di sambuco sopra la guancia infiammata, per sfiammare. (LST)| Foglie messe sulla guancia e fasciata (NMA)| Mettere le foglie di sambuco direttamente, in poltiglia cruda, sulla guancia legati con un fazzoletto, perché addormetava la zona, come anestetico (VMR).

Categoría de uso: Estado general. 
Número de informantes: 1 Partes utilizadas: hojas.

Fare bollire nell'acqua le foglie di sambuco, e bere il decotto come purificante e depuratore (VMU).

Categoría de uso: Patologías del aparato circulatorio.

Número de informantes: 5 Partes utilizadas: flores/inflorescencias y sus partes.

Bere l' infuso dei fiori di Sambuco e mangiare i frutti fa bene alla circolazione. Anche mangiare la mermellata di sambuco, fatta facendo bollire i frutti per un po' e passandoli per il passaverdure. (BLI) $\mid$ Fare bollire le foglie 7 o 8 minuti e lavare le emorroidi. $(M M R, L G I, G P U) \mid$ Si faceva lo sciroppo del Sambuco: prendere I frutti maturi, metterli a macerare, pestarli, e passarli al passaverdura. Poi si allunga con l'acqua e si beve come bevanda come dissetante, pero fa bene per la pressione alta (MGE).

Categoría de uso: Patologías del aparato digestivo.

Número de informantes: 4 Partes utilizadas: frutos/infrutescencias/falsos frutos.

Quando si soffre di stitichezza mangiare mermellata di Sambuco (FAM)| Mangiare la marmellata di fiori di sambuco è lassativo. (MRI) $\mid$ Si mangiava la mermellata e aiutava ad andare in bagno (NMA)| Mermellata di Sambuco: frutti messi a bollire, aggiungere zucchero e bollire un altro po' (TUL).

Categoría de uso: Trastornos musculo-esqueléticos.

Número de informantes: 2 Partes utilizadas: hojas.

Mettere sulla zona infiammata un impacco delle foglie del sambuco $(P C L) \mid$ Mettere $1 \mathrm{o}$ 2 foglie di Sambuco sopra (TUL).

Sector veterinario

Categoría de uso: Conejos.

Número de informantes: 1 Partes utilizadas: corteza.

Mettere la corteccia di Sambuco nell'acqua a macerare, e dare da bere ai conigli d'estate come preventivo e come desinfettante perché I conigli sono molto delicati e si ammalano in estate. (AN3).

Notas Poi rimangono le mani blu per 20 giorni, Era un lusso, non tutti avevano l'economia per fare queste bevande..., Raccolta dopo il 15 agosto, Frutti raccolti ad Agosto, lo faceva suo padre.

DATOS ETNOBOTÁNICOS BIBLIOGRÁFICOS

Nombre vulgar: sambûc (UNGA21), sambuco (MANG98, GUC98, BONZI00, SANS14, GRIZ03).

Número de referencias: 6 Número de citas: 16 .

Número de sectores: 4 Número de categorías: 14 .

Sector agropastoral

Categoría de uso: Viticultura y enología.

Número de referencias: 1 Partes utilizadas:frutos/infrutescencias/falsos frutos.

Colle bacche si falsifica il colore de vini. (UNGA21).

Sector alimentario

Categoría de uso: Conserva de frutas.

Número de referencias: 1 Partes utilizadas: flores/inflorescencias y sus partes (SANS14).

Categoría de uso: Empanadas.

Número de referencias: 1 Partes utilizadas: flores/inflorescencias y sus partes (SANS14).

Categoría de uso: Fritura. 
Número de referencias: 1 Partes utilizadas: flores/inflorescencias y sus partes.

Fritelle di sambuco: alcuni grappoli di fiori di sambuco, 3 uova, $125 \mathrm{~g}$ di farina, 3 cucchiai di vino bianco secco, 1 cucchiaio di latte, 1 cucchiaio di burro fuso, 2 cucchiaini di miele liquido, olio per friggere, zucchero, cannella in polvere, sale. Lavorate la farina con i rossi d'uovo, il burro fuso, il vino bianco, il latte, il miele e una presa di sale, fino ad avere una pastella liscia ma non troppo consistente. Da ultimo, amalgamate gli albumi montati a neve ferma. Scaldate l'olio nella padella per i fritti. Lavate i fiori di sambuco, asciugateli, immergeteli nella pastella tenendoli per il gambo, quindi friggeteli nell'olio fumante. Scolateli ben dorati, asciugateli su dalla carta assorbente, cospargeteli di zucchero e cannella in polvere e serviteli caldi. (GRIZ03).

Categoría de uso: Licor.

Número de referencias: 1 Partes utilizadas: flores/inflorescencias y sus partes (SANS14).

Categoría de uso: Mermelada.

Número de referencias: 1 Partes utilizadas: frutos/infrutescencias/falsos frutos.

Sgranate le bacche di sambuco, raccogliete i frutti, lavateli accuratamente sotto l'acqua corrente, poi fateli cuocere in una pentola, possibilmente di coccio, con mezzo bicchiere d'acqua. Quando saranno completamente sfatti versateli in un telo di lino a trama larga e lasciateli filtrare cosi per una notte, sopra una zuppiera. Versate tutto il succo filtrato nella pentola destinata alla preparazione della confettura, unitevi lo zucchero e fate cuocere a fuoco molto dolce mescolando continuamente. Dopo circa mezz'ora controllare la consistenza della confettura: versatene una goccia su un piatto bagnato, se si solidifica immediatamente significa che è pronta. Invasate quando la preparazione è ancora calda, ma chiudete $i$ vasi solo quando si è raffreddata completamente. Marmellata di sambuco: $1 \mathrm{~kg}$ di bacche di sambuco, $600 \mathrm{~g}$ di zucchero semolato, acqua q.b. lavate il sambuco, quindi mettetelo in una pentola e coprite d'acqua. Fate cuocere a fuoco medio per un quarto d'ora a partire dal momento dell'ebollizione. Versate il tutto in un telo bianco sistemato sopra una terrina e lasciate filtrare per tutta la notte. Ne avrete un succo limpidissimo, pesatelo, quindi unitevi una quantitá di zucchero pari a 3/4 del peso del succo stesso. Mescolate molto accuratamente per far sciogliere lo zucchero e fate bollire a fuoco dolce, rimestando continuamente. Al momento dell'ebollizione alzate la fiamma e proseguite la cottura, mescolando e schiumando sino a che la gelatina avrà raggiunto la giusta consistenza. per verificarla basta versare una goccia di preparazione in un piatto bagnato: se si rapprende immediatamente la gelatina è pronta. Spegnete la fiamma e invasate a caldo. Chiudete $i$ vasi solo quando il composto si è raffreddato. (GRIZ03).

Categoría de uso: Otro alimentario.

Número de referencias: 1 Partes utilizadas: flores/inflorescencias y sus partes.

Melighini di sambuco: mezzo $\mathrm{kg}$ di pasta di pane comprata già pronta dal fornaio, $100 \mathrm{~g}$ di burro, $100 \mathrm{~g}$ di zucchero di canna, $200 \mathrm{~g}$ di farina gialla semolata, 1 rosso d'uovo, 1 manciata di fiori di sambuco. Mettete la pasta al centro della spianatoia infarinata, scavatevi un buco e accomodatevi il burro dopo averlo fatto ammorbidire. Aggiungete pure lo zucchero, la farina gialla finissima e acqua tiepida quel tanto che basta per poter amalgamare il tutto. Deve risultare un impasto omogeneo ma non troppo sodo. Lasciate riposare dodici ore. Passato questo tempo dividetelo in tanti pezzetti che spianerete con il mattarello fino a ridurli dello spessore di $1 \mathrm{~cm}$. Allineate queste focaccine sulla placa del forno dopo averla unta di burro. Servendovi di un pennello da 
Etnobotánica en el Alto Valle del Reno (Toscana y Emilia-Romaña, Italia)

cucina, dorate la superficie con rosso d'uovo con un goccino di latte e di acqua, cospargete con fiori di sambuco e poi con zucchero, coprite con un telo e poi mettete a riposare in luogo fresco e buio per un paio di ore, per dar luogo alla pasta da lievitare. Infornate a fuoco debole, saranno cotti quando la superficie avrà assunto una colorazione molto scura. (GRIZ03).

Sector lúdico/voluptuoso

Categoría de uso: Juego colectivo y bromas.

Número de referencias: 2 Partes utilizadas: tallos leñosos/ramas/ramitas/vástagos.

La fugratta, o "giocà a frugatta coi stiopétti di sambuca":si prende un pezzetto di sambuco svuotato dell'anima e ci si pigiano dentro due palline di stoppa bagnata, uno in fondo e uno in cima, poi con la frugatta, ciò̀ un bastoncino della medesima grandezza del foro del sambuco, che vi entri quindi preciso, si spinge forte e si ottiene quindi uno stioppo o scoppio. (BONZI00)| Lo ‘chioccaballe è un gioco per ragazzi formato da un diritto rammo di sambuco lungo $20 / 30 \mathrm{~cm}$ a cui si toglieva il midollo interno in modo da renderlo cavo: Si chiudevano poi I fori d'entrata e d'uscita con una pallina di canapa grezza masticata. Reggendo lo 'chioccaballe con una mano, si spingeva violentemente con un bastoncino la seconda pallina. Per effetto dell'aria compressa la pallina all'altra estremità usciva a notevole velocità e con un rumore schioccante. Le due palline potevano essere sostituite con due tappini di sughero, bagnati nell'olio per farli scorrere meglio. Sin. meno usato di 'chiccaballe è schiopétto. Il gioco è oggi definitivamente scomparso. (GUC98).

Sector medicinal

Categoría de uso: Afecciones cutáneas y tejidos subcutáneos.

Número de referencias: 2 Partes utilizadas: corteza, hojas, hojas.

Le foglie fresche, contuse, vengono applicate sugli ascessi. La seconda corteccia si utilizza anche per la preparazione di un ungüento, ottenuto tramite cottura in olio d'oliva e successiva aggiunta di cera vergine d'api e strutto, lo si usa su eczemi ed e dermatiti varie.(MANG98) I contandini adoperano le foglie di sambuco per sanare le erisipole(UNGA21).

Categoría de uso: Afecciones del aparato respiratorio.

Número de referencias: 1 Partes utilizadas: frutos/infrutescencias/falsos frutos,.

I frutti ben maturi vengono "spippati" e lasciati riposare tre giorni, dopodiché si spremono e si.

colano attraverso un panno, al succo si unisce pari quantità di zucchero e si fa bollire il tutto per cique minuti. Lo sciroppo cosi ottenuto vienen diluito.

Categoría de uso: Afecciones oftalmológicas.

Número de referencias: 1 Partes utilizadas: hojas.

L'acqua de fiori di sambuco come lavacro nell'infiammazione degli occhi. (UNGA21).

Categoría de uso: Fiebre.

Número de referencias: 1 Partes utilizadas: frutos/infrutescencias/falsos frutos, hojas.

Nella medicina popolare queste si ritengono anche febbrifughe. (UNGA21).

Categoría de uso: Patologías del aparato digestivo.

Número de referencias: 1 Partes utilizadas: frutos/infrutescencias/falsos frutos.

Lo sciroppo è efficace per eliminare $i$ calcoli del fegato. I succo dei frutti viene assunto a piccole dosi come digestivo (MANG98).

Categoría de uso: Trastornos musculo-esqueléticos.

Número de referencias: 1 Partes utilizadas: flores/inflorescencias y sus partes. 


\section{AMARANTHACEAE (incluye CHENOPODIACEAE)}

\section{Beta vulgaris L. subsp. vulgaris}

Nombre vulgar: Bietola selvatica (MGO).

Número de informantes: 1 Número de citas: 1.

Número de sectores: 1 Número de categorías: 1 .

Biotipo: Hemicriptófito.

Tipo corológico: Eurimediterránea.

Abundancia: Común.

Ambiente: Silvestre sobre las costas y cultivada de forma común.

Sector alimentario

Categoría de uso: Verdura cocida.

Número de informantes: 1 Partes utilizadas: hojas.

$\mathrm{Si}$ adoperava cotta, come verdura (MGO).

Beta vulgaris L. subsp. vulgaris Fodder Beet Group

Nombre vulgar: Barba rossa (DAD), Barbabietola (SOT).

Número de informantes: 2 Número de citas: 2.

Número de sectores: 1 Número de categorías: 1.

Biotipo: Hemicriptófito.

Tipo corológico: Cultivadas.

Abundancia: Cultivada.

Ambiente: Cultivada en los huertos.

Sector agropastoral

Categoría de uso: Alimentación animal (incluidos los forrajeros).

Número de informantes: 2 Partes utilizadas: hojas, órganos subterráneos.

Cotte per le pecore e le capre (DAD)| Per I maiali:Barbabietola, sfogliata e lessa insieme ai farfari e alla semola (SOT).

Notas Non è quella rossa, è una varietà che non si semina più, ha la testa rossiccia e bianca caffè, è dolce però è diversa alla barbabietola di zucchero.

\section{DATOS ETNOBOTÁNICOS BIBLIOGRÁFICOS}

Nombre vulgar: barbabiattla (UNGA21).

Número de referencias: 1 Número de citas: 1 .

Número de sectores: 1 Número de categorías: 1.

Sector alimentario

Categoría de uso: Sopas de verduras y potaje.

Número de referencias: 1 Partes utilizadas: órganos subterráneos.

barbabietola da orto, coltivata per uso alimentario (UNGA21). 


\section{Beta vulgaris L. subsp. vulgaris Garden Beet Group}

Nombre vulgar: Barba rossa (DAD).

Número de informantes: 1 Número de citas: 1.

Número de sectores: 1 Número de categorías: 1.

Biotipo: Hemicriptófito.

Tipo corológico: Cultivadas.

Abundancia: Cultivada.

Ambiente: Cultivada de forma común en los huertos y asilvestrada.

Sector alimentario

Categoría de uso: Verdura cocida.

Número de informantes: 1 Partes utilizadas: órganos subterráneos.

Cotte, spellate, e condite (DAD).

\section{Beta vulgaris L. subsp. vulgaris Leaf Beet Group}

Nombre vulgar: Bietola (MGE, DAD), Bietole (TRU).

Número de informantes: 3 Número de citas: 4.

Número de sectores: 1 Número de categorías: 3 .

Biotipo: Hemicriptófito.

Tipo corológico: Cultivadas.

Abundancia: Cultivada.

Ambiente: Cultivada de forma común en los huertos y asilvestrada.

Sector alimentario

Categoría de uso: Relleno de ravioli.

Número de informantes: 2 Partes utilizadas: hojas.

Cotti insieme a rape e patate, o qualsiasi altra verdura per ripieno dei ravioli (DAD) Il ripieno dei tortelloni si fa con ricotta, pane grattugiato o bagnato, uova e spinaci e/o bietola dell'orto. (MGE).

Categoría de uso: Sopas de verduras y potaje.

Número de informantes: 1 Partes utilizadas: hojas.

Cotti in minestre o zuppe insieme ad altre verdure come la rapa, la patata (DAD).

Categoría de uso: Verdura cocida.

Número de informantes: 1 Partes utilizadas: hojas.

Le bietole si coltivavano per fare verdura cotta, saltata in padella. (TRU).

Notas Si fanno per le feste masiccie, ossia le feste del patrone., Non seminare mai la bietola ne niente che sia "di foglie" a Luna nuova, deve essere passato un martedi o un venerdi. I ravioli si fanno per le feste masiccie, ossia le feste del patrone.

DATOS ETNOBOTÁNICOS BIBLIOGRÁFICOS

Nombre vulgar: arbått (UNGA21), bièdola (BONZI00), biéda (GUC98).

Número de referencias: 3 Número de citas: 3 .

Número de sectores: 1 Número de categorías: 1.

Sector alimentario

Categoría de uso: Sopas de verduras y potaje.

Número de referencias: 1 Partes utilizadas: hojas. 
Bietola da erbucce, in Toscana bietola da zuppa (UNGA21).

\section{Chenopodium album $L$.}

Nombre vulgar: Farinandolo (NRE).

Número de informantes: 1 Número de citas: 1.

Número de sectores: 1 Número de categorías: 1 .

Biotipo: Terófito.

Tipo corológico: Amplia distribución.

Abundancia: CCC.

Ambiente: Baldíos, ruinas e infestante en los cultivos de verano y otoño.

Número de exsiccata: 39090 FIAF.

Sector alimentario

Categoría de uso: Verdura cocida.

Número de informantes: 1 Partes utilizadas: hojas.

Foglie lesse come verdura cotta. (NRE).

\section{Chenopodium bonus-henricus $L$.}

Nombre vulgar: Spinacio selvatico, Buonenrico (TGO), Spinaci selvatici (PGI).

Número de informantes: 2 Número de citas: 4.

Número de sectores: 1 Número de categorías: 3 .

Biotipo: Hemicriptófito.

Tipo corológico: Nórdicas.

Abundancia: Común.

Ambiente: En las cabañas, baldíos fertilizados en montaña.

Número de exsiccata:.

\section{Sector alimentario}

Categoría de uso: Relleno de ravioli.

Número de informantes: 1 Partes utilizadas: parte aérea (toda).

Ripieno con ricotta (TGO).

Categoría de uso: Tortilla.

Número de informantes: 1 Partes utilizadas: parte aérea (toda).

non specificato (TGO).

Categoría de uso: Verdura cocida.

Número de informantes: 2 Partes utilizadas: hojas, parte aérea (toda)

Le foglie cotte e condite (PGI) $\mid$ Cotta e condita con olio, (TGO).

Notas ora non ce n'è, c'era quando c'erano I pastori. A porretta hanno detto che si che c'è ma molto in alto. Non è registrato in Venturi (2006) ne'PTP (2008).

DATOS ETNOBOTÁNICOS BIBLIOGRÁFICOS

Nombre vulgar: bietolone, farineti (MANG98).

Número de referencias: 1 Número de citas: 2.

Número de sectores: 2 Número de categorías: 2 . 
Sector alimentario

Categoría de uso: Relleno de ravioli.

Número de referencias: 1 Partes utilizadas: hojas.

Le foglie rientrano altresì nella preparazione di piatti tipici quali i locali tortelli (MANG98).

\section{Sector medicinal}

Categoría de uso: Patologías del aparato digestivo.

Número de referencias: 1 Partes utilizadas: hojas.

Il decotto o le foglie, lessate e condite con olio d'oliva, vengono assunti per favorire una corretta funzionalità intestinale (MANG98).

\section{Spinacia oleracea $L$.}

\section{Nombre vulgar: Spinaci (MGE).}

Número de informantes: 1 Número de citas: 1.

Número de sectores: 1 Número de categorías: 1 .

Biotipo: Terófito.

Tipo corológico: Cultivadas.

Abundancia: Cultivada.

Ambiente: Cultivada en todo el territorio y solo raramente asilvestrada.

Sector alimentario

Categoría de uso: Relleno de ravioli.

Número de informantes: 1 Partes utilizadas: hojas.

Il ripieno dei tortelloni si fa con ricotta, pane grattugiato o bagnato, uova e spinaci e/o bietola dell'orto. (MGE).

Notas Si fanno per le feste masiccie, ossia le feste del patrone.

\section{AMARYLLIDACEAE (incluye LILIACEAE p.p.)}

\section{Allium ascalonicum $L$.}

Nombre vulgar: Scalogno (MGO).

Número de informantes: 1 Número de citas: 1.

Número de sectores: 1 Número de categorías: 1 .

Biotipo: Geófito.

Tipo corológico: Cultivadas.

Abundancia: Cultivada.

Ambiente: Cultivado en huertos.

Sector medicinal

Categoría de uso: Afecciones oftalmológicas.

Número de informantes: 1 Partes utilizadas: órganos subterráneos.

Applicare la prima pellicola dello scalogno sull'orzaiolo (MGO). 


\section{DATOS ETNOBOTÁNICOS BIBLIOGRÁFICOS}

Nombre vulgar: scalåggna (UNGA21), civollaglina (GUC98).

Número de referencias: 2 Número de citas: 2 .

Número de sectores: 1 Número de categorías: 1.

Sector medicinal

Categoría de uso: Patologías del sistema nervioso.

Número de referencias: 1 Partes utilizadas: No especificado.

dal volgo è creduta eccitante (UNGA21).

\section{Allium ampeloprasum L. (=Allium porrum $L_{\text {.) }}$}

Nombre vulgar: Porro (GFR).

Número de informantes: 1 Número de citas: 1.

Número de sectores: 1 Número de categorías: 1.

Biotipo: Geófito.

Tipo corológico: Cultivadas.

Abundancia: Cultivada.

Ambiente: Cultivada de forma común en los huertos.

Sector medicinal

Categoría de uso: Afecciones cutáneas y tejidos subcutáneos.

Número de informantes: 1 Partes utilizadas: órganos subterráneos.

Applicare direttamente il velo della cipolla o del porro sopra le ferite o l'occhio di pernice (GFR).

\section{Allium cepa $L$.}

Nombre vulgar: Cipolla (MVI, GZE, RMA, TUL, TGA, SOT, GFR, VMR, LST, LGI, BEL, GUF, CFR, MGE, GFO, GLA, GAN, BPT, GGI).

Número de informantes: 19 Número de citas: 23.

Número de sectores: 4 Número de categorías: 9.

Biotipo: Geófito.

Tipo corológico: Cultivadas.

Abundancia: Cultivada.

Ambiente: Cultivada de forma común.

Sector agropastoral

Categoría de uso: Horticultura.

Número de informantes: 1 Partes utilizadas: órganos subterráneos.

Le cipolle che germogliavano o che marcivano dell'anno scorso si mettevano come fertilizzante nel composto (GGI).

Sector alimentario

Categoría de uso: Encurtidos y conserva en aceite.

Número de informantes: 3 Partes utilizadas: órganos subterráneos.

Sbollentare le cipolle, farle asciugare un po' e metterli sotto aceto e sale. (BPT)| Sbollentare le cipolle, farli asciugare un pò e metterli sotto aceto e sale. Duravano un 
mese. (GAN)| Le cipolle dell'orto si conservano sotto aceto per l'inverno: Scottare le cipolle in un litro di acqua e un bicchiere d'aceto (vino lasciato andare a male). Poi lasciare asciugare un po e mettere sotto olio. (GLA).

Categoría de uso: Sopas de verduras y potaje.

Número de informantes: 1 Partes utilizadas: órganos subterráneos.

Le cipolle si seminavano negli orti per mettere dentro alle minestre (GFO).

Categoría de uso: Tortilla.

Número de informantes: 2 Partes utilizadas: parte aérea (toda), hojas.

Con la coda della cipolla fresca si fa la frittata. (MGE)| La "coda" della cipolla sbollentata e messa nella frittata.Foglie piu lunghe ed esterne. (CFR)| Cotte e messe nella frittata (CFR).

\section{Sector mágico/ritual/supersticioso}

Categoría de uso: Adivinatorio.

Número de informantes: 1 Partes utilizadas: órganos subterráneos.

Tagliare la cipolla in due pezzi e buttarci del sale sopra. A seconda se fa più o meno rumore, si prevedeva se i mesi dell'anno sarebbero stati più o meno piovosi. (GUF).

Sector medicinal

Categoría de uso: Afecciones cutáneas y tejidos subcutáneos.

Número de informantes: 10 Partes utilizadas: órganos subterráneos.

Applicare il 'velo' della cipolla sul taglio, a mo' di cerotto. (BEL)| Applicare il velo della cipolla sulla ferita, come un cerotto. (LGI) $\mid$ Si faceva un decotto con la cipolla poi si bagnava un pezza nell'decotto e si facevano gli impacchi sull'infezione (LST)| Trittare la cipolla ed applicarla sopra la bruciatura con una garza sopra. Finché non stia meglio (VMR)| Applicare direttamente il velo della cipolla sulla bruciatura. "Fa fermare il sangue". (GFO)| Applicare direttamente il velo della cipolla o del porro sopra l'occhio di pernice o sulla ferita, come un cerotto (GFR)| Foglia strofinata sulla puntura (GGI)| Prendere la pellicola delle foglie di cipolla e applicare sopra. (SOT)| Mettere il velo della cipolla sulla bruciatura (TGA)| Togliere la pelle di una delle foglie del bulbo della cipolla e applicare sopra la ferita (TUL).

Categoría de uso: Afecciones del aparato respiratorio.

Número de informantes: 1 Partes utilizadas: órganos subterráneos.

Bollire 3 cipolle, quando sono cotte, lasciare raffredare, aggiungere un pizzico di sale, e bere un bicchiere prima di andare al letto. (CFR).

Categoría de uso: Patologías del aparato digestivo.

Número de informantes: 1 Partes utilizadas: órganos subterráneos.

Fare cuocere la cipolla il tempo di cottura e bere come rinfrescante. Fa 'andare di corpo'..

(RMA).

Categoría de uso: Patologías del aparato urinario.

Número de informantes: 2 Partes utilizadas: órganos subterráneos.

Per le infezioni delle vie urinarie bere il decotto di cipolla, una o due volte al giorno. (GZE)|.

Per l'infezione di urina' bere il decotto di cipolla, una o due volte al giorno. (MVI).

Notas Seminare le cipolle non troppo profonde, anche se escono fuori un po."Le cipolle. 
devono sentire le campane".

\section{Allium sativum $L$.}

Nombre vulgar: Aglio (LRE, MSR, GGL, TGA, NST, GLA, PIM, RGI, MME, GFR, BFE, LST, GGI, TOA, RMA, REN, PCL, NRO, MGO, MDA, BEL, BBI, RNI, GUF, DAD, BBA, UMI).

Número de informantes: 27 Número de citas: 41.

Número de sectores: 5 Número de categorías: 12.

Biotipo: Geófito.

Tipo corológico: Cultivadas.

Abundancia: Cultivada.

Ambiente: Cultivada de forma común y a menudo subespontánea por los huertos.

Sector agropastoral

Categoría de uso: Antiparasitario.

Número de informantes: 1 Partes utilizadas: órganos subterráneos.

Seminare l'aglio accanto alle rose, tiene lontani I pidocchi. Mettere un spicchio d'aglio accanto alla rosa, lasciando che germogli da solo. (UMI).

\section{Sector alimentario}

Categoría de uso: Aromatizante.

Número de informantes: 3 Partes utilizadas: órganos subterráneos.

Per aromatizzare I funghi arrosti, insieme al rosmarino (BBA)| Per insaporire il brodo di faggioli per fare "pasta e faggioli",con olio, aglio pepe e due foglie di alloro che alla fine si levano (DAD)| Aglio, salvia e rosmarino, tutto trittato per aromatizzare gli arrosti (GUF).

Categoría de uso: Ensalada.

Número de informantes: 1 Partes utilizadas: órganos subterráneos.

Mettere l'aglio nell'insalata e mangiarlo per la pressione alta (RNI).

\section{Sector mágico/medicinal}

Categoría de uso: Vermífugo.

Número de informantes: 9 Partes utilizadas: órganos subterráneos.

Fare una collana di agli e metterla intorno al collo, per una settimana contro i vermi intestinali. (BBI) $\mid$ Fare una collana di agli e quando si vedono i 'bachi' (ossiuri) nelle feci dei bambini, mettergliela sul collo per 15 giorni, per evitare che il bambino venga strozzato quando il baco risale su. (BEL)| "Strofinare sui polsi e sul collo" il bulbo e mettere una collana di agli, finché non si secca. (MDA)| Contro I vermi intestinali, si mettevano una collana di agli intorno al collo finché passava. (MGO)| Per i 'vermi' dei bambini si metteva una collana di agli sul collo. (PCL, NRO)| Fare una collana di agli e metterla al collo finché i 'vermi' non vanno via (REN)| Fare una collana di agli e metterla intorno al collo, contro i vermi intestinali. (RMA)| "Fare una collana di spicchi d'aglio e metterla sul collo del bambino o del lattante, finché non fosse più agitato" (TOA).

\section{Sector mágico/ritual/supersticioso}

Categoría de uso: Protector. 
Número de informantes: 2 Partes utilizadas: órganos subterráneos.

Attaccavano una collana di agli alla porta per tenere il mal occhio lontano, o la 'malingagna' (mala sorta) lontano. (GGI) $\mid$ Si attaccavano alle case per allontanare le streghe (LST).

\section{Sector medicinal}

Categoría de uso: Afecciones cutáneas y tejidos subcutáneos.

Número de informantes: 6 Partes utilizadas: órganos subterráneos.

Applicare la foglia piu esterna della "spolla" d'aglio sulla ferita, protegge, fa l'effetto di un cerotto e disinfetta (BFE)| Applicare direttamente sulla ferita come un cerotto (GFR)| Bagnare con la saliva la buccia dell'aglio e metterla sulla ferita come un cerotto (GUF)| Prendere l'aglio e metterlo a scottare sul piano della stufa, si stroffinava sulla ferita e si lasciava sopra come uno scirotto fino alla mattina dopo. Si lasciava tutta la notte per 2 o 3 sere. (LST)| Prendere un 'gaccio' d'aglio e strofinarlo sul gelone. (MME)| Si usava applicare la buccia dell'aglio sulle ferite o sui tagli, perché fermava il sangue. (RGI).

Categoría de uso: Afecciones del aparato respiratorio.

Número de informantes: 1 Partes utilizadas: órganos subterráneos.

Bollire degli agli nel latte e prendere una tazza la sera, per la tosse. (PIM).

Categoría de uso: Afecciones típicas infantiles.

Número de informantes: 1 Partes utilizadas: órganos subterráneos.

strofinavano l'aglio sulle labbra dei bambini per i vermi intestinali' (GGI).

Categoría de uso: Enfermedades del oído.

Número de informantes: 1 Partes utilizadas: órganos subterráneos.

Friggere l' aglio nell' olio e lasciare raffreddare, quando è tiepido applicare due gocce dentro l'orecchio. (DAD).

Categoría de uso: Patologías del aparato circulatorio.

Número de informantes: 8 Partes utilizadas: órganos subterráneos.

Mangiare un aglio al giorno (GGI)| Mangiare aglio crudo tutte le mattine. (GLA)| Un 'guscio' (spicchio) di aglio, una volta al giorno nei pasti, crudo, ma anche cotto. Aiuta ad abbassare la pressione. (MGO)| Per le emorroidi: inserire uno spicchio d'aglio come supposta. Per la pressione alta: mangiare aglio crudo. (NST)| Fare dei bagni oppure degli impacchi con l'acqua di aglio. (PIM)| Mettere l'aglio nell'insalata e mangiarlo per la pressione alta (RNI)| Mangiare uno spicchio d'aglio una volta al giorno (TGA)| Mangiare 2 o 3 spicchi d'aglio al giorno per abbassare la pressione. (UMI).

Categoría de uso: Patologías del aparato digestivo.

Número de informantes: 7 Partes utilizadas: órganos subterráneos.

Introdurre nell'ano uno spicchio d'aglio al naturale alla sera fino alla mattina. (DAD)| Ingerire uno spicchio d'aglio crudo al giorno. (GGL)| Mangiare un aglio al giorno contro I vermi intestinali (GUF)| Mangiare abbondante aglio nei pasti (MGO)| Mangiare spesso agli crudi per i vermi intestinali. (MSR)| Gli agli mangiati crudi fanno guarire dai vermi intestinali. (RMA)| Mangiare uno spicchio d'aglio crudo tutte le mattine (TGA).

Categoría de uso: Trastornos musculo-esqueléticos.

Número de informantes: 1 Partes utilizadas: órganos subterráneos. 
Schiacciare l'aglio in un mortaio e diluirlo in olio di oliva. Poi mettere il malato a sedere.

davanti al focolare e massaggiare la schiena con questo olio. (LRE).

Notas Poi lavarsi I denti con la salvia per togliere il sapore d'aglio, "Chi al vole un buon aglio,.

lo semini di gennaio", "Mangiando le castagne ballote, da calore, e vengono i vermini".

\section{DATOS ETNOBOTÁNICOS BIBLIOGRÁFICOS}

Nombre vulgar: aglio (MANG98, ZAGN90, SABA75, BADI15), âj (UNGA21), àio (APPO10), àiio (GUC98).

Número de referencias: 7 Número de citas: 21.

Número de sectores: 3 Número de categorías: 12.

\section{Sector alimentario}

Categoría de uso: Aromatizante.

Número de referencias: 2 Partes utilizadas: órganos subterráneos.

Costolette di maiale in umido. Ingredienti:Costolette di maiale a pezzetti,aglio,rosmarino,alloro,salsa concentrata di pomodoro,vino bianco,sale e pepe.Si fanno soffriggere a fuoco lento le costolette con rosmarino aglio ed una foglia di alloro.Se si vuole un piatto meno pesante si scola il grasso della frittura e si sostituisce con olio.Si aggiungono sale e pepe ed un po' di vino bianco,che si lascia sfumare.Si pone quindi la salsadi pomodoro diluita con acqua e si lascia terminare la cottura,aggiungendo eventualmente un po' di brodo di dado, se il liquido del tegame non fosse sufficiente.Badare che il sugo resti piuttosto denso.Si servono con tigelle o polenta. (BADI15)| Ricetta "Zampanelle bianche"di Lústrola: $1 \mathrm{~kg}$ di farina bianca, sale quanto basta (un cucchiaino). Si fa un impasto piuttosto liquido della farina con l'acqua, poi si cuoce nei testi o negli stampi, foderati con le foglie di castagno preparate appositamente. A parte si fan bollire circa $2 \mathrm{~L}$. d'acqua, aggiungendo a ebollizione avvenuta, aglio, olio, pepe e sale quanto basta.In questo pignatto si immerge la pasta cotte nei testi, finché non sia bene inzuppata. A quel punto le zampanelle bianche son pronte da mangiare, si raccomanda però di bere anche il liquido dove si inzuppate, che, oltre ad avere un ottimo sapore, combatte efficacemente il raffredore ed è inoltre diuretico e lassativo. (SABA75)| Radicchi in padella. Ingredienti: Abbondante tarassaco (volg.piscialetto), aglio,olio,pancetta,sale,peperoncino. Si pulisce il tarassaco,lo si lava bene e lo si fa lessare.Una volta scolato si strizza con le mani facendone delle palle.Lo si pone sul tagliere e lo si trita finemente.Intanto nella padella con un po' d'olio si fanno soffriggere l'aglio e la pancetta tritati.Si aggiunge il tarassaco e lo si lascia insaporire. Bene.Prima di toglierlo dal fuoco si mette un po' di peperoncino e si aggiusta di sale. E' un ottimo contorno che in primavera andrebbe mangiato spesso perché è un ottimo depuratore del sangue. (BADI15).

\section{Sector mágico/medicinal}

Categoría de uso: Vermífugo.

Número de informantes: 2 Partes utilizadas: órganos subterráneos. 
In caso di verminosi intestinale si tiene al collo una collana d'aglio (MANG98)| Ai bambini piccoli gli agli venivano fatti odorare oppure legati al collo con una pezzuola o posti sotto il cuscino(ZAGN90).

Sector mágico/ritual/supersticioso

Categoría de uso: Propiciatorio.

Número de referencias: 1 Partes utilizadas: órganos subterráneos.

L'aglio è generalmente considerato simbolo dell'abbondanza. Dice Il prov.: Chi n' campra j'aj.

al dè d'San Zvan, l'è puvratt tott l'an. (UNGA21).

Sector medicinal

Categoría de uso: Afecciones cutáneas y tejidos subcutáneos.

Número de referencias: 1 Partes utilizadas: hojas.

Sovraposizione di foglie di aglio (ZAGN90).

Categoría de uso: Afecciones del aparato respiratorio.

Número de referencias: 1 Partes utilizadas: órganos subterráneos.

Le foglie di castagno sono indispensabili per la riuscita di tutte le ricette montanare che richiedono la cottura fra $\mathrm{i}$ testi. Si provvede a preparare le foglie, raccolte a luna vecchia, in settembre, riunendole in "manocchi“(mazzetti) legati con la punta.

Categoría de uso: Afecciones oro-faríngeas y de la cavidad oral.

Número de referencias: 1 Partes utilizadas: órganos subterráneos.

Sciacqui con un liquido ottenuto facendo bollire dell'acqua con aceto, aglio ed un pizzico di.

sale (ZAGN90).

Categoría de uso: Afecciones típicas infantiles.

Número de referencias: 1 Partes utilizadas: órganos subterráneos.

Nella med. Pop. Si adopera mettendolo ne' cibi a' bambini e anche accostandogliene uno spicchio sotto il naso. (UNGA21)|.

Categoría de uso: Enfermedades del oído.

Número de referencias: 1 Partes utilizadas: órganos subterráneos.

I contadini poi se ne mettono uno spicchio bruciato in un orecchio per levare il dolore di un.

colpo d'aria. (UNGA21).

Categoría de uso: Estado general.

Número de referencias: 1 Partes utilizadas: órganos subterráneos.

Veniva consumato per difendere 1'organismo dal contagio. (MANG98).

Categoría de uso: Otro medicinal.

Número de referencias: 2 Partes utilizadas: órganos subterráneos.

Come disinfettante, se ne tiene uno spicchio in bocca entrando nella stanza di un malato, spec. di malattia contagiosa (UNGA21)| Si consiglia strofinare aglio crudo lungo la colonna vertebrale (MANG98)| In caso di malattie batteriche e virali, viene tenuto in bocca uno spicchio d'aglio(MANG98).

Categoría de uso: Patologías del aparato circulatorio.

Número de referencias: 1 Partes utilizadas: órganos subterráneos.

Si ricorda che l'aglio, fino a qualche anno fa, non era un alimento così comune e diffuso, ma. 


\section{María Teresa Egea Molines}

che veniva appositamente consumato in caso di pressione alta. (MANG98).

Categoría de uso: Patologías del aparato digestivo.

Número de referencias: 1 Partes utilizadas: órganos subterráneos.

Le foglie di castagno sono indispensabili per la riuscita di tutte le ricette montanare che richiedono la cottura fra $\mathrm{i}$ testi. Si provvede a preparare le foglie, raccolte a luna vecchia, in settembre, riunendole in "manocchi"(mazzetti) legati con la punta Ricetta "Zampanelle bianche"di Lústrola: $1 \mathrm{~kg}$ di farina bianca, sale quanto basta (un cucchiaino). Si fa un impasto piuttosto liquido della farina con l'acqua, poi si cuoce nei testi o negli stampi, foderati con le foglie di castagno preparate appositamente. A parte si fan bollire circa 2 L. d'acqua, aggiungendo a ebollizione avvenuta, aglio, olio, pepe e sale quanto basta.In questo pignatto si immerge la pasta cotte nei testi, finché non sia bene inzuppata. A quel punto le zampanelle bianche son pronte da mangiare, si raccomanda però di bere anche il liquido dove si inzuppate, che, oltre ad avere un ottimo sapore, combatte efficacemente il raffredore ed è inoltre diuretico e lassativo(SABA75).

Categoría de uso: Patologías del aparato urinario.

Número de referencias: 1 Partes utilizadas: órganos subterráneos.

Le foglie di castagno sono indispensabili per la riuscita di tutte le ricette montanare che richiedono la cottura fra $i$ testi. Si provvede a preparare le foglie, raccolte a luna vecchia, in settembre, riunendole in "manocchi"(mazzetti) legati con la punta Ricetta "Zampanelle bianche"di Lústrola: $1 \mathrm{~kg}$ di farina bianca, sale quanto basta (un cucchiaino). Si fa un impasto piuttosto liquido della farina con l'acqua, poi si cuoce nei testi o negli stampi, foderati con le foglie di castagno preparate appositamente. A parte si fan bollire circa 2 L. d'acqua, aggiungendo a ebollizione avvenuta, aglio, olio, pepe e sale quanto basta.In questo pignatto si immerge la pasta cotte nei testi, finché non sia bene inzuppata. A quel punto le zampanelle bianche son pronte da mangiare, si raccomanda però di bere anche il liquido dove si inzuppate, che, oltre ad avere un ottimo sapore, combatte efficacemente il raffredore ed è inoltre diuretico e lassativo(SABA75).

Notas Chi n' campra j'aj al dè d'San Zvan, l'è puvratt tott l'an.

\section{Allium vineale $L$.}

Nombre vulgar: Cipolla selvatica (AMA), Erba cipollina (GGI, BLI, RGI).

Número de informantes: 4 Número de citas: 4.

Número de sectores: 1 Número de categorías: 3.

Biotipo: Geófito.

Tipo corológico: Eurimediterránea.

Abundancia: Común.

Ambiente: Sobre los bordes de los cultivos, viñedos, baldíos áridos.

Número de exsiccata: 39046 FIAF, 39084 FIAF.

\section{Sector alimentario}

Categoría de uso: Aromatizante.

Número de informantes: 2 Partes utilizadas: hojas. 
Lavata, si metteva nell'insalata (AMA)| Essicavano le foglie e la mettevano nell'insalata.

Adesso la sua figlia la mette nella pizza (RGI).

Categoría de uso: Ensalada.

Número de informantes: 1 Partes utilizadas: hojas.

Messa in insalata con altre piante (BLI).

Categoría de uso: Otro alimentario.

Número de informantes: 1 Partes utilizadas: hojas.

Il pan molle o zampanella (a Sambuca): la parte verde dell'erba cipollina, aglio selvatico, origano fresco, pomodori conditi, basilico. Bagnare il pane in acqua e aceto, strizzarelo, e mescolare con tutto il resto dell'insalata. (GGI).

Notas "Ora I cinghiali mangiano tutte le radici".

DATOS ETNOBOTÁNICOS BIBLIOGRÁFICOS

Nombre vulgar: cipolline selvatiche (SIRGI91).

Número de referencias: 1 Número de citas: 1.

Número de sectores: 1 Número de categorías: 1.

Sector alimentario

Categoría de uso: Otro alimentario.

Número de referencias: 1 Partes utilizadas: órganos subterráneos.

Gli alimenti del boscaioli consistevano in polenta di granoturco due volte al giorno con formaggio o aringa e un po di vino. Polenta e sempre e solo quella per sei mesi. A volte nei giorni di festa prendeva dalla dispensa un pezzo di lardo per fare la polenta condita con l'aggiunta delle cipolline selvatiche che que e là si trovavano nel bosco. (SIRGI91).

\section{APIACEAE (= UMBELLIFERAE)}

\section{Aegopodium podagraria $L$.}

Nombre vulgar: Erba ciliegina (TIV, GLA, GGI, GFR, CRI), Nogiadella (DBA, BAR), Sambuchino (BPA), Sambuchella (BGI).

Número de informantes: 9 Número de citas: 9.

Número de sectores: 2 Número de categorías: 2 .

Biotipo: Geófito.

Tipo corológico: Nórdicas.

Abundancia: Común.

Ambiente: Bosques de latifolios, barrancos, eras.

Número de exsiccata: 38973 FIAF, 39018 FIAF, 38980 FIAF.

Sector agropastoral

Categoría de uso: Alimentación animal (incluidos los forrajeros).

Número de informantes: 8 Partes utilizadas: hojas, parte aérea (toda).

Per dare da mangiare ai maiali, cruda insieme al gambo rosso. (CRI)| Dare direttamente da mangiare ai maiali, insieme al gambo rosso, l'erba ciliegina, a volt2 
la romice e l'ortica scottata. (GFR)| Per dare da mangiare ai maiali, cruda. Insieme alla romice, e al gambo rosso. (GGI)| alimentazione animale (maiali):Scottare l'ortica e mettere insieme ad un secchio di semola, insieme alle patate che venivano piu piccole (quelle grosse per I uomini) e a l'erba ciliegina. (GLA)| Al naturale, alimentazione animale (maiali) (TIV)| Si usava per dare da mangiare ai conigli (DBA, BAR) $\mid$ Li davano da mangiare ai conigli (BPA).

Sector veterinario

Categoría de uso: Cerdos.

Número de informantes: 1 Partes utilizadas: parte aérea (toda).

In caso di "Male rosso", febbre e debolezza del maiale. Si dava da mangiare cotto agli animali malati, anche insieme all' ortica. (BGI).

Notas è infestante, ma ora non se ne trova piu, è infestante.

DATOS ETNOBOTÁNICOS BIBLIOGRÁFICOS

Nombre vulgar: angiœlica salvâdga (UNGA21).

Número de referencias: 1 Número de citas: 1.

Número de sectores: 1 Número de categorías: 1 .

Sector medicinal

Categoría de uso: Trastornos musculo-esqueléticos.

Número de referencias: 1 Partes utilizadas: parte aérea (toda).

Un tempo adoperata per curare la gotta, ora in disuso (UNGA21).

\section{Apium graveolens $L$.}

Nombre vulgar: Sedano (GLA).

Número de informantes: 1 Número de citas: 1.

Número de sectores: 1 Número de categorías: 1.

Biotipo: Hemicriptófito.

Tipo corológico: Cultivadas.

Abundancia: Común.

Ambiente: Cultivos, baldíos.

\section{Sector alimentario}

Categoría de uso: Encurtidos y conserva en aceite.

Número de informantes: 1 Partes utilizadas: hojas.

Il sedano dell'orto si conservano sotto aceto per l'inverno: Scottare Il sedano in un litro di acqua e un bicchiere d'aceto (vino lasciato andare a male). Poi lasciare asciugare un po e mettere sotto olio. (GLA).

\section{Apium nodiflorum (L.) Lag.}

Nombre vulgar: Canna selvatica (VSI).

Número de informantes: 1 Número de citas: 1.

Número de sectores: 1 Número de categorías: 1.

Biotipo: Hemicriptófito.

Tipo corológico: Eurimediterránea. 
Abundancia: Rara.

Ambiente: Acequias, estanques, charcos.

Número de exsiccata: 39110 FIAF.

Sector agropastoral

Categoría de uso: Horticultura.

Número de informantes: 1 Partes utilizadas: tallos leñosos/ramas/ramitas/vástagos.

Lo stelo della pianta serve come 'piloto' per trapianti, come sostegno per le piantine giovani (VSI).

DATOS ETNOBOTÁNICOS BIBLIOGRÁFICOS

Nombre vulgar: crescione (MANG98).

Número de referencias: 1 Número de citas: 1.

Número de sectores: 1 Número de categorías: 1.

Biotipo: Hemicriptófito.

Tipo corológico: Eurimediterránea.

Abundancia: Rara.

Ambiente: Acequias, estanques, charcos.

Sector medicinal

Categoría de uso: Patologías del aparato urinario.

Número de referencias: 1 Partes utilizadas: parte aérea (toda).

Viene bevuto in caso di prostatite e di infiammazioni delle vie urinarie. Esternamente lo si utilizza in lavande vaginali. (MANG98).

\section{Bunium bulbocastanum L. (cfr.)}

Nombre vulgar: cuculevora (PGI), Le pette (BAN), Pantine (RGI, PSI, GGL, BMA), Pantré.

(VAL, PLU, DBA, BEL).

Número de informantes: 10 Número de citas: 10 .

Número de sectores: 1 Número de categorías: 1.

Biotipo: Geófito.

Tipo corológico: Atlánticas.

Abundancia: Rara.

Ambiente: Campos de trigo, en suelos pesados, ricos en piedra caliza.

\section{Sector alimentario}

Categoría de uso: Golosinas y masticatorias.

Número de informantes: 10 Partes utilizadas: órganos subterráneos.

Si mangiavano I bulbi nei campi incolti, si masticavano erano buone, dolciastri. (PGI)| Si mangiavano mentre si era nei campi. (BAN)| Quando lavoravamo il campo si trovava di tanto in tanto, si raccoglieva la radice, si pelava e si mangiava. 'Era il tartufo dei poveri'. (BMA)| Quando si aravano i campi vergini dove prima si faceva il fieno, si trovavano le pantine, si pelavano e si mangiavano crude. Ha un sapore indefinito, né di aglio né dolce, è un cipollina tonda, si toglie la prima pelle, è tenera e burrosa e deliziosa. (GGL)| Quando si lavoravano i campi, ci si trovavano le 
pantine, che si spellavano e si mangiavano così. (PSI)| Da piccoli mangiavamo il bulbo delle pantine: mentre si lavorava il terreno venivano su e si mangiavano così al naturale, erano dolci. Li mangiavamo in primavera, quando non avevano ancora il fiore, se hanno il fiore il bulbo diventa duro. (RGI)| Nei campi, si trovava spesso la radice e si pelava e si mangiava così. (BEL)| Le radici si mangiavano crude quando eravamo nei campi. (DBA) $\mid$ La radice si raccoglieva quando si era nei campi, e si mangiava così. (PLU)| La radice si raccoglieva quando si era nei campi. (VAL).

Notas un bulbino di sapore dolciastro, nei campi selvatici incolti., fa una nocciola, di sapore dolciastro, Era il tartufo dei poveri., Ha un sapore indefinito né di aglio né dolce, è un cipollina tonda, si toglie la prima pelle, è tenera e burrosa e deliziosa.

\section{Conium maculatum $L$.}

Nombre vulgar: Cicuta (CFR).

Número de informantes: 1 Número de citas: 1.

Número de sectores: 1 Número de categorías: 1 .

Biotipo: Hemicriptófito.

Tipo corológico: Amplia distribución.

Abundancia: Rara.

Ambiente: Ruinas, setos, eras, huertos.

Sector efecto nocivo

Categoría de uso: Tóxicas y venenosas.

Número de informantes: 1 Partes utilizadas: planta entera/viva.

È simile al prezzemolo fino ad un certo punto, veniva in mezzo al fieno, bisognava stare attenti perché è velenosa (CFR).

\section{Daucus carota L. subsp. carota}

Nombre vulgar: Pastricciani (MTO, MSR), Cuculever (ZAN).

Número de informantes: 3 Número de citas: 3.

Número de sectores: 2 Número de categorías: 2.

Biotipo: Hemicriptófito.

Tipo corológico: Europeas.

Abundancia: Bastante Común.

Ambiente: Generalmente sinantrópica en todo el territorio (baldíos, en los caminos, prados.

áridos).

Sector agropastoral

Categoría de uso: Alimentación animal (incluidos los forrajeros).

Número de informantes: 2 Partes utilizadas: planta entera/viva.

La mamma gliela dava ai conigli. (MSR)| Ai conigli piace tanto (MTO).

Sector alimentario

Categoría de uso: Golosinas y masticatorias.

Número de informantes: 1 Partes utilizadas: órganos subterráneos.

La radice bianca si puliva e si mangiava quando stavamo nei campi (ZAN). 
Notas si tira su con la radice, fanno tanti steli, fa un fiore bianco umbellifero, è selvatico, fa un grande cespuglio puzzolente. fa una radice bianca, è dura da strapparae, nei prati, viene su in primavera, fa il fiore a luglio, puzzano. Si mangiava prima della guerra, da ragazzi.

DATOS ETNOBOTÁNICOS BIBLIOGRÁFICOS

Nombre vulgar: carota, (UNGA21), pistinaega (forma spontanea arcôt) (UNGA21), Pastricciàna.

(APPO10), pastnaga, pastenaga (BENE96), pastruciã (GUC98).

Número de referencias: 4 Número de citas: 5.

Número de sectores: 2 Número de categorías: 2 .

\section{Sector alimentario}

Categoría de uso: sin precisar.

Número de referencias: 1 Partes utilizadas: órganos subterráneos.

Pianta coltivata negli orti per la radice rossa carnosa, buona per alim. (UNGA21).

Sector mágico/medicinal

Categoría de uso: Otro mágico/medicinal.

Número de referencias: 1 Partes utilizadas: No especificado.

Le si attribuisce dal volgo la proprietà di provocare I mestrui. (UNGA21).

\section{Daucus carota subsp. sativus (Hoffm.) Arcang.}

Nombre vulgar: Carote (BIO, MIO, GLA), Carota (BLI).

Número de informantes: 4 Número de citas: 4.

Número de sectores: 2 Número de categorías: 3 .

Biotipo: Hemicriptófito.

Tipo corológico: Europeas.

Abundancia: Cultivada.

Ambiente: Cultivado.

Sector alimentario

Categoría de uso: Encurtidos y conserva en aceite.

Número de informantes: 2 Partes utilizadas: órganos subterráneos.

Le carote dell'orto si conservano sotto aceto per l'inverno: Scottare le carote in un litro di acqua e un bicchiere d'aceto (vino lasciato andare a male). Poi lasciare asciugare un po e mettere sotto olio. (GLA)| Carote scottate in metà acqua metà aceto, poi farlo asciugare e mettere sotto olio o sotto aceto (MIO).

Categoría de uso: Sopas de verduras y potaje.

Número de informantes: 1 Partes utilizadas: órganos subterráneos.

La minestra di pane Toscana si fa con il cavolo, faggioli, zuccheti, carota, cavolo verza e un pò di pepolino (BIO).

Sector veterinario

Categoría de uso: Cerdos.

Número de informantes: 1 Partes utilizadas: órganos subterráneos. 
Per prevenire la "Moria" dei maiali (pandemia ). Quando si sentiva dire che c'era la moria, si dava da mangiare ai maiali la 'broda': cuocere l'ortica insieme alle patate, alle carote, al farfaro, alle castagne secche e alla semola. (BLI).

DATOS ETNOBOTÁNICOS BIBLIOGRÁFICOS

Nombre vulgar: carota (MANG98).

Número de referencias: 1 Número de citas: 2.

Número de sectores: 1 Número de categorías: 2.

\section{Sector medicinal}

Categoría de uso: Afecciones cutáneas y tejidos subcutáneos.

Número de referencias: 1 Partes utilizadas: órganos subterráneos.

Empiastri di radice vengono applicati sulle bruciature (MANG98).

Categoría de uso: Afecciones oftalmológicas.

Número de referencias: 1 Partes utilizadas: órganos subterráneos.

Empiastri di radice vengono applicati sugli orzaioli. (MANG98).

\section{Foeniculum vulgare Mill. (= Foeniculum vulgare Mill. subsp. piperitum (Ucria) Coutinho)}

Nombre vulgar: Finocchietto (RGI), Finocchio (GGI, GFR, BSO, BLI), Finocchio selvatico (TAD, NRO, CRI, CFR).

Número de informantes: 9 Número de citas: 12.

Número de sectores: 2 Número de categorías: 4.

Biotipo: Hemicriptófito.

Tipo corológico: Eurimediterránea.

Abundancia: Común.

Ambiente: Baldíos áridos, cultivos.

Número de exsiccata: 39098 FIAF.

Sector alimentario

Categoría de uso: Aromatizante.

Número de informantes: 9 Partes utilizadas: frutos/infrutescencias/falsos frutos, hojas,.

I nonni usavano i 'semi' (frutti) come aromatizzante per le zuppe, insalate... (RGI) Per aromatizzare le castagne cotte con sale. (BLI)| Per aromatizzare le castagne cotte, la carne di coniglio. (BSO)| Per aromatizzare e fissare la rete di maiale con I fegatelli e la carne di maiale, si infila un ramettino (quello delle infruttescenze) alla rete di maiale avvolta. (GFR)| Per aromatizzare e fissare la rete di maiale con I fegatelli e la carne di maiale, si infila un ramettino (quello delle infruttescenze) alla rete di maiale avvolta. Dava sapore e teneva fermo il rotolino. Per aromatizzare "I cerbolloni": castagne sbucciate e cotte. (CFR, GGI)| Con il finocchio selvatico si prepavara il "cerboato": coniglio aperto e riempito di foglie di finocchio fresche, poi si chiude, si lega e si mettere a cuocere. E si prepara anche I fegatelli di maiale, con il fiore di finocchio fissavano la retina. (CRI)| Per aromatizzare I fegatelli, la rete (peritoneo), e I cerbolloni. (NRO)| Le castagne 'mondate' o 'cerboloni': si toglie tutta la pelle esterna, si fanno cuocere con la pelle interna, la sansa, che si toglie quando 
si mangiano. Si cuociono con il finocchio selvatico. Si fanno con le castagne più grosse, con le molane, I marroni, le grossole (forma di marroni pero di colore più sul nero) (TAD).

Categoría de uso: Dulces y golosinas.

Número de informantes: 1 Partes utilizadas: semillas.

I zuccherini erano e sono I dolci tipici dei matrimoni e delle comunioni. Sono dei dolcietti fatti di acqua, farina, zucchero e semi di finocchio che poi fanno inzuppatti in uno sciroppo di acqua e zucchero e fatti raffreddare. (BSO).

\section{Sector medicinal}

Categoría de uso: Patologías del aparato digestivo.

Número de informantes: 1 Partes utilizadas: flores/inflorescencias y sus partes.

Fiori messi nell' acqua bollente e bevuto (TAD).

Categoría de uso: Patologías del aparato urinario.

Número de informantes: 1 Partes utilizadas: flores/inflorescencias y sus partes.

Fiori messi nell' acqua bollente e bevuto (TAD).

Notas Dicono che nella zona la pianta non cresce spontanea, ma altri dicono che dipende della zona, nelle parti basse si cresce spontaneo..

DATOS ETNOBOTÁNICOS BIBLIOGRÁFICOS

Nombre vulgar: finocchio selvatico (SANS14), fnôc da smaint o fnucenna (UNGA21), finocchio.

(MANG98).

Número de referencias: 3 Número de citas: 7.

Número de sectores: 3 Número de categorías: 7.

Sector alimentario

Categoría de uso: Aromatizante.

Número de referencias: 1 Partes utilizadas: tallos herbáceos/escapos, semillas, hojas (SANS14).

Categoría de uso: Licor.

Número de referencias: 1 Partes utilizadas: tallos herbáceos/escapos, semillas, hojas (SANS14).

Categoría de uso: Verdura cocida.

Número de referencias: 1 Partes utilizadas: tallos herbáceos/escapos, semillas, hojas (SANS14).

Sector doméstico

Categoría de uso: Cuidado personal y cosmética.

Número de referencias: 1 Partes utilizadas: flores/inflorescencias y sus partes.

Finocchio forte o selvatico, finochietto, spont. In alcuni luoghi, colt. Per ottenere il seme detto fnucenna. Nella medicina popolare le foglie di finocchio sono adop. dai contadini per detergersi gli occhi in caso di congiuntivite o anche di semplice infiammazione. Le fronde bollite nel vino si somministrano alle donne per moltiplicarne il latte e regolarne i corsi. I fiori di finocchio si prendono a digiuno con un pò di sale per rendere il fiato odoroso. (UNGA21). 


\section{Sector medicinal}

Categoría de uso: Afecciones ginecológicas, complicaciones obstétricas, del postparto y del puerperio.

Número de referencias: 1 Partes utilizadas: parte aérea (toda).

Finocchio forte o selvatico, finochietto, spont. In alcuni luoghi, colt. Per ottenere il seme detto.

fnucenna. Nella medicina popolare le foglie di finocchio sono adop. dai contadini per detergersi gli occhi in caso di congiuntivite o anche di semplice infiammazione. Le fronde bollite nel vino si somministrano alle donne per moltiplicarne il latte e regolarne i corsi. I fiori di finocchio si prendono a digiuno con un pò di sale per rendere il fiato odoroso. (UNGA21).

Categoría de uso: Afecciones oftalmológicas.

Número de referencias: 1 Partes utilizadas: hojas.

Finocchio forte o selvatico, finochietto, spont. In alcuni luoghi, colt. Per ottenere il seme detto.

fnucenna. Nella medicina popolare le foglie di finocchio sono adop. dai contadini per detergersi gli occhi in caso di congiuntivite o anche di semplice infiammazione. Le fronde bollite nel vino si somministrano alle donne per moltiplicarne il latte e regolarne $\mathrm{i}$ corsi. I fiori di finocchio si prendono a digiuno con un pò di sale per rendere il fiato odoroso. (UNGA21).

Categoría de uso: Patologías del aparato digestivo.

Número de referencias: 1 Partes utilizadas: frutos/infrutescencias/falsos frutos. L'infuso viene bevuto per 'togliere 1'aria dallo stomaco'. (MANG98).

\section{Petroselinum crispum (Mill.) Fuss (= Petroselinum sativum Hoffm.)}

Nombre vulgar: Prezzemolo (MTI, IMA, AP2, CRE, GGI, CLO, BEL).

Número de informantes: 7 Número de citas: 7.

Número de sectores: 1 Número de categorías: 3 .

Biotipo: Hemicriptófito.

Tipo corológico: Cultivadas.

Abundancia: Cultivada.

Ambiente: Baldíos, terrenos dedicados a huertos.

Sector medicinal

Categoría de uso: Afecciones cutáneas y tejidos subcutáneos.

Número de informantes: 3 Partes utilizadas: hojas.

Prendere la foglia di prezzemolo, masticarla e strofinarla sopra la puntura, poi aggiungere un po' di succo di limone. (BEL)| Battuto di foglie di prezzemolo fresche messo sulle punture di vespe (CLO)| Battuto di prezzemolo con una fasciatura intorno, quando è passato un po' di tempo del momento della puntura. Se si può mettere qualcosa subito: mettere aceto. (GGI).

Categoría de uso: Afecciones ginecológicas, complicaciones obstétricas, del postparto y del puerperio.

Número de informantes: 1 Partes utilizadas: hojas. 
Bollire un po' una grande quantità di prezzemolo e bere. (CRE).

Categoría de uso: Afecciones típicas infantiles.

Número de informantes: 3 Partes utilizadas: tallos herbáceos/escapos, órganos.

Il gambo del prezzemolo si usava con la stitichezza dei bambini (AP2)| La radice unta di un po di olio, e messa come una suposta. (IMA)| Applicare lo stelo del prezzemolo direttamente nell'ano, stimola la peristalsi. (MTI).

DATOS ETNOBOTÁNICOS BIBLIOGRÁFICOS

Nombre vulgar: prezzemolo (MANG98), prasôl (UNGA21).

Número de referencias: 2 Número de citas: 4.

Número de sectores: 1 Número de categorías: 4.

Sector medicinal

Categoría de uso: Afecciones cutáneas y tejidos subcutáneos.

Número de referencias: 1 Partes utilizadas: hojas.

Il succo fresco viene posto sulle punture d'ape per calmare il dolore ed inibire il gonfiore (MANG98).

Categoría de uso: Afecciones ginecológicas, complicaciones obstétricas, del postparto y del puerperio.

Número de referencias: 1 Partes utilizadas: hojas.

Nella medicina popolare si mangiano in insalata per arrestare la produzione del latte: e a tale effetto le donne se ne fanno anche un mazzetto e se lo mettono al collo cacciandoselo di dietro (UNGA21).

Categoría de uso: Afecciones oro-faríngeas y de la cavidad oral.

Número de referencias: 1 Partes utilizadas: hojas.

Una foglia trittata finemente, addizionata a poco sale e ad una goccia d'olio, viene posta nella carie dentario in caso di mal di denti, foglie fresche vengono masticate per combattere l'alitosi (MANG98).

Categoría de uso: Enfermedades del oído.

Número de referencias: 1 Partes utilizadas: hojas.

Una foglia trittat finemente e avvolta in un pezzetto di garzo nell'orecchio in caso di otite (MANG98).

Notas Nasce quaranta giorni dopo seminato, perché secondo I contadini:“I prasù premma.

d'naser I stan quaranta dè a cà dal dioevel" : I prezzemoli prima di nascere stanno.

quaranta giorni a casa del diavolo.

\section{Pimpinella anisum L.}

Nombre vulgar: Anicini (MGE).

Número de informantes: 1 Número de citas: 1.

Número de sectores: 1 Número de categorías: 1 .

Biotipo: Terófito.

Tipo corológico: Europeas.

Abundancia: Cultivada.

Ambiente: Cultivada, planta aromática y raramente asilvestrada en los baldíos. 


\section{Sector alimentario}

Categoría de uso: Dulces y golosinas.

Número de informantes: 1 Partes utilizadas: semillas.

Per Pasqua e Natale, o per la prima domenica d'ottobre tutti facevano I 'zuccherini': farina di grano, lievito naturale, anicini, zucchero, si faceva un impasto e si metteva in forno. Poi andavano canditi, lo faceva scioglere un bicchiere di zucchero e un bicchiere d'acqua sul fuoco e si giravano tutti, poi diventavano bianchi. (MGE).

\section{AQUIFOLIACEAE}

\section{Ilex aquifolium $\mathrm{L}$.}

Nombre vulgar: Pungitopo (NLA), Agrifoglio (TAD, PCL, MRI, MGO, GLA, BLI, TGO, GUF, VMR, GRI, GGI, GFR, BGI, TRU, NRO, TUL, DAD).

Número de informantes: 18 Número de citas: 26.

Número de sectores: 5 Número de categorías: 8 .

Biotipo: Fanerófito.

Tipo corológico: Eurimediterránea.

Abundancia: Rara.

Ambiente: Bosques (sobre todo hayedos).

Número de exsiccata: 38910 FIAF.

\section{Sector alimentario}

Categoría de uso: Aromatizante.

Número de informantes: 1 Partes utilizadas: frutos/infrutescencias/falsos frutos. Le bebe (frutti) del 'pungitopo' secche si mettevano solo nella carne di capretto e di agnello, a cui dava un aroma particolare (NLA).

Sector caza y pesca

Categoría de uso: Caza de pájaros.

Número de informantes: 2 Partes utilizadas: frutos/infrutescencias/falsos frutos,. Per cacciare merli, tordi e cesene si mettevano sotto l' albero (DAD)| Caccia di cesene, merli e tordi:Le cesene, I merli e I tordi mangiano I frutti, per questo per cacciarli si mettono vicino (TUL).

Sector doméstico

Categoría de uso: Chimenea y horno.

Número de informantes: 2 Partes utilizadas: parte aérea (toda), tallos.

$\mathrm{Si}$ facevano mazzi di agrifoglio e ginestre e si mettevano a seccare queste fascine legate. (NRO)| Per pulire la canna fumaria, si facevano dei "fastellini" fatti di Agrifoglio e Bussolo e si tirava su e giù nella canna fumaria. (TRU).

Categoría de uso: Integración de la renta familiar.

Número de informantes: 5 Partes utilizadas: tallos leñosos/ramas/ramitas/vástagos,.

Sotto Natale, si vendeva a forma di mazzi (GRI, BGI)| Raccolte e vendute a gente di Pescia e Bologna (GFR)| Si raccoglievano dei rami e si vendeva nei paesi per 
ornamento natalizio. (GGI)| Le bacche dell'agrifoglio si vendevano nei vivai. (VMR)| I rami si vendevano a Natale, ai fiorai a Pistoia o Porretta (VMR).

Categoría de uso: Jardín.

Número de informantes: 4 Partes utilizadas: planta entera/viva, parte aérea (toda).

Piantato accanto alle case per riparare dal vento (GFR)| Paravento:Si coltivavano alberi di Agrifoglio, che poi si intrecciavano a rete, per parare il vento (GUF) Paravento:Coltivavano l' albero accanto alle case per parare il vento (NRO)| Paravento:Tutte le case ce l' avevano(NLA).

Sector efecto nocivo

Categoría de uso: Tóxicas y venenosas.

Número de informantes: 1 Partes utilizadas: frutos/infrutescencias/falsos frutos.

Dicevano che è velenoso (GGI).

Sector mágico/ritual/supersticioso

Categoría de uso: Protector.

Número de informantes: 2 Partes utilizadas: planta entera/viva, parte aérea (toda).

Coltivare l'albero davanti a casa manteneva le streghe lontano (GUF)| In ogni casa c' era un agrifoglio perché mantenevano gli spiriti maligni lontano (TGO).

Categoría de uso: Rituales navideños.

Número de informantes: 8 Partes utilizadas: tallos leñosos/ramas/ramitas/vástagos,.

$\mathrm{Si}$ usa regalare rami di Agrifoglio per Natale (BLI)| Si usa regalare rami di agrifoglio per Natale, come portafortuna (GLA)| Mettere il ramo di Agrifoglio alla porta per Natale (MGO)| Per fare l'albero di natale. (MRI)| Regalare un ramo di Agrifoglio a Natale, "portava" fortuna. (NRO)| Per decorare a Natale (PCL)| Regalare un ramoscello di Agrifoglio per Natale porta bene alla casa. (TAD)| Per abbellire le case durante le feste (TUL).

Notas Il pungitopo è l'agrifoglio, e il grattatopo è il pungitopo. Sopra di Case Sarti, si trovano delle case con questo tipo di paravento.

DATOS ETNOBOTÁNICOS BIBLIOGRÁFICOS

Nombre vulgar: ponztôp (UNGA21), agrifoglio, pungitopo (BAL801).

Número de referencias: 2 Número de citas: 4.

Número de sectores: 3 Número de categorías: 4.

Sector caza y pesca

Categoría de uso: Caza de pájaros.

Número de referencias: 1 Partes utilizadas: corteza.

Dalla corteccia si estrae materia per tender la pania agli uccelli. (UNGA21).

Sector doméstico

Categoría de uso: Ornamental.

Número de referencias: 1 Partes utilizadas: tallos leñosos/ramas/ramitas/vástagos. L'agrifoglio è utilizzato nel periodo invernale come pianta decorativa cercati in particolare i rami verdi coperti di bei frutti rossi (BAL801). 


\section{Sector medicinal}

Categoría de uso: Fiebre.

Número de referencias: 1 Partes utilizadas: hojas.

Nella medicina popolare le foglie verdi sono impiegate a far decotti per le febbri intermittenti (UNGA21).

Categoría de uso: Patologías del aparato urinario.

Número de referencias: 1 Partes utilizadas: frutos/infrutescencias/falsos frutos.

Le bacche sono ritenute diuretiche. (UNGA21).

Notas Abbastanza raro nel nostro territorio e relativamente frequente soltanto sul Monte della Croce, presso Porretta.

\section{ARACEAE}

\section{Arum italicum Mill.}

Nombre vulgar: Badilaccio (BEL).

Número de informantes: 1 Número de citas: 1.

Número de sectores: 1 Número de categorías: 1.

Biotipo: Geófito.

Tipo corológico: Esteno-mediterránea.

Abundancia: Común.

Ambiente: Maquias, bosques de monte bajo, desmontes, setos, viñedos, olivares.

Sector medicinal

Categoría de uso: Afecciones cutáneas y tejidos subcutáneos.

Número de informantes: 1 Partes utilizadas: hojas.

Raccogliere la pianta, farla seccare e conservare in un vaso. Prendere la foglia secca, mettere.

a bagno, farla cuocere, e metterla sopra l'infezione al dito. (BEL).

Notas Andava a raccogliere vicino a un fosso, fa dove li pare: a volte nei bordi della strada,.

oppure in mezzo alle raggie, nel campo.

DATOS ETNOBOTÁNICOS BIBLIOGRÁFICOS

Nombre vulgar: pan d'bessa (UNGA21).

Número de referencias: 1 Número de citas: 2 .

Número de sectores: 1 Número de categorías: 2.

\section{Sector medicinal}

Categoría de uso: Afecciones cutáneas y tejidos subcutáneos.

Número de referencias: 1 Partes utilizadas: órganos subterráneos.

$\mathrm{La}$ radice affettata si adopera come callifugo. (UNGA21).

Categoría de uso: Otro medicinal.

Número de referencias: 1 Partes utilizadas: No especificado.

Nella medicina popolare, le comari le sommistrano però ancora in decotto contro l'etisia (UNGA21). 


\section{ARALIACEAE}

\section{Hedera helix L.}

Nombre vulgar: Edera (BLI, GFR, MCL, CRE, BAT, BAN, GCL, VMU, VMR, NRO, GGI, TUL, TIV, MGO).

Número de informantes: 14 Número de citas: 16.

Número de sectores: 4 Número de categorías: 7.

Biotipo: Fanerófito.

Tipo corológico: Eurimediterránea.

Abundancia: Bastante Común.

Ambiente: Bosques mediterráneos (encinares) y submediterráneos (robledales y castañares), .

también cultivada de forma común.

Sector agropastoral

Categoría de uso: Herramientas y objetos agrícolas.

Número de informantes: 1 Partes utilizadas: tallos leñosos/ramas/ramitas/vástagos.

Manico al pennato:attrezzo di taglio per il castagneto (MGO).

Sector artesanal

Categoría de uso: Objetos domésticos.

Número de informantes: 2 Partes utilizadas: tallos leñosos/ramas/ramitas/vástagos.

Mobili, come attaccapanni:Proprietà del legno: è duro, e assorbe bene la vernice, rimane.

lustra. (MGO)| Statuine ornamentali:Fanno dei funghi In legno (TIV).

Sector caza y pesca

Categoría de uso: Caza de pájaros.

Número de informantes: 1 Partes utilizadas: frutos/infrutescencias/falsos frutos.

Gli uccelli mangiano I frutti e cacciatori si mettono vicino per cacciarli (TUL).

Sector doméstico

Categoría de uso: Cuidado personal y cosmética.

Número de informantes: 5 Partes utilizadas: parte aérea (toda), hojas.

Lavaggi dei capelli con decotto di edera (GGI)| Bollire l'edera e lavare I capelli con l'acqua dell'edera. (NRO) | Fare il decotto stretto dell'edera e lavarsi I capelli per dare dei riflessi scuri. (VMR)| Fare il decotto di edera e lavarsi I capelli per scurire I capelli. (VMU)| Edera bollita e per lavare i capelli (GCL).

Categoría de uso: Detergente/tintorial.

Número de informantes: 5 Partes utilizadas: hojas, parte aérea (toda).

Fare bollire l'edera, fare raffreddare l'acqua e poi immergere la 'roba' nera. Questa acqua fissa il colore. (BAT, BAN)| Bollire le foglie di edera, filtrare e mettere a bagno I giubotti scuri, poi sciacquare con l'acqua oppure lavare di nuovo con sapone e risciacquare. Perché I vestiti non perdano il colore. (CRE)| Bollire l'edera e con 


\section{María Teresa Egea Molines}

l'acqua lavare I vestiti scuri. (NRO)| Per lavare i vestiti colorati, si lavava con un decotto di edera. L'edera non fa stingere i vestiti e lava pure. (MCL).

Categoría de uso: Jardín.

Número de informantes: 1 Partes utilizadas: planta entera/viva.

Recinto per siepi con pali di castagno stagionati, per fare il pergolato (GFR).

Categoría de uso: Ornamental.

Número de informantes: 1 Partes utilizadas: tallos leñosos/ramas/ramitas/vástagos.

Per fare mazzi di fiori, si metteva l'edera come accompagnamento. (BLI).

Notas Proprietà del legno: è morbido, non crepa, non fa male, è duro pero poroso e morbido,.

non fa calli.

\section{DATOS ETNOBOTÁNICOS BIBLIOGRÁFICOS}

Nombre vulgar: êrba quatrenna, låddra (UNGA21), edera (MANG98), Lelléra (APPO10),.

léllera (BONZI00, BENE96), éllera (GUC98).

Número de referencias: 6 Número de citas: 10.

Número de sectores: 1 Número de categorías: 5.

\section{Sector medicinal}

Categoría de uso: Afecciones cutáneas y tejidos subcutáneos.

Número de referencias: 2 Partes utilizadas: hojas.

edera, volgarissima sui muri e sugli alberi ovunque. I contadini ne mettono le foglie fresche sulla testa dei bambini che hanno il lattime. Le foglie sono anche usate per ammolire I calli. (UNGA21)| oppure per eliminare calli e verruche. (MANG98).

Categoría de uso: Afecciones típicas infantiles.

Número de referencias: 1 Partes utilizadas: hojas.

edera, volgarissima sui muri e sugli alberi ovunque. I contadini ne mettono le foglie fresche sulla testa dei bambini che hanno il lattime. Le foglie sono anche usate per ammolire I calli. (UNGA21).

Categoría de uso: Estado general.

Número de referencias: 1 Partes utilizadas: hojas.

Si utilizza sia internamente, come cura depurativa primaverile (MANG98).

Categoría de uso: Patologías del aparato circulatorio.

Número de referencias: 1 Partes utilizadas: hojas.

Le foglie cotte, fredde, vengono fasciate sulle vene varicose. (MANG98).

Categoría de uso: Trastornos musculo-esqueléticos.

Número de referencias: 1 Partes utilizadas: hojas.

Sia esternamente, in bagni contro dolori ossei e reumatici. (MANG98).

\section{ASPARAGACEAE (incluye LILIACEAE p.p.)}

\section{Asparagus tenuifolius Lam.}

Nombre vulgar: Asparagi selvatici (VMA, GGI, CFR, AMA), Asparagi (SOT). 
Número de informantes: 5 Número de citas: 8.

Número de sectores: 3 Número de categorías: 6 .

Biotipo: Geófito.

Tipo corológico: Europeas.

Abundancia: Rara.

Ambiente: Bosque submediterráneos de roble melojo y castaño, hayales termófilos. Número de exsiccata: 39096 FIAF.

Sector alimentario

Categoría de uso: Arroces y "risotto".

Número de informantes: 1 Partes utilizadas: brotes.

Asparagi messi nei risotti, da soli o con altre verdure. (AMA).

Categoría de uso: Otro alimentario.

Número de informantes: 1 Partes utilizadas: brotes.

Mangiati crudi come verdura. (AMA).

Categoría de uso: Tortilla.

Número de informantes: 1 Partes utilizadas: brotes.

Sbollentati e messi nella frittata (SOT).

Categoría de uso: Verdura cocida.

Número de informantes: 3 Partes utilizadas: brotes.

Lessi e conditi come verdura cotta. (GGI, CFR, AMA).

Sector doméstico

Categoría de uso: Jardín.

Número de informantes: 1 Partes utilizadas: parte aérea (toda).

Si usa per ornamento nel giardino, l'ha raccolto dal bosco a Casola e l'ha trapiantato nel suo giardino come ornamento (VMA).

Sector religioso

Categoría de uso: Ornamento para altares e iglesias.

Número de informantes: 1 Partes utilizadas: parte aérea (toda).

Si usava per fare I mazzi di fiori fatti di asparagi per quando portavano la madonna. (VMA).

Notas non c'è in PTP (2008). Il suo cognato l'andava a prendere sulla curva per andare alle Mogne, GGI dice che a Lentula ci crescono. SOT abita a Giardino (P.te Venturina), bassa altitudine. Venturi (2006) non lo riporta, Ci sono per l'Acquerino, a Caviana, al valico, conosce delle persone che vanno a cercarli. VMA l'ha preso da Casola (Castel di Casio) e l'ha trapiantato nel suo giardino per ornamento. Una volta c'era anche al Monte la Croce, però sono spariti.

\section{Ruscus aculeatus L.}

Nombre vulgar: Pungitopo (GCL, LGI, GPU, BGI, VMR, TUL, GLA, BLI, BMA), Asparagi selvatici, Pungitopo (BSO), Grattatopi (GGI).

Número de informantes: 11 Número de citas: 12 .

Número de sectores: 4 Número de categorías: 8 .

Biotipo: Caméfito. 
Tipo corológico: Eurimediterránea.

Abundancia: Común.

Ambiente: Encinares, bosques caducifolios termófilos.

Sector agropastoral

Categoría de uso: Vallas y delimitaciones.

Número de informantes: 1 Partes utilizadas: planta entera/viva (BMA).

Sector alimentario

Categoría de uso: Verdura cocida.

Número de informantes: 1 Partes utilizadas: brotes.

Si raccogolgono a primavera, si fanno cuocere e si mangiano conditi. (BSO).

Sector doméstico

Categoría de uso: Chimenea y horno.

Número de informantes: 3 Partes utilizadas: tallos leñosos/ramas/ramitas/vástagos.

Facevano un mazzo con I rami di pungitopo e di ginepro, uno si metteva su e un'altro giu, tirando su e giu. (BLI)| Facevano un mazzo con I rami di pungitopo, e si tirava su e giu nella canna fumaria per pulirla. (GLA)| Si prendevano I rami intreciati con il bussolo, uno tirava da sopra la canna fumaria e l'altro da sotto (TUL).

Categoría de uso: Integración de la renta familiar.

Número de informantes: 1 Partes utilizadas: tallos leñosos/ramas/ramitas/vástagos.

I rami si vendevano a Natale, ai fiorai a Pistoia o Porretta, a Casa Boni ce n'è tanto. (VMR).

Categoría de uso: Jardín.

Número de informantes: 1 Partes utilizadas: planta entera/viva.

Piantato nei giardini, fuori casa (BGI).

Categoría de uso: Ornamental.

Número de informantes: 1 Partes utilizadas: planta entera/viva.

Piantato intorno alle case, come ornamento. (BMA).

Categoría de uso: Repelentes o trampas domésticas.

Número de informantes: 3 Partes utilizadas: tallos leñosos/ramas/ramitas/vástagos.

Per tenere lontani i topi dai formaggi, si mettevano i formaggi su una tavola di pioppo appesa con fil di ferro ai travi del tetto, e si mettevano dei mazzetti di grattatopi sul fil di ferro per evitare che i topi andassero sul formaggio. (GGI)| Prima legavano un ramo nei punti dove si sapeva che passavano i topi, perché diceva che $\mathrm{i}$ topi si pungevano e non si arrampicavano più. (LGI, GPU).

Sector mágico/ritual/supersticioso

Categoría de uso: Propiciatorio.

Número de informantes: 1 Partes utilizadas: tallos leñosos/ramas/ramitas/vástagos.

Mettere un ramo di pungitopo sulle finestre della casa, per portare fortuna (GCL). 
Notas Non c'è nella flora di Venturi (2006).

DATOS ETNOBOTÁNICOS BIBLIOGRÁFICOS

Nombre vulgar: pungitopo (SANS14), ponztôp (UNGA21).

Número de referencias: 2 Número de citas: 2.

Número de sectores: 1 Número de categorías: 1.

Sector alimentario

Categoría de uso: Verdura cocida.

Número de referencias: 1 Partes utilizadas: brotes (SANS14).

\section{ASPLENIACEAE}

\section{Asplenium scolopendrium L. (=Phyllitis scolopendrium (L.) Newman)}

Nombre vulgar: Erba del brugiado (GFO, GAN, DAD), Erba per le bruciature (PCL), Fellegia per il bruciato (NRO), Foglia per al brugiado, Lingua di bue (GGI), Foglie da scottato (GCL), Foglie del brugiado (CRE), Lingua di botta (GLA), Lingua di cane (MRI).

Número de informantes: 10 Número de citas: 10.

Número de sectores: 1 Número de categorías: 1.

Biotipo: Hemicriptófito.

Tipo corológico: Nórdicas.

Abundancia: Rara.

Ambiente: Ombrófila e higrófila: bosques húmedos, pozos, cuevas, sobre todo calcáreas.

Número de exsiccata: 38982 FIAF, 38978 FIAF, 39025 FIAF.

Sector medicinal

Categoría de uso: Afecciones cutáneas y tejidos subcutáneos.

Número de informantes: 10 Partes utilizadas: hojas.

Togliere la nervatura nella parte posteriore della foglia ed applicare direttamente sulla bruciatura (GLA, DAD)| Raschiare con una lama la parte inferiore della foglia e poi applicare la foglia direttamente sulla bruciatura. (GGI, GAN)| Applicare direttamente la foglia sul taglio o sulla bruciatura. (GFO)| Mettere la foglia direttamente sulla bruciatura $(\mathrm{NRO}, \mathrm{PCL}) \mid \mathrm{La}$ foglia si metteva sopra la bruciatura per un po' di tempo (GCL)| Applicare direttamente sulla bruciatura (CRE)| Applicare una foglia sulla ferita (MRI).

Notas Ce l'ha in vaso fuori casa, anche perché è bella., "Anche d'inverno, fra la neve si andava a cercare e si metteva sopra il bruciato", Quando si trovava si raccoglieva con radice e si metteva nella terra con un vaso, cosi si teneva pronta in casa per le emergenze.

DATOS ETNOBOTÁNICOS BIBLIOGRÁFICOS

Nombre vulgar: lingua cervina (BAL801), êrba per la mîlza (UNGA21). 
Número de referencias: 2 Número de citas: 2 .

Número de sectores: 1 Número de categorías: 2.

Sector medicinal

Categoría de uso: Afecciones cutáneas y tejidos subcutáneos.

Número de referencias: 1 Partes utilizadas: No especificado.

Secondo un montanaro, la lingua cervina era una volta utilizzata come rimedio esterno per le.

scottature della pelle. (BAL801).

Categoría de uso: Otro medicinal.

Número de referencias: 1 Partes utilizadas: No especificado.

lingua cervina, felce de pozzi, sorta di felce somigliante al capelvenere, com. Ne'luoghi umidi e ne muri de pozzi, detta anche milzaia, perché adoperata nella med. Fam. Per curare la ostruzione dei visceri. (UNGA21).

Notas Nel nostro territorio è piuttosto rara, la si può trovare nei dirupi ombrosi e umidi che fianchegginao il Rio Maggiore. Al vecchio ponte ad arco che attraversa il Rio nei pressi del distrutto Mulino dei pipistrelli, un centrinaio di metri a monte del Moli.

\section{Ceterach officinarum Willd.}

Nombre vulgar: Erba ruggine (NRE).

Número de informantes: 1 Número de citas: 1.

Número de sectores: 1 Número de categorías: 1.

Biotipo: Hemicriptófito.

Tipo corológico: Europeas.

Abundancia: Común.

Ambiente: Muros, acantilados y pedregales.

Sector medicinal

Categoría de uso: Afecciones del aparato respiratorio.

Número de informantes: 1 Partes utilizadas: hojas.

Fare il 'fiasco' pieno del decotto di foglie e fiori di polmonaria, foglie di farfanella, foglie di.

malva, di cimballaria, di piscialletto e di foglie di erba ruggine. (NRE).

Notas lo faceva la sua nonna..

\section{BALSAMINACEAE}

\section{Impatiens walleriana Hook.f. y otras especies e híbridos}

Nombre vulgar: Canne di vetro (BLI).

Número de informantes: 1 Número de citas: 1.

Número de sectores: 1 Número de categorías: 1.

Biotipo: Terófito.

Tipo corológico: Cultivadas. 
Abundancia: Cultivada.

Ambiente: Cultivada.

Sector doméstico

Categoría de uso: Ornamental.

Número de informantes: 1 Partes utilizadas: planta entera/viva.

Alla porta di tutte le case, ci sono le canne di vetro, che crescono spontanee, ma poi vengono travasate nei vasi per abbellire la casa (BLI).

Notas Cresce spontanea pero viene poi coltivata o travasata nei vasi delle case per abbellire. Venturi (2006) riporta Impatiens balfouri Hooker fil. per Treppio e Impatiens noli-tangere L.

\section{BETULACEAE (incluye CORYLACEAE)}

\section{Alnus glutinosa (L.) Gaertn.}

Nombre vulgar: Ontano (MRI), Ontano nero, Albero dei zoccoli (GGI), Ontano nero (TIV, REN).

Número de informantes: 4 Número de citas: 9.

Número de sectores: 3 Número de categorías: 5 .

Biotipo: Fanerófito.

Tipo corológico: Europeas.

Abundancia: Común.

Ambiente: Bosques y arbustos en las orillas de los ríos y en suelos de turba asfixiados.

Número de exsiccata: 39111 FIAF.

Sector agropastoral

Categoría de uso: Herramientas y objetos agrícolas.

Número de informantes: 1 Partes utilizadas: tallos leñosos/ramas/ramitas/vástagos.

Si usa per fare i catini delle macine, perché è resistente all'acqua (MRI).

Categoría de uso: Horticultura.

Número de informantes: 1 Partes utilizadas: tallos leñosos/ramas/ramitas/vástagos.

Contro le farfalle ai cavoli, mettere dei rami di ontano nero accanto ai cavoli, piantati in terra e dritti, poi facevano la forma a ombrello naturalmente nella parte superiore (GGI).

Sector artesanal

Categoría de uso: Instrumentos y utensilios para la artesanía.

Número de informantes: 1 Partes utilizadas: tallos leñosos/ramas/ramitas/vástagos.

Facevano I rocchetti per arrotolare I fili, perché è un legno resistente, leggero, non si spacca. (REN).

Categoría de uso: Objetos personales y calzado. 
Número de informantes: 3 Partes utilizadas: tallos leñosos/ramas/ramitas/vástagos.

Zoccoli dei carbonai:Facevano gli zoccoli di ontano nero perché è resistente e leggero. (REN)| Zoccoli (TIV)| Gli zoccoli dei carbonai erano fatti di legno di ontano nero perché è resistente e leggero (GGI).

Sector doméstico

Categoría de uso: Integración de la renta familiar.

Número de informantes: 1 Partes utilizadas: tallos leñosos/ramas/ramitas/vástagos,.

si vendeva la legna di ontano a una azienda di Lucca, per Il tannino (MRI) $\mid$ La legna era sempre una risorsa, si scambiava la legna con i Ramazzotti per vino, spesa di alimentari (MRI)| Le legna era sempre una risorsa, come moneta di scambio, per vino e la spesa che non si produceva in casa. L'ontano, il carpine e la roverella erano buoni perché rimettevano velocemente, la quercia e il pioppo non rimettono invece. (MRI).

Notas caratteristiche del legno: è resistente all'acqua, le fibre inmerse nell'acqua non si spaccano, resistente all'umidità, non marcisce. Cresce veloce. Anche la quercia ha le stesse proprietà, non marcisce, però ricresce lentamente. Proprietà del legno: resistente, leggero.

DATOS ETNOBOTÁNICOS BIBLIOGRÁFICOS

Nombre vulgar: untan (UNGA21), anidã (GUC98).

Número de referencias: 2 Número de citas: 2.

Número de sectores: 1 Número de categorías: 2.

Sector artesanal

Categoría de uso: Objetos agrícolas.

Número de referencias: 1 Partes utilizadas: madera.

da legno per lavori che debbono restare sott'acqua. (UNGA21).

Categoría de uso: Objetos personales y calzado.

Número de referencias: 1 Partes utilizadas: madera.

La pianta si usava per fare I zoccoli (GUC98).

\section{Carpinus betulus $L$.}

Nombre vulgar: Carpine (SOT).

Número de informantes: 1 Número de citas: 1.

Número de sectores: 1 Número de categorías: 1 .

Biotipo: Fanerófito.

Tipo corológico: Europeas.

Abundancia: Común.

Ambiente: Bosques mesófilos.

Sector doméstico

Categoría de uso: Chimenea y horno.

Número de informantes: 1 Partes utilizadas: madera.

Buon legno per ardere (SOT). 


\section{DATOS ETNOBOTÁNICOS BIBLIOGRÁFICOS}

Nombre vulgar: carpini (MUCC01), cœrpen (UNGA21).

Número de referencias: 2 Número de citas: 2 .

Número de sectores: 1 Número de categorías: 1.

Sector doméstico

Categoría de uso: Otro doméstico.

Número de referencias: 1 Partes utilizadas: hojas.

Verso la fine d'Agosto s'andava a foglie. Bisognava sceglie le piante bone: se si prende la foglia de'carpini, ce ne vole di più per coprire il testo perché son lunghe e strette, meglio son quelle pastinesi, belle larghe. La sera nelle case si vegliava, si faceva delle tavolate di donne, ragazze e giovanotti pe'spiccollare. S'ammucchiava i vencigli (rametti spogliati delle foglie) e colle foglie si faceva i mazzi e poi s'infilavano con dell'aghi apposta e si faceva la filza. Queste foglie poi andavano seccate e si serbavano. Per fare i necci si metteva i testi al foco e quand'eran caldi, si tuffava le foglie un menusto nell'acqua bolletne e ci si copriva il testo. Sopra ci si metteva la pasta de'necci, un altro strato di foglie, un altro testo, e quelli di fondo eran bell'è cotti. (MUCC01).

\section{Corylus avellana $L$.}

Nombre vulgar: Nocciola culora (NLA), Nocciole (TUL, NRO, BGI), Nocciolo (GGI, GFR, GFO), Colloie, Nocciole (VMU).

Número de informantes: 8 Número de citas: 8 .

Número de sectores: 3 Número de categorías: 5 .

Biotipo: Fanerófito.

Tipo corológico: Europeas.

Abundancia: Común.

Ambiente: En el sotobosque de bosques caducifolios y coníferas.

Sector alimentario

Categoría de uso: Aromatizante.

Número de informantes: 1 Partes utilizadas: semillas.

Per insaporire i formaggi:Noce, mandorla e nocciole "cullora" (il frutto era tondo e piccolo) secche e macinate venivano messi sopra il latte cagliato in una tazza, e il tutto si metteva dentro alle cisterne d' acqua piovana per un po'. (NLA).

Categoría de uso: Dulces y golosinas.

Número de informantes: 1 Partes utilizadas: semillas.

Caramellate, con lo zucchero scaldato sopra le nocciole essicate al sole. Seccate al sole, sgusciate e pulite, venivano conservate sotto miele, per poi fare dolci come il Castagnaccio (BGI).

Categoría de uso: Fruta seca.

Número de informantes: 2 Partes utilizadas: semillas.

Mettere a seccare al sole a Settembre (NRO)| Raccolte a Ottobre, si mettono ad essicare al sole, per l'inverno. (TUL). 


\section{Sector mágico/ritual/supersticioso}

Categoría de uso: Protector.

Número de informantes: 3 Partes utilizadas: tallos leñosos/ramas/ramitas/vástagos.

Si facevano delle crocette nei campi per liberarli dai tuoni, dai lampi e proteggere la raccolta. Le crocette erano fatte con i pezzettini di legno che saltavano fuori dai polloni di salvano o nocciolo che si sbattevano il Giovedi Santo pomeriggio (il Mattutino) per 3-5 ore sui lastroni della chiesta, sul pavimento dell'altare oppure fuori della chiesa. I pezzettini di legno che saltavano fuori si raccoglievano e il 3 Maggio (Santa Croce) si portavano in tutti i campi per fare le crocette e ci si attaccava sopra anche l'ulivo benedetto. (GGI, GFO)| Le Crocette dei campi dove si attaccavano i rami di olivo benedetto erano fatte con i pezzettino di legno che saltavano fuori dai polloni di salvano o nocciolo che si sbattevano il Giovedi Santo pomeriggio (il Mattutino) per 3-5 ore sui lastroni della chiesa, sul pavimento dell'altare oppure fuori della chiesa. I pezzettini di legno che saltavano fuori si raccoglievano e il 3 Maggio (Santa Croce) si portavano in tutti i campi per fare le crocette e attaccarci anche l'ulivo benedetto. (GFR).

\section{Sector medicinal}

Categoría de uso: Estado general.

Número de informantes: 1 Partes utilizadas: semillas.

Mettere a seccare all'ombra tutti I "semi della vita": semi delle ciliege, delle susine ossia le prugne gialle, di zucca, I pinoli, le noci, le culloie o nocciole, le foglie di malva secche, il fiore del gigliopapagone e anche un pò di olio di semi di lino. Poi macinare tutto con il macinino da caffé. E prendere un cucchiaio tutte le mattine a primavera e a ottobre. (VMU).

Notas La cullora è la nocciola tonda e piccola.

\section{DATOS ETNOBOTÁNICOS BIBLIOGRÁFICOS}

Nombre vulgar: nocciole (GRIZ03), nocciolo (SANS14), clûr (UNGA21), culo'ra (BENE96, APPO10), nioccióla (BONZI00).

Número de referencias: 6 Número de citas: 8 .

Número de sectores: 1 Número de categorías: 3 .

\section{Sector alimentario}

Categoría de uso: Dulces y golosinas.

Número de referencias: 1 Partes utilizadas: frutos/infrutescencias/falsos frutos.

Croccante di nocciole: nocciole, zucchero. Tostare in forno le nocciole, con le mani fate saltare via la pellicola abbrustolita, mettere in una casseruola lo zucchero e fatelo fondere a dolce calore, mescolando di quando in quando senza aggiunte di acqua. Quando sarà completamente fuso aggiungere le nocciole, mescolare bene in modo da fare una massa unica che si travasa sul marmo e si lascia raffreddare. Tagliare poi a pezzi non troppo piccoli. (GRIZ03)| Torta di nocciole: $300 \mathrm{~g}$ di faina, $150 \mathrm{~g}$ di burro, $200 \mathrm{~g}$ di zucchero, $200 \mathrm{~g}$ di nocciole tostate e tritate, 3 uova, mezzo bicchiere di latte, una bustina di vanillina, una bustina di lievito. Per decorare, $150 \mathrm{~g}$ di burro, $300 \mathrm{~g}$ di zucchero a velo, $100 \mathrm{~g}$ di nocciole tritate, 3 nocciole intere, 3 ciliegie candite verdi, una tazzina di caffé amaro. Per 1'impasto, lavorare a spuma il 
burro con lo zucchero, aggiungete i tuorli, il latte, la vanillina, la farina, il lievito (GRIZ03).

Categoría de uso: Fruta fresca.

Número de referencias: 2 Partes utilizadas: frutos/infrutescencias/falsos frutos (SANS14).

Albero di bosco o di siepe che da frutto detto clûra, nocciuola, avellana (UNGA21).

Categoría de uso: Pasta y "gnocchi".

Número de referencias: 1 Partes utilizadas: frutos/infrutescencias/falsos frutos.

Salsa di nocciole: 2 cucchiai di olio, $100 \mathrm{~g}$ di nocciole, 1 spicchio di aglio, 1 acciuga, parmigiano. Schiacciate lo spicchio di aglio e fatelo soffriggere con l'olio, quando ha preso colore togliete lo spicchio e aggiungete l'acciuga pulita e tagliata a pezzetti. Aiutandovi con una forchetta fatela sciogliere, a parte grattugiate le nocciole e il parmigiano e mescolateli insieme mettendoli direttamente nella zuppiera. Scolate la pasta e conditeli con l'olio caldissimo nella zuppiera. (GRIZ03).

\section{Ostrya carpinifolia Scop.}

Nombre vulgar: Carpine (MRI, SLU, GGI, MIO), Carpine Nero (TUL, CLO), Carpine nero.

(MGO).

Número de informantes: 7 Número de citas: 8.

Número de sectores: 3 Número de categorías: 7.

Biotipo: Fanerófito.

Tipo corológico: Nórdicas.

Abundancia: Bastante Común.

Ambiente: Arbustos y bosques de monte bajo.

Sector agropastoral

Categoría de uso: Alimentación animal (incluidos los forrajeros).

Número de informantes: 1 Partes utilizadas: hojas.

Di autunno, prima che caschino le foglie dell'albero, facevano delle fascine di rami di oppio, querciole e carpine, per attaccarli d'inverno nella stalla dove stavano le pecore, così loro mangiavano le foglie d'inverno.' (MIO).

Categoría de uso: Herramientas y objetos agrícolas.

Número de informantes: 1 Partes utilizadas: tallos leñosos/ramas/ramitas/vástagos.

Per fare il manico del mazzo, perché è piu resistente e robusto (CLO).

Categoría de uso: Otro agropastoral.

Número de informantes: 1 Partes utilizadas: tallos leñosos/ramas/ramitas/vástagos.

Il carpine nero è ottimo per ardere, per fare il carbone (TUL).

Sector alimentario

Categoría de uso: Golosinas y masticatorias.

Número de informantes: 1 Partes utilizadas: tallos leñosos/ramas/ramitas/vástagos. 
Quando si va a funghi, o si cammina a lungo per I boschi, mettere un pezzettino di legno in bocca. (GGI).

Sector doméstico

Categoría de uso: Chimenea y horno.

Número de informantes: 2 Partes utilizadas: madera.

Quando era sotto $0^{\circ} \mathrm{C}$, brusciavano carpine (chi aveva una macchia di carpine), è la principale specie arborea. (CLO)| Uno dei migliori legni da ardere. (MGO).

Categoría de uso: Detergente.

Número de informantes: 1 Partes utilizadas: tallos leñosos/ramas/ramitas/vástagos.

Fa una cenere ottima per fare il bucato. (SLU).

Categoría de uso: Integración de la renta familiar.

Número de informantes: 1 Partes utilizadas: madera.

Una volta si andava a vendere gli scarti, di quercia e di carpine a Ponte alla Venturina. Erano lavori invernali. (MRI).

Notas "l' uomo senza ingenio, dal culo piglia il legno", Si possono usare anche legni di altri.

alberi, basta chenon siano amari.

\section{DATOS ETNOBOTÁNICOS BIBLIOGRÁFICOS}

Nombre vulgar: carpini (MUCC01).

Número de referencias: 1 Número de citas: 1.

Número de sectores: 1 Número de categorías: 1 .

Biotipo: Fanerófito.

Tipo corológico: Nórdicas.

Abundancia: Bastante Común.

Ambiente: Arbustos y bosques de monte bajo.

Sector doméstico

Categoría de uso: Otro doméstico.

Número de referencias: 1 Partes utilizadas: hojas.

Verso la fine d'Agosto s'andava a foglie. Bisognava sceglie le piante bone: se si prende la foglia de'carpini, ce ne vole di più per coprire il testo perché son lunghe e strette, meglio son quelle pastinesi, belle larghe. La sera nelle case si vegliava, si faceva delle tavolate di donne, ragazze e giovanotti pe'spiccollare. S'ammucchiava i vencigli (rametti spogliati delle foglie) e colle foglie si faceva i mazzi e poi s'infilavano con dell'aghi apposta e si faceva la filza. Queste foglie poi andavano seccate e si serbavano. Per fare i necci si metteva i testi al foco e quand'eran caldi, si tuffava le foglie un menusto nell'acqua bolletne e ci si copriva il testo. Sopra ci si metteva la pasta de'necci, un altro strato di foglie, un altro testo, e quelli di fondo eran bell'è cotti (MUCC01). 


\section{BORAGINACEAE}

\section{Borago officinalis $L$.}

Nombre vulgar: Borragine (BLI, PCL, FAM, CVA, BFE), Radicchi, Borrana (UMI, TOA).

Número de informantes: 7 Número de citas: 10.

Número de sectores: 2 Número de categorías: 4.

Biotipo: Terófito.

Tipo corológico: Eurimediterránea.

Abundancia: Común.

Ambiente: Baldíos, ruinas.

Sector alimentario

Categoría de uso: Fritura.

Número de informantes: 6 Partes utilizadas: hojas, flores/inflorescencias y sus partes.

Le foglie bagnati nella pastella e fritte. (BFE)| Fiori imbevuti nella pastella e fritti (CVA)| Fiori bagnati nella pastella e fritti (FAM)| Foglie bagnate nella pastella e fritte (PCL) $\mid$ Foglie bagnate nella pastella e fritte. (UMI, TOA).

Categoría de uso: Tortilla.

Número de informantes: 1 Partes utilizadas: hojas.

Foglie sbollentate o saltate in padella e messe nella frittata (PCL).

Categoría de uso: Verdura cocida.

Número de informantes: 2 Partes utilizadas: hojas.

Foglie lesse insieme ai altri radicchi. (UMI, TOA).

Sector medicinal

Categoría de uso: Afecciones del aparato respiratorio.

Número de informantes: 1 Partes utilizadas: hojas.

"Si raccoglievano le foglie e si mettevano ad essicare" (BLI).

DATOS ETNOBOTÁNICOS BIBLIOGRÁFICOS

Nombre vulgar: borragine (SANS14), burâzen (UNGA21), borana (BONZI00), borràgine.

(GUC98).

Número de referencias: 4 Número de citas: 8 .

Número de sectores: 3 Número de categorías: 5 .

Sector alimentario

Categoría de uso: Empanadas.

Número de referencias: 1 Partes utilizadas: hojas (SANS14).

Categoría de uso: Ensalada.

Número de referencias: 1 Partes utilizadas: hojas (SANS14).

Categoría de uso: Fritura.

Número de referencias: 2 Partes utilizadas: hojas (SANS14)|.

P. com. Le cui foglie si usano come commestibile ed hanno proprietà emolliente e rinfrescante, off. Ant. Si adoperava la rad. Di questa pianta, bollita contro la febbre 


\section{María Teresa Egea Molines}

terzana: e si credeva che il succo di essa fosse rimedio per rendere feconde le donne. Oggi le massaie ne raccolgono le foglie per farne frittura. (UNGA21).

Sector mágico/medicinal

Categoría de uso: Otro mágico/medicinal.

Número de referencias: 1 Partes utilizadas: parte aérea (toda).

p. com. Le cui foglie si usano come commestibile ed hanno proprietà emolliente e rinfrescante, off. Ant. Si adoperava la rad. Di questa pianta, bollita contro la febbre terzana: e si credeva che il succo di essa fosse rimedio per rendere feconde le donne. Oggi le massaie ne raccolgono le foglie per farne frittura. (UNGA21).

Sector medicinal

Categoría de uso: Estado general.

Número de referencias: 1 Partes utilizadas: parte aérea (toda).

p. com. Le cui foglie si usano come commestibile ed hanno proprietà emolliente e rinfrescante, off. Ant. Si adoperava la rad. Di questa pianta, bollita contro la febbre terzana: e si credeva che il succo di essa fosse rimedio per rendere feconde le donne.

\section{Myosotis arvensis (L.) Hill.}

Nombre vulgar: Nontiscordardime (NST).

Número de informantes: 1 Número de citas: 1.

Número de sectores: 1 Número de categorías: 1.

Biotipo: Terófito.

Tipo corológico: Europeas.

Abundancia: Común.

Ambiente: Baldíos, pastos áridos, cultivos.

Sector doméstico

Categoría de uso: Ornamental.

Número de informantes: 1 Partes utilizadas: flores/inflorescencias y sus partes. I fiori si raccoglievano e si mettevano in casa in un vaso come ornamentale. (NST).

\section{Pulmonaria officinalis $L$. (s. l.)}

Nombre vulgar: Polmonaria (NRE, FAM), senza nome (VMA), Cucchi (GLA), Scarpine della. madonna (BSO).

Número de informantes: 5 Número de citas: 6 .

Número de sectores: 4 Número de categorías: 6 .

Biotipo: Hemicriptófito.

Tipo corológico: n.d.

Abundancia: Rara.

Ambiente: Bosques latifolios (robledales, abedules, hayedos) sobre suelo rico y humificado.

Número de exsiccata: 38948 FIAF. 


\section{Sector alimentario}

Categoría de uso: Fritura.

Número de informantes: 1 Partes utilizadas: flores/inflorescencias y sus partes.

Fiori fritti (FAM).

Categoría de uso: Golosinas y masticatorias.

Número de informantes: 1 Partes utilizadas: flores/inflorescencias y sus partes.

Quando eravamo bambini si ciucavano I fiori quando si era in giro, anche un pò per gioco.

(VMA).

Categoría de uso: Verdura cruda.

Número de informantes: 1 Partes utilizadas: brotes.

Raccogliere I germogli prima della fioritura (fa un fiore viola), e mangiare a pinzimonio, con olio, sale e pepe. (GLA).

\section{Sector doméstico}

Categoría de uso: Ornamental.

Número de informantes: 1 Partes utilizadas: planta entera/viva.

Raccoglie le piante dal bosco e le pianta davanti a casa per bellezza. (BSO).

Sector lúdico/voluptuoso

Categoría de uso: Alimentos/juguetes.

Número de informantes: 1 Partes utilizadas: flores/inflorescencias y sus partes.

Quando eravamo bambini si ciucavano I fiori quando si era in giro, anche un pò per gioco (VMA).

\section{Sector medicinal}

Categoría de uso: Afecciones del aparato respiratorio.

Número de informantes: 1 Partes utilizadas: parte aérea (toda).

Fare il 'fiasco' pieno del decotto di foglie e fiori di polmonaria, foglie di farfanella, foglie di malva, di cimballaria, di piscialletto e di foglie di erba ruggine. (NRE).

Notas è chiamato cucchi, perché viene fiori quando viene il cucco.

DATOS ETNOBOTÁNICOS BIBLIOGRÁFICOS

Nombre vulgar: polmonaria (MANG98), pulmonaeria (UNGA21).

Número de referencias: 2 Número de citas: 3 .

Número de sectores: 1 Número de categorías: 3 .

\section{Sector medicinal}

Categoría de uso: Afecciones del aparato respiratorio.

Número de referencias: 1 Partes utilizadas: hojas.

Il decotto viene bevuto in caso di tosse, di calcolosi ed altre affezioni epatiche, a rafforzare la terapia a livello bronchiale, si applicano sulla shiena delle foglie riscaldate. (MANG98).

Categoría de uso: Estado general.

Número de referencias: 1 Partes utilizadas: hojas.

Nella medicina popolare in decotto delle sue foglie come emolliente (UNGA21).

Categoría de uso: Patologías del aparato digestivo.

Número de referencias: 1 Partes utilizadas: hojas. 
Il decotto viene bevuto in caso di tosse, di calcolosi ed altre affezioni epatiche, a rafforzare la terapia a livello bronchiale, si applicano sulla shiena delle foglie riscaldate. (MANG98).

\section{BRASSICACEAE (= CRUCIFERAE)}

\section{Brassica nigra (L.) K.Koch.}

Nombre vulgar: Senape (UMI, BFE, BAN).

Número de informantes: 3 Número de citas: 3.

Número de sectores: 1 Número de categorías: 1 .

Biotipo: Terófito.

Tipo corológico: Eurimediterránea.

Abundancia: Rara.

Ambiente: Campos de cereales, baldíos, eras.

Sector medicinal

Categoría de uso: Afecciones del aparato respiratorio.

Número de informantes: 3 Partes utilizadas: harina/salvado.

Fare una pappina/crema, asciutta ma calda di farina di lino e di senape, mettere dentro una garza e fare l'impiastro sul petto, sui bronchi. (BAN)| Per mantenere il calore dell'impiastro di lino sul petto, aggiungere all'impiastro farina di senape comprata. (BFE) $\mid$ Seme macinato di senape, comprato in Farmacia. Impiastro fatto della farina di senape cotta in acqua, messo in dentro un "cencio" sul petto (UMI).

Notas farina comprata in farmacia.

\section{Brassica oleracea L. var. acephala DC.}

Nombre vulgar: Cavolo nero (LGI, BOR).

Número de informantes: 2 Número de citas: 2.

Número de sectores: 1 Número de categorías: 1.

Biotipo: Caméfito.

Tipo corológico: Cultivadas.

Abundancia: Cultivada.

Ambiente: Cultivada en los huertos.

Sector alimentario

Categoría de uso: Sopas de verduras y potaje.

Número de informantes: 2 Partes utilizadas: hojas, semillas.

Si faceva la zuppa con il cavolo nero che si piantava nell'orto (BOR)| La zuppa di pane è fatto soffriggendo l'aglio, aggiungere il pomodoro, l'acqua, I faggioli, il cavolo nero, una patata, un pezzo di prosciutto, tanto olio, e fare bollire 2 ore, poi versare sopra un fetta di pane e olio. (LGI).

DATOS ETNOBOTÁNICOS BIBLIOGRÁFICOS

Nombre vulgar: cavolo nero (MANG98).

Número de referencias: 1 Número de citas: 2 . 
Número de sectores: 1 Número de categorías: 2.

Sector medicinal

Categoría de uso: Afecciones cutáneas y tejidos subcutáneos.

Número de referencias: 1 Partes utilizadas: hojas.

Foglie fresche contuse vengono applicate sopra i foruncoli (MANG98).

Categoría de uso: Trastornos musculo-esqueléticos.

Número de referencias: 1 Partes utilizadas: hojas.

Foglie fresche contuse vengono applicate su arti affetti da reumatismi (MANG98).

\section{Brassica oleracea $L$. var. botrytis $L$.}

Nombre vulgar: Cavolfiore (MIO).

Número de informantes: 1 Número de citas: 1.

Número de sectores: 1 Número de categorías: 1 .

Biotipo: Caméfito.

Tipo corológico: Cultivadas.

Abundancia: Cultivada.

Ambiente: Cultivada en los huertos.

Sector alimentario

Categoría de uso: Encurtidos y conserva en aceite.

Número de informantes: 1 Partes utilizadas: flores/inflorescencias y sus partes.

Cavolfiore scottato in metà acqua metà aceto, poi farlo asciugare e mettere sotto olio o sotto.

aceto (MIO).

\section{Brassica oleracea L. var. capitata $L$.}

Nombre vulgar: Cavolo (BLI, BIO, NLA, DAD).

Número de informantes: 4 Número de citas: 4.

Número de sectores: 2 Número de categorías: 4.

Biotipo: Caméfito.

Tipo corológico: Cultivadas.

Abundancia: Cultivada.

Ambiente: Cultivada en los huertos.

Sector alimentario

Categoría de uso: Arroces y "risotto".

Número de informantes: 1 Partes utilizadas: hojas.

"Riso in cagnò", per l' inverno, riso con cavolo (DAD).

Categoría de uso: Ensalada.

Número de informantes: 1 Partes utilizadas: hojas.

Cruda insieme ad altre insalate (NLA).

Categoría de uso: Sopas de verduras y potaje.

Número de informantes: 1 Partes utilizadas: hojas.

La minestra di pane Toscana si fa con il cavolo, faggioli, zuccheti, carota, cavolo verza e un pò di pepolino $(\mathrm{BIO})$. 
Sector medicinal

Categoría de uso: Trastornos musculo-esqueléticos.

Número de informantes: 1 Partes utilizadas: hojas.

Fare un 'impacco' di foglie di cavolo sulla zona infiammata (BLI).

DATOS ETNOBOTÁNICOS BIBLIOGRÁFICOS

Nombre vulgar: capozz, côl (UNGA21), còlo (BENE96, APPO10).

Número de referencias: 3 Número de citas: 3 .

Número de sectores: 1 Número de categorías: 1.

Sector alimentario

Categoría de uso: Arroces y "risotto".

Número de referencias: 1 Partes utilizadas: hojas.

Usato dalle nostre massaie come col: "rif cum I col: riso co' cavoli" (UNGA21).

\section{Brassica oleracea var. sabauda $L$.}

Nombre vulgar: Cavolo verza (BIO).

Número de informantes: 1 Número de citas: 1.

Número de sectores: 1 Número de categorías: 1.

Biotipo: Caméfito.

Tipo corológico: Cultivadas.

Abundancia: Cultivada.

Ambiente: Cultivada en los huertos.

Sector alimentario

Categoría de uso: Sopas de verduras y potaje.

Número de informantes: 1 Partes utilizadas: hojas.

La minestra di pane Toscana si fa con il cavolo, faggioli, zuccheti, carota, cavolo verza e un.

pò di pepolino $(\mathrm{BIO})$.

\section{Brassica rapa $L$.}

Nombre vulgar: Rapa (TOA, NLA, SOT, DAD), Rapa selvatica (GGI), Rape spontanee (RFR).

Número de informantes: 6 Número de citas: 11.

Número de sectores: 2 Número de categorías: 5.

Biotipo: Terófito.

Tipo corológico: Eurimediterránea.

Abundancia: Común.

Ambiente: Cultivada y asilvestrada.

Sector agropastoral

Categoría de uso: Alimentación animal (incluidos los forrajeros).

Número de informantes: 1 Partes utilizadas: hojas.

Tagliata a pezzetti, per le pecore (DAD). 


\section{Sector alimentario}

Categoría de uso: Relleno de ravioli.

Número de informantes: 1 Partes utilizadas: órganos subterráneos.

Cotti insieme a bietole, patate, o qualsiasi altra verdura per il ripieno dei ravioli.

(DAD) $\mid$ Cotti, passati, tagliati con la mezzaluna. (DAD).

Categoría de uso: Sopas de verduras y potaje.

Número de informantes: 2 Partes utilizadas: órganos subterráneos.

Cotti in minestre o zuppe (DAD)| Zuppa con il bulbo e le foglie di rapa (SOT).

Categoría de uso: Tortilla.

Número de informantes: 1 Partes utilizadas: hojas.

Sbollentate e messe nella frittata (SOT).

Categoría de uso: Verdura cocida.

Número de informantes: 5 Partes utilizadas: hojas, órganos subterráneos.

La radice cotta e condita si mangiava tutto l'inverno, si andava nell' orto levavi un po di neve nell' orto e la raccoglievi. Le foglie si mangiano come verdura cotta in un tegamino con un uovo o verdura saltata in padella (NLA)| Foglie di rapa nel tegame con carne di maiale (SOT)| Saltare le cime di rapa insieme all'aglio, e aggiungere le costoline di maiale. (TOA)| Saltare le cime di rapa, e aggiungere le costoline di maiale. (GGI)| Quando levavano il grano, raccoglievano le rape che crescevano spontanee nel campo e si cucinavano le radici e le foglie come verdura cotta, oppure con la carne di maiale nel tegame. (RFR).

Notas Coltivati anche sotto la neve nell'orto familiare, Il maiale deve essere ammazzato nella stagione fredda, "bisogna che abbiano sentito il gelo", perché con il caldo, il sale non prende, per fare prosciutti., Quando levavano il grano, raccoglievano le rape che crescono spontanee nel campo.

\section{Capsella bursa-pastoris (L.) Medik.}

Nombre vulgar: Radicchi, Borsa del Pastore (PCL).

Número de informantes: 1 Número de citas: 2.

Número de sectores: 1 Número de categorías: 2 .

Biotipo: Hemicriptófito.

Tipo corológico: Amplia distribución.

Abundancia: Bastante Común.

Ambiente: Baldíos.

Sector alimentario

Categoría de uso: Ensalada.

Número de informantes: 1 Partes utilizadas: hojas.

Quando le foglie sono giovani e tenere si mangiano crude in insalata e condite (PCL).

Categoría de uso: Verdura cocida.

Número de informantes: 1 Partes utilizadas: hojas.

Quando le foglie sono grandi si mangiano cotte come verdura (PCL). 


\section{DATOS ETNOBOTÁNICOS BIBLIOGRÁFICOS}

Nombre vulgar: borsa del pastore (SANS14), bursa da pastaur, erba borsacchina (UNGA21).

Número de referencias: 2 Número de citas: 2.

Número de sectores: 2 Número de categorías: 2.

\section{Sector alimentario}

Categoría de uso: Ensalada.

Número de referencias: 1 Partes utilizadas: hojas (SANS14).

Sector medicinal

Categoría de uso: Patologías del aparato circulatorio.

Número de referencias: 1 Partes utilizadas: hojas.

com. Nel bol., nota nella med. Ant. E richiamata di nuovo in uso per la sua proprietà contro l'emorragia passiva e la metrorragia. La med. Pop. L'adop. In decoz. Delle sue foglie come astringente ed emmenagoga. (UNGA21).

\section{Diplotaxis tenuifolia (L.) DC.}

Nombre vulgar: Rucola (SCO, RGI), Rucola selvatica (GGI).

Número de informantes: 3 Número de citas: 4.

Número de sectores: 1 Número de categorías: 2.

Biotipo: Hemicriptófito.

Tipo corológico: Atlánticas.

Abundancia: Bastante Común.

Ambiente: Ruinas, baldíos áridos, arenosos.

Número de exsiccata: 38990 FIAF.

\section{Sector alimentario}

Categoría de uso: Ensalada.

Número de informantes: 3 Partes utilizadas: hojas.

Le foglie di rucola si mangiano in insalata con altre piante. (RGI)| Foglie crude in insalata (SCO) $\mid$ Cruda con altre insalate e condita con olio e sale (GGI).

Categoría de uso: Verdura cocida.

Número de informantes: 1 Partes utilizadas: hojas.

Foglie cotte insieme ad altre piante selvatiche (con cicerbite, cicorie, radicchio) (SCO).

Notas Manca in Venturi (2006)e in PTP (2008).

DATOS ETNOBOTÁNICOS BIBLIOGRÁFICOS

Nombre vulgar: rucola selvatica (SANS14).

Número de referencias: 1 Número de citas: 1 .

Número de sectores: 1 Número de categorías: 1.

Sector alimentario

Categoría de uso: Ensalada.

Número de referencias: 1 Partes utilizadas: hojas (SANS14). 


\section{Lunaria annua $L$.}

Nombre vulgar: Gli occhiali del papa (BEL), Medaglione del papa (TSI, FAM), Medaglioni del papa (BFE), Monete del papa (GZE).

Número de informantes: 5 Número de citas: 5.

Número de sectores: 1 Número de categorías: 1.

Biotipo: Hemicriptófito.

Tipo corológico: Europeas.

Abundancia: Rara.

Ambiente: Barrancos, acantilados húmedos y sombreados, en la llanura mediterránea 0 .

submediterránea.

Sector doméstico

Categoría de uso: Ornamental.

Número de informantes: 5 Partes utilizadas: parte aérea (toda),.

Per decorare la casa, si mettono in un vaso gli steli con i frutti sbuucciati. (BEL)| Seccare I rami del Medaglione del papa con I semi e metterli in un vaso in casa come ornamento. (FAM)| In un vaso dentro casa (TSI)| Seccare I rami di Medaglioni del papa con I semi e metterli in un vaso in casa come ornamento. (BFE)| Come ornamento davanti alla casa. (GZE).

Notas Non sa chi è chi le mangia, forse l'istrice, le ha finite lui.

\section{BUXACEAE}

\section{Buxus sempervirens $L$.}

Nombre vulgar: Bussolo (AMA, MDA, BPA, SOT, UMI, TUL, TGA, RMA, NLA, MME, MGE, GZE, GRI, GLA, DAD, BMA, BLI, TIV, BPT, MGO, GFO, GFR, CFR, VMR, TRU, REN, NRO, GGI), Bosso (FAM, PEL, TGO, MRI, GUF), Bussol (VMA).

Número de informantes: 34 Número de citas: 62 .

Número de sectores: 8 Número de categorías: 17.

Biotipo: Nanofanerófito.

Tipo corológico: Eurimediterránea.

Abundancia: Común.

Ambiente: Bosques caducifolios termófilos, acantilados, pedregales.

Número de exsiccata: 38921 FIAF.

Sector agropastoral

Categoría de uso: Herramientas y objetos agrícolas.

Número de informantes: 5 Partes utilizadas: tallos leñosos/ramas/ramitas/vástagos,.

Si usava il bussolo per fare I denti dei rastrelli per rastrellare il fieno nei campi (GGI)| Si usava il bussolo per fare i denti dei rastrelli (TRU, REN, NRO)| Si facevano le mazze per spaccare con il cuneo. (VMR). 
Categoría de uso: Vallas y delimitaciones.

Número de informantes: 7 Partes utilizadas: planta entera/viva.

Un fila di bosso fa da siepe (GUF)| La siepe di bosso serve per difendere le case dalla tramontana $(\mathrm{MRI}) \mid \mathrm{Si}$ piantava il bussolo per fare le siepi, per delimitare terreni. (GGI, TGO)| Siepe e recinto vivo per orti (CFR)| Piantare varie piante in forma di siepe (GFR)| Si usavano come confine delle case (VMR).

Sector alimentario

Categoría de uso: Golosinas y masticatorias.

Número de informantes: 1 Partes utilizadas: tallos leñosos/ramas/ramitas/vástagos.

Nelle passegiate, si tiene un ramettino di bussolo, di sapore amaro, in bocca. ("Per vizio)..

(GFO).

\section{Sector artesanal}

Categoría de uso: Instrumentos y utensilios para la artesanía.

Número de informantes: 3 Partes utilizadas: madera, tallos.

La segatura di bosso si usa per pulire l'oro. (MRI)| Si facevano I chiodi di bussolo per inchiodare materiali in legno (GGI)| Chiodi di legno di bussolo:Sono chiodi grossi, per fare le tavole, perché non cresce con l'umidità. Anche martelli di legno di bussolo per lavorare le statue di marmo. (MGO).

Categoría de uso: Muebles.

Número de informantes: 1 Partes utilizadas: madera.

Si usava il bussolo per fare gli intarsi dei mobili, una striscia più chiara, per decorarli (VMR).

Categoría de uso: Objetos domésticos.

Número de informantes: 6 Partes utilizadas: tallos leñosos/ramas/ramitas/vástagos.

Il legno è usato per fare i manici dei coltelli. (MRI)| Il legno si usa per fare il manico dei coltelli perché è duro e compatto. (PEL)| Oggetti domestici: forchette, tulipani ornamentali: è il legno piu duro che c'è. (BPT)| Per fare figurine, funghi di legno (MGO)| Manici di coltelli, pomelli delle tavole. (TIV)| Si usava il bussolo per fare I manici dei coltelli.

Categoría de uso: Otro artesanal.

Número de informantes: 1 Partes utilizadas: tallos leñosos/ramas/ramitas/vástagos.

Strumenti musicali: flauti,etc. (TIV).

\section{Sector doméstico}

Categoría de uso: Chimenea y horno.

Número de informantes: 21 Partes utilizadas: planta entera/viva, tallos.

Con un gran mazzo di bosso e di prugnolo, tirare su e giù nella canna fumaria (TGO)| Per misurare la temperatura giusta del forno, si introduceva un rametto di bussol, se prendeva fuoco voleva dire che era troppo caldo, se invece schiopettava, allora andava bene. (VMA)| Per fare il pane, e controllare che il forna abbia la temperatura giusta, mettere un mazzo di bussolo dentro. (BLI)| Per controllare la 
temperatura del forno per infornare il pane, si mette dentro un ramo di bussolo: se prende fuoco, è troppo caldo, bisogna aspettare. (BMA)| Per fare il pane correttamente, quando si accende il forno, e questo è troppo caldo, mettere un ramo che faccia una fiammata, e poi si ritira tutto, per evitare che si brusci il pane (DAD)| Per spazzare il forno con un mazzetto. (GFR)| Si usava per 'levare la bronza al forno' : quando si scaldava il forno per fare il pane, di faceva una grande fiamma, e prima di sfornare il pane, per levare il colore di troppo che avrebbe bruciato la corteccia e annerito il pane, si metteva un mazzo di bussolo (che era sempre vicino alle case) che 'levava la bronza'. (GGI)| Per fare il pane, e controllare che il forno abbia la temperatura giusta, mettere un mazzo di bussolo legato a un bastone con forma di spazzola. Spazzare il forno dalle bracce, se I rami di bussolo si bruciava, allora il forno era troppo caldo, bisogna aspettare finché il bussolo diventi nero spazzando il forno. (GLA)| Facevano un fastello di bussoli legato a una corda, uno andava in cima e l'altro rimaneva giù, e tiravano da una parte e dall'altra. Con un fastello di rami legato a un bastone pulivano il forno prima di mettere a cuocere il pane (GRI) Per levare la bronza': per controllare la temperatura del forno per infornare il pane, mettere dentro un ramo di bussolo, se prende fuoco, è troppo caldo, bisogna aspettare. Se non prendecva fuoco, allora 'la bronza era piu debole'. (GZE)| Per preparare la temperatura del forno si usava il bussolo legato a un bastone, si diceva, "si leva la bronza", quando scoppiettava allora era pronto e si poteva infornare il pane. (MGE)| Per regolare la temperatura del forno alegna prima di infornare il pane e evitare di bruciarlo. "Per levare la bronza al pane". Per pulire la canna fumaria si faceva un fascio di bosso legato a una corda, poi si prendeva uno di cima e uno da sotto e si tirava su e giù. (MME)| Per evitare di bruciare il pane cotto a forno a legna:Quando il forno a legna diventa bianco, si leva il fuoco, si mette dentro un ramo di bussolo e si toglie, questo leva il raggi ed evita di bruciare il pane. (NLA) Per controllare la temperatura giusta del forno per infornare I dolci:Per sapere quando il forno è alla temperatura giusta per infornare I dolci, si mette un ramo di bussolo dentro, se diventa nero, allora è ancora troppo caldo, se invece non è tanto nero allora è pronto per infornare I dolci (NRO)| Per evitare di bruciare il pane cotto a forno a legna, e regolare la temperatura del forno: levare il fuoco quando il forno ha raggiunto una certa temperatura, mettere dei rami di bussolo dentro, non deve fiammare, deve schioppetare e poi va tolto. Cosi la "buccia" del pane non si brucia. $(\mathrm{REN}) \mid$ Per controllare la temperatura del forno per infornare il pane, mettere dentro un ramo di bussolo: se prende fuoco, è troppo caldo, bisogna aspettare. (RMA)| Quando il forno è troppo caldo prima di mettere il pane dentro, si metteva a bruciare un mazzo di bussolo (TGA)| Per pulire la canna fumaria, si facevano dei "fastellini" fatti di Agrifoglio e Bussolo e si tirava su e giù nella canna fumaria. (TRU)| Si prendevano I rami intreciati con il pungitopo, uno tirava da sopra la canna fumaria e l'altro da sotto (TUL)| Per controllare la temperatura giusta del forno per infornare il pane, mettere un ramo di bussolo dentro il forno, se fa fiamma vuole dire che è ancora troppo caldo. (UMI)| Si usava per misurare la temperatura del forno, si metteva un ramo di bussolo, se bruciava era troppo caldo, se schiopettava allora era pronto il forno per infornare il pane. (VMR).

Categoría de uso: Integración de la renta familiar. 
Número de informantes: 1 Partes utilizadas: tallos

leñosos/ramas/ramitas/vástagos.

I rami si vendevano a Natale, ai fiorai a Pistoia o Porretta (VMR).

Categoría de uso: Jardín.

Número de informantes: 1 Partes utilizadas: planta entera/viva.

Piantato per la casa, per recinti (SOT).

Categoría de uso: Objetos domésticos y escobas.

Número de informantes: 2 Partes utilizadas: tallos leñosos/ramas/ramitas/vástagos.

Il legno è usato per fare i bastoni per caminare (ver lámina 12). (MRI)| Per fare il manico del coltello di.

cucina (CFR).

Categoría de uso: Repelentes o trampas domésticas.

Número de informantes: 1 Partes utilizadas: tallos leñosos/ramas/ramitas/vástagos.

Antiparassitario nelle panche per la farina: Mettevano a bruciare in una pentola bucata e.

lasciavano il fumo uscire con la panca chiusa. Ogni anno lo facevano prma di mettere la farina nuova. (TGO).

\section{Sector lúdico/voluptuoso}

Categoría de uso: Juego colectivo y bromas.

Número de informantes: 8 Partes utilizadas: tallos leñosos/ramas/ramitas/vástagos,.

Durante la Quaresima, si gioca al "fiore verde", quando uno chiedeva all'altro 'Fiore verde!', l'altro doveva avere in tasca un ramo di bosso, sennò perdeva. A Pasqua, vinceva chi lo chiedeva per primo. (GUF, BPT)| Gioco del "fiore verde": Nella Quaresima, quando si incontrava uno gli si diceva "Io e te facciamo il fiore verde" e l' altro doveva avere in tasca un rametto di bussolo, sennò pagava pegno. (FAM) Gioco del "fiore verde":Sotto Pasqua, quando si incontrava uno gli si diceva "Io e te facciamo il fiore verde" e l' altro doveva avere in tasca un rametto di bussolo, sennò pagava pegno. (CFR, BPA)| Si giocava al "For a al verde" (fuori il verde= fammi vedere): uno glielo diceva all'altro e l'altro doveva fare vedere un ramettino di bussolo, se non ce l'aveva doveva pagare in penitenza fisiche o al bar. (GGI)| Gioco del "fiore verde":Per la Quaresima, si scommetteva al "Fuori il verde", chi non aveva un rametto di bussolo in tasca e non lo tirava fuori, perdeva la scommessa. (UMI)| Si giocava al "Fiore verde": uno glielo diceva all'altro e l'altro doveva dire "31 secco" e mostrare il ramettino di bussolo, se non ce l'aveva doveva pagare in penitenza fisiche o al bar. (VMR).

Sector mágico/ritual/supersticioso

Categoría de uso: Protector.

Número de informantes: 1 Partes utilizadas: planta entera/viva.

La siepe di bosso vicino a casa tiene lontani gli spiriti maligni. (GUF).

Sector medicinal

Categoría de uso: Afecciones oro-faríngeas y de la cavidad oral. 
Etnobotánica en el Alto Valle del Reno (Toscana y Emilia-Romaña, Italia)

Número de informantes: 1 Partes utilizadas: tallos leñosos/ramas/ramitas/vástagos.

Fare un decotto di un rametto di bussolo e fare gli sciacqui di tanto in tanto (MDA).

Sector religioso

Categoría de uso: Ornamento para altares e iglesias.

Número de informantes: 1 Partes utilizadas: tallos leñosos/ramas/ramitas/vástagos.

Facevano delle ghirlande con i rami di bosso, o delle corone decorate con rose fatte di carta. (AMA).

Categoría de uso: Otro religioso.

Número de informantes: 1 Partes utilizadas: tallos leñosos/ramas/ramitas/vástagos.

Si facevano ghirlande di bosso per i morti:"quando uno moriva". (MGO).

Notas non si comprava, si prendevano le piantine di quà e di là, si cercavano le piantine nelle 'bussolaie': una siepe incolta che si dirada dal suolo, dalla quale poi nascono delle piantine di quà e di là. Venivano prese le cime lunghe $30-40 \mathrm{~cm}$ e piantate come talee perché radicano molto bene.. Il bussolo si piantava, poteva poi crescere spontaneo ma di solito le piante si trovano sempre vicino alle case. Proprietà del legno: è durissimo, si può lavorare secco o verde, e non fa il tarloProprietà del legno: non serve per fare attrezzi di cucina perché ha un sapore amarousato per un manico grande.

DATOS ETNOBOTÁNICOS BIBLIOGRÁFICOS

Nombre vulgar: bussolo (GUC80, POLI14), bossel (UNGA21), bùssolo (GUC98), bosso (GUC78), bússolo (BONZI00).

Número de referencias: 6 Número de citas: 10.

Número de sectores: 5 Número de categorías: 5.

Sector agropastoral

Categoría de uso: Vallas y delimitaciones.

Número de referencias: 1 Partes utilizadas: planta entera/viva.

Pianta sempreverde cespugliata che si utlizzava per delimitare strade, aie, orti in modo che le pecore al pascolo non deviassero verso le coltivazioni. (POLI14).

\section{Sector artesanal}

Categoría de uso: Objetos domésticos.

Número de referencias: 2 Partes utilizadas: madera.

Con il legno durissimo e compatto era uso fabbricare le stoviglie da cucina: forchettoni, mestoli, manici per coltelle (POLI14)| bosso, bossolo, p. sempreverde di siepe. Il legno duro e compatto serve spec. a fare oggetti rotondi e di cancelleria. Le foglie sono reputate sudorif. E purgat. Colle foglie I giovani fanno in quaresima il giuoco detto for a vaird, in Tosc. Fuori il verde (UNGA21).

Sector doméstico

Categoría de uso: Jardín.

Número de referencias: 1 Partes utilizadas: planta entera/viva. 
Molte case avevano attorno siepi di bùssolo cui si dava un tempo signifacati magici (GUC98).

\section{Sector lúdico/voluptuoso}

Categoría de uso: Juego colectivo y bromas.

Número de referencias: 4 Partes utilizadas: tallos leñosos/ramas/ramitas/vástagos. Il gioco, che poteva essere indifferentemente giocato fra amici, ma più solitamente fra un ragazzo e una ragazza, si chiamava "fuori al verde"("fora al verde", "fiore verdo“) o più semplicemente si diceva "giogare al verde". I due che decidevano di giocare, dovevano sempre portare addosso un rametto di bosso, o quantomeno indossaer qualcosa di verde, perché il gioco consisteva nel sorprendere l'amico o avversario in situazioni in cui non potesse avere addosso il rametto. La vittoria finale poi )pagamento di pegno) veniva accordata a chi dei due, il giorno di Pasqua, riusciva a sorprendere per primo l'altro gridangdogli appunto "fora al verde", o semplicemente augurandogli la "buona Pasqua". Il pegno consisteva generalmente in un fazzoletto. (GUC78)| Durante la quaresima fino al mattino di Pasqua, si faceva il gioco del "fora al verde": uno diceva per sorpresa ad un altro "fora al verde" e l'altro se aveva in tasca un ramo di bussolo, lo tirava fuori e diceva"dentro il secco! Viva l'ovo benedetto", che aveva vinto l'ovo di pasque. Se non aveva il bussolo, perdeva. (GUC80)| Molte case avevano attorno siepi di bùssolo cui si dava un tempo signifacati magici. Con un rametto della pianta si giocava, durante la quaresima, a fiore verdo detto anche fora al vérde, gioco che reca traccia di antichi rituali primaverili. Due persone si accordavano e uno cercava di cogliere l'altro senza il rametto, pronunciando una delle due frasi sopra dette. L'altro doveva estrarre immediatamente alcune foglie della pianta rispondendo: fora al vérde, dentro al sécco, viva l'óvo benedetto, altrimenti pagava pegno. Il gioco si concludeva il giorno di Pasqua. (GUC98)| bosso, bossolo, p. sempreverde di siepe. Il legno duro e compatto serve spec. a fare oggetti rotondi e di cancelleria. Le foglie sono reputate sudorif. E purgat. Colle foglie I giovani fanno in quaresima il giuoco detto for a vaird, in Tosc. Fuori il verde (UNGA21).

\section{Sector medicinal}

Categoría de uso: Estado general.

Número de referencias: 1 Partes utilizadas: hojas.

bosso, bossolo, p. sempreverde di siepe. Il legno duro e compatto serve spec. a fare oggetti rotondi e di cancelleria. Le foglie sono reputate sudorif. E purgat. Colle foglie I giovani fanno in quaresima il giuoco detto for a vaird, in Tosc. Fuori il verde(UNGA21).

\section{CAMPANULACEAE}

\section{Campanula rapunculus $L$.}

Nombre vulgar: Radicchio amaro (ZAN), Radicchio vero (BSO, BAR), Rapacello (TAT), Raperonzolo (VMA, TAD, FAM), Rapolonzoli (TUL), Raponzolo (VAL, UMI, SCO, MGO, IMA, GGI, GAN, BFE, BEL). 
Número de informantes: 17 Número de citas: 18.

Número de sectores: 1 Número de categorías: 2.

Biotipo: Hemicriptófito.

Tipo corológico: Europeas.

Abundancia: Común.

Ambiente: Campos, baldíos, viñedos, olivares.

Número de exsiccata: 38953 FIAF, 38947 FIAF.

Sector alimentario

Categoría de uso: Ensalada.

Número de informantes: 16 Partes utilizadas: hojas, hojas, órganos subterráneos.

Le foglie si raccolgono con un pò di radice, sono dure da masticare, ma sono buone, si mangiano crude e condite. (ZAN) $\mid$ Si mangiano crude la radice tenera e anche le foglie, in insalata, anche da sola (non mescolata con altre insalate). (BSO, BAR)| La radice è bianca. Si pulisce e si mescola ad altri radicchi. (TAT) $\mid \mathrm{Si}$ lava bene la radice, si spella e si mette nelle insalate con le altre insalate (FAM)| Cruda in insalata e condita (TAD)| Radice e foglie crude in insalata, non deve avere più il fiore (TUL) $\mid$ La radice pulita si mangia cruda in insalata. (VAL, BEL) $\mid$ La radice si mangia nell'insalata, cruda e pelata. (BFE) $\mid$ La radice si mangia nell'insalata cruda e condita, insieme alle uova sode o alla salsiccia. (GAN)| La radice si mangia nell'insalata (IMA, GGI)| La radice va pulita, un po' pelata, e mangiata cruda in insalata (MGO)| Radice pulita e tagliata a pezzetini insieme alle foglie di pimpinella, conditi e mangiate come insalata (SCO)| Mangiare la radice e le foglie, prima che fiorisca, pulite e crude in insalata. (UMI).

Categoría de uso: Verdura cocida.

Número de informantes: 1 Partes utilizadas: órganos subterráneos.

La radice la cuocevano e si mangiava cotta e condita. (VMA).

Notas foglia massiccia, dura da masticare, si mangia solo cruda, con un pò di radice, attaccati alla terra, fanno nei campi sodi, la foglia è come quella dell'alloro a punta, di colore giallino verde. La foglia è liscia.,. La radice è gialla, si trova profonda 10 $\mathrm{cm}$, non si spella ed è amarognola. Non vengono più da quando è Parco. A Bologna lo chiamano Raponzolo. Si trova vicino alla Venturina.

DATOS ETNOBOTÁNICOS BIBLIOGRÁFICOS

Nombre vulgar: armi danza, raponzel (UNGA21), raponzel (UNGA21).

Número de referencias: 1 Número de citas: 2.

Número de sectores: 1 Número de categorías: 1.

\section{Sector alimentario}

Categoría de uso: Ensalada.

Número de referencias: 1 Partes utilizadas: hojas, No especificado.

Più sorta d'erba che si mettono in insalata./ raperonzolo, erba da insalata, comune ne luoghi erbosi. (UNGA21)| erba da insalata (UNGA21).

Notas comune ne luoghi erbosi. 


\section{CANNABACEAE}

\section{Cannabis sativa $L$.}

Nombre vulgar: Cannapa (MGO, CFR, TSI, TAD, SLU, NMA, NLA, MRI, BPT, BLI, BGI), cannapa (BLI), Spago (VMR), chiarata dell'uovo e la stoppa comprata (cannapa dei idraulici) (VMR).

Número de informantes: 12 Número de citas: 18.

Número de sectores: 3 Número de categorías: 4.

Biotipo: Terófito.

Tipo corológico: Cultivadas.

Abundancia: Cultivada.

Ambiente: Cultivada sobre todo en Romaña y en el "Napoletano" por la fibra, en todo el.

territorio en los huertos por la semilla y frecuentemente adventicia.

\section{Sector artesanal}

Categoría de uso: Fibra textil.

Número de informantes: 9 Partes utilizadas: parte aérea (toda).

Cuando si pettinava la fibra, tessevano con filo di cannapa sacchi, lenzuola, coperte (BGI)| "Una volta la coltivavano per tessere" (BLI)| La guinea era un sacchetto tessuto di cannapa che si metteva al collo del cavallo e conteneva "la biada" ossia ghiande, orzo e semola per farlo mangiare. (BLI)| Quando facevano la farina di Castagne, e le facevano asciugare ed seccare sul canniccio, dopo le mettevano in un sacco di cannapa, e si sbatteva forte per sbucciare le castagne (BPT)| I sacchoni erano fatti con la fibra di cannapa, per raccogliere I cereali (MRI)| Le lenzuola erano fatti di fibra di cannapa (MRI)| Conservare il pane:Il cendron, coperta di fibra di cannapa per coprire il pane sopra la paia. (NLA)| Con la fibra della cannapa facevano i sacchi chiamati "cendron", sopra il quale mettevano la cenere da filtrare con l' acqua bollente per fare il bucato (NLA)| Le lenzuola erano fatto con fibra di cannapa. (NMA) Il cendron, coperta di fibra di cannapa per fare il buccato: si mette la cenere sopra e si fa passare l' acqua bollente attraverso. (NMA)| Sacchi di cannapa tessuti nei telai, e usati per mettere il carbone (SLU)| Filavano le fibre con la roca, e tessevano con telai le lenzuola e i teli (SLU)| Lenzuola tessuti di cannapa con orditura di cotone. (TAD)| Il "cendro" è un telo di cannapa messo sulle stecche di pioppo sulla conca, per filtrare la cenere. (TSI).

Sector doméstico

Categoría de uso: Otro doméstico.

Número de informantes: 1 Partes utilizadas: parte aérea (toda).

Legacci per fontaneria (CFR).

\section{Sector medicinal}

Categoría de uso: Afecciones ginecológicas, complicaciones obstétricas, del postparto y del puerperio.

Número de informantes: 1 Partes utilizadas: parte aérea (toda).

Contro le emorragie dopo il parto, si legava tutto il corpo della partoriente con lo spago. (VMR).

Categoría de uso: Trastornos musculo-esqueléticos. 
Número de informantes: 2 Partes utilizadas: parte aérea (toda).

Facevano la chiarata mescolando l'albume dell'uovo con la stoppa e applicandolo direttamente sulla distorsione della caviglia, raffredandosi si induriva e faceva l'effetto di una ingessatura. Stoppa: lo scarto della cannapa (MGO)| Si faceva la chiarata con il chiaro dell'uovo montato e sale. Poi si imbeveva la stoppa e si faciava, diventava come un gesso. (VMR).

Notas Sopra il cendro si metteva la cenere, e si buttava l' acqua bollente.

\section{Humulus lupulus $L$.}

Nombre vulgar: Bracciaboschi (MDA, GAN), Bracciaboschi, Lupolo (SCO), Bracciabosco, Lupolo (VFR), Lupolo selvatico (VMR), Lupolo (BEL).

Número de informantes: 6 Número de citas: 7.

Número de sectores: 1 Número de categorías: 2.

Biotipo: Fanerófito.

Tipo corológico: Europeas.

Abundancia: Común.

Ambiente: Bosques húmedos, setos.

Número de exsiccata: 39099 FIAF.

\section{Sector alimentario}

Categoría de uso: Tortilla.

Número de informantes: 5 Partes utilizadas: brotes.

Scottate e messe nella frittata (MDA, GAN)| Raccolti a maggio, sbollentare le gemme e metterle nella frittata. (SCO)| Facevano la frittata con I germogli di bracciabosco. (VFR)| Fare la frittata con I germogli del lupolo selvatico (già il suo babbo lo faceva). (VMR).

Categoría de uso: Verdura cocida.

Número de informantes: 2 Partes utilizadas: brotes.

Germogli lessi, e conditi con olio e limone (SCO)| I germogli del luppolo vanno cotti e conditi. (BEL).

Notas Si diceva che chi aveva buona vista vedeva il lupolo crescere a vista d'occhio., è spontanea nel iara (letto del fiume). Lo faceva il suo babbo, però a me non me l'ha mai insegnato perché diceva che si assomigliava ad un altro che era tossico e non voleva che sbagliassi... (forse Tamus sp.).

DATOS ETNOBOTÁNICOS BIBLIOGRÁFICOS

Nombre vulgar: luppolo (SANS14), loppel (UNGA21).

Número de referencias: 2 Número de citas: 3 .

Número de sectores: 2 Número de categorías: 3 .

Sector alimentario

Categoría de uso: Pasta y "gnocchi".

Número de referencias: 1 Partes utilizadas: brotes (SANS14).

Sector medicinal

Categoría de uso: Patologías del aparato urinario.

Número de referencias: 1 Partes utilizadas: No especificado. 


\section{María Teresa Egea Molines}

luppolo, p. delle orticacee, coltiva per I fiori adoperati nell'industria della birra. Contiene il lupolo oltre il tannino una sostanza amara e un alcaloide di cui la scienza medica non ha ancora stabilito l'importanza curativa. La medicina popolare ne adopera $\mathrm{i}$ fiori non ancora trasformati in frutti come diuretici e calmanti.(UNGA21).

Categoría de uso: Patologías del sistema nervioso.

Número de referencias: 1 Partes utilizadas: No especificado.

luppolo, p. delle orticacee, coltiva per I fiori adoperati nell'industria della birra. Contiene il lupolo oltre il tannino una sostanza amara e un alcaloide di cui la scienza medica non ha ancora stabilito l'importanza curativa. La medicina popolare ne adopera $\mathrm{i}$ fiori non ancora trasformati in frutti come diuretici e calmanti.(UNGA21).

\section{CAPRIFOLIACEAE (incluye DIPSACACEAE, VALERIANACEAE)}

\section{Dipsacus fullonum $\mathbf{L}$.}

Nombre vulgar: Cardo dei lanaioli (TSI).

Número de informantes: 1 Número de citas: 1.

Número de sectores: 1 Número de categorías: 1.

Biotipo: Hemicriptófito.

Tipo corológico: Eurimediterránea.

Abundancia: Común.

Ambiente: Baldíos, ruinas, escombros, en los caminos.

Sector doméstico

Categoría de uso: Tintorial.

Número de informantes: 1 Partes utilizadas: flores/inflorescencias y sus partes.

Si utilizzavano secchi. Tingevano di colore verde (TSI).

\section{DATOS ETNOBOTÁNICOS BIBLIOGRÁFICOS}

Nombre vulgar: lambard en, sgaerz. (UNGA21).

Número de referencias: 1 Número de citas: 1.

Número de sectores: 1 Número de categorías: 1 .

\section{Sector artesanal}

Categoría de uso: Otro artesanal.

Número de referencias: 1 Partes utilizadas: flores/inflorescencias y sus partes.

volg. Cardo selvatico, detto anche cardo da scardassare e da noi, sgaerz da laena, perchè già adoperato pe'suoi capolini arroncigliati (in dial. Sgaerz o lambardfen) nella follatura de'panni. (UNGA21).

\section{Lonicera caprifolium $\mathbf{L}$.}

Nombre vulgar: Bracciabosco (BEL), Caprifoglio (TAT, BSO), Cucumé (GGL), Bracciaboschi (GFR).

Número de informantes: 5 Número de citas: 5.

Número de sectores: 2 Número de categorías: 2 .

Biotipo: Fanerófito. 
Etnobotánica en el Alto Valle del Reno (Toscana y Emilia-Romaña, Italia)

Tipo corológico: Europeas.

Abundancia: Común.

Ambiente: Bosques caducifolios (robledos, castañares), bosquecillos, setos, viñedos.

Número de exsiccata: 39070 FIAF, 38942 FIAF, 39101 FIAF.

Sector alimentario

Categoría de uso: Golosinas y masticatorias.

Número de informantes: 4 Partes utilizadas: flores/inflorescencias y sus partes.

$\mathrm{Si}$ ciucciava il fiore quando si era in giro. (BEL)| I fiori si ciucciavano mentre si camminava. (TAT, BSO)| Camminando per i campi si ciucciavano i fiori, perché avevano un tipo di miele'. (GGL).

Sector doméstico

Categoría de uso: Ornamental.

Número de informantes: 1 Partes utilizadas: planta entera/viva.

Nell'orto c'è una pianta (fiorisce verso Giugno), presa nel bosco e piantata da lei ' per bellezza' (GFR).

Notas Ce n'era tanta per la strada di Cavanna..

DATOS ETNOBOTÁNICOS BIBLIOGRÁFICOS

Nombre vulgar: caprifolio, ligabôsc (SANS14), uva 'd San Giovanni, caprifoglio (GUC98).

Número de referencias: 2 Número de citas: 2 .

Número de sectores: 1 Número de categorías: 1.

Sector alimentario

Categoría de uso: Ensalada.

Número de referencias: 1 Partes utilizadas: brotes (SANS14).

\section{Valeriana officinalis $\boldsymbol{L}$.}

Nombre vulgar: Valeriana (BLI).

Número de informantes: 1 Número de citas: 1.

Número de sectores: 1 Número de categorías: 1.

Biotipo: Hemicriptófito.

Tipo corológico: Europeas.

Abundancia: Común.

Ambiente: Prados húmedos, riberas, bosque húmedos.

Sector medicinal

Categoría de uso: Patologías del sistema nervioso.

Número de informantes: 1 Partes utilizadas: planta entera/viva.

Quando fiorisce la valeriana si mette a essicare. Per l'esaurimento bere un infuso di valeriana. (BLI).

Notas Venturi (2006) riporta anche V. tripteris..

DATOS ETNOBOTÁNICOS BIBLIOGRÁFICOS

Nombre vulgar: valeriana (MANG98). 
Número de referencias: 1 Número de citas: 1.

Número de sectores: 1 Número de categorías: 1.

Sector medicinal

Categoría de uso: Patologías del sistema nervioso.

Número de referencias: 1 Partes utilizadas: órganos subterráneos.

Le barbe essiccate vengono macinate, al momento del bisogno si assume un cucchiaino di polvere con un pò di zucchero e d'acqua. (MANG98).

\section{Valerianella locusta (L.) Laterr.}

Nombre vulgar: Agnellino (BSO), Bocconcino d'agnello (BAR,BSO), Bocconcino d'agnello (GGL,NST,RGI,RRE), Boconcini di Agnello (TGA), Braga di gallo (BFE, MDA, MME, TAD, TOA, VFR), Caciolino (CBR, MGE), Concin d'agnelli (BEL), Dolcignò (RNI, BAN, BBA, BIO, CFR, CLO, CRE, CRI, GAN, GFR, GGI, GRI, IMA, LGI, MOR, MRI, MSR, MTO, NLA, NMA, NRO, PCL, PIM, RNI, TRU, TUL), Dolcignolo (DAD, FAM), Dolcignoli (BAN, BBA, BIO, CFR, CLO, CRE, CRI, GAN, GFR, GGI, GRI, IMA, LGI, MOR, MRI, MSR, MTO, NLA, NMA, NRO, PCL, PIM, RNI, TRU, TUL), Gallinella(VMA,ZAN, LRE), Gallina grassa (BOR), Gallinella grassa (MRI), Grassa gallina (MSR), La gallinina (MSI), Radicchi (BAR), Valeriana selvatica (TAD), Zampe di gallo (BAD).

Número de informantes: 52 Número de citas: 55.

Número de sectores: 2 Número de categorías: 3.

Biotipo: Terófito.

Tipo corológico: Eurimediterránea.

Abundancia: Común.

Ambiente: Invasoras en los cultivos obviamente cultivada para ensalada más raramente en los prados áridos esteparios.

\section{Sector alimentario}

Categoría de uso: Ensalada.

Número de informantes: 52 Partes utilizadas: hojas.

Foglie crude in insalata. (NRE, GGL) Le foglie si mangiano crude e condite. (NST)| Le foglie crude con le uova sode. (RGI) $\mid$ Le foglie crude e condite in insalata. (BBI, BAD, BOR, PIM, LGI, BAN, RRE)| Si mangiavano crude e condite. (BSO, BAR)| Raccolte a primavera e messe nell'insalata. (TGA) $\mid$ Mangiati crudi in insalata con le uova soda. (BFE) $\mid$ Mangiare le foglie crude in insalata. (MDA) $\mid$ Raccolta e mangiata quando non ha fatto il fiore ancora, se no non è più buona. In insalata con carote $o$ altre insalate. (MME)| Raccogliere le foglie nelle stoppie (dove si seminava il grano), e mangiare crude, in insalata. (TOA)| Le foglie di braga di gallo si mangiavano in insalata. (VFR) $\mid$ Si raccoglievano dove si aveva seminato il grano, si mangiavano crudi e conditi in insalata insieme alle uova soda (CBR)| Le foglie si mangiano anche crude in insalata. (MGE) $\mid \mathrm{Al}$ tempo delle viole (aprile-maggio) raccogliere le foglie di (bo-)concin di agnello e mangiarle crude in insalata condite. (BEL)| Foglie mangiate in insalata insieme a dell'insalata dell'orto. (BBA)| Le foglie si raccoglievano nei campi coltivati e si mangiavano crude. (BIO)| Mangiare le foglie crude dei dolcignoli in insalata, anche insieme alle cicerbite e ai piscialletti. 
$(\mathrm{CFR}) \mid$ Insalata con altre insalate (CLO)| Mangiare crude in insalata. (CRI, CRE)| Mangiati crudi in insalata. (GAN) $\mid$ Cruda in insalata e condita (GFR) $\mid$ Cruda e condita con altre insalate (FAM, GGI) $\mid$ Le foglie mangiate in insalata (radicchio preferito perché è liscio) (GRI)| Ad aprile, si raccoglievano e si mettevano nell'insalata (IMA) $\mid$ Le foglie in insalata condite (MOR) $\mid$ Cruda in insalata (NLA) $\mid$ In primavera si raccoglievano per fare insalata con altre tipi anche dell ' orto (NMA) Mangiata cruda insieme ad altre insalata. (NRO) $\mid$ Mangiare crudi in insalata. (PCL) Le folie tenere vengono mangiate in insalata (TRU) $\mid$ crude con uova soda (TUL) $\mid \mathrm{Si}$ raccoglievano le foglie nelle stoppie e si mangiavano crude insieme alle gigerbite facevano un insalata buonissima (RNI)| Foglie mangiate crude e condite nell'insalata. (MRI)| Le foglie, lavate e mangiate con le uova sode. (MTO, MSR)| Crude in insalata con altre insalate (DAD) $\mid$ le foglie crude in insalata, anche insieme al radicchio, al piscialleto e al cisevda (VMA)| Le foglioline si lavavano bene e si mangiavano crude in insalata. (ZAN) $\mid$ Le foglie giovani mangiate crude in insalata e condite. (LRE) $\mid$ Le foglie crude mangiate in insalata. (MSI) $\mid$ Crudo con altre insalate (TAD)| Si mangiava cruda in insalata. (RMA).

Categoría de uso: Sopas de verduras y potaje.

Número de informantes: 2 Partes utilizadas: hojas.

La zuppa d'estate della nonna era a base solo di piante di campo: soffriegeva l'aglio, si trittavano tutte le foglie del piscialletto, le punte dei vizzadri, dell'ortica, delle orecchie di ciucco, del caciolino e degli striggoli. Poi si aggiungevano e si facevano bollire molto. Poi si poteva aggiungere riso o pasta. (MGE)| L"Acquacotta', la minestra dei poveri, era fatta con gli striggoli, il piscialletto, gli stricapugni, i dolcignoli, i radicchietti, tutti lavati e trinciati, saltati in padella con un po' di unto di maiale e poi si aggiungeva l'acqua e si lasciava cuocere un po'. Poi si metteva una fetta di pane secco sul piatto, si versava la zuppa e si aggiungeva un po' di cacio di pecora. (MSR).

\section{Sector medicinal}

Categoría de uso: Estado general.

Número de informantes: 1 Partes utilizadas: hojas.

Le foglie si mangiano crude e condite. (NST).

Notas Si chiamava così "bocconcino d'agnello" perché veniva raccolta quando l'agnello era pronto (fine Gennaio-Febbraio: le pecore si coprivano con il maschio a settembre, poi partoriva dopo 6 mesi, a gennaio, e dopo un po l'agnello era pronto per mangiare). Era un lavoro di femmina, andavano a raccogliere radicchi con il paniere. La nonna quando li cucinava chiudeva la porta.Quando hanno tagliato il grano ri raccolgono, ora non c'è più nessuno che taglia il grano...però ce n'è ancora....

\section{DATOS ETNOBOTÁNICOS BIBLIOGRÁFICOS}

Nombre vulgar: valerianella (GRIZ03), Caciolino (POLI14), valerianella, grassagallina (SANS14), armi danza, pcan d'pigra,bcan d'pigra (UNGA21), bcan d'pigra (UNGA21), grasagalenna (UNGA21), dulzatt, dulzett (pl), grasagalenna (UNGA21), braga di gaDo (BONZI00),

Número de referencias: 5 Número de citas: 9.

Número de sectores: 1 Número de categorías: 1. 


\section{Sector alimentario}

Categoría de uso: Ensalada.

Número de referencias: 4 Partes utilizadas: hojas.

(SANS14)Insalata mista: Lattughino, valerianella, tarassaco, crescione, olio extra vergine d'oliva, sale. (GRIZ03)| Valeriana selvatica. Specie erbacea che cresce (o meglio cresceva) nei terreni coltivati di freso e destinati alla produzione del fieno. I caciolini erano raccolti per la loro prelibatezza. Si mangiavano crudi in insalata spesso insieme al tarassaco. (POLI14)| Più sorta d'erba che si mettono in insalata./ boccone di pecora nella $\mathrm{n}$. prov. Sorta d'insalata de'campi così detta forse perchè assai gradita alle pecore (UNGA21)| boccone di pecora, nella n. prov., sorta d'insalata de' campi così detta forse perchè assai gradita alle pecore (cfr. Nel parm. Boccone di lepre) (UNGA21)| grassagallina, sorta di radichiella de campi, coltivata anche negli orti per insalata, che si mangia in primavera-detta da alcuni e già dall'Aldr. Porcellana da non confondersi però colla Porcellan oleracea L. (UNGA21)| erba spont. Da insalata (UNGA21) galinella, dolciolina, nel bol. Grassagallina, sorta di radichiella de'campi, colt. Anche negli orti per insalata, che si mangia in primavera (46) (UNGA21).

\section{CARYOPHYLLACEAE}

\section{Dianthus seguieri Vill. (cfr.)}

Nombre vulgar: Garofani selvatici (rossi) (PCL), Garofani (TSI, BPT).

Número de informantes: 3 Número de citas: 3.

Número de sectores: 2 Número de categorías: 2.

Biotipo: Hemicriptófito.

Tipo corológico: Europeas.

Abundancia: Rara.

Ambiente: Prados áridos, bosques estépicos, acantilados.

\section{Sector doméstico}

Categoría de uso: Ornamental.

Número de informantes: 1 Partes utilizadas: parte aérea (toda).

Mettere in casa in un vaso per abbellire. (PCL).

Sector religioso

Categoría de uso: Ornamento para altares e iglesias.

Número de informantes: 2 Partes utilizadas: flores/inflorescencias y sus partes.

Si portavano In chiesa (TSI, BPT).

Notas sicuramente usano diversi Dianthus..

DATOS ETNOBOTÁNICOS BIBLIOGRÁFICOS

Nombre vulgar: garôfen (UNGA21).

Número de referencias: 1 Número de citas: 1 .

Número de sectores: 1 Número de categorías: 1. 


\section{Sector medicinal}

Categoría de uso: Afecciones ginecológicas, complicaciones obstétricas, del postparto y del puerperio.

Número de referencias: 1 Partes utilizadas: semillas.

garofano, pianta spontanea ne luoghi montani, coltivata ne giardini e anche in pontole sulle finestre o sui tetti pel bellissimo fiore. Nella medicina popolare, il seme pestato e bevuto nel vin bianco provoca I corsi delle donne e facilita il parto a quelle che sono in travaglio. Usata estesamente nell'industria profumiera, che ne estrae l'essenza mediante grassi.(UNGA21).

\section{Saponaria officinalis $L$.}

Nombre vulgar: Erba saponina (BGI, NLA), Erba savonada, Saponaria (GGI), Saponaria (PCL, MDA, CFR, MME, CRI, BEL), Erba sapone, Erba savonina (VMR), Pianta del sapone (MGE).

Número de informantes: 11 Número de citas: 15.

Número de sectores: 3 Número de categorías: 5.

Biotipo: Hemicriptófito.

Tipo corológico: Nórdicas.

Abundancia: Común.

Ambiente: Baldíos húmedos a lo lardo de los cursos de agua.

Número de exsiccata: 38915 FIAF.

Sector caza y pesca

Categoría de uso: Ictiotóxico.

Número de informantes: 1 Partes utilizadas: parte aérea (toda).

Nel fiume si prendeva parecchie fiori, si pestavano su una roccia con una pietra e si buttava nel acqua, dopo un po' le trote venivano a galla stordite (come l'effetto della varichina) (NLA).

\section{Sector doméstico}

Categoría de uso: Cuidado personal y cosmética.

Número de informantes: 2 Partes utilizadas:flores/inflorescencias y sus partes.

Dopo aver pescato e pulito i pesci al fiume, prendevano i fiori e si lavavano le mani (GGI)| Fare un decotto di fiori di saponaria: fa una schiuma e con l'acqua lavare i capelli. (BEL).

Categoría de uso: Detergente.

Número de informantes: 5 Partes utilizadas:flores/inflorescencias y sus partes.

Per lavarsi le mani, dove capitava (VMR)| Si lavavano i vestiti con la pianta pestata con 3 pietre (NLA)| Si stoffinavano le foglie e I fiori con l'acqua e si lavavano le mani (VMR)| Fare il decotto dei fiori di saponaria e con l'acqua lavare i panni. (BEL)| $\mathrm{Ci}$ si lavava le mani quando capitava (CRI) $\mid \mathrm{Si}$ raccoglievano vicino al fiume, si portavano a casa, per lavarci le mani, perché lavava e faceva schiuma. (MME).

\section{Sector lúdico/voluptuoso}

Categoría de uso: Juego colectivo y bromas. 
Número de informantes: 1 Partes utilizadas:flores/inflorescencias y sus partes.

I fiori si prendevano si stroffinava e facevano schiuma come il sapone, si faceva per gioco (MGE).

Categoría de uso: Pasatiempos.

Número de informantes: 5 Partes utilizadas:flores/inflorescencias y sus partes.

I bimbi prendevano i fiori e strofinandoli facevano uscire fuori la schiuma, per giocare nel fiume. (BGI)| Quando i ragazzi erano al fiume, prendevano questi fiori e li strofinavano, così veniva fuori la schiuma (GGI)| Si sfregavano i fiori e usciva la schiuma (CFR) I bambini strofinavano i fiori per giocare (MDA)| Fare schiuma o sapone come gioco (PCL).

\section{Silene flos-cuculi (L.) Greuter \& Burdet (= Lychnis flos- cuculi L.)}

Nombre vulgar: Garofanini (GGI).

Número de informantes: 1 Número de citas: 1.

Número de sectores: 1 Número de categorías: 1.

Biotipo: Hemicriptófito.

Tipo corológico: Nórdicas.

Abundancia: Común.

Ambiente: Prados húmedos segados y fertilizados, márgenes de los bosques.

Número de exsiccata: 39095 FIAF.

Sector religioso

Categoría de uso: Procesiones.

Número de informantes: 1 Partes utilizadas: parte aérea (toda).

Nel Corus d'omini, raccoglievano I garofanini insieme a tutti i fiori dell'epoca e si faceva un.

tappetto di fiori per fare la "fiorida" dove passava la processione. (GGI).

Notas non ci sono più sono scomparse.

\section{Silene latifolia subsp. alba (Mill.) Greuter \& Burdet (= Silene alba (Miller) Krause)}

Nombre vulgar: orecchine di levora (lepre) (PGI).

Número de informantes: 1 Número de citas: 1.

Número de sectores: 1 Número de categorías: 1.

Biotipo: Hemicriptófito.

Tipo corológico: Europeas.

Abundancia: Común.

Ambiente: Ruinas y baldíos.

Número de exsiccata: 38926 FIAF.

Sector alimentario

Categoría de uso: Otro alimentario.

Número de informantes: 1 Partes utilizadas: hojas. 
Con le foglie cotte si fanno le polpette: insieme al pane, uovo, e formaggio. Poi si impanavano e si friggono. (PGI).

\section{Silene vulgaris (Moench) Garcke}

Nombre vulgar: Striggoli (BAD, BAN, BOR, BSO, EMA, GGL, LGI, LRE, MDA, MGE, MSR, NRE, NRO, NST, RRE, TAT, VMA), Striggoli d'agnello (RGI), Striggolo (AMA, BBI, BEL, MIO, MSA, MSI, NDI, PEL, PIM, PLU, RMA), Strigoli (AP2, BAR, BFE, BGI, CRE, DAD, GAN, GFR, GGI, GUF, MGO, MTO, REN, SOT, TAD, TGO, TIV, TRU, UMI, VFR), Verzolo (PGI).

Número de informantes: 50 Número de citas: 90.

Número de sectores: 3 Número de categorías: 12 .

Biotipo: Hemicriptófito.

Tipo corológico: Europeas.

Abundancia: Bastante Común.

Ambiente: Baldíos, prados, grava.

Número de exsiccata: 39075 FIAF, 38925 FIAF, 38913 FIAF.

Sector alimentario

Categoría de uso: Arroces y "risotto".

Número de informantes: 24 Partes utilizadas: hojas.

$\mathrm{Si}$ fa il risotto con gli striggoli. (BAD)| Usare i giovani getti per fare il risotto. (BAN)| Fare il soffritto con un po' d'aglio, poi aggiungere le punte degli striggoli cotti e quindi il riso, poi l'acqua. (NDI, LGI)| Usare i germogli per fare il risotto. (LRE)| Risotto fatto con gli strigoli (MDA)| Fare rosolare la cipolla, aggiungere il riso, poi gli striggoli e quindi l'acqua, fare bollire. (MTO, MSR)| Germogli messi nel risotto. (NRE)| Risotto fatto con strigoli, patate e fagioli (NRO)| Con le foglie degli strigoli facevano il risotto (VMA)| $\mathrm{Si}$ fa il risotto allo strigolo, qualche volta aggiungendo anche un po' di patate. (AMA)| Fare il risotto nel modo consueto e aggiungere gli striggoli. (RMA, BBI)| Fare il risotto nel modo consueto con i germogli di striggoli (anche con la pancetta). (BEL)| Mettere i germogli nel risotto fatto nel modo consueto. (MSI)| Le foglie tenere si adoperano per fare il risotto nel modo consueto. (PEL)| Risotto con gli strigoli (AP2)| In primavera, si fa il riso con le patate e striggoli (DAD)| Risotto con aglio e prezzemolo e se si vuole anche un po' di pancetta tagliata (GAN)| Risotto con strigoli e fagioli (MGO)| Fare il risotto con le foglie degli striggoli (TAD)| Le foglie si mettono nel risotto e si fa il risotto agli strigoli (VFR)| Con le foglie si fa il risotto (PGI).

Categoría de uso: Empanadas.

Número de informantes: 1 Partes utilizadas: hojas.

Torta salata o schiaccia alle erbe, con le erbe di staggione: fare la pasta con la farina usando il lievito madre (che era trattato come un tesoro, durava anni e gli si davano delle cure quotidiane per mantenerlo vivo sempre) e aggiungere i 'ciucioli' (siccioli, ricavati facendo cuocere il grasso del maiale e tirandoli fuori via via che venivano a galla), poi stendere la pasta. Fare cuocere le erbe di stagione come il piscialletto, le cicoriette, lo strigolo, l'ortica, i vizzadri, una volta cotte, passarle in padella con un 


\section{María Teresa Egea Molines}

pò di pancetta o lardo, mescolarle al formaggio 'scotta' e 4 uova. Coprire con un'altra sfoglia di pasta, quindi chiudere con la forchetta e cuocere in forno. (BSO).

Categoría de uso: Ensalada.

Número de informantes: 3 Partes utilizadas: hojas.

Le foglie crude e da sole condite come in insalata. Raccolte a primavera. (PLU)| Mangiare in.

insalata crudi e da sole (CRE)| Le foglie si mangiano anche crude condite. (VFR).

Categoría de uso: Otro alimentario.

Número de informantes: 1 Partes utilizadas: hojas.

Con le foglie cotte si fanno le polpette: insieme al pane, uovo, e formaggio. Poi si impanavano e si friggono. (PGI).

Categoría de uso: Pasta y "gnocchi".

Número de informantes: 1 Partes utilizadas: hojas.

Mettere le foglie trittate e crude dentro all'impasto della pasta. (TAD).

Categoría de uso: Relleno de ravioli.

Número de informantes: 10 Partes utilizadas: hojas.

Le punte degli striggoli vanno lessate, mescolate alla ricotta per fare i tortelloni. $(\mathrm{BOR}) \mid$ Le foglie lesse, mescolate alla ricotta per fare il ripieno dei tortelloni. (BSO)| Si facevano i tortellli riepieni di striggoli e ricotta. (NST)| Tritare i germogli e mescolare con la ricotta, come ripieno dei ravioli. (AMA)| Cotte e messe nella frittata. (BEL)| I germogli cotti vengono mescolati con la ricotta come ripieno. (MIO)| I germogli cotti e messi nel ripieno dei tortelli con ricotta. (MSA)| Le foglie tenere si adoperano per il ripieno dei tortelli insieme alla ricotta. (PEL)| Ripieno per tortelloni con ricotta. (PIM)| Fare cuocere gli strigoli e aggiungere al ripieno dei tortelli insieme al formaggio (AP2).

Categoría de uso: Sopas de verduras y potaje.

Número de informantes: 7 Partes utilizadas: hojas.

Minestra: soffriggere aglio e prezzemolo nell'olio, poi aggiungere le foglie di piscialletto, cicorietta, striggoli e 2 patate, se ce l'avevano, poi l'acqua e quando bolle unire la pasta 'gli strapponi' (si faceva la sfoglia di acqua e farina e si strapavano pezzettini, che si facevano bollire un secondo nell'acqua bollente) (BSO)| Agiungere i germogli al minestrone di verdure. (LRE)| La zuppa d'estate della nonna era a base solo di piante di campo: soffriegeva l'aglio, si trittavano tutte le foglie del piscialletto, le punte dei vizzadri, dell'ortica, delle orecchie di ciucco, del caciolino e degli striggoli. Poi si aggiungevano e si facevano bollire molto. Poi si poteva aggiungere riso o pasta. (MGE) $\mid$ L"Acquacotta', la minestra dei poveri, era fatta con gli striggoli, il piscialletto, gli stricapugni, i dolcignoli, i radichietti, tutti lavati e trinciati, saltati un po' in padella con un po' di unto di maiale e poi si aggiungeva l'acqua e si lasciava cuocere un po'. Poi si metteva una fetta di pane secco sul piatto, si versava la zuppa e un po' di cacio di pecora. (MSR)| L"Acquacotta', la minestra dei poveri, era fatta con gli striggoli, il piscialletto, gli stricapugni, le cicervde, i dolcignoli, i radicchietti, tutti lavati e trinciati, saltati in padella con un po' di unto di maiale (pancetta ) o olio e sale e poi si aggiungeva l'acqua e si lasciava cuocere. Si versava in un piatto con una o due fette di pane secco e del cacio di pecora. (MTO) Le foglie di strigoli vanno messi nel minestrone insieme alle patate, al cavolo, alla bietola e altre verdure. (REN) $\mid$ Nella minestra con altre verdure. (TAD). 
Categoría de uso: Tortilla.

Número de informantes: 22 Partes utilizadas: hojas, brotes.

Le foglie saltate in padella e poi con le uova fare la frittata. (MSR, BAN)| Le foglie lesse e mescolate nella frittata. (BSO) $\mid$ Germogli cotti e messi nella frittata. (NRE)| I germogli saltati in padella e aggiunti alla frittata. (RGI)| Cotte e messe nella frittata. (AMA)| Fare saltare i germogli di striggoli e aggiungere le uova per fare la frittata. (BEL) I germogli lessi e messi nella frittata. (MSA)| Lessare le punte degli striggoli e mescolate alle uova per fare la frittata. (NDI)| Scottare le foglie tenere e fare la frittata con le uova. (PEL)| Le foglie lesse e mescolate alla frittata (si lessavano perché c'era carenza di olio). Raccolte a primavera (PLU)| Le foglie lessate e messe nella frittata. (BAR) $\mid$ Germogli saltati e messi nella padella (BFE) $\mid$ Cotte, strizzate e messe nella frittata (TRU, TIV, BGI)| Saltati in padella e aggiungendo direttamente le uova. (MGO)| Sbollentate e messe nella frittata (SOT) $\mid$ Cotta e messa nelle frittate (TAD) $\mid$ Sbollentate e messi nella frittata (UMI) $\mid$ Con le foglie scottate si fa la frittata. (VFR) $\mid$ Con le foglie si fa la frittata. (PGI).

Categoría de uso: Verdura cocida.

Número de informantes: 12 Partes utilizadas: hojas.

Si mangiano le foglie lessate e condite con olio e limone. (BSO, BOR)| Si fanno bollire le foglie e si mangiano lesse e condite, come verdura cotta (EMA)| Germogli saltati in padella con burro. (RRE, GGL)| I germogli si mangiano cotti 'in umido' con la salsiccia. (MSR)| Si mangiano le foglie giovani cotte e condite. (TAT)| Lessi e conditi, oppure lessati e saltati con olio e salciccia. (PIM)| Cotti e conditi (GFR)| Cotta e condita, come verdura cotta o contorni (TAD)| Cotta e condita con limone (TGO)| Le foglie si mangiano cotte come verdura anche con altri radicchi. (VFR).

Sector doméstico

Categoría de uso: Integración de la renta familiar.

Número de informantes: 1 Partes utilizadas: hojas.

La vendevano a della gente che venivano a comprare appositamente gli striggoli da "Cruviciano"?? (MGO).

\section{Sector lúdico/voluptuoso}

Categoría de uso: Juego colectivo y bromas.

Número de informantes: 7 Partes utilizadas: flores/inflorescencias y sus partes.

Quando fiorivano gli strigoli, I bambini facevano schioccare i calici rigonfi dei fiori sugli altri bambini. (BFE)| Il frutto (in realtà è il fiore) 'all'inverso' (tenuto dalla parte del picciolo) schiacciato su un'altra persona fa un 'clic'. (DAD)| Schiopetti, con il fiore 'all'inverso', cioè schiacciato addosso a qualcuno tenendolo per il gambo. (GFR)| Frutti (in realtà fiori), schiacciati sulla fronte. (GGI)| Schiopetti: schiacciando i fiori sulla pelle di un altro, fanno un suono (TIV)| Prendevamo I fiori e si facevano schioppetare come gioco. (VFR)| Da bambini si prendevano I fiori e si schiopettavano (PGI).

Categoría de uso: Pasatiempos.

Número de informantes: 1 Partes utilizadas: flores/inflorescencias y sus partes. Il divertimento consiste nello schiacciare la "pallina", cioè il calice (GUF).

Notas Non ci sono piu come una volta, Si raccolgono a primavera., L'acquacotta è un piatto importato dalla maremma dai carbonai. è la prima verdura, cresce quando 


\section{María Teresa Egea Molines}

neanche la bietola è prontaLa facevano le donne che guardavano le pecore, al canicciolo, o all'essicatoio., si chiamano così perché nell'agnello c'è lo strigol.

DATOS ETNOBOTÁNICOS BIBLIOGRÁFICOS

Nombre vulgar: strigoli (BADI15), silene rigongia, strìdel, ciucchett (SANS14), ciucatt, ciuchett.

(UNGA21).

Número de referencias: 3 Número de citas: 8 .

Número de sectores: 2 Número de categorías: 7.

Sector alimentario

Categoría de uso: Arroces y "risotto".

Número de referencias: 1 Partes utilizadas: hojas.

Risotto con gli strigoli. Ingredienti: Strigoli (silene vulgaris ),olio,cipolla,brodo vegetale,vino bianco,parmigiano,sale e pepe. Si fa soffriggere nell'olio la cipolla tritata finchè non diventa trasparente,poi si aggiungono le foglie degli strigoli, precedentemente lavate,nella quantità di una manciatina per persona, e si bagnano con brodo vegetale (anche di dado). Dopo alcuni minuti di bollitura si versa il riso,si aggiusta di sale e pepe e si continua la cottura aggiungendo un po' vino bianco e del brodo vegetale caldo.La consistenza deve essere quelle di un normale risotto. A cottura ultimata si spegne il fornello e si aggiunge abbondante parmigiano e si fa mantecare. Il sapore è delicato e particolare. (BADI15).

Categoría de uso: Ensalada.

Número de referencias: 2 Partes utilizadas: hojas (SANS14).

I contadini la mangiavano giovane in insalata (UNGA21).

Categoría de uso: Pasta y "gnocchi".

Número de referencias: 1 Partes utilizadas: hojas (SANS14).

Categoría de uso: Relleno de ravioli.

Número de referencias: 1 Partes utilizadas: hojas (SANS14).

Categoría de uso: Tortilla.

Número de referencias: 1 Partes utilizadas: hojas (SANS14).

Categoría de uso: Verdura cocida.

Número de referencias: 1 Partes utilizadas: hojas (SANS14).

Sector lúdico/voluptuoso

Categoría de uso: Juego colectivo y bromas.

Número de referencias: 1 Partes utilizadas: flores/inflorescencias y sus partes.

Erba infesta delle biade, cosi detta per I fiori bianchi rigonfi che I fanciulli si divertono a far scoppiare. (UNGA21).

\section{CELASTRACEAE}

\section{Euonymus europaeus $L$.}

Nombre vulgar: (VMR, GFR)Beretto da prete (NRE), Le lacrime di Maria (GZE). Número de informantes: 4 Número de citas: 4. 
Número de sectores: 3 Número de categorías: 4.

Biotipo: Fanerófito.

Tipo corológico: Europeas.

Abundancia: Común.

Ambiente: Bosques de latifolios (sobre todo robledales y castañares), setos.

Número de exsiccata: 39125 FIAF, 38944 FIAF.

Sector agropastoral

Categoría de uso: Vallas y delimitaciones.

Número de informantes: 1 Partes utilizadas: planta entera/viva.

Si usava fare le siepi con diverse piante: ligustri, spini (prugnolo e biancospino), acero campestre,sanguinelli, berretti da prete. (NRE).

Sector doméstico

Categoría de uso: Jardín.

Número de informantes: 1 Partes utilizadas: planta entera/viva.

Si coltvia nell'orto come ornamentale, è simile al capelli del prete (GFR).

Categoría de uso: Ornamental.

Número de informantes: 1 Partes utilizadas: planta entera/viva.

Come ornamento davanti casa (GZE).

Sector efecto nocivo

Categoría de uso: Tóxicas y venenosas.

Número de informantes: 1 Partes utilizadas: planta entera/viva.

Suo padre diceva di non toccarla perché era tossica (VMR).

\section{Euonymus latifolius (L.) Mill.}

Nombre vulgar: Cappelli del prete (GFR).

Número de informantes: 1 Número de citas: 1.

Número de sectores: 1 Número de categorías: 1 .

Biotipo: Fanerófito.

Tipo corológico: Mediterráneas montañosas.

Abundancia: Rara.

Ambiente: Bosques latifolios (hayas, castaños).

Número de exsiccata: 38943 FIAF.

Sector doméstico

Categoría de uso: Jardín.

Número de informantes: 1 Partes utilizadas: planta entera/viva.

Nell'orto c'è una pianta (fiorisce verso metà Giugno), usata a scopo ornamentale. (GFR). 


\section{COMPOSITAE (= ASTERACEAE)}

\section{Achillea millefolium L. (s. l.)}

Nombre vulgar: Millefiori (TAD, SOT).

Número de informantes: 2 Número de citas: 3.

Número de sectores: 1 Número de categorías: 2.

Biotipo: Hemicriptófito.

Tipo corológico: Nórdicas.

Abundancia: Rara.

Ambiente: Prados áridos, especialmente de montaña y subalpinos.

Número de exsiccata: 38920 FIAF.

Sector medicinal

Categoría de uso: Patologías del aparato digestivo.

Número de informantes: 1 Partes utilizadas: parte aérea (toda).

Non specificato (SOT).

Categoría de uso: Patologías del aparato urinario.

Número de informantes: 2 Partes utilizadas: parte aérea (toda), flores/inflorescencias y.

Non specificato (SOT)| D' estate si raccolgono i fiori e si mettono a seccare per l' inverno..

Mettere i fiori nell'acqua bollente nel vaso da notte e fare "fiumi" (semicupi) (TAD).

DATOS ETNOBOTÁNICOS BIBLIOGRÁFICOS

Nombre vulgar: êrba di tâj (UNGA21).

Número de referencias: 1 Número de citas: 1.

Número de sectores: 1 Número de categorías: 1.

\section{Sector medicinal}

Categoría de uso: Afecciones cutáneas y tejidos subcutáneos.

Número de referencias: 1 Partes utilizadas: flores/inflorescencias y sus partes.

Achillea, millefogli, volg. Erba de' tagli, perchè adoperata a quest'uso e dai contadini anche êrba furmiga, già off. Nella med. Pop. È altresì adoperata come astringente in infuso delle sue foglie e sommità de'fiori. (UNGA21).

\section{Anthemis arvensis L. (cfr.)}

Nombre vulgar: Camomilla (TRU), Camomilla bassa selvatica (RGI), Margherite sfiorite (RGI).

Número de informantes: 2 Número de citas: 3.

Número de sectores: 1 Número de categorías: 1.

Biotipo: Terófito.

Tipo corológico: Esteno-mediterránea.

Abundancia: Común.

Ambiente: Cultivos de cereales, pastos y terrenos abandonados (preferiblemente de silicio).

Número de exsiccata: 38977 FIAF. 


\section{Sector medicinal}

Categoría de uso: Estado general.

Número de informantes: 2 Partes utilizadas: flores/inflorescencias y sus partes.

Fare un infuso con I fiori della camomilla e bere per le infiammazioni (TRU)| Fare un infuso dei fiori della camomilla bassa selvatica e bere per le infiammazioni. (RGI)| Fare un 'infuso' con dei capolini delle margherite sfiorite secche e bere per le infiammazioni. (RGI).

\section{Arctium lappa $L$.}

Nombre vulgar: Farfanaccio (GGL), Farfanacci (TAT), Bardana (VMU, BEL, VMA, CVA),

Lappa (MDA), Farfanaccio, Bardana (GGL), senza nome (CBR).

Número de informantes: 8 Número de citas: 13.

Número de sectores: 4 Número de categorías: 6 .

Biotipo: Hemicriptófito.

Tipo corológico: Europeas.

Abundancia: Rara.

Ambiente: Baldíos, ruinas, bordes de los caminos, setos.

Número de exsiccata: 39089 FIAF.

Sector agropastoral

Categoría de uso: Horticultura.

Número de informantes: 1 Partes utilizadas: hojas.

Le foglie del farfanaccio si usano per proteggere i trapianti di pomodori dal sole, mettendoglieli sopra. (GGL).

\section{Sector doméstico}

Categoría de uso: Otro doméstico.

Número de informantes: 1 Partes utilizadas: hojas.

Le foglie grandi si usavano per avvolgere il burro e il formaggio, che poi venivano messi nelle burraie (cantine delle case) per conservarli. (TAT)| Le foglie si usavano per fare dei bicchierini per bere l'acqua alla fontana. (TAT).

Sector lúdico/voluptuoso

Categoría de uso: Decoraciones y disfraces de niños.

Número de informantes: 1 Partes utilizadas: flores/inflorescencias y sus partes.

I bambini si li mettevano sui vestiti come gioco (CVA).

Categoría de uso: Juego colectivo y bromas.

Número de informantes: 4 Partes utilizadas: frutos/infrutescencias/falsos frutos.

Ci si buttava I frutti sui vestiti per gioco (VMA)| Si giocava tra i ragazzi lanciando i 'grappicini' (infruttescenze), che si attaccavano ai capelli o ai maglioni. (TAT)| I frutti si tiravano adosso tra i ragazzi perché rimanevano attaccati alle vesti. (GGL)| I bambini si divertivano a lanciare I frutti sui capelli o sui maglioni, per farsi dispetti (MDA).

\section{Sector medicinal}

Categoría de uso: Afecciones cutáneas y tejidos subcutáneos. 


\section{María Teresa Egea Molines}

Número de informantes: 4 Partes utilizadas: órganos subterráneos.

Lavare la faccia con il decotto di radice di bardana tante volte al giorno. (BEL)| Si prendevano le foglie si raschiavano con un coltello e si applicavano sulle ferite (VMU)| Lavarsi i capelli con il decotto della radice di bardana per evitare la caduta dei capelli. (GGL)| Applicare le foglie sopra I bruffoli della faccia, finché vanno via. (CBR).

Categoría de uso: Patologías del aparato circulatorio.

Número de informantes: 1 Partes utilizadas: hojas.

Prendere delle foglie giovani di bardana e fare degli impacchi sui piedi 2 o 3 volte, quando.

uno aveva tempo. Fasciare i piedi tutte le sere e il disturbo passava. (BEL).

DATOS ETNOBOTÁNICOS BIBLIOGRÁFICOS

Nombre vulgar: caplâz, lâpa, cappellacci, laux (montagna) (UNGA21), parenti (MANG98).

Número de referencias: 2 Número de citas: 4.

Número de sectores: 2 Número de categorías: 4.

Sector lúdico/voluptuoso

Categoría de uso: Juego colectivo y bromas.

Número de referencias: 1 Partes utilizadas: frutos/infrutescencias/falsos frutos.

...erba comune le cui pallottole rotonde sono conosciute dai ragazzi, che si divertono ad.

attaccarsele alle vesti... (UNGA21).

Sector medicinal

Categoría de uso: Estado general.

Número de referencias: 1 Partes utilizadas: órganos subterráneos.

L'infuso viene bevuto ogni giorno quando si voglia ottenere un valido effetto depurativo, come.

ad esempio in privamera o nelle convalescenze. (MANG98).

Categoría de uso: Patologías del aparato urinario.

Número de referencias: 1 Partes utilizadas: órganos subterráneos.

La med. Pop. L'adopera secca in fusione come diuretica. (UNGA21).

Categoría de uso: Trastornos musculo-esqueléticos.

Número de referencias: 1 Partes utilizadas: hojas.

Una foglia fresca e contusa viene applicata su una zona affetta da reumatismo e rinnovata.

quando inizia ad appassire. (MANG98).

\section{Bellis perennis $L$.}

Nombre vulgar: Pelosini, Prataiole, Margherite senza fiore (VMR), Margherite (GUF, GRI, BOR, GGI, GFR, FAM, GFO), Prataiola, Margherite (TOA).

Número de informantes: 9 Número de citas: 12 .

Número de sectores: 5 Número de categorías: 8 .

Biotipo: Hemicriptófito. 
Tipo corológico: Europeas.

Abundancia: CCC.

Ambiente: Baldíos, prados, lugares pisoteados, generalmente sinantrópica.

Sector alimentario

Categoría de uso: Ensalada.

Número de informantes: 1 Partes utilizadas: hojas.

Mangiare le foglie crude in insalata (VMR).

Categoría de uso: Verdura cocida.

Número de informantes: 1 Partes utilizadas: hojas.

le foglie si raccolgono prima della fioritura e si mangiano cotte e condite (VMR).

Sector doméstico

Categoría de uso: Jardín.

Número de informantes: 1 Partes utilizadas: planta entera/viva.

Ha trapiantato le piantine sul prato per bellezza (VMR).

Sector lúdico/voluptuoso

Categoría de uso: Decoraciones y disfraces de niños.

Número de informantes: 1 Partes utilizadas: flores/inflorescencias y sus partes.

Con il filo e l'ago, passare ogni fiore e legare intorno al collo come una collana. (GFO).

Sector medicinal

Categoría de uso: Estado general.

Número de informantes: 1 Partes utilizadas: hojas.

A primavera si mangiavano queste piante per rinforzare il corpo, crude o cotte e condite..

Categoría de uso: Patologías del sistema nervioso.

Número de informantes: 1 Partes utilizadas: flores/inflorescencias y sus partes.

Seccare I fiori di prataiola al sole e bere il decotto per calmare e per chi soffre di insonnia (TOA).

\section{Sector religioso}

Categoría de uso: Alfombras florales.

Número de informantes: 3 Partes utilizadas: flores/inflorescencias y sus partes.

Per il Corpus Domini, facevano tappeti di margherite per le processioni (FAM)| Per il Corpus d'ominis, si facevano tappeti di margheritine (GFR)| Al Corpus Dominis, per fare tappeti di fiori, quando passava la processione per la Madonna (GGI).

Categoría de uso: Ornamento para altares e iglesias.

Número de informantes: 3 Partes utilizadas: flores/inflorescencias y sus partes.

Si portavano le margherite alla Madonna. (BOR)| Per le feste della Madonna, a Maggio, il "Ben di Maggio", tutte le sere si andava a pregare all'altare, si portavano le margherite all'altare (GRI)| Si usava mettere tante margherite sotto le immagine della Madonna (GUF).

DATOS ETNOBOTÁNICOS BIBLIOGRÁFICOS

Nombre vulgar: margheritina (SANS14), armi danza, margariten o margaritenna (UNGA21), 
margaritenna (UNGA21).

Número de referencias: 2 Número de citas: 4.

Número de sectores: 2 Número de categorías: 2 .

Sector alimentario

Categoría de uso: Ensalada.

Número de referencias: 2 Partes utilizadas: hojas.

(SANS14)| I teneri germogli primaverili del Bellis perennis sono dai contadini mangiati in insalata (UNGA21)| I tneri germogli primaverili del Bellis perennis sono dai contadini mangiati in insalata, v. armisdanza (UNGA21).

Sector lúdico/voluptuoso

Categoría de uso: Pasatiempos.

Número de referencias: 1 Partes utilizadas: flores/inflorescencias y sus partes.

Fiore che ha il monopolio de'responsi amorosi (UNGA21).

\section{Carduus nutans L. (cfr.)}

Nombre vulgar: Cardaroni (REN), Cardaròn (VSI, RGI), Cardi (MRI, BSO), Cardaron (GGI),.

Cardaron, Cardo maschio (NLA), Cardaròli (PSI).

Número de informantes: 8 Número de citas: 11.

Número de sectores: 2 Número de categorías: 5 .

Biotipo: Hemicriptófito.

Tipo corológico: Atlánticas.

Abundancia: Común.

Ambiente: Baldíos áridos, pastos soleados.

Sector alimentario

Categoría de uso: Fritura.

Número de informantes: 1 Partes utilizadas: flores/inflorescencias y sus partes.

In primavera si raccolgono I fiori chiusi, prima che siano pelosi, e si mangiano in frittura (REN).

Categoría de uso: Golosinas y masticatorias.

Número de informantes: 4 Partes utilizadas: flores/inflorescencias y sus partes.

I fiori si raccoglievano quando erano teneri, si toglieva la parte esterna e si mangiavano crudi. (VSI, RGI)| Raccolti quando erano maturi, ossia quando sfiorivano e praticamente rimaneva il frutto. Si spellavano e si mangiavano crudi quando eravamo nei campi. Il fiore bucava e sapeva di carciofo. (BSO)| Quando capitava che si trovavano nei campi incolti si spelavano come il carciofo e si mangiavano crudi. (MRI).

Categoría de uso: Verdura cocida.

Número de informantes: 4 Partes utilizadas: flores/inflorescencias y sus partes.

Si mangiava l'anima dei fiori, come I carciofi, cotti. (GGI)| I fiori maturi si mangiavano, cuocendoli a lungo. (VSI, RGI) $\mid$ Si sbucciava il fiore, e si mangiava il dentro crudo a pinzimonio come gli asparagi (NLA).

Categoría de uso: Verdura cruda.

Número de informantes: 1 Partes utilizadas: frutos/infrutescencias/falsos frutos. 
Si sbucciava il fiore, e si mangiava il dentro crudo a pinzimonio come gli asparagi (NLA).

Sector medicinal

Categoría de uso: Patologías del aparato digestivo.

Número de informantes: 1 Partes utilizadas: flores/inflorescencias y sus partes.

Bere il decotto dei fiori per il mal funzionamento del fegato. (PSI).

\section{Carlina acaulis $L$.}

Nombre vulgar: Scarline (UMI, PCL, BFE, BGI, TIV, DBA, BSO, TRU), Carlina (BEL, NRE), Scarlina, Cardi (MRI), Carline (MDA, BGI), Boneghe (VMU).

Número de informantes: 13 Número de citas: 16.

Número de sectores: 3 Número de categorías: 7.

Biotipo: Hemicriptófito.

Tipo corológico: Europeas.

Abundancia: Común.

Ambiente: Prados y pastos.

Número de exsiccata: 38912 FIAF.

Sector alimentario

Categoría de uso: Encurtidos y conserva en aceite.

Número de informantes: 1 Partes utilizadas:flores/inflorescencias y sus partes.

Adoperavano I fiori come I carciofi, sotto olio (TRU).

Categoría de uso: Golosinas y masticatorias.

Número de informantes: 4 Partes utilizadas: frutos/infrutescencias/falsos frutos,.

Quando si stava nei pascoli si mangiava la parte interna. (NRE)| Si mangiavano mentre si lavorava i campi come spuntino. (MRI) $\mid$ non specificato (BSO) $\mid$ I fiori si pulivano, si toglievano le spine e si mangiavano i cuori crudi mentre si era nei campi. (DBA).

Categoría de uso: Verdura cocida.

Número de informantes: 1 Partes utilizadas:flores/inflorescencias y sus partes.

L'interno del fiore, il bocciolo floreale, cotto veniva mangiato come il carciofo. (TIV).

Categoría de uso: Verdura cruda.

Número de informantes: 1 Partes utilizadas: flores/inflorescencias y sus partes.

Verdura cruda (BGI).

Sector doméstico

Categoría de uso: Integración de la renta familiar.

Número de informantes: 1 Partes utilizadas:flores/inflorescencias y sus partes.

Vendevano I fiori secchi. (TIV).

Categoría de uso: Ornamental.

Número de informantes: 7 Partes utilizadas: parte aérea (toda), flores/inflorescencias y sus partes.

Il 'fiore' (infiorescenza) secco si teneva in casa come ornamento. (BEL)| Fiori essicati messi in un vaso, nella casa (MDA, BGI)| Seccare I fiori delle scarline e 


\section{María Teresa Egea Molines}

metterli in un vaso dentro casa come ornamento. (BFE)| Mettere in casa la pianta secca per abbellire. (PCL)| I fiori secchi si mettono in casa dentro a vasi. (TIV)| Si mettevano I fiori secchi in un vaso in casa come ornamento (UMI).

Sector medicinal

Categoría de uso: Patologías del aparato circulatorio.

Número de informantes: 1 Partes utilizadas:flores/inflorescencias y sus partes.

Fare seccare I fiori delle boneghe, poi macinarle e ridurre in polvere. Prendere un cucchiaino da té la mattina, aiuta a fluidificare il sangue (VMU).

Notas "Non si possono toccare perché sono protette", Quando si andava dietro le pecore se ne vedevano tante nei castagneti. Le pecore pulivano sotto I castagneti, e così potevano crescere le carline e si vedevano. I castagneti erano tutti rastrellati. Alla fonte del Perio (Badi), nel parco, ci sono dei Castagneti che danno un idea di com'era tutto intorno al paese prima. Pero sono prottete, "guai a toccarli"!Le carline erano considerate infestanti all'Alpe di Stagno, dove c'erano campi coltivati. Nascevano tanto e spontanee e si toglievano.

\section{Chondrilla juncea $L$.}

Nombre vulgar: $\mathrm{Cu}$ di raso (AMA), Asparagi selvatici (PGI).

Número de informantes: 2 Número de citas: 3.

Número de sectores: 2 Número de categorías: 3 .

Biotipo: Hemicriptófito.

Tipo corológico: Europeas.

Abundancia: Común.

Ambiente: Baldíos y prados áridos.

Número de exsiccata: 39052 FIAF, 39039 FIAF, 38929 FIAF.

Sector alimentario

Categoría de uso: Ensalada.

Número de informantes: 1 Partes utilizadas: hojas.

Le foglie tenere vengono mangiate crude. È meno amara degli altri radicchi e più tenera. (AMA).

Categoría de uso: Verdura cocida.

Número de informantes: 1 Partes utilizadas: tallos herbáceos/escapos.

Asparaggi selvatici lessi e conditi, insieme alle uova soda (PGI).

Sector medicinal

Categoría de uso: Estado general.

Número de informantes: 1 Partes utilizadas: hojas.

Mangiare i radicchi amari (cu di raso, radicchio, piscialletto) e bere l'acqua di cottura spesso. (AMA).

\section{Chrysanthemum morifolium Ramat y otras especies}

Nombre vulgar: Crisantemi (TSI, NRO, GRI, DAD, BPT).

Número de informantes: 5 Número de citas: 6.

Número de sectores: 1 Número de categorías: 1. 
Biotipo: Terófito.

Tipo corológico: Cultivadas.

Abundancia: Cultivada.

Ambiente: Cultivada en los huertos.

Sector religioso

Categoría de uso: Ornamento para cementerios.

Número de informantes: 5 Partes utilizadas: flores/inflorescencias y sus partes.

Tutti ce l'avevano nell'orto per portarli al cimitero il giorno dei morti, fiorivano tutti gli anni a Ottobre (TSI, BPT)| Prima in ogni orto c' erano i crisamtemi, e a ottobre si raccoglievano per portarli al cimitero. (BPT)| Pianta coltivata negli orti familiari per portare ai morti al cimitero (DAD)| Prima in ogni orto $c^{\prime}$ erano i crisamtemi, e a ottobre si raccoglievano per portarli al cimitero, il giorno dei Morti. (GRI)| Tutte le case le coltivano per portarli il giorno dei santi al cimitero (NRO).

Notas "Ce l' hanno avuti nell'orto familiare per 10 anni, e ogni anno rifioriva", Prima tutti.

avevano crisantemi nell' orto.

\section{Cichorium intybus $L$.}

Nombre vulgar: Cicoria(BPT, CRI, EMA, LRE, MOR, NRE, PCL)Cicoria selvática(BEL, BLI, NRO, PEL, VAL, VMA), Cicorietta(BSO, MTO), Cicoriette(MSR), Culbianco(BBI, BSI, MSA, NRE, NST, RGI, RMA, VSI), Piscialletto(BSI), Radicchi(BFE, BLI, CRE, LRE, RRE)Radicchi amari(VMA)Radicchi del cul bianco(GGL, RRE), Radicchi selvatici(MOR), Radicchio(BOR, EMA, MSI, NST,PEL,PGI, PLU, VSI), Radicchio amaro(AMA, BBI, BIO, NST, PIM)Radicchio di campo(AMA, NDI), Radicchio selvático (TAT), Radicchio vero(AMA), Radichietto(BIO, MSR, MTO), Stricapugni(AN3, GGL).

Número de informantes: 37 Número de citas: 67.

Número de sectores: 2 Número de categorías: 8 .

Biotipo: Hemicriptófito.

Tipo corológico: Europeas.

Abundancia: Común.

Ambiente: En los caminos, en los baldíos y ruinas, e infestante en los huertos.

Número de exsiccata: 39027 FIAF, 38934 FIAF, 38957 FIAF, 39066 FIAF,39067.

Sector alimentario

Categoría de uso: Empanadas.

Número de informantes: 1 Partes utilizadas: hojas.

Torta salata o schiaccia alle erbe, con le erbe di staggione: fare la pasta con la farina usando il lievito madre (che era trattato come un tesoro, durava anni e gli si davano delle cure quotidiane per mantenerlo vivo sempre) e aggiungere i 'ciucioli' (siccioli, ricavati facendo cuocere il grasso del maiale e tirandoli fuori via via che venivano a galla), poi stendere la pasta. Fare cuocere le erbe di stagione come il piscialletto, le cicoriette, lo strigolo, l'ortica, i vizzadri, una volta cotte, passarle in padella con un pò di pancetta o lardo, mescolarle al formaggio 'scotta' e 4 uova. Coprire con un'altra sfoglia di pasta, quindi chiudere con la forchetta e cuocere in forno. (BSO). 


\section{María Teresa Egea Molines}

Categoría de uso: Ensalada.

Número de informantes: 29 Partes utilizadas: hojas.

Quando le foglie sono tenere, si mangiano crude in insalata (BPT)| Le foglie si mangiano crude con le uova sode. (VAL, BEL)| Le foglie della cicoria selvatica si mangiano insieme alle foglie della cicerbita, crude in insalata con le uove sode. (PEL) $\mid$ Le foglie giovani si mangiano crude in insalate e condite. (LRE)| Le foglie si mangiano crude in insalata (MOR) $\mid$ Le foglie si mangiano in insalata crude e condite con le uova sode. Sono i radicchi migliori. (MSA)| Mangiare crudo e condito. (NST)| Le foglie crude si mangiano con le uova sode. (RGI)| A primavera si raccolgono le foglie con la parte superiore della radice, si affettano sottili e si mangiano crude. (RMA)| Raccogliere la pianta dalla rosetta con un po' di radice e mangiare cruda e condita. (NRE) $\mid$ In insalata. (BSI) $\mid$ Le foglie si mangiano crude insieme alle foglie di cucumé, che crescono allo stesso tempo. (VSI)| Raccolta dalla parte inferiore, si mangia cruda in insalata. (BBI)| Mangiare le foglie dei radicchi crudi e come verdura cotta. (BFE)| Mettre le foglie giovani a bagno per un po', e mangiare crude in insalata. (CRE) $\mid$ le foglie crude nel misto con il piscialletto, la galinella, la cisevda. (VMA) $\mid$ Mangiati crudi in insalata. (GGL) $\mid \mathrm{Si}$ mangiano crudi in insalata. (RRE)| Quando ancora non ha fiorito, le foglie si mangiano in insalata. (BLI) $\mid$ Le foglie crude si mangiano in insalata. (MSI) $\mid$ Le foglie piccoline e tenere si mangiano crude in insalata (PGI) $\mid$ Le foglie crude e condite in insalata. (PLU)| $\mathrm{Si}$ mangia in insalata con le uova sode. (PIM)| Le foglie tenere si mangiano crude e condite con l'aglio. (BIO)| Le foglie tenere vanno mangiate crude in insalata con altre insalate. (AMA)| Le foglie della rosetta basale si lavano e si mangiano con le uova sode. (MTO, MSR)| Le foglie mangiate crude e condite con la pancetta rosolata nell'olio. (AN3).

Categoría de uso: Sopas de verduras y potaje.

Número de informantes: 4 Partes utilizadas: hojas.

Minestra: soffriggere aglio e prezzemolo nell'olio, poi aggiungere le foglie di piscialletto, cicorietta, striggoli e 2 patate, se ce l'avevano, poi l'acqua e quando bolle unire la pasta 'gli strapponi' (si faceva la sfoglia di acqua e farina e si strapavano pezzettini, che si facevano bollire un secondo nell'acqua bollente) (BSO)| La nonna faceva sempre degli 'intrugli' (zuppe) la sera con patate, varie specie di radicchi, cotica e fagioli. (VSI)| Mettere nella minestra di verdura qualche foglia di radicchio selvatico. (NST)| L"Acquacotta', la minestra dei poveri, era fatta con gli striggoli, il piscialletto, gli stricapugni, i dolcignoli, i radicchietti, tutti lavati e trinciati, saltati un po' in padella con un po' di unto di maiale e poi si aggiungeva l'acqua e si lasciava cuocere un po'. Poi si metteva una fetta di pane secco sul piatto, si versava la zuppa e un po' di cacio di pecora. (MSR).

Categoría de uso: Sucedáneo del café.

Número de informantes: 3 Partes utilizadas: órganos subterráneos.

Surrogato del caffé: la radice viene tostata e macinata e poi bollita (BPT)| Surrogato del caffé:Radice tostata e bollita (CRI)| Surrogato del caffé:Tostare I semi e farli bollire (NRO).

Categoría de uso: Verdura cocida.

Número de informantes: 21 Partes utilizadas: hojas. 
(BSI)Contorno della carne, quando le foglie sono più dure (BPT)| Cotta e condite $(\mathrm{CRI}) \mid$ Le foglie giovane si mangiano cotte $(\mathrm{PCL}) \mid$ Le foglie più grandi vanno cotte insieme e condite, oppure soffritte con la pancetta tagliata. (LRE)| Le foglie cotte come verdura. (EMA)| Mangiare le foglie cotte e condite (NST)| Foglie lessate come verdura cotta (RGI)| Raccolta dalla parte inferiore, si mangia cotto come verdura. (BBI) $\mid$ Mangiare le foglie dei radicchi cotti come verdura cotta. (BFE)| Mangiare I radicchi cotti come verdura $(\mathrm{CRE}) \mid$ Le foglie raccolte prima della fioritura, cotte e condite (VMA)| Mangiati cotti come contorno (GGL)| Foglie lesse e condite, oppure cotte insieme alla carne di maiale: si scottano le foglie per togliere l'amaro, poi si soffrigge il pomodoro con la carne di maiale e quando è quasi cotto si aggiungono $i$ diversi radicchi scottati. (BOR) $\mid$ Le foglie grandi si fanno bollire come verdura cotta. (PGI)| Le foglie cotte si mangiano come verdura. (NDI, PLU)| Le foglie cotte si mangiano come verdura cotta. (BIO)| Le foglie si mangiano cotte come verdura. (AMA)| Le foglie si mangiano lesse e saltate in padella, insieme ad altri radicchi. (TAT) $\mid$ Le foglie lessate e mangiate come verdura (AN3).

\section{Sector medicinal}

Categoría de uso: Estado general.

Número de informantes: 4 Partes utilizadas: hojas.

Decotto e bevuto di tanto in tanto (CRI)| Mangiare le foglie dei radicchi crudi o cotti, depurano il sangue. (BFE)| Raccoglievano diverse piante come la Malva, la Camomilla e I radicchi amari (foglie), le facevano seccare e le conservavano in dei sacchettini di stoffa. (CRE)| Mangiare i radicchi amari (cu di raso, radicchio, piscialletto) e bere l'acqua di cottura spesso. (AMA).

Categoría de uso: Patologías del aparato digestivo.

Número de informantes: 2 Partes utilizadas: hojas.

Mangiare I radicchi cotti o crudi come depurativi per il mal di stomaco o per I problemi di fegato. (CRE)| Mettere nella minestra di verdura qualche foglia di radicchio selvatico, fa bene al fegato (NST).

Categoría de uso: Patologías del aparato urinario.

Número de informantes: 1 Partes utilizadas: hojas.

Le foglie grandi si fanno bollire come verdura cotta. (PGI)| Le foglie piccoline e tenere si mangiano crude in insalata (PGI).

Notas A primavera si raccolgono le foglie con la parte superiore della radice.

\section{DATOS ETNOBOTÁNICOS BIBLIOGRÁFICOS}

Nombre vulgar: cicoria selvatica, radecc, radecc cavdagn (SANS14), armi danza, streccapoggn (UNGA21), cicôria, radecc., radecc da camp, radecc da café (UNGA21), radecc da cafà o cicòria (UNGA21).

Número de referencias: 2 Número de citas: 7.

Número de sectores: 2 Número de categorías: 4.

Biotipo: Hemicriptófito.

Tipo corológico: Europeas.

Abundancia: Común.

Ambiente: En los caminos, en los baldíos y ruinas, e infestante en los huertos. 
Sector alimentario

Categoría de uso: Ensalada.

Número de referencias: 2 Partes utilizadas: hojas (SANS14).

Più sorta d'erba che si mettono in insalata (UNGA21).

Categoría de uso: Sucedáneo del café.

Número de referencias: 1 Partes utilizadas: órganos subterráneos.

Coltivato per la radice che disseccata e torrefatta è usata come succedanea del caffe. (UNGA21)| Volg. Radicchio o cicoria selvatica, radicchio da caffé coltivato per la radice che disseccata e torreffatta è usata come succedanea del caffé. (UNGA21).

Categoría de uso: Verdura cocida.

Número de referencias: 1 Partes utilizadas: hojas (SANS14).

Sector medicinal

Categoría de uso: Estado general.

Número de referencias: 1 Partes utilizadas: No especificado, parte aérea (toda).

Tutte le varietà di radicchio sono usate nella medicina popolare in infusione come depurativo. (UNGA21)|.

\section{Cichorium intybus L. cv.}

Nombre vulgar: Cicoria (coltivata) (RMA, BAN).

Número de informantes: 2 Número de citas: 2.

Número de sectores: 1 Número de categorías: 1.

Biotipo: Hemicriptófito.

Tipo corológico: Cultivadas.

Abundancia: Cultivada.

Ambiente: Cultivada en los huertos.

Sector alimentario

Categoría de uso: Verdura cocida.

Número de informantes: 2 Partes utilizadas: hojas.

Le foglie cotte e condite come verdura (BAN)| La cicoria coltivata è amara, si mangia cotta come verdura (RMA).

\section{Cirsium vulgare (Savi) Ten.}

Nombre vulgar: Pungenti, Cardo mariano (VMR), Giglio papagone (VMU).

Número de informantes: 2 Número de citas: 6.

Número de sectores: 2 Número de categorías: 4.

Biotipo: Hemicriptófito.

Tipo corológico: Europeas.

Abundancia: Común.

Ambiente: Baldíos, bosques de monte bajo, márgenes de las vías.

Número de exsiccata: 38931 FIAF.

Sector alimentario

Categoría de uso: Ensalada.

Número de informantes: 1 Partes utilizadas: hojas. 
Le foglie piccoline, appena nascono si raccolgono in primavera e si mangiano crude in insalata, tagliati a pezzettini e conditi. (VMR).

Categoría de uso: Verdura cocida.

Número de informantes: 1 Partes utilizadas: hojas.

Le foglie giovani cotte e condite con olio e sale (VMR).

Sector medicinal

Categoría de uso: Afecciones del metabolismo.

Número de informantes: 2 Partes utilizadas: flores/inflorescencias y sus partes.

Fare seccare il fiore, poi macinarlo con il macinino da café e ridurlo in polvere. Diluirlo in acqua un cucchiaino da te e bere la mattina per il colesterolo alto (VMU)| Seccare la pianta adulta e ridurla in polvere. Poi diluire un cucchiaio di polvere nell'acqua e bere la mattina e la sera finché il sangue non fluidifichi. (VMR).

Categoría de uso: Estado general.

Número de informantes: 2 Partes utilizadas: flores/inflorescencias y sus partes.

Mettere a seccare all'ombra tutti I "semi della vita": semi delle ciliege, delle susine ossia le prugne gialle, di zucca, I pinoli, le noci, le culloie o nocciole, le foglie di malva secche, il fiore del gigliopapagone e anche un pò di olio di semi di lino. Poi macinare tutto con il macinino da caffé. E prendere un cucchiaio tutte le mattine a primavera e a ottobre. (VMU)| le foglie piccoline, appena nascono si raccolgono in primavera e si mangiano crude in insalata, tagliati a pezzettini e conditi oppure anche cotti. Servono a remineralizzare il corpo dopo l'inverno. (VMR).

\section{Crepis leontodontoides All. (cfr.)}

Nombre vulgar: Piscialletti (VMR), Ciderchie (VMU).

Número de informantes: 2 Número de citas: 4.

Número de sectores: 2 Número de categorías: 3 .

Biotipo: Hemicriptófito.

Tipo corológico: Mediterráneas montañosas.

Abundancia: Común.

Ambiente: Bosques, arbustos, desmontes (preferiblemente suelos ácidos).

Número de exsiccata: 38932 FIAF.

\section{Sector alimentario}

Categoría de uso: Ensalada.

Número de informantes: 1 Partes utilizadas: hojas.

Mangiare le foglie crude in insalata (VMR).

Categoría de uso: Verdura cocida.

Número de informantes: 2 Partes utilizadas: hojas.

Le foglie si mangiavano cotte e condite (VMU)| le foglie si raccolgono prima della fioritura e.

si mangiano cotte e condite (VMR).

Sector medicinal

Categoría de uso: Estado general.

Número de informantes: 1 Partes utilizadas: hojas. 
A primavera si mangiavano queste piante per rinforzare il corpo e depurare il sangue, crude o cotte e condite. Anche in infuso insieme alle foglie di rosmarino, salvia, e malva, si beveva a diguino la mattina e la sera per 10/15 giorni. (VMR).

Notas Riconosce Taraxacum y Crepis leodontoides come la stessa specie.

\section{Crepis sancta (L.) Bornm. (cfr.)}

Nombre vulgar: Cicerchie (VMR).

Número de informantes: 1 Número de citas: 3.

Número de sectores: 2 Número de categorías: 3.

Biotipo: Terófito.

Tipo corológico: Amplia distribución.

Abundancia: Común.

Ambiente: Baldíos, pastos áridos, ruinas.

Sector alimentario

Categoría de uso: Ensalada.

Número de informantes: 1 Partes utilizadas: hojas.

Mangiare le foglie crude in insalata (VMR).

Categoría de uso: Verdura cocida.

Número de informantes: 1 Partes utilizadas: hojas.

Le foglie si raccolgono prima della fioritura e si mangiano cotte e condite (VMR).

Sector medicinal

Categoría de uso: Estado general.

Número de informantes: 1 Partes utilizadas: hojas.

A primavera si mangiavano queste piante per rinforzare il corpo, crude o cotte e condite..

Notas Cresce nelle stoppie, nei campi di patate.

DATOS ETNOBOTÁNICOS BIBLIOGRÁFICOS

Nombre vulgar: radicchiella, ciocapiat (SANS14).

Número de referencias: 1 Número de citas: 4.

Número de sectores: 2 Número de categorías: 4 .

Sector alimentario

Categoría de uso: Ensalada.

Número de referencias: 1 Partes utilizadas: hojas (SANS14).

Categoría de uso: Verdura cocida.

Número de referencias: 1 Partes utilizadas: hojas (SANS14).

Sector medicinal

Categoría de uso: Patologías del aparato digestivo.

Número de referencias: 1 Partes utilizadas: hojas.

Mangiare le foglie nelle diverse ricette. (SANS14).

Categoría de uso: Patologías del aparato urinario.

Número de referencias: 1 Partes utilizadas: hojas.

Mangiare le foglie nelle diverse ricette. (SANS14). 


\section{Crepis vesicaria $L$.}

Nombre vulgar: Amaroni (MSR, MTO), Capelloni (AMA), Cicoria (FAM), Radicchi (RRE), Radicchio (BAZ, EMA, NST, PLU, TAT, VSI), Radicchio amaro (NST, VFR), Radicchio di campo (BAR, BSO), Radicchio selvático (SLU), Stricapugni (AN3, AP2, BAZ, BEL, EMA, FAM, GGL, GLA, MSI, MSR, MTO, PIM, RFR, RNI, SLU, SOT, TAD, VMA, VSI, ZAN), Stricapugno (MSA, PLU, TAT), Tromboni (RRE).

Número de informantes: 29 Número de citas: 51.

Número de sectores: 3 Número de categorías: 7.

Biotipo: Terófito.

Tipo corológico: Atlánticas.

Abundancia: Común.

Ambiente: Baldíos, viñedos, en los caminos.

Número de exsiccata: 39029 FIAF, 39017 FIAF, 39035 FIAF, 39038 FIAF, 39055.

Sector agropastoral

Categoría de uso: Alimentación animal (incluidos los forrajeros).

Número de informantes: 1 Partes utilizadas: hojas.

Le foglie vecchie si davano ai conigli (SLU).

Sector alimentario

Categoría de uso: Ensalada.

Número de informantes: 19 Partes utilizadas: hojas.

Foglie della rosetta crude in insalata. (AMA)| Le foglie si mangiano crude con le uova sode. (VFR)| Si mangiano le foglie tenere crude, in insalata. La caratteristica di questo radicchio è che quando lo pulivi nell'acqua le foglie si tiravano in dentro e diventavano come delle rosette chiuse nell'acqua. (BSO, BAR)| Si mangiano le foglie crude, tagliate sottili, con sale, olio e aceto. (NST) $\mid$ Le foglie mangiate crude e condite con la pancetta rosolata nell'olio. (AN3)| Le foglie crude insieme all'uovo sodo (AP2)| Le foglie crude, mangiate in insalata quando sono tenere. (BEL)| Mangiati crudi in insalata. (GGL)| Raccogliere le foglie tenere e piccole per mangiare nell'insalata insieme ai vizzadri e alle cicerbite (GLA)| insalata (PIM)| Le foglie nell'insalata, sono amare. (SOT) $\mid$ Da sola in insalata e condita o con altre insalate (TAD)| Le foglie piccoline e tenere si mangiavano in insalata crude e condite $(\mathrm{ZAN}) \mid$ Le foglie mangiate da sole o insieme alla cipolla e condite in insalata. (BAZ) $\mid$ Le foglie tenere si tagliano a pezzettini e si mangiano in insalata. (EMA)| Le foglie si raccoglievano verso Maggio e si mangiavano in insalata (SLU)| Cruda da sola o insieme ad altre insalate (FAM)| Le foglie dello stricapugno si mangiano crude, condite con un soffrito di pancetta. (TAT).

Categoría de uso: Sopas de verduras y potaje.

Número de informantes: 3 Partes utilizadas: hojas.

L"Acquacotta', la minestra dei poveri, era fatta con gli striggoli, il piscialletto, gli stricapugni, i dolcignoli, i radicchietti, tutti lavati e trinciati, saltati un po' in padella con un po' di unto di maiale e poi si aggiungeva l'acqua e si lasciava cuocere un po'. Poi si metteva una fetta di pane secco sul piatto, si versava la zuppa e un po' di cacio di pecora. (MTO, MSR)| La nonna faceva sempre degli 'intrugli' (zuppe) la sera con 
patate, radicchi, (cul bianco, cigerbe, stricapugni, piscialletto), cotica e fagioli. (VSI).

Categoría de uso: Tortilla.

Número de informantes: 3 Partes utilizadas: hojas.

Si mangiano le foglie più mature cotte e in frittata. (BSO, BAR)| Le foglie cotte messe nella frittata. (BAZ).

Categoría de uso: Verdura cocida.

Número de informantes: 22 Partes utilizadas: hojas.

Come verdura cotta, cotte e condite. (AMA)| Le foglie cotte si mangiano con le uove sode. (VFR)| Si mangiano le foglie più mature cotte e condite con olio e limone, o come verdura cotta sulle bruschette. (BSO, BAR)| Mangiare le foglie lessate e condite. (NST)| Le foglie cotte e condite. (PLU)| Le foglie lessate e mangiate come verdura (AN3)| Le foglie dello stricapuggno si mangiano cotte come verdura (AP2)| Si mangiano come verdura le foglie cotte e saltate in padella con la pancetta e un po' di aceto. (BEL) $\mid$ La rosetta basale va cotta e condita, mangiata come verdura. (MSI)| Cuocere le foglie e mangiarle condite come verdura cotta. (RFR)| Le foglie si fanno cuocere e si ripassano con olio e aglio in padella, oppure solo conditi (RNI)| le foglie degli stricapugni cotti e conditi (VMA)| Le foglie più grandi si mangiavano cotte e condite (ZAN)| Le foglie della rosetta basale cotte e condite. (MTO, MSR)| Le foglie amare vanno bollite e condite con olio e sale (BAZ)| Le foglie cotte come verdura. (EMA) $\mid$ Foglie sbollentate e condite (SLU)| Lessa e condita con olio e sale. (MSA) S Si mangiano le foglie lesse e saltate in padella, insieme ad altri radicchi. (TAT)| Si mangiano le foglie cotte e condite (RRE).

\section{Sector medicinal}

Categoría de uso: Patologías del aparato digestivo.

Número de informantes: 1 Partes utilizadas: hojas.

Mangiare le foglie cotte o crude fa molto bene allo intestino (ZAN).

Categoría de uso: Patologías del aparato urinario.

Número de informantes: 2 Partes utilizadas: hojas.

$\mathrm{E}^{\prime}$ diuretico, fa bene ai reni, purifica. (BAR) $\mid \mathrm{E}^{\prime}$ diuretico, fa bene ai reni, purifica:Si mangiano le foglie più mature cotte e condite con olio e limone, o come verdura cotta sulle bruschette. (BSO).

Notas raccolto verso Maggio, poi fa un fiore giallo, quando le foglie erano vecchie li si davano ai conigli.

\section{DATOS ETNOBOTÁNICOS BIBLIOGRÁFICOS}

Nombre vulgar: radicchiella, strecapugno (SANS14).

Número de referencias: 1 Número de citas: 7.

Número de sectores: 2 Número de categorías: 7.

\section{Sector alimentario}

Categoría de uso: Ensalada.

Número de referencias: 1 Partes utilizadas: hojas (SANS14).

Categoría de uso: Pasta y "gnocchi".

Número de referencias: 1 Partes utilizadas: hojas (SANS14).

Categoría de uso: Tortilla. 
Número de referencias: 1 Partes utilizadas: hojas (SANS14).

Categoría de uso: Verdura cocida.

Número de referencias: 1 Partes utilizadas: hojas (SANS14).

Sector medicinal

Categoría de uso: Estado general.

Número de referencias: 1 Partes utilizadas: hojas.

Mangiare le foglie nelle diverse ricette e bere l' acqua di cottura (SANS14).

Categoría de uso: Patologías del aparato digestivo.

Número de referencias: 1 Partes utilizadas: hojas.

Mangiare le foglie nelle diverse ricette e bere l' acqua di cottura (SANS14).

Categoría de uso: Patologías del aparato urinario.

Número de referencias: 1 Partes utilizadas: hojas.

Mangiare le foglie nelle diverse ricette e bere l' acqua di cottura (SANS14).

\section{Cyanus segetum Hill (= Centaurea cyanus L.)}

Nombre vulgar: Fiordaliso (MTO, MSR, BSO, BAR), Fiordalisi (BOR).

Número de informantes: 5 Número de citas: 5.

Número de sectores: 2 Número de categorías: 2 .

Biotipo: Terófito.

Tipo corológico: Esteno-mediterránea.

Abundancia: Rara.

Ambiente: Campos de cereales.

Sector doméstico

Categoría de uso: Ornamental.

Número de informantes: 2 Partes utilizadas: parte aérea (toda).

Si raccoglievano i fiori di fiordaliso per mettere nei vasi in casa o per regalarli. (BSO, BAR).

\section{Sector religioso}

Categoría de uso: Ornamento para altares e iglesias.

Número de informantes: 3 Partes utilizadas: flores/inflorescencias y sus partes.

$\mathrm{Si}$ portavano $\mathrm{i}$ fiordalisi spontenei alla Madonna. (BOR) $\mid \mathrm{Si}$ portavano i fiori selvatici per la Madonna. (MSR)| Si portavano i fiordalisi alla Madonna. (MTO).

Notas 'È da 30 anni che non li vedo più'.

\section{DATOS ETNOBOTÁNICOS BIBLIOGRÁFICOS}

Nombre vulgar: bluen (UNGA21).

Número de referencias: 1 Número de citas: 1.

Número de sectores: 1 Número de categorías: 1.

Sector medicinal

Categoría de uso: Afecciones oftalmológicas.

Número de referencias: 1 Partes utilizadas:.

fiordaliso, ciano, battisegola, fiore de' prati, in addietro impieg. Come astringente nel male. 
degli occhi (UNGA21).

\section{Helianthus annuus $L$.}

Nombre vulgar: Girasoli (BBA).

Número de informantes: 1 Número de citas: 1.

Número de sectores: 1 Número de categorías: 1 .

Biotipo: Terófito.

Tipo corológico: Cultivadas.

Abundancia: Cultivada.

Ambiente: Cultivada.

Sector doméstico

Categoría de uso: Jardín.

Número de informantes: 1 Partes utilizadas: planta entera/viva.

Coltivati nel giardino per abbelire la casa (BBA).

DATOS ETNOBOTÁNICOS BIBLIOGRÁFICOS

Nombre vulgar: gîrasåul (UNGA21).

Número de referencias: 1 Número de citas: 1.

Número de sectores: 1 Número de categorías: 1.

Sector mágico/medicinal

Categoría de uso: Otro mágico/medicinal.

Número de referencias: 1 Partes utilizadas: semillas.

...secondo la med. Empirica tre semi di questa pianta liberano dalla terzana, quattro dalla.

quartana, chi ne mangiasse molti, diventerebbe pazzo. (UNGA21).

\section{Helichrysum italicum (Roth) G.Don}

Nombre vulgar: Scuvichio bianco (NRO), Bruscolo (VMR), Bruscolo bianco (GCL, GFR),

Tignamica (TGA, TAD, PEL, BLI, TGO), Erba che puzza (BEL, BIO).

Número de informantes: 11 Número de citas: 13.

Número de sectores: 3 Número de categorías: 8 .

Biotipo: Caméfito.

Tipo corológico: Eurimediterránea.

Abundancia: Común.

Ambiente: Maquias, bosques de monte bajo, prados áridos.

Número de exsiccata: 39100 FIAF, 38981 FIAF, 39104 FIAF.

Sector doméstico

Categoría de uso: Repelentes o trampas domésticas.

Número de informantes: 1 Partes utilizadas: parte aérea (toda).

Mettere dentro ai cassoni e allo scaldino come antiparassitario o insetticida (NRO).

Sector medicinal

Categoría de uso: Afecciones oro-faríngeas y de la cavidad oral. 
Número de informantes: 2 Partes utilizadas: parte aérea (toda), flores/inflorescencias y.

Si prendeva un ramettino del cesto, si masticava e si metteva il sugo sopra le afte. (VMR)|.

Bollire per 5 minuti e bere il decotto oppure fare degli sciacqui. (GFR).

Categoría de uso: Estado general.

Número de informantes: 1 Partes utilizadas: parte aérea (toda).

Bere infuso di tignamica come depurativo (TGO).

Categoría de uso: Patologías del aparato circulatorio.

Número de informantes: 1 Partes utilizadas: flores/inflorescencias y sus partes.

Bere infuso di Tignamica, Malva e fiori di Tiglio (BLI).

Categoría de uso: Patologías del aparato digestivo.

Número de informantes: 3 Partes utilizadas: flores/inflorescencias y sus partes.

Fare seccare i fiori o i rametti di tignamica all'ombra, farli bollire per 10 minuti ('infuso') e bere un bicchiere la mattina e un altro la sera. (PEL)| Fiori messi nell'acqua bollente, lasciare coperto per $5 \mathrm{~min}$, e bere. (TAD)| Bere 2 volte al giorno il decotto della pianta (TGA).

Categoría de uso: Patologías del aparato urinario.

Número de informantes: 3 Partes utilizadas: flores/inflorescencias y sus partes.

Bollire per 5 minuniti i fiori gialli e bere ogni volta che si ha sete. (GFR)| Si faceva bollire l'acqua con i fiori gialli, che puzzavano. Poi si metteva in un catino e ci si metteva a sedere sopra per lavarsi in caso di cistite. (BIO)| Bere 2 volte al giorno il decotto della pianta (TGA).

Categoría de uso: Patologías del sistema nervioso.

Número de informantes: 1 Partes utilizadas: parte aérea (toda).

"Prendere un bel mazzo di bruscolo bianco, farlo bollire in vino rosso per 30 min.,togliere il bruscolo, e metterci dentro un asciugamano, poi metterlo sulla testa strizzato per $30 \mathrm{~min}$. finché stia meglio (GCL).

\section{Sector veterinario}

Categoría de uso: Ganado bovino.

Número de informantes: 1 Partes utilizadas: parte aérea (toda).

Fare il decotto della parte epigea e fare degli impacchi sulle spalle delle mucche e impiastri per la polmonite: applicando le foglie con l'acqua e legando con una stoffa. (BEL).

Notas Cotta è abortiva,Non ce n'è più, solo sulla strada per la chiesa di San Pellegrino. L'hanno trapiantata nell'orto., Imparato dalla sua nonna. Ha preso la pianta spontanea dal bosco e l'ha coltivato a casa sua., Prima era pieno su. Questo glielo disse una signora che indovinava i mali, e che bisognava camminare tutta una giornata per arrivare fino a lei (GCL).

DATOS ETNOBOTÁNICOS BIBLIOGRÁFICOS

Nombre vulgar: ombrente, ombrenti (MANG98), ombrenti (POLI14).

Número de referencias: 2 Número de citas: 3 .

Número de sectores: 1 Número de categorías: 3. 


\section{Sector medicinal}

Categoría de uso: Afecciones cutáneas y tejidos subcutáneos.

Número de referencias: 1 Partes utilizadas: flores/inflorescencias y sus partes.

Il decotto o 1'infuso viene applicato in impacchi sulle ferite (MANG98).

Categoría de uso: Afecciones oro-faríngeas y de la cavidad oral.

Número de referencias: 1 Partes utilizadas: No especificado.

Elicrisio, pianta erbacea perenne con fiori gialli ed odore acre. Era usata nella medicina popolare contro gli ascessi dentari. (POLI14).

Categoría de uso: Estado general.

Número de referencias: 1 Partes utilizadas: flores/inflorescencias y sus partes.

Il decotto o l'infuso viene bevuto in caso di generiche infiammazione. (MANG98).

\section{Hypochaeris radicata $L$.}

Nombre vulgar: Ingrassaporchi (MRI), Radicchio, Ingrassaporchi (UMI), Raponzoli (CBR), Piattello (PLU, BSO), Radicchio (MRI).

Número de informantes: 5 Número de citas: 9.

Número de sectores: 1 Número de categorías: 2.

Biotipo: Hemicriptófito.

Tipo corológico: Europeas.

Abundancia: Común.

Ambiente: Arenas, prados áridos, baldíos.

Sector alimentario

Categoría de uso: Ensalada.

Número de informantes: 3 Partes utilizadas: hojas.

Mangiare le foglie crude in insalata. (MRI) $\mid$ Foglie tenere mangiate in insalata con le uova sode. (UMI)| le foglie crude e condite in insalata (CBR).

Categoría de uso: Verdura cocida.

Número de informantes: 5 Partes utilizadas: hojas.

Le foglie bollite si mangiano come verdura cotta. (MRI)| Si mangiano le foglie del piattello raccolte a primavera (marzo-aprile) lessate, saltate in padella e mangiate con un uovo sodo. (BSO)| Le foglie cotte e condite. (PLU)| Si mangiavano le foglie cotte come verdura. (MRI) $\mid$ Foglie grandi, lessate e saltati in padella con olio e aglio (UMI) $\mid$ le foglie cotte e condite con olio e aceto (CBR).

Notas È la prima pianta che si mangia dopo la neve., ID:iore giallo, le foglie sono attaccate alla terra, dimensioni uguali al piscialleto, pero il piscialletto a un colore verde vivo, e questo raponzolo invece ha un colore più chiaro, e le foglie sono pelose.

\section{Lactuca sativa $L$.}

Nombre vulgar: Lattuga francese (DAD), Lattuga (LRE).

Número de informantes: 2 Número de citas: 2.

Número de sectores: 2 Número de categorías: 2 .

Biotipo: Hemicriptófito. 
Tipo corológico: Cultivadas.

Abundancia: Cultivada.

Ambiente: Cultivada y subspontanea.

Sector efecto nocivo

Categoría de uso: Efecto perjudicial.

Número de informantes: 1 Partes utilizadas: hojas.

Mangiare la lattuga spesso fa venire bruciore di stomaco. (DAD).

Sector medicinal

Categoría de uso: Patologías del sistema nervioso.

Número de informantes: 1 Partes utilizadas: hojas.

Mangiare lattuga favoriva il sonno (LRE).

\section{Lactuca sativa L. 'Francese'}

Nombre vulgar: Lattuga (DAD).

Número de informantes: 1 Número de citas: 1.

Número de sectores: 1 Número de categorías: 1.

Biotipo: Hemicriptófito.

Tipo corológico: Cultivadas.

Abundancia: Cultivada.

Ambiente: Cultivada.

Sector alimentario

Categoría de uso: Ensalada.

Número de informantes: 1 Partes utilizadas: hojas.

La lattuga francese si coltiva nell'orto e non fa venire bruciore di stomaco quando si mangia in insalata. Altre lattughe a volte fanno venire bruciore di stomaco quando si mangiano, quasta varietà non, è molto digeribile. (DAD).

Notas A primavera (dopo Giunio, già non viene tanto bene). Il seme ha più di 30 anni, glie l' ha dato Ruggero (vicino).Quando si semina, aggiunge un po di concime di coniglio alla terra, oppure un preparato di concime di Gallina, messo a macerare in acqua per una settimana. Quando si trapianta l'insalata, all'inizio annafiare con acqua, dopo "si governa" con l'acqua di concime di gallina una volta alla settimana.A primavera si semina, prima in un bidone con della terra, poi si mettono in vasettini, e quando hanno raggiunto $10 \mathrm{~cm}$ o 6 fogie in terra.Il seme si conserva in un barattolo asciutto, e può durare 2 o 3 anni.

\section{Lactuca serriola $L$.}

Nombre vulgar: Cicerbita (CFR), Radicchi (UMI).

Número de informantes: 2 Número de citas: 4.

Número de sectores: 2 Número de categorías: 3 .

Biotipo: Hemicriptófito.

Tipo corológico: Europeas.

Abundancia: Común.

Ambiente: Baldíos, viñedos, a lo largo de las calles. 
Número de exsiccata: 38986 FIAF, 39000 FIAF.

Sector agropastoral

Categoría de uso: Alimentación animal (incluidos los forrajeros).

Número de informantes: 1 Partes utilizadas: hojas.

Foraggera per i conigli (CFR).

Sector alimentario

Categoría de uso: Ensalada.

Número de informantes: 1 Partes utilizadas: hojas.

Mangiati in insalata (CFR).

Categoría de uso: Verdura cocida.

Número de informantes: 2 Partes utilizadas: hojas.

Da sola e condita (CFR) Foglie grandi, lessate e saltati in padella con olio e aglio (UMI).

\section{DATOS ETNOBOTÁNICOS BIBLIOGRÁFICOS}

Nombre vulgar: lattuga (MANG98).

Número de referencias: 1 Número de citas: 1.

Número de sectores: 1 Número de categorías: 1.

Sector medicinal

Categoría de uso: Otro medicinal.

Número de referencias: 1 Partes utilizadas: látex o savia.

Il 'latte'viene considerato afrodisiaco, un rito magico locale lo utilizza anche come filtro amoroso, consigliandone la nascosta somministrazione per avvicinare la persona amata. (MANG98).

\section{Leucanthemum vulgare (Vaill.) Lam. (s. l.)}

Nombre vulgar: Camomilla selvatica (VMU), Margheritoni (VMA).

Número de informantes: 2 Número de citas: 3 .

Número de sectores: 2 Número de categorías: 3 .

Biotipo: Hemicriptófito.

Tipo corológico: n.d.

Abundancia: Común.

Ambiente: Prados segados.

Número de exsiccata: 38952 FIAF, 39093 FIAF.

Sector medicinal

Categoría de uso: Patologías del aparato urinario.

Número de informantes: 1 Partes utilizadas: parte aérea (toda).

Si raccoglievano le piante di camomilla selvatica, si mettevano a seccare all'ombra e si.

tagliavano a quadretti. Poi si faceva l'infuso e si prendevano per fare urinare (VMU).

Categoría de uso: Patologías del sistema nervioso.

Número de informantes: 1 Partes utilizadas: parte aérea (toda). 
Etnobotánica en el Alto Valle del Reno (Toscana y Emilia-Romaña, Italia)

Si raccoglievano le piante di camomilla selvatica, si mettevano a seccare all'ombra e si.

tagliavano a quadretti e si prendono per dormire la sera come sedativo (VMU).

Sector religioso

Categoría de uso: Ornamento para altares e iglesias.

Número de informantes: 1 Partes utilizadas: flores/inflorescencias y sus partes.

Si usava per fare le ghirlande con I glicini (maggiociondolo), I margheritoni e le rose, quando portavano la madonna, una domenica di maggio. (VMA).

DATOS ETNOBOTÁNICOS BIBLIOGRÁFICOS

Nombre vulgar: artemîlia (UNGA21).

Número de referencias: 1 Número de citas: 1.

Número de sectores: 1 Número de categorías: 1.

Sector medicinal

Categoría de uso: Afecciones ginecológicas, complicaciones obstétricas, del postparto y del puerperio.

Número de referencias: 1 Partes utilizadas:.

Adop. dalle donne contro I mali della matrice (UNGA21).

Notas Ciò dal nome della Regina Artemisia, la quale vuolsi sia stata la prima ad adoperarla a tale uso.

\section{Matricaria chamomilla L.}

Nombre vulgar: Camomilla.

(VMA, REN, GUF, GRI, BBI, RMA, MGE, CAR, BFE, TUL, PLU, NDI, MTO, MTI, MGO, LRE, GGL, BSO, AMA, LST, TIV, TAD, MSR, GFR, BLI, BAN, SOT, RFR, PIM, GFO, CRI, CFR, CBR, BGI, BEL, BAZ, VFR, UMI, TGA, CRO, CRE, CLO, PSI, PIA, NRO, MVI, DAD, NST), Camomilla selvatica (BOR, GCL).

Número de informantes: 50 Número de citas: 87.

Número de sectores: 3 Número de categorías: 12 .

Biotipo: Terófito.

Tipo corológico: Amplia distribución.

Abundancia: Rara.

Ambiente: Invasoras de los cultivos de cereales.

Número de exsiccata: 38892 FIAF.

\section{Sector alimentario}

Categoría de uso: Licor.

Número de informantes: 1 Partes utilizadas: flores/inflorescencias y sus partes.

Cento erbe': 3 foglie di alloro, 3 foglie di limone, 3 coccole di ginepro, 3 fiori di camomilla, 3 foglie di té, 3 foglie di salvia, 3 foglie di rosmarino, mettere a macerare in un litro di acqua bollita con 350 gr di zucchero e a cui siano stati poi aggiunti 40 gr di alcol a $90^{\circ}$. (NST).

Sector doméstico

Categoría de uso: Cuidado personal y cosmética. 
Número de informantes: 6 Partes utilizadas: flores/inflorescencias y sus partes.

Fare un decotto dei fiori e lavarsi i capelli per farli diventare piu chiari (DAD)| Fare il decotto dei fiori di camomilla e lavare i capelli per fare diventare i capelli biondi ancora più biondi. (MVI)| Bollire la camomilla e lavare i capelli chiari con l'acqua di camomilla (NRO) $\mid$ Decotto per lavare i capelli biondi (PIA) $\mid$ Fare il decotto dei fiori di camomilla e lavare i capelli per fare diventare $i$ capelli biondi ancora piu biondi. (PSI) $\mid$ Decotta, per lavare i capelli dei biondi (GCL).

\section{Sector medicinal}

Categoría de uso: Afecciones cutáneas y tejidos subcutáneos.

Número de informantes: 1 Partes utilizadas: flores/inflorescencias y sus partes.

Si mettono a macerare i fiori in olio di oliva per un po' di giorni (CLO).

Categoría de uso: Afecciones del aparato respiratorio.

Número de informantes: 5 Partes utilizadas: flores/inflorescencias y sus partes.

Fare bollire l'acqua e aggiungere I fiori di camomilla da soli oppure nel fiorume insieme agli altri fiori secchi del fieno, poi fare i fumenti coperti di un asciugamano (CRE)| Fare i fumenti con acqua e camomilla per la tosse. (CRO)| Mettere a bollire Ie infiorescenze della camomilla e bere il decotto per il catarro (TGA)| Fare fumenti con il fiorume (I fiori secchi del fieno) per il raffreddore, dentro al fiorume c'erano anche I fiori di camomilla (UMI)| Fare dei fumenti con i fiori di camomilla per il raffreddore. (VFR).

Categoría de uso: Afecciones ginecológicas, complicaciones obstétricas, del postparto y del puerperio.

Número de informantes: 2 Partes utilizadas: flores/inflorescencias y sus partes.

Mettere un po' di fiori nell'acqua bollente e bere. (DAD)| Mettere a bollire Ie infiorescenze della camomilla e bere il decotto per le mestruazioni dolorose (TGA).

Categoría de uso: Afecciones oftalmológicas.

Número de informantes: 12 Partes utilizadas: flores/inflorescencias y sus partes Si raccoglievano I fiori a San Giovanni, si faceva il decotto e e si facevano degli impacchi sugli occhi. (BAZ)| Fare un decotto dei fiori secchi di camomilla e fare degli impacchi sugli occhi. (BEL)| Mettere i fiori freschi o secchi nell' acqua bollente e fare impacchi sugli occhi (BGI)| Lavare gli occhi con la camomilla raccolta nei campi e fatta in infusione, solo un bollore (CBR)| "ogni tanto,finché passa" (CFR)| Bagnare un tessuto nel decotto e mettere sopra gli occhi rossi (CRI)| Impacco sugli occhi (GFO)| Fare degli impacchi di camomilla per le infezioni agli occhi. (PIM)| Fare il decotto dei fiori di camomilla, bagnare le pezze e metterli sugli occhi arrossati. (PSI)| In caso di occhi infiammati, applicare garze bagnate nel decotto di camomilla facendo impacchi. (RFR)| Applicare una stoffa imbevuta nell'infuso di camomilla e malva sugli occhi (SOT)| Facevano bollire la Camomilla selvatica, la passavano per una tela di lino e facevano gli impacchi (CLO).

Categoría de uso: Afecciones oro-faríngeas y de la cavidad oral.

Número de informantes: 7 Partes utilizadas: flores/inflorescencias y sus partes.

Si raccoglievano i fiori e si mettevano a seccare. Fare un infuso e usarlo per lavarsi la bocca. (BAN)| Per il mal di denti fare bollire le infiorescenze e fare sciaqui. Oppure bere infuso di Malva, Salvia e Camomilla (BLI)| Bollire i fiori di camomilla brevemente e mettere un impacco. (GFR)| Per rinfrescare la bocca, per le 
infiammazione alla bocca fare degli sciacqui spesso con l'infuso di camomilla. (MSR)| La camomilla viene raccolta per la "mestrana" e si seccava. In caso di mal di denti, mettere una buona quantità di fiori nell'acqua bollente e fare gargarismi, oppure prendere una garza bagnata nell'infuso forte e fare impacchi sul dente. (TAD)| Mettere a bollire Ie infiorescenze della camomilla e fare sciacqui con il decotto per il mal di denti. (TGA)| Mettevano a seccare le infiorescenze.Fare bollire le infiorescenze, e fare sciaqui per le infiammazione alla boca. (TIV).

Categoría de uso: Afecciones típicas infantiles.

Número de informantes: 3 Partes utilizadas: flores/inflorescencias y sus partes.

Raccogliere I fiori, mettere a seccare a mazzettini, poi bollire e fare bere il decotto ai bambini come rilassante. (LST)| Raccogliere le infiorescenze verso luglio/agosto, metterle a seccare all'ombra e conservarle in un vaso di vetro. Mettere un po' di fiori nell'acqua bollente e lasciare coperto 10 minuti. Fare degli impacchi nelle zone arrossate della pelle dei bimbi. (MSR)| Fare bere un po' di decotto di fiori secchi per il 'mal di pancia' dei bambini piccoli. (PIM).

Categoría de uso: Estado general.

Número de informantes: 16 Partes utilizadas: flores/inflorescencias y sus partes.

Raccolta quando è in fiore, messa a seccare all'ombra. Bollire $10 \mathrm{~min}$. e bere il decotto per tutti i tipi di infiammazione. (AMA) $\mid$ Si raccoglievano, si mettevano a seccare i fiori. Fare un infuso di camomilla e bere. (BAN)| Raccogliere I fiori a giugno e metterli a seccare al sole. Far bollire per 10 minuti 'per rinfrescare'. (BSO)| Raccoglievano diverse piante come la Malva, la Camomilla e I radicchi (foglie), le facevano seccare e le conservavano in dei sacchettini di stoffa. (CRE)| Fare l'infuso di camomilla e bere come 'rinfrescante'. (GGL)| Bere il decotto dei fiori di camomilla per le infiammazioni varie. (LRE)| Raccogliere I fiori, mettere a seccare a mazzettini, poi bollire e fare bere il decotto come antinfiammatorio. (LST)| Bere l'infuso di tanto in tanto. (MGO)| Fare l'infuso di camomilla e berlo come 'rinfrescante'. La raccoglieva e la seccava per averla sempre a casa. (MTO, MSR)| Fare un decotto dei fiori secchi e delle foglie e bere come 'rinfrescante'. (MTI)| Fare il decotto di camomilla e bere come 'rinfrescante'. (NDI)| Bere l'infuso come antinfiammatorio. (PLU)| Fare un decotto di fiori di camomilla e bere di tanto in tanto per sfiammare. Il suo nonno la raccoglieva in autunno e la seccava per l'inverno. (RFR) si essicavano i fiori, si faceva un infuso e si beveva quando uno 'stava male'. (TUL)| Bere il decotto di camomilla selvatica come 'rinfrescante'. (BOR).

Categoría de uso: Patologías del aparato digestivo.

Número de informantes: 12 Partes utilizadas: flores/inflorescencias y sus partes.

Fare l'infuso di camomilla e bere quando si ha il disturbo. (BFE)| Raccogliere la camomilla e farla seccare al sole, poi si facevano degli infusi e si bevevano per il mal di pancia. (CAR)| "Ogni tanto finché passa, qualche cucchiaino di fiori secchi messi a riposare in acqua bollente per 5-10 minuti, con mezzo cucchiaino di zucchero (CFR)| Fare bollire I fiori e bere "l'acqua di camomilla". Si mettevano a seccare I fiori per conservarli. (CRE) $\mid$ Bere il decotto dei fiori di camomilla per il mal di pancia. (LRE)| Bere l'infuso dei fiori della camomilla contro il mal di pancia (MGE)| Raccogliere le infiorescenze verso luglio/agosto, metterle a seccare all'ombra e conservarle in un vaso di vetro. Mettere un po' di fiori nell'acqua 


\section{María Teresa Egea Molines}

bollente e lasciare coperto 10 minuti. Dare un cucchiaio di infuso ai piccoli di 2 o 3 mesi con problemi di stitichezza. (MSR)| Fare il decotto di camomilla e con una pera fare un clistere. (MTI)| Bere l'infuso di camomilla quando si ha mal di pancia (NRO)| Si raccoglieva nei campi e si metteva a seccare. (RMA)| Mettere a bollire Ie infiorescenze della camomilla e bere il decotto per il mal di stomaco (TGA)| Bere il decotto quando si ha mal di stomaco (GCL).

Categoría de uso: Patologías del sistema nervioso.

Número de informantes: 21 Partes utilizadas: flores/inflorescencias y sus partes.

Raccolta quando è in fiore, messa a seccare all'ombra. Cuocere $10 \mathrm{~min}$. e bere il decotto per rilassare. (AMA) $\mid$ Si raccoglievano e si mettevano a seccare i fiori. Fare un infuso di camomilla e bere. (BAN)| Fare bollire i fiori di camomilla e bere per dormire meglio. (BBI)| Fare l'infuso di camomilla e bere quando si ha il disturbo. (BFE) $\mid$ Fare bollire le infirorescenze e bere come calmante. (GRI, BLI)| Raccogliere I fiori a giugno e metterli a seccare al sole, poi farli bollire e fare bere ai bambini come calmante la sera. (BSO)| "qualche cucchiaino di fiori secchi messi a riposare in acqua bollente per 5-10 minuti, con mezzo cucchiaino di zucchero (CFR)| Bere il decotto di camomilla per calmare (CRE)| Fare l'infuso di camomilla e bere contro l'insonnia. (GGL)| Bere un infuso di camomilla per domire (GUF)| Bere il decotto quando si è agitati (MGO)| Raccogliere le infiorescenze verso luglio/agosto, metterle a seccare all'ombra e conservarle in un vaso di vetro. Fare l'infuso di camomilla come rilassante: mettere un po' di fiori nell'acqua bollente e lasciare coperto 10 minuti. Va bene anche per favorire il sonno dei bambini. (MSR)| Fare l'infuso di camomilla come rilassante. La raccoglieva e la seccava per averla sempre a casa. (MTO)| Dare da bere ai bambini l'infuso di camomilla (NRO)| Bere il decotto di fiori secchi come rilassante per dormire. Però non abusare perché la camomilla è forte e 'dava anche debolezza'. (PIM)| Bere l'infuso come calmante, antinfiammatorio, per dormire. (PLU)| Prendere un decotto di camomilla per conciliare il sonno più facilmente. (REN)| Prima di andare al letto, per fare addormentare i nervosi (SOT)| si essicavano i fiori, si faceva un infuso e si beveva quando uno era nervoso. (TUL)| Bere l'infuso dei fiori di camomilla per dormire (VMA).

Categoría de uso: Trastornos musculo-esqueléticos.

Número de informantes: 1 Partes utilizadas: flores/inflorescencias y sus partes.

Fare bollire le infiorescenze, fare un impacco delle foglie e dei fiori oppure berla contro I.

dolori. (BLI).

Notas Piu di 40 anni fa era pieno, ora non cresce niente sotto i pini, Adesso non si trova più, una volta ce n'era tanta., non ce n'è più, non si raccoglie più perché non fanno più fieno, Raccolte quando sono in fiore, e messe ad essicare all'ombra. Fiorisce a maggio, cresce nei posti concimati e recintati sennò è impossibile trovarla fuori. Il suo nonno la raccoglieva in autunno e la seccava per l'inverno. la camomilla non c'è più da quando non ci sono più le galline.

\section{DATOS ETNOBOTÁNICOS BIBLIOGRÁFICOS}

Nombre vulgar: camomilla (MUCC01, MANG98), camamella, brufacûl (UNGA21), camomilla. 
Etnobotánica en el Alto Valle del Reno (Toscana y Emilia-Romaña, Italia)

spontanea (ZAGN90).

Número de referencias: 4 Número de citas: 9.

Número de sectores: 1 Número de categorías: 8 .

Sector medicinal

Categoría de uso: Afecciones cutáneas y tejidos subcutáneos.

Número de referencias: 1 Partes utilizadas: flores/inflorescencias y sus partes.

L'infuso si utilizza esternamente in impacchi su ezcemi ed dermatiti varie (MANG98).

Categoría de uso: Afecciones del aparato respiratorio.

Número de referencias: 1 Partes utilizadas: flores/inflorescencias y sus partes.

Con i vapori si effettuano suffumigi in caso di occhi infiammati e di raffreddore. (MANG98).

Categoría de uso: Afecciones ginecológicas, complicaciones obstétricas, del postparto y del puerperio.

Número de referencias: 1 Partes utilizadas: parte aérea (toda).

L'uso della camomilla spontanea è limitato alla medicina familiare. In questa si ritiene efficace contro I dolori della matrice, bevendola in infuso. Si adoperano le foglie, ma più spesso I fiori, cui si attribuisce inoltre virtù anodina, mollificante, diuretico.(UNGA21),

Categoría de uso: Afecciones oftalmológicas.

Número de referencias: 2 Partes utilizadas: flores/inflorescencias y sus partes.

Per far scomparire gli orzaioli si facevano impacchi con I fiori secchi della camomilla spontanea (ZAGN90)| Con i vapori si effettuano suffumigi in caso di occhi infiammati e di raffreddore. (MANG98).

Categoría de uso: Afecciones típicas infantiles.

Número de referencias: 1 Partes utilizadas: flores/inflorescencias y sus partes.

Li si faceva il bagno coll'acqua di semola e la camomilla, ma no tutti i giorni perché una volta mi disse una vecchia di Lancisa, il bagno demolisce. (MUCC01).

Categoría de uso: Patologías del aparato urinario.

Número de referencias: 1 Partes utilizadas: flores/inflorescencias y sus partes.

Si adoperano le foglie, ma più spesso I fiori, cui si attribuisce inoltre virtù anodina,. mollificante, diuretico. (UNGA21).

Categoría de uso: Patologías del sistema nervioso.

Número de referencias: 1 Partes utilizadas: flores/inflorescencias y sus partes.

Internamente lo si ritiene un blando sedativo (MANG98).

Categoría de uso: Trastornos musculo-esqueléticos.

Número de referencias: 1 Partes utilizadas: flores/inflorescencias y sus partes.

Si prepara un linimento facendo cuocere in olio d'oliva galbuli di ginepro, foglie di canfora e capolini di camomilla, il preparato così ottenuto, dopo filtrazione, serve per massaggi antireumatici. (MANG98).

Notas detta anche brufacul per certi effetti che producono le foglie. 


\section{Petasites hybridus (L.) G.Gaertn., B.Mey. \& Scherb.}

Nombre vulgar: Farfalloni (NLA), Farfanacci (BSO, BAR, BEL), Farfanaccio (NRE, BMA, MRI), Farfanello (GUF), Farfari (MGO, MDA), Farfaro (BLI, SOT, BPT, BGI), Farfallone (GFR, GGI, BPI).

Número de informantes: 17 Número de citas: 23 .

Número de sectores: 7 Número de categorías: 8 .

Biotipo: Geófito.

Tipo corológico: Europeas.

Abundancia: Común.

Ambiente: Lugares húmedos, orillas, bordes de los bosques húmedos.

Sector agropastoral

Categoría de uso: Alimentación animal (incluidos los forrajeros).

Número de informantes: 9 Partes utilizadas: hojas, parte aérea (toda).

A volte si mettevano con il resto dell'erba per la mucca, o loro stesse andavano a angiarle (NLA)| Le foglie si davano da mangiare ai conigli (BEL)| Quando non c'era più tanta erba si mandavano le mucche sul fiume a mangiarle oppure si davano anche alle pecore (però non gli piacevano tanto) (MRI)| Le foglie erano datte da mangiare ai conigli (GUF)| Le foglie crude date da mangiare alle pecore. (MDA) Farfari cotti insieme all'ortica, alle patate, alla frutta, e alla verdura, fa bene ai maiali (MGO)| Cotta per I maiali (BGI)| Si raccoglievano I farfari nei fossi e si davano ai mailai insime all'ortica e gli avanzi di casa (BPT)| Come verdura per gli animali, soprattutto al maiale. Ai maiali si danno le foglie lesse insieme alla semola e alla barbabietola lessa. (SOT).

Categoría de uso: Horticultura.

Número de informantes: 2 Partes utilizadas: hojas.

Le foglie del farfanaccio si usano per proteggere $\mathrm{i}$ trapianti delle piantine di pomodori dal sole, mettendoglieli sopra. (BMA)| Quando si trapiantava l'insalata, si mettevano sopra le foglie del farfanello per protteggerle dal sole (GUF).

\section{Sector alimentario}

Categoría de uso: Fritura.

Número de informantes: 1 Partes utilizadas: hojas.

I gambi della foglia si spellavano, si impanavano e si friggevano: avevano sapore di cardi..

(BPI).

Sector caza y pesca

Categoría de uso: Otro caza y pesca.

Número de informantes: 2 Partes utilizadas: hojas.

Quando si andava a pesca I pesci si avvolgevono per tenerli freschi e si infilzavano con uno stropello a forma di Y e sopra la foglia di farfallone (BPI)| Quando si andava a pesca I pesci si avvolgevono per tenerli freschi e si infilzavanp con uno stropello a fomra di Y e sopra la foglia di farfallone (GGI).

Sector doméstico

Categoría de uso: Otro doméstico. 
Número de informantes: 5 Partes utilizadas: hojas.

Per fare delle bustine per raccogliere le fragole di bosco, e si chiuedevano con la palea. (GFR)| Simulazione di un ombrello:Quando pioveva, per non bagnarsi troppo, si prendeva una foglia grande lungo il fiume e si metteva sopra la testa alla rovescia (GGI)| Per conservare Il burro, si avvolgeva con le foglie grandi e si metteva in un vaso con l'acqua fresca vicino al fiume. (BAR)| Per conservare Il burro, si avvolgeva il burro con le foglie grandi a si metteva in un vaso con l'acqua fresca vicino al fiume, o nelle burraie (che erano cantine sotto terra delle case dove si conservavano gli alimenti). (BSO)| Simulare un ombrello:Quando pioveva, si metteva come un ombrello. (BGI).

Sector lúdico/voluptuoso

Categoría de uso: Decoraciones y disfraces de niños.

Número de informantes: 1 Partes utilizadas: hojas.

Facevamo i cappelli. (NRE).

Sector medicinal

Categoría de uso: Afecciones cutáneas y tejidos subcutáneos.

Número de informantes: 2 Partes utilizadas: hojas.

Sbollentare la foglia: quando bolle l'acqua mettere un attimo le foglie nell'acqua. Mettere le foglie sulla ferita. (BSO, BAR).

Sector veterinario

Categoría de uso: Cerdos.

Número de informantes: 1 Partes utilizadas: parte aérea (toda).

Per prevenire la "Moria" dei maiali (pandemia ). Quando si sentiva dire che c'era la moria, si dava da mangiare ai maiali la 'broda': cuocere l'ortica insieme alle patate, alle carote, al farfaro, alle castagne secche e alla semola. (BLI).

\section{Picris hieracioides $L$.}

Nombre vulgar: Radicchi (PCL), Radicchio (PCL).

Número de informantes: 1 Número de citas: 2.

Número de sectores: 1 Número de categorías: 1 .

Biotipo: Hemicriptófito.

Tipo corológico: Nórdicas.

Abundancia: Común.

Ambiente: Baldíos, a lo largo de los caminos.

Sector alimentario

Categoría de uso: Verdura cocida.

Número de informantes: 1 Partes utilizadas: hojas.

Quando le foglie sono grandi si mangiano cotte come verdura (PCL).

DATOS ETNOBOTÁNICOS BIBLIOGRÁFICOS

Nombre vulgar: armi danza (UNGA21).

Número de referencias: 1 Número de citas: 1.

Número de sectores: 1 Número de categorías: 1. 


\section{María Teresa Egea Molines}

\section{Sector alimentario}

Categoría de uso: Ensalada.

Número de referencias: 1 Partes utilizadas: hojas.

mescolanza', più sorta d'erba che si mettono in insalata e segnatamente da noi il Chaerophillum sativum Pers., cerfoglio, volg. Mescolanza, p. da orto simile al prezzemolo. La mescolanza è l'insalata de'contadini composta de' teneri germogli primaverili di moste piante, quali il Bellis perennis L., il Picris hieracioides L., e varie specie di Sonchus, v. zrâbbla. Entrano nella mescolanza baerba ed bâcc, baerba ed capuzen, ciôcapiât, dulzett, grasagalenna, pcand'pîgra, pimpinaela, radciaela, raponsel, streccapoggn, ecc., v. alle singole voci. Probabilmente la maggior parte delle erbe aromatiche mangereccie, entrate oggi nel novero delle medicinali, quali l'aglio. la maggiorana, la menta, la mercorella, la salvia, ecc. erano anticamente mangiate in insalata. (UNGA21).

\section{Sonchus oleraceus L. (s. l.)}

Nombrevulgar:Cicerba (MSA, RGI, RMA, VSI), Cicerbe (BBI, GGL, GGL, MIO, BAZ), Cicerbita (BBA, BPI, CFR, CRE, FAM, FAM, GAN, GGI, GLA, MDA, MGO, MSR, MTO, NLA, NRO, PCL, PEL, SCO, SLU, TAD, TIV, TRU, TUL), Cicerbita, Cigerbda (MSR), Cicerbite (AMA), Cicerbole (LGI), Cicerchia (BAN, NST), Cicerchie (VFR), Cicervide (PIM), Cicoria (VMR), Cigerbda (MSR, MSR, MTO), Cigerbe (NST), Cigervde (RRE), Cigervida (RFR), Cigevda (NRE, VMA), Frats (AN3), Gerba (BEL), Gerbe (PLU), Gerbelina (TAT), Gerbi (LRE, ZAN), Gerbia (NDI), Gerbie (AMA), Gerbio (PGI), Gigerbite (RNI), Radicchi (BFE, PCL), Radicchio (LGI, PEL, VSI), Spinone (BAR, BSO).

Número de informantes: 53 Número de citas: 96.

Número de sectores: 3 Número de categorías: 10.

Biotipo: Terófito.

Tipo corológico: Amplia distribución.

Abundancia: Bastante Común.

Ambiente: Cultivos fertilizados, muros, márgenes de los caminos.

Número de exsiccata: 39056 FIAF, 38956 FIAF, 39021 FIAF, 39057 FIAF, 38994.

Sector agropastoral

Categoría de uso: Alimentación animal (incluidos los forrajeros).

Número de informantes: 2 Partes utilizadas: hojas.

Foraggera per i congigli (CFR)| Quando erano vecchie li si davano ai conigli (SLU).

Sector alimentario

Categoría de uso: Ensalada.

Número de informantes: 39 Partes utilizadas: hojas.

Cruda in insalata e condita con olio e sale. (MSA) $\mid$ Le foglie tenere crude in insalata. (TAT, RGI)| Si mangiano le foglie tenere crude, in insalata. (RMA)| Le foglie tenere si mangiano crude da sole e condite. (VSI)| Le foglie tenere si mangiano crude e condite in insalata. (BSO, BAR, LRE, BEL, GGL)| Foglie tenere mangiate crude con uova soda e condite. (BBA)| Mangiati in insalata (CFR)| Mangiate crude in insalata. (CRE)| Cruda con altre insalate quando è giovane e tenera (FAM)| 
Mangiare le foglie crude in insalata. (GAN)| Crude insieme ad altre insalate (GGI)| Raccogliere le foglie tenere e piccole per mangiare nell'insalata insieme ai vizzadri e gli stricapugni (GLA)| Foglie tenere mangiate crude e condite. (TIV, MGO)| Cruda e condita (NLA)| Le foglie tenere si mangiano crude in insalata (NRO) $\mid$ Con altre insalate, crude. (SLU) $\mid$ Le folie tenere vengono mangiate in insalata (TRU) $\mid$ Crude e condite (TUL) $\mid$ Le foglie della cicerbita si mangiano crude in insalata insieme alle foglie della cicoria selvatica, con le uove sode. (PEL) $\mid$ Le foglie giovani si mangiano crude e condite. (MTO, MSR)| Le foglie si raccolgono a primavera nei campi e si mangiano crude e condite, anche con altre insalate selvatiche. (LGI)| Le foglie si raccolgono prima della fioritura e non quelle sulla strada e si mangiano crude in insalata. (VMR) $\mid$ Le foglie crude e condite in insalata. (RRE)| Le foglie tenere vanno mangiate crude in insalata con altre insalate. (RFR) $\mid$ Foglie tenere mangiate crude in insalata. (NRE)| Le foglie crude in insalata insieme al radicchio crudo, e alla galinella, al piscialletto (VMA)| Le foglie piccoline e tenere si mangiavano in insalata crude e condite (ZAN)| Le foglie tenere vanno mangiate crude in insalata con altre erbe. (AMA) $\mid$ Le foglie piccoline e tenere si mangiano in insalata (PGI)| Le foglie piccole raccoglievano e si faceva un insalata mixta insieme ai dolcignoli. (RNI)| Mangiare le foglie dei radicchi crudi e come verdura cotta. (BFE)| Quando le foglie sono giovane e tenere si mangiano crude in insalata e condite (PCL).

Categoría de uso: Golosinas y masticatorias.

Número de informantes: 1 Partes utilizadas: tallos herbáceos/escapos.

Il 'getto' (stelo) si pelava e si mangiava, come si faceva con il guzzedro, quando si era nei.

campi e si andava dietro alle pecore. (BEL).

Categoría de uso: Relleno de ravioli.

Número de informantes: 4 Partes utilizadas: hojas.

Cotti, insieme a mollica di pane e formaggio o solo formaggio, e insieme ai piscialleti. Ma si possono mettere anche trittati e crudi. (TAD)| Le foglie cotte e mescolate alla ricotta come ripieno per fare i tortelli. (MTO, MSR) $\mid$ Le foglie delle gerbie cotte e mescolate alla ricotta per fare il ripieno dei tortelloni. (NDI).

Categoría de uso: Sopas de verduras y potaje.

Número de informantes: 2 Partes utilizadas: hojas.

La nonna faceva sempre degli 'intrugli' (zuppe) la sera con patate, radicchi, cotica e fagioli. (VSI)| L"Acquacotta', la minestra dei poveri, era fatta con gli striggoli, il piscialletto, gli stricapugni, le cicervde, i dolcignoli, i radichietti, tutti lavati e trinciati, saltati un po' in padella con un po' di unto di maiale (pancetta ) o olio e sale e poi si aggiungeva l'acqua e si lasciava cuocere. Si versava in un piatto con una o due fette di pane secco e del cacio di.

Categoría de uso: Sucedáneo del café.

Número de informantes: 1 Partes utilizadas: hojas.

Le foglie della cicoria secche insieme alle ghiande secche di quercia, si macinavano, si bolliva e si faceva il caffé. (VMR).

Categoría de uso: Tortilla.

Número de informantes: 4 Partes utilizadas: hojas. 
Foglie bollite e messe nella frittata. (GGL)| Le foglie grandi vanno cotte e messe nella frittata. (MGO)| Lesse e messe nella frittata (TUL)| Saltare le foglie in padella e poi aggiungere le uova per fare la frittata. (AMA).

Categoría de uso: Verdura cocida.

Número de informantes: 40 Partes utilizadas: hojas.

Lessa e condita con olio e sale. (MSA)| Si mangiano le foglie lessate come verdura cotta. (RGI)| Si mangiano le foglie cotte e condite come verdura. (BAN, MIO, RMA)| Si mangiano le foglie cotte, non miste a altre erbe ma da sole. (VSI)| Raccolta dalla parte inferiore, si mangia cotta come verdura. (BBI)| Quando le foglie sono dure, bollirle e condirle come verdura cotta. (GGL)| Le foglie cotte e condite. (BAZ) $\mid$ Le foglie cotte e condite si mangiano come verdura cotta (BPI)| Da sola e condita (CFR) $\mid$ Cotta e condita, da sola o con altre verdure quando è piu grande e dura. (FAM)| Mangiare le foglie anche grandi cotte e condite. (GAN)| Cuocere le foglie di cicerbita (MDA)| Le foglie piu grandi si mangiano cotte come verdura cotta e condita. (NRO)| Foglie cotte insieme ad altre piante selvatiche (con cicoria, rucola, radicchio). Fagioli con cicerbita: cuocere i fagioli con foglie di cicerbita e aglio. (SCO) $\mid$ Cotta da sola o con altre verdure (TAD) $\mid$ Foglie grandi cotte e condite, da sola come verdura. (TIV)| Lesse e condite (TUL) $\mid$ Si mangiano le foglie cotte e condite, da sole o con altre foglie come con il piscialletto. (MTO, MSR)| Le foglie si raccolgono a primavera nei campi e si mangiano come verdura cotta, anche insieme ad altre piante. (LGI)| Le foglie cotte si mangiano come verdura (VFR)| Si mangiano le foglie cotte e condite (RRE, PIM)| Le foglie si raccolgono prima della fioritura e non quelle sulla strada e si cucinano cotte come verdura cotta (VMR)| Si mangiano le foglie lesse e saltate in padella (NST)| Foglie grandi e dure cotte come verdura cotta. (NRE) $\mid$ I frats vanno cotti e mangiati conditi come la verdura cotta (AN3)| Si mangiano le foglie lessate e condite come verdura cotta. (BEL)| Le foglie cotte anche insieme ad altri radicchi (PLU)| Si mangiano le foglie lesse e saltate in padella, insieme ad altri radicchi. (TAT)| Le fogiie più grandi vanno cotte insieme ad altre erbe e condite, oppure soffritte con la pancetta tagliata. (LRE)| Le foglie più grandi si mangiavano cotte e condite (ZAN)| Foglie cotte, mangiate come condimento o verdura cotta. (AMA) $\mid$ Le foglie si mangiano crude in insalata (PGI)| Mangiare le foglie dei radicchi cotti come verdura cotta. (BFE)| Quando le foglie sono grandi si mangiano cotte come verdura (PCL)| Si mangiano le foglie cotte come verdura cotta. (BSO, BAR).

\section{Sector medicinal}

Categoría de uso: Estado general.

Número de informantes: 2 Partes utilizadas: hojas.

Si mangiano le foglie lesse e saltate in padella (NST)| Mangiare le foglie dei radicchi crudi o.

cotti, depurano il sangue. (BFE).

Categoría de uso: Patologías del aparato urinario.

Número de informantes: 1 Partes utilizadas: hojas.

I frats sono diuretici. (AN3). 
Notas le foglie si raccolgono a primavera nei campi, Le verdure non si mangiavano perché venivano condite e l'olio non ce n'era, e poi andavano lavate e non c'era acqua.

DATOS ETNOBOTÁNICOS BIBLIOGRÁFICOS

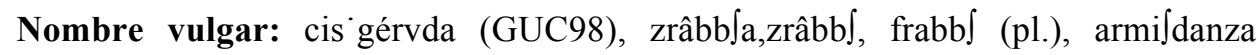
(UNGA21),

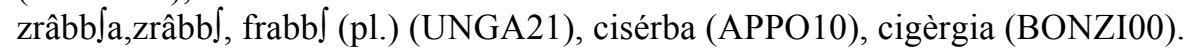

Número de referencias: 4 Número de citas: 5.

Número de sectores: 2 Número de categorías: 2.

Sector alimentario

Categoría de uso: Ensalada.

Número de referencias: 2 Partes utilizadas: hojas.

Tipo di insalata, probabilmente la cicérbita o crespigno (GUC98)| in primavera si

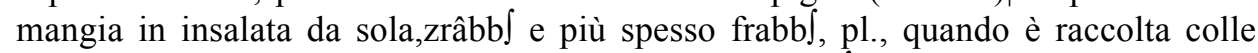
specie affini (S. tenerissimus) per la mescolanza, v. armi danza. (UNGA21).

Sector medicinal

Categoría de uso: Estado general.

Número de referencias: 1 Partes utilizadas: hojas.

Il sugo si adopera come rinfrescante a guisa di quello del radicchio e della borrana (UNGA21).

\section{Tanacetum balsamita L. (=Balsamita major Desf.)}

Nombre vulgar: Erba santa (BEL).

Número de informantes: 1 Número de citas: 1.

Número de sectores: 1 Número de categorías: 1.

Biotipo: Hemicriptófito.

Tipo corológico: Cultivadas.

Abundancia: Cultivada.

Ambiente: Cultivada como condimento, a veces asilvestrada por los jardines.

Número de exsiccata: 39015 FIAF.

Sector religioso

Categoría de uso: Ornamento para altares e iglesias.

Número de informantes: 1 Partes utilizadas: parte aérea (toda).

Si portava alla Madonna, è una pianta coltivata. La sua mamma ce l'aveva in un vaso. (BEL).

DATOS ETNOBOTÁNICOS BIBLIOGRÁFICOS

Nombre vulgar: erba di Santa Maria (SANS14), êrba d'Santa Mari o êrba d' la Madôna.

(UNGA21).

Número de referencias: 2 Número de citas: 3 .

Número de sectores: 2 Número de categorías: 3 . 


\section{Sector alimentario}

Categoría de uso: Licor.

Número de referencias: 1 Partes utilizadas: hojas (SANS14).

Sector medicinal

Categoría de uso: Afecciones típicas infantiles.

Número de referencias: 1 Partes utilizadas: parte aérea (toda).

erba di Santa Maria, menta greca, salvia romana, erba buona, erba romana, adop. Come vermifugo (UNGA21).

Categoría de uso: Patologías del aparato digestivo.

Número de referencias: 1 Partes utilizadas: parte aérea (toda).

Pestata in un mortaio, se ne fanno empiastri da applicarsi sullo stomaco per rinforzarlo. (UNGA21).

\section{Taraxacum campylodes G.E.Haglund (s.l.) (= Taraxacum officinale Weber (s.l.))}

Nombre vulgar: Bocca di leone (TOA), Cicerbite fiore del piscialletto (MGE), Cicoria (VMR), Cicorie di campo (SCO), Cul bianco (GGL, MSR), Dente di Leone (GCL), Fiorume (MSR), Piascialletto (MGO), Pisciacane (UMI), Piscialetto (PCL, EMA), Piscialletti (VMR), Piscialletti amari (GLA), Piscialletto (AMA, AN3, AP2, BAN, BAR, BAZ, BBA, BBI, BEL, BOR, BPT, CBR, CFR, CRO, GGI, GGL, LRE, LST, MGE, MIO, MOR, MRI, MSA, MSR, MTO, NRE, NRO, PGI, PIM, RFR, RMA, RNI, RRE, TAD, TRU, VAL, VFR, VMA, VMU, VSI, ZAN), Radicchi (BAN, BEL, BFE, CRE, CRI, GLA, NER, PCL, RFR, RRE, VAL), Radicchi di campi (NMA, SOT), Radicchi di fiore giallo (LGI), Radicchi selvatici (MOR), Radicchio (BLI, EMA, FAR, GFR, IMA, NLA, PEL, RMA, SCO, TUL, UMI, VSI), Radicchio amaro (MGE), Radicchio di campo (BPT, CFR), Radicchio selvatico (DAD, SLU, TAD), Soffione (GUF, PLU), Tarassaco (CLO, MSR, PEL).

Número de informantes: 70 Número de citas: 14.

Número de sectores: 4 Número de categorías: 15.

Biotipo: Hemicriptófito.

Tipo corológico: n.d.

Abundancia: Bastante Común.

Ambiente: Aclarados de bosques caducifolios, prados fertilizados, ambientes ruderales.

(generalmente sinantrópica).

Número de exsiccata: 38934 FIAF, 39040 FIAF, 39045 FIAF, 38935 FIAF, 38955.

Sector agropastoral

Categoría de uso: Alimentación animal (incluidos los forrajeros).

Número de informantes: 1 Partes utilizadas: hojas.

Le foglie vecchie si davano ai conigli (quelle giovani e tenere si mangiavano in insalata).

Categoría de uso: Horticultura.

Número de informantes: 2 Partes utilizadas: hojas. 
Annaffiare le piante dell'orto con il decotto del piscialletto come concime gli fa bene..

(BSO, BAR).

\section{Sector alimentario}

Categoría de uso: Empanadas.

Número de informantes: 1 Partes utilizadas: hojas.

Torta salata o schiaccia alle erbe, con le erbe di staggione: fare la pasta con la farina usando il lievito madre (che era trattato come un tesoro, durava anni e gli si davano delle cure quotidiane per mantenerlo vivo sempre) e aggiungere i 'ciucioli' (siccioli, ricavati facendo cuocere il grasso del maiale e tirandoli fuori via via che venivano a galla), poi stendere la pasta. Fare cuocere le erbe di stagione come il piscialletto, le cicoriette, lo strigolo, l'ortica, i vizzadri, una volta cotte, passarle in padella con un pò di pancetta o lardo, mescolarle al formaggio 'scotta' e 4 uova. Coprire con un'altra sfoglia di pasta, quindi chiudere con la forchetta e cuocere in forno. (BSO).

Categoría de uso: Ensalada.

Número de informantes: 43 Partes utilizadas: hojas.

Le foglie si raccolgono prima della fioritura e non quelle sulla strada e si mangiano crude in insalata. (VMR)| Le foglie giovani fresche si mangiano crude e condite. (MTO, MSR)| Cruda e condita (GCL)| Foglie tenere mangiate crude e condite. (MGO)| Mangiare le foglie crude in insalata (VMR)| Le foglie del piscialletto crude e condite. (AN3) $\mid$ Le foglie giovani crude in insalata. (BSO, BAR) $\mid$ Si trittavano le foglie e si mangiavano in insalata. (BAZ) $\mid$ Foglie tenere mangiate in insalata, crude e condite (BBA)| Le foglie crude e condite. (BOR) $\mid$ Quando sono teneri si mangiano le foglie crude in insalata, da sole, e condite con olio e aceto (CBR)| Cruda in insalata e condita (GGI)| Le foglie giovane mangiate crude in insalate e condite. (LRE)| Tagliare le foglie e mangiare in insalata con l'aglio (LST) $\mid$ Crudi e conditi (NRO)| Le foglie crude e condite (PGI)| Le foglie si tagliano fini fini e si mangiano crude. (RNI) $\mid$ Le foglie tenere crude si mangiano in insalata. (VFR)| Si mangiavano le foglie crude nel misto dell'insalata insieme alla galinella, al radicchio, alla cisevda. (VMA)| Le foglie piccoline e tenere si mangiavano in insalata crude e condite $(\mathrm{ZAN}) \mid$ Foglie tenere mangiate crude e condite con olio e sale. (GGL)| Le foglie fresche mangiate crude e condite. (BAN)| Le foglie si mangiano crude e condite in insalata. (VAL, BEL)| Mangiare il piscialletto tenero, crudo e condito con sale e aceto. (RRE, RFR)| Le foglie crude in insalata insieme agli altri radicchi. (PEL, MOR)| Si mangiano le foglie sia crude in insalata che cotte come verdura. (RMA)| Mangiare le foglie dei radicchi crudi e come verdura cotta. (BFE)| Le foglie tenere si mangiano crude in insalata (NER) $\mid$ Crude insieme ad altre insalate (NMA) $\mid$ Quando le foglie sono giovane e tenere si mangiano crude in insalata e condite (PCL)| $\mathrm{Si}$ raccolgono le foglie tenere e si metteno nell'insalata (IMA) $\mid$ crude e condite (TUL) Quando le foglie sono tenere, si mangiano crude in insalata (BPT) $\mid$ Crudi con uova sode (CFR) $\mid$ Se le foglie sono tenere, mangiate crude con altre insalate, e condite (DAD) $\mid$ Foglie crude con uova sode (SLU)| Da sole o accompagnate con altre insalate. (TAD)| Foglie tenere mangiate in insalata con le uova sode. (UMI)| Le foglie crude e condite in insalata. (PLU).

Categoría de uso: Relleno de ravioli. 
Número de informantes: 1 Partes utilizadas: hojas.

Cotti, insieme a mollica di pane e formaggio o solo formaggio e insieme alle cicerbite. Ma si.

possono mettere anche trittati e crudi (TAD).

Categoría de uso: Sopas de verduras y potaje.

Número de informantes: 7 Partes utilizadas: hojas.

La zuppa d'estate della nonna era a base solo di piante di campo: soffriegeva l'aglio, si trittavano tutte le foglie del piscialletto, le punte dei vizzadri, dell'ortica, delle orecchie di ciucco, del caciolino e degli striggoli. Poi si aggiungevano e si facevano bollire molto. Poi si poteva aggiungere riso o pasta. (MGE)| L"Acquacotta', la minestra dei poveri, era fatta con gli striggoli, il piscialletto, gli stricapugni, i dolcignoli, i radichietti, tutti lavati e trinciati, saltati un po' in padella con un po' di unto di maiale e poi si aggiungeva l'acqua e si lasciava cuocere un po'. Poi si metteva una fetta di pane secco sul piatto, si versava la zuppa e si aggiungeva un po' di cacio di pecora. (MSR)| Minestra di riso: soffriggere aglio e prezzemolo nell'olio, poi aggiungere le foglie di piscialletto, poi l'acqua e quando bolle unire il riso. (BAR)| Minestra: soffriggere aglio e prezzemolo nell'olio, poi aggiungere le foglie di piscialletto, cicorietta, striggoli e 2 patate, se ce l'avevano, poi l'acqua e quando bolle unire la pasta 'gli strapponi' (si faceva la sfoglia di acqua e farina e si strapavano pezzettini, che si facevano bollire un secondo nell'acqua bollente) (BSO)| L"Acquacotta', la minestra dei poveri, era fatta con gli striggoli, il piscialletto, gli stricapugni, i dolcignoli, i radichietti, tutti lavati e trinciati, saltati in padella con un po' di unto di maiale e poi si aggiungeva l'acqua e si lasciava cuocere un po'. Poi si metteva una fetta di pane secco sul piatto, si versava la zuppa e si aggiungeva un po' di cacio di pecora. (MTO)| La nonna faceva sempre degli 'intrugli' (zuppe) la sera con patate, radicchi, cotica e fagioli. (VSI)| Mettere le foglie del radicchio nella minestra di verdure. (BLI).

Categoría de uso: Sucedáneo del café.

Número de informantes: 1 Partes utilizadas: hojas.

Le foglie della cicoria secche insieme alle ghiande secche di quercia, si macinavano, si bolliva e si faceva il caffé. (VMR).

Categoría de uso: Tortilla.

Número de informantes: 7 Partes utilizadas: hojas.

Le foglie cotte e aggiunte alla frittata. (BSO, BAR)| Cotte, strizzate e messe nella frittata (TRU)| Foglie bollite e messe nella frittata. (GGL) $\mid$ Foglie cotte e messe nella frittata (SOT)| lesse, strizzati e messa nella frittata (GFR, FAR).

Categoría de uso: Verdura cocida.

Número de informantes: 49 Partes utilizadas: hojas.

le foglie cotte e passate come verdura facevano bene allo stomaco. (MGE)| Le foglie si raccolgono prima della fioritura e non quelle sulla strada e si cucinano cotte come verdura cotta (VMR)| Foglie cotte insieme ad altre piante selvatiche (con cicerbite, rucola, radicchio) (SCO)| le foglie si raccolgono prima della fioritura e si mangiano cotte e condite (VMR)| Prima che faccia il fiore, raccogliere le foglie e farle cotte e condite. (AP2)| Si mangiano le foglie cotte come verdura cotta. (BSO, BAR)| Raccolta dalla parte inferiore, si mangia cotta come verdura. (BBI) $\mid$ Si mangiano le foglie cotte come verdura cotta, fa anche bene. (BOR)| Quando sono più vecchi e 
duri si mangiano cotti e conditi come contorno (CBR)| Le foglie del piscialletto vanno lesse e condite. (CRO)| Foglie grandi cotte e condite. (GGI)| Le foglie più grandi vanno cotte insieme ad altre erbe e condite, oppure soffritte con la pancetta tagliata. (LRE) $\mid$ Le foglie cotte e mangiate come verdura lessa (LST) $\mid$ Si mangiano le foglie cotte e condite come verdura. (MIO)| Si mangiano le foglie bollite e condite con olio e sale. (GGL, MRI)| Scottare le foglie e mangiarle condite. (MSA)| Cotta e condita, anche con "altri radicchi" (NRO)| Le foglie cotte e condite (PGI)| Si mangiano le foglie cotte e condite. (PIM)| Le foglie tenere (sensa latte) si fanno cotte e condite (RNI)| Le foglie grandi si mangiano cotte come verdura. (VFR)| Le foglie raccolte prima della fioritura, cotte e condite (VMA)| Le foglie del piscialleto si mangiano cotte e condite (VMU)| Le foglie più grandi si mangiavano cotte e condite (ZAN)| Si mangiano le foglie fresche mangiate cotte. (BAN)| Si mangiano le foglie tagliate sottili e lesse, come verdura cotta. (BEL)| Le foglie si mangiano come verdura cotta. (RRE)| Le foglie tagliate sottili e lessate vengono consumate come verdura cotta. (VAL)| Si mangiano le foglie sia crude in insalata che cotte. (RMA)| Le foglie cotte si mangiano da sole come verdura cotta. (VSI)| Mangiare le foglie dei radicchi cotti come verdura cotta. (BFE)| Mangiare I radicchi cotti come verdura (CRE)| Foglie grandi cotte come verdura cotta o contorno (NER)| Quando le foglie sono piu vecchie o grande si cucinano cotte e condite (NMA)| Foglie cotte e condite (SOT)| Si mangiano le foglie cotte come verdura. (LGI)| Quando le foglie sono grandi si mangiano cotte come verdura (PCL)| lesse e condite (TUL, FAR)| Cotta, come verdura (GFR)| Cotte e conditi (NLA)| Verdura cotta con altre piante selvatiche (SCO)| Quando sono piu vecchie le foglie si mangiano cotte e condite (BPT) $\mid$ Condita con olio e sale,Verdura cotta come contorno al maiale (CFR)| Se le foglie sono grandi e piu vecchie, cotte come contorno o come verdura condita (DAD) $\mid$ Foglie grandi, lessate e saltati in padella con olio e aglio (UMI) | le foglie cotte e condite come verdura cotta (EMA)| Le foglie cotte si mangiano come verdura cotta. (PLU)| Cotta e ripassata in padella con aglio (CLO).

Sector lúdico/voluptuoso

Categoría de uso: Pasatiempos.

Número de informantes: 2 Partes utilizadas: frutos/infrutescencias/falsos frutos. Soffiare l' infruttescenza e farla volare via. (CFR)| Si faceva volare il soffione. (GUF).

\section{Sector medicinal}

Categoría de uso: Afecciones del aparato respiratorio.

Número de informantes: 3 Partes utilizadas: hojas, flores/inflorescencias y sus partes.

Fare il 'fiasco' pieno del decotto di foglie e fiori di polmonaria, foglie di farfanella, foglie di malva, di cimballaria, di piscialletto e di foglie di erba ruggine. (NRE) "Fiorume", fiori e foglie del fieno (di Trifoglio,trafagliolo, ginestrino, erba medica, radicchi, felce, camomilla, margherite, papaveri) Mettere i fiori e le foglie che restano dopo avere preso il fieno, trittate, nell'acqua bollente e respirare il vapore con la testa coperta con un panno (CRI)| La sua mamma metteva un paiolo sulla stufa, e aggiungeva il fiorume. Il fiorume era quello che rimaneva sotto il fieno secco, semi e foglie, c'era di tutto erba medica, lupinella, trifoglio, e altre erbe 
spontanee (tarassaco), fare bollire il tutto finché rimanesse asciutto, poi fare dei fumenti per il raffreddore (MSR).

Categoría de uso: Afecciones ginecológicas, complicaciones obstétricas, del postparto y del puerperio.

Número de informantes: 2 Partes utilizadas: hojas.

Fare cuocere il tarassaco per 10 minuti, filtrare e fare raffreddare coperto. Fa bene per le.

mestruazioni. (BSO, BAR).

Categoría de uso: Estado general.

Número de informantes: 8 Partes utilizadas: hojas.

A primavera si mangiavano queste piante per rinforzare il corpo e depurare il sangue, crude o cotte e condite. Anche in infuso insieme alle foglie di rosmarino, salvia, e malva, si beveva a diguino la mattina e la sera per 10/15 giorni. (VMR) Mangiare i radicchi amari (cu di raso, radicchio, piscialletto) e bere l'acqua di cottura spesso. (AMA)| Fare cuocere il tarassaco per 10 minuti, filtrare e fare raffreddare coperto. Purifica il sangue. (BSO, BAR)| Mangiare le foglie cotte o crude del piscialletto. Fanno bene, per le infiammazioni. (BOR)| Le mangiavano spesso per depurare il corpo (GGI)| Mangiare le foglie dei radicchi crudi o cotti, depurano il sangue. (BFE)| Raccoglievano diverse piante come la Malva, la Camomilla e I radicchi amari (foglie), le facevano seccare e le conservavano in dei sacchettini di stoffa. (CRE).

Categoría de uso: Patologías del aparato digestivo.

Número de informantes: 4 Partes utilizadas: hojas.

le foglie cotte e passate mangiate come verdura facevano bene allo stomaco. (MGE)| Come preventivo o per chi soffriva di fegato, era consigliabili mangiare tarassaco spesso (GGI)| Mangiare I radicchi cotti o crudi come depurativi per il mal di stomaco o per I problemi di fegato. (CRE)| Bere l'acqua dei piscialletti amari per il mal di fegato (GLA).

Categoría de uso: Patologías del aparato urinario.

Número de informantes: 6 Partes utilizadas: hojas.

Fare il decotto delle foglie, mettere in una bottiglia e bere in continuazione. Si raccoglieva e si seccava per l'inverno (TOA)| Mangiare il tarassaco fa bene ai reni, purifica, è diuretico. Decotto: fare cuocere il tarassaco per 10 minuti, filtrare e fare raffreddare coperto. E' diuretico. (BSO, BAR)| Bere il decotto del piscialletto con un po di miele 3 o 4 volte al giorno per diversi giorni. (LST)| Mangiare le foglie del piscialletto cotte: è diuretico. (GGL)| Bere l'acqua del piscialletto cotto, mangiare le foglie cotte e bere l'acqua come diuretico. (BAN).

Notas foto dalla torta fatta da lei con "la scotta": era il formaggio tipo un stracchino grumoloso che si faceva dopo la ricotta, dalla galla si poteva mettere nel café (per un café latte) oppure sul pane, oppure con quella sorta di velo si faceva questo formaggio.

\section{DATOS ETNOBOTÁNICOS BIBLIOGRÁFICOS}

Nombre vulgar: tarassaco (GRIZ03), stricapuggno, radic'c'hio (GUC98), piscialetto (BADI15, POLI14), tarassaco, piscialet (SANS14), radicchi (SIRGI91), 
radecc da purz, pessalaet. (UNGA21), pessalœt (UNGA21), piscialletto, radicchio (MANG98), Piscialètto (APPO10).

Número de referencias: 9 Número de citas: 18.

Número de sectores: 3 Número de categorías: 8 .

\section{Sector alimentario}

Categoría de uso: Ensalada.

Número de referencias: 4 Partes utilizadas: hojas.

(SANS14)Insalata mista: Lattughino, valerianella, tarassaco, crescione, olio extra vergine d'oliva, sale. (GRIZ03)| L'identificazione non coincide con la nostra etnobotanica. Si usa ancora in primavera mangiarlo crudo in insalata o bollito. (GUC98)| Raccolto giovane in primavera si consuma crudo o cotto in insalata (POLI14).

Categoría de uso: sin precisar.

Número de referencias: 1 Partes utilizadas: hojas.

"fino a raggiungere la me, quella vera, che poteva essere un pò sopita solamente quando spuntavano I primi radicchi selvatici nei campi, in primavera" (SIRGI91).

Categoría de uso: Tortilla.

Número de referencias: 1 Partes utilizadas: hojas (SANS14).

Categoría de uso: Verdura cocida.

Número de referencias: 2 Partes utilizadas: hojas (SANS14).

L'identificazione non coincide con la nostra etnobotanica. Si usa ancora in primavera mangiarlo crudo in insalata o bollito (GUC98).

\section{Sector lúdico/voluptuoso}

Categoría de uso: Juego colectivo y bromas.

Número de referencias: 1 Partes utilizadas: flores/inflorescencias y sus partes. giuoco favorito de' fanciulli, che vi soffiano sopra per distaccarlo e da questi detto furtonna, fortuna quando vola. (UNGA21)| Giouco favorito dei fanciulli, che vi soffiano sopra per distaccarlo, e da questi detto furtonna, fortuna quando vola. (UNGA21).

\section{Sector medicinal}

Categoría de uso: Afecciones del aparato respiratorio.

Número de referencias: 1 Partes utilizadas: órganos subterráneos.

L'infuso viene bevuto sia in generiche infiammazioni che in caso di tosse. (MANG98).

Categoría de uso: Estado general.

Número de referencias: 3 Partes utilizadas: hojas, órganos subterráneos.

Radicchi in padella. Ingredienti: Abbondante tarassaco (volg. piscialetto), aglio, olio, pancetta, sale, peperoncino. Si pulisce il tarassaco, lo si lava bene e lo si fa lessare.Una volta scolato si strizza con le mani facendone delle palle.Lo si pone sul tagliere e lo si trita finemente.Intanto nella padella con un po' d'olio si fanno soffriggere l'aglio e la pancetta tritati.Si aggiunge il tarassaco e lo si lascia insaporire bene. Prima di toglierlo dal fuoco si mette un po' di peperoncino e si aggiusta di sale. E' un ottimo contorno che in primavera andrebbe mangiato spesso perché è un ottimo depuratore del sangue(BADI15)/ L'infuso viene bevuto sia in 
generiche infiammazioni che in caso di tosse(MANG98)/ Mangiare le foglie come verdura o minestra e bere l' acqua della cottura (SANS14).

Categoría de uso: Patologías del aparato urinario.

Número de referencias: 2 Partes utilizadas: hojas, No especificado.

Mangiare le foglie come verdura o minestra e bere l' acqua della cottura (SANS14)|

Così chiamato per le qualità diuretiche che gli si attirbuiscono (UNGA21).

Notas Piante di periodi di fame.

\section{Tragopogon pratensis $L$.}

Nombre vulgar: Barba dei frati (VMA).

Número de informantes: 1 Número de citas: 1.

Número de sectores: 1 Número de categorías: 1 .

Biotipo: Hemicriptófito.

Tipo corológico: Nórdicas.

Abundancia: Común.

Ambiente: Prados, baldíos.

Sector alimentario

Categoría de uso: Ensalada.

Número de informantes: 1 Partes utilizadas: hojas, órganos subterráneos.

Si mangiavano le foglie e anche la radice crude nel misto dell'insalata insieme al piscialletto,.

alla galinella, al radicchio, alla cisevda. (VMA).

DATOS ETNOBOTÁNICOS BIBLIOGRÁFICOS

Nombre vulgar: armi danza, baerba ed bâcc (UNGA21).

Número de referencias: 1 Número de citas: 2 .

Número de sectores: 1 Número de categorías: 2 .

\section{Sector alimentario}

Categoría de uso: Ensalada.

Número de referencias: 1 Partes utilizadas: hojas, órganos subterráneos.

Barba di becco, raperonzolo selvaggio, salsefrica ecc. una delle tante erbe che si mangiano in primavera cotte o crude in insalata (UNGA21).

Categoría de uso: Verdura cocida.

Número de referencias: 1 Partes utilizadas: hojas, órganos subterráneos.

Barba di becco, raperonzolo selvaggio, salsefrica ecc. una delle tante erbe che si mangiano in primavera cotte o crude in insalata (UNGA21).

\section{Tussilago farfara $L$.}

Nombre vulgar: Farfanelle (RRE, GGL, BMA), Farfanella (NRE).

Número de informantes: 4 Número de citas: 4.

Número de sectores: 2 Número de categorías: 2 .

Biotipo: Geófito.

Tipo corológico: Europeas.

Abundancia: Común. 
Ambiente: Baldíos, preferiblemente sobre suelo pesado (marga, arcilla) y un poco húmido.

Número de exsiccata: 39074 FIAF, 39008 FIAF, 39076 FIAF.

Sector agropastoral

Categoría de uso: Alimentación animal (incluidos los forrajeros).

Número de informantes: 3 Partes utilizadas: hojas.

Le foglie delle farfafanelle crude si davano da mangiare ai conigli a primavera e gli facevano bene (BMA)| Le foglie crude facevano bene ai conigli in primavera. (RRE, GGL).

Sector medicinal

Categoría de uso: Afecciones del aparato respiratorio.

Número de informantes: 1 Partes utilizadas: hojas.

Fare il 'fiasco' pieno del decotto di foglie e fiori di polmonaria, foglie di farfanella, foglie di malva, di cimballaria, di piscialletto e di foglie di erba ruggine. (NRE).

Notas Fa lungo le strade nei posti umidi, lo faceva la sua nonna.

DATOS ETNOBOTÁNICOS BIBLIOGRÁFICOS

Nombre vulgar: farfarâz (UNGA21), farfarœla, pa d'caval (UNGA21), farfanèlla (GUC98).

Número de referencias: 2 Número de citas: 5 .

Número de sectores: 1 Número de categorías: 3 .

Biotipo: Geófito.

Tipo corológico: Europeas.

Abundancia: Común.

Ambiente: Baldíos, preferiblemente sobre suelo pesado (marga, arcilla) y un poco húmido.

\section{Sector medicinal}

Categoría de uso: Afecciones cutáneas y tejidos subcutáneos.

Número de referencias: 1 Partes utilizadas: No especificado.

farfaraccio, tossilaggine maggiore o dalle foglie grandi, p. com. Ne' luoghi freschi, usata nella med.pop. Per cataplasmi, per la cura delle ulceri e per uso interno in infuso come espettorante (UNGA21).

Categoría de uso: Afecciones del aparato respiratorio.

Número de referencias: 1 Partes utilizadas: No especificado, parte aérea (toda). farfara, farfaro, piè d'asino, in Tosc. Farfarella, dai farm. Tossilagine e dai nostri cont. anche pa d'caval. Erba infesta de'seminati, usata in farm. Gode fama di emolliente, pettorale, stimolante, impiegata in decozioni per la tosse. Se ne è fatto in addietro un attivo commercio colla Germania. Nella med.pop., con un pò d'edera terrestra si dà ai malati di petto e si somministra alle donne per regolarne i corsi. farfaraccio, tossilaggine maggiore o dalle foglie grandi, p. com. Ne' luoghi freschi, usata nella med.pop. Per cataplasmi, per la cura delle ulceri e per uso interno in infuso come espettorante (UNGA21).

Categoría de uso: Afecciones ginecológicas, complicaciones obstétricas, del postparto y del puerperio. 
Número de referencias: 1 Partes utilizadas: parte aérea (toda).

Nella med.pop., con un pò d'edera terrestra si dà ai malati di petto e si somministra alle donne per regolarne i corsi.(UNGA21).

\section{CORNACEAE}

\section{Cornus mas $L$.}

Nombre vulgar: Corniolo (MGO, VMR, RMA, BBI, MRI), Corniole (NLA, MTO, BSO, BAR, AN3, RGI, BSI, BMA, BAN, RFR, NRE, GUF, DAD, BGI, BEL, PIA). Número de informantes: 21 Número de citas: 32 .

Número de sectores: 5 Número de categorías: 11.

Biotipo: Fanerófito.

Tipo corológico: Europeas.

Abundancia: Rara.

Ambiente: Bosques latifolios submediterráneos.

Número de exsiccata: 38907 FIAF.

Sector agropastoral

Categoría de uso: Herramientas y objetos agrícolas.

Número de informantes: 1 Partes utilizadas: tallos leñosos/ramas/ramitas/vástagos.

Per fare il mazzo, perché il legno è resistente e pesante (MRI).

Sector alimentario

Categoría de uso: Encurtidos y conserva en aceite.

Número de informantes: 1 Partes utilizadas: frutos/infrutescencias/falsos frutos. Raccolti non completamente maturi, in Agosto e Settembre, messi sotto aceto e con sale (PIA).

Categoría de uso: Fruta fresca.

Número de informantes: 6 Partes utilizadas: frutos/infrutescencias/falsos frutos. A ottobre si mangiavano mature. Erano gli ultimi frutti freschi insieme alle nespole e alle sorbole. (BEL) $\mid$ Al naturale. (DAD, BGI) $\mid$ Si mangiavano al naturale, anche per I campi quando si incontrava un albero (GUF)| Frutti raccolti maturi e mangiati come le more. (NRE)| I frutti ben maturi si mangiano come frutta fresca. (RFR).

Categoría de uso: Fruta seca.

Número de informantes: 4 Partes utilizadas: frutos/infrutescencias/falsos frutos.

I 'capponi' erano la frutta che si seccava per l'inverno: corniole, ciliegie, susine secche (BAN)| Le corniole seccate al forno si mangiavano come caramelle. (BMA)| I capponi erano la frutta che si seccava per l'inverno: corniole, ciliegie, susine secche (BSI)| Si facevano delle collane di corniole e si facevano seccare, poi si mangiavano come caramelle (RGI).

Categoría de uso: Golosinas y masticatorias.

Número de informantes: 1 Partes utilizadas: frutos/infrutescencias/falsos frutos.

Si mangiavano al naturale, anche per I campi quando si incontrava un albero (GUF).

Categoría de uso: Licor. 
Número de informantes: 10 Partes utilizadas: frutos/infrutescencias/falsos frutos. (BMA)Il Corniolino:1 kg di corniole, 1 litro di alcol, 625 gr di zucchero, $625 \mathrm{gr}$ d'acqua, 5 chiodi di garofano, 1 pizzico di cannella, e la scorza di limone.Lasciare tutto a macerare per 40 giorni, poi filtrare, fare lo sciroppo con lo zucchero e l'acqua e aggiungere. (AN3)| Mettere a macerare un $\mathrm{kg}$ di corniole nel vino rosso fino a coprirle insieme con 750 gr di zucchero per 2 o 3 mesi, poi filtrare e aggiungere 300 gr di alcol. (BSO, BAR)| $1 \mathrm{~kg}$ di corniole(maturi) messi a macerare in alcol puro durante 40 giorni, poi levare le corniole e aggiungere 400 grammi di zucchero e 1 litro di acqua (PIA)| Il liquore di corniole si faceva con acqua, alcol, zucchero e corniole. (BSI, BBI)| Fare macerare i frutti di corniole nella grappa per un mese, poi filtrare. Viene un liquore aspro. (MRI)| il liquore di corniole si faceva con acqua, alcol, zucchero e corniole. (RMA)| Il 'Corniolino':Mettere ii frutti maturi del corniolo a macerare per 40 giorni nel alcol. Poi dopo I 40 giorni firltrare e aggiungere uno sciroppo fatto con lo zucchero e l'acqua messi a bollire. Mescolare tutto. (VMR).

Categoría de uso: Mermelada.

Número de informantes: 4 Partes utilizadas: frutos/infrutescencias/falsos frutos. (MTO)non specificato (BGI)| Fare bollire I frutti, e poi passarle al setaccio e aggiungere zucchero alla fine bollendo un altro po'. (NLA)| Passare la frutta e fare bollire un chilo di zucchero per un chilo di frutta passata per 3 o 4 ore. (BBI).

Sector artesanal

Categoría de uso: Instrumentos y utensilios para la artesanía.

Número de informantes: 1 Partes utilizadas: tallos leñosos/ramas/ramitas/vástagos.

Martelli di legno di corniolo, per lavorare le statue di marmo. (MGO).

Sector doméstico

Categoría de uso: Integración de la renta familiar.

Número de informantes: 1 Partes utilizadas: frutos/infrutescencias/falsos frutos.

Il babbo raccoglieva tutti questi frutti e poi li vendeva a un signore che li raccoglieva tutti. (RMA).

Categoría de uso: Otro doméstico.

Número de informantes: 1 Partes utilizadas: frutos/infrutescencias/falsos frutos.

Quando le donne filavano la lana, si mettevano i 'capponi' di corniolo in bocca per fare saliva.(BSI).

Sector medicinal

Categoría de uso: Patologías del aparato digestivo.

Número de informantes: 1 Partes utilizadas: frutos/infrutescencias/falsos frutos. Mangiare le corniole contro la diarrea (VMR)| Il 'Corniolino':Mettere ii frutti maturi del corniolo a macerare per 40 giorni nel alcol. Poi dopo I 40 giorni firltrare e aggiungere uno sciroppo fatto con lo zucchero e l'acqua messi a bollire. Mescolare tutto. Bere il corniolino per digerire (VMR).

Notas Caratteristiche del legno: pesante e resistente, Frutti raccolti maturi, Quando le donne.

filavano la lana, si metteva in bocca per fare saliva., La marmellata di corniole è. 
qualcosa di nuovo. Prima non si faceva., Una volta si faceva la marmellata con tutto. DATOS ETNOBOTÁNICOS BIBLIOGRÁFICOS

Nombre vulgar: corniolo (SANS14, GRIZ03), pcôren (UNGA21).

Número de referencias: 3 Número de citas: 4.

Número de sectores: 1 Número de categorías: 4.

Sector alimentario

Categoría de uso: Conserva de frutas.

Número de referencias: 1 Partes utilizadas: frutos/infrutescencias/falsos frutos. non specificato (GRIZ03).

Categoría de uso: Fruta fresca.

Número de referencias: 1 Partes utilizadas: frutos/infrutescencias/falsos frutos.

Pianta di bosco con frutto rosso mangereccio. (UNGA21).

Categoría de uso: Golosinas y masticatorias.

Número de referencias: 1 Partes utilizadas: frutos/infrutescencias/falsos frutos (SANS14).

Categoría de uso: Licor.

Número de referencias: 1 Partes utilizadas: frutos/infrutescencias/falsos frutos (SANS14).

\section{Cornus sanguinea $L$.}

Nombre vulgar: Sanguinello (NRE, BEL), Rinsanguino, Sanguinello (MRI), Rinsanguino.

(NLA, TAD), Insanguino (NRO).

Número de informantes: 6 Número de citas: 9.

Número de sectores: 3 Número de categorías: 6 .

Biotipo: Fanerófito.

Tipo corológico: Europeas.

Abundancia: Común.

Ambiente: Bosques latifolios (robledales, castañares), setos.

Número de exsiccata: 39058 FIAF.

Sector agropastoral

Categoría de uso: Alimentación animal (incluidos los forrajeros).

Número de informantes: 1 Partes utilizadas: tallos leñosos/ramas/ramitas/vástagos.

I rami si davano da mangiare alle pecore (BEL).

Categoría de uso: Herramientas y objetos agrícolas.

Número de informantes: 1 Partes utilizadas: tallos leñosos/ramas/ramitas/vástagos.

Per fare il manico del mazzo (MRI).

Categoría de uso: Horticultura.

Número de informantes: 1 Partes utilizadas: tallos leñosos/ramas/ramitas/vástagos.

Per fare le frasche per i fagioli (TAD). 
Categoría de uso: Vallas y delimitaciones.

Número de informantes: 1 Partes utilizadas: planta entera/viva.

Si usava fare le siepi con diverse piante: ligustri, spini (prugnolo e biancospino), acero campestre,sanguinelli, berretti da prete. (NRE).

Sector caza y pesca

Categoría de uso: Caza de pájaros.

Número de informantes: 2 Partes utilizadas: frutos/infrutescencias/falsos frutos.

Si mettevano vicino agli alberi per cacciare gli uccelli che mangiavano I frutti dell'insanguino (NRO) $\mid$ Si usa come 'presa' per la caccia dei tordi (NLA).

Sector doméstico

Categoría de uso: Objetos domésticos y escobas.

Número de informantes: 3 Partes utilizadas: tallos leñosos/ramas/ramitas/vástagos.

Per fare il manico delle scope, perché vengano ben dritte (NLA)| Bastone per camminare. Il legno di corniolo è adatto per fare i bastoni perché è sottile, forte e leggero. (TAD)| Per fare bastoni per camminare. (MRI).

DATOS ETNOBOTÁNICOS BIBLIOGRÁFICOS

Nombre vulgar: sanguinaela (UNGA21), rinsanguine (GUC82), rinsànguine (GUC98).

Número de referencias: 3 Número de citas: 3 .

Número de sectores: 2 Número de categorías: 2 .

Sector artesanal

Categoría de uso: Cestería.

Número de referencias: 1 Partes utilizadas: tallos leñosos/ramas/ramitas/vástagos. arboscello de boschi a rami rossi flessibili, con cui si fanno lavori di panieraio. (UNGA21).

Sector mágico/medicinal

Categoría de uso: Otro mágico/medicinal.

Número de referencias: 1 Partes utilizadas: tallos leñosos/ramas/ramitas/vástagos. Il sangue nell' occhio viene segnato da chi lo sa, sull' acqua corrente, ci vogliono tre bacchettine di rinsanguine, e poi si va sopra all'acqua e poi segni con queste bacchettine "sanguine, rinsanguine, e acqua corria, fa che il sangue nell 'occhio vada via"col segno della croce. (GUC82).

\section{CRASSULACEAE}

\section{Crassula multicava Lem.}

Nombre vulgar: Erba dei calli (MSR).

Número de informantes: 1 Número de citas: 1.

Número de sectores: 1 Número de categorías: 1.

Biotipo: Caméfito. 
Tipo corológico: Cultivadas.

Abundancia: Cultivada.

Ambiente: Cultivada en maceta.

Número de exsiccata: 39080 FIAF, 39031 FIAF.

Sector medicinal

Categoría de uso: Afecciones cutáneas y tejidos subcutáneos.

Número de informantes: 1 Partes utilizadas: hojas.

Ungere la foglia con un po' di olio, applicarla sul callo e poi legare con un fazzoletto (MSR).

Notas la sua mamma già ce l'aveva in vaso.

\section{Sedum acre $L$.}

Nombre vulgar: Erba poranciola (BEL).

Número de informantes: 1 Número de citas: 1.

Número de sectores: 1 Número de categorías: 1.

Biotipo: Caméfito.

Tipo corológico: Europeas.

Abundancia: Común.

Ambiente: Muros, gravas.

Número de exsiccata: 39019 FIAF.

\section{Sector medicinal}

Categoría de uso: Afecciones cutáneas y tejidos subcutáneos.

Número de informantes: 1 Partes utilizadas: hojas.

Si diceva di strofinare l'erba sui 'poranci' (BEL).

Notas erba grassa, attaccata nei muri con il fiore giallo e la foglia piccola.

DATOS ETNOBOTÁNICOS BIBLIOGRÁFICOS

Nombre vulgar: êrba dal sajatt, Saimpervîv, êrba trauna (UNGA21), saimpervîv (UNGA21).

Número de referencias: 1 Número de citas: 2.

Número de sectores: 1 Número de categorías: 2.

\section{Sector medicinal}

Categoría de uso: Afecciones cutáneas y tejidos subcutáneos.

Número de referencias: 1 Partes utilizadas: parte aérea (toda).

semprevivo, volg. Sedo bruciante, erba grassa de luoghi incolti e delle macerie, già off., ancora usata dal volgo come emolliente. Le si attribuiscono le stesse proprietà del semprevivo maggiore. V. urciaela. (UNGA21).

Categoría de uso: Estado general.

Número de referencias: 1 Partes utilizadas: No especificado.

Ancora usata dal volgo come emolliente (UNGA21).

\section{Sedum dasyphyllum $L$.}

Nombre vulgar: Riso di botta (BAT, BAN). 
Número de informantes: 2 Número de citas: 2.

Número de sectores: 1 Número de categorías: 1 .

Biotipo: Caméfito.

Tipo corológico: Eurimediterránea.

Abundancia: Común.

Ambiente: Acantilados (preferiblemente silicio), gravas, muros.

Sector medicinal

Categoría de uso: Patologías del aparato circulatorio.

Número de informantes: 2 Partes utilizadas: hojas.

Schiacciare le foglie, scaldarle un poco nell'olio in un tegamino, bagnare un panno in questo olio e applicarlo sulle emorroidi. (BAN)| Schiacciare le foglie, scaldarle un poco nell'olio in un tegamino, bagnare un panno in questo olio e applicarlo sulle emorroidi (BAT).

DATOS ETNOBOTÁNICOS BIBLIOGRÁFICOS

Nombre vulgar: pippi di muro, pippolo di muro, pitirozzi, piturozzi (MANG98).

Número de referencias: 1 Número de citas: 2 .

Número de sectores: 2 Número de categorías: 2.

Sector mágico/ritual/supersticioso

Categoría de uso: Adivinatorio.

Número de referencias: 1 Partes utilizadas: planta entera/viva.

Un antica tradizione dice che un piantina, messa in terra senza radici, se riesce ad attecchire e.

a fiorire per il giorno dell'Ascensione è presagio di un anno fortunato. (MANG98).

Sector medicinal

Categoría de uso: Afecciones cutáneas y tejidos subcutáneos.

Número de referencias: 1 Partes utilizadas: hojas.

Le foglioline contuse vengono poste sulle ferite infette e sul giradito, unite a mollica di pane masticata portano a rapida maturazione ascessi e foruncoli. (MANG98).

\section{Sedum telephium $L$.}

Nombre vulgar: Erba di San Giovanni (VMA, UMI), Erba per le ferite (BAZ), Foglia della.

madonna (VMU), Pianta grassa (BLI).

Número de informantes: 5 Número de citas: 6 .

Número de sectores: 2 Número de categorías: 3.

Biotipo: Hemicriptófito.

Tipo corológico: Nórdicas.

Abundancia: Cultivada.

Ambiente: Bosques, acantilados húmedos y sombreados. Cultivados en maceta.

Número de exsiccata: 38997 FIAF.

Sector doméstico

Categoría de uso: Ornamental. 
Número de informantes: 1 Partes utilizadas: planta entera/viva.

Coltivato in vaso per ornamento (UMI).

Sector medicinal

Categoría de uso: Afecciones cutáneas y tejidos subcutáneos.

Número de informantes: 4 Partes utilizadas: hojas.

Togliere la 'pellicola' della foglia e metterla sopra la ferita (VMA)| Si apriva la foglia, si toglieva la pellicola e si metteva sopra le ferite. (BAZ)| Pestare la foglia e mettere sopra la ferita (VMU)| "Si levavava la pellicina e si metteva un 'impacco' sopra la ferita" (BLI).

Categoría de uso: Trastornos musculo-esqueléticos.

Número de informantes: 1 Partes utilizadas: hojas.

Togliere il velo posteriore della foglia, e applicare sulla schiena o sulla parte dolente, lasciandola tutta la notte. La mattina dopo sarà secca. Quando sfiorisce, si mettono le foglie in una scatola nel freezer, per conservala. (UMI).

Notas è selvatica anche se fa rara., "Prima ognuno aveva una pianta grassa in casa, anche per le ferite".

\section{DATOS ETNOBOTÁNICOS BIBLIOGRÁFICOS}

Nombre vulgar: fœva grâsa (UNGA21).

Número de referencias: 1 Número de citas: 2.

Número de sectores: 1 Número de categorías: 2 .

Sector medicinal

Categoría de uso: Afecciones cutáneas y tejidos subcutáneos.

Número de referencias: 1 Partes utilizadas: No especificado.

fabaria, erba di S. Giovanni, erba da calli, erba carnosa de luoghi sterili e de muri già usata.

nella med. empirica per le ernie, per le scottature e per I calli. (UNGA21).

Categoría de uso: Otro medicinal.

Número de referencias: 1 Partes utilizadas: No especificado.

fabaria, erba di S. Giovanni, erba da calli, erba carnosa de luoghi sterili e de muri già usata.

nella med. Pop. Per le ernie, per le scottature e per I calli. (UNGA21).

\section{Sempervivum tectorum $L$.}

Nombre vulgar: Levasete (AMA), Semprevivo (VMA), Erba trona (VAL, BEL), (non sa come.

si chiama) (PSI), L'erba per curare al mal di ciglio (GGI), Pianta grassa.

(MMR, LGI).

Número de informantes: 8 Número de citas: 8 .

Número de sectores: 3 Número de categorías: 6 .

Biotipo: Caméfito.

Tipo corológico: Montañosas.

Abundancia: Rara.

Ambiente: Acantilados, pendientes áridas y soleadas, también cultivada. 


\section{Sector alimentario}

Categoría de uso: Golosinas y masticatorias.

Número de informantes: 1 Partes utilizadas: hojas.

Quando erano in giro per il castagneto, raccoglievano questa foglie dalla parte anteriore e la ciucciavano, per levare la sete. (AMA).

\section{Sector mágico/ritual/supersticioso}

Categoría de uso: Propiciatorio.

Número de informantes: 1 Partes utilizadas: planta entera/viva.

Una volta si diceva che portavano fortuna e si mettevano sulle tettoie piccole, per proteggere.

la casa. (VMA).

Categoría de uso: Protector.

Número de informantes: 2 Partes utilizadas: hojas.

Si coltiva sopra i pollai 'per le saette', per proteggere dai fulmini e dai 'troni' (tuoni). $(B E L) \mid$ Si coltiva sopra i pollai 'per le saette', cioè come protezione dai fulmini. (VAL).

\section{Sector medicinal}

Categoría de uso: Afecciones cutáneas y tejidos subcutáneos.

Número de informantes: 1 Partes utilizadas: hojas (PSI).

Categoría de uso: Afecciones del aparato respiratorio.

Número de informantes: 1 Partes utilizadas: hojas.

La pianta pestata e messa sopra l' occhio, per un po', poi passava (GGI).

Categoría de uso: Dolor de cabeza.

Número de informantes: 2 Partes utilizadas: hojas.

Raccogliere la pianta grassa che fa sui tetti, schiacciarla con una pietra, mettere la poltiglia in un fazzoletto e legarlo sulle tempie. (MMR, LGI).

Notas erba grassa, sempre verdi, belli fiori, nei castagneti, le foglie fanno delle spine in cima, pianta grassa foglia lunga, sulla punta fa uno spino, coltivata in un vaso a Cinghion, sembrava una rosa, cresce sul tetto, sulle lastre. sui tetti, a rosetta.

\section{DATOS ETNOBOTÁNICOS BIBLIOGRÁFICOS}

Nombre vulgar: urciœla (UNGA21).

Número de referencias: 1 Número de citas: 3 .

Número de sectores: 2 Número de categorías: 3 .

\section{Sector mágico/medicinal}

Categoría de uso: Preventivo de enfermedades.

Número de referencias: 1 Partes utilizadas: hojas.

La superstizione crede che il semprevivo pestato e somministrato al bambino il primo venerdì.

della sua nascita tenga lontano da esso le convulsioni. (UNGA21).

\section{Sector medicinal}

Categoría de uso: Estado general.

Número de referencias: 1 Partes utilizadas: hojas. 
semprevivo, semprevivo dei tetti, guardacasa, barba di Giobbe, erba da calli, detto anche nel cont. trauna en in mont. (Cereglio) erba dal sajatt. Già off. Nella med. Empirica le foglie sono ancora adoperate per cataplasmi e in infusione hanno riputazione di purgative e antiscorbutiche.(UNGA21).

Categoría de uso: Patologías del aparato digestivo.

Número de referencias: 1 Partes utilizadas: hojas.

semprevivo, semprevivo dei tetti, guardacasa, barba di Giobbe, erba da calli, detto anche nel cont. trauna en in mont. (Cereglio) erba dal sajatt. Già off. Nella med. Empirica le foglie sono ancora adoperate per cataplasmi e in infusione hanno riputazione di purgative e antiscorbutiche.(UNGA21).

\section{CUCURBITACEAE.}

\section{Citrullus lanatus (Thunb.) Matsum. \& Nakai}

Nombre vulgar: Cocomero (TOA).

Número de informantes: 1 Número de citas: 1.

Número de sectores: 1 Número de categorías: 1.

Biotipo: Terófito.

Tipo corológico: Cultivadas.

Abundancia: Cultivada.

Ambiente: Cultivada y esporádicamente asilvestrada.

Sector medicinal

Categoría de uso: Afecciones cutáneas y tejidos subcutáneos.

Número de informantes: 1 Partes utilizadas: frutos/infrutescencias/falsos frutos.

Spalmare la buccia di cocomero sulla parte ustionata. (TOA).

DATOS ETNOBOTÁNICOS BIBLIOGRÁFICOS

Nombre vulgar: cucombra (UNGA21), coco'mbra (APPO10).

Número de referencias: 2 Número de citas: 3.

Número de sectores: 1 Número de categorías: 2.

\section{Sector medicinal}

Categoría de uso: Estado general.

Número de referencias: 1 Partes utilizadas: semillas.

Cocomero, anguria, Nella med.pop. Se ne adoperano I semi bolliti per promuovere l'urina, torre la calidità dei reni e calmare l'ardore della febbre. (UNGA21).

Categoría de uso: Patologías del aparato urinario.

Número de referencias: 1 Partes utilizadas: semillas.

Cocomero, anguria, Nella med.pop. Se ne adoperano I semi bolliti per promuovere l'urina,.

torre la calidità dei reni e calmare l'ardore della febbre. (UNGA21). 


\section{Cucumis sativus $L$.}

Nombre vulgar: Cetrioli (GAN), Cetriolo (TOA, MGO, GGI).

Número de informantes: 4 Número de citas: 4.

Número de sectores: 2 Número de categorías: 2 .

Biotipo: Terófito.

Tipo corológico: Cultivadas.

Abundancia: Cultivada.

Ambiente: Cultivada y esporadicamente asilvestrada.

Sector alimentario

Categoría de uso: Encurtidos y conserva en aceite.

Número de informantes: 1 Partes utilizadas: frutos/infrutescencias/falsos frutos.

Sbollentare I cetrioli, farli asciugare e mettere sotto aceto e sale. Durano un mese. (GAN).

\section{Sector medicinal}

Categoría de uso: Afecciones cutáneas y tejidos subcutáneos.

Número de informantes: 3 Partes utilizadas: frutos/infrutescencias/falsos frutos.

Strofinare la buccia del cetriolo sulla pelle arrossata (MGO, GGI)| Mettere il cetriolo con la.

scorza, a fette sulla parte ustionata. (TOA).

DATOS ETNOBOTÁNICOS BIBLIOGRÁFICOS

Nombre vulgar: zedrån (UNGA21), ciderio' (APPO10).

Número de referencias: 2 Número de citas: 2.

Número de sectores: 1 Número de categorías: 1.

Sector alimentario

Categoría de uso: Encurtidos y conserva en aceite.

Número de referencias: 1 Partes utilizadas: frutos/infrutescencias/falsos frutos.

Pianta da orto coltivata per I prodotti verdi, che si conservano in aceto. (UNGA21).

\section{Cucurbita maxima Duchesne}

Nombre vulgar: Zucca (VMU, SLU, SCO, GFR, BPT), Zucche di mia mamma (DAD).

Número de informantes: 6 Número de citas: 7.

Número de sectores: 3 Número de categorías: 4.

Biotipo: Terófito.

Tipo corológico: Cultivadas.

Abundancia: Cultivada.

Ambiente: Cultivado y a menudo asilvestrado en los huertos.

Sector alimentario

Categoría de uso: Fritura.

Número de informantes: 4 Partes utilizadas: flores/inflorescencias y sus partes. 
Fiori coperti di pastella e fritti (BPT)| Bagnare i fiori nella pastella, con pane gratuggiato, prezzemolo, bietola, formaggio. (GFR)| Fiori imbevuti nella pastella e fritti (SCO)| Con I fiori di zucca, un po' di cipolla e pan grattato, fare le frittata. (SLU).

Categoría de uso: Tortilla.

Número de informantes: 1 Partes utilizadas: flores/inflorescencias y sus partes.

Fiori con cipolla, aglio, pane grattato e uova. (SLU).

Sector doméstico

Categoría de uso: Ornamental.

Número de informantes: 1 Partes utilizadas: frutos/infrutescencias/falsos frutos.

Quando le zucche sono piccole sulla pianta, scrive come faceva la mamma il suo nome "Ada" poi quando crescono il nome appare in relievo, e lo mette in casa per ornamento. (DAD).

Sector medicinal

Categoría de uso: Estado general.

Número de informantes: 1 Partes utilizadas: semillas.

Mettere a seccare all'ombra tutti I "semi della vita": semi delle ciliege, delle susine ossia le prugne gialle, di zucca, I pinoli, le noci, le culloie o nocciole, le foglie di malva secche, il fiore del gigliopapagone e anche un pò di olio di semi di lino. Poi macinare tutto con il macinino da caffé. E prendere un cucchiaio tutte le mattine a primavera e a ottobre. (VMU).

DATOS ETNOBOTÁNICOS BIBLIOGRÁFICOS

Nombre vulgar: zucca (ZAGN90).

Número de referencias: 1 Número de citas: 1.

Número de sectores: 1 Número de categorías: 1 .

Sector medicinal

Categoría de uso: Afecciones típicas infantiles.

Número de referencias: 1 Partes utilizadas: semillas.

Somministrare semi di zucca trittati. (ZAGN90).

\section{Cucurbita pepo $L$.}

Nombre vulgar: Zuccheti (BIO).

Número de informantes: 1 Número de citas: 1.

Número de sectores: 1 Número de categorías: 1 .

Biotipo: Terófito.

Tipo corológico: Cultivadas.

Abundancia: Cultivada.

Ambiente: Cultivada.

Sector alimentario

Categoría de uso: Sopas de verduras y potaje.

Número de informantes: 1 Partes utilizadas: frutos/infrutescencias/falsos frutos. 
La minestra di pane Toscana si fa con il cavolo, faggioli, zuccheti, carota, cavolo verza e un pò di pepolino (BIO).

\section{CUPRESSACEAE}

\section{Juniperus communis $L$.}

Nombre vulgar: Ginepro (RFR, MSA, SOT, MTO, MSR, GGI, FAM, TGO, REN, LRE, BAN, NST, BSO, BAZ, CLO, VMA, TIV, TAD, SLU, GLA, GFR, ECE, BPT, BOR, BEL), Zinepro (TGA, PCL, GRI, NRO, TUL, NLA, BLI), Zinebro (MCL, BMA), Zinevvoro (MOR), Zanepro (NDI).

Número de informantes: 36 Número de citas: 56.

Número de sectores: 6 Número de categorías: 11.

Biotipo: Fanerófito.

Tipo corológico: Nórdicas.

Abundancia: Común.

Ambiente: Pastos y bosques áridos.

Número de exsiccata: 38905 FIAF.

Sector alimentario

Categoría de uso: Aromatizante.

Número de informantes: 14 Partes utilizadas: frutos/infrutescencias/falsos frutos, tallos.

Raccogliere le 'bacche' a settembre quando sono mature e usarle per aromatizzare i ragù e gli arrosti. (BEL)| Si usava per aromatizzare la carne. (BOR)| Per aromatizzare la carne (TAD, BPT)| Il legno si usava per cuocere la carne, in modo da aromatizzarla. (ECE)| Per aromatizzare la selvagina (TIV, GFR)| Per aromatizzare la selvagina alla "cacciatora", mettere a macerare la carne nel vino con aceto, ginepro, cipolla, sedano, salvia. (GLA)| Per cucinare la selvaggina (TUL, SLU)| Le bacche si usano per aromatizzare la cacciagione. (VMA)| Per insaporire gli intringoli della lepre (CLO)| Per cucinare e insaporire il coniglio e il cinghiale. (BLI) $\mid$ Aromatizzare la carne (NLA).

Categoría de uso: Licor.

Número de informantes: 6 Partes utilizadas: frutos/infrutescencias/falsos frutos. 1 giumella' (pugno) di bacche di ginepro verdi, '1 giumella' (pugno) di bacche viola di ginepro mature. Mettere in un vaso a chiusura ermetica con 1 litro di alcol 90 gradi, 1 lirto di acqua, nell'acqua ci diluisci $1 \mathrm{~kg}$ di zucchero, un poco di cannella, 3 chiodi di garofano, Lasciare 40 giorni (se lo lasci di più è meglio. Filtrare e imbottigliare. (BAZ)| Il liquore al ginepro: mettere un rametto di ginepro con tutte le bacche in' infusione', a macerare nella grappa per 40 giorni. Servire dopo I pasti come digestivo. (BSO)| Cento erbe': 3 foglie di alloro, 3 foglie di limone, 3 coccole di ginepro, 3 fiori di camomilla, 3 foglie di té, 3 foglie di salvia, 3 foglie di rosmarino, mettere a macerare in un litro di acqua bollita con $350 \mathrm{gr}$ di zucchero e a cui siano stati poi aggiunti $40 \mathrm{gr}$ di alcol a $90^{\circ}$. (NST)| Liquore digestivo:Lasciare a 
macerare le bacche nel alcol puro o nella grappa con lo zucchero (TAD)| Si fanno I liquori con le bacche di ginepro. (VMA)| "Facevano la grappa, e il liquore" (BLI).

Sector doméstico

Categoría de uso: Chimenea y horno.

Número de informantes: 4 Partes utilizadas: tallos leñosos/ramas/ramitas/vástagos.

Facevano un mazzo con I rami di pungitopo e di ginepro, uno si metteva su e un'altro giu, tirando su e giu. (BLI)| Ginepro secco per accendere il fuoco (GFR)| Per controllare la temperatura del forno per infornare il pane, mettere dentro un ramo di ginepro: se prende fuoco, è troppo caldo, bisogna aspettare. (BMA)| Con I rami di zinepro e degli spini, si puliva la canna fumaria. (NRO).

Categoría de uso: Integración de la renta familiar.

Número de informantes: 1 Partes utilizadas: frutos/infrutescencias/falsos frutos.

Portavamo le bacche di ginepro da vendere a Porretta (BOR).

Sector mágico/medicinal

Categoría de uso: Otro mágico/medicinal.

Número de informantes: 1 Partes utilizadas: frutos/infrutescencias/falsos frutos.

Per la tosse, raccogliere le bacche a settembre, quando sono mature. Prendere 5 bacche il primo giorno, poi il giorno dopo 6, poi 7 fino a 10, e poi tornare indietro: 9, 8, 7, 6... (BEL).

Sector mágico/ritual/supersticioso

Categoría de uso: Protector.

Número de informantes: 6 Partes utilizadas: tallos leñosos/ramas/ramitas/vástagos,.

Si metteva un ramo di ginepro sulla pietra della 'livornina' (finestrina con ringhiera fatta di pietra della porta principale della casa) e si diceva che quando le streghe arrivavano 'gli faceva giorno' contando le spine dei ginepri e dovevano andare via. (BAN)| Coltivata nell'orto o appesa in casa per tenere lontane le streghe. (GFR)| Raccogliere dei rami di ginepro fuori del comune di residenza e tenerli in un vaso, nascosti, per allontanare il mal'occhio. (LRE)| Piantare una pianta di ginepro vicino alla casa per allontanare le streghe (REN)| Rami di ginepro messi nel fenile o in casa. La notte di Natale o di "mallie", quando arrivano le streghe, prima devono contare le foglie del ginepro, cosi si fa giorno e devono andare via. (TGO)| La notte di Natale si metteva un ramo di zinepro in casa per allontanare le streghe (TUL).

Categoría de uso: Rituales navideños.

Número de informantes: 15 Partes utilizadas: tallos leñosos/ramas/ramitas/vástagos,.

Celebrazioni natalizie: fuoco sacro. La vigilia di Natale tutti facevano un gran falò con i ginepri (BPT)| Celebrazioni natalizie: fuoco sacro. Per la festa della luce, festa pagana del solstizio, e anche la notte di Natale. Da tutte le borgate si vedeva un gran fuoco e tutta la vallata appariva illuminata da fuochi grandi. (FAM)| Fuoco sacro, per fare il falò di la vigilia di Natale. Dopo si prendono le braci e si portano in casa nel camino, perché porta bene. (GFR)| Celebrazioni natalizie: fuoco sacro. La notte di Natale tutti facevano un gran falò. (GGI)| Celebrazioni natalizie: fuoco sacro. La 
vigilia di Natale, tutti facevano un gran falò con i ginepri. Durante una settimana prima si raccoglievano i ginepri. (GLA)| Il ginepro si usava per fare il falò di Natale. (MTO, MSR)| La vigilia di Natale, per scaldare Gesù bambino, si brucia un ramo di ginepro, si "abbronza" e si tiene in casa, come buon augurio. L'anno seguente si brucia il vecchio e si abbronza un altro. (SOT) $\mid$ La vigilia di Natale, tutti facevano un gran falò con i ginepri. Il ginepro veniva usato anche come albero di Natale. Legavano ai rami arance, frutti e quello che trovavano. (TIV) $\mid \mathrm{Si}$ usava l'albero di Ginepro per fare l'albero di natale. (VMA)| Celebrazioni natalizie: fuoco sacro. Si faceva un falò, per dare la benedizione di Natale (MCL)| Celebrazioni natalizie: fuoco sacro. La vigilia di Natale, tutti facevano un gran falò con i ginepri, dopo la messa di mezzanotte. Tutti collaboravano a portare la legna di zinepri, e facevano la gara a chi durava di più. E poi si portava un po' di cenere benedetta a casa. (GRI)|A Natale si decorava l' albero di zinepro con arance e mandarini e si legavano scritti, si appendevano cioccolatini. (NRO)| Celebrazioni natalizie: fuoco sacro. Per fare i fuochi di Natale. (TUL)| Si facevano il falò con il zinevvoro a Natale, perché fa scintille. (MOR).

\section{Sector medicinal}

Categoría de uso: Afecciones del aparato respiratorio.

Número de informantes: 4 Partes utilizadas: frutos/infrutescencias/falsos frutos. Fare dei fumenti con le bacche di ginepro per il raffreddore. (MSA)| Fare delle fumenta con le bacche di ginepro cotte per il raffreddore: 'apre' le vie respiratorie. (RFR)| Mettere le coccole di zanepro a bollire nell'acqua e fare dei fumenti per il raffreddore. (NDI)| Fare fumenti con le "coccole" del zinepro per l'asma (PCL).

Categoría de uso: Patologías del aparato digestivo.

Número de informantes: 3 Partes utilizadas: frutos/infrutescencias/falsos frutos.

Il liquore al ginepro: mettere un rametto di ginepro con tutte le bacche in' infusione', a macerare nella grappa per 40 giorni. Servire dopo I pasti come digestivo. (BSO)| Liquore digestivo:Lasciare a macerare le bacche nel alcol puro o nella grappa con lo zucchero (TAD)| Bollire nel vino con lo zucchero 2 o 3 bacche di zinepro come digestivo (BLI).

Categoría de uso: Trastornos musculo-esqueléticos.

Número de informantes: 1 Partes utilizadas: frutos/infrutescencias/falsos frutos. Bollire le coccole di zinepre con rosmarino nel vino e strofinare sul ginocchio dolente o sulla.

parte contusa (TGA).

Sector religioso

Categoría de uso: Rogativas.

Número de informantes: 1 Partes utilizadas: tallos leñosos/ramas/ramitas/vástagos.

Si facevano degli archi con rami di zinepro ed abete per le rogazioni (BLI).

Notas è tutto scomparso, ricetta passata da una amica di Chiapporato (già intervistata)., Raccogliere le bacche a settembre, quando sono mature.Sta morendo, siamo passati per quello che era un bosco di ginepro e sta morendo tutto. 


\section{DATOS ETNOBOTÁNICOS BIBLIOGRÁFICOS}

Nombre vulgar: zanåvver (UNGA21), ginepro (MANG98, SANS14, GRIZ03), ginepri (GUC81), zinepro (POLI14), Zanèvro (APPO10), z inévvaro (GUC98).

Número de referencias: 8 Número de citas: 13 .

Número de sectores: 4 Número de categorías: 6 .

\section{Sector agropastoral}

Categoría de uso: Otro agropastoral.

Número de referencias: 1 Partes utilizadas: tallos leñosos/ramas/ramitas/vástagos. Il ginepro ha un legno odoroso e resistente, ottimo per far pali. (UNGA21).

\section{Sector alimentario}

Categoría de uso: Aromatizante.

Número de referencias: 3 Partes utilizadas: frutos/infrutescencias/falsos frutos.

(SANS14)Beccacce al ginepro: 2 beccacce, 12 bacche di ginepro, burro, acquavite di ginepro, timo, sale, pepe. Pestate le bacche nel mortaio, riducendole in poltiglia: incorporatene un terzo e quattro noci di burro. Mettetele dentro ogni beccaccia. Unite un rametto di timo. Fate cuocere le baccacce in burro piuttosto abbondante a fuoco vivo. Quando saranno ben rosolate, salate, pepate, spolverizzate col resto delle bacche pestate e completate la cottura. All'ultimo scaldate l'acquavite, versatela sulle beccacce, portatele in tavola infiammate. (GRIZ03)| Costine di maiale e di agnello al forno: $1 \mathrm{~kg}$ di costine, $1 \mathrm{~kg}$ di patate, 1 foglia di alloro, rosmarino, ginepro, olio, sale, pepe. Mettere le costine in una teglia che possa andare in tavola, accomodate in un solo strato e non troppo vicine le une alle altre. Copritele con le patate che nel frattempo avete preparato lavate, sbucciate e fatte a quarti. Irrorate con un filo d'olio. Il grasso delle costine sciogliendosi sarà sufficiente come condimento. Salate e pepate generosamente. Cospargete di rosmarino e lauro spezzettato. Mettete le bacche di ginepro in un pezzo di carta robusta, ripiegatela e pestate con un batticarne in modo da spaccarle grossolanamente. Sparpagliatele sulle patate, mettete il coperchio e coprite con stagnola, sigilando bene attorno ai bordi. Infornate in forno già caldo e portate a cottura. Quando costine e patate saranno pronte, togliete il coperchio, alzate il forno al massimo, o meglio ancora, accendete gli infrarossi e lasciate dorare, scuotendo ogni tanto la teglia perché la doratura possa avvenire uniformemente. (GRIZ03)| Le massaie adoperano le bacche per usi di cucina. (UNGA21).

Categoría de uso: Licor.

Número de referencias: 2 Partes utilizadas: frutos/infrutescencias/falsos frutos.

(SANS14)Gineprino: $100 \mathrm{~g}$ di bacche di ginepro, $250 \mathrm{~g}$ di zucchero, $300 \mathrm{~g}$ di acqua, $250 \mathrm{~g}$ di alcohol a 95 gradi. Mettere a macerare le bacche di ginepro in un vaso di vetro con l'alcohol per quattro settimane. Fate uno sciroppo bollendo l'acqua e lo zucchero e lasciatelo raffreddare. Filtrate l'alcol con una garza fittissima, miscelatelo con lo sciroppo, riempite una bottiglia da $65 \mathrm{cl}$. e sigilatela con la cera lacca. Lasciate riposare per almeno nove mesi. (GRIZ03).

\section{Sector mágico/ritual/supersticioso}

Categoría de uso: Rituales navideños.

Número de referencias: 2 Partes utilizadas: parte aérea (toda). 
La viglilia di natale verso mezzanotte si tagliavano i ginepri che cioccavano quando brusciavano, le ragge poi si durava due ore e più a fare il faló. (GUC81)| Ora è una pianta protetta, ma un tempo era considerata infestante. Era molto ricercata per fare il falò natalizio o anche l'albero di Natale. (POLI14).

\section{Sector medicinal}

Categoría de uso: Afecciones cutáneas y tejidos subcutáneos.

Número de referencias: 1 Partes utilizadas: frutos/infrutescencias/falsos frutos, hojas.

In certe zone si fanno cuocere in olio d'oliva solo i galbuli, si aggiunge cera d'api e si filtra il tutto attraverso un panno, tale preparato viene utilizzato per il trattamento delle bruciature. Su zone affette da Herpes zoster (fuoco di Sant'Antonio) si applica un linimento ottenuto facendo soffriggere in olio di oliva dei galbuli e qualche foglia.(MANG98).

Categoría de uso: Trastornos musculo-esqueléticos.

Número de referencias: 1 Partes utilizadas: frutos/infrutescencias/falsos frutos.

Si prepara un linimento facendo cuocere in olio d'oliva galbuli di ginepro, foglie di canfora e capolini di camomilla, il preparato così ottenuto, dopo filtrazione, serve per massaggi antireumatici. (MANG98).

\section{CYPERACEAE}

\section{Carex pendula Huds.}

Nombre vulgar: Garza (MRI), Scarza (TUL, TAD, GFR), Scarza, Garza (GGI).

Número de informantes: 5 Número de citas: 5.

Número de sectores: 1 Número de categorías: 1.

Biotipo: Hemicriptófito.

Tipo corológico: Europeas.

Abundancia: Común.

Ambiente: Bosques higrófilos sobre todo de choperas, riachuelos.

Número de exsiccata: 39117 FIAF, 39007 FIAF.

Sector artesanal

Categoría de uso: Tejer sillas.

Número de informantes: 5 Partes utilizadas: hojas, tallos herbáceos/escapos, parte.

Dalle foglie della garza si faceva la corda con cui si impagliavano le sedie. (MRI)| Per impagliare le sedie si intrecciavano insieme scarza e giunco. (GFR)| Per impagliare le sedie si intrecciavano scarza e giunco, ma la scarza regge di più. (TAD) $\mid$ Si taglia, si fa seccare, poi si mettono in acqua calda per intrecciare le sedie (GGI, TUL).

Notas Venivano dei artiggiani dal Veneto, li si dava vito e alloggio, il materiale necessario e in più li si pagava il lavoro, e facevano delle sedie di legno di ciliegio e impigliate con la garza.(Ver Lámina 12 artesanal). In vece I bastoni piccoli erano di castagno secco. 


\section{DATOS ETNOBOTÁNICOS BIBLIOGRÁFICOS}

Nombre vulgar: scarza (SIRGI91).

Número de referencias: 1 Número de citas: 1.

Número de sectores: 1 Número de categorías: 1.

Sector agropastoral

Categoría de uso: Construcción agrícola (cabañas, etc...).

Número de referencias: 1 Partes utilizadas: hojas.

Se non vi era terreno... una specie di erba lunga e con foglie larghe molto adatta, detta scarza,.

in sostituzione delle piote, per la copertura della baracca (SIRGI91).

\section{DENNSTAEDTIACEAE (incluye HYPOLEPIDACEAE)}

\section{Pteridium aquilinum (L.) Kuhn}

Nombre vulgar: Felce (CRE, MGO, MTO, MSR, MIO, LGI, GLA, BOR, AMA, TUL, TGO, SOT, GFR, CRI, GGL, BMA, BEL), Felce bottaglie (DAD), Felce, Felce aquilina (VMA), Felce femmina (VMU).

Número de informantes: 20 Número de citas: 23.

Número de sectores: 4 Número de categorías: 8 .

Biotipo: Geófito.

Tipo corológico: Amplia distribución.

Abundancia: Común.

Ambiente: Bosques, brezales, baldíos herbáceos, sobre silício.

Número de exsiccata: 38919 FIAF.

Sector agropastoral

Categoría de uso: Cría de ganado bovino.

Número de informantes: 3 Partes utilizadas: hojas.

Si faceva il 'letto' per le mucche con le foglie di felce secche e le foglie di castagno secche (BEL)| Con le foglie si faceva il 'letto' alle bestie (BMA)| Per fare il 'letto' di felci alle mucche. (GGL).

Categoría de uso: Cría de ovejas.

Número de informantes: 5 Partes utilizadas: hojas.

Foglie secche messe a forma di letto e chiamato "concio" (CRI)| Si faceva il letto delle pecore con le felci. (CRI)| Foglie secche per fare il letto delle pecore, quando non c'era il grano (GFR)| Con le foglie secche si facevano i letti per le pecore (TUL, SOT)| Usavano le felci secche per fare le lettiere per le pecore (TGO).

Categoría de uso: Productos lácteos.

Número de informantes: 8 Partes utilizadas: hojas.

Quando facevano il formaggio lo coprivano tutto con le foglie di felce: 'Veniva buonissimo' (AMA)| Per fare il 'rovaggiolo' dal latte fresco, si metteva il latte cagliato con il sale in una 'bacinella' con le felci sotto e sopra e poi si pressava. Si lasciava sgrondare un giorno e si mangiava da fresco (BOR)| Per avvolgere le ravagiole (la prima cagliata). (GFR)| "Il Rovaggiolo" è un tipo di stracchino: si 
faceva cagliare il latte, e il caglio si metteva via via su un stratto di felci, poi si coprivano di un altro stratto di felci, e sopra un altro po di cagliata, cosi via a stratti. Lasciare 1 o 2 giorni a riposare. E poi si mangiava con i necci. (GLA)| Per fare il 'rovaggiolo' (formaggio fresco che si mangiava con la polenta dolce). Si metteva il latte cagliato a 'sgrondare' in una 'bagiolina' di coccio bucata sotto, con sopra foglie di felci. Il giorno dopo era pronto. (LGI)| Per fare il formaggio 'rovaggiolo' si procede così: coprendo il colino con la felce, mettere il latte cagliato e lasciarlo 'sgrondare' bene dal siero, per 1 o 2 giorni. È tipo stracchino, ma un po' acido. (MIO)| Per scolare il siero dalla cagliata quando si faceva il 'rovagliolo', perché così colava bene. Quando facevano il formaggio mettevano il latte cagliato in una forma di terracotta, coprivano la forma con foglie di felce, poi ricoprivano anche il latte cagliato di felci e aggiungevano il sale. Si lasciava riposare un giorno e si mangiava quando si era asciugato. (MTO, MSR).

\section{Sector alimentario}

Categoría de uso: Verdura cocida.

Número de informantes: 1 Partes utilizadas: hojas.

Lo stelo tenero (picciolo fogliare), raccolto prima che si sviluppi del tutto la foglia (che fa 'un ricciolo'), va saltato in padella e mangiato come verdura (MGO).

\section{Sector doméstico}

Categoría de uso: Ornamental.

Número de informantes: 1 Partes utilizadas: hojas.

Per fare una composizione di fiori per casa, mettendo le foglie dietro altri fiori piu vistosi.

(DAD).

Categoría de uso: Ropa de cama y muebles.

Número de informantes: 1 Partes utilizadas: hojas.

Si usavano per fare i materassi perché assorbe 1'umidità (VMA).

Sector medicinal

Categoría de uso: Afecciones del aparato respiratorio.

Número de informantes: 1 Partes utilizadas: flores/inflorescencias y sus partes.

"Fiorume", fiori e foglie del fieno (di Trifoglio,trafagliolo, ginestrino, erba medica, radicchi, felce, camomilla, margherite, papaveri) Mettere i fiori e le foglie che restano dopo avere preso il fieno, trittate, nell'acqua bollente e respirare il vapore con la testa coperta con un panno (CRI).

Categoría de uso: Trastornos musculo-esqueléticos.

Número de informantes: 2 Partes utilizadas: hojas.

Fare il letto di felci fresche e dormirci sopra. (CRE)| Si mettevano le foglie a seccare e poi si.

mettevano come ripieno dei giornali per l'artrosi, le cervicali e il dolore di collo (VMU).

Notas felce infestante dei campi, Il formaggio con le felci si faceva quando c'era poco latte, quando le pecore già non facevano tanto latte, ossia verso l'estate. Non è la felce che cresce nei fossi, ma una felce che cresce a primavera sotto I castagneti. 


\section{DRYOPTERIDACEAE (incluye ASPIDIACEAE)}

\section{Dryopteris filix-mas (L.) Schott}

Nombre vulgar: Felce bottara (MRI).

Número de informantes: 1 Número de citas: 1.

Número de sectores: 1 Número de categorías: 1 .

Biotipo: Geófito.

Tipo corológico: Amplia distribución.

Abundancia: Común.

Ambiente: Bosques.

Número de exsiccata: 39064 FIAF.

Sector doméstico

Categoría de uso: Ornamental.

Número de informantes: 1 Partes utilizadas: planta entera/viva.

La pianta viva accanto ai muri della casa è ornamentale, perché diventa grande e sempre verde. (MRI).

Notas "Bottara" viene da "botta" che in italiano è rospo, per relazione alle zone umide dove crescono queste piante.

\section{DATOS ETNOBOTÁNICOS BIBLIOGRÁFICOS}

Nombre vulgar: fallza ed San Zvan o fallza masti, Dai mont. Felce di San Giovanni (UNGA21), felce maschio (MANG98).

Número de referencias: 2 Número de citas: 3 .

Número de sectores: 2 Número de categorías: 3 .

Sector mágico/ritual/supersticioso

Categoría de uso: Protector.

Número de referencias: 1 Partes utilizadas: semillas.

Crede il volgo che Il seme di questa pianta nasca e cada nella notte di S. Giovanni a mezzanotte in punto, epperò in quella notte e in quell'ora si in traccia di esso seme e chi ne viene in possesso si reputa fortunato, perché tiene lontano I malefici, e per contrario chi non ne trova avrà disgrazia. Il filix mas fu un tempo usitatissimo per uccidere la tenia e tale virtù gli è stata ancora in oggi riconfermata. (UNGA21).

Sector medicinal

Categoría de uso: Patologías del aparato digestivo.

Número de referencias: 1 Partes utilizadas: hojas.

La pianta essiccata e polverizzata viene assunta, con 1'aiuto di un po'd'acqua, in caso di tenia intestinale (MANG98).

Categoría de uso: Patologías del aparato urinario.

Número de referencias: 1 Partes utilizadas: hojas.

Per combattere 1 'enuresi notturna, si consiglia di dormire su di un materasso imbottito con fronde secche di felce maschio. (MANG98). 


\section{Polystichum aculeatum (L.) Roth ex Mert.}

Nombre vulgar: Felce (BSO).

Número de informantes: 1 Número de citas: 1.

Número de sectores: 1 Número de categorías: 1.

Biotipo: Geófito.

Tipo corológico: Europeas.

Abundancia: Rara.

Ambiente: Rocas, bosquecillos.

Número de exsiccata: 39065 FIAF.

Sector agropastoral

Categoría de uso: Avicultura.

Número de informantes: 1 Partes utilizadas: hojas.

Per fare il letto alle galline (BSO).

\section{ELAEAGNACEAE.}

\section{Elaeagnus rhamnoides (L.) A.Nelson (= Hippophae rhamnoides L.)}

Nombre vulgar: Marruga (sono dei spini, I frutti sono gialliaccio o rossiccio chiaro (BAD),

Marughe (VSI, RGI), Marughi (GUF).

Número de informantes: 4 Número de citas: 4.

Número de sectores: 2 Número de categorías: 2 .

Biotipo: Fanerófito.

Tipo corológico: Europeas.

Abundancia: Común.

Ambiente: Prados áridos.

Sector doméstico

Categoría de uso: Integración de la renta familiar.

Número de informantes: 3 Partes utilizadas: planta entera/viva.

La raccoglievano insieme alle corniole, le peterlenghe (per fare marmellate) e le More, e le portavano a Bologna (BAD)| Pianta raccolta e vendutaa un signore che li vendeva a Bologna, all'Università come piante medicinali (RGI)| Pianta raccolta e venduta a un signore che li vendeva a Bologna, all'Università come piante medicinali (VSI).

Sector efecto nocivo

Categoría de uso: Tóxicas y venenosas.

Número de informantes: 1 Partes utilizadas: frutos/infrutescencias/falsos frutos.

Da piccoli ci dicevano sempre di non mangiare I frutti arancioni e spinosi perche sono velenosi. Sopra tutto si usava "al di là dell'acqua" (GUF). 


\section{EQUISETACEAE}

\section{Equisetum arvense $L$.}

Nombre vulgar: Guzzedri (BEL), Guzzedro (GGL, PIM, NDI), Acquaseddolo (GUF).

Número de informantes: 5 Número de citas: 5.

Número de sectores: 3 Número de categorías: 4.

Biotipo: Geófito.

Tipo corológico: Nórdicas.

Abundancia: Bastante Común.

Ambiente: Baldíos húmedos.

Número de exsiccata: 38988 FIAF, 39071 FIAF, 39086 FIAF.

Sector alimentario

Categoría de uso: Golosinas y masticatorias.

Número de informantes: 2 Partes utilizadas: tallos herbáceos/escapos.

(NDI)I germogli dei guzzedri si mangiavano nei campi così al naturale. Su usava la parte del gambo, quando facevano un 'pagnottino' (fusti fertili): sembravano come asparagini, erano acquosi. (BEL).

Sector doméstico

Categoría de uso: Detergente.

Número de informantes: 1 Partes utilizadas: parte aérea (toda).

Per pulire le bottiglie di vetro insieme al gambo rosso (Parietaria) (GUF).

Sector medicinal

Categoría de uso: Patologías del aparato urinario.

Número de informantes: 1 Partes utilizadas: parte aérea (toda).

Bere Il decotto di guzzedro: 'Fa bene per urinare'. (PIM).

Categoría de uso: Trastornos musculo-esqueléticos.

Número de informantes: 1 Partes utilizadas: parte aérea (toda).

Bere l'infuso di tanto in tanto. (GGL).

Notas Ce ne sono due: uno che è piccolo, ha il pelo nel gambo, è cattivo e velenoso. E l'altro che è buono che è più chiaro, fa una sorta di cappellino sul gambo che si mangia.,.

\section{DATOS ETNOBOTÁNICOS BIBLIOGRÁFICOS}

Nombre vulgar: cô d'caval,da contadini anche guvan e guvauna, in montagna guzzaddra (UNGA21), cô d'caval,da contadini anche guvan e guvauna, in montagna guzzaddra, guzzaiddra (UNGA21), ac`quaséddolo, guz irro (GUC98).

Número de referencias: 2 Número de citas: 3 .

Número de sectores: 1 Número de categorías: 2 .

\section{Sector medicinal}

Categoría de uso: Patologías del aparato circulatorio.

Número de referencias: 1 Partes utilizadas: otras partes.

Il succo si adopera come astringente per stagnare il sangue del naso. (UNGA21). 
Categoría de uso: Patologías del aparato urinario.

Número de referencias: 1 Partes utilizadas: parte aérea (toda).

l'acqua distillata di quest'erba si usa dal volgo per guarire I mali della vescica. (UNGA21).

\section{Equisetum telmateia Ehrh.}

Nombre vulgar: Coda cavallina (VMU), Guzzedri (BEL), Guzzedro (PIM, NDI), Acquaseddolo (GUF), Erba cavallina (VMR).

Número de informantes: 6 Número de citas: 8.

Número de sectores: 4 Número de categorías: 6 .

Biotipo: Geófito.

Tipo corológico: Nórdicas.

Abundancia: Bastante Común.

Ambiente: Lugares húmedos y sombreados.

Sector agropastoral

Categoría de uso: Antiparasitario.

Número de informantes: 1 Partes utilizadas: parte aérea (toda).

Mettere in un bidone la coda cavallina, insieme all'ortica, e ai peperoncini. Lasciare macerare da 15 a 20 giorni. Poi con un ciuffo di erba si bagna in questo composto e si spruzza sui pidocchi dei faggioli o dei cavoli. (VMU).

Categoría de uso: Horticultura.

Número de informantes: 1 Partes utilizadas: parte aérea (toda).

Mettere in un bidone la coda cavallina, insieme all'ortica, e ai peperoncini. Lasciare macerare da 15 a 20 giorni. Poi si mette accanto alle piantine come concime. (VMU).

\section{Sector alimentario}

Categoría de uso: Golosinas y masticatorias.

Número de informantes: 2 Partes utilizadas: tallos herbáceos/escapos.

(NDI)I germogli dei guzzedri si mangiavano nei campi così al naturale. Su usava la parte del gambo, quando facevano un 'pagnottino' (fusti fertili): sembravano come asparagini, erano acquosi. (BEL).

Sector doméstico

Categoría de uso: Detergente.

Número de informantes: 1 Partes utilizadas: parte aérea (toda).

Per pulire le bottiglie di vetro insieme al gambo rosso (Parietaria) (GUF).

Sector medicinal

Categoría de uso: Patologías del aparato urinario.

Número de informantes: 2 Partes utilizadas: parte aérea (toda).

Fare il decotto dell'erba cavallina e bere come diuretico (VMR)| Bere Il decotto di guzzedro: 'Fa bene per urinare'. (PIM).

Categoría de uso: Trastornos musculo-esqueléticos.

Número de informantes: 1 Partes utilizadas: parte aérea (toda). 
Essicare la piante, ridurla in polvere con un macinino di café, diuire la polvere nell'acqua, e bere una volta al giorno (VMR).

Notas In posti umidi.

DATOS ETNOBOTÁNICOS BIBLIOGRÁFICOS

Nombre vulgar: cô d'caval (UNGA21), ac 'quaséddolo, guz irro (GUC98).

Número de referencias: 2 Número de citas: 3 .

Número de sectores: 1 Número de categorías: 2.

\section{Sector medicinal}

Categoría de uso: Patologías del aparato circulatorio.

Número de referencias: 1 Partes utilizadas: otras partes.

Il succo si adopera come astringente per stagnare il sangue del naso. (UNGA21).

Categoría de uso: Patologías del aparato urinario.

Número de referencias: 1 Partes utilizadas: parte aérea (toda).

l'acqua distillata di quest'erba si usa dal volgo per guarire I mali della vescica. (UNGA21).

\section{ERICACEAE}

\section{Calluna vulgaris (L.) Hull.}

Nombre vulgar: Scopiccio basso (GGI), Bruscolo nero o "scopiccio" (GFR), Scopiccio (BPA).

Número de informantes: 3 Número de citas: 3.

Número de sectores: 3 Número de categorías: 3 .

Biotipo: Caméfito.

Tipo corológico: Nórdicas.

Abundancia: Común.

Ambiente: Brezales, pastos pobres, arbustos, bosques de coníferas, siempre sobre suelos muy ácidos.

\section{Sector doméstico}

Categoría de uso: Ornamental.

Número de informantes: 1 Partes utilizadas: parte aérea (toda).

$\mathrm{Si}$ raccoglievano le piante fiorite e si mettevano in un vaso in casa come ornamentale, perché durava tanto anche da secca. (GGI).

Sector efecto nocivo

Categoría de uso: Efecto perjudicial.

Número de informantes: 1 Partes utilizadas: planta entera/viva.

Dove c'è l'erica, ci sono le vipere. Piccolo fiore viola/rosa, fiorisce a fine Giugno. (GFR).

\section{Sector medicinal}

Categoría de uso: Patologías del aparato urinario.

Número de informantes: 1 Partes utilizadas: parte aérea (toda). 
Prendere l' infuso ogni tanto (BPA).

Notas lì c'è solo lo 'scopiccio maschio' o 'scope' (erica è il nome che si è imparato dopo,non è dialetto), che fa il fiore bianco, viene grande, anche se lì non viene poi più di 3 metri. Dove ce n'era tanta, delle volte venivano dissodate e se ne ricavava la ceppa chiamata 'la cioca' di dimensioni di 2 mele, però che veniva adoperato per fare un carbone pregiato o solo per il fuoco in casa perché era un legno eccezionale. E lì dove ce n'era tanta, si toglievano tutte, si toglieva la ciocchetta, si brusciava tutto e il terreno era adatto per seminare l'orzo. Con questi scopiccio non si facevano le scope. Poi c'è la 'scopa femmina' che qui non c'è, (lui non l'ha mai vista, ed è convinto che non ci sia). Dice che c'è solo verso San Baronto, con la quale si fanno le granate, perché fa uno stelo sottile fine e regolare senza rametti ed è ottima per spazzare. E infine c'è 'gli scoppicci bassi o scope basse'che sono quelle che sono più stricianti, con il fiore rosa, e sono belle come ornamento.

\section{DATOS ETNOBOTÁNICOS BIBLIOGRÁFICOS}

Nombre vulgar: scôva (UNGA21), Scopìccio (APPO10), scopìccio (GUC98), bruscolo (POLI14).

Número de referencias: 4 Número de citas: 4.

Número de sectores: 1 Número de categorías: 1.

\section{Sector agropastoral}

Categoría de uso: Apicultura.

Número de referencias: 1 Partes utilizadas: planta entera/viva.

Pianta a fiori rosei, che trovasi dappertutto ne boschi, assai cercata dalle api. (UNGA21).

\section{Erica arborea $L$.}

Nombre vulgar: Erica (BPT, FAM), Scopa (GFR), Bruscolo, scopici (VMR), Scopa maschio (MGO), Scopa (fiore bianco), Bruscolo (CRE).

Número de informantes: 6 Número de citas: 6.

Número de sectores: 3 Número de categorías: 3.

Biotipo: Fanerófito.

Tipo corológico: Esteno-mediterránea.

Abundancia: Común.

Ambiente: Maquias, bosques de encinas de monte bajo, garrigas (en suelos silíceos o suelos ácidos).

\section{Sector agropastoral}

Categoría de uso: Herramientas y objetos agrícolas.

Número de informantes: 2 Partes utilizadas: tallos leñosos/ramas/ramitas/vástagos.

Legare i rami dell' erica in forma di scopa,Scope per il Castagneto, per fuori casa (FAM)|.

Scope per le stalle fatte con i rami di scopa ed il manico di castagno (GFR).

Sector artesanal

Categoría de uso: Objetos domésticos. 
Número de informantes: 3 Partes utilizadas: parte aérea (toda), tallos.

$\mathrm{Si}$ facevano le scope. Non lo ricorda bene. (VMR)| Oggetti domestici: forchettoni:Per grattarsi la schiena (BPT)| Per fare cucchiai per cucina, mestoli, etc. (MGO).

\section{Sector medicinal}

Categoría de uso: Afecciones cutáneas y tejidos subcutáneos.

Número de informantes: 1 Partes utilizadas: tallos leñosos/ramas/ramitas/vástagos.

Lavare il rametto di scopa, mettere a bagno per un po' di tempo e poi metterlo in un fazzoletto piegato e applicarlo sulla spellatura. (CRE).

DATOS ETNOBOTÁNICOS BIBLIOGRÁFICOS

Nombre vulgar: scåvva scôva (UNGA21).

Número de referencias: 1 Número de citas: 3 .

Número de sectores: 2 Número de categorías: 3.

Sector agropastoral

Categoría de uso: Cultivos de gusano de seda.

Número de referencias: 1 Partes utilizadas: tallos leñosos/ramas/ramitas/vástagos. I rami servnon per infrascare I bachi da seta (UNGA21).

Categoría de uso: Herramientas y objetos agrícolas.

Número de referencias: 1 Partes utilizadas: tallos leñosos/ramas/ramitas/vástagos. I rami servono per fare granate da stalla (UNGA21).

Sector artesanal

Categoría de uso: Otro artesanal.

Número de referencias: 1 Partes utilizadas: madera.

La radice nodosa è ricercata per lavori di tornio (UNGA21).

\section{Erica scoparia $L$.}

Nombre vulgar: Scopa femmina (MGO), Erica femmina (BPT).

Número de informantes: 2 Número de citas: 2.

Número de sectores: 2 Número de categorías: 2.

Biotipo: Fanerófito.

Tipo corológico: Esteno-mediterránea.

Abundancia: Común.

Ambiente: Maquias y garrigas, sobre todo después de incendios repetidos.

Sector artesanal

Categoría de uso: Instrumentos y utensilios para la artesanía.

Número de informantes: 1 Partes utilizadas: tallos leñosos/ramas/ramitas/vástagos.

Per fare chiodi di scopa (MGO).

Sector doméstico

Categoría de uso: Objetos domésticos y escobas. 
Etnobotánica en el Alto Valle del Reno (Toscana y Emilia-Romaña, Italia)

Número de informantes: 1 Partes utilizadas: tallos leñosos/ramas/ramitas/vástagos.

Raccogliere i rami, pulirli e unirli e legarli di modo di fare una scopa (BPT).

Notas La scopa femmina non ce n' è più, è sparita perché le Acacie soffocano tutto come la.

scopa femmina, i mirtilli. Si usava la (erica) femmina. $C^{\prime}$ erano tante, pero è sparita.. DATOS ETNOBOTÁNICOS BIBLIOGRÁFICOS

Nombre vulgar: scopa (POLI14), scåvva (UNGA21).

Número de referencias: 2 Número de citas: 3 .

Número de sectores: 2 Número de categorías: 2 .

Sector agropastoral

Categoría de uso: Herramientas y objetos agrícolas.

Número de referencias: 2 Partes utilizadas: tallos leñosos/ramas/ramitas/vástagos. Arbusto sempre verde con cui si facevano granate da spazzare cortili stalle ecc. (POLI14)|.

pianta de boschi che serve a far granate per bassi usi. (UNGA21).

Sector artesanal

Categoría de uso: Objetos personales y calzado.

Número de referencias: 1 Partes utilizadas: madera.

Ho sentito dire che qualcuno si costruiva la pipa usando una escrescenza delle radici, un vero e proprio tumore benigno della piante (POLI14).

\section{Vaccinium corymbosum $L$.}

Nombre vulgar: Mirtillo americano (MGO).

Número de informantes: 1 Número de citas: 4.

Número de sectores: 1 Número de categorías: 3 .

Biotipo: Caméfito.

Tipo corológico: Cultivadas.

Abundancia: Cultivada.

Ambiente: Cultivada.

Sector alimentario

Categoría de uso: Conserva de frutas.

Número de informantes: 1 Partes utilizadas: frutos/infrutescencias/falsos frutos.

Si coltivavano anche I mirtilli americani (molto alti) per fare le bevande. Mettere I frutti in una pentola, e strizzarli con le mani, lasciare 8 giorni a fermentare. Poi colare con un telo e alla fine aggiungere la stessa quantità di zucchero. (MGO).

Categoría de uso: Fruta fresca.

Número de informantes: 1 Partes utilizadas: frutos/infrutescencias/falsos frutos.

Si coltivavano anche I mirtilli americani (molto alti) e si mangiavano freschi (MGO)| Si coltiva negli orti per mangiare I frutti come frutta fresca, è come il mirtillo però molto più alto.

Categoría de uso: Mermelada.

Número de informantes: 1 Partes utilizadas: frutos/infrutescencias/falsos frutos. 


\section{María Teresa Egea Molines}

Si coltivavano anche I mirtilli americani (molto alti) e si facevano le marmellate: Bollire I frutti per 2 o 3 ore, poi filtrare tutto per togliere I semini, e aggiungere la stessa quantità di zucchero. Quando ancora è bollente, mettere nei vasi caldi,lasciare raffreddare e poi tapparli quando sono raffreddati (MGO).

\section{Vaccinium myrtillus $L$.}

Nombre vulgar: Mirtilli (BLI, DAD, CLO, VFR, BOR, VMR, MGO, MGE, LST, GLA, GGI, FAM, BPT, SOT, MVI, GZE, BGI), Mirtillo spontaneo (MGO), Pentolini (LGI, GPU, GLA), Pignatini (GUF), Pignatini (a Taviano), Pentolini ( San Pellegrino) (CFR).

Número de informantes: 21 Número de citas: 37.

Número de sectores: 3 Número de categorías: 12.

Biotipo: Caméfito.

Tipo corológico: Nórdicas.

Abundancia: Rara.

Ambiente: Bosques, brezales, arbustos, pastos, siempre sobre suelo humificado ácido.

\section{Sector alimentario}

Categoría de uso: Bebida.

Número de informantes: 4 Partes utilizadas: frutos/infrutescencias/falsos frutos.

Fare bollire leggermente i frutti, filtrare per togliere i semi ed aggiungere un po' di zucchero, imbottigliare e chiudere, si conserva fino all'inverno. (BGI)| Si faceva il succo. (MVI, GZE)| non specificato (SOT).

Categoría de uso: Conserva de frutas.

Número de informantes: 8 Partes utilizadas: frutos/infrutescencias/falsos frutos.

Raccolte, schiacciate, messe a bollire con poco zucchero,si fanno fermentare, poi il liquido viene riscaldato e filtrato (BPT)| Riempire un barattolo di mirtilli e coprire la superficie di zucchero, chiudere e mettere al sole per 40 giorni (FAM)| La sua mamma faceva lo sciroppo di Mirtilli schiacciare bene la frutta e lasciare riposare in un secchio per 5 o 6 giorni per evitare che I moscerini ci vadano sopra, poi la buccia viene su e sotto rimane la polpa. Poi strizzarli con un canovaccio o con il passaverdure (passapomodori). Poi si può fare in due maniere diverse: Aggiungere metà dello zucchero della quantità di frutta (500 o 600 gr per un litro di succo), fare bollire un pò e imbottigliare. Oppure aggiungere 500 o 600 gr per un litro di succo, imbottigliare, chiudere e lasciare al sole per 40 giorni. Però quest'ultimo ha il rischio che dopo può continuare a fermentare e può scoppiare.I sciroppi erano un concentrato, si usavano sopratutto d'estate per dissetare, dopo di essere stato nei campi si diluiva nell'acqua $1 / 3$ di sciroppo per 2/3 di acqua. (GGI)| Lavare I frutti, metterli in un ciotola tritati con la mani e lasciarli a macerare per 20 giorni, girando tutte le mattine. Poi filtrare con un fazzoletto, bollire il succo con lo zucchero (per un $\mathrm{kg}$ di liquido, 800 gr di zucchero) per 2 o 3 min., lasciare raffredare e imbottigliare. È importante lasciare raffredare prima di imbottigliare perché senon fa la muffa ( "I fiori"). (GLA)| Lo sciroppo di mirtilli è una bevanda dissetante, può essere diluito nell'acqua d'estate oppure bevuto anche da solo, oppure messo anche 
sul dolce. Ricetta dello sciroppo: raccogliere la frutta matura, metterla in un secchio o un tino, chiuderlo con un canovaccio perché prenda il meno area possibile. Lasciare riposare 4 o 5 giorni, (deve formarsi una sorta di muffa sopra).Poi strizzarli con le mani per estrarre il succo e togliere i frutti senza succo. Dipende da quanto ne viene fuori. Per un tino piccolo o un secchio ne va messo $1 \mathrm{~kg}$ o 800 gr. di zucchero. Fare bollire il succo con lo zucchero 10 o 15 minuti, poi si imbarattola calda, si chiude e si mette alla rovescia. (LST)| Si faceva lo sciroppo di mirtilli $>$ fare fermentare un pò di giorni I mirtilli, settacciarli, aggiungere lo zucchero e imbottigliare. Non si faceva bollire, poi si allungava con l'acqua. (MGE)| Mettere I frutti in una pentola, e strizzarli con le mani, lasciare 8 giorni a fermentare. Poi colare con un telo e alla fine aggiungere la stessa quantità di zucchero. Poi allungare con l'acqua e bere per la tosse. (MGO)| Lo sciroppo':Sbollentare I mirtilli, strizzare I frutti oppure passarli per il passaverdure. Fare a parte uno sciroppo di acqua e zucchero, dopo averlo fatto raffreddare, mescolare ai frutti. Poi filtrare tutto con un tovagliolino di lino, imbottigliare e bollire 20 minuti per sterilizzare. (VMR).

Categoría de uso: Dulces y golosinas.

Número de informantes: 1 Partes utilizadas: frutos/infrutescencias/falsos frutos.

Lo sciroppo di mirtilli è una bevanda dissetante, può essere diluito nell'acqua d'estate oppure bevuto anche da solo, oppure messo anche sul dolce. Ricetta dello sciroppo: raccogliere la frutta matura, metterla in un secchio o un tino, chiuderlo con un canovaccio perché prenda il meno area possibile. Lasciare riposare 4 o 5 giorni, (deve formarsi una sorta di muffa sopra).Poi strizzarli con le mani per estrarre il succo e togliere i frutti senza succo. Dipende da quanto ne viene fuori. Per un tino piccolo o un secchio ne va messo $1 \mathrm{~kg}$ o 800 gr. di zucchero. Fare bollire il succo con lo zucchero 10 o 15 minuti, poi si imbarattola calda, si chiude e si mette alla rovescia. (LST).

Categoría de uso: Fruta fresca.

Número de informantes: 6 Partes utilizadas: frutos/infrutescencias/falsos frutos.

Si mangiavano come frutta fresca. (BOR) $\mid$ I mirtilli si mangiavano con il vino e lo zucchero, oppure con il limone, o con il vermout. (VFR)| Si mangiavano fresche (MGO)| Mangiati come frutta al naturale (GLA)| Frutta raccolta nel bosco del Castagneto (GUF)| Al naturale. (CFR).

Categoría de uso: Golosinas y masticatorias.

Número de informantes: 3 Partes utilizadas: frutos/infrutescencias/falsos frutos.

Al naturale (CLO)| In passato nei castagneti venivano così tanti 'pentolini' che diventavano neri e quando si andava con le pecore, si mangiavano lì per lì a manciate. (LGI, GPU).

Categoría de uso: Licor.

Número de informantes: 4 Partes utilizadas: frutos/infrutescencias/falsos frutos.

Frutti freschi, uguale quantita di acqua e 3 volte questa quantita di alcol. Lo fa a occhio. (DAD)| Mettere a macerare un chilo di frutta in un litro di alcol, un litro di acqua e un $\mathrm{kg}$ di zucchero, per minimo un anno. Poi si può filtrare, oppure lasciare la frutta dentro e mangiarla via via. $\mathrm{O}$ si può lasciare quanto si vuole nell'alcol, più ci sta meglio è, anche 5 o 6 anni.. (MVI, GZE)| il 'Mirtillino':mettere I frutti maturi a macerare nel alcol per 40 giorni. Poi filtrare e aggiungere uno sciroppo fatto di acqua e zucchero messi a bollire. Mescolare bene e imbottigliare. (VMR). 
Categoría de uso: Mermelada.

Número de informantes: 4 Partes utilizadas: frutos/infrutescencias/falsos frutos.

Bollire I frutti per 2 o 3 ore, poi filtrare tutto per togliere I semini, e aggiungere la stessa quantità di zucchero. Quando ancora è bollente, mettere nei vasi caldi,lasciare raffreddare e poi tapparli quando sono raffreddati (MGO)| non specificato (VMR, SOT)| Si facevano bollire i mirtilli prima da soli, poi si aggiungeva lo zucchero e si lasciava bollire un altro po' fino a raggiungere una consistenza giusta. Si vedeva a occhio, però sicuramente ci voleva più di un'ora. Poi si imbarattolava. (GPU).

\section{Sector doméstico}

Categoría de uso: Integración de la renta familiar.

Número de informantes: 1 Partes utilizadas: frutos/infrutescencias/falsos frutos.

$\mathrm{Si}$ vendevano messi in un paniere piccolo fatto di vimini (GGI).

\section{Sector medicinal}

Categoría de uso: Afecciones del aparato respiratorio.

Número de informantes: 1 Partes utilizadas: frutos/infrutescencias/falsos frutos.

Mettere I frutti in una pentola, e strizzarli con le mani, lasciare 8 giorni a fermentare. Poi colare con un telo e alla fine aggiungere la stessa quantità di zucchero. Poi allungare con l'acqua e bere per la tosse. (MGO).

Categoría de uso: Afecciones oftalmológicas.

Número de informantes: 3 Partes utilizadas: frutos/infrutescencias/falsos frutos. Mangiare I mirtilli fa bene alla vista (BLI) $\mid$ Fa bene per la vista. (MVI, GZE).

Categoría de uso: Estado general.

Número de informantes: 1 Partes utilizadas: frutos/infrutescencias/falsos frutos. Si mangiavano tanti pignatini perche davano energia (CFR).

Categoría de uso: Patologías del aparato circulatorio.

Número de informantes: 1 Partes utilizadas: frutos/infrutescencias/falsos frutos. Mangiare tanti mirtilli fa bene alla circolazione (BLI).

Notas Non ci sono piú per colpa dei cervi, perché il bosco è abbandonato, e mangiano tutto i cervi, Prima erano pieni I campi, a Pianezzi era tutto nero, ora gli animali selvatici mangiano tutto., A volte si compravano anche a della gente dell'Abetone. Apportazione vitaminica durante tutto l' estate, fino alle castagne. I Castagneti di Chiapporato erano pieni di mirtilli, ora non più.Prima c' erano nel sottobosco, ora va a comprarli a un amico che li raccoglie a Corno alle Scale. Ora non ce ne sono più perché non prendono il sole per il bosco fitto. Prima ce n'erano tantissimi nei castagneti, pero ora non ci sono piu. Quando I castagneti erano puliti, ce n'erano tantissimi.

\section{DATOS ETNOBOTÁNICOS BIBLIOGRÁFICOS}

Nombre vulgar: pentolino (San Pellegrino, Monachino), pignattino (Posola, Lagacci,Castello di Sambuca, Pavana) Bagiolo o baggiolo (Sambuca), lampolina, dampolina (Treppio), lampolina (Monte di Badi), pignattino, pigantuzzolo (Stagno, Badi) piuro, piulo (Pracchia, Cutigliano).

Número de referencias: 6 Número de citas: 11.

Número de sectores: 3 Número de categorías: 7. 


\section{Sector alimentario}

Categoría de uso: Licor.

Número de referencias: 1 Partes utilizadas: frutos/infrutescencias/falsos frutos.

Con la fermentazione del succo di questa bacca è possibile ottenere anche il "vino di mirtillo“a basso tenore alcolico, che può essere aumentato se prima si aggiunge al medesimo dello zucchero. (CORR14).

Categoría de uso: sin precisar.

Número de referencias: 1 Partes utilizadas: frutos/infrutescencias/falsos frutos.

conf. tosc. (Vaccinium myrtillus L.) mirtillo, volg. Baggioli, nel pist. Piuri, frutice di bosco, che dà bacche nere grosse come piselli, di sapore aciduletto graditissimo, rinfrescanti.- Servono le bacche a preparare composte da tavola, di cui si fa vivo commercio nel nostro appennino. I fiori sono ricercatissimi dalle api, e dalle foglie si ricava il colore celeste (UNGA21).

\section{Sector doméstico}

Categoría de uso: Tintorial.

Número de referencias: 1 Partes utilizadas: hojas.

conf. tosc. (Vaccinium myrtillus L.) mirtillo, volg. Baggioli, nel pist. Piuri, frutice di bosco, che dà bacche nere grosse come piselli, di sapore aciduletto graditissimo, rinfrescanti.- Servono le bacche a preparare composte da tavola, di cui si fa vivo commercio nel nostro appennino. I fiori sono ricercatissimi dalle api, e dalle foglie si ricava il colore celeste (UNGA21).

Sector medicinal

Categoría de uso: Afecciones del metabolismo.

Número de referencias: 1 Partes utilizadas: hojas.

L'infuso delle foglie si assume in caso di diabete. (MANG98).

Categoría de uso: Afecciones oftalmológicas.

Número de referencias: 1 Partes utilizadas: frutos/infrutescencias/falsos frutos, hojas.

I frutti vengono mangiati per migliorare la vista (MANG98)| con l'infuso delle foglie vengono.

effettuati lavaggi oculari in caso di occhi rossi ed infiammati (MANG98).

Categoría de uso: Patologías del aparato circulatorio.

Número de referencias: 1 Partes utilizadas: hojas.

con 1'infuso delle foglie, assunto oralmente diminuisce un elevato tasso pressorio. (MANG98).

Categoría de uso: Patologías del aparato digestivo.

Número de referencias: 1 Partes utilizadas: frutos/infrutescencias/falsos frutos.

Lo sciroppo preparato con i frutti viene considerato utile in caso di infiammazioni gastro-.

intestinali e di meteorismo. (MANG98).

4.

5.

6.

7. 
8.

9.

10.

11.

12.

13.

14.

15.

16.

17.

18.

19.

20.

21.

22.

23.

24.

25.

26.

27.

28.

29.

30.

\section{EUPHORBIACEAE}

\section{Euphorbia helioscopia $L$.}

Nombre vulgar: (RNI)Erba dei porri (VMR), (non sa come si chiama) (BOR).

Número de informantes: 3 Número de citas: 3.

Número de sectores: 1 Número de categorías: 2.

Biotipo: Terófito.

Tipo corológico: Amplia distribución.

Abundancia: Común.

Ambiente: Baldíos, pastos áridos.

Número de exsiccata: 38941 FIAF, 39014 FIAF.

Sector medicinal

Categoría de uso: Afecciones cutáneas y tejidos subcutáneos.

Número de informantes: 2 Partes utilizadas: látex o savia.

Applicare il latte bianco sui porri sui porri (VMR)| Applicare il liquido bianco di una pianta di cui nome non se la ricorda, sopra I porri. (RNI).

Categoría de uso: Afecciones oro-faríngeas y de la cavidad oral.

Número de informantes: 1 Partes utilizadas: látex o savia. 
Applicare il lattice bianco della pianta sul dente: il dolore passava, però si rompeva anche il dente. (BOR).

DATOS ETNOBOTÁNICOS BIBLIOGRÁFICOS

Nombre vulgar: êrba dal vulâdg (UNGA21).

Número de referencias: 1 Número de citas: 1.

Número de sectores: 1 Número de categorías: 1.

Sector doméstico

Categoría de uso: Tintorial.

Número de referencias: 1 Partes utilizadas: látex o savia.

erba calenzola, erba delle volatiche, erba diavola, erba rogna, fico d'inferno, erba il cui latte posto sopra ia pelle la corrode e tinge di rosso la carta turchina. (UNGA21).

\section{Euphorbia lathyris $L$.}

Nombre vulgar: Erba per i topi (ECE, MGO, GGI, DAD, BGI), Erba contro le talpe (VMA), Erba per le talpe (RRE, BOR), Pianta per le musarangole (BMA).

Número de informantes: 9 Número de citas: 9.

Número de sectores: 1 Número de categorías: 3 .

Biotipo: Hemicriptófito.

Tipo corológico: Amplia distribución.

Abundancia: Rara.

Ambiente: Huertos, ruinas.

Número de exsiccata: 39081 FIAF, 38989 FIAF.

Sector agropastoral

Categoría de uso: Repelentes y trampas.

Número de informantes: 9 Partes utilizadas: planta entera/viva.

Per allontanare i topi si diceva di piantarla nell'orto. (ECE)| Si piantava nell'orto per allontanare le talpe (BOR)| Si coltiva la pianta nell'orto: le talpe sentono l'odore delle radici e si allontanano. (RRE)| Contro le 'musarangole' (le talpe) si coltivava la pianta intorno all'orto. (BMA) Coltivata nell' orto, quando i topi o le talpe mordono la radice si avvelenano sicuramente. (BGI)| Tenere le talpe e i topi lontano dall' ortoPiantare la piante ai limiti dell' orto (DAD)| Si pianta ai bordi dell'orto, per tenere lontano gli animali che vanno sotto terra. (GGI)| Piantare la piante nel confine dell'orto (MGO) Contro le talpe si piantava questa pianta che faceva mezzo metro. (VMA).

\section{DATOS ETNOBOTÁNICOS BIBLIOGRÁFICOS}

Nombre vulgar: rizen salvadg (UNGA21).

Número de referencias: 1 Número de citas: 1 .

Número de sectores: 1 Número de categorías: 1 .

Sector medicinal

Categoría de uso: Patologías del aparato digestivo.

Número de referencias: 1 Partes utilizadas: frutos/infrutescencias/falsos frutos. 
I frutti sono adoperati dalla gente di campagna per purgarsi, ma pericolosa. (UNGA21).

\section{Euphorbia platyphyllos $L$.}

Nombre vulgar: Erba dei porri (VMR).

Número de informantes: 1 Número de citas: 1.

Número de sectores: 1 Número de categorías: 1.

Biotipo: Terófito.

Tipo corológico: Eurimediterránea.

Abundancia: Común.

Ambiente: Cultivos y baldíos húmedos.

Número de exsiccata: 38937 FIAF.

Sector medicinal

Categoría de uso: Afecciones cutáneas y tejidos subcutáneos.

Número de informantes: 1 Partes utilizadas: látex o savia.

Applicare il latte bianco sui porri sui porri (VMR).

\section{FAGACEAE}

\section{Castanea sativa Mill.}

Nombre vulgar: Castagna (VMR), Castagne (CBR, EMA, GUF, NRO, TAD, VMR), Castagno (BAR, BEL, BLI, BMA, BPT, BSO, CLO, CRI, CVA, DAD, FAM, GAN, GFO, GFR, GGI, GRI, GUF, IRE, LST, MDA, MGE, MGO, MRI, NDI, NER, NLA, NRE, NRO, PCL, PIA, REN, TAD, TGO, TIV, TRU, TSI, VMR, VMU, SOT) Castagno pastenese (LRE, MGI, MSR, MTI, MTO, RFR, VMU), Castagno pastinese (FAM, GAN, GLA) Castagno salvano (TRU, MGO) Castagno selvatico(MGO, TRU) Salvano (GFO, GFR, GGI).

Número de informantes: 55 Número de citas: 15.

Número de sectores: 9 Número de categorías: 44.

Biotipo: Fanerófito.

Tipo corológico: Europeas.

Abundancia: Común.

Ambiente: Bosques generalmente sobre terreno ácido.

Número de exsiccata: 38903 FIAF, 39036 FIAF.

Sector agropastoral

Categoría de uso: Alimentación animal (incluidos los forrajeros).

Número de informantes: 3 Partes utilizadas: harina/salvado, hojas.

Si faceva la broda del maiale a base di ortica sbollentata, semola, grano turco, patate (quelle piccole che avanzavano con la buccia), farina dolce (castagne), siero del latte. (VMR)| Si faceva il 'letto' per le mucche con le felci secche e le foglie di castagno secche (BEL) $\mid$ Castagne scelte per dare da mangiare alle pecore (BPT).

Categoría de uso: Apicultura. 
Etnobotánica en el Alto Valle del Reno (Toscana y Emilia-Romaña, Italia)

Número de informantes: 1 Partes utilizadas: tallos leñosos/ramas/ramitas/vástagos.

Una volta si facevano le cassette di castagno con I 'castagni bugi', mettevano una lastra di sasso sopra e sotto. Le lastre di sasso trasmettono il calore all'interno e le api devono faticare meno per mantenere una certa temperatura idonea per fare il miele. (VMU).

Categoría de uso: Construcción agrícola (cabañas, etc...).

Número de informantes: 2 Partes utilizadas: tallos leñosos/ramas/ramitas/vástagos.

Nel essicatoio, per seccare le castagne si mettevano sopra un caniccio fatto di legni di castagno (BSO, BAR).

Categoría de uso: Cría de ovejas.

Número de informantes: 2 Partes utilizadas: hojas, tallos.

Quando si spazzavano le foglie del castagneto, si usavano per fare il letto alle pecore. (BMA)| Abbeveratoio per i cavalli e le pecore: un tronco di castagno lungo scavato dentro e messo nel fiume (TGO).

Categoría de uso: Cuerdas y ataduras.

Número de informantes: 2 Partes utilizadas: corteza.

Con la corteccia dei polloni, si facevano le "stroppe", ossia fascine legate con il sistema femina-maschio. (GFR)| Raccogliere le "ritorte" o le "stroppe" quando non sia Luna Nuova, dopo che sia passato un Martedi o un Venerdi, perché sennò si spezza. Sono I polloni di Castagno nuovi che si usavano per legare le fascine di legna. (TRU).

Categoría de uso: Herramientas y objetos agrícolas.

Número de informantes: 7 Partes utilizadas: tallos leñosos/ramas/ramitas/vástagos.

Manici di utensili lavorativi (accetta, piccone, zappa, palanchino). Per fare i manici perché lo spacco del castagno non tende a rompersi. Parte usata Legno "lo spacco"Si taglia a Luna vecchia (decrescente) "Non il tondo perche tende a marcire". "Tonda: sgrossavano con il pennato, poi rifinivano con la lima". Giagnoni dice che per fare $\mathrm{i}$ manici si prendeva un tronchetto di 1 o 2 metri più o meno, si spaccava in mezzo, allora una metà veniva dritta e l'altra si piegava. Si prendeva sempre quella dritta e con il pennato, l'accettina, la sega a nastro e per ultimo la lima da legna gli davano la forma, anche per reggerlo con la mano. Allora i vecchi avevano una precisione con il pennato straordinaria. Questo lavoro non si poteva fare con i polloni perché questi si piegavano. (CLO)| Per fare il manico del rastrello (REN, GGI)| Si usava legno di castagno per fare il 'cavallo', uno strumento fatto a forma di $\mathrm{V}$ con un palo sotto in orizzontale e un altro in verticale, con il quale si trasportava la legna, e il rastrello per raccogliere le castagne, fatto di un ramo biforcato di castagno ed incastrato in una sorta di pettine di legno. (IRE)| Le braccia del Mulino (TGO)| Rastrelli (MGO)| Manico del pichi o delle zappe o delle mazze. (TRU).

Categoría de uso: Horticultura.

Número de informantes: 4 Partes utilizadas: hojas, tallos.

Il concime di pecora veniva tolto dalle stalle che erano sotto le abitazioni quando erano pulite e veniva messo nelle concimaie, dopo veniva messo uno stratto di foglie di castagno poi un altro stratto di concime, e cosi via. Quando si voleva prendere il 


\section{María Teresa Egea Molines}

concime pronto si prendeva sempre di sotto. (MGE)| Per fare le frasche su sui si arrampicano le piante dei dei fagioli. Si usano i polloni perché venivano usati per 2 o 3 anni. (MRI)| La rasiccia era un concime ricavato da legna o materiale secco in genere del Castagneto (CLO)| Quando si pulivano i castagneti per la raccolta si facevano dei mucchi con tutto i rami e le foglie ricavate, si chiamavano le roste, scavando prima un bucco, di forma che faceva di concime e di trincea per impedire alle castagne di ruzzolare a Valle. E alla fine del Castagneto, si faceva una rosta piu grande per che non passasero dal vicino. (NLA)| A settembre, con la zappa si pelava tutto il castagneto, si facevano dei mucchi della pellatura. A ottobre, c' era l' armondatura, si rimondava il castagneto, l' erba per fare cascare le castagne. A Novembre si dava fuoco. Questo faceva di concime e si chiamava la rasiccia. (NLA).

Categoría de uso: Otro agropastoral.

Número de informantes: 3 Partes utilizadas: tallos leñosos/ramas/ramitas/vástagos,.

Per fare il fuoco nell'essicatoio di Castagne, per fare la farina bene: la farina deve essere fatta esclusivamente con legna di Castagne. (BPT)| Le foglie di castagno venivano raccolte da per terra per pulire le selvie (il sottobosco del castagneto) per poi raccogliere le castagne. Con le foglie di castagno si faceva il letto ai animali: al maiale, all'asino, alle caprette. (LST) $\mid$ La notte, prima di andare al letto, coprire le braci con le bucce delle castagne. Così si mantengono accese fino alla mattina seguente, per riaccendere il fuoco facilmente. Per Accendere il fuoco si usavano le 'fruscole', frasche di castagno che si mettevano a seccare per usarle quando serviva. (MGO).

Categoría de uso: Vallas y delimitaciones.

Número de informantes: 4 Partes utilizadas: tallos leñosos/ramas/ramitas/vástagos.

Recinzione per le galline (BPT)| In primavera, tagliavano il bosco, facevano i pali e li sbucciavano, cosi duravano di piu. E poi facevano le recinzioni agli orti. (DAD)| "Le palanche" è il recinto fatto di legno di castagno, per proteggere gli orti degli animali (NER)| Facevano i palancati come recinzione per gli animali e gli orti. (NLA).

Categoría de uso: Viticultura y enología.

Número de informantes: 2 Partes utilizadas: tallos leñosos/ramas/ramitas/vástagos.

Per fare le botti per il vino (BPT)| Pali di castagno per tener la vite (FAM).

Sector alimentario

Categoría de uso: Aromatizante.

Número de informantes: 12 Partes utilizadas: hojas, madera.

Aromatizzante dei Necci: si mettevano due foglie di castagno secche sopra e sotto la farina di castagne tra $\mathrm{i}$ due 'testi' (BPT)| Raccolte le foglie in estate, si facevano "manocchi" legati con lo stesso stelo e si mettevano a seccare per l' inverno. Poi venivano bagnate in acqua calda o in acqua fredda aspettando due ore. E si mettono due su un testo e due alla rovescia sopra l'impasto. (GGI)| Si fanno delle 'manocchie' di foglie secche, per poi usarle per aromatizzare I necci tra I testi, bagnandole 
previamente. (GUF)| A luna buona di Agosto, si raccolgono le foglie di castagno della varietå delle cararese, perch'e hanno la foglia piu dolce, si mettono ad essicare a mazzetto e poi si mettono le foglie tra le pietre per fare I Necci e aromatizzarli. (IRE)| Raccolte ad Agosto e messe a essiccare legate in gruppo con lo stesso stelo di una foglia, chiamate le "manocchi di foglie". Prima di usarle si mettevano un po' a bagno, poi se ne mettevano due sotto e due alla rovescia tra due testi e in mezzo la pasta di farina di castagne (NLA)| Aromatizzante dei Necci:Tra due testi, si mettono una foglie sotto con la parte posteriore al in su, e due sopra con la parte anteriore al in su (TGO)| Per seccare le castagne si brusciava il legno di castagno innestato (la ciocca) perché li dava profumo. (VMU)| Le foglie di castagno Pastenese, vanno prese in agosto, a luna buona (cioè luna vecchia) e fatte a mazzetti per metterle a seccare. Poi quando si usano tra $\mathrm{i}$ testi per aromatizzare $\mathrm{i}$ 'torti' (dialetto Stagno) o 'necci', vanno prima messe a mollo in acqua bollente. (MGI)| Le foglie di pastenese venivano raccolte a ferragosto ed infilzate per seccarle. Poi si facevano bollire leggermente e si metteva una foglia di castagno sotto e sopra l'impasto dei 'necci' di farina di castagne, tra i 'testi' usati percuocerli. Serviva a dargli un aroma gradevole. (MSR)| Le foglie di Pastenese venivano raccolte a ferragosto ed infilzate per seccarle. Poi si facevano bollire leggermente e si metteva una foglia di castagno sotto e sopra l'impasto dei 'necci' di farina di castagne, tra i 'testi' usati percuocerli. Serviva a dargli un aroma gradevole. (MTO)| Ad agosto si raccoglievano le foglie di castagno innestato (pastenese, calerese, borgabola, ceppa o neratina) non il selvatico che è amaro, si mettevano a seccare a mazzetti. Poi si mettevano a bagno, e si mettevano due foglie sopra e sotto l'impasto dei necci tra i testi, o anche per fare le focaccine. (VMU)| Le foglie si raccolgono dal 10 Giugno ad Agosto, si fanno pacchetti legati con lo stelo e si facevano seccare in grandi colonne, poi le foglie secche si mettono in acqua bollente e quando diventano di un colore scuro si mettono sui testi sul fuoco. Danno un sapore amarino ai necci. (FAM)| Le foglie di 'Pastinese' (castagno innestato) si infilzavano, per prepararle per fare I necci. Perché sono più lunghe. (GLA).

Categoría de uso: Dulces y golosinas.

Número de informantes: 2 Partes utilizadas: harina/salvado.

Con la farina di castagne si faceva le fritelline dolci (LST)| Con la farina di castagne, rosmarino e pinoli si faceva il castagnaccio. (LST)| "Castagnaccio": Farina di castagne, impastata con dei pinoli, dell'uvetta (messa a mollo con acqua e un po d'olio), e alla fine aromatizzato con un po' di rosmarino sopra (SCO).

Categoría de uso: Fritura.

Número de informantes: 5 Partes utilizadas: harina/salvado.

Le fritelle: impasto di farina dolce fritto con il grasso del maiale (LGI, GPU)| "Le fritelle": fare la pastella un pò più liquida che per I torti e friggere. (MTO, MSR)| Si facevano le fritelle di farina di castagne fritte nel grasso di maiale (SLU).

Categoría de uso: Fruta seca.

Número de informantes: 2 Partes utilizadas: frutos/infrutescencias/falsos frutos. Gli 'ansari' erano le castagne che si mettevano dentro a un sacco che si attaccava al 'caniccio' dell'essiccatoio e si mangiavano come caramelle. Per la Befana si davano ai bambini gli ansari, i mandarini, dei fichi, e delle 'chirole' (nocciole). (BSO, BAR). Categoría de uso: Gachas o polenta. 


\section{María Teresa Egea Molines}

Número de informantes: 9 Partes utilizadas: harina/salvado.

La polenta di castagne veniva poi tagliata col filo da cucire (sennò diventa cruda) e sopra una fettina un uovo fritto sopra e la salciccia matta (salciccia di maiale più scura perché con le viscere del maiale). (BSO, BAR)| Polenta dolce (LGI, GPU)| Con la farina di castagne si faceva la polenta dolce (LST)| "La farinata":farina di castagno con acqua e vinello che era la lavata della grappa, mangiare come una crema (MTO, MSR)| La polenta dolce si mangiava con la tortellina (è come un budino salato:) fatto di latte, 1 o 2 uova, sale, pepe, poi si mescolava sul fuoco finché non diventasse una crema, poi si mangiava insieme alla polenta. (MTO)| La polenta dolce si mangiava con ricotta fresca oppure con un sugo fatto di guanciale di maiale fritto con 2 o 3 cucchiate di aceto (PLU)| Si mangiava la "farinata": amalgamare la farina con l'acqua, crerare una crema. Poi metterla a bollire finché non sia abbastanza morbida. Si mangiava con il vino novello. (BAZ).

Categoría de uso: Licor.

Número de informantes: 1 Partes utilizadas: frutos/infrutescencias/falsos frutos.

Facevano la grappa dalle castagne con il distillatore. (VMR).

Categoría de uso: Mermelada.

Número de informantes: 1 Partes utilizadas: frutos/infrutescencias/falsos frutos. facevano la marmellata con i marroni (VMA).

Categoría de uso: Pan y similares.

Número de informantes: 5 Partes utilizadas: harina/salvado.

Le nerattine sono adatte per fare la farina per fare i necci. (FAM)| Con la farina di castagne si facevano I necci la polenta dolce, le fritelline dolci, castagnaccio aromatizzato con il rosmarino e I pinoli. (LST)|" I torti": fare la pastella di farina di castagne un pò piu spessa che per le fritelle, e fare I torti mettendo delle foglie essicate a ferragosto sopra e sotto la pastella, e tra I testi, nel testaio. (MTO, MSR)| "le pattone" era come il pane o come le frigelle, impasto di farina di castagne cotto con il testaio. (MSR)| Con la farina di castagne si facevano i necci che era il nostro pane. (REN).

Categoría de uso: Pasta y "gnocchi".

Número de informantes: 3 Partes utilizadas: harina/salvado.

Gnochetti di farina dolce: impastare la farina dolce in modo che rimanga abbastanza soda e con un mestolo di legno si buttavano via via nell'acqua bollente salata e si mangiavano così senza condimento perché erano saporiti già di suo. (LGI)| Si faceva la sfoglia mischiando metà di farina dolce con metà di farina di grano. (LGI)|" I gnocchi dolci" fare la pastella come per fare I torti, poi mettere l'acqua a bollire, e buttare con nl cucchiao dei pezzi, finché venissero su. (MTO, MSR).

Categoría de uso: Sopas de verduras y potaje.

Número de informantes: 9 Partes utilizadas: frutos/infrutescencias/falsos frutos. Castagne cotte, si seccano le castagne e si fanno bollire con una foglia di alloro (LGI, GPU)| Le "brillà": sono le frusà (castagne arrostite), sbucciate e cotte per poco tempo (BSO, BAR)| Le "castagne cotte": fare cuocere le castagne secche per una giornata intera. (BAR)| Le "brodose": minestra di castagne cotte con il sale. (BAR)| Mangiare la castagne ballòte. (DAD) $\mid$ La vigilia di Natale facevano le castagne secche cotte (tipo minestra) con un pò di alloro. Poi c'erano anche I cerboloni: le castagne con la buccia solo interna (solo la buccia esterna si toglieva) cotte con 
acqua e sale e un pò di alloro. Poi si sbucciavano e si mangiavano. Poi c'erano le mondine $>$ castagne pulite e messe a bollire in acqua e sale senza la buccia interna ne esterna. E le fruggiate:castagne arrostite. (MGE)| Mondine (abrustolite con la padella,sbucciate e cotte in minestra). (NLA) $\mid$ Le pere si mettono a bollire insieme con i balotti (castagne cotte) (RFR)| "le castrone": si levavano la metà della buccia, si cuocevano con il sale (TAD)| le mondine' o 'fruggiate' (le caldarroste): sbucciate, e cotte con l'alloro (TAD).

\section{Sector artesanal}

Categoría de uso: Instrumentos y utensilios para la artesanía.

Número de informantes: 2 Partes utilizadas: tallos leñosos/ramas/ramitas/vástagos.

Per fare la 'fiaccola' con cui si 'sfiaccolano' (scortecciano) i vimini di fiume freschi da mettere al sole a seccare per poi fare i cesti. Prendere un rametto di castagno e fare due tagli trasversali in croce fino a metà lunghezza del rametto (che in pratica si apre logitudinalmente in quattro porzioni), togliere due porzioni opposte, in modo che ne rimangano due a formare una sorta di forbice o pinza. Poi inserire il ramo di salcio di fiume nella pinza, pigiare e tirare il ramo e ripetere sui due lati del ramo. (MRI) $\mid$ Prendere un ramo di castagno, si taglia fino a metà in due parti trasversali a forma di X, come una morsa, poi si passavano pressando sugli 'stropelli' (rami di salice) per scortecciarli. Si passavano prima da un lato, poi si giravano e si passavano dall'altro. (NRE).

Categoría de uso: Muebles.

Número de informantes: 1 Partes utilizadas: tallos leñosos/ramas/ramitas/vástagos.

Le sedie erano fatte con legno di ciliegio o di castagno. (BLI).

Categoría de uso: Objetos domésticos.

Número de informantes: 4 Partes utilizadas: tallos leñosos/ramas/ramitas/vástagos.

Scaldaletto o "il prete":Struttura di legno di castagno, mettevano dentro le braccie e tutto l'insieme dentro al letto per riscaldarlo (BPT)| "il bigongio" `e un instrumento di legno di castagno con forma di conca, era usato per svuotare il pozzo nero, lo portavano in due persone appeso a un palo che teneva ognuno sulle ombra. (IRE)| Mobili e atrezzi di cucina e di casa (PCL)| Per fare il compas (TGO).

\section{Sector doméstico}

Categoría de uso: Chimenea y horno.

Número de informantes: 2 Partes utilizadas: frutos/infrutescencias/falsos frutos,. Mettere le bucce delle castagne sul fuoco per spengere il fuoco. (GUF)| si tagliavano le ceppe dei castagni, per fare il fuoco per seccare le castagne per fare la farina. Doveva farsi solo con legno di castagno e con I ceppi, che brusciavanolentamente, non con le fascine, perché facevano un fuco troppo forte (MRI).

Categoría de uso: Cuidado personal y cosmética.

Número de informantes: 1 Partes utilizadas: hojas.

Le 'manocchie' di foglie di castagno raccolte ad Agosto e messe ad essiccare in gruppo, legate con lo stelo della foglia, si mettevano nel gabinetto per pulirsi il sedere dopo aver defecato. (NLA). 
Categoría de uso: Integración de la renta familiar.

Número de informantes: 1 Partes utilizadas: madera.

A Chiapporato, c'erano I castagneti rosati, si commercializava la legna bianca ai Ramazzotti a Treppio per il tannino (MRI).

Categoría de uso: Objetos domésticos y escobas.

Número de informantes: 3 Partes utilizadas: tallos leñosos/ramas/ramitas/vástagos.

Per fare la "zana", vassoio per seccare e conservare i fagioli. Era una sfoglia di Castagno, che si metteva a seccare nel forno e serviva per mettere i fagioli borlotti con il guscio (si conservavano meglio) ad essicare per poi conservarli, sotto il letto, nella stanza sopra la cucina (la stufa). "Poi quando si volevano cucinare si andava su, si prendeva una manciata, si sgusciavano e si mettevano a bollire" (DAD)| Bastoni per camminare: il pollone scaldato all'estremità si può curvare per fargli prendere la forma del manico. Con un tronco scavato all'internosi fanno vasi per i fiori da mettere sulle finestre. (TGO)| Si usano tronchetti per fare recipienti per piantine ornamentali (TSI).

Categoría de uso: Otro doméstico.

Número de informantes: 13 Partes utilizadas: hojas.

Per evitare che si attachino, al posto del grasso:Raccolte le foglie in estate, si facevano "manocchi" legati con lo stesso stelo, e si mettevano a seccare per l' inverno. Poi venivano bagnate in acqua calda o in acqua fredda aspettando due ore. E si mettono due su un testo e due alla rovescia sopra l'impasto. (GGI)| Per evitare che si attachino, al posto del grasso:Le foglie si raccolgono a fine Agosto-inizio Settembre, si fanno asciugare due giorni e si fanno pacchetti legati con lo spago e le facevano seccare al sole, poi le foglie secche si mettono in acqua bollente si mettono sui testi sul fuoco. (GRI)| Si faceva un cappello di foglie di castagno cucite con degli spini (NDI)| Per conservare il ghiaccio:Mettevano il ghiaccio della neve in una specie di stanzetta-frigorifero, e lo mescolavano con le foglie di castagno, così il ghiaccio si conservava fino all' estate. (NRO, NER)| "Facevamo il cartoccio, una bustina di foglie grandi, messe perpendicolari e una sopra 1 'altra, poi ripiegare ogni bordo nel senso opposto e cucire con uno stecchino (PIA)| Raccogliere le foglie a luna vecchia di agosto, metterle a seccare legate, e mettere a bagno al momento dell'uso. Si adoperano mettendone un paio sia sotto che sopra la pastella dei 'necci' (crespelle di farina di castagne) perché non si attacchino ai testi durante la cottura. (LRE)| Ad Agosto si raccolgono le foglie di castagno 'pastenese' e si mettono a seccare a mazzetti. Poi quando si fanno i 'torti' (chiamati 'necci' a Stagno) si mettono a bagno e si mettono sotto e sopra l'impasto di farina di castagno tra i testi. Le pastenese non si attaccano ai testi. (MSR)| Per fare i necci, seccare le foglie di castagno pastenese infilzate. Poi al momento dell'uso farle bollire e mettere due foglie bagnate sotto e sopra l'impasto, tra i testi per non farlo attaccare. (MTI)| Le foglie di castagno Pastenese, vanno prese in agosto 'a luna buona' (cioè a luna calante) e fatte a mazzetti per seccare. Poi quando si usano tra i testi per fare i 'castagnacci' (dialetto Bargi) vanno prima messe a mollo in acqua bollente. (RFR)| Per evitare che si attachino, al posto del grasso:Le foglie si raccolgono dal 10 Giugno ad Agosto, si fanno pacchetti legati con lo stelo e le facevano seccare in grandi colonne, poi le foglie secche si mettono in acqua bollente e quando diventano 
scuro si mettono sui testi sul fuoco, al posto di untari con il grasso (FAM)| Per fare i Necci ed evitare che si attacchino ai testi.Raccolte dopo il 20 Agosto, quando sono dure. Fare manocchie di foglie infilzati (incrociati, una sopra l'altra) per farli seccare meglio ed aereati. La foglia delle Pastinese è più massicia e grossa, così vengono meno ragnatele e si staccano meglio dai testi. Per usarli si mettevano a mollo prima. (GAN)| Per fare i Necci ed evitare che si attacchino ai testi. (GLA).

Categoría de uso: Repelentes o trampas domésticas.

Número de informantes: 1 Partes utilizadas: harina/salvado.

Contro $\mathrm{i}$ topi in casa: mettere un secchio pieno d'acqua, aspettare che si fermi l'acqua, e mettereci sopra della semola con un po' di farina dolce. Mettere una especie di scalino o piattaforma che permetta ai topi salirci sopra, il topo si tuffa nel secchio e si affoga. (GAN).

Categoría de uso: Ropa de cama y muebles.

Número de informantes: 1 Partes utilizadas: hojas.

Si facevano I materassi con le foglie di castagno secche, perché il tannino desinfetta. (VMU).

Categoría de uso: Tintorial.

Número de informantes: 3 Partes utilizadas: tallos leñosos/ramas/ramitas/vástagos,.

Mettevano a bollire o a macerare i tessuti con il legno macinato. (BPT)| Tintorio:Bollire insieme alla lana per farla diventare marrone. (GFO)| Tintorio:Fare bollire insieme ai tessuti. Dà un colore Nero-Grigio(per il tannino) (TGO).

Sector lúdico/voluptuoso

Categoría de uso: Decoraciones y disfraces de niños.

Número de informantes: 1 Partes utilizadas: tallos leñosos/ramas/ramitas/vástagos.

Per fare corone si prendono dei rami e si legano su se stessi in forma circolare. I gonnellini per giocare agli indiani si fanno usando rami con foglie grandi e poi si legano intorno alla cintura dei bimbi. (CVA).

Categoría de uso: Instrumentos musicales.

Número de informantes: 8 Partes utilizadas: corteza.

Si prende un pollone di castagno a primavera, quando la buccia stacca da sola. Se si taglia un pezzo diventa una tromba, oppure si può tagliare a spirale e attorcigliare, facendo un corno. (BPT) $\mid$ La 'musetta' è un tipo di flauto diritto, fatto togliendo la corteccia per torsione a un pollone a marzo o aprile, quando la pianta è ricca di linfa. Una delle estremità viene otturata con una piccola zeppa di legno che lascia passare parzialmente l'aria. Al di sotto della zeppa vengono fatti il foro quadrato dello sfiatatoio ed alcuni fori rotondi digitali, senza però nessuna particolare logica musicale. Allo stesso modo si fanno i 'Trombettini', con un tratto di corteccia lungo circa $10 \mathrm{~cm}$ : da una delle estremità va fatta più pressione con le dita, mentre l'altra dovrebbe essere piu stretta. Per fare il 'Trombo' la corteccia si toglie tagliando il pollone superficialmente con un taglio a spirale, con questa corteccia fatta a spirale, la univano facendo una nuova spirale più fitta e a forma di trombo. (CVA) $\mid$ Il fischio va fatto a primavera, quando il castagno 'va in amore' e 'fa l'insucchio'. Si deve prendere un pollone di castagno e togliere la corteccia per torsione, poi tagliare un 


\section{María Teresa Egea Molines}

tratto di corteccia lungo $10 \mathrm{~cm}$ circa. A una delle estremità va fatta più pressione con le dita, mentre l'altra dovrebbe essere più stretta. La 'musetta' è invece un tipo di flauto diritto, fatto togliendo la corteccia a un pollone nello stesso modo. Una delle estremità viene otturata con una piccola zeppa di legno che lascia passare parzialmente l' aria. Al di sotto della zeppa vengono fatti il foro quadrato dello sfiatatoio ed alcuni fori rotondi digitali, senza però nessuna particolare logica musicale. (DAD)| La 'musetta' è un tipo di flauto diritto, fatto togliendo la corteccia per torcione a un pollone a marzo o aprile, quando la pianta è ricca di linfa. Una delle estremità viene otturata con una piccola zeppa di legno che lascia passare parzialmente l' aria. Al di sotto della zeppa vengono fatti il foro quadrato dello sfiatatoio ed alcuni fori rotondi digitali, senza però nessuna particolare logica musicale. Il 'trombo' si fa con la corteccia del pollone a marzo o aprile: la corteccia viene tolta tagliando il pollone superficialmente facendo una spirale. Con questa corteccia fatta a spirale la univano facendo una nuova spirale più fitta a forma di trombo. (MDA)| La 'musetta' è un tipo di flauto diritto, fatto togliendo la corteccia per torsione a un pollone a marzo o aprile, quando la pianta è ricca di linfa. Una delle estremità viene otturata con una piccola zeppa di legno che lascia passare parzialmente l'aria. Al di sotto della zeppa vengono fatti il foro quadrato dello sfiatatoio ed alcuni fori rotondi digitali, senza però nessuna particolare logica musicale. Allo stesso modo si fanno i 'Trombettini', con un tratto di corteccia lungo circa $10 \mathrm{~cm}$ : da una delle estremità va fatta più pressione con le dita, mentre l'altra dovrebbe essere piu stretta. Per fare il 'Trombo' la corteccia si toglie tagliando il pollone superficialmente con un taglio a spirale, con questa corteccia fatta a spirale, la univano facendo una nuova spirale più fitta e a forma di trombo. (PCL, NLA) Flauto dei pastori': si stacca la 'buccia' (corteccia) dei polloni e ci si fanno due buchi. Lo suonavano come un flauto traverso. Si fa ad aprile, quando la buccia si stacca perché è 'in succhio' e rimane la 'nicchia'. Si usava un pezzetto di legno di castagno anche nella costruzione di un 'corno' fatto con legno di salice. (TGO)| La 'musetta' è un tipo di flauto diritto, fatto togliendo la corteccia per torsione a un pollone a marzo o aprile, quando la pianta è ricca di linfa. Una delle estremità viene otturata con una piccola zeppa di legno che lascia passare parzialmente l'aria. Al di sotto della zeppa vengono fatti il foro quadrato dello sfiatatoio ed alcuni fori rotondi digitali, senza però nessuna particolare logica musicale. (TIV).

Categoría de uso: Juguetes.

Número de informantes: 2 Partes utilizadas: tallos leñosos/ramas/ramitas/vástagos.

Carrettoli o "barocci" fatti di un piano di legno con 4 ruote che serviva per buttarsi giù dal.

castagneto (BPT)| Carretoli' per buttarsi giù dal castagneto (TGO).

Categoría de uso: Muñecas.

Número de informantes: 1 Partes utilizadas: corteza.

Con la corteccia del castagno si tagliava la Fig. di una bambola con la quale giocavano le.

bambine. (BLI). 


\section{Sector mágico/ritual/supersticioso}

Categoría de uso: Propiciatorio.

Número de informantes: 2 Partes utilizadas: frutos/infrutescencias/falsos frutos. Mangiare castagne cotte la vigilia di Natale portava fortuna. (NRO)| La mattina di Natale,.

fare le castagne secche cotte porta fortuna (TAD).

Categoría de uso: Protector.

Número de informantes: 5 Partes utilizadas: tallos leñosos/ramas/ramitas/vástagos.

Per la festa di santa Croce, 3 Maggio, si piantava in mezzo al grano una croce di Castagno con un ramo di olivo benedetto, come protezione alle intemperie. (CRI)| Il 3 Dicembre, alla festa di Santa Croce, si andava nei boschi e nei campi e si faceva una croce fatta di bastoni di castagno con una rama di ulivo dentro, per proteggere $\mathrm{i}$ campi dalla grandine. (PCL) $\mid$ Si facevano delle crocette nei campi per liberarli dai tuoni, dai lampi e proteggere la raccolta. Le crocette erano fatte con i pezzettini di legno che saltavano fuori dai polloni di salvano o nocciolo che si sbattevano il Giovedi Santo pomeriggio (il Mattutino) per 3-5 ore sui lastroni della chiesta, sul pavimento dell'altare oppure fuori della chiesa. I pezzettini di legno che saltavano fuori si raccoglievano e il 3 Maggio (Santa Croce) si portavano in tutti i campi per fare le crocette e attaccarci anche l'ulivo benedetto. (GFO)| Le Crocette dei campi dove si attaccavano i rami di olivo benedetto erano fatte con i pezzettino di legno che saltavano fuori dai polloni di salvano o nocciolo che si sbattevano il Giovedi Santo pomeriggio (il Mattutino) per 3-5 ore sui lastroni della chiesa, sul pavimento dell'altare oppure fuori della chiesa. I pezzettini di legno che saltavano fuori si raccoglievano e il 3 Maggio (Santa Croce) si portavano in tutti i campi per fare le crocette e attaccarci anche l'ulivo benedetto. (GFR) $\mid$ Si facevano delle crocette nei campi per liberarli dai tuoni, dai lampi e proteggere la raccolta. Le crocette erano fatte con i pezzettini di legno che saltavano fuori dai polloni di salvano o nocciolo che si sbattevano il Giovedi Santo pomeriggio (il Mattutino) per 3-5 ore sui lastroni della chiesta, sul pavimento dell'altare oppure fuori della chiesa. I pezzettini di legno che saltavano fuori si raccoglievano e il 3 Maggio (Santa Croce) si portavano in tutti i campi per fare le crocette e ci si attaccava sopra anche l'ulivo benedetto. (GGI).

\section{Sector medicinal}

Categoría de uso: Afecciones cutáneas y tejidos subcutáneos.

Número de informantes: 4 Partes utilizadas: harina/salvado, corteza, hojas.

Fare un impasto di farina dolce con l'acqua e applicarla sulla bruciatura finché il calore della bruciatura non va via. Ripetere l'operazione finché non passa (CBR)|"A Maggio, il Castagno va in amore, si li toglieva la corteccia e sotto c'era una pellicina che assomigliava alla pelle umana, si metteva sulle ferite e rimarginavano subito, servendo anche come desinfettante. Si chiamava "il grappo". (BLI)| Per le piaghe ai piedi si mettevano dentro ai zoccoli le foglie di castagne. (MGE)| Nei tronchi dei castagni vecchi, fra gli anelli del tronco, dove è mezzo marcio, si trova una pellicola, si sfoglia e si mette sopra le ferite (SOT).

Categoría de uso: Afecciones del aparato respiratorio. 
Número de informantes: 3 Partes utilizadas: frutos/infrutescencias/falsos frutos, hojas.

Prendere l'acqua dove si avevano lessato le castagne, e respirare quel vapore, facendo I fumenti. Si potevano togliere o lasciare le castagne calde. (EMA)| Mettere la polenta dolce calda sui piedi e guarivano della polmonite. (MGE)| Mettere nell'acqua bollente I 'cemolini' (germogli pieni di resina) dei pini, insieme alle foglie del Castagno e alle foglie di Malva. Lasciare un pò a riposo e aggiungere del miele. Bere finché passa. (VMR).

Categoría de uso: Otro medicinal.

Número de informantes: 2 Partes utilizadas: hojas.

Mettere dentro il cappello 3 o 4 foglie di castagno per evitare l'insolazione (BLI)| Mettere.

dentro il capello 3 o 4 foglie di castagno per evitare l'insolazione (IRE).

Categoría de uso: Trastornos musculo-esqueléticos.

Número de informantes: 1 Partes utilizadas: corteza.

"Il suo nonno era un guaritore, aggiustava le ossa e teneva sempre preparato queste DOCCE" Le docce le faceva con la corteccia di Castagno, per mettere intorno alle fratture, e immobilizzare l'articolazione o l'osso fratturato"Applicata come un gesso (BLI).

\section{Sector religioso}

Categoría de uso: Alfombras florales.

Número de informantes: 1 Partes utilizadas: tallos leñosos/ramas/ramitas/vástagos.

"il busgio" è la polverina che si trova dentro ai tronchi di castagno marciti e vuoti all'interno. Con il busgio si fanno i disegni per le infiorate del Corpus Domini (a maggio), colorando di marrone insieme al giallo della ginestra (FAM).

\section{Sector veterinario}

Categoría de uso: Aves de corral.

Número de informantes: 1 Partes utilizadas: harina/salvado.

L'impasto fatto di ortica cotta, farina dolce e semola è rinfrescante per le galline e 'le sfiamma'. (MGO).

Categoría de uso: Cerdos.

Número de informantes: 1 Partes utilizadas: semillas.

Per prevenire la "Moria" dei maiali (pandemia ). Quando si sentiva dire che c'era la moria, si dava da mangiare ai maiali la 'broda': cuocere l'ortica insieme alle patate, alle carote, al farfaro, alle castagne secche e alla semola. (BLI).

Notas "Il montanaro mangia pan di legno e beve vin di nuvoli""Quando gli uomini vanno a camminare su verso campoli, al prataccio, in cima""Quando gli uomini vanno a camminare su verso campoli, al prataccio, in cima"Ci sono altre varietà di Castagno come le Molone (che sono grosse), il Marrone (quà ce ne sono pochi, è la castagna migliore, fresca, perché non si conserva) e la Salvana (che è l'unicaselvatica,ed è insipida, tutte le altre sono innestate. )Estrazione del Tanino del Castagno che tinge di colore "superiride". Le "pastinese" sono una varietà di castagne pelosette e dolci.Le foglie di Pastenese si raccolgono a agosto. Se si fanno con le foglie del castagno selvatico le foglie non si staccano dal testo.Le foglie di 
Pastenese vanno raccolte in agosto 'a luna buona' (cioè a luna vecchia). Le foglie di Pastenese vanno raccolte in agosto 'a luna buona', cioè a luna calante.Le foglie di pastenese venivano raccolte a ferragostoLe foglie di pastenese venivano raccolte a ferragosto Mangiare tante castagne ballotte, da calore, e vengono i verminiNeratine (diz.Pav.): castagna primaticcia piccola e di colore scuro.Pastinese"pelo vicino, piccolino"Molana " piu grossa"Grossola "grosse, assomigliano alle francese". Marrone e la Salvana (innestata, non domestica)Ogni 5 anni, si montava sui Castagni e si potavano (ora è dal 72 che non si fa piu).Pastinese (pelose e dolci, foglie piu adatte per i necci, perché non si attacca ai testi)Per non fare la farina attaccarsi ai testi, al posto del olio o del grasso.Raccolte a Luna Vecchia e messe ad essiccare.Poi rimangono le mani blu per 20 giorniRaccogliere le foglie a Luna Vecchia di Agosto, Raccolto in Luna Calante,200 anni fa già lo usavano.si sentiva dire 'li farò una polenta dolce sui piedi'Si taglia a Luna vecchia (decrescente) "Non il tondo perche tende a marcire". "Tonda: sgrossavano con il pennato, poi rifinivano con la lima". Giagnoni dice che per fare i manici si prendeva un tronchetto di 1 o 2 metri più o meno, si spaccava in mezzo, allora una metà veniva dritta e l'altra si piegava. Si prendeva sempre quella dritta e con il pennato, l'accettina, la sega a nastro e per ultimo la lima da legna gli davano la forma, anche per reggerlo con la mano. Allora i vecchi avevano una precisione con il pennato straordinaria. Questo lavoro non si poteva fare con i polloni perché questi si piegavano.Tecnica antiparassitaria per la farina di castagne: quando insacchettavano la farina di castagne, pressavano fortemente la farina, e così le farfalle non entravano.Per evitare che le farfalle non andassero alla farina di castagne.

\section{DATOS ETNOBOTÁNICOS BIBLIOGRÁFICOS}

Nombre vulgar: castagne, arscióni (GUC98), castagno (BER78, MANG98, BENE96, POLI14, GUC98), castagno, asg'dóni (GUC98), castagne (SABA75, MUCC01, BADI15, GUC98), balòtto (APPO10), castagna (APPO10), Castagne (GRIZ03), muligare (GUC98), Castâgn (UNGA21), scerbolóni (GUC98).

Número de referencias: 12 Número de citas: 75.

Número de sectores: 6 Número de categorías: 23.

\section{Sector agropastoral}

Categoría de uso: Alimentación animal (incluidos los forrajeros).

Número de referencias: 1 Partes utilizadas: frutos/infrutescencias/falsos frutos, tallos.

Castagne secche non commestibili per varie ragioni. Venivano macinate a parte e la farina era utilizzata per gli animali. (GUC98)| Il vinciólo o i vincióo è un fascio di rami con foglie attaccate, ricavati dalla potatura di castagni, cerri o pioppi, d'inverno, si davano da mangiare a conigli o pecore. (GUC98).

Categoría de uso: Construcción agrícola (cabañas, etc...).

Número de referencias: 1 Partes utilizadas: tallos leñosos/ramas/ramitas/vástagos. Lunghe listarelle di castagno che servivano a formare il graticciato del canìccio (GUC98)| Gli asg'dóni erano lunghe listarelle di castagno che servivano a formare il graticciato del canìccio. (GUC98)| Il canìccio è un essiccatoio per le castagne, edificio a due piani divisi da un graticcio di listelle di castagno, dette arèlle o asgdóni, anche se già negli anni fra le due guerre, si preferiva usare una rete 


\section{María Teresa Egea Molines}

metallica. Al piano superiore si mettono le castagne da seccare, sotto si accende un fuoco con ciocchi di castagno ricoperti di zanza. in modo che faccia calore ma non fiamma, per evitare il pericolo di incendio o di seccare troppo le castagne. (GUC98).

Categoría de uso: Cuerdas y ataduras.

Número de referencias: 1 Partes utilizadas: tallos leñosos/ramas/ramitas/vástagos. Con un rascello verde di castagno si faceva un legaccio per fascine ottenuto mediante torsione su un lato di un giovane ramoscello verde di castagno all' apposto con operazione di torsione al contrario si otteneva un cappio. (POLI14).

Categoría de uso: Horticultura.

Número de referencias: 1 Partes utilizadas: corteza, madera.

bugo'n, sost.m. $=$ 'terriccio ricavato dalla macerazione del tronco di castagno'.v.puliscon (pulisco'n, sost.m= nelle altre zone convivono pulisco'n, pulisco'ne, pulo'n e triccio. (BENE96)| Puliscon, sost.m.='terriccio ricavato dalla macerazione del tronco di castagno' A Bargi, il termine tradizionale è bugo'on (v.) nelle altre zone convivono pulisco'n, pulisco'ne, pulo'n e triccio. (BENE96).

Categoría de uso: Otro agropastoral.

Número de referencias: 1 Partes utilizadas: frutos/infrutescencias/falsos frutos, tallos.

La zanza, la buccia interna delle castagne, si toglieva alle castagne essiccate veniva conservata e usata per coprire il fuoco nel canìccio, affinché non si alzassero fiamme. (GUC98)| Fascine di polloni di castagno, quercia e olmo, con foglie (vinciò) si facevano di solito nel periodo dell'armondadura (def.: ripulire, una serie di operazioni quali ad es. segare l'erba, rastrellare le foglie cadute e bruciarle, tagliare i piccoli arbusti, costruire le ròste etc, che venivano eseguite nei primi giorni di settembre nel castagneto per ripulirlo in vista della caduta e successiva raccolta delle castagne. L'operazione, accuratissima, durava diversi giornie e vedeva spesso impiegato tutto il nucleo famigliare. ripulendo le plonare attorno ai castagni, ma cne pulendo le altre piante. Si usava metterle sulla cima del pagliaio per proteggere il fieno della pioggia. (GUC98).

\section{Sector alimentario}

Categoría de uso: Aromatizante.

Número de referencias: 1 Partes utilizadas: hojas.

I necci con le foglie. Ingredienti :Farina di castagne,acqua, sale. Strumenti occorrenti: Il trespolo,i testi (dischi di terracotta), foglie di castagno raccolte d'estate e seccate all'ombra.Si mettono i testi a scaldare sul la fiamma del camino.Le foglie invece vengono messe a bollire per alcuni minuti nel paiolo.Si prepara poi un impasto piuttosto tenero con farina di castagne, acqua e un pizzico di sale.Quando i testi sono caldi si ammucchiano tutti insieme per rendere uniforme il calore.Poi si prende un testo lo si mette nel trespolo e vi si stendono sopra due foglie. Su di esse si pone una cucchiaiata abbondante di impasto che si ricopre con altre due foglie.Si pone sopra ad esse un altro testo e così via,fino ad esaurimento.Dopo pochi minuti i necci sono cotti. Liberati dalle foglie,morbidi e profumati,sono pronti per essere mangiati con ricotta o coppa di testa (BADI15).

Categoría de uso: Conserva de frutas.

Número de referencias: 3 Partes utilizadas: frutos/infrutescencias/falsos frutos. 
castagna lessata con buccia (APPO10)| frùsà castagne arrosto (APPO10)| frusolòtti caldarroste (APPO10)| lànsari, sost.m.pl.- 'castagne non del tutto seccate (in dialetto pasìte) lessate con la buccia'. Si dice invece castagne còtte 'castagne secche lessate senza buccia'. (BENE96)| Con quelle verdi si faceva i ballotti: basta mettelle nell'acqua fredda a bollire. (MUCC01)| Le tigliate son castage sbucciate, lasciate colla zanza sola e messa nell'acqua fredda col finocchio oppure 1'alloro e un pò di sale: si mangiano col latte (MUCC01)| Le frugiate invece vanno fatte sulla padella bucata al fuoco. Nelle cucine c'era que'camini grandi che ci s'entrava dentro: s'appoggiava la padella sul servitore e via via si dava un colpo. A mezza cottura vanno levate, messe in un panno di lana, bruzzolate col vino e tenute lì un quarto d'ora. Dopo si rimettevano nella padella a fini di cocere. Ora le castrano perché le fanno su fornelli, ma se sono belle avvizzite e si fanno sul fuoco, non c'è n'è bisogno: ne scoppia poche. (MUCC01)| Per minestra si prendeva le frugiate cotte a mezzo, si mondavano bene della buccia nera e della zanza e si bollivano coll'alloro e col finocchio e una brancatina di sale: si diceva "le mondine". Si faceva uguale colle castagne secche, ma veniva un brodo più nero. (MUCC01).

Categoría de uso: Dulces y golosinas.

Número de referencias: 1 Partes utilizadas: harina/salvado.

mistòcche, sost.m.= 'specie di biscotto secco di farina di castagne, cotto in forno' (BENE96).

Categoría de uso: Fritura.

Número de referencias: 1 Partes utilizadas: harina/salvado.

Il castagnaccio non si faceva mai: lo fate più ora, per dolce, ma che voi che si siucpasse la farina per un di più... Semmai, se veniva qualcuno e per le feste, si faceva le frittelle, però il più delle volte, se si voleva sciupà l'olio, si faceva i necci fritti (MUCC01).

Categoría de uso: Gachas o polenta.

Número de referencias: 2 Partes utilizadas: harina/salvado.

Migliàccio Tipo di castagnaccio (APPO10)| Il più si faceva con la farina. I necci erano il pane. Si spenge la farina stacciata coll'acqua e un po'di sale. Ora si fanno colle forme e vengano buoni lo stesso. Era un lavoro lugno e bisognava avecci sempre farina e foglie.... Ora lo vedi, si fanno quasi per complimento (per cortesia, per fare festa a un visitatore), come prima si faceva le fritelle. Io no, me li fo sempre. Per fare i necci si metteva i testi al foco e quand'eran caldi, si tuffava le foglie un menusto nell'acqua bolletne e ci si copriva il testo. Sopra ci si metteva la pasta de'necci, un altro strato di foglie, un altro testo, e quelli di fondo eran bell'è cotti. (MUCC01)| E bona anche la polenda colle salcicce, colla frittata e la carne secca... ma mi va un pò a occhio (mi sembra uno spreco), perché colla farina che ci fo una polenda ci fo i necci tre volte. A falla ci vol poco. Si butta la farina nell'acqua che bolle piano, tutta in una volta e si gira forte. (MUCC01)| I magnufatoli invece bisogna sta piu attenti perché son meno sodi e qualche raciolo (grumo) ci viene sempre. Bisogna scosta'l'acqua bollente dal foco per butta'la farina. Dopo venti minuti, anche meno, che si gira, son cotti: si scodellano belli caldi e ci si versa sopra il latte freddo: il latte resta per conto suo perché i manufatoli fanno subito la pellicina sopra. (MUCC01)| La farinata coll'aceto:si faceva alle veglie, si spenge a freddo la farina e ci si mette un mezzo bicchiere d'aceto. Quando si mette sul fuoco 
assoda un pò, ma se ci si tiene un quarto d'ora e si mescola, torna fina fina e allora si leva, è pronta. Viene un pò pizzichente. Era proprio usanche che a una cert'ora nelle veglie si faceva la farinata. (MUCC01).

Categoría de uso: Otro alimentario.

Número de referencias: 6 Partes utilizadas: harina/salvado,.

Il matus gi, farina di castagne o di granoturco cotta in acqua bollente (GUC98)| Il miàccio, è un dolce fatto con sangue di maiale, fritto o bolito, cui si aggiungono vari ingredienti come farina, uva passa ecc, più raramente castagnaccio. (GUC98)| mistòcca, piccola focaccia di farina di castagne, da misto, mescolaio (GUC98)| polénta dólce, polenta fatta con farina di castagne (GUC98)| polenta di granoturco messa a fetta in una zuppiera e condita con strati di ragú (GUC98)| castagnaccio, castagnaccio $\mathrm{n}$ forno, sost.m.= 'torta di farina di castagne cotta in forno' A Badi e Stagno la stessa preparazione si chiama anche miaccio o castagnaccio da forno. A Bargi castagnaccio significa anche 'schiacciatina di farina di castagne cotta fra due dischi di terracotta o pietra, detti 'testi', invece a Badi e a Stagno quest'ultima si chiama tòrto (BENE96)| pato'na, sost.f.='schiattina di farina di castagne cotta in forno di consistenza molto compatta e dallo spessore di circa due centimentri' (BENE96)| frugià, frugiade, sost.f.pl.= 'castagne arrostite' (BENE96)| Castagnaccio, Ingredienti: farina di castagne $4 \mathrm{hg}$, un pugno di farina di farro, latte e acqua tiepida quanto basta, mezzo bicchiere di olio extra vergine di oliva, un pizzico di sale, due presine di bicarbonato, un pugno di uvetta passa, un tappo di liquore (rum), un hg di pinoli. In una terrina mettere la farina di castagne e di farro, mescolare con acqua tiepida e latte (in eguali proporzioni) fino ad otterner un composto non troppo duro, ma neanche troppo morbido, di consistenza elastica, aggiustare aggiungendo un po 'di olio di oliva. A questo punto aggiungere il bicarbonato, il sale, i pinoli (lasciarne un pugnetto per decorare la parte superiore). Infine aggiungere 1'uvetta ben strizzata, precedentemente messa a bagno con acqua tiepida e il liquore. Si fanno alcuni tagli sul castagnaccio sol coltello, per evitare che mentre si cuoce faccia crepe. Decorare con i pinoli. Mettere in forno preriscaldato a $200 \mathrm{C}$ e cuocere per circa 20 minuti. (GRIZ03)| Coniglio con le castagne. Ingredienti: castagne, salsiccia, coniglio, funghi, vino, olio, sale e pepe, carota, sedano, cipolla, prezzemolo. Incidete le castagne con un coltello afilato, poi arrostitele cercando di mantenerle il più possibile morbide senza farle annerire. Succiatele e mettetele da parte. Punzecchiate la salsiccia, poi mettetela in una teglia nel forno, apritela e lasciatela cuocere senza aggiungere alcun condimento. Tagliate a pezzetti il coniglio e soffriggetelo in una padella con olio, sale e pep. Quando sarà uniformemente dorato, unite la carota, il sedano, la cipolla e il prezzemolo tritati e infine aggiungete anche i funghi precedentemente fatti rinvenire nell'acqua tiepida. Quando le verdure saranno appassite bagnate il vino, mettete il coperchio e portate a cottura a fuoco bassissimo. Al momento di servire a tavola riscaldate in un unico contenitore il coniglio con la salsiccia e le castagne in modo che s'insaporiscano per alcuni minuti, dopo di che sistemate i pezzi di coniglio al centro del piatto da portata contornati dalla salsiccia fatta a pezzi e dalle castagne. (GRIZ03)| Fritelle di castagne. $200 \mathrm{~g}$ di farina di castagne, $50 \mathrm{~g}$ di cioccolata in polvere, $50 \mathrm{~g}$ di uva sultanina, un pò di latte, una presina di sale, zucchero a velo, olio per friggere. Mettere tutti gli ingredienti in una ciotola e stemperateli insieme. Prendere una padella con dell'olio per friggere, 
quando sarà caldo prendete con un cucchiaio l'impasto e versatelo nell olio, quando le frittelle saranno cotte, spolveratele con lo zucchero a velo e mangiatele calde. (GRIZ03)| Marmellata di castagne. $1 \mathrm{~kg}$ di castagne, zucchero, acqua, un bicchierino di rhum, 2 bacchette di vaniglia. Sbucciate le castagne, lessatele e ancora calde togliete la seconda buccia, passatele al setaccio e pesatele. Mettete lo zucchero pari al peso delle castagne in una pentola e aggiungete un bicchiere scarso di acqua per ogni kilogrammo di zucchero. Fate sciogliere lo zucchero, aggiungete la polpa e due bacchette di vaniglia. Fate cuocere per 50 minuti circa, togliere dal fuoco e aggiungere un bicchierino di rhum. Mettete nei vasi quando è ancora caldo. (GRIZ03)| Tartufi di castagneÑ 20 castagne, 1 hg di mandorle, $50 \mathrm{~g}$ di zucchero, 1 noce di burro, latte, cioccolata in polvere o codine di cioccolata.Togliere la buccia esterna e fare bollire le castagne in acqua salata. Tagliere la pellicina, passare e fare un purè con burro, zucchero e latte. Aggiungere le mandorle ben tritate. Lasciare raffreddare, fare delle palline come noci e passare nel cioccolato. (GRIZ03)| Torta di castagne: una bustina di lievito da $16 \mathrm{~g}$., un bicchiere di latte, $500 \mathrm{~g}$ di farina di castagne, 3 uova, $30 \mathrm{~g}$ di zucchero a velo, una noce di burro, 100 gr di zucchero normale, $100 \mathrm{~g}$ di canditi misti, una scorza di limone grattugiato. Preparare sopra a un tagliere i $500 \mathrm{~g}$ di castagne, aggiungere la bustina di lievito, sbattere le tre uova con un cucchiaio, versare nel preparato il bicchiere di latte, aggiungere la noce di burro, lo zucchero normale, i canditi misti e infine la scorza di limone grattugiato. Fare l'impasto manualmente con tutti gli ingredienti sino ad ottenere una crema omogenea. Accendere il forno a temperatura ben calda (circa $150 \mathrm{C}$ ). Prendere una casseruola e ungerla bene con olio e burro. Versarci l'impasto ottenuto e farlo cuocere circa 45 minuti nel forno. Dopo aver tolto la torta dal forno ornarla con zucchero a velo. (GRIZ03)| Le mondine sono le caldarroste o castagne non ancora completamente seccate nel caniccio, fatta successivamente bollire in acqua. (GUC98)| I nécci sono piccole focaccie di farina di castagne e acqua cotta fra i tèsti, i nécci guèrci sono necci a cui si aggiungevano pezzetti di grasegli oppure di salsiccia, coppa di testa, pancetta. (GUC98)| Castagne conservate con vari accorgimenti, sottoterra. Probabilmente da mollicara da mollis perché diventano tenere. (GUC98)| ... alimento di primo ordine, ind. Per legname, med. Per la scorza da cui si trae in tannino. Si distinguono le varietà: Castâgn salvan (Castanea vesca o silv), castagno selvatico, castâgn in $\int$ dè, castagno domestico, che fornisce eccellenti frutti detti maron, marroni, a Lizz. castagn sborga, castagno che dà marroni da caldarroste, castagn pastneol, castagno che da marroni da balogie. (UNGA21)| ballòtta, castagna lessata con la bucia. (GUC98)| castagne fresche succiate, di solito, gròssole o maróni, cotte in acqua appena salata o più raramente a bagnomaria. Dopo la cottura si toglieva la zanza e si mangiavano nel latte o caffelatte (GUC98)| Castagne sbucciate delle due bucce e fatte bollire. (BONZI00)| La mistócca è un pane di farina di castagne (BONZI00)| Castagne tagliate in cima e bollite (BONZI00)| Ricetta “Zampanelle bianche"di Lústrola: $1 \mathrm{~kg}$ di farina bianca, sale quanto basta (un cucchiaino). Si fa un impasto piuttosto liquido della farina con l'acqua, poi si cuoce nei testi o negli stampi, foderati con le foglie di castagno preparate appositamente. A parte si fan bollire circa 2 L. d'acqua, aggiungendo a ebollizione avvenuta, aglio, olio, pepe e sale quanto basta.In questo pignatto si immerge la pasta cotte nei testi, finché non sia bene inzuppata. A quel punto le 


\section{María Teresa Egea Molines}

zampanelle bianche son pronte da mangiare, si raccomanda però di bere anche il liquido dove si inzuppate, che, oltre ad avere un ottimo sapore, combatte efficacemente il raffredore ed è inoltre diuretico e lassativo. (SABA75)| Ricetta "Matusjii: Per realizzare questa gustosa e semplicissima ricetta occorre portare un paiolo d'acqua leggermente salata ad ebollizione, poi versarvi poco a poco la farina di castagne e mescolare con la "paltina"di legno fino a raggiungere la giusta densità. Lasciare bollire per 20 minuti circa poi versare nei piatti con la "ramaiola"(mestolo forato) e lasciare stemprare (raffreddare). Consumare infine i matuji ancora caldi versandovi sopra latte, formaggio pecorino grattugiato o ricotta. (SABA75).

Categoría de uso: Pasta y "gnocchi".

Número de referencias: 1 Partes utilizadas: harina/salvado.

Magnùffoli' Pasta fatta con farina di castagne (APPO10).

Categoría de uso: Sopas de verduras y potaje.

Número de referencias: 1 Partes utilizadas: frutos/infrutescencias/falsos frutos.

balòtto, sost.m.='castagna lessata con la bucca'. Alcuni informatori ricordano che il tipo.

tradizionale era balugio (come il bolognese balùs (BENE96).

Sector artesanal

Categoría de uso: Objetos domésticos.

Número de referencias: 1 Partes utilizadas: madera.

Il cóppo è un attrezzo di legno, di solito di castagno, similie al coppo da tetto, si usava per tenere fermo col piede il paiolo mentre si mescolava la polenta. Di forma curva e leggermente tronco conica, aveva fissata nella parte inferiore una listella di legno che impediva al piede di scivolare. Lungo mezzo metro, era largo circa la metà. (GUC98)| La quartróla è un recipiente di legno, cilindrico o tronco conico a volte scavato da un unico tronco di castagno, con uno o due manici. (GUC98).

\section{Sector doméstico}

Categoría de uso: Chimenea y horno.

Número de referencias: 1 Partes utilizadas: harina/salvado.

Zanza, sost.f.= 'buccia interna delle castagne'. La zanza, raccolta dopo la battitura, veniva conservata e utilizzata l'anno successivo per coprire il fuoco nel canniccio affinché non si alzassero le fiamme. Poiché in queste zone non esiste la coltivazione dell'ulivo, il termine riveste il significcato dell'italiano 'sansa' parte residua delle olive disoleate'. (BENE96).

Categoría de uso: Jardín.

Número de referencias: 1 Partes utilizadas: tallos leñosos/ramas/ramitas/vástagos. Lapalanca era una tavoletta a punta, di solito di castagno, usata per formare steccati nella.

recinzione di orti o giardini. (GUC98).

Categoría de uso: Otro doméstico.

Número de referencias: 4 Partes utilizadas: hojas.

Il manòcchio era una mazzetta di foglie di castagno per i necci (BONZI00)| Le manòc 'c'hie erano fatte con le foglie di castagno, che venivano messe in mazzetti legati con piccoli rami di castagno poi con un grosso ago ed uno spago si infilavano i mazzetti così preparati e si facevano seccare all'ombra. Si usavano per isolare i 
tèsti arroventati per far cuocere i nécci o le cine. (GUC98)| Il mannocchio è un mazzetto di foglie di castagne legate insieme ed essicate che fatte rinvenire nell'acqua si utilizzavano per cuocere i necci isolando il testo arroventato dalla pasta di farina dolce. (POLI14)| Le foglie di castagno sono indispensabili per la riuscita di tutte le ricette montanare che richiedono la cottura fra i testi. Si provvede a preparare le foglie, raccolte a luna vecchia, in settembre, riunendole in "manocchi“(mazzetti) legati con la punta della "rama"(ramo) e poi in "file"con l'ago e lo spago, e ponendole infine a seccare al sole. (SABA75).

\section{Sector lúdico/voluptuoso}

\section{Categoría de uso: Alimentos/juguetes.}

Número de referencias: 1 Partes utilizadas: harina/salvado.

I didali erano piccoli dolci ottenuti dai bambini riempiendo un ditale di farina di castagne e.

poi mettendolo a cuocere sulla piastra della stufa. (GUC98).

Categoría de uso: Instrumentos musicales.

Número de referencias: 2 Partes utilizadas: corteza, tallos.

La muSétta è un fischio rudimentale fatto con i pezzi di corteccia. (BONZI00)| Lo zufolo fatto con la corteccia di castango ma più corto della musetta. (GUC98)| trombo , strumento in disuso simile alla musétta, ricavato da corteccia di castagno arrotolata e munito di ancia primitiva. (GUC98)| La mu sétta è un tipo di flauto diritto, molto primitivo ed usato di solito come gioco per ragazzi. Si ottiene togliendo la corteccia, per torsione, a un pollone di castagno o più raramente di pioppo o gelso, formando una canna di $20 \mathrm{~cm}$ circa. L'operazione è possibile ovviamente solo quando le suddette piante sono ricche di linfa, in marzo o aprile. una delle estremità della canna viene quindi zeppata, cioè otturata con una piccola zeppa di legno che lascia passare solo parzialmente alcuni fori rotondi digitali, senza però nessuna particolare logica musicale. È probabile che in tempi passati la musetta fosse costruita con regole più precise o con particolari scopi rituali nonostante la sua effimera durata. Infatti, anche mettendo a bagno lo strumento dopo l'uso, la corteccia in due settimane si secca, e la m. è inutilizzabile. (GUC98).

Categoría de uso: Juego colectivo y bromas.

Número de referencias: 1 Partes utilizadas: frutos/infrutescencias/falsos frutos.

La cincimbróla è un gioco infantile consistente nell'indovinare il numero di castagne che il.

compagno tiene nascoste in una mano. (BONZI00).

\section{Sector medicinal}

Categoría de uso: Afecciones del aparato respiratorio.

Número de referencias: 2 Partes utilizadas: harina/salvado, hojas.

Se uno aveva raffreddore la farinata coll'aceto faceva bene, come ora si prende l'aspirina. La farinata coll'aceto:si faceva alle veglie, si spenge a freddo la farina e ci si mette un mezzo bicchiere d'aceto. Quando si mette sul fuoco assoda un pò, ma se ci si tiene un quarto d'ora e si mescola, torna fina fina e allora si leva, è pronta. Viene un pò pizzichente. Era proprio usanche che a una cert'ora nelle veglie si faceva la farinata. (MUCC01)/ L'infuso delle foglie viene bevuto per calmare la tosse secca e stizzosa.(MANG98). 
Categoría de uso: Otro medicinal.

Número de referencias: 1 Partes utilizadas: tallos leñosos/ramas/ramitas/vástagos. Contro il singhiozzo oppure per calmare dolori di milza dovuti ad uno sforzo, si mastica un.

pezzetto di ramo giovane. (MANG98).

Categoría de uso: Patologías del aparato digestivo.

Número de referencias: 1 Partes utilizadas: frutos/infrutescencias/falsos frutos.

I necci erano il pane. Si spenge la farina stacciata coll'acqua e un po di sale..era un lavoro lungo e bisognava sempre avecci farina e foglie perché ormai è venuta come 1'oro...io senza necci non ci posso sta'perché sento che m'accomodano l'intestino (metterlo in migliori condizioni di funzionamento, anche guarirlo di piccoli disturbi).(MUCC01).

Notas Se pióv al dì d Sènta Crós (14 Settembre) tènt castagnn e póc nós. (Se piove il giorno di.

Santa Croce, tante castagne e poche noci.

\section{Castanea sativa Mill. 'Biancoline'}

Nombre vulgar: Castagne biancoline (BAR).

Número de informantes: 1 Número de citas: 1.

Número de sectores: 1 Número de categorías: 1.

Biotipo: Fanerófito.

Tipo corológico: Europeas.

Abundancia: Común.

Ambiente: Bosques generalmente sobre terreno ácido.

Sector alimentario

Categoría de uso: Gachas o polenta.

Número de informantes: 1 Partes utilizadas: harina/salvado.

Le castagne biancoline erano buone per fare farina per la polenta ed erano"salvagghe" (BAR).

Notas c' erano anche le castagne Calarese (pelo bianco) - "salvagghe"e I Castagni Marroni.

\section{Castanea sativa Mill. 'Calerese'}

Nombre vulgar: Castagne (TAD), Castagne calerese (MRI, GGI).

Número de informantes: 3 Número de citas: 3 .

Número de sectores: 1 Número de categorías: 1 .

Biotipo: Fanerófito.

Tipo corológico: Europeas.

Abundancia: Común.

Ambiente: Bosques generalmente sobre terreno ácido.

Sector alimentario

Categoría de uso: Sopas de verduras y potaje.

Número de informantes: 3 Partes utilizadas: frutos/infrutescencias/falsos frutos. 
Castagne cotte: sono le castagne secche e cotte, con I marroni, pastenese, calarese. (TAD)| Per fare I cerbolloni, che sono castagne sbucciate e cotte erano ottime: I marroni (più dolci e grosse), le grossolane, le molane (pero sono le peggio perché la sanza lega di più) e le calerese che si sbucciavano bene però erano più rare (a Frassignoni ce n'erano di più). (GGI)| Le calerese (simili ai marroni) sono ottime per fare le caldarroste (MRI).

Notas Calarese (simili ai marroni) sono frutti lisci, si sguciano facilmente, sono più dolci,.

ottime per caldarroste. Più dolci.

\section{Castanea sativa Mill. 'Nerattine'}

Nombre vulgar: Castagne nerattine (GGI).

Número de informantes: 1 Número de citas: 1.

Número de sectores: 1 Número de categorías: 1.

Biotipo: Fanerófito.

Tipo corológico: Europeas.

Abundancia: Común.

Ambiente: Bosques generalmente sobre terreno ácido.

Sector alimentario

Categoría de uso: Pan y similares.

Número de informantes: 1 Partes utilizadas: harina/salvado.

La farina di castagne si faceva macinando un misto di castagne presciso perché durava di più (fino all'anno seguente), non tarmolava, e non pigliava l'insucchio (il sapore dell'insucchio): con le Grossolane, le Molane, le Nerattine, e le Pastenese (che li dava il sapore dolce). Le calerese non sono buone per la farina. Però si sbucciano bene. La farina poi si usava per fare i necci, il pane della montagna. (GGI).

\section{Castanea sativa Mill. 'Salvano'}

Nombre vulgar: Castagno salvano (LGI), Castagno salvano o selvatico (MGO), Castagno salvano (TRU, MGO), Castagno selvatico (MGO, TRU), Salvano (GFO, GFR, GGI).

Número de informantes: 2 Número de citas: 3.

Número de sectores: 3 Número de categorías: 3 .

Biotipo: Fanerófito.

Tipo corológico: Europeas.

Abundancia: Común.

Ambiente: Bosques generalmente sobre terreno ácido.

Sector alimentario

Categoría de uso: Gachas o polenta.

Número de informantes: 1 Partes utilizadas: harina/salvado.

Salvano (era un pò peggio, un pò più rossino) si seccava anche per farina, per fare polenta o I necci (LGI). 
Sector artesanal

Categoría de uso: Muebles.

Número de informantes: 1 Partes utilizadas: tallos

leñosos/ramas/ramitas/vástagos.

Con il salvano si facevano I mobili. (MGO).

Sector doméstico

Categoría de uso: Chimenea y horno.

Número de informantes: 1 Partes utilizadas: madera.

Il castagno salvano (è quello selvatico) si usava molto per fare il fuoco, però deve essere stagionato bene e la conservazione è importantissima: deve conservarsi senza umidità, e deve seccare per 3 anni. Se non è pericoloso: perché il legno del castagno schizza al camino, per il tannino. (MGO).

Notas I marroni era un altra varietà innestata.

\section{Castanea sativa Mill. 'Grossolane'}

Nombre vulgar: Castagne grossolane (GGI), Castagne grossole (TAD).

Número de informantes: 2 Número de citas: 3.

Número de sectores: 1 Número de categorías: 2 .

Biotipo: Fanerófito.

Tipo corológico: Europeas.

Abundancia: Común.

Ambiente: Bosques generalmente sobre terreno ácido.

Sector alimentario

Categoría de uso: Pan y similares.

Número de informantes: 1 Partes utilizadas: harina/salvado.

La farina di castagne si faceva macinando un misto di castagne presciso perché durava di più (fino all'anno seguente), non tarmolava, e non pigliava l'insucchio (il sapore dell'insucchio): con le Grossolane, le Molane, le Nerattine, e le Pastenese (che li dava il sapore dolce). Le calerese non sono buone per la farina. Però si sbucciano bene. La farina poi si usava per fare i necci, il pane della montagna. (GGI).

Categoría de uso: Sopas de verduras y potaje.

Número de informantes: 2 Partes utilizadas: frutos/infrutescencias/falsos frutos.

Per fare I cerbolloni, che sono castagne sbucciate e cotte erano ottime: I marroni (più dolci e grosse), le grossolane, le molane (pero sono le peggio perché la sanza lega di più) e le calerese che si sbucciavano bene però erano più rare (a Frassignoni ce n'erano di più). (GGI)| Le castagne 'mondate' o 'cerboloni': si toglie tutta la pelle esterna, si fanno cuocere con la pelle interna, la sansa, che si toglie quando si mangiano. Si cuociono con il finocchio selvatico. Si fanno con le castagne più grosse, con le molane, I marroni, le grossole (forma di marroni pero di colore più sul nero) (TAD).

DATOS ETNOBOTÁNICOS BIBLIOGRÁFICOS

Nombre vulgar: gròssola (GUC98). 
Número de referencias: 1 Número de citas: 1.

Número de sectores: 1 Número de categorías: 1.

Sector alimentario

Categoría de uso: Sopas de verduras y potaje.

Número de referencias: 1 Partes utilizadas: frutos/infrutescencias/falsos frutos. tipo di castagna molto grande con buccia scura. Era usata soprattutto per fare scerbolóni.

(GUC98).

\section{Castanea sativa Mill. 'Marroni'}

Nombre vulgar: Castagne (TAD, GGI), Marroni (DAD).

Número de informantes: 3 Número de citas: 4.

Número de sectores: 1 Número de categorías: 1.

Biotipo: Fanerófito.

Tipo corológico: Europeas.

Abundancia: Común.

Ambiente: Bosques generalmente sobre terreno ácido.

Sector alimentario

Categoría de uso: Sopas de verduras y potaje.

Número de informantes: 3 Partes utilizadas: frutos/infrutescencias/falsos frutos.

Per fare I cerbolloni, che sono castagne sbucciate e cotte erano ottime: I marroni (più dolci e grosse), le grossolane, le molane (pero sono le peggio perché la sanza lega di più) e le calerese che si sbucciavano bene però erano più rare (a Frassignoni ce n'erano di più). (GGI)| Castagne cotte: sono le castagne secche e cotte, con I marroni, pastenese, calarese. (TAD)| I marroni sono le castagne piú saporite, pero non si essiccano e non si fa la farina perche viene amara, solo per fare Frugiate, $\mathrm{i}$ cervolloni. (DAD)| Le castagne 'mondate' o 'cerboloni': si toglie tutta la pelle esterna, si fanno cuocere con la pelle interna, la sansa, che si toglie quando si mangiano. Si cuociono con il finocchio selvatico. Si fanno con le castagne più grosse, con le molane, I marroni, le grossole (forma di marroni pero di colore più sul nero) (TAD).

Notas Ci sono anche le Mollane, le Neratine e le Pastinese(la più dolce).

\section{Castanea sativa Mill. 'Molane'}

Nombre vulgar: Castagne molane (TAD, GGI), Castagne Mollane (BSO, BAR).

Número de informantes: 4 Número de citas: 5.

Número de sectores: 1 Número de categorías: 2 .

Biotipo: Fanerófito.

Tipo corológico: Europeas.

Abundancia: Común.

Ambiente: Bosques generalmente sobre terreno ácido.

Sector alimentario

Categoría de uso: Pan y similares. 


\section{María Teresa Egea Molines}

Número de informantes: 1 Partes utilizadas: harina/salvado.

La farina di castagne si faceva macinando un misto di castagne presciso perché durava di più (fino all'anno seguente), non tarmolava, e non pigliava l'insucchio (il sapore dell'insucchio): con le Grossolane, le Molane, le Nerattine, e le Pastenese (che li dava il sapore dolce). Le calerese non sono buone per la farina. Però si sbucciano bene. La farina poi si usava per fare i necci, il pane della montagna. (GGI).

Categoría de uso: Sopas de verduras y potaje.

Número de informantes: 3 Partes utilizadas: frutos/infrutescencias/falsos frutos.

Le castagne 'mondate' o 'cerboloni': si toglie tutta la pelle esterna, si fanno cuocere con la pelle interna, la sansa, che si toglie quando si mangiano. Si cuociono con il finocchio selvatico. Si fanno con le castagne più grosse, con le molane, I marroni, le grossole (forma di marroni pero di colore più sul nero) (TAD)| Per fare le caldarroste o "frugiàn" (BSO, BAR)| Castagne Mollane erano salvagghe e buone per fare le caldarroste o "frugiàn" (BAR).

Notas Le castagne si mangiano in tanti Per conservare le castagne una volta raccolte, si mettono a mollo per 8 giorni, dopo si mettono ad asciugare al sole, ed infine in una cassetta, così si conservano e non vanno a male.

\section{Castanea sativa Mill. 'Pastenese'}

Nombre vulgar: Castagne "pastenese" (selvatiche) (BSO), Castagne pastenese, selvatiche (BAR),

Castagne pastenese (GGI), Castagno pastenese (MRI), Pastenese (BAR), Castagno pastenese (LRE, MGI, MSR, MTI, MTO, RFR, VMU), Castagno pastinese (FAM, GAN, GLA).

Número de informantes: 5 Número de citas: 7.

Número de sectores: 2 Número de categorías: 4.

Biotipo: Fanerófito.

Tipo corológico: Europeas.

Abundancia: Común.

Ambiente: Bosques generalmente sobre terreno ácido.

Sector alimentario

Categoría de uso: Conserva de frutas.

Número de informantes: 2 Partes utilizadas: frutos/infrutescencias/falsos frutos.

Castagne "pastenese" (selvatiche), per fare I bollòti, si fanno bollite con la buccia (BAR, BSO).

Categoría de uso: Pan y similares.

Número de informantes: 2 Partes utilizadas: harina/salvado.

La farina di castagne si faceva macinando un misto di castagne presciso perché durava di più (fino all'anno seguente), non tarmolava, e non pigliava l'insucchio (il sapore dell'insucchio): con le Grossolane, le Molane, le Nerattine, e le Pastenese (che li dava il sapore dolce). Le calerese non sono buone per la farina. Però si sbucciano bene. La farina poi si usava per fare i necci, il pane della montagna. (GGI)| La farina di Castagno Pastenese è ottima per fare farina e per fare I torti: fare 
un impasto di acqua e farina di castagne abbastanza liquido, coprire un testo caldo di foglie di pastenese, mettere sopra un pò di impasto e coprire con un altro strato di foglie e un testo caldo, e così via. (MRI).

Categoría de uso: Sopas de verduras y potaje.

Número de informantes: 2 Partes utilizadas: frutos/infrutescencias/falsos frutos.

Castagne cotte: sono le castagne secche e cotte, con I marroni, pastenese, calarese. (TAD)| Castagne "pastenese" (selvatiche o "salvagghe"), per fare I bollòti, si fanno bollite con la buccia- (BAR).

\section{Sector doméstico}

Categoría de uso: Otro doméstico.

Número de informantes: 1 Partes utilizadas: hojas.

Ad Agosto si raccolgono le foglie di castagno 'pastenese' e si mettono a seccare a mazzetti. Poi quando si fanno i 'torti' (chiamati 'necci' a Stagno) si mettono a bagno e si mettono sotto e sopra l'impasto di farina di castagno tra i testi. Le pastenese non si attaccano ai testi. (MRI).

Notas Anche le castagne "molane" sono buone per farina, e poi c'è il "castagno rosìn"che è un.

castagno rosiccio., A Stagno si chiamano Torti, a Badi Necci.

DATOS ETNOBOTÁNICOS BIBLIOGRÁFICOS

Nombre vulgar: castagne pastinese (MUCC01), pastnés`e (GUC98).

Número de referencias: 2 Número de citas: 2.

Número de sectores: 1 Número de categorías: 1.

\section{Sector doméstico}

Categoría de uso: Otro doméstico.

Número de referencias: 1 Partes utilizadas: hojas.

Verso la fine d'Agosto s'andava a foglie. Bisognava sceglie le piante bone: se si prende la foglia de'carpini, ce ne vole di più per coprire il testo perché son lunghe e strette, meglio son quelle pastinesi, belle larghe. La sera nelle case si vegliava, si faceva delle tavolate di donne, ragazze e giovanotti pe'spiccollare. S'ammucchiava i vencigli (rametti spogliati delle foglie) e colle foglie si faceva i mazzi e poi s'infilavano con dell'aghi apposta e si faceva la filza. Queste foglie poi andavano seccate e si serbavano. Per fare i necci si metteva i testi al foco e quand'eran caldi, si tuffava le foglie un menusto nell'acqua bolletne e ci si copriva il testo. Sopra ci si metteva la pasta de'necci, un altro strato di foglie, un altro testo, e quelli di fondo eran bell'è cotti. (MUCC01).

Notas rìccia, un altro tipo di castagna.

\section{Fagus sylvatica $L$.}

Nombre vulgar: Faggio (MGE, GLA, SLU, MGO, PCL, TRU, TGO).

Número de informantes: 7 Número de citas: 11.

Número de sectores: 6 Número de categorías: 9.

Biotipo: Fanerófito.

Tipo corológico: Europeas. 
Abundancia: Común.

Ambiente: Bosques mesófilos.

Sector agropastoral

Categoría de uso: Horticultura.

Número de informantes: 1 Partes utilizadas: hojas.

Foglie secce: concime per le patate "Per fare venire le patate bianche e buone" (TGO).

Categoría de uso: Productos lácteos.

Número de informantes: 1 Partes utilizadas: tallos leñosos/ramas/ramitas/vástagos.

Facevano le cascine di faggio per fare il formaggio, perché il faggio non rilascia sostanze, e non macchia. Le cascine erano fatte con una corda per adattare la forma e la grandezza della caciotta. (TRU).

\section{Sector alimentario}

Categoría de uso: Golosinas y masticatorias.

Número de informantes: 1 Partes utilizadas: hojas, semillas.

Le foglie si masticavano come dissetante, avevano sapore di fragola. I semi si mangiavano, ma in dosi eccessive davano sonnolenza. (TGO).

Sector artesanal

Categoría de uso: Muebles.

Número de informantes: 1 Partes utilizadas: tallos leñosos/ramas/ramitas/vástagos.

Mobili di casa:Le seggiole erano di legno di faggio (PCL).

Categoría de uso: Objetos domésticos.

Número de informantes: 1 Partes utilizadas: tallos leñosos/ramas/ramitas/vástagos.

Per fare cucchiai per cucina, mestoli, etc. (MGO).

Sector caza y pesca

Categoría de uso: Caza de pájaros.

Número de informantes: 1 Partes utilizadas: tallos leñosos/ramas/ramitas/vástagos.

Trappole per cacciare i passerotti:Si metteva un'asse di quercia o di castagno, sollevata con un palo in una estremità, quando il passerotto arrivava, spostava il palo e l'asse cascava, intrappolando l'uccello. (SLU).

\section{Sector doméstico}

Categoría de uso: Chimenea y horno.

Número de informantes: 3 Partes utilizadas: madera.

Il legno di faggio è il migliore per fare il fuoco (GLA)| La legna da ardere, dal faggio come degli altri alberi, viene tagliata a Primavera, quando ha l'insucchio (la linfa), così bruccia più lentamente e meglio. (MGO)| È il migliore legno da usare per il focolare domestico. Si taglia verde verso maggio o giugno, e si lascia stagionare fino ad Ottobre per usare tutto l'inverno dello stesso anno, sennò l'anno seguente li vengono I tarli. (TRU). 
Categoría de uso: Integración de la renta familiar.

Número de informantes: 1 Partes utilizadas: madera.

Con il faggio si faceva un ottimo carbone che si vendeva alle fonderie (TGO).

Sector medicinal

Categoría de uso: Patologías del aparato digestivo.

Número de informantes: 1 Partes utilizadas: tallos leñosos/ramas/ramitas/vástagos.

La bracce del faggio si pestava, si metteva nell'acqua e si filtrava. Poi si beveva per il mal di.

pancia. (MGE).

Notas Viene tagliato a Luna Vecchia, quando ancora ha le foglie: da fine Agosto a Settembre., Nel bosco, specialmente su terreni calcarei.

DATOS ETNOBOTÁNICOS BIBLIOGRÁFICOS

Nombre vulgar: fâz (UNGA21), al fasoli (SANS14), faggio (MANG98, GUC98).

Número de referencias: 4 Número de citas: 7.

Número de sectores: 4 Número de categorías: 6 .

Sector agropastoral

Categoría de uso: Alimentación animal (incluidos los forrajeros).

Número de referencias: 1 Partes utilizadas: semillas, hojas.

faggio, albero de'boschi più alti del $\mathrm{n}$. appennino, che può raggiungere notevole altezza in 80- 100 anni. Dà legno bianco-nocciuola flessibile, usato in mont. In lavori leggeri, come sedie, manichi, scatole, ecc. Ha foglie foragg. Gradite alle pecore e capre, e seme (smaind ed fâz, faggiuole) pure foraggere e che dà olio d'ulivo. Il faggio è inoltre buon combustibile, il carbone che se ne ricava è il migliore per gli usi domestici. Dalla distillazione del faggio i chimici estraggono il creosoto, potente antisettico, usato in med. e chirurgia. (UNGA21).

\section{Sector alimentario}

Categoría de uso: Golosinas y masticatorias.

Número de referencias: 1 Partes utilizadas: frutos/infrutescencias/falsos frutos. (SANS14).

\section{Sector artesanal}

Categoría de uso: Muebles.

Número de referencias: 1 Partes utilizadas: madera.

faggio, albero de'boschi più alti del n. appennino, che può raggiungere notevole altezza in 80- 100 anni. Dà legno bianco-nocciuola flessibile, usato in mont. In lavori leggeri, come sedie, manichi, scatole, ecc. Ha foglie foragg. Gradite alle pecore e capre, e seme (smaind ed fâz, faggiuole) pure foraggere e che dà olio d'ulivo. Il faggio è inoltre buon combustibile, il carbone che se ne ricava è il migliore per gli usi domestici. Dalla distillazione del faggio i chimici estraggono il creosoto, potente antisettico, usato in med. e chirurgia. (UNGA21).

Categoría de uso: Objetos agrícolas.

Número de referencias: 2 Partes utilizadas: madera. 


\section{María Teresa Egea Molines}

La vasóra era una specie di grande vassoio, arnese trapezoidale concavo circa $40 \mathrm{~cm}$ per 70, spesso ricavato da un unico blocco di legno, di solito faggio. Si adoperava per mondare la pula dai semi dei cereali, ma soprattutto le castagne secche dalla zanza. Si usava (di solito le donne) afferrandola con le mani ai lati esterni ed appoggiandola sul ventre con la base minore. Con un secco movimento si lanciava in aria il contenuto permettendo all'aria di far volar via la pula mentre i semi o le castagne ricadevano dentro. (GUC98)| faggio, albero de'boschi più alti del n. appennino, che può raggiungere notevole altezza in 80-100 anni. Dà legno bianconocciuola flessibile, usato in mont. In lavori leggeri, come sedie, manichi, scatole, ecc. Ha foglie foragg. Gradite alle pecore e capre, e seme (smaind ed fâz, faggiuole) pure foraggere e che dà olio d'ulivo. Il faggio è inoltre buon combustibile, il carbone che se ne ricava è il migliore per gli usi domestici. Dalla distillazione del faggio i chimici estraggono il creosoto, potente antisettico, usato in med. e chirurgia. (UNGA21).

\section{Sector medicinal}

Categoría de uso: Afecciones cutáneas y tejidos subcutáneos.

Número de referencias: 1 Partes utilizadas: madera.

Il decotto, ottenuto facendo bollire in acqua il carbone del legno, è ritenuto attivo nella cura di Herpes zoster, alcuni invece usano l'acqua di carbone di faggio solo in seguito per favorire un ripristino della corretta circolazione con 1'eliminazione.

Categoría de uso: Otro medicinal.

Número de referencias: 1 Partes utilizadas: tallos leñosos/ramas/ramitas/vástagos. Rametti freschi vengono succhiati in caso di dolori a fegato e milza durant un intensa attività.

fisica. (MANG98).

\section{Quercus cerris $L$.}

Nombre vulgar: Cerro (GGL, VMR), Cerro maschio (BGI).

Número de informantes: 3 Número de citas: 4.

Número de sectores: 2 Número de categorías: 2 .

Biotipo: Fanerófito.

Tipo corológico: Eurimediterránea.

Abundancia: Común.

Ambiente: Bosques sobre todo sobre suelo subácido con estancamiento de agua en. profundidad.

\section{Sector alimentario}

Categoría de uso: Sucedáneo del café.

Número de informantes: 1 Partes utilizadas: frutos/infrutescencias/falsos frutos.

Con le ghiande delle querce (di tutti I tipi, anche I cerri) si seccavano, si macinavano e insieme alle foglie della cicoria secche e si bolliva per fare caffé. (VMR).

Sector doméstico

Categoría de uso: Chimenea y horno.

Número de informantes: 2 Partes utilizadas: madera. 
La migliore legna per riscaldare la casa, perché brucia piano (GGL)| Ottimo fuoco (BGI).

Notas in tempo di guerra., c'era un detto: 'café, café, se ti incontro cicoria, te senti che orzo'. Si faceva con le querce di tutti I tipi, anche con I cerri.

DATOS ETNOBOTÁNICOS BIBLIOGRÁFICOS

Nombre vulgar: za'rr, gianda, janda (UNGA21), cerri (GUC98), za'rr (UNGA21), cèro (GUC98),

cere, cerre (UNGA21), cerr (UNGA21).

Número de referencias: 2 Número de citas: 7.

Número de sectores: 3 Número de categorías: 3.

Sector agropastoral

Categoría de uso: Alimentación animal (incluidos los forrajeros).

Número de referencias: 2 Partes utilizadas: frutos/infrutescencias/falsos frutos, tallos.

Nella valle del Reno, Zerr, a Castiglione e Baragazza cerr (Quercus Cerris L.). Cerro, p. ghiandifera, il cui frutto a Cast. E Barag. Chiamasi cere e cerre, in altri luoghi gianda, ghianda, ed è amara come quella del leccio. Il legno è buono per combustibile, la scorza per conceria e le ghiande sono mangiate dai majali. (UNGA21)| Il vinciólo o i vincióo è un fascio di rami con foglie attaccate, ricavati dalla potatura di castagni, cerri o pioppi, d'inverno, si davano da mangiare a conigli o pecore. (GUC98).

\section{Sector artesanal}

Categoría de uso: Otro artesanal.

Número de referencias: 1 Partes utilizadas: corteza.

Nella valle del Reno, Zerr, a Castiglione e Baragazza cerr (Quercus Cerris L.). Cerro, p. ghiandifera, il cui frutto a Cast. E Barag. Chiamasi cere e cerre, in altri luoghi gianda, ghianda, ed è amara come quella del leccio. Il legno è buono per combustibile, la scorza per conceria e le ghiande sono mangiate dai majali. (UNGA21).

\section{Sector doméstico}

Categoría de uso: Otro doméstico.

Número de referencias: 1 Partes utilizadas: madera.

Nella valle del Reno, Zerr, a Castiglione e Baragazza cerr (Quercus Cerris L.). Cerro, p. ghiandifera, il cui frutto a Cast. E Barag. Chiamasi cere e cerre, in altri luoghi gianda, ghianda, ed è amara come quella del leccio. Il legno è buono per combustibile, la scorza per conceria e le ghiande sono mangiate dai majali. (UNGA21).

\section{Quercus ilex L.}

Nombre vulgar: Leccio (BPT, BGI).

Número de informantes: 2 Número de citas: 2.

Número de sectores: 1 Número de categorías: 1.

Biotipo: Fanerófito. 
Tipo corológico: Esteno-mediterránea.

Abundancia: Común.

Ambiente: Bosques áridos, maquias.

Sector agropastoral

Categoría de uso: Herramientas y objetos agrícolas.

Número de informantes: 2 Partes utilizadas: tallos leñosos/ramas/ramitas/vástagos.

Per fare un manico grande di una mazza di ferro (BGI)| Mazza di legno per spaccare la legna (BPT).

Notas Legno forte, più duro che quello dell' ornello, è un albero importato.

DATOS ETNOBOTÁNICOS BIBLIOGRÁFICOS

Nombre vulgar: leccio (SIRGI91).

Número de referencias: 1 Número de citas: 1.

Número de sectores: 1 Número de categorías: 1.

Sector alimentario

Categoría de uso: Bebida.

Número de referencias: 1 Partes utilizadas: frutos/infrutescencias/falsos frutos.

"Quando pioveva molto, in baracca seccavamo le ghiande di leccio vicino al fuoco, poi le.

trituravamo fra due biette di ferro, per fare il caffé nel paiolo" (SIRGI91).

\section{Quercus pubescens Willd.}

Nombre vulgar: Quercia (MSR, MGO, GGL, VMR, CLO, FAM, SOT, SLU, BLI, BGI), Querciole (MIO), Quercie (BAZ).

Número de informantes: 12 Número de citas: 15.

Número de sectores: 4 Número de categorías: 8.

Biotipo: Fanerófito.

Tipo corológico: Europeas.

Abundancia: Bastante Común.

Ambiente: Bosques y arbustos áridos en las zona submediterránea, generalmente sobre suelo.

calcáreo.

Sector agropastoral

Categoría de uso: Alimentación animal (incluidos los forrajeros).

Número de informantes: 5 Partes utilizadas: frutos/infrutescencias/falsos frutos, hojas.

Per dare da mangiare ai maiali (BGI)| Si appendeva al collo del cavallo la guinea (un sacchetto tessuto di cannapa) e conteneva "la biada" ossia ghiande, orzo e semola per farlo mangiare. (BLI)| Forragera per le pecore:"Vinciò":Fascie di rami con le foglie, raccolti l'ultima settimana di Agosto e la prima di settembre, messi ad essicare per conservare per l'inverno. (SLU)| Venivano ripullite, tagliate, e con i rami si facevano i "vencigli", per le pecore, per l'inverno. (SOT)| Di autunno, prima che caschino le foglie dell'albero, facevano delle fascine di rami di oppio, querciole 
e carpine, per attaccarli d'inverno nella stalla dove stavano le pecore, così loro mangiavano le foglie d'inverno.' (MIO).

Categoría de uso: Cría de ganado bovino.

Número de informantes: 1 Partes utilizadas: hojas.

Per fare il letto alle mucche si usavano le foglie della quercia, per evitare usare la paglia, che in inverno si usava tritata con il fieno, per fare massa, e dargliela da mangiare (FAM).

Categoría de uso: Herramientas y objetos agrícolas.

Número de informantes: 1 Partes utilizadas: tallos leñosos/ramas/ramitas/vástagos.

Rami giovani legati in forma di scopa sterne, per fuori casa. (FAM).

Sector alimentario

Categoría de uso: Pan y similares.

Número de informantes: 1 Partes utilizadas: harina/salvado.

Facevano il pane con la farina di vecce e di ghiande di quercia, quando non c'era nient'altro..

Le ghiande le tostavano e le macinavano. (BAZ).

Categoría de uso: Sucedáneo del café.

Número de informantes: 2 Partes utilizadas: frutos/infrutescencias/falsos frutos.

Le ghiande tostate, macinate e messe a bollire, (CLO)| Con le ghiande delle querce (di tutti I tipi, anche I cerri) si seccavano, si macinavano e insieme alle foglie della cicoria secche e si bolliva per fare caffé. (VMR).

Sector caza y pesca

Categoría de uso: Caza de pájaros.

Número de informantes: 1 Partes utilizadas: tallos leñosos/ramas/ramitas/vástagos.

Trappole per cacciare i passerotti:Si metteva un'asse di quercia o di castagno, sollevata con un palo in una estremità, quando il passerotto arrivava, spostava il palo e l'asse cascava, intrappolando l'uccello. (SLU).

Sector doméstico

Categoría de uso: Chimenea y horno.

Número de informantes: 3 Partes utilizadas: madera, tallos.

La migliore legna per riscaldare la casa, perché brucia piano (GGL)| Anche la quercia è un buon legno da ardere (non il cerro) (MGO)| I 'bacchetti' di quercia sono i migliori per accendere il fuoco. (MSR).

Categoría de uso: Detergente.

Número de informantes: 1 Partes utilizadas: tallos leñosos/ramas/ramitas/vástagos.

Fa una cenere ottima per fare il bucato. (SLU).

Notas Ai maiali li davano la quercia più comune (Q. pubescens) poi c'era anche il Cerro maschio (Q.coccifera, o Q. spinosa), che era ottima da bruciare, la quercia sugerina ma che qua non matura per fare il sughero, e il Leccio, importato.

DATOS ETNOBOTÁNICOS BIBLIOGRÁFICOS

Nombre vulgar: Quercia (SIRGI91), quercia (GUC98), Botìola (APPO10). 
Número de referencias: 3 Número de citas: 5 .

Número de sectores: 3 Número de categorías: 4.

Sector agropastoral

Categoría de uso: Alimentación animal (incluidos los forrajeros).

Número de referencias: 1 Partes utilizadas: tallos leñosos/ramas/ramitas/vástagos. "I contadini con poca terra... frasche di quercia o pioppo per alimentare pecore e mucche nell'inverno" (SIRGI91).

Categoría de uso: Otro agropastoral.

Número de referencias: 1 Partes utilizadas: tallos leñosos/ramas/ramitas/vástagos. Fascine di polloni di castagno, quercia e olmo, con foglie (vinciò) si facevano di solito nel periodo dell'armondadura, ripulendo le plonare attorno ai castagni, ma cne pulendo le altre piante. Si usava metterle sulla cima del pagliaio per proteggere il fieno della pioggia..

Sector alimentario

Categoría de uso: Bebida.

Número de referencias: 1 Partes utilizadas: frutos/infrutescencias/falsos frutos. "Quando pioveva molto, in baracca seccavamo le ghiande di leccio vicino al fuoco, poi le trituravamo fra due biette di ferro, per fare il caffé nel paiolo" (SIRGI91).

Sector doméstico

Categoría de uso: Objetos domésticos y escobas.

Número de referencias: 1 Partes utilizadas: madera.

La trómba è un condotto inclinato terminante con due corti mezzi tronchi di quercia a imbuto, murati e chiusi da una paratoia. Serviva a portare l'acqua del mulino dal botàccio al ródo. (GUC98).

\section{GENTIANACEAE}

\section{Centaurium erythraea Rafn.}

Nombre vulgar: Pianta per la febbre, la biondella (PLU), Erba della febbre (BEL).

Número de informantes: 2 Número de citas: 3.

Número de sectores: 2 Número de categorías: 2 .

Biotipo: Hemicriptófito.

Tipo corológico: Europeas.

Abundancia: Común.

Ambiente: Barros, arenas húmedas (también salobres), caminos sombreados, montes y.

garrigas.

Sector doméstico

Categoría de uso: Cuidado personal y cosmética.

Número de informantes: 1 Partes utilizadas: parte aérea (toda).

Lavare i capelli con i fiori schiarisce i capelli. (PLU). 


\section{Sector medicinal}

Categoría de uso: Fiebre.

Número de informantes: 2 Partes utilizadas: flores/inflorescencias y sus partes.

Fare cuocere l'erba 2 o 3 minuti e bere il decotto dei fiori 2 o 3 volte al giorno. $(\mathrm{BEL}) \mid$ Bere un tazzina del decotto della pianta una volta al giorno. (PLU).

Notas non si trovano più, fa un fiore rosa, e fa $30-40 \mathrm{~cm}$, preparazione Perché lei diceva 'infuso' ma poi spiegava che andava fatto bollire un po...erba della febbre: fiorisce a maggio o giugno, anche in mezzo al fieno, è selvatica, fa anche intorno a casa.

\section{Gentiana asclepiadea L. (cfr.)}

Nombre vulgar: Genziana (TAD, TOA, REN, NRO, NLA, TUL, BGI, VMU, VMR, PGI, FAR), Genziana (fiore viola) (CRE).

Número de informantes: 12 Número de citas: 22 .

Número de sectores: 2 Número de categorías: 10.

Biotipo: Hemicriptófito.

Tipo corológico: Montañosas.

Abundancia: Común.

Ambiente: Desmontes, arbustos, bosques húmedos.

\section{Sector alimentario}

Categoría de uso: Golosinas y masticatorias.

Número de informantes: 1 Partes utilizadas: órganos subterráneos.

Si tenevano in bocca le barbe come dissetante (FAR).

Categoría de uso: Licor.

Número de informantes: 3 Partes utilizadas: órganos subterráneos.

Liquore "Criptamarol": lo faceva il prete e gran conoscitore di Botanica di Castelluccio Don Oliviero Giovannino, glielo dava alle persone con cui aveva più confidenza o simpatia, ma nessuno sapeva la ricetta, solo sa che aveva la radice di Genziana. Il prete faceva anche degli scambi con il liquore. (PGI) $\mid \mathrm{Si}$ andava a prenderla nei campi dove Il terreno era umido, scalzavano le radici, si puliscono e si mettono in infuso nella grappa o nel vino. Fa digerire e mantiene sfiammato lo stomaco. (VMU, VMR).

\section{Sector medicinal}

Categoría de uso: Afecciones oro-faríngeas y de la cavidad oral.

Número de informantes: 1 Partes utilizadas: órganos subterráneos.

Mettere la radice nell'acqua bollente e bere. (BGI).

Categoría de uso: Afecciones típicas infantiles.

Número de informantes: 2 Partes utilizadas: órganos subterráneos.

Una cuchiaiata piccola per i bambini (TUL)| Davano Il decotto di genziana ai bambini, anche come calmante (CRE).

Categoría de uso: Estado general.

Número de informantes: 6 Partes utilizadas: órganos subterráneos.

Mettere la radice nell' acqua bollente e bere. (BGI)| si faceva un decotto con la radice (NLA) | Bere il decotto della radice di Genziana come depurativo (NRO)| Fare 


\section{María Teresa Egea Molines}

il decotto della radice di Genziana e prendere per 3 o 4 giorni. (REN)| Seccare le radici di Genziana, bollirle e bere il decotto di continuo. (TOA)| Bere l'infuso della radice della Genzianella o della Genziana per depurare il corpo dopo l'inverno. (VMR).

Categoría de uso: Otro medicinal.

Número de informantes: 1 Partes utilizadas: órganos subterráneos.

Si metteva la 'barba' (radice ) fresca in bocca per far passare la voglia di fumare, perché era.

amara. (TAD).

Categoría de uso: Patologías del aparato circulatorio.

Número de informantes: 1 Partes utilizadas: órganos subterráneos.

Quando uno si sente la pressione alta, bere le barbe della genziana bollite (TUL).

Categoría de uso: Patologías del aparato digestivo.

Número de informantes: 5 Partes utilizadas: órganos subterráneos.

Per fare venire 1' appetito si faceva bere un decotto di Genziana (BGI)| Si fa bollire la radice e si beve. (TAD)| Seccare le radici di Genziana, bollirle e bere il decotto di continuo. (TOA) $\mid \mathrm{Si}$ andava a prenderla nei campi dove Il terreno era umido, scalzavano le radici, si puliscono e si mettono in infuso nella grappa o nel vino. Fa digerire e mantiene sfiammato lo stomaco. (VMU)| non specificato (CRE).

Categoría de uso: Patologías del aparato urinario.

Número de informantes: 1 Partes utilizadas: órganos subterráneos.

Bere il decotto della radice di Genziana per le coliche dei reni (NRO).

Categoría de uso: Patologías del sistema nervioso.

Número de informantes: 1 Partes utilizadas: órganos subterráneos.

Seccare le radici di Genziana, bollirle e bere il decotto di continuo. (TOA).

DATOS ETNOBOTÁNICOS BIBLIOGRÁFICOS

Nombre vulgar: genziaena (UNGA21), genziana, scenziana (MANG98), genziana (BAL801).

Número de referencias: 3 Número de citas: 4.

Número de sectores: 1 Número de categorías: 2.

Sector medicinal

Categoría de uso: Estado general.

Número de referencias: 2 Partes utilizadas: No especificado, órganos subterráneos.

genziana asclepiadea, a fiori azurri, de nostri boschi montani cui si attribuiscono più virtù, spc. Usata come antifebbrifuga. (UNGA21)| Cure depurative per 'il cambio del sangue'vengono eseguite ad ogni primavera, soprattutto da giovani ed anziani (MANG98).

Categoría de uso: Patologías del aparato digestivo.

Número de referencias: 1 Partes utilizadas: órganos subterráneos.

Per aumentare 1'appetito. (MANG98).

Notas Nei prati presso la punta nord del lago di Pratignano, vicino alla sorgente che ivi si trova. Sul finire dell' estate, (il 23 agosto), altri ne vidi nel fosso della Nuda, nel punto in cui viene attraversato dalla 'via dei signori'. 


\section{Gentiana lutea L. (cfr.)}

Nombre vulgar: Genziana (GGI).

Número de informantes: 1 Número de citas: 1.

Número de sectores: 1 Número de categorías: 1.

Biotipo: Hemicriptófito.

Tipo corológico: Montañosas.

Abundancia: Rara.

Ambiente: Prados y pastos de montaña (calcáreo).

Sector medicinal

Categoría de uso: Estado general.

Número de informantes: 1 Partes utilizadas: órganos subterráneos.

Bere il decotto di tanto in tanto per eliminare le tossine dell'inverno (GGI).

Notas Dice che i vecchi dicevano di stare attenti a non confonderla con il veratro, velenoso, che ha le foglie disposte diverse (uno ce le ha alterne e l'altro opposte, secondo il suo disegno).

DATOS ETNOBOTÁNICOS BIBLIOGRÁFICOS

Nombre vulgar: genziana (SANS14), genziana maggiore (BAL801).

Número de referencias: 2 Número de citas: 2.

Número de sectores: 1 Número de categorías: 1.

Sector alimentario

Categoría de uso: Licor.

Número de referencias: 1 Partes utilizadas: órganos subterráneos (SANS14).

\section{Gentianopsis ciliata (L.) Ma (= Gentiana ciliata L.) (cfr.)}

Nombre vulgar: Genzianella (VMU, VMR).

Número de informantes: 2 Número de citas: 4.

Número de sectores: 2 Número de categorías: 3 .

Biotipo: Terófito.

Tipo corológico: Montañosas.

Abundancia: Rara.

Ambiente: Pastos áridos, pinares, brezales, subalpinos.

Sector alimentario

Categoría de uso: Licor.

Número de informantes: 2 Partes utilizadas: órganos subterráneos.

Si andava a prenderla nei campi dove Il terreno era umido, scalzavano le radici, si puliscono e.

si mettono in infuso nella grappa o nel vino. Fa digerire e mantiene sfiammato lo stomaco. (VMU, VMR).

Sector medicinal

Categoría de uso: Estado general.

Número de informantes: 1 Partes utilizadas: órganos subterráneos. 


\section{María Teresa Egea Molines}

Bere l'infuso della radice della Genzianella o della Genziana per depurare il corpo dopo.

l'inverno. (VMR).

Categoría de uso: Patologías del aparato digestivo.

Número de informantes: 1 Partes utilizadas: órganos subterráneos.

$\mathrm{Si}$ andava a prenderla nei campi dove Il terreno era umido, scalzavano le radici, si puliscono e si mettono in infuso nella grappa o nel vino. Fa digerire e mantiene sfiammato lo stomaco. (VMU).

\section{GERANIACEAE}

\section{Pelargonium zonale (L.) L'Hér. ex Aiton}

Nombre vulgar: Geranio (MGE, CBR, LST).

Número de informantes: 3 Número de citas: 4.

Número de sectores: 2 Número de categorías: 2 .

Biotipo: Caméfito.

Tipo corológico: Cultivadas.

Abundancia: Cultivada.

Ambiente: Cultivado en jardines, en maceta.

Sector doméstico

Categoría de uso: Ornamental.

Número de informantes: 1 Partes utilizadas: planta entera/viva.

Nel borgo tutti avevamo i gerani, che mettevamo d'inverno dentro casa. (LST).

Sector medicinal

Categoría de uso: Afecciones cutáneas y tejidos subcutáneos.

Número de informantes: 3 Partes utilizadas: hojas.

Applicare sulla ferita le foglie di geranio un pò pestate $(\mathrm{CBR}) \mid$ Lavavano la foglia dei gerani, la mettevano sopra l'infezione (da un taglio quando c'entrava lo sporco), la faciavano poi la cambiavano ogni giorno. La foglia tirava fuori l'infezione. (LST) Per le ferite si applicava una foglia di geranio e si fasciava. (MGE).

\section{GROSSULARIACEAE (incluye SAXIFRAGACEAE p.p.)}

\section{Ribes rubrum $L$.}

Nombre vulgar: Ribes (BGI, CLO, GRI).

Número de informantes: 3 Número de citas: 3.

Número de sectores: 1 Número de categorías: 3 .

Biotipo: Nanofanerófito.

Tipo corológico: Cultivadas.

Abundancia: Cultivada.

Ambiente: Bosques húmedos y lugares frescos. 
Sector alimentario

Categoría de uso: Fruta fresca.

Número de informantes: 1 Partes utilizadas: frutos/infrutescencias/falsos frutos.

Si coltivavano nell'orto (nel bosco non si trovavano),si mangiavano come frutta fresca (GRI).

Categoría de uso: Golosinas y masticatorias.

Número de informantes: 1 Partes utilizadas: frutos/infrutescencias/falsos frutos.

Al naturale (CLO).

Categoría de uso: Mermelada.

Número de informantes: 1 Partes utilizadas: frutos/infrutescencias/falsos frutos.

I ribes vengono aggiunti alla mermellata di mele o di pere, facendo prima scottare $i$ frutti e poi levandoli i semi con un colino. (BGI).

Notas Si coltivavano nell'orto (nel bosco non si trovavano), Apportazione vitaminica durante tutto l' estate, fino alle castagne. Manca in Venturi (2006), ce n' era nei confini dei campi.

DATOS ETNOBOTÁNICOS BIBLIOGRÁFICOS

Nombre vulgar: rîbes (UNGA21).

Número de referencias: 1 Número de citas: 3.

Número de sectores: 2 Número de categorías: 3 .

Sector alimentario

Categoría de uso: Conserva de frutas.

Número de referencias: 1 Partes utilizadas: frutos/infrutescencias/falsos frutos.

Frutto di sapore aciduletto gradito, che si usa a far conserve e sciroppi. (UNGA21).

Sector medicinal

Categoría de uso: Patologías del aparato urinario.

Número de referencias: 1 Partes utilizadas: tallos leñosos/ramas/ramitas/vástagos,.

Nella medicina popolare, vengono somministrate le foglie e I ramoscelli in infuso come diuretico e antiartritico (UNGA21).

Categoría de uso: Trastornos musculo-esqueléticos.

Número de referencias: 1 Partes utilizadas: tallos leñosos/ramas/ramitas/vástagos,.

Nella medicina popolare, vengono somministrate le foglie e I ramoscelli in infuso come diuretico e antiartritico (UNGA21).

\section{Ribes uva-crispa $L$.}

Nombre vulgar: Uva spina (CLO, GRI, TAD).

Número de informantes: 3 Número de citas: 3.

Número de sectores: 1 Número de categorías: 3 .

Biotipo: Nanofanerófito.

Tipo corológico: Cultivadas.

Abundancia: Cultivada.

Ambiente: Bosques y pastos de la zona de montaña y de cumbre. 
Sector alimentario

Categoría de uso: Dulces y golosinas.

Número de informantes: 1 Partes utilizadas: frutos/infrutescencias/falsos frutos.

Per decorare le torte di frutta. Tutti la coltivavamo nell' orto insieme alle more e ai lamponi.

(TAD).

Categoría de uso: Fruta fresca.

Número de informantes: 1 Partes utilizadas: frutos/infrutescencias/falsos frutos.

Si coltivavano nell'orto (nel bosco non si trovavano),si mangiavano come frutta fresca (GRI).

Categoría de uso: Golosinas y masticatorias.

Número de informantes: 1 Partes utilizadas: frutos/infrutescencias/falsos frutos. Al naturale (CLO).

Notas Si coltivavano nell'orto (nel bosco non si trovavano), era l'aportazione vitaminica durante.

tutta l' estate, fino alle castagne. Per GGI era coltivata e in passato tutti avevano nell'orto Ribes e uva spina.

\section{HYPERICACEAE (incluye GUTTIFERAE)}

\section{Hypericum perfoliatum $L$.}

Nombre vulgar: Scacciadiavoli (VAL, BEL), Iperico (VMR, RNI, PIM, NRO, MCL, GGI, GAN, FAM), Iperico, Erba di san Giovanni (VMU), Scacciadiavoli, Iperico (VAL).

Número de informantes: 11 Número de citas: 16.

Número de sectores: 2 Número de categorías: 6 .

Biotipo: Hemicriptófito.

Tipo corológico: Europeas.

Abundancia: Común.

Ambiente: Bosques, matorrales, setos, márgenes de caminos.

Número de exsiccata: 38918 FIAF.

Sector mágico/ritual/supersticioso

Categoría de uso: Protector.

Número de informantes: 2 Partes utilizadas: parte aérea (toda).

Per allontanare le streghe, tenere un mazzo di scacciadiavoli in casa. Nelle stalle serve per evitare il malocchio alle mucche. (BEL)| Per allontanare le streghe, tenere un mazzo di scacciadiavoli in casa. (VAL).

Sector medicinal

Categoría de uso: Afecciones cutáneas y tejidos subcutáneos.

Número de informantes: 10 Partes utilizadas: flores/inflorescencias y sus partes.

"Olio rosso": lasciare a macerare i fiori nell'olio di oliva per 40 giorni al sole (FAM) Raccogliere I fiori di iperico il giorno di San Giovanni, metterli sotto olio in un barattolo chiuso con una stoffa, al sole per 40 giorni nel "tempo del solleone", ossia 
Etnobotánica en el Alto Valle del Reno (Toscana y Emilia-Romaña, Italia)

dal 21 Luglio al 21 Agosto. Poi filtrare e tappare il barattolo con un tappo di sughero. Applicare direttamente. (GAN)| Raccolti i fiori, si mettevano a macerare nell'olio extravergine d' oliva dentro un vaso sigillato con appena un po' di vino, durante 40 giorni al sole. Suo babbo non toglieva I fiori, li lasciava dentro. (GGI) Raccolti i fiori a San Giovanni, vengono messi nell'olio per 40 giorni al sole. (MCL) Non sa bene come si fa perché lo faceva la nonna del suo marito, lo mettevano al sole d'estate (NRO)| Applicare l'olio di iperico (una volta macerato) sulle bruciature. (PIM)| Mettere I fiori a macerare nell'olio di oliva e applicare sulle bruciature con uno straccio. (RNI)| Raccogliere I fiori di iperico a mezzo giorno a pieno sole del 24 giugno (San Giovanni), sommergerli nell'olio di oliva extravergine e lasciare al sole per 40 giorni in un barattolo chiuso. Poi filtrare e applicare sulle bruciature, ma non subito perché con l'olio aumenta la bruciatura. Applicare solo quando si è calmata la bruciatura, anche sui tagli, sugli eczemi, cicatrici. (VMR)| Mettere a macerare I fiori nell'olio di oliva per 15 giorni al sole in un barattolo chiuso. Poi filtrare e applicare sulle ferite. (VMU)| Mettere a macerare la pianta in una bottiglia d'olio chiusa, la vigilia di San Giovanni (23 giugno notte) per un mese, poi filtrare. Applicare l'olio sulle bruciature. (VAL).

Categoría de uso: Afecciones ginecológicas, complicaciones obstétricas, del postparto y del puerperio.

Número de informantes: 1 Partes utilizadas: flores/inflorescencias y sus partes.

Raccogliere I fiori di iperico a mezzo giorno a pieno sole del 24 giugno (San Giovanni), sommergerli nell'olio di oliva e lasciare al sole per 40 giorni. Poi filtrare e applicare sulle ragadi dei capezzoli (VMR).

Categoría de uso: Afecciones típicas infantiles.

Número de informantes: 1 Partes utilizadas: flores/inflorescencias y sus partes.

Raccogliere I fiori di iperico a mezzo giorno a pieno sole del 24 giugno (San Giovanni), sommergerli nell'olio di oliva e lasciare al sole per 40 giorni. Poi filtrare e applicare sul sedere rosso dei bambini (VMR).

Categoría de uso: Patologías del sistema nervioso.

Número de informantes: 1 Partes utilizadas: flores/inflorescencias y sus partes.

Macerare il fiori nel vino o nella grappa per 2 o 3 mesi e prenderne 1 cucchiaino da caffè la.

sera. (FAM).

Categoría de uso: Trastornos musculo-esqueléticos.

Número de informantes: 1 Partes utilizadas: flores/inflorescencias y sus partes.

Raccogliere I fiori di iperico a mezzo giorno a pieno sole del 24 giugno (San Giovanni), sommergerli nell'olio di oliva e lasciare al sole per 40 giorni. Poi filtrare e applicare sui dolori dei reumatismi. (VMR).

Notas I carbonai se lo portavano sempre in Sardegna per le bruciature, I boscaioli lo portavano sempre con sé per quando si tagliavano, Se lo portavano sempre dietro i carbonai della Sardegna, Lo faceva la sua nonna., Mettere a macerare la pianta in una bottiglia d'olio chiusa, la vigilia di San Giovanni (23 giugno notte).

\section{DATOS ETNOBOTÁNICOS BIBLIOGRÁFICOS}

Nombre vulgar: êrba ed San Zvân (UNGA21), fiore di San Giovanni (MANG98).

Número de referencias: 2 Número de citas: 5. 
Número de sectores: 2 Número de categorías: 5.

Sector mágico/ritual/supersticioso

Categoría de uso: Protector.

Número de referencias: 1 Partes utilizadas: No especificado.

erba di San Giovanni, iperico, detta anche cacciadiavoli, perché si crede abbia la virtù contro.

i malefici. (UNGA21).

\section{Sector medicinal}

Categoría de uso: Afecciones cutáneas y tejidos subcutáneos.

Número de referencias: 1 Partes utilizadas: flores/inflorescencias y sus partes.

I fiori lasciati macerare in olio di oliva forniscono un linimento valido per il trattamento delle.

bruciature. (MANG98).

Categoría de uso: Patologías del aparato digestivo.

Número de referencias: 1 Partes utilizadas: hojas (UNGA21).

Categoría de uso: Patologías del aparato urinario.

Número de referencias: 1 Partes utilizadas: flores/inflorescencias y sus partes (UNGA21).

Categoría de uso: Trastornos musculo-esqueléticos.

Número de referencias: 1 Partes utilizadas: parte aérea (toda) (UNGA21).

\section{IRIDACEAE}

\section{Crocus vernus (L.) Hill (s.l.)}

Nombre vulgar: Pappagalli (TAT), Campaggiolo (GLA), Bucaneve (NLA), Campagioli (CRI).

Número de informantes: 4 Número de citas: 4.

Número de sectores: 2 Número de categorías: 4.

Biotipo: Geófito.

Tipo corológico: n.d.

Abundancia: Común.

Ambiente: Prados, pastos, bosques.

\section{Sector alimentario}

Categoría de uso: Golosinas y masticatorias.

Número de informantes: 1 Partes utilizadas: órganos subterráneos.

Quando eravamo nei campi mangiavamo la cipollina dei pappagalli. Si mangiava il bulbo, si spellava ed aveva un sapore dolciastro. (TAT).

Categoría de uso: Otro alimentario.

Número de informantes: 1 Partes utilizadas: flores/inflorescencias y sus partes.

Colorante alimentare: raccogliere i pistilli e metterli a seccare, poi metterli nella sfoglia quando le uova erano troppo bianche e la sfoglia non veniva abbastanza gialla. (GLA). 
Categoría de uso: Tortilla.

Número de informantes: 1 Partes utilizadas: hojas.

Si faceva la frittata con le foglie del bucaneve (NLA).

Sector doméstico

Categoría de uso: Ornamental.

Número de informantes: 1 Partes utilizadas: flores/inflorescencias y sus partes.

Raccolte per mettere in un bicchiere per abbellire la casa (CRI).

Notas Fa un fiore violetto chiaro e a volte bianco. Si trova nei prati, fiorisce appena va via la neve, le foglie sono come la cipolla. Si mangiava il bulbo, si spellava ed aveva un sapore dolciastro. Anche se i vecchi poi ci hanno detto che erano tossici,, però noi ne abbiamo mangiati tanti. Per aromatizzare e colorare è necessario mettere una dose superiore allo zafferano comprato.

\section{Gladiolus italicus Mill.}

Nombre vulgar: Gladioli selvatici (MTO, MSR).

Número de informantes: 2 Número de citas: 2.

Número de sectores: 1 Número de categorías: 1 .

Biotipo: Geófito.

Tipo corológico: Eurimediterránea.

Abundancia: Común.

Ambiente: Campos de cereales.

Número de exsiccata:.

Sector religioso

Categoría de uso: Ornamento para altares e iglesias.

Número de informantes: 2 Partes utilizadas: flores/inflorescencias y sus partes.

Si portavano i fiori selvatici per la Madonna. (MTO, MSR).

\section{JUGLANDACEAE}

\section{Juglans regia $L$.}

Nombre vulgar: Mallo di noce (LST), Marlo di Noce (BBA), Merla di Noce (GLA, NRO), Noce (AN3, BAN, BAT, BAZ, BBI, BEL, BGI, BLI, BPA, BSO, CAR, CLO, CRI, CRO, CVA, DAD, GAN, GCL, GFO, GFR, GGI, GUF, GZE, LST, MGO, MIO, MRI, MVI, NLA, NMA, NRO, NST, PCL, PIL, PSI, REN, RFR, TGA, TGO, TUL, VAL, VFR, VMR), Noce malisa (RFR), Noci (VMU).

Número de informantes: 46 Número de citas: 71.

Número de sectores: 5 Número de categorías: 13.

Biotipo: Fanerófito.

Tipo corológico: Amplia distribución.

Abundancia: Común.

Ambiente: Cultivada por el fruto y la madera, en todo el territorio y frecuentemente adventicia. 


\section{Sector alimentario}

Categoría de uso: Aromatizante.

Número de informantes: 2 Partes utilizadas: semillas, hojas.

Per insaporire i formaggi: Noce, mandorla e nocciole "cullora" secche e macinate venivano messi sopra il latte cagliato in una tazza, poi il tutto si metteva dentro alle cisterne d' acqua piovana per un po'. (NLA)| Le foglie di noce si seccavano e si adoperavano per fare i 'necci' perché gli dava un aroma buono. (NST).

Categoría de uso: Dulces y golosinas.

Número de informantes: 1 Partes utilizadas: semillas.

Caramellate, con lo zucchero scaldato sopra le noci essicate al sole (BGI).

Categoría de uso: Fruta seca.

Número de informantes: 3 Partes utilizadas: semillas.

Mettere a seccare al sole a Settembre (NRO)| "Spunto per la veglia" dopo cena: Le noci secche con pane, mela e un po' di vino (DAD)| Mangiati come frutta secca. (RFR).

Categoría de uso: Licor.

Número de informantes: 23 Partes utilizadas: frutos/infrutescencias/falsos frutos, . Prendere 30 noci (mallo verde, quando dentro non è ancora fatto), 1 litro e mezzo di alcol, 750 gr di zucchero, 2 grammi di cannella reggina trittati, 10 chiodi di garofano, 4 litri di acqua, la buccia del limone. Lasciare macerare per 40 giorni al buio o alla penombra in cantina,e filtrare. (AN3)| Sono due tipi di liquori il Nocino e il Nociato. Il Nocino si fa con 33 Noci, 750 gr. Di zucchero, Mezzo litro di acqua, e un litro e mezzo di alcool da liquori: Il 24 Giugno (Giorno di San Giovanni), si raccolgono 33 noci ancora verdi, si forano con una forcetta, si tagliano in 4 spicchi, si pongono in un contenitore di vetro che possa contenere il doppio, si aggiunge poi l'acqua, lo zucchero, l'alcol. Si chiude il recipiente e si lascia al sole per 60 giorni, agitandolo ogni 4 o 5 giorni. A fine Agosto lo si filtra e il Nocino è pronto. Il Nociato si fa con le noci usate per il Nocino e un litro di vino bianco secco o di Vermut: nello stesso contenitore dove è stato preparato il Nocino, dopo aver tolto l'alcool, ricoprite le noci con il vino o il vermut, lasciare riposare per una settimana, filtrare, conservare in luogo fresco e servire come aperitivo. (BAZ)| Raccogliere 21 noci prese verso il 24 giugno, mettere a macerare in un litro di alcol, mezzo di litro di acqua, 500 gr di zucchero, 1,5 gr di cannella e 7 chiodi di garofano, lasciare a riposare per 3 settimane e filtrare. (VAL, BEL)| A San Giovanni, raccolte e messe nel alcol a macerare...non sa le quantità. (BGI)| Il nocino: raccogliere il 24 Giugno 19 noci verdi, spaccarle in due. Mettere in infusione un litro di Alcol 90 gradi per 40 giorni. Poi fare lo sciroppo: fare bollire $800 \mathrm{ml}$ d'acqua e scioglere $400 \mathrm{gr}$ di zucchero. Filtrare le noci e mescolare lo sciroppo all'acqua delle noci. Bere dopo un mese. Servire dopo i pasti come digestivo. foto. (BSO)| Il Nocino: liquore che si prepara con il mallo di noce raccolto a San Giovani. Non sa la ricetta (CAR) "nocino", con le noci raccolte da giugno a luglio, spaccate a metà e messe dentro l' alcol puro di 95C. Ricetta della mamma chimata la nonna: "28 nocine tagliate, 1 litro di alcol puro, 900 gr.zucchero, 1scorza limone, 1stecca vaniglia,4 chiodi di garofano, 1pizzico di cannella. Stringere lo zucchero in acqua calda e lasciare 40 giorni (CRI)| Fanno il nocino con le noci acerbe, pero lei non sa la ricetta (CRO)| Il 
Nocino. Raccogliere le noci per San Giovanni. (CVA)| Ricetta della suocera chimata la nonna: "28 nocine tagliate, 1 litro di alcol puro, 900 gr.zucchero, 1scorza limone, 1stecca vaniglia,4 chiodi di garofano, 1 pizzico di cannella. Stringere lo zucchero in acqua calda e lasciare 40 giorni (DAD)| Raccogliere le noci a San Giovanni, mettere a macerare un chilo di frutta in un litro di alcol, un litro di acqua e un $\mathrm{kg}$ di zucchero, per minimo un anno, poi si può filtrare oppure lasciare la frutta dentro e mangiarla via via. $\mathrm{O}$ si può lasciare quanto si vuole nell'alcol, piu ci sta meglio è, anche 5 o 6 anni.. (MVI, GZE)| Prendere il mallo della noce verso Giugno (quando la noce ancora non c'è) farla a pezzetti. Per $2 \mathrm{~kg}$ di frutti, mettere un Litro di alcol e lasciare a macerare per 7 o 8 giorni al buio in un barattolo chiuso ermeticamente. Separatamente fare uno sciroppo fatto di 1 litro acqua per $1 \mathrm{~kg}$ zucchero. Filtrare la frutta macerata con l'alcol e aggiungerlo allo sciroppo. Imbottigliare e più si invecchia, più buona è. Poi si beve in inverno quando è freddo (dopo aver spallato la neve per esempio, per riscaldarsi). Oppure in compagni quando in inverno ci vengono a trovare. (LST)| Il nocino' si faceva a giugno con le noci fresche (ancora con il mallo verde), messi a macerare nell'alcol mescolato a uno sciroppo di zucchero e acqua bollito. (MIO)| "il nocino" si fa mettendo a macerare le noci nel alcol per una settimana, poi si filtra e si aggiunge zucchero e acqua. Non si ricorda delle proporzioni (NMA)| Raccogliere le noci il 24 Giugno, il giorno di San Giovanni. Prendere 15 noci spezzate in 4 parti, 1/2 Litro di acqua, 1/2 litro di alcool 90 gradi, $1 / 2 \mathrm{~kg}$ di zucchero, un limone grattugiato e il sugo, un cucchiaio di caffé macinato. Mettere tutto in un vaso e riporlo per un giorno al sole poi scuoterlo affinché lo zucchero si sciolga e lasciarlo in un posto fermo per 40 giorni poi filtrare e imbottigliare. (PIL)| Raccogliere il giorno di San Giovanni 22 noci e metterle a macerare in un litro di alcol. (PSI) $\mid$ Raccogliere 7 o 8 noci con il mallo attaccato per la vigilia di san Giovanni (23 giugno) e mettere a macerare nell'alcol con lo zucchero per 40 giorni, poi filtrare. (RFR)| Liquore "il Nocino"Macerare nel alcol le noci acerbe (TGO)| Raccogliere le Noci per San Giovanni e poi si fa con l'alcol (TUL)| Il liquore il "nocino": mettere a macerare 25 noci verdi raccolte a San Giovanni in un litro di alcol e dello zucchero, durante 40 giorni. Poi filtrare. Poi si risciacquavano le noce con un altro pò di alcol e veniva un liquorino più leggerino che si beveva anche per merenda. (VFR)| Il 'Nocino':raccogliere le noci la sera di San Giovani. La tradizione dice che si debono rubare e raccogliere scalzi. Poi vanno tagliati con il coltello di legno a forma di croce. Mettere i frutti a macerare nel vino e alcol insieme allo zucchero, al limone e ai chiodi di garofano per 40 giorni al sole. Le proporzioni sono segrete. Poi filtrare e imbotigliare. (VMR).

\section{Sector doméstico}

Categoría de uso: Cuidado personal y cosmética.

Número de informantes: 9 Partes utilizadas: frutos/infrutescencias/falsos frutos, hojas.

Mettere a macerare per 10 o 15 giorni il mallo della noce nell'acqua. Quando l'acqua diventa nera fare l'ultimo risciacquo dopo il sapone di marsiglia con l'acqua di mallo di noce. (LST)| Per tingersi I capelli di scuro, si bollivano le foglie di noce, e si lavavano I capelli con l'acqua. (BAZ)| Il mallo di noce, la 'buccia', si raccoglie fresca, verde e si fa bollire nell'acqua finché non diventa nera. Poi si lavano i capelli 


\section{María Teresa Egea Molines}

con questa acqua, per scurirli. (BBI)| Per pulire e scurire i capelli fare bollire le foglie di noce e poi lavare i capelli con l'acqua di cottura. (BEL)| Per scurire I capelli, bollire il mallo di noce e lavarsi I capelli. (GUF)| Per tingere i capelli: foglie giovane fatte bollire finché l' acqua diventi "dura", bagnare un panno e metterlo sui capelli (NLA)| Bollire il mallo di noce e lavare I capelli scuri con l'acqua di mallo di noce. (NRO)| Bollire la buccia di noce e lavare i capelli per renderli più lucidi. (PSI)| Fare un infuso di mallo di noce e lavarsi I capelli, per farli diventare lucidi. (TGA).

Categoría de uso: Tintorial.

Número de informantes: 18 Partes utilizadas: frutos/infrutescencias/falsos frutos, hojas.

Tintorio:Bollire le buccie verdi delle noci insieme ai vestiti, viene un colore cammello (BBA)| Tintorio:Bollire la merla di noce, filtrare e mettere a bollire $\mathrm{i}$ tessuti da tingere con l'acqua della merla di nocce (GLA)| Tintorio-verde e marrone:Quando le noci cascavano, si mettevano in un barattolo a marcire, e diventavano marroni, poi si mettevano a bollire con i tessuti da tingere di colore marrone, e a secondo della quantità di marlo di noce, i vestiti diventavano di un colore più scuro o marrone chiaro. Se invece si bollivano i vestiti con le nocci verdi, si tingevano di colore verde (NRO)| Il mallo di noce si usa per tingere la lana, ma anche le calze di lana, in colore cammello (come terra cotta). Si raccolgono le noci quando cominciano a cadere quando sono verdi, verso settembre. Bollirle, colare l'acqua e con questa lavare la lana. (BAT, BAN)| Tintorio-verde militare:Mettere a bollire il mallo di noce insieme ai tessuti da tingere, e poi immergere il tessuto in acqua e aceto. (BLI) $\mid$ Si mettevano a macerare il mallo di noce in acqua con i vestiti per un paio di giorni (BPA)| Tintorio (avena, cammello.):Quando le noce cascavano, raccogliere il "mallo" di noce, e bollire la lana insieme al marlo di noce nell'acqua.Frutto (bucce di noce) (GAN)| Foglie fresche messe a bollire per un po', poi si colavano, e questa acqua si metteva a ribollire con le matasse di lana. Colore Camello. Poi non stingeva più. (GCL)| Tintorio. Bollire malli di noci insieme ai vestiti per tingerli di colore verde (GFO)| Per tingere la lana di colore avana/nocciolo, raccogliere il marlo di noce quando sono cascate, e farle bollire con la lana. Per tingere la lana di colore marrone scuro, raccogliere le noci quando già sono marcite. (GFO)| Per tingere la lana di colore avana/nocciolo, raccogliere i malli delle noci quando sono cascate e farli bollire con la lana. Per tingere la lana di colore marrone scuro, raccogliere le noci quando già sono marcite. Per tingere vestiti, bollirli insieme ai malli di noce. (GFR)| Mallo di noce messi a bollire in un paiolo con i tessuti, colore marrone "avena scuro" (GGI)| Raccogliere le noci acerbe, verdi, a fine luglio o agosto, farle bollire con la lana. Tinge da verde a marrone. (MRI)| Per tingere le scarpe nere, insieme alla 'calligine' (fuliggine). Pertingere i tessuti, li mettevano a bollire con il mallo di noce finché diventavano marroni. Però il colore non teneva, dopo un po' cascava la tinta. (NLA)| Per tingere I vestiti, bollire I vestiti con la "merla di noce". (PCL)| Per tingere la lana colore noce: Mettere a bollire le foglie nell'acqua, togliere le foglie, e mettere a bollire la lana nel decotto. (REN)| Tintorio:Bollire insieme ai tessutiColore Marrone (nome scientifico: Blu toglone) (TGO)| Con la buccia del frutto, o il Mallo di Noce, si fa bollire tanto tempo dell'acqua con il mallo e I vestiti da tingere,e si fa restringere. Per tingere di marrone. (TUL). 


\section{Sector lúdico/voluptuoso}

Categoría de uso: Fumable.

Número de informantes: 3 Partes utilizadas: hojas.

Foglie secche e macinate, fumate come il tabacco (CRI)| Si usava la foglia secca di noce per fare le sigarette. (REN)| Le foglie di noce secche si usavano come surrogato delle sigarette. Venivano essicate, trinciate e fumate. (RFR).

Categoría de uso: Instrumentos musicales.

Número de informantes: 1 Partes utilizadas: tallos leñosos/ramas/ramitas/vástagos.

A primavera, si separa la corteccia dal legno e facendo dei buchi sulla corteccia si faceva un flauto. Tagliando la corteccia elicoidalmente e impostandola como un trombo si suonava il trombo. (TUL).

\section{Sector mágico/ritual/supersticioso}

Categoría de uso: Efecto negativo.

Número de informantes: 1 Partes utilizadas: planta entera/viva.

"Non bisogna stare all' ombra del nocce che fa male" (CLO).

Categoría de uso: Protector.

Número de informantes: 2 Partes utilizadas: planta entera/viva.

Per tenere lontane le streghe: si piantava un coltello sul tronco del noce e si credeva che le streghe andando sul noce, poi non potessero più scendere a causa del coltello (REN, GGI).

\section{Sector medicinal}

Categoría de uso: Afecciones cutáneas y tejidos subcutáneos.

Número de informantes: 1 Partes utilizadas: madera.

Mettere sulla pelle arrossata il trinciato del legno che fa il tarlo, asciuga l'umidità. (MGO).

Categoría de uso: Estado general.

Número de informantes: 1 Partes utilizadas: semillas.

Mettere a seccare all'ombra tutti I "semi della vita": semi delle ciliege, delle susine ossia le prugne gialle, di zucca, I pinoli, le noci, le culloie o nocciole, le foglie di malva secche, il fiore del gigliopapagone e anche un pò di olio di semi di lino. Poi macinare tutto con il macinino da caffé. E prendere un cucchiaio tutte le mattine a primavera e a ottobre. (VMU).

Categoría de uso: Patologías del aparato digestivo.

Número de informantes: 4 Partes utilizadas: frutos/infrutescencias/falsos frutos,. Prendere 30 noci (mallo verde, quando dentro non è ancora fatto), 1 litro e mezzo di alcol, 750 gr di zucchero, 2 grammi di cannella reggina trittati, 10 chiodi di garofano, 4 litri di acqua, la buccia del limone. Lasciare macerare per 40 giorni al buio o alla penombra in cantina,e filtrare. (AN3)| Il nocino: raccogliere il 24 Giugno 19 noci verdi, spaccarle in due. Mettere in infusione un litro di Alcol 90 gradi per 40 giorni. Poi fare lo sciroppo: fare bollire $800 \mathrm{ml}$ d'acqua e scioglere $400 \mathrm{gr}$ di zucchero. Filtrare le noci e mescolare lo sciroppo all'acqua delle noci. Bere dopo un mese. Servire dopo i pasti come digestivo. foto. (BSO)| Arrostita sulle bracce, e 
mangiarne 1 o 2 (CRI)| Bere il nocino dopo I pasti per digerire, fa bene al fegato. (VFR).

Notas "invece di tè e biscotti" la sera si prendeva questo spuntino per la veglia prima di andare al letto. Vanno raccolte con la buccia, che non sia rotta, si rompeva male, e si mangiavano così, Raccogliere 21 noci prese verso il 24 giugno,Raccogliere le noci a San Giovanni. Il tarlo trincia il legno dell'abete anche.Raccogliere 21 noci prese verso il 24 giugno, Raccogliere 21 noci prese verso il 24 giugno, Raccogliere 7 o 8 noci con il mallo attaccato per la vigilia di san Giovanni (23 giugno) Raccogliere le noci a San Giovanni,Raccogliere le noci a San Giovanni,Raccogliere le noci acerbe, verdi, a fine luglio o agosto,Vanno raccolte con la buccia, che non sia rotta, si rompeva male, e si mangiavano così.'Non coltivate niente sotto il fico e il noce".

\section{DATOS ETNOBOTÁNICOS BIBLIOGRÁFICOS}

Nombre vulgar: noce (MANG98, SANS14), nùs,nûl pêfga (UNGA21), noci (GUC98, BADI15), bócco (BONZI00), No'se (APPO10), nós` (BER81), culóra (GUC98).

Número de referencias: 8 Número de citas: 13.

Número de sectores: 3 Número de categorías: 7.

\section{Sector alimentario}

Categoría de uso: Licor.

Número de referencias: 2 Partes utilizadas: frutos/infrutescencias/falsos frutos.

(SANS14)| Il mallo di noce è impiegato in liquoreria. (UNGA21).

Categoría de uso: Otro alimentario.

Número de referencias: 1 Partes utilizadas: semillas.

Il castagnaccio. Ingredienti: Farina di castagne,olio,noci o pinoli,sale. Si pone le farina di castagne in una terrina,vi aggiunge un po' $d$ 'olio extravergine d'oliva,un pizzico di sale,e acqua poco per volta mentre si rimescola con una frusta fino ad ottenere una crema molto tenera.Vi si aggiungono noci tritate o pinoli.Si unge poi una teglia e si versa la pastella facendone uno strato dello spessore di $2 \mathrm{~cm}$. Si pone la teglia nel forno ad una temperature di $180^{\circ}$ e la si lascia per mezz'ora,o fino a che non si vede che la superficie è asciutta e tutta screpolata. (BADI15).

\section{Sector lúdico/voluptuoso}

Categoría de uso: Juego colectivo y bromas.

Número de referencias: 2 Partes utilizadas: frutos/infrutescencias/falsos frutos.

Il bócco è una grossa noce per tirare a un mucchietto di castagne in un gioco infantile (BONZI00)| La papa è un gioco infantile fatto con le palline o con le noci. Si disponevano in fila e la prima a sinistra era il papa. Se veniva colpita dal bòcco, si vincevano tutte le altre. (GUC98).

\section{Sector medicinal}

Categoría de uso: Afecciones del metabolismo.

Número de referencias: 1 Partes utilizadas: hojas.

Le foglie, in infusione se fresche, decotte circa cinque minuti se secche, forniscono un 'acqua' efficace in caso di diabete. (MANG98). 
Categoría de uso: Dolor de cabeza.

Número de referencias: 1 Partes utilizadas: hojas.

Lo stesso preparato si ritiene utile per combattere il mal di testa. (MANG98).

Categoría de uso: Otro medicinal.

Número de referencias: 1 Partes utilizadas: frutos/infrutescencias/falsos frutos.

Gi antichi colle noci, cipolla e sale facevano un impiastro contro il morso del cane rabbioso. Dice il proverbio: pan e nul magnaer da spuf, forse dal sparge, marite, nuces ecc (UNGA21).

Categoría de uso: Patologías del aparato digestivo.

Número de referencias: 2 Partes utilizadas: frutos/infrutescencias/falsos frutos.

I malli ancora immaturi vengono fatti macerare nel vino rosso per una quarantina di giorni, una volta filtrato il cosiddetto 'nocino'viene bevuto come gradevole digestivo. (MANG98)| Nella medicina popolare si adopera il succo del mallo come astringente. (UNGA21).

Notas Pèn e nós magné da spós (Pane e noci mangiare da sposi, Castel di Casio).

\section{JUNCACEAE}

\section{Juncus inflexus $\mathrm{L}$.}

Nombre vulgar: Giunco (TAD, GFR, MRI, MOR, GGL, BPA), Giunchi, vinchi (NLA).

Número de informantes: 7 Número de citas: 8.

Número de sectores: 3 Número de categorías: 3 .

Biotipo: Hemicriptófito.

Tipo corológico: Europeas.

Abundancia: Común.

Ambiente: Pantanos, zanjas, prados húmedos.

Número de exsiccata: 39119 FIAF, 38971 FIAF, 39118 FIAF, 38971 FIAF.

Sector agropastoral

Categoría de uso: Cuerdas y ataduras.

Número de informantes: 4 Partes utilizadas: tallos herbáceos/escapos, hojas.

Il giunco inumidito per legare i pomodori e la vite (BPA)| Per legare i pomodori e la vite (GGL)| Il giunco si adoperava per legare I pomodori e la vite (MOR)| Si intrecciavano per fare delle corde per legare le fascine di legna (MRI).

Sector artesanal

Categoría de uso: Tejer sillas.

Número de informantes: 3 Partes utilizadas: tallos herbáceos/escapos.

Per fare intrecciature, si facevano seccare e poi venivano invinchiti, cioè messi a mollo per impagliare (NLA)| Per impagliare le sedie si intrecciavano insieme scarza e giunco. Il giunco si faceva seccare e poi si bagnava prima di usarlo. (GFR)| Per impagliare le sedie si intrecciavano scarza e giunco, ma il giunco regge meno. (TAD). 
Sector doméstico

Categoría de uso: Objetos domésticos y escobas.

Número de informantes: 1 Partes utilizadas: tallos herbáceos/escapos.

Si facevano dei cestini piccolini provisori per raccogliere I frutti del sottobosco. (MRI).

Notas Ora ce n'è molto meno, perché I suoi habitat sono cambiati per l'abbandondo dell'uomo..sparita per la vegetazione invasiva. Anche se non dura nel tempo, facevano come I cesti di vimini.

40. LAMIACEAE (= LABIATAE)

\section{Clinopodium nepeta (L.) Kuntze subsp. glandulosum (Req.) Govaerts (= Calamintha nepeta (L.) Savi)}

Nombre vulgar: Empitella selvatica (VMU), Empitella (BFE, BBA), L'empitella (NRO),

Nepetella (LST, TAD, REN, PIM, PEL, NLA, DAD, BIO), Pipitella (MGO).

Número de informantes: 13 Número de citas: 14.

Número de sectores: 2 Número de categorías: 3.

Biotipo: Hemicriptófito.

Tipo corológico: Montañosas.

Abundancia: Bastante Común.

Ambiente: Prados áridos, baldíos, muros.

Número de exsiccata: 39004 FIAF.

Sector agropastoral

Categoría de uso: Apicultura.

Número de informantes: 1 Partes utilizadas: parte aérea (toda).

Quando sciamma un alveare, prima di introdurre il nuovo, si puliscono le arnie:"gli si da gli odori": si prende il timo previamente seccato all'ombra, insieme alla salvia, al rosmarino, e all'empitella selvatica e si spazzola l'arnia con questo composto dentro alle pareti. (VMU).

\section{Sector alimentario}

Categoría de uso: Aromatizante.

Número de informantes: 12 Partes utilizadas: hojas, parte aérea (toda).

Per aromatizzare i funghi. (TAD, BBA)| Per aromatizzare le minestre, I funghi e le zucchine (BFE)| Per aromatizzare I funghi. (NLA, VMU)| Per insaporire I funghi (NRO)| Per aromatizzare i funghi (PEL, BIO)| Per insaporire i funghi sotto olio, insieme a pepe e una foglia di alloro (DAD)| Mettere un po' di foglie di nepetella nelle zucche o nei funghi (PIM)| Per aromatizzare I funghi (MGO, REN).

Categoría de uso: Relleno de ravioli.

Número de informantes: 1 Partes utilizadas: hojas.

Per fare il ripieno dei tortelli si metteva la ricotta di pecora, il parmigiano, la nepetella o il prezzemolo e le uova (LST). 
Etnobotánica en el Alto Valle del Reno (Toscana y Emilia-Romaña, Italia)

Notas "Non ce ne più tanta, per nei castagneti non ci arriva più luce, ne area, e le bestie mangiano tutto".

DATOS ETNOBOTÁNICOS BIBLIOGRÁFICOS

Nombre vulgar: impitella, empitella (MANG98), nepetella (SANS14), empitèlla (BONZI00).

Número de referencias: 3 Número de citas: 5.

Número de sectores: 2 Número de categorías: 4.

\section{Sector alimentario}

Categoría de uso: Aromatizante.

Número de referencias: 1 Partes utilizadas: hojas.

Le foglie fresche o essiccate, servono ad aromatizzare i funghi sott'olio (MANG98).

Categoría de uso: Ensalada.

Número de referencias: 1 Partes utilizadas: hojas (SANS14).

Sector medicinal

Categoría de uso: Afecciones típicas infantiles.

Número de referencias: 1 Partes utilizadas: hojas.

Il succo della pianta fresca o il suo decotto, vengono somministrati ai bimbi affetti da acetone,i (MANG98).

Categoría de uso: Patologías del aparato digestivo.

Número de referencias: 1 Partes utilizadas: hojas.

1 decotto viene bevuto in caso di verminosi e di altre affezioni intestinali (MANG98).

\section{Lavandula angustifolia Mill.}

Nombre vulgar: Lavanda (GAN, VMR, VAL, PEL, LRE, GLA, GFR, GCL, BEL, BBA, PGI), Spigo (BFE).

Número de informantes: 12 Número de citas: 12 .

Número de sectores: 2 Número de categorías: 2.

Biotipo: Nanofanerófito.

Tipo corológico: Esteno-mediterránea.

Abundancia: Rara.

Ambiente: Maquias bajas y jarales (ácidos).

Sector agropastoral

Categoría de uso: Apicultura.

Número de informantes: 1 Partes utilizadas: flores/inflorescencias y sus partes.

Si coltivavano le lavande per le api (PGI).

\section{Sector doméstico}

Categoría de uso: Ambientador.

Número de informantes: 11 Partes utilizadas: flores/inflorescencias y sus partes. Mettere in sacchetti di stoffa (I sacchetti delle bomboniere, dei confetti) e mettere nella biancheria (BBA)| Si metteva la lavanda secca in un secchio in casa per profumare l'ambiente. (VAL, BEL)| Sacchettini per profumare la biancheria (GCL)| 
Fiori messi in sacchettini per profumare gli armadi (GFR)| Fare mazzetti e metterli nella biancheria per profumarla (GLA)| Mettere a seccare i fiori di lavanda, fare dei sacchettini e mettere dentro alla biancheria. (LRE)| Si coltiva la lavanda, si fa seccare e si mette dentro agli armadi per profumare la biancheria. (PEL)| Mettere la lavanda secca in dei sacchettini nei armadi per profumare la biancheria (VMR)| I fiori secchi messi in dei sacchettini per profumare la biancheria (GAN)| La nonna lo metteva negli armadi per profumare. (BFE).

Notas Quando veniva il dottore, si muovevano I fiori secchi nel secchio per profumare.

l'ambiente., La varietà che usava la sua nonna è una varietà selvatica,è un cespuglio però non 1 'ha mai vista.

DATOS ETNOBOTÁNICOS BIBLIOGRÁFICOS

Nombre vulgar: lavandla (UNGA21).

Número de referencias: 1 Número de citas: 3 .

Número de sectores: 2 Número de categorías: 3.

Sector doméstico

Categoría de uso: Ambientador.

Número de referencias: 1 Partes utilizadas: No especificado.

spico, lavanda, p. odorosa. Una delle erbe di S. Giovanni, cui si attribuisce virtù contro I malefici. Il pop. L'acquista in questo giorno per metterne I rametti fra la biancheria. Nella medicina popolare è ritenuta vermifuga e ne viene usato l'infuso come tonico e antispasm. (UNGA21).

\section{Sector medicinal}

Categoría de uso: Afecciones típicas infantiles.

Número de referencias: 1 Partes utilizadas: No especificado.

spico, lavanda, p. odorosa. Una delle erbe di S. Giovanni, cui si attribuisce virtù contro I malefici. Il pop. L'acquista in questo giorno per metterne I rametti fra la biancheria. Nella medicina popolare è ritenuta vermifuga e ne viene usato l'infuso come tonico e antispasm.(UNGA21).

Categoría de uso: Estado general.

Número de referencias: 1 Partes utilizadas: No especificado.

spico, lavanda, p. odorosa. Una delle erbe di S. Giovanni, cui si attribuisce virtù contro I malefici. Il pop. L'acquista in questo giorno per metterne I rametti fra la biancheria. Nella medicina popolare è ritenuta vermifuga e ne viene usato l'infuso come tonico e antispasm.(UNGA21).

\section{Melissa officinalis $L$.}

Nombre vulgar: Melissa (NST, GGI).

Número de informantes: 2 Número de citas: 2.

Número de sectores: 1 Número de categorías: 2 .

Biotipo: Hemicriptófito.

Tipo corológico: Eurimediterránea.

Abundancia: Rara. 
Ambiente: Baldíos, ruinas, a menudo cultivados y asilvestrados.

Sector medicinal

Categoría de uso: Patologías del aparato circulatorio.

Número de informantes: 1 Partes utilizadas: parte aérea (toda).

Bere spesso l'acqua di melissa ossia il decotto di melissa. (GGI).

Categoría de uso: Patologías del aparato digestivo.

Número de informantes: 1 Partes utilizadas: hojas.

Fare l'infuso di menta, melissa e salvia con un po' di limone per digerire meglio. (NST).

\section{DATOS ETNOBOTÁNICOS BIBLIOGRÁFICOS}

Nombre vulgar: melissa, erba limone (SANS14), calamainta (UNGA21), melissa (MANG98), limonina (GUC98).

Número de referencias: 4 Número de citas: 5 .

Número de sectores: 2 Número de categorías: 3 .

\section{Sector alimentario}

Categoría de uso: Aromatizante.

Número de referencias: 1 Partes utilizadas: hojas (SANS14).

\section{Sector medicinal}

Categoría de uso: Patologías del aparato digestivo.

Número de referencias: 1 Partes utilizadas: hojas.

...nella med. Pop. Si fanno bollire le foglie in infuso succedaneo a quello della melissa, v. Erba limauna. (UNGA21).

Categoría de uso: Patologías del sistema nervioso.

Número de referencias: 2 Partes utilizadas: hojas.

Viene bevuto anche più volte al giorno e sempre la sera prima di coricarsi (MANG98) $\mid$...nella med. Pop. Si fanno bollire le foglie in infuso succedaneo a quello della melissa, v. erba limauna. (UNGA21).

\section{Mentha spicata L. (s.l.)}

Nombre vulgar: (NLA)Menta (NMA, GLA), Menta selvatica (MGE, AN3), Menta. (NST, BIO, PIM, BLI, RMA).

Número de informantes: 10 Número de citas: 11.

Número de sectores: 3 Número de categorías: 7.

Biotipo: Hemicriptófito.

Tipo corológico: n.d.

Abundancia: Común.

Ambiente: Baldíos, márgenes de las carreteras, prados, barrancos, lugares húmedos. Número de exsiccata: 38895 FIAF.

Sector alimentario

Categoría de uso: Aromatizante.

Número de informantes: 1 Partes utilizadas: hojas.

Mettere la menta selvatica negli arrosti per aromatizzare (GLA). 
Categoría de uso: Licor.

Número de informantes: 2 Partes utilizadas: hojas.

"il mentarello" (NMA)| Liquore Cent'erbe della Nonna: 5 o 6 foglie di salvia, 5 o 6 foglie di Basilico, una bustina di te (una volta lo vendevano sciolto in bottega), germogli di pino, rosmarino e menta selvatica. 1 etto zucchero, 1 etto di alcol, 1 etto di acqua. Lasciare tutto sotto alcol per 21 giorni. Bollire lo zucchero e l'acqua e passare tutto e mescolare. (AN3).

Sector doméstico

Categoría de uso: Cuidado personal y cosmética.

Número de informantes: 1 Partes utilizadas: hojas.

Le foglie si strofinavano per profumarsi un po', e si mettevano anche sotto Il braccio come.

deodorante quando si andava a messa per esempio (NLA).

Categoría de uso: Detergente.

Número de informantes: 1 Partes utilizadas: hojas.

Per fare il bucato si bolliva l'acqua e si metteva dentro un ramo di menta selvatica per.

profumare i panni. (RMA).

Sector medicinal

Categoría de uso: Afecciones del aparato respiratorio.

Número de informantes: 2 Partes utilizadas: hojas.

Mettere nell'acqua bollente foglie di salvia con rosmarino e menta e fare inalazioni con la testa sopra la pentola con l'acqua coperti da un asciugamano. (BLI)| Fare le fumenti con la menta selvatica per il raffreddore (MGE).

Categoría de uso: Patologías del aparato circulatorio.

Número de informantes: 2 Partes utilizadas: hojas.

La sera prendere un decotto di foglie di menta. (PIM)| Mettere la foglia direttamente sopra le.

emorroidi, sfiammava, rinfrescava. (NLA).

Categoría de uso: Patologías del aparato digestivo.

Número de informantes: 2 Partes utilizadas: hojas.

Si fa bollire la pianta e si beve. (BIO)| Fare l'infuso di menta, melissa e salvia con un po' di.

limone per digerire meglio. (NST).

Notas ricette tramandate dalle nonna e dalla mamma. La sua nonna lo faceva con la grappa.

invece dell'alcol, che loro stessi distillavano con le vinacce dell'uva.,.

DATOS ETNOBOTÁNICOS BIBLIOGRÁFICOS

Nombre vulgar: menta (SANS14).

Número de referencias: 1 Número de citas: 3 .

Número de sectores: 2 Número de categorías: 3 .

Sector alimentación.

Categoría de uso: Aromatizante. 
Número de referencias: 1 Partes utilizadas: hojas (SANS14).

Categoría de uso: Licor.

Número de referencias: 1 Partes utilizadas: hojas (SANS14).

Sector medicinal

Categoría de uso: Patologías del aparato digestivo.

Número de referencias: 1 Partes utilizadas: hojas (SANS14).

\section{Mentha $x$ piperita $L$.}

Nombre vulgar: Menta (LGI, BEL).

Número de informantes: 2 Número de citas: 2.

Número de sectores: 1 Número de categorías: 2 .

Biotipo: Hemicriptófito.

Tipo corológico: Cultivadas.

Abundancia: Cultivada.

Ambiente: Cultivada.

Sector medicinal

Categoría de uso: Afecciones del aparato respiratorio.

Número de informantes: 1 Partes utilizadas: hojas.

Fare dei fumenti di timo, foglie e gemme di pino, origano e menta (coltivata). È da 20 anni.

che coltiva la menta e non si perde più. (BEL).

Categoría de uso: Patologías del aparato digestivo.

Número de informantes: 1 Partes utilizadas: hojas.

Raccogliere la menta, metterla seccare per l'inverno, poi farla bollire poco e bere. (LGI).

DATOS ETNOBOTÁNICOS BIBLIOGRÁFICOS

Nombre vulgar: menta (MANG98).

Número de referencias: 1 Número de citas: 3.

Número de sectores: 1 Número de categorías: 2 .

\section{Sector medicinal}

Categoría de uso: Patologías del aparato digestivo.

Número de referencias: 1 Partes utilizadas: hojas.

Assunto tiepido dopo i pasti miligliori la digestione. (MANG98).

Categoría de uso: Patologías del sistema nervioso.

Número de referencias: 1 Partes utilizadas: hojas.

La menta è ritenuta sedativo ancora più efficace della camomilla, si ritiene infatti che mentre la camomilla a lungo andare risulti eccitante, la menta può essere bevuta anche ogni sera mantenendo comunque il suo effetto calmante. (MANG98)| Alcuni ritengono inoltre che l'infuso di menta sia utile per combattere il mal di mare e le vertigini.(MANG98). 


\section{Ocimum basilicum $L$.}

Nombre vulgar: Basilico (TUL, RMA, LST, BSI, BBI, AN3, CRO).

Número de informantes: 7 Número de citas: 8.

Número de sectores: 2 Número de categorías: 4.

Biotipo: Terófito.

Tipo corológico: Cultivadas.

Abundancia: Cultivada.

Ambiente: Jardines y huertos.

\section{Sector alimentario}

Categoría de uso: Aromatizante.

Número de informantes: 1 Partes utilizadas: hojas.

Tutti coltivano Il basilico, si secca e si mette nel pomodoro per la pasta o nelle minestre. Lei lo vende anche secco nella sua bottega attualmente (CRO).

Categoría de uso: Licor.

Número de informantes: 5 Partes utilizadas: hojas.

Liquore Cent'erbe della Nonna: 5 o 6 foglie di salvia, 5 o 6 foglie di Basilico, una bustina di te (una volta lo vendevano sciolto in bottega), germogli di pino, rosmarino e menta selvatica. 1 etto zucchero, 1 etto di alcol, 1 etto di acqua. Lasciare tutto sotto alcol per 21 giorni. Bollire lo zucchero e l'acqua e passare tutto e mescolare. (AN3)| Mettere a macerare un chilo di zucchero, una manciata di foglie di basilico, la buccia di un limone, un litro di alcol, lasciare a riposare 40 giorni e filtrare. (BSI, BBI)| Tutti facevano il liquore di basilico come digestivo: 150 foglie di basilico a macerare in un litro di alcol per 3 giorni. Poi fare lo sciropo di $1 \mathrm{~kg}$ di zucchero per 1 $\mathrm{kg}$ di acqua. Filtrare le foglie e aggiungere lo sciroppo. Poi imbottigliare e si bevevano dopo cena quando si è con gli amici. (LST)| Mettere a macerare un chilo di zucchero, una manciata di foglie di basilico, la buccia di un limone, un litro di alcol. Lasciare riposare 40 giorni e filtrare. (RMA).

\section{Sector medicinal}

Categoría de uso: Afecciones oro-faríngeas y de la cavidad oral.

Número de informantes: 1 Partes utilizadas: hojas.

Bollire 7 foglie e fare sciacqui per 2 o 3 giorni. (TUL).

Categoría de uso: Patologías del aparato digestivo.

Número de informantes: 1 Partes utilizadas: hojas.

Tutti facevano il liquore di basilico come digestivo: 150 foglie di basilico a macerare in un litro di alcol per 3 giorni. Poi fare lo sciropo di $1 \mathrm{~kg}$ di zucchero per 1 $\mathrm{kg}$ di acqua. Filtrare le foglie e aggiungere lo sciroppo. Poi imbottigliare e si bevevano dopo cena quando si è con gli amici. (LST).

Notas ricette tramandate dalle nonna e dalla mamma. La sua nonna lo faceva con la grappa invece dell'alcol, che loro stessi distillavano con le vinacce dell'uva.

DATOS ETNOBOTÁNICOS BIBLIOGRÁFICOS

Nombre vulgar: bafalecc (UNGA21), basilico (MANG98).

Número de referencias: 2 Número de citas: 3 .

Número de sectores: 3 Número de categorías: 3 . 


\section{Sector mágico/medicinal}

Categoría de uso: Otro mágico/medicinal.

Número de referencias: 1 Partes utilizadas: órganos subterráneos.

Gli si attribuisce virtù di agevolare il parto, solo a tenerne indosso la radice. (UNGA21).

\section{Sector mágico/ritual/supersticioso}

Categoría de uso: Efecto negativo.

Número de referencias: 1 Partes utilizadas: parte aérea (toda).

avevano opinione I med. Antichi e si crede anche oggi fra il volgo che ad annasarlo faccia nascere nel cervello vermetti simili agli scorpioni, e ciò per l'acuto dolore di capo che ingenera l'odore di quest'erba. (UNGA21).

\section{Sector medicinal}

Categoría de uso: Dolor de cabeza.

Número de referencias: 1 Partes utilizadas: hojas.

L'infuso viene bevuto per combattere il mal di testa. (MANG98).

Notas Vuolsi che il basilico creca più alto e rigoglioso seminandolo con ingiurie maledizioni.

\section{Origanum vulgare $L$.}

Nombre vulgar: Origano (GUF).

Número de informantes: 1 Número de citas: 1.

Número de sectores: 1 Número de categorías: 1 .

Biotipo: Hemicriptófito.

Tipo corológico: Europeas.

Abundancia: Común.

Ambiente: Bosques ralos, arbustos, acantilados soleados.

Sector alimentario

Categoría de uso: Aromatizante.

Número de informantes: 1 Partes utilizadas: flores/inflorescencias y sus partes.

Come aromatizzante dei piatti (GUF).

\section{DATOS ETNOBOTÁNICOS BIBLIOGRÁFICOS}

Nombre vulgar: mazurœna salvâdga (UNGA21).

Número de referencias: 1 Número de citas: 1 .

Número de sectores: 1 Número de categorías: 1 .

\section{Sector alimentario}

Categoría de uso: Aromatizante.

Número de referencias: 1 Partes utilizadas: parte aérea (toda).

foglie adoperate in addietro spec. a condire le acciughe,percio detta ancora erba da acciughe, acciughero. (UNGA21). 


\section{Rosmarinus officinalis $L$.}

Nombre vulgar: Rosmarino (TGA, VMR, GLA, CBR, BLI, NST, AN3, SCO, MOR, LST, GUF, DAD, CLO, BBA, VMU).

Número de informantes: 15 Número de citas: 18.

Número de sectores: 3 Número de categorías: 9.

Biotipo: Nanofanerófito.

Tipo corológico: Esteno-mediterránea.

Abundancia: Común.

Ambiente: Maquias y garrigas (calcáreas).

\section{Sector agropastoral}

Categoría de uso: Apicultura.

Número de informantes: 1 Partes utilizadas: parte aérea (toda).

Quando sciamma un alveare, prima di introdurre il nuovo, si puliscono le arnie:"gli si da gli odori": si prende il timo previamente seccato all'ombra, insieme alla salvia, al rosmarino, e all'empitella selvatica e si struscia l'arnia con questo composto dentro alle pareti, come spazzandola. (VMU).

\section{Sector alimentario}

Categoría de uso: Aromatizante.

Número de informantes: 7 Partes utilizadas: parte aérea (toda), hojas, tallos.

Per aromatizzare I funghi arrosti, insieme all'aglio (BBA)| Per aromatizzare gli arrosti insieme alla Salvia (CLO)| Per insaporire i funghi sotto olio, insieme a pepe e una foglia di alloro (DAD)| Aglio, salvia e rosmarino, tutto trittato per aromatizzare gli arrosti (GUF)| Con la farina di castagne, rosmarino e pinoli si faceva il castagnaccio. (LST)| Mettere delle foglie di salvia e rosmarino nella conserva di pomodoro: 1. Bollire I pomodori passarli. 2. Scollarli in un telo. 3. Aggiungere l'acido salicilico che si comprava in farmacia e salvia e rosmarino 4. Ribollire con il sale. 5. Mettere in forno finché non diventa densa. Poi usare una cucchiata di conserva nelle minestre, come concentrato di pomodoro. (MOR)| Aromatizzare il castagnaccio, mettere alla fine sopra. (SCO).

Categoría de uso: Licor.

Número de informantes: 2 Partes utilizadas: parte aérea (toda).

Liquore Cent'erbe della Nonna: 5 o 6 foglie di salvia, 5 o 6 foglie di Basilico, una bustina di te (una volta lo vendevano sciolto in bottega), germogli di pino, rosmarino e menta selvatica. 1 etto zucchero, 1 etto di alcol, 1 etto di acqua. Lasciare tutto sotto alcol per 21 giorni. Bollire lo zucchero e l'acqua e passare tutto e mescolare. (AN3) Cento erbe': 3 foglie di alloro, 3 foglie di limone, 3 coccole di ginepro, 3 fiori di camomilla, 3 foglie di té, 3 foglie di salvia, 3 foglie di rosmarino, mettere a macerare in un litro di acqua bollita con 350 gr di zucchero e a cui siano stati poi aggiunti 40 gr di alcol a $90^{\circ}$. (NST).

Sector medicinal

Categoría de uso: Afecciones del aparato respiratorio.

Número de informantes: 3 Partes utilizadas: parte aérea (toda). 
Mettere nell'acqua bollente foglie di salvia con rosmarino e menta e fare inalazioni con la testa sopra la pentola con l'acqua coperti da un asciugamano. (BLI)| Fare dei fumenti, mettendo le foglie di salvia e rosmarino nell'acqua bollente per il raffreddore (CBR)| Fare I fumenti con la radice di regolizia, I fiori di sambuco, il rosmarino e la salvia. (GLA).

Categoría de uso: Afecciones oro-faríngeas y de la cavidad oral.

Número de informantes: 1 Partes utilizadas: parte aérea (toda).

Bere il decotto di Salvia e Rosmarino per il mal di denti (SCO).

Categoría de uso: Estado general.

Número de informantes: 1 Partes utilizadas: parte aérea (toda).

Fare l'infuso delle foglie di rosmarino, salvia, piscialletto (prima del fiore) e malva, si beveva a diguino la mattina e la sera per 10/15 giorni. (VMR).

Categoría de uso: Patologías del aparato digestivo.

Número de informantes: 1 Partes utilizadas: parte aérea (toda).

Bere l'infuso di rosmarino e salvia per digerire (VMR).

Categoría de uso: Patologías del aparato urinario.

Número de informantes: 1 Partes utilizadas: parte aérea (toda).

Bere il decotto di Salvia e Rosmarino per l'infiammazione di orina (SCO).

Categoría de uso: Trastornos musculo-esqueléticos.

Número de informantes: 1 Partes utilizadas: parte aérea (toda).

Bollire le coccole di zinepre con rosmarino nel vino e strofinare sul ginocchio dolente o sulla.

parte contusa (TGA).

Notas ricette tramandate dalle nonna e dalla mamma. La sua nonna lo faceva con la grappa.

invece dell'alcol, che loro stessi distillavano con le vinacce dell'uva.

\section{DATOS ETNOBOTÁNICOS BIBLIOGRÁFICOS}

Nombre vulgar: rosmarino (BADI15, SANS14), romarino (GRIZ03), ufmaren (UNGA21), rosmarino, tremarino (MANG98), Rasmarìn (APPO10), Smarìn (APPO10), osmarìn (BENE96), ramerino (BONZI00).

Número de referencias: 8 Número de citas: 14.

Número de sectores: 2 Número de categorías: 7.

Sector alimentario

Categoría de uso: Aromatizante.

Número de referencias: 3 Partes utilizadas: hojas, frutos/infrutescencias/falsos frutos (SANS14).

Costine di maiale e di agnello al forno: $1 \mathrm{~kg}$ di costine, $1 \mathrm{~kg}$ di patate, 1 foglia di alloro, rosmarino, ginepro, olio, sale, pepe. Mettere le costine in una teglia che possa andare in tavola, accomodate in un solo strato e non troppo vicine le une alle altre. Copritele con le patate che nel frattempo avete preparato lavate, sbucciate e fatte a quarti. Irrorate con un filo d'olio. Il grasso delle costine sciogliendosi sarà sufficiente come condimento. Salate e pepate generosamente. Cospargete di rosmarino e lauro spezzettato. Mettete le bacche di ginepro in un pezzo di carta robusta, ripiegatela e pestate con un batticarne in modo da spaccarle grossolanamente. Sparpagliatele sulle patate, mettete il coperchio e coprite con stagnola, sigilando bene attorno ai bordi. 


\section{María Teresa Egea Molines}

Infornate in forno già caldo e portate a cottura. Quando costine e patate saranno pronte, togliete il coperchio, alzate il forno al massimo, o meglio ancora, accendete gli infrarossi e lasciate dorare, scuotendo ogni tanto la teglia perché la doratura possa avvenire uniformemente. (GRIZ03)| Costolette di maiale in umido. Ingredienti:Costolette di maiale a pezzetti,aglio,rosmarino,alloro,salsa concentrata di pomodoro,vino bianco,sale e pepe.Si fanno soffriggere a fuoco lento le costolette con rosmarino aglio ed una foglia di alloro.Se si vuole un piatto meno pesante si scola il grasso della frittura e si sostituisce con olio.Si aggiungono sale e pepe ed un po' di vino bianco,che si lascia sfumare.Si pone quindi la salsadi pomodoro diluita con acqua e si lascia terminare la cottura,aggiungendo eventualmente un po' di brodo di dado, se il liquido del tegame non fosse sufficiente.Badare che il sugo resti piuttosto denso.Si servono con tigelle o polenta. (BADI15).

Categoría de uso: Licor.

Número de referencias: 1 Partes utilizadas: hojas (SANS14).

Sector medicinal

Categoría de uso: Afecciones del aparato respiratorio.

Número de referencias: 1 Partes utilizadas: hojas (SANS14).

Categoría de uso: Estado general.

Número de referencias: 2 Partes utilizadas: parte aérea (toda), hojas.

Nella pratica familiare, usano le donne bollirlo per far bianca la pelle e buono il fiato. (UNGA21)| Il macerato delle foglie nel vino bianco viene bevuto come rinforzante organico. (MANG98).

Categoría de uso: Patologías del aparato circulatorio.

Número de referencias: 1 Partes utilizadas: hojas.

L'infuso delle sole foglie viene bevuto "per mandare in acqua il sangue grosso", ovvero per diminuire un elevato tasso pressorio. (MANG98).

Categoría de uso: Patologías del aparato digestivo.

Número de referencias: 1 Partes utilizadas: hojas (SANS14).

Categoría de uso: Patologías del sistema nervioso.

Número de referencias: 1 Partes utilizadas: parte aérea (toda).

Un infuso misto di rosmarino e salvia viene ritenuto ottimo sedativo in caso di ansia o di.

agitazione. (MANG98).

\section{Salvia officinalis $L$.}

Nombre vulgar: Salvia (PIM, BBI, BIO, TGA, SCO, PEL, NDI, MCL, CFR, MSI, GLA, GGI, CBR, BLI, RNI, NST, BAZ, AN3, BGI, SLU, NRO, MOR, GUF, DAD, CLO, VMU), Salvia, "la pianta della vita" (cultura celta) (VMR).

Número de informantes: 27 Número de citas: 45.

Número de sectores: 4 Número de categorías: 11.

Biotipo: Caméfito.

Tipo corológico: Esteno-mediterránea.

Abundancia: Cultivada. 
Ambiente: Acantilados áridos y pedregales (calcáreos), cultivados en huertos y jardines.

Sector agropastoral

Categoría de uso: Apicultura.

Número de informantes: 1 Partes utilizadas: parte aérea (toda).

Quando sciamma un alveare, prima di introdurre il nuovo, si puliscono le arnie:"gli si da gli odori": si prende il timo previamente seccato all'ombra, insieme alla salvia, al rosmarino, e all'empitella selvatica e si struscia l'arnia con questo composto dentro alle pareti, come spazzandola. (VMU).

\section{Sector alimentario}

Categoría de uso: Aromatizante.

Número de informantes: 6 Partes utilizadas: hojas.

Per aromatizzare gli arrosti inieme al Rosmarino (CLO)| Per insaporire i funghi sotto olio, insieme a pepe e una foglia di alloro (DAD)| Per insaporire il brodo di faggioli per fare "pasta e faggioli",con olio, aglio pepe e due foglie che alla fine si levano e minestra di faggioli. (DAD) $\mid$ Aglio, salvia e rosmarino, tutto trittato per aromatizzare gli arrosti (GUF)| Mettere delle foglie di salvia e rosmarino nella conserva di pomodoro: 1. Bollire I pomodori passarli. 2. Scollarli in un telo. 3. Aggiungere l'acido salicilico che si comprava in farmacia e salvia e rosmarino 4. Ribollire con il sale. 5. Mettere in forno finché non diventa densa. Poi usare una cucchiata di conserva nelle minestre, come concentrato di pomodoro. (MOR)| Per aromatizzare gli arrosti (SLU, NRO)| Per cucinare I fagioli in umido. (NRO)| La salvia si mette nell'arrosto per aromatizzare (SLU).

Categoría de uso: Fritura.

Número de informantes: 1 Partes utilizadas: hojas.

Foglie impanate e fritte (BGI).

Categoría de uso: Licor.

Número de informantes: 3 Partes utilizadas: hojas.

Liquore Cent'erbe della Nonna: 5 o 6 foglie di salvia, 5 o 6 foglie di Basilico, una bustina di te (una volta lo vendevano sciolto in bottega), germogli di pino, rosmarino e menta selvatica. 1 etto zucchero, 1 etto di alcol, 1 etto di acqua. Lasciare tutto sotto alcol per 21 giorni. Bollire lo zucchero e l'acqua e passare tutto e mescolare. (AN3)| Ricetta tramandata dalla sua mamma: 1 litro di grappa, 3 etti di zucchero, 55 foglie di salvia, 30 giorni in infusione poi filtrare. È un digestivo. (BAZ)| Cento erbe': 3 foglie di alloro, 3 foglie di limone, 3 coccole di ginepro, 3 fiori di camomilla, 3 foglie di té, 3 foglie di salvia, 3 foglie di rosmarino, mettere a macerare in un litro di acqua bollita con 350 gr di zucchero e a cui siano stati poi aggiunti 40 gr di alcol a $90^{\circ}$. (NST).

\section{Sector doméstico}

Categoría de uso: Cuidado personal y cosmética.

Número de informantes: 3 Partes utilizadas: hojas.

Usavano le foglie per pulirsi I denti (GUF)| Sfregare I denti con la salvia, per sbiancarli..

(RNI)| Stroffinare la foglia di salvia sui denti per sbiancare I denti. (VMR). 


\section{María Teresa Egea Molines}

\section{Sector medicinal}

Categoría de uso: Afecciones del aparato respiratorio.

Número de informantes: 6 Partes utilizadas: hojas.

Mettere nell'acqua bollente foglie di salvia con rosmarino e menta e fare inalazioni con la testa sopra la pentola con l'acqua coperti da un asciugamano. (BLI)| Fare dei fumenti, mettendo le foglie di salvia e rosmarino nell'acqua bollente per il raffreddore (CBR)| Decotto di foglie di salvia, "acqua di salvia" bevuta finché non senti che va via. (GGI)| Fare I fumenti con la radice di regolizia, I fiori di sambuco, il rosmarino e la salvia. (GLA)| Fare bollire per qualche minuto 2 o 3 foglie di salvia nel latte, aggiungere un po' di miele e bere per il raffreddore. (MSI)| Prendere degli infusi di foglie di salvia per la tosse (VMU).

Categoría de uso: Afecciones ginecológicas, complicaciones obstétricas, del postparto y del puerperio.

Número de informantes: 1 Partes utilizadas: hojas.

Mangiare (masticare di tanto in tanto, fare il decotto, mangiarla fritta)le foglie crude contro I problemi di mestruazione, della menopausa (come le caldane) (VMR).

Categoría de uso: Afecciones oro-faríngeas y de la cavidad oral.

Número de informantes: 10 Partes utilizadas: hojas, parte aérea (toda).

Bere infuso di Malva con Salvia e Camomilla (BLI)| Masticare la foglia di salvia e tenere un pò in bocca contro le infiammazioni in bocca, oppure fare il decotto di salvia e fare degli sciacqui. (CBR)| Per il mal di denti si mettevano un paio di foglie fresche sulle gengive. Per il mal di gola si facevano sciacqui con il decotto. (CFR) Infuso insieme ai chiodi di garofano, facendone sciacqui (MCL)| Per le infiammazioni in bocca, bolllire tutta la pianta di salvia e fare degli sciacqui. (NDI) Per il mal di denti, fare sciacqui con l' acqua di Malva e Salvia. (NRO)| Fare bollire le foglie e fare degli sciacqui. (PEL)| Bere il decotto di Salvia e Rosmarino per il mal di denti (SCO)| Pestare le foglie e applicarle sui denti o sulle gengive (TGA)| Fare gargarismi con l'infuso di salvia tutte le notti. (VMR).

Categoría de uso: Estado general.

Número de informantes: 3 Partes utilizadas: hojas, parte aérea (toda).

Si fanno bollire le foglie della salvia insieme alla malva e si bevono come 'rinfrescante'. (BIO)| Bere il decotto della pianta di salvia 'per rinfescare il fisico', per le infiammazioni. (NDI) $\mid$ Fare l'infuso delle foglie di rosmarino, salvia, piscialletto (prima del fiore) e malva, si beveva a diguino la mattina e la sera per 10/15 giorni. (VMR).

Categoría de uso: Patologías del aparato digestivo.

Número de informantes: 6 Partes utilizadas: hojas, parte aérea (toda).

Ricetta tramandata dalla sua mamma: 1 litro di grappa, 3 etti di zucchero, 55 foglie di salvia, 30 giorni in infusione poi filtrare. È un digestivo. (BAZ)| Bollire mezzo limone con 4 o 5 foglie di salvia e bere. Fa digerire. (BBI)| Bere il decotto della pianta di salvia per 'andare di corpo'. Rinfresca il fisico. (NDI)| Fare l'infuso di menta, melissa, e salvia con un po' di limone per digerire meglio. (NST)| Prendere il decotto di foglie di salvia per aiutare a digerire. (PIM)| Bere l'infuso di rosmarino e salvia per digerire (VMR).

Categoría de uso: Patologías del aparato urinario. 
Número de informantes: 2 Partes utilizadas: hojas.

Bere il decotto di salvia 'per l'infezione di urina'. (MSI)| Bere il decotto di Salvia e Rosmarino per l'infiammazione di orina (SCO).

Notas Ricette tramandate dalla nonna e dalla mamma. La sua nonna lo faceva con la grappa invece dell'alcol, che loro stessi distillavano con le vinacce dell'uva., la pianta della vita' e i suoi usi è stato tramandato dal mio babbo e dai suoi genitori ma proviene dalla cultura celtica che era insediata qui (Monte Cavallo-Granaglione$\mathrm{BO})$.

\section{DATOS ETNOBOTÁNICOS BIBLIOGRÁFICOS}

Nombre vulgar: salvia (MANG98), 〔œlvia (UNGA21).

Número de referencias: 2 Número de citas: 5 .

Número de sectores: 1 Número de categorías: 4.

Sector medicinal

Categoría de uso: Afecciones oro-faríngeas y de la cavidad oral.

Número de referencias: 1 Partes utilizadas: hojas.

Il decotto si utilizza per sciacqui in caso di infiammazioni del cavo orofaringeo e di mal di denti. (MANG98).

Categoría de uso: Patologías del aparato circulatorio.

Número de referencias: 1 Partes utilizadas: hojas.

L'infuso viene bevuto per rinforzare la memoria e per abbassare la pressione. (MANG98).

Categoría de uso: Patologías del aparato digestivo.

Número de referencias: 1 Partes utilizadas: hojas.

La usa assunzione si ritiene utile anche in caso di colite (MANG98).

Categoría de uso: Patologías del sistema nervioso.

Número de referencias: 1 Partes utilizadas: hojas.

L'infuso viene bevuto per rinforzare la memoria e per abbassare la pressione. La usa assunzione si ritiene utile anche in caso di ansia e agitazione (MANG98).

\section{Stachys recta $L$.}

Nombre vulgar: Erba della paura (PLU), Erba della paura (TIV, NRO, NLA, MCL, GGI, GFR, GCL, DAD, CRI).

Número de informantes: 10 Número de citas: 10.

Número de sectores: 1 Número de categorías: 1.

Biotipo: Hemicriptófito.

Tipo corológico: Mediterráneas montañosas.

Abundancia: Común.

Ambiente: Acantilados, pedregales, prados áridos (calcáreos).

Número de exsiccata: 39047 FIAF, 38987 FIAF.

Sector mágico/medicinal

Categoría de uso: Contra el miedo y los traumas.

Número de informantes: 10 Partes utilizadas: parte aérea (toda). 


\section{María Teresa Egea Molines}

Per le persone che hanno avuto una paura, come uno shock, un trauma con qualche animale, o anche nel caso di qualcuno che balbettava: si lava la paura con questa erba che va raccolta la mattina, la vigilia di San Giovanni presto, quando ancora c'è la rugiada e va seccata all'ombra. Al momento dell'uso, prendere un mazzetto, mettere in un tegamino con 3 foglie di olivo benedetto e un pezzo di candela benedetta della candelora ( 2 febbraio) in un litro di acqua. Fare bollire il tutto per 30-40 min, poi colare e fare bere 9 goccioline. Poi si mettono le mani nell'acqua e si passano su tutto il corpo della persona con la 'paura': prima le braccia, poi le gambe.. La preghiera va ripetuta 3 volte. Il rito si fa 3 volte per 3 giorni consecutivi e poi un volta al giorno per altri 3 giorni. Quando è stata lavata una persona con la paura, l'acqua diventa come gelatinosa, filacciosa, si 'stringe' (addensa).. (PLU)| In caso di traumi o paura fare un decotto della pianta, l' acqua va tenuta ferma. Con questa acqua si lava la persona per tre volte in giorni senza la R. Quando si lava la persona e la paura è andata via, l' acqua diventa sporca, appare come una ragnatela. (CRI) Raccolta qualsiasi giorno dopo san Giovanni (24 giugno). Prendere un mazzettino di pianta e farla bollire per 30 minuti e con questo decotto lavare il viso, le mani, i piedi della persona che ha avuto la paura, mentre si dicono certe parole e si fanno certi gesti. Il trattamento va fatto tre volte, in giorni senza "R". Dopo avere lavato la persona, l' acqua subito diventa densa e appare con due strati diversi, come se ci fosse una ragnatela o qualcosa di denso. Quando è cosi, la paura è andata via. Il tutto è tramandato la notte di Natale, da certe persone che hanno il potere di guarire a certe persone, quando la persona con il potere sta per morire. (DAD)| C'era una signora che 'lavava la paura': prendeva cinque piatti con l'infusione dell'erba, prendendo un po'di infuso da ogni piatto e lavando il viso, le mani, i piedi e le braccia. Per tre giorni. (GCL)| Contro la paura, dopo aver subito un trauma: Lavare con il decotto della pianta la persona per tre giorni consecutivi, lavando le mani, i piedi, il viso. Lo faceva la sua mamma. (GFR)| Contro la paura, dopo aver subito un trauma: ad esempio, una persona che ha avuto un incidente di macchina e ha paura della macchina, o un bimbo che cominciava a camminare e dopo essere caduto non era più capace di camminare. La persona che ha avuto la paura viene lavata, una volta lavati, se l' acqua diventa densa, la paura è andata via. (MCL, GGI)| Certe donne a cui erano stati tramandati i poteri (di guarire) potevano lavare la paura il Giovedi Santo. Informatore: 'Lo facevano'. I lavaggi venivano fatti con il decotto dell'erba, mentre si dicevno delle parole e preghiere tramandati da certe persone a certe persone. Se la persona lavata aveva paura, il decotto diventava "sporco" e gli passava la paura. (NLA)| "Se uno prendeva paura, certe donne avevano il dono di potere 'lavare la paura': si fa un decotto della pianta e si mette in una bacinella, poi se nel decotto usato per lavare si vedevano degli "stracci", voleva dire che la persona aveva paura e che gli era andata via". La pianta veniva seccata per essere usata. (NRO)| Contro la paura, dopo un trauma vissuto: Raccolta qualsiasi giorno dopo san Giovanni (24 giugno). Prendere un mazzettino di pianta e farla bollire per 30 minuti e con questo decotto lavare il viso, le mani, i piedi della persona che ha avuto la paura, mentre si dicono certe parole e si fanno certi gesti. Il trattamento va fatto tre volte, in giorni senza "R". Dopo avere lavato la persona, l' acqua subito diventa densa e appare con due strati diversi, come se ci fosse una ragnatela o qualcosa di denso. Quando è cosi, la paura è andata via. Il tutto è tramandato la notte di Natale, 
da certe persone che hanno il potere di guarire a certe persone, quando la persona con il potere sta per morire. La sua mamma lo faceva. (TIV).

Notas Va raccolta la mattina, la vigilia di SanGiovanni presto, quando ancora c'è la rugiada e va seccata all'ombra. Si tramanda la notte di Natale a chi voleva, a lei lo l'ha tramandato il suo nonno, va fatta con fede, con preghiere cristiane (preghiera rivolta a San Giovanni Battista), in forma gratuita, senza pretendere niente, le offerte date vanno ridonate alla chiesa. Ora se ne trova poca e piccola, perché si trovava anche nei terreni arati, se non lavorano più la terra non trova più il suo habitat,più i cinghiali, i daini..hanno rovinato tutto.

\section{DATOS ETNOBOTÁNICOS BIBLIOGRÁFICOS}

Nombre vulgar: erba lavandaia (MANG98), êrba de la pôra (UNGA21).

Número de referencias: 2 Número de citas: 2 .

Número de sectores: 1 Número de categorías: 1.

Sector mágico/medicinal

Categoría de uso: Contra el miedo y los traumas.

Número de referencias: 2 Partes utilizadas: parte aérea (toda).

Il decotto, a cui taluni aggiungono dell' acqua benedetta, viene usato per fare delle abluzioni, da effettuarsi versando il liquido rigorosamente dal capo verso I piedi per tre volte, e aiutandolo a scorrere massagiando con le mani dall'alto verso il basso. L'acqua da trasparente diviene opaca e filamentosa "come ragnatela", l'operazione viene ripetuta, a distanza di due giorni, fino a che l'acqua non resta trasparente anche dopo le abluzioni il che indica che ogni paura o postumo di trauma è passato. (MANG98)| volg. Erba giudaica, erba strega, erba della paura, così detta perchè le donne lavano colla decozione di essa I loro bambini, allor quando sono stati assaliti da qualche improvviso timore, in campagna detta anche barbunoega. Si crede che purghi il sangue dalla paura. Le donne perciò prendono di quest'erba, la fanno bollire e ne lavano da capo a piedi il bambino, che ritengono abbia guastato il sangue per una paura. Se nel lavarlo l'acqua diventa torbida e fa certi agglomeramenti, ch'esse chiamano strâz, stracci, vuol dire che la paura se n'è andata, in caso contrario bisogna ripetere l'operazione. (UNGA21).

\section{Teucrium chamaedrys $L$.}

Nombre vulgar: La querciola (BEL), Erba querciola (TAT, SOT, PLU, NDI, MVI, GZE, DBA), Pianta per la digestione (SLU).

Número de informantes: 9 Número de citas: 10 .

Número de sectores: 1 Número de categorías: 2 .

Biotipo: Caméfito.

Tipo corológico: Eurimediterránea.

Abundancia: Común.

Ambiente: Prados áridos, márgenes de los bosques, encinares y robledales xerófilos.

Número de exsiccata: 38996 FIAF. 


\section{Sector medicinal}

Categoría de uso: Afecciones del metabolismo.

Número de informantes: 1 Partes utilizadas: parte aérea (toda).

Bere il decotto della pianta fa dimagrire. (BEL).

Categoría de uso: Patologías del aparato digestivo.

Número de informantes: 9 Partes utilizadas: parte aérea (toda), hojas.

Fare bollire l'acqua, poi aggiungere l'erba e bere l'infuso per il mal di stomaco. (DBA) $\mid$ Le foglie mangiate così'. (MVI, GZE)| Bere diverse volte al giorno il decotto dell'erba querciola per l'infiammazione di stomaco, come rinfrescante. (NDI)| Bere una tazza del decotto al giorno per una settimana. (PLU) $\mid$ non specificato (SOT)| Suo padre la fa seccare a mazzettini. Fare bollire l'acqua, dopo aggiungerci l'erba e bere l'infuso per il mal di stomaco. (TAT)| Prendere una quantità abbondante dell'erba querciola, fare il decotto e bere la mattina. (BEL)| decotto e bevuto di tanto in tanto (SLU).

Notas fa le foglie come la quercia ma piccole, prima c'era, ora non si trova piu, Prima ce n'era tanta, la vedevi da per tutto, ora non si vede piu, perché adesso è tutto sporco, è tutto un "porchaio". Ora c'è poca., fa la foglia come quella della quercia,ma piccole.

\section{DATOS ETNOBOTÁNICOS BIBLIOGRÁFICOS}

Nombre vulgar: êrba quarzôla (UNGA21).

Número de referencias: 1 Número de citas: 2 .

Número de sectores: 1 Número de categorías: 2.

Sector medicinal

Categoría de uso: Estado general.

Número de referencias: 1 Partes utilizadas: parte aérea (toda).

Erba querciola, camedrio, calamandrina, una specie del Teucrium, comune in montagna, già adoperata in medicina come sternut. E antispam. Le sommità sono ancora usate come amaro, tonico.(UNGA21).

Categoría de uso: Patologías del aparato digestivo.

Número de referencias: 1 Partes utilizadas: parte aérea (toda).

Erba querciola, camedrio, calamandrina, una specie del Teucrium, comune in montagna, già adoperata in medicina come sternut. E antispam. Le sommità sono ancora usate come amaro, tonico. (UNGA21).

\section{Thymus serpyllum L. (s. l.)}

Nombre vulgar: Timo (LST, BEL, VMU), Timo selvatico (CRI, BPT, VMR), (non ha nome).

(MGO), Pepolino (BIO, GAN), Pepolino, Prezzemolino (TAD).

Número de informantes: 10 Número de citas: 12 .

Número de sectores: 3 Número de categorías: 4.

Biotipo: Caméfito.

Tipo corológico: n.d.

Abundancia: Común.

Ambiente: Prados áridos (prefereriblemente sobre silicio). 
Número de exsiccata: 38940 FIAF, 38972 FIAF.

\section{Sector agropastoral}

Categoría de uso: Apicultura.

Número de informantes: 2 Partes utilizadas: parte aérea (toda).

Quando sciamma un alveare, prima di introdurre il nuovo, si puliscono le arnie:"gli si da gli odori": si prende il timo previamente seccato all'ombra, insieme alla salvia, al rosmarino, e all'empitella selvatica e si struscia l'arnia con questo composto dentro alle pareti, come spazzandola. (VMU)| Contro la varola, spazzolare con l'alloro e con il timo l'arnia, così non li muoiono mai. (VMU)| Si prendeva una manciata di timo selvatico e si pulivano le arnie e I bugni quando sciamavano e si metteva lo sciame nuovo. (VMR).

Categoría de uso: Productos lácteos.

Número de informantes: 4 Partes utilizadas: parte aérea (toda).

Per aromatizzare il "presame" (il caglio): Trittare tutta la pianta, e quando si riempie il "buzzo" dell'agnello di latte aggiungere il trittotp insieme al latte. (MGO)| Aromatizzante del caglio: nello stomaco dell'agnello pieno di latte, aggiungere un pizzico di pepolino tritato. (GAN)| Quando capitava che non avevamo più il caglio fatto con lo stomaco dell'agnello con il primo latte, allora mettevano in un po' di latte l'erba e poi questa faceva cagliare il latte. (TAD) $\mid$ Timo schiacciato e mescolato con il caglio secco e trinciato, per insaporire il formaggio (BPT).

\section{Sector alimentario}

Categoría de uso: Aromatizante.

Número de informantes: 4 Partes utilizadas: parte aérea (toda), hojas.

Il pepolino si adopera nella minestra di pane Toscana fatta di cavolo, faggioli, zuccheti, carota, cavolo verza (BIO)| Raccogliere il timo a maggio, seccare e usarlo per aromatizzare gli arrosti (BEL)| Per aromatizzare I funghi e il minestrone (LST)| Per insaporire gli arrosti(CRI).

\section{Sector medicinal}

Categoría de uso: Afecciones del aparato respiratorio.

Número de informantes: 1 Partes utilizadas: hojas.

Racogliere il timo a maggio e metterlo a seccare, metterlo nell'acqua bollente e fare dei.

fumenti di timo, foglie e gemme di pino, origano, e menta (coltivata). (BEL).

Notas Fiorisce due volte a Maggio e a Settembre e va raccolta tutta la pianta,quando è in fiore., Si facevano palline e si conservavano in un vaso, raccogliere il timo amaggio. (in toscana lo chiamano il pepolino).

\section{DATOS ETNOBOTÁNICOS BIBLIOGRÁFICOS}

Nombre vulgar: peppolino (BONZI00), timo (GRIZ03, SANS14), temm salvâdg (UNGA21).

Número de referencias: 4 Número de citas: 6.

Número de sectores: 3 Número de categorías: 4.

Sector agropastoral

Categoría de uso: Productos lácteos. 
Número de referencias: 1 Partes utilizadas: parte aérea (toda).

erba che viene pestata col caglio (BONZI00).

Sector alimentario

Categoría de uso: Aromatizante.

Número de referencias: 3 Partes utilizadas: hojas, No especificado, parte aérea (toda).

(SANS14)| L'odore del timo si ritiene preservativo del mal caduco (UNGA21)| Beccacce al ginepro: 2 beccacce, 12 bacche di ginepro, burro, acquavite di ginepro, timo, sale, pepe. Pestate le bacche nel mortaio, riducendole in poltiglia: incorporatene un terzo e quattro noci di burro. Mettetele dentro ogni beccaccia. Unite un rametto di timo. Fate cuocere le baccacce in burro piuttosto abbondante a fuoco vivo. Quando saranno ben rosolate, salate, pepate, spolverizzate col resto delle bacche pestate e completate la cottura. All'ultimo scaldate l'acquavite, versatela sulle beccacce, portatele in tavola infiammate. (GRIZ03).

\section{Sector medicinal}

Categoría de uso: Afecciones del aparato respiratorio.

Número de referencias: 1 Partes utilizadas: No especificado.

Nella medicina familiare, sono attribuite all'una e all'altra p. virtù stimolanti ed espettoranti. (UNGA21).

Categoría de uso: Patologías del sistema nervioso.

Número de referencias: 1 Partes utilizadas: No especificado.

Nella medicina familiare, sono attribuite all'una e all'altra p. virtù stimolanti ed espettoranti. (UNGA21).

\section{LAURACEAE}

\section{Cinnamomum verum J. Presl}

Nombre vulgar: Cannella (LST, DAD, CRI, BEL, BAZ, AN3).

Número de informantes: 6 Número de citas: 9.

Número de sectores: 2 Número de categorías: 2.

Biotipo: Fanerófito.

Tipo corológico: Exóticas.

Abundancia: Cultivada.

Ambiente: Ausente.

Sector alimentario

Categoría de uso: Licor.

Número de informantes: 6 Partes utilizadas: corteza, frutos/infrutescencias/falsos.

Prendere 30 noci (mallo verde, quando dentro non è ancora fatto), 1 litro e mezzo di alcol, 750 gr di zucchero, 2 grammi di cannella reggina trittati, 10 chiodi di garofano, 4 litri di acqua, la buccia del limone. Lasciare macerare per 40 giorni al buio o alla penombra in cantina,e filtrare. (AN3)| Il Corniolino:1 $\mathrm{kg}$ di corniole, 1 
litro di alcol, 625 gr di zucchero, 625 gr d'acqua, 5 chiodi di garofano, 1 pizzico di cannella, e la scorza di limone.Lasciare tutto a macerare per 40 giorni, poi filtrare, fare lo sciroppo con lo zucchero e l'acqua e aggiungere. (AN3)| Vin brulé: fare bollire il vino con la buccia del limone, la cannella e I chiodi di garofano. Si beveva nelle veglie, tutti offrivano il vin brulé. (AN3)| 1 giumella' (pugno) di bacche di ginepro verdi, '1 giumella' (pugno) di bacche viola di ginepro mature. Mettere in un vaso a chiusura ermetica con 1 litro di alcol 90 gradi, 1 lirto di acqua, nell'acqua ci diluisci $1 \mathrm{~kg}$ di zucchero, un poco di cannella, 3 chiodi di garofano, Lasciare 40 giorni (se lo lasci di più è meglio. Filtrare e imbottigliare. (BAZ)| Raccogliere 21 noci prese verso il 24 giugno, mettere a macerare in un litro di alcol, mezzo di litro di acqua, 500 gr di zucchero, 1,5 gr di cannella e 7 chiodi di garofano, lasciare a riposare per 3 settimane e filtrare. (BEL)| Ricetta della suocera chimata la nonna: "28 nocine tagliate, 1 litro di alcol puro, 900 gr.zucchero, 1scorza limone, 1stecca vaniglia,4 chiodi di garofano, 1pizzico di cannella. Stringere lo zucchero in acqua calda e lasciare 40 giorni (DAD, CRI)| Il vin brulé si faceva nell'inverno quando si era in compagnia: uno spicchio di mela, un pò di cannella, chiodi di garofano, mettere a bollire, appena bolle un pò, si dava fuoco per togliere l'alcol. (LST).

Sector medicinal

Categoría de uso: Patologías del aparato digestivo.

Número de informantes: 1 Partes utilizadas: corteza.

Prendere 30 noci (mallo verde, quando dentro non è ancora fatto), 1 litro e mezzo di alcol, 750 gr di zucchero, 2 grammi di cannella reggina trittati, 10 chiodi di garofano, 4 litri di acqua, la buccia del limone. Lasciare macerare per 40 giorni al buio o alla penombra in cantina,e filtrare. (AN3).

\section{Laurus nobilis $L$.}

Nombre vulgar: Alloro (NST, BMA, TUL, TAD, SCO, NRO, MSR, MGE, LST, LRE, LGI, GUF, GGI, GFR, DAD, CFR, BLI, AMA, VMU).

Número de informantes: 19 Número de citas: 25.

Número de sectores: 4 Número de categorías: 7.

Biotipo: Fanerófito.

Tipo corológico: Esteno-mediterránea.

Abundancia: Común.

Ambiente: Lugares soleados, casi en todas partes cultivado o naturalizado.

Sector agropastoral

Categoría de uso: Apicultura.

Número de informantes: 1 Partes utilizadas: hojas.

Contro la varola, spazzolare con l'alloro e con il timo l'arnia, così non li muoiono mai. (VMU).

\section{Sector alimentario}

Categoría de uso: Aromatizante.

Número de informantes: 16 Partes utilizadas: hojas. 


\section{María Teresa Egea Molines}

Quando si fanno le castagne cotte, aggiungere un po' di foglie di alloro nell'acqua. Anche per aromatizzare i piatti di carne. Per cucinare i fegatelli di maiale, si adopera qualche foglia di alloro per aromatizzare. (AMA)| Per aromatizzare le castagne cotte con sale. (BLI)| Per aromatizzare le castagne secche (GUF, GGI, CFR)| Per insaporire i funghi sotto olio, salvia, pepe e una foglia di alloro. Per insaporire il brodo di faggioli per fare "pasta e faggioli",con olio, aglio pepe e due foglie di alloro che alla fine si levano. (DAD)| Per insaporire le castagne secche, quando sono quasi cotte, aggiungere la cima dell' alloro data fuoco messa nella pentola e coperta. Una foglia d' alloro per insaporire i funghi sotto olio insieme alla salvia, pepe. (DAD) Per le castagne secche, cotte si mettono 2 o 3 foglie di alloro secche. (GFR)| Per aromatizzare le castagne cotte. (LGI)| Aggiungere una o due foglie di alloro alle castagne cotte (secche). (LRE)| Si usavano le foglie di alloro per aromatizzare l'arrosto, le castagne 'ciarbolotti' (le castagne sbucciate e cotte con la pellicina) con il sale oppure I 'ballotti' (le castagne cotte con la bucia). (LST)| La vigilia di Natale facevano le castagne secche cotte (tipo minestra) con un pò di alloro. Poi c'erano anche I cerboloni: le castagne con la buccia solo interna (solo la buccia esterna si toglieva) cotte con acqua e sale e un pò di alloro. Poi si sbucciavano e si mangiavano. (MGE)| Per aromatizzare le castagne cotte, si mette nell'acqua qualche foglia di alloro (MSR)| Per aromatizzare le castagne cotte (secche e poi cotte), mettere qualche foglia alla fine della cottura. (NRO)| Per insaporire il fegato con le cipolle:soffrigere la cipolla con il fegato e alla fine aggiungere l' alloro (SCO)| le mondine' o 'fruggiate' (le caldarroste): sbucciate, e cotte con l'alloro (TAD)| Per aromatizzare la carne e le castagne cotte. (TUL).

Categoría de uso: Licor.

Número de informantes: 2 Partes utilizadas: hojas.

Liquore di alloro: prendere 20 foglie di alloro, metterle in un recipiente con un litro di alcol, 600 grammi di zucchero, 700 gr di alcol. Lasciare a bagno per tre giorni, dopodiché fare bollire per cinque minuti circa, quindi fare raffreddare e filtrare nelle bottiglie. (BMA)| Cento erbe': 3 foglie di alloro, 3 foglie di limone, 3 coccole di ginepro, 3 fiori di camomilla, 3 foglie di té, 3 foglie di salvia, 3 foglie di rosmarino, mettere a macerare in un litro di acqua bollita con 350 gr di zucchero e a cui siano stati poi aggiunti 40 gr di alcol a $90^{\circ}$. (NST).

Sector doméstico

Categoría de uso: Ambientador.

Número de informantes: 1 Partes utilizadas: tallos leñosos/ramas/ramitas/vástagos.

Mettere rami di alloro nei armadi, nelle credenze umide, nella vetrine basse, per assorbire 1'.

umidità probabilmente. (NRO).

Categoría de uso: Otro doméstico.

Número de informantes: 1 Partes utilizadas: hojas.

Per conservare I funghi secchi nei barattoli di vetro mettere qualche foglia di alloro sopra e.

dei chicchi di pepe (GFR). 


\section{Sector medicinal}

Categoría de uso: Estado general.

Número de informantes: 1 Partes utilizadas: hojas.

Liquore di alloro:prendere 20 foglie di alloro, metterle in un recipiente con un litro di alcol, 600 grammi di zucchero, 700 gr di alcol. Lasciare a bagno per tre giorni, dopodiché fare bollire per cinque minuti circa, quindi fare raffreddare, filtrare e mettere nelle bottiglie. (BMA).

Categoría de uso: Patologías del aparato digestivo.

Número de informantes: 1 Partes utilizadas: hojas.

Liquore di alloro:prendere 20 foglie di alloro, metterle in un recipiente con un litro di alcol, 600 grammi di zucchero, 700 gr di alcol. Lasciare a bagno per tre giorni, dopodiché fare bollire per cinque minuti circa, quindi fare raffreddare, filtrare e mettere nelle bottiglie. (BMA).

Notas è coltivato, fa digerire. Ricetta tramandata dalla nonna.

\section{DATOS ETNOBOTÁNICOS BIBLIOGRÁFICOS}

Nombre vulgar: alloro (GRIZ03, SANS14, BADI15), mlôr (UNGA21), alòro (BONZI00).

Número de referencias: 5 Número de citas: 10.

Número de sectores: 3 Número de categorías: 7.

\section{Sector alimentario}

Categoría de uso: Aromatizante.

Número de referencias: 3 Partes utilizadas: hojas, frutos/infrutescencias/falsos frutos (SANS14).

Costolette di maiale in umido.Ingredienti:Costolette di maiale a pezzetti,aglio,rosmarino,alloro,salsa concentrata di pomodoro,vino bianco,sale e pepe.Si fanno soffriggere a fuoco lento le costolette con rosmarino aglio ed una foglia di alloro.Se si vuole un piatto meno pesante si scola il grasso della frittura e si sostituisce con olio.Si aggiungono sale e pepe ed un po' di vino bianco,che si lascia sfumare.Si pone quindi la salsadi pomodoro diluita con acqua e si lascia terminare la cottura,aggiungendo eventualmente un po' di brodo di dado, se il liquido del tegame non fosse sufficiente.Badare che il sugo resti piuttosto denso.Si servono con tigelle o polenta. (BADI15)| Costine di maiale e di agnello al forno: $1 \mathrm{~kg}$ di costine, $1 \mathrm{~kg}$ di patate, 1 foglia di alloro, rosmarino, ginepro, olio, sale, pepe. Mettere le costine in una teglia che possa andare in tavola, accomodate in un solo strato e non troppo vicine le une alle altre. Copritele con le patate che nel frattempo avete preparato lavate, sbucciate e fatte a quarti. Irrorate con un filo d'olio. Il grasso delle costine sciogliendosi sarà sufficiente come condimento. Salate e pepate generosamente. Cospargete di rosmarino e lauro spezzettato. Mettete le bacche di ginepro in un pezzo di carta robusta, ripiegatela e pestate con un batticarne in modo da spaccarle grossolanamente. Sparpagliatele sulle patate, mettete il coperchio e coprite con stagnola, sigilando bene attorno ai bordi. Infornate in forno già caldo e portate a cottura. Quando costine e patate saranno pronte, togliete il coperchio, alzate il forno al massimo, o meglio ancora, accendete gli infrarossi e lasciate dorare, scuotendo ogni tanto la teglia perché la doratura possa avvenire uniformemente. (GRIZ03). 
Categoría de uso: Licor.

Número de referencias: 1 Partes utilizadas: hojas (SANS14).

Sector mágico/ritual/supersticioso

Categoría de uso: Adivinatorio.

Número de referencias: 1 Partes utilizadas: parte aérea (toda).

Dall'alloro si suole in campagna prendere augurio della buona o cattiva stagione. Se ne gettano alcune foglie sul fuoco: se abbruciando fanno rumore, la raccolta sarà buona, al contrario no. (UNGA21).

Categoría de uso: Protector.

Número de referencias: 1 Partes utilizadas: parte aérea (toda).

V'è in Bologna come in altri luoghi, l'usanza di ornare la vigilia di Natale le botteghe e le case con un gran ramo d'alloro, e ciò dicesi per allontanare gli spiriti magligni. Si vede in campagna l'alloro usato per insegna delle osterie, onde il prov "al ban ven al n'ha bisogn ed frasca" (UNGA21).

\section{Sector medicinal}

Categoría de uso: Afecciones cutáneas y tejidos subcutáneos.

Número de referencias: 1 Partes utilizadas: hojas.

Nella medicina popolare colle foglie di lauro si sanano le punture dalle vespi. (UNGA21).

Categoría de uso: Afecciones ginecológicas, complicaciones obstétricas, del postparto y del puerperio.

Número de referencias: 1 Partes utilizadas: hojas.

Le stesse foglie applicate alle mammelle fanno retrocedere il latte (UNGA21).

Categoría de uso: Enfermedades del oído.

Número de referencias: 1 Partes utilizadas: hojas.

In decozione si dicono efficaci contro la sordità. (UNGA21).

\section{LEGUMINOSAE}

\section{Cicer arietinum $L$.}

Nombre vulgar: Ceci (NRE, EMA).

Número de informantes: 2 Número de citas: 2.

Número de sectores: 1 Número de categorías: 1.

Biotipo: Terófito.

Tipo corológico: Cultivadas.

Abundancia: Cultivada.

Ambiente: Cultivado en los huertos. Asilvestrado a lo largo de los setos y en los cultivos.

\section{Sector alimentario}

Categoría de uso: Sucedáneo del café.

Número de informantes: 2 Partes utilizadas: frutos/infrutescencias/falsos frutos. 
I ceci si mettevano insieme all'orzo da caffé, si tostavano insieme e si facevano bollire, poi si aggiungeva mezzo bicchiere di vino, come surrogato del café. (EMA)| Tostare l'orzo insieme ai ceci, macinare e bollire come surrogato del caffè. (NRE).

DATOS ETNOBOTÁNICOS BIBLIOGRÁFICOS

Nombre vulgar: zåi (UNGA21).

Número de referencias: 1 Número de citas: 4.

Número de sectores: 3 Número de categorías: 4.

Sector agropastoral

Categoría de uso: Alimentación animal (incluidos los forrajeros).

Número de referencias: 1 Partes utilizadas: semillas.

I ceci rossi sono dati per biada alle bestie (UNGA21).

Sector alimentario

Categoría de uso: Sopas de verduras y potaje.

Número de referencias: 1 Partes utilizadas: semillas.

I ceci freschi o secchi si sogliono mangiare cotti in minestra (UNGA21).

Categoría de uso: Sucedáneo del café.

Número de referencias: 1 Partes utilizadas: semillas.

I ceci neri sono tostati e macinati adoperati per succedaneo al caffé. (UNGA21).

Sector medicinal

Categoría de uso: Estado general.

Número de referencias: 1 Partes utilizadas: harina/salvado.

La farina di cece si dice risolvente. (UNGA21).

\section{Cytisophyllum sessilifolium (L.) O.Lang (=Cytisus sessilifolius $L_{\text {.) }}$}

Nombre vulgar: Strillini (VSI, BDI).

Número de informantes: 2 Número de citas: 2.

Número de sectores: 1 Número de categorías: 1.

Biotipo: Fanerófito.

Tipo corológico: Montañosas.

Abundancia: Común.

Ambiente: Bosques latifolios (robledales, castañares) y arbustos.

Número de exsiccata: 39114 FIAF, 39032 FIAF.

Sector artesanal

Categoría de uso: Cestería.

Número de informantes: 2 Partes utilizadas: tallos leñosos/ramas/ramitas/vástagos.

Raccolti dal 10 Luglio al 15 Agosto (o 20 Agosto, dipende dalle zone) quando hanno l'insucchio. Vanno spellati subito. Quando li lavora, li mette in acqua calda 24 ore prima. È difficili lavorarli, deve bagnarli di tanto in tanto. I rami che partono da terra sono più maleabili., si troncano meno, sono piu forti, migliori. (BDI)| Vanno raccolti e spellati freschi con un rametto della stessa pianta piegato in due, facendo 


\section{María Teresa Egea Molines}

passare il ramo da spellare per l'estremità piegata. Poi si mettono a bagno per fare i cesti. (VSI).

Notas Raccolti dal 10 Luglio al 15 Agosto (o 20 Agosto, dipende dalle zone) quando hanno l'insucchio.

DATOS ETNOBOTÁNICOS BIBLIOGRÁFICOS

Nombre vulgar: vinco (GUC98).

Número de referencias: 1 Número de citas: 1 .

Número de sectores: 1 Número de categorías: 1.

Sector artesanal

Categoría de uso: Cestería.

Número de referencias: 1 Partes utilizadas: tallos leñosos/ramas/ramitas/vástagos.

Tipo di ginestra si utilizzavano gli steli per piccoli lavori di intreccio. (GUC98).

\section{Cytisus scoparius (L.) Link}

Nombre vulgar: Ginestra (MGE), Roggiole,Ginestra dei carbonai (GGI), Ginestre. (REN, NRO, MGO, BPT, CLO, TGO), Ginestra (quadrata) (BLI), Roggiole.

(NLA, TIV, MRI, MDA, GRI, GLA, GFR, GAN, DAD, BSO), Ginestra dei carbonai.

(FAM).

Número de informantes: 20 Número de citas: 26.

Número de sectores: 5 Número de categorías: 11.

Biotipo: Fanerófito.

Tipo corológico: Europeas.

Abundancia: Común.

Ambiente: Brezales en terreno ácido.

Número de exsiccata: 39102 FIAF, 38909 FIAF.

Sector agropastoral

Categoría de uso: Construcción agrícola (cabañas, etc...).

Número de informantes: 1 Partes utilizadas: tallos leñosos/ramas/ramitas/vástagos.

Si usavano le ginestre per coprire le capanne agricole, le concimaie, la legnaie piccole. (MGE).

Categoría de uso: Cuerdas y ataduras.

Número de informantes: 2 Partes utilizadas: tallos leñosos/ramas/ramitas/vástagos,.

Le ginestre si usavano come legacci per legare le fascine, si facevano "le ritorte": erano.

fascine di legna legate con la ginestra che veniva ritorta. (MGE)| Per legare le fascine di legna (GGI)..

Categoría de uso: Horticultura.

Número de informantes: 1 Partes utilizadas: parte aérea (toda).

Concime per il grano: la cenere delle ginestre bruciate. (TGO).

Categoría de uso: Otro agropastoral. 
Etnobotánica en el Alto Valle del Reno (Toscana y Emilia-Romaña, Italia)

Número de informantes: 2 Partes utilizadas: tallos leñosos/ramas/ramitas/vástagos,.

Per rinforzare le 'roste': a primavera si cominciava a pulire il castagneto e si rifacevano le roste, canali in modo che le castagne che cadevano venivano a cadere dentro. Si faceva il solco e si mettevano le ginestre sul bordo per evitare che le castagne andassero di sotto. (MGE) $\mid$ Concime per il marciolo (grano di altitudine): Quando pulivano i campi, tutte le raggie, le ginestre, e gli arbusti e le erbe, si amucchiavano e si copriva con la "pellice"(l' erba), queste erano le iove. Poi le davano fuoco, e il carbone risultante con la cenere si spargeva per il campo e li dava vigoria alla terra.Cosi pulivano il campo e facevano il concime allo stesso tempo.Quando la terra o il marzolo non erano forti si diceva "metteli 2.

\section{Sector artesanal}

Categoría de uso: Fibra textil.

Número de informantes: 1 Partes utilizadas: parte aérea (toda).

Una volta la coltivavano per tessere (BLI).

Sector doméstico

Categoría de uso: Chimenea y horno.

Número de informantes: 13 Partes utilizadas: tallos leñosos/ramas/ramitas/vástagos,.

Si seccavano le ginestre per accendere il fuoco. (MGE)| La pianta secca aiuta ad accendere il fuoco, al posto alla carta (BPT)| La pianta secca aiuta ad accendere nel posto alla carta (MGO)| Si facevano mazzi insieme all' agrifoglio e si mettevano a seccare queste fascine legate. (NRO)| Raccolte verdi, e messe a seccare a fascine. Poi sono utili per accendere il fuoco. (REN)| Per accendere il fuoco usare all'inizio i rami di roggiole (BSO)| Raccolte e messe ad essiccare per accendere il fuoco (DAD)| Raccolte d'estate e messe ad essiccare per accendere il fuoco (GAN)| Roggiole secche per accendere il fuoco (GFR)| Raccolte d'estate e messe ad essiccare al sole, per accendere il fuoco d'inverno (GLA)| Raccolte d'estate e messe, fatti "fastelli" e messi a seccare per accendere il fuoco. (GRI)| Raccolte e messe ad essiccare al sole per accendere il fuoco. (MDA)| Per accendere il fuoco (GGI).

Categoría de uso: Integración de la renta familiar.

Número de informantes: 2 Partes utilizadas: parte aérea (toda).

Nei anni 50 si commercializaba a una azienda di Pisa come cardiotonico. Tagliavano gli stelli, facevano facetti e li vendevano per anni (MRI)| Tagliavano le roggiole a falcetti, e caricavano dei camion pieni, que vendevano alla industria farmaceutica di Val di Brana e Candeglia, che li usavano per la estrazione di sparteina (per patologie cardiache) (TIV).

Categoría de uso: Objetos domésticos y escobas.

Número de informantes: 1 Partes utilizadas: tallos leñosos/ramas/ramitas/vástagos.

Si legavano i rami con forma di scopa (NLA).

Sector religioso

Categoría de uso: Alfombras florales.

Número de informantes: 1 Partes utilizadas: flores/inflorescencias y sus partes. 
Per il Corpus Domini (Maggio), facevano le infiorate, disegni per terra con il giallo delle.

ginestre e il marrone del Castagno (del "busgio") (FAM).

Categoría de uso: Ornamento para altares e iglesias.

Número de informantes: 1 Partes utilizadas: parte aérea (toda).

La $2^{\circ}$ Domenica di luglio ritornavano i carbonai dalla Maremma, si festeggiava la Madonna.

dei Maremmani, e si mettevano negli altarini rami di ginestre dei carbonai (FAM).

\section{Sector veterinario}

Categoría de uso: Conejos.

Número de informantes: 1 Partes utilizadas: parte aérea (toda).

Fa stare bene ai conigli, la ginestra è sempre verde tutto l'anno, si da da mangiare ai conigli. "Li fa stare bene" (NRO).

Notas prima della plastica si usavano per legare le fascine di legna, Le ginestre si tagliano a settembre, formando fascine che si mettono a seccare.

\section{Galega officinalis $L$.}

Nombre vulgar: Veccione (GGI).

Número de informantes: 1 Número de citas: 1.

Número de sectores: 1 Número de categorías: 1.

Biotipo: Hemicriptófito.

Tipo corológico: Europeas.

Abundancia: Común.

Ambiente: Baldíos húmedos.

Sector agropastoral

Categoría de uso: Alimentación animal (incluidos los forrajeros).

Número de informantes: 1 Partes utilizadas: parte aérea (toda).

Portavamo gli animali vicino perché andassero a mangiarla. (GGI).

DATOS ETNOBOTÁNICOS BIBLIOGRÁFICOS

Nombre vulgar: galainga (UNGA21).

Número de referencias: 1 Número de citas: 2 .

Número de sectores: 2 Número de categorías: 2 .

Sector agropastoral

Categoría de uso: Alimentación animal (incluidos los forrajeros).

Número de referencias: 1 Partes utilizadas: parte aérea (toda).

capraggine, ruta capraria, erba foragg. E da sovescio, spontanea in alcuni luoghi, già usata in farm. E vanta per molte virtù ma ora dimenticata- salvo che i montanari ne adoperano la polvere della radice per curare il male de denti. (UNGA21).

Sector medicinal

Categoría de uso: Afecciones oro-faríngeas y de la cavidad oral.

Número de referencias: 1 Partes utilizadas: órganos subterráneos. 
capraggine, ruta capraria, erba foragg. E da sovescio, spontanea in alcuni luoghi, già usata in farm. E vanta per molte virtù ma ora dimenticata- salvo che i montanari ne adoperano la polvere della radice per curare il male de denti. (UNGA21).

\section{Laburnum anagyroides Medik.}

Nombre vulgar: Maggiociondolo (MVI, GZE, GUF, GGL, SLU), Maggiociondolo, Legno puzzolo,.

Mairì (GGI), Almaio (VSI, BSI), Glicini, maggiociondolo (VMA).

Número de informantes: 9 Número de citas: 11.

Número de sectores: 4 Número de categorías: 5 .

Biotipo: Fanerófito.

Tipo corológico: Europeas.

Abundancia: Común.

Ambiente: Bosques latifolios (sobre todo robledales y castañares).

Número de exsiccata: 39087 FIAF.

Sector agropastoral

Categoría de uso: Herramientas y objetos agrícolas.

Número de informantes: 2 Partes utilizadas: madera.

Si usava per fare il 'mazzo' (mazza di legno per spaccare la legna) perché era un legno molto.

duro. (GGI, SLU).

Sector efecto nocivo

Categoría de uso: Tóxicas y venenosas.

Número de informantes: 1 Partes utilizadas: planta entera/viva (GGL).

Sector mágico/ritual/supersticioso

Categoría de uso: Rituales de Mayo.

Número de informantes: 5 Partes utilizadas: tallos leñosos/ramas/ramitas/vástagos,.

Il primo maggio i ragazzi lasciavano un ramo fiorito davanti alla casa delle ragazze belle di notte, di nascosto. Davanti alla casa delle ragazze brutte si portavano invece delle cose brutte, come un carro sul terrazzo. (VSI, BSI)| Bouquet di fiori da regalare alle belle ragazze. Il 30 aprile si celebra il cantarmaggio e i ragazzi portano alle case delle belle ragazze dei bouquet di fiori fatti di maggiociondolo e rami di abete, mentre cantavano sotto la loro finestra. Invece alle ragazze più brutte si portava del fieno. (GUF)| Il primo maggio, se a un ragazzo piaceva una ragazza andava con un ramo di maggiociondolo e lo metteva a casa sua. (GZE)| Il primo maggio, se a un ragazzo gli piaceva una ragazza andava con un ramo di maggiociondolo e lo metteva a casa sua. (MVI).

Sector religioso

Categoría de uso: Alfombras florales.

Número de informantes: 2 Partes utilizadas: tallos leñosos/ramas/ramitas/vástagos.

Con i fiori dell'almaio decoravano le strade dove passava la processione. (VSI, BSI). 
Categoría de uso: Ornamento para altares e iglesias.

Número de informantes: 1 Partes utilizadas: tallos leñosos/ramas/ramitas/vástagos.

Si usava per fare le ghirlande con I glicini (maggiociondolo), I margheritoni e le rose, quando portavano la madonna, una domenica di maggio. (VMA).

Notas Frutto velenoso, con fiori gialli, Si sono seccati per un cancro., "dicono che è tossica".

\section{DATOS ETNOBOTÁNICOS BIBLIOGRÁFICOS}

Nombre vulgar: màiio (GUC98), mâj (UNGA21), arbogno (MANG98).

Número de referencias: 3 Número de citas: 3.

Número de sectores: 2 Número de categorías: 2 .

Sector mágico/ritual/supersticioso

Categoría de uso: Rituales de Mayo.

Número de referencias: 2 Partes utilizadas: tallos leñosos/ramas/ramitas/vástagos. Ramo o mazzetto di maggiocióndolo fiorito o di un sempreverde che si donava all'innamorata soprattutto nella notte fra il 30 aprile e il 1 maggio, notte in cui si cantavano i maggi. (GUC98)| majo, maggio ciondolino, in Tosc. Majella, p. leguminosa assai cercata dalle api e dalla quale si trae il ramo, maj, in Tosc. Maggio che in val di Setta nel mese di maggio si porta attorno cantando I maggi all'uso toscano. (UNGA21).

Sector medicinal

Categoría de uso: Otro medicinal.

Número de referencias: 1 Partes utilizadas: corteza.

Nel trattamento della febbre maltese (Brucella melitensis) si somministravano quantità minime (un cucchiaio) del decotto acquoso della corteccia privata della parte suberificata, dosi superiori risultano estremamente tossiche. (MANG98).

\section{Lens culinaris Medik.}

Nombre vulgar: leri (VSI).

Número de informantes: 1 Número de citas: 1.

Número de sectores: 1 Número de categorías: 1 .

Biotipo: Terófito.

Tipo corológico: Cultivadas.

Abundancia: Cultivada.

Ambiente: Cultivada.

Sector agropastoral

Categoría de uso: Alimentación animal (incluidos los forrajeros).

Número de informantes: 1 Partes utilizadas: harina/salvado.

Per fare la biada delle mucche si portava al mulino le vecce, I leri (lenticchie), ruvie (pisello selvatico). E per fare la broda per il maiale si macinava l'orzo e l'avena. (VSI). 


\section{DATOS ETNOBOTÁNICOS BIBLIOGRÁFICOS}

Nombre vulgar: laint (UNGA21).

Número de referencias: 1 Número de citas: 2.

Número de sectores: 1 Número de categorías: 2.

Sector medicinal

Categoría de uso: Afecciones cutáneas y tejidos subcutáneos.

Número de referencias: 1 Partes utilizadas: hojas.

lent, lenticchia, p. leguminosa da minestra. Le foglie nella med. Fam. Si adoperano per sanare.

I tagli. La bollitura di esse con un po di sale si prende per isciogliere il corpo. (UNGA21).

Categoría de uso: Estado general.

Número de referencias: 1 Partes utilizadas: hojas.

lent, lenticchia, p. leguminosa da minestra. Le foglie nella med. Fam. Si adoperano per sanare i tagli. La bollitura di esse con un po di sale si prende per isciogliere il corpo. (UNGA21).

\section{Lotus corniculatus $L$.}

Nombre vulgar: Ginestrino (CRI, RMA, MRI), Ginestrino, fiorume (GLA, GGI).

Número de informantes: 5 Número de citas: 5.

Número de sectores: 2 Número de categorías: 2.

Biotipo: Hemicriptófito.

Tipo corológico: Europeas.

Abundancia: Bastante Común.

Ambiente: Mayoritariamente en ambientes creados por el hombre (prados segados y fertilizados, pastos áridos, baldíos cubiertos de hierbas y también cultivados como forraje).

Sector agropastoral

Categoría de uso: Alimentación animal (incluidos los forrajeros).

Número de informantes: 2 Partes utilizadas: parte aérea (toda).

Si coltivava come foraggera per mucche e pecore (MRI)| Ogni anno coltivavano grano, orzo, segale (per farina per il pane e per gli animali), lupini, ginestrino,trifoglio, erba spagna, per fare il fieno. E si tenevano I semi ogni anno per l'anno prossimo (RMA).

Sector medicinal

Categoría de uso: Afecciones del aparato respiratorio.

Número de informantes: 3 Partes utilizadas: flores/inflorescencias y sus partes.

"Fiorume", fiori e foglie del fieno (di trifoglio o "trafagliolo", ginestrino, erba medica, radicchi, felce, camomilla, margherite, papaveri) Mettere i fiori e le foglie che restano dopo avere preso il fieno, trittate, nell'acqua bollente e respirare il vapore con la testa coperta con un panno (CRI)| Fare I fumenti con il fiorume che erano tutti I fiori 2 foglie restanti dal fieno (GLA, GGI). 
Notas Fumenti: fiori del fieno, di piante spontanee come il trifoglio, l'erba spagna e il ginestrino.

\section{Lupinus albus $L$.}

Nombre vulgar: Lupini (PCL, MME, EMA, TOA, BFE, RMA, MRI), Lupini (con fiore giallo) (AMA), Lupino (GGI, BPT).

Número de informantes: 10 Número de citas: 16.

Número de sectores: 3 Número de categorías: 7.

Biotipo: Terófito.

Tipo corológico: Cultivadas.

Abundancia: Cultivada.

Ambiente: Cultivado como forraje y por la semilla.

Sector agropastoral

Categoría de uso: Alimentación animal (incluidos los forrajeros).

Número de informantes: 2 Partes utilizadas: frutos/infrutescencias/falsos frutos, parte.

Si coltivava come foraggera per fieno per le mucche o le pecore (MRI)| Ogni anno coltivavano grano, orzo, segale (per farina per il pane e per gli animali), lupini, ginestrino,trifoglio, erba spagna, per fare il fieno. E si tenevano I semi ogni anno per l'anno prossimo (RMA).

Categoría de uso: Horticultura.

Número de informantes: 2 Partes utilizadas: semillas.

Raccogliere I semi, seccarli e macinarli. Applicare la farina di semi di lupini nel terreno dell'orto come concime, però non deve toccare mai la pianta, sennò la brucia. Applicare la farina sempre a $10 \mathrm{~cm}$ della pianta. (BFE) $\mid$ Scottare I seme, e applicare l'acqua di cottura come concime per I fiori. (TOA).

\section{Sector alimentario}

Categoría de uso: Otro alimentario.

Número de informantes: 8 Partes utilizadas: semillas.

Raccogliere I semi di lupini, metterli a macerare in un fosso, sotto la corrente del fiume, in un sacchetto e attaccati a un sasso, per una settimana, per togliergli l'amaro. (BFE)| I lupini erano seminati, poi si raccoglievano, si facevano bollire, e si mettevano per 10 giorni a spurgare nei fossi, per toglierli l'amaro, avvolti in un panno di cannapa. Si toglievano la pellicina, si aggiungeva del sale e si mangiavano così. (EMA)| Si mettevano a seccare I frutti, e poi si facevano lessi e conditi oppure nella minestra. (MME)| Si mangiavano I lupini crudi, si mettevano nel fosso per un pò e poi si mangiavano con il sale (MRI) $\mid$ Si raccoglievano, si mettevano ad essicare, poi si cuocevano e si mettevano a bagno per vari giorni. Bisogna cambiare l'acqua spesso, oppure, mettere I lupini cotti in un sacco in un fosso, cosi tirava fuori l'amaro. Si mangiavano spellati (PCL)| Raccogliere I semi di lupini, metterli a macerare in un fosso, sotto la corrente del fiume, in un sacchetto e attaccati a un sasso, per 4 o 5 giorni, per toglierlgi l'amaro. Poi scottati (acqua usata come concime), e messi sotto sale. (TOA)| Mettere I semi freschi in un sacco a mollo nei fossi, legato sotto le pietre, per vari giorni, cambiando di posto di tanto in tanto per 
vari giorni ("li purificavano". Poi si mangiavano con un po di sale come aperitivo. (AMA)| Semi freschi mangiati come i fagioli freschi con sale (BPT).

Categoría de uso: Sopas de verduras y potaje.

Número de informantes: 1 Partes utilizadas: semillas.

Si mettevano a seccare I frutti, e poi si facevano lessi e conditi oppure nella minestra. (MME).

Categoría de uso: Sucedáneo del café.

Número de informantes: 1 Partes utilizadas: semillas.

In tempi difficili si tostavano i semi di lupino e se ne ricavava una specie di caffè. (GGI).

\section{Sector medicinal}

Categoría de uso: Afecciones del metabolismo.

Número de informantes: 1 Partes utilizadas: flores/inflorescencias y sus partes.

Per il diabete, dicevano di prendere un lupino, 'mandarlo giu' 2 volte al giorno. (EMA).

Categoría de uso: Parásitos externos.

Número de informantes: 1 Partes utilizadas: semillas.

Lavarsi la testa con l' acqua dei lupini, ossia il decotto. (PCL).

Notas Venturi (2006) non lo riporta. Si coltivavano sul terreno sodo. Se ne faceva una sola fila per campo.

\section{DATOS ETNOBOTÁNICOS BIBLIOGRÁFICOS}

Nombre vulgar: luven (UNGA21), lupini (GUC81), Lupìna (APPO10), Luvìni (APPO10),

Dupino (BONZI00).

Número de referencias: 4 Número de citas: 6 .

Número de sectores: 3 Número de categorías: 3 .

Sector alimentario

Categoría de uso: Verdura cruda.

Número de referencias: 1 Partes utilizadas: semillas.

lupino, p. legum. Di più specie, di cui la più comune è il lupinus albus L. I semi sono amarissimi. Macerati, sono magiati dal volgo leggermente salati. Le madri si servono della povere di lupino per divezzare I bambini, imbrattandosene il capezzole delle mammelle. Vuole la tradizione che il lupino fosse maledetto da G. C. altri dice dalla Madonna, attraversando un campo di lupini secchi, nel fuggire in Egitto, per il rumore che facevano a passar loro vicino. (UNGA21).

\section{Sector lúdico/voluptuoso}

Categoría de uso: Juego colectivo y bromas.

Número de referencias: 1 Partes utilizadas: semillas.

Il Gioco dei lupini: uno andava a mettere in bagno magari un chilo o due di lupini, poi diceva: 'stasera si giocano'. Si andava, si giocavano a sette e mezzo, si giocava a qualunque cosa, e magari... poi alla fine chi perdeva pagava i lupini, e poi si mangiava tutti insieme (GUC81). 


\section{Sector medicinal}

Categoría de uso: Afecciones ginecológicas, complicaciones obstétricas, del postparto y del puerperio.

Número de referencias: 1 Partes utilizadas: semillas.

lupino, p. legum. Di più specie, di cui la più comune è il lupinus albus L. I semi sono amarissimi. Macerati, sono magiati dal volgo leggermente salati. Le madri si servono della povere di lupino per divezzare I bambini, imbrattandosene il capezzole delle mammelle. Vuole la tradizione che il lupino fosse maledetto da G. C. altri dice dalla Madonna, attraversando un campo di lupini secchi, nel fuggire in Egitto, per il rumore che facevano a passar loro vicino.(UNGA21).

\section{Medicago sativa $L$.}

Nombre vulgar: Erba medica (MRI), Erba spagna (RMA, GUF).

Número de informantes: 3 Número de citas: 3.

Número de sectores: 1 Número de categorías: 1.

Biotipo: Hemicriptófito.

Tipo corológico: Europeas.

Abundancia: Común.

Ambiente: Baldíos, campos, prados áridos.

Sector agropastoral

Categoría de uso: Alimentación animal (incluidos los forrajeros).

Número de informantes: 3 Partes utilizadas: frutos/infrutescencias/falsos frutos, parte.

Si coltivava per mucche e pecore (MRI) $\mid$ Era coltivata e seccata per dare da mangiare ai conigli (GUF)| Ogni anno coltivavano grano, orzo, segale (per farina per il pane e per gli animali), lupini, ginestrino,trifoglio, erba spagna, per fare il fieno. E si tenevano I semi ogni anno per l'anno prossimo (RMA).

DATOS ETNOBOTÁNICOS BIBLIOGRÁFICOS

Nombre vulgar: erba medica, spagna (SANS14), erba mèlica (BONZI00), spaggna (GUC98), spâgna (UNGA21).

Número de referencias: 4 Número de citas: 5 .

Número de sectores: 1 Número de categorías: 2.

Sector alimentario

Categoría de uso: Ensalada.

Número de referencias: 1 Partes utilizadas: hojas (SANS14).

Categoría de uso: Verdura cocida.

Número de referencias: 1 Partes utilizadas: hojas (SANS14). 


\section{Medicago sativa L. y otras especies}

Nombre vulgar: Erba medica (MSR), Erba medica, erba merica (CRI), Erba medica, fiorume (MSR), Erba spagna, fiorume (GLA, GGI), Fiorume (VMU, VMR, VFR, UMI, TRU, PSI, MSA, LRE, CRE).

Número de informantes: 13 Número de citas: 15.

Número de sectores: 2 Número de categorías: 2.

Biotipo: Hemicriptófito.

Tipo corológico: Europeas.

Abundancia: Común.

Ambiente: Baldíos, campos, prados áridos.

Sector medicinal

Categoría de uso: Afecciones del aparato respiratorio.

Número de informantes: 13 Partes utilizadas: flores/inflorescencias y sus partes.

La sua mamma metteva un paiolo sulla stufa, e aggiungeva il fiorume. Il fiorume era quello che rimaneva sotto il fieno secco, semi e foglie, c'era di tutto erba medica, lupinella, trifoglio, e altre erbe spontanee (tarassaco), fare bollire il tutto finché rimanesse asciutto, poi fare dei fumenti per il raffreddore (MSR)| "Fiorume", fiori e foglie del fieno (di Trifoglio,trafagliolo, ginestrino, erba medica, radicchi, felce, camomilla, margherite, papaveri) Mettere i fiori e le foglie che restano dopo avere preso il fieno, trittate, nell'acqua bollente e respirare il vapore con la testa coperta con un panno (CRI)| Fare I fumenti con il fiorume che erano tutti I fiori 2 foglie restanti dal fieno (GLA, GGI)| Fare bollire l'acqua e aggiungere I fiori di camomilla da soli oppure nel fiorume insieme agli altri fiori secchi del fieno, poi fare I fumenti coperti di un asciugamano (CRE)| Fare bollire, l'acqua, aggiungere il fiorume e fare le inalazioni. (LRE) $\mid$ Fare dei fumenti con il fiorume due volte al giorno per il raffreddore. (PSI, MSA) $\mid$ Fare dei fumenti dei fiori del fieno. (TRU)| Fare fumenti con il fiorume (I fiori secchi del fieno) per il raffreddore (UMI)| Fare dei fumenti con il fiorume per il raffreddore. (VFR)| Fare I fumenti con il fiorume (semi e fiore di tutte le erbe del fieno) con un asciugamano in testa (VMR)| Mettere nell'acqua calda una manciata di fiorume e fare dei fumenti contro la tosse. (VMU).

\section{Sector veterinario}

Categoría de uso: Ganado bovino.

Número de informantes: 1 Partes utilizadas: parte aérea (toda).

Non si fa andare a pascolo alle pecore ne alle mucche nel guaime(l'erba che cresce dopo la prima o la seconda falciatura) senno le bestie scoppiavano, li veniva il gas. Invece il maggengo (il fieno del primo taglio del fieno è quello più sostanzioso. (MSR).

Notas Fumenti: fiori del fieno, di piante spontanee come il trifoglio, l'erba spagna e il ginestrino, Il fiorume è I seme e I fiori di tutte le erbe del fieno.

\section{Onobrychis viciifolia Scop.}

Nombre vulgar: Lupinella, Fiorume (MSR), Lupinella,fiorume (MSR).

Número de informantes: 1 Número de citas: 2. 
Número de sectores: 1 Número de categorías: 1 .

Biotipo: Hemicriptófito.

Tipo corológico: Mediterráneas montañosas.

Abundancia: Común.

Ambiente: Prados y pastos.

Sector medicinal

Categoría de uso: Afecciones del aparato respiratorio.

Número de informantes: 1 Partes utilizadas: flores/inflorescencias y sus partes.

La sua mamma metteva un paiolo sulla stufa, e aggiungeva il fiorume. Il fiorume era quello che rimaneva sotto il fieno secco, semi e foglie, c'era di tutto erba medica, lupinella, trifoglio, e altre erbe spontanee (tarassaco), fare bollire il tutto finché rimanesse asciutto, poi fare dei fumenti per il raffreddore (MSR).

Notas Erba medica, trifoglio, lupinella, erbe selvatiche (tarassaco), fieno, piante spontanee, fiorume (semi e foglie).

DATOS ETNOBOTÁNICOS BIBLIOGRÁFICOS

Nombre vulgar: lipinœla (UNGA21).

Número de referencias: 1 Número de citas: 1.

Número de sectores: 1 Número de categorías: 1 .

Sector agropastoral

Categoría de uso: Alimentación animal (incluidos los forrajeros).

Número de referencias: 1 Partes utilizadas: parte aérea (toda).

Erba foraggera (UNGA21).

\section{Phaseolus vulgaris $L$.}

Nombre vulgar: Faggioli (MME, MSR, TRU, LGI, BIO), Faggiolini (TRU), Faggioli (Borlotti) (MRI), Faggioli con l'occhio (VMR).

Número de informantes: 7 Número de citas: 9.

Número de sectores: 3 Número de categorías: 4.

Biotipo: Terófito.

Tipo corológico: Cultivadas.

Abundancia: Cultivada.

Ambiente: Cultivada de forma común y subspontanea en los huertos pero nunca verdaderamente asilvestrado.

\section{Sector alimentario}

Categoría de uso: Sopas de verduras y potaje.

Número de informantes: 3 Partes utilizadas: semillas, frutos/infrutescencias/falsos.

La minestra di pane Toscana si fa con il cavolo, faggioli, zuccheti, carota, cavolo verza e un pò di pepolino (BIO)| La zuppa di pane è fatto soffriggendo l'aglio, aggiungere il pomodoro, l'acqua, I faggioli, il cavolo nero, una patata, un pezzo di prosciutto, tanto olio, e fare bollire 2 ore, poi versare sopra un fetta di pane e olio. (LGI)| I faggioli si seminavano nei nostri orti per fare le minestre (TRU)| I faggiolini si coltivavano nei nostri orti per fare le minestre (TRU). 


\section{Sector doméstico}

Categoría de uso: Integración de la renta familiar.

Número de informantes: 2 Partes utilizadas: frutos/infrutescencias/falsos frutos.

A Stagno seminavano tanti faggioli e le vendevano bene. (MSR)| Si scambiavano I faggioli con l'olio ai toscani della campagna. (MRI) $\mid$ Si vendevano i faggioli in più che si riusciva a fare. (MRI).

\section{Sector mágico/medicinal}

Categoría de uso: Verrugas.

Número de informantes: 2 Partes utilizadas: semillas.

Prendere lo stesso numero di faggioli con l'occhio dei porri che si ha. Si segna con il segno della croce ogni porro. Si sotterrano In un punto e si va via da quel punto facendoci il giro senza passarci sopra. Quando I faggiolo sono marci, I porri sono andati via. (VMR) Per curare i porri, si buttava un numero di faggioli uguale al numero di porri nel pozzo nero. Quando i fagioli fossero marciti, i porri sarebbero andati via. (MME).

Notas Non seminare mai i faggioli dopo San Giovanni (è troppo tardi)., I faggiolini vanno coltivati "né a luna vecchia né a luna nuova, ma una volta che la luna ha già rinnovato, deve passare un martedi e un venerdi, e si può seminare, sennò li vengono I pidocchi" Sui pochi terreni piani e irrigabili che c'erano, si preferiva coltivare I faggioli borlotti a I trifogli e l'erba medica forragere, perché il faggioli si vendevano anche.

\section{DATOS ETNOBOTÁNICOS BIBLIOGRÁFICOS}

Nombre vulgar: fagioli (BADI15), fasò (APPO10), fasgióo da la frascca (GUC98), fasgióo dal ciòcco (GUC98), fasgióo mànghia tutto (GUC98), falôl (UNGA21).

Número de referencias: 4 Número de citas: 6.

Número de sectores: 1 Número de categorías: 1.

Sector alimentario

Categoría de uso: Otro alimentario.

Número de referencias: 1 Partes utilizadas: semillas.

Fagioli tonno e cipolla. Ingredienti:Fagioli freschi sgranati,cipolle fresche,tonno sott'olio,olio extravergine d'oliva, sale e pepe. Si fanno lessare i fagioli,si scolano e si lasciano raffreddare.Si tagliano a fettine sottili alcune cipolline fresche ed assieme al tonno sminuzzato si uniscono ai fagioli. Si condiscono con abbondante olio sale e pepe. E' un piatto unico chi si mangia bene d'estate.(BADI15).

\section{Phaseolus vulgaris L. 'Bianchi'}

Nombre vulgar: Faggioli o "faggioli di Roman" o Faggioli borlotti o Faggioli bianchi (DAD).

Número de informantes: 1 Número de citas: 1.

Número de sectores: 1 Número de categorías: 1 .

Biotipo: Terófito.

Tipo corológico: Cultivadas.

Abundancia: Cultivada. 
Ambiente: Cultivada de forma común y subspontanea en los huertos per nunca verdaderamente asilvestrado.

Sector alimentario

Categoría de uso: Verdura cocida.

Número de informantes: 1 Partes utilizadas: frutos/infrutescencias/falsos frutos. Minestra di faggioli: cuocere I faggioli a parte, dopo aver fatto pane al forno a legna, mettere una pentola di faggioli coperti. Il giorno dopo si finiscono di fare sulla stufa o con il gas. Poi soffrigere aglio, pepe, e conserva di pomodoro, aggiungere i faggioli cotti, con una foglia di salvia, soffriggere un pò, aggiungere acqua, o brodo e alla fine, un po di pasta. (DAD).

Notas A settembre,I faggioli vanno su per la frasca, quando I faggioli sono secchi nella pianta, si prendono I baccelli secchi di fondo per farli seccare sotto al letto (nella stanza sopra la cucina, con la stufa) con Ia buccia nelle zanne (sfoglie di castagno) Quando si volevano cucinare, si andavo su si prendevano si sbucciavano e si cucinavano.Il seme che coltiva Ada è tramandato dalla sua nonna, alla sua mamma e dalla sua mamma a lei, e quindi ha più di 60 anni.I faggioli presi da sotto, e messi al sole per qualche giorno, senza sbucciare sopra un sacco di yuta.Si seminano direttamente in terra a Maggio. "Se si prende quelli di cima, facevano incima e basta" (I semi vanno presi da sotto, sennò le piante facevano meno faggioli).

\section{Pisum sativum L.}

Nombre vulgar: Roviglie (MME, NST), Ruvie, pisello selvatico (VSI).

Número de informantes: 3 Número de citas: 3.

Número de sectores: 2 Número de categorías: 2 .

Biotipo: Terófito.

Tipo corológico: Cultivadas.

Abundancia: Común.

Ambiente: Cultivos, baldíos, a menudo subespontáneo.

Sector agropastoral

Categoría de uso: Alimentación animal (incluidos los forrajeros).

Número de informantes: 2 Partes utilizadas: semillas, harina/salvado.

Si coltivavano le roviglie (piselli selvatici), per le mucche (cotte e crude), la farina si usava come foraggera (NST)| Per fare la biada delle mucche si portava al mulino le vecce, I leri (lenticchie), ruvie (pisello selvatico). E per fare la broda per il maiale si macinava l'orzo e l'avena. (VSI).

\section{Sector alimentario}

Categoría de uso: Verdura cruda.

Número de informantes: 1 Partes utilizadas: semillas.

Si mangiavano solo freschi, crudi. (MME).

Notas È una specie di pisello coltivato. Manca in Venturi(2006). 


\section{Robinia pseudoacacia $L$.}

Nombre vulgar: Cacia (TRU), Acacia (UMI, TAD, SLU, NLA, MTO, FAM, CRI, BIO, BFE, BEL, TIV, TUL, BGI), Acacio (BAN), Acascio (MRI), Accaggio,Acascio (RFR), Cascia (LST).

Número de informantes: 18 Número de citas: 21.

Número de sectores: 2 Número de categorías: 5.

Biotipo: Fanerófito.

Tipo corológico: Amplia distribución.

Abundancia: Común.

Ambiente: Escarpes, baldíos, setos.

Sector agropastoral

Categoría de uso: Herramientas y objetos agrícolas.

Número de informantes: 1 Partes utilizadas: tallos leñosos/ramas/ramitas/vástagos.

Si usava il legno di Cacia per fare I denti dei rastrelli (TRU).

Categoría de uso: Otro agropastoral.

Número de informantes: 3 Partes utilizadas: planta entera/viva.

Si pianta in terreni franosi perché la radici crescono veloce (BGI)| La piantavano per I terreni franosi, perche e molto ramicata, tiene il terreno bene, fa radici lunghe pero superficiale. Fino ad un certo punto perche quando cresce tanto bisogna tagliarlo, perche essendo molto pesante puo cascare tutto. (TUL)| Si coltivava nei terreni franosi, nelle scarpate per tenere il terreno, però dopo quando crescono un pò bisognaba tagliarli perché diventano alti e leggeri e cascano/si sradicano con la neve. (TRU).

\section{Sector alimentario}

Categoría de uso: Conserva de frutas.

Número de informantes: 1 Partes utilizadas: flores/inflorescencias y sus partes.

Si mettevano i fiori nell'acqua e si lasciavano fermentare. Veniva fuori una specie di spumante (TIV).

Categoría de uso: Fritura.

Número de informantes: 15 Partes utilizadas: flores/inflorescencias y sus partes. (MTO)Passare i fiori nella pastella e friggerli. (BEL)| I fiori di acacia bagnati nella pastella e fritte. (BFE)| Fiori bagnate nella pastella e fritti (UMI, BGI)| Si fanno le frittelle di fiori di acacia. (BIO)| Fiori imbevuti nella pastella e fritti (NLA, CRI)| Fiori bagnati nella pastella e fritti (FAM)| Fritte con la pastella (SLU)| Bagnati nella pastella e fritti (TAD)| Infiorescenze mature, passate nella pastella e fritte. (BAN)| Le infiorescenze mature vanno passate nella pastella e fritte. (RFR, MRI)| I fiori di cascia fritti con la pastella (LST).

Categoría de uso: Tortilla.

Número de informantes: 1 Partes utilizadas: flores/inflorescencias y sus partes. Infiorescenze messe nella frittata (TIV).

Notas Le fritelle dei fiori di Acacia è qualcosa di moderno. 


\section{DATOS ETNOBOTÁNICOS BIBLIOGRÁFICOS}

Nombre vulgar: acacia, acâg (SANS14), Cascia (POLI14), acâg' (UNGA21), acàsscio.

(GUC98).

Número de referencias: 4 Número de citas: 5.

Número de sectores: 3 Número de categorías: 4.

Sector alimentario

Categoría de uso: Empanadas.

Número de referencias: 1 Partes utilizadas: flores/inflorescencias y sus partes (SANS14).

Categoría de uso: Golosinas y masticatorias.

Número de referencias: 1 Partes utilizadas: flores/inflorescencias y sus partes (SANS14).

\section{Sector artesanal}

Categoría de uso: Objetos agrícolas.

Número de referencias: 1 Partes utilizadas: madera.

La "caretta" era un attrezzo per piccoli movimenti di terra, e altri materiali sfusi, realizzata in legno compresa la ruota cerchiata di ferro, con vasca a sezione triangolare. Il telaio in genere era di acacia (cascia) e la vasca in pioppo. Ne esisteva anche un tipo per donna con vasca piú piccola. (POLI14).

Sector medicinal

Categoría de uso: Trastornos musculo-esqueléticos.

Número de referencias: 1 Partes utilizadas: flores/inflorescencias y sus partes.

...I fior d'acag, I fiori d'acacia, sono dagli empirici ordinati in decotto, come antispasm..

(UNGA21).

\section{Spartium junceum $L$.}

Nombre vulgar: (non sa come si chiama) (VSI), Ginestre di spagna (BPA), Ginestre (VMU).

Número de informantes: 3 Número de citas: 3.

Número de sectores: 2 Número de categorías: 3 .

Biotipo: Fanerófito.

Tipo corológico: Eurimediterránea.

Abundancia: Común.

Ambiente: Arbustos en estaciones soleadas.

Sector agropastoral

Categoría de uso: Construcción agrícola (cabañas, etc...).

Número de informantes: 1 Partes utilizadas: tallos leñosos/ramas/ramitas/vástagos.

Per costruire i tetti delle capanne agricole e per fare tettoie per coprire gli attrezzi agricoli si usava mettere dei pali paralleli e tra questi rami fitti di questa pianta. (VSI). 
Categoría de uso: Cuerdas y ataduras.

Número de informantes: 1 Partes utilizadas: tallos leñosos/ramas/ramitas/vástagos.

Per legare i pomodori (BPA).

\section{Sector artesanal}

Categoría de uso: Fibra textil.

Número de informantes: 1 Partes utilizadas: parte aérea (toda).

In tempo di guerra si faceva la stoffa di ginestra (VMU).

\section{DATOS ETNOBOTÁNICOS BIBLIOGRÁFICOS}

Nombre vulgar: vinco (GUC98), znœstra (UNGA21), róggiola (GUC98).

Número de referencias: 2 Número de citas: 3 .

Número de sectores: 1 Número de categorías: 2.

Sector artesanal

Categoría de uso: Cestería.

Número de referencias: 1 Partes utilizadas: tallos leñosos/ramas/ramitas/vástagos. Tipo di ginestra si utilizzavano gli steli per piccoli lavori di intreccio. (GUC98).

Categoría de uso: Fibra textil.

Número de referencias: 1 Partes utilizadas: parte aérea (toda). utilizzata per le fibre tessili che dànno buon tiglio. (UNGA21).

\section{Trifolium pratense $L$.}

Nombre vulgar: Erba trifoglio (SOT), Trifoglio (RRE, GGL, RMA, PCL, MRI), Trifoglio, fiorume (GLA, GGI), Trifoglio, Fiorume (MSR), Trifoglio, trafagliolo (CRI), Trifoglio,fiorume (MSR).

Número de informantes: 10 Número de citas: 11.

Número de sectores: 3 Número de categorías: 3.

Biotipo: Terófito.

Tipo corológico: Eurimediterránea.

Abundancia: Bastante Común.

Ambiente: Prados, pastos, baldíos, y también cultivados como forraje.

Número de exsiccata: 38911 FIAF.

Sector agropastoral

Categoría de uso: Alimentación animal (incluidos los forrajeros).

Número de informantes: 4 Partes utilizadas: parte aérea (toda),

D'estate gli si davano alle pecore, erba trifoglio ed erba selvatica, e d'inverno gli si dava del fieno (SOT)| Foraggera per fieno per le mucche o le pecore (MRI)| I campi si coltivavano alternativamente: nello stesso campo si seminavano prima le patate, dopo il grano, e dopo nelle stoppie se seminava il segale insieme al trifoglio e al ginestrino. Il segale si falciava alto e perché così rimanesse per fare il fieno. Oppure dopo il grano si seminavano le vecce. (PCL) $\mid$ Ogni anno coltivavano grano, orzo, segale (per farina per il pane e per gli animali), lupini, ginestrino,trifoglio, erba spagna, per fare il fieno. E si tenevano I semi ogni anno per l'anno prossimo (RMA). 
Sector lúdico/voluptuoso

Categoría de uso: Fumable.

Número de informantes: 1 Partes utilizadas: flores/inflorescencias y sus partes.

I fiori secchi sulla pianta si sbriciolavano, si mettevano sulla carta e si faceva una sigaretta.

che si fumava. (GGL).

\section{Sector medicinal}

Categoría de uso: Afecciones del aparato respiratorio.

Número de informantes: 5 Partes utilizadas: flores/inflorescencias y sus partes.

Mettere $\mathrm{i}$ fiori del trifoglio in un recipiente con acqua bollente coperto con un imbuto messo con la parte stretta verso l'alto e aspirare il vapore. (RRE)| Fare I fumenti con il fiorume che erano tutti I fiori 2 foglie restanti dal fieno (GLA, GGI)| La sua mamma metteva un paiolo sulla stufa, e aggiungeva il fiorume. Il fiorume era quello che rimaneva sotto il fieno secco, semi e foglie, c'era di tutto erba medica, lupinella, trifoglio, e altre erbe spontanee (tarassaco), fare bollire il tutto finché rimanesse asciutto, poi fare dei fumenti per il raffreddore (MSR)| "Fiorume", fiori e foglie del fieno (di Trifoglio o "trafagliolo", ginestrino, erba medica, radicchi, felce, camomilla, margherite, papaveri) Mettere i fiori e le foglie che restano dopo avere preso il fieno, trittate, nell'acqua bollente e respirare il vapore con la testa coperta con un panno (CRI).

Notas Tecniche di coltivo:Quando I trifogli sono marroni, si riprendono I semi nei panieri per seminare., Fumenti: fiori del fieno, di piante spontanee come il trifoglio, l'erba spagna e il ginestrino, Erba medica, trifoglio, lupinella, erbe selvatiche (tarassaco), fieno, erbe spontanee.

\section{DATOS ETNOBOTÁNICOS BIBLIOGRÁFICOS}

Nombre vulgar: trifoglio dei prati (SANS14), Trafoiio'lo (APPO10), trefàgliolo (BONZI00).

Número de referencias: 3 Número de citas: 3.

Número de sectores: 1 Número de categorías: 1.

\section{Sector alimentario}

Categoría de uso: Golosinas y masticatorias.

Número de referencias: 1 Partes utilizadas: flores/inflorescencias y sus partes (SANS14).

\section{Trifolium sp. pl.}

Nombre vulgar: Quatrifoglio (GFO).

Número de informantes: 1 Número de citas: 1.

Número de sectores: 1 Número de categorías: 1 .

Biotipo: Terófito o Hemicriptófito.

Tipo corológico: n.d.

Abundancia: Común.

Ambiente: Prados. 
Sector mágico/ritual/supersticioso

Categoría de uso: Propiciatorio.

Número de informantes: 1 Partes utilizadas: planta entera/viva.

Quando si trova un quadrifoglio si avrà fortuna. (GFO).

\section{Ulex europaeus $L$.}

Nombre vulgar: Incoronacristi (REN).

Número de informantes: 1 Número de citas: 1.

Número de sectores: 1 Número de categorías: 1.

Biotipo: Fanerófito.

Tipo corológico: Atlánticas.

Abundancia: Común.

Ambiente: Arbustos y maquias submediterráneo (silicio).

Número de exsiccata: 39001 FIAF.

Sector doméstico

Categoría de uso: Repelentes o trampas domésticas.

Número de informantes: 1 Partes utilizadas: tallos leñosos/ramas/ramitas/vástagos.

Contro I topi nella dispensa: Vicino al prosciutto, o sopra il formaggio si mettevano dei rami di incoronacristi, per evitare che I topi andassero sopra. (REN).

Notas Venturi (2006): uniche stazioni presso Cave di Torri (sotto M. Calvario) e pressi di C. Mosca.

DATOS ETNOBOTÁNICOS BIBLIOGRÁFICOS

Nombre vulgar: znœstra dai spôn (UNGA21).

Número de referencias: 1 Número de citas: 1.

Número de sectores: 1 Número de categorías: 1.

Sector agropastoral

Categoría de uso: Alimentación animal (incluidos los forrajeros).

Número de referencias: 1 Partes utilizadas: No especificado.

Pianta foraggera de luoghi umidi montani, detta anche trifoglio giallo, ginestra selvatica (UNGA21).

\section{Vicia faba $L$.}

Nombre vulgar: Fave (NRE).

Número de informantes: 1 Número de citas: 1.

Número de sectores: 1 Número de categorías: 1 .

Biotipo: Terófito.

Tipo corológico: Cultivadas.

Abundancia: Cultivada.

Ambiente: En los cultivos.

Sector mágico/medicinal

Categoría de uso: Verrugas. 
Número de informantes: 1 Partes utilizadas: frutos/infrutescencias/falsos frutos.

Per curare i porri, si diceva di sotterrare in un incrocio un numero di fave uguale al numero di porri che si avevano. (NRE).

DATOS ETNOBOTÁNICOS BIBLIOGRÁFICOS

Nombre vulgar: faeva (UNGA21).

Número de referencias: 1 Número de citas: 1.

Número de sectores: 1 Número de categorías: 1.

Sector mágico/ritual/supersticioso

Categoría de uso: Otro mágico/ritual/supersticioso.

Número de referencias: 1 Partes utilizadas: semillas.

fava, legume noto, estes. Colt. Ne campi. La fava aveva ant. Un significato funerario. Fino al sec. XVII nelle nostre campagne usavasi cuocere il giorno de morti molta fava e dispensarla per l'amor di Dio. Da ciò la fava da morto de'dolciaj. (UNGA21).

\section{Vicia sativa $L$.}

Nombre vulgar: Vecce (NMA, GFR, MME, BAZ, VSI, UMI, MSR, MRI), Viscia (CLO).

Número de informantes: 9 Número de citas: 11 .

Número de sectores: 3 Número de categorías: 3 .

Biotipo: Terófito.

Tipo corológico: Amplia distribución.

Abundancia: Común.

Ambiente: Prados áridos, pastos, cultivos, y también cultivado.

Sector agropastoral

Categoría de uso: Alimentación animal (incluidos los forrajeros).

Número de informantes: 5 Partes utilizadas: frutos/infrutescencias/falsos frutos,.

Si seminavano le vecce per dare i semi ai volatili. Si raccoglievano con le rete e quando erano ben asciutte, si mettevano nell'aia di casa e si sbattevano con il "correggiato" (due bastoni legati con strisce di pelle), si separavano i gusci dai semi, e poi le donne li mettevano in un paniere e quando tirava aria, li muovevano nel paniere per togliere i residui del baccello. Per galline e piccioni (MRI)| Le vecce si macinavano e si aggiungeva questo sfarinato alla broda del maiale (MSR)| Dopo il grano si seminavano anche le vecce, I frutti macinati per I brodi per le bestie, erano ottime per farli fare più latte. (UMI)| Le vecce si seminavano per gli animali (UMI)| Per fare la biada delle mucche si portava al mulino le vecce, I leri (lenticchie), ruvie (pisello selvatico). E per fare la broda per il maiale si macinava l'orzo e l'avena. (VSI) $\mid$ Alimento per gli animali (CLO).

Sector alimentario

Categoría de uso: Pan y similares.

Número de informantes: 3 Partes utilizadas: harina/salvado. 
Facevano il pane con la farina di vecce e di ghiande di quercia, quando non c'era nient'altro (BAZ) $\mid$ La farina delle vecce veniva mescolata con la farina di grano o di segale, per fare il pane. Si faceva per bisogno. (MSR, MME).

Sector religioso

Categoría de uso: Ornamento para altares e iglesias.

Número de informantes: 2 Partes utilizadas: planta entera/viva.

Il giovedi santo si portavano in chiesa le vecce fini e bianche che erano state seminate e fatte crescere al buio, mettendole in un vaso che si teneva dentro al forno (GFR)| Il giorno prima della Quaresima si seminava al buio in un vaso di terra annaffiata e si portava al sepolcro il Giovedì di Pasqua, mettendo in mezzo una candelina. (NMA).

Notas La rosiccia si faceva: per pulire, per concimare e per evitare che nascano meno erbacee.A Stagno, I terreni erano a terrazze, la terra è friabile, si vangano le zolle e voltano in giù, poi la prima fila la bruciavamo, e poi brusciava tutto sotto piano piano. Poi seminavano segale, marzolo o Vecce.I campi si coltivavano alternativamente: nello stesso campo si seminavano prima le patate, dopo il grano, e dopo nelle stoppie se seminava il segale insieme al trifoglio e al ginestrino. Il segale si falciava alto e perché così rimanesse per fare il fieno. Oppure dopo il grano si seminavano le vecce.

\section{LILIACEAE}

\section{Lilium bulbiferum L. (= Lilium bulbiferum L. subsp. croceum (Chaix) Baker)}

Nombre vulgar: Gigli (arancioni) (PCL), Gigli selvatici (MTO, MSR), Giglio arancione (BOR).

Número de informantes: 4 Número de citas: 4.

Número de sectores: 2 Número de categorías: 2.

Biotipo: Geófito.

Tipo corológico: Montañosas.

Abundancia: Rara.

Ambiente: Prados húmedos subalpinos, vegetación de altas hierbas, bosque de monte bajo.

Sector doméstico

Categoría de uso: Ornamental.

Número de informantes: 1 Partes utilizadas: parte aérea (toda).

Mettere in casa in un vaso per abbellire. (PCL).

Sector religioso

Categoría de uso: Ornamento para altares e iglesias.

Número de informantes: 3 Partes utilizadas: flores/inflorescencias y sus partes.

Si portavano i fiori selvatici per la Madonna. (MTO, MSR)| Si portavano anche i gigli. 
arancioni alla Madonna. (BOR).

Notas Non ci sono più l'istrice ha mangiato tutto.

\section{Lilium candidum $L$.}

Nombre vulgar: Gigli (BBA).

Número de informantes: 1 Número de citas: 1.

Número de sectores: 1 Número de categorías: 1.

Biotipo: Geófito.

Tipo corológico: Eurimediterránea.

Abundancia: Común.

Ambiente: Parques, jardines, cultivada como ornamental, no muestra tendencia a asilvestrarse.

Sector doméstico

Categoría de uso: Jardín.

Número de informantes: 1 Partes utilizadas: planta entera/viva.

Si prendevano e si coltivavano nel giardino per abbelire la casa (BBA).

Notas Il suo marito curava le piante dell'orto e lei le piante del giardino.

\section{LINACEAE}

\section{Linum usitatissimum $L$.}

Nombre vulgar: Lino (NST, VMU, PGI, AMA, VFR, SOT, RMA, PIM, PEL, PCL, MGE, LRE, GGI, CRO, CAR, BFE, BEL, BAN, AN3, TGA).

Número de informantes: 20 Número de citas: 26.

Número de sectores: 3 Número de categorías: 7.

Biotipo: Terófito.

Tipo corológico: Cultivadas.

Abundancia: Cultivada.

Ambiente: Cultivada y subspontaneizada.

Sector artesanal

Categoría de uso: Fibra textil.

Número de informantes: 1 Partes utilizadas: parte aérea (toda).

Un tempo si coltivava e si tesseva (TGA).

Sector medicinal

Categoría de uso: Afecciones del aparato respiratorio.

Número de informantes: 16 Partes utilizadas: semillas, harina/salvado.

Fare degli impacchi dei semi di lino sul petto per la tosse. (AN3)| Fare una pappina/crema, asciutta ma calda di farina di lino e di senape, mettere dentro una garza e fare l'impiastro sul petto, sui bronchi. (BAN)| Fare degli impiastri di semi di lino cotti sul petto per la bronchite o la tosse. (BEL)| Fare un impiastro di farina di lino con acqua bollente, mettere su una garza e applicare il tutto sul petto. (BFE)| Fare degli 'impiastri' con I semi di lino riscaldati finché non si formi una poltiglia, 
applicare bolltente sul petto (CAR)| I semi di lino vanno cotti e messi in un panno poi appoggiare il tutto sul petto (CRO)| Mettere I semi di lino riscaldati insieme alla semola di grano su un panno e metterlo sul petto. (GGI)| Fare degli 'impacchi' (impiastri) di farina di lino sul petto per la tosse. (LRE)| Si facevano degli 'impiastri' di farina di lino calda sul petto per la tosse (MGE)| Cuocere I semi di lino in un po' d'acqua e applicare sul petto o sulla gola. (PCL)| bollire i semi di lino (comprati) e bere l'acqua. (PEL)| Fare degli impacchi di semi di lino cotti sul petto la sera. (PIM)| fare un 'impacco' (cataplasma) di semi di lino bolliti sul petto. (RMA)| Impiastro di farina di lino e aceto (SOT)| Mettere impacchi di semi di lino sul petto, sfiamma. (TGA)| Fare degli "cataplasmi" con I semi di lino riscaldati finché non si formi una poltiglia, applicare bolltente sul petto. Si compravano. (VFR).

Categoría de uso: Afecciones ginecológicas, complicaciones obstétricas, del postparto y del puerperio.

Número de informantes: 2 Partes utilizadas: semillas.

Fare degli impiastri di semi di lino cotti e applicarli sui capezzoli. (BEL)| Fare un 'impacco'.

(cataplasma) sulla mammella per favorire la montata di latte. (RMA).

Categoría de uso: Afecciones oro-faríngeas y de la cavidad oral.

Número de informantes: 3 Partes utilizadas: semillas, harina/salvado.

Bollire i semi di lino per 10 minuti, finché si forma una specie di pellicola e metterli in un panno, per fare degli impacchi sulla parte del corpo infiammata, cambiando il panno spesso. Per il mal di gola, mal di denti. (AMA)| Fare degli impacchi di farina di lino sulla guancia infiammata per gli ascessi ai denti (PGI)| Mettere farina di lino sopra gli ascessi direttamente (TGA).

Categoría de uso: Estado general.

Número de informantes: 2 Partes utilizadas: semillas, aceite.

Bollire i semi di lino per 10 minuti, finché si forma una specie di pellicola e metterli in un panno, per fare degli impacchi sulla parte del corpo infiammata, cambiando il panno spesso. Per applicazioni esterne su qualsiasi parte del corpo infiammata. (AMA)| Mettere a seccare all'ombra tutti I "semi della vita": semi delle ciliege, delle susine ossia le prugne gialle, di zucca, I pinoli, le noci, le culloie o nocciole, le foglie di malva secche, il fiore del gigliopapagone e anche un pò di olio di semi di lino. Poi macinare tutto con il macinino da caffé. E prendere un cucchiaio tutte le mattine a primavera e a ottobre. (VMU).

Categoría de uso: Patologías del aparato digestivo.

Número de informantes: 1 Partes utilizadas: semillas.

Mettere a mollo nell'acqua bollente i semi di lino e lasciarli tutta la notte. La mattina dopo.

bere. (NST).

\section{Sector veterinario}

Categoría de uso: Ganado bovino.

Número de informantes: 1 Partes utilizadas: semillas.

Bollire i semi e metterli in mezzo alla biada, per 'rinfrescare' l'animale quando ha problemi di stomaco. (AMA).

Notas farina comprata in farmacia, tempo fa lo seminavano e qui lo tessevano. 


\section{DATOS ETNOBOTÁNICOS BIBLIOGRÁFICOS}

Nombre vulgar: lino (MANG98), len (UNGA21).

Número de referencias: 2 Número de citas: 5 .

Número de sectores: 1 Número de categorías: 3.

Sector medicinal

Categoría de uso: Afecciones cutáneas y tejidos subcutáneos.

Número de referencias: 2 Partes utilizadas: semillas, harina/salvado.

Impacchi di semi bolliti vengono applicati sugli ascessi, oppure sul petto in caso di tosse. (MANG98) lino, pianta estesamente coltivata ne campi e in alcuni luoghi spontanee, da cui si ricava materia atta a filarsi e il cui seme è utilizzato nell'industria e in farmacia. Nella medicina popolare il seme è adoperato come rinfrescante e contro la tosse. L'impiastro di farina di seme di lino viene praticato come emolliente e maturante(UNGA21).

Categoría de uso: Afecciones del aparato respiratorio.

Número de referencias: 2 Partes utilizadas: semillas.

lino, pianta estesamente coltivata ne campi e in alcuni luoghi spontanee, da cui si ricava materia atta a filarsi e il cui seme è utilizzato nell'industria e in farmacia. Nella medicina popolare il seme è adoperato come rinfrescante e contro la tosse. L'impiastro di farina di seme di lino viene praticato come emolliente e maturante(UNGA21).

Categoría de uso: Estado general.

Número de referencias: 1 Partes utilizadas: semillas.

lino, pianta estesamente coltivata ne campi e in alcuni luoghi spontanee, da cui si ricava materia atta a filarsi e il cui seme è utilizzato nell'industria e in farmacia. Nella medicina popolare il seme è adoperato come rinfrescante e contro la tosse. L'impiastro di farina di seme di lino viene praticato come emolliente e maturante(UNGA21).

\section{LORANTHACEAE}

\section{Loranthus europaeus Jacq.}

Nombre vulgar: Vischio (BEL, GGI, BGI).

Número de informantes: 3 Número de citas: 5 .

Número de sectores: 2 Número de categorías: 2.

Biotipo: Fanerófito.

Tipo corológico: Europeas.

Abundancia: Rara.

Ambiente: Bosques.

Sector caza y pesca

Categoría de uso: Caza de pájaros.

Número de informantes: 2 Partes utilizadas: frutos/infrutescencias/falsos frutos.

Le bacche hanno un lattice che fa da colla, mettendola su una superficie, gli uccelli rimangono attaccati (BGI)| "La pania è una colla ricavata dal vischio per fare la 
caccia di frodo, è collosa, si metteva sulle tavole oppure con un pennello sui rami, sulle frasche in modo che gli uccelli rimanevano attaccati" (GGI).

Sector doméstico

Categoría de uso: Repelentes o trampas domésticas.

Número de informantes: 1 Partes utilizadas: frutos/infrutescencias/falsos frutos.

Per intrappolare le mosche, si spalmava la bacca su una carta e le mosche si attaccavano a questa. (BEL).

DATOS ETNOBOTÁNICOS BIBLIOGRÁFICOS

Nombre vulgar: vessti (UNGA21).

Número de referencias: 1 Número de citas: 1 .

Número de sectores: 1 Número de categorías: 1.

Sector caza y pesca

Categoría de uso: Caza de pájaros.

Número de referencias: 1 Partes utilizadas: No especificado.

Entrambe queste piante sono adoperate per preparare la pania degli uccellatori (UNGA21).

\section{LYTHRACEAE (incluye PUNICACEAE)}

\section{Punica granatum L.}

Nombre vulgar: Granate (GFR).

Número de informantes: 1 Número de citas: 1.

Número de sectores: 1 Número de categorías: 1.

Biotipo: Fanerófito.

Tipo corológico: Cultivadas.

Abundancia: Cultivada.

Ambiente: Cultivada como ornmental o por el fruto y asilvestrada en los jardines.

Sector mágico/ritual/supersticioso

Categoría de uso: Protector.

Número de informantes: 1 Partes utilizadas: frutos/infrutescencias/falsos frutos. Per allontanare le streghe si coltivava nell'orto a casa (come lei) o c'era chi teneva un frutto.

appeso in casa. (GFR).

DATOS ETNOBOTÁNICOS BIBLIOGRÁFICOS

Nombre vulgar: melograno (SANS14), mailgranae (UNGA21).

Número de referencias: 2 Número de citas: 2 .

Número de sectores: 2 Número de categorías: 2.

Sector alimentario

Categoría de uso: Fruta fresca.

Número de referencias: 1 Partes utilizadas: frutos/infrutescencias/falsos frutos (SANS14). 


\section{Sector medicinal}

Categoría de uso: Patologías del aparato digestivo.

Número de referencias: 1 Partes utilizadas: frutos/infrutescencias/falsos frutos. melograno, p. delle mirt. Spont. Nelle siepi, orn. E colt. Pel frutto detto mailagranae, melagranata. Nella medicina popolare il succo è somministrato in bevanda come astringente. Presso taluno ha fama vermifuga. (UNGA21).

\section{MALVACEAE (incluye TILIACEAE p.p.)}

\section{Malva sylvestris $L$.}

Nombre vulgar: Malva (AMA, BAN, BAT, BAZ, BBA, BEL, BFE, BIO, BLI, BLI, BMA, BOR, BPT, BSI, BSO, CAR, CBR, CFR, CRE, CRI, DAD, EMA, FAM, GAN, GCL, GFR, GGI, GGL, GLA, GRI, GZE, LRE, LST, MDA, MGO, MIO, MRI, MSA, MSI, MSR, MTI, MVI, NDI, NLA, NMA, NRE, NST, PEL, PGI, PLU, REN, REN, RFR, RGI, RMA, RRE, SCO, SOT, TAD, TAT, TGA, TIV, TOA, TRU, TUL, UMI, VAL, VFR, VMA, VMR, VMU, ZAN), Malva selvática (NRO, SLU), Malvia (RNI).

Número de informantes: 73 Número de citas: 14.

Número de sectores: 2 Número de categorías: 11.

Biotipo: Hemicriptófito.

Tipo corológico: Nórdicas.

Abundancia: Bastante Común.

Ambiente: Baldíos, lugares pisoteados, acumulaciones de escombros y basura.

Número de exsiccata: 39049 FIAF, 38983 FIAF, 39048 FIAF.

Sector alimentario

Categoría de uso: Arroces y "risotto".

Número de informantes: 2 Partes utilizadas: hojas.

Con le foglie di malva fare il risotto nel modo consueto (VAL, BEL).

Sector medicinal

Categoría de uso: Afecciones cutáneas y tejidos subcutáneos.

Número de informantes: 6 Partes utilizadas: hojas, parte aérea (toda), hojas,.

Applicare direttamente delle foglie di malva sulle bruciature. (CRE)| Fare impacchi del decotto di malva (GCL)| Fare degli impacchi di decotto di malva sulla parte infiammata. (GGL)| Lavare i geloni con un decotto di foglie di malva. (MVI, GZE)| Bollire un po' le barbe, le foglie e I fiori, poi fare gli impacchi con del cotone imbevuto nel decotto (MGO).

Categoría de uso: Afecciones del aparato respiratorio.

Número de informantes: 14 Partes utilizadas: hojas, órganos subterráneos.

Cuocere la radice e le foglie fresche per 10 minuti e berla spesso. Oppure mettere le radici e foglie fresche nell'acqua bollente e mettere la testa sopra coperta da un asciugamano per fare le fumenta. (AMA)| Bere il decotto di malva, 'quando uno respira male'. (BEL)| Fare l'iinfuso di malva e fare degli sciacqui. Dopo la raccolta delle patate, raccogliere I fiori e foglie di malva per metterli a seccare per 
conservarle per tutto l'inverno (BFE)| Infuso usato per sciacqui per le infiammazioni della bocca, oppure viene bevuto in caso di mal di gola (BPT)| Raccolte a primavera,si mettevano a seccare per l'inverno. Fare bollire le foglie e I fiori freschi o secche per 2 minuti, e fare degli sciacqui. Ma si può anche bere. (CRE)| Fare fumenti di malva, mettendo nell'acqua bollente delle foglie di malva e mettendo la testa sopra coperta da un asciugamano. (GGL)| Bere il decotto dei fiori e foglie di malva per la tosse. (MTI)| Mettere qualche foglia nell' acqua bollente e coprire per 10 minuti (NMA)| Fare il 'fiasco' pieno del decotto di foglie e fiori di polmonaria, foglie di farfanella, foglie di malva, di cimballaria, di piscialletto e di foglie di erba ruggine. (NRE)| Mettere a bollire I fiori e le foglie della malva e bere per il catarro (TGA)| Bere spesso il decotto di malva. (VAL)| Mettere nell'acqua bollente I 'cemolini' (germogli pieni di resina) dei pini, insieme alle foglie del Sambuco e alle foglie di Malva. Lasciare un pò a riposo e aggiungere del miele. (VMR)| Bevuto "un po di volte". (SLU)| Fare dei fumenti con le foglie di malva per il raffredore (RNI).

Categoría de uso: Afecciones ginecológicas, complicaciones obstétricas, del postparto y del puerperio.

Número de informantes: 3 Partes utilizadas: parte aérea (toda), flores/inflorescencias y.

Fare cuocere tutta la pianta fresca della malva, filtrare e fare dei lavaggi per problemi legati alle le mestruazioni: dolori mestruali, malessere, come rinfrescante e antiinfiammatorio. (BSO) $\mid$ Mettere a bollire I fiori e le foglie della malva e bere per il mal di mestruazioni (TGA)| Fare il decotto con le foglie fresche di malva 1:2. (VMU).

Categoría de uso: Afecciones oftalmológicas.

Número de informantes: 6 Partes utilizadas: hojas, flores/inflorescencias y sus partes.

Fare un impasto con le foglie di malva pestate e la pasta madre e mettere sopra gli occhi arrossati. (MVI, GZE)| Fare degli impacchi di decotto di malva (gambo e foglie, senza fiori) e applicarli sugli occhi (NDI)| Cuocere un po' di foglie fresche o secche, bagnare nel decotto un fazzoletto e mettere sugli occhi per un po'. (NLA) Fare impacchi del decotto di malva sugli occhi infiammati o arrossati. (REN)| Applicare una stoffa imbevuta nell'infuso di camomilla e malva sugli occhi (SOT).

Categoría de uso: Afecciones oro-faríngeas y de la cavidad oral.

Número de informantes: 30 Partes utilizadas: hojas, órganos subterráneos.

Cuocere le radici e le foglie fresche per 10 minuti, bere spesso il decotto, oppure metterle in un panno e appoggiarlo sulla parte infiammata, legato con un fazzoletto. (AMA)| Cuocere leggermente le foglie e lavare la bocca con l'acqua di malva (BAN)| Mal di gola: bere di tanto in tanto il decotto di malva. Mal di denti: bagnare una pezza nel decotto di malva e metterla sul dente. (VAL, BEL)| Per il mal di denti, bere infuso di Malva con Salvia e Camomilla (BLI)| Infuso usato per sciacqui per le infiammazioni della bocca, oppure viene bevuto in caso di mal di gola (BPT)| Si pestavano le foglie di malva e si faceva un cataplasma sulla guancia dove c'era il dente che faceva male (CAR)| Quando fanno male i denti bere (quando si ha sete) il decotto delle foglie (CRI)| Sciacqui della bocca per il mal di denti (GCL)| Applicare la pianta cotta sulla parte infiammata e coprire con una garza. (GGL)| Fare degli sciacqui con l'infuso di malva per il mal di denti. (GRI)| Fare il decotto di malva, 
farlo raffreddare e fare degli sciacqui in bocca. (LRE)| Fare degli sciacqui prima di andare al letto con l'infuso di malva per il mal di denti. (LST)| Fare l'infuso delle foglie di malva e fare sciacqui. (MDA)| Bollire un po' le 'barbe', le foglie e I fiori, poi fare gli sciacqui di tanto in tanto (MGO)| Fare degli sciacqui in bocca (MRI)| Fare degli sciacqui in bocca con il decotto di malva per il mal di gola. (MSA) Raccogliere la pianta a fine agosto, quando fiorisce, lavarla e metterla a seccare, appesa all'ombra, poi conservarla in un sachetto di carta. Fare il decotto bollendo per 5 o 6 minuti. Per le gengiviti fare gli sciacqui 4 o 5 volte al giorno, per il mal di gola fare i gargarismi 4 o 5 volte al giorno, oppure bere il decotto spesso. (MSR)| Fare degli sciacqui in bocca con il decotto di malva (gambo con foglie, senza fiori), come rinfrescante. (NDI)| Fare degli impacchi di malva per gli ascessi ai denti (PGI)| Sciacqui bucali per il mal di boca (SOT)| Si raccolgono i fiori e le foglie e si mettono a seccare per conservarle. Fare un infuso e bere. (TAD)| Fare degli sciacqui del decotto di malva per il mal di denti. (TAT)| Le foglie e I fiori della malva messi a bollire un po', e con l'acqua fare degli sciacqui (TGA)| Mettevano a seccare tutta la pianta, e quando serviva facevano l'infuso. Fare degli sciacqui oppure berla. (TIV)| Bere di tanto in tanto "l'acqua di malva". (TOA)| Fare degli sciaqui di decotto di malva per le infiammazioni alla bocca. (TRU)| Fare degli sciacqui con l'infuso di malva per l'infiammazione delle gengivi (VMA)| Per il mal di denti, fare sciacqui con 1' acqua di Malva e Salvia. (NRO)| Fare 'scottare', bollire un pò le foglie di malvia, filtrare e fare degli sciacqui e bere il decotto per le infiammazioni in bocca. Fare degli impacchi di foglie cotte, metterle dentro di un telo di cotone e si poi si mettevano sopra la guancia, quando si aveva un gonfiore de un dente. (RNI).

Categoría de uso: Estado general.

Número de informantes: 19 Partes utilizadas: hojas, órganos subterráneos.

Cuocere la radice e le foglie fresche, per 10 minuti e berla spesso. La sua mamma dopo masticava le radici e le foglie. (AMA)| Si fanno bollire le foglie della salvia insieme alla malva e si bevono come 'rinfrescante'. (BIO)| Raccoglierla, metterla a seccare per l'inverno, fare il decotto delle foglie di malva e berlo. (BOR)| Fare cuocere per 10 minuti tutta la pianta della malva, filtrare e bere come 'rinfrescante', antiinfiammatorio. (BSO)| 5 a 10 foglie fresche o secche in acqua bollente, lasciando riposare 5 minuti (GRI, CFR)| Raccoglievano diverse piante come la Malva, la Camomilla e I radicchi (foglie), le facevano seccare e le conservavano in dei sacchettini di stoffa. (CRE)| Bere il decotto di malva per infiammazioni varie. (LRE)| Bere il decotto di malva per le infiammazioni. (MSA)| Il decotto è 'rinfrescante'. (MSI)| Fare un decotto dei fiori secchi e delle foglie e bere come 'rinfrescante'. (MTI)| Bere l'infuso della parte epigea della malva come calmante e antiinfiammatorio. (PLU)| Bere il decotto per tutti I tipi di infiammazione. (REN)| Bere il decotto di malva come rinfrescante. (RRE, RFR)| Bere il decotto di malva come 'rinfrescante'. (TAT)| Bollire le foglie di malva e bere per sfiammare. (VFR)| Fare il decotto delle foglie di malva e bere come antinfiammatorio. Anche insieme al rosmarino, alla salvia e al piscialletto in infusione: Fare l'infuso delle foglie di rosmarino, salvia, piscialletto (prima del fiore) e malva, si beveva a diguino la mattina e la sera per 10/15 giorni. (VMR)| Mettere a seccare all'ombra tutti I "semi della vita": semi delle ciliege, delle susine ossia le prugne gialle, di zucca, I pinoli, le noci, le culloie o nocciole, le foglie di malva secche, il fiore del gigliopapagone e 
anche un pò di olio di semi di lino. Poi macinare tutto con il macinino da caffé. E prendere un cucchiaio tutte le mattine a primavera e a ottobre. (VMU).

Categoría de uso: Patologías del aparato circulatorio.

Número de informantes: 5 Partes utilizadas: parte aérea (toda), flores/inflorescencias y.

Fare degli impacchi di malva sulla parte infiammata. (VAL, BEL)| Bere infuso di Tignamica, Malva e fiori di Tiglio (BLI)| Fare un 'infuso' facendo cuocere le foglie e i fiori di malva e bere. (RGI)| Fare il decotto delle foglie di malva e bere contro le emorroidi (VMR).

Categoría de uso: Patologías del aparato digestivo.

Número de informantes: 26 Partes utilizadas: hojas, órganos subterráneos.

Cuocere la radice e le foglie fresche, per 10 minuti e berla spesso. La sua mamma dopo masticava le radici e le foglie. (AMA) $\mid$ Raccogliere le radice, le foglie e I fiori, lavare e tagliare fine, mettere a bollire e bere. (BBA)| Bere il decotto di malva 'per andare in bagno'. (BEL)| Le foglie di malva cotte e bevute di tanto in tanto per l'infiammazione dell'intestino (BMA)| Raccoglierla, metterla a seccare per l'inverno, fare il decotto delle foglie di malva e berlo. (BOR)| Fare il decotto della pianta di malva fresca e berlo. (RMA, BSI)| Fare l'acqua di malva: "levare un bollore alle foglie di malva" e bere contro il mal di pancia (CBR) 5 a 10 foglie fresche o secche in acqua bollente, lasciando riposare 5 minuti (CFR)| Farsi bagni di infuso di malva (DAD) $\mid$ Cuocere le radici, le foglie e I fiori per 10 minuti, e bere ogni tanto. Prima si seccavano per conservarli, "ora li congela perché sennò sa di fieno" (GFR)| Bere il decotto di malva quando si ha male. (GGL)| Bere il decotto di malva per il mal di pancia. (LRE)| Fare l'infuso di foglie di malva e bere l'infuso finché passa il mal di stomaco. (MDA)| Bollire un po' le 'barbe', le foglie e I fiori, poi bere di tanto in tanto (MGO)| Fare un decotto con qualche foglia di malva e bere di tanto in tanto. (MRI)| Bere il decotto di malva per il mal d'intestino. (NDI)| fare bollire poco la pianta (l"infuso') e bere. (PEL)| Fare un 'infuso' facendo cuocere le foglie e i fiori di malva e bere. (RGI)| Foglie messa nell'acqua bollente (SOT)| Bere il decotto di malva spesso per l'appendicite. (TAT)| Mettere a bollire I fiori e le foglie della malva e bere per il mal di stomaco (TGA)| Fare il decotto delle foglie di malva e bere come lassativo (VMR)| Fare il decotto con le foglie fresche di malva 1:2. (VMU)| Si faceva il decotto delle foglie di mava e si beveva per l'intestino (ZAN)| Bevuto "un po' di volte". (SLU).

Categoría de uso: Patologías del aparato urinario.

Número de informantes: 27 Partes utilizadas: hojas, órganos subterráneos.

Cuocere la radice e le foglie fresche, per 10 minuti e berla spesso. La sua mamma dopo masticava le radici e le foglie. (AMA)| Fare bollire le foglie di malva e bere l'acqua di malva di tanto in tanto. (BAT, BAN)| Suo padre raccoglieva tutta la pianta della malva insieme alla radice e faceva il decotto, lo beveva quando aveva problemi alla vescica, per le infiammazioni urinarie (BAZ) $\mid$ Raccogliere le radice, le foglie e I fiori, lavare e tagliare fine, mettere a bollire e bere. (BBA)| Bere spesso il decotto di malva o fare degli impacchi locali. (VAL, BEL)| Fare il decotto della pianta di malva fresca e berlo. (RMA, BSI)| "quando bruciava la pipi, si mettevano a bollire 5 010 foglie di malva e si beveva di tanto in tanto" (CFR)| Quando si ha difficoltà a urinare bere (quando si ha sete) il decotto delle foglie (CRI)| Raccogliere tutta la 


\section{María Teresa Egea Molines}

pianta e mettere ad essiccare, poi conservare in sacchetti di carta, e quando si usa mettere nell' acqua bollente, e coprire durante 5 o $10 \mathrm{~min}$. (DAD)| Fare dei lavaggi con il decotto della malva per sfiammare quando si ha infezione di urina (EMA) Foglie secche o fresche messe nell' acqua bollente, e bevuto spesso (FAM)| Bere spesso "l'acqua di malva":il decotto di malva. (GAN)| Cuocere le radici, le foglie e I fiori per 10 minuti, e bere ogni tanto. (GFR)| Bere di tanto in tanto il decotto. (GGI)| Cuocere per $10 \mathrm{~min}$. le foglie e I fiori della malva, lasciare a riposo per tutta la notte, e la mattina a digiuno, scolare e bere. (GLA)| Bere l'infuso di malva per la cistite (LST)| Bere il decotto di malva per la cistite o il 'mal di urina'. (MSA)| Bere 2 litri di acqua di malva al giorno per la prostata. (MTI)| Bollire le foglie di malva facendogli appena levare il bollore, bere 2 volte al giorno. (NST)| non specificato (REN)| Bere l'infuso di malva per l'infezione di orina (SCO)| Bere di tanto in tanto (TUL)| Bollire I fiori e le foglie di malva, e bere il decotto di continuo. (UMI)| Fare lavaggi con il decotto dei fiori (GCL).

Categoría de uso: Trastornos musculo-esqueléticos.

Número de informantes: 2 Partes utilizadas: parte aérea (toda), hojas.

Fare bollire le infiorescenze, e fare un impacco oppure berla contro I dolori. (BLI)| Fare il.

decotto delle foglie di malva e applicare con impacchi sulla parte infiammata. (MIO).

Notas "La nonna a San Giovanni, la mattina andava a raccogliere Sambuco, Malva, piantaggine, per poi metterle a seccare per l'inverno a mazzi, non so a che cosa servivano, secondo me non servivano a niente, le prendeva giusto per tradizione". Cura di Primaveraè una pianta infestanteFiori e foglie raccolte quando sono in fiore. Il terreno è selvatico perché non lo coltivano più. Ce n'è tanto meno.Mettere a seccare la pianta tagliata a pezzettini. Raccogliere la pianta a fine Agosto, quando fiorisce. Raccolte quando sono in fiore, e messe ad essicare all'ombre. Si mettevano a seccare le barbe, le foglie e I fiori raccolti verso settembre/ottobre, quando piu dura era meglio era. Si mettevano a seccare le barbe, le foglie e I fiori raccolti verso settembre/ottobre, quando piu dura era meglio era. Si mettevano a seccare le barbe, le foglie e I fiori raccolti verso settembre/ottobre, quando piu dura era meglio era. $\mathrm{Si}$ seccavano solo i fiori, perché le foglie si trovavano sempre Si seccavano solo i fiori, perché le foglie si trovavano sempre. Va raccolta sempre e messa a seccare per conservarla.

\section{DATOS ETNOBOTÁNICOS BIBLIOGRÁFICOS}

Nombre vulgar: malva (ZAGN90, MANG98), maelva (UNGA21).

Número de referencias: 3 Número de citas: 10.

Número de sectores: 1 Número de categorías: 9.

Sector medicinal

Categoría de uso: Afecciones cutáneas y tejidos subcutáneos.

Número de referencias: 1 Partes utilizadas: hojas.

Esternamente la foglia fresca contusa viene applicata su foruncoli ed ascessi (MANG98).

Categoría de uso: Afecciones del aparato respiratorio.

Número de referencias: 1 Partes utilizadas: hojas, órganos subterráneos. 
o mescolata con il latte per sanare la tosse (UNGA21).

Categoría de uso: Afecciones ginecológicas, complicaciones obstétricas, del postparto y del puerperio.

Número de referencias: 1 Partes utilizadas: órganos subterráneos.

Le radici di quest'erba, ridotta alla consistenza di mucillagine, si danno per facilitare il parto (UNGA21).

Categoría de uso: Afecciones oftalmológicas.

Número de referencias: 1 Partes utilizadas: hojas, órganos subterráneos.

e si somministra in infusione per calmare il dolore degli occhi infiammati (UNGA21).

Categoría de uso: Afecciones oro-faríngeas y de la cavidad oral.

Número de referencias: 1 Partes utilizadas: hojas.

Con il decotto si effettuano sciacqui orali. (MANG98).

Categoría de uso: Estado general.

Número de referencias: 2 Partes utilizadas: hojas, órganos subterráneos.

I contadini ne mangiano le foglie in insalata per sciogliere il corpo.Nella medicina popolare è.

usata come rinfrescante ed emolliente, (UNGA21)| ttorno a casa nostra non manca mai la malva: la usiamo per le tisane contro gli incalorimenti, prendendo tutta la pianta, meglio se con il fiore (ZAGN90).

Categoría de uso: Patologías del aparato circulatorio.

Número de referencias: 1 Partes utilizadas: hojas.

le foglie di malva bollite sono adoperate a mò d'impiastro per le emorroidi (UNGA21).

Categoría de uso: Patologías del aparato digestivo.

Número de referencias: 1 Partes utilizadas: hojas.

Per via interna l'infuso è ritenuto efficace antinfiammatorio del tratto gastointestinale e delle.

vie genito-urinarie, utile anche in caso di aerofagia (MANG98).

Categoría de uso: Patologías del aparato urinario.

Número de referencias: 1 Partes utilizadas: hojas.

Per via interna l'infuso è ritenuto efficace antinfiammatorio del tratto gastointestinale e delle.

vie genito-urinarie (MANG98).

\section{Tilia americana $L$.}

Nombre vulgar: Tiglio (BMA).

Número de informantes: 1 Número de citas: 1.

Número de sectores: 1 Número de categorías: 1.

Biotipo: Fanerófito.

Tipo corológico: Cultivadas.

Abundancia: Cultivada.

Ambiente: Cultivada en los parques y a los largo de las avenidas.

Número de exsiccata: 39050 FIAF. 
Sector medicinal

Categoría de uso: Patologías del sistema nervioso.

Número de informantes: 1 Partes utilizadas: flores/inflorescencias y sus partes.

Fare un infuso dei fiori di tiglio per calmare. (BMA).

\section{Tilia platyphyllos Scop.}

Nombre vulgar: Tiglio (VAL, TAD, GGI, FAM, CFR, BEL, TGA, VMR, BLI, SLU, MGE, MGO).

Número de informantes: 12 Número de citas: 15.

Número de sectores: 2 Número de categorías: 8.

Biotipo: Fanerófito.

Tipo corológico: Europeas.

Abundancia: Rara.

Ambiente: Bosques húmedos, barrancos, a menudo con olmo, fresno, aliso, haya.

Sector artesanal

Categoría de uso: Muebles.

Número de informantes: 1 Partes utilizadas: madera.

Mobili e cornici (MGO).

Sector medicinal

Categoría de uso: Afecciones cutáneas y tejidos subcutáneos.

Número de informantes: 1 Partes utilizadas: flores/inflorescencias y sus partes.

Mettere degli impacchi dell'infuso di fiori di tiglio sulla pelle infiammata. (MGO).

Categoría de uso: Afecciones del aparato respiratorio.

Número de informantes: 1 Partes utilizadas: flores/inflorescencias y sus partes.

I fiori del tiglio che c'èra vicino casa si faceva in infuso e si beveva contro la tosse. (MGE).

Categoría de uso: Estado general.

Número de informantes: 1 Partes utilizadas: flores/inflorescencias y sus partes.

Si raccoglievano i fiori, si essicavano, e si prendevano in infuso ogni tanto, 'faceva bene'..

Categoría de uso: Patologías del aparato circulatorio.

Número de informantes: 1 Partes utilizadas: flores/inflorescencias y sus partes.

Bere infuso di Tignamica, Malva e fiori di Tiglio (BLI).

Categoría de uso: Patologías del aparato digestivo.

Número de informantes: 1 Partes utilizadas: tallos

leñosos/ramas/ramitas/vástagos.

Brusciare il ramo nel fuoco (attenti perché sennò sparisce), quando è incandescente, lo si bagna, poi si mette a seccare e si macina(anche con il macinino da caffé). Mettere un cucchiaio o di più (si faceva a occhio, non c'era pericolo un pò di più o un pò di meno) nell'acqua, diluire e bere 2 o 3 volte al giorno finché non passi. (VMR).

Categoría de uso: Patologías del aparato urinario.

Número de informantes: 1 Partes utilizadas: semillas.

Bere il decotto dei semi di Tiglio per urinare piu frequentemente e meglio (TGA). 
Categoría de uso: Patologías del sistema nervioso.

Número de informantes: 8 Partes utilizadas: flores/inflorescencias y sus partes.

Fare 'l'infuso' (decotto) di fiori di tiglio freschi o secchi, come calmante per dormire meglio. (VAL, BEL)| I fiori di Tiglio in infuso, si bevevano come calmante (CFR)| Fiori raccolti d' estate e messi ad essiccare per l' inverno, per potere dormire (FAM) Si raccoglievano i fiori e si essicavano, poi si mettevano nell'acqua bollente e si beveva per calmare e per potere dormire (GGI)| Bere prima di andare a dormire (MGO)| Fiori raccolti d' estate da agosto e messi ad essiccare per l' inverno, poi messi nell' acqua calda per 5 min. e bevuto come calmante (TAD)| Fare l'infuso delle foglie del tiglio che si andavano a raccogliere dagli alberi del bosco, e bere come sedativo o sonnifero (VMR).

Notas Proprietà del legno: è duro come il bosso, assorbe totalmente la vernice, non torge, non "riprova", non crepa, non fa il tarlo, quando è secco non si spezza.

DATOS ETNOBOTÁNICOS BIBLIOGRÁFICOS

Nombre vulgar: telli (UNGA21), tiglio (MANG98).

Número de referencias: 2 Número de citas: 5.

Número de sectores: 2 Número de categorías: 4.

Sector doméstico

Categoría de uso: Tinta o utensilio para escribir.

Número de referencias: 1 Partes utilizadas: madera.

Col carbone di tiglio si fanno matite da disegno (UNGA21).

Sector medicinal

Categoría de uso: Afecciones del aparato respiratorio.

Número de referencias: 1 Partes utilizadas: flores/inflorescencias y sus partes.

$\mathrm{Si}$ assume in caso di tosse. (MANG98).

Categoría de uso: Fiebre.

Número de referencias: 1 Partes utilizadas: flores/inflorescencias y sus partes.

I fiori vengono somministrati nella medicina familiare in decôt ed telli, decozione di tiglio,

come antispasmodico e diaforetico. (UNGA21).

Categoría de uso: Patologías del sistema nervioso.

Número de referencias: 2 Partes utilizadas: flores/inflorescencias y sus partes.

I fiori vengono somministrati nella medicina familiare in decôt ed telli, decozione di tiglio, come antispasmodico e diaforetico. (UNGA21)| $\mathrm{Si}$ assume in caso di agitazione e di insonnia (MANG98).

\section{MORACEAE}

\section{Ficus carica $L$.}

Nombre vulgar: Fichi (AN3, GAN), Fico (VMU, VMR, UMI, RFR, MVI, MGI, GZE, GGL, GGI, GUF, CFR), Fico acerbo (MCL).

Número de informantes: 13 Número de citas: 15. 
Número de sectores: 4 Número de categorías: 4.

Biotipo: Fanerófito.

Tipo corológico: Amplia distribución.

Abundancia: Común.

Ambiente: Acantilados sombreados, muros.

Sector alimentario

Categoría de uso: Fruta seca.

Número de informantes: 1 Partes utilizadas: frutos/infrutescencias/falsos frutos.

I fichi si mettevano a seccare aperti alla metà, in delle graticole dentro al forno, dopo aver tolto il pane si mettevano nel forno per delle ore. E si faceva in 3 o 4 volte. (AN3).

Categoría de uso: Mermelada.

Número de informantes: 1 Partes utilizadas: frutos/infrutescencias/falsos frutos.

Si fa la marmellata di ficchi, mettendoli a bollire sulla stufa finché non abbia la consistenza desiderata. (GAN) |Cuocere le pere e i fichi senza buccia per 4 o 5 ore, passarlo con il passaverdura, e aggiungere un po' di succo di limone o di arancio. Mettere nei vasi quando ancora bolle, tappare subito i barattoli e metterli a testa all'ingiù. (MSR).

Sector efecto nocivo

Categoría de uso: Efecto perjudicial.

Número de informantes: 1 Partes utilizadas: planta entera/viva.

"Non coltivare niente sotto il fico e il noce perche non cresce niente" (CFR).

Sector lúdico/voluptuoso

Categoría de uso: Fumable.

Número de informantes: 1 Partes utilizadas: tallos leñosos/ramas/ramitas/vástagos.

Pipe fatte con il manico di ramo di fico e il fornello di terra cotta (GUF).

Sector medicinal

Categoría de uso: Afecciones cutáneas y tejidos subcutáneos.

Número de informantes: 12 Partes utilizadas: látex o savia.

Si stacca una foglia dal fico e il lattice che esce dal picciolo si mette subito sopra $i$ porri, ripetere varie volte per vari giorni (CFR)| Togliere un foglia e mettere direttamente il lattice sopra le verruche per una settimana. (GGI)| Applicare direttamente il 'latte' (lattice) dei fichi acerbi sui porri, finché vanno via. (GGL) Togliere una foglia di fico, e appoggiarla sopra il porro, per applicare il lattice sul porro (GUF)| Applicare il lattice del fico sui porri. (MVI, GZE)| Applicare il 'latte' di fico sui 'poranci'. (RFR, MGI)| Applicare il lattice di fico direttamente sui porri, finché non vadano via. (UMI)| Applicare il latte del fico sui porri (VMR)| Applicare il lattice sui porri. (VMU)| Strappando la foglia o il fico, viene fuori il lattice che si applica direttamente sui porri (MCL).

DATOS ETNOBOTÁNICOS BIBLIOGRÁFICOS

Nombre vulgar: fichi (GRIZ03), fîg vardecc (UNGA21), brugiòtti (BONZI00).

Número de referencias: 3 Número de citas: 3 . 
Número de sectores: 2 Número de categorías: 2 .

\section{Sector alimentario}

Categoría de uso: Otro alimentario.

Número de referencias: 1 Partes utilizadas: frutos/infrutescencias/falsos frutos.

Torta delicata: $110 \mathrm{~g}$ di farina bianca, $100 \mathrm{gr}$ di zucchero, $400 \mathrm{gr}$ di fichi, $300 \mathrm{~g}$ di uva, $100 \mathrm{~g}$ di burro, 1/4 di litro di latte, 2 uova, scorza grattugiata di un limone. Stemperare $100 \mathrm{~g}$ di farina col latte, unire le uova sbattute, lo zucchero e la scorza di limone. Sbucciare i fichi, tagliarli a spicchi e metterli con l' uva in una tortiera imburrata ed infarinata. Versare sopra la pastella ed informare per un ora a 180 gradi. (GRIZ03).

Sector medicinal

Categoría de uso: Afecciones del aparato respiratorio.

Número de referencias: 1 Partes utilizadas: frutos/infrutescencias/falsos frutos.

Il fico è creduto pettorale e si usa in campagna appassito in decozione per guarire la tosse..

(UNGA21).

\section{Morus nigra $L$.}

Nombre vulgar: Gelso (MRI).

Número de informantes: 1 Número de citas: 2.

Número de sectores: 1 Número de categorías: 1 .

Biotipo: Fanerófito.

Tipo corológico: Cultivadas.

Abundancia: Cultivada.

Ambiente: Cultivado en todo el territorio por el fruto, y raramente subespontáneo.

Sector doméstico

Categoría de uso: Integración de la renta familiar.

Número de informantes: 1 Partes utilizadas: hojas.

Vendevano la foglia secca agli allevatori di bachi da seta di Pistoia. (MRI)| Le foglie erano raccolte come alimento per I bacchi di seta. (MRI).

Notas "sono scomparsi tutti".

\section{MYRTACEAE}

\section{Eucalyptus camaldulensis Dehnh.}

Nombre vulgar: Eucalipto (BLI).

Número de informantes: 1 Número de citas: 1.

Número de sectores: 1 Número de categorías: 1 .

Biotipo: Fanerófito.

Tipo corológico: Cultivadas.

Abundancia: Cultivada. 


\section{María Teresa Egea Molines}

Ambiente: A lo largo de la costa Tirrenia, en Italia del Sur, Sicilia, Cerdeña, Córcega.

\section{Sector medicinal}

Categoría de uso: Afecciones del aparato respiratorio.

Número de informantes: 1 Partes utilizadas: hojas.

Mettere nell'acqua bollente foglie di salvia con rosmarino, menta e eucalipto e fare inalazioni con la testa sopra la pentola con l'acqua coperti da un asciugamano. (BLI).

Notas E` possibile che usino anche altre specie di Eucalyptus.

\section{Syzygium aromaticum (L.) Merr. \& L.M. Perry}

Nombre vulgar: Chiodi di garofano (MCL, VMR, PGI, LST, DAD, CRI, BEL, BAZ, AN3).

Número de informantes: 9 Número de citas: 13.

Número de sectores: 2 Número de categorías: 3 .

Biotipo: Fanerófito.

Tipo corológico: Exóticas.

Abundancia: Cultivada.

Ambiente: Ausente.

Sector alimentario

Categoría de uso: Licor.

Número de informantes: 8 Partes utilizadas: flores/inflorescencias y sus partes.

Prendere 30 noci (mallo verde, quando dentro non è ancora fatto), 1 litro e mezzo di alcol, 750 gr di zucchero, 2 grammi di cannella reggina trittati, 10 chiodi di garofano, 4 litri di acqua, la buccia del limone. Lasciare macerare per 40 giorni al buio o alla penombra in cantina,e filtrare. (AN3) $\mid$ Il Corniolino:1 $\mathrm{kg}$ di corniole, 1 litro di alcol, 625 gr di zucchero, 625 gr d'acqua, 5 chiodi di garofano, 1 pizzico di cannella, e la scorza di limone.Lasciare tutto a macerare per 40 giorni, poi filtrare, fare lo sciroppo con lo zucchero e l'acqua e aggiungere. (AN3)| Vin brulé: fare bollire il vino con la buccia del limone, la cannella e I chiodi di garofano. Si beveva nelle veglie, tutti offrivano il vin brulé. (AN3)| 1 giumella' (pugno) di bacche di ginepro verdi, '1 giumella' (pugno) di bacche viola di ginepro mature. Mettere in un vaso a chiusura ermetica con 1 litro di alcol 90 gradi, 1 lirto di acqua, nell'acqua ci diluisci $1 \mathrm{~kg}$ di zucchero, un poco di cannella, 3 chiodi di garofano, Lasciare 40 giorni (se lo lasci di più è meglio. Filtrare e imbottigliare. (BAZ)| Raccogliere 21 noci prese verso il 24 giugno, mettere a macerare in un litro di alcol, mezzo di litro di acqua, 500 gr di zucchero, 1,5 gr di cannella e 7 chiodi di garofano, lasciare a riposare per 3 settimane e filtrare. (BEL)| Ricetta della suocera chimata la nonna: "28 nocine tagliate, 1 litro di alcol puro, 900 gr.zucchero, 1scorza limone, 1stecca vaniglia,4 chiodi di garofano, 1pizzico di cannella. Stringere lo zucchero in acqua calda e lasciare 40 giorni (DAD, CRI) $\mid$ Il vin brulé si faceva nell'inverno quando si era in compagnia: uno spicchio di mela, un pò di cannella, chiodi di garofano, mettere a bollire, appena bolle un pò, si dava fuoco per togliere l'alcol. (LST)| Vin brulé: vino, zucchero e chiodi di garofano, si faceva bollire un pò. (PGI)| Il 'Nocino':raccogliere le noci la sera di San Giovani. La tradizione dice che si debono 
rubare e raccogliere scalzi. Poi vanno tagliati con il coltello di legno a forma di croce. Mettere i frutti a macerare nel vino e alcol insieme allo zucchero, al limone e ai chiodi di garofano per 40 giorni al sole. Le proporzioni sono segrete. Poi filtrare e imbotigliare. (VMR).

\section{Sector medicinal}

Categoría de uso: Afecciones oro-faríngeas y de la cavidad oral.

Número de informantes: 2 Partes utilizadas: flores/inflorescencias y sus partes.

Infuso insieme a foglie di salvia, facendone sciacqui (MCL)| Applicare sul dente che fa male il chiodo di garofano (PGI).

Categoría de uso: Patologías del aparato digestivo.

Número de informantes: 1 Partes utilizadas: flores/inflorescencias y sus partes.

Prendere 30 noci (mallo verde, quando dentro non è ancora fatto), 1 litro e mezzo di alcol, 750 gr di zucchero, 2 grammi di cannella reggina trittati, 10 chiodi di garofano, 4 litri di acqua, la buccia del limone. Lasciare macerare per 40 giorni al buio o alla penombra in cantina,e filtrare. (AN3).

Notas ricetta passata da una amica: Vilma di chiapporato., Raccogliere 21 noci prese verso il.

24 giugnoIl vino a Castelluccio non si coltivava perché è troppo alto, solo c'era l'uva fragola ma questa fa un vino di bassa gradazaione alcolica. Avere il vino era già un lusso.

\section{OLEACEAE}

\section{Fraxinus angustifolia Vahl subsp. oxycarpa (Willd.) Franco \& Rocha Afonso (cfr.) (= Fraxinus oxycarpa Bieb.) (s.l.) (cfr.))}

Nombre vulgar: Frassino (VMR).

Número de informantes: 1 Número de citas: 3.

Número de sectores: 2 Número de categorías: 3.

Biotipo: Fanerófito.

Tipo corológico: Europeas.

Abundancia: Rara.

Ambiente: Bosques húmedos, barrancos.

Sector alimentario

Categoría de uso: Otro alimentario.

Número de informantes: 1 Partes utilizadas: látex o savia.

Si faceva la manna per dolcificare: Tagliavano la corteccia in primavera (quando c'era l'insucchio) e usciva fuori una linfa, la raccoglievano, la seccavano e la macinavano. Poi si usava come dolcificante nell'caffé o nel latte. (VMR).

Sector medicinal

Categoría de uso: Patologías del aparato circulatorio.

Número de informantes: 1 Partes utilizadas: corteza. 


\section{María Teresa Egea Molines}

non specificato. Le sembra che mettevano la corteccia nell'acqua. (VMR).

Categoría de uso: Patologías del aparato digestivo.

Número de informantes: 1 Partes utilizadas: látex o savia.

La manna (Tagliavano la corteccia in primavera, quando c'era l'insucchio, e usciva fuori una linfa, la raccoglievano, la seccavano e la macinavano. ) si mangiava contro la stitichezza come lassativa. (VMR).

\section{Fraxinus excelsior $L$.}

Nombre vulgar: Frassino (SOT, GGI).

Número de informantes: 2 Número de citas: 2.

Número de sectores: 1 Número de categorías: 1.

Biotipo: Fanerófito.

Tipo corológico: Europeas.

Abundancia: Común.

Ambiente: Bosques húmedos, barrancos húmedos.

Sector agropastoral

Categoría de uso: Herramientas y objetos agrícolas.

Número de informantes: 2 Partes utilizadas: tallos leñosos/ramas/ramitas/vástagos.

Per fare manici di accette. Dice che per fare I manici si prendeva un trochetto di 1, 2 metro più o meno si spaccava in mezzo, allora una metà veniva dritta e l'altra si piegava. Si prendeva sempre quella dritta e con il pennato, l'accettina, la sega a nastro e per ultimo la lima da legna li davano la forma anche per reggerlo con la mano. Allora i vecchi avevano una precisione con il pennato extraordinaria. Questo lavoro non si poteva fare con i polloni perché questi si piegavano. Il legno era resistente però pestava tanto le mani (facevano venire velocemente i calli) (GGI) Per stanghe da carri e manici dei carri: legno più grigio, non pesta le mani, resistente e leggero. (SOT).

Notas Proprietà del legno: resistente(è più resistente del ornello, fa un diametro più grande di.

$50 \mathrm{~cm}$ e arriva a più di $30 \mathrm{~m}$, invece l'ornello massimo 15 metri e $30 \mathrm{~cm}$ di diametro).

\section{Fraxinus ornus $L$.}

Nombre vulgar: Ornello (AP2, TRU, TIV, SOT, REN, MGO, IRE, GGI, CFR, BPA, BGI), Orniello (MOR, MRI, TAT), Nos Mattala, Ornello (VMA), Frassino (TAD, GUF), Nosgiadella (PIM, EMA).

Número de informantes: 19 Número de citas: 24.

Número de sectores: 5 Número de categorías: 8 .

Biotipo: Fanerófito.

Tipo corológico: Europeas.

Abundancia: Común.

Ambiente: Bosques degradados en el área submediterránea.

Número de exsiccata: 38946 FIAF, 39116 FIAF. 
Sector agropastoral

Categoría de uso: Herramientas y objetos agrícolas.

Número de informantes: 11 Partes utilizadas: tallos leñosos/ramas/ramitas/vástagos.

Manici di zappe, accette,mazza di ferro non tanto grande. (BGI)| Manico del picco o delle zappe (BPA)| strumenti di lavoro: zappe, accette: legno robusto e forte che ritarda la formazione dei calli, ci si aggrappa bene (CFR)| Per fare il manico del rastrello. Dice che per fare I manici si prendeva un tronchetto di 1, 2 metro più $o$ meno si spaccava in mezzo, allora una metà veniva dritta e l'altra si piegava. (era una proprietà del frassino) Si prendeva sempre quella dritta e con il pennato, l'accettina, la sega a nastro e per ultimo la lima da legna li davano la forma anche per reggerlo con la mano. Allora i vecchi avevano una precisione con il pennato extraordinaria. Questo lavoro non si poteva fare con i polloni perché questi si piegavano. Il legno era resistente però pestava tanto le mani (facevano venire velocemente i calli) (GGI)| Manico del martello (IRE)| Manico di attrezzi (MGO)| Per fare il manico del rastrello $(\mathrm{REN}) \mid$ La buccia è verdastra e liscia, è più duro che il frassino (SOT)| Manico delle vanghe o delle zappe (TIV)| Si usavano il primo pezzo della pianta, stagionati un anno, per fare I manici dei pichi o delle zappe o delle mazze (TRU)| Il legno di orniello si usa per fare il manico delle accette e delle zappe (TAT).

\section{Sector artesanal}

Categoría de uso: Otro artesanal.

Número de informantes: 1 Partes utilizadas: madera.

Si facevano gli scii con il legno della 'nos mattala', li si portava il legno dal falegname e li.

facevano per fare le gare da scii. (VMA).

\section{Sector doméstico}

Categoría de uso: Objetos domésticos y escobas.

Número de informantes: 1 Partes utilizadas: tallos leñosos/ramas/ramitas/vástagos.

I rami sono usati per fare bastoni per camminare (Lámina 12). (MRI).

Sector medicinal

Categoría de uso: Trastornos musculo-esqueléticos.

Número de informantes: 1 Partes utilizadas: corteza.

Mettere la corteccia dell'ornello nell'acqua, quando diventava blu, dicevano che si doveva bere sempre che uno aveva sete. (GGI).

\section{Sector veterinario}

Categoría de uso: Aves de corral.

Número de informantes: 6 Partes utilizadas: corteza.

Per le galline: macerato della corteccia nell' acqua che diventava blu. (GUF)| Mettere la corteccia della nosgiadella nell'acqua dove bevono le galline, che diventa blu, come disinfettante intestinale. (EMA)| Mettere a macerare la corteccia nell'acqua nel 'trogalo' (contenitore di legno). Diventava verde/azzurra e veniva fatta 


\section{María Teresa Egea Molines}

bere alle galline. (PIM)| Si pelava l'ornella, si levava la buccia, e si metteva a bagno nell'acqua, che diventava rosastra. Si dava da bere alle galline quando stavano male. (AP2)| Mettevano a macerare la corteccia nell'acqua che acquistava un colore blu e la facevano bere ai polli per fermare l'epidemia (GGI)| Mettevano a macerare la corteccia nell' acqua che acquistava un colore blu da bere alle galline (TIV).

Categoría de uso: Conejos.

Número de informantes: 1 Partes utilizadas: corteza.

Per la diarrea o la perdita di pelo dei conigli: dare da bere la corteccia messa a macerare nell' acqua che diventava blu. (TAD).

Categoría de uso: Conejos.

Número de informantes: 2 Partes utilizadas: tallos leñosos/ramas/ramitas/vástagos.

Si metteva un ramo in acqua e si dava da bere ai conigli soggetti a malattia. (MRI, MOR).

Categoría de uso: Ovejas y cabras.

Número de informantes: 1 Partes utilizadas: corteza.

Meteorismo delle capre dovuto al consumo eccessivo di erba fresca: mettevano a macerare la corteccia nell' acqua che acquistava un colore blu, poi la mettevano negli abbeveratoi per fargliela bere. 'Quando le capre scoppiavano, perché avevano mangiato erba fresca e si gonfiavano. (CFR).

Notas (è più resistente del ornello, fa un diametro più grande di $50 \mathrm{~cm}$ e arriva a più di $30 \mathrm{~m}$, invece l'ornello massimo 15 metri e $30 \mathrm{~cm}$ di diametro), Proprietà del legno: è duro per lavorare però "pesta le mani", era infesttante, l'ornello è il legno più duro è più duro che il carpine nero. Si chiamava la nosgiadella perché avevano la forma simile alla noce.

DATOS ETNOBOTÁNICOS BIBLIOGRÁFICOS

Nombre vulgar: nos' giadèlla (BAL48, GUC98), ornèllo (BONZI00).

Número de referencias: 3 Número de citas: 3 .

Número de sectores: 1 Número de categorías: 1.

Sector agropastoral

Categoría de uso: Avicultura.

Número de referencias: 1 Partes utilizadas: corteza, hojas.

Si mettevano le foglie e corteccia a bagno nell'acqua dove bevevano le galline per ottenere un.

blando desinfettante. (GUC98).

\section{Ligustrum vulgare $L$.}

Nombre vulgar: Ligustre (NRE).

Número de informantes: 1 Número de citas: 2.

Número de sectores: 1 Número de categorías: 1.

Biotipo: Nanofanerófito.

Tipo corológico: Europeas.

Abundancia: Común. 
Ambiente: Bosques caducifolios termófilos, sobre todo en los márgenes y en los matorrales en.

degradación, setos.

Número de exsiccata: 39122 FIAF.

Sector agropastoral

Categoría de uso: Vallas y delimitaciones.

Número de informantes: 1 Partes utilizadas: planta entera/viva.

Si usava fare le siepi con diverse piante: ligustri, spini (prugnolo e biancospino), acero.

campestre,sanguinelli, berretti da prete. (NRE) $\mid$ Si coltiva fuori casa come siepe (NRE).

Notas Davanti a casa sua..

DATOS ETNOBOTÁNICOS BIBLIOGRÁFICOS

Nombre vulgar: ulivœla (UNGA21).

Número de referencias: 1 Número de citas: 3 .

Número de sectores: 2 Número de categorías: 3.

Sector doméstico

Categoría de uso: Tinta o utensilio para escribir.

Número de referencias: 1 Partes utilizadas: frutos/infrutescencias/falsos frutos.

Con le bacche e l'aggiunta di solfato di ferro si ottiene un buon inchiostro. (UNGA21).

Categoría de uso: Tintorial.

Número de referencias: 1 Partes utilizadas: frutos/infrutescencias/falsos frutos.

Con le bacche si fa un bel verde per la seta e lana (UNGA21).

Sector medicinal

Categoría de uso: Afecciones oro-faríngeas y de la cavidad oral.

Número de referencias: 1 Partes utilizadas: hojas.

Le foglie sono adoperate nella medicina popolare per curare le ulceri della bocca. (UNGA21).

\section{Olea europaea $L$.}

Nombre vulgar: Olivo (NRO, VMR, MGE, GLA, VMU, TOA, TGA, SOT, GCL, PCL, NMA, NLA, FAM, CLO, CFR, BPA, GUF, GGI, GFO, ECE, CRI, PLU, GFR), Olivo benedetto (DAD), Ulivo (GZE), Olio (LLU, NDI), Olio di oliva (AMA), Oliva (VFR, RNI).

Número de informantes: 30 Número de citas: 47.

Número de sectores: 4 Número de categorías: 11.

Biotipo: Fanerófito.

Tipo corológico: Esteno-mediterránea.

Abundancia: Cultivada.

Ambiente: Silvestre y cultivado en toda el área mediterránea. 


\section{Sector doméstico}

Categoría de uso: Detergente.

Número de informantes: 1 Partes utilizadas: aceite.

Fare una emulsione di olio e acqua e pulire i mobili (GFR).

Sector mágico/medicinal

Categoría de uso: Contra el miedo y los traumas.

Número de informantes: 1 Partes utilizadas: hojas.

Per le persone che hanno avuto una paura, come uno shock, un trauma con qualche animale, qualcuno che balbettava...si lava la paura con questa erba che va raccolta la mattina, la vigilia di SanGiovanni presto, quando ancora c'è la ruggiada, va seccata all'ombra, e poi nel momento dell'uso, prendere un mazzetto mettere in un tegamino con 3 foglie di olivo benedetto e un pezzo di candela benedetta della candelora, il 2 febbraio, in un litro di acqua. Fare bollire il tutto per 30-40 min, poi collare, e fare bere 9 goccioline, poi mettere le mani nell'acqua, e si passa per tutto il corpo della persona con "paura", prima le braccia, poi le gambe.. la preghiera va ripetuta 3 volte. Il rito si fa 3 volte in 3 giorni consecutivi, un volta al giorno per 3 giorni. Quando si ha lavato una persona, l'acqua diventa come gelatina, con fili, si stringe.. (PLU).

\section{Sector mágico/ritual/supersticioso}

Categoría de uso: Propiciatorio.

Número de informantes: 8 Partes utilizadas: tallos leñosos/ramas/ramitas/vástagos.

La Domenica delle palme si benedice un ramo d' olivo e si appende alle case come benedizione di Dio per la casa. Lui porta anche due foglioline nel portafoglio. (CRI)| Si tiene un ramo di ulivo benedetto per tutto l'anno vicino ad un oggetto sacro e si brucia la Domenica delle palme, quando si rinnova con un altro ramo benedetto dell'anno nuovo. (ECE)| Benedizione della casa: la Domenica delle palme viene benedetto e appeso in casa, per benedire la casa. Benedizione dei campi: un ramo di ulivo benedetto viene legato a un palo di castagno nei campi per benedire i campi. (GFO)| Mettere un ramo di ulivo benedetto (che danno alla chiesa) sulla finestra o la porta (foto), per benedire e proteggere la casa. (GGI, GFR)| La domenica prima di Pasqua si benedivano dei rami di ulivo e si distribuiva alle case, perché benediva la casa. (GUF)| Si tiene appeso in casa un rametto di olivo che è stato benedetto nella domenica prima di Pasqua. (DAD) $\mid$ Nei campi si faceva una croce vicino ai campi di grano, con un ramo di ulivo benedetto per proteggere i coltivi. (GZE).

Categoría de uso: Protector.

Número de informantes: 12 Partes utilizadas: tallos leñosos/ramas/ramitas/vástagos,.

Contro le avversità, per tenere lontano i temporali e la grandine: i primi di giugno mettevano degli altarini ai bordi dei campi fatti di una croce di pioppo, un rametto di olivo benedetto e una candela. La croce si faceva con le bacchette spaccate. Il venerdi santo, al 'mattutino' i ragazzini in chiesa si mettevano intorno ad un tavolo con un rametto di pioppo e lo spaccavano sul tavolo. (NMA, CFR, BPA)| Per togliere il malocchio, si metteva un piatto con dell'acqua sulla testa della persona, e 
si buttavano sul piatto delle gocce d'olio: se sparivano, allora la persona aveva il malocchio e si rifaceva finche le gocce non rimanevano come tali nell'acqua. (CLO) Per la festa di santa Croce, 3 Maggio, si piantava in mezzo al grano una croce di Castagno con un ramo di olivo benedetto, come protezione alle intemperie. (CRI) Contro le avversità, per tenere lontano i temporali e la grandine: i primi di giugno mettevano degli altarini ai bordi dei campi fatti di una croce di pioppo, un rametto di olivo benedetto e una candela. (FAM)| Mettere un ramo di ulivo benedetto sulle crocette nei campi perché libera dai tuoni e dai lampi e protegge la raccolta. Le Crocette dei campi dove si attacavano i rami di olivo benedetto erano fatte con $\mathrm{i}$ pezzettini di legno che saltavano fuori dai polloni di castagno salvano o di nocciolo che si sbattevano il Giovedi Santo pomeriggio (il Mattutino) per 3-5 ore sui lastroni della chiesa, sul pavimento dell'altare oppure fuori della chiesa. I pezzettini di legno che saltavano fuori si raccoglievano e il 3 Maggio (Santa Croce) si portavano in tutti i campi per fare le crocette e attaccarci anche l'ulivo benedetto. (GFO)| I rami di ulivo benedetto (che danno alla chiesa) si mettono sulle crocette nei campi perché liberano dai tuoni, dai lampi, protegge la raccolta. Le Crocette dei campi dove si attaccavano i rami di olivo benedetto erano fatte con i pezzettino di legno che saltavano fuori dai polloni di salvano o nocciolo che si sbattevano il Giovedi Santo pomeriggio (il Mattutino) per 3-5 ore sui lastroni della chiesa, sul pavimento dell'altare oppure fuori della chiesa. I pezzettini di legno che saltavano fuori si raccoglievano e il 3 Maggio (Santa Croce) si portavano in tutti i campi per fare le crocette e attaccarci anche l'ulivo benedetto. (GFR)| Si facevano delle crocette nei campi per liberarli dai tuoni, dai lampi e proteggere la raccolta. Le crocette erano fatte con i pezzettini di legno che saltavano fuori dai polloni di salvano o nocciolo che si sbattevano il Giovedi Santo pomeriggio (il Mattutino) per 3-5 ore sui lastroni della chiesta, sul pavimento dell'altare oppure fuori della chiesa. I pezzettini di legno che saltavano fuori si raccoglievano e il 3 Maggio (Santa Croce) si portavano in tutti i campi per fare le crocette e ci si attaccava sopra anche l'ulivo benedetto. (GGI)| Il giorno di Santa Croce, si andava ai campi a mettere una croce di pioppo, e sopra si legava un rametto di ulivo benedetto, con una candela per la Candelora. Era una celebrazione o una sorta di rituale religioso per tenere lontane le tormente dai campi coltivati. (GUF)| Le donne 'con il dono' mettevano un piatto con acqua sulla testa della persona e buttavano nel piatto tre gocce d' olio: se sparivano voleva dire che la persona aveva il malocchio e ripetevano la pratica finché il malocchio non se ne andava e le gocce rimanevano intere nell' acqua. (NLA)| Il 3 Dicembre, alla festa di Santa Croce, si andava nei boschi e nei campi e si faceva una croce fatta di bastoni di castagno con una rama di ulivo dentro, per proteggere i campi dalla grandine. (PCL).

\section{Sector medicinal}

Categoría de uso: Afecciones cutáneas y tejidos subcutáneos.

Número de informantes: 10 Partes utilizadas: aceite.

Olio bollito, lasciato freddare ed spalmato (NDI) $\mid$ mettere subito dopo la bruciatura l'olio di oliva, anche se all'inizio fa male, perché frigge, poi sollieva e guarisce (AMA) $\mid$ Applicare dell'olio di oliva sulle screpolature dal freddo (RNI)| Si metteva la neve e l'olio in una bottiglia, si teneva in casa, si sciogeva piano piano e si 
metteva sopra le bruciature. (VFR) $\mid$ Olio sbattuto con acqua (fare un'emulsione) (CFR)| Olio di oliva e limone spalmato sulle mani (GCL)| Fare bollire l'olio di oliva, aspettare che si raffreddi e applicarlo sopra le bruciature. (NDI)| Mettere dopo la bruciatura dell' olio (NLA)| Fare la crema bollendo olio di oliva con cera d'api, e una volta che sarà fredda, applicare sulle mani screpolate (SOT)| Agitare tanto l'olio con l'acqua per fare un'emulsione e applicare direttamente. (TGA)| Per le bruciature, mettere subito a mollo in acqua fredda oppure dell'olio di oliva. Se vengono le piaghe, mettere delle foglie di bertonica (TOA).

Categoría de uso: Afecciones del aparato respiratorio.

Número de informantes: 2 Partes utilizadas: aceite.

Ungere l'olio di oliva sulla pianta dei piedi. 'Ci mettevamo a sedere vicino alla stufa, con i piedi sulla stufa e la mamma ci massagiava i piedi con l'olio di oliva. (PLU) Mettere un pò di olio di oliva sulla carta gialla bucata con un ago e riscaldata. Applicare la carta con I fori e con l'olio d'olivo riscaldata sul petto quando si respirava male che si aveva la tosse con il rantolo.(VMU).

Categoría de uso: Afecciones oro-faríngeas y de la cavidad oral.

Número de informantes: 1 Partes utilizadas: aceite.

Applicare un fazzoletto con olio caldo sulla gola."se uno attraversava un fossetto con I.

gocchioni, andavano giù alle parti basse" (LLU).

Categoría de uso: Afecciones típicas infantiles.

Número de informantes: 1 Partes utilizadas: aceite.

Fare una emulsione sbattendo olio e limone e applicare direttamente sull'arrossamento della.

pelle dei bambini (GLA).

Categoría de uso: Enfermedades del oído.

Número de informantes: 6 Partes utilizadas: aceite.

Un paio di gocce di olio caldo sull' orecchio. (TGA)| Mettere due gocce di olio scaldato nell' orecchio (FAM)| Applicare una goccia di olio caldo sull'orecchio. (MGE)| Applicare un po' di olio caldo sull'orecchio. (NDI)| Al naturale, riscaldato,2 gocce di olio caldo sull' orecchio (NLA)| Mettere un pò d'olio caldo nell'orecchio (TGA) Con un cotone mettere un pò di olio caldo sul orecchio per il mal d'orecchio (VMR).

Categoría de uso: Patologías del aparato digestivo.

Número de informantes: 1 Partes utilizadas: aceite.

Mangiare 3 cucchiai di olio crudo la mattina come lassativo (GLA).

Categoría de uso: Trastornos musculo-esqueléticos.

Número de informantes: 2 Partes utilizadas: aceite.

Fare una emulsione con l'olio e il bianco dell'uovo, e applicare sulla slogatura, come se fosse un gesso. (GUF)| Riscaldare in un tegamino l' olio di oliva, e applicarlo sul torcicollo (NRO).

Notas "la sua mamma segnava, con delle parole che imparavano di memoria,. Per le bruciature da Taviano in giù, dicevano l' acqua, da Taviano in su l'Olio (pero secondo lui l' olio 'fa cuocere'). Le segnature si tramandano la notte di Natale a chi voleva, a lei gli l'ha tramandato il suo nonno, va fatta con fede, con preghiere cristiane, di forma gratuita, senza pretendere niente, le offerte date vanno ridonnate 
alla chiesa.La sua mamma Estella lavava la paura, segnava il fuoco di Sant Antonio, segnava I bacchi ai bambini”.

\section{DATOS ETNOBOTÁNICOS BIBLIOGRÁFICOS}

Nombre vulgar: olio (SABA75), oliva (ZAGN90, GUC82), ulîv (UNGA21), olio d'uliva (UNGA21), olivo (MANG98).

Número de referencias: 5 Número de citas: 11.

Número de sectores: 4 Número de categorías: 10.

\section{Sector alimentario}

Categoría de uso: Otro alimentario.

Número de referencias: 1 Partes utilizadas: aceite.

Ricetta "Zampanelle bianche"di Lústrola: $1 \mathrm{~kg}$ di farina bianca, sale quanto basta (un cucchiaino). Si fa un impasto piuttosto liquido della farina con l'acqua, poi si cuoce nei testi o negli stampi, foderati con le foglie di castagno preparate appositamente. A parte si fan bollire circa 2 L. d'acqua, aggiungendo a ebollizione avvenuta, aglio, olio, pepe e sale quanto basta.In questo pignatto si immerge la pasta cotte nei testi, finché non sia bene inzuppata. A quel punto le zampanelle bianche son pronte da mangiare, si raccomanda però di bere anche il liquido dove si inzuppate, che, oltre ad avere un ottimo sapore, combatte efficacemente il raffredore ed è inoltre diuretico e lassativo. (SABA75).

Sector mágico/ritual/supersticioso

Categoría de uso: Otro mágico/ritual/supersticioso.

Número de referencias: 1 Partes utilizadas: aceite.

Il maldocchio si segnava con l'olio d'oliva, le parole che si dicono si insegnano il giorno di Pasqua o la sera della vigilia di Natale. Si fa il segno della Croce e poi si dice "Malocchio mal di capo salta addosso a chi te l'ha dato, e se fossi mai stato io salta addosso pure a me“e "invidia e perfidia ritorni addoso a chi ce 1'ha”. Poi ci si mette l'acqua e poi ci si mette nove gocce d'olio, tre tre tre, facendo sempre la croce, in croce..ci si dice le parole, poi l'acqua si butta via, ci si butta dietro le spalle. Se c'è il maldocchio, si sparge l'olio, se non c'è la goccia rimane intera. (GUC82).

Categoría de uso: Protector.

Número de referencias: 2 Partes utilizadas: tallos leñosos/ramas/ramitas/vástagos,.

Il ramo d'olivo viene distribuito nelle case la domenica delle palme, e se ne mette un ramoscello sulle finestre per scongiuro de temporali (UNGA21)| Il 3 Maggio, il giorno di Santa Croce facevano delle croci di pioppo. Doveva essere di pioppo perche poi si spaccavano, si mondavano e poi si spaccavano, e poi ci si metteva, la candelina benedetta che è fatta del 2 febbraio, la Candelora, e 1'olivo benedetto che benedivano la domenica prima di Pasqua. Preservava i campi dai temporali (GUC82).

\section{Sector medicinal}

Categoría de uso: Afecciones cutáneas y tejidos subcutáneos.

Número de referencias: 1 Partes utilizadas: aceite. 


\section{María Teresa Egea Molines}

le foglie pestate e mescolate all'olio d'uliva serono a far disparire I porri (UNGA21). Categoría de uso: Afecciones del aparato respiratorio.

Número de referencias: 1 Partes utilizadas: aceite.

Le foglie di castagno sono indispensabili per la riuscita di tutte le ricette montanare che richiedono la cottura fra $\mathrm{i}$ testi. Si provvede a preparare le foglie, raccolte a luna vecchia, in settembre, riunendole in "manocchi“(mazzetti) legati con la punta.

Categoría de uso: Afecciones típicas infantiles.

Número de referencias: 1 Partes utilizadas: aceite.

Per togliere il cosiddetto "lattime" le donne ungevano il capo del bambino con olio d'oliva, quando la crosta lattea aveva assorbito l'olio, la pettivanavo a volte usando quelle cartoline postali dal bordo smerlato. (ZAGN90).

Categoría de uso: Patologías del aparato circulatorio.

Número de referencias: 1 Partes utilizadas: hojas.

Una tazza di decotto al giorno viene bevuta in caso di pressione alta. (MANG98).

Categoría de uso: Patologías del aparato digestivo.

Número de referencias: 1 Partes utilizadas: aceite.

Ricetta "Zampanelle bianche"di Lústrola: $1 \mathrm{~kg}$ di farina bianca, sale quanto basta (un cucchiaino). Si fa un impasto piuttosto liquido della farina con l'acqua, poi si cuoce nei testi o negli stampi, foderati con le foglie di castagno preparate appositamente. A parte si fan bollire circa 2 L. d'acqua, aggiungendo a ebollizione avvenuta, aglio, olio, pepe e sale quanto basta.In questo pignatto si immerge la pasta cotte nei testi, finché non sia bene inzuppata. A quel punto le zampanelle bianche son pronte da mangiare, si raccomanda però di bere anche il liquido dove si inzuppate, che, oltre ad avere un ottimo sapore, combatte efficacemente il raffredore ed è inoltre diuretico e lassativo.(SABA75).

Categoría de uso: Patologías del aparato urinario.

Número de referencias: 1 Partes utilizadas: aceite.

Ricetta "Zampanelle bianche"di Lústrola: $1 \mathrm{~kg}$ di farina bianca, sale quanto basta (un cucchiaino). Si fa un impasto piuttosto liquido della farina con l'acqua, poi si cuoce nei testi o negli stampi, foderati con le foglie di castagno preparate appositamente. A parte si fan bollire circa 2 L. d'acqua, aggiungendo a ebollizione avvenuta, aglio, olio, pepe e sale quanto basta.In questo pignatto si immerge la pasta cotte nei testi, finché non sia bene inzuppata. A quel punto le zampanelle bianche son pronte da mangiare, si raccomanda però di bere anche il liquido dove si inzuppate, che, oltre ad avere un ottimo sapore, combatte efficacemente il raffredore ed è inoltre diuretico e lassativo.(SABA75).

Sector religioso

Categoría de uso: Otro religioso.

Número de referencias: 1 Partes utilizadas: tallos leñosos/ramas/ramitas/vástagos. Il ramo d'olivo viene distribuito nelle case la domenica delle palme, e se ne mette un.

ramoscello sulle finestre per scongiuro de temporali (UNGA21). 


\section{Syringa vulgaris $L$.}

Nombre vulgar: Lille (BPA).

Número de informantes: 1 Número de citas: 1.

Número de sectores: 1 Número de categorías: 1.

Biotipo: Fanerófito.

Tipo corológico: Montañosas.

Abundancia: Cultivada.

Ambiente: Bosques, setos. Cultivada en jardines.

Sector mágico/ritual/supersticioso

Categoría de uso: Rituales de Mayo.

Número de informantes: 1 Partes utilizadas: flores/inflorescencias y sus partes.

Per il cantamaggio, il 30 maggio (aprile?), si facevano degli scherzi alle ragazze: a quelle belle si portava a casa l'unico fiore fiorito (lillà), e a quelle brutte si lasciava una palla di fieno sul cancello di casa. (BPA).

\section{ORCHIDACEAE}

\section{Anacamptis morio (L.) R.M.Bateman, Pridgeon \& M.W. Chase (cfr.) (= Orchis morio L. (cfr.))}

Nombre vulgar: Fior del cucco (NLA).

Número de informantes: 1 Número de citas: 2.

Número de sectores: 2 Número de categorías: 2 .

Biotipo: Geófito.

Tipo corológico: Europeas.

Abundancia: Común.

Ambiente: Prados áridos, matorrales.

Número de exsiccata: 38927 FIAF, 38938 FIAF, 38949 FIAF.

Sector alimentario

Categoría de uso: Golosinas y masticatorias.

Número de informantes: 1 Partes utilizadas: flores/inflorescencias y sus partes.

Si ciucciava il miele dei fiori quando si trovavano in giro. (NLA).

Sector doméstico

Categoría de uso: Ornamental.

Número de informantes: 1 Partes utilizadas: parte aérea (toda).

Per fare I mazzi e portarli in casa per bellezza (NLA).

Notas I vecchi dicevano che fioriva quando cantava il cucco..

DATOS ETNOBOTÁNICOS BIBLIOGRÁFICOS

Nombre vulgar: sconcordia masti (UNGA21), pan del cucco (BAL802), pã dal cucco (GUC98).

Número de referencias: 3 Número de citas: 3 .

Número de sectores: 1 Número de categorías: 1. 
Sector mágico/ritual/supersticioso

Categoría de uso: Propiciatorio.

Número de referencias: 1 Partes utilizadas: órganos subterráneos.

cuncordia, chiamano con questo nome I bolognesi l'Orchis maculata L., volg. Concordia, giglio basilico, e la Gymnadenia conopsea, R. Brow, orchidea odorosa, due piante che hanno la radice palmata, mentre dicono scuncordia l'Orchis latifolia L., orchide a larghe foglie, l'Orchis morio,L. pancuccolo, giglio caprino, ed altre specie di Orchis, che hanno la radice tonda. - I montanari (Porretta) chiamano, cuncordia e scuncordia famma le prime due e concordia e sconcordia masti le altre, e le donne loro reputano propizievole agli amori possedere le radici delle une e delle altre insieme- L'Orchis maculata e la Gymnadenia sono poi adoperate in med. per la rad., ritenuta efficace contro i catarri gastrici e le diarree infantili. (UNGA21).

\section{Vanilla planifolia Jacks. ex Andrews}

Nombre vulgar: Vaniglia (DAD, CRI).

Número de informantes: 2 Número de citas: 2.

Número de sectores: 1 Número de categorías: 1.

Biotipo: Geófito.

Tipo corológico: Exóticas.

Abundancia: Cultivada.

Ambiente: Ausente.

Sector alimentario

Categoría de uso: Licor.

Número de informantes: 2 Partes utilizadas: frutos/infrutescencias/falsos frutos. Ricetta della suocera chimata la nonna: "28 nocine tagliate, 1 litro di alcol puro, 900 gr.zucchero, 1scorza limone, 1stecca vaniglia,4 chiodi di garofano, 1pizzico di cannella. Stringere lo zucchero in acqua calda e lasciare 40 giorni (DAD, CRI).

\section{PAPAVERACEAE}

\section{Chelidonium majus $L$.}

Nombre vulgar: Celidonia (TAD), Erba dei poranci (BEL), Erba dei porri (TGA, PSI, PCL, GGI, BLI), Erba per i poranci (SOT), Erba per I porri (TIV, MGO), erba per i porri (NLA), Senza nome (PLU).

Número de informantes: 12 Número de citas: 12.

Número de sectores: 1 Número de categorías: 1.

Biotipo: Hemicriptófito.

Tipo corológico: Europeas.

Abundancia: Común.

Ambiente: Muros, acantilados.

Número de exsiccata: 38924 FIAF, 38979 FIAF. 


\section{Sector medicinal}

Categoría de uso: Afecciones cutáneas y tejidos subcutáneos.

Número de informantes: 12 Partes utilizadas: látex o savia, hojas, parte aérea (toda).

Tagliare una foglia e viene fuori il lattice, mettere subito sopra i porri, per un po di giorni finche va via (TAD)| Applicare la linfa gialla 3 o 4 volte al giorno sulle verruche per 10 giorni. (BEL)| Togliere un foglia e mettere direttamente il lattice giallo sopra i poranci per un po' di giorni finché vanno via (GGI, BLI)| Applicare la linfa della pianta sul porro direttamente. (PCL) Applicare il lattice della pianta sui porri. (PSI)| Spezzare la pianta e mettere sopra il porro, 2 o 3 volte al giorno per 1530 giorni. (TGA) $\mid$ Lavare i porri con il latex della pianta. (SOT) $\mid$ Togliere una foglia e mettere direttamente il lattice giallo sopra i porri (MGO)| Si metteva la linfa della pianta che era arancione sui porri (NLA)| Togliere un foglia e mettere direttamente il lattice giallo sopra i porri per un po di giorni finché va via (TIV)| Appliccare il latte giallo sui porri. Dopo un po' passavano. (PLU).

Notas Pero la pelle resta macchiata, Lui non l'ha mai fatto, però dice che tutti lo facevano.

\section{DATOS ETNOBOTÁNICOS BIBLIOGRÁFICOS}

Nombre vulgar: chelidonia, celidonia (MANG98), êrba di pôr, êrba pr'i cal (UNGA21).

Número de referencias: 2 Número de citas: 3 .

Número de sectores: 1 Número de categorías: 2 .

Sector medicinal

Categoría de uso: Afecciones cutáneas y tejidos subcutáneos.

Número de referencias: 2 Partes utilizadas: látex o savia.

Il latice si applica ripetutamente su calli e verruche per ottenere l'eliminazione (MANG98)| ...Per il suo latte cautico, se n'è fatto grande uso nella med. Pop. E attualmente si adopera ancora come corrosivo de'porri. (UNGA21).

Categoría de uso: Afecciones oftalmológicas.

Número de referencias: 1 Partes utilizadas: No especificado.

Si adopera inoltre per la vista, e I contadini dicono di avere imparato questo dalle rondini, le.

quali si valgono di quest'erba per ridare la vista ai pulcini (UNGA21).

\section{Papaver rhoeas $L$.}

Nombre vulgar: Papavero, Fioracci (MTO, MSR), Papavero (BLI, GUF, GGI, CFR, BPA),. Papaveri (BOR, CRI).

Número de informantes: 9 Número de citas: 9.

Número de sectores: 4 Número de categorías: 5 .

Biotipo: Terófito.

Tipo corológico: Mediterráneas montañosas.

Abundancia: Común. 
Ambiente: Invasoras de los campos de cereales, a menudo sobre ruinas y escombros.

\section{Sector alimentario}

Categoría de uso: Verdura cocida.

Número de informantes: 2 Partes utilizadas: hojas.

Ad aprile, raccogliere le foglie quando ancora non ha fatto il fiore e mangiarle cotte e condite. (MTO, MSR).

\section{Sector lúdico/voluptuoso}

Categoría de uso: Decoraciones y disfraces de niños.

Número de informantes: 4 Partes utilizadas: flores/inflorescencias y sus partes.

Con il pistillo del fiore privato dei petali premevano sulla pelle per fare un 'tatuaggio' che assomigliava alla puntura del vaccino del vaiolo (CFR, BPA)| Con il pistillo del fiore privato dei petali premevano sulla pelle per 'tatuarsi' la stella sulla fronte (GGI)| Con il pistillo del fiore privato dei petali premevano sulla pelle per fare un 'tatuaggio' che assomigliava alla puntura del vaccino del vaiolo (GUF).

Sector medicinal

Categoría de uso: Afecciones del aparato respiratorio.

Número de informantes: 1 Partes utilizadas: flores/inflorescencias y sus partes.

"Fiorume", fiori e foglie del fieno (di Trifoglio,trafagliolo, ginestrino, erba medica, radicchi, felce, camomilla, margherite, papaveri) Mettere i fiori e le foglie che restano dopo avere preso il fieno, trittate, nell'acqua bollente e respirare il vapore con la testa coperta con un panno (CRI).

Categoría de uso: Afecciones típicas infantiles.

Número de informantes: 1 Partes utilizadas: semillas.

Gli emigranti quando partivano si portavano dei semi di papavero per fare addormentare I bambini (BLI).

Sector religioso

Categoría de uso: Ornamento para altares e iglesias.

Número de informantes: 1 Partes utilizadas: flores/inflorescencias y sus partes.

Si portavano i papaveri alla Madonna. (BOR).

Notas Ad aprile, raccogliere le foglie quando ancora non ha fatto il fiore. Non le usano più, perché non si vedono più. La mattina le donne andavano dietro le pecore e facevano I radicchi (Castel di Casio), raccoglievano la cicerbda, I fioracci o il papavero e le mettevano nel gremiule. Non si usava seminare, allora si andava nei campi.

\section{DATOS ETNOBOTÁNICOS BIBLIOGRÁFICOS}

Nombre vulgar: papavero, rosetta (SANS14), rufått (UNGA21).

Número de referencias: 2 Número de citas: 3.

Número de sectores: 2 Número de categorías: 3.

Biotipo: Terófito.

Tipo corológico: Mediterráneas montañosas.

Abundancia: Común. 
Ambiente: Invasoras de los campos de cereales, a menudo sobre ruinas y escombros.

Sector alimentario

Categoría de uso: Ensalada.

Número de referencias: 1 Partes utilizadas: hojas (SANS14).

Categoría de uso: Verdura cocida.

Número de referencias: 1 Partes utilizadas: hojas (SANS14).

Sector efecto nocivo

Categoría de uso: Tóxicas y venenosas.

Número de referencias: 1 Partes utilizadas: parte aérea (toda).

Vuole il popolo che sia velenoso (UNGA21).

\section{PHYTOLACCACEAE}

\section{Phytolacca americana $L$.}

Nombre vulgar: Uva dal bisse (GUF).

Número de informantes: 1 Número de citas: 1.

Número de sectores: 1 Número de categorías: 1.

Biotipo: Geófito.

Tipo corológico: Amplia distribución.

Abundancia: Común.

Ambiente: Huertos, baldíos.

Sector efecto nocivo

Categoría de uso: Tóxicas y venenosas.

Número de informantes: 1 Partes utilizadas: planta entera/viva.

Ha delle bacche rosse, e sempre dicevano "non ti avvicinare", "non mangiarle". Era accusata di essere velenosa. (GUF).

\section{PINACEAE}

\section{Abies alba Mill.}

Nombre vulgar: Abete (BLI, TGA, PLU, BEL, GUF, PCL).

Número de informantes: 6 Número de citas: 6.

Número de sectores: 4 Número de categorías: 4.

Biotipo: Fanerófito.

Tipo corológico: Montañosas.

Abundancia: Común.

Ambiente: Bosques de montaña en el rango del haya.

Sector artesanal

Categoría de uso: Objetos domésticos. 
Número de informantes: 1 Partes utilizadas: tallos leñosos/ramas/ramitas/vástagos.

Il comodino di casa era fatto di legno di abete (PCL).

Sector mágico/ritual/supersticioso

Categoría de uso: Rituales de Mayo.

Número de informantes: 1 Partes utilizadas: tallos leñosos/ramas/ramitas/vástagos.

Bouquet di fiori da regalare alle belle ragazze. Il 30 aprile si celebra il cantarmaggio e i ragazzi portano alle case delle belle ragazze dei bouquet di fiori fatti di maggiociondolo e rami di abete, mentre cantavano sotto la loro finestra. Invece alle ragazze più brutte si portava del fieno. (GUF).

\section{Sector medicinal}

Categoría de uso: Trastornos musculo-esqueléticos.

Número de informantes: 3 Partes utilizadas: resina.

$\mathrm{Si}$ faceva un taglio alla corteccia dell'abete e fuoriusciva 'la raggia', che si raccoglieva in un pentolina (era come un miele), poi si metteva un po' di resina su una cartina della sigaretta e si applicava sul ginocchio che faceva male. (BEL) Applicare la resina sopra I punti infiammati (PLU)| Non sa bene come lo usavano. Applicare la resina sulla parte dolente. (TGA).

Sector religioso

Categoría de uso: Rogativas.

Número de informantes: 1 Partes utilizadas: tallos leñosos/ramas/ramitas/vástagos.

Si facevano degli archi con rami di zinepro ed abete per le rogazioni (BLI).

Notas la raggia, che si raccoglieva in un pentolina (era come un miele).

DATOS ETNOBOTÁNICOS BIBLIOGRÁFICOS

Nombre vulgar: abete (MANG98, BORR77), abédo (GUC98, APPO10).

Número de referencias: 4 Número de citas: 5.

Número de sectores: 2 Número de categorías: 3 .

Sector mágico/ritual/supersticioso

Categoría de uso: Rituales de Mayo.

Número de referencias: 1 Partes utilizadas: tallos leñosos/ramas/ramitas/vástagos. Per il Calendimaggio, la sera del 30 aprile, i giovanotti portavano... rami d'abete da un casolare all'altro cantando ad ogni porta alcune strofe della canzone del Maggio specie quelle in cui si saluta la famiglia, si augurano buoni raccolti, e fanno voti per gli animali domestici. Ad ogni casa dove abitava una ragazza un giovane del luogo offriva alla donzella un ramo d'abete mentre tutti assieme cantavano: "Sopra 1'uscio c'é un bel fiore e c'è (il nome del giovane) che fa il favore. Sopra l'uscio c'è una rosa e unaltr'anno una bella sposa". La ragazza prendeva il "majio"così si chiavama il ramo d'abete. Lo conservava gelosamente fino alla domenica dopo, giorno in cui i giovanotti sia tutti assieme sia ciascuno per proprio conto si recavano a casa della donzella che glielo consegnava ornato di nastri colorati esprimendo il desiderio di vederlo piantato sopra uno degli abeti vicino alla casa. (BORR77). 


\section{Sector medicinal}

Categoría de uso: Afecciones del aparato respiratorio.

Número de referencias: 1 Partes utilizadas: resina, brotes.

La "ragia" viene raccolta tramite incisioni effettuate sul tronco, si mescola poi con dello zucchero a formare pillole che vengono succhiate in caso di tosse. Taluni, come balsamico ed espettorante, utilizzano anche il decotto delle gemme. (MANG98).

Categoría de uso: Trastornos musculo-esqueléticos.

Número de referencias: 1 Partes utilizadas: resina.

La resina, inoltre si utilizza per preparare dei cerotti antireumatici, utili anche in caso di distorsioni: si pone della resina su carta paglia, si riscalda sul fuoco e si applica sulla parte, dove rimane per due-tre settimane. (MANG98).

\section{Pinus nigra J.F.Arnold (s.l.)}

Nombre vulgar: Pino (VMR, PLU, CBR, BEL, GGL, MGE, AN3).

Número de informantes: 7 Número de citas: 9.

Número de sectores: 3 Número de categorías: 5.

Biotipo: Fanerófito.

Tipo corológico: Cultivadas.

Abundancia: Cultivada.

Ambiente: Reforestaciones.

Número de exsiccata: 38898 FIAF.

\section{Sector alimentario}

Categoría de uso: Licor.

Número de informantes: 1 Partes utilizadas: brotes.

Liquore Cent'erbe della Nonna: 5 o 6 foglie di salvia, 5 o 6 foglie di Basilico, una bustina di te (una volta lo vendevano sciolto in bottega), germogli di pino, rosmarino e menta selvatica. 1 etto zucchero, 1 etto di alcol, 1 etto di acqua. Lasciare tutto sotto alcol per 21 giorni. Bollire lo zucchero e l'acqua e passare tutto e mescolare. (AN3). Categoría de uso: Mermelada.

Número de informantes: 1 Partes utilizadas: brotes.

Si raccoglievano a primavera,le punte tenere chiare dei pini delle abetaie (germogli) e si faceva la marmellata, poi si metteva sul pane e si mangiava. Non si ricorda delle proporzioni. (MGE).

\section{Sector doméstico}

Categoría de uso: Chimenea y horno.

Número de informantes: 1 Partes utilizadas: frutos/infrutescencias/falsos frutos.

Per avviare il fuoco, usare pigne secche. (GGL).

\section{Sector medicinal}

Categoría de uso: Afecciones del aparato respiratorio.

Número de informantes: 5 Partes utilizadas: hojas, brotes, resina, brotes.

(non specificato) (BEL) $\mid$ La raggia (linfa) del pino si sciogle nell'acqua e si facevano I fumenti (CBR) $\mid$ Si raccoglievano a primavera,le punte tenere chiare dei pini delle 


\section{María Teresa Egea Molines}

abetaie (germogli) e si faceva la marmellata. Per la tosse si prendeva la marmellata con le punte (germogli) del pino, a cucchiaiate, o mangiate. (MGE)| Fare I fumenti con le 'bacche' del pino per il raffreddore o la tosse (PLU)| Mettere nell'acqua bollente I 'cemolini' (germogli pieni di resina) dei pini, insieme alle foglie del Sambuco e alle foglie di Malva. Lasciare un pò a riposo e aggiungere del miele. Bere finché passa. (VMR).

Categoría de uso: Trastornos musculo-esqueléticos.

Número de informantes: 1 Partes utilizadas: resina.

Applicare la resina sopra i punti infiammati (PLU).

Notas ricette tramandate dalle nonna e dalla mamma. La sua nonna lo faceva con la grappa.

invece dell'alcol, che loro stessi distillavano con le vinacce dell'uva..

\section{DATOS ETNOBOTÁNICOS BIBLIOGRÁFICOS}

Nombre vulgar: pino (MANG98).

Número de referencias: 1 Número de citas: 1 .

Número de sectores: 1 Número de categorías: 1 .

Sector medicinal

Categoría de uso: Afecciones del aparato respiratorio.

Número de referencias: 1 Partes utilizadas: brotes.

Le 'cimoncine'vengono lasciate in acqua bollente e l'infuso è bevuto in caso di tosse e di altre.

affezione delle vie respiratorie. (MANG98).

\section{Pinus pinea $L$.}

Nombre vulgar: Pinoli (VMU, SCO, LST).

Número de informantes: 3 Número de citas: 3.

Número de sectores: 2 Número de categorías: 2 .

Biotipo: Fanerófito.

Tipo corológico: Eurimediterránea.

Abundancia: Común.

Ambiente: Dunas, maquias, pendientes áridas.

Sector alimentario

Categoría de uso: Dulces y golosinas.

Número de informantes: 2 Partes utilizadas: semillas.

Con la farina di castagne, rosmarino e pinoli si faceva il castagnaccio. (LST)| "Castagnaccio": Farina di castagne, impastata con dei pinoli, dell'uvetta (messa a mollo con acqua e un po d'olio), e alla fine aromatizzato con un po' di rosmarino sopra (SCO).

Sector medicinal

Categoría de uso: Estado general.

Número de informantes: 1 Partes utilizadas: semillas.

Mettere a seccare all'ombra tutti I "semi della vita": semi delle ciliege, delle susine ossia le prugne gialle, di zucca, I pinoli, le noci, le culloie o nocciole, le foglie di 
malva secche, il fiore del gigliopapagone e anche un pò di olio di semi di lino. Poi macinare tutto con il macinino da caffé. E prendere un cucchiaio tutte le mattine a primavera e a ottobre. (VMU).

DATOS ETNOBOTÁNICOS BIBLIOGRÁFICOS

Nombre vulgar: pinoli (GRIZ03), pen, pgnû (UNGA21).

Número de referencias: 2 Número de citas: 2.

Número de sectores: 1 Número de categorías: 1.

\section{Sector alimentario}

Categoría de uso: Dulces y golosinas.

Número de referencias: 2 Partes utilizadas: semillas.

Torta della nona con pinoli: per la pasta, $3 \mathrm{hg}$ di farina, $1 \mathrm{hg}$ di burro a quadretti, 1 uovo, 1 e 1/2 hg di zucchero, 1 bustina di lievito, 1,25 hg di yogurt. Per la crema, 6 tuorli, 8 cucchiai di zucchero, 4 cucchiai di farina, 1 litro di latte, 1 bustina di vanillina o scorza di limone, pinoli. Impastare gli ingredienti sulla spianatoia. Foderare con la pasta la tortiera. Cuocere per 15 minuti a $180 \mathrm{C}$. Mescolare i tuorli e lo zucchero con un cucchiaio di legno, aggiungere la farina, quindi il latte gradualmente. Cuocere mescolando a farlo bollire per 5 minuti. Versare la crema tiempida sulla torta, coprire coi pinoli e infornare per 10 minuti a 180 circa. (GRIZ03)| I pgnû sono usati in confetture e condimenti (UNGA21).

\section{PIPERACEAE}

\section{Piper nigrum $L$.}

Nombre vulgar: Pepe (BEL, MTO, DAD).

Número de informantes: 3 Número de citas: 3.

Número de sectores: 2 Número de categorías: 2 .

Biotipo: Fanerófito.

Tipo corológico: Exóticas.

Abundancia: Cultivada.

Ambiente: Ausente.

Sector alimentario

Categoría de uso: Aromatizante.

Número de informantes: 2 Partes utilizadas: semillas.

Per insaporire i funghi sotto olio, salvia, pepe e una foglia di alloro. Per insaporire il brodo di faggioli per fare "pasta e faggioli",con olio, aglio pepe e due foglie di alloro che alla fine si levano, oppure la minestra di faggioli (DAD)| La polenta dolce si mangiava con la tortellina (è come un budino salato:) fatto di latte, 1 o 2 uova, sale, pepe, poi si mescolava sul fuoco finché non diventasse una crema, poi si mangiava insieme alla polenta. (MTO).

\section{Sector medicinal}

Categoría de uso: Afecciones ginecológicas, complicaciones obstétricas, del postparto y del puerperio. 
Número de informantes: 1 Partes utilizadas: frutos/infrutescencias/falsos frutos.

Per il dolore di mestruazioni, mangiare uovo con pepe. (BEL).

DATOS ETNOBOTÁNICOS BIBLIOGRÁFICOS

Nombre vulgar: pepe (SABA75).

Número de referencias: 1 Número de citas: 4.

Número de sectores: 2 Número de categorías: 4.

Sector alimentario

Categoría de uso: Aromatizante.

Número de referencias: 1 Partes utilizadas: frutos/infrutescencias/falsos frutos.

Ricetta "Zampanelle bianche"di Lústrola: $1 \mathrm{~kg}$ di farina bianca, sale quanto basta (un cucchiaino). Si fa un impasto piuttosto liquido della farina con l'acqua, poi si cuoce nei testi o negli stampi, foderati con le foglie di castagno preparate appositamente. A parte si fan bollire circa 2 L. d'acqua, aggiungendo a ebollizione avvenuta, aglio, olio, pepe e sale quanto basta.In questo pignatto si immerge la pasta cotte nei testi, finché non sia bene inzuppata. A quel punto le zampanelle bianche son pronte da mangiare, si raccomanda però di bere anche il liquido dove si inzuppate, che, oltre ad avere un ottimo sapore, combatte efficacemente il raffredore ed è inoltre diuretico e lassativo. (SABA75).

Sector medicinal

Categoría de uso: Afecciones del aparato respiratorio.

Número de referencias: 1 Partes utilizadas: frutos/infrutescencias/falsos frutos.

Le foglie di castagno sono indispensabili per la riuscita di tutte le ricette montanare che richiedono la cottura fra $i$ testi. Si provvede a preparare le foglie, raccolte a luna vecchia, in settembre, riunendole in "manocchi“(mazzetti) legati con la punta.

Categoría de uso: Patologías del aparato digestivo.

Número de referencias: 1 Partes utilizadas: frutos/infrutescencias/falsos frutos.

Le foglie di castagno sono indispensabili per la riuscita di tutte le ricette montanare che richiedono la cottura fra $\mathrm{i}$ testi. Si provvede a preparare le foglie, raccolte a luna vecchia, in settembre, riunendole in "manocchi"(mazzetti) legati con la punta.

Categoría de uso: Patologías del aparato urinario.

Número de referencias: 1 Partes utilizadas: frutos/infrutescencias/falsos frutos.

Le foglie di castagno sono indispensabili per la riuscita di tutte le ricette montanare che richiedono la cottura fra i testi. Si provvede a preparare le foglie, raccolte a luna vecchia, in settembre, riunendole in "manocchi“(mazzetti) legati con la punta.

\section{PLANTAGINACEAE (incluye SCROPHULARIACEAE p.p.)}

\section{Cymbalaria muralis P.Gaertn., B.Mey. \& Scherb. (= Linaria cymbalaria (L.) Miller)}

Nombre vulgar: Cimballaria, Erba della scalmanella (NRE).

Número de informantes: 1 Número de citas: 1.

Número de sectores: 1 Número de categorías: 1. 
Biotipo: Hemicriptófito.

Tipo corológico: Amplia distribución.

Abundancia: Común.

Ambiente: Acantilados, muros y estaciones ruderales.

Número de exsiccata: 39121 FIAF.

Sector medicinal

Categoría de uso: Afecciones del aparato respiratorio.

Número de informantes: 1 Partes utilizadas: hojas.

Fare il 'fiasco' pieno del decotto di foglie e fiori di polmonaria, foglie di farfanella, foglie di.

malva, di cimballaria, di piscialletto e di foglie di erba ruggine. (NRE).

Notas la "scalmanella" vuole dire agitazione.

\section{Digitalis lutea L. (s. l.) (cfr.)}

Nombre vulgar: Erba per i tagli (NST), Erba sitouna (AN3).

Número de informantes: 2 Número de citas: 2.

Número de sectores: 2 Número de categorías: 2 .

Biotipo: Hemicriptófito.

Tipo corológico: n.d.

Abundancia: Común.

Ambiente: Bosques aclarados y de monte bajo.

Sector medicinal

Categoría de uso: Afecciones cutáneas y tejidos subcutáneos.

Número de informantes: 1 Partes utilizadas: hojas (NST).

Sector veterinario

Categoría de uso: Ganado bovino.

Número de informantes: 1 Partes utilizadas: órganos subterráneos.

Con le foglie e il bulbo si facevano dei impacchi alle mucche sotto alla gola quando avevano.

degli ascessi alla pelle. (AN3).

Notas I vecchi la adoperavano secca, la seccavano, la trinciavano e la conservavano in dei sacchetti di stoffa'.

\section{DATOS ETNOBOTÁNICOS BIBLIOGRÁFICOS}

Nombre vulgar: non ha un nome dialettale (UNGA21).

Número de referencias: 1 Número de citas: 1 .

Número de sectores: 1 Número de categorías: 1.

\section{Sector medicinal}

Categoría de uso: Patologías del aparato circulatorio.

Número de referencias: 1 Partes utilizadas: hojas.

raccolta per le sue virtù cardiache, che vengono parificate a quelle della purpurea, e le sue foglie sono in commercio sostituite a quelle della digitale vera, benchè 
facilmente riconoscibili per I diversi caratteri. V. al riguardo opusc. Della F.P.M. n.3.

Notas erba araelda o erba naelda, I vecchi farmacisti indicavano con tali nomi la Digitalis.

purpurea, digitale non propria della n. regione e solo colt. Eccezionalmente in qualche.

giard. Per orn. La D. lutea, L. e D.ferruginea L. de'nostri boschi collini e mont.

\section{Plantago lanceolata $L$.}

Nombre vulgar: Orecchie di somaro (EMA), Orecchie di topo, Radicchio (PEL), Radicchi,.

Codiron d'asino (PCL), Orecchio di ciucco, Radicchio. (MGE), Erba del checchio. (BAN).

Número de informantes: 5 Número de citas: 6 .

Número de sectores: 3 Número de categorías: 5.

Biotipo: Hemicriptófito.

Tipo corológico: Europeas.

Abundancia: Bastante Común.

Ambiente: Baldíos, a lo largo de las carreteras, campos, viñedos, generalmente sinantrópica.

Número de exsiccata: 38954 FIAF.

\section{Sector agropastoral}

Categoría de uso: Alimentación animal (incluidos los forrajeros).

Número de informantes: 1 Partes utilizadas: hojas.

Si davano le foglie crude da mangiare ai congli (EMA).

Sector alimentario

Categoría de uso: Ensalada.

Número de informantes: 2 Partes utilizadas: hojas.

le foglie della pianta senza il fiore, crude in insalata insieme agli altri radicchi. (PEL)|.

Quando le foglie sono giovane e tenere si mangiano crude in insalata e condite (PCL).

Categoría de uso: Sopas de verduras y potaje.

Número de informantes: 1 Partes utilizadas: hojas.

La zuppa d'estate della nonna era a base solo di piante di campo: soffriegeva l'aglio, si trittavano tutte le foglie del piscialletto, le punte dei vizzadri, dell'ortica, delle orecchie di ciucco, del caciolino e degli striggoli. Poi si aggiungevano e si facevano bollire molto. Poi si poteva aggiungere riso o pasta. (MGE).

Categoría de uso: Verdura cocida.

Número de informantes: 1 Partes utilizadas: hojas.

Quando le foglie sono grandi si mangiano cotte come verdura (PCL).

\section{Sector medicinal}

Categoría de uso: Afecciones cutáneas y tejidos subcutáneos. 
Número de informantes: 1 Partes utilizadas: hojas.

Sbollentare le foglie e applicare l'acqua sul 'cecchio'. (BAN).

DATOS ETNOBOTÁNICOS BIBLIOGRÁFICOS

Nombre vulgar: cinque nervi (MANG98).

Número de referencias: 1 Número de citas: 2 .

Número de sectores: 1 Número de categorías: 2.

Sector medicinal

Categoría de uso: Afecciones cutáneas y tejidos subcutáneos.

Número de referencias: 1 Partes utilizadas: hojas.

Le foglie fresche contuse vengono applicate sulle ferite o sulle slogature, tutta la pianta bollita.

in acqua vienen applicata sul fuoco di Sant'Antonio (herpes zoster) (MANG98).

Categoría de uso: Trastornos musculo-esqueléticos.

Número de referencias: 1 Partes utilizadas: hojas.

Le foglie fresche contuse vengono applicate sulle ferite o sulle slogature, (MANG98).

\section{Plantago major $L$.}

Nombre vulgar: Erba dei canarini (VMR), (non sa come si chiama) (NST), 5 Nervi (PCL, NRO), 7 nervi (CRI), 7 Nervi (IMA), Erba delle botte, 7 nervi (FAM), Lingua d'oca (AP1), Orecchie d'asino (PIM, MTO, MTI, MSR), Petacciola (TGA), Piantacciola (GGI).

Número de informantes: 14 Número de citas: 16.

Número de sectores: 3 Número de categorías: 3.

Biotipo: Hemicriptófito.

Tipo corológico: Europeas.

Abundancia: Bastante Común.

Ambiente: Baldíos herbáceos, sobre todos pisoteados, a lo largo de las calles, caminos y en las casas.

Número de exsiccata: 38933 FIAF, 38991 FIAF.

Sector agropastoral

Categoría de uso: Avicultura.

Número de informantes: 1 Partes utilizadas: frutos/infrutescencias/falsos frutos.

Facevamo dei mazzettini delle spighe e glieli davamo ai passeri, merli, e a tutti gli uccelli dal becco grosso. (VMR).

Sector alimentario

Categoría de uso: Relleno de ravioli.

Número de informantes: 1 Partes utilizadas: hojas.

Le foglie lesse da sole o insieme alla bietola per mettere nel ripieno dei tortelli (VMR).

\section{Sector medicinal}

Categoría de uso: Afecciones cutáneas y tejidos subcutáneos. 


\section{María Teresa Egea Molines}

Número de informantes: 13 Partes utilizadas: hojas.

Strofinare la foglia sulle punture di insetto. (NST)| Fare degli impacchi di foglie di Cinquenervi sulla ferita (NRO)| Fare degli impacchi di piantaggine sulla spina per tirarla fuori (PCL)| Togliere la nervatura della foglia nella parte posteriore e mettere sopra il foruncolo (CRI)| Togliere la nervatura della foglia nella parte posteriore e mettere sopra la bruciatura con una fasciatura. (CRI)| Applicare un impacco sulle mani gonfie (IMA)| Foglie pestate tra due sassi con un po' d' alcol e messe sopra la ferita (FAM)| Applicare 2 o 3 foglie sopra I foruncoli per fare tirare il pus. (AP1) Una volta c'era meno pulizia e gli ascessi erano più comuni. La sua mamma metteva a bagno nell'olio di oliva le foglie fresche delle orecchie d'asino per un giorno, quindi metteva le foglie sopra all'ascesso e le cambiava di tanto in tanto, così 'buttava fuori' il pus. (MTO, MSR)| Mettere le foglie di orecchie d'asino a macerare nell'olio un giorno. Applicare la foglia direttamente sull'ascesso per tirare fuori il pus. Nel caso di spine, quando si toglie la foglia, la spina rimaneva attaccata alla foglia. (PIM, MTI)| Per togliere via il pus, sulle ferite, sulle infezioni, e sopra I fignoli. (TGA)| Si prendeva la foglia alla rovescia, si tiravano i fili, e si rasava un po' con il coltello, si metteva sopra la spina, e si faciava per la sera. La mattina dopo il pus era sulla foglia e la ferita pulita (GGI).

Notas "I cardelini vanno a mangiare la spiga".

\section{DATOS ETNOBOTÁNICOS BIBLIOGRÁFICOS}

Nombre vulgar: piantâzen (UNGA21), oréc 'c’hie d'as'no, oréc c'hie 'd somaro (GUC98).

Número de referencias: 2 Número de citas: 5 .

Número de sectores: 1 Número de categorías: 3 .

Sector medicinal

Categoría de uso: Afecciones cutáneas y tejidos subcutáneos.

Número de referencias: 1 Partes utilizadas: hojas.

Le foglie di piantaggine bollite nell'olio insieme ad altre erbe aromatiche sono indicate contro l'erpete di viso. (UNGA21)| Le stesse foglie pestate e mescolate con bianco d'ovo guariscono le scottature. (UNGA21).

Categoría de uso: Afecciones del aparato respiratorio.

Número de referencias: 1 Partes utilizadas: hojas.

La bollitura delle folgie col latte si prende per guarire la tosse (UNGA21).

Categoría de uso: Afecciones oftalmológicas.

Número de referencias: 1 Partes utilizadas: hojas.

Nella medicina popolare la piantaggine si adopera come rinfrescante nell'infiammazione degli occhi, bagnangoli coll'infuso delle sue foglie. (UNGA21).

\section{Veronica beccabunga $L$.}

Nombre vulgar: Crescion (PEL, ECE, VAL, TIV, PCL, NMA, NLA, GGI, BEL), Crescione (UMI, PIM, GAN, CRE, CFR).

Número de informantes: 14 Número de citas: 24.

Número de sectores: 3 Número de categorías: 7.

Biotipo: Caméfito. 
Tipo corológico: Europeas.

Abundancia: Común.

Ambiente: Barrancos con agua corriente, manantiales, ambientes soleados húmedos por.

infiltraciones o manantiales.

Número de exsiccata: 39051 FIAF, 39003 FIAF.

Sector alimentario

Categoría de uso: Ensalada.

Número de informantes: 12 Partes utilizadas: órganos subterráneos.

Le radici crude e pulite in insalata. (VAL, BEL) $\mid$ Cruda con altre insalate oppure anche da sola, e condita con olio e sale (GGI)| Da consumare cruda con altre insalate (NLA) Insieme ad altre insalate di campo (NMA)| Cruda in insalata con altre insalatine (PCL) $\mid$ Cruda con altre insalate e condita con olio e sale (TIV) $\mid$ Le foglie mangiate nell'insalata insieme ad altre insalatine di campo (CFR)| Da consumare cruda e condita. (CRE)| Le foglie giovani si aggiungono all'insalata di campo (GAN)| Le foglie crude e condite in insalata. (PIM)| Le foglie crude mangiate in insalata, insieme ad altre insalate. (UMI).

Categoría de uso: Tortilla.

Número de informantes: 1 Partes utilizadas: hojas.

Aggiungere le foglie all'uovo quando si fa la frittata. Lo facevano la nonna e la mamma..

Categoría de uso: Verdura cocida.

Número de informantes: 2 Partes utilizadas: hojas, parte aérea (toda).

Cotte e condite (NLA)| Cotta e condita con altre piante. (PCL).

Sector medicinal

Categoría de uso: Estado general.

Número de informantes: 3 Partes utilizadas: hojas.

L'acqua di crescion (il decotto) 'rinfresca'. (BEL)| Mangiato in insalate (GGI)| Fare bollire per 10 minuti il crescion e bere. (PEL).

Categoría de uso: Patologías del aparato digestivo.

Número de informantes: 1 Partes utilizadas: hojas.

L'acqua di crescion (il decotto) 'purga. (BEL)| Bere il decotto di crescione 'per andare in.

bagno'. (BEL).

Categoría de uso: Patologías del aparato urinario.

Número de informantes: 2 Partes utilizadas: parte aérea (toda), hojas.

Bollire il crescione e lavarsi con l'acqua. (PIM)| Bollire il crescione e bere di continuo l'acqua. (UMI).

Sector veterinario

Categoría de uso: Ganado bovino.

Número de informantes: 2 Partes utilizadas: órganos subterráneos.

Quando la mucca stava male, il veterinario gliela dava da mangiare per purgarla (VAL, BEL). 
Notas è depurativo stelo robusto, foglia massiccia, leggermente amarognola', Ce n'era tanta nella sorgente "Rovareggia" (a un km di Camugnano, però è sparito nei anni 50 per l'acquedotto, e ora non ce n'è più crescione.

DATOS ETNOBOTÁNICOS BIBLIOGRÁFICOS

Nombre vulgar: crescione (MANG98), bœcabonga (UNGA21).

Número de referencias: 2 Número de citas: 2.

Número de sectores: 1 Número de categorías: 1.

Sector medicinal

Categoría de uso: Estado general.

Número de referencias: 2 Partes utilizadas: hojas.

il decotto viene bevuto in grandi quantità come efficace antinfiammatorio (MANG98)|.erba affine alla veronica, com. Ne' luoghi freschi, tenuta dal volgo come rimedio antiscorbutico, usata in farm. (UNGA21).

\section{POACEAE (= GRAMINACEAE)}

\section{Arundo donax L.}

Nombre vulgar: Canne (MRI, BOR, RRE), Canna (MGO).

Número de informantes: 4 Número de citas: 5.

Número de sectores: 3 Número de categorías: 3 .

Biotipo: Geófito.

Tipo corológico: Amplia distribución.

Abundancia: Común.

Ambiente: Cultivada para setos y para varios usos agrícolas y asilvestrada.

Sector artesanal

Categoría de uso: Cestería.

Número de informantes: 1 Partes utilizadas: tallos leñosos/ramas/ramitas/vástagos.

Facevano delle ceste con i rami di borgognoni e canne, che vendevano a San Remo per l'esportazione dei fiori. (RRE).

Sector doméstico

Categoría de uso: Integración de la renta familiar.

Número de informantes: 3 Partes utilizadas: tallos leñosos/ramas/ramitas/vástagos.

facevano dei cesti con canne e borgognoni che vendevano a San Remo per l'esportazione dei fiori (MRI, BOR)| Facevano delle ceste con I rami di borgognoni e canne i che vendevano a San Remo per l'esportazione dei fiori. (RRE).

Sector veterinario

Categoría de uso: Ovejas y cabras.

Número de informantes: 1 Partes utilizadas: tallos leñosos/ramas/ramitas/vástagos. 
Quando una pecora si rompeva la gamba, si faceva un tipo di ingessatura, facendo una steccatura, tagliando la canna trasversalmente a metà e mettendo ogni metà intorno alla frattura, con una fasciatura. (MGO).

DATOS ETNOBOTÁNICOS BIBLIOGRÁFICOS

Nombre vulgar: câna (UNGA21).

Número de referencias: 1 Número de citas: 1.

Número de sectores: 1 Número de categorías: 1.

Sector mágico/ritual/supersticioso

Categoría de uso: Otro mágico/ritual/supersticioso.

Número de referencias: 1 Partes utilizadas:.

La superstizione popolare attribuisce alla canna verde virtù contro le serpi, le quali appena.

toccate con essa restano morte. (UNGA21).

\section{Avena sativa L. 'Invernina'}

Nombre vulgar: Avena marzolina, Avena invernina (MRI).

Número de informantes: 1 Número de citas: 1.

Número de sectores: 1 Número de categorías: 1 .

Biotipo: Terófito.

Tipo corológico: Cultivadas.

Abundancia: Común.

Ambiente: Campos, baldíos, estaciones ruderales.

Sector agropastoral

Categoría de uso: Alimentación animal (incluidos los forrajeros).

Número de informantes: 1 Partes utilizadas: frutos/infrutescencias/falsos frutos.

Si coltiva l'avena marzolina e invernina per dare da mangiare agli animali (MRI).

\section{Avena sativa L. 'Marzolina'}

Nombre vulgar: Avena marzolina (GGL), Avena marzolina, Avena invernina (MRI).

Número de informantes: 2 Número de citas: 2.

Número de sectores: 1 Número de categorías: 1.

Biotipo: Terófito.

Tipo corológico: Cultivadas.

Abundancia: Común.

Ambiente: Campos, baldíos, estaciones ruderales.

Sector agropastoral

Categoría de uso: Alimentación animal (incluidos los forrajeros).

Número de informantes: 2 Partes utilizadas: frutos/infrutescencias/falsos frutos.

L'avena marzolina, veniva seminata a febbraio o marzo, e rendeva di più, aveva la spiga più grossa, la pianta era più bassa che l'avena invernina che invece era alta. Da 
mangiare per le bestie: mucche e pecore (GGL)| Si coltiva l'avena marzolina e invernina per dare da mangiare agli animali (MRI).

Notas Prima quando ce n'erano tanti vigneti, si seminava l'avena marzolina (seminata a febbraio-marzo), di spiga grossa e pianta bassa: rendeva di più, poi c'era anche 1'avena invernina (pianta più alta e spiga più piccola).

\section{Brachypodium pinnatum (L.) P.Beauv.}

Nombre vulgar: Palea (GGI, GFR).

Número de informantes: 2 Número de citas: 2.

Número de sectores: 2 Número de categorías: 2 .

Biotipo: Hemicriptófito.

Tipo corológico: Europeas.

Abundancia: Común.

Ambiente: Prados áridos, bosques, escarpas.

Sector doméstico

Categoría de uso: Otro doméstico.

Número de informantes: 1 Partes utilizadas: hojas.

Per chiudere le bustine per raccogliere le fragole di bosco fatte con Farfallone (Petasites). (GFR).

Sector lúdico/voluptuoso

Categoría de uso: Instrumentos musicales.

Número de informantes: 1 Partes utilizadas: hojas.

Si fischiava tenendo la palea tra le dita. (GGI).

\section{Brachypodium sylvaticum (Huds.) P. Beauv.}

Nombre vulgar: Palea (VMU).

Número de informantes: 1 Número de citas: 2 .

Número de sectores: 2 Número de categorías: 2.

Biotipo: Hemicriptófito.

Tipo corológico: Europeas.

Abundancia: Común.

Ambiente: Bosques de latifolios (bosques de alisos, robledales, etc).

\section{Sector alimentario}

Categoría de uso: Otro alimentario.

Número de informantes: 1 Partes utilizadas: parte aérea (toda).

In tempo di guerra a Ottobre, si raccoglieva la parte vicino alla radice che sembra già secca, e anche la radice (sono grosse e gialle) si faceva seccare sulla stufa, poi la macinavano insieme alla farina, ma anche da sola e facevano le tigelle, le focaccie con questa specie di farina con I testi, si mettevano sul fuoco e quando diventano bianchi si metteva l'impasto sopra. (VMU).

Sector medicinal

Categoría de uso: Patologías del aparato urinario. 
Número de informantes: 1 Partes utilizadas: parte aérea (toda).

La palea si usava per le vie urinarie come infuso (VMU).

\section{Cynodon dactylon (L.) Pers.}

Nombre vulgar: Graminia (FAM, BLI, GGI, NLA), Gramigna (UMI, RFR, MTO, VMU, MRI, BEL, NST, MSR, TOA, NDI, CRE).

Número de informantes: 15 Número de citas: 22.

Número de sectores: 3 Número de categorías: 7.

Biotipo: Geófito.

Tipo corológico: Amplia distribución.

Abundancia: Bastante Común.

Ambiente: Baldíos, setos, terrenos pisoteados e infestante en los cultivos.

Número de exsiccata: 39059 FIAF.

\section{Sector alimentario}

Categoría de uso: Arroces y "risotto".

Número de informantes: 1 Partes utilizadas: órganos subterráneos.

Graminia (la parte tenera) insieme a pomodori, zucchine, bietola (NLA).

Categoría de uso: Sopas de verduras y potaje.

Número de informantes: 1 Partes utilizadas: órganos subterráneos.

Graminia (la parte tenera) insieme a pomodori, zucchine, bietola (NLA).

Sector mágico/medicinal

Categoría de uso: Vermífugo.

Número de informantes: 1 Partes utilizadas: órganos subterráneos.

Quando si capiva che i bambini avevano 'l'acetone", gli si legavano le 'radici' intorno alla gola e alla pancia. (CRE).

\section{Sector medicinal}

Categoría de uso: Estado general.

Número de informantes: 3 Partes utilizadas: órganos subterráneos.

Bere il decotto della radice di gramigna 'sfiamma'. (NDI)| Raccogliere le radici di gramigna, lavarle e fare il decotto, contro l'infiammazione. (TOA)| Mettere a bollire la radice nell'acqua e berla (GGI).

Categoría de uso: Patologías del aparato circulatorio.

Número de informantes: 3 Partes utilizadas: órganos subterráneos.

Bere spesso il decotto di gramigna, come rinfrescante (nel senso di antiinfiammatorio). (MSR)| Lavare le 'radici' (rizomi) di gramigna, fare il decotto e berlo al mattino. (NST) $\mid$ Mettere a bollire la radice nell'acqua e berla (GGI).

Categoría de uso: Patologías del aparato digestivo.

Número de informantes: 4 Partes utilizadas: órganos subterráneos.

Bere il decotto di gramigna 'per andare in bagno'. (BEL)| Bollire 5 minuti, e bere il decotto ogni tanto durante la giornata. (CRE)| Bere il decotto di gramigna quando si ha bruciore di stomaco (MRI)| Lavare la radice piccola e bianca e farla bollire. Bere come diuretico. (VMU).

Categoría de uso: Patologías del aparato urinario. 


\section{María Teresa Egea Molines}

Número de informantes: 9 Partes utilizadas: órganos subterráneos.

Fare il decotto delle 'radici' di gramigna e berlo di tanto in tanto. (BEL)| Bollire le 'radici' della gramigna e bere il decotto di continuo. (MSR)| Fare bollire le radici della gramigna e bere l'acqua. (MTO)| Lavare le 'radici' (rizomi) di gramigna, fare il decotto e berlo al mattino. (NST)| Bere il decotto di gramigna di tanto in tanto. (RFR) $\mid$ Bollire la radice della gramigna e bere il decotto di continuo (UMI)| Bollire "le barbe" della gramigna e bere il decotto per 'l'infezione di urina'. (BLI)| Radice messa ad essiccare per conservarla, va bevuto il decotto spesso (FAM)| Mettere a bollire la radice nell'acqua e berla (GGI).

Notas "L' ho usata molto dopo che mi hanno operato di appendicite.".

DATOS ETNOBOTÁNICOS BIBLIOGRÁFICOS

Nombre vulgar: gramaggna (UNGA21), gramigna (MANG98).

Número de referencias: 2 Número de citas: 5.

Número de sectores: 1 Número de categorías: 4.

Sector medicinal

Categoría de uso: Dolor de cabeza.

Número de referencias: 1 Partes utilizadas: órganos subterráneos.

Le contadine, quando hanno mal di capo, si stuzzicano con quest'erba le nari per farne uscire il sangue. V. anche sangunaela (UNGA21).

Categoría de uso: Patologías del aparato digestivo.

Número de referencias: 1 Partes utilizadas: órganos subterráneos.

...nella med. Popolare è adoperata in decotto per calmare I dolori del ventre, per facilitare le.

orine e per uccidere I vermi. (UNGA21).

Categoría de uso: Patologías del aparato urinario.

Número de referencias: 2 Partes utilizadas: órganos subterráneos.

...nella med. Popolare è adoperata in decotto per calmare I dolori del ventre, per facilitare le orine e per uccidere I vermi. (UNGA21)| Il rizoma viene bollito per ottenere un 'acqua'bevuta in caso di cistite e di altre infiammazioni a livello delle vie urinarie(MANG98).

Categoría de uso: Trastornos musculo-esqueléticos.

Número de referencias: 1 Partes utilizadas: órganos subterráneos.

A Mammiano si ritiene che tale preparato sia utile anche nel trattamento dei dolori reumatici,.

sia per assunzione interna che in frizioni locali. (MANG98).

\section{Hordeum vulgare $L$.}

Nombre vulgar: Orzo (DAD, PIM, TUL, TIV, SOT, NRE, LGI, CRI, CLO, BBA, MGO, BLI), Orzo.

vestito (UMI), Orzo da caffé (EMA), Orzo Mondo (UMI).

Número de informantes: 14 Número de citas: 18.

Número de sectores: 5 Número de categorías: 7.

Biotipo: Terófito.

Tipo corológico: Cultivadas. 
Abundancia: Cultivada.

Ambiente: Cultivado.

Sector agropastoral

Categoría de uso: Alimentación animal (incluidos los forrajeros).

Número de informantes: 3 Partes utilizadas: frutos/infrutescencias/falsos frutos, parte.

Si appendeva al collo del cavallo la guinea (un sacchetto tessuto di cannapa) e conteneva "la biada" ossia ghiande, orzo e semola per farlo mangiare. (BLI)| Orzo e fieno secco per I conigli. (MGO)| "L'orzo vestito" era buono per fare I beveroni alle bestie, perché dassero più latte. (UMI).

Sector alimentario

Categoría de uso: Pan y similares.

Número de informantes: 1 Partes utilizadas: harina/salvado.

Il pane si faceva una volta alla settimana, con del grano seminato, insieme all'orzo che lo.

faceva più scuro e più tenero, e un pò di segale che lo faceva più duro (MGO).

Categoría de uso: Sucedáneo del café.

Número de informantes: 10 Partes utilizadas: semillas.

Tostare I semi, macinarli con il macinino e farli bollire (TIV, BBA)| Semi tostati, macinati e messi a bollire. (CLO) $\mid$ Semi tostati e bolliti (CRI) $\mid$ Con i frutti tostati facevano il caffè (LGI)| Tostare l'orzo insieme ai ceci, macinare e bollire come surrogato del caffè. (NRE)| Semi tostati, macinati e messi a bollire, (SOT)| Semi tostati e bolliti, bevuto come il café. (TUL)| C'era una varietà di orzo a posta per il café diversa da quella che si coltivava per gli animali. Si coltivava solo per fare il café. Insieme ai ceci, si tostavano sul fuoco con l'apposita tostatrice poi si cuocevano e si aggiungerva mezzo bicchiere di vino. (EMA)| "L'orzo mondo" veniva tostao I semi, macinati con il macinino e farti bollire. (UMI).

Sector mágico/ritual/supersticioso

Categoría de uso: Adivinatorio.

Número de informantes: 1 Partes utilizadas: frutos/infrutescencias/falsos frutos. Leggevano il futuro con il fondo dell'orzo, lasciando posare il fondo dell'orzo usato come.

surrogato del caffe'. (CLO).

Sector medicinal

Categoría de uso: Afecciones del aparato respiratorio.

Número de informantes: 1 Partes utilizadas: frutos/infrutescencias/falsos frutos. Bollire le mele a spicchi, insieme a chicchi di uva passita (zibbibbo), prugne secche o ciliegie.

secche e chicchi d'orzo, e bere per 2 o 3 giorni. (NRE).

Categoría de uso: Estado general.

Número de informantes: 1 Partes utilizadas: frutos/infrutescencias/falsos frutos.

Bere il decotto di orzo 'sfiamma'. (PIM). 
Sector veterinario

Categoría de uso: Cerdos.

Número de informantes: 1 Partes utilizadas: frutos/infrutescencias/falsos frutos.

Come alimento energetico post-parto per i maiali si usava la 'broda', fatta con la 'rimanenza' delle patate (patate piccole, scarti di raccolta) cotte, semola cruda, orzo crudo e ortica cotta a parte, tutto mescolato. (DAD).

Notas È importante che il fieno e l'orzo siano ben secchi, mai dargli erba fresca ai conigli., L'orzo si.

seminava a primavera insieme al grano.

DATOS ETNOBOTÁNICOS BIBLIOGRÁFICOS

Nombre vulgar: orz, orz tudasc (UNGA21), orzo (BAL97).

Número de referencias: 2 Número de citas: 4.

Número de sectores: 2 Número de categorías: 3.

Sector alimentario

Categoría de uso: Sucedáneo del café.

Número de referencias: 2 Partes utilizadas: frutos/infrutescencias/falsos frutos,.

Coll'orzo tostato e macinato si fa quel caffé, che dicesi cafa d'orz, caffé d'orzo (UNGA21)| Un cenno particolare merito l'orzo, cereale anticchissimo, forse il primo conosciuto dagli uomini. Nella nostra montagna veniva coltivato in superfici limitate per ottenere il caffé di poveri”, infatti i semi di orzo, abbrustoliti e macinati, servivano come surrogato del café. (BAL97).

Sector medicinal

Categoría de uso: Afecciones del aparato respiratorio.

Número de referencias: 1 Partes utilizadas: frutos/infrutescencias/falsos frutos.

Hordeum zeocriton L. (orz tudasc), Coll'orzo tostato e macinato si fa quel caffé, che dicesi cafa d'orz, caffé d'orzo. Nella medicina popolare, l'orzo bollito si prende contro I raffreddori di petto e la tosse, e ciò corrisponde precisamente al decotto d'orzo mondato che Ippocrate prescriveva per gli attacchi di petto e chiamava tisana. 'e medicinale assia lassativa.(UNGA21).

Categoría de uso: Patologías del aparato digestivo.

Número de referencias: 1 Partes utilizadas: frutos/infrutescencias/falsos frutos. 'e medicinale assia lassativa. (UNGA21).

\section{Hordeum vulgare L. 'Vestito'}

Nombre vulgar: Orzo Vestito (UMI).

Número de informantes: 1 Número de citas: 1.

Número de sectores: 1 Número de categorías: 1.

Biotipo: Terófito.

Tipo corológico: Cultivadas.

Abundancia: Cultivada.

Ambiente: Cultivada.

Sector agropastoral

Categoría de uso: Alimentación animal (incluidos los forrajeros). 
Número de informantes: 1 Partes utilizadas: frutos/infrutescencias/falsos frutos.

Per fare dei beveroni alle bestie perché dassero più latte (UMI).

\section{Oryza sativa $L$.}

Nombre vulgar: Riso (MTO, MSR, LGI, GPU, BSO).

Número de informantes: 5 Número de citas: 5.

Número de sectores: 1 Número de categorías: 2.

Biotipo: Terófito.

Tipo corológico: Cultivadas.

Abundancia: Cultivada.

Ambiente: Cultivos.

Sector alimentario

Categoría de uso: Dulces y golosinas.

Número de informantes: 3 Partes utilizadas: frutos/infrutescencias/falsos frutos.

La torta di riso: cuocere il riso nel latte, aggiungere lo zucchero, la scorza del limone, I pinoli, uva passa. Mettere in forno finché non sia dorato. (BSO)| Torta di riso:Bollire il riso nel latte la sera prima, poi si fa freddare e la mattina dopo si sbattono 10 uova, e si aggiunge un metà bicchiere di liquore rosso (Archenius si comprava a Porretta) quindi aggiungere lo zucchero, poi mettere il chiaro d'uovo sbattuto sopra con un penellino e in fine dei chicchini di tutti i colori (si compravano a Rio) (LGI, GPU).

Categoría de uso: Empanadas.

Número de informantes: 2 Partes utilizadas: frutos/infrutescencias/falsos frutos.

"Torta di riso": cuocere il riso nell'acqua e alla fine aggiungere Il latte, lasciare cuocere un altro pò (no nel latte direttamente sennò rimane duro), poi deve asciugare. Aggiungere 4 uova per un litro di latte sbattute, e del cedro condito, zucchero e liquore di Mandorle Amare. Dopo si metteva tutto in una "ruola" (teglia bassa di Rame) sul bracere con il coperchio. e si finiva di cuocere. Si faceva quando si sposava qualcuno. (MTO, MSR).

Notas Era la torta che si faceva a Chiapporato, e a Stagno, la faceva la Mamma di Iole, la zia.

Beta di Purissima..

\section{Secale cereale $L$.}

Nombre vulgar: Segale (TIV, MME, MGO, LGI, GRI, GGI, PLU, UMI, RMA).

Número de informantes: 9 Número de citas: 12.

Número de sectores: 3 Número de categorías: 4.

Biotipo: Terófito.

Tipo corológico: Cultivadas.

Abundancia: Cultivada.

Ambiente: Campos, baldíos, ruinas.

Sector agropastoral

Categoría de uso: Alimentación animal (incluidos los forrajeros). 
Número de informantes: 2 Partes utilizadas: parte aérea (toda).

Ogni anno coltivavano grano, orzo, segale (per farina per il pane e per gli animali), lupini, ginestrino,trifoglio, erba spagna, per fare il fieno. E si tenevano I semi ogni anno per l'anno prossimo (RMA)| I campi si coltivavano alternativamente: nello stesso campo si seminavano prima le patate, dopo il grano, e dopo nelle stoppie se seminava il segale insieme al trifoglio e al ginestrino. Il segale si falciava alto e perché così rimanesse per fare il fieno. Oppure dopo il grano si seminavano le vecce. (UMI).

Categoría de uso: Cuerdas y ataduras.

Número de informantes: 1 Partes utilizadas: tallos herbáceos/escapos.

Il segale fa una paglia lunga. A casa sua si coltivava un quadretto nell'orto di segale per.

legare I covoni del grano (PLU).

Sector alimentario

Categoría de uso: Pan y similares.

Número de informantes: 7 Partes utilizadas: harina/salvado,.

Si faceva il pane di segale o misto con la farina di grano. Veniva un pane scuro. (GGI)| Si faceva il pane una volta alla settimana, con farina di grano e un pò di farina di segale, che lo faceva più scuro e lo manteneva morbido. (GRI)| Nell'Alpe di stagno si coltivava la segale (per fare il pane) l'orzo per fare il café (LGI)| Il pane si faceva una volta alla settimana, con del grano seminato, insieme all'orzo che lo faceva piu scuro e più tenero, e un pò di segale che lo faceva più duro (MGO)| La farina delle vecce veniva mescolata con la farina di grano o di segale, per fare il pane. Si faceva per bisogno. (MME)| Si faceva il pane con farina di segale, che coltivavano, perché era più digeribile che con la farina di grano. Il pane si faceva anche con patate passate, farina di segale settaciata e siero del formaggio. Dopo una settimana era ancora morbido. (RMA)| Facevano il pane con un po di grano e un po di segale (TIV).

\section{Sector doméstico}

Categoría de uso: Integración de la renta familiar.

Número de informantes: 2 Partes utilizadas: tallos herbáceos/escapos, parte aérea.

Vendevano la paia a commercianti e grossisti di segale per fare capelli e borse di segale (GGI)| La seccavano e vendevano la pailla (TIV).

Notas Ogni anno coltivavano grano, orzo, segale (per farina per il pane e per gli animali), lupini, ginestrino,trifoglio, erba spagna, per fare il fieno. E si tenevano I semi ogni anno per l'anno prossimo.

DATOS ETNOBOTÁNICOS BIBLIOGRÁFICOS

Nombre vulgar: segale (BAL97), såigla (UNGA21), segala (MUCC01).

Número de referencias: 3 Número de citas: 4.

Número de sectores: 3 Número de categorías: 4.

Sector alimentario

Categoría de uso: Otro alimentario. 
Número de referencias: 1 Partes utilizadas: harina/salvado.

Nelle terre più ingrate trovava posto la segale, cereale adatto alla panificazione, ottimo per essere mischiato alla farina di frumento. (BAL97).

Categoría de uso: Pan y similares.

Número de referencias: 1 Partes utilizadas: semillas.

coltivata specialmente in montagna per il grano con cui si fa pane eccellente e sano (UNGA21).

Sector artesanal

Categoría de uso: Objetos personales y calzado.

Número de referencias: 1 Partes utilizadas: tallos herbáceos/escapos.

La paglia di segale, lunga fine e resistente, aveva in passato diverse utilizzazioni (coperture,.

imballaggi, cappelli...) (BAL97).

Sector medicinal

Categoría de uso: Afecciones ginecológicas, complicaciones obstétricas, del postparto y del puerperio.

Número de referencias: 1 Partes utilizadas: No especificado.

Per fa veni i dolori alla svelta, la Pellegrina li dava la segala, li diceva tutto come dovevano.

fa (MUCC01).

\section{Sorghum bicolor (L.) Moench (= Sorghum bicolor (L.) Moench subsp. saccharatum L.)}

Nombre vulgar: Sagina (PIM), Saggina (DAD).

Número de informantes: 2 Número de citas: 3.

Número de sectores: 3 Número de categorías: 3.

Biotipo: Terófito.

Tipo corológico: Cultivadas.

Abundancia: Cultivada.

Ambiente: Baldíos, campos.

Sector doméstico

Categoría de uso: Objetos domésticos y escobas.

Número de informantes: 1 Partes utilizadas: tallos herbáceos/escapos.

Si facevano granate (scope) per spazzare il forno, il camino e dentro casa (PIM).

Sector mágico/ritual/supersticioso

Categoría de uso: Propiciatorio.

Número de informantes: 1 Partes utilizadas: tallos

leñosos/ramas/ramitas/vástagos.

Tenere in casa una scopa piccola di saggina appesa al muro porta fortuna. (DAD).

Sector veterinario

Categoría de uso: Cerdos.

Número de informantes: 1 Partes utilizadas: semillas. 
Si davano da mangiare i semi ai maiali, perché 'li rinfrescano' (sono antiinfiammatori). (PIM).

DATOS ETNOBOTÁNICOS BIBLIOGRÁFICOS

Nombre vulgar: saggina (GUC98).

Número de referencias: 1 Número de citas: 1.

Número de sectores: 1 Número de categorías: 1.

Sector doméstico

Categoría de uso: Objetos domésticos y escobas.

Número de referencias: 1 Partes utilizadas: parte aérea (toda).

Il granadèllo è uno scopino di saggina usato di solito per pulire la madia o il tavoléro..

(GUC98).

\section{Triticum aestivum $L$.}

Nombre vulgar: (RGI, NRE)Grano (VMU, DAD, PLU, CRI, ZAN, NRO, MME, MGO, GUF, GRI, GGI, MGE, CLO, VSI, GFR, RMA, BLI), Al grà (PCL), Pane bagnato, spiaccicato (VMR), Grano (REN, NLA, MMR, LGI, GPU, MTO, MTI, MSR, RFR, GLA, IMA, PEL, GGL, BPT), Semola (CBR).

Número de informantes: 36 Número de citas: 53.

Número de sectores: 7 Número de categorías: 18.

Biotipo: Terófito.

Tipo corológico: Cultivadas.

Abundancia: Cultivada.

Ambiente: Cultivado en todos los lugares en grandes extensiones en muchas variedades.

Sector agropastoral

Categoría de uso: Alimentación animal (incluidos los forrajeros).

Número de informantes: 2 Partes utilizadas: frutos/infrutescencias/falsos frutos,. Si appendeva al collo del cavallo la guinea (un sacchetto tessuto di cannapa) e conteneva "la biada" ossia ghiande, orzo e semola per farlo mangiare. (BLI)| Con la crusca si facevano le focacine, oppure era dato alle galline (RMA).

Categoría de uso: Cría de ovejas.

Número de informantes: 1 Partes utilizadas: hojas.

Foglie secche per fare il letto delle pecore (GFR).

Categoría de uso: Cuerdas y ataduras.

Número de informantes: 1 Partes utilizadas: tallos herbáceos/escapos.

Si intrecciavano 2 pugni di grano alto e si usava per legare il grano (VSI).

Categoría de uso: Horticultura.

Número de informantes: 1 Partes utilizadas: harina/salvado.

Antiparassitario: la farina buttata sopra le piante evita i pidocchi (CLO).

Sector alimentario

Categoría de uso: Dulces y golosinas.

Número de informantes: 1 Partes utilizadas: harina/salvado. 
Per Pasqua e Natale, o per la prima domenica d'ottobre tutti facevano I 'zuccherini': farina di grano, lievito naturale, anicini, zucchero, si faceva un impasto e si metteva in forno. Poi andavano canditi, so faceva scioglere un bicchiere di zucchero e un bicchiere d'acqua sul fuoco e si giravano tutti, poi diventavano bianchi. (MGE).

Categoría de uso: Pan y similares.

Número de informantes: 6 Partes utilizadas: harina/salvado.

Il grano si seminava per fare la farina e poi il pane. (GGI)| Si faceva il pane una volta alla settimana, con farina di grano e un pò di farina di segale, che lo faceva più scuro e lo manteneva morbido. (GRI)| le "cine" sono foccacine di farina di grano, acqua, sale e lievito usata per assaggiare il giusto calore del forno. (GUF)| Il pane si faceva una volta alla settimana, con del grano seminato, insieme all'orzo che lo faceva piu scuro e più tenero, e un pò di segale che lo faceva più duro (MGO)| La farina delle vecce veniva mescolata con la farina di grano o di segale, per fare il pane. Si faceva per bisogno. (MME)| Ogni anno coltivavano grano, orzo, segale (per farina per il pane e per gli animali), lupini, ginestrino,trifoglio, erba spagna, per fare il fieno. E si tenevano I semi ogni anno per l'anno prossimo (RMA)| Con la crusca si facevano le focacine, oppure era dato alle galline (RMA).

Categoría de uso: Sucedáneo del café.

Número de informantes: 1 Partes utilizadas: frutos/infrutescencias/falsos frutos.

Semi tostati, macinati e con I macinini e bollito. (PCL).

Sector artesanal

Categoría de uso: Tejer sillas.

Número de informantes: 1 Partes utilizadas: tallos herbáceos/escapos.

Si intrecciavano le sedie con la paglia di grano, per rivestire le sedie: "Durante l'inverno I.

bambini arrotollavano la pailla poi facevano le matasse e poi si rivestivano le sedie" (BLI).

\section{Sector doméstico}

Categoría de uso: Chimenea y horno.

Número de informantes: 1 Partes utilizadas: harina/salvado.

le "cine" sono foccacine di farina di grano, acqua, sale e lievito usata per assaggiare il giusto calore del forno. (GUF).

\section{Sector mágico/medicinal}

Categoría de uso: Otro mágico/medicinal.

Número de informantes: 2 Partes utilizadas: harina/salvado.

Quando si aveva gli occhi rossi (emorragie), prendere due pezzi di stoffa rossa tagliata a cerchio, mettere sulle tempie con della pasta di pane. (NRO)| Quando si aveva gli occhi il sangue nei occhi, impastare farina di grano con aceto, mettere sulle tempie. Mettere sopra due cerchi di stoffa rossa, a modo di cerotto. (PCL).

\section{Sector mágico/ritual/supersticioso}

Categoría de uso: Otro mágico/ritual/supersticioso.

Número de informantes: 1 Partes utilizadas: tallos herbáceos/escapos. 


\section{María Teresa Egea Molines}

Per San Giuseppe, si facevano dispetti alle femmine, si portava la pianta del cascadente e dell pailla di grano davanti alle case delle ragazze per dire che erano vecchie o vacche... (ZAN).

Categoría de uso: Propiciatorio.

Número de informantes: 3 Partes utilizadas: frutos/infrutescencias/falsos frutos, parte.

Per sant'Antonio (17 Gennaio) si benedice il grano e il fieno e poi si porta un sacchettino di grano benedetto alle galline e uno di fieno benedetto alle capre e alle mucche. (CRI)| Un mazzetto di spighe di grano appeso in casa. (GFR)| Il grano si mette in casa in un vaso perché porta abbondanza (PLU).

\section{Sector medicinal}

Categoría de uso: Afecciones cutáneas y tejidos subcutáneos.

Número de informantes: 6 Partes utilizadas: harina/salvado.

Bruciature, mani screpolate: mettere un po' di strutto, con un po' di farina e un po' di cera di candela in un tegamino, scaldare fino a che tutto sia ben sciolto e lasciare raffredare. (DAD)| Con la farina bianca di grano (semola) insieme all'aceto si fa un impacco sugli ascessi. (VMU)| Applicare il pane bagnato sulle infezioni da spine e fasciato. Tira fuori il pus. (VMR)| Per fare maturare il forunculo che viene al collo, mettere la pappa sopra, fatta di pane, latte e succhero (GGI)| Applicare un pò di pane masticato, insieme a un pò di zucchero, un pò di lardo sul frignolo. Questa pappa tira fuori il pus.j (MGO)| Applicare la mollica di pane bagnata nel latte con lo zucchero, e fasciarlo. Aiuta alla supurazione, tira fuori il pus. (NRE)| Pane masticato, "biasciotto di pane":si mastica un pò di pane, si applica sul forunculo o la spina con pus e si fascia. Sfiamma e tira fuori la spina. (VMU).

Categoría de uso: Afecciones del aparato respiratorio.

Número de informantes: 4 Partes utilizadas: harina/salvado.

Scaldare la crusca, metterla dentro un sacchetto di stoffa, e mettere sulla gola. (BPT) $\mid$ Fare bollire la crusca nell'acqua, metterla su una 'pezza di lino' e mettere il tutto intorno al collo. (GGL)| Tostare la crusca del grano, metterla in un panno e appoggiarlo sul petto (PEL)| Si facevano degli 'impiastri' caldi di semola (la setacciatura del grano che si coltivava) sul petto per la tosse (MGE).

Categoría de uso: Afecciones ginecológicas, complicaciones obstétricas, del postparto y del puerperio.

Número de informantes: 1 Partes utilizadas: harina/salvado.

Per fare aumentare il latte alle mamme si faceva una pappa di farina di grano cotta con acqua o latte. (IMA).

Categoría de uso: Afecciones oro-faríngeas y de la cavidad oral.

Número de informantes: 8 Partes utilizadas: harina/salvado.

Impasto di farina di grano con acqua: applicare l'impacco dell'impasto sulla parte infiammata e legare con un fazzoletto per tutta la notte (GLA)| Fare un impiastro sulla parte infiammata del impasto di farina di grano e aceto, per tutta la notte, fino alla mattina. (MME)| Fare un impasto con farina, acqua e aceto, mettere sulla parte infiammata e legarlo con un fazzoleto (NRO)| Fare un impacco con farina di grano e aceto e applicarlo con una garza o una stoffa sulla parte infiammata, per sfiammare. (RFR)| Fare un cataplasma con la farina di grano non setacciata e l'aceto (VMR)| 
Mettere sopra il foruncolo il "BIASCIOTTO" fatto di zucchero e pane masticato nella bocca (CRI)| "Fare un impacco di sugna d'agnello, la mollica d pane e l'aceto sulll'ascesso, tira via" (RGI)| Masticare una fetta di pane,"biasciotto di pane" (VMU).

Categoría de uso: Patologías del aparato digestivo.

Número de informantes: 5 Partes utilizadas: harina/salvado.

2 cucchiai di farina di grano, un po' di zucchero e un po' di acqua per fare consistenza crema, il tutto mescolato in un bicchiere (DAD)| Per il bruciore di stomaco, la mattina prendere un po' di fior di farina di grano e diluire piano piano nell'acqua. (MTO, MSR)| Bere un bicchiere di acqua in cui è stato diluito un cucchiaio di farina. (MTI)| Mangiare la semola cotta per il mal di pancia (CBR).

Categoría de uso: Trastornos musculo-esqueléticos.

Número de informantes: 6 Partes utilizadas: harina/salvado,.

Fare una 'spoglia', poltiglia di farina e acqua abbastanza densa, e applicare direttamente sulla parte infiammata, legando con un fazzoletto. (MMR, LGI, GPU)| Una manciata di foglie fresche di verbena tritate, insieme a un cucchiaio di grano e un bianco d' uovo, tutto dentro a un fazzoletto e messo la notte sul ginocchio. Mettere sotto il ginocchio un asciugamo. La mattina dopo tutta l'acqua sarà sull'asciugamano. (NLA)| Impacco e fasciatura, tipo gessatura:Fare la "chiarata":bianco d' uovo con farina di grano sulla caviglia e fasciare il tutto (PCL)| Impacco di farina di grano, chiarata d'uovo e legarlo con un panno (REN).

Notas La 'loppa' è la copertura del grano, e 'sloppare il grano' vuole dire toglierli l'impurità del grano: nell'aia (lastricata a lastroni di pietra, per non sporcare il grano), si sloppava il grano, prendendo I 'manelli' (quello che con la mano si riusciva a prendere per falciare le piante a mano e poi legarle), venivano sbattuti e il chicco di grano usciva, la paia rimaneva legata, si toglieva e rimaneva il chicco con la loppa (quello che riveste il chicco del grano compreso il baffo sopra). Poi venivano raccolto il grano con l'impurità, e per pulire il chicco del grano, si andavo su un serretto si metteva un telo steso e con una brezza di vento si ricuperava il grano pulito.

\section{DATOS ETNOBOTÁNICOS BIBLIOGRÁFICOS}

Nombre vulgar: sémmola (BENE96), grano (MANG98, BADI15, GUC98), semola (MUCC01, MATT, GUC81), Bìga (APPO10), Brancadèllo (APPO10), co'vo (APPO10), formento'n (APPO10), Pigno'n (APPO10), Rémmola (APPO10), guaìmme (APPO10).

Número de referencias: 8 Número de citas: 17.

Número de sectores: 4 Número de categorías: 8 .

\section{Sector alimentario}

Categoría de uso: Gachas o polenta.

Número de referencias: 2 Partes utilizadas: harina/salvado. sémmola,sost.f.='crusca'. È una parola toscana ma non fiorentina,dove si dice crusca. A Stagno si dice sémmola mentre a Bargi e a Badi si ha rémmola (BENE96)| La farinadina è la pappa per bambini (soprattutto lattanti) composta da farina di grano tostata, acqua, latte, zucchero. (GUC98).

Categoría de uso: Otro alimentario. 
Número de referencias: 1 Partes utilizadas:.

Paste fritte. Ingredienti: Farina di grano tipo 0, olio di semi o strutto,(uovofacoltativo), lievito di birra,sale.Si pone la farina sul tagliere e si aggiunge un pizzico di sale, lievito di birra in quantità bastante,un po' d'olio di semi o strutto,volendo anche un uovo.Si fa l'impasto aggiungendo acqua tiepida fino ad ottenere una pasta morbida. Si spiana la pasta col matterello poi si fanno delle strisce di circa $10 \mathrm{~cm} \mathrm{di}$ larghezza e dello spessore di $3 / 4 \mathrm{~mm}$.Si tagliano le strisce a rettangoli o losanghe. Si lasciano lievitare sul tagliere,poi si friggono in abbondante olio o strutto. Si mangiano con formaggio fresco,salumi,o cosparse di zucchero (BADI15).

\section{Sector lúdico/voluptuoso}

Categoría de uso: Juego colectivo y bromas.

Número de referencias: 1 Partes utilizadas: semillas.

La vigilia dopo che avevano mangiato si radunavano magari in una casa e giocavano anche a 'semolin'. Era un gioco per il quale prendevano tanti centesimi, poi prendevano della semola, li ruffolavano tutti tramezzo a questa semola, poi magari, se eravamo in dieci, dodici, quindici, venti.. facevano venti mucchietti..davanti a ognuno, un mucchietto di semola avanti ognuno e te dovevi cercare questi centesimi tramezzo a questo semolin, a questa semola..vincevi secondo quanti ne trovavi. (GUC81).

\section{Sector mágico/ritual/supersticioso}

Categoría de uso: Efecto negativo.

Número de referencias: 1 Partes utilizadas: harina/salvado.

La semolata era molto offensiva. Veniva fatta di notte alle persone che non si comportavano moralmente bene, sopratutto se davano scandalo. Ecco come veniva fatta: si preparava semola e patate trinciate (il magime dei suini) e si gettavano nella strada che conduceva all'abitazione della persona scandalosa. (MATT).

\section{Sector medicinal}

Categoría de uso: Afecciones cutáneas y tejidos subcutáneos.

Número de referencias: 1 Partes utilizadas: harina/salvado.

Poco pane viene bollito nel latte ad ottenere la cosidetta "pappina di latte“, una volta tiepida la si applica sugli ascessi e su varie forme infette quali "giradito"e "patereccio”. (MANG98)| L'acqua di semola viene usata in bagni rinfrescanti sia per bambini che per adulti, anche in presenza di dermatiti alergiche.(MANG98).

Categoría de uso: Afecciones típicas infantiles.

Número de referencias: 1 Partes utilizadas: harina/salvado.

Li si faceva il bagno coll'acqua di semola e la camomilla, ma no tutti i giorni perché una volta.

mi disse una vecchia di Lancisa, il bagno demolisce. (MUCC01).

Categoría de uso: Patologías del aparato digestivo.

Número de referencias: 1 Partes utilizadas: harina/salvado.

La cosiddetta "acqua di crusca“ottenuta facendo bollire in acqua della crusca per dieci minuti e lasciandola in infusione altrettanto tempo. Viene bevuta in caso di infiammazioni del tratto gastrointestinale e genito-urinario. (MANG98).

Categoría de uso: Patologías del aparato urinario. 
Número de referencias: 1 Partes utilizadas: harina/salvado.

La cosiddetta "acqua di crusca“ottenuta facendo bollire in acqua della crusca per dieci minuti e lasciandola in infusione altrettanto tempo. Viene bevuta in caso di infiammazioni del tratto gastrointestinale e genito-urinario. (MANG98).

\section{Triticum aestivum L. 'Marzolo'}

Nombre vulgar: Grano marzolo (UMI, MGO, TIV, MSR, GGI), Grano Marzolo (GLA).

Número de informantes: 6 Número de citas: 7.

Número de sectores: 1 Número de categorías: 2.

Biotipo: Terófito.

Tipo corológico: Cultivadas.

Abundancia: Cultivada.

Ambiente: Cultivada.

Sector alimentario

Categoría de uso: Pan y similares.

Número de informantes: 3 Partes utilizadas: harina/salvado.

Il grano marzolo è un grano più resistente, si faceva il pane con la farina di grano e segale (GGI)| Grano Marzolo. Si seminava a Marzo, in alto verso Stagno, perché rendeva di più. Usato per fare il pane. (MSR)| Grano di altitudine, va seminato a Marzo, si faceva il pane con un po di farina di segale (TIV).

Categoría de uso: Pasta y "gnocchi".

Número de informantes: 3 Partes utilizadas: harina/salvado.

Farina per fare la sfoglia: è equivalente al grano duro di tipo 0 (GLA)| "Le donne preferiscono il grano marzolo per fare la sfoglia perché viene meglio:più elastica e regge di più (MGO)| Il grano marzolo è ottimo per fare la sfoglia della pasta. (UMI)| Il grano marzolo si seminava a Primavera e era ottimo per fare la sfoglia. E similar al grano tipo 00. (UMI).

Notas Il grano marzolo va seminato a primavera (a marzo) con l'orzo, c'era anche il grano.

sardo che ha la spinga con il baffone, il grano moti, il grano vergilio.

\section{Triticum aestivum L. 'Mentana'}

Nombre vulgar: Grano "il mentana" (MTO).

Número de informantes: 1 Número de citas: 1.

Número de sectores: 1 Número de categorías: 1.

Biotipo: Terófito.

Tipo corológico: Cultivadas.

Abundancia: Cultivada.

Ambiente: Cultivada.

Sector alimentario

Categoría de uso: Pan y similares.

Número de informantes: 1 Partes utilizadas: harina/salvado. 
Si coltivava il Grano "il Mentana" (che aveva la spiga quadrata) per fare il pane (MTO).

\section{Triticum aestivum L.'Terminillo'}

Nombre vulgar: Grano terminillo (UMI).

Número de informantes: 1 Número de citas: 1.

Número de sectores: 1 Número de categorías: 1.

Biotipo: Terófito.

Tipo corológico: Cultivadas.

Abundancia: Cultivada.

Ambiente: Cultivada.

Sector alimentario

Categoría de uso: Otro alimentario.

Número de informantes: 1 Partes utilizadas: harina/salvado.

Il grano terminillo era ottimo per fare il pane (UMI).

\section{Triticum durum Desf.}

Nombre vulgar: Semola (GAN, VMR), Semola (grano) (BLI), Grano (semola) (GGI), Grano duro. (semola) (DAD, MGO).

Número de informantes: 6 Número de citas: 9.

Número de sectores: 4 Número de categorías: 7.

Biotipo: Terófito.

Tipo corológico: Cultivadas.

Abundancia: Cultivada.

Ambiente: Cultivada.

Sector agropastoral

Categoría de uso: Alimentación animal (incluidos los forrajeros).

Número de informantes: 1 Partes utilizadas: harina/salvado.

Si faceva la broda del maiale a base di ortica sbollentata, semola, grano turco, patate (quelle piccole che avanzavano con la buccia), farina dolce (castagne), siero del latte. (VMR).

\section{Sector doméstico}

Categoría de uso: Cuidado personal y cosmética.

Número de informantes: 1 Partes utilizadas: harina/salvado.

Semola cotta in acqua per fare I pediluvi (BLI).

Categoría de uso: Repelentes o trampas domésticas.

Número de informantes: 1 Partes utilizadas: harina/salvado.

Contro $\mathrm{i}$ topi in casa: mettere un secchio pieno d'acqua, aspettare che si fermi l'acqua, e mettereci sopra della semola con un po' di farina dolce. Mettere una especie di scalino o piattaforma che permetta ai topi salirci sopra, il topo si tuffa nel secchio e si affoga. (GAN). 


\section{Sector medicinal}

Categoría de uso: Afecciones del aparato respiratorio.

Número de informantes: 1 Partes utilizadas: harina/salvado.

Mettere I semi di lino risaldati insieme alla semola di grano su un panno e metterlo sul petto. (GGI).

Categoría de uso: Trastornos musculo-esqueléticos.

Número de informantes: 1 Partes utilizadas: harina/salvado.

Mettere la semola scaldata in un sachetto, a volte mettendo in mezzo alla semola un testo caldo, per mantenere la temperatura, poi mettere il sacchetto nella parte addolorata, e assorbe l'umidità. (GGI).

\section{Sector veterinario}

Categoría de uso: Aves de corral.

Número de informantes: 1 Partes utilizadas: harina/salvado.

L'impasto fatto di ortica cotta, farina dolce e semola è rinfrescante per le galline e 'le.

sfiamma'. (MGO).

Categoría de uso: Cerdos.

Número de informantes: 3 Partes utilizadas: harina/salvado.

Per prevenire la "Moria" dei maiali (pandemia ). Quando si sentiva dire che c'era la moria, si dava da mangiare ai maiali la 'broda': cuocere l'ortica insieme alle patate, alle carote, al farfaro, alle castagne secche e alla semola. (BLI)| Come alimento energetico post-parto per i maiali si usava la 'broda', fatta con la 'rimanenza' delle patate (patate piccole, scarti di raccolta) cotte, semola cruda, orzo crudo e ortica cotta a parte, tutto mescolato. (DAD)| Quando I maiali stavano poco bene gli davano da mangiare l'ortiga cotta con la semola e la patata. (GGI).

\section{Zea mays $L$.}

Nombre vulgar: Grano turco.

(TOA, NLA, GGI, VFR, CBR, GFR, NRE, MMR, LGI, GPU, DAD, SLU, MTO, MSR, VMR), Grano turco, formentone (VSI), Formentone (TAT, DBA, RMA, NMA, MRI, BPA), Gran turco (FAM), Granoturco (GUF), Grano Turco (SOT).

Número de informantes: 25 Número de citas: 29.

Número de sectores: 6 Número de categorías: 12 .

Biotipo: Terófito.

Tipo corológico: Cultivadas.

Abundancia: Cultivada.

Ambiente: Cultivada de forma común.

Sector agropastoral

Categoría de uso: Alimentación animal (incluidos los forrajeros).

Número de informantes: 1 Partes utilizadas: frutos/infrutescencias/falsos frutos.

Si faceva la broda del maiale a base di ortica sbollentata, semola, grano turco, patate (quelle piccole che avanzavano con la buccia), farina dolce (castagne), siero del latte. (VMR). 


\section{María Teresa Egea Molines}

\section{Sector alimentario}

Categoría de uso: Empanadas.

Número de informantes: 2 Partes utilizadas: harina/salvado.

Magnuffoli':fare rosolare il prezzemolo e gli altri aromi con la pancetta, aggiungere i fagioli crudi e le patate, quindi l'acqua, fare cuocere un po', e poi la farina di grano turco e fare bollire 30 minuti. Poi mettere nel forno, e dopo tagliare a fette, si frigge o si arrostisce. (MSR)| "I Magnuffoli":fare rosolare gli aromi come il prezzemolo con la pancetta, aggiungere I faggioli crudi e le patate, quindi l'acqua, fare cuocere un pò, e poi la farina di grano turco e fare bollire 30 minuti. Poi mettere nel forno, e dopo tagliare a fette, si frigge o si arrostisce. (MTO).

Categoría de uso: Ensalada.

Número de informantes: 1 Partes utilizadas: semillas.

Infrutescenza fresca, sgranata, e cotte in insalata (SLU).

Categoría de uso: Gachas o polenta.

Número de informantes: 1 Partes utilizadas: harina/salvado.

Con la farina di formentone si faceva la polenta con il sugo (VSI).

Categoría de uso: Verdura cocida.

Número de informantes: 2 Partes utilizadas: frutos/infrutescencias/falsos frutos.

Infrutescenza fresca, sgranata, e cotte come contorno (SLU) $\mid \mathrm{Si}$ cuocevano e si mangiavano.

conditi (VSI).

\section{Sector doméstico}

Categoría de uso: Ropa de cama y muebles.

Número de informantes: 11 Partes utilizadas: frutos/infrutescencias/falsos frutos,. Le panocchie venivano attaccate al soffitto per fare essiccare le 'foglie' (brattee), una volta seccate le 'foglie' si usavano per imbottire il "cagnariccio" (materasso). (NMA, BPA)| Il 'saccone' era un sotto-materasso fatto di 'sfoglie' di formentone (quelle che avvolgono la pannocchia). Poi sopra si metteva un altro materasso di lana. (MRI)| Si facevano i materassi di 'sfoglie' secche di formentone (quelle che avvolgono la pannocchia) : 'il sacco'. (RMA)| Ripieni di materassi:Mettevano le 'foglie' (brattee) secche che coprivano la pannocchia di granturco, dentro a una specie di sacco di canapa. (FAM)| Ripieni di materassi:Per fare il saccone, con le 'foglie' (brattee) secche e un sacco di canapa e riempito (DAD)| Una volta avevamo i materassi fatti con le 'foglie' del grano turco (MMR, LGI, GPU)| Materassi di 'sfoglie' secche di grano turco, con due aperture, per aggiustarle ogni giorno, chiamati 'sacconi', che si mettevano sotto quelli di lana. (NRE)| Ripieni di materassi:Sacchi di canapa imbottiti di 'foglie' di grano turco secche, che si cambiavano ogni anno. (SLU).

\section{Sector lúdico/voluptuoso}

Categoría de uso: Fumable.

Número de informantes: 1 Partes utilizadas: frutos/infrutescencias/falsos frutos. Gli stigmi secchi si usavano come il tabacco, da fumare con la pipa. (GUF).

\section{Sector mágico/ritual/supersticioso}

Categoría de uso: Propiciatorio.

Número de informantes: 1 Partes utilizadas: frutos/infrutescencias/falsos frutos. 
Appeso in casa, porta abbondanza (GFR).

\section{Sector medicinal}

Categoría de uso: Afecciones del aparato respiratorio.

Número de informantes: 5 Partes utilizadas: harina/salvado.

La polenta calda avvolta con un panno e messa sul petto. (TAT, DBA)| Fare un impiastro: stendere in un panno l'impasto di farina di formentone e acqua e applicarlo sul petto. (NRE)| La polenta calda dentro di un tovagliolo appogiati sul petto, porta benefici per da anche tanta umidità. (CBR)| Fare una poltigia con la semola di grano turco coltivato qui, come la polenta, poi metterne un pò su una stoffa e poi apoggiare sul petto ben caldo. Fa sudare. (VFR).

Categoría de uso: Afecciones oro-faríngeas y de la cavidad oral.

Número de informantes: 2 Partes utilizadas: harina/salvado.

Mescolare la farina del grano turco (macinato) con aceto, e mettere sulla guancia nella parte.

dolente. (GGI)| impiastro di farina grano turco. (SOT).

Categoría de uso: Dolor de cabeza.

Número de informantes: 1 Partes utilizadas: harina/salvado.

Pestavano insieme le 'barbe' (rizomi) della felce ('liquirizia') insieme a chicchi di granturco, facevano cuocere il tutto per un po' e poi mettevano la poltiglia in un fazzoletto che si metteva sulla testa, così il mal di testa passava. (NLA).

Categoría de uso: Patologías del aparato urinario.

Número de informantes: 1 Partes utilizadas: frutos/infrutescencias/falsos frutos.

Raccogliere "I baffi di Grano Turco" (gli stigmi)) fare il decotto e bere in continuazione per la prostata (TOA).

Notas Il grano turco "formentone" di colore giallo era per fare farina, e il grano turco formentone rosso-verde era da mangiare.

\section{DATOS ETNOBOTÁNICOS BIBLIOGRÁFICOS}

Nombre vulgar: grano turco (ZAGN90, GUC98), granturco (MUCC01), formento'n (BENE96, APPO10), formintån (UNGA21).

Número de referencias: 6 Número de citas: 6 .

Número de sectores: 2 Número de categorías: 3.

Sector doméstico

Categoría de uso: Objetos domésticos y escobas.

Número de referencias: 1 Partes utilizadas: hojas.

Il paiaccio era il materasso imbottito di foglie di granoturco (GUC98).

\section{Sector medicinal}

Categoría de uso: Afecciones cutáneas y tejidos subcutáneos.

Número de referencias: 1 Partes utilizadas: harina/salvado.

Fare degli impiastri di farina di granoturco per farli venire a supporazione (ZAGN90).

Categoría de uso: Afecciones del aparato respiratorio.

Número de referencias: 1 Partes utilizadas: harina/salvado. 
A bimbi, quando avevano il raffreddore, li si fasciava la polenda gialla su piedini. (MUCC01).

\section{Zea mays L. 'Americano'}

Nombre vulgar: Mais americano (MRI).

Número de informantes: 1 Número de citas: 1.

Número de sectores: 1 Número de categorías: 1 .

Biotipo: Terófito.

Tipo corológico: Cultivadas.

Abundancia: Cultivada.

Ambiente: Cultivada.

Sector agropastoral

Categoría de uso: Alimentación animal (incluidos los forrajeros).

Número de informantes: 1 Partes utilizadas: frutos/infrutescencias/falsos frutos.

Il mais Americano si coltivava per dare da mangiare agli animali, perché era più produttivo..

(MRI).

\section{Zea mays L. 'Nostrano'}

Nombre vulgar: Mais nostrano (MRI).

Número de informantes: 1 Número de citas: 1 .

Número de sectores: 1 Número de categorías: 1.

Biotipo: Terófito.

Tipo corológico: Cultivadas.

Abundancia: Cultivada.

Ambiente: Cultivada.

Sector alimentario

Categoría de uso: Gachas o polenta.

Número de informantes: 1 Partes utilizadas: frutos/infrutescencias/falsos frutos.

Mais nostrano: si teneva ogni anno da riseminare, il chicco era rottondegiante, più piccoli, resa minore ma sapore più gustoso per la Polenta. Non dava problemi di malattie nei coltivi (MRI).

\section{POLYGONACEAE}

\section{Rumex acetosa $L$.}

Nombre vulgar: Schiareggiola, Insallegiola (GGI), Erba brusca (VMA, RMA, RFR, PIM, MRI, MIO), Erba brusca, Erba dolce (NST), Insallegica, Erba brusca (BBI), Insallegiola (MGE, CRI, CLO), Sallegiola (GFR), Schiareggiola (NLA, BPI), Schiarregiola (FAM), Straiggola (BPA).

Número de informantes: 18 Número de citas: 19. 
Número de sectores: 2 Número de categorías: 3 .

Biotipo: Hemicriptófito.

Tipo corológico: Nórdicas.

Abundancia: Común.

Ambiente: Prados segados y fertilizados.

Número de exsiccata: 39002 FIAF, 39106 FIAF.

Sector alimentario

Categoría de uso: Ensalada.

Número de informantes: 1 Partes utilizadas: hojas.

Per insaporire l' insalata (GGI).

Categoría de uso: Golosinas y masticatorias.

Número de informantes: 17 Partes utilizadas: hojas, tallos herbáceos/escapos.

Quando eravamo nei campi mangiavamo Ie foglie piccole e giovani. (MIO)| Si mangiavano le foglie quando si era in giro. (PIM, MRI)| Nei campi, i ragazzi ciucciavano le foglie. (RFR) $\mid$ Si masticava e si mangiava il succo dello stelo, che era acido. (RMA)| Quando eravamo in giro si prendeva una foglia o due e si ciuciavano. (VMA)| Si masticavano le foglie, che hanno un sapore aspro/acido. (NST)| lo stelo è acido, si ciucciava mentre si camminava, è dissetante. (BBI)| Al naturale (CLO)| Quando eravamo ragazzi, si masticava come dissetante (CRI)| le foglie si mangiavano così quando si era in giro (MGE)| Messa in bocca, dissetava (GFR)| Sa di limone, toglieva la sete. (BPI)| Si ciucciava il succo dolce (NLA)| I ragazzi la tengono in bocca per i campi, sapore di limone e aceto (FAM)| Caminando si prendeva una foglia e ti la mettevi in bocca (BPA)| Raccolta e mangiata così (GUF).

Sector medicinal

Categoría de uso: Afecciones cutáneas y tejidos subcutáneos.

Número de informantes: 1 Partes utilizadas: hojas.

Quando uno tocca l' ortica e li viene l' urticaria, passarci sopra la schiarregiola (GGI).

Notas distingue R. acetosella e R. acetosa e dice che venivano usate entrambe., si chiama così a tutte le piante con il pedunculo separato., no ce n'è più, ora non ce n'è più, erba dolce selvatica, foglie ad elica. Usano entrambe le specie. distingue $\mathrm{R}$. acetosella e R. acetosa e dice che venivano usate entrambe.basta che avessero un sapore acido.Quando uno tocca l'ortica e li viene l' urticaria, soprattutto non deve bagnarsi, perché peggiora. Diversa della Straiggola ed botta, cattiva da mangiare..

DATOS ETNOBOTÁNICOS BIBLIOGRÁFICOS

Nombre vulgar: êrba brossca, êrba salenna (UNGA21), acetosa, êrba brossca (SANS14), èrba.

dal bòtte (GUC98).

Número de referencias: 3 Número de citas: 7.

Número de sectores: 3 Número de categorías: 6 .

Sector agropastoral

Categoría de uso: Alimentación animal (incluidos los forrajeros).

Número de referencias: 1 Partes utilizadas: hojas. 
acetosa, erba gradita al bestiame... (UNGA21).

Sector alimentario

Categoría de uso: Golosinas y masticatorias.

Número de referencias: 1 Partes utilizadas: frutos/infrutescencias/falsos frutos, brotes (SANS14).

Categoría de uso: sin precisar.

Número de referencias: 1 Partes utilizadas: hojas.

...coltivato negli orti per usi culinari (UNGA21).

Sector medicinal

Categoría de uso: Afecciones cutáneas y tejidos subcutáneos.

Número de referencias: 1 Partes utilizadas: hojas.

le foglie pestate e mescolate all'olio d'uliva serono a far disparire I porri (UNGA21).

Categoría de uso: Estado general.

Número de referencias: 1 Partes utilizadas: hojas.

...detta anche êrba salenna insieme alla R. acetosella L. e alla R. scutatus L. de luoghi montani. Tutte e tre le piante contengono acido ossalico, detto sale d'acetosella. Le foglie sono rinfrescativ e antiscorb., le radici diuretiche (UNGA21).

Categoría de uso: Patologías del aparato urinario.

Número de referencias: 1 Partes utilizadas: órganos subterráneos.

..le radicie diuretiche.. (UNGA21).

\section{Rumex acetosella $L$.}

Nombre vulgar: Straigola (CFR, GUF), Barcecola (BSO, BAR), Barcecola, Sarregiola delle serpi.

(DBA), Bicecola (NDI), Erba brusca, Mignarra (ZAN), Insallegica (BAN), .

Insallegica, Erba brusca (BBI), Insallegiola (NRE, DAD, CLO), Sallegica (BSI),

Sallegiola (GFR), Sarriciola (TAD), Schiareggiola (BPI, GGI, FAM), Straiggola (BPA), Vignarra (PGI).

Número de informantes: 20 Número de citas: 21.

Número de sectores: 2 Número de categorías: 3 .

Biotipo: Hemicriptófito.

Tipo corológico: Amplia distribución.

Abundancia: Común.

Ambiente: Baldíos áridos y arenosos (ácidos).

Número de exsiccata: 39022 FIAF, 39094 FIAF, 39022 FIAF, 38999 FIAF.

Sector alimentario

Categoría de uso: Ensalada.

Número de informantes: 1 Partes utilizadas: hojas.

Mangiata cruda insieme ad altre insalata. (GUF).

Categoría de uso: Golosinas y masticatorias.

Número de informantes: 19 Partes utilizadas: hojas, hojas, tallos herbáceos/escapos,. 
Le foglie aspre come limone si mangiavano mentre si era nei campi. (DBA, BAR)| Le foglioline piu tenere che crescevano piu in alto e il ramettino si mangiavano nei campi mentre si camminava. (BSO)| Le foglie e lo stelo tenero sbucciato si mangiavano mentre si cammina per i campi. (NDI) $\mid$ Si ciuciava il plò (lo stelo), era di sapore brusco, "brusc" (acido), facevano a bolate ( di quà e di là) (ZAN)| Si mangiavano quando si andava a giro con le pecore. (BAN)| lo stelo è acido, si ciucciava mentre si camminava, è dissetante. (BBI) $\mid$ Al naturale (CLO)| "la biaci"(la masticchi in dialetto), sapore acido, è dissetante. (DAD) $\mid \mathrm{Si}$ mangiavano quando si 'andava a pecore'. (NRE)| Si masticava e si mangiava il succo dello stelo, che era acido. (BSI)| Messa in bocca, dissetava (GFR)| I germogli teneri si mangiavano come caramelle mentre si camminava (TAD) $\mid$ Sa di limone, toglieva la sete. (BPI)| I ragazzi la tengono in bocca per i campi, sapore di limone e aceto (FAM)| Caminando si prendeva una foglia e ti la mettevi in bocca (BPA) $\mid$ Si teneva in bocca. (CFR)| Raccolta e mangiata così (GUF)| Il gambo e anche le foglie della vignarra si masticava quando si caminava, aveva un sapore "brusco" (acido) (PGI).

\section{Sector medicinal}

Categoría de uso: Afecciones cutáneas y tejidos subcutáneos.

Número de informantes: 1 Partes utilizadas: hojas.

Quando uno tocca l' ortica e li viene l' urticaria, passarci sopra la schiarregiola (GGI).

Notas ce n'erano tante una volta, il campo accanto alla casa era pieno e ora non ne vedo piu,.

\section{DATOS ETNOBOTÁNICOS BIBLIOGRÁFICOS}

Nombre vulgar: insaleggiola (MANG98), strìggola, insaléggiola, vignóla (GUC98).

Número de referencias: 2 Número de citas: 4.

Número de sectores: 2 Número de categorías: 3.

\section{Sector alimentario}

Categoría de uso: Ensalada.

Número de referencias: 2 Partes utilizadas: hojas.

Le foglie vengono comunemente consumate in insalata. (MANG98)| Di sapore brusco, veniva consumata, in primavera, nelle insalate. (GUC98).

\section{Sector medicinal}

Categoría de uso: Estado general.

Número de referencias: 1 Partes utilizadas: tallos herbáceos/escapos.

il succo del gambo viene assunto per aumentare 1'apporto di vitamine e sali minerali. (MANG98).

Categoría de uso: Patologías del aparato digestivo.

Número de referencias: 1 Partes utilizadas: tallos herbáceos/escapos.

il succo del gambo viene assunto per favorire la digestione. (MANG98).

\section{Rumex crispus $L$.}

Nombre vulgar: Semini rossi (EMA). 
Número de informantes: 1 Número de citas: 1.

Número de sectores: 1 Número de categorías: 1.

Biotipo: Hemicriptófito.

Tipo corológico: Amplia distribución.

Abundancia: Común.

Ambiente: Baldíos, ruinas, cultivos.

Número de exsiccata: 38939 FIAF.

Sector veterinario

Categoría de uso: Ganado bovino.

Número de informantes: 1 Partes utilizadas: semillas.

Quando le mucche mangiavano l'erba fresca si gonfiavano, quindi si mettevano I semini rossi dentro alla biada, e poi stavano meglio. (EMA).

DATOS ETNOBOTÁNICOS BIBLIOGRÁFICOS

Nombre vulgar: rombice, romice (MANG98).

Número de referencias: 1 Número de citas: 1 .

Número de sectores: 1 Número de categorías: 1 .

Sector medicinal

Categoría de uso: Afecciones cutáneas y tejidos subcutáneos.

Número de referencias: 1 Partes utilizadas: hojas.

Le foglie, unite a sapone e riscaldate sotto la cenere, vengono applicate sui brufoli. (MANG98).

\section{Rumex obtusifolius $L$.}

Nombre vulgar: Romice (GGI, GFR), Erba di botta (GGL).

Número de informantes: 3 Número de citas: 3.

Número de sectores: 2 Número de categorías: 2.

Biotipo: Hemicriptófito.

Tipo corológico: Europeas.

Abundancia: Rara.

Ambiente: Baldíos húmedos, prados, cultivos irrigados.

Número de exsiccata: 38975 FIAF, 39068 FIAF.

Sector agropastoral

Categoría de uso: Alimentación animal (incluidos los forrajeros).

Número de informantes: 2 Partes utilizadas: hojas.

Dare direttamente da mangiare ai maiali (GFR)| Per dare da mangiare ai maiali, cruda, insieme all'erba ciliegina e al gambo rosso. (GGI).

\section{Sector veterinario}

Categoría de uso: Ganado bovino.

Número de informantes: 1 Partes utilizadas: semillas.

I semi mescolati con un po' di farina di orzo o di grano si davano da mangiare alle bestie quando avevano diarrea (per aver mangiato tanta erba fresca a primavera dopo tanti mesi di secco). (GGL). 


\section{POLYPODIACEAE}

\section{Polypodium vulgare L. (s. l.)}

Nombre vulgar: Felce, Liquirizia (PGI), Felce (CFR), Felce da liquirizia, non ha nome (VSI), Liquirizia (TIV, TAD, MDA, GGI), Regolizia (GLA, BPA), Rigolizia (NLA, GUF), Felce dolce (TGO).

Número de informantes: 12 Número de citas: 14.

Número de sectores: 2 Número de categorías: 6.

Biotipo: Hemicriptófito.

Tipo corológico: n.d.

Abundancia: Común.

Ambiente: Bosques, muros, también arbóreos.

Número de exsiccata: 38923 FIAF.

\section{Sector alimentario}

Categoría de uso: Dulces y golosinas.

Número de informantes: 1 Partes utilizadas: órganos subterráneos.

La radice della felce si mangiava per passare il tempo, come caramelle (PGI).

Categoría de uso: Golosinas y masticatorias.

Número de informantes: 9 Partes utilizadas: órganos subterráneos.

$\mathrm{Si}$ ciuciava la radice della felce caminando per il bosco (CFR)| Mentre si camminava, si raccoglieva questa felce, si spellava (il rizoma) e si metteva in bocca: sa di liquirizia. (VSI)| Si teneva in bocca (GGI)| Radice con sapore a liquirizia, per camminare si metteva in bocca. (MDA)| Nei campi, quando portavamo a pascolare le bestie, o a raccogliere le erbe, tenevamo in bocca la liquirizia e la ciuciavamo. (TAD)| Radice con sapore a liquirizia (BPA, TIV)| In campagna, si prendeva, si puliva e si masticava. (GUF)| Sapore di liquirizia (NLA).

Categoría de uso: Otro alimentario.

Número de informantes: 1 Partes utilizadas: órganos subterráneos.

Radice nera, secca e pestata usata come surrogato dello zucchero (TGO).

Sector medicinal

Categoría de uso: Afecciones del aparato respiratorio.

Número de informantes: 1 Partes utilizadas: órganos subterráneos.

Fare I fumenti con la radice di regolizia, I fiori di sambuco, il rosmarino e la salvia. (GLA).

Categoría de uso: Dolor de cabeza.

Número de informantes: 1 Partes utilizadas: órganos subterráneos.

Pestavano insieme le 'barbe' (rizomi) della felce ('liquirizia') insieme a chicchi di granturco, facevano cuocere il tutto per un po' e poi mettevano la poltiglia in un fazzoletto che si metteva sulla testa, così il mal di testa passava. (NLA).

Categoría de uso: Patologías del aparato circulatorio.

Número de informantes: 1 Partes utilizadas: órganos subterráneos.

Si metteva in bocca la radice della liquirizia, si spellava e si ciuciava quando si aveva la pressione bassa (giramento di testa, spossatezza) (GGI).

Notas Il sapore assomiglia a quello della liquirizia. 


\section{DATOS ETNOBOTÁNICOS BIBLIOGRÁFICOS}

Nombre vulgar: regolìzia (GUC98).

Número de referencias: 1 Número de citas: 1 .

Número de sectores: 1 Número de categorías: 1.

Sector alimentario

Categoría de uso: Golosinas y masticatorias.

Número de referencias: 1 Partes utilizadas: órganos subterráneos.

La radice della felce dolce di zapore dolce-amaro, rachiata, veniva masticata dai ragazzi. (GUC98).

\section{PORTULACACEAE}

\section{Portulaca oleracea $L$.}

Nombre vulgar: Erba porcellina (GCL).

Número de informantes: 1 Número de citas: 1.

Número de sectores: 1 Número de categorías: 1 .

Biotipo: Terófito.

Tipo corológico: Amplia distribución.

Abundancia: Común.

Ambiente: Campos, huertos, baldíos.

Sector agropastoral

Categoría de uso: Alimentación animal (incluidos los forrajeros).

Número de informantes: 1 Partes utilizadas: parte aérea (toda).

La davano da mangiare ai maiali (GCL).

Notas "Non ce n'è più".

DATOS ETNOBOTÁNICOS BIBLIOGRÁFICOS

Nombre vulgar: badilàccio (GUC98), portulaca (SANS14), purzlaena (UNGA21).

Número de referencias: 3 Número de citas: 7 .

Número de sectores: 3 Número de categorías: 5.

\section{Sector alimentario}

Categoría de uso: Ensalada.

Número de referencias: 2 Partes utilizadas: hojas.

(SANS14) Si usava mettere qualche foglia nell'insalata (GUC98).

Categoría de uso: Golosinas y masticatorias.

Número de referencias: 1 Partes utilizadas: hojas.

Nella medicina popolare, le foglie di porcellana mitigano la sete. Tenendole in bocca, calmano il dolore de denti e sanano le ulceri della gola. (UNGA21).

Categoría de uso: Licor.

Número de referencias: 1 Partes utilizadas: hojas (SANS14).

Sector mágico/medicinal

Categoría de uso: Vermífugo. 
Número de referencias: 1 Partes utilizadas: hojas.

Pestate e poste sull'umbelico de bambini, si crede abbiano virtù di far morire I vermi. (UNGA21).

Sector medicinal

Categoría de uso: Afecciones oro-faríngeas y de la cavidad oral.

Número de referencias: 1 Partes utilizadas: hojas.

Nella medicina popolare, le foglie di porcellana mitigano la sete. Tenendole in bocca, calmano il dolore de denti e sanano le ulceri della gola. (UNGA21).

\section{PRIMULACEAE}

\section{Primula vulgaris Huds.}

Nombre vulgar: Ciuciamele (BSO), Cucumé, Radicchio (VSI), Bugamelli (MSR), Ciuciameli (BEL), Cucamegli (IMA, NMA, GFR, CRI), Cucamelli (LGI, GPU), Cucumegli (ZAN), Cucumei (NST, RMA), Cucumelli (VMA), Cucumeo (BSI), Primula, Cucumelli (PGI), Primule (MRI, BOR, BGI), Ciucciamerli (TAT), Cucumé (MIO, VSI).

Número de informantes: 22 Número de citas: 31 .

Número de sectores: 2 Número de categorías: 7.

Biotipo: Hemicriptófito.

Tipo corológico: Europeas.

Abundancia: Común.

Ambiente: Bosques latifolios (sobre todo hayedos, robledales, bosques de carpes).

Número de exsiccata: 39069 FIAF.

Sector alimentario

Categoría de uso: Ensalada.

Número de informantes: 2 Partes utilizadas: flores/inflorescencias y sus partes.

I fiori si mettono nell'insalata. (BSO)| Le foglie tenere si mangiano crude insieme alle foglie.

del cul bianco, che crescono allo stesso tempo. (VSI).

Categoría de uso: Golosinas y masticatorias.

Número de informantes: 16 Partes utilizadas: flores/inflorescencias y sus partes. Quando si stava in giro, si ciucciavano i fiori. (MSR) $\mid$ Il fiore si succhiava mentre si camminava. (BSO) $\mid$ Si ciucciava il fiore quando si era in giro. (BEL)| Al naturale (CRI)| Succiavano il miele dei fiori (GFR)| In primavera, i bimbi le staccavano per succhiarle il nettare (NMA)| I fiori erano delle trombettine che si ciucciavano mentre si camminava. Erano dolci. (LGI, GPU)| I fiori si ciuciavano quando si caminava. (ZAN)| Si ciucciavano i fiori, che avevano un sapore dolciastro. (BSI, RMA)| I fiori si ciuciavno quando si era in giro (VMA)| I fiori si mangiavano quando si era in giro (PGI)| I bambini ciucciano i fiori nel campo (BGI)| I fiori delle primule si ciucciavano mentre si camminava. (BOR) $\mid$ I bambini ciucciavano e mangiavano $i$ fiori, erano come trombette, come un fischio. (MRI).

Categoría de uso: Relleno de ravioli. 


\section{María Teresa Egea Molines}

Número de informantes: 5 Partes utilizadas: hojas.

Le foglie dei ciucciamerli si usavano cotti come ripieno dei tortelli. (TAT) $\mid$ Le foglie crude, tritate, mescolate con la ricotta come ripieno dei tortelloni (al posto della bietola). (BEL)| Le foglie tritate crude e mescolate alla ricotta. (PLU)| Quando non c'erano altre verdure, d'inverno, si raccoglievano le foglie dei cucumé, cotti e mescolati con la ricotta per il ripieno dei tortelloni. (MIO)| Bollire le foglie di cucumei e mescolarle con la ricotta, come ripieno per i tortelloni. (NST).

Categoría de uso: Sopas de verduras y potaje.

Número de informantes: 2 Partes utilizadas: hojas.

"Minestra di pane con cucamegli": si fa con cucamegli, faggioli, patate, faggiolini, carote.

coltivate (IMA) $\mid$ Le foglie si aggiungevano alla minestra (NMA).

Categoría de uso: Verdura cocida.

Número de informantes: 3 Partes utilizadas: hojas.

Le foglie vanno cotte insieme ad altri radicchi amari, perché è più dolce. (BSO)| Le foglie si cuocevano insieme ad altre erbe. (LGI)| Le foglie dei cucumé si mangiano cotte come verdure. (VSI).

Sector lúdico/voluptuoso

Categoría de uso: Alimentos/juguetes.

Número de informantes: 2 Partes utilizadas: flores/inflorescencias y sus partes.

Con I fiori si soffiava dentro e facevamo dei fischietti (VMA)| Con I fiori si facevano dei fichietti (PGI).

Categoría de uso: Pasatiempos.

Número de informantes: 1 Partes utilizadas: flores/inflorescencias y sus partes. I bambini 'suonavano la trombetta' con i fiori (BGI).

Notas Quando non c'erano altre verdure, d'inverno, si raccoglievano le foglie dei cucumé, l'elvira le cuoveva con altre.

\section{DATOS ETNOBOTÁNICOS BIBLIOGRÁFICOS}

Nombre vulgar: primula (SANS14), cucamègli (GUC98), premmivair (UNGA21), cucumî (in mont. Porretta), (a Porretta) le primule, v.premmivair. (UNGA21), premmavaira (UNGA21), cucumé (APPO10).

Número de referencias: 4 Número de citas: 8 .

Número de sectores: 2 Número de categorías: 5 .

Sector alimentario

Categoría de uso: Ensalada.

Número de referencias: 1 Partes utilizadas: flores/inflorescencias y sus partes (SANS14).

Categoría de uso: Golosinas y masticatorias.

Número de referencias: 2 Partes utilizadas: flores/inflorescencias y sus partes.

(SANS14).

I bambini in primavera, staccavano il fiore per succhiarne il nettare. (GUC98).

Categoría de uso: Relleno de ravioli.

Número de referencias: 1 Partes utilizadas: flores/inflorescencias y sus partes (SANS14). 


\section{Sector medicinal}

Categoría de uso: Afecciones oftalmológicas.

Número de referencias: 1 Partes utilizadas: flores/inflorescencias y sus partes.

premmivair zali, pl., in mont. Cucumî (P.acaulis.Jacq. O P.grandiflora, Lamk.) primule, primavere a fiori giallo-solfini, comuniss. Ovunque. Dalle primule I nostri cont. staccano il fiore, che credono abbia la virtù di conservare la vista. Epperò se lo passano davanti agli occhi, tenendolo stretto fra il pollice e l'indice e accompagnando l'atto colla cantilena: fiuren di primavera, mantegnim la mi lumera, mantegnim la mi guardoe, o fioreo di prima estae.(UNGA21).

Categoría de uso: Patologías del sistema nervioso.

Número de referencias: 1 Partes utilizadas: flores/inflorescencias y sus partes.

Premmavaira, primula, primavera gialla a mazzetti, primula de'campi già usata in farmacia. Nella med. Pop. Coll'acqua de fiori disseccati si prepara un calmante assai apprezzato. La pianta è colt. Negli orti. (UNGA21)| Nella medicina popolare coll'acqua de fiori disseccati si prepara un calmante assai apprezzato.(UNGA21).

\section{RANUNCULACEAE}

\section{Clematis vitalba $L$.}

Nombre vulgar: Vitalba (BLI, CRO, LLU, NLA, PLU, TGA), Vizzadri (AP2, BAN, BAR, BAZ, BBI, BEL, BFE, BOR, BPA, BPI, BSI, BSO, CFR, CRE, CRI, DAD, EMA, FAM, FAR, GAN, GFR, GGI, GGL, GLA, GUF, GZE, LGI, LRE, MDA, MGE, MGI, MGO, MIO, MME, MOR, MRI, MSA, MSI, MSR, MTO, MVI, NDI, NER, NRO, NST, PGI, REN, RFR, RGI, RNI, RRE, SCO, SLU, SOT, TRU, TUL, UMI, VFR, VMA, VMR, VMU), Vizzatoli(LST), Vizzeder (ZAN).

Número de informantes: 70 Número de citas: 98.

Número de sectores: 3 Número de categorías: 10.

Biotipo: Fanerófito.

Tipo corológico: Europeas.

Abundancia: Común.

Ambiente: Bosques caducifolios submediterráneos, setos.

Número de exsiccata: 38916 FIAF, 39078 FIAF.

Sector agropastoral

Categoría de uso: Cuerdas y ataduras.

Número de informantes: 1 Partes utilizadas: tallos leñosos/ramas/ramitas/vástagos.

I rami si usano per legare i fascetti di legna. (MRI).

Sector alimentario

Categoría de uso: Arroces y "risotto".

Número de informantes: 1 Partes utilizadas: brotes.

Si prepara il risotto nel modo consueto. (NDI).

Categoría de uso: Empanadas.

Número de informantes: 1 Partes utilizadas: hojas. 


\section{María Teresa Egea Molines}

Torta salata o schiaccia alle erbe, con le erbe di staggione: fare la pasta con la farina usando il lievito madre (che era trattato come un tesoro, durava anni e gli si davano delle cure quotidiane per mantenerlo vivo sempre) e aggiungere i 'ciucioli' (siccioli, ricavati facendo cuocere il grasso del maiale e tirandoli fuori via via che venivano a galla), poi stendere la pasta. Fare cuocere le erbe di stagione come il piscialletto, le cicoriette, lo strigolo, l'ortica, i vizzadri, una volta cotte, passarle in padella con un pò di pancetta o lardo, mescolarle al formaggio 'scotta' e 4 uova. Coprire con un'altra sfoglia di pasta, quindi chiudere con la forchetta e cuocere in forno. (BSO).

Categoría de uso: Ensalada.

Número de informantes: 1 Partes utilizadas: brotes.

Mangiare I germogli giovani crudi in insalata. (GLA).

Categoría de uso: Pasta y "gnocchi".

Número de informantes: 1 Partes utilizadas: brotes.

Sbollentare I germogli e aggiungerli all'impasto dei gnocchi (GLA).

Categoría de uso: Relleno de ravioli.

Número de informantes: 1 Partes utilizadas: brotes.

Germogli cotti e mescolati alla ricotta per il ripieno dei tortelloni. (MIO).

Categoría de uso: Sopas de verduras y potaje.

Número de informantes: 3 Partes utilizadas: brotes, hojas.

Mettere le punte della vitalba nella minestra di verdure. (BLI)| La zuppa d'estate della nonna era a base solo di piante di campo: soffriegeva l'aglio, si trittavano tutte le foglie del piscialletto, le punte dei vizzadri, dell'ortica, delle orecchie di ciucco, del caciolino e degli striggoli. Poi si aggiungevano e si facevano bollire molto. Poi si poteva aggiungere riso o pasta. (MGE)| Punte fresche messe nella minestra (SLU).

Categoría de uso: Tortilla.

Número de informantes: 64 Partes utilizadas: brotes, hojas.

Germogli cotti e messi nella frittata. (MGO, BLI)| I germogli delle vitalbe vanno cotti e messe nella frittata (CRO)| Fare bollire le punte dei vizzadri e aggiungere alla frittata. (LLU)| Sbollentate e messe nella frittata (SOT, GFR, FAM, NLA)| I germogli di vitalba sbollentati e mescolati alla frittata. (PLU)| Cotte e messe nella frittata (TGA)| I germogli dei vizzadri vanno cotti e messe nella frittata (AP2)| Soffriggere i germogli dei vizzadri e aggiungere le uova per fare una frittata. (LRE, BAN)| Fare cuocere i germogli dei vizzadri, poi aggiungere alle uova per fare una frittata. (BSO, BAR)| Le punte lessate e poi messe nella frittata. (BAZ)| Sbollentare i germogli di vizzadri e metterli nella frittata. (BBI)| Punte di vizzadri sbollentate e messe nella frittata. (BFE) $\mid$ Le punte dei vizzadri vanno bollite e poi mescolate alle uova per fare la frittata. (BOR)| Punte' di vizzadri sbollentate e messe nella frittata. (BPI)| I germogli scottati si mettevano nella frittata. (BSI)| Germogli sbollentati e poi messi nella frittata (SCO, GUF, CFR)| Germogli cotti e messe nella frittata. (GAN, CRE)| Bolliti e messi nella frittata (DAD)| Fare bollire I germogli e poi aggiungere alle uova per fare la frittata (EMA)| lesse e messe nella frittata (TUL, FAR) $\mid$ Cotte, scolate bene e messe nella frittata (GGI)| Germogli scottati e messi nell'uovo per la fare la frittata. (RFR, MSI, MRI, MGI, GGL)| Sbollentare le punte dei vizzadri e fare la frittata. (REN, MME, GLA)| Bollire i germogli e metterli nella frittata. (MVI, MTO, MSR, GZE)| Si cuocevano le punte e si faceva la frittata. (LGI) $\mid$ Germogli scottati e messi nella frittata. (MDA)| Le punte dei vizzadri si fanno 
bollire e si mettono nella frittata. (MGE)| I germogli di vizzadri cotti e aggiunti alla frittata. (RGI, MOR)| I germogli scottati e messi nella frittata. (MSA)| I germogli lessi e aggiunti alle uova per fare la frittata. (NDI) $\mid$ Sbolentare I germogli e metterle nella frittata (NRO, NER)| Germogli sbollentati e messi nella frittata. (NRE)| Scottare i germogli di vizzadri e metterli nella frittata. (NST)| I germogli vanno bolliti e messi nella frittata (PGI)| Lessare I germogli dei vizzadri e fare la frittata. (RNI) $\mid$ Punte fresche messe nella frittata (SLU) $\mid$ Germogli cotti (o saltati in padella) e messi nella frittata. (TRU)| Punte di vizzadri, raccolti in primavera, cotte e messe nella frittata. (UMI)| I germogli si fanno sbollentare e si fa la frittata. (VFR)| I germogli dei vizzadri cotti e messi dentro nella frittata. (VMU, VMA)| Fare la frittata con I germogli dei vizzadri (VMR)| Raccogliere le punte fresche, scottarle o rosolarle, e fare la frittata insieme. (LST).

Categoría de uso: Verdura cocida.

Número de informantes: 15 Partes utilizadas: brotes.

Da sola e condita (NLA) I germogli di vitalba vengono sbollentati per ammorbidirli e poi saltati in padella con aglio. (PLU)| I germogli vanno cotti e conditi. (BEL)| Germogli cotti e conditi come contorno (CFR)| Germogli cotti e conditi (CRE)| Fare bollire I germogli e mangiarli lessi e conditi. (EMA)| Germogli cotti e conditi. (MIO)| Germogli bolliti e conditi con olio e sale. (MRI)| I germogli saltati come verdura. (MSA)| Lessare le punte dei vizzadri e condire con olio e sale. (NDI)| Germogli cotti. (RRE)| Germogli lessi e conditi con olio e sale (SCO)| I germogli si fanno cuocere e si mangiano conditi (VFR)| I germogli dei vizzadri cotti e conditi. (VMA)| Si mangiavano come gli asparagi, cotti e conditi (ZAN).

\section{Sector lúdico/voluptuoso}

Categoría de uso: Fumable.

Número de informantes: 10 Partes utilizadas: tallos leñosos/ramas/ramitas/vástagos,.

Lo stelo secco e grosso essendo bucato si poteva fumare (CRI, NLA)| Il fusto era bucato, si fumava come fossero sigarette. (BBI) $\mid$ Si fumava un pezzo di un ramo secco, tagliato in modo da sembrare un sigaro. (BPA)| I ramettini che sono bucati si fumavano: 'Ci si bruciava la lingua, più che altro'. (BSI)| Prendere uno stelo dei vizzadri secco e fumarlo (DAD)| Rami di vizzadri secchi usati come sigarette $($ GUF $) \mid$ I ramoscelli secchi si fumavano (PGI)| Il rametto secco si fumava. (SOT)| Si fumavano I ramettini della vitalba. (VMR).

Notas A primavera si raccolgono e si preparano, Crudi sono tossici, Raccolti di primavera/estate.

\section{DATOS ETNOBOTÁNICOS BIBLIOGRÁFICOS}

Nombre vulgar: vitalba, vizeibra (SANS14), vizadri (BADI15), vizadro (GUC98), vizzatoro (POLI14), vidêrba (UNGA21).

Número de referencias: 5 Número de citas: 9.

Número de sectores: 3 Número de categorías: 6 .

\section{Sector alimentario}

Categoría de uso: Ensalada.

Número de referencias: 1 Partes utilizadas: brotes (SANS14). 
Categoría de uso: Tortilla.

Número de referencias: 3 Partes utilizadas: brotes (SANS14).

Frittata con i "vizadri” (vitalbe). Ingredienti:Germogli di vitalba (clematis vitalba), uova,parmigiano,olio, sale e pepe.Si raccolgono i germogli di vitalba di 4 o $5 \mathrm{~cm}$ di lunghezza.Si fanno lessare,si scolano e si triturano grossolanamente. Si prepara la base della frittata con uova,parmigiano grattugiato,sale e pepe,poi si aggiungono le vitalbe.Il composto si frigge in padella con poco olio. Il sapore assomiglia a quello della frittata coi carciofi (BADI15)| In primavera i germogli dei vizadri venivano raccolti, bolliti, poi usati per frittate. (GUC98).

Categoría de uso: Verdura cocida.

Número de referencias: 1 Partes utilizadas: brotes (SANS14).

\section{Sector lúdico/voluptuoso}

Categoría de uso: Fumable.

Número de referencias: 2 Partes utilizadas: tallos leñosos/ramas/ramitas/vástagos. I rametti secchi molto parosi venivano fumati dai ragazzi. Il fumo di per se innocuo dava forte bruciore alla lingua e se aspirato forti attacchi di tosse. Sballo di atri tempi. (POLI14)| I ragazzi usavano fumare, per gioco, pezzi della pianta adulta tagliati in modo da sembrare un sigaro, non era un sostituto del tabacco o altro ma la pianta, molto porosa, permetteva di tirare come con un sigaro vero. (GUC98).

\section{Sector medicinal}

Categoría de uso: Afecciones oro-faríngeas y de la cavidad oral.

Número de referencias: 1 Partes utilizadas: flores/inflorescencias y sus partes.

In montagna, I medici empirici ne adoperano I fiori e le foglie bollite contro I mali cancherosi della bocca. Nella medicina popolare, le giovani vette in decozione sono ritenute efficaci contro le malattie intestinali (UNGA21).

Categoría de uso: Patologías del aparato digestivo.

Número de referencias: 1 Partes utilizadas: brotes.

In montagna, I medici empirici ne adoperano I fiori e le foglie bollite contro I mali cancherosi della bocca. Nella medicina popolare, le giovani vette in decozione sono ritenute efficaci contro le malattie intestinali (UNGA21).

\section{Helleborus foetidus $L$.}

Nombre vulgar: Cascadente (ZAN), Erba nocca, Cascadente (VSI), Erba noca (TAD).

Número de informantes: 3 Número de citas: 3.

Número de sectores: 3 Número de categorías: 3 .

Biotipo: Caméfito.

Tipo corológico: Atlánticas.

Abundancia: Común.

Ambiente: Márgenes de los bosques, bosques de monte bajo.

Número de exsiccata: 39085 FIAF.

Sector mágico/ritual/supersticioso

Categoría de uso: Otro mágico/ritual/supersticioso. 
Número de informantes: 1 Partes utilizadas: planta entera/viva.

Per San Giuseppe, si facevano dispetti alle femmine, si portava la pianta del cascadente e dell pailla di grano davanti alle case delle ragazze per dire che erano vecchie o vacche... (ZAN).

\section{Sector medicinal}

Categoría de uso: Para provocar enfermedad.

Número de informantes: 1 Partes utilizadas: órganos subterráneos.

La radice si applicava su una ferita e provocava gonfiore e bruciore, così andavano dal medico e siccome il medico non conosceva questa pianta, li metteva a casa per infortunio..

\section{Sector veterinario}

Categoría de uso: Ovejas y cabras.

Número de informantes: 1 Partes utilizadas: órganos subterráneos.

Quando le pecore avevano la zoppaia per gli unghielli, glieli toglievano e usavano l'erba.

noca...non si ricorda bene come (TAD).

DATOS ETNOBOTÁNICOS BIBLIOGRÁFICOS

Nombre vulgar: cascadenti femmine (ZAGN90), cascadente femmina, erba del mael zitan (UNGA21), erba nocca (MANG98), érba zitóna, cascadente (ZAGN90), cascadénti (APPO10), Cascadenti femmina (BERT67).

Número de referencias: 5 Número de citas: 8.

Número de sectores: 3 Número de categorías: 5 .

Sector mágico/medicinal

Categoría de uso: Otro mágico/medicinal.

Número de referencias: 1 Partes utilizadas: órganos subterráneos.

Le radici potevano inoltre venir poste in un sacchetto da far tenere costantemente a stretto.

contatto del sofferente,contro le emorroidi. (ZAGN90).

Sector medicinal

Categoría de uso: Parásitos externos.

Número de referencias: 1 Partes utilizadas: órganos subterráneos.

erba del mael zitan (Helleborus viridis L.) erba nocca, cavolo di lupo, ed (H.foetidus L.), elabro puzzolente, volg. Erba nocca bastarda, cavolo di lupo.. La med. pop. l'adopera inoltre come vermif., pericoloso. I cont. credono che a masticarne le foglie caschino i denti.

Categoría de uso: Patologías del aparato circulatorio.

Número de referencias: 1 Partes utilizadas: órganos subterráneos.

L'applicazione di un unguento composto da radici di cascadenti femmine, ridotte in poltiglia e.

mescolate con l'olio. (ZAGN90).

\section{Sector veterinario}

Categoría de uso: Cerdos. 


\section{María Teresa Egea Molines}

Número de referencias: 1 Partes utilizadas: órganos subterráneos.

erba del mael zitan (Helleborus viridis L.) erba nocca, cavolo di lupo, ed (H.foetidus L.), elabro puzzolente, volg. Erba nocca bastarda, cavolo di lupo _la prima detta anche dai mont. (Porretta) cascadente maschio, e la seconda cascadente femmina, ed entrambe dai nostri cont. erba dal mael zitan, _ perchè adop. dagli empirici a curare una malattia de'maiali con caratteri non bene determinati e che tuttavia può essere il mal rosso. Le radici di tali piante avendo proprietà drastiche sono in questo caso applicate alle orecchie de'maiali come risolutive e l'operaz. dicesi zitunadura, raggiatura. L'elleboro fu consciuto anche dagli ant. e adoperato in med. e veter. La med. pop. l'adopera inoltre come vermif., pericoloso. I cont. credono che a masticarne le foglie caschino i denti. (UNGA21).

Categoría de uso: Ganado bovino.

Número de referencias: 2 Partes utilizadas: órganos subterráneos.

La radice si innesta sotto la coda di mucche e maiali affetti di febbre o altra malattia batterica, la parte dell'innesto rigonfierà ben presto in maniera evidente, e l'animal perverrà a rapida guarigione. (MANG98)| Poteva colpire I bovini a seguito di malattie da raffreddamento oppure a causa di eccessivi strapazzi. Era curato con la cosidetta erba zitona o cascadente, che veniva appesa tramite uno spago ed un ago di lana alla giogaia (paròl): la pratica provocava un ascesso di fissazione ed un'anacoresi dando luogo alla formazione di una grossa prominenza (l'aróneva): l'aróna radunava tutto il male in quel punto. (ZAGN90).

Notas Da Porrettani appellasi Cascadente femmina.

\section{Helleborus viridis L. (s. l.)}

Nombre vulgar: Cascadente(VSI, ZAN), Erba noca(TAD), Erba nocca(VSI), Cascadente (AP2, BAN, BAR, BBI, BEL, BSI, CFR, CFR, ECE, MSA, NDI, RRE), Cascadente (il fiore)(DBA), Cascadenti(CFR, FAM, GGI, GGL, GUF, PIM, SLU), Elleboro (CLO), Erba noca AP2, BAN, BGI, BGI, GAN, GFR, GGL, GLA, NER, PCL, PCL, TAD, TIV), Erba noca (radice)(TRU), Erba noca femmina(NDI), Erba nocca(AMA,, BAD, BBI, BEL, BPT, BSI, ECE, GGI, LLU, LLU, MSA, NST, RFR, RGI), Erba nocca femmina(VMR), La nocca (BAR), La nocca (radice) (DBA), Nebiaccio(CLO), Nebio (CLO), Nocchia(MRI), Pan del lupo (TRU).

Número de informantes: 37 Número de citas: 48.

Número de sectores: 4 Número de categorías: 11.

Biotipo: Geófito.

Tipo corológico: n.d.

Abundancia: Común.

Ambiente: Bosques de monte bajo, bosques submediterráneos aclarados, setos.

Número de exsiccata: 38976 FIAF, 39016 FIAF, 38917 FIAF, 39079 FIAF.

Sector caza y pesca

Categoría de uso: Ictiotóxico.

Número de informantes: 1 Partes utilizadas: látex o savia.

Si metteva la pianta dentro una balletta (sacco di canapa) si schiacciava con un sasso, e si. 
buttava al fiume, i pesci salivano a galla (BGI).

\section{Sector mágico/ritual/supersticioso}

Categoría de uso: Efecto negativo.

Número de informantes: 1 Partes utilizadas: planta entera/viva.

Ai bambini dicevano sempre non la toccate per ché vi cascheranno i denti! (CFR).

Categoría de uso: Rituales de Mayo.

Número de informantes: 1 Partes utilizadas: parte aérea (toda).

Quando si cantava il maggio, si andava a cantare davanti alle case. Nelle case che non.

aprivano ed non offrivano da bere, si lasciava il cascadente fuori la porta (CFR).

\section{Sector medicinal}

Categoría de uso: Afecciones cutáneas y tejidos subcutáneos.

Número de informantes: 1 Partes utilizadas: parte aérea (toda).

Lavare I porri con il decotto di tutta la pianta. (PCL).

Categoría de uso: Afecciones oro-faríngeas y de la cavidad oral.

Número de informantes: 1 Partes utilizadas: órganos subterráneos.

Applicare la radice dell'erba noca femmina dentro al buco del dente, per il mal di denti. Il.

dolore passa, però i denti cascano. (NDI).

Categoría de uso: Para provocar enfermedad.

Número de informantes: 9 Partes utilizadas: flores/inflorescencias y sus partes.

Per non fare il servizio militare, masticavano il fiore e li cascavano i denti (FAM) Quando gli impiegati si facevano un taglio e prendevano l'infortunio del lavoro, introducevano la radice del cascadente, così gli veniva la febbre e il dottore non riusciva a capire perché e loro prendevano più giorni di infortunio. (GGL)| Tossico, faceva venire l'infiammazione alla gamba. Si metteva la radice fresca tagliata sopra una ferita, la gamba si infiammava tanto e così loro prendevano l'infortunio al lavoro. (AMA)| Prendere una radice e infilarla in una ferita. Viene la febbre e così si evitava di fare il servizio militare. (BAD)| Prendere una radice e infilarla in una ferita provocava la febbre, e così si aveva una settimana in più di infortunio (i medici non capivano perché...). (LLU)| La radice si applicava su una ferita e provocava gonfiore e bruciore, così andavano dal medico e siccome il medico non conosceva questa pianta, li metteva a casa per infortunio. (RGI)| Quando uno si faceva una ferita sul lavoro, si infilava una radice dell'erba noca (simile a un ago), e iI ginocchio si infiammava tanto, così davano più giorni di infortunio. (ECE) Quando gli uomini andavano in cantiere, in galleria, nei boschi, dopo un po' non ce la facevano più e allora si facevano una ferita apposta e poi per non guarire si mettevano una foglia per provocare l'infiammazione e andare in infortunio. (BAR, DBA).

Categoría de uso: Patologías del aparato circulatorio.

Número de informantes: 1 Partes utilizadas: flores/inflorescencias y sus partes.

Spazzare' le emorroidi con il fiore fresco dell'erba nocca maschio. (NDI).

Sector veterinario

Categoría de uso: Cerdos. 


\section{María Teresa Egea Molines}

Número de informantes: 11 Partes utilizadas: órganos subterráneos.

Per il mal rossino del maiale li mettevano in un buco fatto all'orecchio, a radice seca del cascadente. (CFR)| Per il "mal rosso" dei maiali:Trittare la radice, fare un buco sull'orecchio del maiale, e introdurre la radice trittata. (GUF)| In caso di stati influenzali o febbre, la radice si metteva in un taglio che si faceva sull'orecchio dei maiali. (SLU)| Quando il maiale o la mucca avevano febbre (non mangiavano), si riscaldava una radice fresca di cascadente sul fuoco, si levava la pellicola che la copre (sfilandola) e con la lesina si forava il 'paiolo' della bestia (la gola), infilando dentro la radice. Poi il 'paiolo' diventava grossisimo e dopo un po' la bestia guariva. (GGL)| Per il malessere generale e debolezza del maiale:La radice essiccata la mettono dentro un taglio che li facevano al maiale sul orecchio. (GGI)| Per curare la febbre dei maiali. Se la malattia si manifestava dalla metà dell'animale alla testa, fare una ferita all'orecchio e inserire la radice. Se invece la malattia si manifestava dalla metà in giù, mettere la radice sotto la coda. (GAN)| Quando il maiale non mangiava, gli si faceva una ferita nell' orecchio con la lesina del calzaiolo e gli si metteva un pezzo di radice essicata. Così gli veniva la febbre e guariva. (NER)| Per il Male dei maiali: fare una ferita sull'orecchio del maiale e introdurre la radice secca dell'erba noca. (PCL)| Per il malessere e la debolezza del maiale: la radice essiccata la mettono dentro un taglio che gli facevano sull' orecchio. (TIV)| Quando I maiali stavano male, mettevano un pezzo di radice in un apposito bucco dell'orecchia del maiale. (VMR)| Mettere la radice in un buco nell'orecchio, per il 'mal rossino'. (MRI).

Categoría de uso: Ganado bovino.

Número de informantes: 11 Partes utilizadas: órganos subterráneos.

Fare un buco al 'paiolo' della mucca (collo), pulire le 'barbe' (radici) e arrotolarle con un po' di canapa, poi inserire nel buco del 'paiolo' che era diventato enorme. Dopo un po' la mucca guariva. (RRE)| Nocare le bestie (mucche): Quando le mucche avevano la polmonite li foravano la pelle, poi introducevano nel foro la radice secca e produceva una palla grossa, così le toglieva l'infezione. (AP2)| Non si ricorde come ma si usava per la protata delle bestie (l'infiammazione) (PIM)| Quando il maiale o la mucca avevano febbre (non mangiavano), si riscaldava una radice fresca di cascadente sul fuoco, si levava la pellicola che la copre (sfilandola) e con la lesina si forava il 'paiolo' della bestia (la gola), infilando la radice nel buco. Poi il 'paiolo' diventava grossisimo e dopo un po' la bestia si gonfiava e guariva. (GGL) Raccogliere la radice dell'erba noca femmina (quella che fa solo la foglia) quando non è luna nuova e farla seccare (così è più potente). Lui teneva le radici secche in una scatolina. Quando le mucche avevano la broncopolmonite, fare un buco sulla coda e inserire la radice, secca o fresca: si infilava una radice di $607 \mathrm{~cm}$ in un buco che si faceva tra la spalla e il collo con un ago. (NDI) $\mid$ Quando le mucche avevano le vesciche in bocca, strofinare le radici secche (più secca meglio è) sulla bocca. (LLU)| Per la polmonite delle mucche. Si introduceva la radice in un buco fatto sulla pelle. All'animale veniva la febbre e dopo guariva. 'È come la penicillina'. (NST)| Quando la mucca era malata, gli si faceva un buco nel 'paiolo' e si inseriva la radice secca del cascadente. (BSI, BBI)| Quando le bestie avevano la polmonite, foravano il 'paiolo' (la pelle del collo), inserivano una radice e questo gli faceva passare la 
febbre. (BEL)| Quando la mucca aveva 'la stone' ossia la tosse, le si faceva un buco nel 'paiolo' e ci si inseriva la radice secca del cascadente' (MSA).

Categoría de uso: Ovejas y cabras.

Número de informantes: 10 Partes utilizadas: órganos subterráneos.

Facevano un taglio nell'orecchio all'animale e ci inserivano la radice dell'erba nocca: piano piano gli veniva come una bruciatura intorno e guarivano. (BAN)| Stati influenzali, per la febbre delle pecore. La radice si metteva in un taglio che si faceva sull'orecchio delle pecore. (SLU)| Per la debolezza e il malessere delle pecore. La radice essiccata la mettono dentro un taglio che facevano alla pecora sull' orecchio. (BGI) $\mid$ Quando le pecore erano gonfie, gli alzavano la coda, facevano un incisione e ci mettevano un pezzettino di radice. Poi stavano meglio. (GFR)| Recupero delle pecore dopo un aborto. Quando le pecore abortivano e non si erano ripulite dall'aborto, si introduceva la radice dell'erba noce secca nella vagina delle pecore. (GLA) $\mid$ Quando le pecore avevano la zoppaia per gli unghielli, glieli toglievano e usavano l'erba noca...non si ricorda bene come (TAD)| Quando le pecore abortivano, si metteva la radice dell'erba noca essicata e tagliata a forma di stecchino in un buco nella coda, per un giorno intero. Poi la pecora gonfiava tutta. Serviva come disinfettante. (TRU)| Raccogliere la radice dell'erba noca femmina (quella che fa solo la foglia) quando non è luna nuova e farla seccare (così è più potente). Lui teneva le radici secche in una scatolina. Quando le pecore avevano la broncopolmonite, fare un buco sulla coda e inserire la radice, secca o fresca. Per le pecore si infilava un pezzo di radice piccolo $(2 \mathrm{o} 3 \mathrm{~cm})$ sotto la coda. Anche se una pecora abortiva (non 'viene in caldo'), gli si faceva questo, gli veniva la febbre e l'animale 'si ripuliva'. Se una pecora non faceva agnelli, mettere la nocca in un buco. Gli veniva la febbre, così 'si disinfettava' e ritornava feconda. (NDI)| Per il malessere generale e la debolezza delle pecore: radice secca applicata direttamente sotto la coda (BPT)| Malessere e debolezza generale delle pecore. Facevano un buco nell'orecchio della pecora, dentro gli veniva messo la radice essicata. Cosi gli veniva la febbre forte e poi guariva (CLO).

Categoría de uso: Todos los animales.

Número de informantes: 1 Partes utilizadas: órganos subterráneos.

Quando le pecore, i maiali oppure le mucche avevano la broncopolmonite (o sembrava così, perché avevano il petto grosso), si forava l'orecchio con la lesina del calzolaio, facendogli una ferita e inserendoci la radice secca dell'erba noca, che andava tenuta lì per qualche giorno. Il buco diventava più grosso e in qualche giorno gli animali guarivano. (RFR).

Notas nel bosco e sui prati, Gli anziani dicevano che se lo mettevi in bocca faceva cadere il dente, $\mathrm{Ci}$ sono due di erba noca, una maschio, di questo l'uso che si faceva, che fa un ombrellino e non fa fiori, e poi c' è un altra che è la l'erba noca femmina fa solo la foglia non fa il fiore. Raccogliere la radice dell'erba noca femmina (solo foglia) raccolta quando non è luna nuova e farla seccare (così è più potente). Lui le teneva in una scatolina. nel bosco e sui prati 'è il primo fiore che fiorisce in primavera'. Non se ne vede più perché non ci sono più le bestie (una volta le bestie mangiavano certe piante e certe altre non, e cosi gestivano la flora In modo che facevano che ci fossero certe piante e certe altre no...)Si raccoglievano e si facevano seccare a mazzetti, attaccati al soffitto. 


\section{DATOS ETNOBOTÁNICOS BIBLIOGRÁFICOS}

Nombre vulgar: cascadente maschio, erba del mael zitan (UNGA21), cascadénti, èrba nòcca (GUC98), érba zitóna, cascadente (ZAGN90), cascadénti (APPO10), Cascadenti maschio, erba del mal citone (BERT67).

Número de referencias: 5 Número de citas: 6 .

Número de sectores: 2 Número de categorías: 2.

Sector medicinal

Categoría de uso: Parásitos externos.

Número de referencias: 1 Partes utilizadas: órganos subterráneos.

erba del mael zitan (Helleborus viridis L.) erba nocca, cavolo di lupo, ed (H.foetidus L.), elabro puzzolente, volg. Erba nocca bastarda, cavolo di lupo _la prima detta anche dai mont. (Porretta) cascadente maschio, e la seconda cascadente femmina, ed entrambe dai nostri cont. erba dal mael zitan, _ perchè adop. dagli empirici a curare una malattia de'maiali con caratteri non bene determinati e che tuttavia può essere il mal rosso. Le radici di tali piante avendo proprietà drastiche sono in questo caso applicate alle orecchie de'maiali come risolutive e l'operaz. dicesi zitunadura, raggiatura. L'elleboro fu consciuto anche dagli ant. e adoperato in med. e veter. La med. pop. l'adopera inoltre come vermif., pericoloso. I cont. credono che a masticarne le foglie caschino i denti.(UNGA21).

\section{Sector veterinario}

Categoría de uso: Cerdos.

Número de referencias: 3 Partes utilizadas: No especificado, órganos subterráneos.

Era usato per fare dei setoni (introdurre un corpo estraneo sotto la pelle dell'animale) ai maili afflitti dal mal rósso, malattia dei suini non meglio identificata che produceva chiazze rosse e febbre. (GUC98)| erba del mael zitan (Helleborus viridis L.) erba nocca, cavolo di lupo, ed (H.foetidus L.), elabro puzzolente, volg. Erba nocca bastarda, cavolo di lupo _la prima detta anche dai mont. (Porretta) cascadente maschio, e la seconda cascadente femmina, ed entrambe dai nostri cont. erba dal mael zitan, _ perchè adop. dagli empirici a curare una malattia de'maiali con caratteri non bene determinati e che tuttavia può essere il mal rosso. Le radici di tali piante avendo proprietà drastiche sono in questo caso applicate alle orecchie de'maiali come risolutive e l'operaz. dicesi zitunadura, raggiatura. L'elleboro fu consciuto anche dagli ant. e adoperato in med. e veter. La med. pop. l'adopera inoltre come vermif., pericoloso. I cont. credono che a masticarne le foglie caschino i denti. (UNGA21)| La radice dell'érba zitóna, privata della corteccia, veniva applicata ad un orecchio a cui era stato precedentemente applicato un foro. (ZAGN90).

Notas Da que'del paese appellasi Cascadente maschio, e dai Bolognesi erba del Mal Citone. 


\section{RHAMNACEAE.}

\section{Ziziphus jujuba Mill.}

Nombre vulgar: Le zizole o le gugiole (GUF).

Número de informantes: 1 Número de citas: 1.

Número de sectores: 1 Número de categorías: 1.

Biotipo: Fanerófito.

Tipo corológico: Europeas.

Abundancia: Cultivada.

Ambiente: Cultivada en el territorio por el fruto.

Sector alimentario

Categoría de uso: Fruta fresca.

Número de informantes: 1 Partes utilizadas: frutos/infrutescencias/falsos frutos.

A novembre si raccolgono e si mettono sulla paglia per farli maturare, in realta marciscono, e solo cosi si possono mangiare (GUF).

Notas "Vai in brodo di giugiole" detto che vuol dire quando uno è innamorato. Non appare in Venturi(2006)..

\section{ROSACEAE}

\section{Crataegus rhipidophylla Gand. (= Crataegus oxyacantha $L$. (s.l.))}

Nombre vulgar: Biancospino (PIM, GGI, FAM, PLU, CRE, MSR, NST, GGL, VAL, EMA, BEL, NRE, BGI), Spinbianco (GUF), Spini, Biancospino (REN, PCL, MME), Spini bianchi (VSI), Buccino, Biancospino (VMR).

Número de informantes: 19 Número de citas: 25.

Número de sectores: 5 Número de categorías: 9.

Biotipo: Fanerófito.

Tipo corológico: Europeas.

Abundancia: Común.

Ambiente: Bosques caducifolios sobre suelo rico (sobre todo robles) y sus fases de. degradación. C. Monogyna: arbustos, setos, bosques xerófilos degradados.

Número de exsiccata: 39124 FIAF, 39089 FIAF, 39088 FIAF, 39088 FIAF, 38930.

Sector agropastoral

Categoría de uso: Herramientas y objetos agrícolas.

Número de informantes: 5 Partes utilizadas: tallos leñosos/ramas/ramitas/vástagos.

Manico di martelli (BGI)| Si facevano le scope per pulire il castagneto con i rami di spinbianco, lasciandoli alcuni giorni sotto delle pietre per prendere la forma. (GUF) Gli spini sono robusti e ramificati, raspavano (megli che gli strozzghi: prugnolo selvatico) bene il castagneto. I rami vengono legati con lo spago o con il fil di ferro e attaccati ad un bastone. (MME)| Con I rami si fanno le scope per fuori della casa e 
per le stalle (PCL)| Gli spini sono robusti e ramificati, raspavano (megli che gli strozzghi: prugnolo selvatico) bene il castagneto. I rami vengono legati con lo spago o con il fil di ferro e attaccati a un bastone. (REN).

Categoría de uso: Vallas y delimitaciones.

Número de informantes: 2 Partes utilizadas: planta entera/viva.

Si usava fare le siepi con diverse piante: ligustri, spini (prugnolo e biancospino), acero campestre,sanguinelli, berretti da prete. (NRE)| Gli spini bianchi si piantavano per fare le siepi dei recinti delle pecore (VSI).

\section{Sector alimentario}

Categoría de uso: Golosinas y masticatorias.

Número de informantes: 3 Partes utilizadas: frutos/infrutescencias/falsos frutos.

Verso settembre e ottobre quando le bacche erano mature si mangiavano mentre si era nei campi (VAL, BEL)| I frutti maturi del biancospino blu si mettevano in bocca quando si era in giro. (EMA).

Sector doméstico

Categoría de uso: Chimenea y horno.

Número de informantes: 1 Partes utilizadas: tallos leñosos/ramas/ramitas/vástagos.

Per pulire la canna fumaria, fare una fascina di biancospino e farla andare su e giù. (GGL).

\section{Sector mágico/medicinal}

Categoría de uso: Verrugas.

Número de informantes: 1 Partes utilizadas: hojas.

Fare un 'pesto' di foglie di biancospino, applicarlo sopra i porri come un impacco e poi.

seppellirlo. (NST).

Sector medicinal

Categoría de uso: Afecciones del aparato respiratorio.

Número de informantes: 1 Partes utilizadas: tallos leñosos/ramas/ramitas/vástagos.

Fare bollire un ramo di biancospino per 2 minuti e bere oppure fare dei fumenti. (MSR).

Categoría de uso: Afecciones oro-faríngeas y de la cavidad oral.

Número de informantes: 1 Partes utilizadas: flores/inflorescencias y sus partes.

Mescolare il decotto dei fiori di biancospino con il bianco dell'uovo e applicare sulla parte.

infiammata, legandolo con un fazzoletto alla testa. 'Tira fuori l'infiammazione'. (CRE).

Categoría de uso: Patologías del aparato circulatorio.

Número de informantes: 3 Partes utilizadas: flores/inflorescencias y sus partes.

Bere il decotto (cotto poco) di fiori di biancospino per la pressione alta. (BEL) Raccogliere I fiori quando sono ancora più chiusi che aperti, (tra lo sbocciato e non). Quando c'era bisogno, bere l'infuso per calmare e per le palpitazioni. (PLU)| Bere 
l'infuso del buccino come sedativo o per la tachicardia, però va usato con prudenza, bisogna sapere le dosi (lei non le sa). (VMR).

Categoría de uso: Patologías del sistema nervioso.

Número de informantes: 8 Partes utilizadas: flores/inflorescencias y sus partes.

Fare il decotto dei fiori di biancospino freschi o secchi, per dormire meglio. (BEL)| I fiori raccolti si mettevano ad essiccare, poi messi in acqua bollente. (GGI, FAM) Seccare i fiori di biancospino e bere l'infuso quando uno è nervoso. (GGL)| Bere il decotto delle foglie di biancospino 'per andare a dormire'. (NST)| Prendere il decotto dei fiori di biancospinio quando uno si sente depresso. (PIM)| Raccogliere i fiori quando sono ancora più chiusi che aperti, (tra lo sbocciato e non). Quando c'era bisogno, bere l'infuso per calmare e per le palpitazioni. (PLU)| Bere l'infuso del buccino come sedativo o per la tachicardia, però va usato con prudenza, bisogna sapere le dosi (lei non le sa). (VMR).

Notas Verso Settembre e Ottobre quando le bacche erano mature..

DATOS ETNOBOTÁNICOS BIBLIOGRÁFICOS

Nombre vulgar: sp $\tilde{i}$ bianco (GUC98), biancospino, spen bianc (SANS14), biancospino.

(MANG98), spen bianc, maruga bianc, coegapojj (UNGA21), pruno (BONZI00).

Número de referencias: 5 Número de citas: 8 .

Número de sectores: 3 Número de categorías: 6 .

Sector agropastoral

Categoría de uso: Herramientas y objetos agrícolas.

Número de referencias: 1 Partes utilizadas: tallos leñosos/ramas/ramitas/vástagos. I rami d'inverno, venivano usati per confezionare scope che erano poste sotto pesanti sassi per.

renderle piatte. In primavera venivano poi usate per pulire i prati, castagnei e stalle. (GUC98).

\section{Sector alimentario}

Categoría de uso: Golosinas y masticatorias.

Número de referencias: 1 Partes utilizadas: frutos/infrutescencias/falsos frutos, hojas, (SANS14).

\section{Sector medicinal}

Categoría de uso: Estado general.

Número de referencias: 1 Partes utilizadas: flores/inflorescencias y sus partes.

Si prepara spesso un infuso misto con fiori di tiglio e foglie di menta, lo si ritiene, oltre che sedativo, valido antifiammatorio (MANG98).

Categoría de uso: Patologías del aparato circulatorio.

Número de referencias: 1 Partes utilizadas: flores/inflorescencias y sus partes (SANS14).

Categoría de uso: Patologías del aparato digestivo.

Número de referencias: 1 Partes utilizadas: frutos/infrutescencias/falsos frutos. cosi detta perchè si crede abbia virtù astringente, invece bollito questo frutto dà sciroppo dissolvente (UNGA21). 
Categoría de uso: Patologías del sistema nervioso.

Número de referencias: 2 Partes utilizadas: flores/inflorescencias y sus partes.

(SANS14)| Si prepara spesso un infuso misto con fiori di tiglio e foglie di menta, lo si ritiene, oltre che sedativo, valido antifiammatorio, a scopo ansiolitico si utilizza anche l'infuso di soli fiori di biancospino, oppure di fiori e frutti. (MANG98).

\section{Cydonia oblonga Mill.}

Nombre vulgar: Mele cotogne (RFR, MGO), Mele e Pere cotogne (AN3).

Número de informantes: 3 Número de citas: 4.

Número de sectores: 2 Número de categorías: 3.

Biotipo: Fanerófito.

Tipo corológico: Cultivadas.

Abundancia: Cultivada.

Ambiente: Cultivada por el fruto en toda el área mediterranea y submediterránea y subspontaneo en la Península y en las islas.

Sector alimentario

Categoría de uso: Dulces y golosinas.

Número de informantes: 1 Partes utilizadas: frutos/infrutescencias/falsos frutos.

Con le mele cotogne si fanno I dolci. (MGO).

Categoría de uso: Mermelada.

Número de informantes: 2 Partes utilizadas: frutos/infrutescencias/falsos frutos.

Le mele cotogne si usavano per fare marmellate. (MGO)| Marmellata "al savor":

Fare bollire mele o pere coltivate, con un pò di succo d'uva, 1 o 2 mele cotogne oppure 1 o 2 pere cotogne, viene una marmellata aspra. (AN3).

Sector doméstico

Categoría de uso: Ambientador.

Número de informantes: 1 Partes utilizadas: frutos/infrutescencias/falsos frutos.

Si mettevano negli armadi per profumare la biancheria, perché hanno un buon profumo e duravano tanto tempo. (RFR).

Notas Il frutto non è buono fresco, è schiacciato, grosso, sotto I castagni ne fanno tanti, maturano a fine settembre, sono rosse con macchie piccole bianche. Va piantata a Nord, a Sud non ne fanno.

DATOS ETNOBOTÁNICOS BIBLIOGRÁFICOS

Nombre vulgar: maila gdaggna (UNGA21).

Número de referencias: 1 Número de citas: 2 .

Número de sectores: 2 Número de categorías: 2 .

Sector alimentario

Categoría de uso: Conserva de frutas.

Número de referencias: 1 Partes utilizadas: frutos/infrutescencias/falsos frutos.

melo cotogno, il cui frutto detto mala gdaggna, mela cotogna,si utilizza nella preparazione di conserve. Nella medicina popolare il succo di questo frutto è somministrato come espettorante. (UNGA21). 


\section{Sector medicinal}

Categoría de uso: Afecciones del aparato respiratorio.

Número de referencias: 1 Partes utilizadas: frutos/infrutescencias/falsos frutos. melo cotogno, il cui frutto detto mala gdaggna, mela cotogna,si utilizza nella preparazione di conserve. Nella medicina popolare il succo di questo frutto è somministrato come espettorante. (UNGA21).

\section{Fragaria vesca $L$.}

Nombre vulgar: Fragole (MGO, GRI, GGI, VFR, MSR, MRI, BSO, BAN, GFR, FAM, SOT, BOR), Fragoline di bosco (SCO, CFR, TAD), Fragole,Fròle (BAR), Fròle (GUF), Fragoline (CLO), Fragole selvatiche (VMA), Fragola (GCL).

Número de informantes: 20 Número de citas: 30 .

Número de sectores: 3 Número de categorías: 7.

Biotipo: Hemicriptófito.

Tipo corológico: Amplia distribución.

Abundancia: Común.

Ambiente: Hayedos, pinares, bosques de abetos, sobre todo en la zonas aclaradas, setos.

Número de exsiccata: 38891 FIAF.

\section{Sector alimentario}

Categoría de uso: Bebida.

Número de informantes: 3 Partes utilizadas: frutos/infrutescencias/falsos frutos.

Sciroppo di fragole: mettere la frutta a macerare qualche giorno con lo zucchero, poi colare il tutto e imbottigliare. Va bevuto allungato come bevanda. (BOR)| non specificato (SOT)| Si facevano I sciroppi con le fragoline di bosco che si trovavano sotto I pioppi (TAD).

Categoría de uso: Conserva de frutas.

Número de informantes: 2 Partes utilizadas: frutos/infrutescencias/falsos frutos.

Riempire un barattolo fragole del bosco e coprire la superficie di zucchero, chiudere e mettere al sole per 40 giorni (FAM)| Mettere i frutti in una botiglia e metterla al sole e aggiungere zucchero. Si prende allungato con il doppio d'acqua. (GFR).

Categoría de uso: Fruta fresca.

Número de informantes: 9 Partes utilizadas: frutos/infrutescencias/falsos frutos.

Le fragoline di bosco venivano consumate fresche, venivano anche raccolte dalle donne che le andavano a vendere a Porretta. (BAN)| $\mathrm{Si}$ raccoglievano e si mangiavano come frutta fresca. (BAR, BSO) $\mid \mathrm{Si}$ consumavano fresche come frutta. (MRI)| Erano consumate fresche. (MSR)| Le fragole si mangiavano con il vino e lo zucchero, oppure con il limone, o con il vermout. (VFR)| Si mangiavano le fragoline di bosco condite con il vino e lo zucchero, oppure con il limone oppure c'era chi le mangiava con il vermut. (CFR)| Fragole condite con limone e zucchero (SCO)| Come dessert si mangiano fragole con vino e pane. (GUF).

Categoría de uso: Golosinas y masticatorias.

Número de informantes: 1 Partes utilizadas: frutos/infrutescencias/falsos frutos.

Al naturale (CLO). 
Categoría de uso: Mermelada.

Número de informantes: 2 Partes utilizadas: frutos/infrutescencias/falsos frutos.

Bollire i frutti per un po, aggiiungere $1 ' 80 \%$ di zucchero, continuare a bollire per un altro po, mettere subito in barattoli e chiudere. (GFR)| non specificato (SOT).

\section{Sector doméstico}

Categoría de uso: Integración de la renta familiar.

Número de informantes: 11 Partes utilizadas: frutos/infrutescencias/falsos frutos. le donne andavano a cercare fragoline di bosco per venderle a Porretta. (BAN)| si raccoglievano si portavano a vendere al ristorante Gabana che li vendeva a Bologna oppure a una Pasticceria di Castiglione dei Pepoli (BAR)| Mamma vendeva le fragole, le more, I lamponi alla gente di fuori (BOR)| Venduta sulla porrettana ai passanti (GFR)| Si vendevano messi in un paniere piccolo fatto di vimini (GGI)| $\mathrm{Si}$ vendevano messi in un paniere piccolo fatto di vimini, insieme ai lamponi. (GRI)| Li vendevano a Treppio a gente di Porretta che venivano a comprarli, forse per gelateria. (MGO)| Era l'unica cosa che veniva gestito dai bambini, il resto delle risorse era gestito dal capofamiglia. I bambini andavano a raccogliere I lamponi e le fragole a Foragati (sopra Stagno), e poi li vendevano (MRI)| Oltre a essere consumate fresche, le fragole di bosco venivano raccolte e vendute come integrazione del reddito. Era l'unica cosa che veniva gestito dai bambini, il resto delle risorse era gestito dal capofamiglia. I bambini andavano a raccogliere $\mathrm{i}$ lamponi e le fragole a Foragati (sopra Stagno) e poi li vendevano (MRI)| Frutti raccolti nel giardino e venduti a Porretta (MSR)| Le donne vendevano le fragole nei panieri a San Pellegrino, per strada. E le vendevano ache a Porretta per fare i gelati. (VMA)| Avvolte si scambiava la farina di castagne (chi aveva il mulino) con le fragole del bosco appena raccolte. (GUF).

\section{Sector medicinal}

Categoría de uso: Patologías del aparato urinario.

Número de informantes: 1 Partes utilizadas: hojas.

Bevuto "un po di volte". (GCL).

Notas Non ci sono piu, perché il bosco è abbandonato, e mangiano tutto i cervi, Prima dell'Abetaia, era tutto rosso, di fragole, Quando I castagneti erano puliti, ce n'erano tantissimi, Ce n'erano tantissimi fragole nei castagneti quando questi erano puliti, ed avevano un sapore unico.

\section{Malus domestica Borkh.}

Nombre vulgar: Mele (CRO, RMA, PIM, NRE, AN3, MSI, BAZ), Mela (UMI, GGI, GUF, LST).

Número de informantes: 11 Número de citas: 12 .

Número de sectores: 3 Número de categorías: 6 .

Biotipo: Fanerófito.

Tipo corológico: Cultivadas.

Abundancia: Cultivada.

Ambiente: Cultivada de forma común. 


\section{Sector alimentario}

Categoría de uso: Fruta seca.

Número de informantes: 1 Partes utilizadas: frutos/infrutescencias/falsos frutos.

Bollire in un tegamino le mele intere con la buccia e lo zucchero sopra, quando la mela si sfa, si stende sul marmo. Quando diventava dura si tagliava a cubetti e poi si mangiavano come caramelle (BAZ).

Categoría de uso: Licor.

Número de informantes: 1 Partes utilizadas: frutos/infrutescencias/falsos frutos. Il vin brulé si faceva nell'inverno quando si era in compagnia: uno spicchio di mela, un pò di cannella, chiodi di garofano, mettere a bollire, appena bolle un pò, si dava fuoco per togliere l'alcol. (LST).

Categoría de uso: Mermelada.

Número de informantes: 2 Partes utilizadas: frutos/infrutescencias/falsos frutos.

Pulire la frutta, pesarla, aggiungere 500 gr di zucchero per $1 \mathrm{~kg}$ di frutta, lasciare fermentare per 24 ore, e poi fare bollire fino alla consistenza voluta (dipende dalla qualità della frutta). (MSI)| Marmellata "al savor": Fare bollire mele o pere coltivate, con un pò di succo d'uva, 1 o 2 mele cotogne oppure 1 o 2 perecotogne, viene una marmellata aspra. (AN3).

\section{Sector doméstico}

Categoría de uso: Ambientador.

Número de informantes: 1 Partes utilizadas: frutos/infrutescencias/falsos frutos. D'inverno si mettevano le mele in mezzo alla biancheria per profumarla (GUF).

\section{Sector medicinal}

Categoría de uso: Afecciones del aparato respiratorio.

Número de informantes: 6 Partes utilizadas: frutos/infrutescencias/falsos frutos. Bollire le mele con un po' di limone, mangiarle e bere l'acqua. (UMI, GGI)| Togliere semi e noccioli alle ciliegie, alle mele, alle pere, e alle susine, tagliarle a fette e metterle a seccare al sole. Queste si chiamano i 'caponi', che bolliti in acqua e bevuti si adoperano per guarire il mal di gola (GUF)| Bollire le mele con la buccia, a spicchi, insieme a chicchi di uva passita, prugne secche o ciliegie secche, chicchi d'orzo e miele.Bere per 2 o 3 giorni. (NRE)| La sera prima di andare al letto bere un tazza di mele cotte in acqua e zucchero per 10 minuti. (PIM)| Fare uno sciroppo di mele cotte a spicchi, con poca acqua e con miele e prenderlo a modo di sciroppo. (RMA).

Categoría de uso: Patologías del aparato digestivo.

Número de informantes: 1 Partes utilizadas: frutos/infrutescencias/falsos frutos.

Le mele cotte si prendevano per andare in bagno (CRO).

Notas Proverbio"l'acqua di mele cotte, la fa bene alla fredura l'omo che al tole moglie le matto.

adiritura", Le mele e le pere si conservavano sotto al letto, durante l'inverno.

\section{DATOS ETNOBOTÁNICOS BIBLIOGRÁFICOS}

Nombre vulgar: mele (GRIZ03, GUC98), melo (MANG98).

Número de referencias: 3 Número de citas: 5.

Número de sectores: 3 Número de categorías: 5. 


\section{Sector alimentario}

Categoría de uso: Dulces y golosinas.

Número de referencias: 1 Partes utilizadas:frutos/infrutescencias/falsos frutos.

I capóni sono ciliegie o susine a cui si toglie il nocciolo o mele e pere tagliate a fette poi fatte seccare al sole. Per estensione, anche le ciliegie che si seccano naturalmente sulla pianta. Sono golosità di un tempo, venivano magiati d'inverno o messi a bollire per ricarvarne decotti medicinali (GUC98).

Categoría de uso: Mermelada.

Número de referencias: 1 Partes utilizadas: frutos/infrutescencias/falsos frutos.

Confettura di mele e rosa canina: $2 \mathrm{~kg}$ di mele, mezzo $\mathrm{kg}$ di petali di rosa profumati e sani, uno e mezzo kg di zucchero, un limone. Sbucciare, tagliare e mettere le mele con succo e scorza di limone in una casseruola. Unire i petali di rose lavati alle mele e rimescolare. Aggiungere $250 \mathrm{ml}$ di acqua e lasciare riposare per mezz'ora poi porre sul fuoco e fare bollire adagio. Quando le mele sono cotte, passare tutto al settaccio, quindi unire lo zucchero e cuocere mescolando spesso. Quando la marmellata avrà raggiunto la densità del miele, toglierla dal fuoco e versarla nei vasi. Chiudere subito ermeticamente e conservare al buio. (GRIZ03).

\section{Sector mágico/medicinal}

Categoría de uso: Verrugas.

Número de referencias: 1 Partes utilizadas: frutos/infrutescencias/falsos frutos.

In presenza di porri e verruche, si prende una mela e si divide in quattro spicchi con ognuno dei quali si traccia il segno di una croce sopra la parte (si `segna'), eseguita tale operazione la mela viene ricomposta e sotterratta. Quando sarà marcita, il porro o la verruca cade. (MANG98).

\section{Sector medicinal}

Categoría de uso: No especificado.

Número de referencias: 1 Partes utilizadas: frutos/infrutescencias/falsos frutos.

I capóni sono ciliegie o susine a cui si toglie il nocciolo o mele e pere tagliate a fette poi fatte seccare al sole. Per estensione, anche le ciliegie che si seccano naturalmente sulla pianta. Sono golosità di un tempo, venivano magiati d'inverno o messi a bollire per ricarvarne decotti medicinali (GUC98).

Categoría de uso: Patologías del aparato digestivo.

Número de referencias: 1 Partes utilizadas: frutos/infrutescencias/falsos frutos.

Mele cotte vengono mangiate in caso di collite. (MANG98).

\section{Malus domestica Borkh. 'Antiche'}

Nombre vulgar: Mele antiche (RNI), Mela (varietà antica) (BFE).

Número de informantes: 2 Número de citas: 2 .

Número de sectores: 2 Número de categorías: 2 .

Biotipo: Fanerófito.

Tipo corológico: Cultivadas.

Abundancia: Cultivada.

Ambiente: Cultivada. 


\section{Sector alimentario}

Categoría de uso: Licor.

Número de informantes: 1 Partes utilizadas: semillas.

Liquore di semi di mela selvatica e antica: 3 etti di alcol 95 gradi, 4 etti di acqua, 4 etti di zucchero, 1 bicchiere di semi di mela. Prendere 3 etti di alcol e mettere I semi di mela a macerare per 10 giorni in un barattolo chiuso e scuotterli una volta al giorno. Poi fare bollire l'acqua con lo zucchero e farlo scioglere, si porta a bollore. Farlo raffreddare. Unire tutto quanto e lasciare riposare per 40 giorni. (RNI).

Sector doméstico

Categoría de uso: Ambientador.

Número de informantes: 1 Partes utilizadas: frutos/infrutescencias/falsos frutos. I nonni mettevano questa varietà antica di mela dentro gli armadi per profumare (BFE).

Notas Ricetta del liquore tramandata da una sigora di lagacci, si fa con una qualità antica di mela. Mela Antica: frutti verdi tendendo al giallognolo. Vanno raccolte a Novembre verdi, maturano gradualmente fino, e durano fino ad aprile. Ha un albero a casa sua alle Fabbriche, se vuole che ne faccia pocche però più grandi, lo pota.

\section{Malus domestica Borkh. 'Bobbole'}

Nombre vulgar: Mele Bobbole (RFR).

Número de informantes: 1 Número de citas: 1.

Número de sectores: 1 Número de categorías: 1.

Biotipo: Fanerófito.

Tipo corológico: Cultivadas.

Abundancia: Cultivada.

Ambiente: Cultivada.

Sector alimentario

Categoría de uso: Fruta fresca.

Número de informantes: 1 Partes utilizadas: frutos/infrutescencias/falsos frutos.

Le "mele bobbole" si mangiavano come frutta fresca (RFR).

Notas "Mele bobbole"(rosse e bianche, striate, piccole, maturano a Ottobre o Novembre) fanno tanto profumo. "Pierino ce l'ha, a casa del fabbro, alla pozza per lavare. La "mela toscana" (come le Renette, domestica, gialline, grosse)"sono tutte finite. E le "mele rosoline" (maturano a Ottobre, mezzane, rosse).

\section{Malus domestica Borkh. 'Rosa romana'}

Nombre vulgar: Mele "Rosa Romana" (NRE), Rose romane (MSA), Mela rosa romana (MRI),.

Mele rose romane (EMA).

Número de informantes: 4 Número de citas: 6.

Número de sectores: 1 Número de categorías: 2.

Biotipo: Fanerófito.

Tipo corológico: Cultivadas. 
Abundancia: Cultivada.

Ambiente: Cultivada.

Sector alimentario

Categoría de uso: Conserva de frutas.

Número de informantes: 2 Partes utilizadas: frutos/infrutescencias/falsos frutos.

$\mathrm{Si}$ facevano le mele cotte al forno (NRE)| Le "Rose romane" sono delle mele grosse, sono.

buone al forno e crude, raccolte I primi di Novembre, e durano fino a Maggio (MSA).

Categoría de uso: Fruta fresca.

Número de informantes: 4 Partes utilizadas: frutos/infrutescencias/falsos frutos.

La mela "rosa romana": mela estiva, matura fine Luglio-inizio Agosto, fa il frutto colore rosa e si mangia come frutta fresca (MRI)| Le mele "rosa romana" erano molto dolci, si mangiavano fresche. (NRE)| Mele da inverno, anche quando cadevano erano sempre buone, si mangiavano così (EMA)| Le "Rose romane" sono delle mele grosse, sono buone al forno e crude, raccolte I primi di Novembre, e durano fino a Maggio (MSA).

Notas Mele "Rosa Romana" ( più dolci, resistenti, dura tanto tempo, maturano tarde, a Autunno e sono molto profumate). Sono un po schiacciate, gialle e di leggere rosso da una parte.

\section{Malus domestica Borkh. 'Rosino'}

Nombre vulgar: Mele rosino (PLU).

Número de informantes: 1 Número de citas: 2.

Número de sectores: 1 Número de categorías: 1 .

Biotipo: Fanerófito.

Tipo corológico: Cultivadas.

Abundancia: Cultivada.

Ambiente: Cultivada.

Sector alimentario

Categoría de uso: Fruta fresca.

Número de informantes: 1 Partes utilizadas: frutos/infrutescencias/falsos frutos.

Mele piccole rosse, da mangiare come frutta. (PLU).

\section{Malus domestica Borkh. 'Rossa'}

Nombre vulgar: Mela rossa (MGO).

Número de informantes: 1 Número de citas: 1.

Número de sectores: 1 Número de categorías: 1.

Biotipo: Fanerófito.

Tipo corológico: Cultivadas.

Abundancia: Cultivada.

Ambiente: Cultivada. 


\section{Sector alimentario}

Categoría de uso: Fruta fresca.

Número de informantes: 1 Partes utilizadas: frutos/infrutescencias/falsos frutos.

La mela rossa si mangia come frutta fresca tutto l' inverno. (MGO).

Notas Era metà gialla metà rossa, più grossa, dura tanto, regge tutto l'inverno fino a marzo, ed.

è schiacciata.

\section{Malus sylvestris (L.) Mill.}

Nombre vulgar: Mela (BLI, TUL), Mele selvatiche (GGI, RNI, PGI), Melo selvatico (REN).

Número de informantes: 6 Número de citas: 7.

Número de sectores: 2 Número de categorías: 5 .

Biotipo: Fanerófito.

Tipo corológico: Europeas.

Abundancia: Común.

Ambiente: Bosques de latifolios submediterráneos (un poco ácidos).

Sector alimentario

Categoría de uso: Fruta fresca.

Número de informantes: 1 Partes utilizadas: frutos/infrutescencias/falsos frutos.

Si raccoglievano verdi a Settembre e si lasciavano sulla pailla fino alla maturazione. (TUL).

Categoría de uso: Fruta seca.

Número de informantes: 2 Partes utilizadas: frutos/infrutescencias/falsos frutos.

Si mettevano ad essicare per l'inverno. (BLI)| Le mele selvatiche si seccavano al sole e poi con un agu si infilavano e si facevano delle collane per seccarle con el refe (filo duro). (PGI).

Categoría de uso: Licor.

Número de informantes: 1 Partes utilizadas: semillas.

Liquore di semi di mela selvatica e antica: 3 etti di alcol 95 gradi, 4 etti di acqua, 4 etti di zucchero, 1 bicchiere di semi di mela. Prendere 3 etti di alcol e mettere I semi di mela a macerare per 10 giorni in un barattolo chiuso e scuotterli una volta al giorno. Poi fare bollire l'acqua con lo zucchero e farlo scioglere, si porta a bollore. Farlo raffreddare. Unire tutto quanto e lasciare riposare per 40 giorni. (RNI).

Categoría de uso: Mermelada.

Número de informantes: 2 Partes utilizadas: frutos/infrutescencias/falsos frutos.

Si faceva la marmellata di pere selvatiche e mele selvatiche: farle bollire con la buccia e un bicchiere d'acqua, si possono lasciare a pezzi oppure passare per il passaverdure. Aggiungere 2 o 3 etti di zucchero per kg di frutta, fare bollire finché non raggiungesse la consistenza giusta (si metteva una cucchiaiata sul piatto e si piegava, non deve colare)Poi si imbarattolava si metteva sopra un pò di rum e si chiudevano. (RNI, GGI).

Sector doméstico

Categoría de uso: Ambientador. 
Número de informantes: 1 Partes utilizadas: frutos/infrutescencias/falsos frutos.

Mettere dentro gli armadi e le casse, in mezzo ai vestiti,per profumare la biancheria, o I vestiti (REN).

Notas Mele bianche, giallino pallido, e tonde. Non sono buone da mangiare, però profumano tanto.

DATOS ETNOBOTÁNICOS BIBLIOGRÁFICOS

Nombre vulgar: melo selvatico (SANS14).

Número de referencias: 1 Número de citas: 1.

Número de sectores: 1 Número de categorías: 1.

Sector alimentario

Categoría de uso: Fruta fresca.

Número de referencias: 1 Partes utilizadas: frutos/infrutescencias/falsos frutos (SANS14.

\section{Mespilus germanica $L$.}

Nombre vulgar: Nespole (NST, VMA, RNI, GUF, EMA, BEL, BBA, AN3).

Número de informantes: 8 Número de citas: 9.

Número de sectores: 2 Número de categorías: 3 .

Biotipo: Fanerófito.

Tipo corológico: Europeas.

Abundancia: Rara.

Ambiente: Raramente cultivado y silvestre en los bosques latifolios sobre terreno subácido (castañares, robledales).

\section{Sector alimentario}

Categoría de uso: Fruta fresca.

Número de informantes: 7 Partes utilizadas: frutos/infrutescencias/falsos frutos.

Le nespole si fanno maturare nella paia, anche se hanno poca polpa sono molto buone e si conservano per mesi (AN3)| Mangiate come frutta (BBA)| A ottobre si mangiavano le nespole mature. Insieme con le sorbole e le corniole erano gli ultimi frutti della stagione. (BEL) $\mid$ Le nespole vanno mangiate quando sembrano marcie. (EMA) | Frutta fresca (GUF)| Le nespole vanno raccolte prima che venga il gelo, vanno messe nella pailla a maturare nell'inverno, e via via che maturano si mangiano. (RNI)| Si raccoglievano I frutti acerbi e si mettevano a maturare sulla paglia. Oppure si raccoglievano mature dalla pianta (VMA).

Categoría de uso: Mermelada.

Número de informantes: 1 Partes utilizadas: frutos/infrutescencias/falsos frutos. In autunno si faceva la marmellata di nespole alla maniera antica: mettere la frutta con una bottiglia di vino, farla cuocere finché non sia bella cotta, passarla per un passaverdura in modo da ricavare soltanto la polpa, poi aggiungere lo zucchero a occhio, e mettere il composto nel forno della stuffa, perché non si attacchi alla pentola, finché non si veda che si sia rassodato. (EMA).

Sector medicinal

Categoría de uso: Patologías del aparato digestivo. 
Número de informantes: 1 Partes utilizadas: frutos/infrutescencias/falsos frutos.

Le nespole 'stringono', per la diarrea. (NST).

Notas Raccolte a Ottobre o Novembre, si lasciano a maturare vicino alle mele selvatiche oppure sulla pailla. A Lastrone ce n' è,., Aveva regalato I frutti a una signora che non li conosceva, e le aveva buttato via pensando che erano marcie, invece così erano buoni!.

DATOS ETNOBOTÁNICOS BIBLIOGRÁFICOS

Nombre vulgar: nespolo (SANS14), nœspel (UNGA21).

Número de referencias: 2 Número de citas: 2.

Número de sectores: 1 Número de categorías: 1.

Sector alimentario

Categoría de uso: Fruta fresca.

Número de referencias: 1 Partes utilizadas: frutos/infrutescencias/falsos frutos (SANS14).

\section{Mespilus germanica L. 'Autoctono'}

Nombre vulgar: Nespolo autoctono (MRI).

Número de informantes: 1 Número de citas: 1.

Número de sectores: 1 Número de categorías: 1.

Biotipo: Fanerófito.

Tipo corológico: Europeas.

Abundancia: Rara.

Ambiente: Raramente cultivado y silvestre en los bosques latifolios sobre terreno subácido.

(castañares, robledales).

Sector alimentario

Categoría de uso: Fruta fresca.

Número de informantes: 1 Partes utilizadas: frutos/infrutescencias/falsos frutos. I frutti del nespolo sono buoni da mangiare come frutta fresca. (MRI).

\section{Prunus armeniaca $L$.}

Nombre vulgar: Albicocche (GUF).

Número de informantes: 1 Número de citas: 1.

Número de sectores: 1 Número de categorías: 1 .

Biotipo: Fanerófito.

Tipo corológico: Cultivadas.

Abundancia: Cultivada.

Ambiente: Cultivada de forma común.

Sector alimentario

Categoría de uso: Fruta seca.

Número de informantes: 1 Partes utilizadas: semillas.

Le nocciole delle albicocche si seccavano e si mangiavano (GUF). 


\section{DATOS ETNOBOTÁNICOS BIBLIOGRÁFICOS}

Nombre vulgar: mugnœga, mugnœg (UNGA21), Mugnàga (APPO10), mugnaga (BENE96).

Número de referencias: 3 Número de citas: 4.

Número de sectores: 1 Número de categorías: 2.

Sector medicinal

Categoría de uso: Afecciones típicas infantiles.

Número de referencias: 1 Partes utilizadas: frutos/infrutescencias/falsos frutos.

il frutto maturo è usato come vermifugo (UNGA21).

Categoría de uso: Fiebre.

Número de referencias: 1 Partes utilizadas: frutos/infrutescencias/falsos frutos. il frutto maturo disseccato, in infusione contro le frebbri acute (UNGA21).

\section{Prunus avium (L.) L.}

Nombre vulgar: Ciliegio (CRE, BLI, PGI, TIV), Ciliegie (UMI, VMU, NRE, TAD, PCL, MSR, MSI, GUF, EMA, BPA, MVI, GZE, CLO, BSI, BAN, GFR, FAM, TOA), Ciliegie Duroni, Biancolina, Marasca (MGO), Ciliegie biancoline (VSI), Ciliegie, Ciliegie selvatiche (MRI), Ciliegie selvatiche (BBA).

Número de informantes: 27 Número de citas: 40.

Número de sectores: 6 Número de categorías: 17.

Biotipo: Fanerófito.

Tipo corológico: Europeas.

Abundancia: Común.

Ambiente: Cultivada en gran escala y a menudo subespontanea.

Sector agropastoral

Categoría de uso: Herramientas y objetos agrícolas.

Número de informantes: 1 Partes utilizadas: tallos leñosos/ramas/ramitas/vástagos.

Per manici (TIV).

Sector alimentario

Categoría de uso: Bebida.

Número de informantes: 1 Partes utilizadas: frutos/infrutescencias/falsos frutos. Fare appassire I gambi di ciliegia (quasi seccare), e fare un decotto con questi. Poi conservare in una bottiglia e bere ogni volta che si ha sete, come bevanda. È diuretica e fa bene per la prostata (TOA).

Categoría de uso: Conserva de frutas.

Número de informantes: 2 Partes utilizadas: frutos/infrutescencias/falsos frutos. Riempire un barattolo di ciliegie senza il nocciolo, e coprire la superficie di zucchero, chiudere e mettere al sole per 40 giorni (FAM)| Ciliegie sciroppate. Per fare ciliegie sciroppate: mettere ciliegie in un vaso, aggiungere 4 etti di zucchero per un litro di acqua bollita e già raffreddata, chiudere e mettere a bollire di nuovo il barattolo a bollire per 5 minuti. (GFR).

Categoría de uso: Fruta fresca. 
Número de informantes: 1 Partes utilizadas: frutos/infrutescencias/falsos frutos. Si mangiano le ciliegie come frutta fesca. (MGO).

Categoría de uso: Fruta seca.

Número de informantes: 4 Partes utilizadas: frutos/infrutescencias/falsos frutos.

I capponi erano la frutta che si seccava per l'inverno: corniole, ciliegie, susine secche (BAN)| I 'capponi' erano la frutta che si seccava per l'inverno: corniole, ciliegie, susine secche (BSI, BAN)| Le ciliegie selvatiche chiamate 'biancoline' erano amare e dolci. Si facevano seccare e si mangiavano come le caramelle. (VSI)| I 'capponi' era la frutta come le ciliegie selvatiche, oppure anche i duroni, che si mettevano nel forno a seccare e si mangiavano come caramelle. (MRI).

Categoría de uso: Golosinas y masticatorias.

Número de informantes: 2 Partes utilizadas: frutos/infrutescencias/falsos frutos, látex.

Quando si andava in giro, si raccoglievano e si mangiavano in giro. (CLO)| Le ciliegie secche che si trovavano per terra degli alberi di Ciliegio si prendevano e si mangiavano come caramelle. (PGI)| Quando venivano tagliati gli alberi di ciliegio selvatico del bosco fuoriusciva una specie di gomma che era di colore ambra. Noi si teneva in bocca come delle caramelle. (PGI).

Categoría de uso: Licor.

Número de informantes: 2 Partes utilizadas: frutos/infrutescencias/falsos frutos. Mettere a macerare un chilo di frutta in un litro di alcol, un litro di acqua e un $\mathrm{kg}$ di zucchero per minimo un anno. Poi si può filtrare, oppure lasciare la frutta dentro e mangiarla via via. $\mathrm{O}$ si può lasciare quanto si vuole nell'alcol, più ci sta meglio è, anche 5 o 6 anni.. (MVI, GZE).

Categoría de uso: Mermelada.

Número de informantes: 6 Partes utilizadas: frutos/infrutescencias/falsos frutos.

(GUF)Facevano la marmellata con le ciliegie (BPA)| Mettere la frutta con una bottiglia di vino, farla cuocere finché non sia bella cotta, passarla per un passaverdura in modo da ricavare soltanto la polpa, poi aggiungere lo zucchero a occhio, e mettere il composto nel forno della stuffa, perché non si attacchi alla pentola, finché non si veda che si sia rassodato. (EMA)| Pulire la frutta, pesarla, aggiungere $500 \mathrm{gr}$ di zucchero per $1 \mathrm{~kg}$ di frutta, lasciare fermentare per 24 ore, e poi fare bollire fino alla consistenza voluta (dipende dalla qualità della frutta). (MSI) $\mid$ Mettere a macerare per una notte le ciliegie (senza nocciolo e senza gambo), con lo zucchero (per un kg di frutta, 600 gr di zucchero). Poi cuocere il tutto per 4 o 5 ore, passarlo con il passaverdura, e aggiungere un po' di succo di limone o di arancio. Mettere nei vasi quando ancora bolle, tappare subito i barattoli e metterli a testa all'ingiù. (MSR)| Mettere a macerare per una notte le ciliegie (senza nocciolo e senza gambo), con lo zucchero (per un kg di frutta, $600 \mathrm{gr}$ di zucchero). Poi cuocere il tutto per 4 o 5 ore, passarlo con il passaverdura e aggiungere un po' di succo di limone o di arancio. Mettere nei vasi quando ancora bolle, tapparli subito e metterli a capo all'ingiù. (MSR)| Cuocere per 4 o 5 ore sulla stufa a legna le ciliegie snocciolate con lo zucchero: $1 \mathrm{~kg}$ di frutta per uno di zucchero (BBA).

Sector artesanal

Categoría de uso: Muebles. 
Número de informantes: 3 Partes utilizadas: madera.

Il comodino di casa era fatto di legno di ciliegio (PCL)| Sedie (TAD)| Le sedie erano fatte con legno di ciliegio o di castagno. (BLI).

Sector doméstico

Categoría de uso: Integración de la renta familiar.

Número de informantes: 1 Partes utilizadas: semillas.

I noccioli di ciliegio selvatico li vendevano ai vivai per innestarli (VMR).

Categoría de uso: Otro doméstico.

Número de informantes: 3 Partes utilizadas: frutos/infrutescencias/falsos frutos, látex.

I 'capponi' erano la frutta che si seccava per l'inverno: corniole, ciliegie, susine secche. Quando le donne filavano la lana, si metteva in bocca per fare saliva. (BAN)| I 'capponi' erano la frutta che si seccava per l'inverno: corniole, ciliegie, susine secche.Quando le donne filavano la lana, si metteva in bocca per fare saliva. (BSI)| La gomma che usciva dagli alberi selvatici di ciliegio (nel bosco) si usava come colla per I francobolli. (PGI).

Sector mágico/ritual/supersticioso

Categoría de uso: Rituales de Mayo.

Número de informantes: 2 Partes utilizadas: tallos leñosos/ramas/ramitas/vástagos.

Il primo maggio, se a un ragazzo piaceva una ragazza andava con un ramo di ciliegio e lo.

metteva a casa sua. (MVI, GZE).

Sector medicinal

Categoría de uso: Afecciones cutáneas y tejidos subcutáneos.

Número de informantes: 1 Partes utilizadas: madera.

Mettere sulla pelle arrossata il trinciato del legno che fa il tarlo, asciuga l'umidità. (MGO).

Categoría de uso: Afecciones del aparato respiratorio.

Número de informantes: 3 Partes utilizadas: frutos/infrutescencias/falsos frutos.

Togliere il nocciolo alle ciliegie, alle mele, alle pere, e alle susine, tagliarle a fette e metterle a secare al sole. Queste si chiamano I cap'oni, che bolliti in acqua e bevuti si adoperano per guarire il mal di gola (GUF)| Bollire le mele a spicchi, insieme a chicchi di uva passita (zibbibbo), prugne secche o ciliegie secche e chicchi d'orzo, e bere per 2 o 3 giorni. (NRE)| Bere di tanto in tanto il decotto dei gambi di ciliegie secchi. (CRE).

Categoría de uso: Estado general.

Número de informantes: 1 Partes utilizadas: semillas.

Mettere a seccare all'ombra tutti I "semi della vita": semi delle ciliege, delle susine ossia le prugne gialle, di zucca, I pinoli, le noci, le culloie o nocciole, le foglie di malva secche, il fiore del gigliopapagone e anche un pò di olio di semi di lino. Poi macinare tutto con il macinino da caffé. E prendere un cucchiaio tutte le mattine per un pò di giorni, a primavera e a ottobre. (VMU).

Categoría de uso: Patologías del aparato digestivo. 
Número de informantes: 1 Partes utilizadas: frutos/infrutescencias/falsos frutos. "Quando cascavano I figaletti a Luglio o Agosto (frutti con gambo e nocciolo essicati naturalmente sull'albero), si raccoglievano e si conservavano. Quando si sentiva del bisogno si prendeva un decotto come digestivo" (UMI).

Categoría de uso: Patologías del aparato urinario.

Número de informantes: 2 Partes utilizadas: frutos/infrutescencias/falsos frutos.

"Fare appassire I gambi di ciliegia (quasi seccare), e fare un decotto con questi. Poi conservare in una bottiglia e bere ogni volta che si ha sete, come bevanda. È diuretica e fa bene per la prostata (TOA)| "Quando cascavano I figaletti a Luglio o Agosto (frutti con gambo e nocciolo essicati naturalmente sull'albero), si raccoglievano e si conservavano. Quando si sentiva del bisogno si prendeva un decotto come diuretico" (UMI).

Notas Proprietà del legno:rimane liscio però è più facile che si spezzi, Ci sono "duroni" (innestate), "la biancolina" (ciliegie a forma di cuore,sull'albero durano poco, sono meno buone, sono metà rosse, metà bianche., Quando le donne filavano la lana, si metteva in bocca per fare saliva.

\section{DATOS ETNOBOTÁNICOS BIBLIOGRÁFICOS}

Nombre vulgar: ciliegio (GRIZ03), ciliegie (GUC98), ciliegio selvatico (SANS14), figaletti (BONZI00), cilesa (BER78), cilégia (BONZI00), duràscola (GUC98), z ambèlla (GUC98).

Número de referencias: 5 Número de citas: 9.

Número de sectores: 3 Número de categorías: 4.

\section{Sector alimentario}

Categoría de uso: Dulces y golosinas.

Número de referencias: 2 Partes utilizadas: frutos/infrutescencias/falsos frutos.

Crostata di ciliegie: $300 \mathrm{~g}$ di farina, 1 limone, $150 \mathrm{~g}$ di burro, $150 \mathrm{~g}$ di zucchero, 3 tuorli d'uovo, $250 \mathrm{~g}$ di marmellate di ciliegie. Preparare la farina a fontana e mettervi al centro i tuorli delle uova e metà dell'albume di un solo uovo. Aggiungere il burro precedentemente fatto ammorbidire fuori dal frigorifero, lo zucchero e la buccia del limone grattugiata. Impastate e lasciare riposare l'impasto almento mezz ora in luogo fresco. Imburrare una teglia rotonda, dividere la pasta e stenderne poco più della metà sul fondo della teglia e spalmarvi la marmellata di ciliegie. Il restante impasto va usato per farne tante listarelle da adagiare prima in senso verticale, partendo dal centro e poi sovrapponendo in senso orizzontale. Terminato il reticolo, fare delle listarelle più lunghe da mettere ai bordi, in modo da rifinire tutta la circonferenza della crostata. Cuocere in forno a $200 \mathrm{C}$ per 40 minuti, fino a quando assumerà un bel colore biscotto. (GRIZ03)| I capóni sono ciliegie o susine a cui si toglie il nocciolo o mele e pere tagliate a fette poi fatte seccare al sole. Per estensione, anche le ciliegie che si seccano naturalmente sulla pianta. Sono golosità di un tempo, venivano magiati d'inverno o messi a bollire per ricarvarne decotti medicinali (GUC98).

Categoría de uso: Fruta fresca.

Número de referencias: 1 Partes utilizadas: frutos/infrutescencias/falsos frutos (SANS14). 


\section{Sector doméstico}

Categoría de uso: Otro doméstico.

Número de referencias: 1 Partes utilizadas: frutos/infrutescencias/falsos frutos.

Ciliegie o susine seccate sull'albero e cadute in terra, oppure secche in genere. Le suddette.

usate, specialmente dalle vecchie, per salivare quando filavano. (BONZI00).

\section{Sector medicinal}

Categoría de uso: No especificado.

Número de referencias: 1 Partes utilizadas: frutos/infrutescencias/falsos frutos.

I capóni sono ciliegie o susine a cui si toglie il nocciolo o mele e pere tagliate a fette poi fatte seccare al sole. Per estensione, anche le ciliegie che si seccano naturalmente sulla pianta. Sono golosità di un tempo, venivano magiati d'inverno $\mathrm{o}$ messi a bollire per ricarvarne decotti medicinali(GUC98).

Notas Giuggno la cilesa in puggno (In giugno maturano le ciliegie, in montagna).

\section{Prunus avium (L.) L. 'Acquaiole'}

Nombre vulgar: Acquarola (MSR), Ciliegie acquaiole (VMR), Ciliegie"acquaiole" (MRI).

Número de informantes: 3 Número de citas: 3.

Número de sectores: 1 Número de categorías: 1.

Biotipo: Fanerófito.

Tipo corológico: Europeas.

Abundancia: Común.

Ambiente: Cultivada.

Sector alimentario

Categoría de uso: Fruta fresca.

Número de informantes: 3 Partes utilizadas: frutos/infrutescencias/falsos frutos.

$\mathrm{Si}$ andava a raccogliere le ciliegie di diverse varietà selvatiche e domestiche $\mathrm{s}$ si mangiavano come frutta fresca (MSR)| Le acquaiole sono un tipo di ciliegie selvatiche, duravano poco ed erano tenere, si mangiavano fresche (VMR)| "Le acquiole" si mangiano come frutta fresca. (MRI).

Notas Durone, Maresche, Amarene, "Acquarola"(dolce, e un po' amara), "Amarognole" (sono nere, dolci e amarognole nel giardino, e selvatiche). "È peggio che la gramigna, si attacca da per tutto", "Le Acquaiole", è un ciliegio selvatico non innestato, fanno il frutto rotondo, sono le prime che maturano, fanno nei campetti, a Marzabotto, hanno un albero. "Marchiane" o Marosticanesono a forma di cuore,dimensioni come I duroni, rosate-giallastro (anche quando sono maturi), dolce, e piene d'acqua, non sono carnose come I duroni. Si mangiano dall'albero, non si conservano nel transporto. I "Duroni": varietà innestata, I frutti sono grossi, piatti e carnosi, sono più resistenti. Loro hanno un durone vecchio. e le "Ciliegie selvatiche" con frutti piccoli. È il primo che fiorisce.. 


\section{Prunus avium (L.) L. 'Amarognole'}

Nombre vulgar: Ciliegie amarognole (MSR).

Número de informantes: 1 Número de citas: 1.

Número de sectores: 1 Número de categorías: 1.

Biotipo: Fanerófito.

Tipo corológico: Europeas.

Abundancia: Común.

Ambiente: Cultivada.

Sector alimentario

Categoría de uso: Fruta fresca.

Número de informantes: 1 Partes utilizadas: frutos/infrutescencias/falsos frutos.

$\mathrm{Si}$ andava a raccogliere le ciliegie di diverse varietà selvatiche e domestiche s si mangiavano come frutta fresca (MSR).

Notas Durone, Maresche, Amarene, "Acquarola"(dolce, e un po' amara), "Amarognole" (sono nere, dolci e amarognole nel giardino, e selvatiche). "È peggio che la gramigna, si attacca da per tutto".

\section{Prunus avium (L.) L. 'Duroni'}

Nombre vulgar: Duroni, ciliegie innestate (CAR), Duroni (MSR, GGL).

Número de informantes: 3 Número de citas: 3.

Número de sectores: 1 Número de categorías: 2.

Biotipo: Fanerófito.

Tipo corológico: Europeas.

Abundancia: Común.

Ambiente: Cultivada.

Sector alimentario

Categoría de uso: Conserva de frutas.

Número de informantes: 1 Partes utilizadas: frutos/infrutescencias/falsos frutos.

Le ciliegie sotto alcol: si usavano I duroni, che sono più grossi e duri. Si coprivano di alcol e si lasciavano macerare. Si mangiavano così uno o due con un pò di alcol. (CAR).

Categoría de uso: Fruta fresca.

Número de informantes: 2 Partes utilizadas: frutos/infrutescencias/falsos frutos. "I duroni" si mangiano come frutta fresca. (GGL)| Si andava a raccogliere le ciliegie di diverse varietà selvatiche e domestiche $\mathrm{s}$ si mangiavano come frutta fresca (MSR).

Notas Crescono nel campo da sole, I Duroni (un pò a forma di cuore, piu piccole, più scure) erano domestiche. Le "Marchiane" (a forma di cuore) erano altre domestiche.

\section{Prunus avium (L.) L. 'Marosticane'}

Nombre vulgar: Ciliegie Marosticane (MRI). 
Número de informantes: 1 Número de citas: 2.

Número de sectores: 2 Número de categorías: 2.

Biotipo: Fanerófito.

Tipo corológico: Europeas.

Abundancia: Común.

Ambiente: Cultivada.

Sector alimentario

Categoría de uso: Fruta fresca.

Número de informantes: 1 Partes utilizadas: frutos/infrutescencias/falsos frutos.

Le Marosticane erano ciliegie a forma di cuore che andavano mangiate subito. (MRI).

\section{Sector doméstico}

Categoría de uso: Integración de la renta familiar.

Número de informantes: 1 Partes utilizadas: frutos/infrutescencias/falsos frutos.

Le Marosticane, erano delle ciliegie a forma di cuore, e alle feste di Treppio, le andavano a vendere, anche se arrivavano tutte schiacciate, perché sono ciliegie da mangiare subito (MRI).

\section{Prunus cerasifera Ehrh.}

Nombre vulgar: Prugne selvatiche (EMA), Rusticane (GLA).

Número de informantes: 2 Número de citas: 3.

Número de sectores: 1 Número de categorías: 3.

Biotipo: Fanerófito.

Tipo corológico: Amplia distribución.

Abundancia: Cultivada.

Ambiente: Cultivado raramente y subspontaneo en los jardines.

Sector alimentario

Categoría de uso: Licor.

Número de informantes: 1 Partes utilizadas: frutos/infrutescencias/falsos frutos.

Facevano la grappa con le prugne selvatiche (EMA).

Categoría de uso: Mermelada.

Número de informantes: 1 Partes utilizadas: frutos/infrutescencias/falsos frutos.

Prugne aspere (diverse al Prugnolo).Si fanno bollire i frutti con lo zucchero, e si convarsa nei barattoli (GLA).

Categoría de uso: Otro alimentario.

Número de informantes: 1 Partes utilizadas: frutos/infrutescencias/falsos frutos.

Per fare la pasta madre: Mettere in un litro di acqua un cucchiaio di zucchero, sale, qualche rusticane strizzato e un po' di farina. Lasciare al riposo per una settimana, aggiungendo un po' di farina tutte le notti. Era il lievito per il pane. (GLA).

DATOS ETNOBOTÁNICOS BIBLIOGRÁFICOS

Nombre vulgar: rustican (UNGA21), mirabolano, rustican (SANS14).

Número de referencias: 2 Número de citas: 2 .

Número de sectores: 1 Número de categorías: 2 . 


\section{Sector alimentario}

Categoría de uso: Fruta fresca.

Número de referencias: 1 Partes utilizadas: frutos/infrutescencias/falsos frutos. albero coltivato per il suo frutto detto nell'Emilia rusticano, mangiato preferibilmente acerbo..

(UNGA21).

Categoría de uso: Golosinas y masticatorias.

Número de referencias: 1 Partes utilizadas: frutos/infrutescencias/falsos frutos (SANS14).

\section{Prunus cerasus $L$.}

Nombre vulgar: Amarene (DAD, FAM), Ciliegie amarene (GGL, MOR, NRE, BOR), Amarene, Marasche selvatiche (PGI), Ciliegie marasche (RGI, PLU, GLA, BSO, BAZ, BAT, BAN), Ciliegie maresca (AMA), Ciliegie maresche (NRO, GAN), Marasche (VFR, MSR, VMA, PEL, MRI), Marasche, Amarene selvatiche (CAR).

Número de informantes: 26 Número de citas: 33.

Número de sectores: 1 Número de categorías: 6 .

Biotipo: Fanerófito.

Tipo corológico: Cultivadas.

Abundancia: Cultivada.

Ambiente: A menudo cultivado y asilvestrado.

Número de exsiccata: 38894 FIAF.

\section{Sector alimentario}

Categoría de uso: Bebida.

Número de informantes: 3 Partes utilizadas: frutos/infrutescencias/falsos frutos.

Sciroppo di amarene: dopo $30 \mathrm{~min}$. di ebollizione si leva il succo, perché sennò cambia il sapore! A questo liquido si aggiunge lo zucchero (meno della stessa quantità). Poi si fa bollire tutto insieme un altro po', si imbottiglia, si chiudono le bottiglie, si avvolgono in un panno dentro una pentola e si fa ribollire il tutto un altro po'. Bevanda dissetante: si prende un cucchiaio di sciroppo di amarene e si diluisce con acqua (FAM)| Sciroppo di amarene: mettere la frutta a macerare qualche giorno con lo zucchero, poi colare il tutto e imbottigliare. Va bevuto allungato come bevanda. (BOR) $\mid$ Sciroppo di amarene: un centinaio di foglie di amarene raccolte a Luglio o Agosto, 800 gr di zucchero, un litro di vino. Bollire il tutto per 20 minuti. (NRE).

Categoría de uso: Conserva de frutas.

Número de informantes: 17 Partes utilizadas: frutos/infrutescencias/falsos frutos, hojas,.

Tagliare le amarene lasciando un pezzo di gambo ai frutti, mettere in un barattolo, coprire la superficie di zucchero, chiudere il barattolo sigillato e lasciare al sole un mese. (DAD)| Mettere le marasche selvatiche in un barattolo, coprire di zucchero, lasciare al sole 40 giorni. Mangiare come dessert, è un modo di conservare la frutta. (PGI)| Le ciliegie amarene vanno coperte di zucchero. Pesare la metà di ciliegie senza gambo, la metà di ciliegie con la metà del gambo, il tutto coperto con lo 


\section{María Teresa Egea Molines}

zucchero. Mettere al sole finché non sia sciolto. Si mangiano tre o quatro ciliegine con il sugo, come un liquore (MOR)| Schiacciare le ciliegie marasche, farle fermentare per 48 ore, colare il liquido. Per ogni litro di liquido aggiungere un chilo di zucchero, fare bollire per 2 o 3 minuti e quando è freddo imbottigliare. (BAT, BAN) $\mid \mathrm{Ci}$ sono due forme di fare il "Maraschino". 'Il Maraschino con le foglie' (bevanda leggermente alcolica da diluire con l'acqua): 100 foglie e 1 litro vino rosso, mettere a macerare con lo zucchero in un barattolo chiuso per 30 giorni al sole. E il "Maraschino al sole": mettere i frutti con un pò di gambo, li tagliavano $50 \mathrm{~cm}$ di gambo, con lo zucchero al sole. (BAZ)| Fare le marasche sotto zucchero: tagliare il picciolo delle marasche lasciandoli un pezzo, riempire il barattolo e coprire con lo zucchero. Lasciare al sole finché lo zucchero non si sia sciolto. (BSO)| Riempire un barattolo di ciliegie, coprire di zucchero, chiudere e metterlo alla finestra "tutta l'estate". (GLA)| Le ciliegie marasche messe nei vasi con lo zucchero, si mettono al sole per un po'. (PLU)| Con le ciliegie marasche si fa una specie di liquore a giugnoluglio: a un kg di marasche aggiungere 200 grammi di zucchero in un barattolo, poi chiudere, rovesciare e lasciare al sole finché lo zucchero si sia sciolto. (RGI)| Il 'maraschino' è fatto di un $\mathrm{kg}$ di maresche, con un pezzettino di gambo, messi in un barattolo con 7 o 8 etti di zucchero e lasciati a macerare al sole per 60 giorni. (AMA)| Mettere a macerare I frutti maturi con un po' di zucchero per due notti, poi passarli per un canovaccio e un collino. Bollire il liquido per un po' di tempo e imbottigliare. (GAN)| Mettere le ciliegie in un barattolo, poi mettere lo zucchero sopra, chiudere e mettere al sole finché lo zucchero non sia sciolto. (NRO) Maraschino: prendere le ciliegie mature, la sua mamma tagliava il peduncolo di una ciliegia e di una lo lasciava. Mettere un chilo di marasche per un chilo di zucchero, chiudere il barattolo e lasciarlo al sole per 20 giorni. (MRI)| Per fare il 'maraschino' riempire un vaso di ciliegie, coprire con lo zucchero e lasciare a riposare al sole. Con le ciliegie marasche è più difficile che bachino che con le amarene. (PEL)| Le marasche si mettevano in un barattolo, si coprivano di alcol e zucchero e si mettevano al sole per un mese (VMA)| Tagliare il picciolo dei frutti (così non assorbe troppo liquido), riempire un vaso di vetro, coprire con lo zucchero, e chiudere il vaso. Lasciare un mese al sole. Poi è pronto, si può mangiare come frutta in conserva oppure allungare il liquido e berlo come dissettante. (CAR).

Categoría de uso: Fruta fresca.

Número de informantes: 4 Partes utilizadas: frutos/infrutescencias/falsos frutos.

Le amarene si mangiano come frutta fresca. (GGL)| "Le marasche" si mangiano come frutta fresca. (MRI) $\mid \mathrm{Si}$ mangiano le ciliegie come frutta fesca. (MGO)| Si andava a raccogliere le ciliegie di diverse varietà selvatiche e domestiche $\mathrm{s}$ si mangiavano come frutta fresca (MSR).

Categoría de uso: Fruta seca.

Número de informantes: 1 Partes utilizadas: frutos/infrutescencias/falsos frutos. I Caponi': si mettevano I frutti a seccare al sole e poi si mettevano In bocca e si masticavano.

come le caramelle. (BAZ).

Categoría de uso: Licor.

Número de informantes: 6 Partes utilizadas: hojas, frutos/infrutescencias/falsos frutos,. 
Il ":cherry": mettere a macerare 35 foglie di ciliegie marasche in un litro di vino rosso, per 4 giorni, poi filtrare. Fare un sciroppo facendo bollire $400 \mathrm{gr}$ di acqua e 400 gr di zucchero. Quando è freddo mescolare il macerato delle foglie con $200 \mathrm{gr}$ di Alcol 90 gradi e lo sciroppo. Lasciare a riposare per un mese. (BSO)| Tagliare il picciolo delle amarene un pezzettino, e metterle in un vaso a bocca larga, aggiungere 4 cucchiai di zucchero coprire il tutto con grappa. Dopo 40 giorni filtrare. (BAZ)| Mettere la stessa quantità di alcol, di acqua e di zucchero (500 g aprox di ognuno), in un vaso pieno di ciliegie con il gambo, e solo con un taglio. Mettere al sole, e quando lo zucchero è sciolto, ossia aprox. 2 o 3 mesi, è pronto. (GFR)| Si metteva a macerare 40 grammi di nocciole di ciliegie selvatiche nel alcol, poi si filtrava e si aggiungeva zucchero e acqua. (NMA) $\mid$ Con le foglie si faceva il maraschino, non si ricorda la ricetta, dovrebbe cercarla nei appunti. (VFR)| Il liquore di polpa marasche: Prendere la polpa di un $\mathrm{kg}$ di frutti di marasche, 6 etti di zucchero, mettere "in fusione' per 24 ore in un vaso. Farlo bollire per 8 minuti, lasciare riposare e aggiungere 2 etti di alcol. Liquore con le nocciole di marasche: prendere le nocciole di un $\mathrm{kg}$ di marasche, aggiungerci 3 etti di alcol e lasciare "in fusione" per 40 giorni. Fare bollire 3 etti di acqua con 3 etti di zucchero, poi fare raffreddare e unire lo sciroppo alle nocciole. Poi si filtrava il tutto e si faceva invecchiare 2 mesi. (CAR).

Categoría de uso: Mermelada.

Número de informantes: 1 Partes utilizadas: frutos/infrutescencias/falsos frutos. Marmellata asprigna: si leva il nocciolo, si fa bollire per da 2 a 4 ore lo zucchero, poi riempire subito i barattoli e metterle alla rovescia per fare il sotto vuoto (FAM).

Notas è una ciliegia aspera e contiene tanta acqua, per questo non si vendeva, Le foglie di.

amarene si raccolgono a luglio o agosto. L'ha imparato dalla sua zia di Badi., Prima ce n'era molti di più alberi di ciliegie. I merli li mangiavano come ora, la differenza è che prima ce n'erano molti di più. Le conserve si fanno per le feste.

\section{DATOS ETNOBOTÁNICOS BIBLIOGRÁFICOS}

Nombre vulgar: marâsca (UNGA21), amareno, visciole (SANS14), capo'ni (APPO10),.

zrîlacquarôla (UNGA21), cilésa (APPO10).

Número de referencias: 3 Número de citas: 6 .

Número de sectores: 2 Número de categorías: 5.

\section{Sector alimentario}

Categoría de uso: Conserva de frutas.

Número de referencias: 1 Partes utilizadas: frutos/infrutescencias/falsos frutos.

Sciroppo di marasca e di visciola (UNGA21).

Categoría de uso: Fruta fresca.

Número de referencias: 1 Partes utilizadas: frutos/infrutescencias/falsos frutos, hojas (SANS14).

Categoría de uso: Fruta seca.

Número de referencias: 1 Partes utilizadas: frutos/infrutescencias/falsos frutos. ciliegie secche (APPO10).

Categoría de uso: Licor. 
Número de referencias: 1 Partes utilizadas: frutos/infrutescencias/falsos frutos, hojas.

(SANS14).

Sector medicinal

Categoría de uso: Patologías del aparato urinario.

Número de referencias: 1 Partes utilizadas: frutos/infrutescencias/falsos frutos.

La medicina familiare prescrive l'infuso de gambi come diuretico. (UNGA21).

\section{Prunus domestica $L$.}

Nombre vulgar: Prugne (MSA, GRI, BAD, EMA, BPT, PIM, PGI, FAM, BSI, BLI, NMA, GLA), Susine (TGA, GUF, TUL, BBA, BMA, BAN, GLA), Susine selvatiche (viole) (GAN, REN), Susine amare (NRE), Prugne nere "susino" (FAM), Susine, Prugne giallo tonde (VMU).

Número de informantes: 22 Número de citas: 33 .

Número de sectores: 3 Número de categorías: 8 .

Biotipo: Fanerófito.

Tipo corológico: Cultivadas.

Abundancia: Cultivada.

Ambiente: Cultivado de forma común y subspontaneo (o bien silvestre).

Sector alimentario

Categoría de uso: Conserva de frutas.

Número de informantes: 3 Partes utilizadas: frutos/infrutescencias/falsos frutos.

Riempire un barattolo di prugne, coprire di zucchero, chiudere e metterelo alla finestra "tutta l'estate". (GLA)| Si fanno bollire i frutti con lo zucchero, e si convarsa nei barattoli (NMA)| Bollire un litro di acqua con un kilo di zucchero. Mettere in un barattolo uno stratto di susine pigiate, e aggiungere sopra un po di acqua e zucchero bollito, poi un altro stratto di susine pigiate e un altro po di acqua e zucchero, e cosi consecutivamente. Poi chiudere e fare il sotto vuoto. (GLA)| Le susine selvatiche vanno snocciolate, messe a bollire con un po d'acqua, poi aggiunger la stessa quantità di zucchero, e rimettere a bollire un altro pò (REN).

Categoría de uso: Fruta fresca.

Número de informantes: 1 Partes utilizadas: frutos/infrutescencias/falsos frutos. Mangiati a settembre, quando maturano (NRE).

Categoría de uso: Fruta seca.

Número de informantes: 8 Partes utilizadas: frutos/infrutescencias/falsos frutos.

Si mettevano ad essicare per l'inverno. (BLI)| I 'capponi' erano la frutta che si seccava per l'inverno: corniole, ciliegie, susine secche (BSI)| i capponi: prugne tagliate in due e messe ad seccare sulle cassette di legno per un mese, poi si consevavano in saccetti di tela per l' inverno (FAM)| Le prugne secche venivano succhiate come carmelle. Le donne che filavano la canapa tenevano in bocca delle prugne secche, per fare saliva. (NRE)| Le prugne si seccavano al sole e poi con un agu si infilavano e si facevano delle collane per seccarle con el refe (filo duro). (PGI)| Seccavano la frutta per l'inverno (PIM)| I capponi erano la frutta che si seccava per l'inverno: corniole, ciliegie, susine secche (BAN)| Le susine si 
seccavano al forno e si mangiavano come caramelle (BMA)| Si facevano seccare per conservarle per l'inverno (NRE).

Categoría de uso: Mermelada.

Número de informantes: 6 Partes utilizadas: frutos/infrutescencias/falsos frutos. (BPT) $\mid$ Mettere la frutta con una bottiglia di vino, farla cuocere finché non sia bella cotta, passarla per un passaverdura in modo da ricavare soltanto la polpa, poi aggiungere lo zucchero a occhio, e mettere il composto nel forno della stuffa, perché non si attacchi alla pentola, finché non si veda che si sia rassodato. (EMA) Mermellata asprigna: si leva il noccio, si fa bollire da 2 a 4 ore con lo zucchero $(\mathrm{FAM}) \mid$ Bollire la frutta snocciolata con la stessa quantità di zucchero per 4 o 5 ore (BBA)| Prugne selvatiche (TUL)| Lavare le susine, e bollirle con la stessa quantità di zucchero o un pò meno, finché si stringe e diventa densa..

\section{Sector doméstico}

Categoría de uso: Otro doméstico.

Número de informantes: 2 Partes utilizadas: frutos/infrutescencias/falsos frutos.

Le donne che filavano la canapa tenevano in bocca delle prugne secche, per fare saliva..

(NRE, BAN).

\section{Sector medicinal}

Categoría de uso: Afecciones del aparato respiratorio.

Número de informantes: 2 Partes utilizadas: frutos/infrutescencias/falsos frutos.

Bollire le mele a spicchi, insieme a chicchi di uva passita (zibbibbo), prugne secche o ciliegie secche e chicchi d'orzo, e bere per 2 o 3 giorni. (NRE)| Togliere il nocciolo alle ciliegie, alle mele, alle pere, e alle susine, tagliarle a fette e metterle a secare al sole. Queste si chiamano I caponi, che bolliti in acqua e bevuti si adoperano per guarire il mal di gola (GUF).

Categoría de uso: Estado general.

Número de informantes: 1 Partes utilizadas: semillas.

Mettere a seccare all'ombra tutti I "semi della vita": semi delle ciliege, delle susine ossia le prugne gialle, di zucca, I pinoli, le noci, le culloie o nocciole, le foglie di malva secche, il fiore del gigliopapagone e anche un pò di olio di semi di lino. Poi macinare tutto con il macinino da caffé. E prendere un cucchiaio tutte le mattine a primavera e a ottobre. (VMU).

Categoría de uso: Patologías del aparato digestivo.

Número de informantes: 6 Partes utilizadas: frutos/infrutescencias/falsos frutos.

Mangiare le prugne per la stitichezza. (BAD)| Mangiate fresche (FAM)| Mangiare le prugne secche (GRI)| Frutta secca "caponi di prugne":Per la stitichezza, mangiare caponi di prugne, ossia prugne seccate al sole e senza il nocciolo (GUF)| Le prugne secche vanno bollite e per la stitichezza bere questo decotto la sera. (MSA)| Bere il decotto di susine per la stitichezza (TGA).

Notas Fa bene per la stitichezza, Quando le donne filavano la lana, si metteva in bocca per.

fare saliva.). 


\section{DATOS ETNOBOTÁNICOS BIBLIOGRÁFICOS}

Nombre vulgar: susine (GUC98), figaletti (BONZI00), proggn (UNGA21), sus ina s'gnara.

(GUC98).

Número de referencias: 3 Número de citas: 5.

Número de sectores: 3 Número de categorías: 4.

\section{Sector alimentario}

Categoría de uso: Dulces y golosinas.

Número de referencias: 1 Partes utilizadas: frutos/infrutescencias/falsos frutos.

I capóni sono ciliegie o susine a cui si toglie il nocciolo o mele e pere tagliate a fette poi fatte seccare al sole. Per estensione, anche le ciliegie che si seccano naturalmente sulla pianta. Sono golosità di un tempo, venivano magiati d'inverno o messi a bollire per ricarvarne decotti medicinali (GUC98).

Sector doméstico

Categoría de uso: Otro doméstico.

Número de referencias: 1 Partes utilizadas: frutos/infrutescencias/falsos frutos.

Ciliegie o susine seccate sull'albero e cadute in terra, oppure secche in genere. Le suddette.

usate, specialmente dalle vecchie, per salivare quando filavano. (BONZI00).

Sector medicinal

Categoría de uso: No especificado.

Número de referencias: 1 Partes utilizadas: frutos/infrutescencias/falsos frutos.

I capóni sono ciliegie o susine a cui si toglie il nocciolo o mele e pere tagliate a fette poi fatte seccare al sole. Per estensione, anche le ciliegie che si seccano naturalmente sulla pianta. Sono golosità di un tempo, venivano magiati d'inverno o messi a bollire per ricarvarne decotti medicinali(GUC98).

Categoría de uso: Patologías del aparato digestivo.

Número de referencias: 1 Partes utilizadas: frutos/infrutescencias/falsos frutos.

Le prugne secche in decotto vengono usate nella medicina popolare per le loro qualità.

lassative. (UNGA21).

\section{Prunus dulcis (Mill.) D.A. Webb}

Nombre vulgar: Mandorla (SCO, NLA), Mandorle amare (CFR).

Número de informantes: 3 Número de citas: 3.

Número de sectores: 1 Número de categorías: 2 .

Biotipo: Fanerófito.

Tipo corológico: Cultivadas.

Abundancia: Cultivada.

Ambiente: Cultivado de forma común y raramente asilvestrado.

Sector alimentario

Categoría de uso: Aromatizante.

Número de informantes: 1 Partes utilizadas: semillas. 
Per insaporire i formaggi: Noci, mandorle e nocciole "cullora" secche e macinate venivano messe sopra il latte cagliato in una tazza, poi il tutto si metteva dentro alle cisterne d' acqua piovana per un po'. (NLA).

Categoría de uso: Dulces y golosinas.

Número de informantes: 2 Partes utilizadas: frutos/infrutescencias/falsos frutos, Torta di riso:500 gr di riso cucinato nel latte e raffredato, sbattere 8 uova e mescolare tutto con le mandorle, la buccia del limone, mezzo bicchiere di cognac, e buccie di arancia sotto zucchero. (SCO) $\mid$ Mandorle amare si mettevano nei dolci (CFR).

Notas Secondo Venturi (2006)non è presente (cita P. domestica, P. avium, P. spinosa).

\section{Prunus laurocerasus $L$.}

Nombre vulgar: Lauro (PIL, GUF, DAD).

Número de informantes: 3 Número de citas: 4.

Número de sectores: 2 Número de categorías: 2.

Biotipo: Fanerófito.

Tipo corológico: Cultivadas.

Abundancia: Cultivada.

Ambiente: Cultivada como ornamental.

Número de exsiccata: 38889 FIAF.

\section{Sector alimentario}

Categoría de uso: Licor.

Número de informantes: 3 Partes utilizadas: frutos/infrutescencias/falsos frutos. "laurino" è un liquore fatto con le bacche del lauro, alcol, zucchero e acqua, ed è digestivo (GUF, DAD) 500 gr di zucchero, 500 gr d' acquea, 1 litro di alcool a 95 gradi, 350 gr di bacche di lauro. "Mettere in infusione" le bacche nell'alcool e si lasciano per 15 giorni a macerare. Levare circa 1/5 di bacche e pestarle poi rimettere nell'alcool con le altre per una settimana preparare lo sciroppo con acqua e zucchero. Lasciare raffreddare, filtrare e imbottigliare. (PIL).

Sector medicinal

Categoría de uso: Patologías del aparato digestivo.

Número de informantes: 1 Partes utilizadas: frutos/infrutescencias/falsos frutos. "laurino" è un liquore fatto con le bacche del lauro, alcol, zucchero e acqua, ed è digestivo (DAD).

DATOS ETNOBOTÁNICOS BIBLIOGRÁFICOS

Nombre vulgar: lauroceraso (SANS14), làuro (GUC98).

Número de referencias: 2 Número de citas: 2 .

Número de sectores: 1 Número de categorías: 1.

Biotipo: Fanerófito.

Tipo corológico: Cultivadas.

Abundancia: Cultivada.

Ambiente: Cultivada como ornamental. 
Sector alimentario

Categoría de uso: Licor.

Número de referencias: 1 Partes utilizadas: frutos/infrutescencias/falsos frutos (SANS14).

\section{Prunus persica (L.) Batsch.}

Nombre vulgar: Pesche (NLA), Pesca (TOA, CRO).

Número de informantes: 3 Número de citas: 3.

Número de sectores: 2 Número de categorías: 3.

Biotipo: Fanerófito.

Tipo corológico: Cultivadas.

Abundancia: Cultivada.

Ambiente: Cultivada en grande escala y asilvestrado en los arbustos y bosques de monte bajo latifolios.

\section{Sector alimentario}

Categoría de uso: Aromatizante.

Número de informantes: 1 Partes utilizadas: semillas.

Per aromatizzare la carne di capra e pecore quando è troppo dolce: Frutti secchi ("bebbe") di pungitopo (Ilex aquifolium), insieme a noccioli di pesche secche e pepe, il tutto macinato(NLA).

Categoría de uso: Licor.

Número de informantes: 1 Partes utilizadas: semillas.

Liquore con nocciole di Pesca:Mettere via via le nocciole di pesca in un vaso, quando si raggiunge 20 o 30 nocciole, pulirli con l'acqua e riempire il vaso di nocciole e di alcol 90 gradi, e si lascia per 40 giorni.Dopo filtrare prendere il liquido e prendere la stessa quantità di acqua e di zucchero $(1 \mathrm{~L}$ alcol $=1 \mathrm{~L} \mathrm{H} 2 \mathrm{O}=1 \mathrm{~kg}$ di zucchero).Prendere i noccioli che sono stati macerati nell'alcol, lavarli con l'acqua per fare lo sciroppo. Fare bollire l'acqua di lavaggio e lo zucchero in modo di fare uno sciroppo. Poi mescolare lo sciroppo all'alcol. Si prende come bevanda, dopo aver mangiato, si offre agli amici. (CRO).

Sector medicinal

Categoría de uso: Enfermedades del oído.

Número de informantes: 1 Partes utilizadas: semillas.

Schiacciare il nocciolo della pesca, prendere il "bibio" (dentro), rosolare nell'olio e poi farlo raffredare. Applicare sull'orecchio con l'aiuto di un cotone, ogni mezz'ora. (TOA).

Notas Macinato con il macinino del café (che è piu grosso), lo faceva la nonna, poi la mamma e ora lei..Si prende come bevanda, dopo aver mangiato, si offre agli amici.

\section{Prunus spinosa $L$.}

Nombre vulgar: Spini, Strozzighi (NRO, PCL), Prugnolo (AMA, BSO, BAR, NDI, TGO, NRE), Strozzighi (VSI, RGI, VMR, SLU, BAZ, ZAN, RMA, BSI, VMA, 
TUL, MTI, MRI), Rusticane, prugnolo selvatico (BEL), Rusticane (BBA), Espino selvatico,Frutto Strozzaprete,Strozzigo(pav.) (CFR), Prugnoli (AN3, BMA, TGO, VMR), Spino nero (BGI), Strozzaprete (CAR), Strozzapreti (BGI).

Número de informantes: 27 Número de citas: 33.

Número de sectores: 4 Número de categorías: 10.

Biotipo: Fanerófito.

Tipo corológico: Europeas.

Abundancia: Común.

Ambiente: Bosques de monte bajo, arbustos, setos, muros.

Número de exsiccata: 38904 FIAF.

Sector agropastoral

Categoría de uso: Herramientas y objetos agrícolas.

Número de informantes: 1 Partes utilizadas: tallos leñosos/ramas/ramitas/vástagos.

Con I rami si fanno le scope per fuori della casa e per le stalle (PCL).

Categoría de uso: Vallas y delimitaciones.

Número de informantes: 3 Partes utilizadas: planta entera/viva,.

Si usava fare le siepi con diverse piante: gli spini (prugnolo e biancospino), l'acero campestre, i sanguinelli, i beretti da prete. (NRE)| Siepe (TGO)| Si fa la siepe di strozzighi (MRI).

\section{Sector alimentario}

Categoría de uso: Bebida.

Número de informantes: 1 Partes utilizadas: frutos/infrutescencias/falsos frutos.

Fare cuocere i frutti per 20 minuti nell'acqua, poi passare con il passaverdure e aggiungere.

zucchero. (BEL).

Categoría de uso: Fruta fresca.

Número de informantes: 4 Partes utilizadas: frutos/infrutescencias/falsos frutos. Mangiate fresche (BBA)| I frutti maturi si mangiavano al naturale. (MTI) $\mid \mathrm{E}^{\prime}$ un frutto aspro e agro, simile ai mirtilli però piu grossi (TUL) $\mid$ Si mangiavano i frutti maturi (VMA).

Categoría de uso: Fruta seca.

Número de informantes: 1 Partes utilizadas: frutos/infrutescencias/falsos frutos.

A ottobre si raccoglievano dei rami di prugnolo e si mettevano a seccare, poi piano piano si appassivano e si mangiavano come frutta secca. Se non si fa così sono 'bruschi' (aspri). (NDI).

Categoría de uso: Golosinas y masticatorias.

Número de informantes: 3 Partes utilizadas: frutos/infrutescencias/falsos frutos.

Quando si è nel campo, ciucciare i frutti maturi toglie la sete. (BSI) $\mid$ I frutti maturi tolgono la sete. (RMA) | I frutti si mangiavano quando si era in giro. (ZAN).

Categoría de uso: Licor.

Número de informantes: 13 Partes utilizadas: frutos/infrutescencias/falsos frutos. Raccogliere gli strozzighi per le feste di Natale (perché devono prendere il freddo). Mettere a macerare un $\mathrm{kg}$ di bacche di strozzighi in un Litro di Alcool puro per 40 giorni. Da parte fare lo sciroppo di acqua (mezzo litro) e zucchero (500 gr), farlo 


\section{María Teresa Egea Molines}

scioglere. Poi strizzare con un canovaccio gli strozzighi ben stretto e aggiungere al liquido lo sciroppo. (CFR)| Con I prugnoli si faceva la grappa (AN3)| Mettere a macerare un $\mathrm{kg}$ di prugnoli nel vino rosso fino a coprirli insieme con $750 \mathrm{gr}$ di zucchero per 2 o 3 mesi. Poi filtrare e aggiungere 300 gr di alcol. (BSO, BAR) Mettere a macerare i prugnoli con un po' di spirito e con un po' di zucchero, al sole. (AMA)| Mettere a macerare i frutti nella grappa. Non si ricorda le proporzioni (BGI)| Si faceva anche il liquore con gli strozzighi pero non si ricorda la ricetta (BAZ) $\mid$ non specificato... (MRI) $\mid$ Grappa con strozzighi (SLU)| Facevano i liquori con gli strozzighi, e anche la grappa, ma non sa la ricetta (VMA)| Lo "Strozzighino": mettere I frutti maturi a macerare nel alcol per 40 giorni. Poi filtrare e aggiungere uno sciroppo fatto di acque e zucchero messi a bollire. Mescolare bene e imbottigliare. (VMR)| Liquore 'strozzighino': un litro e mezzo di vino bianco, un litro di alcol puro, un $\mathrm{kg}$ di strozzighi, un $\mathrm{kg}$ di zucchero. Lasciare riposare per un mese e mescolare di tanto in tanto. Dopo 3 mesi filtrare. (BMA)| Il liquore di bacche di strozzighi: Mettere un $\mathrm{kg}$ di bacche raccolte per dicembre, in un litro di alcol 'in fusione" per 40 giorni. Mescolare con un cucchiaio di legno, prendere tutto e passare con un canovaccio strizzando fortemente.Fare bollire $500 \mathrm{gr}$ di acqua in $500 \mathrm{gr}$ di zucchero e fare raffreddare. Poi unire lo sciroppo alla parte alcolica. Filtrare di nuovo e imbottigliare. (CAR).

\section{Sector doméstico}

Categoría de uso: Chimenea y horno.

Número de informantes: 2 Partes utilizadas: planta entera/viva, tallos.

Con un gran mazzo di bosso e di prugnolo, tirare su e giù nella canna fumaria (TGO)| Con I rami di zinepro e degli spini, si puliva la canna fumaria. (NRO).

Categoría de uso: Integración de la renta familiar.

Número de informantes: 2 Partes utilizadas: planta entera/viva.

Pianta raccolta e venduta a un signore che li vendeva a Bologna, all'Università come piante.

medicinali (VSI, RGI).

\section{Sector medicinal}

Categoría de uso: Patologías del aparato digestivo.

Número de informantes: 3 Partes utilizadas: frutos/infrutescencias/falsos frutos.

Liquore 'strozzighino': un litro e mezzo di vino bianco, un litro di alcol puro, un kg di strozzighi, un $\mathrm{kg}$ di zucchero. Lasciare riposare per un mese e mescolare di tanto in tanto. Dopo 3 mesi filtrare. Fa digerire (BMA)| Mangiare I prugnoli contro la diarrea (VMR)| Prendere il liquore di bacche di strozzighi come digestivo: Mettere un $\mathrm{kg}$ di bacche raccolte per dicembre, in un litro di alcol 'in fusione" per 40 giorni. Mescolare con un cucchiaio di legno, prendere tutto e passare con un canovaccio strizzando fortemente.Fare bollire $500 \mathrm{gr}$ di acqua in $500 \mathrm{gr}$ di zucchero e fare raffreddare. Poi unire lo sciroppo alla parte alcolica. Filtrare di nuovo e imbottigliare. (CAR).

Notas Etnomicologica: sotto il prugnolo cresce un fungo che si chiama "il prugnolo", A Ottobre si raccoglievano dei rami di prugnolo e si mettevano a seccare, I liquori li facevano chi aveva soldi, perché lo zucchero costava e non tutti potevano comprarlo, e anche l'alcool. 


\section{DATOS ETNOBOTÁNICOS BIBLIOGRÁFICOS}

Nombre vulgar: prugnolo selvatico, prugnól (SANS14), prugnolo (GRIZ03), prugnôl (UNGA21), strozzi, strozzighi (BONZI00), stròz go (GUC98), strozzigo (POLI14).

Número de referencias: 6 Número de citas: 7.

Número de sectores: 1 Número de categorías: 2 .

Sector alimentario

Categoría de uso: Golosinas y masticatorias.

Número de referencias: 1 Partes utilizadas: frutos/infrutescencias/falsos frutos (SANS14).

Categoría de uso: Licor.

Número de referencias: 3 Partes utilizadas: frutos/infrutescencias/falsos frutos.

(SANS14)Liquore di prugnolo: un pugno di prugnoli selvatici, $40 \mathrm{~g}$ di miele, $11 \mathrm{di}$ grappa. Fate macerare in mezzo litro di grappa i prugnoli per 40 giorni, agitando il barattolo di tanto in tanto. Aggiungete la grappa rimasta con il miele sciolto in una pentola a bagnomaria. Mescolare insieme al macerato e mettete il barattolo al sole per 10 giorni. Dopo di che filtrate e mettete in bottiglia. (GRIZ03)| Se ne prepara un liquore assai gradevole. (UNGA21).

\section{Pyrus communis L.}

Nombre vulgar: Pere zuccarine (RFR), Pero (MTO, GGI, MRI), Pera a cestello (MGO), Pere (GUF, MSI, BPA, AN3, TUL, GFR), Pera a capanna, vendemiana, pera coscia (MGO), Pere snace (RMA, BSI), Pere snace, cestello, volpine, (VSI, RGI), Peròsal, Pera volpina (AN3), Le Cosce di donna (AN3).

Número de informantes: 15 Número de citas: 21.

Número de sectores: 5 Número de categorías: 14.

Biotipo: Fanerófito.

Tipo corológico: Cultivadas.

Abundancia: Cultivada.

Ambiente: Ampliamente cultivada.

Sector agropastoral

Categoría de uso: Alimentación animal (incluidos los forrajeros).

Número de informantes: 1 Partes utilizadas: frutos/infrutescencias/falsos frutos. Per le bestie. (RFR).

Categoría de uso: Herramientas y objetos agrícolas.

Número de informantes: 1 Partes utilizadas: tallos leñosos/ramas/ramitas/vástagos.

Per fare il mazzo, perché il legno è resistente e pesante (MRI).

Sector alimentario

Categoría de uso: Conserva de frutas.

Número de informantes: 2 Partes utilizadas: frutos/infrutescencias/falsos frutos. 
Le pere a cestello si mangiano cotte. (MGO)| Pelate le pere, tagliarli a pezzi, farli bollire per 3 ore, al massimo con un bicchiere d'acqua. Mettere nei barattoli e quando ancora sono caldi chiudere. (GFR).

Categoría de uso: Fruta fresca.

Número de informantes: 2 Partes utilizadas: frutos/infrutescencias/falsos frutos.

Le pere si mangiavano come frutta fresca. (MGO)| Si raccoglievano verdi a Settembre e si.

lasciavano sulla pailla fino alla maturazione. (TUL).

Categoría de uso: Fruta seca.

Número de informantes: 1 Partes utilizadas: frutos/infrutescencias/falsos frutos.

Le pere venivano essicate per mangiarle d'inverno (AN3).

Categoría de uso: Licor.

Número de informantes: 4 Partes utilizadas: frutos/infrutescencias/falsos frutos.

Il vino di pere era fatto con le pere raccolte a fine estate-autunno. Quando sono mature (diventano marrone scuro) vengono messe a macerare in un tino di vino per 4 o 5 giorni, con il tappo. Veniva fuori un vino di pere frizzante e dolciastro. Va bevuto subito con le caldorroste o le 'fruisà'. (BSI)| Il vino di pere era fatto con le pere raccolte a fine estate-autunno, messe a macerare in un tino (una botte) per 4 o 5 giorni, con il tappo. Veniva fuori un vino di pere frizzante e dolciastro. Va bevuto subito con le caldorroste o le 'fruisà'. (RMA)| Il vino di pere si faceva mettendo le pere a macerare nei tini di legno con il buco di sotto per 13 giorni (come si fa con l'uva, però tenendole un po' più di tempo). Veniva un vino tipo sidro, le pere aspre fermentano e diventano buone. Era un modo di usare le pere perché non si sciupassero. (VSI, RGI).

Categoría de uso: Mermelada.

Número de informantes: 3 Partes utilizadas: frutos/infrutescencias/falsos frutos. (BPA)Marmellata "al savor": Fare bollire mele o pere coltivate, con un pò di succo d'uva, 1 o 2 mele cotogne oppure 1 o 2 perecotogne, viene una marmellata aspra. (AN3)| Pulire la frutta, pesarla, aggiungere 500 gr di zucchero per $1 \mathrm{~kg}$ di frutta, lasciare fermentare per 24 ore, e poi fare bollire fino alla consistenza voluta (dipende dalla qualità della frutta). (MSI) | Cuocere le pere e i fichi senza buccia per 4 o 5 ore, passarlo con il passaverdura, e aggiungere un po' di succo di limone o di arancio. Mettere nei vasi quando ancora bolle, tappare subito i barattoli e metterli a testa all'ingiù. (MSR).

Categoría de uso: Otro alimentario.

Número de informantes: 1 Partes utilizadas: frutos/infrutescencias/falsos frutos. Coprire le pere d'acqua, farle bollire per tante ore finché non diventa ristretto e si mangiava con la polenta di grano turco, perché viene un sugo aspro buone per insaporire la polenta. (AN3).

Sector artesanal

Categoría de uso: Muebles.

Número de informantes: 1 Partes utilizadas: madera.

Buon legno per fare mobili (GGI).

Categoría de uso: Objetos domésticos. 
Etnobotánica en el Alto Valle del Reno (Toscana y Emilia-Romaña, Italia)

Número de informantes: 1 Partes utilizadas: tallos

leñosos/ramas/ramitas/vástagos.

Per fare cucchiai per cucina, mestoli, etc. (MGO).

Sector doméstico

Categoría de uso: Ambientador.

Número de informantes: 1 Partes utilizadas: frutos/infrutescencias/falsos frutos.

Le 'cosce di donna' erano una varietà di pere innestate che non marcivano e duravano tutto.

l'inverno, si mettevano nell'armadio per profumare (AN3).

Categoría de uso: Integración de la renta familiar.

Número de informantes: 1 Partes utilizadas: frutos/infrutescencias/falsos frutos.

Il babbo raccoglieva tutti questi frutti e poi li vendeva a un signore che li raccoglieva tutti e.

poi li rivendeva (RMA).

Sector medicinal

Categoría de uso: Afecciones del aparato respiratorio.

Número de informantes: 1 Partes utilizadas: frutos/infrutescencias/falsos frutos.

Togliere il nocciolo alle ciliegie, alle mele, alle pere, e alle susine, tagliarle a fette e metterle a secare al sole. Queste si chiamano I caponi, che vanno bolliti in acqua e bevuti per guarire il mal di gola (GUF).

Categoría de uso: Patologías del aparato urinario.

Número de informantes: 1 Partes utilizadas: hojas.

Fare bollire le foglie del pero e bere il decotto spesso. (MTO).

Notas Caratteristiche del legno: pesante e resistente. Adesso sono abbandonati. $\mathrm{Ci}$ sono delle e pere raccolte a fine estate-autunno.Ora ce ne sono poche, bisognarebbe girare per ritrovarle, una volta ce n'erano tante.

DATOS ETNOBOTÁNICOS BIBLIOGRÁFICOS

Nombre vulgar: pere (GUC98), pera (ZAGN90).

Número de referencias: 2 Número de citas: 3 .

Número de sectores: 3 Número de categorías: 3.

Sector alimentario

Categoría de uso: Dulces y golosinas.

Número de referencias: 1 Partes utilizadas: frutos/infrutescencias/falsos frutos.

I capóni sono ciliegie o susine a cui si toglie il nocciolo o mele e pere tagliate a fette poi fatte seccare al sole. Per estensione, anche le ciliegie che si seccano naturalmente sulla pianta. Sono golosità di un tempo, venivano magiati d'inverno o messi a bollire per ricarvarne decotti medicinali (GUC98).

Sector mágico/medicinal

Categoría de uso: Otro mágico/medicinal.

Número de referencias: 1 Partes utilizadas:.

Per far cessare il singhiozzo si dice: "Na pera, na mela, na pesca balena tre volte lo dirò senza.

mai respirerò." (ZAGN90). 
Sector medicinal

Categoría de uso: No especificado.

Número de referencias: 1 Partes utilizadas: frutos/infrutescencias/falsos frutos.

I capóni sono ciliegie o susine a cui si toglie il nocciolo o mele e pere tagliate a fette poi fatte seccare al sole. Per estensione, anche le ciliegie che si seccano naturalmente sulla pianta. Sono golosità di un tempo, venivano magiati d'inverno o messi a bollire per ricarvarne decotti medicinali (GUC98).

\section{Pyrus communis L. 'Antica'}

Nombre vulgar: Pera antica (MGE).

Número de informantes: 1 Número de citas: 1.

Número de sectores: 1 Número de categorías: 1 .

Biotipo: Fanerófito.

Tipo corológico: Cultivadas.

Abundancia: Cultivada.

Ambiente: Cultivada.

Sector alimentario

Categoría de uso: Fruta fresca.

Número de informantes: 1 Partes utilizadas: frutos/infrutescencias/falsos frutos.

Si mangiavano le pere antiche che duravano tutto l'inverno (MGE).

\section{Pyrus communis L. 'Bolognese'}

Nombre vulgar: Pero bolognese (MRI).

Número de informantes: 1 Número de citas: 1.

Número de sectores: 1 Número de categorías: 1 .

Biotipo: Fanerófito.

Tipo corológico: Cultivadas.

Abundancia: Cultivada.

Ambiente: Cultivada.

Sector alimentario

Categoría de uso: Fruta fresca.

Número de informantes: 1 Partes utilizadas: frutos/infrutescencias/falsos frutos. Il pero bolognese si mangia fresco, per la trebbiatura del grano. (MRI).

Notas Pero Bolognese. Matura ad Agosto. Sono dolci e piccoli. Erano pronto per la trebbiatura del grano.

\section{Pyrus communis L. 'Cana'}

Nombre vulgar: Pera cana (BAR).

Número de informantes: 1 Número de citas: 1.

Número de sectores: 1 Número de categorías: 1 .

Biotipo: Fanerófito.

Tipo corológico: Cultivadas. 
Abundancia: Cultivada.

Ambiente: Cultivada.

Sector alimentario

Categoría de uso: Fruta fresca.

Número de informantes: 1 Partes utilizadas: frutos/infrutescencias/falsos frutos.

Le pere cane, sono dure, tonde, schiacciate, si tenevano sotto il letto per farle maturare e si aspettava che maturassero, si sceglievano ogni volta quelle marrone scure, si mangiavano col pane come collazione, ce ne sono ancora nel cigno (BAR).

\section{Pyrus communis L. 'Cestello'}

Nombre vulgar: Pera cestello (RGI), Pere cestello (RNI).

Número de informantes: 2 Número de citas: 2.

Número de sectores: 1 Número de categorías: 1.

Biotipo: Fanerófito.

Tipo corológico: Cultivadas.

Abundancia: Cultivada.

Ambiente: Cultivada.

Sector alimentario

Categoría de uso: Fruta fresca.

Número de informantes: 2 Partes utilizadas: frutos/infrutescencias/falsos frutos.

Le diverse varietà di pere si mangiavano come frutta (RGI)| Facevano 7 o 8 pere in un unico.

rametto, si mangiavano come frutta (RNI).

Notas Pera cestello (tipo snaccia), Pere snace (rotonde) ce l'ha qualcuno che conosce,Pere.

volpine (a punta), Pere zuccherine (fanno I frutti a giugno). Pera a cestello è una pera tonda, pù.

piccola,matura fine settembre, a Novembre, è l'ultima che matura, a volte anche con la.

neve, dolce/agro, è buona cotta, dura tanto, in un gambo ne fa 4 o 5 pere.

\section{Pyrus communis L. 'Cosce di donna'}

Nombre vulgar: Le Cosce di Donna (AN3).

Número de informantes: 1 Número de citas: 1.

Número de sectores: 1 Número de categorías: 1.

Biotipo: Fanerófito.

Tipo corológico: Cultivadas.

Abundancia: Cultivada.

Ambiente: Cultivada.

Sector doméstico

Categoría de uso: Ambientador.

Número de informantes: 1 Partes utilizadas: frutos/infrutescencias/falsos frutos. 
Le 'cosce di donna' erano una varietà di pere innestate che non marcivano e duravano tutto l'inverno, si mettevano nell'armadio per profumare (AN3).

\section{Pyrus communis L. 'Della iesola'}

Nombre vulgar: Pere dela iesola (MSR).

Número de informantes: 1 Número de citas: 1.

Número de sectores: 1 Número de categorías: 1.

Biotipo: Fanerófito.

Tipo corológico: Cultivadas.

Abundancia: Cultivada.

Ambiente: Cultivada.

Sector alimentario

Categoría de uso: Fruta fresca.

Número de informantes: 1 Partes utilizadas: frutos/infrutescencias/falsos frutos.

Pere de la iesola. è un pero antico, invernale, matura a natale, non tanto dolce. I frutti vanno raccolti a settembre e maturano in inverno, durano tanto tempo. A provalecchio. È sparita, non ce n'è come prima, "dice che è perché prima c'erano le cacche di gallina" (MSR).

\section{Pyrus communis L. 'Granello'}

Nombre vulgar: Pere granello (PLU).

Número de informantes: 1 Número de citas: 1.

Número de sectores: 1 Número de categorías: 1.

Biotipo: Fanerófito.

Tipo corológico: Cultivadas.

Abundancia: Cultivada.

Ambiente: Cultivada.

Sector alimentario

Categoría de uso: Conserva de frutas.

Número de informantes: 1 Partes utilizadas: frutos/infrutescencias/falsos frutos.

I frutti si raccolgono duri, e si lasciavano maturare nella paglia, oppure si facevano cotti: cuocere per una giornata e mezza. Il sugo diventava la "sabadina" e si mangiava con il pane fatto di parino di grano o di grano turco come cena. (PLU).

Notas Nella vallata su di qui non ce ne sono più. Prima tutti avevano uno.

\section{Pyrus communis L. 'Snace'}

Nombre vulgar: Pere snace (RGI, RMA).

Número de informantes: 2 Número de citas: 2.

Número de sectores: 1 Número de categorías: 1.

Biotipo: Fanerófito.

Tipo corológico: Cultivadas.

Abundancia: Cultivada.

Ambiente: Cultivada. 
Sector alimentario

Categoría de uso: Fruta fresca.

Número de informantes: 2 Partes utilizadas: frutos/infrutescencias/falsos frutos.

Le pere snace si mangiavano come frutta fresca (RMA)| Le diverse varietà di pere si mangiavano come frutta (RGI).

Notas Pera cestello (tipo snaccia), Pere snace (rotonde) ce l'ha qualcuno che conosce,Pere volpine (a punta), Pere zuccherine (fanno I frutti a giugno).

\section{Pyrus communis L. 'Spadonne'}

Nombre vulgar: Pere spadonne (RFR), Pere spadonne. (RFR).

Número de informantes: 1 Número de citas: 2.

Número de sectores: 1 Número de categorías: 1 .

Biotipo: Fanerófito.

Tipo corológico: Cultivadas.

Abundancia: Cultivada.

Ambiente: Cultivada.

Sector alimentario

Categoría de uso: Conserva de frutas.

Número de informantes: 1 Partes utilizadas: frutos/infrutescencias/falsos frutos.

Le "pere spadonne" erano dure, si mangiano cotte, maturano in autunno. (RFR)| Sono pere molto dure, sono buone cotte. Maturano in Autunno. (RFR).

\section{Pyrus communis L. 'Volpina'}

Nombre vulgar: Pera volpina. (RFR), Pere volpine (RGI), Peròsal, Pera volpina (AN3), Pera.

volpina (RFR).

Número de informantes: 3 Número de citas: 4.

Número de sectores: 1 Número de categorías: 4.

Biotipo: Fanerófito.

Tipo corológico: Cultivadas.

Abundancia: Cultivada.

Ambiente: Cultivada.

Sector alimentario

Categoría de uso: Conserva de frutas.

Número de informantes: 1 Partes utilizadas: frutos/infrutescencias/falsos frutos.

Le pere si mettono a bollire insieme con i balotti (castagne cotte) (RFR).

Categoría de uso: Fruta fresca.

Número de informantes: 1 Partes utilizadas: frutos/infrutescencias/falsos frutos.

Le diverse varietà di pere si mangiavano come frutta (RGI).

Categoría de uso: Otro alimentario.

Número de informantes: 1 Partes utilizadas: frutos/infrutescencias/falsos frutos. 


\section{María Teresa Egea Molines}

Coprire le pere d'acqua, farle bollire per tante ore finché non diventa ristretto e si mangiava con la polenta di grano turco, perché viene un sugo aspro buone per insaporire la polenta. (AN3).

Categoría de uso: Sopas de verduras y potaje.

Número de informantes: 1 Partes utilizadas: frutos/infrutescencias/falsos frutos.

Pera volpina. Le pere si mettono a bollire insieme con i balotti (castagne cotte) (RFR).

Notas "Pera Volpiina" sono piccole, rosiccie, matura d'inverno a novembre.

\section{Pyrus communis L. 'Zuccarine'}

Nombre vulgar: Pere zuccarine (RFR), Pere zuccherine (RGI).

Número de informantes: 2 Número de citas: 2.

Número de sectores: 1 Número de categorías: 1.

Biotipo: Fanerófito.

Tipo corológico: Cultivadas.

Abundancia: Cultivada.

Ambiente: Cultivada.

Sector alimentario

Categoría de uso: Fruta fresca.

Número de informantes: 2 Partes utilizadas: frutos/infrutescencias/falsos frutos.

Le "pere zuccarine" sono piccole, scure, e di sapore dolce. (RFR)| Le diverse varietà di pere si mangiavano come frutta (RGI).

Notas Anche un altra varietà "Pera Volpiina" (piccola, rosiccie, matura d'inverno a novembre), Pera cestello (tipo snaccia), Pere snace (rotonde) ce l'ha qualcuno che conosce,Pere volpine (a punta), Pere zuccherine (fanno I frutti a giugno).

\section{Pyrus pyraster (L.) Burgsd.}

Nombre vulgar: Pere selvatiche (RNI, LST, GGI, BSI, BAR, VSI, RGI), pere selvatiche (BAR).

Número de informantes: 7 Número de citas: 12.

Número de sectores: 3 Número de categorías: 5.

Biotipo: Fanerófito.

Tipo corológico: Europeas.

Abundancia: Común.

Ambiente: Bosques latifolios de suelo húmedo y rico en sustancias nutritivas.

Sector agropastoral

Categoría de uso: Portainjertos.

Número de informantes: 2 Partes utilizadas: planta entera/viva.

Si raccoglievano i semi per fare delle piante usate come portainnesti (VSI, RGI).

Sector alimentario

Categoría de uso: Fruta fresca.

Número de informantes: 1 Partes utilizadas: frutos/infrutescencias/falsos frutos.

Le pere selvatiche si mangiano quando diventano scure nere. (BAR). 
Categoría de uso: Licor.

Número de informantes: 3 Partes utilizadas: frutos/infrutescencias/falsos frutos. Il vino di pere era fatto con le pere raccolte a fine estate-autunno. Quando sono mature (diventano marrone scuro) vengono messe a macerare in un tino di vino per 4 o 5 giorni, con il tappo. Veniva fuori un vino di pere frizzante e dolciastro. Va bevuto subito con le caldorroste o le 'fruisà'. (BSI)| il vino di pere selvatiche si faceva togliendogli i semi, mettendo le pere a macerare nei tini di legno con il buco di sotto per 13 giorni (come si fa con l'uva, però un po' più di tempo). Veniva un vino tipo sidro: le pere aspre fermentano e diventano buone. Era un metodo di usare le pere selvatiche perché non si sciupassero. (RGI)| il vino di pere selvatiche si faceva togliendoli i semi, mettendo le pere a macerare nei tini di legno con il bucco di sotto per 13 giorni (uguale che con l'uva però un pò più di tempo) e veniva un vino tipo sidro, le pere aspre fermentano e diventano buone. Era un metodo di usare le pere perché non si sciuparino.Il vino di pere era fatto con le pere raccolte a fine estate-autunno,quando sono mature (che diventano marron scuro) messe a macerare in un tino di vino(una bote) con il tappo, e veniva fuori un vino di pere frizzante e dolciastro. Va bevuto subito con le caldorroste o le "fruisà", Ora ce ne sono poche, bisognarebbe girare per ritrovarle, una volta ce n'erano tante) e tonda, e scura quando matura (VSI).

Categoría de uso: Mermelada.

Número de informantes: 3 Partes utilizadas: frutos/infrutescencias/falsos frutos.

$\mathrm{Si}$ faceva la marmellata di pere selvatiche e mele selvatiche: farle bollire con la buccia e un bicchiere d'acqua, si possono lasciare a pezzi oppure passare per il passaverdure. Aggiungere 2 o 3 etti di zucchero per $\mathrm{kg}$ di frutta, fare bollire finché non raggiungesse la consistenza giusta (si metteva una cucchiaiata sul piatto e si piegava, non deve colare)Poi si imbarattolava si metteva sopra un pò di rum e si chiudevano. (RNI, GGI)| Prendere $1 \mathrm{~kg}$ o $2 \mathrm{~kg}$ di pere elvatiche e aggiungere $800 \mathrm{o}$ 850 gr di zucchero, farlo bollire un oretta e passarlo con il passaverdure poi farla bollire per 20 minuti di nuovo. Imbarattolare e chiudere e mettere a.

Sector doméstico

Categoría de uso: Integración de la renta familiar.

Número de informantes: 3 Partes utilizadas: frutos/infrutescencias/falsos frutos,. le per selvatiche si vendevano al ristorante Gabana (BAR)| I semi erano raccolti e venduti a un signore che li rivendeva a Bologna per fare delle piante per piantaggioni grandi perché è più resistente (VSI, RGI).

Notas Le pere raccolte a fine estate-autunno. Ce ne stanno ancora però ora è tutto rovo! Prima tagliavano l'erba e si vedevano bene!, Adesso sono abbandonati, non sono Innestate.

\section{DATOS ETNOBOTÁNICOS BIBLIOGRÁFICOS}

Nombre vulgar: pero selvatico (SANS14).

Número de referencias: 1 Número de citas: 1.

Número de sectores: 1 Número de categorías: 1.

Sector alimentario

Categoría de uso: Fruta fresca. 
Número de referencias: 1 Partes utilizadas: frutos/infrutescencias/falsos frutos (SANS14).

\section{Rosa canina L. (s. l.)}

Nombre vulgar: Peterlenghe (RGI, GPU, EMA, GLA, ZAN, VMA, MGE, PCL, PGI), Peterlenga (TUL, RRE, NRO, GGI, VSI, RMA, PIM, NRE, GFR, BSI), Peterlenghe (frutto) Raggie alte (pianta) (LGI), Pinzinculo, Rosa canina, Raggia canina (BEL), Rosa canina (BPT, BPA, DBA, BSO), Peterlenga, Raggie.

Número de informantes: 31 Número de citas: 41.

Número de sectores: 4 Número de categorías: 10.

Biotipo: Nanofanerófito.

Tipo corológico: Europeas.

Abundancia: Común.

Ambiente: Bosques degradados (con robles caducifolios, hayas, abetos, pinos), arbustos y setos.

Número de exsiccata: 38901 FIAF.

Sector alimentario

Categoría de uso: Bebida.

Número de informantes: 1 Partes utilizadas: frutos/infrutescencias/falsos frutos.

Si facevano le tisane con I frutti secchi delle peterlenghe come bevanda, per piacere (PGI).

Categoría de uso: Fruta fresca.

Número de informantes: 1 Partes utilizadas: frutos/infrutescencias/falsos frutos. Mangiati, schiacciando il frutto e mangiando la polpa, scartando I semi (PCL).

Categoría de uso: Golosinas y masticatorias.

Número de informantes: 12 Partes utilizadas: frutos/infrutescencias/falsos frutos,. Si ciucciavano i frutti quando si era in giro. (BSI)| Frutti maturi, strizzati e ciucciati (GFR)| I germogli venivano pelati e mangiati come spuntini. (NRE)| I bambini mangiavano le 'punte' delle raggie o peterlenghe. (PIM)| Si ciucciavano i frutti, però se se ne mangiavano tanti poi bruciava il culo. (RMA)| I frutti si mangiavano così quando si era in giro (MGE)| Si mangiavano le peterlenghe. (PGI)| I getti nuovi delle delle peterlenghe si pelavano e si mangiava così quando eravamo bambini, avevano un gusto dolce amaro. Anche la polpa si mangiava uguale. (VMA)| I frutti si ciuciava quando si era in giro. (ZAN) $\mid$ Quando si andava dietro alle pecore, non si sapeva cosa fare, e via via si mangiavano e si ciucciavano questi frutti che si trovavano nei cigli a cespugli. (LGI)| A primavera si tagliavano i germogli teneri di pinzinculo, si spellavano e si mangiavano nei campi. (BEL)| I germogli si sbucciavano e si mangiavano così nei campi, erano buoni! (BSO).

Categoría de uso: Licor.

Número de informantes: 3 Partes utilizadas: frutos/infrutescencias/falsos frutos,. non specificato (VSI)| Riempire un cuarto di una bottiglia con I petali dei fiori della rosa canina, aggiungere 1 o 2 cucchiai di zucchero e riempire di grappa. Lasciare riposare per un mese e poi filtrare. Il liquore prende un colore rosaceo bellissimo. (DBA, BSO). 
Categoría de uso: Mermelada.

Número de informantes: 8 Partes utilizadas: frutos/infrutescencias/falsos frutos. Mettere a bollire i frutti e filtrare con il setaccio, poi aggiungere lo zucchero (GGI) non specificato (TIV, VSI)| Bollire 20 minuti con un po di zucchero. (GLA) Venivano bolliti, poi filtrati e aggiunti dello zucchero (BPA)| Fare bollire $1 \mathrm{~kg}$ di frutti con $1 \mathrm{~kg}$ di zucchero per un'ora, poi passarli con il passaverdura, fare bollire di nuovo e ancora bollente imbarattolare nei vasi e ribaltarli. (BSO)| Fare bollire "le nappe", e poi passarle al setaccio e aggiungere zucchero. (BGI)| Fare bollire "le nappe", e poi passarle al setaccio e aggiungere zucchero, alla fine bollendo un altro po'. (NLA).

Sector artesanal

Categoría de uso: Instrumentos y utensilios para la artesanía.

Número de informantes: 2 Partes utilizadas: tallos leñosos/ramas/ramitas/vástagos.

Rocca per filare la lana: è come un palo con un buco dentro fatto a croce, con il quale.

filavano la lana, per arrotolare la lana e poi fare il filo. (PCL, NRO).

Sector doméstico

Categoría de uso: Integración de la renta familiar.

Número de informantes: 8 Partes utilizadas: planta entera/viva,.

Raccolte con radici si vendevano ai vivaisti di Pistoia per fare gli innesti con le rose (GGI)| Si vendevano come portainnesti, per innestare la rosa (NLA)| Si raccoglievano le peterlenghe e si vendevano (EMA) $\mid$ le peterlenghe le cercavano per fare delle medicine e noi gliele andavamo a raccoglierle e le vendevamo (GPU) Pianta raccolta e venduta a un signore che li vendeva a Bologna, all'Università come piante medicinali (VSI, RGI)| La gente le raccoglieva e li vendeva a dei signori. (VMA)| Le raccoglievano con la radice e la vendevano ai signori che venivano da Pistoia per innestare. Le vendevano a 100 lire l' una come portainnesti (BGI).

Categoría de uso: Jardín.

Número de informantes: 1 Partes utilizadas: planta entera/viva.

Per innestare la rosa (BPT).

Sector medicinal

Categoría de uso: Afecciones del aparato respiratorio.

Número de informantes: 4 Partes utilizadas: frutos/infrutescencias/falsos frutos,. Fare cuocere un po' i frutti di peterlenga e bere per la tosse. (RRE)| Non lo ricorda (TUL)| I fiori di rosa canina venivano essicati all'ombra per l'influenza e per la febbre, per l'influenza e per le infezioni. Darli un bollore ai fiori con l'acqua aggiungere un pò di miele e bere una tazza la mattina e la sera finché passano. (VMU)| le peterlenghe vanno fatte in 'infuso' bollite (decotto) e poi si deve bere l'acqua. (BOR).

Categoría de uso: Patologías del aparato urinario.

Número de informantes: 1 Partes utilizadas: frutos/infrutescencias/falsos frutos. Fare bollire un po' i frutti del pinzinculo e bere spesso per l'infiammazione della prostata, delle vie urinarie, dei reni, quando non si può urinare bene. (NDI). 


\section{María Teresa Egea Molines}

Notas Lo faceva la sua mamma., Pero rende poco,raccoglievano peterlenghe "era la sopravivenza dei vecchi come il carbone".

DATOS ETNOBOTÁNICOS BIBLIOGRÁFICOS

Nombre vulgar: rosa canina (GRIZ03), rosa selvatica, pizzincul (SANS14), peterlinghe, petterlenghe (MANG98), pizincûl, patarlainga, rofa di mâta o rofa ed r fza, rofa ed zoeda (UNGA21), Paterlénga (APPO10), peterlinga (BONZI00), paterlénga, piterlénga (GUC98).

Número de referencias: 8 Número de citas: 15.

Número de sectores: 2 Número de categorías: 10.

Sector alimentario

Categoría de uso: Arroces y "risotto".

Número de referencias: 1 Partes utilizadas: flores/inflorescencias y sus partes.

Scottare il riso in acqua bollente e i petali di rosa canina più sale, scolare, aggiungendoci olio, foderare una casseruola col burro, condire il riso con parmigiano e sale, noce moscata e pepe bianco. Infornare per quindici minuti circa e servire con petali di rosa canina in superficie. (GRIZ03).

Categoría de uso: Conserva de frutas.

Número de referencias: 1 Partes utilizadas: flores/inflorescencias y sus partes (SANS14).

Categoría de uso: Golosinas y masticatorias.

Número de referencias: 1 Partes utilizadas: flores/inflorescencias y sus partes (SANS14).

Categoría de uso: Mermelada.

Número de referencias: 1 Partes utilizadas: flores/inflorescencias y sus partes.

Confettura di mele e rosa canina: $2 \mathrm{~kg}$ di mele, mezzo $\mathrm{kg}$ di petali di rosa profumati e sani, uno e mezzo kg di zucchero, un limone. Sbucciare, tagliare e mettere le mele con succo e scorza di limone in una casseruola. Unire i petali di rose lavati alle mele e rimescolare. Aggiungere $250 \mathrm{ml}$ di acqua e lasciare riposare per mezz'ora poi porre sul fuoco e fare bollire adagio. Quando le mele sono cotte, passare tutto al settaccio, quindi unire lo zucchero e cuocere mescolando spesso. Quando la marmellata avrà raggiunto la densità del miele, toglierla dal fuoco e versarla nei vasi. Chiudere subito ermeticamente e conservare al buio. Marmellata di frutti di rosa canina: $800 \mathrm{~g}$ di frutti di rosa canina, $500 \mathrm{~g}$ di zucchero semolato, acqua q.b. Passate i furtti sott l'acqua corrente, lasciateli asciugare, staccate i piccioli e poi fateli cuocere in abbondante acqua per circa un paio d'ore. Quando sono molto morbidi scolateli e passateli al passaverdura, poi al setaccio. Mettete la purea così ottenuta nella pentola destinata alla preparazione, unitevi lo zucchero e fate cuocere a calore dolce, mescolando frequentemente. Dopo circa $45 \mathrm{~min}$ controllate la consistenza della marmellata, se è giusta spegnete la fiamma, altrimenti continuate la cottura per altri 5 o $10 \mathrm{~min}$. Schiumate, lasciate intiepidire, invasate. Marmellata con petali di rosa canina: $1 \mathrm{~kg}$ di petali, $1 \mathrm{~kg}$ di zucchero, 2 bicchieri di acqua, un pò di cannella, cuocere a fuoco lento tutti gli ingredienti fino ad ottenere una marmellata gelatinosa, mescolando di tanto in tanto con un cucchiaio di legno, mettere in vasetti a fare il sottovuoto. (GRIZ03). 


\section{Sector medicinal}

Categoría de uso: Afecciones del aparato respiratorio.

Número de referencias: 1 Partes utilizadas: flores/inflorescencias y sus partes.

Sciroppo per la tosse: 1 litro di marsala, 30 grammi di petali di rosa canina, 100 gr di ceccole.

di rosa canina. (GRIZ03).

Categoría de uso: Estado general.

Número de referencias: 1 Partes utilizadas: frutos/infrutescencias/falsos frutos.

I frutti freschi vengono mangiati come integratore vitaminico. (MANG98).

Categoría de uso: Otro medicinal.

Número de referencias: 1 Partes utilizadas: frutos/infrutescencias/falsos frutos.

Un tempo usata contro la rabbia canina (UNGA21).

Categoría de uso: Patologías del aparato circulatorio.

Número de referencias: 1 Partes utilizadas: frutos/infrutescencias/falsos frutos.

Il frutto secco, triturato, viene mangiato in caso di emorragie interne ed esterne, in quest'ultimo caso lo si applica anche localmente per rafforzare 1'attività emostatica. (MANG98).

Categoría de uso: Patologías del aparato digestivo.

Número de referencias: 1 Partes utilizadas: frutos/infrutescencias/falsos frutos. oggi usata in decozione come diuretica e purgativa (UNGA21).

Categoría de uso: Patologías del aparato urinario.

Número de referencias: 1 Partes utilizadas: frutos/infrutescencias/falsos frutos. oggi usata in decozione come diuretica e purgativa (UNGA21)| non specificato (UNGA21).

Notas Paterlènga, paterlènga, chi li ha fatti se li tenga.

\section{Rosa cv.}

Nombre vulgar: Rosa antica (BGI, UMI, TOA), Rosa (GUF, TUL, CAR), Rose (VMA, GRI, GLA), Rosa di una volta (LRE), Rose profumate (LGI).

Número de informantes: 11 Número de citas: 16.

Número de sectores: 3 Número de categorías: 8 .

Biotipo: Nanofanerófito.

Tipo corológico: Cultivadas.

Abundancia: Cultivada.

Ambiente: Jardines y huertos.

Número de exsiccata: 38897 FIAF.

Sector alimentario

Categoría de uso: Bebida.

Número de informantes: 2 Partes utilizadas: flores/inflorescencias y sus partes.

Raccogliere I petali di rosa e metterli a seccare per l'inverno. Poi metterla in acqua calda e.

bere come bevanda. (UMI, TOA).

Categoría de uso: Licor.

Número de informantes: 2 Partes utilizadas: flores/inflorescencias y sus partes. 


\section{María Teresa Egea Molines}

Il Rosolio": in un recipiente si riempiva a stratti di petali di rose e sopra lo zucchero pestato per giorni fino a riempire il recipiente. Si copriva con un canovaccio e si metteva al sole. Quando lo zucchero era sciolto, si aggiungeva dell'acqua diluita nell'alcol. Poi si lasciava tutto macerare per un p`o e si filtrava. Veniva un liquore molto dolce, servito in dei bicchierino piccolissimi del 'servito da rosolio' (anni 5060), quando c'erano ospiti in casa e si voleva offrire qualcosa. (CAR)| Per insaporire la grappa, mettere a macerare le foglie della rosa antica (BGI).

Categoría de uso: Mermelada.

Número de informantes: 1 Partes utilizadas: flores/inflorescencias y sus partes.

Bollire i petali di rosa profumata 20 minuti con un po' di zucchero. (GLA).

Categoría de uso: Otro alimentario.

Número de informantes: 2 Partes utilizadas: flores/inflorescencias y sus partes.

Raccogliere I petali di rosa antica e mettere come condimento della pasta. (UMI, TOA).

Categoría de uso: Tortilla.

Número de informantes: 3 Partes utilizadas: flores/inflorescencias y sus partes.

Mettere nella frittata I fiori delle rose coltivate (TUL)| Mettere I petali di rosa antica tipica.

(molto profumata) nella padella con le uova per fare la frittata di rose antiche. (UMI, TOA).

\section{Sector doméstico}

Categoría de uso: Ambientador.

Número de informantes: 2 Partes utilizadas: flores/inflorescencias y sus partes.

Mettere i petali di rosa antica seccati negli armadi per profumare la biancheria (UMI) $\mid$ Mettere a seccare i fiori di rosa, fare sacchettini e metterli dentro alla biancheria. (LRE).

\section{Sector religioso}

Categoría de uso: Alfombras florales.

Número de informantes: 2 Partes utilizadas: flores/inflorescencias y sus partes.

Il giorno del Corpus Domini, si fanno le infiorate, ossia disegni con fiori sulle strade percorse dalle processioni religiose (GUF)| Quando eravamo su, avevamo tante rose e per la festa di San Michele c' era tanta gente, era bello. Io portavo un paniere pieno di rose che faceva un profumo buonissimo e li buttavo per terra intorno alla Chiesa...' (LGI).

Categoría de uso: Ornamento para altares e iglesias.

Número de informantes: 2 Partes utilizadas: flores/inflorescencias y sus partes.

Per le feste della Madonna, a Maggio, il "Ben di Maggio", tutte le sere si andava a pregare all'altare, si portavano le margherite e le rose all'altare (GRI)| Si usava per fare le ghirlande con I glicini (maggiociondolo), I margheritoni e le rose, quando portavano la madonna, una domenica di maggio. (VMA).

Notas Le rose antiche avevano un odore fortissimo, non come quelle di ora.

\section{Rosa 'Híbrido de te'}

Nombre vulgar: Rose (BBA). 
Número de informantes: 1 Número de citas: 1.

Número de sectores: 1 Número de categorías: 1 .

Biotipo: Nanofanerófito.

Tipo corológico: Cultivadas.

Abundancia: Cultivada.

Ambiente: Jardines y huertos.

Sector doméstico

Categoría de uso: Jardín.

Número de informantes: 1 Partes utilizadas: planta entera/viva.

Coltivati nel giardino per abbelire la casa (BBA).

\section{Rubus 'European Blackberry' agregado}

Nombre vulgar: More domestiche (LST, MGO), More (TAD).

Número de informantes: 3 Número de citas: 4.

Número de sectores: 2 Número de categorías: 4.

Biotipo: Nanofanerófito.

Tipo corológico: Cultivadas.

Abundancia: Cultivada.

Ambiente: Cultivado en huertos.

Sector alimentario

Categoría de uso: Conserva de frutas.

Número de informantes: 1 Partes utilizadas: frutos/infrutescencias/falsos frutos.

Mettere I frutti in una pentola, e strizzarli con le mani, lasciare 8 giorni a fermentare.

Poi collare I frutti con un telo, e alla fine aggiungere la stessa quantità di zucchero.

Poi allungare con l'acqua e bere per la tosse. (MGO).

Categoría de uso: Dulces y golosinas.

Número de informantes: 1 Partes utilizadas: frutos/infrutescencias/falsos frutos.

Per decorare le torte di frutta. Tutti la coltivavamo nell' orto uva spina, more e lamponi.

Categoría de uso: Mermelada.

Número de informantes: 1 Partes utilizadas: frutos/infrutescencias/falsos frutos.

Prendere $1 \mathrm{~kg}$ o $2 \mathrm{~kg}$ di more domestiche e aggiungere 800 o 850 gr di zucchero, farlo bollire un oretta e passarlo con il passaverdure poi farla bollire per 20 minuti di nuovo. Imbarattolare e chiudere e mettere a testa in giù. (LST).

\section{Sector medicinal}

Categoría de uso: Afecciones del aparato respiratorio.

Número de informantes: 1 Partes utilizadas: frutos/infrutescencias/falsos frutos.

Mettere I frutti in una pentola, e strizzarli con le mani, lasciare 8 giorni a fermentare. Poi collare I frutti con un telo, e alla fine aggiungere la stessa quantità di zucchero. Poi allungare con l'acqua e bere per la tosse. (MGO). 


\section{Rubus hirtus Waldst. \& Kit.}

Nombre vulgar: Rovo (CRI, VMR, MGO), More, Rovo selvatico (MGE), More dei rovi, Rovi (VMR).

Número de informantes: 4 Número de citas: 6.

Número de sectores: 3 Número de categorías: 4.

Biotipo: Nanofanerófito.

Tipo corológico: Europeas.

Abundancia: Común.

Ambiente: Hayedos y bosques mesófilos.

Número de exsiccata: 38890 FIAF.

Sector alimentario

Categoría de uso: Conserva de frutas.

Número de informantes: 2 Partes utilizadas: frutos/infrutescencias/falsos frutos.

Mettere I frutti in una pentola, strizzarli con le mani e lasciare otto giorni a fermentare. Poi colare I frutti con un telo e alla fine aggiungere la stessa quantità di zucchero. (MGO)| Lo sciroppo':Sbollentare I rovi strizzare I frutti oppure passarli per il passaverdure. Fare a parte uno sciroppo di acqua e zucchero, dopo averlo fatto raffreddare, mescolare ai frutti. Poi filtrare tutto con un tovagliolino di lino, imbottigliare e bollire 20 minuti per sterilizzare (VMR).

Categoría de uso: Mermelada.

Número de informantes: 2 Partes utilizadas: frutos/infrutescencias/falsos frutos.

Con le more di rovo selvatico si fa la marmellata: bollire I frutti per poco tempo, passarli per il setaccio (a posta per togliere I semini), il liquido si fa bollire per 5 ore insieme allo zucchero, poi si mettono nei vasi e così si conservano.Non si ricorda delle quantità. (MGE)| non specificato (VMR).

Sector mágico/medicinal

Categoría de uso: Otro mágico/medicinal.

Número de informantes: 1 Partes utilizadas: hojas.

Contro gli eczemi: A digiuno, prima del levare del sole, prendere la foglia al rovescio e spruzzare l' acqua della rugiada che c'è nella parte inferiore della foglia dove c'è il male. Ripetere per tre mattine. (CRI).

Sector medicinal

Categoría de uso: Patologías del aparato digestivo.

Número de informantes: 1 Partes utilizadas: frutos/infrutescencias/falsos frutos.

Mangiare I le more dei rovi contro la diarrea (VMR).

DATOS ETNOBOTÁNICOS BIBLIOGRÁFICOS

Nombre vulgar: rovo (MANG98), more (GRIZ03).

Número de referencias: 2 Número de citas: 4.

Número de sectores: 2 Número de categorías: 3 .

Sector alimentario

Categoría de uso: Mermelada. 
Número de referencias: 2 Partes utilizadas: hojas, frutos/infrutescencias/falsos frutos.

Con le more il tutto il territorio si preparano marmellate, sciroppi e torte. (MANG98)| Marmellata di more: more selvatiche $2 \mathrm{~kg}$, zucchero $1 \mathrm{~kg}$, limoni 2, acqua $1 / 2$ bicchiere. Lavare le more in acqua fredda, sgocciolare bene, intanto far bollire l'acqua per 2 o $3 \mathrm{~m}$ inuti con lo zucchero e I limoni spremuti, quando bolle versare le more, lasciare fereme mezza giornata. Mettere a bollire il tutto chiumando ogni tanto, quando è abbastanza denso invasare in vasetti ermetici finchè il composto è bollente. (GRIZ03).

\section{Sector medicinal}

Categoría de uso: Afecciones cutáneas y tejidos subcutáneos.

Número de referencias: 1 Partes utilizadas: hojas.

La pagina inferiore della foglia fresca, privata del rivestimento, si applica sulle ferite. (MANG98).

Categoría de uso: Afecciones del aparato respiratorio.

Número de referencias: 1 Partes utilizadas: brotes.

Le cime bollite in acqua forniscono un valido rimedio contro la tosse, in caso di mal di gola vengono applicate localmente foglie fresche riscaldate e se ne beve l'infuso.lo sciroppo oltre che come alimento, è bevuto caldo in caso di bronchite. (MANG98).

\section{Rubus idaeus $L$.}

Nombre vulgar: Lampone (MIO, AN3, MVI, LGI, MSR, MRI, GZE, MGO, LST, BOR), Lamponi (GCL, TAD, MGE, GLA, GGI, GFR, GAN, FAM, BBA, SOT, BGI), Lampone selvatico (TIV, CVA, BPT), Lamponi selvatici (MGO).

Número de informantes: 24 Número de citas: 42.

Número de sectores: 2 Número de categorías: 8 .

Biotipo: Nanofanerófito.

Tipo corológico: Nórdicas.

Abundancia: Común.

Ambiente: Desmontes y aclarados de bosques (hayedos, abetos), nitrófilo.

Número de exsiccata: 38899 FIAF.

\section{Sector alimentario}

Categoría de uso: Bebida.

Número de informantes: 3 Partes utilizadas: frutos/infrutescencias/falsos frutos.

Sciroppo di lampone: mettere la frutta a macerare qualche giorno con lo zucchero, poi colare il tutto e imbottigliare. Va bevuto allungato come bevanda. (BOR) Lamponata, si fa bollendo leggermente $\mathrm{i}$ frutti, filtrare per togliere $\mathrm{i}$ semi ed aggiungere un pò di zucchero, imbottigliare e chiudere, si conserva fino al inverno. (BGI)| non specificato (SOT).

Categoría de uso: Conserva de frutas.

Número de informantes: 12 Partes utilizadas: frutos/infrutescencias/falsos frutos. Lo sciroppo di lamponi è una bevanda dissetante, può essere diluito nell'acqua d'estate oppure bevuto anche da solo, oppure messo anche sul dolce. Ricetta dello 


\section{María Teresa Egea Molines}

sciroppo: raccogliere la frutta matura, metterla in un secchio o un tino, chiuderlo con un canovaccio perché prenda il meno area possibile. Lasciare riposare 4 o 5 giorni, (deve formarsi una sorta di muffa sopra).Poi strizzarli con le mani per estrarre il succo e togliere i frutti senza succo. Dipende da quanto ne viene fuori. Per un tino piccolo o un secchio ne va messo $1 \mathrm{~kg}$ o 800 gr. di zucchero. Fare bollire il succo con lo zucchero 10 o 15 minuti, poi si imbarattola calda, si chiude e si mette alla rovescia. (LST)| Mettere I frutti in una pentola, strizzarli con le mani, lasciare 8 giorni a fermentare. Poi colare I frutti con un telo e alla fine aggiungere la stessa quantità di zucchero. (MGO)| Si faceva uno sciroppo con i lamponi selvatici, la 'lamponata'. Lamponi raccolti, schiacciati, messi a bollire con poco zucchero, si fanno fermentare, poi il liquido viene riscaldato e filtrato. Era una "bevanda per ammazzare 1' acqua". (BPT)| Sciroppo di lamponi. Raccogliere i lamponi, lasciarli una settimana in un secchio, finché viene sopra la muffa. Strizzare con un panno e aggiungere per un litro di succo un chilo di zucchero, inbarattolare e lasciare 30 o 40 giorni al sole. Al volte scoppiava. Ultimamente si fanno bollire $30 \mathrm{~min}$. invece di lasciare al sole 30 giorni. Si beve diluito, metà sciroppo di lampone e metà acqua. (CVA)| Lasciavano in un secchio un po' di giorni a fermentare, poi strizzavano, filtravano il succo dei lamponi e aggiungevano zucchero. (TIV)| Strizzare I lamponi, mettere qualche giorno in una bacinella a fermentare, passare per il passaverdure. Non si ricorda se lo bollivano o no. (BBA)| Raccolti i lamponi, si lasciano a fermentare in un secchio per otto giorni all' area aperta senza coprirlo, perché i moscerini possano andare sopra. Poi si filtra con un telo di lino per levare i semi, si strizza bene, e si fa bollire con l' acqua. (FAM)| Riempire un barattolo di lamponi e coprire la superficie di zucchero, chiudere e mettere al sole per 40 giorni (FAM) Mettere a macerare I frutti maturi con un po' di zucchero per due notti, poi passarli per un canovaccio e un collino. Bollire il liquido per un po' e imbottigliare. (GAN) Mettere $\mathrm{i}$ frutti in una botiglia e metterla al sole, aggiungere zucchero e prendere allungato con il doppio d'acqua. (GFR)| La sua mamma faceva lo sciroppo di Lamponi schiacciare bene la frutta e lasciare riposare in un secchio per 5 o 6 giorni per evitare che I moscerini ci vadano sopra, poi la buccia viene su e sotto rimane la polpa. Poi strizzarli con un canovaccio o con il passaverdure (passapomodori). Poi si può fare in due maniere diverse: Aggiungere metà dello zucchero della quantità di frutta (500 o 600 gr per un litro di succo), fare bollire un pò e imbottigliare. Oppure aggiungere 500 o 600 gr per un litro di succo, imbottigliare, chiudere e lasciare al sole per 40 giorni. Però quest'ultimo ha il rischio che dopo può continuare a fermentare e può scoppiare..I sciroppi erano un concentrato, si usavano sopratutto d'estate per dissetare, dopo di essere stato nei campi si diluiva nell'acqua $1 / 3$ di sciroppo per $2 / 3$ di acqua. (GGI)| Lavare I frutti, metterli in un ciotola tritati con la mani e lasciarli a macerare per 20 giorni, girando tutte le mattine. Poi filtrare con un fazzoletto, bollire il succo con lo zucchero (per un kg di liquido, 800 gr di zucchero) per 2 o 3 min., lasciare raffredare e imbottigliare. È importante lasciare raffredare prima di imbottigliare perché sennò fa la muffa ( "I fiori") (GLA)| Si faceva lo sciroppo di lamponi fare fermentare un pò di giorni I lamponi settacciarli, aggiungere lo zucchero e imbottigliare. Non si faceva bollire, poi si allungava con l'acqua. (MGE).

Categoría de uso: Dulces y golosinas. 
Número de informantes: 2 Partes utilizadas: frutos/infrutescencias/falsos frutos. Lo sciroppo di lamponi è una bevanda dissetante, può essere diluito nell'acqua d'estate oppure bevuto anche da solo, oppure messo anche sul dolce. Ricetta dello sciroppo: raccogliere la frutta matura, metterla in un secchio o un tino, chiuderlo con un canovaccio perché prenda il meno area possibile. Lasciare riposare 4 o 5 giorni, (deve formarsi una sorta di muffa sopra).Poi strizzarli con le mani per estrarre il succo e togliere i frutti senza succo. Dipende da quanto ne viene fuori. Per un tino piccolo o un secchio ne va messo $1 \mathrm{~kg}$ o 800 gr. di zucchero. Fare bollire il succo con lo zucchero 10 o 15 minuti, poi si imbarattola calda, si chiude e si mette alla rovescia. (LST)| Per decorare le torte di frutta. Tutti la coltivavamo nell' orto uva spina, more e lamponi (TAD).

Categoría de uso: Fruta fresca.

Número de informantes: 5 Partes utilizadas: frutos/infrutescencias/falsos frutos.

Si mangiavano come frutta fresca. (GZE)| Consumati come frutta fresca. (MSR, MRI)|.

Mangiate fresche (BBA)| Mangiare i lamponi freschi come frutta. (GCL).

Categoría de uso: Golosinas y masticatorias.

Número de informantes: 1 Partes utilizadas: frutos/infrutescencias/falsos frutos.

Quando si andava dietro alle pecore, non si sapeva cosa fare, e via via si mangiavano e si.

ciucciavano questi frutti che si trovavano nei cigli a cespugli. (LGI).

Categoría de uso: Licor.

Número de informantes: 3 Partes utilizadas: frutos/infrutescencias/falsos frutos. Mettere a macerare un chilo di frutta in un litro di alcol, un litro di acqua e un $\mathrm{kg}$ di zucchero, per minimo un anno. Poi si può filtrare, oppure lasciare la frutta dentro e mangiarla via via. $\mathrm{O}$ si può lasciare quanto si vuole nell'alcol, piu ci sta meglio è, anche 5 o 6 anni.. (MVI, GZE)| Non si ricorda (BBA).

Categoría de uso: Mermelada.

Número de informantes: 8 Partes utilizadas: frutos/infrutescencias/falsos frutos. Mettere a macerare I frutti di lamponi per 24 ore e coperti di zucchero, all'area. Per 3 $\mathrm{kg}$ di frutta, $1 \mathrm{~kg}$ di zucchero. Dopo si fanno bollire per 3 o 4 ore e si imbarattolano (AN3)| non specificato (SOT, MVI, GZE)| Bollire I frutti per 2 o 3 ore, poi filtrare tutto per togliere I semini, e aggiungere la stessa quantità di zucchero. Quando ancora è bollente, mettere nei vasi caldi,lasciare raffreddare e poi tapparli quando sono raffreddati (MGO)| Mettere a bollire un $\mathrm{kg}$ di lamponi con 500 grammi di zucchero, per 3 o 4 ore finché la marmellata sia abbastanza ritirata. (MIO)| Messi a bollire con meno della meta di zucchero. (BGI)| Bollire i frutti per un po, aggiungere $1^{\prime} 80 \%$ di zucchero, continuare a bollire per un altro po, mettere subito in barattoli e chiudere. (GFR).

Sector doméstico

Categoría de uso: Integración de la renta familiar.

Número de informantes: 7 Partes utilizadas: frutos/infrutescencias/falsos frutos.

In poco tempo facevano dei kili, e le vendevano a Porretta. (GZE)| Si vendevano messi in un paniere piccolo fatto di vimini (GGI)| Mamma vendeva le fragole, le more, I lamponi alla gente di fuori (BOR)| Venduti sulla porrettana ai passanti 
(GFR)| Era l'unica cosa che veniva gestito dai bambini, il resto delle risorse era gestito dal capofamiglia. I bambini andavano a raccogliere I lamponi e le fragole a Foragati (sopra Stagno), e poi li vendevano (MRI)| Frutti raccolti nel giardino e venduti a Porretta (MSR) $\mid$ Li vendevano a Treppio a gente di Porretta che venivano a comprarli, forse per gelateria. (MGO).

Notas Non ci sono piu per colpa dei cervi, Ora non ci sono piu lamponi, Non ci sono piu, perché il bosco è abbandonato, e mangiano tutto i cervi, Alla pidocchina, C'erano le lamponaie una volta, sul Monte la Pidocchina, a Pianezzi, Case Sarti, Cavanna era pieno, ora sono scomparse tutte per I daini...Ma non lo facevano in tutte le case, lo faceva chi aveva la volontà di andare sulle montagne a raccogliere. I sciroppi erano un concentrato, si usavano sopratutto d'estate per dissetare, dopo di essere stato nei campi si diluiva nell'acqua $1 / 3$ di sciroppo per $2 / 3$ di acqua. "Ma da mangiare tanti lamponi, viene la cistite" A Lastrone hanno coltivato tante piante e D'estate le sue piante facevano fino a $70 \mathrm{~kg}$.

DATOS ETNOBOTÁNICOS BIBLIOGRÁFICOS

Nombre vulgar: framboa (UNGA21).

Número de referencias: 1 Número de citas: 1.

Número de sectores: 1 Número de categorías: 1.

\section{Sector alimentario}

Categoría de uso: Conserva de frutas.

Número de referencias: 1 Partes utilizadas: frutos/infrutescencias/falsos frutos.

lampone, frutice spont. In montagna e coltivata negli orti, usato in farmacia per sciroppo con nome di rovo ideo. Sull'appennino se ne preparano gelatine e composte, di cui si fa esteso commercio. (UNGA21).

\section{Rubus ulmifolius Schott.}

Nombre vulgar: Raggie (NDI, BEL, CFR, VMR, NRO, VSI), Spini, Rovo (NLA), Raggia (CLO, CRI, RIV), Rovo (BGI, BLI, NLA, SOT), More (EMA, BOR, MSR, MSI, BPA, AMA, LGI, RMA, QNE, BSI, BAT, BAN, CVA, BPT), More, Rovo di bosco (LST), Raggie selvatiche (MGO), Ragge (MMR, LGI, RFR, PIM), Rovi, more (BAN, BSO), More da rovo (VMA), More selvatiche (AN3, VMA), Proniccioni bassi (CRO), Rovici (UMI), Spini (NLA).

Número de informantes: 39 Número de citas: 54.

Número de sectores: 5 Número de categorías: 18.

Biotipo: Nanofanerófito.

Tipo corológico: Eurimediterránea.

Abundancia: Común.

Ambiente: Setos, baldíos, bosques de monte bajo.

Número de exsiccata: 38970 FIAF, 38896 FIAF.

Sector agropastoral

Categoría de uso: Cuerdas y ataduras.

Número de informantes: 1 Partes utilizadas: tallos leñosos/ramas/ramitas/vástagos. 
Le grosse raggie si mettevano a bagno, con il pennato si toglievano le spine e si usavano per.

legare il grano (VSI).

Categoría de uso: Herramientas y objetos agrícolas.

Número de informantes: 1 Partes utilizadas: parte aérea (toda).

Per fare scope per pulire il castagneto "le grana'de":Si raccoglievano e si mettevano sopra un.

lastra di pietra per farle seccare con la forma di scopa (NLA).

Categoría de uso: Horticultura.

Número de informantes: 1 Partes utilizadas: parte aérea (toda).

Concime per il 'marciolo' (grano di altitudine). Quando pulivano i campi, tutte le raggie, le ginestre e gli altri arbusti e erbe si ammucchiavano e si copriva con la "pellice" (l' erba): queste erano le 'iove'. Poi gli davano fuoco e il carbone risultante con la cenere si spargeva per il campo e dava vigoria alla terra. Quando la terra o il marciolo non erano forti si diceva "metteli 2 iove!" (CLO).

Categoría de uso: Otro agropastoral.

Número de informantes: 1 Partes utilizadas: planta entera/viva.

Concime per il marciolo (grano di altitudine): Quando pulivano i campi, tutte le raggie, le ginestre, e gli arbusti e le erbe, si amucchiavano e si copriva con la "pellice"(l' erba), queste erano le iove. Poi le davano fuoco, e il carbone risultante con la cenere si spargeva per il campo e li dava vigoria alla terra.Cosi pulivano il campo e facevano il concime allo stesso tempo.Quando la terra o il marzolo non erano forti si diceva "metteli 2 iove!" (CLO).

\section{Sector alimentario}

Categoría de uso: Bebida.

Número de informantes: 1 Partes utilizadas: frutos/infrutescencias/falsos frutos. non specificato (SOT).

Categoría de uso: Conserva de frutas.

Número de informantes: 5 Partes utilizadas: frutos/infrutescencias/falsos frutos.

Raccolte, schiacciate, messe a bollire con poco zucchero,si fanno fermentare, poi il liquido viene riscaldato e filtrato (BPT)| Raccogliere le more, lasciarle una settimana in un secchio, finché viene sopra la muffa. Strizzare con un panno e aggiungere un chilo di zucchero per un litro di succo, imbarattolare e lasciare 30 o 40 giorni al sole. Al volte scoppiava. Lo sciroppo di more è piu dolciastro di quello di lamponi. (CVA)| Lo sciroppo di more è una bevanda dissetante, può essere diluito nell'acqua d'estate oppure bevuto anche da solo, oppure messo anche sul dolce. Ricetta dello sciroppo: raccogliere la frutta matura, metterla in un secchio o un tino, chiuderlo con un canovaccio perché prenda il meno area possibile. Lasciare riposare 4 o 5 giorni, (deve formarsi una sorta di muffa sopra).Poi strizzarli con le mani per estrarre il succo e togliere i frutti senza succo. Dipende da quanto ne viene fuori. Per un tino piccolo o un secchio ne va messo $1 \mathrm{~kg}$ o 800 gr. di zucchero. Fare bollire il succo con lo zucchero 10 o 15 minuti, poi si imbarattola calda, si chiude e si mette alla rovescia. (LST)| In una bacinella, mettere a fermentare per 2 giorni le more, così le bucce e I semi salgono a galla. Filtrare con un panno di canapa, poi bollire 5 minuti: $1 \mathrm{~kg}$ liquido per $1 \mathrm{~kg}$ di zucchero. E dissetante, allungato con dell' acqua. (NRO)| Lo 


\section{María Teresa Egea Molines}

sciroppo':Sbollentare le raggie strizzare I frutti oppure passarli per il passaverdure. Fare a parte uno sciroppo di acqua e zucchero, dopo averlo fatto raffreddare, mescolare ai frutti. Poi filtrare tutto con un tovagliolino di lino, imbottigliare e bollire 20 minuti per sterilizzare (VMR).

Categoría de uso: Dulces y golosinas.

Número de informantes: 2 Partes utilizadas: frutos/infrutescencias/falsos frutos.

Lo sciroppo di more è una bevanda dissetante, può essere diluito nell'acqua d'estate oppure bevuto anche da solo, oppure messo anche sul dolce. Ricetta dello sciroppo: raccogliere la frutta matura, metterla in un secchio o un tino, chiuderlo con un canovaccio perché prenda il meno area possibile. Lasciare riposare 4 o 5 giorni, (deve formarsi una sorta di muffa sopra).Poi strizzarli con le mani per estrarre il succo e togliere i frutti senza succo. Dipende da quanto ne viene fuori. Per un tino piccolo o un secchio ne va messo $1 \mathrm{~kg}$ o 800 gr. di zucchero. Fare bollire il succo con lo zucchero 10 o 15 minuti, poi si imbarattola calda, si chiude e si mette alla rovescia. (LST)| Si usavano I frutti di raggie per decorare le torte (CFR).

Categoría de uso: Fruta fresca.

Número de informantes: 6 Partes utilizadas: frutos/infrutescencias/falsos frutos.

Come dessert, si mangiavano le more con vino e zucchero. (QNE, BSI, BAT, BAN)| Frutti.

consumati freschi. (RMA)| Si mangiano come frutta fresca. (MGO).

Categoría de uso: Golosinas y masticatorias.

Número de informantes: 6 Partes utilizadas: frutos/infrutescencias/falsos frutos, brotes.

Quando si andava dietro alle pecore, non si sapeva cosa fare, e via via si mangiavano e si ciucciavano questi frutti che si trovavano nei cigli a cespugli. (LGI) $\mid$ I bambini mangiavano le 'punte' delle raggie o peterlenghe. (PIM) $\mid$ I germogli spellati si mangiavano nei campi, erano piu amari di quelli delle rose canine. (BEL) Le punte tenere delle raggie spellate si mangiavano crude quando si camminava. (NDI)| A primavera, quando si tornava di scuola, si prendevano le punte delle raggie, si spellavano e si mangiavano. (NRO) $\mid$ I germogli spellati si mangiavano nei campi, (BSO).

Categoría de uso: Licor.

Número de informantes: 2 Partes utilizadas: frutos/infrutescencias/falsos frutos. Il 'morino' è fatto di un kg di more, messe a macerare 2 settimane, con 5 etti di zucchero e un po' di alcol. Poi va passato per togliere i semi, e può venire allungato con l'acqua come bevanda. (AMA) $1 \mathrm{~kg}$ di more selvatiche, $600 \mathrm{gr}$ di alcol, $600 \mathrm{gr}$ di zucchero, 500 gra di acqua, Lasciare macerare per 40 giorni le more nell'alcol, aggiungere il sciroppo fatto con bollendo l'acqua e lo zucchero. Filtrare, passare le more, filtrare di nuovo e imbottigliare (AN3).

Categoría de uso: Mermelada.

Número de informantes: 14 Partes utilizadas: frutos/infrutescencias/falsos frutos. non specificato (SOT, VMR, BPT, BPA)| Pulire la frutta, pesarla, aggiungere $500 \mathrm{gr}$ di zucchero per $1 \mathrm{~kg}$ di frutta, lasciare fermentare per 24 ore e poi fare bollire fino alla consistenza voluta (dipende dalla qualità della frutta). (MSI)| Mettere a macerare per una notte le more con lo zucchero (per un $\mathrm{kg}$ di frutta, $600 \mathrm{gr}$ di zucchero). Poi cuocere il tutto per 4 o 5 ore, passarlo con il passaverdura e 
aggiungere un po' di succo di limone o di arancio. Mettere nei vasi quando ancora bolle, tapparli subito e metterli a capo all'ingiù. (MSR)| Fare bollire I frutti, e poi passarle al setaccio e aggiungere zucchero alla fine bollendo un altro po. (NLA)| I frutti vengono passati per toglierli I semii e poi si mettono a macerare I frutti di more per 24 ore, coprire di zucchero, all'area. Per $3 \mathrm{~kg}$ di frutta, $1 \mathrm{~kg}$ di zucchero. Dopo si fanno bollire per 3 o 4 ore e si imbarattolano (AN3)| Facevano le marmellate con le more dei rovi, perché ce n'era di piú (VMA)| Fare bollire I proniccioni bassi, settacciare per togliere I semini (con il setaccio della farina) e aggiungere zucchero, lasciare bollire finché non raggiunge la consistenza giusta (CRO) $\mid$ Con i frutti si fa la marmellata (CRI)| Fanno la marmellata di raggie (l'ha visto fare) non sa la ricetta. (CFR)| Prendere le more di raggie o di more, purlirle, farle bollire con un goccino d'acqua, si fa adensare, si passa per il passapomodori, pesare la polpa. E aggiungere 4 etti di zucchero per $1 \mathrm{~kg}$ di more. Fare bollire un altro pò, si sciogle lo zucchero, si imbarattola e si fa il sottovuoto facendoli bollire per 30 minuti con degli stracci in mezzo. (RNI)| Messi a bollire con meno della metà di zucchero. (BGI).

Categoría de uso: Tortilla.

Número de informantes: 2 Partes utilizadas: brotes.

Le punte tenere delle raggie soffritte e fatte come frittata. (RFR)| Punte di rovici (more) teneri raccolti a primavera, sbollentati e messi nella frittata. (UMI).

\section{Sector doméstico}

Categoría de uso: Integración de la renta familiar.

Número de informantes: 3 Partes utilizadas: frutos/infrutescencias/falsos frutos.

Mamma vendeva le fragole, le more, I lamponi alla gente di fuori (BOR)| Si raccogiievano le more e si vendevano (EMA)| Il babbo raccoglieva tutti questi frutti e poi li vendeva a un signore che li raccoglieva tutti. (RMA)| Oltre a essere consumate fresche, le more venivano raccolte e vendute come integrazione del reddito.Il babbo le raccoglieva insieme ad altri frutti e poi li vendeva a un signore che li raccoglieva tutti. (RMA).

Categoría de uso: Tintorial.

Número de informantes: 1 Partes utilizadas: frutos/infrutescencias/falsos frutos.

Per tingere la lana in rosso-viola: mettere a bollire la lana con acqua e more, e poi immergere in acqua e aceto. (BLI).

\section{Sector mágico/medicinal}

Categoría de uso: Otro mágico/medicinal.

Número de informantes: 2 Partes utilizadas: tallos herbáceos/escapos, hojas.

Quando un travaglio di parto durava molto a lungo, pulivano dalle spine un ramo di raggia e lo legavano intorno alla pancia della donna, coperto da una fascia. (CRE) La sua mamma segnava gli eczemi, recitando delle preghiere e passando la foglia di raggia sull'eczema. (TIV).

\section{Sector medicinal}

Categoría de uso: Afecciones cutáneas y tejidos subcutáneos.

Número de informantes: 1 Partes utilizadas: hojas.

Con le foglie fresche si faceva un pesto e si metteva sopra. (CLO). 
Categoría de uso: Afecciones del aparato respiratorio.

Número de informantes: 1 Partes utilizadas: tallos leñosos/ramas/ramitas/vástagos.

Fare un decotto dei polloni teneri di raggie selvatiche e fare gargarismi di tanto in tanto.

Categoría de uso: Afecciones oro-faríngeas y de la cavidad oral.

Número de informantes: 3 Partes utilizadas: flores/inflorescencias y sus partes.

Fare bollire un po' di foglie di raggie secche o fresche e fare dei gargarismi 2 o 3 volte al giorno. Le foglie si possono raccogliere, seccare e mettere in un vasetto per conservarle. (MMR, LGI)| Bollire 2 o 3 minuti le foglie di rovo e bere per il mal di gola (BAN).

DATOS ETNOBOTÁNICOS BIBLIOGRÁFICOS

Nombre vulgar: rovo, râza (SANS14), rovo (MANG98), more (GRIZ03), râza, maura d'râza (UNGA21), Raggia (APPO10), raggia (BENE96), rovo, ràggia (GUC98).

Número de referencias: 7 Número de citas: 12 .

Número de sectores: 2 Número de categorías: 7.

Sector alimentario

Categoría de uso: Conserva de frutas.

Número de referencias: 1 Partes utilizadas: frutos/infrutescencias/falsos frutos, brotes (SANS14).

Categoría de uso: Fruta fresca.

Número de referencias: 1 Partes utilizadas: frutos/infrutescencias/falsos frutos, brotes (SANS14).

Categoría de uso: Golosinas y masticatorias.

Número de referencias: 1 Partes utilizadas: frutos/infrutescencias/falsos frutos, brotes (SANS14).

Categoría de uso: Licor.

Número de referencias: 1 Partes utilizadas: frutos/infrutescencias/falsos frutos, brotes (SANS14).

Categoría de uso: Mermelada.

Número de referencias: 2 Partes utilizadas: hojas, frutos/infrutescencias/falsos frutos.

Con le more il tutto il territorio si preparano marmellate, sciroppi e torte. (MANG98)| Marmellata di more: more selvatiche $2 \mathrm{~kg}$, zucchero $1 \mathrm{~kg}$, limoni 2, acqua $1 / 2$ bicchiere. Lavare le more in acqua fredda, sgocciolare bene, intanto far bollire l'acqua per 2 o $3 \mathrm{~m}$ inuti con lo zucchero e I limoni spremuti, quando bolle versare le more, lasciare fereme mezza giornata. Mettere a bollire il tutto chiumando ogni tanto, quando è abbastanza denso invasare in vasetti ermetici finchè il composto è bollente. (GRIZ03).

\section{Sector medicinal}

Categoría de uso: Afecciones cutáneas y tejidos subcutáneos.

Número de referencias: 1 Partes utilizadas: hojas. 
La pagina inferiore della foglia fresca, privata del rivestimento, si applica sulle ferite. (MANG98).

Categoría de uso: Afecciones del aparato respiratorio.

Número de referencias: 2 Partes utilizadas: brotes, frutos/infrutescencias/falsos frutos.

Le cime bollite in acqua forniscono un valido rimedio contro la tosse, in caso di mal di gola vengono applicate localmente foglie fresche riscaldate e se ne beve l'infuso.lo sciroppo oltre che come alimento, è bevuto caldo in caso di bronchite. (MANG98)|.

\section{Sanguisorba minor Scop.}

Nombre vulgar: Pimpinella (SCO, NRE, GGL), Salvastrella (TRU).

Número de informantes: 4 Número de citas: 4.

Número de sectores: 1 Número de categorías: 1.

Biotipo: Hemicriptófito.

Tipo corológico: Europeas.

Abundancia: Común.

Ambiente: Prados áridos, garrigas, baldíos.

Número de exsiccata: 39073 FIAF.

Sector alimentario

Categoría de uso: Ensalada.

Número de informantes: 4 Partes utilizadas: hojas.

Le foglie crude si mettono nell'insalata come la rucola. (GGL)| Mettere le foglie crude in insalata con altre erbe. (NRE) $\mid$ Foglie di pimpinella insieme alla radice di raponzolo in insalata conditi con olio e sale (SCO)| Mettere in insalata con altre foglie. Dà un gusto buono all'insalata (TRU).

Notas Ora non si trovano più perché I terreni sono incolti., Prima era pieno di salvastrella, ora non ce n'è più perché gli animali hanno mangiato tutto.

DATOS ETNOBOTÁNICOS BIBLIOGRÁFICOS

Nombre vulgar: pimpinella (SANS14), armi danza,pimpinaella (UNGA21), pimpinaella (UNGA21).

Número de referencias: 2 Número de citas: 7.

Número de sectores: 4 Número de categorías: 6 .

Sector alimentario

Categoría de uso: Ensalada.

Número de referencias: 2 Partes utilizadas: hojas (SANS14).

Erba dei campi coltivata negli orti per insalata (UNGA21).

Sector mágico/medicinal

Categoría de uso: Otro mágico/medicinal.

Número de referencias: 1 Partes utilizadas: órganos subterráneos.

Le fatucchiere di campagna fanno credere che...tal radice sulla sua persona non possa mai.

divenire incinta. (UNGA21). 


\section{María Teresa Egea Molines}

Categoría de uso: Preventivo de enfermedades.

Número de referencias: 1 Partes utilizadas: órganos subterráneos.

Le fatucchiere di campagna fanno credere che la radice di quest'erba pestata e posta sulla.

carne nuda preservi da qualsiasi contagio (UNGA21).

Sector mágico/ritual/supersticioso

Categoría de uso: Adivinatorio.

Número de referencias: 1 Partes utilizadas: flores/inflorescencias y sus partes.

Il fiore della pimpinella s'apre, quando il tempo vuol cambiare. (UNGA21).

Categoría de uso: Otro mágico/ritual/supersticioso.

Número de referencias: 1 Partes utilizadas: órganos subterráneos.

Le fatucchiere di campagna fanno credere che la radice di quest'erba e posta sulla carne nuda preservi da qualsiasi contagio e che la donna che porta tal radice sulla sua persona non possa mai divernire incinta. (UNGA21).

\section{Sector medicinal}

Categoría de uso: Patologías del aparato digestivo.

Número de referencias: 1 Partes utilizadas: parte aérea (toda).

La pimpinella entra nella composizione dell'acqua della Masotta (UNGA21).

Notas L'insalae l'an è bôna e l'an è boela, quand'an j'aintra la pimpinaella. Il fiore della pimpinella s'apre quando il tempo vuol cambiare.

\section{Sorbus aria (L.) Crantz}

Nombre vulgar: (TIV)Sorbo (BPT), Lane (NLA, GFR), Lano (NRO, VMR, CFR, SLU, GGI), Ciliegio lane (BPI), Lane, Ciliegio lano (GGI), Lani (PCL).

Número de informantes: 11 Número de citas: 17.

Número de sectores: 5 Número de categorías: 7.

Biotipo: Fanerófito.

Tipo corológico: Europeas.

Abundancia: Común.

Ambiente: Bosques de latifolios (sobre todo robledales).

Sector agropastoral

Categoría de uso: Herramientas y objetos agrícolas.

Número de informantes: 1 Partes utilizadas: tallos leñosos/ramas/ramitas/vástagos.

Mazza di legno per spaccare la legna (BPT).

Sector alimentario

Categoría de uso: Fruta fresca.

Número de informantes: 3 Partes utilizadas: frutos/infrutescencias/falsos frutos.

Il frutto matura d' estate. (GFR)| Mangiati come frutta al naturale (GGI)| Al naturale (SLU).

Categoría de uso: Golosinas y masticatorias.

Número de informantes: 3 Partes utilizadas: frutos/infrutescencias/falsos frutos. 
Etnobotánica en el Alto Valle del Reno (Toscana y Emilia-Romaña, Italia)

Le bacche si mangiano quando sono molto mature (GGI, BPI)| Si mangiava cosi, dall'albero..

(CFR).

Categoría de uso: Mermelada.

Número de informantes: 3 Partes utilizadas: frutos/infrutescencias/falsos frutos.

Fare bollire "le nappe", e poi passarle al setaccio e aggiungere zucchero alla fine bollendo un altro po. (NLA)| Fare la marmellata con I frutti maturi dei lani, era astringente (VMR)| Fare bollire "le nappe", e poi passarle al setaccio e aggiungere zucchero. (TIV).

Sector caza y pesca

Categoría de uso: Caza de pájaros.

Número de informantes: 5 Partes utilizadas: planta entera/viva,.

I cacciatori ci facevano sotto il capanno per cacciare i merli. (VMR, GGI)| Si mettevano sotto il lano per cacciare gli uccelli che andavano a mangiarsi I frutti (PCL)| I cacciatori si mettono sotto l'albero mentre I merli ed I tordi vanno a mangiare I frutti del lano. (TIV)| Si mettevano sotto agli alberi di lano per cacciare I merli (NRO).

Sector doméstico

Categoría de uso: Chimenea y horno.

Número de informantes: 1 Partes utilizadas: madera.

Legno ottimo da ardere, meglio che il castagno (GGI).

Sector medicinal

Categoría de uso: Patologías del aparato digestivo.

Número de informantes: 1 Partes utilizadas: frutos/infrutescencias/falsos frutos.

Mangiare a cucchiate la marmellata di lane come astringente per la diarrea finché passase.

(VMR).

Notas "ci sono due qualità di lane che fanno I frutti con sapori diversi: una fa I frutti farinacei e dolci e si mangiavano come le peterlenghe (spuntino campestre) e le altre sono morbide però legano di più".

DATOS ETNOBOTÁNICOS BIBLIOGRÁFICOS

Nombre vulgar: mattallo (MANG98).

Número de referencias: 1 Número de citas: 1.

Número de sectores: 1 Número de categorías: 1.

\section{Sector medicinal}

Categoría de uso: Patologías del aparato digestivo.

Número de referencias: 1 Partes utilizadas: frutos/infrutescencias/falsos frutos,.

I frutti e la corteccia, privata dalla parte suberificata, appena sobllentati o il loro infuso, forniscono un' acqua ritenuta insostituibile nella cura di febbri maltesi ed epatite, se ne deve bere una tazza al giorno, il decotto della sola corteccia viene utilizzato anche in altre affezioni epatiche.(MANG98). 


\section{Sorbus aucuparia $L$.}

Nombre vulgar: Sorbo degli uccellatori (TIV), Sorbo degli ucellatori (TGO, GGI, GFR, DAD).

Número de informantes: 5 Número de citas: 5.

Número de sectores: 1 Número de categorías: 1.

Biotipo: Fanerófito.

Tipo corológico: Europeas.

Abundancia: Común.

Ambiente: Bosques de montaña (hayedos, bosques de abetos) y subalpinos, arbustos de.

rododendros.

Número de exsiccata: 38992 FIAF.

Sector caza y pesca

Categoría de uso: Caza de pájaros.

Número de informantes: 5 Partes utilizadas: frutos/infrutescencias/falsos frutos.

Per cacciare gli uccelli si mettevano sotto l' albero (TIV)| Per cacciare uccelli si mettevano sotto l' albero (DAD)| Per cacciare gli uccelli che mangiavano i frutti (GFR)| Si mettevano sotto i sorbi per cacciare gli uccelli che andavano a mangiare $\mathrm{i}$ frutti (GGI)| Per cacciare gli uccelli si mettevano sotto l' albero, perché le mangiano gli uccelli. (TGO).

Notas Cresce sopra i 1000 metri, non sono comestibili.

\section{Sorbus domestica $L$.}

Nombre vulgar: Sorbolo (MRI), Sorbo (TGO, GGI, BPT), Sorbe (BPT), Sorbole (NST, BSI, VMA, RNI, RMA, NDI, GGL, EMA, BEL, AN3), Sòrbole (GUF).

Número de informantes: 15 Número de citas: 18.

Número de sectores: 3 Número de categorías: 6 .

Biotipo: Fanerófito.

Tipo corológico: Eurimediterránea.

Abundancia: Rara.

Ambiente: Bosques submediterráneos, también cultivados por el fruto.

Número de exsiccata: 38893 FIAF.

Sector agropastoral

Categoría de uso: Alimentación animal (incluidos los forrajeros).

Número de informantes: 1 Partes utilizadas: tallos leñosos/ramas/ramitas/vástagos.

Per fare il mazzo, perché il legno è resistente e pesante (MRI).

Categoría de uso: Herramientas y objetos agrícolas.

Número de informantes: 2 Partes utilizadas: tallos leñosos/ramas/ramitas/vástagos.

Mazza di legno per spaccare la legna (BPT)| Il sorbo si usa per fare le mazze da usare con i cunei. (MRI). 
Etnobotánica en el Alto Valle del Reno (Toscana y Emilia-Romaña, Italia)

\section{Sector alimentario}

Categoría de uso: Conserva de frutas.

Número de informantes: 1 Partes utilizadas: frutos/infrutescencias/falsos frutos.

Bollire i frutti con un po d' acqua e zucchero e conservare nei barattoli (GGI).

Categoría de uso: Fruta fresca.

Número de informantes: 11 Partes utilizadas: frutos/infrutescencias/falsos frutos.

Le sorbe si mangiano mature (BPT) $\mid$ lo mettevano a maturare sulla paglia. Se non si mettevano a "marcire" erano immangiabili. (TGO)| Le sorbole si fanno maturare nella paia, anche se hanno poca polpa sono molto buone e si conservano per mesi. (AN3) $\mid$ A ottobre si mangiavano le sorbole mature. Insieme con le nespole e le corniole erano gli ultimi frutti della stagione. (BEL)| Mettere le sorbole in mezzo alla paglia, finché non maturino: si apriva alla metà balla di paglia e si mettevano all'interno. (EMA) $\mid$ Le sorbole vanno raccolte a ottobre acerbe e messe in una cassa con la paglia sotto e sopra. (GGL)| Le sorbole si raccoglievano a settembre- ottobre e si portavano a maturare dentro casa, aspettando che ogni frutto maturasse al suo momento. (NDI) Si mangiano quando son o mature, ossia quando sono nere, e fanno bene per la stitichezza (RMA)| Le sorbole si mangiano quando sembrano marcie, sono buonissime, morbidissime. (RNI)| Le sorbole si mangiano come frutta ammezzimento, si trovavano ai bordi dei campi erano selvatici, e si raccoglievano da per terra, perché diventano degli alberi grandi. Ci mette tanto tempo per fruttificare, e cresce lentamente, ora sta scomparendo perché li tagliano per fare legna da ardere (quando tagliano il bosco) perché non le conoscono. (VMA)| Si mangiavano al naturale, anche per I campi quando si incontrava un albero (GUF).

Categoría de uso: Licor.

Número de informantes: 2 Partes utilizadas: frutos/infrutescencias/falsos frutos.

Il vino di sorbole era fatto con le sorbole messe a macerare in un tino (una botte) per 4 o 5 giorni, con il tappo. Veniva fuori un vino di sorbole frizzante e dolciastro. Va bevuto subito con le caldorroste o le 'fruisà'. (RMA, BSI).

\section{Sector medicinal}

Categoría de uso: Patologías del aparato digestivo.

Número de informantes: 1 Partes utilizadas: frutos/infrutescencias/falsos frutos.

Le sorbole 'stringono', per la diarrea. (NST).

Notas Caratteristiche del legno: pesante e resistente. Si trovavano ai bordi dei campi erano selvatici, e si raccoglievano da per terra, perché diventano degli alberi grandi. $\mathrm{Ci}$ mette tanto tempo per fruttificare, e cresce lentamente, ora sta scomparendo perché li tagliano per fare legna da ardere (quando tagliano il bosco) perché non le conoscono.

\section{DATOS ETNOBOTÁNICOS BIBLIOGRÁFICOS}

Nombre vulgar: sorbo (SANS14, GUC98), sôrbel (UNGA21), So`rbole (APPO10), sòrbolo (GUC98).

Número de referencias: 4 Número de citas: 5 .

Número de sectores: 3 Número de categorías: 3.

Sector agropastoral

Categoría de uso: Herramientas y objetos agrícolas. 
Número de referencias: 1 Partes utilizadas: tallos leñosos/ramas/ramitas/vástagos. Il mazzo era la mazza di legno, di solito di sorbo o di olmo, cerchiata di ferro alle estremità, si usava per spaccare i tronchi più grossi piantando nel legno delle biétte. (GUC98).

\section{Sector alimentario}

Categoría de uso: Fruta fresca.

Número de referencias: 1 Partes utilizadas: frutos/infrutescencias/falsos frutos. (SANS14).

\section{Sector medicinal}

Categoría de uso: Afecciones ginecológicas, complicaciones obstétricas, del postparto y del puerperio.

Número de referencias: 1 Partes utilizadas: tallos leñosos/ramas/ramitas/vástagos. Il frutto è dal volgo reputato astringente e si usa spesso come rimedio contro il flusso.

(UNGA21).

\section{Sorbus torminalis (L.) Crantz}

Nombre vulgar: Ulastro (DAD), Ciliegiastri,Olivastri, Durascoli (TIV), Ulastro, Olivastro,

Oloastro (GGI, CRI).

Número de informantes: 4 Número de citas: 5.

Número de sectores: 2 Número de categorías: 2.

Biotipo: Fanerófito.

Tipo corológico: Europeas.

Abundancia: Común.

Ambiente: Bosques latifolios (sobre todo robledales).

Sector alimentario

Categoría de uso: Fruta fresca.

Número de informantes: 1 Partes utilizadas: frutos/infrutescencias/falsos frutos.

Al naturale. (DAD).

Sector caza y pesca

Categoría de uso: Caza de pájaros.

Número de informantes: 4 Partes utilizadas: frutos/infrutescencias/falsos frutos,. I cacciatori di uccelli si mettono vicino alle piante, perche gli uccelli vanno a mangiare I frutti marroni. (TIV)| I cacciatori ci facevano sotto il capanno per cacciare i merli. (GGI, CRI, DAD).

Notas Dice che ce n'è poco.

DATOS ETNOBOTÁNICOS BIBLIOGRÁFICOS

Nombre vulgar: pîtar, caegapojj (UNGA21).

Número de referencias: 1 Número de citas: 1 .

Número de sectores: 1 Número de categorías: 1 . 
Sector alimentario

Categoría de uso: Golosinas y masticatorias.

Número de referencias: 1 Partes utilizadas: frutos/infrutescencias/falsos frutos.

I frutti mangiati dai ragazzi sono detti caepojj. (UNGA21).

\section{RUBIACEAE}

\section{Coffea arabica $L$.}

Nombre vulgar: Café (PIL), Caffé (GGL).

Número de informantes: 2 Número de citas: 2.

Número de sectores: 2 Número de categorías: 2 .

Biotipo: Fanerófito.

Tipo corológico: Exóticas.

Abundancia: Cultivada.

Ambiente: Ausente.

Sector alimentario

Categoría de uso: Licor.

Número de informantes: 1 Partes utilizadas: frutos/infrutescencias/falsos frutos.

Raccogliere le noci il 24 Giugno, il giorno di San Giovanni. Prendere 15 noci spezzate in 4 parti, 1/2 Litro di acqua, 1/2 litro di alcool 90 gradi, 1/2 kg di zucchero, un limone grattugiato e il sugo, un cucchiaio di caffé macinato. Mettere tutto in un vaso e riporlo per un giorno al sole poi scuoterlo affinché lo zucchero si sciolga e lasciarlo in un posto fermo per 40 giorni poi filtrare e imbottigliare. (PIL).

Sector veterinario

Categoría de uso: Ganado bovino.

Número de informantes: 1 Partes utilizadas: frutos/infrutescencias/falsos frutos. Quando la mucca non riesce a ruminare (prima mangiava poi si metteva a riposare e ruminava) è come una indigestione del centopelli (omaso). Dare da bere alla mucca due o tre volte al giorno un po di aceto, vino, café, e sale grosso in un bottiglia di vetro. Se non guariva così, allora moriva. (GGL).

\section{RUTACEAE}

\section{Citrus limon (L.) Osbeck}

Nombre vulgar: Limone (BBI, UMI, EMA, GGI, GCL, CRO, GAN, VAL, PIL, NST, NMA, DAD, CRI, BEL, AN3, CFR, VFR, BSO), Limoni (VMR, LST).

Número de informantes: 20 Número de citas: 26.

Número de sectores: 3 Número de categorías: 9.

Biotipo: Fanerófito.

Tipo corológico: Cultivadas.

Abundancia: Cultivada. 
Ambiente: Cultivada.

\section{Sector alimentario}

Categoría de uso: Bebida.

Número de informantes: 1 Partes utilizadas: frutos/infrutescencias/falsos frutos.

Per passare la serata quando si stava insieme agli amici, si preparava sempre il vin brulé: fare bollire il vino insieme alla scorza del limone e dell'arancio e allo zucchero. Quando inizia a bollire dare fuoco. (BSO).

Categoría de uso: Fruta fresca.

Número de informantes: 2 Partes utilizadas: frutos/infrutescencias/falsos frutos.

Le fragole si mangiavano con il vino e lo zucchero, oppure con il limone, o con il vermout.Oppure anche i mirtilli si mangiavano con il vino e lo zucchero, oppure con il limone, o con il vermout. (VFR) $\mid$ Si mangiavano le fragoline di bosco condite con il vino e lo zucchero, oppure con il limone oppure c'era chi le mangiava con il vermut. (CFR).

Categoría de uso: Licor.

Número de informantes: 10 Partes utilizadas: frutos/infrutescencias/falsos frutos, hojas.

Prendere 30 noci (mallo verde, quando dentro non è ancora fatto), 1 litro e mezzo di alcol, 750 gr di zucchero, 2 grammi di cannella reggina trittati, 10 chiodi di garofano, 4 litri di acqua, la buccia del limone. Lasciare macerare per 40 giorni al buio o alla penombra in cantina,e filtrare. (AN3) $\mid$ Il Corniolino:1 $\mathrm{kg}$ di corniole, 1 litro di alcol, 625 gr di zucchero, 625 gr d'acqua, 5 chiodi di garofano, 1 pizzico di cannella, e la scorza di limone.Lasciare tutto a macerare per 40 giorni, poi filtrare, fare lo sciroppo con lo zucchero e l'acqua e aggiungere. (AN3)| Vin brulé: fare bollire il vino con la buccia del limone, la cannella e I chiodi di garofano. Si beveva nelle veglie, tutti offrivano il vin brulé. (AN3)| 67 foglie di cedrina, 800 grammi di acqua, mezzo litro di alcool, scorza di limone non trattato e 500 grammi di zucchero. Lasciare macerare per 21 giorni e muovere tutti i giorni. (BEL)| Ricetta della suocera chimata la nonna: "28 nocine tagliate, 1 litro di alcol puro, 900 gr.zucchero, 1scorza limone, 1 stecca vaniglia, 4 chiodi di garofano, 1 pizzico di cannella. Stringere lo zucchero in acqua calda e lasciare 40 giorni (DAD, CRI) $\mid$ Si metteva a macerare 10 foglie nel alcol (NMA)| Cento erbe': 3 foglie di alloro, 3 foglie di limone, 3 coccole di ginepro, 3 fiori di camomilla, 3 foglie di té, 3 foglie di salvia, 3 foglie di rosmarino, mettere a macerare in un litro di acqua bollita con 350 gr di zucchero e a cui siano stati poi aggiunti 40 gr di alcol a 90 ${ }^{\circ}$. (NST)| Raccogliere le noci il 24 Giugno, il giorno di San Giovanni. Prendere 15 noci spezzate in 4 parti, 1/2 Litro di acqua, 1/2 litro di alcool 90 gradi, $1 / 2 \mathrm{~kg}$ di zucchero, un limone grattugiato e il sugo, un cucchiaio di caffé macinato. Mettere tutto in un vaso e riporlo per un giorno al sole poi scuoterlo affinché lo zucchero si sciolga e lasciarlo in un posto fermo per 40 giorni poi filtrare e imbottigliare. (PIL)| 67 foglie di cedrina, 800 grammi di acqua, mezzo litro di alcool, scorza di limone non trattato, e 500 grammi di zucchero, lasciare macerare per 21 giorni e muovere tutti I giorni (VAL) Limoncino:Con 3 o 4 limoni comprati non trattati in un litro di alcol. Poi fare lo sciroppo con un $\mathrm{kg}$ di zucchero e un $\mathrm{kg}$ di acqua. Filtrare I limoni e aggiungere lo sciroppo. (LST)| Il 'Nocino':raccogliere le noci la sera di San Giovani. La tradizione 
dice che si debono rubare e raccogliere scalzi. Poi vanno tagliati con il coltello di legno a forma di croce. Mettere i frutti a macerare nel vino e alcol insieme allo zucchero, al limone e ai chiodi di garofano per 40 giorni al sole. Le proporzioni sono segrete. Poi filtrare e imbotigliare. (VMR).

Categoría de uso: Mermelada.

Número de informantes: 1 Partes utilizadas: frutos/infrutescencias/falsos frutos. Lavare I pomodori verdi dell'orto, tagliarli a fettine, levare I semi, persarli e per $1 \mathrm{~kg}$ di pomodori mettere 2 limoni tagliati finemente, e 7 etti di zucchero, bollire I pomodori un pò finché si stringe e prende la consistenza della mermellata. (GAN).

Sector doméstico

Categoría de uso: Cuidado personal y cosmética.

Número de informantes: 2 Partes utilizadas: frutos/infrutescencias/falsos frutos. Con acqua e limone ci facevamo la messa in piega. (CRO)| Applicazione diretta di alcol con.

limone per sbiancare la pelle (GCL).

Categoría de uso: Detergente.

Número de informantes: 1 Partes utilizadas: frutos/infrutescencias/falsos frutos. Si usa il succo di limone per lavarsi le mani tinte degli ebbi (GGI).

\section{Sector medicinal}

Categoría de uso: Afecciones cutáneas y tejidos subcutáneos.

Número de informantes: 1 Partes utilizadas: frutos/infrutescencias/falsos frutos. Aggiungere un po' di succo di limone dopo avere strofinato la puntura con foglie di prezzemolo masticate. (BEL).

Categoría de uso: Afecciones del aparato respiratorio.

Número de informantes: 2 Partes utilizadas: frutos/infrutescencias/falsos frutos.

Prendere mezzo bicchiere di acqua calda con del miele e mezzo limone strizzato contro la tosse (EMA)| Bollire le mele con un po' di limone a fette, mangiarle e bere l'acqua. (UMI).

Categoría de uso: Patologías del aparato digestivo.

Número de informantes: 4 Partes utilizadas: frutos/infrutescencias/falsos frutos. Prendere 30 noci (mallo verde, quando dentro non è ancora fatto), 1 litro e mezzo di alcol, 750 gr di zucchero, 2 grammi di cannella reggina trittati, 10 chiodi di garofano, 4 litri di acqua, la buccia del limone. Lasciare macerare per 40 giorni al buio o alla penombra in cantina,e filtrare. (AN3)| Bollire mezzo limone con 4 o 5 foglie di salvia e bere. Fa digerire. (BBI)| Limone spremuto e diluito con acqua e zucchero "a Pavana" (CFR)| Bollire mezzo limone con 4 o 5 foglie di salvia e bere. Fa digerire. Anche con menta e melissa. (NST).

DATOS ETNOBOTÁNICOS BIBLIOGRÁFICOS

Nombre vulgar: limone (MANG98), Dimone (BONZI00).

Número de referencias: 2 Número de citas: 2.

Número de sectores: 1 Número de categorías: 1.

Sector medicinal

Categoría de uso: Afecciones del aparato respiratorio. 
Número de referencias: 1 Partes utilizadas: frutos/infrutescencias/falsos frutos.

Il succo di limone con miele viene assunto quotidianamente in caso di tosse. (MANG98).

\section{Citrus sinensis (L.) Osbeck}

Nombre vulgar: Arancio (BSO).

Número de informantes: 1 Número de citas: 1.

Número de sectores: 1 Número de categorías: 1.

Biotipo: Fanerófito.

Tipo corológico: Cultivadas.

Abundancia: Cultivada.

Ambiente: Cultivada.

Sector alimentario

Categoría de uso: Bebida.

Número de informantes: 1 Partes utilizadas: frutos/infrutescencias/falsos frutos.

Per passare la serata quando si stava insieme agli amici, si preparava sempre il vin brulé: fare bollire il vino insieme alla scorza del limone e dell'arancio e allo zucchero. Quando inizia a bollire dare fuoco. (BSO).

\section{Ruta graveolens $\boldsymbol{L}$.}

Nombre vulgar: Ruta (PGI).

Número de informantes: 1 Número de citas: 1.

Número de sectores: 1 Número de categorías: 1.

Biotipo: Caméfito.

Tipo corológico: Eurimediterránea.

Abundancia: Común.

Ambiente: Pendientes cubiertas de hierba y acantilados.

Sector alimentario

Categoría de uso: Licor.

Número de informantes: 1 Partes utilizadas: parte aérea (toda).

Mettere un rametto di ruta in una bottiglia e riempirla di grappa. (PGI).

DATOS ETNOBOTÁNICOS BIBLIOGRÁFICOS

Nombre vulgar: rûda (UNGA21).

Número de referencias: 1 Número de citas: 3 .

Número de sectores: 1 Número de categorías: 3.

\section{Sector medicinal}

Categoría de uso: Afecciones típicas infantiles.

Número de referencias: 1 Partes utilizadas: tallos leñosos/ramas/ramitas/vástagos. Nella medicina popolare è adoperata come vermifuga. Le donne prendono un ramoscello, lo pestano insieme ad uno spicchio d'aglio e con un poco di aceto lo mettono in un pezzo di pane bucato, ciò che si dice puzzatt, pozzetto, e lo dànno a mangiare ai bimbi. 
Categoría de uso: Otro medicinal.

Número de referencias: 1 Partes utilizadas: tallos leñosos/ramas/ramitas/vástagos. La ruta ha ancora parte nella composizione dell'aceto dei 7 ladri, che ha fama contro I contagi. (UNGA21).

Categoría de uso: Trastornos musculo-esqueléticos.

Número de referencias: 1 Partes utilizadas: tallos leñosos/ramas/ramitas/vástagos. $\mathrm{Si}$ adopera pure pestata e applicata come empiastro in certe enfiagioni. (UNGA21).

Notas si dice dal volgo che la ruta sia nemica delle serpi e che quando la donnola vuole combattere contro queste mangi ruta o vada a soffregarsi su di essa.

\section{SALICACEAE}

\section{Populus nigra $L$.}

Nombre vulgar: Pioppo (GUF, FAM, CFR, BPA, TSI, MRI, GGI, BLI, VMU, GFO, PIM, MTI, SOT, SLU), Pioppo vetrino (VSI), Fioppa (NMA).

Número de informantes: 16 Número de citas: 19.

Número de sectores: 4 Número de categorías: 9.

Biotipo: Fanerófito.

Tipo corológico: Europeas.

Abundancia: Común.

Ambiente: Silvestre a lo largo de los ríos y en los lagos.

Número de exsiccata: 39115 FIAF.

Sector agropastoral

Categoría de uso: Alimentación animal (incluidos los forrajeros).

Número de informantes: 2 Partes utilizadas: hojas.

Forragera per le pecore:"Vinciò":Fascie di rami con le foglie, raccolti l'ultima settimana di Agosto e la prima di settembre, messi ad essicare per conservare per l'inverno. (SLU)| Lungo il fiume, si potavano da picoletti, e si facevano i "vencigli", messi a seccare al sole, e date alle pecore, per l'inverno (SOT).

Categoría de uso: Cría de cerdos y productos porcinos.

Número de informantes: 2 Partes utilizadas: madera.

Il legno di pioppo si usa per fare il 'trogolo' (MTI)| Per fare il 'trogolo', un recipiente di legno di pioppo (PIM).

Categoría de uso: Otro agropastoral.

Número de informantes: 1 Partes utilizadas: tallos leñosos/ramas/ramitas/vástagos.

Ha una capacità di combustione molto grande e veloce, perciò si usava tagliando la legna a pezzi picooli ( "stluzze) e provocava una grande fiammata. Era usato con la veddega per I motori a vapore per trebbiare il grano. Brusciava come la carta. (VSI).

Categoría de uso: Productos lácteos.

Número de informantes: 1 Partes utilizadas: tallos leñosos/ramas/ramitas/vástagos.

Asse di pioppo per fare il formaggio perche non tinge e non rilascia odore (GFO). 


\section{Sector artesanal}

Categoría de uso: Objetos domésticos.

Número de informantes: 1 Partes utilizadas: madera.

Si fascevano le cassepanche di pioppo per conservare la farina di grano che si metteva pressata e poi doveva essere tagliata a tocchi. (VMU).

Categoría de uso: Objetos personales y calzado.

Número de informantes: 2 Partes utilizadas: tallos leñosos/ramas/ramitas/vástagos.

Gli zoccoli erano fatti di legno di pioppo (BLI)| Facevano I zoccoli di pioppo (GFO).

\section{Sector doméstico}

Categoría de uso: Integración de la renta familiar.

Número de informantes: 2 Partes utilizadas: madera, tallos.

Vendevano il legno alle cartiere insieme a quello del salgòn, erano venduti ai trasformatori (GGI)| commercio del legno per fare le cassette di legno da frutta "Derroni di Vignola" alla Romagna (MRI).

Categoría de uso: Objetos domésticos y escobas.

Número de informantes: 3 Partes utilizadas: madera, tallos.

Il legno di pioppo si usa per fare le pale per prendere la farina. (MTI)| Per fare le pale per prendere la farina. (PIM) $\mid$ Sulla conca si mettevano pali di pioppo per tenere il "cendro" (TSI).

Sector mágico/ritual/supersticioso

Categoría de uso: Protector.

Número de informantes: 5 Partes utilizadas: tallos leñosos/ramas/ramitas/vástagos.

Contro le avversità, per tenere lontano i temporali e la grandine: i primi di giugno mettevano degli altarini ai bordi dei campi fatti di una croce di pioppo, un rametto di olivo benedetto e una candela. La croce si faceva con le bacchette spaccate. Il venerdi santo, al 'mattutino' i ragazzini in chiesa si mettevano intorno ad un tavolo con un rametto di pioppo e lo spaccavano sul tavolo. (CFR, BPA, NMA)| Contro le avversità, per tenere lontano i temporali e la grandine: i primi di giugno mettevano degli altarini ai bordi dei campi fatti di una croce di pioppo, un rametto di olivo benedetto e una candela. (FAM) $\mid$ Il giorno di Santa Croce, si andava ai campi a mettere una croce di pioppo, e sopra si legava un rametto di ulivo benedetto, con una candela per la Candelora. Era una celebrazione o una sorta di rituale religioso per tenere lontane le tormente dai campi coltivati. (GUF).

Notas Rami raccolti con le foglie l'ultima settimana di agosto fino al il primo di settembre, quando finisce il sole. Crescono lungo il fiume, caratteristiche del legno: è resistente, non si spacca, (diverso del Pioppo della pianura, si chiama così pioppo vetrino perché si spacc facilmente. La legna di pioppo non rimette.oggi non ce n'è più questo tipo di commercio perché le cassette sono di plastica oppure viene dall'estero. Ormai il legname non ha più interesse commerciale. 


\section{DATOS ETNOBOTÁNICOS BIBLIOGRÁFICOS}

Nombre vulgar: pioppi (GUC98), Pioppo (SIRGI91), pioppo. (POLI14), fiòppa (APPO10, BENE96), pioppo (GUC98), pioppa, pioppo (GUC82), albero (POLI14).

Número de referencias: 6 Número de citas: 9.

Número de sectores: 5 Número de categorías: 6 .

\section{Sector agropastoral}

Categoría de uso: Alimentación animal (incluidos los forrajeros).

Número de referencias: 2 Partes utilizadas: tallos leñosos/ramas/ramitas/vástagos. Il vinciólo o i vincióo è un fascio di rami con foglie attaccate, ricavati dalla potatura di castagni, cerri o pioppi, d'inverno, si davano da mangiare a conigli o pecore. (GUC98)| "I contadini con poca terra... frasche di quercia o pioppo per alimentare pecore e mucche nell'inverno" (SIRGI91).

\section{Sector artesanal}

Categoría de uso: Objetos agrícolas.

Número de referencias: 1 Partes utilizadas: madera.

La "caretta" era un attrezzo per piccoli movimenti di terra, e altri materiali sfusi, realizzata in legno compresa la ruota cerchiata di ferro, con vasca a sezione triangolare. Il telaio in genere era di acacia (cascia) e la vasca in pioppo. Ne esisteva anche un tipo per donna con vasca piú piccola. (POLI14).

\section{Sector doméstico}

Categoría de uso: Chimenea y horno.

Número de referencias: 1 Partes utilizadas: madera.

fiòppa, sost.f.='pioppo', è il tipo normale nell'area emiliana ma si espande anche in qualche zona dell'adiacente Toscana, soprattutto nelle zone di Firenzuola e Sambuca. Esistono alcuni proverbi: chi vo'l fare dal fo'go a $n$ amìgo adro'vi dla fiòppa e dal figo' chi vuol fare del fuoco a un amico usi del pioppo e del fico, perché bruciavano velocemente, chi d fiòppa chi d no'sge ognùn l'ha la sa cro'ge' chi di pioppo e chi di noce ognuno ha la sua croce. (BENE96).

Categoría de uso: Objetos domésticos y escobas.

Número de referencias: 1 Partes utilizadas: madera.

Il tavoléro è un tagliere per la sfoglia, spianatoia, di solito costruito in legno di pioppo o salice. Su questo si versava anche la polenta di granoturco o di castagne per lasciarla un poco raffreddare in modo da poterla tagliare a fette. (GUC98).

\section{Sector lúdico/voluptuoso}

Categoría de uso: Instrumentos musicales.

Número de referencias: 1 Partes utilizadas: tallos leñosos/ramas/ramitas/vástagos. La mu sétta è un tipo di flauto diritto, molto primitivo ed usato di solito come gioco per ragazzi. Si ottiene togliendo la corteccia, per torsione, a un pollone di castagno o più raramente di pioppo o gelso, formando una canna di $20 \mathrm{~cm}$ circa. L'operazione è possibile ovviamente solo quando le suddette piante sono ricche di linfa, in marzo o aprile. una delle estremità della canna viene quindi zeppata, cioè otturata con una piccola zeppa di legno che lascia passare solo parzialmente alcuni fori rotondi digitali, senza però nessuna particolare logica musicale. È probabile che in tempi 


\section{María Teresa Egea Molines}

passati la musetta fosse costruita con regole più precise o con particolari scopi rituali nonostante la sua effimera durata. Infatti, anche mettendo a bagno lo strumento dopo l'uso, la corteccia in due settimane si secca, e la m. è inutilizzabile.(GUC98).

Sector mágico/ritual/supersticioso

Categoría de uso: Protector.

Número de referencias: 1 Partes utilizadas: tallos leñosos/ramas/ramitas/vástagos. Il 3 Maggio, il giorno di Santa Croce facevano delle croci di pioppo. Doveva essere di pioppo perche poi si spaccavano, si mondavano e poi si spaccavano, e poi ci si metteva, la candelina benedetta che è fatta del 2 febbraio, la Candelora, e 1'olivo benedetto che benedivano la domenica prima di Pasqua. Preservava i campi dai temporali (GUC82).

Notas Esistono alcuni proverbi: chi vo'l fare dal fo'go a $n$ amìgo adro'vi dla fiòppa e dal figo' chi vuol fare del fuoco a un amico usi del pioppo e del fico, perché bruciavano velocemente, chi $d$ fiòppa chi $d$ no'sge ognùn l'ha la sa cro'ge' chi di pioppo e chi di noce ognuno ha la sua croce.

\section{Populus tremula $L$.}

Nombre vulgar: Pioppo nostrano, Pioppo tremulo (MRI), pioppo nostrano, pioppo tremulo (MRI).

Número de informantes: 1 Número de citas: 4.

Número de sectores: 3 Número de categorías: 4.

Biotipo: Fanerófito.

Tipo corológico: Nórdicas.

Abundancia: Común.

Ambiente: Bosques de montaña, sobre todo húmedos, más raramente hasta la llanura.

Número de exsiccata: 39060 FIAF.

Sector agropastoral

Categoría de uso: Alimentación animal (incluidos los forrajeros).

Número de informantes: 1 Partes utilizadas: hojas.

Le foglie di pioppo si davano da mangiare ai conigli (MRI).

Categoría de uso: Productos lácteos.

Número de informantes: 1 Partes utilizadas: madera.

Per fare le assi usate per conservare le forme di formaggio per la stagionatura. (MRI).

Sector artesanal

Categoría de uso: Objetos domésticos.

Número de informantes: 1 Partes utilizadas: madera.

Per fare le tavole dei mobili in casa. (MRI).

Sector doméstico

Categoría de uso: Integración de la renta familiar.

Número de informantes: 1 Partes utilizadas: planta entera/viva. 
Quando nasceva una figlia si piantava un pioppo, perche cosi a 18 anni, vendeva la legna per potere sposarla.(è un albero che cresce veloce, come l'acacia) (MRI).

Notas per piantare I pioppi basta mettere un ramo per terra in autunno e cresce veloce., Il Pioppo. Non ha nodi, prende il colore bene.

\section{Salix alba $L$.}

Nombre vulgar: Borgogna (NRE) Borgognone (RRE) Borgognoni (MRI) Salgò (VMR) Salgon (PLU), Salgón (GGI), Salgòn (GGL, VSI) Salgon basso (VSI), Salica (REN), Salice (SOT, TGO, VMR), Salice bianco (VMR), Salice di fiume (MRI) Salicon (MRI) Salicone (TRU) Stropelli (BDI, BPI, GGI, MSR, NRE) Stropelli (rami) (GGI,, MRI,, GGL, VSI) Veddega (ECE) Veticadelfiume (pianta) (GGI), Vimini (MSR).

Número de informantes: 16 Número de citas: 32.

Número de sectores: 7 Número de categorías: 14.

Biotipo: Fanerófito.

Tipo corológico: Europeas.

Abundancia: Común.

Ambiente: Lugares húmedos.

Número de exsiccata: 39012 FIAF, 38964 FIAF, 39061 FIAF, 39034 FIAF, 38966.

Sector agropastoral

Categoría de uso: Cuerdas y ataduras.

Número de informantes: 4 Partes utilizadas: tallos leñosos/ramas/ramitas/vástagos.

Quando si spellavano con "la cagna" fatta di castagno, per poi metterli a seccare al sole, le bucce ricavate si usavano per legare le viti (NRE)| Suo nonno teneva l'albero basso, così produceva dei rami lunghi che venivano usati per legare i covoni del grano. Si usavano per fare dei "gubbioni" per portare la legna. (VSI)| In autunno si tagliavano le stroppe, poi si mettevano in un capanno fino a giugno, quando si tagliava il grano. Si mettevano a bagno, così diventavano flessibili e si adoperavano per legare i covoni del grano (GGL)| Usati per legare i pomodori. Venivano messi prima a bagno nella fonte. (MRI).

Categoría de uso: Herramientas y objetos agrícolas.

Número de informantes: 5 Partes utilizadas: tallos leñosos/ramas/ramitas/vástagos,.

Per fare le basi dei rastrelli, per rastellare il fieno, il manico doveva essere di 3 o 4 $\mathrm{m}$, sicché deve essere leggero sennò si faceva più fatica.è un legno resistente, però leggero quando è secco. Non 'pestava' la mano (non faceva venire i calli), perché era poroso. (GGI)| Per fare la base del rastrello dove si attaccano i denti (REN)| Manici degli utensili, rastrelli. E' leggero e resistente. (SOT)| Tagliare il legno del salicone quando ancora ha la linfa per fare i manici delle zappe. E per fare i catini delle macine, perché è resistente all'acqua. Le rete sono due bastoni di salicon legati con una corda in modo opportuno per caricarsi addosso il fieno, le vecce... (MRI)| Si usava il legno per fare il manico dei rastrelli (TRU).

Categoría de uso: Otro agropastoral. 
Número de informantes: 1 Partes utilizadas: tallos leñosos/ramas/ramitas/vástagos.

Ha una capacità di combustione molto grande e veloce, perciò si usava tagliando la legna a pezzi picooli ( "stuzze) e provocava una grande fiammata. Era usato con il pioppo per I motori a vapore per trebbiare il grano. Brusciava come la carta. (VSI) Si usava per trovare l'acqua: si prendeva una stroppa piegata in giù e quando sentiva l'acqua si allargava. (VSI).

\section{Sector artesanal}

Categoría de uso: Cestería.

Número de informantes: 6 Partes utilizadas: tallos leñosos/ramas/ramitas/vástagos.

Le borgogne sono quelli più grossi, vengono I cesti più spessi, sono di colore gialloverdastro. Le piante erano di 2 o 3 mestri perché le persone le lascavano basse. Si prendevano I rametti lisci di un anno, che non avevano rametti. Ne ricavavano gli stopelli per fare i corbelli: cesti grandi che si mettevano sui cavalli o sui muli per caricare l'uva. Oppure le gorgole. Quando si spellavano con "la cagna" fatta di castagno, per poi metterli a seccare al sole, le bucce ricavate si usavano per legare le viti. (NRE)| I rami dei borgognoni erano più adatti per fare i panieri perché erano belli lisci, senza ramoscelli. Insieme alle canne facevano dei panieri che vendevano a San Remo per l'esportazione dei fiori. (RRE)| Venivano allevati perché gli stropi si usavano per fare le ceste a San Remo. Suo nonno teneva l'albero basso, così faceva i rami lunghi. (VSI)| Per fare i cesti. I rami, chiamati stropelli, si tagliavano a maggiogiugno e ad agosto quando hanno la linfa e si spellavano con una 'fiaccola' fatta con un ramo di castagno: 'si sfiaccolava', ossia si toglieva la corteccia degli stropelli freschi. Si spellavano a giugno e a settembre e si mettevano al sole, così si seccavano già scortecciati e bianchi. Si usavano i getti giovani che si spellavano facilmente. (MRI)| Raccolti da Maggio ad Agosto, meglio d'estate, vanno spellati subito e messi a seccare al sole. (BDI)| Per fare la base dei rastrelli per il fieno. Il manico doveva essere di 3 o $4 \mathrm{~m}$, sicché deve essere leggero sennò si faceva più fatica. (GGI).

Categoría de uso: Muebles.

Número de informantes: 1 Partes utilizadas: tallos leñosos/ramas/ramitas/vástagos.

Si usavano per fare le culle per i bambini. Per lo stesso scopo si potevano usare anche i salici o borgognoni. (GGI).

Sector caza y pesca

Categoría de uso: Otro caza y pesca.

Número de informantes: 2 Partes utilizadas: tallos leñosos/ramas/ramitas/vástagos.

Quando si andava a pesca I pesci si avvolgevono per tenerli freschi e si infilzavanp con uno stropello a fomra di Y e sopra la foglia di farfallone (BPI)| Quando si andava a pesca I pesci si avvolgevono per tenerli freschi e si infilzavano con uno stropello a forma di Y e sopra la foglia di farfallone. Con gli stropelli si faceva anche la nassa per pescare. (GGI). 


\section{Sector doméstico}

Categoría de uso: Integración de la renta familiar.

Número de informantes: 3 Partes utilizadas:
tallosleñosos/ramas/ramitas/vástagos.

I rami dei borgognoni erano più adatti per fare I panieri perché erano belli lisci, senza ramocelli. Insieme alle canne facevano dei panieri che vendevano a San Remo per l'esportazione dei fiori. (RRE)| Coltivavano I borgognoni per fare I cesti insieme alle canne che vendevano a San Remo per l'esportazione dei fiori (MRI)| Vendevano il legno alle cartiere insieme a quello del pioppo. (GGI).

\section{Sector lúdico/voluptuoso}

Categoría de uso: Instrumentos musicales.

Número de informantes: 1 Partes utilizadas: corteza.

Corno: quando la pianta è 'in succhio' (primavera), si stacca la 'buccia' (corteccia) di un ramo e insieme a un pezzo di legno di Castagno fanno il corno. (TGO).

Categoría de uso: Pasatiempos.

Número de informantes: 1 Partes utilizadas: tallos
leñosos/ramas/ramitas/vástagos.

Con il salice si faceva un mulinello nel fiume, usando due rami legati con una corda. Si gira il bastoncino in mezzo, poi si lascia e fa un mulinello. (MRI).

\section{Sector medicinal}

Categoría de uso: Dolor de cabeza.

Número de informantes: 1 Partes utilizadas: corteza.

Si essicava la corteccia del tronco del salgo, si polverizzava e si diluiva nell'acqua. Bere un bicchiere la mattina e la sera contro la febbre (VMR).

Categoría de uso: Fiebre.

Número de informantes: 1 Partes utilizadas: corteza.

Si essicava la corteccia del tronco del salgo, si polverizzava e si diluiva nell'acqua. Bere un.

bicchiere la mattina e la sera contro la febbre (VMR).

\section{Sector veterinario}

Categoría de uso: Ganado bovino.

Número de informantes: 3 Partes utilizadas: tallos leñosos/ramas/ramitas/vástagos.

Quando le bestie mangiavano tanta erba medica fresca gonfiavano e potevano anche morire. Prima li si forava nel lato destro, per farlo sgonfiare. Si prendeva un ramo grande ('stroppa') del salgon, si torceva, si legava alle corna mettendolo dentro alla bocca, in modo che non potesse chiudere la bocca. La bestia con la lingua sfregava il ramo e dopo un po' ruttava, risolvendo il problema. (GGL)| Quando le bestie stavano male (perché mangiavano l'erba fresca...) prendevano gli stropelli glielo fasciavano intorno alla bocca, legandoglielo. Se non funzionava si chiamava alla persona più pratica della zona che lo foravano. (MSR)| Quando le mucche avevano la febbre, gli si legava in bocca un ramo grosso di veddega. Infatti quando erano libere ed erano ammalate, la cercavano da sole e la mangiavano ed era un segno di malattia. (ECE).

Categoría de uso: Otro veterinario. 
María Teresa Egea Molines

Número de informantes: 1 Partes utilizadas: tallos leñosos/ramas/ramitas/vástagos.

Quando i conigli hanno la pancia gonfia, gli si danno i rami di salgon da mangiare (PLU).

Categoría de uso: Ovejas y cabras.

Número de informantes: 1 Partes utilizadas: tallos leñosos/ramas/ramitas/vástagos.

Quando le pecore avevano febbre, gli si legava in bocca un ramo grosso di veddega. Infatti quando erano libere ed erano ammalate, la cercavano da sole e la mangiavano ed era un segno di malattia. (ECE).

Notas Tagliare a primavera quando c'è l'insucchio, se si strappa viene fuori l'acqua.è un albero alto che fa nei corsi d'acqua, fa delle messe verdi chiaro, ogni anno vanno tagliati. Si spezzano facilmente, sono fragili, se non vanno potati.

DATOS ETNOBOTÁNICOS BIBLIOGRÁFICOS

Nombre vulgar: sàlgio (GUC98), sâls da poel (UNGA21), stropèllo, stropegli, védga (GUC98),.

salice (GUC98), Salice (APPO10), Salgòn (APPO10), Stropèii (APPO10),

Stròppa (APPO10), stropèlli (o stropèii) (BENE96), struppèlli (BENE96).

Número de referencias: 4 Número de citas: 11.

Número de sectores: 4 Número de categorías: 5.

Sector agropastoral

Categoría de uso: Cuerdas y ataduras.

Número de referencias: 1 Partes utilizadas:.

tipo di salice, probabilmente Salix incana, Cresce sulle rive dei fossi, ha rami giallorossastri e veniva spesso capitozzato e i rami usati per legare le viti ed altre piante o per grossolani lavori di intreccio. (GUC98).

Categoría de uso: Viticultura y enología.

Número de referencias: 1 Partes utilizadas: No especificado.

coltivato per far pali a sostegno delle viti, per lo più a capitozza (UNGA21).

Sector artesanal

Categoría de uso: Cestería.

Número de referencias: 1 Partes utilizadas: tallos leñosos/ramas/ramitas/vástagos.

Si usavano per intrecciare panieri (GUC98).

Sector doméstico

Categoría de uso: Objetos domésticos y escobas.

Número de referencias: 1 Partes utilizadas: madera.

Il tavoléro è un tagliere per la sfoglia, spianatoia, di solito costruito in legno di pioppo o salice. Su questo si versava anche la polenta di granoturco o di castagne per lasciarla un poco raffreddare in modo da poterla tagliare a fette. (GUC98).

Sector lúdico/voluptuoso

Categoría de uso: Instrumentos musicales.

Número de referencias: 1 Partes utilizadas: tallos leñosos/ramas/ramitas/vástagos.

Subio'lo Specie di flauto ricavato da un bastone di salice svuotato. (APPO10). 


\section{Salix alba var. vitellina (L.) Stokes (= Salix alba L. subsp. vitellina (L.) Arcang.)}

Nombre vulgar: Salcio (MRI), Salgon (pianta), Stropegli, Stroppe (rami) (RRE), Salice (GGL), Salice giallo (FAM, GGI), Stropla da vimini, Saigòn da stropei (ECE), Vetrice, Stropello (BPA), Vimini (GRI, NER, IRE, GUF).

Número de informantes: 11 Número de citas: 16.

Número de sectores: 4 Número de categorías: 6.

Biotipo: Fanerófito.

Tipo corológico: Europeas.

Abundancia: Común.

Ambiente: Lugares húmedos.

Número de exsiccata: 38963 FIAF.

Sector agropastoral

Categoría de uso: Cuerdas y ataduras.

Número de informantes: 7 Partes utilizadas: tallos leñosos/ramas/ramitas/vástagos.

I rami del salcio sono più rossastri, arancioni, più elastici. Vanno mantenuti nell'acqua e rimangono sempre flessibili, non si rompono. Sono adatti per legare le viti oppure i 'piloti' degli innesti. (MRI)| Gli 'stropegli' (rametti piccoli secondari) gialli si usano per legare le viti e i pomodori. Le 'stroppe' (rami primari più lunghi) si usano per legare il grano, il fieno. (RRE)| Per legare i pomodori (GGL)| Con i ramettini piccoli si fanno legacci per legare le viti e i pomodori. Sono meglio degli stropelli perché sono flessibili, hanno la prorietà che quando vengono arrotolati non si rompono. (GGI)| (in italiano: salice da vimini). Tutti i contadini lo piantavano per produrre legacci con cui legare tutto: le fascine, le viti, le rose, il grano... Si usavano i rami giovani, perché ogni anno lo potavano. (ECE)| Per legare i pomodori e la vite (BPA)| Per legare la vite (GUF).

\section{Sector artesanal}

Categoría de uso: Cestería.

Número de informantes: 4 Partes utilizadas: tallos leñosos/ramas/ramitas/vástagos.

Raccolti a primavera, quando hanno l' insucchio per poi sbucciarli. Le gorgole è un gran cesto tondo che si portava sulle spalle per portare il fieno.Rami, getti grossi (FAM) Si usava sia per fare panieri che gorgole (ceste grandi per il fieno e il concime) (GGI)| Venivano tagliati e sbucciate e poi intrecciati (BPA)| Per fare i panieri e le 'gorgole'. La 'gorgola' è una cesta grande a forma cilindrica, con diametro di 1 metro per $50 \mathrm{~cm}$ di altezza, la superficie laterale era chiusa da ampie maglie di vimini non mondati, il fondo chiuso da maglie a raggiera con foro tondo al centro. Si usava per trasportare erba o fieno. (GUF).

Categoría de uso: Muebles.

Número de informantes: 1 Partes utilizadas: tallos leñosos/ramas/ramitas/vástagos. 
Si usavano per fare le culle per i bambini. per lo stesso scopo si potevano usare anche gli.

stropelli. (GGI).

Categoría de uso: Objetos domésticos.

Número de informantes: 1 Partes utilizadas: tallos leñosos/ramas/ramitas/vástagos.

La culla dei bambini erano fatte di vimini (IRE).

Sector caza y pesca

Categoría de uso: Otro caza y pesca.

Número de informantes: 2 Partes utilizadas: tallos leñosos/ramas/ramitas/vástagos.

"La filza" è un rametto di salice mondato terminante ad uncino nel quale si infilava per una branchia I pesci eventualmente pescati (GUF)| La nassa è una specie di gabbia fatta di vimini usata per pescare (NER).

Sector doméstico

Categoría de uso: Integración de la renta familiar.

Número de informantes: 1 Partes utilizadas: tallos leñosos/ramas/ramitas/vástagos.

Facevano cestini piccoli per vendere le fragole e I lamponi ai passanti (GRI).

DATOS ETNOBOTÁNICOS BIBLIOGRÁFICOS

Nombre vulgar: sâls da ligaer (UNGA21), Salgo'n, salgo'ne, saligo'ne, salcio (BENE96).

Número de referencias: 2 Número de citas: 2.

Número de sectores: 1 Número de categorías: 1.

Sector agropastoral

Categoría de uso: Cuerdas y ataduras.

Número de referencias: 1 Partes utilizadas: tallos leñosos/ramas/ramitas/vástagos.

Salcio da o per legare, vincaja adoperta per legar siepi e viti. (UNGA21).

\section{Salix caprea $L$.}

Nombre vulgar: Saigon che si spacca (ECE), Salica, Gattici (MGO), Salica, Vetica bottara,.

Bebine (GGI), Vedega bottara (MRI), Vettiche bottare (RRE), Veddeghe.

(VSI, ECE), Fioppini (NRO), Salgon selvatico, Veddega (GGL), Topi (BEL),

Topini (TAT, DBA, BSO, BAR).

Número de informantes: 13 Número de citas: 17.

Número de sectores: 2 Número de categorías: 4.

Biotipo: Fanerófito.

Tipo corológico: Europeas.

Abundancia: Común.

Ambiente: Bosques húmedos.

Número de exsiccata: 38974 FIAF, 38960 FIAF, 39026 FIAF, 39033 FIAF, 39113. 
Sector agropastoral

Categoría de uso: Cría de ganado bovino.

Número de informantes: 1 Partes utilizadas: tallos leñosos/ramas/ramitas/vástagos.

Il legname si usa per fare i gioghi degli animali, perché è leggero e compatto. (ECE). Categoría de uso: Herramientas y objetos agrícolas.

Número de informantes: 5 Partes utilizadas: tallos leñosos/ramas/ramitas/vástagos.

Il legname si usa per fare i manici, perché è leggero e compatto. (ECE)| Per fare manici di attrezzi. Lo lavora verde, li mette a seccare appesi e attaccati ad un chiodo, così vengono diritti. Si tagliano quando hanno l'insucchio, così vengono più duri e durano di più. Se viene tagliato senza l'insucchio marcisce prima e dura molto meno. (MGO)| Per fare manici per le pale (non per accetta). Per fare le basi dei rastrelli, per rastellare il fieno, il manico doveva essere di 3 o $4 \mathrm{~m}$, sicché deve essere leggero sennò si faceva più fatica.è un legno resistente, però leggero quando è secco. Non 'pestava' la mano (non faceva venire i calli), perché era poroso. (GGI)| Per fare i manici degli attrezzi, e 'i catini delle macine', perché ha delle dimensioni grosse, uno spessore grande. (MRI)| Per fare i manici delle pale o del forcone, perché è un legno forte, però da secco è leggerissimo (RRE).

Sector doméstico

Categoría de uso: Chimenea y horno.

Número de informantes: 2 Partes utilizadas: tallos leñosos/ramas/ramitas/vástagos,.

è legna da ardere (ECE)| Usa il legno come legno da ardere. (MRI).

Categoría de uso: Ornamental.

Número de informantes: 9 Partes utilizadas: tallos leñosos/ramas/ramitas/vástagos,.

Le "bebbine", sono gemme che fanno come del cotone, all' inizio di marzo, e si usano per decorare la casa. (NRO) $\mid$ I rami fioriti si mettono in un vaso per bellezza. (TAT, DBA, BSO, BAR, GGL)| Fare seccare I rami con I fiori (le bebbe o topini) e mettere in un vaso. (GGI)| I rami fioriti si mettono nei vasi in casa per bellezza, a marzo-aprile. (BEL)| A primavera raccoglievano le 'buttate' colorate e le gemme e si usavano come ornamento in casa. (VSI).

Notas Cresce veloce, e dopo 10 o 15 anni muore., Proprietà del legno: leggero e flessibile,

resistente e stopposo. Ha la foglia più tonda. Vetica bottara è quello che fa le bebbine 0 .

I toppini (le infiorescenze)..

\section{Salix eleagnos Scop.}

Nombre vulgar: Salice di fiume, Vedeghe di fiume, Stropelli (rami),Veddega (MRI), Vetica del.

fiume (pianta), Stropelli (rami) (GGI), Vetiche (FAM), Vetiche di fiume, Stropelli. (GGI). 
Número de informantes: 3 Número de citas: 7.

Número de sectores: 4 Número de categorías: 5.

Biotipo: Fanerófito.

Tipo corológico: Montañosas.

Abundancia: Común.

Ambiente: Arenas húmidas de las costas (calcáreas).

Número de exsiccata: 38958 FIAF, 39077 FIAF, 38967 FIAF.

Sector agropastoral

Categoría de uso: Cuerdas y ataduras.

Número de informantes: 1 Partes utilizadas: tallos leñosos/ramas/ramitas/vástagos.

Usati per legare i pomodori. Venivano messi prima a bagno nella fonte. (MRI).

Sector artesanal

Categoría de uso: Cestería.

Número de informantes: 3 Partes utilizadas: tallos leñosos/ramas/ramitas/vástagos.

Per fare i cesti. I rami, chiamati stropelli, si tagliavano a maggio-giugno e ad agosto quando hanno la linfa e si spellavano con una 'fiaccola' fatta con un ramo di castagno: 'si sfiaccolava', ossia si toglieva la corteccia degli stropelli freschi. Si spellavano a giugno e a settembre e si mettevano al sole, così si seccavano già scortecciati e bianchi. Si usavano i getti giovani che si spellavano facilmente. (MRI)| Per fare cesti. (GGI)| Per fare I panieri, si raccolgono a marzo (FAM).

Categoría de uso: Muebles.

Número de informantes: 1 Partes utilizadas: tallos leñosos/ramas/ramitas/vástagos.

Si usano per fare le culle per i bambini. Per lo stesso scopo si potevano usare anche i salici o borgognoni. (GGI).

Sector caza y pesca

Categoría de uso: Otro caza y pesca.

Número de informantes: 1 Partes utilizadas: tallos leñosos/ramas/ramitas/vástagos.

Quando si andava a pesca I pesci si avvolgevono per tenerli freschi e si infilzavano con uno stropello a forma di Y e sopra la foglia di farfallone. Con gli stropelli si faceva anche la nassa per pescare. (GGI).

Sector lúdico/voluptuoso

Categoría de uso: Pasatiempos.

Número de informantes: 1 Partes utilizadas: tallos leñosos/ramas/ramitas/vástagos.

Con il salice si faceva un mulinello nel fiume, usando due rami legati con una corda. Si gira il bastoncino in mezzo, poi si lascia e fa un mulinello. (MRI).

Notas Una volta venivano tagliati, potati, usati per fare gli stropelli e rimanevano giovani piante, ora invece diventano delle piante grosse, ombreggianti. Prima tagliando e usando queste piante si puliva il fiume. Con le piene se questi alberi 
diventano vecchi vengono poi srradicati nel letto del fiume, e fanno da tappo, l'acqua si ristagna, ostacolano i ponti vecchi.

\section{Salix purpurea $L$.}

Nombre vulgar: Stropelli (NRE), Vetica del fiume (pianta), Stropelli (rami) (GGI), Vetiche.

(FAM), Vimini del fiume (IRE), Vetiche di fiume, Stropelli (GGI).

Número de informantes: 4 Número de citas: 8.

Número de sectores: 3 Número de categorías: 4 .

Biotipo: Fanerófito.

Tipo corológico: Europeas.

Abundancia: Común.

Ambiente: Guijarrales acuáticos (calcáreos), a menudo cultivada.

Número de exsiccata: 38968 FIAF, 39062 FIAF.

Sector agropastoral

Categoría de uso: Cuerdas y ataduras.

Número de informantes: 1 Partes utilizadas: tallos leñosos/ramas/ramitas/vástagos.

Quando si spellavano con "la cagna" fatta di castagno, per poi metterli a seccare al sole, le.

bucce ricavate si usavano per legare le viti. (NRE).

Sector artesanal

Categoría de uso: Cestería.

Número de informantes: 4 Partes utilizadas: tallos leñosos/ramas/ramitas/vástagos.

Hanno la corteccia rossa, si chiamano anche gli stropelli, crescono lungo I fiumi, sono.

selvatici, si facevano le fiasche. (NRE)| Per fare cesti. (GGI) $\mid$ Per fare I panieri, si raccolgono a marzo (FAM)| Per fare I cesti (IRE).

Categoría de uso: Muebles.

Número de informantes: 1 Partes utilizadas: tallos leñosos/ramas/ramitas/vástagos.

Si usano per fare le culle per i bambini. Per lo stesso scopo si potevano usare anche i salici o borgognoni. (GGI).

Sector caza y pesca

Categoría de uso: Otro caza y pesca.

Número de informantes: 2 Partes utilizadas: tallos leñosos/ramas/ramitas/vástagos.

Quando si andava a pesca I pesci si avvolgevono per tenerli freschi e si infilzavano con uno stropello a forma di Y e sopra la foglia di farfallone. Con gli stropelli si faceva anche la nassa per pescare. (GGI)| Per costruire nasse per la pesca delle anguille. La nassa 'e uno strumento fatto di vimini di fiume con forma concava, si 
mette nel fiume, nei fossi la sera per pescare anguille. E' fatto di forma che l' anguilla entra però non riesce ad uscire. (IRE).

Notas Lungo il fiume, I salici (giallo e nero) rispetto alla vetica si lavorano meglio. Quando i rami hanno il diametro di un dito si usano per fare i cesti per il fieno o il letame e le ceste grosse come le 'gorgole'. C'è uno più giallo e uno più scuro. I rametti più sottili sono i migliori per fare $\mathrm{i}$ cesti: si piegano ma non si rompono.

\section{Salix triandra $L$.}

Nombre vulgar: Salice nero, Borgognone (GGI), Borgognoni (MRI).

Número de informantes: 2 Número de citas: 4.

Número de sectores: 2 Número de categorías: 3.

Biotipo: Fanerófito.

Tipo corológico: Nórdicas.

Abundancia: Común.

Ambiente: Lugares húmedos.

Número de exsiccata: 38962 FIAF.

Sector agropastoral

Categoría de uso: Cuerdas y ataduras.

Número de informantes: 1 Partes utilizadas: tallos leñosos/ramas/ramitas/vástagos.

Con i ramettini piccoli si fanno legacci per legare le viti e i pomodori. Sono meglio degli stropelli perché sono flessibili, hanno la prorietà che quando vengono arrotolati non si rompono. (GGI).

Sector artesanal

Categoría de uso: Cestería.

Número de informantes: 2 Partes utilizadas: tallos leñosos/ramas/ramitas/vástagos.

I giovani rami dell'anno ('getti') vanno bagnati e scaldati vicino al fuoco e poi lavorati per fare le 'gorgole' per portare il fieno. (MRI)| Si usava sia per fare panieri che gorgole (ceste grandi per il fieno e il concime) (GGI).

Categoría de uso: Muebles.

Número de informantes: 1 Partes utilizadas: tallos leñosos/ramas/ramitas/vástagos.

Si usano per fare le culle per i bambini. per lo stesso scopo si potevano usare anche gli.

stropelli. (GGI).

\section{SANTALACEAE (incluye LORANTHACEAE p.p.)}

\section{Viscum album $L$.}

Nombre vulgar: Vischio (ECE, BEL, BGI).

Número de informantes: 3 Número de citas: 3. 
Número de sectores: 2 Número de categorías: 2.

Biotipo: Fanerófito.

Tipo corológico: Europeas.

Abundancia: Rara.

Ambiente: Hemiparásito sobre varios árboles y arbustos.

Sector doméstico

Categoría de uso: Integración de la renta familiar.

Número de informantes: 1 Partes utilizadas: parte aérea (toda).

A Capodanno si vendevano. (BGI).

Sector mágico/ritual/supersticioso

Categoría de uso: Rituales navideños.

Número de informantes: 2 Partes utilizadas: parte aérea (toda), planta entera/viva.

Si metteva in casa per le feste, per bellezza e per i riti natalizi, come porta bene. (BEL)|A.

Natale qualcuno regalava il vischio per portare fortuna e si teneva in casa. (ECE).

Notas zona montana sui rami dei pini e degli abeti.Cresce sulle Quercie, sono gialli, Per le feste, per bellezza per I riti natalizi,come porta bene, una volta si diceva che era velenosa, cresce in un ramo di quercia sopratutto, fa delle bache gialle, delle foglie piccole come il bosso e cicciose grasse. Rino ha visto il vischio sull'Alpe di stagno su qualche faggio. I frutti sono bianchi-argento.

DATOS ETNOBOTÁNICOS BIBLIOGRÁFICOS

Nombre vulgar: vessti (UNGA21).

Número de referencias: 1 Número de citas: 1.

Número de sectores: 1 Número de categorías: 1.

Sector caza y pesca

Categoría de uso: Caza de pájaros.

Número de referencias: 1 Partes utilizadas: No especificado.

Entrambe queste piante sono adoperate per preparare la pania degli uccellatori (UNGA21).

\section{SAPINDACEAE (incluye ACERACEAE, HIPPOCASTANACEAE)}

\section{Acer campestre $L$.}

Nombre vulgar: Acero (MRI, PCL, TIV, BPT), Oppio (SOT, MIO), Acero campestre (NRE).

Número de informantes: 7 Número de citas: 7.

Número de sectores: 2 Número de categorías: 6 .

Biotipo: Fanerófito.

Tipo corológico: Europeas.

Abundancia: Común. 
Ambiente: Bosques mesófilos, sobre suelo rico, y cultivado de forma común en setos y viñedos.

Número de exsiccata: 39123 FIAF.

Sector agropastoral

Categoría de uso: Alimentación animal (incluidos los forrajeros).

Número de informantes: 2 Partes utilizadas: hojas.

Si tagliavano i rami d' estate e si mettevano ad essiccare legati per l' inverno, per dare da mangiare alle pecore (BPT)| Di autunno, prima che caschino le foglie dell'albero, facevano delle fascine di rami di oppio, querciole e carpine, per attaccarli d'inverno nella stalla dove stavano le pecore, così loro mangiavano le foglie d'inverno.' (MIO).

Categoría de uso: Herramientas y objetos agrícolas.

Número de informantes: 1 Partes utilizadas: tallos leñosos/ramas/ramitas/vástagos.

Legno leggero e forte (SOT).

Categoría de uso: Otro agropastoral.

Número de informantes: 1 Partes utilizadas: tallos leñosos/ramas/ramitas/vástagos.

Per tenere I terreni frananti (TIV).

Categoría de uso: Vallas y delimitaciones.

Número de informantes: 1 Partes utilizadas: planta entera/viva.

Si usava fare le siepi con diverse piante: gli spini (prugnolo e biancospino), l'acero campestre, i sanguinelli, i beretti da prete. (NRE).

Sector artesanal

Categoría de uso: Muebles.

Número de informantes: 1 Partes utilizadas: tallos leñosos/ramas/ramitas/vástagos.

Il tavolo e la vetrina erano di acero (PCL).

Categoría de uso: Objetos domésticos.

Número de informantes: 1 Partes utilizadas: madera.

Per fare I tavolieri come il pioppo nostrano, perché è un legno bianco. (MRI).

Notas l' Acero è arrivato nel 1931, Il legno non è buono da ardere,Pianta infestante.

DATOS ETNOBOTÁNICOS BIBLIOGRÁFICOS

Nombre vulgar: ôpi (UNGA21), óppio (GUC98).

Número de referencias: 2 Número de citas: 2.

Número de sectores: 1 Número de categorías: 1.

Sector agropastoral

Categoría de uso: Viticultura y enología.

Número de referencias: 1 Partes utilizadas: tallos leñosos/ramas/ramitas/vástagos. pianta che serve di sostegno alla vite. (UNGA21). 


\section{Aesculus hippocastanum $L$.}

Nombre vulgar: Marron d'india (RFR), Castagne d'india (MGE), Castagno d'india (NLA, UMI, REN, GAN), Ipocastano, Castagno d'india (RMA), Ippocastano (VMR, LST), Castagna d'india (BIO).

Número de informantes: 10 Número de citas: 10 .

Número de sectores: 4 Número de categorías: 6.

Biotipo: Fanerófito.

Tipo corológico: Amplia distribución.

Abundancia: Común.

Ambiente: Cultivada de forma común como ornamental.

Número de exsiccata: 39103 FIAF, 39109 FIAF.

Sector agropastoral

Categoría de uso: Alimentación animal (incluidos los forrajeros).

Número de informantes: 1 Partes utilizadas: frutos/infrutescencias/falsos frutos. Per maiali e cavalli. Dargli da mangiare i marroni d'india li fa ingrassare (RFR).

Sector doméstico

Categoría de uso: Integración de la renta familiar.

Número de informantes: 1 Partes utilizadas: frutos/infrutescencias/falsos frutos. La gente raccoglievano le castagne d'india e le vendevano a un signore. In piazza a Vizzero ce ne sono tanti. (MGE).

Sector mágico/medicinal

Categoría de uso: Otro mágico/medicinal.

Número de informantes: 1 Partes utilizadas: frutos/infrutescencias/falsos frutos. Emorroidi: tenere il frutto in tasca finché passa. (GAN).

Categoría de uso: Preventivo de enfermedades.

Número de informantes: 4 Partes utilizadas: frutos/infrutescencias/falsos frutos. Tenere una castagna d'india in tasca tiene lontane le malattie (REN)| Portare una castagna d'india in tasca per allontanare il raffreddore (UMI)| Se porti una castagna d'India in tasca non ti vene il raffreddore'. (RMA)| Quando cascano le 'castagne' si raccolgono e si mettono in tasca o in camera per prevenire il raffreddore. (LST).

Sector medicinal

Categoría de uso: Patologías del aparato circulatorio.

Número de informantes: 2 Partes utilizadas: frutos/infrutescencias/falsos frutos. Grattugiare il frutto secco della castagna d'india e mescolare con dell'olio, quindi applicare direttamente sulle emorroidi. (BIO)| Lavarsi con l'acqua del decotto di Castagne di India e portare sempre 1 o 2 castagne dietro (NLA).

Categoría de uso: Trastornos musculo-esqueléticos.

Número de informantes: 1 Partes utilizadas: frutos/infrutescencias/falsos frutos.

Bollire le castagne e farci il bagno per I reumatismi. (VMR).

Notas Ce n'è uno alla chiesa a Bargi.

DATOS ETNOBOTÁNICOS BIBLIOGRÁFICOS

Nombre vulgar: marån d'Endia (UNGA21), castagno d'India (MANG98). 
Número de referencias: 2 Número de citas: 2 .

Número de sectores: 2 Número de categorías: 2.

Sector agropastoral

Categoría de uso: Antiparasitario.

Número de referencias: 1 Partes utilizadas: semillas.

I semi stessi tenuti in macerazione per 24 ore in otto o dici litti d'acqua servono agli ortolani per distruggere I bruchi, gli insetti e le larve delle piante, inaffiandole con quest'acqua (UNGA21).

Sector medicinal

Categoría de uso: Patologías del aparato circulatorio.

Número de referencias: 1 Partes utilizadas: frutos/infrutescencias/falsos frutos.

Il frutto grattugiato, viene applicato localmente. (MANG98).

70. SCROPHULARIACEAE

\section{Scrophularia scopolii Hoppe ex Pers.}

Nombre vulgar: Bertonica (TOA, BFE), Bettonica (TAD).

Número de informantes: 3 Número de citas: 4.

Número de sectores: 1 Número de categorías: 2.

Biotipo: Hemicriptófito.

Tipo corológico: Europeas.

Abundancia: Común.

Ambiente: Bosques aclarados.

Número de exsiccata: 38965 FIAF.

Sector medicinal

Categoría de uso: Afecciones cutáneas y tejidos subcutáneos.

Número de informantes: 3 Partes utilizadas: hojas.

Applicare le foglie della bertonica sul foruncolo per tirare fuori il pus. (BFE)| Ferite: applicare la foglia della bertonica sopra la ferita, legata con un foulard. Bruciature: mettere subito a mollo in acqua fredda oppure dell'olio di oliva. Se vengono le piaghe, mettere delle foglie di bertonica (TOA)| La sera, bagnare la foglia con la saliva e metterla sopra la ferita finché voglia starci. (TAD).

Categoría de uso: Afecciones oro-faríngeas y de la cavidad oral.

Número de informantes: 1 Partes utilizadas: hojas.

Si apriva l'acesso, e si metteva una foglia cruda in bocca, sopra finché reggevano (perché era.

cattiva), poi si sputava. "Sfiammava". (TOA).

Notas Ora la bertonica è rara perché non si coltivano più I campi.

\section{Verbascum thapsus $L$.}

Nombre vulgar: (non si ricorda) (TGA), Tasso varbasso (PIM), Sasso bardasso (MGE, CBR), 
Tasso barbasso, Verbasco (NRO), Erba delle botte (BEL).

Número de informantes: 6 Número de citas: 7.

Número de sectores: 2 Número de categorías: 5 .

Biotipo: Hemicriptófito.

Tipo corológico: Europeas.

Abundancia: Común.

Ambiente: Baldíos áridos, ruinas.

Sector doméstico

Categoría de uso: Cuidado personal y cosmética.

Número de informantes: 1 Partes utilizadas: hojas.

Per lavarsi I denti, prendendo una foglia e strofinandola sui denti (TGA).

Sector medicinal

Categoría de uso: Afecciones del aparato respiratorio.

Número de informantes: 1 Partes utilizadas: flores/inflorescencias y sus partes.

Si raccoglievano e si seccavano i fiori. Poi si beveva il decotto per la tosse. (PIM).

Categoría de uso: Patologías del aparato circulatorio.

Número de informantes: 3 Partes utilizadas: hojas, flores/inflorescencias y sus partes.

Si usavano la foglie del sasso bardasso per le emorroidi, ma non si ricorda come $(\mathrm{CBR}) \mid$ non se lo ricorda. (MGE)| "In un tegame con l'olio, fare un po' cuocere I fiori" (NRO).

Categoría de uso: Patologías del aparato urinario.

Número de informantes: 1 Partes utilizadas: hojas.

Bere il decotto delle foglie del sasso bardasso contro l'infezione d'urina. (MGE).

Categoría de uso: Trastornos musculo-esqueléticos.

Número de informantes: 1 Partes utilizadas: hojas.

Applicare la foglia sulla contusione e fasciare. (BEL).

Notas Lei si è sempre lavata I denti con quelle foglie e a 89 anni ancora conserva tutti I denti!, foglie veluttate, grandi, fiori gialli a spiga, Il suo nonno lo usava.

DATOS ETNOBOTÁNICOS BIBLIOGRÁFICOS

Nombre vulgar: tâs bardâs (UNGA21), tasso bardasso (MANG98).

Número de referencias: 2 Número de citas: 5 .

Número de sectores: 3 Número de categorías: 4.

Sector doméstico

Categoría de uso: Cuidado personal y cosmética.

Número de referencias: 1 Partes utilizadas: flores/inflorescencias y sus partes.

E coi fiori lasciati per qualche tempo nella lisciva si pretende di dare ai capelli il colore dell'oro. (UNGA21).

Sector mágico/medicinal

Categoría de uso: Otro mágico/medicinal.

Número de referencias: 1 Partes utilizadas: planta entera/viva.

Nella medicina popolare è ancora usata conto l'itterizia: e le donne fanno orinare l'ammalato. 


\section{María Teresa Egea Molines}

su questa pianta, credendo che ciò serva a far fuggire il male. (UNGA21).

\section{Sector medicinal}

Categoría de uso: Afecciones cutáneas y tejidos subcutáneos.

Número de referencias: 2 Partes utilizadas: hojas, flores/inflorescencias y sus partes.

In caso di eczemi si è soliti sia effettuare impacchi locali con foglie sbollentate, sia berne il decotto o 1'infuso (MANG98)| I fiori pestati vengono impiegati come empiastro contro le punture delle vespi ed altri insetti. (UNGA21).

Categoría de uso: Patologías del aparato circulatorio.

Número de referencias: 1 Partes utilizadas: flores/inflorescencias y sus partes.

In caso di emorroidi si è soliti sia effettuare impacchi locali con foglie sbollentate, sia berne il decotto o l'infuso. Alcuni, sempre per il trattamento delle emorroidi, preparano un linimento facendo soffriggere i fiori in olio d'oliva (MANG98).

\section{SOLANACEAE}

\section{Atropa belladona $L$.}

Nombre vulgar: Belladonna (SOT, TIV, NLA, GGI, CFR).

Número de informantes: 5 Número de citas: 5.

Número de sectores: 2 Número de categorías: 2.

Biotipo: Hemicriptófito.

Tipo corológico: Montañosas.

Abundancia: Rara.

Ambiente: Desmontes húmedos, bosques de monte bajo, claros de bosques latifolios.

(sobre todo hayedos, más raramente robledales).

Número de exsiccata: 39010 FIAF.

Sector efecto nocivo

Categoría de uso: Tóxicas y venenosas.

Número de informantes: 4 Partes utilizadas: semillas, frutos/infrutescencias/falsos.

Anticamente hanno avvelenato della gente con i semi (CFR)| Bacche belle e viole, qualcuno le ha mangiato pensando che fossero dei frutti di bosco ed si è avvelenato (GGI) $\mathrm{Ci}$ sono due piante varieta: la femmina è quella tossica, si va in coma, e il maschio non. (NLA)| Era una pianta da evitare (TIV).

Sector medicinal

Categoría de uso: Patologías del aparato digestivo.

Número de informantes: 1 Partes utilizadas: hojas.

"lo usavano quando soffrivano di disturbi digestivi, tipo gastrite, perché rilassava." (SOT).

Notas Il medico lo usava come sedativo. 


\section{Capsicum annuum $L$.}

Nombre vulgar: Peperoncini (VMU), Peperoncino (LST).

Número de informantes: 2 Número de citas: 3.

Número de sectores: 2 Número de categorías: 3 .

Biotipo: Nanofanerófito.

Tipo corológico: Cultivadas.

Abundancia: Cultivada.

Ambiente: Cultivada.

Sector agropastoral

Categoría de uso: Antiparasitario.

Número de informantes: 1 Partes utilizadas: frutos/infrutescencias/falsos frutos.

Mettere in un bidone la coda cavallina, insieme all'ortica, e ai peperoncini. Lasciare macerare da 15 a 20 giorni. Poi con un ciuffo di erba si bagna in questo composto e si spruzza sui pidocchi dei faggioli o dei cavoli. (VMU).

Categoría de uso: Horticultura.

Número de informantes: 1 Partes utilizadas: frutos/infrutescencias/falsos frutos.

Mettere in un bidone la coda cavallina, insieme all'ortica, e ai peperoncini. Lasciare macerare.

da 15 a 20 giorni. Poi si mette accanto alle piantine come concime. (VMU).

Sector mágico/ritual/supersticioso

Categoría de uso: Protector.

Número de informantes: 1 Partes utilizadas: frutos/infrutescencias/falsos frutos.

$\mathrm{Si}$ attaccavano alle case per allontanare le streghe (LST).

DATOS ETNOBOTÁNICOS BIBLIOGRÁFICOS

Nombre vulgar: pevrån (UNGA21).

Número de referencias: 1 Número de citas: 1.

Número de sectores: 1 Número de categorías: 1.

Sector alimentario

Categoría de uso: Encurtidos y conserva en aceite.

Número de referencias: 1 Partes utilizadas: frutos/infrutescencias/falsos frutos.

p. il cui frutto pizzicante è conservato in aceto. (UNGA21).

\section{Lycopersicon esculentum Mill.}

Nombre vulgar: Pomodori (NMA), Pomodori acerbi (MSI), Pomodori verdi (GAN), Pomodoro (TOA).

Número de informantes: 4 Número de citas: 5.

Número de sectores: 2 Número de categorías: 4.

Biotipo: Terófito.

Tipo corológico: Cultivadas.

Abundancia: Cultivada.

Ambiente: Cultivado en grande escala y a menudo subspontaneo en escombros, guijarrales, ruinas. 
Sector alimentario

Categoría de uso: Conserva de frutas.

Número de informantes: 1 Partes utilizadas: frutos/infrutescencias/falsos frutos.

Si bollono i pomodori e si imbottiglia in bottiglie (NMA).

Categoría de uso: Fruta seca.

Número de informantes: 1 Partes utilizadas: frutos/infrutescencias/falsos frutos.

Si bollono i pomodori, si strizzano, e si mettono ad essiccare al sole su un tavolo di legno, poi si conservano in barattoli (NMA).

Categoría de uso: Mermelada.

Número de informantes: 2 Partes utilizadas: frutos/infrutescencias/falsos frutos.

Con gli ultimi pomodori della stagione, i pomodori che ingialliscono, acerbi, fare la marmellata, con tutta la scorza di un limone tagliata a pezzettini, $500 \mathrm{gr}$ di zucchero per $1 \mathrm{~kg}$ di pomodori e fare bollire fino a raggiungere la consistenza voluta. (MSI)| Lavare I pomodori verdi dell'orto, tagliarli a fettine, levare I semi, persarli e per $1 \mathrm{~kg}$ di pomodori mettere 2 limoni tagliati finemente, e 7 etti di zucchero, bollire I pomodori un pò finché si stringe e prende la consistenza della mermellata. (GAN).

\section{Sector medicinal}

Categoría de uso: Afecciones cutáneas y tejidos subcutáneos.

Número de informantes: 1 Partes utilizadas: frutos/infrutescencias/falsos frutos. Tagliare il pomodoro a metà e applicarlo sulla parte ustionata. (TOA).

Notas Non si deve imbottigliare mai a Luna Nova puo ribollire e scoppiare. Si imbottiglia dopo la Luna Nova (nera) quando abbiano passati 2 "R", ossia un martedi e un venerdi.

\section{Nicotiana tabacum $L$.}

Nombre vulgar: (GGL)Tabacco (REN, BPT), Tabacco (MGO, BLI, TGA, NLA, MSR, MCL, GLA), Sigaro (SLU), Tabacco da sigaro (SLU).

Número de informantes: 11 Número de citas: 12.

Número de sectores: 3 Número de categorías: 6 .

Biotipo: Terófito.

Tipo corológico: Cultivadas.

Abundancia: Cultivada.

Ambiente: Cultivos.

Sector agropastoral

Categoría de uso: Antiparasitario.

Número de informantes: 2 Partes utilizadas: hojas.

Antiparassitario per i pidocchi delle rose:Macerato di Tabacco (BPT)| Macerare il tabacco e spruzzare sui cavoli o I faggioli, contro "I bruci" (I pidocchi). (REN).

Categoría de uso: Horticultura.

Número de informantes: 1 Partes utilizadas: hojas.

Mettere a macerare due sigari toscani dentro a un litro di acqua, e spruzzare sulle piante dell'orto, contro I pidocchi (GGL). 
Sector doméstico

Categoría de uso: Repelentes o trampas domésticas.

Número de informantes: 1 Partes utilizadas: hojas.

Per allontare le tarme dagli armadi: mettere delle foglie secche di tabacco negli armadi. (GLA).

\section{Sector medicinal}

Categoría de uso: Afecciones oro-faríngeas y de la cavidad oral.

Número de informantes: 5 Partes utilizadas: hojas.

Le spuntature del tabacco, le parti che avanzavano, si mettevano sui denti (SLU)| Mettere il tabacco sopra il dente (MCL)| Trinciare il tabacco da un sigaro e applicarlo sul dente bucato. (MSR)| "la nicotina" si mette dentro a un'ostia e si mette il tutto sopra il dente (NLA)| Mettere tabacco trinciato sopra il dente bucato (TGA)| Le spuntature del tabacco, le parte che avanzavano, si mettevano sui denti (SLU).

Categoría de uso: Dolor de cabeza.

Número de informantes: 1 Partes utilizadas: hojas.

Tenevano il tabacco in una scatolina, lo annusavano e starnutivano, così gli passava il mal di testa. (BLI).

Categoría de uso: Parásitos externos.

Número de informantes: 1 Partes utilizadas: hojas.

Fare dei lavaggi con l'acqua del decotto del tabacco (anche da un sigaro comprato), finché andavano via. (MGO).

Notas Sigaro toscano, Loro l'avevano coltivata in un vaso nel "campo del miglio"., Si coltivava in posti nascosti, perché era vietato.

\section{Solanum americanum Mill. (= Solanum nigrum L.)}

Nombre vulgar: Erba mora (GGI).

Número de informantes: 1 Número de citas: 1.

Número de sectores: 1 Número de categorías: 1.

Biotipo: Terófito.

Tipo corológico: Amplia distribución.

Abundancia: Bastante Común.

Ambiente: Campos, baldíos, ruinas.

Sector caza y pesca

Categoría de uso: Ictiotóxico.

Número de informantes: 1 Partes utilizadas: parte aérea (toda).

Raccogliere la pianta, pestarla con due pietre del fiume e metterla in un sacco dentro al fiume. I pesci si avvelenavano e venivano su. (GGI).

DATOS ETNOBOTÁNICOS BIBLIOGRÁFICOS

Nombre vulgar: êrba muraela (UNGA21).

Número de referencias: 1 Número de citas: 2.

Número de sectores: 1 Número de categorías: 2 .

Sector medicinal

Categoría de uso: Afecciones del aparato respiratorio. 


\section{María Teresa Egea Molines}

Número de referencias: 1 Partes utilizadas: No especificado.

solano, volg. Erba morella, p. delle solanacee com. Ne muri e fra le macerie con prop. Venef. Peric. Gli antichi le attribuivano virtù diuretiche. Nella med. Pop. È usata in infuso come diuretiche e anticattarali. Il Cresc. La consigliava per sanare il vino dalla muffa, infondendone un mazzettino nella parte superiore della botte.(UNGA21).

Categoría de uso: Patologías del aparato urinario.

Número de referencias: 1 Partes utilizadas: No especificado.

solano, volg. Erba morella, p. delle solanacee com. Ne muri e fra le macerie con prop. Venef. Peric. Gli antichi le attribuivano virtù diuretiche. Nella med. Pop. È usata in infuso come diuretiche e anticattarali. Il Cresc. La consigliava per sanare il vino dalla muffa, infondendone un mazzettino nella parte superiore della botte.(UNGA21.

\section{Solanum tuberosum $L$.}

Nombre vulgar: Patate (BLI, DAD, VMR), Patata.

(MOR, MME, MGE, BAZ, TUL, TIV, TGA, RFR, LST, GGI, GFO, CFR, BSI, TRU, NS.

T, NRE, NMA, MSR, MGO, BOR, BFE, BBI, TAD, LGI, RMA).

Número de informantes: 28 Número de citas: 39.

Número de sectores: 5 Número de categorías: 10.

Biotipo: Terófito.

Tipo corológico: Cultivadas.

Abundancia: Cultivada.

Ambiente: Cultivada de forma común y subspontanea en los cultivos.

Sector agropastoral

Categoría de uso: Alimentación animal (incluidos los forrajeros).

Número de informantes: 1 Partes utilizadas: órganos subterráneos.

Si faceva la broda del maiale a base di ortica sbollentata, semola, grano turco, patate (quelle piccole che avanzavano con la buccia), farina dolce (castagne), siero del latte. (VMR).

\section{Sector alimentario}

Categoría de uso: Pan y similares.

Número de informantes: 1 Partes utilizadas: órganos subterráneos.

Si faceva il pane con farina di segale, che coltivavano, perché era più digeribile che con la farina di grano. Il pane si faceva anche con patate passate, farina di segale settaciata e siero del formaggio. Dopo una settimana era ancora morbido. (RMA).

Categoría de uso: Relleno de ravioli.

Número de informantes: 1 Partes utilizadas: órganos subterráneos.

Cotti insieme a rape, bietole, o qualsiasi altra verdura per ripieno dei ravioli (DAD).

Categoría de uso: Sopas de verduras y potaje.

Número de informantes: 4 Partes utilizadas: semillas, órganos subterráneos.

La zuppa di pane è fatto soffriggendo l'aglio, aggiungere il pomodoro, l'acqua, I faggioli, il cavolo nero, una patata, un pezzo di prosciutto, tanto olio, e fare bollire 2 
ore, poi versare sopra un fetta di pane e olio. (LGI)| Le patate si seminavano per fare le minestre (BLI, TAD)| Cotti in minestre o zuppe insieme ad altre verdure come la rapa, la bietola (DAD).

\section{Sector lúdico/voluptuoso}

Categoría de uso: Fumable.

Número de informantes: 1 Partes utilizadas: hojas.

Foglie seccate di patata, sbriciolate sulla cartina e fumate quando non c' era tabacco. (DAD).

\section{Sector medicinal}

Categoría de uso: Afecciones cutáneas y tejidos subcutáneos.

Número de informantes: 9 Partes utilizadas: órganos subterráneos.

Applicare direttamente sulla bruciatura una fetta di patata. (NST, BBI)| Applicare una fetta di patata sulla parte ustionata (BFE)| Applicare una fetta di patata fresca sulla bruciatura. (BOR)| Strofinare una fetta di patata sulla pelle arrossata (MGO)| Tagliare una fetta di patata e applicarla strofinandola sulla bruciatura. (MSR)| Si prende una fetta di patata e si mette sopra (NMA)| Applicare una fetta di patata sulla bruciatura. (NRE)| Applicare una fetta di patata sopra bruciatura (TRU).

Categoría de uso: Afecciones oftalmológicas.

Número de informantes: 12 Partes utilizadas: órganos subterráneos.

Applicare direttamente sull'occhio arrossato una fetta di patata. (NST, BBI)| Applicare una fetta di patata sull'occhio infiammato (BFE)| Applicare una fetta di patata sugli occhi arrossati (che sembra che brucino) per tutta la notte quando si è a letto e cambiare la fetta quando diventa nera. (BSI)| Fette di patata cruda messe sugli occhi per sfiammarli (CFR)| Fette di patate applicate sugli occhi e cambiate spesso (GFO)| Fetta di patata applicata direttamente sull' occhio (GGI)| Applicare una fetta di patata sopra gli occhi rossi. (LST)| Si grattugiava la patata e si applicava direttamente sugli occhi infiammati. (RFR)| Tagliare una fetta di patata e applicare sopra l'occhio infiammato. (TGA)| Fette di patata cruda messi sugli occhi per sfiammare gli occhi (TIV)| Una fetta di patata sugli occhi, sfiamma. (TUL).

Categoría de uso: Afecciones oro-faríngeas y de la cavidad oral.

Número de informantes: 5 Partes utilizadas: órganos subterráneos.

Applicare una fetta di patata sopra l'infiammazione (sulla guancia). (BAZ)| Si applicava una fetta di patata sulla guancia infiammata e si fasciava intorno alla testa. (MGE)| Appoggiare una fetta di patata sull'infiammazione, legata con un fazzoletto oppure no. (MME)| Applicare una fetta di patata sul dente (MOR)| Fette di patate messa nel posto infiammato e fasciato con un pezzo di stoffa intorno alla testa. (TAD).

Categoría de uso: Patologías del aparato digestivo.

Número de informantes: 2 Partes utilizadas: órganos subterráneos.

Grattata la patata cruda e strizzata, liquido bevuto la mattina (CFR)| Grattugiare la patata e strizzare la patata e bere il succo. (TGA).

Sector veterinario

Categoría de uso: Cerdos.

Número de informantes: 3 Partes utilizadas: órganos subterráneos. 
Come alimento energetico post-parto per i maiali si usava la 'broda', fatta con la 'rimanenza' delle patate (patate piccole, scarti di raccolta) cotte, semola cruda, orzo crudo e ortica cotta a parte, tutto mescolato. (DAD)| Quando I maiali stavano poco bene gli davano da mangiare l'ortiga cotta con la semola e la patata. (GGI)| Per prevenire la "Moria" dei maiali (pandemia). Quando si sentiva dire che c'era la moria, si dava da mangiare ai maiali la 'broda': cuocere l'ortica insieme alle patate, alle carote, al farfaro, alle castagne secche e alla semola. (BLI).

Notas I campi si coltivavano alternativamente: il primo si coltivava sempre le patate, che una volta raccolte, avevano fatto di concime per il campo. L'anno dopo si puo coltivare il grano, e la primavera successiva la segale, l'orzo, l'erba medica, ginestrina, trifoglio (per fare il fieno per gli animali). Lo facevano spesso agli uomini che saldavano.Quando si raccoglievano le patate per conservarle si faceva una bucca di un metro, poi si metteva un po di pailla sotto, si riempiva di patate appen a raccolte e si coprivano di pailla. Così si consevavano e rimanevano sempre come appena raccolte. Le patate vanno conservate al buio sennon diventano tossiche.oi quando stavano per finire, le ultime che rimanevano con gli occhi si usavano per seminare.Seminare in Luna Calante, deve aver passato $1 / 4$ di vita della Luna piena, il primo Martedi o Venerdi.

DATOS ETNOBOTÁNICOS BIBLIOGRÁFICOS

Nombre vulgar: patate (BADI15), patata (BER81, MATT), pataeda (UNGA21).

Número de referencias: 4 Número de citas: 6 .

Número de sectores: 3 Número de categorías: 4.

\section{Sector alimentario}

Categoría de uso: Otro alimentario.

Número de referencias: 1 Partes utilizadas: órganos subterráneos.

Patate la forno con funghi. Ingredienti :Patate, funghi porcini,parmigiano,olio, sale e pepe. Si fanno lessare le patate badando che restino un po' durette. Si pelano e si tagliano a fette dello spessore di 4 o $5 \mathrm{~mm}$.Si prendono alcuni porcini giovani (bastano tre' o quattro) e si tagliano a Fettine sottili.In una pirofila si pone uno strato di patate e sopra uno strato di porcini e si condisce il tutto con olio,sale pepe ed una buona spolverata di parmigiano. Si fanno tanti strati fino ad esaurimento delle patate, badando di non mettere i funghi sullo ultimo strato (diventerebbero secchi).Si mettono al forno a $150^{\circ}$ per mezz'ora Costituiscono un ottimo secondo (BADI15).

Categoría de uso: Sopas de verduras y potaje.

Número de referencias: 1 Partes utilizadas: órganos subterráneos.

Zuppa di cavolo nero. Ingredienti:Cavolo nero,sedano,porro,patate,fagioli borlotti,pancetta,olio,cotenne di maiale, concentrato di pomodoro,pane raffermo,aglio,prezzemolo,sale e pepe. In una pentola di terracotta si mettono a cuocere i fagioli borlotti messi a mollo la sera prima. Si tritano intanto il cavolo nero,un porro,una costa di sedano e si aggiungono ai fagioli. Dopo qualche tempo si mettono le patate (non in grande quantità) tagliate a dadi. Si fa poi un bel battuto di aglio e prezzemolo e si mette a soffriggere con l'olio, senza farli strinare,poi si aggiunge il concentrato di pomodoro sciolto nell'acqua.Quando il tutto si è insaporito, lo si versa nella pentola,che dovrà bollire per almeno 4 ore. Se si vuole che la zuppa sia più saporita si mettono a bollire con le verdure anche alcune cotiche 
di maiale. Si pongono poi alcune fettine di pane nel piatto e vi si versano sopra le verdure col brodo. La zuppa ora è pronta,ma conviene lasciarla riposare un pochino prima di mangiarla (BADI15)| Minestra di patate. Ingredienti: Patate,olio,scalogno,brodo,vino bianco,due o trè pomodorini,sale e pepe.Si pulisce lo scalogno e si fa soffriggere leggermente in un tegame con olio extravergine D'oliva.Si pelano le patate e si tagliano a dadini.Si aggiungono poi allo scalogno facendole insaporire un po' e si versa del brodo di dado o di carne.Si uniscono mezzo bicchiere di vino bianco secco,sale e pepe.Si continua poi ad aggiungere liquido fino alla cottura delle patate. Per ultimi si mettono due o trè pomodorini e si controlli che vi sia liquido sufficiente per cuocere la pasta.Si butta la pasta (ditali rigati o altro,.Si serve con abbondante (BADI15).

Sector mágico/ritual/supersticioso

Categoría de uso: Efecto negativo.

Número de referencias: 1 Partes utilizadas: harina/salvado.

La semolata era molto offensiva. Veniva fatta di notte alle persone che non si comportavano moralmente bene, sopratutto se davano scandalo. Ecco come veniva fatta: si preparava semola e patate trinciate (il magime dei suini) e si gettavano nella strada che conduceva all'abitazione della persona scandalosa. (MATT).

\section{Sector medicinal}

Categoría de uso: Afecciones cutáneas y tejidos subcutáneos.

Número de referencias: 1 Partes utilizadas: órganos subterráneos.

La medicina popolare ne usa la fecola per cataplasmi ed è rimedio empirico l'applicazione.

della raschiatura di essa sulle ustioni (UNGA21).

Notas Con polenta e patata, ogni fam l'è sazià. (Castel di Casio).

\section{THEACEAE}

\section{Camellia sinensis (L.) Kuntze}

Nombre vulgar: Te (NST, AN3).

Número de informantes: 2 Número de citas: 2.

Número de sectores: 1 Número de categorías: 1.

Biotipo: Fanerófito.

Tipo corológico: Exóticas.

Abundancia: Cultivada.

Ambiente: Ausente (cultivada in la zona de Lucca de forma experimental).

\section{Sector alimentario}

Categoría de uso: Licor.

Número de informantes: 2 Partes utilizadas: hojas.

Liquore Cent'erbe della Nonna: 5 o 6 foglie di salvia, 5 o 6 foglie di Basilico, una bustina di te (una volta lo vendevano sciolto in bottega), germogli di pino, rosmarino e menta selvatica. 1 etto zucchero, 1 etto di alcol, 1 etto di acqua. Lasciare tutto sotto 
alcol per 21 giorni. Bollire lo zucchero e l'acqua e passare tutto e mescolare. (AN3) Cento erbe': 3 foglie di alloro, 3 foglie di limone, 3 coccole di ginepro, 3 fiori di camomilla, 3 foglie di té, 3 foglie di salvia, 3 foglie di rosmarino, mettere a macerare in un litro di acqua bollita con 350 gr di zucchero e a cui siano stati poi aggiunti 40 gr di alcol a $90^{\circ}$. (NST).

Notas ricette tramandate dalle nonna e dalla mamma. La sua nonna lo faceva con la grappa invece dell'alcol, che loro stessi distillavano con le vinacce dell'uva..

DATOS ETNOBOTÁNICOS BIBLIOGRÁFICOS

Nombre vulgar: tè (MANG98).

Número de referencias: 1 Número de citas: 1.

Número de sectores: 1 Número de categorías: 1.

Sector medicinal

Categoría de uso: Afecciones oftalmológicas.

Número de referencias: 1 Partes utilizadas: hojas.

L'infuso zuccherato viene considerato valido bagno oculare in caso di infiammazioni e congiuntiviti (MANG98).

\section{THYMELAEACEAE}

\section{Daphne laureola $L$.}

Nombre vulgar: Laurella (GGI).

Número de informantes: 1 Número de citas: 1.

Número de sectores: 1 Número de categorías: 1.

Biotipo: Fanerófito.

Tipo corológico: Atlánticas y Mediterráneas.

Abundancia: Rara.

Ambiente: Bosques latifolios sobre terrenos ligeramente ácidos (roble, castaños, más.

raramente hayas o encinas).

Sector efecto nocivo

Categoría de uso: Tóxicas y venenosas.

Número de informantes: 1 Partes utilizadas: planta entera/viva.

Ha uno stelo duro, come il salice, con una nappa di foglie, bacche nere ed è tossico. (GGI).

\section{ULMACEAE}

\section{Ulmus minor Mill.}

Nombre vulgar: Olmo (RRE, GGL, PIM, SOT, SLU).

Número de informantes: 5 Número de citas: 8.

Número de sectores: 4 Número de categorías: 5. 
Biotipo: Fanerófito.

Tipo corológico: Europeas.

Abundancia: Común.

Ambiente: Bosques, setos, baldíos.

Número de exsiccata: 38995 FIAF.

Sector agropastoral

Categoría de uso: Alimentación animal (incluidos los forrajeros).

Número de informantes: 1 Partes utilizadas: hojas.

Forragera per le pecore:Fascie di rami con le foglie, messi ad essicare per conservare per l'inverno (SLU).

Categoría de uso: Herramientas y objetos agrícolas.

Número de informantes: 1 Partes utilizadas: tallos leñosos/ramas/ramitas/vástagos.

Per fare i gioghi sul collo delle bestie. (SOT).

\section{Sector artesanal}

Categoría de uso: Otro artesanal.

Número de informantes: 1 Partes utilizadas: madera.

Si usa il legno dell'olmo per fare il 'giogo della campana', la struttura a cui è appesa la campana per farla suonare. (PIM).

Sector doméstico

Categoría de uso: Detergente.

Número de informantes: 1 Partes utilizadas: tallos leñosos/ramas/ramitas/vástagos.

L'olmo è la pianta che migliore cenere dava per fare il bucato. (SLU).

Sector medicinal

Categoría de uso: Afecciones cutáneas y tejidos subcutáneos.

Número de informantes: 4 Partes utilizadas: agallas, corteza.

Applicare il liquido delle galle dell'olmo sulle ferite, finché si stava meglio. Il liquido è denso e forma una pellicola sulla ferita. (RRE, GGL)| Mettere dei panni bagnati nel decotto di corteccia di olmo sull'eczema. (PIM)| A giugno il 'frutto' (galla) fa "l'olio di San Giovanni". Aprire il 'frutto' ed applicare direttamente sulla affezione. (SLU).

Notas Rami raccolti con le foglie l'ultima settimana di agosto fino al il primo di settembre, quando finisce il sole, caratteristica del legno: è un legno che ha un peso specifico uguale, per quello si usa per fare il giogo della campana,.

DATOS ETNOBOTÁNICOS BIBLIOGRÁFICOS

Nombre vulgar: aulum (UNGA21), olmo (MANG98, GUC98).

Número de referencias: 3 Número de citas: 5 .

Número de sectores: 2 Número de categorías: 5 .

Sector agropastoral

Categoría de uso: Alimentación animal (incluidos los forrajeros).

Número de referencias: 1 Partes utilizadas: hojas. 
... e per le foglie alim. Al bestiame (UNGA21).

Categoría de uso: Herramientas y objetos agrícolas.

Número de referencias: 1 Partes utilizadas: tallos leñosos/ramas/ramitas/vástagos. Il mazzo era la mazza di legno, di solito di sorbo o di olmo, cerchiata di ferro alle estremità, si usava per spaccare i tronchi più grossi piantando nel legno delle biétte. (GUC98).

Categoría de uso: Otro agropastoral.

Número de referencias: 1 Partes utilizadas: tallos leñosos/ramas/ramitas/vástagos. Fascine di polloni di castagno, quercia e olmo, con foglie (vinciò) si facevano di solito nel periodo dell'armondadura, ripulendo le plonare attorno ai castagni, ma cne pulendo le altre piante. Si usava metterle sulla cima del pagliaio per proteggere il fieno della pioggia..

Categoría de uso: Viticultura y enología.

Número de referencias: 1 Partes utilizadas: parte aérea (toda).

p. estes. Colt. Nella n. prov. Per sostegno alla vite e per le foglie alim. Al bestiame (UNGA21).

\section{Sector medicinal}

Categoría de uso: Afecciones cutáneas y tejidos subcutáneos.

Número de referencias: 1 Partes utilizadas: corteza.

La corteccia priva della parte suberificata viene cotta in olio d'oliva, dopodiché si aggiunge.

cera vergine d'api e strutto, il preparato si applica su eczemi e dermatiti varie. (MANG98).

\section{URTICACEAE}

\section{Parietaria officinalis $L$. (s. l.)}

Nombre vulgar: Erba vetrina, Gambo rosso (REN), Gambo rosso (VMR, GFR, QNE, GGI, CRI, BAN), Parietaria, Gambo rosso (PCL), Erba vetrina (TOA, GAN), Parietaria (PCL), Vetriola (BIO).

Número de informantes: 11 Número de citas: 14.

Número de sectores: 3 Número de categorías: 5.

Biotipo: Hemicriptófito.

Tipo corológico: n.d.

Abundancia: Común.

Ambiente: Suelos boscosos eutróficos, escombros, terrenos abandonados, a menudo nitrófilos y en ambientes sombreados.

\section{Sector agropastoral}

Categoría de uso: Alimentación animal (incluidos los forrajeros).

Número de informantes: 7 Partes utilizadas: parte aérea (toda).

Per dargli da mangiare ai maiali (REN)| Il gambo rosso crudo si usava per l'alimentazione dei conigli (QNE, BAN)| La davano da mangiare ai maiali cruda $(\mathrm{CRI}) \mid$ Per dare da mangiare ai maiali, cruda. Insieme alla romice e all'erba ciliegina. 
(GGI)| Per dare da mangiare direttamente ai maiali, gli faceva bene. Si usava insieme al gambo rosso, l'erba ciliegina, a volta la romice e l'ortica scottata. (GFR)| Si dava da mangiare ai maiali la pianta cruda.

\section{Sector doméstico}

Categoría de uso: Detergente.

Número de informantes: 4 Partes utilizadas: parte aérea (toda).

Lavare il vetro con l'erba vetrina e dell'acqua (GAN)| Per lavare I bichieri, o per lavare I fiaschi con l'erba vetrina e l'acqua, e alla fine un po' di aceto. (REN)| Per lavare le bottiglie, mettere l' ortica insieme al gambo rosso dentro con l' acqua, agitare e strofinare. (GGI)| La parte epigea era usata per lavare le bottiglie di vetro (PCL).

\section{Sector medicinal}

Categoría de uso: Estado general.

Número de informantes: 1 Partes utilizadas: parte aérea (toda).

Bere il decotto dell'erba vetriola tutte le sere per le infiammazione, fa bene per tutto. (BIO).

Categoría de uso: Patologías del aparato circulatorio.

Número de informantes: 1 Partes utilizadas: parte aérea (toda).

"Rosolare nell'olio l'erba vetrina, e applicare poi l'olio sulle emorroidi" (TOA).

Categoría de uso: Patologías del aparato urinario.

Número de informantes: 1 Partes utilizadas: hojas.

Per desinfettare la vescica e I reni, bere 3 o 4 volte al giorno una tazza di infuso delle foglie del gambo rosso, finché passa (VMR).

Notas La Carla quando c'era lo faceva tutte le sere sempre e diceva "bevilo anche te!".

\section{DATOS ETNOBOTÁNICOS BIBLIOGRÁFICOS}

Nombre vulgar: gambi rossi (GUC98), erba vetriola, parietaria, vetriolo (MANG98), vidariôl.

(UNGA21).

Número de referencias: 3 Número de citas: 5.

Número de sectores: 2 Número de categorías: 4.

\section{Sector doméstico}

Categoría de uso: Detergente.

Número de referencias: 1 Partes utilizadas: parte aérea (toda).

La pianta era talvolta usata per lavare le bottiglie. (GUC98).

\section{Sector medicinal}

Categoría de uso: Afecciones cutáneas y tejidos subcutáneos.

Número de referencias: 1 Partes utilizadas: parte aérea (toda).

Le foglie fresche contuse si applicano localmente sul fuoco di Sant'Antonio (MANG98).

Categoría de uso: Estado general.

Número de referencias: 1 Partes utilizadas: parte aérea (toda). 
L'infuso misto con capelvenere viene bevuto come valido antinfiammatorio (MANG98).

Categoría de uso: Patologías del aparato urinario.

Número de referencias: 1 Partes utilizadas: parte aérea (toda).

L'infuso si beve per aumentare la diuresi ed in caso di prostatite. (MANG98).

\section{Urtica dioica $L$.}

Nombre vulgar: Ortica (AMA, AMA, AMA, AP2, BAZ, BBA, BBA, BBA, BBI, BBI, BEL, BFE, BGI, BIO, BLI, BPT, BSO, CFR, CLO, CRE, CRI, CRO, DAD, FAM, GAN, GCL, GFR, GGI, GGL, GLA, GZE, IMA, LGI, LLU, LRE, LST, MCL, MDA, MGE, MGO, MIO, MRI, MSA, MSR, MVI, NDI, NER, NLA, NRE, NRO, PCL, PEL, PGI, PIA, PLU, RFR, RMA, RNI, SCO, SLU, SOT, TAD, TGA, TIV, TOA, TUL, UMI, VAL, VMR, VMU), Ortiche (AN3), Ortiga (BAR, BOR, BPI, BSO, GGI, GPU, MMR, TAT).

Número de informantes: 72 Número de citas: 19.

Número de sectores: 6 Número de categorías: 28.

Biotipo: Hemicriptófito.

Tipo corológico: Amplia distribución.

Abundancia: Bastante Común.

Ambiente: Terrenos abandonados, montones de basura, nitrófila, en las casas o también en los.

aclarados de los bosques.

Número de exsiccata: 39105 FIAF.

Sector agropastoral

Categoría de uso: Alimentación animal (incluidos los forrajeros).

Número de informantes: 23 Partes utilizadas: parte aérea (toda), hojas, planta entera/viva.

L'ortica cotta insime alla crusca si usava come alimentazione per le galline e i maiali (VAL, BEL)| alimentazione animale (maiali),Cotto e aggiunto alle patate e altre piante forragere (BGI)| si davano ai mailai insieme ai farfari e agli avanzi di casa (BPT)| Cotta ,alimentazione animale (maiali) (DAD)| alimentazione animale (maiali),Cotta messa nella broda con il resto degli alimenti(semola,patata,erba ciliegina), fa bene al maiale per sfiammare e per farli venire il pelo lucido (GAN)| Per dare da mangiare ai maiali (GCL)| Dare direttamente da mangiare ai maiali, insieme al gambo rosso, l'erba ciliegina, a volta la romice e l'ortica scottata. (GFR) alimentazione animale (maiali):Scottare l'ortica e mettere insieme ad un secchio di semola, insieme alle patate che venivano piu piccole (quelle grosse per I uomini) e a l'erba ciliegina (GLA)| Si cuoceva l'ortica per le galline (LGI)| Faceva bene ai maiali: si 'sfilavano' e si mettevano nell'impasto con la semola. (LLU)| Fare un impasto fatto di ortica cotta per I maili insieme alla crusca, al grano turco, e alla semola cruda. Fa bene ai maiali, è rinfrescante. (MDA)| Per dare da mangiare ai maiali cotte con le patate (NER)| La nonna prendeva le piante d'ortica e con un guanto di lana la sfilava, poi la cuoceva per I maiali (NRO)| Si dava da mangiare ai maiali la pianta cotta (PCL)| L'ortica li si dava da mangiare al maiale, faceva bene 
(PGI) L'ortica trittata insieme all'impasto con la farina faceva bene alle galline, faceva de ricostituente (PLU) $\mid$ Cotta per i maiali, li facevano bene. (SLU)| Cotta messa nella con il resto degli alimenti, fa bene al maiale (TIV)| Ortica bollita insieme alla semola, fa bene ai maiali. (UMI) $\mid \mathrm{Si}$ faceva la broda del maiale a base di ortica sbollentata, semola, grano turco, patate (quelle piccole che avanzavano con la buccia), farina dolce (castagne), siero del latte. (VMR)| Si cuoceva insieme ad altre cose per darla da mangiare ai maiali, era rinfrescante. (BOR)| L'ortica cotta si dava da mangiare ai maiali insieme al gambo rosso, si dava anche ai cavalli per fargli venire il pelo lucido e vigoroso. (GGI).

Categoría de uso: Antiparasitario.

Número de informantes: 8 Partes utilizadas: parte aérea (toda), hojas, órganos.

Mettere a macerare l'ortica nell'acqua per qualche giorno, e poi spruzzare sul cavolo e sui faggioli come antiparassitario contro I pidocchi (BBA)| Messa a macerare per 48 ore e spruzzata sulle piante dell'orto contro i pidocchi. (BGI) $\mid$ Decotta e spruzzata per le piante dell' orto, evita i pidocchi (CLO)| Macerare le barbe dell' ortica nell 'acqua per 8 giorni ed spruzzare si cavoli e ai faggiolini per tenere "il brugio" (i bacchi) lontano. (DAD)| Contro I pidocchi dei faggioli:Macerare l'Ortica per una settimana, spruzzato sui faggioli, con un pennello (che era un ramo di una pianta qualsiasi) (GGI)| Cuocere l'ortica, e spruzzare il decotto raffreddato con l'aiuto di un pennello sulle piante. (MGO)| L'acqua di ortica si fa lasciando a macerare l'ortica finché non sia tutta sfatta. Si applica sulle piante dell'orto e sulle patate, è un veleno per gli insetti. (PEL)| Mettere in un bidone la coda cavallina, insieme all'ortica, e ai peperoncini. Lasciare macerare da 15 a 20 giorni. Poi con un ciuffo di erba si bagna in questo composto e si spruzza sui pidocchi dei faggioli o dei cavoli. (VMU).

Categoría de uso: Avicultura.

Número de informantes: 1 Partes utilizadas: parte aérea (toda).

Il decotto di ortica va dato alle galline per stimolarle a fare più uova. (MGO).

Categoría de uso: Horticultura.

Número de informantes: 3 Partes utilizadas: parte aérea (toda), hojas.

Mettere in un bidone la coda cavallina, insieme all'ortica, e ai peperoncini. Lasciare macerare da 15 a 20 giorni. Poi si mette accanto alle piantine come concime. (VMU)| Annaffiare le piante dell'orto con il decotto d'ortiga come concime gli fa bene (BSO, BAR).

\section{Sector alimentario}

Categoría de uso: Arroces y "risotto".

Número de informantes: 4 Partes utilizadas: hojas, brotes, hojas, brotes.

Soffriti e aggiunto il riso come per un risotto (BGI)| Risotto all'ortica, con le punte tenere.

dell'ortica (BLI)| Risotto con l'ortica (IMA)| Risotto all'ortica (foglie giovani o germogli) (TGA).

Categoría de uso: Empanadas.

Número de informantes: 1 Partes utilizadas: hojas.

Torta salata o schiaccia alle erbe, con le erbe di staggione: fare la pasta con la farina usando il lievito madre (che era trattato come un tesoro, durava anni e gli si davano delle cure quotidiane per mantenerlo vivo sempre) e aggiungere i 'ciucioli' (siccioli, 


\section{María Teresa Egea Molines}

ricavati facendo cuocere il grasso del maiale e tirandoli fuori via via che venivano a galla), poi stendere la pasta. Fare cuocere le erbe di stagione come il piscialletto, le cicoriette, lo strigolo, l'ortica, i vizzadri, una volta cotte, passarle in padella con un pò di pancetta o lardo, mescolarle al formaggio 'scotta' e 4 uova. Coprire con un'altra sfoglia di pasta, quindi chiudere con la forchetta e cuocere in forno. (BSO).

Categoría de uso: Ensalada.

Número de informantes: 2 Partes utilizadas: brotes, hojas.

Mangiare I germogli crudi in insalata. Quando I germogli sono giovani non bucano (CRE)| Mangiare le foglie giovani crude in insalata con olio e sale, oppure un poco scottate con olio e sale, fa bene per l'anemia. (VMR).

Categoría de uso: Pasta y "gnocchi".

Número de informantes: 40 Partes utilizadas: hojas, brotes, hojas, brotes.

Cuocere l'ortica, strizzarla e aggiungere all'impasto delle tagliatelle (VAL, BEL, AMA)| Fare cuocere l'ortica e aggiungerla all'impasto delle tagliatelle (AP2)| Tagliatelle all'ortica:Sfoglia all'ortica:Lessare l'ortica, strizzarla, trittarla e aggingerla all'impasto fatto di un uovo ogni etto di farino (BBA)| Bollire i germogli e mettere dentro la sfoglia della pasta per i tortelli per colorarla di verde. (BBI)| Tagliatelle all'ortica:Cotte, passate per il passaverdure, e aggiunte all'impasto (BGI)| $\mathrm{Si}$ raccolgono le punte dell'ortica, si fanno bollire e si tritano, quindi si aggiungono alla sfoglia per fare I ravioli. (BIO)| Cotti e messi nell'impasto di ravioli e tortelli per colorarlo di verde. (BLI)| Bollita, passata per passaverdura e messa nell' impasto. (BPT)| Lessata insieme alla Bietola o spinaci, passata per passaverdure e mischiata all' impasto (CFR)| I germogli cotti e mescolato all'impasto delle tagliatelle. (GAN, CRE)| L'ortica lessa va messa dentro alla "spoglia" delle tagliatelle (CRO)| Cotta, strizzata e messa nell'impasto della pasta, per fare tagliatelle e lasagne. (DAD) Cotta, strizzata e messa nell'impasto della pasta: 3uova, 500 gr di farina, mezzo bicchiere di acqua (DAD)| Punte bollite, strizzate e passate, messe dentro l'impasto della sfoglia: 1 uovo per 100 gr di farina, mezzo bicchiera d'acqua, un po olio di oliva e sale (GCL)| Spuntate e bollite, messe nell impasto dei tortelli (GFR)| Germogli cotti e mescolati all'impasto della sfoglia delle tagliatelle per farlo verde. (GGL)| Le parti tenere bollite si mettono nella sfoglia per fare I tortelli. (IMA)| Si fa la pasta verde aggiungendo le punte cotte all'impasto normale. (LGI)| Raccogliere le punte dell'ortica, farle bollire e metterle dentro all'impasto della pasta per fare le tagiatelle verdi. (LST)| Per fare la sfoglia verde, cuocere l'ortica trittarla e aggiungere all'impasto. (MGE) $\mid$ Germogli cotti e mescolati all'impasto per farlo verde. (MIO)| Germogli cotti e mescolati all'impasto dei tortelloni o della pasta. (MRI)| I germogli cotti e messi nella sfoglia per le tagliatelle e I tortelloni. (MSA)| Cotta e mischiata nell'impasto della sfoglia dei tortelloni. (MSR)| Aggiungere i germogli lessi nell'impasto con semola per fare le tagliatelle all'ortica. (NDI) Germogli cotti e mescolati all'impasto della pasta fresca. (NRE)| I germogli dell'ortica vanno cotti e messe nellal sfoglia per fare le tagliatelle (PGI)| Le foglie giovani sbollentate e mescolate all'impasto della pasta fresca, per fare la sfoglia verde (PLU)| Per fare le lasagne o le tagliatelle verdi, scottavano le punte dell'ortica e le mescolavano alla sfoglia. (RFR)| Aggiungere i germogli cotti di ortica all'impasto della sfoglia. (RMA)| Raccogliere I germogli, scottarle, schiacciarli e aggiungerli alla sfoglia della pasta (RNI)| Fare bollire I germogli d'ortica, poi 
schiacciarli, (ora si possono fare delle palline e conservare In frigo), e fare la sfoglia d'ortica per fare le tagliatelle o l'impasto dei tortelli (RNI)| Tagliatelle all'ortica:Raccogliere le punte giovani dell'ortica, lessarli, strizzarle e aggiungerle all'impasto normale delle tagliatelle. (SCO)| Tagliatelle all'ortica:Bollite e passate nel passaverdure, aggiunte all'impasto (SOT)| Ortica viene lessata e passata e poi mischiata con farina e uova (TAD)| Impasto dei ravioli, foglie (giovani o germogli) cotte e messe dentro all'impasto normale (TGA)| Si fa la pasta verde, aggiungendo all'impasto della sfoglia I germolgi d'ortica cotti. (AN3)| Cime cotte e passate per il passaverdura, aggiunta al impasto della pasta sfoglia normale per fare le papardelle e le lasagne (BPI)| Cime cotte e passate per il passaverdura, aggiunta al impasto della pasta sfoglia normale (GGI).

Categoría de uso: Relleno de ravioli.

Número de informantes: 25 Partes utilizadas: hojas, parte aérea (toda), brotes, hojas,.

Cuocere l'ortica, strizzarla e mescolarla con la ricotta, come ripieno dei tortelloni. (AMA)| Lessare l'ortica, strizzarla e trittarla e mescolare alla ricotta (BBA)| L'ortica cotta messa nel ripieno dei tortelli. (BEL)| Ripieno di tortelli fatti con ortica cotta e ricotta. (BFE)| Lesse e con formaggio (CFR)| L'ortica lessa e messa dentro al ripieno dei tortelloni. (CRO)| Cotta, strizzata e insieme a pane bagnato e strizzato, ricotta, formaggio stagionato, tutto ben tritato e aggiunte 2 uova (DAD)| Ripieno dei tortelloni fatti con I germogli di ortica cotti e formaggio (GLA)| Bollire i germogli di ortica e aggiungere al ripieno dei tortelli. (GZE)| Fare bollire le punte dell'ortica e metterle insieme alla ricotta per il ripieno dei tortelli. (LST)| Germogli cotti e mescolati all'impasto dei tortelloni. (MIO)| Germogli cotti e mescolati alla ricotta per il ripieno dei tortelloni. (MRI)| Cotta e mischiata con la ricotta come ripieno dei tortelli. (MSR)| Bollire i germogli di ortica e aggiungerli al ripieno dei tortelli. (MVI)| Ripieno insieme alla ricotta (NLA)| Fare i tortelli con il ripieno di ricotta e ortica. (PEL)| l'ortica trittata, mescolata alla ricotta e messa all'interno dei tortellini (PLU)| Raccogliere I germogli, scottarle, schiacciarli e aggiungerli al ripieno dei tortelli (RNI)| Fare bollire l'ortica e aggiungere il formaggio per fare il ripieno dei tortelli (RNI)| Cuocere l'ortica, strizzarla e mescolarla con la ricotta, come ripieno dei tortelloni (TIV, SCO)| Sbollentate e mescolate alla ricotta per il ripieno dei tortelli (UMI)| L'ortica cotta viene usata per fare i tortelli. (VAL)| Mettere le foglie lesse nel ripieno dei tortelli insieme ad altre piante come la bietola, o all'erba dei canarini perché ha un sapore forte (VMR)| Cime, cotte e impastate con formaggio (GGI, BPI).

Categoría de uso: Sopas de verduras y potaje.

Número de informantes: 1 Partes utilizadas: hojas.

La zuppa d'estate della nonna era a base solo di piante di campo: soffriegeva l'aglio, si trittavano tutte le foglie del piscialletto, le punte dei vizzadri, dell'ortica, delle orecchie di ciucco, del caciolino e degli striggoli. Poi si aggiungevano e si facevano bollire molto. Poi si poteva aggiungere riso o pasta. (MGE).

Categoría de uso: Tortilla.

Número de informantes: 9 Partes utilizadas: hojas, brotes.

Soffriggere l'ortica e aggiungere le uova per fare una frittata. (LRE, AMA)| L'ortica cotta e messa nella frittata. (VAL, BEL)| Cotta, strizzata e messa nella frittata 


\section{María Teresa Egea Molines}

(DAD) $\mid$ Germogli sbollentati e messi nella frittata. (GGL)| Sbollentare I germogli di ortica e fare la frittata (GLA)| Germogli scottati e messi nell'uovo per fare la frittata. (RFR)| Foglie lesse e messe nella frittata (SCO).

Categoría de uso: Verdura cocida.

Número de informantes: 4 Partes utilizadas: hojas, parte aérea (toda).

Lessa e condita con aceto. (CFR)| I germogli lessi e mangiati come verdura cotta (PLU)| Cotta.

e condita (SLU)| Verdura cotta e condita (TAD).

\section{Sector artesanal}

Categoría de uso: Fibra textil.

Número de informantes: 3 Partes utilizadas: parte aérea (toda).

Cuando si pettinava la fibra, facevano sacchi d'ortica (BGI)| Una volta la coltivavano per.

tessere (BLI)| Sacchi di ortica per mettere il grano. Tessuti nei telai di Treppio (SLU).

\section{Sector doméstico}

Categoría de uso: Cuidado personal y cosmética.

Número de informantes: 20 Partes utilizadas: parte aérea (toda), hojas, órganos.

Per rinforzare I capelli, si faceva bollire l'ortica, e si facevano delle frizioni sui capelli. (BAZ)| Fare cuocere le foglie d'ortica nell'acqua e lavarsi capelli con questa acqua, per rinforzare i capelli. (BBI) $\mid$ Con l'acqua dell'ortica ci si lava i capelli e fa bene. (BIO)| Rizomi ("le barbe") bolliti, per lavare i capelli e per rinforzarli (CRI)| Per fortificare i capelli quando questi stanno cascando, mettere a bollire le 'radici' (rizomi) e lavare i capelli. (DAD)| Per fare venire lucidi i capelli lavare con un infuso d'ortica (FAM)| Fare un decotto (per 10 min.) delle foglie d'ortica, e lavarsi I capelli con iI decotto per ravvivare il colore, per lavare I capelli dalla forfora. (GFR)| Fare sciacqui con il decotto di ortica, lasciandolo in testa, per evitare la caduta dei capelli. (GLA)| Mettere a macerare un pò l'ortica nell'acqua. Dopo aversi lavato I capelli con il sapone di marsiglia fare l'ultimo risciacquo con l'acqua d'ortica. Sgrassa I capelli (LST)| Lavare I capelli con il decotto delle 'barbe' (rizomi), per fortificare i capelli (NLA)| Pare epigea cotta, per lavare i capelli. (NRE)| Per lavare i capelli scuri, con un decotto delle foglie (PIA)| Bollire nell'acqua l'ortica e lavare I capelli con l'acqua. (RNI)| Per lavarsi i capelli e rinforzarli, lavarseli con l' infuso di ortica (TAD)| Bollire l'ortica e lavarsi I capelli con l'acqua (TUL)| Per rinforzare il cuoio capelluto, mettere in testa, un macerato di ortica, preparato con i rizomi ("le barbe") pestati d'ortica lasciati a macerare per 4 o 5 giorni nell'acqua. (UMI)| Fare la tintura di ortica per rinforzare I capelli:un pugno di foglie ortica I mezzo bicchiere di alcol. Lasciare riposare 10 giorni. Filtrare e con un batufolo stoffinare sui capelii. (VMR)| Fare il decotto di ortica e lavarsi I capelli. (VMU)| Dopo essersi lavati i capelli con il sapone, fare l'ultimo risciacquo con il decotto di ortiga, per renderli lucidi. (BSO)| Radici' (rizomi) d' ortiga macerate per 15 o 20 giorni con grappa bianca e un po' di acqua, con un po' di rosmarino, lavare I capelli con questa soluzione per fortificare I capelli (GGI).

Categoría de uso: Detergente.

Número de informantes: 5 Partes utilizadas: hojas, parte aérea (toda). 
Lavare I paioli di rame unti, con l'ortica fresca, e rimanevano lucidissimi. (GFR)| Per pulire le bottiglie dell'olio. (GZE)| Per pulire le bottiglie dell'olio (MVI)| La parte epigea era usata per lavare le bottiglie di vetro (PCL) $\mid$ Per lavare le bottiglie, mettere l' ortica insieme al gambo rosso dentro con l' acqua, agitare e strofinare. (GGI).

Categoría de uso: Detergente/tintorial.

Número de informantes: 1 Partes utilizadas: hojas.

Bollire le foglie di Ortica, poi mettere a bagno I giubotti con l'acqua dell'ortica per un po' e.

poi sciacquare con sapone o senza. Per evitare che perdesse colore (CRE).

\section{Sector medicinal}

Categoría de uso: Afecciones cutáneas y tejidos subcutáneos.

Número de informantes: 2 Partes utilizadas: hojas.

Per prevenire e curare la caduta di capelli, fare un decotto di ortiga e lavarsi i capelli con.

l'acqua del decotto. (MMR, GPU).

Categoría de uso: Afecciones ginecológicas, complicaciones obstétricas, del postparto y del puerperio.

Número de informantes: 2 Partes utilizadas: hojas.

Fare cuocere l'ortiga per 10 minuti, filtrare e fare raffreddare coperto. Fa bene per le. mestruazioni. (BSO, BAR).

Categoría de uso: Afecciones oro-faríngeas y de la cavidad oral.

Número de informantes: 1 Partes utilizadas: hojas.

Bollire l'ortica, "il tempo della verdura", poi mettere le molle sul fuoco a arroventare e poi.

metterle dentro il decotto. Filtrare e bere di tanto in tanto. (TOA).

Categoría de uso: Estado general.

Número de informantes: 7 Partes utilizadas: hojas, brotes, parte aérea (toda).

L'acqua dell'ortica bollita fa bene a tutto, è 'rinfrescante'. (BIO)| Bere una volta al giorno per una settimana (a Primavera e Autumno), un decotto di Ortica fresca. Bollire per 5 minuti I germogli di ortica e bere. Rilassante, 'per il calore', cure di Primavera e di Autunno, 'fa bene a tutto'. (MDA)| Bevuto di tanto in tanto (SOT)| Mangiare le foglie giovani crude in insalata con olio e sale, oppure un poco scottate con olio e sale, fa bene per l'anemia. (VMR)| Fare cuocere l'ortiga per 10 minuti, filtrare e fare raffreddare coperto. Purifica il sangue. (BSO, BAR)| Bere l'acqua di ortiga per l'anemia, quando uno ha sensazione di stanchezza: fare il decotto di ortiga, filtrare e bere l'acqua spesso. (GGI).

Categoría de uso: Otro medicinal.

Número de informantes: 1 Partes utilizadas: parte aérea (toda).

Ortica macerata in grappa bianca per un po' di giorni e applicata sul cuoio capelluto frizionando (MCL).

Categoría de uso: Parásitos externos.

Número de informantes: 2 Partes utilizadas: parte aérea (toda).

Cuocere l'ortica, applicarla sopra I capelli, e lavarli con l'acqua d'ortica (BLI) Bollire la pianta fino a farla una "poltiglia" e applicare il tutto sopra I capelli strofinando. (TGA). 


\section{María Teresa Egea Molines}

Categoría de uso: Patologías del aparato digestivo.

Número de informantes: 1 Partes utilizadas: hojas.

Bere l'acqua d'ortica ogni volta che si ha sete. Sfiamma lo stomaco (CRE).

Categoría de uso: Patologías del aparato urinario.

Número de informantes: 5 Partes utilizadas: hojas, brotes.

Bere quando si ha sete l'acqua d'ortica (decotto). Fare I lavaggi con il decotto d'ortica. (CRE)| Bere spesso il decotto di ortica. (GAN)| Le foglie cotte 5 minuti nell'acqua, poi filtrare e bere 2 litri di decotto 5 o 6 volte al giorno. È diuretico e scioglie I calcoli renali. (VMR)| Fare cuocere l'ortiga per 10 minuti, filtrare e fare raffreddare coperto. E' diuretico. (BSO, BAR).

Categoría de uso: Trastornos musculo-esqueléticos.

Número de informantes: 7 Partes utilizadas: parte aérea (toda), hojas.

Sbattere l'ortica sui ginocchi (contro i reumatismi). (BEL)| Macerare le foglie in alcol puro per 2 giorni,applicare con lavaggi e massaggi (CFR)| Frizionare l'ortica fresca sui ginocchi (CRI)| Strofinare l' ortica sulla parte dolente (GGI, FAM)| Battere l'ortica nel punto dove c'era dolore (PLU)| Lei si metteva i guanti, prendeva l'ortiga e la strofinava sulla schiena alla sua nonna: la schiena diventava rossa e gonfia, però poi il mal di schiena passava. (TAT).

\section{Sector veterinario}

Categoría de uso: Aves de corral.

Número de informantes: 1 Partes utilizadas: parte aérea (toda).

L'impasto fatto di ortica cotta, farina dolce e semola è rinfrescante per le galline e 'le sfiamma'. (MGO).

Categoría de uso: Cerdos.

Número de informantes: 6 Partes utilizadas: parte aérea (toda), hojas.

Per il "Male rosso" del maiale, in caso di febbre e debolezza del maiale, si dava all'animale ortica cotta e sambucchella (BGI)| Per prevenire la "Moria" dei maiali (pandemia ). Quando si sentiva dire che c'era la moria, si dava da mangiare ai maiali la 'broda': cuocere l'ortica insieme alle patate, alle carote, al farfaro, alle castagne secche e alla semola. (BLI)| Alimento post-parto per i maiali:La broda: Rimanenza delle patate (specie di patate piccole) cotte, aggiunto semola cruda, orzo crudo e ortica cotto per conto suo. Tutto mescolato (DAD)| Per il mal rosso del maiale gli si dava da mangiare l'ortica cotta. (FAM)| Dare da mangiare l'ortica cotta al maiale quando questo non aveva appetito oppure quando aveva la diarrea. (RNI)| Quando I maiali stavano poco bene gli davano da mangiare l'ortiga cotta con la semola e la patata. (GGI).

Categoría de uso: Ovejas y cabras.

Número de informantes: 1 Partes utilizadas: hojas.

Disinfettante, diuretico per le pecore (DAD).

Notas "Macerato d' ortica puzza di pozzo nero"Ora sta sparendo pure l' ortica, una volta veniva molto di più, Sono migliori che gli spinaci, è un uso ricente, prima non lo faceva, Si fanno per le feste masiccie, ossia le feste del patrone. Ora si trovano solo nelle parti recintate, perché gli animali mangiano tutto. Lavare prima con l'acqua fredda, cosi va via l'amargo. Raccogliere le punte dell'ortica in posti dove non si avvicinino I cani. 


\section{DATOS ETNOBOTÁNICOS BIBLIOGRÁFICOS}

Nombre vulgar: urtîga maschio (UNGA21), ortica (MANG98, GRIZ03, SANS14).

Número de referencias: 4 Número de citas: 20.

Número de sectores: 5 Número de categorías: 16.

Biotipo: Hemicriptófito.

Tipo corológico: Amplia distribución.

Abundancia: Bastante Común.

Ambiente: Terrenos abandonados, montones de basura, nitrófila, en las casas o también en los aclarados de los bosques.

\section{Sector agropastoral}

Categoría de uso: Alimentación animal (incluidos los forrajeros).

Número de referencias: 1 Partes utilizadas: parte aérea (toda).

Disseccata, l'ortica à ottimo foragio invernale per pollame (UNGA21).

Categoría de uso: Antiparasitario.

Número de referencias: 1 Partes utilizadas: hojas.

Le foglie macerate in acqua si usano come insetticida (SANS14).

Sector alimentario

Categoría de uso: Ensalada.

Número de referencias: 2 Partes utilizadas: hojas.

(SANS14)| Nella medicina popolare è ancora considerata diuretica. Se ne mangiano le cime.

lessate e condite in insalata per isciogliere I calcoli della vescica. (UNGA21).

Categoría de uso: Pasta y "gnocchi".

Número de referencias: 2 Partes utilizadas: hojas.

(SANS14)Tagliatelle all'ortica, 4 hg di farina, 4 uova, mezzo kilo di ortiche crude. Raccogliere le punte delle ortiche, lavarle e cuocerle in acqua bollente, Intanto preparate sulla spianatoia la farina, fare un buco e mettere le uova al centro, scolare le ortiche, strizzarle bene e tritarle finemente poi aggiungerle alla farina e alle uova e impastare il tutto formando una palla liscia ed omogenea. Tirare la sfoglia sottile e tagliarla a striscioline di mezzo $\mathrm{cm}$. Cuocere le tagliatelle in abbondante acqua salate e condirle a piacere. (GRIZ03).

Categoría de uso: Relleno de ravioli.

Número de referencias: 1 Partes utilizadas: hojas (SANS14).

Categoría de uso: Tortilla.

Número de referencias: 1 Partes utilizadas: hojas (SANS14).

Sector doméstico

Categoría de uso: Cuidado personal y cosmética.

Número de referencias: 1 Partes utilizadas: hojas.

Rafforzare il capelli, farli diventare più lucidi e contro la forfora (SANS14).

Categoría de uso: Detergente/tintorial.

Número de referencias: 1 Partes utilizadas: parte aérea (toda).

Le donne si servono di tutta la pianta di fresco raccolta per lavare I drappi neri. (UNGA21). 
Sector mágico/medicinal

Categoría de uso: Otro mágico/medicinal.

Número de referencias: 1 Partes utilizadas: hojas.

Le donne di campagna credono che a stropicciarsi il petto coll'ortica lo aumenti, ma è pratica.

pericolosa. (UNGA21).

Sector medicinal

Categoría de uso: Afecciones cutáneas y tejidos subcutáneos.

Número de referencias: 1 Partes utilizadas: flores/inflorescencias y sus partes.

Con l'infuso dell'infiorescenza vengono praticati bagni più volte al giorno su micosi cutanee, taluni affermano che questo rimedio sua valido anche in caso di Herpes. Per la detersione del cuoio capelluto affetto da forfora e da squame, utilizzano il decotto del 'cimale' ovvero delle sommità fiorite.(MANG98).

Categoría de uso: Afecciones del aparato respiratorio.

Número de referencias: 1 Partes utilizadas: hojas.

Il decotto delle foglie si utilizza per via interna in caso di febbre alta, di diarrea, come.

coadiuvante in svariate affezzioni polmonari per combattere l'enuresi notturna. (MANG98).

Categoría de uso: Afecciones ginecológicas, complicaciones obstétricas, del postparto y del puerperio.

Número de referencias: 1 Partes utilizadas: hojas.

Le foglie fresche frizionate sul corpo (SANS14).

Categoría de uso: Estado general.

Número de referencias: 1 Partes utilizadas: hojas.

Mangiare l' ortica cotta e bere l'acqua di cottura (SANS14).

Categoría de uso: Fiebre.

Número de referencias: 1 Partes utilizadas: hojas.

Il decotto delle foglie si utilizza esternamente, come shampoo (MANG98).

Categoría de uso: Patologías del aparato digestivo.

Número de referencias: 1 Partes utilizadas: hojas.

Il decotto delle foglie si utilizza per via interna in caso di febbre alta, di diarrea, come.

coadiuvante in svariate affezzioni polmonari per combattere 1'enuresi notturna. (MANG98).

Categoría de uso: Patologías del aparato urinario.

Número de referencias: 3 Partes utilizadas: hojas.

Nella medicina popolare è ancora considerata diuretica. Se ne mangiano le cime lessate e condite in insalata per isciogliere I calcoli della vescica. (UNGA21)| Mangiare l' ortica cotta e bere l'acqua di cottura (SANS14)| Il decotto delle foglie si utilizza per via interna in caso di febbre alta, di diarrea, come coadiuvante in svariate affezzioni polmonari per combattere l'enuresi notturna.(MANG98).

Notas L' Urtiga femmina è Urtica urens. 
76. VERBENACEAE

\section{Aloysia citriodora Palau (= Lippia triphylla (L'Hér.) O. Kuntze)}

Nombre vulgar: Acedrina (LST), Cedrina (VAL, BEL).

Número de informantes: 3 Número de citas: 3.

Número de sectores: 1 Número de categorías: 1 .

Biotipo: Fanerófito.

Tipo corológico: Cultivadas.

Abundancia: Cultivada.

Ambiente: Baldíos, a lo largo de las carreteras.

Sector alimentario

Categoría de uso: Licor.

Número de informantes: 3 Partes utilizadas: hojas.

Non si ricorda bene della ricetta. Lo facevano la sua nonna e la sua mamma: mettere un pò di foglie a macerare nell'alcol poi fare lo sciroppo, filtrare le foglie e aggiungere allo sciroppo. Tutti coltivavano la pianta nell'orto (LST)| 67 foglie di cedrina, 800 grammi di acqua, mezzo litro di alcool, scorza di limone non trattato e 500 grammi di zucchero. Lasciare macerare per 21 giorni e muovere tutti i giorni. (BEL) 67 foglie di cedrina, 800 grammi di acqua, mezzo litro di alcool, scorza di limone non trattato, e 500 grammi di zucchero, lasciare macerare per 21 giorni e muovere tutti I giorni (VAL).

Notas La cedrina si tiene in vaso e si tiene fuori anche d'inverno.

DATOS ETNOBOTÁNICOS BIBLIOGRÁFICOS

Nombre vulgar: erba luigia (SANS14), êrba zedrenna (UNGA21).

Número de referencias: 2 Número de citas: 3.

Número de sectores: 2 Número de categorías: 2 .

Sector alimentario

Categoría de uso: Licor.

Número de referencias: 1 Partes utilizadas: hojas (SANS14).

Sector medicinal

Categoría de uso: Trastornos musculo-esqueléticos.

Número de referencias: 1 Partes utilizadas: hojas (SANS14).

\section{Verbena officinalis $L$.}

Nombre vulgar: Erba del versamento (NLA, DAD), Verbena (TUL, BLI).

Número de informantes: 4 Número de citas: 5.

Número de sectores: 2 Número de categorías: 2 .

Biotipo: Hemicriptófito.

Tipo corológico: Europeas.

Abundancia: Bastante Común.

Ambiente: Sobre los márgnes de las calles, baldíos pisoteados (sinantropica). 
Número de exsiccata: 38993 FIAF.

\section{Sector medicinal}

Categoría de uso: Trastornos musculo-esqueléticos.

Número de informantes: 4 Partes utilizadas: hojas, parte aérea (toda).

Raccogliere un manciata grande di foglie fresche, tritare queste foglie (deve uscirne del liquido verde, sennò vuol dire che non sono abbastanza tenere o fresche), aggiungere un bianco d'uovo, 2 cucchiai di farina di grano e mezzo cucchiao di sale. La sera mettere sul ginocchio e fasciare tutto. Mettere sotto un asciugamano perché la mattina dopo ti leva via tutta l' acqua "e ti porta via il male" (DAD)| Una manciata di foglie fresche tritate, insieme a un cucchiaio di grano e un bianco d' uovo, tutto dentro a un fazzoletto e messo la notte sul ginocchio. Mettere sotto il ginocchio un asciugamo. La mattina dopo tutta l'acqua sarà sull'asciugamano. (NLA)| La Notte, prendere 3 etti di pianta fresca e fare un decotto, fare un impacco nei ginocchi, mettendo la foglie cotte con l'acqua dentro un panno, e ripetere 3 o 4 sere. (BLI)| "un bel po' di pianta tritata, con un chiaro d'uovo e un po' di farina, mescolare tutto e mettere sulla parte infiammata per tutta la notte" (TUL).

Sector veterinario

Categoría de uso: Equinos.

Número de informantes: 1 Partes utilizadas: parte aérea (toda).

In caso di fratture alle zampe, appendere il cavallo alle trave della casa con un tessuto di canapa, lavare la gamba fratturata con acqua e sale e mettere spesso impacchi di verbena al naturale. (BLI).

DATOS ETNOBOTÁNICOS BIBLIOGRÁFICOS

Nombre vulgar: verbêna (UNGA21).

Número de referencias: 1 Número de citas: 1.

Número de sectores: 1 Número de categorías: 1 .

Sector mágico/medicinal

Categoría de uso: Contra el miedo y los traumas.

Número de referencias: 1 Partes utilizadas: parte aérea (toda).

Oggi la verbena o eba croce è ancora indicata per una delle erbe che sanano la paura e quando un bambino ne è stato preso si fa bollire quest'erba e coll'acqua si lava il bambino e la paura scappa. (UNGA21).

\section{VIOLACEAE}

\section{Viola alba Besser subsp. dehnhardtii (Ten.) W. Becker}

Nombre vulgar: Viole (MTO, NDI, MSR, AMA), Viola (VMR, MRI, BEL).

Número de informantes: 7 Número de citas: 8.

Número de sectores: 4 Número de categorías: 4.

Biotipo: Hemicriptófito.

Tipo corológico: Eurimediterránea.

Abundancia: Común. 
Ambiente: Bosques claros, desmontes, setos, lugares herbáceos.

Sector agropastoral

Categoría de uso: Avicultura.

Número de informantes: 1 Partes utilizadas: flores/inflorescencias y sus partes.

Si usava per fare covare più uova alle galline. A Marzo, quando andavano a covare, gli mettevano un mazzo di fiori di viola nel nido. Le galline ci rimanevano perché si riscaldavano di piu, o forse per l'odore. (AMA).

\section{Sector alimentario}

Categoría de uso: Ensalada.

Número de informantes: 2 Partes utilizadas: flores/inflorescencias y sus partes.

Per bellezza i fiori di viola si mettevano nell'insalata. (BEL)| Mangiavamo i fiori di viole.

crude e condite con l'olio come sfizio. (MRI).

Sector mágico/medicinal

Categoría de uso: Preventivo de enfermedades.

Número de informantes: 3 Partes utilizadas: flores/inflorescencias y sus partes.

"La prima viola che vedi, si prendeva e si sfioravano gli occhi, per portare buon augurio per non diventare ciechi" (VMR)| Strofinare sugli occhi le prime viole che si trovano, per prevenire problemi alla vista. (MSR)| La prima viola che si trovava si strofinava sugli occhi per prevenire qualsiasi disturbo. (NDI).

\section{Sector medicinal}

Categoría de uso: Afecciones oftalmológicas.

Número de informantes: 2 Partes utilizadas: flores/inflorescencias y sus partes.

Fare l'acqua delle viole (decotto) e con delle pezze imbevute in quest'acqua lavare gli occhi e.

poi appoggiarcele sopra. (MTO, MSR).

\section{Viola odorata $L$.}

Nombre vulgar: Viola (CRI, CRE), Viole (BOR).

Número de informantes: 3 Número de citas: 3.

Número de sectores: 2 Número de categorías: 2 .

Biotipo: Hemicriptófito.

Tipo corológico: Eurimediterránea.

Abundancia: Común.

Ambiente: Márgenes de los bosques, setos, lugares herbáceos y silvestres, a menudo cultivados en los jardines y asilvestrada.

\section{Sector doméstico}

Categoría de uso: Ambientador.

Número de informantes: 2 Partes utilizadas: flores/inflorescencias y sus partes.

Seccare i fiori di viola e metterli in sacchetti di stoffa nei cassetti o nella biancheria. $(\mathrm{CRE}) \mid$ Una volta si mettevano le viole tra la biancheria per profumare, perché non c'era niente altro. (BOR). 
Sector mágico/medicinal

Categoría de uso: Preventivo de enfermedades.

Número de informantes: 1 Partes utilizadas: flores/inflorescencias y sus partes.

"La prima viola che vedi, si prendeva e si sfioravano gli occhi, per portare buon augurio per non diventare ciechi" (CRI).

DATOS ETNOBOTÁNICOS BIBLIOGRÁFICOS

Nombre vulgar: viola (SANS14), viôla (UNGA21).

Número de referencias: 2 Número de citas: 3 .

Número de sectores: 2 Número de categorías: 3 .

Sector alimentario

Categoría de uso: Ensalada.

Número de referencias: 1 Partes utilizadas: flores/inflorescencias y sus partes (SANS14).

Sector medicinal

Categoría de uso: Dolor de cabeza.

Número de referencias: 1 Partes utilizadas: flores/inflorescencias y sus partes.

I fiori di viola pestati e applicati alla fronte sono adoperati in campagna per far cessare il dolore di capo. (UNGA21).

Categoría de uso: Fiebre.

Número de referencias: 1 Partes utilizadas: flores/inflorescencias y sus partes.

Si prendono in infuso come sudorifero (UNGA21).

\section{Viola tricolor $L$.}

Nombre vulgar: Panzé (BSO), Viola bianca (GZE).

Número de informantes: 2 Número de citas: 5.

Número de sectores: 4 Número de categorías: 5.

Biotipo: Terófito y Hemicriptófito.

Tipo corológico: Europeas.

Abundancia: Común.

Ambiente: Campos, pastos.

Número de exsiccata: 38950 FIAF, 38922 FIAF.

Sector alimentario

Categoría de uso: Ensalada.

Número de informantes: 1 Partes utilizadas: planta entera/viva.

I fiori si mettevano nell'insalata (BSO).

Sector doméstico

Categoría de uso: Ornamental.

Número de informantes: 1 Partes utilizadas: planta entera/viva.

Nei prati si raccoglievano questi fiori bianchi e si portavano in casa per mettere in un vaso, per bellezza. (BSO). 


\section{Sector medicinal}

Categoría de uso: Afecciones ginecológicas, complicaciones obstétricas, del postparto y del puerperio.

Número de informantes: 1 Partes utilizadas: planta entera/viva.

Quando si aveva infiammazioni urinarie, irritazioni, dolori o altri problemi mestruali, fiori si mettevano nell'acqua quando bolliva, poi si lasciava macerare 10 minuti senza bollire e si beveva (BSO).

Categoría de uso: Estado general.

Número de informantes: 1 Partes utilizadas: planta entera/viva.

I fiori si mettevano nell'acqua quando bolliva, poi si lasciava macerare 10 minuti senza bollire e si beveva rinfrescava e rilassava (BSO).

Sector religioso

Categoría de uso: Ornamento para altares e iglesias.

Número de informantes: 1 Partes utilizadas: parte aérea (toda).

Si mettevano per bellezza davanti alla Vergine. (GZE).

Notas non fanno più, erano alte $40 \mathrm{~cm}$, facevano in mezzo al grano, si vedevano da lontano.

\section{DATOS ETNOBOTÁNICOS BIBLIOGRÁFICOS}

Nombre vulgar: viola gialla (MANG98).

Número de referencias: 1 Número de citas: 2 .

Número de sectores: 1 Número de categorías: 2 .

Sector medicinal

Categoría de uso: Afecciones del aparato respiratorio.

Número de referencias: 1 Partes utilizadas: parte aérea (toda).

$\mathrm{Si}$ raccolgono solamente piante a fiori gialli, si utilizzano in caso di tosse (MANG98).

Categoría de uso: Patologías del aparato urinario.

Número de referencias: 1 Partes utilizadas: parte aérea (toda).

Si raccolgono solamente piante a fiori gialli, si utilizzano per aumentare la diuresi. (MANG98).

\section{VITACEAE}

\section{Vitis labrusca L.}

Nombre vulgar: L'uva americana, uva fragolino (MGE), Uva fragola (TAD, MVI, GZE, MRI), uva.

fragola (MRI), Vite americana, Vite fragola (TIV), Uva americana (SLU), uva. americana (GGI).

Número de informantes: 8 Número de citas: 11.

Número de sectores: 2 Número de categorías: 7.

Biotipo: Fanerófito.

Tipo corológico: Cultivadas. 
Abundancia: Cultivada.

Ambiente: Cultivada y raramente asilvestrada.

Sector alimentario

Categoría de uso: Fruta fresca.

Número de informantes: 2 Partes utilizadas: frutos/infrutescencias/falsos frutos. L'uva americana si mangiava per pasqua, si conservava sui fogli di giornale. (MGE)| L' uva fragola è buona da mangiare come frutta fresca. (MRI).

Categoría de uso: Fruta seca.

Número de informantes: 1 Partes utilizadas: frutos/infrutescencias/falsos frutos. l'uva fragola si conservava appesa ai travi, durante l'inverno (MRI).

Categoría de uso: Licor.

Número de informantes: 2 Partes utilizadas: frutos/infrutescencias/falsos frutos. Mettere a macerare un chilo di frutta in un litro di alcol, un litro di acqua e un $\mathrm{kg}$ di zucchero, per minimo un anno. Poi si può filtrare, oppure lasciare la frutta dentro e mangiarla via via. $\mathrm{O}$ si può lasciare quanto si vuole nell'alcol, più ci sta meglio è, anche 5 o 6 anni.. (MVI, GZE).

Categoría de uso: Mermelada.

Número de informantes: 2 Partes utilizadas: frutos/infrutescencias/falsos frutos. Fare bollire i frutti con meno de la metà dei frutti di zucchero e imbarattolare (TAD)| non specificato (TIV).

Sector medicinal

Categoría de uso: Afecciones del aparato respiratorio.

Número de informantes: 1 Partes utilizadas: frutos/infrutescencias/falsos frutos. Vino bollito con lo zucchero per curare bronchiti, polmoniti, influenza (SLU).

Categoría de uso: Afecciones oftalmológicas.

Número de informantes: 2 Partes utilizadas: látex o savia.

In primavera, quado un tralcio della vite 'piange', si mette subito nell' occhio, come un colirio (GGI)| si usa la linfa come collirio (TIV).

Categoría de uso: Dolor de cabeza.

Número de informantes: 1 Partes utilizadas: frutos/infrutescencias/falsos frutos. Bere un bicchiere di vino caldo per il mal di testa. (SLU).

\section{Vitis vinifera $L$.}

Nombre vulgar: (REN, AMA, SOT, NST, NRO, GFR, GAN, VAL, NDI, MSA, GGI, VMA, VMU, NMA, GGL, DAD, CRO, CRI, AN3, EMA, BAR, SCO, BAZ)Uva (VSI, RGI), Vite (GZE, SLU, NLA, GUF, PGI), Uva (MRI, RFR, MOR, MGE, GLA, NRE), uva (PIM), Uva zibibbo (NRE).

Número de informantes: 37 Número de citas: 52.

Número de sectores: 5 Número de categorías: 18.

Biotipo: Fanerófito.

Tipo corológico: Cultivadas.

Abundancia: Cultivada.

Ambiente: Cultivada y asilvestrada. 


\section{Sector alimentario}

Categoría de uso: Bebida.

Número de informantes: 4 Partes utilizadas: frutos/infrutescencias/falsos frutos.

Il vino di uva si faceva mettendo l'uva a macerare nei tini di legno con il bucco di sotto per una settimana (VSI, RGI)| Si faceva il vino (che era già un lusso), poi si faceva il "Mezzo vino" (rifacevano il vino con le stesse uve) e poi il "terzanello" che era l'acqua con qui lavavano I tini. (PGI) $\mid$ Si beveva il vin brulé con vino e zucchero (BAZ).

Categoría de uso: Dulces y golosinas.

Número de informantes: 1 Partes utilizadas: frutos/infrutescencias/falsos frutos.

"Castagnaccio": Farina di castagne, impastata con dei pinoli, dell'uvetta (messa a mollo con.

acqua e un po d'olio), e alla fine aromatizzato con un po' di rosmarino sopra (SCO). Categoría de uso: Fruta seca.

Número de informantes: 2 Partes utilizadas: frutos/infrutescencias/falsos frutos. Si facevano seccare per conservarle per l'inverno (NRE)| Seccavano la frutta per l'inverno.

(PIM).

Categoría de uso: Golosinas y masticatorias.

Número de informantes: 1 Partes utilizadas: frutos/infrutescencias/falsos frutos.

Quando erano bambini e andavano a raccogliere le castagne, mangiavano pane e uva e si mettevano dei dittali fatti con la camera d'area della bicicletta, per raccogliere le castagne (BAR).

Categoría de uso: Licor.

Número de informantes: 1 Partes utilizadas: frutos/infrutescencias/falsos frutos.

Con le vinacce si faceva la grappa (EMA).

Categoría de uso: Mermelada.

Número de informantes: 1 Partes utilizadas: frutos/infrutescencias/falsos frutos.

Marmellata "al savor": Fare bollire mele o pere coltivate, con un pò di succo d'uva, 1 o 2 .

mele cotogne oppure 1 o 2 perecotogne, viene una marmellata aspra. (AN3).

Categoría de uso: Otro alimentario.

Número de informantes: 1 Partes utilizadas: frutos/infrutescencias/falsos frutos.

Mettere in un litro di acqua un cucchiaio di zucchero, sale e un po' di uva acida strizzata..

Lasciare al riposo per una settimana, aggiungendo un po' di farina tutte le notti. (GLA).

\section{Sector doméstico}

Categoría de uso: Cuidado personal y cosmética.

Número de informantes: 7 Partes utilizadas: frutos/infrutescencias/falsos frutos.

Prima si lavano i capelli con l' aceto. (CRI)| Lavare I capelli con l'aceto fa diventare I capelli più morbidi (CRO)| Lavare i capelli con l' aceto per farli venire piu lucidi (DAD)| Per rinforzare I capelli: applicare aceto diluito nell'acqua. (GGL)| Lavarsi i capelli con aceto ed acqua. (NMA)| L'aceto si usava per lavarsi la bocca come colutorio (NRE)| Per evitare essere punte dalle api quando uno si avvicina. 


\section{María Teresa Egea Molines}

Spruzzare vino bianco e acqua alle api, per ubriacarle ed evitare di essere punti. (VMU)| Contro gli insetti. Quando si andava a funghi, per evitare di prendere insetti, spalmare aceto per il corpo (VMU).

Sector lúdico/voluptuoso

Categoría de uso: Fumable.

Número de informantes: 3 Partes utilizadas: hojas, corteza.

Le foglie della vite secche si usavano come il tabacco, da fumare con la pipa. (GUF)| La.

'buccia' secca e tritata fumata nella pipa (NLA)| Si fumava la vite (SLU).

Categoría de uso: Otro lúdico.

Número de informantes: 1 Partes utilizadas: frutos/infrutescencias/falsos frutos. Una volta ci tenevano molto al vino, era l'unico divertimento che c'era, si diceva 'andiamo a fare il fiasco', facevano a gara a chi aveva il vino migliore. La gente faceva poco orto, ma le vigne erano un giardino. (VMA).

\section{Sector medicinal}

Categoría de uso: Afecciones cutáneas y tejidos subcutáneos.

Número de informantes: 6 Partes utilizadas: frutos/infrutescencias/falsos frutos.

Lavare le ferite con acqua bollita e aceto (CRO)| Desinfettare le ferite con l'aceto (EMA)| Quando non lascia niente dentro la pelle, e quando si puo mettere subito dopo la puntura, se passa un po di tempo allora mettere un impacco di prezzemolo trittato (GGI)| Battuto di prezzemolo con una fasciatura intorno, quando è passato un po' di tempo del momento della puntura. Se si può mettere qualcosa subito: mettere aceto. (GGI)| L'aceto si usa sulle bruciature (MSA)| Desinfettare le ferite con l'aceto e pipi (NDI)| L'aceto si usa come desinfettante sulle ferite (VAL).

Categoría de uso: Afecciones del aparato respiratorio.

Número de informantes: 10 Partes utilizadas: frutos/infrutescencias/falsos frutos. Mettere il vino in un tegame, si dava fuoco, si aggiungeva lo zucchero e si beveva (MGE)| Raffreddore: si beveva vin brulé: vino bollito con lo zucchero o Latte e miele. (MOR)| Fare bollire il vino, quando viene su l'alcol, lo bruciavano sulla superficie e poi si aggiungeva lo zucchero. Bere per la tosse (RFR)| Bollire le mele a spicchi, insieme a chicchi di uva passita (zibbibbo), prugne secche o ciliegie secche e chicchi d'orzo, e bere per 2 o 3 giorni. (NRE)| Bere il vin brulé, vino bollito con un po di cognac e un po di zucchero (GZE)| Acqua, sale e aceto Fare gargarismi con acqua, sale e aceto (GAN)| Fare fumenti con il vino riscaldato. (GFR)| Per il mal di gola fare gargarismi con acqua e aceto (NRO)| Fare dei fumenti con aceto e acqua (NST) $\mid$ Impiastro di farina di lino e aceto (SOT).

Categoría de uso: Afecciones oro-faríngeas y de la cavidad oral.

Número de informantes: 3 Partes utilizadas: frutos/infrutescencias/falsos frutos.

Per il dolore dei denti si applicava della grappa sopra il dente, come anestetizzante. (MRI)| Sciacqui con acqua e aceto (GFR)| "Fare un impacco di sugna d'agnello, la mollica d pane e l'aceto sulll'ascesso, tira via" (RGI).

Categoría de uso: Dolor de cabeza.

Número de informantes: 3 Partes utilizadas: frutos/infrutescencias/falsos frutos.

Bere vino caldo per il mal di testa (SLU)| Fazzoletto con aceto legato alla testa (DAD)| Fare. 
degli impacchi di acqua fredda e di acqua e aceto (NST).

Categoría de uso: Otro medicinal.

Número de informantes: 1 Partes utilizadas: frutos/infrutescencias/falsos frutos. Un cucchiaino di café di vino (DAD).

Categoría de uso: Parásitos externos.

Número de informantes: 2 Partes utilizadas: frutos/infrutescencias/falsos frutos. Lavare I capelli con l'aceto per elimare I pidocchi (AMA)| Lavare la testa con l'aceto contro I.

pidocchi (REN).

Sector veterinario

Categoría de uso: Cerdos.

Número de informantes: 1 Partes utilizadas: frutos/infrutescencias/falsos frutos.

Li mettevano un bastone in bocca per tenerla aperta, e con aceto, acqua e sale, li strusciavano dentro la bocca ai maiali quando avevano le vesciche (e non mangiavano) (NST).

Categoría de uso: Ganado bovino.

Número de informantes: 1 Partes utilizadas: frutos/infrutescencias/falsos frutos. Problemi digestivi delle mucche:Dare da bere alla mucca due o tre volte al giorno un po di aceto, vino, café, e sale grosso in un bottiglia di vetro. Se non guariva così, allora moriva. (GGL).

Notas "le vesciche" vuol dire quando il maiale non mangiava.

DATOS ETNOBOTÁNICOS BIBLIOGRÁFICOS

Nombre vulgar: (MUCC01), vino (MUCC01), vîd (UNGA21), Vìda (APPO10), vite (BER79), negreti (GUC98), maiólo (GUC98), morastèllo (GUC98), vaĩa (GUC98), squizina (GUC98).

Número de referencias: 5 Número de citas: 10.

Número de sectores: 1 Número de categorías: 3.

Sector medicinal

Categoría de uso: Afecciones cutáneas y tejidos subcutáneos.

Número de referencias: 1 Partes utilizadas: frutos/infrutescencias/falsos frutos.

Per i tagli si faceva anche così: s'aprivano, ci si metteva dentro il sale e l'aceto e si fasciava.

bello strinto (stretto). Il giorno dopo: presciutto, una carne rosa... (MUCC01).

Categoría de uso: Afecciones del aparato respiratorio.

Número de referencias: 1 Partes utilizadas: frutos/infrutescencias/falsos frutos.

Il vino ferrato: si preparava una brocca di vino, si metteva alla fiamma il soffione (tubo di ferro attraverso il quale si soffia per ravvivare la fiamma) e quando era bello rosso infocato, ci si tuffava, quel bel vino caldo che sapeva di ferro faceva guarí il raffreddore.(MUCC01).

Categoría de uso: Patologías del aparato digestivo.

Número de referencias: 1 Partes utilizadas: hojas (UNGA21).

Notas Il padre stortarello, la madre verderella, la figlia tanto bella, che tut i la vón basé (o magné). La vid, la fóia, l'uva. 


\section{Vitis vinifera L. 'Barbera'}

Nombre vulgar: Uva barbera (AN3).

Número de informantes: 1 Número de citas: 1.

Número de sectores: 1 Número de categorías: 1 .

Biotipo: Fanerófito.

Tipo corológico: Cultivadas.

Abundancia: Cultivada.

Ambiente: Cultivada.

Sector alimentario

Categoría de uso: Licor.

Número de informantes: 1 Partes utilizadas: frutos/infrutescencias/falsos frutos.

Con le vinacce delle varieta di vite che si coltivavano si distillava e si faceva la grappa, con la quale si facevano I liquori. (AN3).

\section{Vitis vinifera L. 'Morastello'}

Nombre vulgar: Uva morastello (GUF, MRI).

Número de informantes: 2 Número de citas: 2.

Número de sectores: 1 Número de categorías: 2.

Biotipo: Fanerófito.

Tipo corológico: Cultivadas.

Abundancia: Cultivada.

Ambiente: Cultivada.

Sector alimentario

Categoría de uso: Bebida.

Número de informantes: 1 Partes utilizadas: frutos/infrutescencias/falsos frutos. Il vino si fa con l'uva morastello (MRI).

Categoría de uso: Fruta seca.

Número de informantes: 1 Partes utilizadas: frutos/infrutescencias/falsos frutos.

Uva appesa ai chiodi dei travi a passire (GUF).

Notas Uva morastello (con le foglie piu arotondate).

\section{Vitis vinifera L. 'Nigratein'}

Nombre vulgar: Uva nigratein (AN3), Uva negratina (GUF).

Número de informantes: 2 Número de citas: 2.

Número de sectores: 1 Número de categorías: 2.

Biotipo: Fanerófito.

Tipo corológico: Cultivadas.

Abundancia: Cultivada.

Ambiente: Cultivada.

Sector alimentario

Categoría de uso: Bebida.

Número de informantes: 1 Partes utilizadas: frutos/infrutescencias/falsos frutos. 
Con le vinacce delle varieta di vite che si coltivavano si distillava e si faceva la grappa, con la quale si facevano I liquori. (AN3).

Categoría de uso: Fruta seca.

Número de informantes: 1 Partes utilizadas: frutos/infrutescencias/falsos frutos.

Uva appesa ai chiodi dei travi a passire (GUF).

\section{Vitis vinifera L. 'Saslà'}

Nombre vulgar: saslà(frutta secca) (AN3), Uva passita, "a zibebe", "saslà"(frutta secca) (AN3).

Número de informantes: 1 Número de citas: 2.

Número de sectores: 1 Número de categorías: 1 .

Biotipo: Fanerófito.

Tipo corológico: Cultivadas.

Abundancia: Cultivada.

Ambiente: Cultivada.

Sector alimentario

Categoría de uso: Dulces y golosinas.

Número de informantes: 1 Partes utilizadas: frutos/infrutescencias/falsos frutos.

Dolce di natale tipico di Castiglione dei pepoli e di Casalecchio, "Pinza": fare l'impasto con 2 uova, 1 etto di burro, 2 etti di farina di grano duro, e 1 etto di zucchero. A stratti mettere un pò di impasto, e un pò di marmellata al savor e uva passita. (AN3).

\section{Vitis vinifera L. 'Zibebe'}

Nombre vulgar: uva passita, "a zibebe", (AN3), Uva passita, "a zibebe", "saslà"(frutta secca) (AN3).

Número de informantes: 1 Número de citas: 2 .

Número de sectores: 1 Número de categorías: 1 .

Biotipo: Fanerófito.

Tipo corológico: Cultivadas.

Abundancia: Cultivada.

Ambiente: Cultivada.

Sector alimentario

Categoría de uso: Dulces y golosinas.

Número de informantes: 1 Partes utilizadas: frutos/infrutescencias/falsos frutos.

Dolce di natale tipico di Castiglione dei pepoli e di Casalecchio, "Pinza": fare l'impasto con 2 uova, 1 etto di burro, 2 etti di farina di grano duro, e 1 etto di zucchero. A stratti mettere un pò di impasto, e un pò di marmellata al savor e uva passita. (AN3). 


\section{XANTHORRHOEACEAE}

\section{Aloe arborescens Mill.}

Nombre vulgar: Pianta grassa (DBA, BAR).

Número de informantes: 2 Número de citas: 2.

Número de sectores: 1 Número de categorías: 1.

Biotipo: Nanofanerófito.

Tipo corológico: Cultivadas.

Abundancia: Cultivada.

Ambiente: Jardines, a veces asilvestrada en cantilados marítimos.

Sector medicinal

Categoría de uso: Afecciones cutáneas y tejidos subcutáneos.

Número de informantes: 2 Partes utilizadas: hojas.

Spellare la foglia della pianta grassa e applicarla sulla bruciatura. (DBA, BAR).

Notas È una pianta coltivata e arrivata da 30 anni. 

Parte 5 Discusión 



\section{Capítulo 1}

\section{Informantes}

\section{Características de los informantes}

Como ha sido evidenciado en el capítulo de Metodología, han sido entrevistados un total de 113 informantes, de edades comprendidas desde los 43 años hasta los 103 años, con una edad media total de 78,30 años. La mayoría de informantes pertenecen al municipio de Sambuca Pistoiese (43,36\%) y de Camugnano (32,74\%), y el resto al municipio de Castiglione dei Pepoli (7,97\%), de Granaglione (7,08\%), de Castel di Casio (5,31\%) y por último de Porretta Terme (3,53\%) (Fig. 19). Han sido entrevistados 49 informantes (43,36\%) en la parte toscana (Sambuca Pistoiese), 64 en la parte emiliana (56,63\% en Camugnano, Castiglione dei Pepoli, Granaglione, Castel di Casio y Porretta Terme).

Los informantes son mayoritariamente de avanzada edad: 58 informantes $(51,33 \%$ ) tienen entre 61 y 80 años, 47 informantes $(41,59 \%)$ son mayores de 80 años y solamente 8 informantes $(7,08 \%)$ tienen entre 41 y 60 años. La mayoría son mujeres (67 informantes, $59,29 \%$ ) y la mayor parte de los informantes tienen un nivel de educación elemental, ya que 70 informantes $(61,94 \%)$ han estudiado sólo hasta Primaria, 26 (23\%) informantes hasta la Secundaria, $10(8,85 \%)$ informantes hasta Bachillerato y solo 7 (6,19\%) han llegado hasta la Universidad. Los sectores laborales más comunes e importantes entre los informantes son el sector agroforestal (38 informantes), como empleados (34 informantes) y el sector doméstico (26 informantes), aunque una parte considerable de los informantes (36 informantes, $31,9 \%)$ se ha dedicado a más de un sector laboral.

El conocimiento se distribuye de forma muy parecida entre hombres y mujeres como sucede en el estudio de plantas alimentarias de la provincia de Bolonia de Sansanelli y Tassoni (2014). Pero cabe mencionar como las mujeres conocen más plantas útiles conforme aumentan de edad (Tab. 13), en cambio los hombres que más plantas conocen tienen entre 61 y 80 años, lo cual podría ser debido a que estos pierden la memoria y las capacidades de conversación antes que las mujeres (al igual que se observa en la zona boloñesa en el estudio de Sansanelli y Tassoni, 2014). No se puede afirmar que las mujeres posean un mayor conocimiento que los hombres como en varios estudios etnobotánicos (Nebel et al., 2006; Pieroni et al., 2005), ya que los datos más importantes son proporcionados por hombres de 61-80 años (tanto en número de especies, como en número de usos, como en número de sectores y categorías) (Tab. 13). 
En cambio resalta como el conocimiento tradicional sobre plantas aumenta con el nivel de estudios de los informantes, sobre todo se denota claramente en los hombres, ya que los que más número de especies y de usos han sabido proporcionar han sido los pocos informantes que han llegado hasta la universidad. Igualmente, las mujeres que más número de especies y más usos saben tienen un nivel de estudios superior. Estos datos denotan que los informantes que tienen un mayor nivel de estudios-educación tienen un mayor conocimiento tradicional de las plantas, contrariamente de como suele pasar en otros estudios etnobotánicos (Pieroni et al., 2005). Esto puede ser debido a una mayor sensibilidad por la cultura, una mayor comprensión de los objetivos de la investigación, una mayor disposición y confianza hacia el proyecto así como una mayor capacidad de retención o memoria.

\section{Distribución del conocimiento entre los informantes}

Cada informante conoce una media de 21,2 $\pm 14,4$ especies y 30,2 $\pm 23,5$ usos diferentes y cita las especies para un número medio de $5,1 \pm 2,4$ sectores de uso y 17,2 $\pm 10,3$ categorías de uso (Tab. 13). Gran parte del conocimiento etnobotánico registrado según estos parámetros es común a todos los informantes entrevistados en el área en estudio. Sin embargo, han sido registradas diferencias estadísticas significativas principalmente respecto a la provincia de residencia (entre el margen toscano y el margen emiliano), al número de sectores conocidos y al nivel de educación.

La distribución del conocimiento ha resultado ser heterogéneo (como en Cornara et al., 2014; Signorini et al., 2009). Aunque la media por persona es de $21,2 \pm 14,4$ especies y 30,2 $\pm 23,5$ citas diferentes (Tab. 13), un solo informante proporcionó 103 especies (y 165 citas), ya que fue el informante (y a su vez intermediario) que más veces fue entrevistado y con el que más confianza se tuvo. Después destaca el segundo informante que proporcionó 65 especies (y 96 citas), quien fue un informante "típico o medio" el cual fue entrevistado como la mayoría del resto de personas (en cuanto al grado de confianza y el tiempo dedicado). El resto de informantes proporcionaron un número de especies muy variado desde 59 especies hasta una sola especie, disminuyendo progresivamente, como sucede en Signorini et al. (2009). Sólo un informante conoce $36,65 \%$ de las plantas (103 especies), y otro informante conoce $23,13 \%$ (65 especies), la mitad de los informantes (56 informantes, 49,55\%) conocen menos de 20 especies $(7,11 \%)$, lo cual evidencia que el tipo de plantas que conocen los informantes es muy diferente entre ellos (Fig. 20).

En la Tab. 13, se expone la distribución del conocimiento etnobotánico considerando los informantes subdivididos por área regional. Resalta como los valores medios del número de especies, el número de usos, el número de sectores y el número de categorías es mayor en la parte toscana que en la parte emiliana, aunque la diferencia no sea muy grande. 


\section{María Teresa Egea Molines}

Tab. 13. Resumen estadístico de la información registrada.

Valores medios (y desviación estándar) calculados considerando los informantes subdivididos por áreas $\mathrm{N}=$ número total de informantes, $\mathrm{Ns}=$ número de las especies, $\mathrm{Nc}=$ número de citas, $\mathrm{Ns}=$ número de sectores, $\mathrm{Ncat}=$ número de categorías. $\mathrm{F}=$ mujer, $\mathrm{H}=$ hombre.

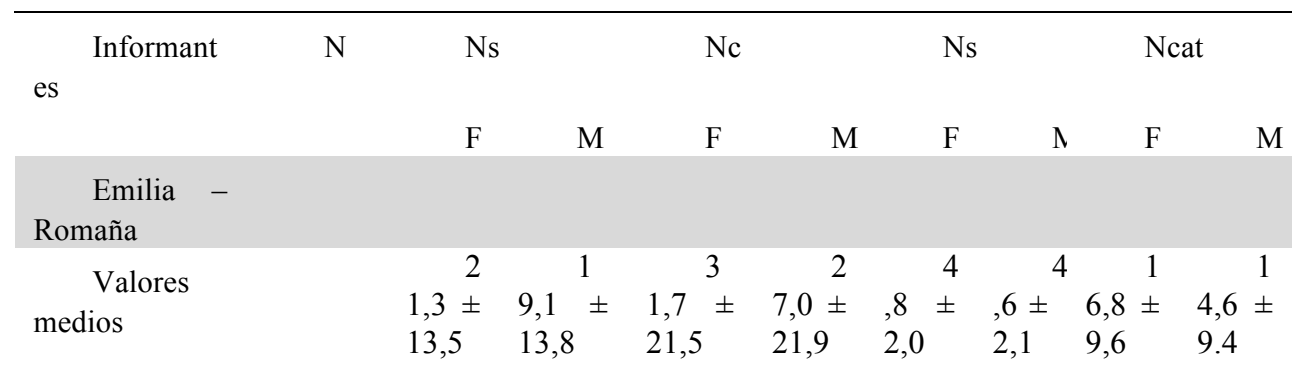

Clases de

edad

$40-60$

$$
\begin{array}{llllllllllll}
1 & & 1 & & 3 & & & 4 & & 4 & 1 & \\
9,4 \pm & 4,0 & \pm & 0,0 & \pm & 9,0 \pm & , 6 & \pm & , 0 \pm & 6,0 \pm & 4,0 \pm \\
12,0 & 0,0 & & 23,2 & 0,0 & 1,6 & 0,0 & 7,8 & & 0,0
\end{array}
$$

$61-80$

$$
\begin{array}{lllllllllll}
8 & 2 & 1,8 \pm & 4,9 \pm & 3,3 \pm & 6,5 \pm & , 1 & \pm & , 6 \pm & 7,6 \pm & 9,8 \pm \\
& 12,9 & 13,7 & 27,7 & 23,9 & 2,2 & 1,8 & 10,6 & 8,7
\end{array}
$$

$>80$

$$
\begin{aligned}
& 421,8 \pm 3,7 \pm 0,1 \pm 7,0 \pm \quad 4 \pm \quad, 7 \pm 6,3 \pm 0,1 \pm \\
& \begin{array}{llllllll}
15,7 & 12,5 & 25,0 & 13,7 & 1,9 & 2,0 & 9,6 & 8,5
\end{array}
\end{aligned}
$$

Nivel de

educación

Primaria

$\begin{array}{rrrrrrrrrrrrrrr} & & & 1 & & 1 & & 2 & 2 & 4 & 4 & 1 & 1 \\ 5 & 5 & 9,9 \pm & 4,7 & \pm & 7,7 & \pm & 0,0 \pm & 4 & \pm & , 1 \pm & 5,5 \pm & 2,0 & \pm\end{array}$ $\begin{array}{llllllll}13,1 & 9,7 & 21,2 & 14,9 & 1,9 & 1,6 & 9,3 & 7,6\end{array}$

Secundari

$\begin{array}{rrrrrrrrr}2 & 1 & 3 & 2 & 5 & 4 & 1 & 1\end{array}$

a

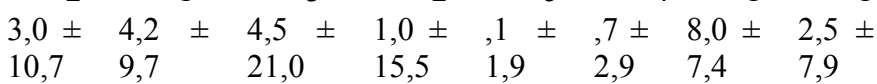

Educación

superior

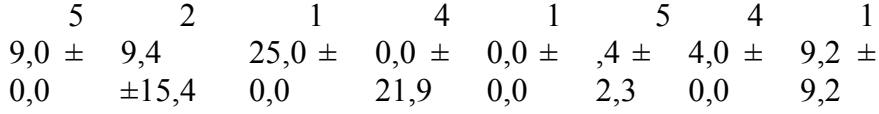

ad

Universid

Totales

valores medios

$\begin{array}{rrrrrrrr}1 & 5 & 1 & 9 & 5 & 8 & 1 & 3\end{array}$

$2,0 \pm 2,0 \pm 9,0 \pm 1,0 \pm \quad, 0 \pm \quad, 0 \pm \quad 4,0 \pm \quad 8,0 \pm$

$\begin{array}{llllllll}5,6 & 0,0 & 9,9 & 0,0 & 1,4 & 0,0 & 5,6 & 0,0\end{array}$

AVRB

\section{Toscana}

Valores

$\begin{array}{llllllll}2 & 2 & 3 & 4 & 5 & 7 & 1 & 2\end{array}$

medios

$2,2 \pm 8,7 \pm 0,9 \pm 3,4 \pm \quad, 3 \pm, 3 \pm 7,8 \pm 3,6 \pm$

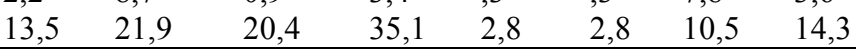




\begin{tabular}{|c|c|c|c|c|c|c|c|c|c|c|}
\hline \multicolumn{11}{|l|}{ Clases de edad } \\
\hline $40-60$ & 0 & 0 & - & - & - & - & - & - & - & - \\
\hline $61-80$ & 14 & 14 & $\begin{array}{l}22,3 \\
\pm\end{array}$ & $\begin{array}{l}30,3 \pm \\
24,9\end{array}$ & $\begin{array}{l}30,8 \pm \\
21,9\end{array}$ & $\begin{array}{l}43,3 \\
\pm\end{array}$ & $\begin{array}{l}5,1 \pm \\
2,9\end{array}$ & $\begin{array}{l}7,2 \\
\pm\end{array}$ & $\begin{array}{l}18,1 \\
\pm\end{array}$ & $\begin{array}{l}23,6 \\
\pm\end{array}$ \\
\hline$>80$ & 14 & 7 & $\begin{array}{l}14,7 \\
22,1 \\
\pm \\
12,8\end{array}$ & $\begin{array}{l}25,4 \pm \\
15,5\end{array}$ & $\begin{array}{l}30,1 \pm \\
19,7\end{array}$ & $\begin{array}{l}40,1 \\
40,6 \\
\pm \\
24,7\end{array}$ & $\begin{array}{l}5,5 \pm \\
2,8\end{array}$ & $\begin{array}{l}2,9 \\
7,6 \\
\pm \\
2,6\end{array}$ & $\begin{array}{l}12,1 \\
17,4 \\
\pm 8,9\end{array}$ & $\begin{array}{l}15,6 \\
23,4 \\
\pm \\
12,6\end{array}$ \\
\hline $\begin{array}{l}\text { Nivel de } \\
\text { educación }\end{array}$ & & & & & & & & & & \\
\hline Primaria & 19 & 11 & $\begin{array}{l}21,8 \\
\pm\end{array}$ & $\begin{array}{l}24,7 \pm \\
15,9\end{array}$ & $\begin{array}{l}30,6 \pm \\
21,7\end{array}$ & $\begin{array}{l}37,1 \\
\pm\end{array}$ & $\begin{array}{l}5,4 \pm \\
2,9\end{array}$ & $\begin{array}{l}6,6 \\
\pm\end{array}$ & $\begin{array}{l}17,4 \\
\pm\end{array}$ & $\begin{array}{l}20,9 \\
\pm\end{array}$ \\
\hline Secundaria & 4 & 7 & $\begin{array}{l}13,9 \\
27,0 \\
\pm \\
14,5\end{array}$ & $\begin{array}{l}34,4 \pm \\
31,9\end{array}$ & $\begin{array}{l}35,8 \pm \\
20,6\end{array}$ & $\begin{array}{l}24,4 \\
50,4 \\
\pm \\
53,5\end{array}$ & $\begin{array}{l}6,3 \pm \\
2,1\end{array}$ & $\begin{array}{l}2,9 \\
7,7 \\
\pm \\
2,8\end{array}$ & $\begin{array}{l}10,6 \\
23,5 \\
\pm \\
10,6\end{array}$ & $\begin{array}{l}12,9 \\
25,2 \\
\pm \\
18,5\end{array}$ \\
\hline $\begin{array}{l}\text { Educación } \\
\text { superior }\end{array}$ & 3 & 1 & $\begin{array}{l}18,0 \\
\pm 8,7\end{array}$ & $\begin{array}{l}26,0 \pm \\
0,0\end{array}$ & $\begin{array}{l}26,7 \pm \\
13,8\end{array}$ & $\begin{array}{l}33,0 \\
\pm 0,0\end{array}$ & $\begin{array}{l}3,3 \pm \\
1,5\end{array}$ & $\begin{array}{l}8,0 \\
\pm \\
0,0\end{array}$ & $\begin{array}{l}12,7 \\
\pm 6,6\end{array}$ & $\begin{array}{l}26,0 \\
\pm 0,0\end{array}$ \\
\hline Universidad & 2 & 2 & $\begin{array}{l}23,0 \\
\pm \\
22,6\end{array}$ & $\begin{array}{l}31,5 \pm \\
23,3\end{array}$ & $\begin{array}{l}30,5 \pm \\
31,8\end{array}$ & $\begin{array}{l}43,0 \\
\pm \\
25,4\end{array}$ & $\begin{array}{l}5,5 \pm \\
4,9\end{array}$ & $\begin{array}{l}9,5 \\
\pm \\
2,1\end{array}$ & $\begin{array}{l}18,0 \\
\pm \\
17,0\end{array}$ & $\begin{array}{l}31,0 \\
\pm \\
12,7\end{array}$ \\
\hline $\begin{array}{l}\text { Totales valores } \\
\text { medios AVRT }\end{array}$ & 28 & 21 & $25,0 \pm$ & 17,7 & $35,8 \pm 2$ & & $6,2 \pm$ & & $20,3=$ & 12,5 \\
\hline $\begin{array}{lr}\text { Total } & \text { AVR } \\
\text { (AVRT } & \mathrm{y} \\
\text { AVRB) } & \\
\end{array}$ & 67 & 46 & $21,2 \pm$ & 14,4 & $30,2 \pm$ & & $5,1=$ & & 17,2 & 10.3 \\
\hline
\end{tabular}

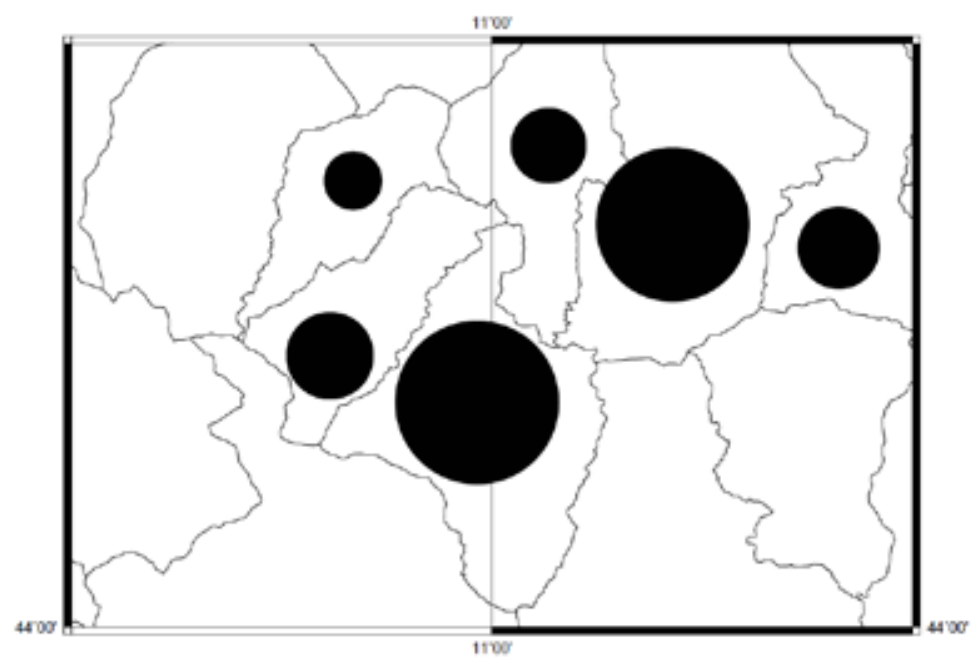

Fig. 17. Mapa de número de informantes por municipio. 


\section{María Teresa Egea Molines}

Fig. 17. Mapa de número de informantes por municipio.

La superficie del círculo es proporcional al número de informantes. En el mapa en la parte superior, de izquierda a derecha: Porretta Terme, Castel di Casio, Camugnano, Castiglione dei Pepoli, en la parte inferior, de izquierda a derecha, Granaglione, Sambuca Pistoiese.

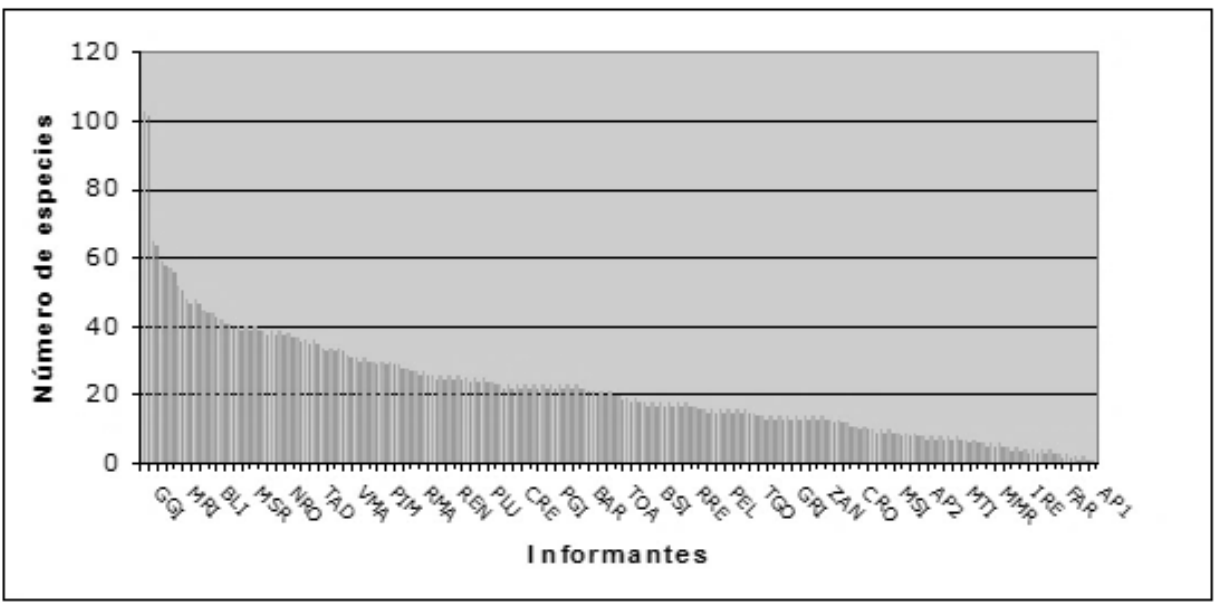

Fig. 18. Distribución del conocimiento etnobotánico en el AVR. 



\section{Capítulo 2}

\section{Etnoflora}

En el catálogo florístico se han recogido 4053 citas sobre 333 taxones de plantas vasculares pertenecientes 79 familias botánicas. En el catálogo se ha realizado una exposición descriptiva y cualitativa de ciertas plantas que no han sido el objeto principal de la investigación, pero sin embargo permiten describir la cultura en estudio y pueden ser objeto de futuras investigaciones, como son las plantas alimentarias cultivadas en los huertos, los frutales, las variedades antiguas, las plantas forrajeras, las plantas cultivadas a nivel comercial en grandes extensiones o bien las plantas ornamentales.

Por todo lo expuesto, el análisis cuantitativo de la etnoflora incluye exclusivamente las plantas silvestres y cultivadas, sólo si son utilizadas para fines diferentes para los cuales son normalmente cultivadas, al igual que han sido realizados otros estudios etnobotánicos italianos como Signorini, et al. (2009); o en el caso de Uncini Manganelli y Tomei, (1998) y Pieroni (1999) en los que se centran solo en las plantas silvestres o naturalizadas. La etnoflora estudiada en profundidad incluye 3667 citas sobre 1165 usos etnobotánicos relativos a 281 taxones diferentes pertenecientes a 76 familias botánicas.

\section{Familias}

De las 76 familias registradas, Compositae ha sido la familia botánica más mencionada (548 citas; $14,9 \%$ de las citas totales), seguida por Rosaceae (442; $12,0 \%)$, Urticaceae $(205 ; 5,6 \%)$, Malvaceae $(155 ; 4,2 \%)$, Ranunculaceae (149; 4,0\%), Fagaceae (141; 3,8\%) y Lamiaceae (128; 3,5\%) (Tab. 14).

La familia que más especies incluye es Rosaceae (38 especies; 13,5\% de las especies totales citadas), seguidas de Compositae $(27 ; 9,6 \%)$, Leguminosae (17; $6,0 \%)$, Lamiaceae $(12 ; 15,7 \%)$, Poaceae $(10 ; 13,15 \%)$, Apiaceae $(9 ; 11,8 \%)$ у Salicaceae $(8 ; 10,5 \%)$. El 60,52 \% de las familias incluyen sólo una o dos especies botánicas. Estos resultados coinciden con los estudios etnobotánicos de dos áreas montañosas, lluviosas y de carácter centroeuropeo con numerosos pastos y bosques, del nordeste de Portugal (Carvalho, 2005) y del norte de España, Cantabria (Pardode-Santayana, 2003), ya que aunque en diferente orden, las familias etnobotánicas más importantes son Leguminosae, Lamiaceae, Compositae y Rosaceae. Estas similitudes son normales ya que se trata de ambientes biogeográficos muy parecidos, 
y en el caso del estudio de Cantabria, incluso se trata de una zona de transición entre la región biogeográfica mediterránea y eurosiberiana (Pardo-de-Santayana, 2008). En cambio en el estudio etnobotánico del Poniente Granadino (Benítez Cruz, 2009), de carácter mediterráneo vemos como la familias más importantes cambian, ya que estas son Compositae, Lamiaceae, Poaceae y Leguminosae. Por otra parte también encontramos similitudes con las comunidades de montaña alpina del norte de Italia como los Móquenos (Bersntol, Trentino) (Obón et al., 2012) y los Cimbros (Rivera et al., 2012) los cuales usan prevalentemente especies de las familias Rosaceae y Compositae al igual que las comunidades del AVR. Sin embargo en el AVR, notamos como Leguminosae tiene una importancia mucho mayor respecto a estas comunidades alpinas ya que se trata de un territorio más térmico y de menores altitudes, en cambio los Cimbros y Móquenos utilizan mayoritariamente especies pertenecientes a la familia Pinaceae ya que se encuentran en zonas más frías. Se puede observar la importancia de las familias tanto de origen Mediterráneo (como Compositae, Lamiaceae y Rosaceae) como de origen Centroeuropeo (Ranunculaceae, Fagaceae, Leguminosae), debido a que el territorio estudiado se encuentra en la línea biogeográfica que separa ambas regiones biogeográficas (Adamovic, 1933; Pignatti et al., 2001). Merece la pena resaltar como las familias Ranunculaceae, Urticaceae y Malvaceae constituyen después de las Compositae y de las Rosaceae, las familias más conocidas tanto por número de citas, como por número de informantes que las citan. Sin embargo, éstas familias tan populares están compuestas por solo 3 especies en el caso de Ranunculaceae (Clematis vitalba L.; Helleborus foetidus L.; Helleborus viridis L. (s.1.)) y Malvaceae (Malva sylvestris L.; Tilia americana L.; Tilia platyphyllos Scop.) y 2 especies en el caso de Urticaceae (Parietaria officinalis L.; Urtica dioica L.). En cuanto a la versatilidad de las familias, resaltan Rosaceae y Compositae por tener una gran diversidad de aplicaciones diferentes (43 y 42 categorías de uso respectivamente) y sobre todo Fagaceae que a pesar de tener solo 7 especies, éstas son las más versátiles presentando 47 aplicaciones diferentes (categorías de uso) en 10 sectores diferentes. Leguminosae es la familia que en más sectores de uso diferentes se utiliza (11 sectores).

Tab. 14. Las 20 familias botánicas más importantes.

Según el número de especies que incluyen el número de citas, el número de informantes, el número de sectores y el número de categorías, con los respectivos índices analíticos sobre la importancia relativa de cada especie.

\begin{tabular}{|c|c|c|c|c|c|c|}
\hline & \multirow[t]{3}{*}{ Familia } & Númer & Núme & Número & Númer & Número de \\
\hline & & \multirow{2}{*}{\multicolumn{3}{|c|}{$\begin{array}{l}\mathrm{O} \quad \mathrm{de} \\
\text { especies }\end{array}$}} & o de & categorías $\quad \mathrm{o}$ \\
\hline & & & & & sectores & usos \\
\hline & Rosaceae & 38 & 442 & 93 & 9 & 43 \\
\hline & Compositae & 27 & 584 & 96 & 9 & 42 \\
\hline ae & Leguminos & 17 & 112 & 60 & 11 & 31 \\
\hline
\end{tabular}


María Teresa Egea Molines

\begin{tabular}{|c|c|c|c|c|c|c|}
\hline & Lamiaceae & 12 & 128 & 54 & 5 & 19 \\
\hline & Рoaceae & 10 & 125 & 58 & 9 & 36 \\
\hline & Aniaceae & 9 & 45 & 33 & 5 & 12 \\
\hline & Salicaceae & 8 & 105 & 38 & 8 & 23 \\
\hline & Fagaceae & 7 & 141 & 53 & 10 & 47 \\
\hline & Oleaceae & 6 & 79 & 45 & 8 & 22 \\
\hline & Solanaceae & 6 & 58 & 37 & 9 & 17 \\
\hline & Brassicacea & 6 & 17 & 13 & 3 & 5 \\
\hline $\begin{array}{l}\mathrm{e} \\
\mathrm{ace}\end{array}$ & Caryophyll & 5 & 110 & 58 & 5 & 18 \\
\hline cea & Amaryllida & 5 & 59 & 36 & 5 & 17 \\
\hline eae & Plantaginac & 5 & 49 & 30 & 4 & 13 \\
\hline & Ericaceae & 5 & 49 & 24 & 6 & 20 \\
\hline $\mathrm{e}$ & Crassulacea & 5 & 18 & 15 & 4 & 9 \\
\hline eae & Caprifoliac & 4 & 62 & 55 & 3 & 7 \\
\hline & Vitaceae & 4 & 51 & 33 & 5 & 15 \\
\hline ae & Polygonace & 4 & 44 & 32 & 4 & 5 \\
\hline ae & Gentianace & 4 & 30 & 15 & 3 & 12 \\
\hline
\end{tabular}

Comparando las familias más citadas en la parte toscana con la parte boloñesa, las tres más citadas en ambas partes son Compositae, Rosaceae, Urticaceae. Sin embargo destacan en la parte pistoyesa las familias Fagaceae y Oleaceae, mientras son menos importantes en la parte boloñesa. Y en la parte boloñesa resaltan Caryophyllaceae respecto a la parte pistoyesa en la que tienen una relevancia menor.

Si observamos los estudios florísticos realizados en el territorio en Le Valli della Limentra Orientale e Limentrella (situada entre Pistoia y Prato, en la parte este del municipio Sambuca Pistoiese) por Venturi (2006) y en el Parco dei laghi di Suviana e Brasimone por Sirotti (2005), vemos como las familias más importantes en estas floras parciales coinciden con las familias más importantes de la etnoflora aunque ésta última abarque un territorio mayor.

A partir de la Tab. 15, se puede ver como la familia más importante de la etnoflora es Rosaceae (38 especies), mientras en los dos estudios florísticos y parciales del territorio estudiado, ésta no es la más importante recogiendo solo 36 especies. Esto puede indicar que probablemente todas esas especies son utilizadas por la población local, ya que el número de especies de la etnoflora es mayor que el 
de la flora registrada para esa familia, o bien que simplemente el número de especies de la etnoflora es mayor que el de las floras debido a que la etnoflora abarca un territorio mayor que ambas floras parciales. Sin embargo, Compositae es la familia que más especies presenta en el territorio, pero pocas de ellas son especies útiles (Tab. 15). El número de especies de cada familia en las distintas floras de la parte toscana, de la parte emiliana y de la etnoflora (que considera tanto la zona toscana como la emiliana) demuestra la homogeneidad biogeográfica que existe en este territorio de frontera. El análisis de las familias Rosaceae y Salicaceae denota la gran profundidad del conocimiento etnobotánico y el alto grado de utilidad que la comunidad otorga a la flora local, ya que el número de especies utilizadas de la familia Rosaceae en el AVR es superior al del número de especies recogidos por las floras parciales en ambas zonas, y el número de especies de la familia Salicaceae utilizadas es muy parecido al número de especies registradas por las floras parciales mencionadas.

Tab. 15. Número de especies usadas de las 6 familias más importantes.

Según los estudios florísticos de Venturi (2006) y Sirotti (2005) y según la etnoflora.

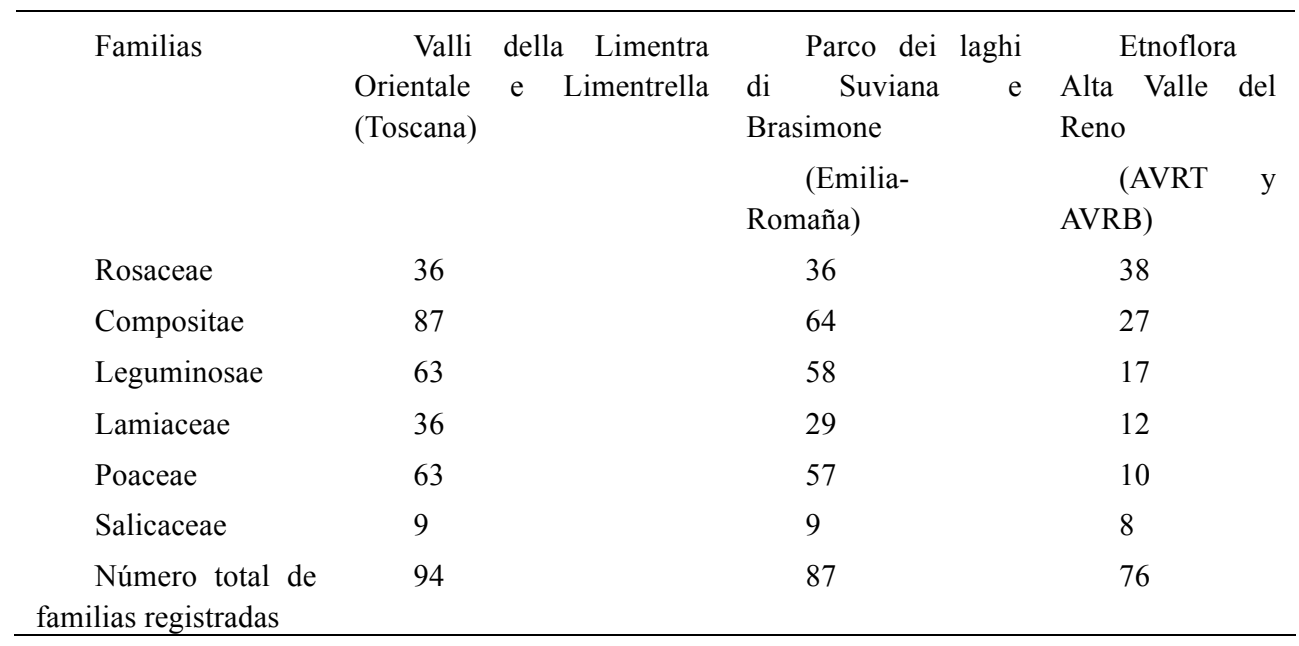

\section{Especies botánicas}

Durante la investigación etnobotánica han sido registradas 281 especies útiles con 1165 usos y 3667 citas. A través del análisis de las especies (Tab. 16), se puede apreciar una vez más, que el conocimiento etnobotánico es heterogéneo. Más de la mitad de las especies (146; 52\% del total) han sido citadas por menos de 4 informantes. Solamente 4 especies fueron citadas por más de la mitad de los informantes (más de 70; más del 61,9\% de los informantes), las cuales corresponden a las especies más conocidas por la población: Malva sylvestris L. (73 informantes, 140 citas), Urtica dioica L. (72 informantes, 191 citas), Taraxacum campylodes G.E.Haglund (s.1.) (70 informantes, 141 citas), Clematis vitalba L. (70 informantes, 98 citas). 


\section{María Teresa Egea Molines}

De hecho, según el índice RFC (Frecuencia Relativa de Citas), estas 4 plantas tienen la misma importancia relativa, en cuanto son las especies más usadas en la comunidad o las plantas más consideradas como útiles en la comunidad: Malva sylvestris L. $(\mathrm{RFC}=0,64)$, Urtica dioica $\mathrm{L} .(\mathrm{RFC}=0,63)$, Clematis vitalba $\mathrm{L} .(\mathrm{RFC}=0,61)$ y Taraxacum campylodes G.E.Haglund (s.1.) (RFC=0,61).

Las especies más citadas por los informantes son Urtica dioica (191 citas), Taraxacum campylodes G.E.Haglund (s.1.) (141 citas), Malva sylvestris L. (140 citas), Castanea sativa Mill. (108 citas) y Clematis vitalba L. (98 citas).

Igualmente, el índice UV (Valor de Uso) nos indica que las especies que más usos tienen pero que a su vez son más conocidas o citadas son Urtica dioica L. (UV=1,21) seguida de Castanea sativa Mill. (UV=0,79), Taraxacum campylodes G.E.Haglund (s.1.) (UV=0,76), Clematis vitalba $\mathrm{L}$. (UV=0,70), Malva sylvestris $\mathrm{L}$. (UV=0,66).

Las plantas más importantes culturalmente según el índice de importancia relativa (RI) de cada especie son, Castanea sativa Mill. $(\mathrm{RI}=0,83)$, lo cual refleja la importancia que ha tenido este árbol durante siglos en el territorio, y por otra parte, Urtica dioica $\mathrm{L}$. $(\mathrm{RI}=0,83)$ seguramente por su abundancia en las zonas antropizadas. A continuación también son muy importantes Taraxacum campylodes G.E.Haglund (s.1.) (RI= 0,70) y Buxus sempervirens $\mathrm{L} .(\mathrm{RI}=0,68)$ aunque su versatilidad es menor.

Las especies que presentan una mayor versatilidad, entendida como mayor número de sectores y de categorías de uso (Signorini, 2009) son Castanea sativa Mill. (9 sectores de uso, 35 categorías de uso,), seguida por Buxus sempervirens L. (8 sectores de uso y 17 categorías de uso), Sambucus nigra L. (7 sectores y 24 categorías de uso) y Triticum aestivum L. (7 sectores y 16 categorías de uso). En cambio, si se consideran solamente las categorías de uso (las diferentes aplicaciones) las especies más versátiles son Castanea sativa Mill. (35 categorías de uso y 9 sectores), Urtica dioica L. (28 categorías de uso, 6 sectores de uso), Sambucus nigra L. (24 categorías de uso, 7 sectores de uso) y Rubus ulmifolius Schott (18 categorías de uso y 5 sectores de uso).

Por último, considerando el índice CV (Valor cultural), las especies con mayor importancia relativa a nivel cultural son Urtica dioica L. $(\mathrm{CV}=0,38)$, Castanea sativa Mill. $(\mathrm{CV}=0,25)$, Taraxacum campylodes G.E.Haglund (s.1.) $(\mathrm{CV}=0,16)$, Clematis vitalba $\mathrm{L}$. $(\mathrm{CV}=0,11)$, Buxus sempervirens $\mathrm{L} .(\mathrm{CV}=0,10)$.

Tab. 16. Las 20 especies botánicas más importantes.

Según el número de citas, el número de los informantes que las han citado, el número de sectores y el número de categorías de uso. $\mathrm{RFC}=$ Frecuencia Relativa de Citas, $\mathrm{UV}=$ Valor de uso, $\mathrm{RI}=$ índice de Importancia Relativa, $\mathrm{CV}=$ Valor cultural

\begin{tabular}{|c|c|c|c|c|c|c|c|c|}
\hline $\begin{array}{l}\text { Especie } \\
\text { botánica }\end{array}$ & $\begin{array}{l}\text { Número } \\
\text { de citas }\end{array}$ & $\begin{array}{l}\text { Número de } \\
\text { informantes }\end{array}$ & $\begin{array}{l}\text { Número } \\
\text { de } \\
\text { sectores }\end{array}$ & $\begin{array}{l}\text { Número } \\
\text { de } \\
\text { categorías }\end{array}$ & RFC & UV & RI & $\mathrm{CV}$ \\
\hline $\begin{array}{l}\text { Urtica dioica } \\
\text { L. }\end{array}$ & 191 & 72 & 6 & 28 & 0.64 & 1.21 & 0.83 & 0.39 \\
\hline $\begin{array}{l}\text { Taraxacum } \\
\text { campylodes } \\
\text { G.E.Haglund (s.1.) }\end{array}$ & 141 & 70 & 4 & 15 & 0.62 & 0.76 & 0.70 & 0.16 \\
\hline
\end{tabular}


Etnobotánica en el Alto Valle del Reno (Toscana y Emilia-Romaña, Italia)

\begin{tabular}{|c|c|c|c|c|c|c|c|c|}
\hline $\begin{array}{l}\text { Malva } \\
\text { sylvestris L. }\end{array}$ & 140 & 73 & 2 & 11 & 0.65 & 0.66 & 0.61 & 0.07 \\
\hline $\begin{array}{l}\text { Castanea } \\
\text { sativa Mill. }\end{array}$ & 108 & 48 & 9 & 35 & 0.42 & 0.79 & 0.83 & 0.25 \\
\hline $\begin{array}{l}\text { Clematis } \\
\text { vitalba L. }\end{array}$ & 98 & 70 & 3 & 10 & 0.62 & 0.70 & 0.65 & 0.11 \\
\hline $\begin{array}{l}\text { Sonchus } \\
\text { oleraceus (L.) } \\
\text { L. (s. 1.) }\end{array}$ & 96 & 53 & 3 & 10 & 0.47 & 0.51 & 0.53 & 0.06 \\
\hline $\begin{array}{l}\text { Silene } \\
\text { vulgaris } \\
\text { (Moench) } \\
\text { Garcke }\end{array}$ & 90 & 50 & 3 & 12 & 0.44 & 0.50 & 0.51 & 0.06 \\
\hline $\begin{array}{l}\text { Matricaria } \\
\text { chamomilla L. }\end{array}$ & 87 & 50 & 3 & 12 & 0.44 & 0.48 & 0.51 & 0.05 \\
\hline $\begin{array}{l}\text { Juglans regia } \\
\text { L. }\end{array}$ & 71 & 46 & 5 & 13 & 0.41 & 0.57 & 0.59 & 0.10 \\
\hline $\begin{array}{l}\text { Sambucus } \\
\text { nigra L. }\end{array}$ & 69 & 37 & 7 & 24 & 0.33 & 0.49 & 0.64 & 0.09 \\
\hline $\begin{array}{l}\text { Cichorium } \\
\text { intybus L. }\end{array}$ & 67 & 37 & 2 & 8 & 0.33 & 0.38 & 0.36 & 0.02 \\
\hline $\begin{array}{l}\text { Buxus } \\
\text { sempervirens } \\
\text { L. }\end{array}$ & 62 & 34 & 8 & 17 & 0.30 & 0.49 & 0.68 & 0.10 \\
\hline $\begin{array}{l}\text { Juniperus } \\
\text { communis L. }\end{array}$ & 56 & 36 & 6 & 11 & 0.32 & 0.45 & 0.58 & 0.07 \\
\hline $\begin{array}{l}\text { Valerianella } \\
\text { locusta (L.) } \\
\text { Laterr. }\end{array}$ & 55 & 52 & 2 & 3 & 0.46 & 0.47 & 0.47 & 0.04 \\
\hline $\begin{array}{l}\text { Rubus } \\
\text { ulmifolius } \\
\text { Schott }\end{array}$ & 54 & 39 & 5 & 18 & 0.35 & 0.40 & 0.54 & 0.06 \\
\hline $\begin{array}{l}\text { Crepis } \\
\text { vesicaria L. }\end{array}$ & 51 & 29 & 3 & 7 & 0.26 & 0.29 & 0.37 & 0.02 \\
\hline $\begin{array}{l}\text { Helleborus } \\
\text { viridis L. (s. 1.) }\end{array}$ & 48 & 37 & 4 & 11 & 0.33 & 0.38 & 0.48 & 0.04 \\
\hline $\begin{array}{l}\text { Olea europaea } \\
\text { L. }\end{array}$ & 47 & 30 & 4 & 11 & 0.27 & 0.32 & 0.43 & 0.03 \\
\hline $\begin{array}{l}\text { Triticum } \\
\text { aestivum L. }\end{array}$ & 45 & 35 & 7 & 16 & 0.31 & 0.36 & 0.63 & 0.07 \\
\hline $\begin{array}{l}\text { Vitis vinifera } \\
\text { L. }\end{array}$ & 43 & 30 & 5 & 13 & 0.27 & 0.33 & 0.48 & 0.04 \\
\hline
\end{tabular}


Separando las especies citadas en la parte toscana y en la parte emiliana, merece la pena resaltar como Castanea sativa Mill. y Buxus sempervirens L. son mucho más importantes en la parte toscana (ocupando el segundo lugar y quinto lugar de importancia respectivamente) mientras en la parte boloñesa ocupan el 10 y 26 lugar. En cambio Sonchus oleraceus (L.) L. (s.1.), Silene vulgaris (Moench) Garcke y Cichorium intybus L. son más citados en la parte boloñesa (4, 5, y 7 lugar), mientras en la parte toscana ocupan 11, 13 y 23 lugar. El número de especies útiles conocidas en la parte boloñesa (AVRB) (529 especies) es más importante que el número de especies útiles recogidas en la parte toscana (AVRT) (212 especies), aunque el número de citas obtenidas no son tan dispares: 1912 en el AVRB respecto a 1755 en el AVRT. Por tanto esto puede ser un indicio de un mayor conocimiento tradicional de las plantas locales en la parte emiliana respecto a la toscana.

Por otra parte, en los mapas de las Figuras 19, 21, 22 se ilustra la distribución del conocimiento etnobotánico en los diferentes municipios del AVR en Toscana (AVRT) como en Emilia-Romaña (AVRB). En éstos se pone de relieve como los municipios Sambuca Pistoiese y Camugnano presentan un mayor número tanto de especies útiles como de citas etnobotánicas por municipio.

Comparando el número de especies con usos tradicionales conocidas por municipio con respecto al número de informantes entrevistados por municipio (es decir las diferencias entre la Fig. 21 y 19), la proporción (número de especies útiles dividido por número de informantes por municipio) denota como el municipio con mayor conocimiento etnobotánico proporcional es Castiglione dei Pepoli $(15,8)$ seguido por Castel di Casio (15,5), Granaglione (14,8) y Porretta Terme (10,25). En cambio Camugnano y Sambuca Pistoiese presentan un número de especies con usos tradicionales menor respecto al número de entrevistados (4,23 y 4,32 respectivamente). Esto denota que el conocimiento etnobotánico proporcional es mayor en los municipios emilianos respecto al toscano.

\section{Sectores y Categorías de uso}

Han sido recogidos 12 sectores de usos principales divididos en un total de 121 categorías secundarias de usos o aplicaciones de usos (Fig. 23, Tab. 17). Los sectores más subdivididos en distintas categorías de uso (por tanto más versátiles), son el alimentario con 24 aplicaciones diferentes, el medicinal con 19 aplicaciones, el agropastoral con 17 y el doméstico con 14. Este resultado caracteriza la población en estudio y el orden de importancia que tienen los sectores en cuanto a la especificidad que les dan a las plantas en cada ámbito de la vida cotidiana y de la cultura local.

El grado de versatilidad de los sectores alimentario, medicinal, agropastoral y doméstico coincide con la importancia de los sectores según el número de citas, la diversidad de especies que se utilizan y el número de informantes que los mencionan (Fig. 23). Aunque el orden de importancia de los sectores de uso para el que más diversidad de especies se usan cambia débilmente, siendo (por orden decreciente) el medicinal (147 especies; 52,3\%, 53 familias), el alimentario (142 especies; 50,5\%, 
49 familias), el doméstico (102 especies, 36,3\%, 47 familias) y el agropastoral (77 especies; 27,4\%, 33 familias) (Fig. 23, Tab. 17).

Los sectores más populares y conocidos por número de citas y por número de informantes que los citan, son el alimentario (108 informantes y 1455 citas), el medicinal (104 informantes y 1008 citas), el doméstico (87 informantes y 404 citas) y el agropastoral (73 informantes y 308 citas) (Tab. 17).

El mismo orden de importancia ha sido encontrado con la clasificación de los sectores según el índice Valor de Uso o Use value general (UVtotal): alimentario $(12,87)$, medicinal $(8,92)$, doméstico $(3,57)$ y agropastoral $(2,72)$ (Tab. 17).

Aunque el orden de importancia de cada sector cambia en función de los criterios de análisis utilizados (número de citas, número de informantes, número de categorías, número de especies), se puede observar que las plantas eran utilizadas en todos los aspectos para cubrir las necesidades básicas para la vida cotidiana familiar. Vemos como los sectores menos importantes no forman necesidades fundamentales para la supervivencia y el bienestar de las personas o bien se caracterizan por ser más propios de la cultura de antaño, más tradicional y vernacular, por ello han sufrido una gran erosión por los cambios en las costumbres locales y en la forma de vida, como el lúdico/voluptuoso, el religioso, caza y pesca, mágico/medicinal, efecto nocivo.

Tab. 17. Sectores de aplicación de los usos etnobotánicos.

Según el orden de importancia del número de especies utilizadas, el número de familias, el número de citas, el número de informantes, el número de categorías de uso, partes usadas y UVtotal $=$ índice de Valor de uso total. Partes usadas= número de las partes de las plantas utilizadas para cada sector.

\begin{tabular}{|c|c|c|c|c|c|c|c|}
\hline Sector & $\begin{array}{l}\text { Númer } \\
\text { o de } \\
\text { especi } \\
\text { es }\end{array}$ & $\begin{array}{l}\text { Núme } \\
\text { ro de } \\
\text { famili } \\
\text { as }\end{array}$ & $\begin{array}{l}\text { Núme } \\
\text { ro de } \\
\text { citas }\end{array}$ & $\begin{array}{l}\text { Número } \\
\text { de } \\
\text { informant } \\
\text { es }\end{array}$ & $\begin{array}{l}\text { Categor } \\
\text { ía de } \\
\text { uso }\end{array}$ & $\begin{array}{l}\text { UVtot } \\
\text { al }\end{array}$ & $\begin{array}{l}\text { Parte } \\
\text { s } \\
\text { usad } \\
\text { as }\end{array}$ \\
\hline Medicinal & 147 & 53 & 1008 & 104 & 19 & 8,92 & 25 \\
\hline Alimentario & 142 & 49 & 1455 & 108 & 24 & 12,87 & 23 \\
\hline Doméstico & 102 & 47 & 404 & 87 & 14 & 3,57 & 15 \\
\hline Agropastoral & 77 & 33 & 308 & 73 & 17 & 2,72 & 13 \\
\hline Artesanal & 31 & 18 & 85 & 31 & 8 & 0,75 & 5 \\
\hline $\begin{array}{l}\text { Mágico/ritual/supersti } \\
\text { cioso }\end{array}$ & 27 & 20 & 104 & 44 & 7 & 0,92 & 12 \\
\hline Veterinario & 26 & 17 & 86 & 44 & 8 & 0,76 & 8 \\
\hline Lúdico/voluptuoso & 22 & 16 & 86 & 38 & 9 & 0,76 & 7 \\
\hline Religioso & 19 & 13 & 38 & 20 & 5 & 0,33 & 4 \\
\hline Caza y pesca & 17 & 11 & 37 & 17 & 3 & 0,32 & 6 \\
\hline Mágico/medicinal & 14 & 9 & 40 & 28 & 5 & 0,35 & 8 \\
\hline Efecto nocivo & 12 & 12 & 16 & 11 & 2 & 0,14 & 4 \\
\hline Sector & $\begin{array}{l}\text { Númer } \\
0 \quad \text { de }\end{array}$ & $\begin{array}{l}\text { Núme } \\
\text { ro de }\end{array}$ & $\begin{array}{l}\text { Núme } \\
\text { ro de }\end{array}$ & $\begin{array}{l}\text { Número } \\
\text { de }\end{array}$ & $\begin{array}{l}\text { Categor } \\
\text { ía de }\end{array}$ & $\begin{array}{l}\text { UVtot } \\
\text { al }\end{array}$ & $\begin{array}{l}\text { Parte } \\
\mathrm{s}\end{array}$ \\
\hline
\end{tabular}


María Teresa Egea Molines

\begin{tabular}{|c|c|c|c|c|c|c|c|}
\hline & $\begin{array}{l}\text { especi } \\
\text { es }\end{array}$ & $\begin{array}{l}\text { famili } \\
\text { as }\end{array}$ & citas & $\begin{array}{l}\text { informant } \\
\text { es }\end{array}$ & uso & & $\begin{array}{l}\text { usad } \\
\text { as }\end{array}$ \\
\hline Medicinal & 147 & 53 & 1008 & 104 & 19 & 8,92 & 25 \\
\hline Alimentario & 142 & 49 & 1455 & 108 & 24 & 12,87 & 23 \\
\hline Doméstico & 102 & 47 & 404 & 87 & 14 & 3,57 & 15 \\
\hline Agropastoral & 77 & 33 & 308 & 73 & 17 & 2,72 & 13 \\
\hline Artesanal & 31 & 18 & 85 & 31 & 8 & 0,75 & 5 \\
\hline $\begin{array}{l}\text { Mágico/ritual/supersti } \\
\text { cioso }\end{array}$ & 27 & 20 & 104 & 44 & 7 & 0,92 & 12 \\
\hline Veterinario & 26 & 17 & 86 & 44 & 8 & 0,76 & 8 \\
\hline Lúdico/voluptuoso & 22 & 16 & 86 & 38 & 9 & 0,76 & 7 \\
\hline Religioso & 19 & 13 & 38 & 20 & 5 & 0,33 & 4 \\
\hline Caza y pesca & 17 & 11 & 37 & 17 & 3 & 0,32 & 6 \\
\hline Mágico/medicinal & 14 & 9 & 40 & 28 & 5 & 0,35 & 8 \\
\hline Efecto nocivo & 12 & 12 & 16 & 11 & 2 & 0,14 & 4 \\
\hline
\end{tabular}

Las categorías de uso o las aplicaciones de uso más relevantes también caracterizan detalladamente la cultura de estudio y la relación entre el medio vegetal y el medio humano en el Alto Valle del Reno. En la Tab. 18 vemos las 20 categorías más importantes, y se puede apreciar que la categoría en la que más diversidad de especies utilizan son: afecciones del aparato respiratorio (sector medicinal, 49 especies), patologías del aparato digestivo (sector medicinal, 48 especies), afecciones cutáneas y tejidos subcutáneos (sector medicinal, 45 especies), licor (sector alimentario, 43 especies), estado general (sector medicinal, 35 especies) e integración de la renta familiar (sector doméstico, 34 especies). Considerando que el sector medicinal es el que más especies diferentes utiliza, resalta la importancia relativa que tienen los licores y la integración de la renta familiar en el uso tradicional de las plantas en el AVR.

El orden de importancia vuelve a cambiar según los criterios de análisis, y podemos observar como las categorías más utilizadas (es decir más citadas) son: ensalada (247 citas), verdura cocida (212 citas), afecciones cutáneas y tejidos subcutáneos (177 citas), afecciones del aparato respiratorio (159 citas), licor (158 citas) y patologías del aparato digestivo (142 citas) (Tab. 18). En cambio las categorías más populares y conocidas entre los informantes son: ensalada (80 informantes), afecciones cutáneas y tejidos subcutáneos (76 informantes), tortilla (75 informantes), golosinas y masticatorias (74 informantes), patologías del aparato digestivo (66 informantes) y afecciones del aparato respiratorio (59 informantes). Esto nos vuelve a demostrar que los sectores básicos son el alimentario, y dentro de éste las preparaciones básicas son ensaladas, verdura cocida y tortilla; mientras que en el sector medicinal las principales afecciones tratadas a base de plantas son las afecciones cutáneas y tejidos subcutáneos seguidos del aparato respiratorio y digestivo. 
Etnobotánica en el Alto Valle del Reno (Toscana y Emilia-Romaña, Italia)

Tab. 18. Categorías de uso por orden de importancia.

Según el número de especies, el número de familias, el número de citas, el número de informantes. Se incluyen el número de partes de las plantas utilizadas para cada categoría.

\begin{tabular}{|c|c|c|c|c|c|}
\hline Categoría de uso & $\begin{array}{l}\text { Número de } \\
\text { especies }\end{array}$ & $\begin{array}{l}\text { Número de } \\
\text { familias }\end{array}$ & $\begin{array}{l}\text { Número } \\
\text { de citas }\end{array}$ & $\begin{array}{l}\text { Número de } \\
\text { informantes }\end{array}$ & $\begin{array}{l}\text { Partes } \\
\text { usadas }\end{array}$ \\
\hline $\begin{array}{l}\text { Afecciones del aparato } \\
\text { respiratorio }\end{array}$ & 49 & 26 & 159 & 59 & 15 \\
\hline $\begin{array}{l}\text { Patologías del aparato } \\
\text { digestivo }\end{array}$ & 48 & 21 & 142 & 66 & 16 \\
\hline $\begin{array}{l}\text { Afecciones cutáneas y } \\
\text { tejidos subcutáneos }\end{array}$ & 45 & 30 & 177 & 76 & 13 \\
\hline Licor & 43 & 19 & 158 & 48 & 9 \\
\hline Estado general & 35 & 18 & 100 & 46 & 12 \\
\hline $\begin{array}{l}\text { Integración de la renta } \\
\text { familiar }\end{array}$ & 34 & 19 & 84 & 26 & 9 \\
\hline Verdura cocida & 33 & 14 & 212 & 74 & 8 \\
\hline Golosinas y masticatorias & 30 & 18 & 133 & 53 & 12 \\
\hline Ensalada & 28 & 13 & 247 & 80 & 7 \\
\hline $\begin{array}{l}\text { Patologías del aparato } \\
\text { urinario }\end{array}$ & 28 & 13 & 81 & 52 & 11 \\
\hline $\begin{array}{l}\text { Alimentación animal } \\
\text { (incluidos los forrajeros) }\end{array}$ & 26 & 15 & 83 & 46 & 6 \\
\hline $\begin{array}{l}\text { Herramientas y objetos } \\
\text { agrícolas }\end{array}$ & 26 & 13 & 63 & 26 & 4 \\
\hline $\begin{array}{l}\text { Trastornos musculo- } \\
\text { esqueléticos }\end{array}$ & 24 & 20 & 47 & 27 & 9 \\
\hline $\begin{array}{l}\text { Afecciones oro-faríngeas } \\
\text { y de la cavidad oral }\end{array}$ & 23 & 17 & 98 & 57 & 14 \\
\hline Conserva de frutas & 21 & 6 & 73 & 34 & 3 \\
\hline $\begin{array}{l}\text { Patologías del aparato } \\
\text { circulatorio }\end{array}$ & 20 & 16 & 44 & 29 & 8 \\
\hline Ornamental & 20 & 18 & 39 & 26 & 6 \\
\hline Mermelada & 18 & 7 & 73 & 38 & 4 \\
\hline Horticultura & 18 & 13 & 27 & 17 & 8 \\
\hline Tortilla & 15 & 12 & 125 & 75 & 4 \\
\hline
\end{tabular}

Comparando los sectores de uso citados en la parte toscana del área de estudio con la parte boloñesa, se nota como en ambas partes los sectores más relevantes son el alimentario, el medicinal, el doméstico y el agropastoral. Merece la pena resaltar como en la parte pistoyesa son más citados los sectores mágico/ritual/supersticiosos (75 citas con respecto a 29 citas en la parte boloñesa), artesanal (60 citas con 
respecto a 25 citas en la parte boloñesa), lúdico/voluptuoso (59 citas con respecto a 27 citas) y caza y pesca (33 citas con respecto a 4 citas en la parte boloñesa).

\section{Nombres vernaculares}

La fitonímia popular constituye un campo complejo e interdisciplinar dentro de la Etnobotánica y un patrimonio de información valiosa en diferentes ámbitos. Además de ser "un bien por ellos mismos, como testimonio de riqueza lingüística, pueden suministrar abundante información sobre usos, costumbres, rasgos morfológicos, fenológicos y ecológicos, distribución geográfica y otros caracteres de las plantas que denominan" tal y como afirma Vallès (1996).

La fitonímia en el dialecto del Alto Valle del Reno ha sido objeto de estudio por parte de botánicos y de lingüistas. De hecho, la información sobre nombres de plantas se encuentra dispersa en multitud de fuentes variopintas (Vallès, 1996). Resaltan los diccionarios dialectales (Appoggi, 2010; Beneforti, 1998; Bonzi, 2000; Ferrari, 1997; Guccini, 1989; Guccini 1998; Malagoli, 1930; Montemagni, 1984) así como las recopilaciones lingüísticas inéditas (Poli, c. 2014) o publicadas en la web de las asociaciones locales (Lustrola, 2015), en los que se encuentran numerosas aportaciones sobre la fitonímia local. Igualmente, los estudios etnofarmacológicos y etnobotánicos de Ungarelli (1921), Sansanelli y Tassoni (2014) y Uncini Manganelli y Tomei (1998) son un fuente importante de nombres vernaculares de las plantas relacionados geográficamente y culturalmente con el Alto Valle del Reno. Merece la pena mencionar también el estudio sobre la fitonímia en el dialecto "altorenano" y sus orígenes longobardas en Alto Reno Toscano I (2016). Además existen numerosas citas sobre los nombres locales de las plantas en la variada literatura local, aunque no siempre los nombres vernaculares registrados en la bibliografía han sido asociados con una especies botánica, y en los casos en los que se le haya asociado, el método seguido es a menudo cuestionable.

La complejidad del estudio de los nombres populares de las plantas se intensifica con la complejidad lingüista del área de estudio, donde el dialecto local se caracteriza por un conjunto de influencias toscanas y emilianas (Signorini, 2003) que crean un sistema dialectal por sí mismo denominado el galo-toscano, como ha sido explicado anteriormente. Por esto, en el presente estudio que abarca la Etnobotánica del Alto Valle del Reno en toda su interdisciplinaridad, hemos recogido los datos relativos a los nombres de las plantas teniendo en cuenta la importancia de las particularidades que albergan, pero dentro de las posibilidades y recursos de una tesis doctoral.

A lo largo de la investigación se ha podido apreciar como los nombres vernaculares y sus dinámicas cambian no sólo de pueblo en pueblo (por ejemplo Vaccinium myrtillus L. es llamado pentolini en San Pellegrino al Cassero, y en cambio se llama en Taviano, el pueblo colindante, pignattini), sino también de casa en casa, de familia en familia y de persona a persona. El conocimiento de las plantas locales es el resultado del cúmulo de experiencias personales, de la capacidad de observación de cada persona, de los intercambios y las relaciones interpersonales e intergeneracionales, además de estar condicionado por la memoria, la cual tiene un 
fuerte componente emocional y selectivo. Por esto los nombres vernaculares utilizados por los informantes en ésta investigación suelen seguir unos criterios comunes entre los informantes que se intentan analizar aquí, pero son siempre característicos y particulares en cada informante.

En el trabajo de campo han sido recogidos 814 nombres relativos a 281 taxones, lo cual es un número bastante alto de nombres populares de plantas, testimonio de que existe todavía una cultura popular viva en el territorio estudiado como se afirma en Vallés et al. (2005).

Nueve especies mencionadas por los informantes han sufrido una pérdida de conocimiento, ya que son recordados por sus usos tradicionales, pero el nombre vernacular ya ha sido olvidado por los 9 informantes que las han citado respectivamente, sin embargo otros informantes sí que se acordaban de nombres populares de las mismas plantas. Se trata de Thymus serpyllum L. (s.1.), Euphorbia helioscopia L., Plantago major L., Sempervivum tectorum L., Spartium junceum L., Verbascum thapsus L., Arctium lappa L., Chelidonium majus L. y Pulmonaria officinalis L.

A partir del análisis del sistema nomenclatural de las plantas se denota como existen dos tipologías de nombres en el Alto Valle del Reno, al igual que analiza Benítez Cruz (2009) en el Poniente Granadino (España), los nombres simples y los nombres compuestos. Los simples, formados por una sola palabra, suelen referirse a especies bastante conocidas por la población (designación muy extendida de una planta e inequívoca como "castagno" para Castanea sativa Mill., "noce” para Juglans regia L., "faggio” para Fagus sylvatica L.), mientras que los compuestos suelen estar formados por el nombre común más un adjetivo o epíteto (sobre todo "selvatico" y palabras equivalentes en dialecto, o "femmina" y "maschio"). También suelen estar formados por "erba" (hierba), "pianta" (planta) o una parte de la planta, como "fior" (flor) o "foglia" (hoja) o "barba" (raíz) o "semi" (semillas), seguidas del uso de la planta o de la afección para la cual se utiliza en la medicina tradicional (como "erba per al brugiado" es decir "hierba para la quemadura" o seguidas de otros sustantivos.

A continuación se exponen las siguientes categorías según la clasificación de Vallès et al. (2005), que representan los modos de formación de los nombres vernaculares de las plantas en el Alto Valle del Reno, con algunos ejemplos ilustradores (Tab. 19). En algunas ocasiones los nombres pueden pertenecer a más de una categoría. Resaltan los nombres vernaculares relacionados con animales y los nombres relacionados con los usos o las propiedades de las mismas plantas.

Además también se usa mucho el epíteto "selvatico" o en dialecto "salvano" ("timo selvatico", "radicchio selvatico", "valeriana selvatica", "prugnolo selvatico", "malva selvatica", "susine selvatiche", "amarene selvatiche", "marasche selvatiche", "ciliegio selvatico", "castagno salvano", etc.) para las plantas silvestres y al contrario, "domestico" ("more domestiche") para las plantas cultivadas es muy poco utilizado. El sufijo "astro" añadido a un nombre de una planta, cambia la especie a la que normalmente está asociada por ejemplo: "olivastri" o "ciliegiastri" para denominar Sorbus torminalis (L.) Crantz. El término "bòtta" o "bottara" es recurrente, como en "lingua di bòtta" (Asplenium scolopendrium L.), "riso di bòtta" (Sedum dasyphyllum L.). Según los informantes y Guccini (1998) "bòtta” significa 


\section{María Teresa Egea Molines}

sapo, y en cambio "bottara" se utiliza para diferenciar dos especies del mismo género, como "felce bottara" (Dryopteris filix-mas (L.) Schott) o "felce bottaglie" (Pteridium aquilinum (L.) Kuhn). Un informante asegura que el término "bottara", (sapo en dialecto) se utiliza por la relación que tienen estas plantas con las zonas húmedas donde crecen y por analogía, donde se encuentran los sapos. También resaltan los nombres vernaculares relacionados con la coincidencia que existe con el periodo de recolecta de la parte útil con otro fenómeno contemporáneo, por ejemplo: "fior del cucco", ya que la floración de la inflorescencia utilizada se da en los mismos días o mismo periodo de cuando el denominado pájaro "cucco" canta. $\mathrm{O}$ bien el "bocconcino d'agnello", cuyas hojas se recolectan justo cuando el cordero o "agnello" estaba listo para su sacrificio, es decir en enero o febrero.

Tab. 19. Categorización y criterios de formación de los nombres vernaculares.

De las plantas en el AVR, con ejemplos ilustradores

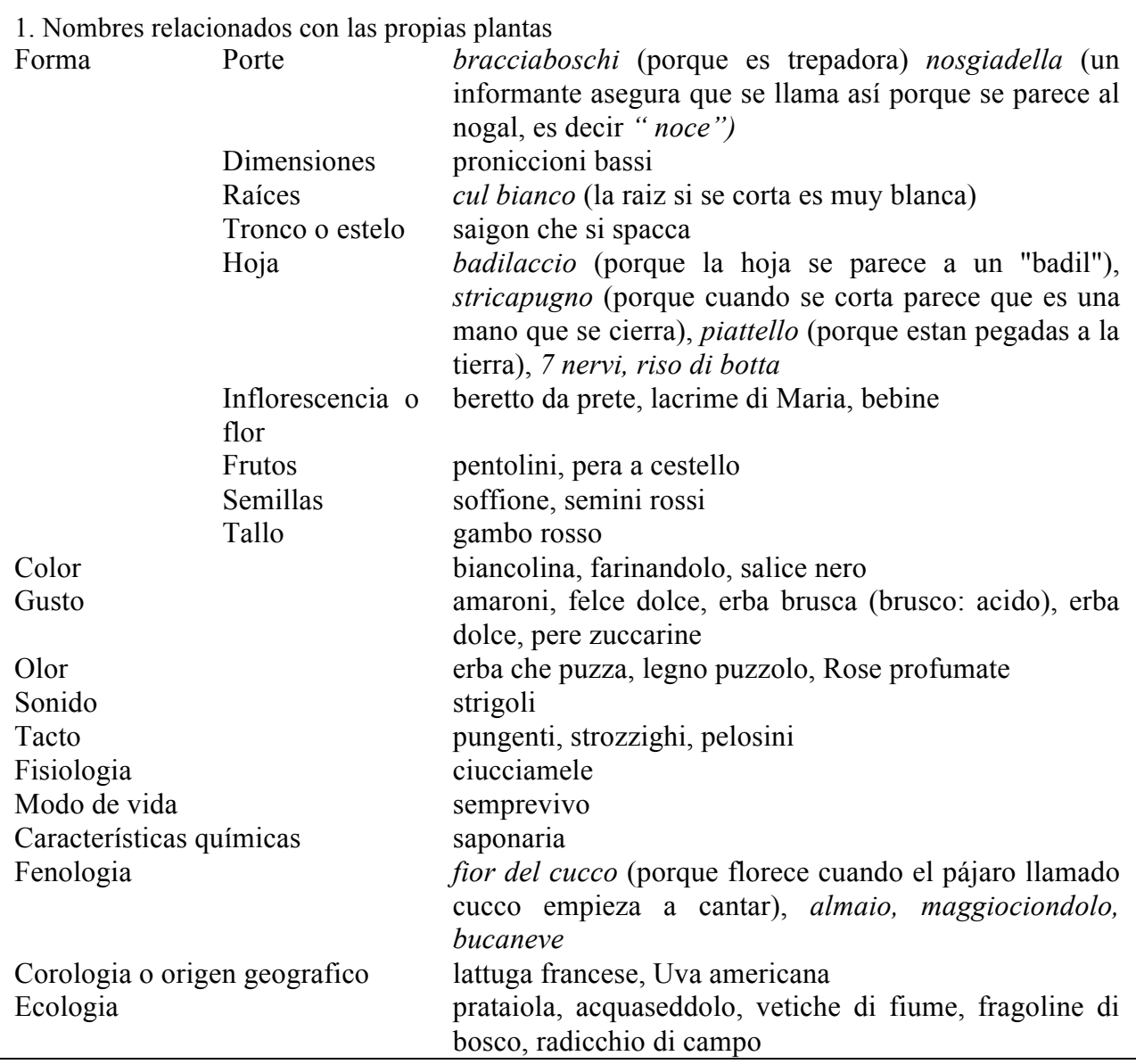




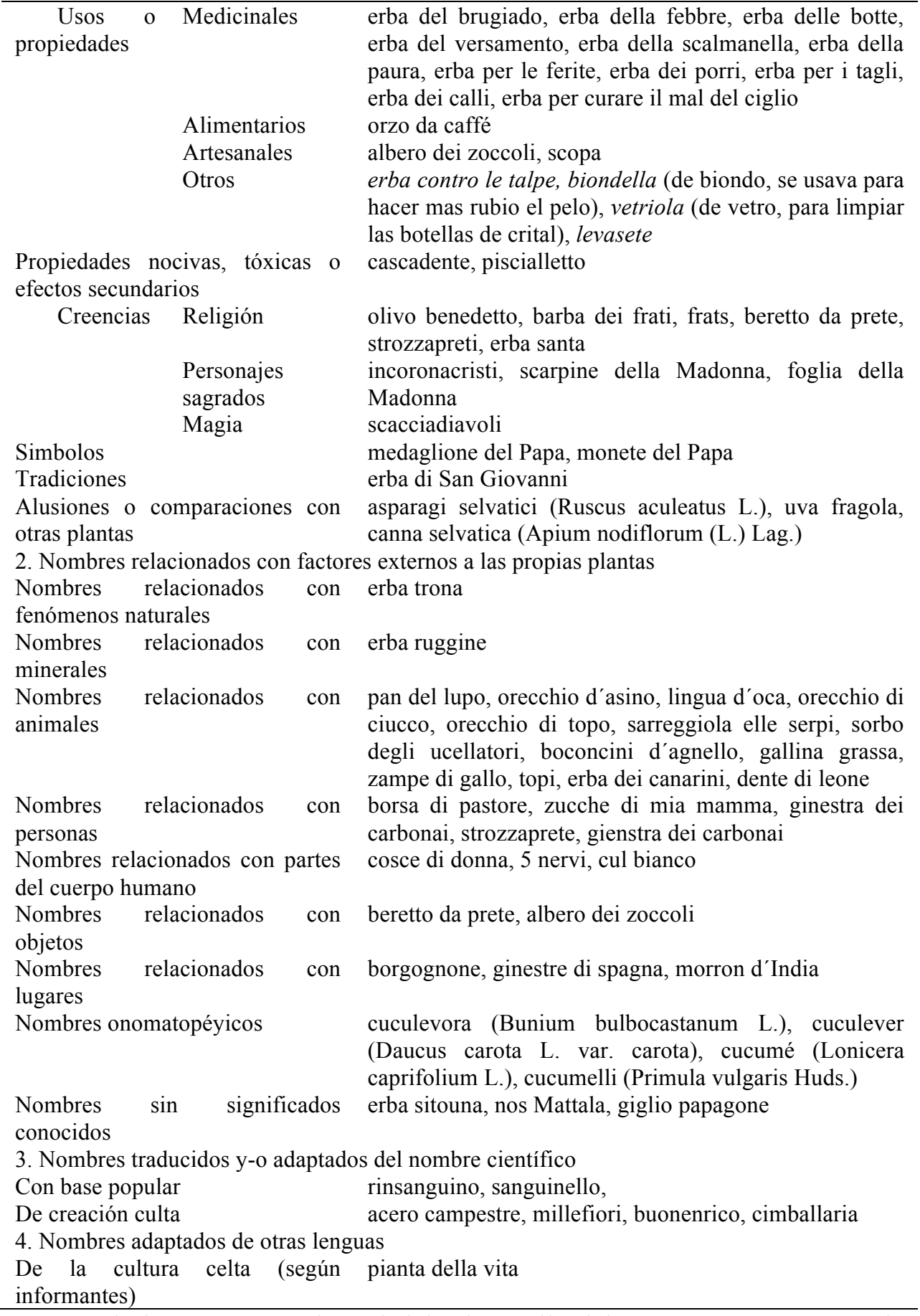

En el sistema nomenclatural del Alto Valle del Reno, es muy común la sinonimia entre los nombres populares, es decir que se utiliza el mismo 
nombre vernacular para denominar diferentes taxones en diferentes modalidades:

- Diferentes informantes llaman con el mismo nombre a diferentes especies botánicas distinguidas perfectamente por cada uno, como en el caso de "asparagi selvatici" para llamar Asparagus tenuifolius Lam., Chondrilla juncea L., Ruscus aculeatus L., ya que en los dos últimos casos se utilizan los brotes jóvenes para comer como los típicos espárragos de Asparagus acutifolius L.; "bracciabosco" se emplea tanto para llamar Humulus lupulus L., como Lonicera caprifolium L. ya que las dos tienen el mismo porte y el nombre vernacular está asociado al porte de la planta trepadora, que significa "que abraza el bosque"; "bruscolo" para denominar tanto Erica arborea L. como Helichrysum italicum (Roth) G.Don., ambas son arbustos leñosos, por lo que puede dar a pensar que "bruscolo" en dialecto esté relacionado con los arbustos. "Pianta grassa" para designar Aloe arborescens Mill., Sedum telephium L., Sempervivum tectorum L. ya que las tres son plantas crasas; "pungitopo" para denominar tanto Ilex aquifolium L. como Ruscus aculeatus L. (esto es característico de Sambuca Pistoiese) ya que presentan las mismas características morfológicas con pequeños pinchos y frutos rojos o "erba delle botte" es utilizado por informantes diferentes para llamar tanto Plantago major L. como Verbascum thapsus L. ya que se utilizan para la misma afección, como "erba dei porri" para denominar Chelidonium majus L., Euphorbia helioscopia L. y Euphorbia platyphyllos L. También “cucumé" es utilizado por informantes diferentes para denominar tanto Lonicera caprifolium L. como Primula vulgaris Huds., y con otras variantes como "cucumei", "cucumegli", "cucumelli", "cucumeo" tienen todas en común el hecho que chupan el néctar o "la miel” (según los informantes) de las flores.

- El mismo informante llama con el mismo nombre vernacular diferentes especies del mismo género, las cuales las identifica como diferentes pero les otorga el mismo uso indistintamente, normalmente se trata de especies distintas del mismo género como "a cquaséddolo" para denominar tanto Equisetum arvense L. como Equisetum telmateja Ehrh, o "borgognoni" para llamar tanto Salix alba L. como Salix triandra L., algunos informantes llaman y utilizan de la misma manera "sallegiola" y "erba brusca" tanto Rumex acetosa L. como Rumex acetosella L. (aunque para otros informantes "sallegiola" sea solo Rumex acetosella L.). "Spini" es utilizado para nombrar a los arbustos espinosos Crataegus rhipidophylla Gand., Prunus spinosa L. y Rubus ulmifolius Schott indistintamente ya que las tres tienen en común la presencia de espinas entre otros caracteres.

- El mismo informante llama con el mismo nombre dos especies diferentes del mismo género aunque las distinga perfectamente e incluso les otorgue usos diferentes a cada uno, como el caso de "palea" para 
Etnobotánica en el Alto Valle del Reno (Toscana y Emilia-Romaña, Italia)

denominar tanto Brachypodium pinnatum (L.) P.Beauv. como Brachypodium sylvaticum (Huds.) P.Beauv (en este caso, el informante le otorga un uso a una de ellas pero a la otra no le otorga ninguno, aunque las distingue muy bien).

- El mismo informante llama con el mismo nombre vernacular diferentes especies que él percibe como una única especie, la denominada under differentiation (Berlin, 1973), como es el caso de los "stropelli" utilizados para denominar Salix alba L., Salix eleagnos Scop., Salix purpurea L. Este fenómeno es común en el caso de las especies botánicas poco diferenciadas, como por ejemplo Parietaria officinalis L. y Parietaria diffusa M. et B. o las agamoespecies del grupo de Taraxacum campylodes G.E.Haglund (s.1.) (Signorini et al., 2013). Y más complejo todavía es el caso de los nombres vulgares que incluyen especies botánicas bien diferentes como "ortica" o "ortiga" indican varias especies del género Urtica utilizadas para los mismos usos y no diferenciadas entre ellas. En estos casos se ha optado por escribir el nombre de una única especie botánica utilizando el término "s.1." como en Parietaria officinalis L. (s. 1.), Taraxacum campylodes G.E.Haglund (s.1.).

El grado de correspondencia entre la etnotaxonomía y la taxonomía botánica es del 90,79\%. Es decir que el 9,21\% de los nombres vernaculares presentan under differentiation, o sea, se refieren a más de una especie botánica, en la mayoría de los casos pertenecientes al mismo género, aunque también pertenecen a géneros e incluso familias diferentes.

Por ello la unidad sistemática elemental de la taxonomía popular fue individuada por Berlin (1973) como folk generic y por Signorini et al. (2008) como "etnoespecie", y queda aquí evidenciado que depende de cada informante, con lo cual se trata de un sistema nomenclatural a veces subjetivo difícilmente comparable con la sistemática botánica que al contrario organiza en categorías en función de caracteres morfológicos, biosistemáticos, corológicos y moleculares, vistos como expresión de su historia evolutiva (filogénesis) (Signorini et al., 2013).

Por otra parte, la polisemia también es importante en el sistema nomenclatural y manifiesta los diferentes nombres que recibe un mismo taxón (Benítez Cruz, 2009). Se trata de que para una misma especie botánica, se distinguen varias entidades etnotaxonómicas que pueden corresponder, por ejemplo, a subespecies, variedades locales, partes diferentes de la misma planta o diferentes fases de desarrollo de la planta, correspondiendo en cada caso a usos diferentes (Signorini et al., 2013). En este fenómeno también se dan diferentes modalidades:

- Para la misma especie se utilizan diferentes nombres vernaculares para designar las diferentes partes de la misma planta, aunque a menudo se utilizan para referirse a la planta entera, por ejemplo "peterlenghe" son los frutos y "raggia canina" o "rosa canina" la planta entera de Rosa 
canina L. (s.1.), "erba noca" o "la nocca" es la raíz y "cascadente" es la planta entera o solo la flor de Helleborus viridis L. (s.1.), "cicerbite" es la flor y "piscialletto" la planta entera de Taraxacum campylodes G.E.Haglund (s.1.), "strozzighi" o "strozzaprete" son los frutos y "prugnoli" es la planta entera de Prunus spinosa L., "more" son los frutos y "rovi" la planta entera de Rubus hirtus Waldst. \& Kit., "stroppe" o "stropelli" son las ramas y "vetiche di fiume" la planta entera de Salix alba L., Salix eleagnos Scop. y Salix purpurea L., o "stropelli" son las ramas y "borgogna" la planta entera de Salix alba L.

- Para la misma especie se utilizan dos nombres vernaculares diferentes dependiendo del estado de maduración, como el caso de “a cquaséddolo”, según Guccini (1998), en Pàvana, se le llama así las plantas del género Equisetum en el estado de maduración inicial, en cambio cuando se desarrolla totalmente es denominada "guzirro". Pero en cambio en Castiglione dei Pepoli, "guzzedro" es denominado a ambas especies del género Equisetum en su estado inicial (el tallo fértil).

- También encontramos el caso de cuando un mismo informante llama a la misma especie en diferentes formas dialectales, influenciado por los tecnicismos como valeriana selvatica o braga di gallo (Valerianella locusta (L.) Laterrade), tasso barbasso o verbasco (Verbascum thapsus L.), cicoria o cul bianco (Cichorium intybus L.) pero también influenciados por los dialectos de los pueblos cercanos, como Sonchus oleraceus L. (s.1.) es denominado igualmente cicerbite o gerbie, o para otro informante tanto "cicerbita" como "cigerbda" y para otro "cigerbe" y "cicerhia".

- Más raros son los casos de over differentiation (Berlin, 1973) es decir cuando una especie botánica viene distinguida por más de una identidad botánica desde el punto de vista de los informantes, que a veces puede corresponder a fases diferentes de desarrollo vegetativo o de gestión de la planta, que muestran una morfología o aspecto diferente, y según la percepción de los informantes, corresponden a plantas diferentes. Es el caso de Salix alba L. que para un informante es salice di fiume, vedeghe di fiume o veddega, y sus ramos son stroppeli, cuando la planta es podada cada año y mantiene un aspecto joven de tronco bajo y ramo jóvenes y largos, los cuales son utilizados para realizar molinillos de agua, para hacer cestas o como cuerdas y ataduras. En cambio la misma especie Salix alba L., dejada crecer en medio del bosque hasta más de 20 metros de aspecto totalmente diferente, es para el mismo informante otra planta completamente diferente cuyo leño es utilizado para realizar objetos y herramientas agrícolas. También se da en el caso de los radicchi, a menudo según el estado de crecimiento de las hojas, pueden presentar un aspecto diferente, y pueden ser considerados dos etnoespecies diferentes, como Cichorium intybus L. es considerado "cul bianco" y como "piscialletto", Taraxacum campylodes G.E.Haglund 
(s.1.) es considerado como "cicoria" y como "piscialletto", y para otro informante Taraxacum campylodes G.E.Haglund (s.l.) es considerado como "cul bianco" y como "piascialletto".

Especial atención merece la categoría etnotaxonómica de los denominados "radicchi/radicchio" y sus diferentes variantes con epítetos o adjetivos los cuales representan sobre todo plantas de la familia Compositae, aunque también de otras familias como Campanulaceae. La característica sobre la cual la etnotaxonomía la clasifica como una identidad etnobotánica es el uso y las características de las hojas, las cuales se comen crudas, como ensalada o cocidas como verdura cocida. En este caso depende del informante, para algunos, diferentes especies eran las mismas plantas y no las distinguía dependiendo también del lugar de crecimiento y del estado de maduración (por ejemplo entre Taraxacum campylodes G.E.Haglund (s.1.) y Cichorium intybus L.), otros informantes distinguen las especies pero las llaman igual aunque las combinan y las usan en función del sabor y de la textura de las hojas. Por otra parte algunos "radicchi" pueden ser denominados por el mismo informante en la categoría etnotaxonómica más general y amplia como "radicchio" pero también como subcategoría más específica y detallada por ejemplo: "radicchio" o "stricapugno", "radicchio" o "piscialletto". Es decir, dentro de los "radicchio" los distinguen con epítetos "radicchio amaro", "radicchio vero", "radicchio di campo" (por ejemplo un informante llama "radicchio vero" a Campanula rapunculus L. y a "radicchio de campo" Crepis vesicaria L.). Para algunos informantes Sonchus oleraceus L. (s.1.) son solo radicchi, para otros forman parte de los "radicchi" pero los subcategorizan como gerbie por ejemplo, y para otros no forman parte de los "radicchi", categorizándolos a parte más bien por sus características morfológicas que por sus usos alimentarios, como "spinone", ya que presentan pequeñas espinas en el margen de las hojas.

A través de este análisis de los nombres vernaculares de las plantas, se puede ver como la lengua y la botánica están interrelacionadas y pueden ser muy útiles una para la otra (Vallès et al., 2005).

Las especies botánicas (más de 10) con más versatilidad de nombres vernaculares son las utilizadas en el sector alimentario por la población tradicional (Tab. 20), además de ser las más citadas por la población como Taraxacum campylodes G.E.Haglund (s.1.) (141 citas), Sonchus oleraceus (L.) L. (s.1.) (96 citas). 
Tab. 20. Especies que presentan un mayor número de nombres vernaculares.

\begin{tabular}{ll}
\hline Especies & Número de nombres vernaculares \\
Sonchus oleraceus (L.) L. (s. 1.) & 27 \\
Taraxacum campylodes G.E.Haglund (s.l.) & 22 \\
Salix alba L. & 19 \\
Valerianella locusta (L.) Laterr. & 18 \\
Cichorium intybus L. & 17 \\
Helleborus viridis L. (s. 1.) & 15 \\
Primula vulgaris Huds. & 15 \\
Rumex acetosella L. & 15 \\
Salix caprea L. & 13 \\
Prunus spinosa L. & 12 \\
Crepis vesicaria L. & 11 \\
Rubus ulmifolius Schott & 11 \\
Salix alba var. vitellina (L.) Stokes & 11 \\
\hline
\end{tabular}

Comparando los nombres vernaculares de las plantas recogidos durante la investigación en el AVR con los nombres vernaculares de las plantas documentados en la bibliografía local y a los cuales se les asociaba una especie botánica, se observa como el grado de novedad de la fitonímia recogida es del $88,2 \%$ : de los 814 nombres vernaculares, 718 no son registrados en la bibliografía (Tab. 21). Las diferencias menores como los acentos 'o 'y los plurales no han sido considerados como diferencias a la hora de cuantificar los nombres vernaculares novedosos respecto a la bibliografía, con el fin de poder dar una idea general y resaltar las novedades más evidentes. En cambio las diferencias de género si han sido consideradas. El gran grado de novedad que hemos encontrado en los fitónimos respecto a la bibliografía consultada es debido a diferentes motivos: porque no aparece la especie en la bibliografía local, porque aparece con un nombre vernacular diferente, o bien porque aparece en la bibliografía con un nombre muy similar aunque con pequeñas diferencias: en el caso de Prunus cerasus L. en el AVR es denominado "amarene", “amarene selvatiche”, “ciliegie amarene”, “ciliegie marasche”, "ciliegie maresca”, "ciliegie maresche”. En cambio en la bibliografía resulta como "amareno", "visciole”, "cilésa”, "marâsca”, "zrîlacquarôla”. 
Tab. 21. Nombres vernaculares recogidos en el AVR.

Sin correspondencia en la bibliografía local consultada

\section{Especie botánica}

Acer campestre L.

Achillea millefolium L. (s. 1.)

Aegopodium podagraria L.

Aesculus hippocastanum L.

Allium ascalonicum L.

Allium ampeloprasum L.

Allium cepa L.

Allium vineale L.

Alnus glutinosa (L.) Gaertn.

Aloe arborescens Mill.

Aloysia citriodora Palau

Anacamptis morio (L.) R.M.Bateman, Pridgeon \& M.W.Chase

Anthemis arvensis L. (cfr.)

Apium nodiflorum (L.) Lag.

Arctium lappa L.

Arum italicum Mill.

Arundo donax L.

Asparagus tenuifolius Lam.

Asplenium scolopendrium L.

Atropa belladona L.

Bellis perennis L.

$\begin{aligned} & \text { Nombre vernacular no registrado en } \\ & \text { bibliografía local }\end{aligned}$

acero, acero campestre

millefiori

erba ciliegina, nogiadella, sambuchella, sambuchino

ippocastano, marron d'india

scalogno

porro

cipolla

cipolla selvatica, erba cipollina

albero dei zoccoli, ontano, ontano nero

pianta grassa

acedrina, cedrina

fior del cucco

camomilla, camomilla bassa selvatica, margherite sfiorite

canna selvatica

bardana, farfanacci, farfanaccio, lappa

badilaccio

canna, canne

asparagi, asparagi selvatici

erba del brugiado, erba per le bruciature, fellegia per il bruciato, foglia per al brugiado, foglie da scottato, foglie del brugiado, lingua di botta, lingua di bue, lingua di cane

belladonna

margherite, margherite senza fiore, pelosini, prataiola, prataiole 


\begin{tabular}{|c|c|}
\hline Especie botánica & $\begin{array}{l}\text { Nombre vernacular no registrado en } \\
\text { bibliografía local }\end{array}$ \\
\hline Beta vulgaris L. subsp. vulgaris & bietola selvatica \\
\hline Borago officinalis L. & borragine, borrana, radicchi \\
\hline Brachypodium pinnatum (L.) P.Beauv. & palea \\
\hline Brachypodium sylvaticum (Huds.) P.Beauv. & palea \\
\hline Brassica nigra (L.) K.Koch & senape \\
\hline Brassica oleracea L. var. capitata L. & cavolo \\
\hline Brassica rapa L. & rapa selvatica, rape spontanee \\
\hline Bunium bulbocastanum L. (cfr.) & cuculevora, le pette, pantré \\
\hline Buxus sempervirens L. & bussol \\
\hline Calluna vulgaris (L.) Hull & bruscolo nero, scopiccio basso \\
\hline Campanula rapunculus L. & $\begin{array}{l}\text { radicchio amaro, radicchio vero, rapacello, } \\
\text { raperonzolo, rapolonzoli, raponzolo }\end{array}$ \\
\hline Cannabis sativa L. & cannapa, spago, stoppa \\
\hline Capsella bursa-pastoris (L.) Medik. & radicchi \\
\hline Capsicum annuum L. & peperoncini, peperoncino \\
\hline Carduus nutans L. (cfr.) & $\begin{array}{l}\text { cardaròli, cardaròn, cardaroni, cardi, cardo } \\
\text { maschio }\end{array}$ \\
\hline Carex pendula Huds. & garza \\
\hline Carlina acaulis L. & boneghe, cardi, carlina, carline \\
\hline Castanea sativa Mill. 'Salvano' & castagno salvano, salvano, castagno selvatico \\
\hline Castanea sativa Mill. 'Pastenese' & $\begin{array}{l}\text { castagno pastinese, castagne } \\
\text { castagne pastenese, castagne } \\
\text { castagno pastenese, pastenese }\end{array}$ \\
\hline Centaurium erythraea Rafn. & $\begin{array}{l}\text { erba della febbre, la biondella, pianta per la } \\
\text { febbre }\end{array}$ \\
\hline Ceterach officinarum Willd. & erba ruggine \\
\hline Chelidonium majus L. & $\begin{array}{l}\text { celidonia, erba dei poranci, erba dei porri, erba } \\
\text { per i poranci, erba per i porri }\end{array}$ \\
\hline Chenopodium album L. & farinandolo \\
\hline Chenopodium bonus-henricus L. & buonenrico, spinaci selvatici, spinacio selvatico \\
\hline Chondrilla juncea L. & asparagi selvatici, cu di raso \\
\hline Cicer arietinum L. & ceci \\
\hline Cichorium intybus L. & $\begin{array}{l}\text { cicoria, cicoria selvatica, cicorietta, cicoriette, } \\
\text { cul bianco, piscialletto, radicchi, radicchi amari, } \\
\text { radicchi del culbianco, radicchi, selvatici, } \\
\text { radicchio, radicchio amaro, radicchio di campo, } \\
\text { radicchio selvatico, radicchio vero, radichietto, } \\
\text { stricapugni }\end{array}$ \\
\hline
\end{tabular}




\begin{tabular}{|c|c|}
\hline Especie botánica & $\begin{array}{l}\text { Nombre vernacular no registrado en } \\
\text { bibliografía local }\end{array}$ \\
\hline Cinnamomum verum J. Presl & cannella \\
\hline Cirsium vulgare (Savi) Ten. & cardo mariano, giglio papagone, pungenti \\
\hline Citrullus lanatus (Thunb.) Matsum. \& Nakai & cocomero \\
\hline Citrus sinensis (L.) Osbeck & arancio \\
\hline Clematis vitalba L. & vitalba, vizzadri, vizzatoli, vizzeder \\
\hline $\begin{array}{l}\text { Clinopodium nepeta subsp. glandulosum (Req.) } \\
\text { Govaerts }\end{array}$ & $\begin{array}{l}\text { empitella, empitella selvatica, l'empitella, } \\
\text { nepetella, pipitella }\end{array}$ \\
\hline Coffea arabica L. & caffé \\
\hline Conium maculatum L. & cicuta \\
\hline Cornus sanguinea L. & insanguino, rinsanguino, sanguinello \\
\hline Corylus avellana L. & colloie, nocciola culora \\
\hline Crassula multicava Lem. & erba dei calli \\
\hline Crataegus rhipidophylla Gand. & $\begin{array}{l}\text { biancospino, buccino, spinbianco, spini, spini } \\
\text { bianchi }\end{array}$ \\
\hline Crepis leontodontoides All. (cfr.) & ciderchie, piscialletti \\
\hline Crepis sancta (L.) Bornm. (cfr.) & cicerchie \\
\hline Crepis vesicaria $\mathrm{L}$. & $\begin{array}{l}\text { amaroni, capelloni, cicoria, radicchi, radicchio } \\
\text { radicchio amaro, radicchio di campo, radicchio } \\
\text { selvatico, stricapugni, stricapugno, tromboni }\end{array}$ \\
\hline Crocus vernus (L.) Hill (s.1.) & bucaneve, campaggiolo, campagioli, pappagalli \\
\hline Cucumis sativus L. & cetriolo \\
\hline Cucurbita maxima Duchesne & zucche di mia mamma \\
\hline Cyanus segetum Hill & fiordalisi, fiordaliso \\
\hline Cydonia oblonga Mill. & mele cotogne \\
\hline $\begin{array}{l}\text { Cymbalaria muralis P.Gaertn., B.Mey. \& } \\
\text { Scherb. }\end{array}$ & cimballaria, erba della scalmanella \\
\hline Cynodon dactylon (L.) Pers. & graminia \\
\hline Cytisophyllum sessilifolium (L.) O.Lang & strillini \\
\hline Cytisus scoparius (L.) Link & ginestra, ginestra dei carbonai, ginestre \\
\hline Daphne laureola L. & laurella \\
\hline Daucus carota L. var. carota & cuculever \\
\hline Dianthus seguieri Vill. (cfr.) & garofani, garofani selvatici (rossi) \\
\hline Digitalis lutea L. (s. 1.) (cfr.) & erba per i tagli, erba sitouna \\
\hline Diplotaxis tenuifolia (L.) DC. & rucola \\
\hline Dipsacus fullonum L. & cardo dei lanaioli \\
\hline Dryopteris filix-mas (L.) Schott & felce bottara \\
\hline
\end{tabular}




\begin{tabular}{|c|c|}
\hline Especie botánica & $\begin{array}{l}\text { Nombre vernacular no registrado en } \\
\text { bibliografía local }\end{array}$ \\
\hline Elaeagnus rhamnoides (L.) A.Nelson & spini \\
\hline Equisetum arvense $\mathrm{L}$. & acquaseddolo, guzzedri, guzzedro \\
\hline Equisetum telmateja Ehrh. & $\begin{array}{l}\text { acquaseddolo, coda cavallina, erba cavallina, } \\
\text { guzzedri, guzzedro }\end{array}$ \\
\hline Erica arborea L. & bruscolo, erica, scopa, scopa maschio, scopici \\
\hline Erica scoparia L. & erica femmina, scopa femmina \\
\hline Eucalyptus camaldulensis Dehnh. & eucalipto \\
\hline Euonymus europaeus L. & beretto da prete, le lacrime di maria \\
\hline Euonymus latifolius (L.) Mill. & cappelli del prete \\
\hline Euphorbia helioscopia L. & erba dei porri \\
\hline Euphorbia lathyris L. & $\begin{array}{l}\text { erba contro le talpe, erba per i topi, erba per le } \\
\text { talpe, pianta per le musarangole }\end{array}$ \\
\hline Euphorbia platyphyllos L. & erba dei porri \\
\hline Ficus carica L. & fico acerbo \\
\hline Foeniculum vulgare Mill. & finocchietto \\
\hline Fragaria vesca L. & $\begin{array}{l}\text { fragola, fragole, fragole selvatiche, fragoline, } \\
\text { fragoline di bosco }\end{array}$ \\
\hline $\begin{array}{l}\text { Fraxinus angustifolia subsp. oxycarpa (Willd.) } \\
\text { Franco \& Rocha Afonso }\end{array}$ & frassino \\
\hline Fraxinus excelsior L. & frassino \\
\hline Fraxinus ornus L. & frassino, nos mattala, orniello \\
\hline Galega officinalis L. & veccione \\
\hline Gentianopsis ciliata (L.) Ma (cfr.) & genzianella \\
\hline Gladiolus italicus Mill. & gladioli selvatici \\
\hline Helianthus annuus L. & girasoli \\
\hline Helichrysum italicum (Roth) G.Don & $\begin{array}{l}\text { bruscolo, bruscolo bianco, erba che puzza, } \\
\text { scuvichio bianco, tignamica }\end{array}$ \\
\hline Helleborus foetidus L. & erba noca \\
\hline Helleborus viridis L. (s. 1.) & $\begin{array}{l}\text { cascadente (il fiore), elleboro, erba noca, erba } \\
\text { noca (radice), erba noca femmina, erba nocca } \\
\text { femmina, la nocca, la nocca (radice) } \\
\text { nebiaccio, nebio, nocchia, pan del lupo }\end{array}$ \\
\hline Hordeum vulgare L. & orzo da caffé, orzo mondo \\
\hline Humulus lupulus L. & bracciaboschi, bracciabosco, lupolo selvatico \\
\hline Hypericum perfoliatum L. & erba di san giovanni, iperico, scacciadiavoli \\
\hline Hypochaeris radicata $\mathrm{L}$. & ingrassaporchi, piattello, radicchio, raponzoli \\
\hline Juglans regia L. & mallo di noce, marlo di noce, merla di noce, \\
\hline
\end{tabular}




\begin{tabular}{|c|c|}
\hline Especie botánica & $\begin{array}{l}\text { Nombre vernacular no registrado en } \\
\text { bibliografía local } \\
\text { noce malisa }\end{array}$ \\
\hline Juncus inflexus L. & giunchi, giunco \\
\hline Juniperus communis L. & zanepro, zinebro, zinepro, zinevvoro \\
\hline Laburnum anagyroides Medik. & $\begin{array}{l}\text { almaio, glicini, legno puzzolo, maggiociondolo, } \\
\text { mairì }\end{array}$ \\
\hline Lactuca sativa L. & lattuga, lattuga francese \\
\hline Lactuca serriola L. & cicerbita, radicchi \\
\hline Lavandula angustifolia Mill. & lavanda, spigo \\
\hline Leucanthemum vulgare (Vaill.) Lam. (s. 1.) & camomilla selvatica, margheritoni \\
\hline Ligustrum vulgare $\mathrm{L}$. & ligustre \\
\hline Lilium bulbiferum L. & $\begin{array}{l}\text { gigli (arancioni), gigli selvatici, giglio } \\
\text { arancione }\end{array}$ \\
\hline Lonicera caprifolium L. & bracciaboschi, bracciabosco, cucumé \\
\hline Loranthus europaeus Jacq. & vischio \\
\hline Lotus corniculatus L. & fiorume, ginestrino \\
\hline Lunaria annua L. & $\begin{array}{l}\text { gli occhiali del papa, medaglione del papa, } \\
\text { medaglioni del papamonete del papa }\end{array}$ \\
\hline Lupinus albus L. & lupino \\
\hline Lycopersicon esculentum Mill. & $\begin{array}{l}\text { pomodori, pomodori acerbi, pomodori verdi, } \\
\text { pomodoro }\end{array}$ \\
\hline Malus domestica Borkh. & mela \\
\hline Malus domestica Borkh. 'Antiche' & mela (varietà antica), mele antiche \\
\hline Malus domestica Borkh. 'Rosa romana' & mele "rosa romana", rose romane \\
\hline Malus sylvestris (L.) Mill. & mela, mele selvatiche \\
\hline Malva sylvestris L. & malva selvatica, malvia \\
\hline Matricaria chamomilla L. & camomilla, camomilla selvatica \\
\hline Medicago sativa L. y otras especies & erba medica, erba merica, erba spagna, fiorume \\
\hline Mentha spicata L. (s.1.) & menta selvatica \\
\hline Mespilus germanica L. & nespole \\
\hline Morus nigra L. & gelso \\
\hline Myosotis arvensis (L.) Hill & nontiscordardime \\
\hline Nicotiana tabacum L. & sigaro, tabacco, tabacco da sigaro \\
\hline Olea europaea L. & olio di oliva, olivo benedetto, ulivo \\
\hline Onobrychis viciifolia Scop. & fiorume, lupinella \\
\hline Origanum vulgare $\mathrm{L}$. & origano \\
\hline Ostrya carpinifolia Scop. & carpine nero \\
\hline Papaver rhoeas L. & fioracci \\
\hline
\end{tabular}




\begin{tabular}{|c|c|}
\hline Especie botánica & $\begin{array}{l}\text { Nombre vernacular no registrado en } \\
\text { bibliografía local }\end{array}$ \\
\hline Parietaria officinalis L. (s. 1.) & erba vetrina, vetriola \\
\hline Pelargonium zonale (L.) L'Hér. ex Aiton & geranio \\
\hline $\begin{array}{l}\text { Petasites hybridus (L.) "G.Gaertn., B.Mey. \& } \\
\text { Scherb." }\end{array}$ & farfallone, farfalloni, farfanello, farfari, farfaro \\
\hline Phaseolus vulgaris L. & fagioli (borlotti), fagioli con l'occhio \\
\hline Phytolacca americana L. & uva dal bisse \\
\hline Picris hieracioides Sibth. \& Sm. & radicchi, radicchio \\
\hline Plantago lanceolata L. & $\begin{array}{l}\text { codiron d'asino, erba del checchio, orecchie di } \\
\text { somaro, orecchie di topo, orecchio di ciucco, } \\
\text { radicchi, radicchio }\end{array}$ \\
\hline Plantago major L. & $\begin{array}{l}5 \text { nervi, } 7 \text { nervi, erba dei canarini, erba delle } \\
\text { botte }\end{array}$ \\
\hline & lingua d'oca, petacciola, piantacciola \\
\hline Polypodium vulgare L. (s. 1.) & $\begin{array}{l}\text { felce, felce da liquirizia, felce dolce, liquirizia, } \\
\text { rigolizia }\end{array}$ \\
\hline Polystichum aculeatum (L.) Roth ex Mert. & felce \\
\hline Populus nigra L. & fioppa, pioppo vetrino \\
\hline Populus tremula L. & pioppo nostrano, pioppo tremulo \\
\hline Portulaca oleracea L. & erba porcellina \\
\hline Primula vulgaris Huds. & $\begin{array}{l}\text { bugamelli, ciucciamerli, ciuciamele, ciuciameli } \\
\text { ciuciamerli, cucamegli, cucamelli, cucumegli, } \\
\text { cucumei, cucumelli, cucumeo, radicchio }\end{array}$ \\
\hline Prunus armeniaca L. & albicoche \\
\hline Prunus avium (L.) L. & $\begin{array}{l}\text { biancolina, ciliegie biancoline, ciliegie duroni } \\
\text { ciliegio selvatico, marasca }\end{array}$ \\
\hline Prunus avium (L.) L. 'Duroni' & ciliegie innestate, duroni \\
\hline Prunus avium (L.) L. 'Marosticane' & ciliegie marosticane \\
\hline Prunus cerasifera Ehrh. & prugne selvatiche, rusticane \\
\hline Prunus cerasus L. & $\begin{array}{l}\text { amarene, amarene selvatiche, ciliegie amarene } \\
\text { ciliegie marasche, ciliegie maresca, ciliegie } \\
\text { maresche, marasche selvatiche }\end{array}$ \\
\hline Prunus domestica L. & $\begin{array}{l}\text { prugne, prugne giallo tonde } \\
\text { susine selvatiche (viole) }\end{array}$ \\
\hline Prunus dulcis (Mill.) D.A. Webb & mandorla, mandorle amare \\
\hline Prunus persica (L.) Batsch & pesca, pesche \\
\hline Prunus spinosa L. & $\begin{array}{l}\text { espino selvatico, frutto strozzaprete, rusticane } \\
\text { spini, spini (frutti viola), spino nero, }\end{array}$ \\
\hline
\end{tabular}




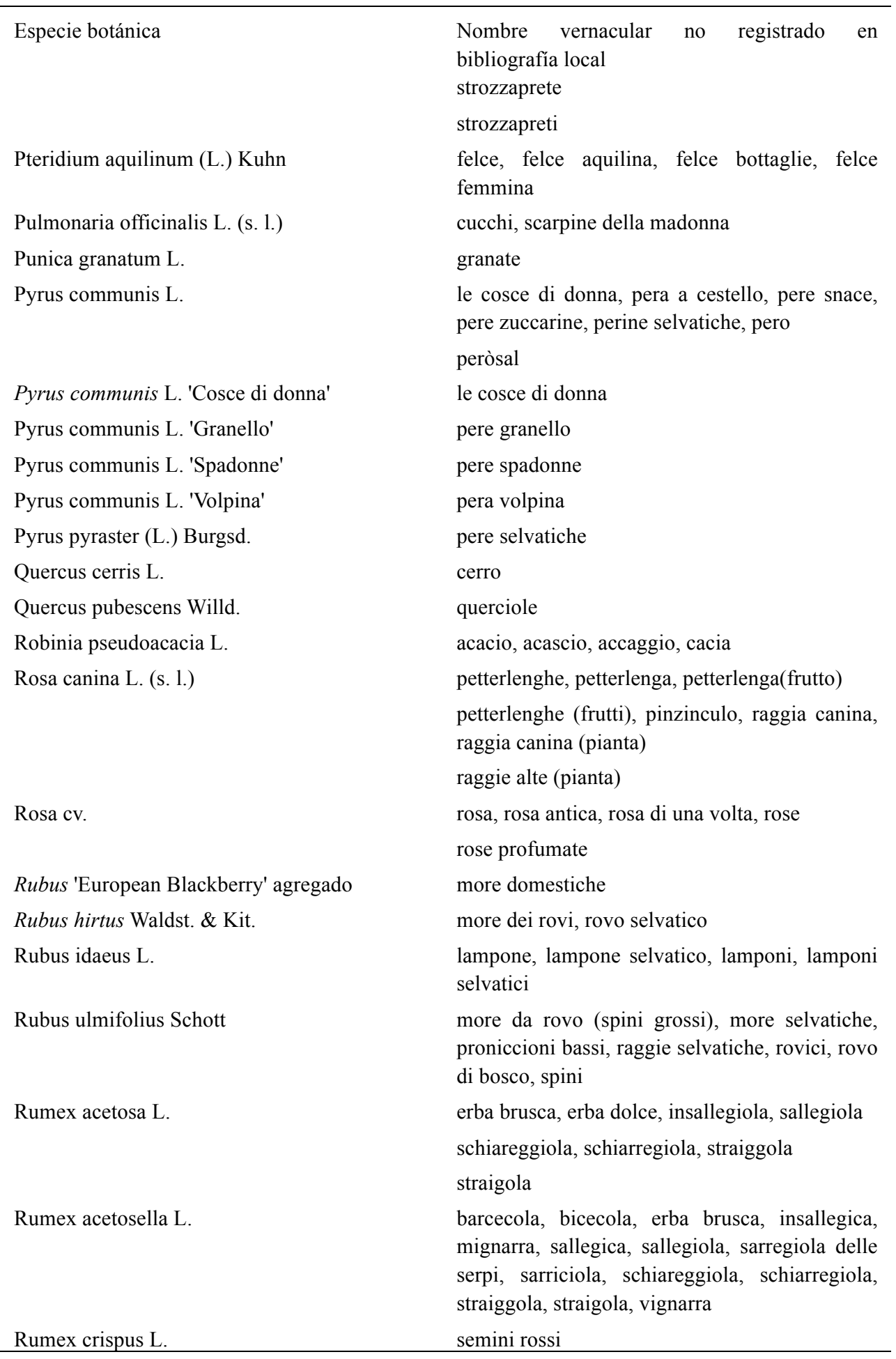




\begin{tabular}{|c|c|}
\hline Especie botánica & $\begin{array}{l}\text { Nombre vernacular no registrado en } \\
\text { bibliografía local }\end{array}$ \\
\hline Rumex obtusifolius L. & erba di botta, romice \\
\hline Ruscus aculeatus L. & asparagi selvatici, grattatopi, pungitopo \\
\hline Ruta graveolens L. & ruta \\
\hline Salix alba L. & $\begin{array}{l}\text { borgogna, borgognone, borgognoni, salgò, } \\
\text { salgon basso, salgòn basso, salica, salice } \\
\text { bianco, salice di fiume, salicon, salicone, } \\
\text { veddega, vetica del fiume (pianta), vetiche di } \\
\text { fiume, vimini }\end{array}$ \\
\hline Salix alba var. vitellina (L.) Stokes & $\begin{array}{l}\text { saigòn da stropei, salice, salice giallo, stropegli, } \\
\text { stropello, stropla da vimini, stroppe (rami), } \\
\text { vetrice, vimini }\end{array}$ \\
\hline Salix caprea L. & $\begin{array}{l}\text { bebine, fioppini, gattici, saigon che si spacca } \\
\text { salgon selvatico, salica, topi, topini, veddega, } \\
\text { veddeghe, vedega bottara, vetica bottara, } \\
\text { vettiche bottare }\end{array}$ \\
\hline Salix eleagnos Scop. & $\begin{array}{l}\text { stropelli, stropelli (rami), veddega, vedeghe di } \\
\text { fiume, vetica del fiume (pianta), vetiche, } \\
\text { vetiche di fiume }\end{array}$ \\
\hline \multirow[t]{2}{*}{ Salix purpurea L. } & $\begin{array}{l}\text { stropelli, stropelli (rami), vetica del fiume } \\
\text { (pianta) }\end{array}$ \\
\hline & vetiche, vetiche di fiume, vimini del fiume \\
\hline Salix triandra $\mathrm{L}$. & borgognone, borgognoni, salice nero \\
\hline Salvia officinalis L. & la pianta della vita \\
\hline Sambucus ebulus L. & ebbi, ebbiacci, ebbio, mangiarrughe \\
\hline Sanguisorba minor Scop. & salvastrella \\
\hline Saponaria officinalis L. & $\begin{array}{l}\text { erba sapone, erba saponina, erba savonada, erba } \\
\text { savonina, pianta del sapone, saponaria }\end{array}$ \\
\hline Scrophularia scopolii Hoppe ex Pers. & bertonica, bettonica \\
\hline Sedum acre L. & erba poranciola \\
\hline Sedum dasyphyllum L. & riso di botta \\
\hline Sedum telephium L. & $\begin{array}{l}\text { erba di san giovanni, erba per le ferite, foglia } \\
\text { della madonna, pianta grassa }\end{array}$ \\
\hline Sempervivum tectorum $\mathrm{L}$. & $\begin{array}{l}\text { erba trona, l'erba per curare al mal di ciglio, } \\
\text { levasete, pianta grassa, semprevivo }\end{array}$ \\
\hline Silene flos-cuculi (L.) Greuter \& Burdet & garofanini \\
\hline $\begin{array}{l}\text { Silene latifolia subsp. alba (Mill.) Greuter \& } \\
\text { Burdet }\end{array}$ & orecchine di levora (lepre) \\
\hline Silene vulgaris (Moench) Garcke & strigoli d'agnello, verzolo \\
\hline Solanum americanum Mill. & erba mora \\
\hline
\end{tabular}




\begin{tabular}{|c|c|}
\hline Especie botánica & $\begin{array}{l}\text { Nombre vernacular no registrado en } \\
\text { bibliografía local }\end{array}$ \\
\hline Sonchus oleraceus (L.) L. (s. 1.) & $\begin{array}{l}\text { cicerba, cicerbe, cicerbie, cicerbita, cicerbite, } \\
\text { cicerbole, cicerchia, cicerchie, cicervide, } \\
\text { cicoria, cigerbda, cigerbe, cigervde, cigervida, } \\
\text { cigevda, cisevda, frats, gerba, gerbe, gerbelina, } \\
\text { gerbi, gerbia, gerbie, gerbio, gigerbite, radicch, } \\
\text { radicchio, spinone }\end{array}$ \\
\hline Sorbus aria (L.) Crantz & $\begin{array}{l}\text { ciliegio lane, ciliegio lano, lane, lani, lano, } \\
\text { sorbo }\end{array}$ \\
\hline Sorbus aucuparia L. & sorbo degli uccellatori \\
\hline Sorbus torminalis (L.) Crantz & $\begin{array}{l}\text { ciliegiastri, durascoli, olivastri, olivastro, } \\
\text { oloastro, ulastro }\end{array}$ \\
\hline Spartium junceum L. & ginestre, ginestre di spagna \\
\hline Stachys recta L. & erba della paura \\
\hline Syringa vulgaris L. & lille \\
\hline Syzygium aromaticum (L.) Merr. \& L.M.Perry & chiodi di garofano \\
\hline Tanacetum balsamita L. & erba santa \\
\hline Taraxacum campylodes G.E.Haglund (s.1.) & $\begin{array}{l}\text { bocca di leone, cicerbite (fiore del piscialletto), } \\
\text { cicoria, cicorie di campo, cul bianco, dente di } \\
\text { leone, fiorume, pisciacane, piscialletti, } \\
\text { piscialletti amari, piscialletto, radicchi di campi, } \\
\text { radicchi di fiore giallo, radicchi selvatici, } \\
\text { radicchio amaro, radicchio di campo, radicchio } \\
\text { selvatico, soffione }\end{array}$ \\
\hline Teucrium chamaedrys L. & $\begin{array}{l}\text { erba querciola, la querciola, pianta per la } \\
\text { digestione }\end{array}$ \\
\hline Thymus serpyllum L. (s. 1.) & prezzemolino, timo selvatico \\
\hline Tilia americana L. & tiglio \\
\hline Tragopogon pratensis L. & barba dei frati \\
\hline Trifolium pratense L. & fiorume, trafagliolo, trifoglio \\
\hline Trifolium sp. pl. & quatrifoglio \\
\hline Triticum aestivum $\mathrm{L}$. & al grà \\
\hline Triticum durum Desf. & $\begin{array}{l}\text { grano (semola), grano duro (semola), semola } \\
\text { semola (grano) }\end{array}$ \\
\hline Ulex europaeus L. & incoronacristi \\
\hline Urtica dioica $\mathrm{L}$. & ortiga \\
\hline Vaccinium corymbosum L. & mirtillo americano \\
\hline Vaccinium myrtillus L. & mirtillo spontaneo \\
\hline Valerianella locusta (L.) Laterr. & agnellino, bocconcino d'agnello, boconcini di \\
\hline
\end{tabular}




\begin{tabular}{|c|c|}
\hline Especie botánica & $\begin{array}{l}\text { Nombre vernacular no registrado en } \\
\text { bibliografía local } \\
\text { agnello, braga di gallo, concin d'agnelli } \\
\text { dolcignò, dolcignoli, dolcignolo, galinella } \\
\text { gallina grassa, gallinella, gallinella grassa, la } \\
\text { gallinina, radicchi, valeriana selvatica, zampe di } \\
\text { gallo }\end{array}$ \\
\hline Vanilla planifolia Jacks. ex Andrews & vaniglia \\
\hline Verbascum thapsus L. & $\begin{array}{l}\text { erba delle botte, sasso bardasso, tasso varbasso, } \\
\text { verbasco }\end{array}$ \\
\hline Verbena officinalis L. & erba del versamento \\
\hline Veronica beccabunga L. & crescion \\
\hline Vicia faba L. & fave \\
\hline Vicia sativa L. & vecce \\
\hline Viola alba subsp. dehnhardtii (Ten.) W. Becker & viole \\
\hline Viola tricolor L. & panzé, viola bianca \\
\hline Viscum album L. & vischio \\
\hline Vitis labrusca L. & $\begin{array}{l}\text { uva americana, uva fragola, vite americana } \\
\text { vite fragola }\end{array}$ \\
\hline Vitis vinifera $L$. & uva, uva zibibbo \\
\hline Vitis vinifera L. 'Barbera' & uva barbera \\
\hline Vitis vinifera L. 'Nigratein' & uva negratina \\
\hline Vitis vinifera L. 'Saslà' & saslà (frutta secca) \\
\hline Vitis vinifera L. 'Zibebe' & a zibebe, uva passita \\
\hline Zea mays L. & formentone \\
\hline
\end{tabular}

Vemos que muchos de los nombres recogidos en nuestra investigación han sufrido una perdida cultural, ya que son tecnicismos o italianismos. Hay que considerar que algunos estudios bibliográficos estudiados han sido realizados en las décadas pasadas con lo cual puede que todavía se conservara más el dialecto local. En cambio por otra parte algunos de los nombres citados en bibliografía que no se encuentran en nuestra investigación, son sobre todo los de origen boloñés (Ungarelli, 1921), ya que en la mayoría de los casos existe una distancia considerable territorial, por esto no corresponden.

La particularidad del sistema dialectal que existe en el AVR y las influencias toscanas y emilianas que contiene, se ponen de manifiesto separando los nombres vernaculares citados en la parte toscana (o pistoiese) de aquellos citados en la parte emiliana (o boloñesa), y al mismo tiempo contrastándolos con los nombres vernaculares recogidos en los trabajos etnofarmacológicos realizados en la provincia 
di Bolonia (Ungarelli, 1921) y en la provincia di Pistoia (zona colindante con AVR) (Uncini Manganelli y Tomei, 1998).

En algunos casos se ve como los nombres de la parte boloñesa corresponden con la provincia de Bolonia como es lógico, e igualmente en la parte toscana. Pero cabe resaltar como en el AVR (tanto en la parte toscana como boloñesa) es utilizado un nombre que no aparece ni en Bolonia ni en Pistoia, como en el caso de Chelidonium majus L. llamada "erba dei poranci" o el caso de Laburnum anagyroides Medik. llamado "maggiociondolo" solo en AVR, lo cual muestra la particularidad el dialecto del AVR.

En cambio se puede observar como en la parte toscana, Prunus cerasifera Ehrh. tiene una mayor influencia emiliana que la parte boloñesa, ya que se utiliza el mismo nombre vernacular "rustican/e" en cambio en la parte boloñesa se emplea "prugne selvatiche". Igualmente, en la parte boloñesa, Veronica beccabunga L. está más influenciado por Toscana que por Emilia, ya que se denomina igualmente "crescion", en la parte toscana y en la zona pistoyesa estudiada por Uncini Manganelli y Tomei (1998), en cambio en la provincia de Bolonia se denomina "bocabonga". Por otra parte, Stachys recta L. denominada "erba della paura" en ambas partes del valle, muestra tener más bien influencias boloñesas, ya que en Ungarelli (1921) aparece como "êrba de la pôra" en cambio en Uncini Manganelli y Tomei (1998) aparece como "erba lavandala" (Tab. 22).

Tab. 22. Evolución territorial del dialecto del AVR.

E influencia de la cultura boloñesa y de la cultura pistoyesa: ejemplos de nombres vernaculares de especies botánicas en Bolonia, en la parte boloñesa del AVR, en la parte pistoyesa del AVR y en Pistoia. Fuentes: Nombre vernacular Bolonia Ungarelli (1921), Nombre vernacular Pistoia Uncini-Manganelli y Tomei (1998)

\begin{tabular}{|c|c|c|c|c|}
\hline $\begin{array}{l}\text { Especie } \\
\text { botánica }\end{array}$ & $\begin{array}{l}\text { Nombre } \\
\text { vernacular } \\
\text { Bolonia }\end{array}$ & $\begin{array}{l}\text { Nombre vernacular parte } \\
\text { boloñesa del AVR } \\
\text { (AVRB) }\end{array}$ & $\begin{array}{l}\text { Nombre vernacular } \\
\text { parte pistoyesa del } \\
\text { AVR (AVRT) }\end{array}$ & $\begin{array}{l}\text { Nombre } \\
\text { vernacular } \\
\text { Pistoia }\end{array}$ \\
\hline $\begin{array}{l}\text { Aesculus } \\
\text { hippocastanum } \\
\text { L. }\end{array}$ & $\begin{array}{l}\text { marån } \\
\text { d'endia }\end{array}$ & $\begin{array}{l}\text { castagna/e d'india, } \\
\text { ippocastano,marron } \\
\text { d'india }\end{array}$ & castagno d'india & $\begin{array}{l}\text { castagno } \\
\text { d'india }\end{array}$ \\
\hline $\begin{array}{l}\text { Castanea sativa } \\
\text { Mill. }\end{array}$ & castâgn & $\begin{array}{l}\text { castagna, farina dolce, } \\
\text { castagne, } \\
\text { castagno } \\
\text { castagno pastenese, } \\
\text { calerese, pastenese, } \\
\text { ceppa e neratina }\end{array}$ & $\begin{array}{l}\text { castagne, castagno, } \\
\text { castagno pastinese, } \\
\text { castagno salvano o } \\
\text { selvatico, castagno } \\
\text { salvano, castagno } \\
\text { selvatico, salvano }\end{array}$ & castagno \\
\hline $\begin{array}{l}\text { Chelidonium } \\
\text { majus L. }\end{array}$ & $\begin{array}{l}\text { êrba di pôr, } \\
\text { êrba pr'i cal }\end{array}$ & $\begin{array}{l}\text { erba dei poranci, erba dei } \\
\text { porri }\end{array}$ & $\begin{array}{l}\text { celidonia,erba dei } \\
\text { porri, erba per i } \\
\text { poranci, erba per } \mathrm{i} \\
\text { porri }\end{array}$ & $\begin{array}{l}\text { chelidonia, } \\
\text { celidonia }\end{array}$ \\
\hline
\end{tabular}




\begin{tabular}{|c|c|c|c|c|}
\hline $\begin{array}{l}\text { Crataegus } \\
\text { rhipidophylla } \\
\text { Gand. }\end{array}$ & $\begin{array}{l}\text { spen bianc, } \\
\text { maruga } \\
\text { bianc, } \\
\text { coegapojj }\end{array}$ & $\begin{array}{l}\text { biancospino, } \\
\text { biancospino, } \\
\text { bianchi }\end{array}$ & $\begin{array}{l}\text { biancospino, } \\
\text { spinbianco, spini, } \\
\text { biancospino }\end{array}$ & biancospino \\
\hline $\begin{array}{l}\text { Cynodon } \\
\text { dactylon (L.) } \\
\text { Pers. }\end{array}$ & gramaggna & gramigna & gramigna, graminia & gramigna \\
\hline $\begin{array}{l}\text { Foeniculum } \\
\text { vulgare Mill. }\end{array}$ & $\begin{array}{lr}\text { fnôc } & \text { da } \\
\text { smaint } & o \\
\text { fnucenna } & \end{array}$ & finocchietto, finocchio & $\begin{array}{l}\text { finocchio, } \\
\text { finocchio selvatico }\end{array}$ & finocchio \\
\hline $\begin{array}{l}\text { Gentiana } \\
\text { asclepiadea L. } \\
\text { (cfr.) }\end{array}$ & genziaena & genziana & genziana & $\begin{array}{l}\text { genziana, } \\
\text { scenziana }\end{array}$ \\
\hline $\begin{array}{l}\text { Helleborus } \\
\text { foetidus L. }\end{array}$ & $\begin{array}{l}\text { cascadente } \\
\text { femmina, } \\
\text { erba del } \\
\text { mael zitan }\end{array}$ & cascadente, erba nocca & erba noca & erba nocca \\
\hline $\begin{array}{l}\text { Hypericum } \\
\text { perfoliatum L. }\end{array}$ & $\begin{array}{l}\text { êrba ed san } \\
\text { zvân }\end{array}$ & $\begin{array}{l}\text { iperico, iperico, erba di } \\
\text { san giovanni, } \\
\text { scacciadiavoli, iperico }\end{array}$ & iperico & $\begin{array}{l}\text { fiore di san } \\
\text { giovanni }\end{array}$ \\
\hline $\begin{array}{l}\text { Juglans regia } \\
\text { L. }\end{array}$ & nùs,nûl pêfga & $\begin{array}{l}\text { mallo di noce, noce,noce } \\
\text { malisa,noci }\end{array}$ & $\begin{array}{l}\text { marlo di noce, } \\
\text { merla di noce, noce }\end{array}$ & noce \\
\hline $\begin{array}{l}\text { Juniperus } \\
\text { communis L. }\end{array}$ & zanåvver & $\begin{array}{l}\text { ginepro, zanepro, } \\
\text { zinebro, zinevvoro }\end{array}$ & $\begin{array}{l}\text { ginepro, zinebro, } \\
\text { zinepro }\end{array}$ & ginepro \\
\hline $\begin{array}{l}\text { Laburnum } \\
\text { anagyroides } \\
\text { Medik. }\end{array}$ & mâj & $\begin{array}{l}\text { almaio, glicini, } \\
\text { maggiociondolo, }\end{array}$ & $\begin{array}{l}\text { maggiociondolo, } \\
\text { legno puzzolo, } \\
\text { mairì }\end{array}$ & arbogno \\
\hline $\begin{array}{l}\text { Matricaria } \\
\text { chamomilla L. }\end{array}$ & $\begin{array}{l}\text { camamella, } \\
\text { brufacûl }\end{array}$ & $\begin{array}{l}\text { camomilla, camomilla } \\
\text { selvatica }\end{array}$ & $\begin{array}{l}\text { camomilla, } \\
\text { camomilla selvatica }\end{array}$ & camomilla \\
\hline $\begin{array}{l}\text { Ocimum } \\
\text { basilicum L. }\end{array}$ & balalecc & basilico & basilico & basilico \\
\hline $\begin{array}{l}\text { Olea europaea } \\
\text { L. }\end{array}$ & $\begin{array}{l}\text { olio d'uliva, } \\
\text { ulîv }\end{array}$ & $\begin{array}{l}\text { olio, olio di oliva, oliva, } \\
\text { olivo, olivo benedetto, } \\
\text { ulivo }\end{array}$ & olio, oliva, olivo & olivo \\
\hline $\begin{array}{l}\text { Parietaria } \\
\text { officinalis L. } \\
\text { (s. 1.) }\end{array}$ & vidariôl & gambo rosso, vetriola & $\begin{array}{l}\text { erba vetrina, gambo } \\
\text { rosso, parietaria }\end{array}$ & $\begin{array}{l}\text { erba } \\
\text { vetriola, } \\
\text { parietaria, } \\
\text { vetriolo }\end{array}$ \\
\hline $\begin{array}{l}\text { Plantago } \\
\text { lanceolata } \mathrm{L} \text {. }\end{array}$ & & $\begin{array}{l}\text { erba del checchio, } \\
\text { orecchie di somaro, } \\
\text { orecchie di topo, } \\
\text { radicchio, orecchio di } \\
\text { ciucco, radicchio. }\end{array}$ & $\begin{array}{l}\text { radicchi, codiron } \\
\text { d'asino }\end{array}$ & cinque nervi \\
\hline
\end{tabular}


Etnobotánica en el Alto Valle del Reno (Toscana y Emilia-Romaña, Italia)

\begin{tabular}{|c|c|c|c|c|}
\hline $\begin{array}{l}\text { Prunus } \\
\text { cerasifera } \\
\text { Ehrh. }\end{array}$ & rustican & prugne selvatiche & rusticane & \\
\hline $\begin{array}{l}\text { Pulmonaria } \\
\text { officinalis L. } \\
\text { (s. 1.) }\end{array}$ & pulmonaeria & $\begin{array}{l}\text { polmonaria, } \\
\text { della madonna, }\end{array}$ & cucchi, polmonaria & polmonaria \\
\hline $\begin{array}{l}\text { Rosa canina L. } \\
\text { (s. 1.) }\end{array}$ & $\begin{array}{l}\text { pizincûl, } \\
\text { patarlainga, } \\
\text { ro } \int \mathrm{a} \text { di mâta } \\
\text { o ro } \int \mathrm{a} \text { ed } \\
\text { r } \int \mathrm{za} \text {, ro } \int \mathrm{a} \text { ed } \\
\text { zoeda }\end{array}$ & $\begin{array}{l}\text { peterlenga, peterlenghe, } \\
\text { peterlenghe (frutti), rosa } \\
\text { canina (pianta), } \\
\text { peterlenghe (frutto) } \\
\text { raggie alte (pianta), } \\
\text { pinzinculo, pinzinculo, } \\
\text { rosa canina, raggia } \\
\text { canina, raggia canina } \\
\text { (pianta) } \\
\text { peterlenga(frutto), rosa } \\
\text { canina }\end{array}$ & $\begin{array}{l}\text { perterlenghe, } \\
\text { peterlenga, } \\
\text { peterlenga, raggie } \\
\text { canina, } \\
\text { peterlenghe, rosa } \\
\text { canina, }\end{array}$ & $\begin{array}{l}\text { peterlinghe, } \\
\text { petterlenghe }\end{array}$ \\
\hline $\begin{array}{l}\text { Rosmarinus } \\
\text { officinalis L. }\end{array}$ & u.maren & rosmarino & rosmarino & $\begin{array}{l}\text { rosmarino, } \\
\text { tremarino }\end{array}$ \\
\hline $\begin{array}{l}\text { Rumex } \\
\text { acetosella L. }\end{array}$ & ponztôp & $\begin{array}{l}\text { barcecola, barcecola, } \\
\text { sarregiola delle serpi, } \\
\text { bicecola, erba brusca, } \\
\text { mignarra, insallegica, } \\
\text { insallegica, erba brusca, } \\
\text { insallegiola, sallegica, } \\
\text { vignarra }\end{array}$ & $\begin{array}{l}\text { insallegiol, } \\
\text { sallegiola, } \\
\text { sarriciola, } \\
\text { schiareggiola, } \\
\text { insallegiola, } \\
\text { schiarregiola, } \\
\text { straiggola, straigola }\end{array}$ & insaleggiola \\
\hline $\begin{array}{l}\text { Stachys recta } \\
\text { L. }\end{array}$ & $\begin{array}{l}\text { êrba de la } \\
\text { pôra }\end{array}$ & erba della paura & erba della paura & $\begin{array}{l}\text { erba } \\
\text { lavandaia }\end{array}$ \\
\hline $\begin{array}{l}\text { Taraxacum } \\
\text { campylodes } \\
\text { G.E.Haglund } \\
\text { (s.l.) }\end{array}$ & $\begin{array}{l}\text { radecc da } \\
\text { purz, } \\
\text { pessalaet. }\end{array}$ & $\begin{array}{lr}\begin{array}{l}\text { cicerbite } \\
\text { piscialletto), }\end{array} & \text { radicchio } \\
\text { amaro, } & \text { piscialletto, } \\
\text { cicoria, cul } & \text { bianco, } \\
\text { piscialletto, piscialletti, } & \text { piscialletto, piscialletto, } \\
\text { cul bianco, piscialletto, } & \text { radicchi, } \\
\text { radicchi } & \text { selvatici, } \\
\text { piscialletto, } & \text { radicchio, } \\
\text { radicchi di } & \text { fiore giallo, } \\
\text { radicchio } & \text { selvatico, } \\
\text { radicchio, } & \text { piscialleto, } \\
\text { soffione, } & \text { tarassaco, } \\
\text { fiorume, } & \text { tarassaco, } \\
\text { radicchio } & \end{array}$ & $\begin{array}{l}\text { bocca di leone, } \\
\text { cicorie di campo, } \\
\text { dente di leone, } \\
\text { piascialletto, } \\
\text { radicchi, radicchi di } \\
\text { campi, piscialletti } \\
\text { amari, radicchio, } \\
\text { radicchio } \\
\text { campo, radicchio } \\
\text { selvatico, } \\
\text { pisciacane, } \\
\text { soffione, tarassaco }\end{array}$ & $\begin{array}{l}\text { piscialletto, } \\
\text { radicchio }\end{array}$ \\
\hline
\end{tabular}


María Teresa Egea Molines

\begin{tabular}{lllll}
\hline $\begin{array}{l}\text { Verbascum } \\
\text { thapsus L. }\end{array}$ & tâs bardâs & $\begin{array}{l}\text { erba delle botte, sasso } \\
\text { bardasso, tasso varbasso }\end{array}$ & $\begin{array}{l}\text { tasso verbasco } \\
\text { varbasso, }\end{array}$ & $\begin{array}{l}\text { tasso } \\
\text { bardasso }\end{array}$ \\
$\begin{array}{l}\text { Veronica } \\
\text { beccabunga L. }\end{array}$ & bœcabonga & crescion, crescione & crescion, crescione & crescione \\
\hline
\end{tabular}

En este breve análisis se discuten las influencias culturales toscanas y emilianas sobre el AVR y el dialecto “altorenano", además de proporcionar valiosa información sobre la distribución geográfica de las especies en cuestión. La Tab. 22 ilustra bien el fenómeno que se da en el sistema dialectal del AVR y da una idea que como ocurre en estas zonas, el paso progresivo, o transición, de la cultura emiliana a la toscana.

Como asegura Signorini (2003), el dialecto del AVR está en un estado crítico ya que está fuertemente amenazado por la desaparición completa. El autor afirmaba ya en el 2003, que el dialecto hablado en Treppio (Sambuca Pistoiese) desapareció por completo ya en los años 70; el resto de los dialectos del AVR era hablado solo por pocas personas de más de 80 años, y estaba previsto que en los siguientes 10 o 20 años desaparecería del todo. A pesar de éstos pronósticos negativos que se ven ya reflejados en algunos nombres vernaculares de las plantas recogidos en nuestra investigación marcados en gran parte por tecnicismos e italianismos, hemos podido describir una gran parte del sistema nomenclatural del AVR, con un importante número de nombres vernaculares de las plantas asociados a su distribución geográfica.

\section{Análisis ecológico}

\subsection{Biotipos}

El análisis de los tipos biológicos ha sido realizado a través de las clasificaciones proporcionadas por Pignatti (1982) que a su vez sigue el sistema de Raunkiaer. En la Fig. 24 se puede apreciar como la mayoría de las plantas de interés etnobotánico en el AVR son fanerófitos $(102=37 \%)$, seguidos de hemicriptófitos $(81=29 \%)$, terófitos $(41=15 \%)$, geófitos $(26=9 \%)$ y caméfitos $(17=6 \%)$.

La prevalencia del uso de fanerófitos en el AVR testimonia la gran importancia de los árboles y la fuerte caracterización forestal del territorio estudiado. Esta prevalencia de especies arbustivas en los usos etnobotánicos es normal ya que la población ha dependido mucho de sus bosques (ver Introducción). Resalta por no coincidir con la flora de cualquier área de Italia Norte-Central sobre todo en zonas de piedemonte o montañosas, en cuyas altitudes y latitudes, predominan normalmente las plantas perennes, es decir los hemicriptófitos, lo cual se confirma en el espectro biológico estudiados en la flora de Le Valli della Limentra Orientale e Limentrella (situada entre Pistoia y Prato, en la parte este del municipio Sambuca Pistoiese) según Venturi (2006) (Fig. 19), así como en la flora del Parco dei laghi di Suviana e Brasimone de Sirotti (2005), en la que también predominan los hemicriptófitos $(47,1 \%)$, seguidos de los terófitos $(18,4 \%)$ y los geófitos $(15,6 \%)$. En cambio, este perfil ecológico del uso tradicional de las plantas sí que coincide, 
una vez más, con la tradición etnobotánica de las comunidades alpinas del Norte de Italia de los Cimbros y los Móquenos (Obón, 2012; Rivera, 2012), los cuales utilizan en porcentajes muy similares a las comunidades del AVR, fanerófitos $(39,3 \%$ Móquenos, 44,3\% Cimbros), hemicriptófitos (24,6\% Móquenos, 19,5\% Cimbros), terófitos (15,5\% Móquenos, 14,3\% Cimbros) y geófitos (9,0\% Móquenos, 10,3\% Cimbros).

Al confrontar los tipos biológicos de la etnoflora en el Alto Valle del Reno con los tipos biológicos de la flora de Toscana (Fig. 26), de Emilia-Romaña (Fig. 27) y de Italia (Fig. 28), y según los datos de Pignatti (1994), se observa claramente como las formas biológicas de interés etnobotánico en las que prevalecen los fanerófitos y los hemicriptófitos, contrastan con la prevalencia de hemicriptófitos y terófitos en la flora de Italia, Toscana y Emilia-Romaña.

En cambio, en otros estudios como el del Poniente Granadino de Benítez Cruz (2009), un área no boscosa, en la etnoflora predominan los hemicriptófitos y los terófitos, teniendo los fanerófitos un tercer lugar de importancia. Según Benítez Cruz, el elevado porcentaje de hemicriptófitos, fanerófitos y caméfitos en la etnoflora puede ser debido a que éstos son recursos que permanecen o se desarrollan periódicamente en los mismos lugares, lo que propicia su localización y facilita la recolección, además de que en los dos últimos casos, la biomasa que presentan es más abundante y el periodo de recolección puede ser considerablemente mayor.

\subsection{Corología}

En acorde con la clasificación corológica realizada por Pignatti (1982), las plantas de interés etnobotánico más importantes son de origen europeas (32\%), cultivadas, eurimediterráneas y de amplia distribución (Fig. 29). Al margen de las cultivadas que demuestran tener una relevante importancia en la cultura local, la distribución de la etnoflora corresponde totalmente a las características biogeográficas del territorio estudiado, ya que éste se encuentra justo en la línea biogeográfica que separa la región centroeuropea con la región mediterránea. Por ello predominan tanto las europeas como las eurimediterráneas y las plantas de amplia distribución, es decir las presentes en dos regiones biogeográficas diferentes así como las plantas cosmopolitas que incluyen las plantas que crecen en ambientes alterados.

\subsection{Ambientes y hábitat}

Las plantas de interés etnobotánico son obtenidas en 14 ambientes diferentes. Considerando que las plantas pueden crecer en más de un ambiente, la suma del número de especies supera el número de especies totales de la etnoflora del AVR. En la Fig. 40, observamos como las plantas de interés etnobotánico son mayoritariamente recolectadas en lugares antropizados y modificados por la actividad humana, prevalentemente en "cultivos, plantas adventicias, jardines, y huertos" (109 especies, 38,7\%), seguidos por "caminos, baldíos, muros, setos" (85 especies, 30,2\%). Esta prevalencia del uso de plantas de ambientes antropizados por parte de la cultura tradicional es un resultado común en diferentes estudios etnobotánicos en Italia y en España (Benítez Cruz, 2009; Obón et al., 2012; Pieroni 
et al., 2005; Rivera et al., 2012; Signorini et al., 2008; Tardío et al., 2005) aunque muy pocos estudian y discuten este aspecto (Signorini et al., 2009). Los motivos que explican esta afirmación son varios: por la fácil accesibilidad a las zonas antropizadas, normalmente en proximidades de los lugares habitados; porque muchas plantas recolectadas en ambientes alterados pueden comportarse como adventicias en diferentes prácticas agrícolas, por lo que han coevolucionado de alguna manera con la presencia del hombre; a menudo los habitantes trasplantan las plantas útiles a los jardines de las casas o en zonas accesibles a ellos (práctica que todavía siguen haciendo) que posteriormente se han reproducido naturalmente en las mismas; y por último puede que algunas especies de interés etnobotánico fueran cultivadas antiguamente y se hayan asilvestrado posteriormente (Signorini et al., 2009).

Cabe resaltar la importancia de las plantas recolectadas en ambientes más naturales como "bosques mixtos latifolios, caducifolios y de monte bajo" (80 especies, 28,4\%) debido a la abundancia de estos ambientes en el territorio y a que a menudo los centros habitados y las casas se encuentran rodeados de este tipo de ambientes, de ahí se explica de nuevo la utilización mayoritaria de los fanerófitos. A éstos les siguen por orden de importancia los "prados, pastos" (42 especies, 14,9\%), que pueden ser considerados seminaturales o semiartificiales, y el ambiente más antropizados "áreas marginales, ambientes ruderales, carreteras, cerca de las casas" (41 especies, 14,6\%). La importancia relativa del ambiente de recolección de "prados, pastos" y "áreas marginales, ambientes ruderales, carreteras, cerca de las casas" puede ser debido a la alta diversidad florística que presentan estás zonas en el territorio, como se demuestra en Venturi (2006) y en Sirotti (2005) pero también al hecho de que ciertas especies crecen y se reproducen cerca y gracias a la acción del hombre. La poca representación de las plantas casi exclusivamente adquiridas en las tiendas demuestra que las plantas utilizadas tradicionalmente por la comunidad de estudio eran sobre todo locales. Es curioso observar como los hábitats en los que habitualmente se recolectan las especies útiles en el AVR corresponden de nuevo a los hábitats de recolección más comunes de las comunidades alpinas de las minorías étnicas de los Cimbros (Rivera et al., 2012) y los Móquenos (Obón et al., 2012), ya que éstos también suelen recolectar las especies útiles en los bosques $(30,6 \%$ Cimbros, $32 \%$ Móquenos), los huertos y jardines (23,1\% Cimbros; 18,2\% Móquenos) y los prados (12,4\% Cimbros, 16,0\% Móquenos).

\subsection{Abundancia y estado de conservación}

A pesar de que el objetivo principal de la investigación haya sido el estudio etnobotánico de las plantas silvestres, vemos como la plantas cultivadas tienen una importante representación, como es lógico ya que las personas las cultivaban para un fin y una utilidad en particular y para tenerlas más accesibles. E1 53\% de la etnoflora es silvestre, el $22 \%$ es cultivado, el $23 \%$ son tanto cultivadas como asilvestradas, y el $2 \%$ son ausentes en la zona, es decir se adquieren en las tiendas locales o se recolectan fuera del territorio (Fig. 31).

Según los datos referidos en Pignatti (1982) sobre la abundancia de las especies en el territorio, el $52 \%$ de las plantas son comunes, el $28 \%$ son cultivadas o ausentes 
(y por tanto compradas) y el $12 \%$ de las plantas son raras (en la zona de estudio) (Fig. 32). Es evidente que las personas utilizan las plantas que son más fáciles de conseguir.

Durante la investigación han sido registradas las percepciones de los informantes sobre el estado de abundancia de las especies útiles así como los factores que influyen en él. Estas informaciones describen la percepción ambiental por parte de la comunidad de las especies útiles en su condición de recurso. Además constituyen noticias valiosas sobre la gestión tradicional de ciertas especies locales y de sus hábitats que pueden ser utilizadas en estrategias de conservación de dichas especies como recursos locales (Albuquerque et al.,2008). En la Tab. 23 se muestran las especies en su condición de recurso para la población, que han sufrido un proceso de dismunición o incluso desaparición total. Las especies que no presentan un factor como causa percibida, corresponden a especies para las cuales los informantes han comunicado su percepción en cuanto a su disminución sin precisar los factores-causa. Solo una especie es considerada en aumento en la zona Ilex aquifolium L., debido a que tradicionalmente los ramos se recolectaban y se vendían bien a las floristerías y las personas de las ciudades cercanas, por tanto la gente local empezó a cultivarlos y reproducirlos por ser un recurso y fuente de integración de la renta familiar.

Tab. 23. Especies en proceso de disminución o desaparición.

En el territorio en su condición de recurso para la población local, según la percepción de los informantes.

\begin{tabular}{|c|c|c|}
\hline Especies & $\begin{array}{l}\text { Factores } \\
\text { (interpretados) }\end{array}$ & $\begin{array}{l}\text { Factores percibidos como } \\
\text { causa según la expresión del } \\
\text { informante }\end{array}$ \\
\hline Asparagus tenuifolius Lam. & No especificado & $\begin{array}{l}\text { L'ha preso da Casola (Castel } \\
\text { di Casio) e l'ha trapiantato nel } \\
\text { suo giardino per ornamento. } \\
\text { Una volta c'era anche al } \\
\text { Monte la Croce, però sono } \\
\text { spariti. }\end{array}$ \\
\hline Brassica rapa L. & $\begin{array}{l}\text { Abandono de las prácticas } \\
\text { agrícolopastorales y forestales } \\
\text { tradicionales }\end{array}$ & $\begin{array}{l}\text { Quando levavano il grano, } \\
\text { raccoglievano le rape che } \\
\text { crescevano spontanee nel } \\
\text { campo. }\end{array}$ \\
\hline $\begin{array}{l}\text { Bunium bulbocastanum L. } \\
\text { (cfr.) }\end{array}$ & $\begin{array}{l}\text { Introducción y protección de } \\
\text { animales ungulados por el } \\
\text { Parque Regional }\end{array}$ & $\begin{array}{l}\text { Ora non si trova più, la } \\
\text { mangiano i cinghiali. }\end{array}$ \\
\hline Campanula rapunculus L. & $\begin{array}{l}\text { Gestión convencional-formal- } \\
\text { ética del territorio del Parque } \\
\text { Regional }\end{array}$ & $\begin{array}{l}\text { Non vengono più da quando è } \\
\text { Parco. }\end{array}$ \\
\hline Carduus nutans L. (cfr.) & Abandono de las prácticas & Si spellavano e si mangiavano \\
\hline
\end{tabular}


María Teresa Egea Molines

\begin{tabular}{|c|c|c|}
\hline Especies & $\begin{array}{l}\text { Factores principales } \\
\text { (interpretados) } \\
\text { agrícolopastorales y forestales } \\
\text { tradicionales }\end{array}$ & $\begin{array}{l}\text { Factores percibidos como } \\
\text { causa según la expresión del } \\
\text { informante } \\
\text { crudi quando eravamo nei } \\
\text { campi. }\end{array}$ \\
\hline Carlina acaulis L. & $\begin{array}{l}\text { Gestión convencional-formal- } \\
\text { ética del territorio del Parque } \\
\text { Regional } \\
\text { Abandono de las prácticas } \\
\text { agrícolopastorales y forestales } \\
\text { tradicionales }\end{array}$ & $\begin{array}{l}\text { Le carline erano considerate } \\
\text { infestanti all'Alpe di Stagno, } \\
\text { dove c'erano campi coltivati. } \\
\text { Nascevano tanto e spontanee e } \\
\text { si toglievano. } \\
\text { Ora sono prottete, non si } \\
\text { possono piu raccogliere. } \\
\text { Quando si andava dietro le } \\
\text { pecore se ne vedevano tante } \\
\text { nei castagneti. Le pecore } \\
\text { pulivano sotto I castagneti, e } \\
\text { così potevano crescere le } \\
\text { carline e si vedevano. I } \\
\text { castagneti erano tutti } \\
\text { rastrellati. Alla fonte del Perio } \\
\text { (Badi), nel parco, ci sono dei } \\
\text { Castagneti che danno un idea } \\
\text { di com'era tutto intorno al } \\
\text { paese prima. }\end{array}$ \\
\hline Centaurium erythraea Rafn & No especificado & $\begin{array}{l}\text { Non si trovano piu, fiorisce a } \\
\text { maggio o giugno, anche in } \\
\text { mezzo al fieno, è selvatica, }\end{array}$ \\
\hline Ceterach officinarum Willd. & No especificado & No especificado \\
\hline $\begin{array}{l}\text { Clinopodium nepeta subsp. } \\
\text { glandulosum (Req.) Govaerts }\end{array}$ & $\begin{array}{l}\text { Introducción y protección de } \\
\text { animales ungulados por el } \\
\text { Parque Regional } \\
\text { Abandono de las prácticas } \\
\text { agrícolopastorales y forestales } \\
\text { tradicionales }\end{array}$ & $\begin{array}{l}\text { Non ce ne più tanta, per nei } \\
\text { castagneti non ci arriva più } \\
\text { luce, ne area, e le bestie } \\
\text { mangiano tutto. }\end{array}$ \\
\hline Cyanus segetum Hill & No especificado & $\begin{array}{l}\text { È un fiorellino celeste } \\
\text { spontaneo. 'È da } 30 \text { anni che } \\
\text { non li vedo più'. }\end{array}$ \\
\hline Cytisus scoparius (L.) Link & $\begin{array}{l}\text { Abandono de las prácticas } \\
\text { agrícolopastorales y forestales } \\
\text { tradicionales }\end{array}$ & $\begin{array}{l}\text { Si usava la (erica) femmina. } \mathrm{C}^{\prime} \\
\text { erano tante, pero è sparita. } \\
\text { Secondo Giagnoni non c'è mai } \\
\text { stata invece.La scopa femmina } \\
\text { non ce n' è più, è sparita } \\
\text { perché le Acacie soffocano } \\
\text { tutto come la scopa femmina, I }\end{array}$ \\
\hline
\end{tabular}




\begin{tabular}{ll}
\hline Especies & $\begin{array}{l}\text { Factores principales } \\
\text { (interpretados) }\end{array}$ \\
Erica scoparia L. & No especificado \\
Fragaria vesca L. & Abandono de las prácticas \\
& agrícolopastorales y forestales \\
& tradicionales Reforestaciones \\
& de coníferas \\
& Introducción y protección de \\
animales ungulados por el & Parque Regional
\end{tabular}

Gentiana asclepiadea L. (cfr.)

Gentiana lutea L. (cfr.)

Helichrysum italicum (Roth) Derrumbamientos geológicos G.Don

Helleborus viridis L. (s. 1.)

Juncus inflexus L.

Juniperus communis L.
No especificado

Abandono de las prácticas agrícolopastorales y forestales tradicionales

Abandono prácticas agrícolas tradicionales

Abandono de las prácticas agrícolopastorales y forestales tradicionales

No especificado
Factores percibidos como causa según la expresión del informante mirtilli...

No especificado

Ce n'erano tantissimi fragole nei castagneti quando questi erano puliti, ed avevano un sapore unico. Non ci sono piu, perché il bosco è abbandonato, e mangiano tutto i cervi. Prima dell'Abetaia, era tutto rosso, di fragole. Quando i castagneti erano puliti, ce n'erano tantissimi

No especificado

Il posto dove andava sempre a raccoglierla è invaso dalla vegetazione e dal bosco e non ci si passa neanche.

Prima era pieno sullo scoglio sopra la sua casa ora la frana ha fatto sparire tutte le piante. Non ce n'è più, solo sulla strada per la chiesa di San Pellegrino. L'hanno trapiantata nell'orto.

Non se ne vede più perché non ci sono più le bestie. Una volta le bestie mangiavano certe piante e certe altre non, e cosi gestivano la flora In modo che facevano che ci fossero certe piante e certe altre no.

Ora ce n'è molto meno, perché I suoi habitat sono cambiati per l'abbandondo della terra da parte dell'uomo. E' sparita per la vegetazione invasiva.

Raccogliere le bacche a settembre, quando sono mature.Sta morendo, siamo passati per quello che era un bosco di ginepro e sta morendo tutto. è tutto 


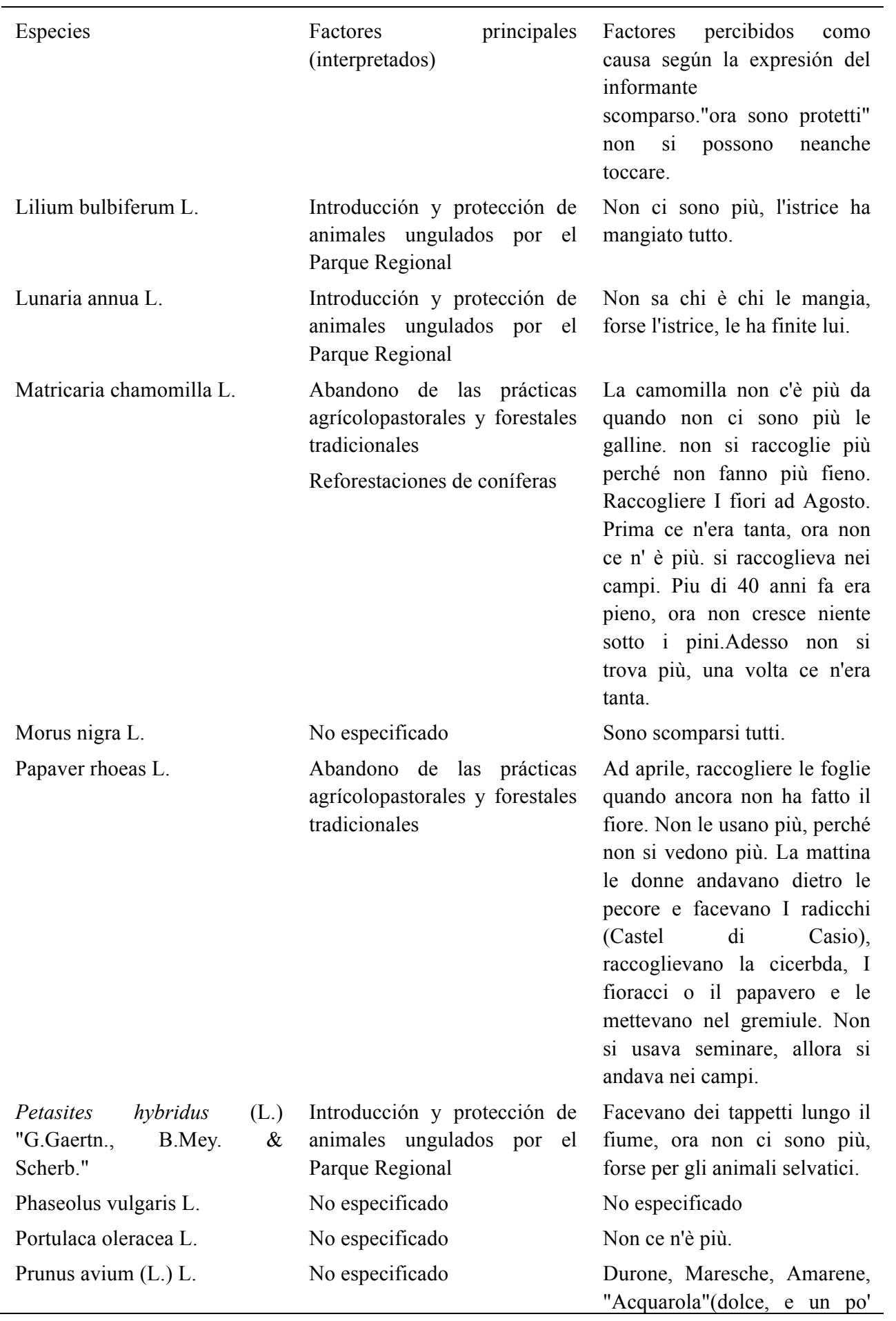




\begin{tabular}{|c|c|c|}
\hline Especies & $\begin{array}{l}\text { Factores } \\
\text { (interpretados) }\end{array}$ & $\begin{array}{l}\text { Factores percibidos como } \\
\text { causa según la expresión del } \\
\text { informante } \\
\text { amara), "Amarognole" (sono } \\
\text { nere, dolci e amarognole nel } \\
\text { giardino, e selvatiche). "E } \\
\text { peggio che la gramigna, si } \\
\text { attacca da per tutto". }\end{array}$ \\
\hline $\begin{array}{lll}\text { Prunus avium (L.) L. } & \text { L. } \\
\text { 'Marosticane' } & & \end{array}$ & No especificado & No especificado \\
\hline Prunus cerasus L. & No especificado & $\begin{array}{l}\text { Prima ce n'era molti di più } \\
\text { alberi di ciliegie. I merli li } \\
\text { mangiavano come ora, la } \\
\text { differenza è che prima ce } \\
\text { n'erano molti di più. }\end{array}$ \\
\hline Pyrus communis L. & No especificado & $\begin{array}{l}\text { Adesso sono abbandonati, le } \\
\text { pere raccolte a fine estate- } \\
\text { autunno.Ora ce ne sono poche, } \\
\text { bisognarebbe girare per } \\
\text { ritrovarle, una volta ce n'erano } \\
\text { tante. }\end{array}$ \\
\hline Pyrus communis L. 'Granello' & $\begin{array}{l}\text { Abandono de las prácticas } \\
\text { agrícolopastorales y forestales } \\
\text { tradicionales }\end{array}$ & $\begin{array}{l}\text { Nella vallata su di qui non ce } \\
\text { ne sono più.. Prima tutti } \\
\text { avevano uno. }\end{array}$ \\
\hline Pyrus communis L. 'Spadonne' & No especificado & No especificado \\
\hline Pyrus communis L. 'Volpina' & No especificado & No especificado \\
\hline Pyrus pyraster (L.) Burgsd. & $\begin{array}{l}\text { Abandono de las prácticas } \\
\text { agrícolopastorales y forestales } \\
\text { tradicionales }\end{array}$ & Adesso sono abbandonati. \\
\hline Rosa cv. & No especificado & No especificado \\
\hline Rubus idaeus L. & $\begin{array}{l}\text { Introducción y protección de } \\
\text { animales ungulados por el } \\
\text { Parque Regional }\end{array}$ & $\begin{array}{l}\text { C'erano le lamponaie una } \\
\text { volta, sul Monte la } \\
\text { Pidocchina, a Pianezzi, Case } \\
\text { Sarti, Cavanna. era pieno, ora } \\
\text { sono scomparse tutte per I } \\
\text { daini... A Lastrone avevano } \\
\text { coltivato tante piante, D'estate } \\
\text { le sue piante facevano fino a } \\
70 \text { kg, Non ci sono piu per } \\
\text { colpa dei cervi, Non ci sono } \\
\text { piu, perché il bosco è } \\
\text { abbandonato, e mangiano tutto } \\
\text { i cervi, Ora ci sono } 90 \% \text { di } \\
\text { menos che prima, Ora non ci }\end{array}$ \\
\hline
\end{tabular}


María Teresa Egea Molines

\begin{tabular}{|c|c|c|}
\hline Especies & $\begin{array}{l}\text { Factores } \\
\text { (interpretados) }\end{array}$ & $\begin{array}{l}\text { Factores percibidos como } \\
\text { causa según la expresión del } \\
\text { informante } \\
\text { sono piu lamponi. }\end{array}$ \\
\hline Rubus ulmifolius Schott & No especificado & $\begin{array}{l}\text { I proniccioni bassi fanno le } \\
\text { spine grosse, fanno dei cesti in } \\
\text { terra, bassi, cesti a modo di } \\
\text { siepe, adesso non ci sono più } \\
\text { come una volta, si vendevano, } \\
\text { era selvatica si trovava da per } \\
\text { tutto. }\end{array}$ \\
\hline Rumex acetosa L. & No especificado & Non ce n`è più. \\
\hline Salix alba L. & $\begin{array}{l}\text { Abandono de las prácticas } \\
\text { agrícolopastorales y forestales } \\
\text { tradicionales }\end{array}$ & $\begin{array}{l}\text { Prima c'era una fila di } \\
\text { borgognoni lungo il corso di } \\
\text { acqua. Ora si è seccato e sono } \\
\text { morti tutti.salici di fiume: ci } \\
\text { sono due varietà; una piu } \\
\text { verde-gialliastro, getti piu } \\
\text { lunghi, meno flessibile, piu } \\
\text { duri.foto dei rami secchi sopra } \\
\text { la legna, albero unico nel } \\
\text { campo lugno corso d'acqua } \\
\text { (perché non si gestisce l'acqua } \\
\text { in modo tradizionale) c'è } \\
\text { rimasto solo uno perch'non c'è } \\
\text { più acqua. Vanno potati tutti } \\
\text { gli anni. }\end{array}$ \\
\hline
\end{tabular}

Salix alba var. vitellina (L.) Abandono de las prácticas Stokes agrícolopastorales y forestales tradicionales

Si usavano i rami giovani, perché ogni anno lo potavano. Ora invece si invecchia, e $1 ' 80 \%$ è sparita e si usano i legacci sintetici... Si riproduce per talea. Zone umede. Erano tenuti alti perché gli animali non li mangiassero.

Salix triandra L.

Abandono de las prácticas agrícolopastorales y forestales tradicionales
Prima c'era una fila di borgognoni lungo il corso di acqua. Ora si è seccato e sono morti tutti. Siccome non possiamo più gestire 1' acqua del torrente come una volta, c'è rimasto solo uno perché non c'è più acqua. Vanno potati tutti gli anni.

Non ci sono più sono 


\begin{tabular}{|c|c|}
\hline Especies & $\begin{array}{l}\text { Factores } \\
\text { (interpretados) }\end{array}$ \\
\hline \multicolumn{2}{|l|}{$\&$ Burdet } \\
\hline $\begin{array}{l}\text { Silene vulgaris (Moench) } \\
\text { Garcke }\end{array}$ & No especificado \\
\hline Sorbus domestica L. & $\begin{array}{l}\text { Abandono de las prácticas } \\
\text { agrícolopastorales y forestales } \\
\text { tradicionales }\end{array}$ \\
\hline
\end{tabular}

Sorbus torminalis (L.) Crantz No especificado

Factores percibidos como causa según la expresión del informante scomparse

Ora ce n'è poca.

Stachys recta L.

No especificado

Si trovavano ai bordi dei campi erano selvatici, e si raccoglievano da per terra, perché diventano degli alberi grandi. Ci mette tanto tempo per fruttificare, e cresce lentamente, ora sta scomparendo perché li tagliano per fare legna da ardere (quando tagliano il bosco) perché non lo conoscono più.

Dice che ce n'è poco.

Ora se ne trova poca e piccola, perché si trovava anche nei terreni arati, se non lavorano più la terra non trova più il suo habitat,più i cinghiali, i daini...hanno rovinato tutto. $\mathrm{Si}$ trova solo a Monte di vigo (Montovolo), in terra povera, rocciosa.

Taraxacum campylodes Introducción y protección de Non si trova più niente. Nel G.E.Haglund (s.1.) animales ungulados por el Parque Regional dopo guerra si andava a cercare I piscialletti. Meno frequente. Ogni anno prende I semi e la risemina dentro al recinto, sennò I cervi mangiano tutta quella spontanea e non ne lasciano nessuna pianta.Dominio delle donne.

Teucrium chamaedrys L. Abandono de las prácticas

Prima ce n'era tanta, la vedevi agrícolopastorales y forestales tradicionales da per tutto, ora non si vede piu, perché adesso è tutto sporco, è tutto un "porchaio",. Ora c'è poca. prima c'era, ora non si trova più. cocciole 
María Teresa Egea Molines

\begin{tabular}{|c|c|c|}
\hline Especies & $\begin{array}{l}\text { Factores } \\
\text { (interpretados) }\end{array}$ & $\begin{array}{l}\text { Factores percibidos como } \\
\text { causa según la expresión del } \\
\text { informante } \\
\text { dell'olmo,conteneva un liquido } \\
\text { con dei moscerini"raccogliere } \\
\text { quando la pianta è matura. Ora } \\
\text { sono morti tutti. }\end{array}$ \\
\hline \multirow[t]{11}{*}{ Vaccinium myrtillus L. } & $\begin{array}{l}\text { Introducción y protección de } \\
\text { animales ungulados por el } \\
\text { Parque Regional }\end{array}$ & $\begin{array}{l}30 \text { anni fa era tutto nero, ora } \\
\text { hanno mangiato tutto cervi e } \\
\text { cinghiali. }\end{array}$ \\
\hline & & $\begin{array}{l}\text { Apportazione vitaminica } \\
\text { durante tutto l' estate, fino alle } \\
\text { castagne. }\end{array}$ \\
\hline & & $\begin{array}{l}\text { I Castagneti di Chiapporato } \\
\text { erano pieni di mirtilli, ora non } \\
\text { più. }\end{array}$ \\
\hline & & $\begin{array}{l}\text { Non ci sono piu per colpa dei } \\
\text { cervi. }\end{array}$ \\
\hline & & $\begin{array}{l}\text { Non ci sono piu, perché il } \\
\text { bosco è abbandonato, e } \\
\text { mangiano tutto i cervi. }\end{array}$ \\
\hline & & $\begin{array}{l}\text { Ora non ce ne sono più ma } \\
\text { prima ce n'erano tanti. }\end{array}$ \\
\hline & & $\begin{array}{l}\text { Ora non ce ne sono più perché } \\
\text { non prendono il sole per il } \\
\text { bosco fitto. }\end{array}$ \\
\hline & & $\begin{array}{l}\text { Prima ce n'erano tantissimi nei } \\
\text { castagneti, pero ora non ci } \\
\text { sono più. }\end{array}$ \\
\hline & & $\begin{array}{l}\text { Prima erano pieni I campi, a } \\
\text { Pianezzi era tutto nero, ora gli } \\
\text { animali selvatici mangiano } \\
\text { tutto. }\end{array}$ \\
\hline & & $\begin{array}{l}\text { Quando I castagneti erano } \\
\text { puliti, ce n'erano tantissimi. }\end{array}$ \\
\hline & & $\begin{array}{l}\text { Si può fare ancora oggi pero } \\
\text { comprando I frutti. }\end{array}$ \\
\hline Valeriana officinalis L. & No especificado & No especificado \\
\hline $\begin{array}{l}\text { Valerianella locusta } \text { (L.) } \\
\text { Laterr. }\end{array}$ & $\begin{array}{l}\text { Abandono de las prácticas } \\
\text { agrícolopastorales y forestales } \\
\text { tradicionales }\end{array}$ & $\begin{array}{l}\text { La maggioranza sono spariti } \\
\text { per vecchiaia. Ora non si } \\
\text { trovano più, qualcuna } \\
\text { nell'orto". Cresce presto verso } \\
\text { marzo, aprile. In tempo di }\end{array}$ \\
\hline
\end{tabular}




\begin{tabular}{|c|c|c|}
\hline Especies & $\begin{array}{l}\text { Factores } \\
\text { (interpretados) }\end{array}$ & $\begin{array}{l}\text { Factores percibidos como } \\
\text { causa según la expresión del } \\
\text { informante } \\
\text { guerra si andava a cercarle } \\
\text { perché non c'era più niente. È } \\
\text { da } 40 \text { anni che non si trova } \\
\text { più, ora si semina e si trova } \\
\text { quella coltivata dentro agli } \\
\text { orti. Non si trovano più } \\
\text { spontanee, ora semmai le } \\
\text { seminano. Non si trovano più } \\
\text { spontanee, ora semmai le } \\
\text { seminano. Prima che facessero } \\
\text { la Centrale nucleare venivano } \\
\text { su come un prato di erba, } \\
\text { come una stessa, } \\
\text { parecchi...ora lo semina però } \\
\text { non vengono bene, e non sono } \\
\text { così saporiti. Prima si } \\
\text { seminavano le patate, poi una } \\
\text { volta raccolte, il grano, dopo } \\
\text { averlo tagliato rimane la } \\
\text { "stoppia" e li crescono i } \\
\text { dolcignoli. Al tempo delle } \\
\text { viole, Aprile-Maggio } \\
\text { raccogliere le foglie di ("bo- } \\
\text { ")concin di agnello.facevano } \\
\text { nei campi ad aprile-maggio. } \\
\text { Quando hanno tagliato il } \\
\text { grano ri raccolgono, ora non } \\
\text { c'è più nessuno che taglia il } \\
\text { grano...però ce n'è ancora. }\end{array}$ \\
\hline Veronica beccabunga L. & Obras públicas recientes & $\begin{array}{l}\text { Ce n'era tanta nella sorgente } \\
\text { "Rovareggia" (a un km di } \\
\text { Camugnano, però è sparito nei } \\
\text { anni } 50 \text { per l'acquedotto, e ora } \\
\text { non ce n'è più crescione. }\end{array}$ \\
\hline Vicia faba L. & $\begin{array}{l}\text { Abandono de las prácticas } \\
\text { agrícolopastorales y forestales } \\
\text { tradicionales }\end{array}$ & $\begin{array}{l}\text { Non li coltivano più come una } \\
\text { volta. }\end{array}$ \\
\hline Viola tricolor L. & $\begin{array}{l}\text { Abandono de las prácticas } \\
\text { agrícolopastorales y forestales } \\
\text { tradicionales }\end{array}$ & $\begin{array}{l}\text { Non fanno più, erano alte } 40 \\
\mathrm{~cm} \text {, facevano in mezzo al } \\
\text { grano, si vedevano da lontano, } \\
\text { Non si trova più, ho visto una } \\
\text { pianta sul lago brasimone. }\end{array}$ \\
\hline
\end{tabular}


Los factores que han provocado la disminución o desaparación según los informantes de éstas plantas se resumen a continuación:

- Muchas de las especies cultivadas ya no se cultivan en el territorio como ciertas variedades de judías, las patatas, etc. Las variedades antiguas de Vicia faba L, Prunus cerasus L., Pyrus communis L., también han disminuido mucho ya que ahora nadie cuida ni poda los pocos ejemplares de la zona, por lo que acaban secando y muriendo, y no se vuelven a cultivar o injertar.

- La introducción, proliferación y protección por parte del Parque de los animales ungulados es un importante factor de extinción de muchas especies según los informantes que están haciendo desaparecer especies como Juniperus communis L., Rubus idaeus L, Lilium bulbiferum L., Lunaria annua L., Vaccinium myrtillus L., Bunium bulbocastanum L.

- El uso y la recolección de ciertas especies estaban asociadas a prácticas agrícolas y pastorales, que con su abandono dichas plantas han desaparecido según la percepción de los informantes, lo cual puede ser cierto o bien puede simplemente que ellos ya no las vean. Es el caso de Brassica rapa L. y Viola tricolor L. que crecían en medio del trigo, o la Matricaria chamomilla L. que crecía en medio del heno, o bien de Carlina acaulis L., Stachys recta L. y Valerianella locusta L. que crecían en los campos arados, fertilizados y trabajados, o Bunium bulbocastanum L. que se encontraba cuando araban los campos.

- El pastoreo difundido en el territorio y la cría de otros animales como las numerosas gallinas, fertilizaban los terrenos, hacían que el castañar estuviera siempre limpio y aireado junto a la gestión tradicional por parte del hombre, el cual también mantenía limpio el sotobosque, y creaban unas condiciones para el crecimiento abundante de especies como Fragaria vesca L., Vaccinium myrtillus L., Carlina acaulis L. En cambio ahora con el abandono de los castañares y la invasión de la vegetación silvestre, muchas especies no encuentran el hábitat y se han vuelto raras.

- Según los informantes las nuevas normativas prohiben la gestión tradicional de las especies fluviales y de los encauzamientos de las aguas para la irrigación tradicional. Esto ha provocado que muchas especies cultivadas en antiguos cauces de regadío tradicional por ejemplo de Salix se sequen y mueran, además de que según ellos den lugar a inundaciones (provocando a su vez la destrucción de la flora fluvial) y a una vegetación fluvial más pobre, inestable y caótica.

- Los derrumbamientos de los terrenos también son considerados como un resultado del abandono de las prácticas agroforestales, del abandono de la gestión tradicional del territorio y de las nuevas políticas de gestión. Estos han hecho desaparecer según los informantes por ejempolo especies de Helichrysum italicum (Roth) G.Don. 
- La reforestaciones de coníferas y su consecuente abandono, han provocado la desaparición de especies como Matricaria chamomilla L., Fragaria vesca L., Vaccinium myrtillus L. que antes abundaban en la zona.

Cabe mencionar, que la mayoría de los usos tradicionales de las plantas estaban relacionados con el modo de vida tradicional y con las prácticas agropastorales tradicionales. Muchas especies se recolectaban mientras hacían otras tareas agrícolas. Puede que el informante ya no vea dicha planta porque ya no camina por el bosque como antes, ya no mira como antes el campo o incluso ya no va hasta los lugares donde solía verlas. Al cambiar la forma de vida, los hábitos y dejar de hacer las actividades que se realizaban en los bosques o en los campos, ya no ven ciertas plantas, con lo cual en su percepción ambiental, han desaparecido.

En los testimonios que se presentan en la Tab. 23 (y en el catálogo etnobotánico) se observa como los propios informantes realizan una labor de conservación de las especies útiles que les interesan para protegerlas de los factores que según ellos hacen desaparecer las especies en su condición de recurso. Las numerosas noticias recogidas sobre la percepción ambiental de las especies útiles, también incluyen informaciones sobre los hábitats idóneos de crecimiento, las gestiónes tradicionales de las plantas y de sus hábitats. En su conjunto, los factores percibidos como amenazas de las especies relacionadas con el pasado, con su vida tradicional y rural, están relacionados con todos los cambios ocurridos en el territorio y en la gestión de este en el periodo moderno. La creación de la Central nuclear, del Centro de investigación ENEA y del Parque Regional, el abandono de las prácticas agricoforestales y las reforestaciones de coníferas y las obras recientes como la creación del acueducto secando antiguos manantiales, son los principales factores que amenazan la biodiversidad útil local. Un factor muy interesante mencionado por los informantes es también el corte indiscriminado de árboles para leña por parte de la población que ya no posee los conocimientos tradicionales sobre la utilidad de las plantas y sobre su ecología, como el caso de Sorbus domestica L. Por ello, numerosos informantes recolectan ciertas especies de interés y las cultivan en sus huertos y jardines para protegerlas y conservarlas, así como para utilizarlas, tenerlas más cercanas o disponibles. Lo cual confirma lo que asegura Albuquerque et al. (2008), es decir que la Etnobotánica y la percepción ambiental local pueden constituir importantes informaciones en las estrategias de bioconservación local.

Las especies con interés etnobotánico que forman parte de las listas sobre de la flora protegida silvestre y rara en Emilia-Romaña a través de la ley regional LR 2/77 (RERAL, 1977) son solo 10 especies (el 3,5\%) que se muestran en la Tab. 24. En lo que concierne la región Toscana, 14 son las especies útiles del Alto valle que están protegidas a través de la ley regional LR 56/2000 (BURT, 2000), y para Dianthus seguieri Vill., Ilex aquifolium L. y Primula vulgaris Huds, está limitada su cosecha según la ley regional mencionada (Foggi et al, 2007). 


\section{María Teresa Egea Molines}

Tab. 24. Especies útiles en la etnobotánica del AVR que están protegidas.

En Emilia-Romaña y en Toscana, con la nomenclatura según Pignatti (1982), como han sido nombradas en las correspondientes leyes.

Especies de la etnoflora (Pignatti, 1982)

Gentiana asclepiadea L.

Gentiana lutea L.

Lilium bulbiferum L. subsp. croceum (Chaix) Baker

Abies alba Miller

Dianthus seguieri Vill.

Gentiana ciliata L.

Ilex aquifolium L.

Orchis morio L.

Phyllitis scolopendrium (L.) Newman

Sempervivum tectorum $\mathrm{L}$.

Asparagus tenuifolius Lam.

Atropa belladona L.

Buxus sempervirens L.

Centaurea cyanus L.

Digitalis lutea L. (s. 1.)

Helleborus viridis L. (s. 1.)

Laurus nobilis L.

Lavandula angustifolia Miller

Loranthus europaeus Jacq.

Stachys recta L.

Viscum album L.

Total

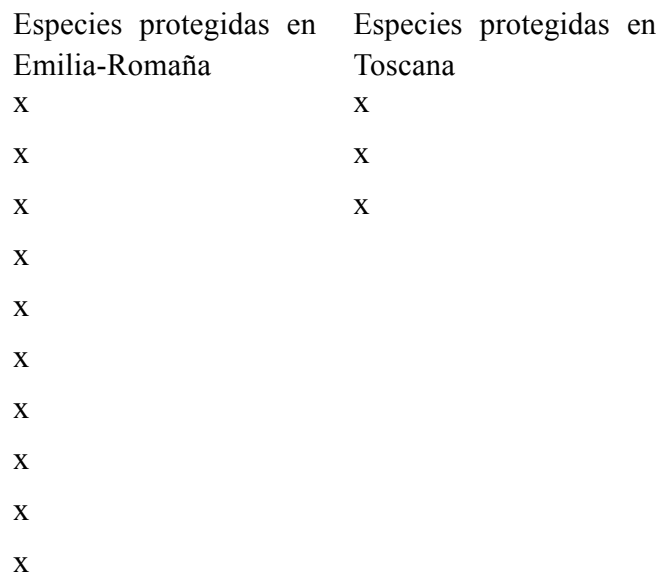

Las únicas especies que están protegidas en Emilia-Romaña y en Toscana contemporáneamente son Gentiana asclepiadea L., Gentiana lutea L. y Lilium bulbiferum L. subsp. croceum (Chaix) Baker.

Dado que no existe un estudio florístico total del territorio estudiado no se puede hacer una comparación entre la etnoflora recogida durante la investigación etnobotánica con la flora relevada por los estudios botánicos, y, por tanto, no se puede realizar el índice de etnobotanicidad (Portéres, 1970). Sin embargo merece la pena notar los pocos casos en los que los informantes conocen especies que no han sido relevadas por los dos estudios botánicos realizados en Le Valli della Limentra Orientale e Limentrella (situada entre Pistoia y Prato, en la parte este del municipio Sambuca Pistoiese) por Venturi 
(2006) y en el Parco dei laghi di Suviana y Brasimone realizo por Sirotti (2005). Resaltan las especies Asparagus tenuifolius Lam. que no ha sido registrado ni por Sirotti (2005) ni por Venturi (2006) pero en cambio es conocida y utilizada por los informantes y cuyo ejemplar (39096 FIAF) fue recogido en Castelluccio (Porretta Terme); Foeniculum vulgare Mill. tampoco ha sido registrado por ambos estudio florísticos, sin embargo los informantes utilizaban la especie y se encontró en Pàvana, el ejemplar 39098 FIAF. Igualmente Diplotaxis tenuifolia (L.) DC no ha sido registrada por los estudios botánicos pero es conocida por los informantes quienes mostraron el ejemplar 38990 FIAF en Pàvana. Otros casos menos concretos se exponen en el Anexo II, sobre especies conocidas por los informantes las cuales, según ellos, crecen en la zona, pero que no han sido registrados por los estudios botánicos. Esto puede ser debido a diferentes motivos: el conocimiento etnobotánico es mayor que el conocimiento formal en esos casos precisos; los estudios botánicos no han sido llevados con profundidad o en la totalidad del territorio; los estudios botánicos no han llevado a cabo el trabajo de campo en las proximidades de las casas, donde en cambio crecen muchas especies de interés etnobotánico, las especies en cuestión crecen en lugares que no interesaban en los estudios botánicos, o las especies conocidas por los informantes ya desaparecieron en la zona cuando los estudios botánicos fueron realizados. 


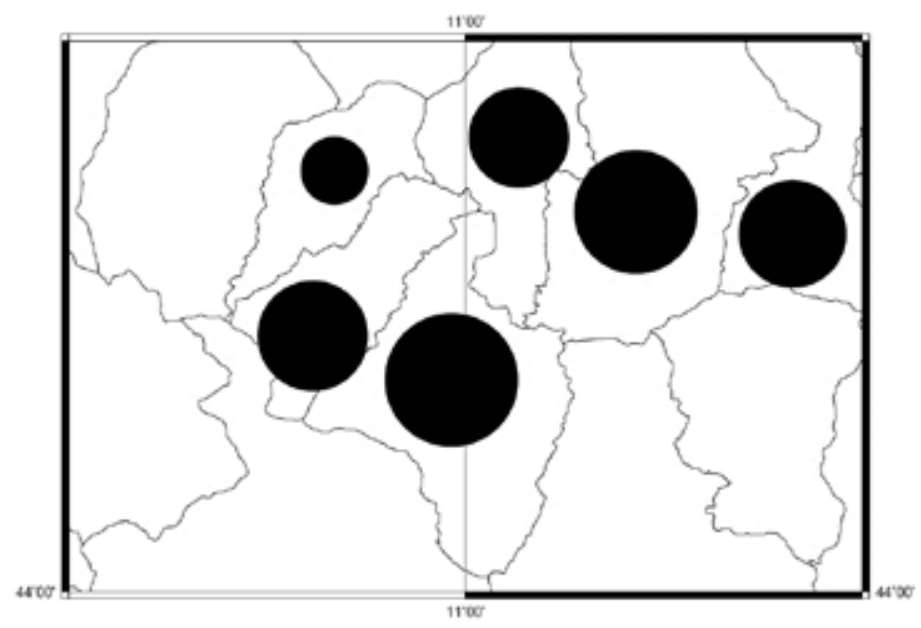

Fig. 19. Mapa del número de especies usadas por municipio.

La superficie del círculo es proporcional al número de especies. En el mapa en la parte superior, de izquierda a derecha: Porretta Terme, Castel di Casio, Camugnano, Castiglione dei Pepoli, en la parte inferior, de izquierda a derecha, Granaglione, Sambuca Pistoiese.

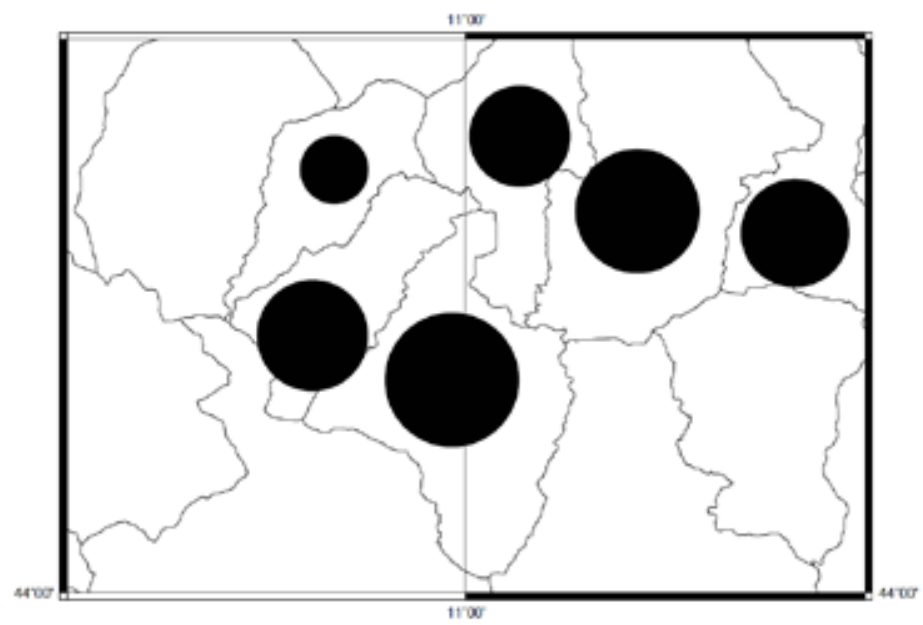

Fig. 20. Mapa del número de citas por municipio.

La superficie del círculo es proporcional al número de citas. En el mapa en la parte superior, de izquierda a derecha: Porretta Terme, Castel di Casio, Camugnano, Castiglione dei Pepoli, en la parte inferior, de izquierda a derecha, Granaglione, Sambuca Pistoiese. 
Etnobotánica en el Alto Valle del Reno (Toscana y Emilia-Romaña, Italia)

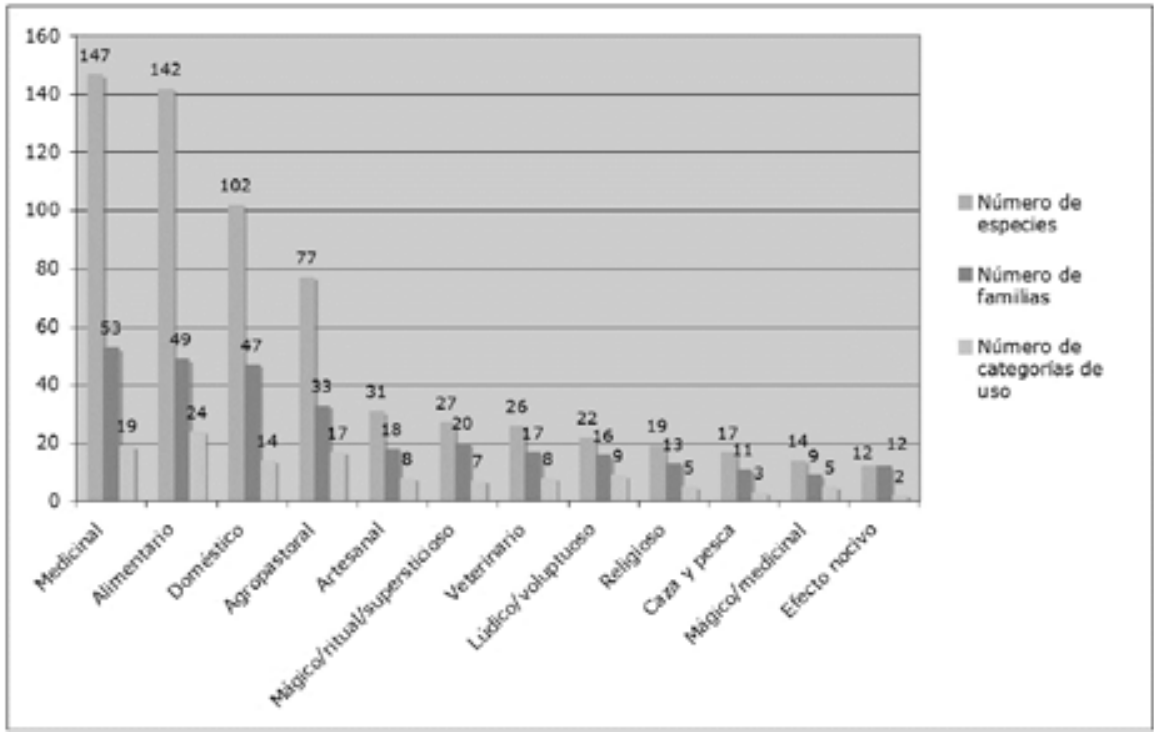

Fig. 21. Importancia relativa de los diferentes sectores de los usos etnobotánicos.

Según el número de especies utilizadas, el número de familias botánicas y el número de categorías de uso aplicadas a cada sector.

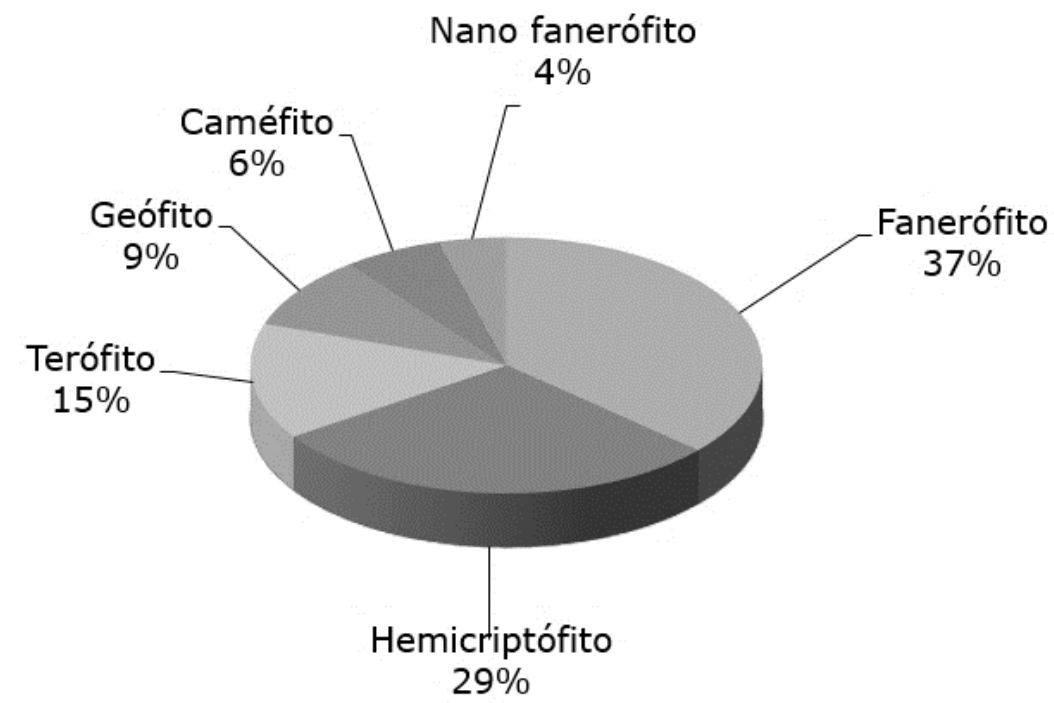

Fig. 22. Tipos biológicos de la etnoflora del AVR 


\section{María Teresa Egea Molines}

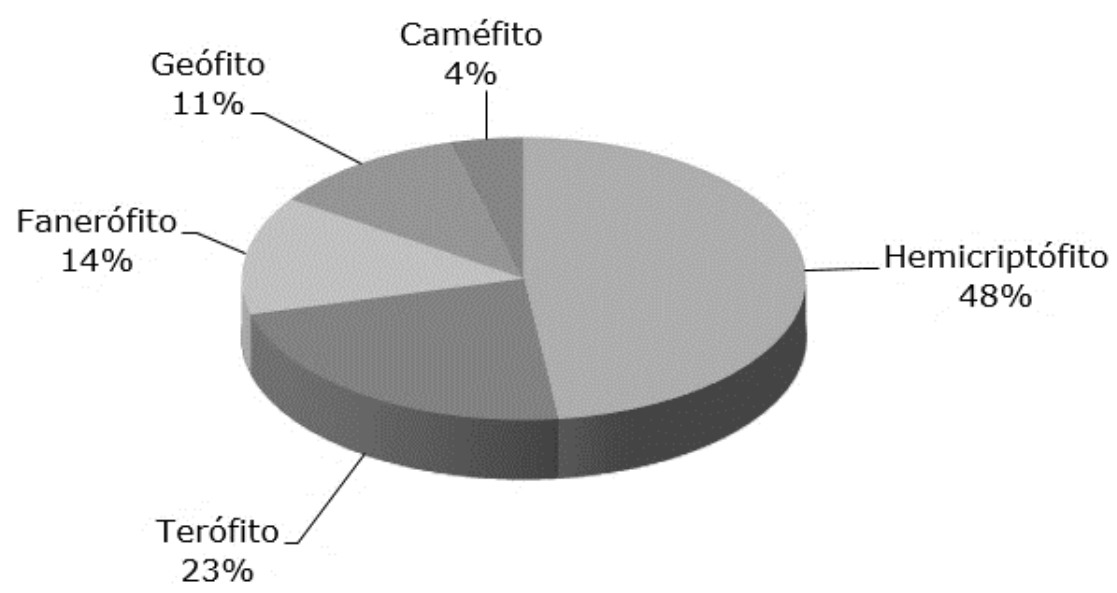

Fig. 23. Tipos biológicos de la flora de Le Valli della Limentra Orientale e Limentrella, y su distribución porcentual (Venturi, 2006).

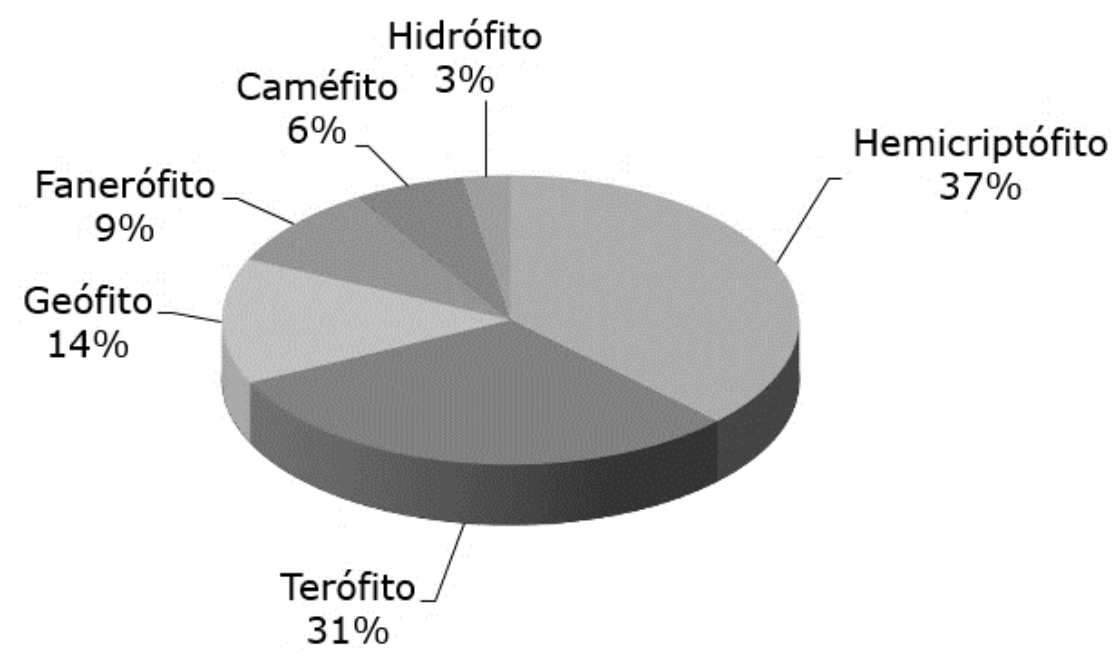

Fig. 24. Tipos biológicos de la flora de Toscana, distribución porcentual. Datos: (Pignatti, 1994). 
Etnobotánica en el Alto Valle del Reno (Toscana y Emilia-Romaña, Italia)

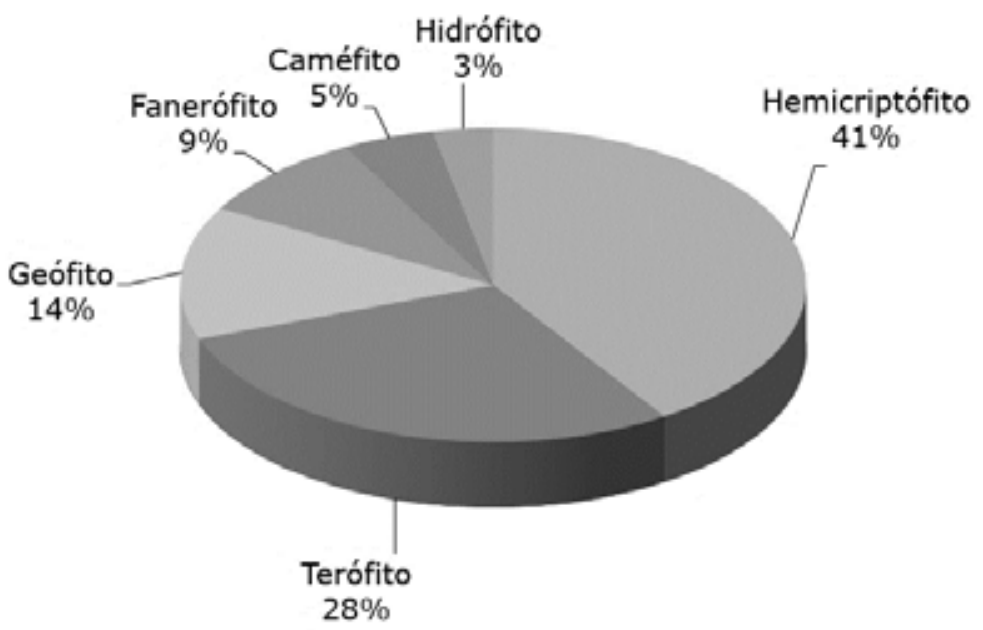

Fig. 25. Tipos biológicos de la flora de Emilia-Romaña, distribución porcentual. Datos: (Pignatti, 1994).

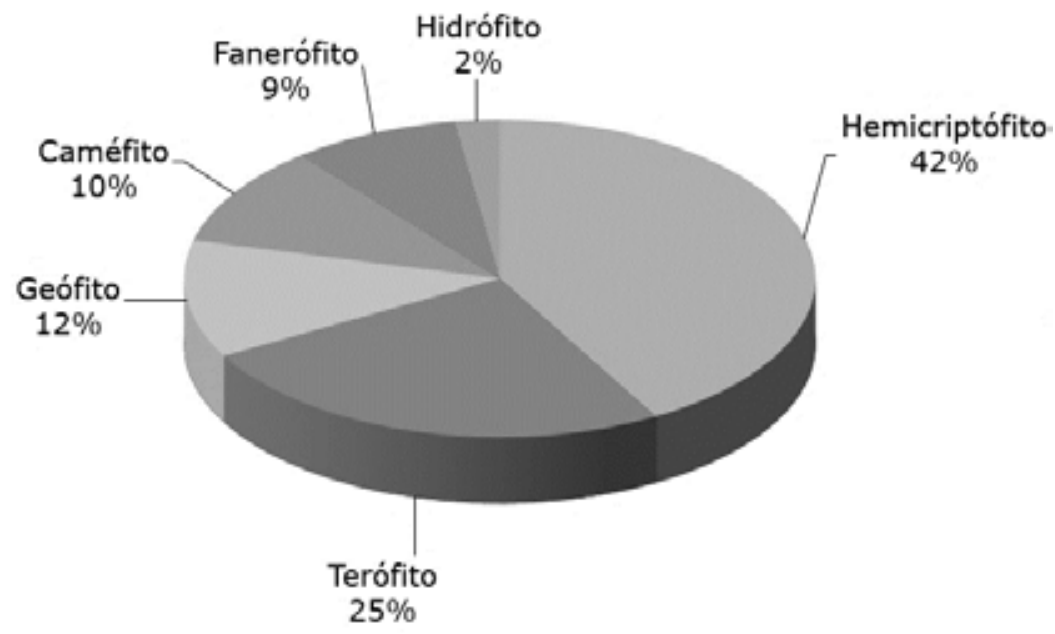

Fig. 26. Tipos biológicos de la flora de Italia, distribución porcentual. Datos: (Pignatti, 1994). 


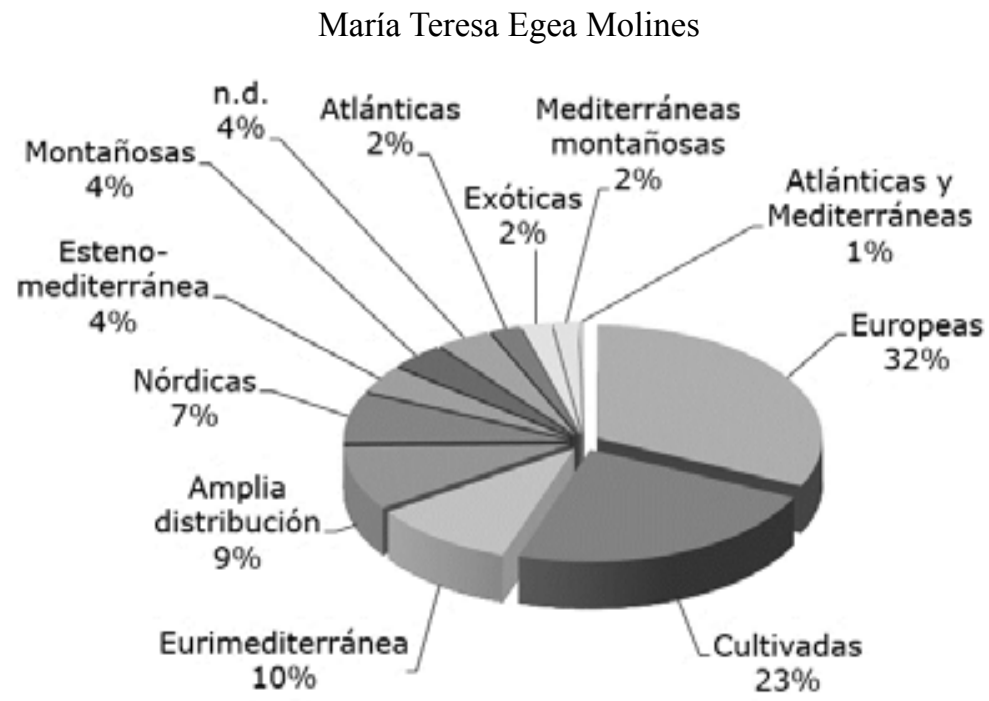

Fig. 27. Espectro corológico de la etnoflora del AVR.

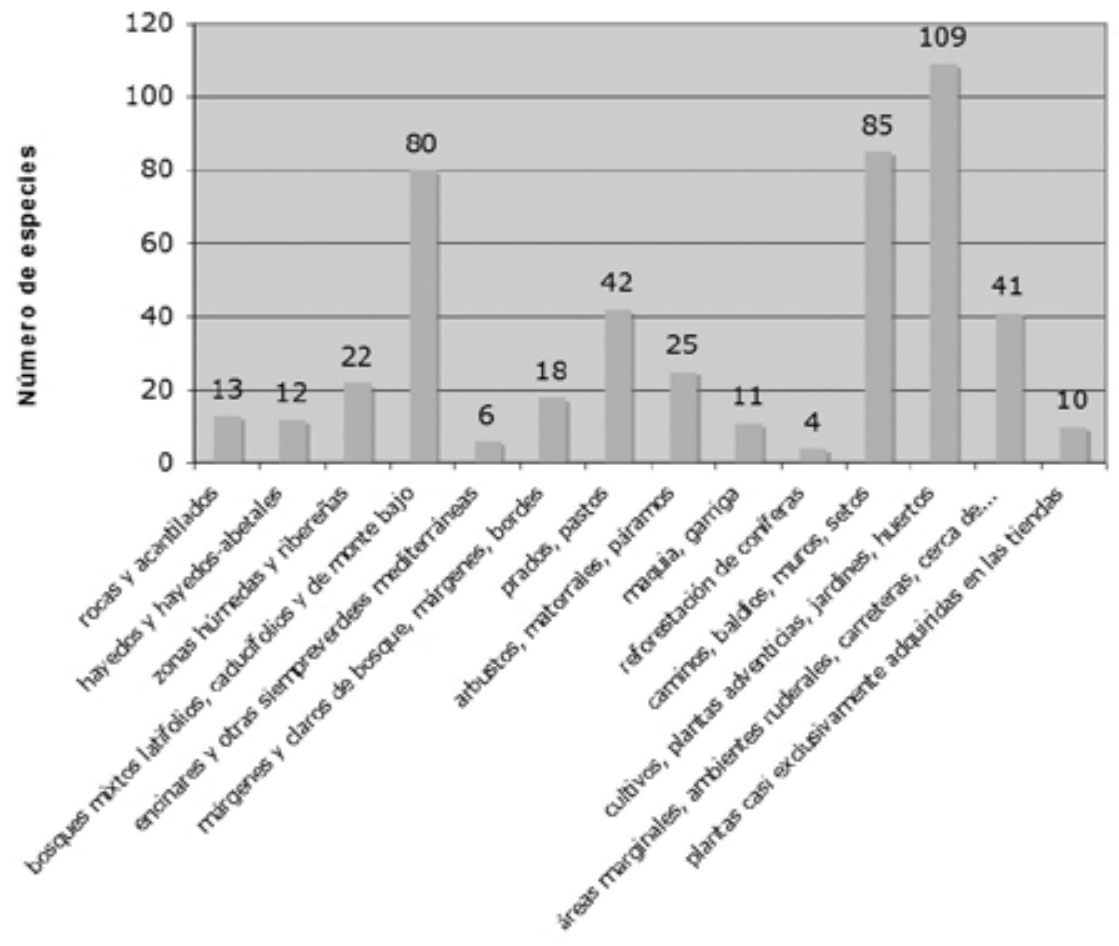

Fig. 28. Ambientes de recolección de plantas de interés en el AVR. 


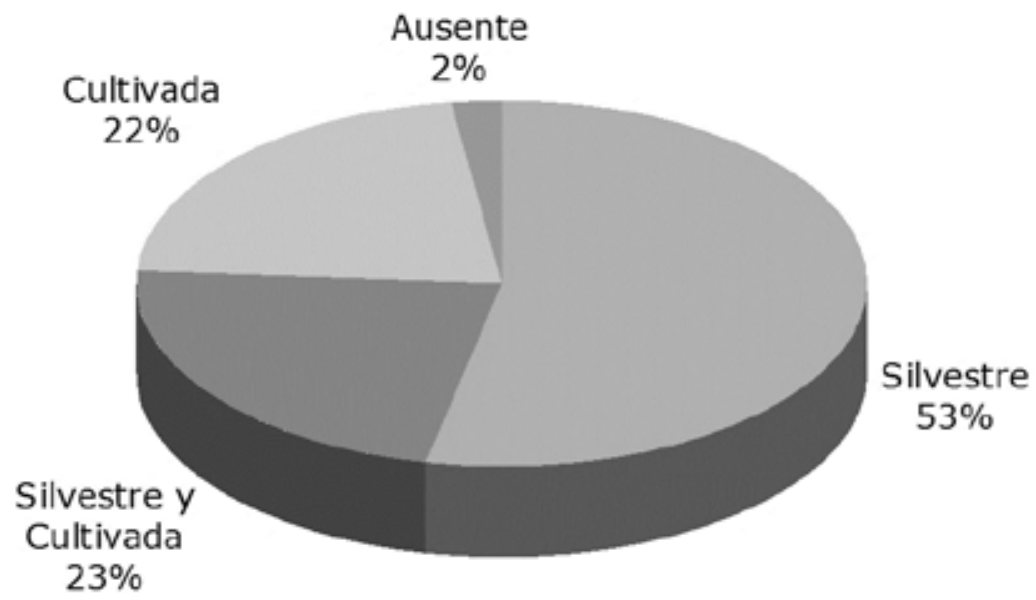

Fig. 29. Distribución de las especies silvestres y cultivadas en la etnoflora.

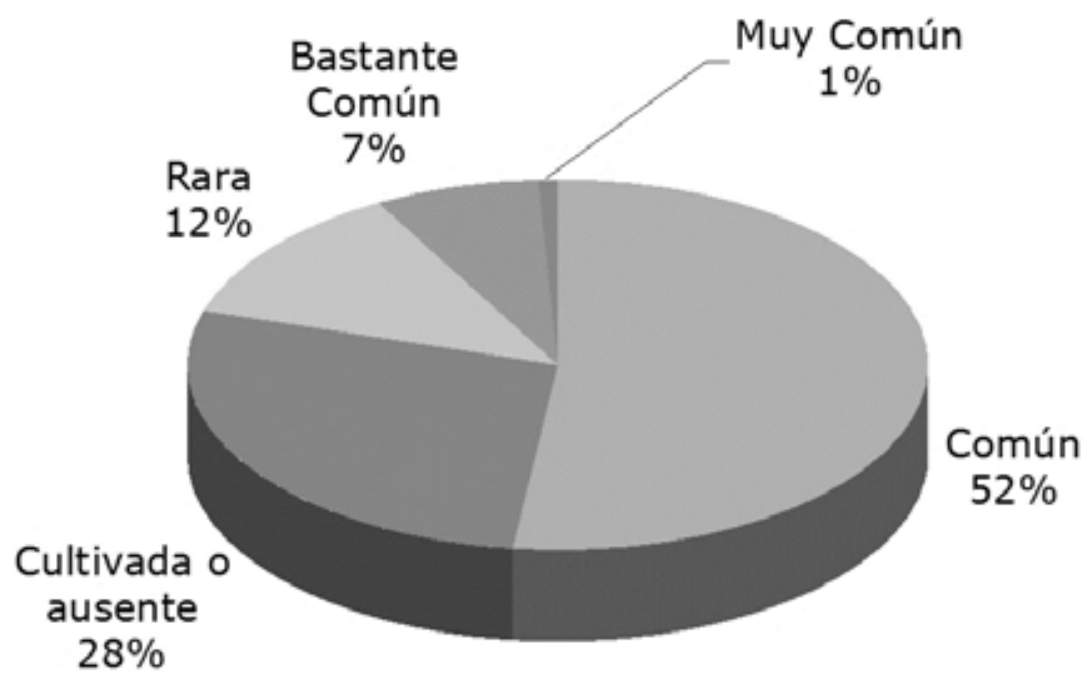

Fig. 30. Frecuencia de la etnoflora en el AVR. Especies silvestres, cultivadas e importadas (ausentes). 


\section{Capítulo 3}

\section{Usos tradicionales por sectores}

Los sectores que se discuten en primer lugar y de manera más profunda son los sectores más importantes y los que están relacionados con éstos es decir: los alimentarios, medicinales, mágico-medicinales y veterinarios. El resto de los sectores han sido analizado en un segundo lugar de forma más general, por orden de importancia es decir, doméstico, agropastoral, artesanal, mágico/ritual/supersticioso, lúdico/voluptuoso, religioso, caza y pesca, efecto nocivo.

\section{Alimentarios}

\subsection{Sistema alimentario tradicional}

La gastronomía del territorio, al igual que el dialecto, está caracterizada por la frontera geográfica entre Emilia-Romaña y Toscana. Los platos característicos muestran tradiciones gastronómicas de ambas regiones, fundiéndose en gustosas contaminaciones. Al lado de las típicas "minestre" emilianas (como se llaman en la zona boloñesa a todos los guisos y pastas, no solo a las sopas como en el resto de Italia), encontramos sopas de cereales o de hojas verdes y carnes de caza aromatizadas con plantas locales, típicos de Toscana, así como los platos a base de castañas y hongos (o funghi) (ERT, 2012). Características de la montaña también son las recetas a base de los productos del sotobosque y la pasta fresca hecha con harina de castaña o de trigo, a las que les añaden plantas silvestres para dar sabor y color o como relleno con el queso fresco local.

Durante las entrevistas realizadas a los informantes y las conversaciones mantenidas con los habitantes del territorio, diferentes son los testimonios sobre la disponibilidad de la comida en los tiempos en los que la gente vivía y dependía de los recursos locales. Algunos sostienen que antes del abandono de la vida rural y de la creación de las vías de comunicación, las personas que disponían de tierra para cultivar (de propiedad pero sobre todo en aparcería) obtenían todos los productos necesarios para una alimentación buena para toda la familia, y tienen muy buenos recuerdos de épocas espartanas pero felices con productos genuinos y de sabores inigualables. En cambio, otros testimonios tienen recuerdos de épocas de mucha hambre, penurias y sufrimiento en las que la alimentación era muy mísera sólo a base de harina de castaña. Ciertos informantes sostienen que dependía sobre todo de 
la accesibilidad a la tierra (geográfica y política) y de la astucia y ganas de trabajar que tuvieran las personas, ya que los recursos naturales existían y eran abundantes pero también implicaban duro trabajo y tanta mano de obra, por eso las familias a veces adoptaban a niños pobres o huérfanos, que podían ayudar en los trabajos agrícolas. Como sostienen Zagnoni y Borghi (2010), una prueba indirecta del hecho de que efectivamente los regímenes alimentarios de la montaña no fueran carentes y míseros, es la fuerte presión demográfica que existía en el territorio, el cual exportó durante siglos hombres y mano de obra hacia la llanura y las ciudades cercanas. La gran población de la montaña que se dio a partir de finales de la Edad Media y su crecimiento rápido, era el resultado de una prevalencia evidente de los nacimientos respecto a las muertes, y esto se debía sin lugar a dudas, a regímenes alimentarios adecuados. Seguramente la imagen que daba la montaña de pobre y mísera a los ciudadanos y campesinos de la colina se debía más bien al tipo de vestidos, la modestia de las casas y el difundido analfabetismo, es decir, de aquello que no se encontraban en la montaña y que los habitantes de ésta no podían comprar por falta de dinero, pero seguramente no por la calidad y abundancia de comida y recursos alimentarios (Zagnoni y Borghi, 2010).

Fue durante los siglos XII y XIII hasta el siglo XIX, con el aumento de la población y la exigencia de aumentar las producciones locales destinadas a la alimentación, que el cultivo de la castaña se difundió en la montaña de toda Italia. Fue durante ese periodo que las castañas conquistaron un rol totalmente protagonista en los regímenes alimentarios de la montaña sustituyendo e integrando a los cereales. En el Alto Valle del Reno, se denominaba "pan di legno" que junto al "vin di nuvoli", el poco vino cultivado en las limitadas zonas del territorio, proporcionaban el alimento básico de los habitantes de la montaña durante muchos meses. Las castañas secas, transformadas en harina, proporcionaban la materia prima para los "necci", "polente", y "castagnacci" que eran la base de la alimentación de los habitantes de la montaña (Zagnoni y Borghi, 2010). Los usos alimentarios típicos del AVR han sido ampliamente documentados en la literatura local desde todos sus aspectos, sobre la cual encontramos la siguiente poesía que resume los múltiples usos alimentarios que se le otorgaba en AVR a la castaña, en Zagnoni y Borghi (2010), extraído de Roda (1989):

"E bella la castagna!

E liscia e ben vestita

è un frutto di montagna é dolce e saporita.

Se vien dalla pignatta

col nome di ballotta

per tutti i denti è fatta

perché nell'acqua è cotta.

Se vien dalla padella

col nome di frugiata

la castagnetta bella

é subito sbucciata.

Se viene dal paiolo

col nome di mondina

va giù come di volo 
e tutta si sfarina.

Insomma in tutti i modi

si mangia la castagna cantiamo pur le lodi

al frutto della montagna."

Desde la recogida de las castañas y la molienda de la harina de castañas, los habitantes se alimentaban durante todo el invierno a base de productos de harina de castañas, pero también maíz, muy poco trigo y centeno, junto con alguna conserva de verduras, judías secas y patatas de la última cosecha, hasta que se acabaran. Cada familia, tenía un huerto, en el que en invierno podían todavía recolectar coles y nabos. La fruta era seleccionada según las variedades, y algunos sostienen que existían variedades de peras y manzanas que maduraban en todos los meses del año, por esto siempre tenían fruta en casa. Otras especies como Sorbus domestica L. y Mespilus germanica L., se recolectaban e iban madurando poco a poco y muchos otros frutos eran secados para poder consumirlos durante el escaso periodo invernal (como higos, uva, melocotones y frutos de Cornus mas L.). Además se hacían muchas mermeladas y conservas de frutas silvestres y domésticas para poder consumirlas durante el invierno. A partir de la primavera con el crecimiento de las primeras hojas verdes de las plantas silvestres, la dieta familiar se complementaba con sopas, tortas saladas, ensaladas y verduras cocidas a base de plantas silvestres y de plantas que crecían en el huerto. Todos concebían las plantas silvestres como elementos depurativos después de tantos meses de inviernos a base de harinas. Durante el verano, había más frutas y los huertos daban de sí bastante producción para satisfacer las necesidades de cada familia. Los informantes cuentan que las personas estaban todo el día comiendo frutas, flores, brotes, incluso trozos de cortezas que encontraban mientras trabajaban en los campos, mientras caminaban y como pasatiempo. Además eran muy importante los frutos del bosque, que incluso cultivaban en los huertos, como fuente principal de vitaminas. Según los testimonios, en verano comían, lo más posible, frutos rojos para prepararse para la dieta más rígida invernal. Era muy común conservar la abundante fruta de verano en forma de licores o conservas de frutas de diferentes tipos, para poder consumirlos durante el invierno.

La alimentación tradicional era cíclica como las estaciones y dependía totalmente de los productos que las plantas locales podían proporcionar. Cada familia poseía animales, por lo general, ovejas y cabras, que integraban el sistema alimentario local con productos lácteos, pero también vacas, cerdos, conejos y gallinas, que eran el suplemento cárnico de la dieta familiar, siempre aromatizados con las plantas locales, al igual que la carne de caza. Con la presencia de la ganadería difundida y la abundancia de salvajina las familias se procuraban una gran variedad de encurtidos típicos de la montaña (Zagnoni y Borghi, 2010). El queso curado y fresco también acompañaba las castañas, los cereales y las legumbres, la pasta, las ensaladas y las verduras cocidas. Las recetas recogidas durante las entrevistas tienen una característica común: son recetas muy poco elaboradas en las que la combinación de ingredientes cárnicos, lácteos y vegetales es muy escasa. Respecto al estudio de la alimentación tradicional del AVR, resalta el profundo estudio sobre la alimentación de la montaña tosco-boloñesa a base de los recursos naturales desde la Edad Media hasta la Edad Moderna, de Zagnoni y Borghi (2010), 
además del estudio realizado a base de entrevistas a los familiares de la escuela de Grizzana Morandi sobre la alimentación tradicional a base de plantas locales (ICGM, 2003), y las recetas tradicionales escritas por los habitantes en Badi (2015).

Han sido analizadas las plantas silvestres utilizadas para fines alimenticios así como las cultivadas sólo si son utilizadas para usos diferentes para los cuales son cultivados normalmente (por ejemplo, en el caso de la vid, cultivada para hacer vino, el uso tradicional del vino no es considerado, o bien los tomates cultivados en el huerto para comer las bayas crudas y condimentadas o para hacer la salsa de tomate tampoco es considerado). De ésta manera se ha documentado la fitoalimurgia del Alto Valle del Reno, es decir las ciencias que nacen del empirismo del hombre, guiado por el instinto de la supervivencia, del estrecho contacto con la naturaleza y con sus potenciales recursos vegetales (Camangi et al., 2013). Las plantas cultivadas en los huertos o compradas en los mercados para usos alimentarios no han sido objeto de estudio, ya que necesitarían una metodología diferente y estudios más específicos, como se ha explicado anteriormente. Han sido registrados 1455 citas relativas a 142 especies botánicas (50,5\% de las especies de interés etnobotánico), pertenecientes a 49 familias. Han sido recogidos 325 usos alimentarios diferentes, clasificados en 24 categorías en las que se incluyen los usos aromáticos y de licorería, golosinas y masticatorias entre muchos otros.

\subsection{Partes usadas}

Las partes de las plantas más utilizadas para fines alimenticios son al igual que en otras zonas como en el Nordeste de Portugal (Carvalho, 2005) o bien en la provincia de Bolonia (Sansanelli y Tassoni, 2014) las hojas (47\%) y los frutos (27\%). Las partes más utilizadas en el AVR coinciden totalmente con los resultados del estudio de Sansanelli y Tassoni (2014): hojas, frutos, brotes y flores. A menudo no se utiliza sólo una parte de la planta sino que se combinan varias partes de las plantas para el mismo uso alimentario o para usos alimentarios diferentes. Sobre todo las hojas se utilizan junto a todo tipo de órganos como con los brotes, órganos subterráneos, flores, tallos herbáceos, frutos y semillas (Fig. 33).

\subsection{Familias botánicas con usos alimentarios}

Las 142 especies usadas para la alimentación tradicional en el AVR pertenecen a 49 familias. Rosaceae es la familia que más especies alimentarias incluye con un total de 33 especies botánicas (el 23,23\% de las especies alimentarias citadas), seguidas de Compositae con 17 especies (11,97\% de las especies alimentarias citadas), Lamiaceae con 7 especies (4,92\% de las especies alimentarias citadas), Fagaceae con 6 especies (4,22\% de las especies alimentarias citadas) y Leguminosae con 4 especies (2,81\% de las especies alimentarias citadas) (Tab. 25). 


\section{María Teresa Egea Molines}

Tab. 25. Familias botánicas utilizadas con fines alimentarios.

Ordenadas por el número de especies utilizadas. El número de citas registradas y el número de informantes que las han citado (por orden decreciente del número de especies, del número de citas y del número de informantes)

\begin{tabular}{|c|c|c|c|c|c|c|}
\hline Familias & $\begin{array}{l}\text { Número } \\
\text { de } \\
\text { especies }\end{array}$ & \% Especies & $\begin{array}{l}\text { Número de } \\
\text { citas }\end{array}$ & $\%$ de las citas & $\begin{array}{l}\text { Número de } \\
\text { informantes }\end{array}$ & $\begin{array}{l}\% \text { de } \\
\text { informantes }\end{array}$ \\
\hline Rosaceae & 33 & 23,23 & 274 & 18,83 & 79 & 69,91 \\
\hline Compositae & 17 & 11,97 & 354 & 24,32 & 83 & 73,45 \\
\hline Lamiaceae & 7 & 4,92 & 32 & 2,19 & 25 & 22,12 \\
\hline Fagaceae & 6 & 4,22 & 26 & 1,78 & 20 & 17,69 \\
\hline Leguminosae & 4 & 2,81 & 24 & 1,64 & 22 & 19,46 \\
\hline Apiaceae & 4 & 2,81 & 22 & 1,51 & 20 & 17,69 \\
\hline Poaceae & 4 & 2,81 & 14 & 0,96 & 13 & 11,50 \\
\hline Vitaceae & 4 & 2,81 & 6 & 0,41 & 6 & 5,30 \\
\hline Plantaginaceae & 3 & 2,11 & 20 & 1,37 & 16 & 14,15 \\
\hline Rutaceae & 3 & 2,11 & 17 & 1,16 & 14 & 12,38 \\
\hline Brassicaceae & 3 & 2,11 & 8 & 0,54 & 5 & 4,42 \\
\hline Amaranthaceae & 3 & 2,11 & 6 & 0,41 & 4 & 3,53 \\
\hline Caryophyllaceae & 2 & 1,40 & 82 & 5,63 & 48 & 42,47 \\
\hline Caprifoliaceae & 2 & 1,40 & 58 & 3,98 & 53 & 46,90 \\
\hline Polygonaceae & 2 & 1,40 & 38 & 2,61 & 30 & 26,54 \\
\hline Ericaceae & 2 & 1,40 & 31 & 2,13 & 20 & 17,69 \\
\hline Lauraceae & 2 & 1,40 & 28 & 1,92 & 22 & 19,46 \\
\hline Adoxaceae & 2 & 1,40 & 20 & 1,37 & 15 & 13,27 \\
\hline Boraginaceae & 2 & 1,40 & 12 & 0,82 & 8 & 7,07 \\
\hline Asparagaceae & 2 & 1,40 & 7 & 0,48 & 5 & 4,42 \\
\hline Gentianaceae & 2 & 1,40 & 6 & 0,41 & 4 & 3,53 \\
\hline Betulaceae & 2 & 1,40 & 5 & 0,34 & 5 & 4,42 \\
\hline Pinaceae & 2 & 1,40 & 4 & 0,27 & 4 & 3,53 \\
\hline Equisetaceae & 2 & 1,40 & 4 & 0,27 & 2 & 1,76 \\
\hline Orchidaceae & 2 & 1,40 & 3 & 0,20 & 3 & 2,65 \\
\hline Violaceae & 2 & 1,40 & 3 & 0,20 & 3 & 2,65 \\
\hline Urticaceae & 1 & 0,70 & 89 & 6,11 & 52 & 46,01 \\
\hline Ranunculaceae & 1 & 0,70 & 87 & 5,97 & 68 & 60,17 \\
\hline Juglandaceae & 1 & 0,70 & 29 & 1,99 & 26 & 23,00 \\
\hline Primulaceae & 1 & 0,70 & 28 & 1,92 & 22 & 19,46 \\
\hline Cornaceae & 1 & 0,70 & 26 & 1,78 & 20 & 17,69 \\
\hline
\end{tabular}


Etnobotánica en el Alto Valle del Reno (Toscana y Emilia-Romaña, Italia)

\begin{tabular}{lllllll}
\hline Familias & $\begin{array}{l}\text { Número } \\
\text { de }\end{array}$ & \% Especies & $\begin{array}{l}\text { Número de } \\
\text { citas }\end{array}$ & \% de las citas & $\begin{array}{l}\text { Número de } \\
\text { informantes }\end{array}$ & $\begin{array}{l}\text { \% de } \\
\text { informantes }\end{array}$ \\
& 1 & & & & 17 & 15,04 \\
Cupressaceae & 1 & 0,70 & 20 & 1,37 & 17 & 15,04 \\
Campanulaceae & 1 & 18 & 1,23 & 11 & 9,73 \\
Polypodiaceae & 1 & 0,70 & 11 & 0,75 & 8 & 7,07 \\
Myrtaceae & 1 & 0,70 & 10 & 0,68 & 6,30 \\
Cannabaceae & 1 & 0,70 & 7 & 0,48 & 6 & 3,53 \\
Amaryllidaceae & 1 & 0,70 & 4 & 0,27 & 4 & 2,65 \\
Solanaceae & 1 & 0,70 & 4 & 0,27 & 3 & 2,65 \\
Iridaceae & 1 & 0,70 & 3 & 0,20 & 3 & 2,65 \\
Verbenaceae & 1 & 0,70 & 3 & 0,20 & 3 & 1,76 \\
Malvaceae & 1 & 0,70 & 2 & 0,13 & 2 & 1,76 \\
Papaveraceae & 1 & 0,70 & 2 & 0,13 & 2 & 1,76 \\
Theaceae & 1 & 0,70 & 2 & 0,13 & 2 & 1,76 \\
Dennstaedtiaceae & 1 & 0,70 & 1 & 0,06 & 2 & 0,88 \\
Aquifoliaceae & 1 & 0,70 & 1 & 0,06 & 1 & 0,88 \\
Buxaceae & 1 & 0,70 & 1 & 0,06 & 1 & 0,88 \\
Crassulaceae & 1 & 0,70 & 1 & 0,06 & 1 & 0,88 \\
Oleaceae & 1 & 0,70 & 1 & 0,06 & 1 & 0,88 \\
Rubiaceae & 1 & 0,70 & 1 & 0,06 & 1 & \\
\hline
\end{tabular}

Considerando las mismas informaciones reveladas en Camangi et al. (2013) sobre las plantas prevalentemente silvestres utilizadas en la fitoalimurgia de Italia, vemos como en la presente investigación han sido recogidas la mitad del total de las familias utilizadas en toda Italia para fines alimenticios (49 familias en el AVR y 98 familias en Italia). Las familias más importantes en cuanto al número de especies para usos alimentarios en el AVR no corresponden con el orden de importancia a nivel italiano (Tab. 26). En Camangi et al. (2013) se asegura que existe una gran diferencia entre el Norte y el Sur de Italia: en la primera prevalecen Rosaceae y en la segunda en cambio, Compositae, Brassicaceae y Liliaceae. Por esto podemos constatar que el uso de las plantas alimentarias en la tradición del AVR en cuanto a las familias botánicas corresponde a la cultura fitoalimúrgica del Norte de Italia. De hecho, comparando el orden de importancia de las familias con usos alimentarios en el AVR vemos como coincide con el estudio etnobotánico realizado por Sansanelli y Tassoni (2014) en la provincia de Bolonia, en los que igual que en este estudio las familias con más especies con usos alimentarios son las Rosaceae (14 especies), Compositae (9 especies) y Lamiaceae ( 7 especies, exactamente igual que en el AVR). Destaca el alto consumo de especies de las familias Fagaceae y Rosaceae con 
respecto a Italia, así como el escaso consumo de Brassicaceae respecto al resto de Italia.

Tab. 26. Las familias de plantas en las tradiciones fitoalimúrgicas italianas.

Número de especies y porcentaje del total. Datos de (Camangi et al., 2013)

\begin{tabular}{lll}
\hline Familias & Número de especies & Porcentaje \\
Compositae & 156 & $18,80 \%$ \\
Brassicaceae & 62 & $7,50 \%$ \\
Rosaceae & 56 & $6,80 \%$ \\
Labiatae & 55 & $6,60 \%$ \\
Leguminosae & 49 & $5,90 \%$ \\
Apiaceae & 47 & $5,70 \%$ \\
Liliaceae & 38 & $4,60 \%$ \\
Poaceae & 21 & $2,50 \%$ \\
Chenopodiaceae & 21 & $2,50 \%$ \\
Polygonaceae & 18 & $2,20 \%$ \\
Boraginaceae & 14 & $1,70 \%$ \\
Rutaceae & 12 & $1,40 \%$ \\
Otras & 279 & $33,70 \%$ \\
\hline
\end{tabular}

Casi la mitad de las familias (23 familias botánicas, 46,93\%) representan una sola especie como Urticaceae, Ranunculaceae, Juglandaceae, Primulaceae, Cornaceae, Malvaceae. Como sucede en el estudio etnobotánico de Carvalho (2005) en el Nordeste de Portugal, es curioso notar como varias de las familias alimentarias que incluyen solo una especie, constituyen las familias más citadas, como Urticaceae (89 citas, 6,11\% de las citas relativas a los usos alimentarios), Ranunculaceae (87 citas, 5,97\% de las citas relativas a los usos alimentarios) o Juglandaceae (29 citas, 1,99\% de las citas relativas a los usos alimentarios).

Sin embargo, las familias más conocidas son Compositae (354 citas, 24,32\%) Rosaceae (274 citas, 18,83\%), Urticaceae (89 citas, 6,11\%) y Ranunculaceae (82 citas, 5,63\%), e igualmente, las más populares en cuanto al número de informantes que las citan son Compositae (83 informantes, $73,45 \%$ de los informantes) y Rosaceae (79 informantes, 69,91\% de los informantes) pero las siguen Ranunculaceae (68 informantes, 60,17\%), Caprifoliaceae (53 informantes, 46,90\%). 


\subsection{Especies alimentarias más citadas, más populares, más versátiles}

Casi la totalidad de los informantes entrevistados (108 informantes, 95,57\% de los informantes totales) han citado al menos una especie alimentaria. De las 142 especies citadas con usos alimentarios tradicionales, el 32,39\% (46 especies) han sido citadas solo por un informante y el $17,60 \%$ han sido citadas solo por dos informantes. Esto denota una vez más que el conocimiento sobre el uso tradicional de las plantas para fines alimentarios es muy heterogéneo. Además 59,25\% (64 informantes) de los informantes que citaron usos alimentarios a base de plantas son mujeres, y 40,74\% eran hombres, lo cual muestra que al contrario de lo que se puede pensar generalmente, los hombres tienen una participación importante en el uso tradicional de las plantas para fines alimentarios.

En la Tab. 27 se puede apreciar como las mujeres (116) saben poco más que los hombres (103) en cuanto a número de especies, sin embargo en cuanto al número de citas, el de las mujeres casi duplica al de los hombres. En la Tab. 28 vemos como existen diferencias en el orden de importancia entre las categorías alimentarios, en las que generalmente las mujeres saben más que los hombres incluso en los licores (para el que las mujeres han proporcionado 122 citas respecto a las 36 de los hombres). Los hombres conocen más golosinas, quizás por estar más tiempo en el campo.

Tab. 27. Distribución del conocimiento fitoalimúrgico entre los informantes.

Según el sexo.

\begin{tabular}{llll}
\hline Sexo & Número de especies & Número de citas & Número de categorías \\
Hombres & 103 & 549 & 22 \\
Mujeres & 116 & 906 & 24 \\
\hline
\end{tabular}

Tab. 28. Importancia de las categorías alimentarias en función del sexo.

\begin{tabular}{llll}
\hline $\begin{array}{l}\text { Categorías alimentarias } \\
\text { Hombres }\end{array}$ & $\begin{array}{l}\text { Número de } \\
\text { citas }\end{array}$ & $\begin{array}{l}\text { Categorías alimentarias } \\
\text { Mujeres }\end{array}$ & $\begin{array}{l}\text { Número } \\
\text { de citas }\end{array}$ \\
Ensalada & 82 & Ensalada & $\begin{array}{l}\text { Mujeres } \\
\text { Verdura cocida }\end{array}$ \\
Golosinas y masticatorias & 80 & Verdura cocida & 132 \\
Tortilla & 71 & Licor & 122 \\
Aromatizante & 52 & Tortilla & 73 \\
Licor & 37 & Golosinas y masticatorias & 62 \\
Mermelada & 36 & Conserva de frutas & 44 \\
Conserva de frutas & 34 & Aromatizante & 43 \\
Fruta fresca & 29 & Mermelada & 39 \\
\hline
\end{tabular}


María Teresa Egea Molines

\begin{tabular}{llll}
\hline Pasta y "gnocchi" & 15 & Pasta y "gnocchi" & 29 \\
Sopas de verduras y potaje & 14 & Fruta fresca & 26 \\
Fruta seca & 12 & Sopas de verduras y potaje & 23 \\
Relleno de ravioli & 12 & Arroces y "risotto" & 22 \\
Arroces y "risotto" & 11 & Fritura & 18 \\
Fritura & 10 & Dulces y golosinas & 14 \\
Sucedáneo del café & 10 & Bebida & 13 \\
Bebida & 9 & Sucedáneo del café & 12 \\
Dulces y golosinas & 6 & Fruta seca & 10 \\
Otro alimentario & 5 & Otro alimentario & 9 \\
Pan y similares & 2 & Empanadas & 5 \\
Verdura cruda & 2 & Pan y similares & 4 \\
Encurtidos y conserva en aceite & 1 & Encurtidos y conserva en aceite & 1 \\
& & Gachas o polenta & 1 \\
& & Verdura cruda & 1 \\
\hline
\end{tabular}

En la Tab. 29 se exponen las 30 especies más importantes según el número de categorías alimentarias. Se observa como las plantas más conocidas (según los criterios del número de citas y el número de informantes que las citan, aunque en distinto orden) son Taraxacum campylodes G.E.Haglund (s.1.), Sonchus oleraceus (L.) L. (s.1.), Urtica dioica L., Clematis vitalba L., Silene vulgaris (Moench) Garcke, Valerianella locusta (L.) Laterr., Crepis vesicaria L, Cichorium intybus L. y Rubus ulmifolius Schott.

Sin embargo en cuanto a la versatilidad de las especies, todas mantienen los primeros rangos de importancia menos Valerianella locusta (L.) Laterr. que tan solo es usada en dos categorías diferentes como "ensalada" y como "sopas de verdura y potaje".

Las especies alimentarias más importantes en el AVR corresponden a las típicas especies utilizadas tanto en el sur de Italia como en el Norte de Italia (Ghirardini et al., 2007). En cambio, en el mismo trabajo sostienen que Borago officinalis L. es el taxón más citado en toda Italia, lo cual no coincide con las características fitoalimúrgicas del Alto Valle del Reno, en el que sólo ha aparecido en 9 citas $(0,61 \%$ de las citas totales sobre usos alimentarios en el AVR).

Tab. 29. Especies alimentarias en la tradición del AVR.

Las 30 especies más importantes según el número de categorías utilizadas, el número de citas y el número de informantes

\begin{tabular}{llll}
\hline Especies botánicas & $\begin{array}{l}\text { Número de } \\
\text { categorías }\end{array}$ & $\begin{array}{l}\text { Número de } \\
\text { citas }\end{array}$ & $\begin{array}{l}\text { Número de } \\
\text { informantes }\end{array}$ \\
Silene vulgaris (Moench) Garcke & 9 & 81 & 48 \\
Urtica dioica L. & 8 & 89 & 52 \\
Clematis vitalba L. & 8 & 87 & 68 \\
\hline
\end{tabular}




\begin{tabular}{|c|c|c|c|}
\hline Rubus ulmifolius Schott & 8 & 38 & 31 \\
\hline Taraxacum campylodes G.E.Haglund (s.1.) & 7 & 112 & 64 \\
\hline Sonchus oleraceus (L.) L. (s. 1.) & 7 & 91 & 53 \\
\hline Rubus idaeus L. & 7 & 35 & 24 \\
\hline Vaccinium myrtillus L. & 7 & 30 & 20 \\
\hline Prunus avium (L.) L. & 7 & 22 & 18 \\
\hline Cornus mas L. & 6 & 26 & 20 \\
\hline Sambucus nigra L. & 6 & 19 & 15 \\
\hline Cichorium intybus L. & 5 & 59 & 37 \\
\hline Primula vulgaris Huds. & 5 & 28 & 22 \\
\hline Rosa canina L. (s. 1.) & 5 & 25 & 21 \\
\hline Prunus spinosa L. & 5 & 22 & 21 \\
\hline Fragaria vesca L. & 5 & 17 & 15 \\
\hline Rosa cv. & 5 & 10 & 6 \\
\hline Crepis vesicaria $\mathrm{L}$. & 4 & 47 & 29 \\
\hline Juglans regia L. & 4 & 29 & 26 \\
\hline Prunus cerasus L. & 4 & 28 & 23 \\
\hline Citrus limon (L.) Osbeck & 4 & 15 & 13 \\
\hline Carduus nutans L. (cfr.) & 4 & 10 & 22 \\
\hline Carlina acaulis L. & 4 & 7 & 7 \\
\hline Malus sylvestris (L.) Mill. & 4 & 6 & 5 \\
\hline Asparagus tenuifolius Lam. & 4 & 6 & 4 \\
\hline Robinia pseudoacacia L. & 3 & 17 & 16 \\
\hline Veronica beccabunga L. & 3 & 15 & 13 \\
\hline Polypodium vulgare L. (s. 1.) & 3 & 11 & 11 \\
\hline Sorbus aria (L.) Crantz & 3 & 9 & 8 \\
\hline Borago officinalis L. & 3 & 9 & 6 \\
\hline
\end{tabular}

Ciertas especies menos populares y citadas corresponden a especies que eran utilizadas en periodos de hambrunas, como Brachypodium sylvaticum (Huds.) P.Beauv, cuya base de las hojas eran secadas y molidas como sustituto o integrante de la harina de cereales o de castañas para hacer los sucedáneos del pan. Con Vicia sativa L. se hacía harina y se mezclaba con las bellotas de Quercus pubescens L. que se tostaban y se molían para hacer pan en tiempos de hambrunas cuando no disponían de las harinas más apreciadas y comunes para hacer pan, como el trigo, el centeno o las castañas. Valerianella locusta (L.) Laterr. también era según un informante una planta que se iba a buscar cuando no había nada para comer como Taraxacum campylodes G.E.Haglund (s.1.) que también eran muy buscados según los informantes en tiempos de hambruna en la post-guerra. Las hojas de Cichorium 
intybus L. y las bellotas de Quercus pubescens Willd. se usaban tostadas, molidas y cocidas para hacer un sucedáneo del café en tiempos de guerra. También las semillas de Lupinus albus L. eran tostadas para realizar un sucedáneo de café en tiempos difíciles.

\subsection{Categorías alimentarias más importantes}

Los usos alimentarios de las plantas locales citados por los informantes han sido clasificados en categorías según el modo de preparación y la modalidad en la que se comían. La verdura cruda se refiere a la preparación de ciertas partes de plantas crudas y aliñadas pero no contienen hojas verdes, como en el caso de la ensalada. La categoría "otro alimentario" se ha utilizado para casos singulares y raros, que aunque seguramente habrían podido ser clasificados en el resto de categorías, tienen todos una particularidad que las diferencia y por eso han sido clasificados como casos raros (los cuales han sido citados solo una vez por un solo informante): como el colorante alimentario a base de Crocus vernus (L.) Hill (s.1.), los edulcorantes a base de Fraxinus angustifolia subsp. oxycarpa (Willd.) Franco \& Rocha Afonso y de Polypodium vulgare L. (s. 1.), las albóndigas a base de Silene latifolia Poir. subsp. alba (Mill.) Greuter \& Burdet, la levadura natural a base de Prunus cerasifera Ehrh. y Vitis vinifera L. o la salsa de la pasta a base de Rosa cv.

Como en el resto de Italia, las plantas silvestres son muy usadas para la realización de ensaladas, tortillas, rellenos de pasta fresca, sopas y potajes. Sólo en Toscana han sido contabilizadas más de 100 especies silvestres utilizadas sólo para sopas y potajes (Camangi et al., 2013).

En el Alto Valle del Reno, resalta particularmente la preparación de licores a base de plantas locales (43 especies, 30,28\% de las especies alimentarias) y el número de citas (158 citas, $10,85 \%$ de las citas) y el número de informantes que los han citado (48 informantes, 42,47\% de los informantes) (Tab. 30). La relevancia de este uso culinario también la reencontramos en la provincia de Bolonia en segundo lugar de importancia por número de especies, después de las ensaladas (Sansanelli y Tassoni, 2014). La importancia del particular uso de los licores a base de plantas nos ha llevado a realizar estudios más profundos materializados en dos artículos científicos: uno sobre la historia de los licores medicinales, el análisis de la influencia cultural europea en ellos, así como la influencia del conocimiento formal a lo largo de la historia, en Egea et al. (2015) y otro que ha sido enviado recientemente sobre la importancia de las bebidas alcohólicas a base de plantas en el AVR. También tienen una gran importancia las ensaladas a base de plantas sobre todo de la familia Compositae, Caprifoliaceae y Plantaginaceae, las verduras cocidas en las que se utilizan mucho especies de Compositae, Ranunculaceae y Caryophyllaceae. 


\section{Etnobotánica en el Alto Valle del Reno (Toscana y Emilia-Romaña, Italia)}

Tab. 30. Usos alimentarios clasificados por categorías.

Número de especies utilizadas, familias botánicas, número de citas y número de informantes que las citan. Por orden del número de especies referidas.

\begin{tabular}{|c|c|c|c|c|}
\hline $\begin{array}{l}\text { Categorías } \\
\text { alimentarias }\end{array}$ & $\begin{array}{l}\text { Número } \\
\text { de }\end{array}$ & Familias utilizadas & $\begin{array}{l}\text { Número } \\
\text { de citas }\end{array}$ & $\begin{array}{l}\text { Número de } \\
\text { informantes }\end{array}$ \\
\hline Licor & $\begin{array}{l}\text { especies } \\
43\end{array}$ & $\begin{array}{l}\text { Adoxaceae, Compositae, Cornaceae, Cupressaceae, } \\
\text { Ericaceae, Fagaceae, Gentianaceae, Juglandaceae, } \\
\text { Lamiaceae, Lauraceae, Myrtaceae, Orchidaceae, Pinaceae, } \\
\text { Rosaceae, Rubiaceae, Rutaceae, Theaceae, Verbenaceae, } \\
\text { Vitaceae }\end{array}$ & 158 & 48 \\
\hline $\begin{array}{l}\text { Verdura } \\
\text { cocida }\end{array}$ & 33 & 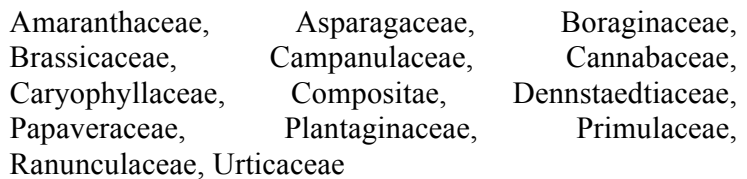 & 212 & 74 \\
\hline $\begin{array}{l}\text { Golosinas y } \\
\text { masticatorias }\end{array}$ & 30 & $\begin{array}{l}\text { Apiaceae, Betulaceae, Boraginaceae, Buxaceae, } \\
\text { Caprifoliaceae, Compositae, Cornaceae, Crassulaceae, } \\
\text { Equisetaceae, Ericaceae, Fagaceae, Gentianaceae, } \\
\text { Iridaceae, Orchidaceae, Polygonaceae, Polypodiaceae, } \\
\text { Primulaceae, Rosaceae }\end{array}$ & 133 & 53 \\
\hline Ensalada & 28 & $\begin{array}{lcc}\text { Amaryllidaceae, } & \text { Brassicaceae, } & \text { Campanulaceae, } \\
\text { Caprifoliaceae, } & \text { Caryophyllaceae, } & \text { Compositae, } \\
\text { Plantaginaceae, } & \text { Polygonaceae, } & \text { Primulaceae, } \\
\text { Ranunculaceae, Rosaceae, Urticaceae, Violaceae }\end{array}$ & 247 & 80 \\
\hline $\begin{array}{l}\text { Conserva de } \\
\text { frutas }\end{array}$ & 21 & $\begin{array}{l}\text { Adoxaceae, Ericaceae, Fagaceae, Leguminosae, Rosaceae, } \\
\text { Solanaceae }\end{array}$ & 73 & 34 \\
\hline Mermelada & 18 & $\begin{array}{l}\text { Adoxaceae, Cornaceae, Ericaceae, Pinaceae, Rosaceae, } \\
\text { Rutaceae, Solanaceae }\end{array}$ & 73 & 38 \\
\hline Tortilla & 15 & $\begin{array}{l}\text { Amaranthaceae, Asparagaceae, Boraginaceae, } \\
\text { Cannabaceae, Caryophyllaceae, Compositae, Iridaceae, } \\
\text { Leguminosae, Plantaginaceae, Ranunculaceae, Rosaceae, } \\
\text { Urticaceae }\end{array}$ & 125 & 75 \\
\hline Aromatizante & 14 & $\begin{array}{l}\text { Amaryllidaceae, Apiaceae, Aquifoliaceae, Betulaceae, } \\
\text { Cupressaceae, Fagaceae, Juglandaceae, Lamiaceae, } \\
\text { Lauraceae, Rosaceae }\end{array}$ & 80 & 43 \\
\hline $\begin{array}{lr}\text { Sopas } & \text { de } \\
\text { verduras } & \text { y } \\
\text { potaje } & \end{array}$ & 14 & $\begin{array}{l}\text { Caprifoliaceae, Caryophyllaceae, Compositae, Fagaceae, } \\
\text { Leguminosae, Plantaginaceae, Poaceae, Primulaceae, } \\
\text { Ranunculaceae, Rosaceae, Urticaceae }\end{array}$ & 37 & 17 \\
\hline Fruta fresca & 13 & Cornaceae, Ericaceae, Rosaceae, Rutaceae & 45 & 31 \\
\hline $\begin{array}{l}\text { Dulces } \\
\text { golosinas }\end{array}$ & 13 & $\begin{array}{l}\text { Adoxaceae, Apiaceae, Betulaceae, Ericaceae, } \\
\text { Juglandaceae, Pinaceae, Polypodiaceae, Rosaceae }\end{array}$ & 20 & 9 \\
\hline Otro & 13 & $\begin{array}{l}\text { Amaryllidaceae , Asparagaceae, Caryophyllaceae, } \\
\text { Iridaceae, Oleaceae, Poaceae, Polypodiaceae, Rosaceae, } \\
\text { Vitaceae }\end{array}$ & 14 & 10 \\
\hline Bebida & 12 & Adoxaceae, Ericaceae, Rosaceae, Rutaceae & 22 & 14 \\
\hline
\end{tabular}




\begin{tabular}{|c|c|c|c|c|}
\hline $\begin{array}{l}\text { Categorías } \\
\text { alimentarias }\end{array}$ & $\begin{array}{l}\text { Número } \\
\text { de } \\
\text { especies }\end{array}$ & Familias utilizadas & $\begin{array}{l}\text { Número } \\
\text { de citas }\end{array}$ & $\begin{array}{l}\text { Número de } \\
\text { informantes }\end{array}$ \\
\hline Fruta seca & 10 & $\begin{array}{l}\text { Betulaceae, Cornaceae, Juglandaceae, Rosaceae, } \\
\text { Solanaceae, Vitaceae }\end{array}$ & 22 & 16 \\
\hline $\begin{array}{l}\text { Relleno de } \\
\text { ravioli }\end{array}$ & 9 & $\begin{array}{l}\text { Amaranthaceae, Caryophyllaceae, Compositae, } \\
\text { Lamiaceae, Plantaginaceae, Primulaceae, Ranunculaceae, } \\
\text { Urticaceae }\end{array}$ & 50 & 36 \\
\hline $\begin{array}{l}\text { Sucedáneo del } \\
\text { café }\end{array}$ & 9 & Compositae, Fagaceae, Leguminosae, Poaceae & 22 & 15 \\
\hline Fritura & 7 & $\begin{array}{l}\text { Adoxaceae, Boraginaceae, Compositae, Lamiaceae, } \\
\text { Leguminosae }\end{array}$ & 28 & 21 \\
\hline $\begin{array}{l}\text { Arroces y } \\
\text { "risotto" }\end{array}$ & 6 & $\begin{array}{l}\text { Asparagaceae, Caryophyllaceae, Malvaceae, Poaceae, } \\
\text { Ranunculaceae, Urticaceae }\end{array}$ & 33 & 30 \\
\hline Empanadas & 5 & Caryophyllaceae, Compositae, Ranunculaceae, Urticaceae & 5 & 1 \\
\hline $\begin{array}{l}\text { Pasta y } \\
\text { "gnocchi" }\end{array}$ & 3 & Caryophyllaceae, Ranunculaceae, Urticaceae & 44 & 41 \\
\hline $\begin{array}{l}\text { Pan y } \\
\text { similares }\end{array}$ & 3 & Fagaceae, Leguminosae & 6 & 5 \\
\hline Verdura cruda & 3 & Boraginaceae, Compositae & 3 & 3 \\
\hline $\begin{array}{l}\text { Encurtidos y } \\
\text { conserva en } \\
\text { aceite }\end{array}$ & 2 & Compositae, Cornaceae & 2 & 2 \\
\hline $\begin{array}{l}\text { Gachas o } \\
\text { polenta }\end{array}$ & 1 & Fagaceae & 1 & 1 \\
\hline
\end{tabular}

Merece la pena comentar el uso difundido de la denominada categoría "Golosinas y masticatorias" ("spuntino campestre") que son los frutos, raíces, bulbos, brotes, flores e incluso cortezas que se usaban para comer durante el día fuera del ambiente doméstico, mientras se hacían las actividades agropastorales, durante las largas caminatas (ya que antes solían caminar mucho por los numerosos caminos de montaña para ir de una comunidad a otra o desde las casas a los campos y bosques), o bien simplemente como pasatiempo o incluso como juego. Estos usos alimentarios de gran importancia a nivel cultural estaban asociados a la forma de vida de antaño, rural y de montaña. Las partes de las plantas, normalmente jóvenes, se recolectaban y se comían directamente, o bien se mantenían en la boca y se chupaban. Era una práctica alimentaria utilizada por muchos niños y personas jóvenes, pero también por mujeres y por hombres que caminaban (buscando hongos o por otros motivos) porque quitaban la sed, como las ramitas de Buxus sempervirens L., las hojas de Sempervivum tectorum L., las hojas de Fagus sylvatica L. que además de quitar la sed, sabían a fresa según el informante. El néctar de flores de Primula vulgaris Huds., Lonicera caprifolium L., Anacamptis morio (L.) R.M.Bateman, Pridgeon \& M.W.Chase, se chupaba como si fuera miel. Muchos de esos manjares eran según los informantes auténticas delicias que se limitaban a 
pocas unidades pero que eran muy gustosas, normalmente dulces pero también ácidas como el caso de las jóvenes hojas de Rumex acetosella L. o "erba brusca" (que significa gusto ácido). Era el caso de Bunium bulbocastanum L. (cfr.) cuyo rizoma se comía sólo cuando trabajaban los campos, porque arando la tierra salían y sólo así los encontraban. En la actualidad este uso alimentario tradicional ha desaparecido completamente junto con las prácticas agrícolas tradicionales a las cuales estaba asociado. El uso alimentario de las "golosinas y masticatorias" tiene la misma importancia y sufre el mismo abandono en la parte sur de Italia según Pieroni et al. (2005) y así como en la provincia de Bolonia según Sansanelli y Tassoni (2014).

Especial atención necesita la categoría etnotaxonómica de los "radicchi" que representan una aplicación independiente en el ámbito de la alimentación a base de plantas silvestres. Esta categoría etnogastronómica y etnotaxonómica corresponde a lo que en ciencias de la nutrición se llama "green leafy vegetables" y se encuentra también bajo otros nombres en el sur de Italia como "ta chortà" (en grecánico) en Calabria (Nebel et al., 2006) y "foglié" en Potenza (Pieroni et al., 2005), "radecc" en Bolonia (Sansanelli y Tassoni, 2014) y "žutenica/žućenica" o "radič/radić" en el sur de Croacia (Łukasz et al., 2013).

La categoría etnogastronómica "radicchi" se basa en las hojas verdes que se recolectan en primavera, antes de que la planta florezca. Hacía parte del dominio femenino, los informantes cuentan que "las mujeres cuando iban detrás de las ovejas iban recolectando las hojas y las ponían en el delantal, o en la cesta hecha de Salix $s p$., después las llevaban a la casa y cuando la abuela los cocinaba, cerraba la puerta de la cocina". La forma de recolección prestaba atención a combinar hojas más amargas con hojas más dulces como sucede también en el estudio de Nebel et al. (2006). Los modos de preparación culinarios dependen del estado de desarrollo de la planta, si las hojas eran tiernas y jóvenes se comían crudas, pero si eran grandes y en su estado de desarrollo más tardío entonces se comían cocidas, esto también sucede en Sansanelli y Tassoni (2014). Una forma muy común y apreciada por los habitantes es comerlos crudos junto a un huevo cocido, pero también crudos y aliñados con sal, aceite y vinagre, cocidos y condimentados o bien salteados en la sartén con aceite y ajo, como en Nebel et al. (2006). En las formas de preparación de los "radicchi" también se evidencian las influencias toscanas y emilianas en la tradición alimentaria del Alto Valle del Reno. Resalta la típica sopa de la tradición rural Toscana denominada "acquacotta" a base de hojas verdes salteadas en la sartén con aceite o con manteca de cerdo (cuando no disponían de aceite), cuando están salteadas se añade agua para hervir, y se sirve sobre rebanadas de pan. Las sopas cocinadas con los "radicchi" junto con patatas, judías y chicharrón se llaman "intrugli", y si a éstos se le añadía pasta fresca o arroz se llamaban "minestre". Sin embargo otra de las formas de cocinar los "radicchi" es el típico "erbazzon" de Emilia-Romaña, la cual se trata de realizar una empanada a base de una masa hecha de agua y harina y manteca de cerdo, y rellenarla con hojas verdes silvestres cocidas.

Otra categoría etnogastronómica y etnotaxonómica son los "asparagi selvatici" que se refieren a brotes de plantas silvestres recolectados en primavera, cocidos y aliñados como típicamente se hace con los brotes de Asparagus acutifolius L. a base 
de Asparagus tenuifolius Lam., Chondrilla juncea L., Ruscus aculeatus L., y Clematis vitalba L.

Las recetas y modos de preparación recogidos, adaptados a las exigencias socioeconómicas actuales pueden tener grandes beneficios en las microeconomías del territorio, siendo ya parte integral de la cultura en cuestión y teniendo un gran valor añadido por realizarse a base de productos locales, que a menudo son olvidados o infrautilizados.

\subsection{Mezcla de plantas alimentarias}

Las recetas recogidas y los modos de preparación no son muy elaborados y laboriosos. Las formas de preparación más complejas son la pasta fresca rellena de queso y especies como Clematis vitalba L., Plantago major L., Primula vulgaris Huds., Silene vulgaris (Moench) Garcke, Sonchus oleraceus L., Urtica dioica L., las pastas realizadas con especies silvestres dentro de la pasta como la harina del castaño silvestre, Silene vulgaris (Moench) Garcke y Urtica dioica L., o la empanada, citada por un solo informante realizada con una pasta de harina y agua y rellena de diferentes hojas de especies silvestres como Clematis vitalba L., Cichorium intybus L., Silene vulgaris (Moench) Garcke, Taraxacum campylodes G.E.Haglund (s.1.) y Urtica dioica L. También los licores y las bebidas presentan algunas recetas un poco más complejas, aunque la mayoría de ellas también se hacen de forma muy simple y directa.

Las mezclas de las plantas es un aspecto muy interesante en el ámbito de la fitoalimurgia y de la nutracéutica, por las sinergias que pueden encontrarse en las combinaciones de especies silvestres y en las formas de cocinarlas. En el AVR, solo 215 usos de plantas (14,77\% de las citas totales) se realizan mezclando especies diferentes. Las especies que más se utilizan combinándolas con otras son fundamentalmente las que se consumen crudas, en ensaladas mixtas a base de varias especies similares, o bien cocidas como verdura mixta, es decir la etnoespecie "radicchi", como Taraxacum campylodes G.E.Haglund (s.1.), Sonchus oleraceus L., Valerianella locusta (L.) Laterr. En estas mezclas de plantas, se combinaban las plantas más dulces y blandas como la Valerianella locusta (L.) Laterr., Veronica beccabunga L., Silene vulgaris (Moench) Garcke y Sonchus oleraceus L. joven, con las hojas más maduras, duras y más amargas como las de Taraxacum campylodes G.E.Haglund (s.1.), Cichorium intybus y Crepis vesicaria L. También las especies aromáticas como Citrus limon (L.) Osbeck, Laurus nobilis L., Syzygium aromaticum (L.) Merr. \& L.M.Perry, y Cinnamomum verum J. Presl. se utilizan para condimentar ciertas preparaciones (Tab. 31). 
Etnobotánica en el Alto Valle del Reno (Toscana y Emilia-Romaña, Italia)

Tab. 31. Especies más empleadas en las mezclas.

Utilizadas en las preparaciones alimentarias tradicionales.

Especies que forman parte de más mezclas

Taraxacum campylodes G.E.Haglund (s.1.)

Sonchus oleraceus (L.) L. (s. 1.)

Citrus limon (L.) Osbeck

Valerianella locusta (L.) Laterr.

Laurus nobilis L.

Silene vulgaris (Moench) Garcke

Crepis vesicaria L.

Juglans regia L.

Syzygium aromaticum (L.) Merr. \& L.M.Perry

Cichorium intybus L.

Cinnamomum verum J. Presl

Veronica beccabunga L.

Rubus ulmifolius Schott

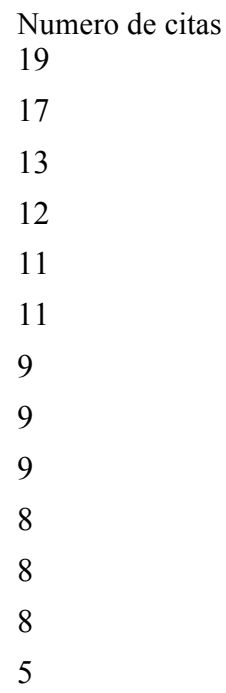

Las categorías alimentarias en las que más mezclas se utilizan en la cultura etnogastronómica del AVR son los licores (56), las ensaladas (41), las sopas de verdura y potaje (25), la verdura cocida (25) y como aromatizantes (17). En cambio las categorías con una sola especie son las conservas de frutas, los encurtidos y conservas en aceite, las frituras, las gachas o polenta, las golosinas y masticatorias, las pastas y "gnocchi", las tortillas y la verdura cruda (es decir partes de plantas que se comen crudas pero no son ensaladas, sino aperitivos como el "pinzimonio") (Tab. $32)$.

Tab. 32. Categorías alimentarias en las que más mezclas de plantas se utilizan. Las más citadas.

\begin{tabular}{ll}
\hline Categorías alimentarias & Citas sobre mezclas de especies \\
Licor & 56 \\
Ensalada & 41 \\
Sopas de verduras y potaje & 26 \\
Verdura cocida & 25 \\
Aromatizante & 17 \\
Fruta fresca & 10 \\
Mermelada & 8 \\
Sucedáneo del café & 6 \\
Arroces y "risotto" & 5 \\
Empanadas & 5 \\
\hline
\end{tabular}


María Teresa Egea Molines

\begin{tabular}{ll}
\hline Pan y similares & 5 \\
Dulces y golosinas & 3 \\
Relleno de ravioli & 3 \\
Bebida & 2 \\
Otro alimentario & 2 \\
Fruta seca & 1 \\
Total de citas sobre mezclas & 215 \\
\hline
\end{tabular}

\subsection{Alimentos funcionales 0 especies nutracéuticas}

En la cultura popular, es muy común que las plantas se consuman de forma multicontextual, por ejemplo tanto para fines alimentarios como medicinales (Pieroni et al., 2002). El $26 \%$ de las especies alimentarias registradas en el AVR tienen un rol medicinal al mismo tiempo que alimentario (37 de las 142 especies alimentarias). Se trata de las plantas "alimentarias funcionales" o de los "alimentos medicinales" las cuales se consumen tanto por sus propiedades nutricionales como por sus beneficios en la salud o sus propiedades medicinales (Pieroni y Quave, 2006). De los informantes entrevistados, 37,16\% (42 de los 113 informantes totales) usan alimentos medicinales a base de plantas como prácticas de salud doméstica, los cuales son concebidos como hábitos sanos que a menudo previenen las patologías además de curar muchas otras. En la Tab. 33 se presentan las especies consideradas como alimentos funcionales en función de las indicaciones terapéuticas que se les aplica y las categorías a las que corresponden (empleadas en el sector medicinal). Han sido registradas 90 citas sobre 37 especies alimentarias funcionales utilizadas para paliar, curar o prevenir 10 tipos de categorías medicinales. Las indicaciones terapéuticas y las propiedades detalladas de cada alimento medicinal han sido registradas tal y como fueron descritas por los informantes, en italiano, intentando no transcribir la nosología vernacular empleada al sistema de clasificación farmacéutico y al léxico formal. Por tanto se han mantenido términos émicos como "contro" o "purificano", tal y como ha sido realizado en el estudio de alimentos medicinales en un valle cercano situado también en el Apenino Tosco-Emiliano, en el noroeste de Toscana, por Pieroni (2000), en la cual se encuentran varias similitudes con la tradición alimentaria-funcional del AVR. La mayoría de las especies nutracéuticas registradas han sido clasificadas por sus fines alimentarios (según el objetivo principal de la investigación). Solo Allium sativum L., Lactuca sativa L., Mespilus germanica L., Piper nigrum L. son plantas cultivadas usadas por la población para el uso común para el cual son cultivadas es decir, aromatizante, ensalada, fruta y aromatizante respectivamente, por tanto no aparecen en las listas de especies con fines etnoalimentarios de la presente investigación (aunque si en el catálogo cualitativo etnoflorístico), y sin embargo sí que han sido consideradas y analizadas en sus funciones de alimentos medicinales. Por otra parte, Teucrium chamaedrys L. es considerado como alimento medicinal sin ser alimento por sí mismo, aunque la forma de administración sea la de masticatorias. 
Las afecciones que más se tratan a través de alimentos son las patologías del aparato digestivo, para las que se utilizan 24 especies alimentarias con 41 usos diferentes, con las que se obtienen efectos como antiinflamatorios del estómago, antiparasitarios, astringente para las diarreas, laxantes, digestivos, coleréticos y colagogos. En segundo lugar se encuentran las afecciones de la categoría denominada "estado general" que se refieren a los efectos depurativos, antiinflamatorios generales, depuradores de la sangre, regenerativos, energéticos, desintoxicantes, remineralizante, reconstituyente, para el cual se utilizan 13 especies alimentarias con 19 usos diferentes. En tercer lugar de importancia se encuentran las patologías del sistema urinario para el cual se utilizan 5 especies alimentarias con 10 usos diferentes, para obtener efectos diuréticos principalmente y según un informante incluso para problemas de próstata. Estas tres primeras categorías de afecciones corresponden a las típicas afecciones que normalmente se tratan con alimentos funcionales, como sucede en la provincia de Bolonia (Sansanelli y Tassoni, 1014), en el noroeste de la provincia toscana de Luca (Pieroni, 2000), en la región del norte de Italia, Lombardía (Vitalini et al., 2013) y en el sur de Italia, en Potenza (Pieroni et al., 2005). Sin embargo resalta en la tradición alimentaria funcional del AVR, el empleo de los alimentos medicina para tratar afecciones del aparato respiratorio (3 especies, 6 citas), afecciones oftalmológicas (1 especie, 3 citas), Afecciones ginecológicas, complicaciones obstétricas, del post-parto y del puerperio (dos especies, 2 citas), afecciones del metabolismo (una especie, una cita), dolores de cabeza (una especie, una cita) patologías del sistema nervioso (una especie, una cita) (Tab. 33).

Tab. 33. Categorías medicinales para las que se utilizan plantas alimentarias.

Alimentos funcionales en orden de importancia según el número de usos y de especies.

Categorías medicinales de los alimentos funcionales

Patologías del aparato digestivo
Especies utilizadas como alimentos medicinales

Allium sativum L.

Cichorium intybus L.

Cinnamomum verum J. Presl

Citrus limon (L.) Osbeck

Cornus mas L.

Crepis vesicaria L.

Fraxinus angustifolia subsp. oxycarpa (Willd.) Franco \& Rocha Afonso

Juglans regia L.

Juniperus communis L.

Laurus nobilis L.

Mespilus germanica L.

Ocimum basilicum L.
Número de usos

1

2

1

1

2

1

1 3

3

1

1

1 


\begin{tabular}{|c|c|c|}
\hline \multirow[t]{13}{*}{$\begin{array}{l}\text { Categorías medicinales de los alimentos } \\
\text { funcionales }\end{array}$} & $\begin{array}{l}\text { Especies utilizadas como alimentos } \\
\text { medicinales }\end{array}$ & $\begin{array}{l}\text { Número de } \\
\text { usos }\end{array}$ \\
\hline & Prunus domestica L. & \\
\hline & Prunus laurocerasus L. & 1 \\
\hline & Prunus spinosa L. & 3 \\
\hline & Rubus hirtus Waldst. \& Kit. & 1 \\
\hline & Salvia officinalis L. & 1 \\
\hline & Sambucus nigra L. & 4 \\
\hline & Sorbus aria (L.) Crantz & 1 \\
\hline & Sorbus domestica L. & 1 \\
\hline & $\begin{array}{l}\text { Syzygium aromaticum (L.) Merr. \& } \\
\text { L.M.Perry }\end{array}$ & 1 \\
\hline & $\begin{array}{l}\text { Taraxacum campylodes G.E.Haglund } \\
\text { (s.1.) }\end{array}$ & 3 \\
\hline & Teucrium chamaedrys L. & 2 \\
\hline & Triticum aestivum $\mathrm{L}$. & 1 \\
\hline \multicolumn{2}{|l|}{ Patologías del aparato digestivo Total } & 41 \\
\hline \multirow[t]{13}{*}{ Estado general } & Bellis perennis L. & 1 \\
\hline & Chondrilla juncea L. & 1 \\
\hline & Cichorium intybus L. & 2 \\
\hline & Cirsium vulgare (Savi) Ten. & 1 \\
\hline & Crepis leontodontoides All. (cfr.) & 1 \\
\hline & Crepis sancta (L.) Bornm. (cfr.) & 1 \\
\hline & Laurus nobilis $\mathrm{L}$. & 1 \\
\hline & Sonchus oleraceus (L.) L. (s. 1.) & 2 \\
\hline & $\begin{array}{l}\text { Taraxacum campylodes G.E.Haglund } \\
\text { (s.l.) }\end{array}$ & 5 \\
\hline & Urtica dioica L. & 1 \\
\hline & Vaccinium myrtillus L. & 1 \\
\hline & Valerianella locusta (L.) Laterr. & 1 \\
\hline & Veronica beccabunga L. & 1 \\
\hline \multicolumn{2}{|l|}{ Estado general Total } & 19 \\
\hline \multirow[t]{5}{*}{ Patologías del aparato urinario } & Cichorium intybus L. & 2 \\
\hline & Crepis vesicaria $\mathrm{L}$. & 2 \\
\hline & Prunus avium (L.) L. & 1 \\
\hline & Sonchus oleraceus (L.) L. (s. 1.) & 1 \\
\hline & $\begin{array}{l}\text { Taraxacum campylodes G.E.Haglund } \\
\text { (s.l.) }\end{array}$ & 4 \\
\hline
\end{tabular}




\begin{tabular}{|c|c|c|}
\hline $\begin{array}{l}\text { Categorías medicinales de los alimentos } \\
\text { funcionales }\end{array}$ & $\begin{array}{l}\text { Especies utilizadas como alimentos } \\
\text { medicinales }\end{array}$ & $\begin{array}{l}\text { Número de } \\
\text { usos }\end{array}$ \\
\hline \multicolumn{2}{|c|}{ Patologías del aparato urinario Total } & 10 \\
\hline \multirow[t]{5}{*}{ Afecciones del aparato respiratorio } & Citrus limon (L.) Osbeck & 1 \\
\hline & Malus domestica Borkh. & 2 \\
\hline & Pinus nigra J.F.Arnold (s.1.) & 1 \\
\hline & Vaccinium myrtillus L. & 1 \\
\hline & Vitis labrusca L. & 1 \\
\hline \multicolumn{2}{|l|}{ Afecciones del aparato respiratorio Total } & 6 \\
\hline \multirow[t]{3}{*}{ Patologías del aparato circulatorio } & Allium sativum L. & 3 \\
\hline & Sambucus nigra L. & 2 \\
\hline & Vaccinium myrtillus L. & 1 \\
\hline \multicolumn{2}{|l|}{ Patologías del aparato circulatorio Total } & 6 \\
\hline Afecciones oftalmológicas & Vaccinium myrtillus L. & 3 \\
\hline \multicolumn{2}{|l|}{ Afecciones oftalmológicas Total } & 3 \\
\hline \multirow{2}{*}{$\begin{array}{l}\text { Afecciones ginecológicas, complicaciones } \\
\text { obstétricas, del post-parto y del puerperio }\end{array}$} & Piper nigrum L. & 1 \\
\hline & Salvia officinalis L. & 1 \\
\hline \multicolumn{2}{|l|}{$\begin{array}{l}\text { Afecciones ginecológicas, complicaciones } \\
\text { obstétricas, del post-parto y del puerperio } \\
\text { Total }\end{array}$} & 2 \\
\hline Afecciones del metabolismo & Lupinus albus L. & 1 \\
\hline \multicolumn{2}{|l|}{ Afecciones del metabolismo Total } & 1 \\
\hline \multirow{3}{*}{$\begin{array}{l}\text { Dolor de cabeza } \\
\text { Dolor de cabeza Total } \\
\text { Patologías del sistema nervioso }\end{array}$} & Vitis vinifera $L$. & 1 \\
\hline & & 1 \\
\hline & Lactuca sativa L. & 1 \\
\hline \multicolumn{2}{|l|}{ Patologías del sistema nervioso Total } & 1 \\
\hline
\end{tabular}

Las preparaciones culinarias que más han resaltado para consumir los alimentos medicinales son los licores, bebidas fermentadas, vinos y grapas aromatizadas caseras (es decir, bebidas tradicionales alcohólicas), los cuales, aparte de tener una gran función nutricional y gastronómica, destacan por tener un importante rol en las prácticas de salud domésticas y una relevante función cultural y social (Egea et al., 2016). Las especies son muy variadas y las partes utilizadas también como las flores de Syzygium aromaticum (L.) Merr. \& L.M.Perry, la corteza de Cinnamomum verum J. Presl, las hojas de Salvia officinalis L., Prunus laurocerasus L., Ocimum basilicum L., Laurus nobilis L., los frutos de Juniperus communis L., Juglans regia L., Cornus mas L., Citrus limon (L.) Osbeck, Vitis labrusca L., Vitis vinifera L., normalmente utilizados para fines digestivos, aunque estas dos últimas también para el dolor de cabeza y afecciones respiratorias, e incluso el licor de Prunus 
laurocerasus L. es utilizado para prevenir las enfermedades, lo cual denota como este tipo de preparaciones son percibidas como prácticas saludables. Como describen Pieroni y Giusti (2009) en los Alpes, los informantes del AVR también aseguran que estos usos a base de alcohol empezaron a ser más populares a partir de los años 1960 aproximadamente, cuando las condiciones económicas del país comenzaron a mejorar, permitiendo a las aisladas comunidades rurales de la montaña acceder al alcohol industrial, ya que antaño los vinos y los licores medicinales se vendían en las boticas (Egea et al., 2015).

La otra preparación culinaria más importante es la que corresponde a la categoría etnotaxonómica y etnogastronómica de los radicchi, los cuales representan un alimento medicinal de gran importancia por sus propiedades depurativas, desintoxicantes, diuréticas, coleréticas y colagogas, además de como antiinflamatorias del aparato digestivo e incluso antiinflamatorias generales. Se recolectan en primavera y según la percepción de los habitantes sirven para "purificar la sangre" y "remineralizar el cuerpo" después de la dieta invernal a base de harina de castaña y privada de frutas y verduras. Se trata de Chondrilla juncea L., Cichorium intybus L., Cirsium vulgare (Savi) Ten., Crepis leontodontoides All. (cfr.), Crepis sancta (L.) Bornm. (cfr.), Crepis vesicaria L., Taraxacum campylodes G.E.Haglund (s.1.), Valerianella locusta (L.) Laterr., Veronica beccabunga L. Cuando se consumen hervidas, el agua de cocción de los radicchi se consume por sus grandes propiedades coleréticas y depurativas. La característica organoléptica del sabor amargo de esta etnoespecie es considerado como un signo saludable, "que hace bien" y "purifica", al igual que sucede en el sur de Italia con la etnoespecie $t a$ chòrta (Nebel et al., 2006).

Estas dos preparaciones coinciden en la provincia toscana de Lucca (Pieroni, et al., 2000). Pero cabe mencionar como el otro grupo de alimentos medicinales más importante en la provincia toscana es el formado por las especies aromáticas con efectos digestivos, característico de las colinas toscanas. Sin embargo en el AVR, el tercer grupo de preparaciones culinarias de alimentos medicinales está compuesto por formas crudas prevalentemente de frutas, propio de un territorio de montaña. Las frutas como Sorbus domestica L., Prunus domestica L., Prunus spinosa L., Rubus hirtus Waldst. \& Kit., Vaccinium myrtillus L. se consumen crudas normalmente para patologías del aparato digestivo como astringentes o laxantes. Lupinus albus L. se come crudo para la diabetes, y Allium sativum L. también se consume crudo como antiparasitario y antihipertensivo.

Destacan algunas preparaciones particulares de alimentos medicinales como el producto tradicional edulcorante "la manna" realizado a partir de la savia de Fraxinus angustifolia subsp. oxycarpa (Willd.) Franco \& Rocha Afonso y utilizado para endulzar el café o la leche, también se consumía como laxante. Para los dolores menstruales se comía huevo con pimienta (Piper nigrum L.), y para el dolor de barriga se comía la sémola de trigo (Triticum aestivum L.) cocida, o las mermeladas con flores y frutos de Sambucus nigra L., y de Sorbus aria (L.) Crantz. como laxantes, la mermelada de brotes de Pinus nigra J.F.Arnold (s.1.) para la tos, o la bebida a base de Sambucus nigra L. que además de quitar la sed hace bien para los hipertensos, entre otros. 
Etnobotánica en el Alto Valle del Reno (Toscana y Emilia-Romaña, Italia)

Al contrario que en el sur de Italia (Pieroni et al., 2005), las preparaciones culinarias basadas en plantas y consideradas como parte del sistema de salud tradicional no son exclusivamente practicadas por las mujeres en el hogar. En la Tab. 34 se puede apreciar como en el AVR, la mujeres predominan en el ámbito de los alimentos funcionales, aunque los hombres también tienen un cierto conocimiento, ya que éstos han citado un $25,5 \%$ de usos referidos a alimentos funcionales a base de plantas (23 citas de 90 citas sobre especies utilizadas en alimentos funcionales) y conocen 14 especies utilizadas como alimentos funcionales (frente a las 37 que conocen las mujeres). Resalta como los hombres utilicen el vino (de Vitis vinifera L. y de Vitis labrusca L.) como alimento medicinal y las mujeres no. En cuanto a las categorías medicinales resalta como los hombres tratan el dolor de cabeza y las mujeres no. En cambio, como es natural, las mujeres utilizan las plantas como alimento medicina para las afecciones ginecológicas, complicaciones obstétricas, del post-parto y del puerperio, así como para afecciones oftalmológicas, y para las patologías del sistema nervioso, afecciones que los hombres no tratan con los alimentos medicina.

Tab. 34. Distribución del conocimiento del uso de los alimentos medicinales.

En función del sexo de los informantes y de las categorías alimentarias funcionales.

\begin{tabular}{lll}
\hline $\begin{array}{l}\text { Sexo de los } \\
\text { informantes } \\
\text { Hombres }\end{array}$ & Categorías alimentarias funcionales utilizadas & Citas \\
& Patologías del aparato digestivo & 9 \\
& Afecciones del aparato respiratorio & 4 \\
& Estado general & 4 \\
& Patologías del aparato urinario & 3 \\
Hombres Total & Patologías del aparato circulatorio & 2 \\
Mujeres & Dolor de cabeza & 1 \\
& & 23 \\
& Patologías del aparato digestivo & 32 \\
& Estado general & 15 \\
& Patologías del aparato urinario & 7 \\
Patologías del aparato circulatorio & 4 \\
& Afecciones oftalmológicas & 3 \\
& Afecciones ginecológicas, complicaciones obstétricas, del post-parto y del & 2 \\
& puerperio & \\
& Afecciones del aparato respiratorio & 2 \\
& Patologías del sistema nervioso & 1 \\
& Afecciones del metabolismo & 1 \\
\hline
\end{tabular}




\subsection{Contraste regional en las categorías alimentarias}

Como ya se ha comentado anteriormente la gastronomía tradicional del AVR está influenciada tanto por la cultura boloñesa (emiliana) como por la cultura pistoyesa (toscana).

A través del análisis de los mapas ilustradores de la distribución del conocimiento fitoalimúrgico en los diferentes municipios del AVR en Toscana (AVRT) como en Emilia-Romaña (AVRB) (Fig. 36 y Fig. 37), observamos como los municipios Sambuca Pistoiese y Camugnano destacan por tener un número importante de citas alimentarias así como de especies.

Comparando el número de especies alimentarias conocidas por municipio (Fig. 28) con respecto al número de informantes entrevistados por municipio (Fig. 19), la proporción (número de especies alimentarias dividido por número de informantes por municipio) denota como el municipio con mayor conocimiento alimentario proporcional es Castiglione dei Pepoli $(8,7)$ seguido por Granaglione $(7,25)$, Porretta Terme y Castel di Casio (con el mismo índice proporcional 6,5) seguidos en último lugar por Sambuca Pistoiese $(1,91)$ y Camugnano $(1,84)$.

Por tanto aunque el número total de especies y citas es elevado en Sambuca Pistoiese y Camugnano es simplemente porque se ha entrevistado a más personas ya que el conocimiento proporcional de los informantes de Castiglione dei Pepoli seguido por Granaglione, Porretta Terme y Castel di Casio es mayor tal y como hemos visto.

Destacan los municipios boloñeses del AVR por conocer un número más importante de especies alimentarias respecto a los informantes entrevistados.

En la Tab. 35, se pueden observar las categorías alimentarias que han sido citadas en la parte boloñesa (AVRB) y en la parte pistoyesa (AVRT), para poder interpretar ciertos usos alimentarios en el AVR.

Efectivamente se notan diferencias claras entre las zonas pertenecientes a las distintas regiones (Tab. 35). La tradición de los licores caseros a base de plantas parece una costumbre más boloñesa que toscana, así como las sopas de verduras y la pasta fresca rellena (como ravioli). En cambio, se nota como las frituras son mucho más comunes en la parte pistoyesa, lo cual es lógico por la mayor accesibilidad al aceite de oliva para freír, ya que en las colinas pistoyesas abunda el olivo y por tanto el aceite, así como se comprueba que el uso de plantas aromatizantes es más común en la parte toscana como se comentaba anteriormente. Por otra parte, se ve como el único uso de empanadas se realiza en la parte boloñesa (ya que en Bolonia es típico el "erbazzon") así como para las gachas y polentas (que son más características del Norte de Italia). En cambio los encurtidos y las verduras crudas se encuentran solo en la parte pistoyesa ya que en Toscana son muy característicos los encurtidos toscanos así como las verduras crudas en pinzimonio (verdura cruda que se unta en una salsa realizada con aceite de oliva, vinagre, sal y eventualmente algunas plantas aromáticas). 
Etnobotánica en el Alto Valle del Reno (Toscana y Emilia-Romaña, Italia)

Tab. 35. Categorías alimentarias según el orden de importancia regional.

\begin{tabular}{llll} 
Categorías alimentarias en el AVRB & Categorías alimentarias en el AVRT \\
Ensalada & 144 & Ensalada & 103 \\
Verdura cocida & 139 & Verdura cocida & 73 \\
Licor & 127 & Tortilla & 57 \\
Golosinas y masticatorias & 91 & Aromatizante & 50 \\
Tortilla & 68 & Conserva de frutas & 42 \\
Relleno de ravioli & 37 & Golosinas y masticatorias & 42 \\
Mermelada & 32 & Mermelada & 41 \\
Conserva de frutas & 31 & Licor & 31 \\
Aromatizante & 30 & Fruta fresca & 23 \\
Sopas de verduras y potaje & 27 & Fritura & 20 \\
Pasta y "gnocchi" & 26 & Pasta y "gnocchi" & 18 \\
Arroces y "risotto" & 22 & Relleno de ravioli & 13 \\
Fruta fresca & 22 & Sucedáneo del café & 13 \\
Fruta seca & 15 & Bebida & 12 \\
Dulces y golosinas & 13 & Arroces y "risotto" & 11 \\
Bebida & 10 & Sopas de verduras y potaje & 10 \\
Sucedáneo del café & 9 & Dulces y golosinas & 7 \\
Fritura & 8 & Fruta seca & 7 \\
Otro alimentario & 7 & Otro alimentario & 7 \\
Empanadas & 5 & Verdura cruda & 3 \\
Pan y similares & 4 & Encurtidos y conserva en aceite & 2 \\
Gachas o polenta & 1 & Pan y similares & 2 \\
ALIMENTARIAS TOTAL & 868 & ALIMENTARIAS TOTAL & 587 \\
\hline & & &
\end{tabular}

Podemos decir, que aunque el AVR albergue una identidad común basada en una historia común y los elementos del agua, la montaña y la frontera, cada parte del AVR tiene bien marcada la cultura regional a la que pertenece administrativamente, y cómo los límites administrativos influyen drásticamente en la cultura, más que los factores ambientales, geográficos, sociales e históricos.

\subsection{Usos novedosos alimentarios respecto a la bibliografía local}

De los 325 usos registrados (es decir, número de categorías por especies registradas) en el AVR sobre los usos alimentarios de las plantas, solo 77 usos han sido documentados previamente en la literatura local correspondientes a 31 especies alimentarias. Por lo que han sido recogidos 248 usos novedosos (categorías por especies) sobre las plantas alimentarias en el AVR. Sin embargo, han sido citados usos en detalle (modos de preparación o administración) novedosos de todas las especies registradas. AVR.

En las Fig. 34 y Fig. 35 se ilustran las prácticas tradicionales alimentarias del 


\section{Medicinales}

\subsection{Sistema de salud tradicional}

El sistema de salud tradicional se basa en la representación de la enfermedad según la cosmovisión y las creencias de la comunidad. La epidemiología ha ido variando a lo largo de la historia en función de los modos de vida, de las epidemias y del acceso a los sistemas de salud.

En cuanto a las enfermedades de antaño, la población fue atacada por varias epidemias. Los habitantes del AVR recuerdan con amargura la gripe letal denominada "la spagnola" o "la febbre gialla" alrededor de la primera guerra mundial. "La febbre maltese" durante los años 50 y 60 fue otra enfermedad infecciosa que se transmitía a través de la leche infectada de los animales que abortaban, según los informantes. Así como el virus "l'asiatica" que atacó a la población durante los años 55 y 56 , como recuerdan los informantes.

Entre la primera y la segunda Guerra Mundial, la pulmonía provocó la muerte de muchas personas, hasta la llegada de la penicilina. La tuberculosis también afectó la población durante el tiempo de guerra, ya que los hombres que regresaban de ella la contagiaban al resto de la población. De hecho había un centro de cura en Montecatone (Imola, Bolonia) para este tipo de enfermedades.

La mortalidad perinatal e infantil era muy elevada. La meningitis atacaba a muchos niños, tanto es que se suele decir "cada semana moría un niño". La muerte era concebida a menudo como una liberación, ya que suponía una persona menos por alimentar, por esto se decía: "la muerte la ha ayudado". Existía una selección natural desde el nacimiento.

En cuanto a las afecciones menores, las personas sufrían dolencias relacionadas con la falta de higiene y la forma de vida basada en trabajos agroforestales. Eran muy comunes los forúnculos, los abscesos y otro tipo de infecciones en la piel.

Los informantes constatan que en tiempos pasados las personas tenían más resistencia, convivían con el dolor. A menudo los informantes empiezan hablando de la medicina tradicional y de la cura de las afecciones a base de los recursos naturales diciendo "me la tenevo" ("la aguantaba").

El sistema tradicional de salud seguía un itinerario terapéutico en función de las tipologías y de la gravedad de las afecciones.

La medicina popular se basaba principalmente en una medicina familiar que utilizaba los recursos naturales para tratar las afecciones más comunes. Han sido recogidas numerosas citas sobre el uso de derivados de animales, orina, insectos, minerales, además de las plantas locales para tratar las afecciones.

A través de la alimentación se procuraba prevenir las enfermedades o paliar los males menores. Según los informantes, las madres y las abuelas eran las que mayormente se encargaban de curar y tratar al resto de la familia y sobre todo a los hijos. Las mujeres y los hombres estaban siempre en el campo o en el bosque trabajando, por lo cual debían automedicarse con los recursos más cercanos de los que disponían de forma más fácil y rápido, ya que no podían sustraer tiempo al trabajo que proporcionaba los alimentos a la familia entera. 
Los testimonios de la vida tradicional del AVR aseguran que en tiempos pasados, en cada comunidad siempre había ciertas personas que sabían particularmente de remedios y preparados medicinales a base de plantas, a las cuales se recurría cuando las afecciones no se conseguían curar en el hogar. Estas figuras sanitarias tradicionales tenían más experiencia y conocimientos sobre el uso medicinal de las plantas y su eficiencia e importancia era reconocida por el resto de la comunidad. Entre ellas se encuentran las denominadas "segnatrici", personas que heredan la capacidad o el don de curar ciertas enfermedades a través de un ritual a base de rezos cristianos y signos particulares. La medicina mágico-ritual era bastante utilizada en el ámbito de la medicina tradicional, en la cual también se recurría a las plantas locales. Son muy comunes los ritos de índole cristiana, aunque muchos informantes los asocian más bien a un acto de sincretismo en el que se comulga el cristianismo y la fe católica con el paganismo. De hecho, muchas personas cristianas no creían en estos ritos, ya que los asocian a el paganismo, pero ante la enfermedad suelen recurrir a ellos para curarse (porque como dicen ellos: "no se pierde nada"). Otra Fig. de la medicina tradicional eran las denominadas "praticona" o "allevatrici", es decir mujeres que con pasión, tanta experiencia y sabiduría tradicional asistía a todos los partos de la comunidad que ocurrían en las casas.

Cuando la medicina familiar y la medicina tradicional no bastaban para curar las afecciones, las personas se dirigían al médico o bien a la farmacia. Según los testimonios, "siempre ha habido un médico en el centro municipal". En Badi (Castel di Casio), ya en el 1800 había un médico, el cual había heredado "el carnet de médico" (o "la patente”) de su padre. El médico asistía a las casas de los enfermos que no podían caminar y se les pagaba solo para ciertos servicios. La asistencia médica ha sido siempre bastante accesible en la zona, según los informantes. De hecho, durante las entrevistas etnobotánicas, muchos informantes responden a las preguntas sobre la cura de afecciones "ibamos al médico o a la farmacia", lo cual denota un buen acceso a la asistencia sanitaria convencional, a pesar de las largas distancias que debían recorrer.

La emigración generalizada hacia las ciudades cercanas que hubo después de la segunda guerra mundial causó un cambio importante en el itinerario terapéutico tradicinal. Cuando la población emigrada regresó a las comunidades de origen, trajeron consigo la costumbre de dirigirse directamente al médico o a la farmacia incluso como primer recurso medicinal (como aseguran los informantes), cambiando así el itinerario terapéutico tradicional y excluyendo los conocimientos tradicionales como recursos primarios de curación.

En el territorio se encuentran dos farmacias históricas que existen desde el siglo XIX, la Farmacia Lorenzini en Porretta Terme y la Farmacia Ercolani en Castiglione dei Pepoli, a las que la población recurría incluso como primera asistencia sanitaria: "Antes era normal caminar toda la noche para poder acceder a la farmacia de Porretta Terme para los del vertiente este o a la farmacia Ercolani para los del vertiente oeste, o incluso se llamaba enseguida al médico que solían asistir a las casas en los casos más graves".

El itinerario terapéutico a veces se alargaba para ciertas enfermedades como el Herpes zoster o "fuoco di Sant'Antonio" o también en el caso de las verrugas, para las que a menudo después de asistir a los médicos (medicina convencional) sin éxito, 


\section{María Teresa Egea Molines}

recurren a las "segnatrici". Incluso son los propios médicos los que envían a sus pacientes a estas tradipracticantes, para tratar ciertas patologías con una eficacia comprobada y reconocida por la población.

\subsection{Familias botánicas con usos medicinales}

En el sector medicinal, han sido recogidas 1008 citas relativas a 147 especies sobre 334 usos diferentes, clasificados en 24 categorías de usos diferentes, que corresponden a las diferentes indicaciones terapéuticas generales. Las especies medicinales registradas pertenecen a 53 familias (Tab. 36). Compositae y Malvaceae son las familias más citadas con aproximadamente la misma importancia ( 157 y 153 citas respectivamente, es decir el 15,57\% y 15,17\% de todas las citas medicinales), y las más conocidas entre los informantes (citadas por 63 informantes y 74 informantes respectivamente). Compositae es la familia para la que más especies fueron mencionadas, sin embargo resalta Malvaceae por tener solo 3 especies a pesar de su gran popularidad, debido sobre todo a la popular Malva sylvestris L. Esta característica de Malvaceae la encontramos igual Cerdeña (Signorini, et al., 2009). La segunda familia con más especies medicinales es Rosaceae (16 especies, 10,88\% de las especies medicinales), seguida de Lamiaceae (8 especies; 5,44\%), Poaceae (6 especies; 4,08\%), Leguminosae (5 especies; 3,40\%).

Tab. 36. Familias botánicas utilizadas con fines medicinales.

Con el número de especies que representan, el número de citas registradas y el número de informantes que las han citado (por orden decreciente del número de especies, del número de citas y del número de informantes)

\begin{tabular}{lllllll}
\hline Familias & $\begin{array}{l}\text { Número } \\
\text { de } \\
\text { especies }\end{array}$ & $\begin{array}{l}\% \\
\text { especies }\end{array}$ & $\begin{array}{l}\text { Número } \\
\text { de citas }\end{array}$ & $\begin{array}{l}\% \\
\text { citas }\end{array}$ & $\begin{array}{l}\text { Número de } \\
\text { informantes }\end{array}$ & $\begin{array}{l}\% \\
\text { informantes }\end{array}$ \\
Compositae & 20 & 13,60 & 157 & 15,57 & 63 & 60,57 \\
Rosaceae & 16 & 10,88 & 60 & 5,95 & 35 & 33,65 \\
Lamiaceae & 8 & 5,44 & 59 & 5,85 & 32 & 30,76 \\
Poaceae & 6 & 4,08 & 64 & 6,34 & 41 & 39,42 \\
Leguminosae & 5 & 3,40 & 27 & 2,67 & 16 & 15,38 \\
Plantaginaceae & 5 & 3,40 & 24 & 2,38 & 18 & 17,30 \\
Crassulaceae & 5 & 3,40 & 13 & 1,28 & 13 & 12,5 \\
Amaryllidaceae & 4 & 2,72 & 41 & 4,06 & 28 & 26,92 \\
Solanaceae & 4 & 2,72 & 38 & 3,76 & 29 & 27,88 \\
\hline
\end{tabular}


Etnobotánica en el Alto Valle del Reno (Toscana y Emilia-Romaña, Italia)

\begin{tabular}{|c|c|c|c|c|c|c|}
\hline Familias & $\begin{array}{l}\text { Número } \\
\text { de } \\
\text { especies }\end{array}$ & $\begin{array}{l}\% \\
\text { especies }\end{array}$ & $\begin{array}{l}\text { Número } \\
\text { de citas }\end{array}$ & $\begin{array}{l}\% \\
\text { citas }\end{array}$ & $\begin{array}{l}\text { Número de } \\
\text { informantes }\end{array}$ & $\begin{array}{l}\% \\
\text { informantes }\end{array}$ \\
\hline Gentianaceae & 4 & 2,72 & 23 & 2,28 & 13 & 12,5 \\
\hline Malvaceae & 3 & 2,04 & 153 & 15,17 & 74 & 71,15 \\
\hline Oleaceae & 3 & 2,04 & 28 & 2,77 & 20 & 19,23 \\
\hline Pinaceae & 3 & 2,04 & 10 & 0,99 & 7 & 6,73 \\
\hline Ericaceae & 3 & 2,04 & 8 & 0,79 & 7 & 6,73 \\
\hline Cucurbitaceae & 3 & 2,04 & 5 & 0,49 & 4 & 3,84 \\
\hline Urticaceae & 2 & 1,36 & 33 & 3,27 & 21 & 20,19 \\
\hline Vitaceae & 2 & 1,36 & 31 & 3,07 & 23 & 22,11 \\
\hline Papaveraceae & 2 & 1,36 & 14 & 1,38 & 13 & 12,5 \\
\hline Ranunculaceae & 2 & 1,36 & 13 & 1,28 & 12 & 11,53 \\
\hline Aspleniaceae & 2 & 1,36 & 11 & 1,09 & 11 & 10,57 \\
\hline Fagaceae & 2 & 1,36 & 11 & 1,09 & 7 & 6,73 \\
\hline Scrophulariaceae & 2 & 1,36 & 10 & 0,99 & 8 & 7,69 \\
\hline Apiaceae & 2 & 1,36 & 9 & 0,89 & 8 & 7,69 \\
\hline Equisetaceae & 2 & 1,36 & 5 & 0,49 & 3 & 2,88 \\
\hline Brassicaceae & 2 & 1,36 & 4 & 0,39 & 4 & 3,84 \\
\hline Myrtaceae & 2 & 1,36 & 4 & 0,39 & 4 & 3,84 \\
\hline Euphorbiaceae & 2 & 1,36 & 4 & 0,39 & 3 & 2,88 \\
\hline Violaceae & 2 & 1,36 & 4 & 0,39 & 3 & 2,88 \\
\hline Lauraceae & 2 & 1,36 & 3 & 0,29 & 2 & 1,92 \\
\hline Boraginaceae & 2 & 1,36 & 2 & 0,19 & 2 & 1,92 \\
\hline Caprifoliaceae & 2 & 1,36 & 2 & 0,19 & 2 & 1,92 \\
\hline Polygonaceae & 2 & 1,36 & 2 & 0,19 & 1 & 0,96 \\
\hline Adoxaceae & 1 & 0,68 & 32 & 3,17 & 23 & 22,11 \\
\hline Linaceae & 1 & 0,68 & 24 & 2,38 & 20 & 19,23 \\
\hline Hypericaceae & 1 & 0,68 & 14 & 1,38 & 10 & 9,61 \\
\hline Moraceae & 1 & 0,68 & 12 & 1,19 & 12 & 11,53 \\
\hline Cupressaceae & 1 & 0,68 & 8 & 0,79 & 8 & 7,69 \\
\hline Rutaceae & 1 & 0,68 & 7 & 0,69 & 7 & 6,73 \\
\hline Juglandaceae & 1 & 0,68 & 6 & 0,59 & 6 & 5,76 \\
\hline Ulmaceae & 1 & 0,68 & 4 & 0,39 & 4 & 3,84 \\
\hline Verbenaceae & 1 & 0,68 & 4 & 0,39 & 4 & 3,84 \\
\hline Dennstaedtiaceae & 1 & 0,68 & 3 & 0,29 & 3 & 2,88 \\
\hline Geraniaceae & 1 & 0,68 & 3 & 0,29 & 3 & 2,88 \\
\hline Polypodiaceae & 1 & 0,68 & 3 & 0,29 & 3 & 2,88 \\
\hline
\end{tabular}


María Teresa Egea Molines

\begin{tabular}{lllllll}
\hline Familias & $\begin{array}{l}\text { Número } \\
\text { de } \\
\text { especies }\end{array}$ & $\begin{array}{l}\% \\
\text { especies }\end{array}$ & $\begin{array}{l}\text { Número } \\
\text { de citas }\end{array}$ & $\begin{array}{l}\% \\
\text { citas }\end{array}$ & $\begin{array}{l}\text { Número de } \\
\text { informantes }\end{array}$ & $\begin{array}{l}\% \\
\text { informantes }\end{array}$ \\
Sapindaceae & 1 & 0,68 & 3 & 0,29 & 3 & 2,88 \\
Cannabaceae & 1 & 0,68 & 3 & 0,29 & 2 & 1,92 \\
Xanthorrhoeaceae & 1 & 0,68 & 2 & 0,19 & 2 & 1,92 \\
Cornaceae & 1 & 0,68 & 2 & 0,19 & 1 & 0,96 \\
Salicaceae & 1 & 0,68 & 2 & 0,19 & 1 & 0,96 \\
Araceae & 1 & 0,68 & 1 & 0,09 & 1 & 0,96 \\
Betulaceae & 1 & 0,68 & 1 & 0,09 & 1 & 0,96 \\
Buxaceae & 1 & 0,68 & 1 & 0,09 & 1 & 0,96 \\
Piperaceae & 1 & 0,68 & 1 & 0,09 & 1 & 0,96 \\
\hline
\end{tabular}

Análogamente al perfil general de las familias de los usos etnobotánicos recogidos, más de la mitad de las familias citadas (38 familias, 71,69\%) representan solo una o dos especies.

\subsection{Especies medicinales más citadas, más populares, más versatiles}

Gran parte de las personas entrevistadas han mencionado plantas con usos medicinales (104 informantes de los 113, es decir 92,03\%). Malva sylvestris L. (138 citas, 73 informantes) y Matricaria chamomilla L. (80 citas, 47 informantes) fueron mencionados por gran parte de los informantes entrevistados y han mostrado ser las especies mejor conocidas y más usadas a nivel medicinal, como sucede en Casentino, un área toscana del Apenino Tosco-Romañolo (Camangi et al.,2003). Adhiriendo a la interpretación de Camangi et al. (2003), su gran popularidad puede ser debido a la gran difusión de éstas especies, fácil reconocimiento y un hábitat de crecimiento antropizado, cerca de las casas y los caminos. En cambio un gran número de especies presentan un único uso (51 especies, 34,69\%) y son citadas por un único informante (60 especies, 40,81\%), lo cual demuestra una vez más que el conocimiento tradicional sobre plantas medicinales es heterogeneo en la comunidad y que esos usos son características de zonas restringidas o propias de ciertas familias o núcleos de población (Camangi et al., 2003), como es el caso de Arum italicum L., Ceterach officinarum Willd., Valeriana officinalis L., Cymbalaria muralis P.Gaertn., B.Mey. \& Scherb., Atropa belladonna L.

Sobre la versatilidad de las especies, Malva sylvestris L. es como en el resto de Italia una auténtica "panacea" (Nicoletti et al., 2013). Junto a Matricaria chamomilla L. siguen siendo las especies con las que más tipos de afecciones diferentes se tratan (10 categorías cada una), aunque también resaltan Urtica dioica L. y Gentiana asclepiadea L. (cfr.) con 9 y 8 categorías diferentes de aplicación, y Allium sativum L. y Olea europaea L. con 7 categorías cada uno (Tab. 37). 
Etnobotánica en el Alto Valle del Reno (Toscana y Emilia-Romaña, Italia)

Tab. 37. Especies medicinales en la tradición del AVR.

Las 30 especies más importantes según el número de categorías utilizadas, el número de citas y el número de informantes

\begin{tabular}{|c|c|c|c|}
\hline Especies & $\begin{array}{l}\text { Número } \\
\text { categorías }\end{array}$ & Número de citas & $\begin{array}{l}\text { Número de } \\
\text { informantes }\end{array}$ \\
\hline Malva sylvestris L. & 10 & 138 & 73 \\
\hline Matricaria chamomilla L. & 10 & 80 & 47 \\
\hline Urtica dioica L. & 9 & 30 & 21 \\
\hline Gentiana cfr. asclepiadea L. & 8 & 18 & 10 \\
\hline Sambucus nigra L. & 7 & 32 & 23 \\
\hline Allium sativum L. & 7 & 25 & 19 \\
\hline Olea europaea L. & 7 & 25 & 19 \\
\hline Tilia platyphyllos Scop. & 7 & 14 & 12 \\
\hline Triticum aestivum $\mathrm{L}$. & 6 & 31 & 27 \\
\hline Salvia officinalis L. & 6 & 28 & 19 \\
\hline Vitis vinifera $L$. & 6 & 27 & 22 \\
\hline Helichrysum italicum (Roth) G.Don & 6 & 11 & 9 \\
\hline Rosmarinus officinalis L. & 6 & 8 & 6 \\
\hline Linum usitatissimum $\mathrm{L}$. & 5 & 24 & 20 \\
\hline Taraxacum campylodes G.E.Haglund (s.1.) & 5 & 24 & 17 \\
\hline Hypericum perfoliatum L. & 5 & 14 & 10 \\
\hline Prunus avium (L.) L. & 5 & 8 & 7 \\
\hline Solanum tuberosum L. & 4 & 28 & 23 \\
\hline Cynodon dactylon (L.) Pers. & 4 & 19 & 14 \\
\hline Allium cepa L. & 4 & 14 & 14 \\
\hline Helleborus viridis L. (s. 1.) & 4 & 12 & 11 \\
\hline Castanea sativa Mill. & 4 & 10 & 7 \\
\hline Zea mays L. & 4 & 9 & 9 \\
\hline Vaccinium myrtillus L. & 4 & 6 & 5 \\
\hline Verbascum thapsus L. & 4 & 6 & 5 \\
\hline Crataegus rhipidophylla Gand. & 3 & 13 & 10 \\
\hline Prunus domestica L. & 3 & 9 & 8 \\
\hline Juniperus communis L. & 3 & 8 & 8 \\
\hline Nicotiana tabacum L. & 3 & 8 & 7 \\
\hline Cichorium intybus L. & 3 & 8 & 6 \\
\hline
\end{tabular}

Han sido registrados numerosos usos sobre plantas medicinales con gran interés fitoterapéutico merecedores de estudios más profundos y específicos. Es curioso notar el uso tradicional con numerosos beneficios a nivel hepático y digestivo de la 


\section{María Teresa Egea Molines}

especie Teucrium chamaedrys L. en decocción o infusión de las partes aéreas o de las hojas, tal y como sucede en otras partes de Italia, como en Casentino (Camangi et al., 2003), al mismo tiempo que como cita el mismo autor, ha sido publicado el Decreto del Ministro de la Salud del 30.05.2003 de Italia la prohibición del uso herborístico y farmacéutico de dicha planta por sus fuerte poder hepatotóxico (Camangi et al., 2003).

\subsection{Categorías medicinales más importantes}

Los usos medicinales más citados y conocidos están relacionados con afecciones cutáneas y tejidos subcutáneos (incluidos irritaciones, quemaduras, picaduras de insectos, heridas, etc.; con 177 citas y mencionadas por 76 informantes), seguidas de afecciones del aparato respiratorio (159 citas, por 59 informantes), de las patologías del aparato digestivo (142 citas, por 66 informantes) y afecciones o síntomas del estado general de salud (100 citas, por 46 informantes)(Tab. 38). Este última categoría se refiere a plantas que tienen un efecto holístico y terapéutico sobre el cuerpo, el cual es considerado como un todo (Signorini et al., 2009). El efecto de estas plantas es denominado en la nosología local como "refrescante" ("rinfrescante"), "purificador", "depurativo", "antiinflamatorio general" o "para reforzar el cuerpo" ("per rinforzare il corpo") y se refieren a un efecto curativo y positivo sobre el cuerpo sin saber precisamente el origen del mal. Como afirma Signorini et al. (2009) este tipo de indicación terapéutica es muy común en la etnobotánica italiana.

Comparando este perfil epidemiológico desde el punto de vista del uso tradicional de las plantas, resalta como a diferencia de otra regiones italianas del Norte de Italia (Cornara et al., 2014, Vitalini et al., 2013) o mediterráneas (Carrió y Vallès, 2012; Signorini et al., 2009) las patologías del aparato digestivo no son las más tratadas con plantas, ya que para las afecciones cutáneas han sido registrados más usos (177 citas contra 142 citas del digestivo), mencionados por un número mayor de informantes (76 informantes respecto a 66 informantes del digestivo). Igualmente para las afecciones respiratorias han sido citadas más especies (aunque sólo una) (49 especies contra 48 especies del digestivo) que para el aparato digestivo.

El cuadro epidemiológico que describe el tratamiento tradicional de las afecciones a partir de los recursos naturales es característico de una zona de montaña con clima frío y duro (importancia de especies diferentes para tratar el aparato respiratorio), en el que la dieta familiar era a base de casi solamente harina de castañas que según los informantes provocaba acidez o inflamaciones de estómago (importancia de las patologías del aparato digestivo) y en la que los trabajos manuales basados en las actividades agroforestales eran causa de importantes afecciones cutáneas, así como la falta de higiene. Merece la pena resaltar como encontramos el mismo cuadro epidemiológico en las comunidades alpinas del Norte de Italia de las minorías étnicas de los Moquenos (Obón et al.,2012) y los Cimbros (Rivera et al., 2012) en las que las afecciones más tratadas con plantas son el sistema respiratorio (Frecuencia Relativa $=14,4$ y 8,7 respectivamente), las 
afecciones dermatológicas (Frecuencia Relativa $=8,3$ y 19,9) y el sistema digestivo (Frecuencia relativa $=23,5$ y 17,0 ).

Tab. 38. Categorías medicinales y su reparto en familias botánicas.

Número de especies utilizadas, número de citas y número de informantes que las citan. Por orden del número de especies referidas.

\begin{tabular}{|c|c|c|c|c|}
\hline $\begin{array}{l}\text { Categorías } \\
\text { medicinales }\end{array}$ & $\begin{array}{l}\text { Número } \\
\text { de } \\
\text { especies }\end{array}$ & Familias & $\begin{array}{l}\text { Número } \\
\text { de citas }\end{array}$ & $\begin{array}{l}\text { Número de } \\
\text { informantes }\end{array}$ \\
\hline $\begin{array}{l}\text { Afecciones del } \\
\text { aparato } \\
\text { respiratorio }\end{array}$ & 49 & $\begin{array}{l}\text { Adoxaceae, Amaryllidaceae, } \\
\text { Aspleniaceae, Boraginaceae, } \\
\text { Brassicaceae, Compositae, } \\
\text { Crassulaceae, Cupressaceae, } \\
\text { Dennstaedtiaceae, Ericaceae, } \\
\text { Fagaceae, Lamiaceae, } \\
\text { Leguminosae, Linaceae, } \\
\text { Malvaceae, Myrtaceae, Oleaceae, } \\
\text { Papaveraceae, Pinaceae, } \\
\text { Plantaginaceae, Poaceae, } \\
\text { Polypodiaceae, Rosaceae, } \\
\text { Rutaceae, Scrophulariaceae, } \\
\text { Vitaceae }\end{array}$ & 159 & 59 \\
\hline $\begin{array}{l}\text { Patologías del } \\
\text { aparato digestivo }\end{array}$ & 48 & $\begin{array}{l}\text { Adoxaceae, Amaryllidaceae, } \\
\text { Apiaceae, Compositae, Cornaceae, } \\
\text { Cupressaceae, Fagaceae, } \\
\text { Gentianaceae, Juglandaceae, } \\
\text { Lamiaceae, Lauraceae, Linaceae, } \\
\text { Malvaceae, Myrtaceae, Oleaceae, } \\
\text { Plantaginaceae, Poaceae, Rosaceae, } \\
\text { Rutaceae, Solanaceae, Urticaceae }\end{array}$ & 142 & 66 \\
\hline $\begin{array}{l}\text { Afecciones } \\
\text { cutáneas y tejidos } \\
\text { subcutáneos }\end{array}$ & 45 & $\begin{array}{l}\text { Adoxaceae, Amaryllidaceae, } \\
\text { Apiaceae, Araceae, Aspleniaceae, } \\
\text { Compositae, Crassulaceae, } \\
\text { Cucurbitaceae, Ericaceae, } \\
\text { Euphorbiaceae, Fagaceae, } \\
\text { Geraniaceae, Hypericaceae, } \\
\text { Juglandaceae, Malvaceae, } \\
\text { Moraceae, Oleaceae, Papaveraceae, } \\
\text { Plantaginaceae, Poaceae, } \\
\text { Polygonaceae, Ranunculaceae, } \\
\text { Rosaceae, Rutaceae, } \\
\text { Scrophulariaceae, Solanaceae, } \\
\text { Ulmaceae, Urticaceae, Vitaceae, } \\
\text { Xanthorrhoeaceae }\end{array}$ & 177 & 76 \\
\hline
\end{tabular}


María Teresa Egea Molines

\begin{tabular}{|c|c|c|c|c|}
\hline $\begin{array}{l}\text { Categorías } \\
\text { medicinales }\end{array}$ & $\begin{array}{l}\text { Número } \\
\text { de } \\
\text { especies }\end{array}$ & Familias & $\begin{array}{l}\text { Número } \\
\text { de citas }\end{array}$ & $\begin{array}{l}\text { Número de } \\
\text { informantes }\end{array}$ \\
\hline Estado general & 35 & $\begin{array}{l}\text { Adoxaceae, Betulaceae, } \\
\text { Caprifoliaceae, Compositae, } \\
\text { Cucurbitaceae, Ericaceae, } \\
\text { Gentianaceae, Juglandaceae, } \\
\text { Lamiaceae, Lauraceae, Linaceae, } \\
\text { Malvaceae, Pinaceae, } \\
\text { Plantaginaceae, Poaceae, Rosaceae, } \\
\text { Urticaceae, Violaceae }\end{array}$ & 100 & 46 \\
\hline $\begin{array}{l}\text { Patologías del } \\
\text { aparato urinario }\end{array}$ & 28 & $\begin{array}{l}\text { Amaryllidaceae, Apiaceae, } \\
\text { Compositae, Equisetaceae, } \\
\text { Ericaceae, Gentianaceae, } \\
\text { Lamiaceae, Malvaceae, } \\
\text { Plantaginaceae, Poaceae, Rosaceae, } \\
\text { Scrophulariaceae, Urticaceae }\end{array}$ & 81 & 52 \\
\hline $\begin{array}{l}\text { Trastornos } \\
\text { musculo- } \\
\text { esqueléticos }\end{array}$ & 24 & $\begin{array}{l}\text { Adoxaceae, Amaryllidaceae, } \\
\text { Brassicaceae, Cannabaceae, } \\
\text { Compositae, Crassulaceae, } \\
\text { Cupressaceae, Dennstaedtiaceae, } \\
\text { Equisetaceae, Fagaceae, } \\
\text { Hypericaceae, Lamiaceae, } \\
\text { Malvaceae, Oleaceae, Pinaceae, } \\
\text { Poaceae, Sapindaceae, } \\
\text { Scrophulariaceae, Urticaceae, } \\
\text { Verbenaceae }\end{array}$ & 47 & 27 \\
\hline $\begin{array}{l}\text { Afecciones oro- } \\
\text { faríngeas y de la } \\
\text { cavidad oral }\end{array}$ & 23 & $\begin{array}{l}\text { Adoxaceae, Buxaceae, Compositae, } \\
\text { Euphorbiaceae, Gentianaceae, } \\
\text { Lamiaceae, Linaceae, Malvaceae, } \\
\text { Myrtaceae, Oleaceae, Poaceae, } \\
\text { Ranunculaceae, Rosaceae, } \\
\text { Scrophulariaceae, Solanaceae, } \\
\text { Urticaceae, Vitaceae }\end{array}$ & 98 & 57 \\
\hline $\begin{array}{l}\text { Patologías del } \\
\text { aparato } \\
\text { circulatorio }\end{array}$ & 20 & $\begin{array}{l}\text { Adoxaceae, Amaryllidaceae, } \\
\text { Compositae, Crassulaceae, } \\
\text { Ericaceae, Gentianaceae, } \\
\text { Lamiaceae, Malvaceae, Oleaceae, } \\
\text { Poaceae, Polypodiaceae, } \\
\text { Ranunculaceae, Rosaceae, } \\
\text { Sapindaceae, Scrophulariaceae, } \\
\text { Urticaceae }\end{array}$ & 44 & 29 \\
\hline $\begin{array}{l}\text { Afecciones } \\
\text { ginecológicas, } \\
\text { complicaciones } \\
\text { obstétricas, del } \\
\text { post-parto y del } \\
\text { puerperio }\end{array}$ & 12 & $\begin{array}{l}\text { Apiaceae, Cannabaceae, } \\
\text { Compositae, Hypericaceae, } \\
\text { Lamiaceae, Linaceae, Malvaceae, } \\
\text { Piperaceae, Poaceae, Urticaceae, } \\
\text { Violaceae }\end{array}$ & 18 & 10 \\
\hline
\end{tabular}


Etnobotánica en el Alto Valle del Reno (Toscana y Emilia-Romaña, Italia)

\begin{tabular}{|c|c|c|c|c|}
\hline $\begin{array}{l}\text { Categorías } \\
\text { medicinales }\end{array}$ & $\begin{array}{l}\text { Número } \\
\text { de } \\
\text { especies }\end{array}$ & Familias & $\begin{array}{l}\text { Número } \\
\text { de citas }\end{array}$ & $\begin{array}{l}\text { Número de } \\
\text { informantes }\end{array}$ \\
\hline $\begin{array}{l}\text { Patologías del } \\
\text { sistema nervioso }\end{array}$ & 11 & $\begin{array}{l}\text { Caprifoliaceae, Compositae, } \\
\text { Gentianaceae, Hypericaceae, } \\
\text { Malvaceae, Rosaceae }\end{array}$ & 45 & 33 \\
\hline $\begin{array}{l}\text { Afecciones } \\
\text { oftalmológicas }\end{array}$ & 7 & $\begin{array}{l}\text { Amaryllidaceae, Compositae, } \\
\text { Ericaceae, Malvaceae, Solanaceae, } \\
\text { Violaceae, Vitaceae }\end{array}$ & 38 & 30 \\
\hline $\begin{array}{l}\text { Afecciones típicas } \\
\text { infantiles }\end{array}$ & 7 & $\begin{array}{l}\text { Amaryllidaceae, Apiaceae, } \\
\text { Compositae, Gentianaceae, } \\
\text { Hypericaceae, Oleaceae, } \\
\text { Papaveraceae }\end{array}$ & 12 & 12 \\
\hline Dolor de cabeza & 7 & $\begin{array}{l}\text { Crassulaceae, Poaceae, } \\
\text { Polypodiaceae, Salicaceae, } \\
\text { Solanaceae, Vitaceae }\end{array}$ & 10 & 8 \\
\hline Parásitos externos & 4 & $\begin{array}{l}\text { Leguminosae, Solanaceae, } \\
\text { Urticaceae, Vitaceae }\end{array}$ & 6 & 6 \\
\hline Otro medicinal & 4 & $\begin{array}{l}\text { Fagaceae, Gentianaceae, } \\
\text { Urticaceae, Vitaceae }\end{array}$ & 5 & 5 \\
\hline $\begin{array}{l}\text { Enfermedades del } \\
\text { oído }\end{array}$ & 3 & $\begin{array}{l}\text { Amaryllidaceae, Oleaceae, } \\
\text { Rosaceae }\end{array}$ & 9 & 8 \\
\hline $\begin{array}{l}\text { Afecciones del } \\
\text { metabolismo }\end{array}$ & 3 & $\begin{array}{l}\text { Compositae, Lamiaceae, } \\
\text { Leguminosae }\end{array}$ & 4 & 4 \\
\hline $\begin{array}{l}\text { Para provocar } \\
\text { enfermedad }\end{array}$ & 2 & Ranunculaceae & 10 & 10 \\
\hline Fiebre & 2 & Gentianaceae, Salicaceae & 3 & 3 \\
\hline
\end{tabular}

Como se puede ver en la Tab. 39, el uso de plantas medicinales para las afecciones principales prevalece como parte del dominio femenino, ya que las mujeres tienen el doble de citas que los hombres, aunque estos también tienen una buena representación y también se encargan de los cuidados de salud primarios. Como es natural, las mujeres se ocupan exclusivamente de los propios dolores y problemas ginecológicos, que apenas han sido mencionados por los hombres (17 citas de las mujeres, respecto a una cita de los hombres), pero también destacan por ocuparse de las afecciones típicas infantiles (10 citas de las mujeres, respecto a 2 de los hombres) y de la fiebre (3 citas respecto a ninguna de los hombres). Las mujeres se ocupan mayoritariamente de todas las afecciones de la familia excepto para la categoría de las afecciones oftalmológicas (20 citas respecto 4 citas de las mujeres) y la categoría "para provocar enfermedad" (6 citas respecto a 4 citas de mujeres), para las que los hombres han proporcionado más informaciones. La última categoría es una práctica a base de Helleborus viridis L. (s.1.), que normalmente realizaban los hombres para provocar una alta fiebre (o inflamación) en el propio cuerpo, con el fin de obtener la baja por causa desconocida (ya que decían que los médicos no conseguían diagnosticar el origen de la fiebre) y así evitaban ir a trabajar a los duros 


\section{María Teresa Egea Molines}

trabajos masculinos cuando estaban agotados (en las minas y las obras de grandes infraestructuras).

Tab. 39. Distribución de los usos medicinales.

En función del sexo y de las categorías medicinales.

Sexo de los informantes

Hombres
Hombres Total

Categorías medicinales

Afecciones cutáneas y tejidos subcutáneos

Afecciones del aparato respiratorio

Patologías del aparato digestivo

Estado general

Afecciones oro-faríngeas y de la cavidad oral

Afecciones oftalmológicas

Patologías del aparato urinario

Patologías del sistema nervioso

Trastornos musculo-esqueléticos

Patologías del aparato circulatorio

Para provocar enfermedad

Dolor de cabeza

Enfermedades del oído

Afecciones típicas infantiles

Parásitos externos

Afecciones del metabolismo

Afecciones ginecológicas, complicaciones obstétricas, del post-parto y del puerperio

Otro medicinal

Mujeres

69

65

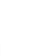

(1)

Afecciones cutáneas y tejidos subcutáneos 108

Patologías del aparato digestivo $\quad 99$

Afecciones del aparato respiratorio 94

Afecciones oro-faríngeas y de la cavidad oral 65

Patologías del aparato urinario $\quad 64$

Estado general 61

Trastornos musculo-esqueléticos $\quad 34$

Patologías del aparato circulatorio 32

Patologías del sistema nervioso 31

Afecciones oftalmológicas 18

Afecciones ginecológicas, complicaciones obstétricas, del 17 post-parto y del puerperio

Afecciones típicas infantiles $\quad 10$

Dolor de cabeza 6

Enfermedades del oído

Otro medicinal 4

Citas 
Etnobotánica en el Alto Valle del Reno (Toscana y Emilia-Romaña, Italia)

\begin{tabular}{lll}
\hline Sexo de los informantes & Categorías medicinales & Citas \\
& Para provocar enfermedad & 4 \\
& Parásitos externos & 4 \\
& Afecciones del metabolismo & 3 \\
& Fiebre & 3 \\
Mujeres Total & & 663 \\
\hline
\end{tabular}

\subsection{Nosología popular (de campo y bibliográfica) clasificada por categorías}

En el sistema de salud tradicional las categorías medicinales tienen una terminología y una clasificación propia de la cosmovisión del grupo cultural. La forma de percibir las enfermedades se pone de manifiesto en las denominaciones émicas y dialectales que les otorgan. En la Tab. 40, se muestra la nosología del grupo cultural, es decir, el sistema de clasificación tradicional de las enfermedades. Las formas de interpretar las patologías, los síntomas o afecciones se exponen a través de términos en dialecto, de formas de hablar y de entender la enfermedad, así como las formas de representación de las enfermedades. Como en otras culturas tradicionales, se puede apreciar como en el sistema tradicional de salud del AVR, el concepto de enfermedad es concebido como un desequilibrio entre el frío y el calor del cuerpo. De hecho, a muchas plantas locales se les atribuye la propiedad de "refrescar", para tratar afecciones consideradas como "calientes" o "con exceso de calor". Las inflamaciones en general, las afecciones del sistema digestivo (problemas de digestión, de hígado o acidez de estómago), patologías del sistema circulatorio (hemorroides), las molestias o afecciones del embarazo, parto o puerperio, así como los problemas menstruales son consideradas patologías calientes, y son tratadas con plantas "refrescantes". Por ejemplo, para denominar la acidez de estómago se dice "cuando uno está calentado" ("quando uno è riscaldato").

De la misma manera, se recurre a menudo al calor para curar patologías consideradas como exceso de frio. Por ejemplo, la tos se trata masajeando los pies encima de la estufa con aceite o con manteca de cerdo calientes, la pulmonitis se curaba poniendo una gacha caliente de harina de castañas en los pies, las enfermedades de la vías respiratorias se tratan aplicando materiales calientes sobre los bronquios, que según los informantes absorben la humedad, el mal. Para las curas postparto, se decía que las mujeres debían permanecer calientes.

Han sido recogidos 32 términos en dialecto para indicar las diferentes afecciones cutáneas, lo que indica el profundo conocimiento que tiene la comunidad de este tipo de patologías. 


\section{María Teresa Egea Molines}

Tab. 40. Comparación de la nosología popular del AVR (dialecto).

La explicación en italiano y las categorías a las que pertenece. En negrita los téminos e informaciones extraídos de la investigación bibliográfica, el resto de informaciones son citadas por los informantes durante el trabajo de campo.

\begin{tabular}{|c|c|c|c|}
\hline Categoría de uso & & $\begin{array}{l}\text { Indicación terapéutica, } \\
\text { explicación en italiano según } \\
\text { el informante }\end{array}$ & Nosología popular \\
\hline $\begin{array}{l}\text { Afecciones cutáneas } \\
\text { tejidos subcutáneos }\end{array}$ & $\mathrm{y}$ & $\begin{array}{l}\text { arrossamento della pelle } \\
\text { dovuto alla tramontana }\end{array}$ & le voladeghe \\
\hline $\begin{array}{l}\text { Afecciones cutáneas } \\
\text { tejidos subcutáneos }\end{array}$ & $\mathrm{y}$ & ascessi & giradito o patereccio \\
\hline $\begin{array}{l}\text { Afecciones cutáneas } \\
\text { tejidos subcutáneos }\end{array}$ & $\mathrm{y}$ & ascesso & $\begin{array}{l}\text { ascessi con il pus dentro causate da } \\
\text { spini }\end{array}$ \\
\hline $\begin{array}{l}\text { Afecciones cutáneas } \\
\text { tejidos subcutáneos }\end{array}$ & $\mathrm{y}$ & ascesso, erisipela & resìppola \\
\hline $\begin{array}{l}\text { Afecciones cutáneas } \\
\text { tejidos subcutáneos }\end{array}$ & $\mathrm{y}$ & bruciare & brusàre \\
\hline $\begin{array}{l}\text { Afecciones cutáneas } \\
\text { tejidos subcutáneos }\end{array}$ & $\mathrm{y}$ & bruciata & brusàda \\
\hline $\begin{array}{l}\text { Afecciones cutáneas } \\
\text { tejidos subcutáneos }\end{array}$ & $\mathrm{y}$ & bruciore & brusore \\
\hline $\begin{array}{l}\text { Afecciones cutáneas } \\
\text { tejidos subcutáneos }\end{array}$ & $\mathrm{y}$ & bruffolo, infezione della pelle & il frignolo \\
\hline $\begin{array}{l}\text { Afecciones cutáneas } \\
\text { tejidos subcutáneos }\end{array}$ & $\mathrm{y}$ & brufolo & brùgolo \\
\hline $\begin{array}{l}\text { Afecciones cutáneas } \\
\text { tejidos subcutáneos }\end{array}$ & $\mathrm{y}$ & brufolo, foruncolo & fìgnolo \\
\hline $\begin{array}{l}\text { Afecciones cutáneas } \\
\text { tejidos subcutáneos }\end{array}$ & $\mathrm{y}$ & ferite con infiammazioni & le spellature \\
\hline $\begin{array}{l}\text { Afecciones cutáneas } \\
\text { tejidos subcutáneos }\end{array}$ & $\mathrm{y}$ & ferite con piccola emorragia & festatura \\
\hline $\begin{array}{l}\text { Afecciones cutáneas } \\
\text { tejidos subcutáneos }\end{array}$ & $\mathrm{y}$ & ferite, ascessi, foruncoli & giradito \\
\hline $\begin{array}{l}\text { Afecciones cutáneas } \\
\text { tejidos subcutáneos }\end{array}$ & $\mathrm{y}$ & ferite, 'occhio di pernice' & $\begin{array}{l}\text { Occhio di pernice, veniva quando si } \\
\text { lavorava tanto nei campi sulle mani } \\
\text { (come I porri) }\end{array}$ \\
\hline $\begin{array}{l}\text { Afecciones cutáneas } \\
\text { tejidos subcutáneos }\end{array}$ & $\mathrm{y}$ & foruncoli & cecchi o chechio \\
\hline $\begin{array}{l}\text { Afecciones cutáneas } \\
\text { tejidos subcutáneos }\end{array}$ & $\mathrm{y}$ & foruncoli & cecchi (forti) bruggoli (più leggeri) \\
\hline Afecciones cutáneas & $\mathrm{y}$ & foruncoli & cecchio \\
\hline
\end{tabular}




\begin{tabular}{|c|c|c|}
\hline Categoría de uso & $\begin{array}{l}\text { Indicación terapéutica, } \\
\text { explicación en italiano según } \\
\text { el informante }\end{array}$ & Nosología popular \\
\hline \multicolumn{3}{|l|}{ tejidos subcutáneos } \\
\hline $\begin{array}{l}\text { Afecciones cutáneas } \\
\text { tejidos subcutáneos }\end{array}$ & foruncoli infezione della pelle & cecchio, forunculo \\
\hline $\begin{array}{l}\text { Afecciones cutáneas } \\
\text { tejidos subcutáneos }\end{array}$ & foruncolo & tiècchio \\
\hline $\begin{array}{l}\text { Afecciones cutáneas } \\
\text { tejidos subcutáneos }\end{array}$ & geloni nei piedi & slóni \\
\hline $\begin{array}{l}\text { Afecciones cutáneas } \\
\text { tejidos subcutáneos }\end{array}$ & grosso brufolo, foruncolo. & céc'cchio \\
\hline $\begin{array}{l}\text { Afecciones cutáneas } \\
\text { tejidos subcutáneos }\end{array}$ & grosso foruncolo & bùgno \\
\hline $\begin{array}{l}\text { Afecciones cutáneas } \\
\text { tejidos subcutáneos }\end{array}$ & herpes & févre sórda \\
\hline $\begin{array}{l}\text { Afecciones cutáneas } \\
\text { tejidos subcutáneos }\end{array}$ & herpes zoster & fuoco di Sant 'Antonio \\
\hline $\begin{array}{l}\text { Afecciones cutáneas } \\
\text { tejidos subcutáneos }\end{array}$ & $\begin{array}{l}\text { infezione cutanea all'unghia, } \\
\text { "nel giradito" }\end{array}$ & $\begin{array}{l}\text { "il flemole", "giradito","dito } \\
\text { marcio" }\end{array}$ \\
\hline $\begin{array}{l}\text { Afecciones cutáneas } \\
\text { tejidos subcutáneos }\end{array}$ & $\begin{array}{l}\text { infezione situata intorno } \\
\text { all'unghia, patereccio. }\end{array}$ & giràndola \\
\hline $\begin{array}{l}\text { Afecciones cutáneas } \\
\text { tejidos subcutáneos }\end{array}$ & lacerazione & castròn \\
\hline $\begin{array}{l}\text { Afecciones cutáneas } \\
\text { tejidos subcutáneos }\end{array}$ & $\begin{array}{l}\text { pellicine che crescono intorno } \\
\text { alle unghie delle mani }\end{array}$ & càgne \\
\hline $\begin{array}{l}\text { Afecciones cutáneas } \\
\text { tejidos subcutáneos }\end{array}$ & porri & poranci \\
\hline $\begin{array}{l}\text { Afecciones cutáneas } \\
\text { tejidos subcutáneos }\end{array}$ & prurito & rósa \\
\hline $\begin{array}{l}\text { Afecciones cutáneas } \\
\text { tejidos subcutáneos }\end{array}$ & $\begin{array}{l}\text { puntura di insetto (api e } \\
\text { calabroni) }\end{array}$ & beccho \\
\hline $\begin{array}{l}\text { Afecciones cutáneas } \\
\text { tejidos subcutáneos }\end{array}$ & punture d'insetti & foròtto \\
\hline $\begin{array}{l}\text { Afecciones del aparat } \\
\text { respiratorio }\end{array}$ & abbassamento di voce & roncón \\
\hline $\begin{array}{l}\text { Afecciones del aparat } \\
\text { respiratorio }\end{array}$ & asmatico & bòlgio \\
\hline $\begin{array}{l}\text { Afecciones del aparat } \\
\text { respiratorio }\end{array}$ & colpo di vento improvviso & fulécchio \\
\hline $\begin{array}{l}\text { Afecciones del aparat } \\
\text { respiratorio }\end{array}$ & difficoltà a respirare & rantèllo \\
\hline
\end{tabular}




\begin{tabular}{|c|c|c|}
\hline Categoría de uso & $\begin{array}{l}\text { Indicación terapéutica, } \\
\text { explicación en italiano según } \\
\text { el informante }\end{array}$ & Nosología popular \\
\hline $\begin{array}{l}\text { Afecciones del aparato } \\
\text { respiratorio }\end{array}$ & $\begin{array}{l}\text { malattie da raffreddamento e } \\
\text { vie aeree }\end{array}$ & bolsa \\
\hline $\begin{array}{l}\text { Afecciones del aparato } \\
\text { respiratorio }\end{array}$ & raffreddore & ferdura \\
\hline $\begin{array}{l}\text { Afecciones del aparato } \\
\text { respiratorio }\end{array}$ & raffreddore & ferdùra \\
\hline $\begin{array}{l}\text { Afecciones del aparato } \\
\text { respiratorio }\end{array}$ & raffreddore & ferdura, fredura \\
\hline $\begin{array}{l}\text { Afecciones del aparato } \\
\text { respiratorio }\end{array}$ & $\begin{array}{l}\text { raffreddore, infezione leggera } \\
\text { della gola }\end{array}$ & raffreddore, raspore in gola \\
\hline $\begin{array}{l}\text { Afecciones del aparato } \\
\text { respiratorio }\end{array}$ & $\begin{array}{l}\text { raffredore (con infezione delle } \\
\text { vie respiratorie superiori) }\end{array}$ & raffredore con muco \\
\hline $\begin{array}{l}\text { Afecciones del aparato } \\
\text { respiratorio }\end{array}$ & ripetuti colpi di tosse & fülca \\
\hline $\begin{array}{l}\text { Afecciones del aparato } \\
\text { respiratorio }\end{array}$ & sinusite & mal di ciglio, male alle sopraciglie \\
\hline $\begin{array}{l}\text { Afecciones del aparato } \\
\text { respiratorio }\end{array}$ & tosse, catarro & il rantolo, tosse con il rantolo \\
\hline $\begin{array}{l}\text { Afecciones } \\
\text { metabolismo }\end{array}$ & colesterolo alto & $\begin{array}{l}\text { Quando uno si bucava e aveva il } \\
\text { sangue grosso, spesso(pieno di } \\
\text { grasso) }\end{array}$ \\
\hline $\begin{array}{l}\text { Afecciones ginecológicas, } \\
\text { complicaciones } \\
\text { obstétricas, del post-parto } \\
\text { y del puerperio }\end{array}$ & antiinfiammatorio generico & rinfrescante \\
\hline $\begin{array}{l}\text { Afecciones ginecológicas, } \\
\text { complicaciones } \\
\text { obstétricas, del post-parto } \\
\text { y del puerperio }\end{array}$ & ferite o ragadi ai capezzoli & le seddole \\
\hline $\begin{array}{l}\text { Afecciones ginecológicas, } \\
\text { complicaciones } \\
\text { obstétricas, del post-parto } \\
\text { y del puerperio }\end{array}$ & $\begin{array}{l}\text { infiammazione urinaria, } \\
\text { irritazione, mestruazioni }\end{array}$ & infiammazione femminile \\
\hline $\begin{array}{l}\text { Afecciones } \\
\text { oftalmológicas }\end{array}$ & $\begin{array}{l}\text { (quando brusciavano gli } \\
\text { occhi) }\end{array}$ & marziani \\
\hline $\begin{array}{l}\text { Afecciones } \\
\text { oftalmológicas }\end{array}$ & infiammazione agli occhi & mal agli occhi \\
\hline $\begin{array}{l}\text { Afecciones } \\
\text { oftalmológicas }\end{array}$ & infiammazione agli occhi & occhi arrossati \\
\hline
\end{tabular}




\begin{tabular}{|c|c|c|}
\hline Categoría de uso & $\begin{array}{l}\text { Indicación terapéutica, } \\
\text { explicación en italiano según } \\
\text { el informante }\end{array}$ & Nosología popular \\
\hline $\begin{array}{l}\text { Afecciones } \\
\text { oftalmológicas }\end{array}$ & infiammazione occhi & rinfresca \\
\hline $\begin{array}{l}\text { Afecciones } \\
\text { oftalmológicas }\end{array}$ & miglioramenti oculari & per la vista \\
\hline $\begin{array}{l}\text { Afecciones oro-faríngeas } \\
\text { y de la cavidad oral }\end{array}$ & afte sulle gengivi & $\begin{array}{l}\text { afte provacate dal formaggio o dal } \\
\text { latte crudo }\end{array}$ \\
\hline $\begin{array}{l}\text { Afecciones oro-faríngeas } \\
\text { y de la cavidad oral }\end{array}$ & antiinfiammatorio & rinfresca \\
\hline $\begin{array}{l}\text { Afecciones oro-faríngeas } \\
\text { y de la cavidad oral }\end{array}$ & ascesso del dente & ecèsso \\
\hline $\begin{array}{l}\text { Afecciones oro-faríngeas } \\
\text { y de la cavidad oral }\end{array}$ & fastidio in gola & rasghìn \\
\hline $\begin{array}{l}\text { Afecciones oro-faríngeas } \\
\text { y de la cavidad oral }\end{array}$ & gengivite & frisò in bocca \\
\hline $\begin{array}{l}\text { Afecciones oro-faríngeas } \\
\text { y de la cavidad oral }\end{array}$ & $\begin{array}{l}\text { gengiviti, mal di gola,mal di } \\
\text { denti, infiammazioni in bocca }\end{array}$ & mal di gengivi \\
\hline $\begin{array}{l}\text { Afecciones oro-faríngeas } \\
\text { y de la cavidad oral }\end{array}$ & infiammazione alla bocca & rinfrescante \\
\hline $\begin{array}{l}\text { Afecciones oro-faríngeas } \\
\text { y de la cavidad oral }\end{array}$ & infiammazione in bocca & rinfresca \\
\hline $\begin{array}{l}\text { Afecciones oro-faríngeas } \\
\text { y de la cavidad oral }\end{array}$ & mal di denti & dente bucato \\
\hline $\begin{array}{l}\text { Afecciones oro-faríngeas } \\
\text { y de la cavidad oral }\end{array}$ & mal di denti, stomatiti & mal di bocca \\
\hline $\begin{array}{l}\text { Afecciones oro-faríngeas } \\
\text { y de la cavidad oral }\end{array}$ & mal di gola & raschio di gola \\
\hline $\begin{array}{l}\text { Afecciones oro-faríngeas } \\
\text { y de la cavidad oral }\end{array}$ & orecchioni & gocchioni \\
\hline $\begin{array}{l}\text { Afecciones típicas } \\
\text { infantiles }\end{array}$ & coliche dei lattanti & mal di pancia' dei bambini piccoli \\
\hline $\begin{array}{l}\text { Afecciones } \\
\text { infantiles }\end{array}$ & vermifugo & contro acetone \\
\hline $\begin{array}{l}\text { Afecciones } \\
\text { infantiles }\end{array}$ & arrossamenti del sedere & sedere manimesso \\
\hline Estado general & antiinfiammatorio generale & incalorimenti \\
\hline Estado general & antiinfiammatorio generale & per scioglere il corpo \\
\hline Estado general & antiinfiammatorio generico & $\begin{array}{l}\text { mal in corpo, mal di pancia, } \\
\text { diuretica }\end{array}$ \\
\hline
\end{tabular}




\begin{tabular}{|c|c|c|c|}
\hline \multicolumn{2}{|l|}{ Categoría de uso } & $\begin{array}{l}\text { Indicación terapéutica, } \\
\text { explicación en italiano según } \\
\text { el informante }\end{array}$ & Nosología popular \\
\hline Estado general & & antiinfiammatorio generico & rinfrescante \\
\hline Estado general & & antiinfiammatorio generico & rinfrescante, decongestionante \\
\hline Estado general & & antiinfiammatorio generico & rinfrescante,rilassava \\
\hline Estado general & & antiinfiammatorio generico & sfiamma \\
\hline Estado general & & antinfiammatorio & risolvente \\
\hline Estado general & & antinfiammatorio generico & rinfrescante \\
\hline Estado general & & depurativo & guarisce il sangue \\
\hline Estado general & & depurativo & il cambio del sangue \\
\hline Estado general & & depurativo & $\begin{array}{l}\text { per fare la pel bianca e buono il } \\
\text { fiato }\end{array}$ \\
\hline Estado general & & depurativo' e diuretico & depurativo \\
\hline Estado general & & depurativo, rilassante & $\begin{array}{l}\text { per il calore', cure di Primavera e di } \\
\text { Autunno, fa bene a tutto }\end{array}$ \\
\hline Estado general & & per purificare il sangue' & per purificare il sangue \\
\hline Estado general & & per purificare il sangue' & purifica il sangue \\
\hline Fiebre & & febbre & févre \\
\hline Otras afecciones & & $\begin{array}{l}\text { sensibilità delle estremità del } \\
\text { corpo }\end{array}$ & formigolìo \\
\hline $\begin{array}{l}\text { Patologías del } \\
\text { circulatorio }\end{array}$ & aparato & antiipertensivo & $\begin{array}{l}\text { per mandare in acqua il sangue } \\
\text { grosso", ovvero per diminuire un } \\
\text { elevato tasso pressorio. }\end{array}$ \\
\hline $\begin{array}{l}\text { Patologías del } \\
\text { circulatorio }\end{array}$ & aparato & $\begin{array}{l}\text { diuretico/problemi } \\
\text { circolazione o cardiaci }\end{array}$ & per chi soffriva di cuore \\
\hline $\begin{array}{l}\text { Patologías del } \\
\text { circulatorio }\end{array}$ & aparato & emorroidi & rinfrescante \\
\hline $\begin{array}{l}\text { Patologías del } \\
\text { circulatorio }\end{array}$ & aparato & pressione alta, tachicardia & batticuore \\
\hline $\begin{array}{l}\text { Patologías del } \\
\text { circulatorio }\end{array}$ & aparato & problemi cardiaci & debolezza di cuore o cuore stanco \\
\hline $\begin{array}{l}\text { Patologías del } \\
\text { circulatorio }\end{array}$ & aparato & problemi cardiaci & parpitazioni, calmante cardiaco \\
\hline $\begin{array}{l}\text { Patologías del } \\
\text { circulatorio }\end{array}$ & aparato & problemi di circolazione & piedi gonfi \\
\hline $\begin{array}{l}\text { Patologías del } \\
\text { digestivo }\end{array}$ & aparato & acidità di stomaco & quando uno è riscaldato \\
\hline $\begin{array}{l}\text { Patologías del } \\
\text { digestivo }\end{array}$ & aparato & bruciore di stomaco & fortóri \\
\hline
\end{tabular}




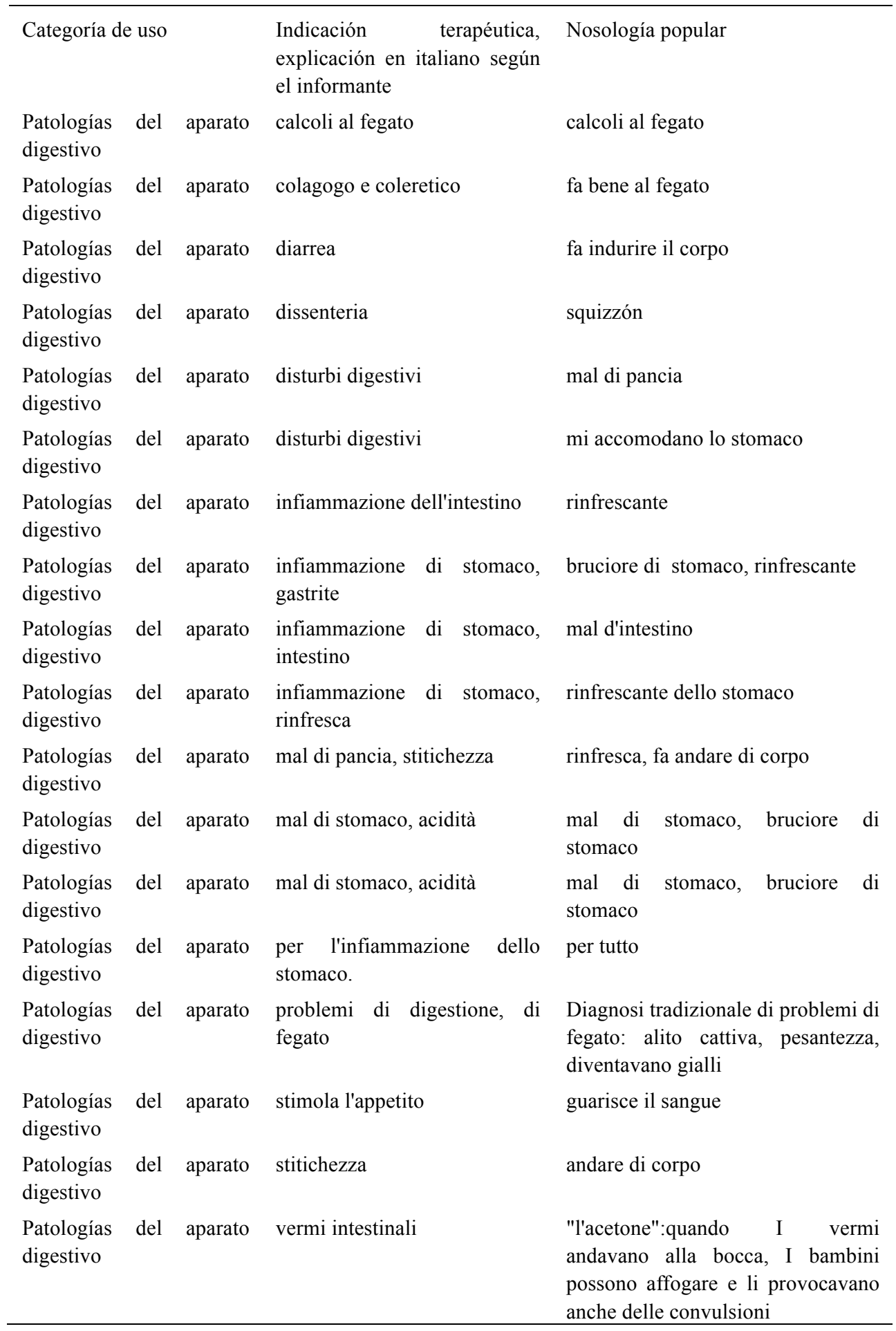




\begin{tabular}{|c|c|c|c|c|}
\hline \multicolumn{3}{|c|}{ Categoría de uso } & \multirow{2}{*}{$\begin{array}{l}\text { Indicación terapéutica, } \\
\text { explicación en italiano según } \\
\text { el informante } \\
\text { vermi intestinali }\end{array}$} & \multirow{2}{*}{$\begin{array}{l}\text { Nosología popular } \\
\text { bachi }\end{array}$} \\
\hline $\begin{array}{l}\text { Patologías } \\
\text { digestivo }\end{array}$ & del & aparato & & \\
\hline $\begin{array}{l}\text { Patologías } \\
\text { urinario }\end{array}$ & del & aparato & diuretico & quando si sentiva del bisogno \\
\hline $\begin{array}{l}\text { Patologías } \\
\text { urinario }\end{array}$ & del & aparato & diuretico & $\begin{array}{l}\text { per chi urinava poco, problemi di } \\
\text { reni }\end{array}$ \\
\hline $\begin{array}{l}\text { Patologías } \\
\text { urinario }\end{array}$ & del & aparato & $\begin{array}{l}\text { diuretico e per infiammazioni } \\
\text { delle vie urinarie }\end{array}$ & per la prostata \\
\hline $\begin{array}{l}\text { Patologías } \\
\text { urinario }\end{array}$ & del & aparato & $\begin{array}{l}\text { diuretico, infezioni di } \\
\text { urina,"mal della pietra", per } \\
\text { infiammazione della vescica e } \\
\text { della prostata. }\end{array}$ & mal della pietra \\
\hline $\begin{array}{l}\text { Patologías } \\
\text { urinario }\end{array}$ & del & aparato & $\begin{array}{l}\text { diuretico, infezioni } \quad \text { vie } \\
\text { urinarie }\end{array}$ & infezione di urina \\
\hline $\begin{array}{l}\text { Patologías } \\
\text { urinario }\end{array}$ & del & aparato & infezione dielle vie urinarie & Infezione di urina \\
\hline $\begin{array}{l}\text { Patologías } \\
\text { urinario }\end{array}$ & del & aparato & infezione urinaria & cistite \\
\hline $\begin{array}{l}\text { Patologías } \\
\text { urinario }\end{array}$ & del & aparato & $\begin{array}{l}\text { Infiammazione del sistema } \\
\text { urinario }\end{array}$ & rinfrescante \\
\hline $\begin{array}{l}\text { Patologías } \\
\text { urinario }\end{array}$ & del & aparato & infiammazioni urinarie & mal di urina,cistite \\
\hline $\begin{array}{l}\text { Patologías } \\
\text { urinario }\end{array}$ & del & aparato & prostata & quando gli uomini non urinavano \\
\hline $\begin{array}{l}\text { Patologías } \\
\text { nervioso }\end{array}$ & del & sistema & calmante & per I nervi \\
\hline $\begin{array}{l}\text { Patologías } \\
\text { nervioso }\end{array}$ & del & sistema & calmante (contro l'insonnia) & guarisce il sangue \\
\hline $\begin{array}{l}\text { Patologías } \\
\text { nervioso }\end{array}$ & del & sistema & calmante per i bambini & calmante \\
\hline $\begin{array}{l}\text { Patologías } \\
\text { nervioso }\end{array}$ & del & sistema & depressione & esaurimento \\
\hline $\begin{array}{l}\text { Patologías } \\
\text { nervioso }\end{array}$ & del & sistema & favorisce il sonno & palpitazioni, calmante cardiaco \\
\hline $\begin{array}{l}\text { Patologías } \\
\text { nervioso }\end{array}$ & del & sistema & favorisce il sonno & per andare a dormire \\
\hline $\begin{array}{l}\text { Patologías } \\
\text { nervioso }\end{array}$ & del & sistema & favorisce il sonno & per dormire \\
\hline Patologías & del & sistema & favorisce il sonno & per l'insonnia \\
\hline
\end{tabular}


Etnobotánica en el Alto Valle del Reno (Toscana y Emilia-Romaña, Italia)

\begin{tabular}{llll}
\hline Categoría de uso & $\begin{array}{l}\text { Indicación } \\
\text { explicación en italiano según } \\
\text { el informante }\end{array}$ & \multicolumn{1}{c}{$\begin{array}{l}\text { terapéutica, } \\
\text { nervioso }\end{array}$} & dolori \\
$\begin{array}{l}\text { Trastornos } \\
\text { esqueléticos }\end{array}$ & musculo- & antidolorifero & umidità nella schiena \\
$\begin{array}{l}\text { Trastornos } \\
\text { esqueléticos }\end{array}$ & musculo- & $\begin{array}{l}\text { antiinfimmatorio, } \\
\text { antidolorifico }\end{array}$ & per sfiammare I nervi \\
$\begin{array}{l}\text { Trastornos } \\
\text { esqueléticos }\end{array}$ & musculo- & contusioni, antiinfiammatorio \\
$\begin{array}{l}\text { Trastornos } \\
\text { esqueléticos }\end{array}$ & musculo- & crampi & grànchi \\
$\begin{array}{l}\text { Trastornos } \\
\text { esqueléticos }\end{array}$ & musculo- & dolori reumatici & mal di ossa, reumatismi \\
$\begin{array}{l}\text { Trastornos } \\
\text { esqueléticos }\end{array}$ & musculo- & infiammazione dei ginocchi & acqua nei ginocchi \\
$\begin{array}{l}\text { Trastornos } \\
\text { esqueléticos }\end{array}$ & musculo- & infiammazioni & dolori e mal di schiena \\
$\begin{array}{l}\text { Trastornos } \\
\text { esqueléticos }\end{array}$ & musculo- & storta al piede & tracolani \\
$\begin{array}{l}\text { Trastornos } \\
\text { esqueléticos }\end{array}$ & musculo- & strappo alla schiena & sdèrnello \\
\hline & & & \\
\hline
\end{tabular}

\subsection{Mezcla de plantas}

Al igual que en el ámbito alimentario, han sido recogidos solo 119 citas (de las 1008 citas medicinales, 11,8\%) sobre mezclas de plantas para tratar las diferentes afecciones relativas a 47 especies (Tab. 41). Las especies que más se mezclan son Medicago sativa L. debido a la popular preparación denominada "fiorume" (con 14 citas, mencionadas por 13 informantes) que consistía en una mezcla de hojas, flores y semillas secas del heno, que se encontraba después de retirar el heno seco en el suelo, se recogía y se guardaba en bolsas de papel o tela. El "fiorume" se trataba de una mezcla de especies que crecen en medio del heno cultivadas o adventicias como Lotus corniculatus L., Trifolium pratense L., Taraxacum campylodes G.E.Haglund (s.1.), Pteridium aquilinum (L.) Kuhn, Matricaria chamomilla L., Papaver rhoeas L. que se recogían ya secas y se utilizaban en infusión para hacer inhalaciones para los resfriados. Las panaceas Matricaria chamomilla L.y Malva sylvestris L. también son mezcladas entre ellas mimas y con otras especies conocidas como Salvia officinalis L., Taraxacum campylodes G.E.Haglund (s.1.) o Sambucus nigra L. Se puede observar como las preparaciones medicinales son al igual que las alimentarias preparaciones principalmente simples basadas en una sola especie (Tab. 41). 


\section{María Teresa Egea Molines}

Tab. 41. Especies más frecuentes en mezclas medicinales.

Mezcladas en las preparaciones medicinales tradicionales con otras especies citadas.

Especies más mezcladas

Medicago sativa L. y otras especies

Salvia officinalis L.

Malva sylvestris L.

Rosmarinus officinalis L.

Taraxacum campylodes G.E.Haglund (s.1.)

Trifolium pratense L.

Citrus limon (L.) Osbeck

Matricaria chamomilla L.

Linum usitatissimum L.

Lotus corniculatus L.

Malus domestica Borkh.

Prunus avium (L.) L.

Prunus domestica L.

Las categorías medicinales para las que más mezclas de especies se emplean son las afecciones del aparato respiratorio (69 citas, debido en parte por la importancia que tiene en esta categoría la mezcla de especies "fiorume"), seguida del estado general (21 citas) y del aparato digestivo (13 citas) (Tab. 42).

Tab. 42. Categorías medicinales en las que más mezclas de plantas se utilizan. Según el número de citas.

\begin{tabular}{ll}
\hline Categorías medicinales & Citas sobre mezclas de plantas \\
Afecciones del aparato respiratorio & 69 \\
Estado general & 21 \\
Patologías del aparato digestivo & 13 \\
Afecciones oro-faríngeas y de la cavidad oral & 7 \\
Patologías del aparato circulatorio & 3 \\
Afecciones cutáneas y tejidos subcutáneos & 2 \\
Afecciones oftalmológicas & 2 \\
Patologías del aparato urinario & 2 \\
Total de citas sobre mezclas & 119 \\
\end{tabular}




\subsection{Partes usadas, formas de preparación y de administración}

Las partes de las plantas más utilizadas son las hojas (283 citas, 61 especies), las flores (flores/inflorescencias y sus partes sumidades floridas, con 152 citas, 24 especies), órganos subterráneos (raíces/bulbos/tubérculos/rizomas, 121 citas, 14 especies, frutos (o infrutescencias/falsos frutos, 112 citas, 30 especies) y partes aereas ( 97 citas, 25 especies). En el 7,04\% (71 citas) de las citas, los informantes han mencionado el uso de partes diferentes de las plantas contemporáneamente para un único uso medicinal. La prevalencia de hojas es un resultado habitual en los estudios etnobotánicos sobre plantas medicinales llevados a cabo en Italia y en Europa como asegura Signorini et al. (2009).

Las formas de preparación de los remedios más frecuentes son la decocción (334 citas, 62 especies), seguidas de "al natural”, es decir sin realizar ningún tipo de transformación o elaboración de la parte de la planta (269 citas, 72 especies), infusión (169 citas, 39 especies). En cuarto lugar se encuentran las denominadas formas "otra preparación" que incluye formas de preparación particulares propias de un lugar concreto o de una familia en concreto (como el carbón de Tilia platyphyllos Scop. para la gastroenteritis, o el polvo de Salix alba L. para la fiebre, ambos de Monte Cavallo, Granaglione), pero también incluyen todos los alimentos medicinales, es decir formas de preparación culinarias e incluso el vinagre o el vino, los cuales tienen una gran representación en la cultura del AVR.

Como se puede ver en la Fig. 40, las formas de preparación de los remedios son muy sencillas, las formas galénicas más elaboradas han sido citadas muy pocas veces como pomadas ( 2 citas, 2 especies), jarabe ( 1 cita, 1 especie), puede que sea un síntoma de que el conocimiento etnofarmocobotánico haya sufrido grandes pérdidas (de hecho 6 formas de preparación de 6 especies medicinales han sido olvidadas) o bien puede que simplemente, como en las demás características de la etnobotánica del AVR, sea una característica más de una cultura rural sencilla la cual no podía dedicar mucho tiempo a elaboraciones complicadas, entre otros motivos, por el gran trabajo que tenían en las actividades domésticas y agroforestales. Además en 26 citas y para un total de 21 especies, las preparaciones pueden ser varias, como infusión o cocción, infusión o decocción, infusión o macerado en agua, etc. Por otra parte las pautas a seguir en las formas de administración de las plantas medicinales no generales y poco precisas, siendo la descripción más común "tomar de vez en cuando", "tomar antes de acostarse" (probablemente por la falta de tiempo), o bien "preparar una botella de decocción y beberla cuando se tiene sed". Estas características denotan una tradición medicinal poco precisa y meticulosa, guíada por el instinto más que por reglas y dosis. De hecho, existe también una nomenclatura en la galénica vernacular, ya que a menudo el término "infusión” era empleado para describir una decocción breve, o incluso para designar un macerado alcohólico, un oleolito o un hidrolito.

Como es muy común, algunas plantas medicinales se recolectaban, se secaban a la sombra, y se conservaban en una bolsa de tela durante todo el año, como las flores de Matricaria chamomilla L., las partes aéreas o las hojas de Malva sylvestris L. o las hojas de Borago officinalis L. y de Taraxacum campylodes G.E.Haglund (s.1.). 


\section{María Teresa Egea Molines}

Al igual que las formas de preparación, las formas de administración más comunes son sencillas y fáciles de preparar. Las formas más citadas son la forma oral (394 citas, 74 especies) y la aplicación directa (314 citas, 63 especies) (normalmente de plantas frescas al natural o bien de emplastos crudos, cocidos o compresas bañadas en infusion o decocciones). Las inhalaciones y vahos son también muy comunes dado la importancia que tienen las afecciones respiratorias en el AVR, así como las formas de administración que se basan en comer con fines alimentarios las especies con beneficios en la salud tienen una buena representación en las prácticas sanitarias tradicionales, como ha sido discutido anteriormente (Fig. 41).

\subsection{Contraste e influencia regional en el conocimiento etnofarmacobotánico}

Contrastando los datos sobre los usos medicinales de la plantas en la parte boloñesa con la parte pistoiesa del AVR, se puede observar como el conocimiento etnofarmacológico es mayor en la parte boloñesa ya que en ésta han sido registrados 554 citas sobre 119 especies medicinales sobre 19 categorías de indicaciones terapéuticas diferentes. En cambio en la parte pistoiesa, han sido recogidos 454 citas sobre 92 especies medicinales referidas a 17 categorías terapéuticas diferentes.

A través del análisis de los mapas ilustradores de las Figuras 33 y 34 sobre la distribución del conocimiento etnofarmacobotánico en los diferentes municipios del AVR en Toscana (AVRT) como en Emilia-Romaña (AVRB), observamos una vez más como los municipios Sambuca Pistoiese y Camugnano presentan un mayor número tanto de especies medicinales como de citas por municipio.

Comparando el número de especies medicinales conocidas por municipio con respecto al número de informantes entrevistados por municipio (es decir las diferencias entre la Fig. 42 y la Fig. 19), la proporción (número de especies medicinales dividido por número de informantes por municipio) denota como el municipio con mayor conocimiento medicinal proporcional es Granaglione $(7,5)$ seguido por Castiglione dei Pepoli $(6,14)$, Castel di Casio $(5,16)$ y Porretta Terme (2,5). En cambio Camugnano y Sambuca Pistoiese presentan un número de especies medicinales menor respecto al número de entrevistados $(1,71$ y 1,87 respectivamente). Destacan una vez más al igual que en el conocimiento fitoalimúrgico, los municipios boloñeses del AVR, por conocer más número de especies medicinales respecto a los informantes entrevistados.

En la parte pistoiesa no han sido mencionados usos medicinales referidos a afecciones del metabolismo ni a la fiebre. Aunque no hay grandes diferencias sobre la importancia de las afecciones tratadas con plantas, en la parte boloñesa predominan los usos de plantas para tratar patologías del aparato digestivo (90 citas), mientras en la parte toscana predominan las afecciones cutáneas (93 citas) (Tab. 43). 
Etnobotánica en el Alto Valle del Reno (Toscana y Emilia-Romaña, Italia)

Tab. 43. Categorías medicinales según la importancia regional en el AVR.

AVRB (Alto Valle del Reno, parte boloñesa), AVRT (Alto Valle del Reno parte pistoiesa)

\begin{tabular}{|c|c|c|c|}
\hline $\begin{array}{l}\text { CATEGORIAS MEDICINALES } \\
\text { EN AVRB }\end{array}$ & $\begin{array}{l}\text { Número } \\
\text { de citas }\end{array}$ & $\begin{array}{l}\text { CATEGORIAS MEDICINALES } \\
\text { EN AVRT }\end{array}$ & $\begin{array}{l}\text { Número } \\
\text { de citas }\end{array}$ \\
\hline Patologías del aparato digestivo & 90 & $\begin{array}{l}\text { Afecciones cutáneas y tejidos } \\
\text { subcutáneos }\end{array}$ & 93 \\
\hline $\begin{array}{l}\text { Afecciones del aparato } \\
\text { respiratorio }\end{array}$ & 88 & $\begin{array}{l}\text { Afecciones del aparato } \\
\text { respiratorio }\end{array}$ & 71 \\
\hline $\begin{array}{l}\text { Afecciones cutáneas y tejidos } \\
\text { subcutáneos }\end{array}$ & 84 & $\begin{array}{l}\text { Afecciones oro-faríngeas y de la } \\
\text { cavidad oral }\end{array}$ & 53 \\
\hline Estado general & 69 & Patologías del aparato digestivo & 52 \\
\hline Patologías del aparato urinario & 46 & Patologías del aparato urinario & 35 \\
\hline $\begin{array}{l}\text { Afecciones oro-faríngeas y de la } \\
\text { cavidad oral }\end{array}$ & 45 & Estado general & 31 \\
\hline $\begin{array}{l}\text { Patologías del aparato } \\
\text { circulatorio }\end{array}$ & 26 & Trastornos musculo-esqueléticos & 28 \\
\hline Patologías del sistema nervioso & 22 & Patologías del sistema nervioso & 23 \\
\hline Afecciones oftalmológicas & 18 & Afecciones oftalmológicas & 20 \\
\hline $\begin{array}{l}\text { Afecciones ginecológicas, } \\
\text { complicaciones obstétricas, del } \\
\text { post-parto y del puerperio }\end{array}$ & 14 & $\begin{array}{l}\text { Patologías del aparato } \\
\text { circulatorio }\end{array}$ & 18 \\
\hline Para provocar enfermedad & 9 & Afecciones típicas infantiles & 6 \\
\hline Afecciones típicas infantiles & 6 & Dolor de cabeza & 5 \\
\hline Dolor de cabeza & 5 & Enfermedades del oído & 5 \\
\hline Afecciones del metabolismo & 4 & Parásitos externos & 5 \\
\hline Enfermedades del oído & 4 & $\begin{array}{l}\text { Afecciones ginecológicas, } \\
\text { complicaciones obstétricas, del } \\
\text { post-parto y del puerperio }\end{array}$ & 4 \\
\hline Fiebre & 3 & Otro medicinal & 4 \\
\hline Otro medicinal & 1 & Para provocar enfermedad & 1 \\
\hline Parásitos externos & 1 & & \\
\hline Trastornos musculo-esqueléticos & 19 & & \\
\hline Medicinal Total & 554 & Medicinal Total & 454 \\
\hline
\end{tabular}

\subsection{Usos novedosos medicinales respecto a la bibliografía local}

De los 334 usos medicinales diferentes registrados durante las entrevistas etnobotánicas solo 45 usos han sido previamente documentados en la bibliografía local relacionados con solo 13 especies medicinales. Por lo que a lo largo de esta investigación han sido relevados 289 usos novedosos.

En la Lámina 9 se ilustran ciertas prácticas tradicionales medicinales del AVR. 


\section{Mágico-Medicinales}

En el tratamiento y prevención de varias afecciones o patologías se utilizan especies botánicas asociadas a prácticas mágico-rituales. Ciertas afecciones son tratadas exclusivamente por ciertas personas llamadas las "segnatrici" que realizan el ritual sincrético de la "segnatura" en el que se mezclan creencias paganas y con la fe cristiana.

La medicina tradicional está compuesta por figuras sanitarias tradicionales cuya experiencia y eficiencia en la cura de enfermedades es reconocida por la comunidad entera. La medicina tradicional se limita en este territorio a las "segnatrici", personas que han heredado la capacidad o el don de curar ciertas enfermedades a través de un ritual a base de rezos cristianos y signos particulares, a veces repetidos por lo menos 3 veces.

Es un rito mayoritariamente cristiano a veces asociado también al paganismo. El don de la "segnatura" se transmite la víspera de Navidad, noche en la que se enseñan los rezos y los signos a la persona elegida. El don se transmite a cualquier persona que tenga buenas intenciones, fe cristiana y que lo practique sin recibir dinero a cambio, y debe elegirlo la persona que lo transmite. Las enfermedades que se tratan mediante este rito son:

- "la paura" es decir "el miedo", entendida como cualquier trauma que se manifieste como el tartamudeo, el ansia, el malestar, el miedo a la oscuridad o a los coches. Los rezos para curar esta patología están dirigidos a San Juan y la especie utilizada para "lavar el miedo" es Stachys recta L., debe recolectarse la víspera de San Juan, el 24 de Junio al amanecer con el rocío.

- "fuoco di Sant'Antonio" o Herpes zoster. Cada tradipracticante lo realiza en un modo, algunos lo hacían con la sangre propia extraída con un alfiler, otros con el anillo de boda, etc.

- "sdernello" es decir una fuerte contracción muscular.

- "i poranci" es decir las verrugas.

- "eresipole" es decir una enfermedad infecciosa de la piel.

Otras prácticas mágico-medicinales no necesitan ser realizadas por el tradipracticantes sino que se realizan por las mismas personas que sufren las afecciones (Tab. 44). Han sido registradas 40 citas relativas a 14 especies diferentes pertenecientes a 9 familias botánicas. Estas especies han sido mencionadas en 16 usos mágico-medicinales sobre 5 categorías de uso diferentes: otro mágicomedicinal, verrugas, vermífugo, contra el miedo y los traumas y preventivo de enfermedades. Estos usos han sido citados por 28 informantes (24,77\%).

Ciertas patologías tratadas con prácticas mágico-rituales a base de especies son muy variadas y peculiares, y han sido clasificadas por "otro mágico-medicinal" ya que constituyen usos particulares de cada comunidad o familia. Encontramos prácticas que tratan desde la tos a base de un rito con Juniperus communis L., a las hemorragias oculares a través de un rito con una tela roja y un emplasto a base de Triticum aestivum L., los eccemas a través de hojas de Rubus ulmifolius Schott acompañados de rezos, o bien los problemas del parto atando ramos de Rubus ulmifolius Schott alrededor de la barriga de la paridora. 
En cambio, han sido registrados otros usos más comunes que se encuentran también en otras zonas de Italia, es la cura de las verrugas a base de ciertos ritos con Phaseolus vulgaris L. o Vicia faba L., o la prevención de enfermedades como llevar frutos de Aesculus hippocastanum L. para prevenir los resfriados, son usos que se encuentran también en Casentino por ejemplo (Camangi et al., 2003).

Tab. 44. Categoría mágico/medicinales en el AVR.

En orden de importancia según el número de especies, el número de citas, y el número de informantes que las citan

\begin{tabular}{llll}
\hline $\begin{array}{l}\text { Categorías } \\
\text { mágico/medicinales }\end{array}$ & Número de especies & Número de citas & Número de informantes \\
Vermífugo & 5 & 13 & 13 \\
$\begin{array}{l}\text { Otro mágico/medicinal } \\
\begin{array}{l}\text { Preventivo de } \\
\text { enfermedades }\end{array}\end{array}$ & 5 & 7 & 7 \\
$\begin{array}{l}\text { Contra el miedo y los } \\
\text { traumas }\end{array}$ & 2 & 8 & 8 \\
$\quad$ Verrugas & 1 & 11 & 10 \\
\hline
\end{tabular}

Solamente dos usos mágico-medicinales han sido documentados en la bibliografía revisada de Allium sativum L. como vermífugo (Ungarelli, 1921) y de Stachys recta L. para los ritos "contra la paura" (Uncini Manganelli y Tomei, 1998; Ungarelli, 1921). Han sido registrados 14 usos mágico-medicinales novedosos respecto a la bibliografía local.

\section{Veterinarios}

Los usos tradicionales de las plantas para fines veterinarios son prácticas totalmente abandonadas ya que pocos tienen animales en la actualidad, y las fincas que tienen crías de animales se rigen sobre todo por las reglas veterinarias y sanitarias para gestionar a sus animales.

Aun así, han sido registradas 86 citas sobre 39 usos etnoveterinarios relativos a 26 especies pertenecientes a 17 familias botánicas. Los usos han sido clasificados en 8 categorías de usos diferentes que corresponden al tipo de animales que tratan: aves de corral, cerdos, conejos, equinos, ganado bovino, otro veterinario, ovejas y cabras, y todos los animales. Estos usos han sido citados por 44 informantes.

Las familias más comunes en la etnoveterinaria no corresponden a las familias de las especies más usadas en el resto de Italia según Nicoletti et al. (2013), ya que en el AVR las más importantes son Ranunculaceae (34 citas, 2 especies), Oleaceae (10 citas, 1 especie), Urticaceae ( 8 citas, 1 especie), Poaceae (7 citas, 4 especies) y 


\section{María Teresa Egea Molines}

Salicaceae (5 citas, 1 especie), en cambio en Italia las más importantes son Asteraceae, Lamiaceae, Leguminosae (Fabaceae), Poaceae, Apiaceae.

La planta más conocida y viva en la memoria de los informantes es Helleborus viridis L. (s.1.) (citada por 34 informantes) cuyas raíces se utilizan para curar tanto ovejas y cabras como el ganado bovino y cerdos, para éstos últimos las enfermedades que trataban eran denominadas en la nosología local como "mal rosso", "mal cittone" o "mèl ziton". El uso del género Helleborus en el ámbito etnoveterinario está muy difundido en muchos territorios de Toscana (Camangi et al., 2003) (Fig.39, Imagen 9.3).

Las otras especies más conocidas en la zona y más versátiles son Fraxinus ornus L. (citada por 10 informantes) (Fig. 39, Imagen 9.9) cuya corteza o ramas se utilizan tanto para curar aves de corral, como conejos, ovejas y cabras y Urtica dioica L. (citada por 8 informantes) cuyas partes aéreas o hojas se utilizan para patologías de las aves de corral, de ovejas y cabras y de cerdos, y se le atribuyen propiedades como antiinflamatorias, antisépticas, diuréticas y antipiréticas en estos animales. La mayor cantidad de remedios es para cerdos (11 especies, 30 citas, 18 informantes) seguido de los remedios para ganado bovino (11 especies, 24 citas y 17 informantes) (Tab. 45).

Tab. 45. Categorías etnoveterinarias en el AVR.

En orden de importancia según el número de especies, el número de citas, y el número de informantes que las citan.

\begin{tabular}{llll}
\hline Categorías veterinarias & Número de especies & Número de citas & Número de informantes \\
Cerdos & 11 & 30 & 18 \\
Ganado bovino & 11 & 24 & 17 \\
Ovejas y cabras & 6 & 15 & 14 \\
Aves de corral & 4 & 9 & 7 \\
Conejos & 3 & 3 & 3 \\
Otro veterinario & 2 & 3 & 3 \\
Equinos & 1 & 1 & 1 \\
Todos los animales & 1 & 1 & 1 \\
\hline
\end{tabular}

La nosología etnoveterinaria no es tan específica como la etnomedicinal y se basa principalmente en la prevención de infecciones, en desinfectar y en diagnosticar desequilibrios en los animales según comportamientos anómalos o generales: "cuando está mal", "cuando está débil". Como el "male rosso" o "mal rosso", que es diagnosticado porque encuentran el cerdo débil, con malestar general, al no comer y no moverse de su establo. Destaca como conciben la acción terapéutica de Helleborus viridis L. (s.l.), ya que según los informantes, la raíz de esta especie al ser introducida en el cuerpo del animal, produce una fiebre importante, seguramente por la toxicidad de la especie (BOE, 2004), que aunque sea 
provocada por la planta, sirve para desinfectar (ya que la fiebre es el mecanismo a través del cual el sistema inmunitario se activa) y curar otras infecciones de origen desconocido, como las denominadas "broncopolmonite" o "polmonite". Por esto la especie es utilizada para afecciones generales (como malestar general) de diferentes animales: vacas, ovejas y cerdos. La desinfección general que causaba la planta se utilizaba también para purificar las ovejas después de un aborto y les devolvía según los informantes hasta la fertilidad. Los tratamientos preventivos también eran muy usados, como en el caso de los conejos, ya que son muy sensibles a las infecciones, o bien en caso de amenazas de epidemias de origen desconocido "moria del maiale". Las afecciones más mencionadas específicamente son las del aparato respiratorio como "polmonite" "stati influenzali, febbre" (estados gripales, fiebre) o "la stone" (la tos de la vaca) y las del aparato digestivo como la hinchazón de las vacas y de las ovejas, la indigestión de la vacas por comer hierba fresca, etc. El término "rinfrescante" al igual que para las personas, es también muy usado para tratar estados generales de los animales, como depurativos y antiinflamatorios generales.

Respecto al contraste bibliográfico de los usos etnoveterinarios, solo un uso registrado en la investigación etnobotánica ha sido documentado previamente por 3 fuentes bibliográficas: Borghi y Zagnoni (1990) o ZAGN90; Guccini (1998) o GUC98 y Ungarelli (1921) o UNGA21. El uso registrado en la bibliografía era el uso de las raíces de Helleborus viridis L. (s.1.) para ciertas enfermedades de los cerdos. Han sido registrados un total de 38 usos novedosos sobre la etnoveterinaria del AVR respecto a la bibliografía local.

\section{Domésticos}

El tercer sector más importante por número de especies citadas y por número de citas es el sector doméstico para el cual han sido mencionadas 404 citas sobre 151 usos domésticos, relativos a 102 especies y pertenecientes a 47 familias botánicas. Las familias botánicas más citadas han sido Rosaceae (57 citas), Fagaceae (30 citas) y Urticaceae (30 citas). Los datos etnobotánicos domésticos han sido clasificados en 14 sectores diferentes (Tab. 46). La categoría más importante es la del uso de las especies prevalentemente silvestres para la integración de la renta familiar (34 especies, 84 citas, 26 informantes), es decir para su venta en pequeñas cantidades a los comerciantes locales, o incluso como moneda de intercambio con otros productos. Es muy interesante ver como la población utilizaba los recursos naturales para obtener productos que no se encontraban en la zona como el intercambio de semillas de Phaseolus vulgaris L., los cuales crecían bien en estas zonas, a cambio del aceite de oliva de las colinas toscanas que era escaso en la montaña. Han sido registradas 34 especies utilizadas para ser vendidas o como intercambio. Especies como Fragaria vesca L. y Rubus idaeus L., entre otros frutos del bosque, eran reservadas para las niñas o las madres para que pudieran recolectarlas y venderlas, y así obtener el poco dinero que conseguían para ellas, ya que eran trabajos menos duros. Estas especies solían venderse a los artesanos de helados de las ciudades cercanas, a los viveros de Pistoia, a las floristerías de las ciudades cercanas y a otro tipo de comerciantes. Las mujeres y niñas vendían las pequeñas cestas que hacían 


\section{María Teresa Egea Molines}

ellas mismas con ramas de Salix sp., llenas de frutos del bosque en la carretera porrettana que conectaba Pistoia con Bolonia y la cual era muy circulada por los habitantes de las ciudades.

La categoría ornamental también tiene gran importancia en la comunidad (20 especies, 39 citas, 26 informantes). Es muy común recolectar las plantas bonitas silvestres y trasplantarlas en el propio jardín como planta ornamental, como pasa como Asparagus tenuifolius Lam., Bellis perennis L., Euonymus europaeus L., Pulmonaria officinalis L. (s.1.). También es muy común recolectar las flores silvestres de los campos y llevarlas a casa para ponerlas en un jarrón con agua como ornamento, como se suele hacer con Lilium bulbiferum L., Myosotis arvensis (L.) Hill o incluso con las flores secas de Carlina acaulis L.

El uso de especies para el cuidado personal y cosmética era muy común en los usos domésticos (14 especies diferentes, 61 citas, 33 informantes). Resaltan las hojas de Mentha spicata L. (s.1.) que se aplicaban sobre las axilas como desodorante cuando iban a misa. Más comunes son los usos de las hojas de Salvia officinalis L. para limpiar los dientes y el uso de la espuma de Saponaria officinalis L. para lavarse las manos (Nicoletti et al., 2013).

Resalta la especie Juglans regia L. (28 citas, 25 informantes) por su uso como tinte natural a base de la decocción de sus frutos para teñir el pelo pero también para teñir la ropa y la lana de color tierra o bien de color verde. Buxus sempervirens L. destaca por su uso muy difundido (26 citas, 24 informantes) para controlar la temperatura justa del horno de leña, se ponía dentro una rama, si salía quemada quería decir que estaba demasiado fuerte, o bien otros dicen que absorbía el exceso de temperatura para cocer el pan y evitar que se quemara la parte externa del pan, se llamaba "levare la bronza". Y junto con otras especies como Prunus spinosa L. e Ilex aquifolium L. se ataban juntas y se utilizaban para limpiar el humero.

Otro uso muy común es el de utilizar las hojas de Castanea sativa Mill. de la variedad "Pastenese" para realizar los típicos necci a base de harina de castañas, que eran el pan de la montaña, ya que además de evitar que la masa se pegara a las piedras con las que se preparaban, les daba una aroma agradable.

Tab. 46. Categorías de usos domésticos.

En orden de importancia según el número de especies, el número de citas, y el número de informantes que las citan.

\begin{tabular}{llll}
\hline Categorías domésticas & $\begin{array}{l}\text { Número de } \\
\text { especies }\end{array}$ & $\begin{array}{l}\text { Número de } \\
\text { citas }\end{array}$ & $\begin{array}{l}\text { Número de } \\
\text { informantes }\end{array}$ \\
Integración de la renta familiar & 34 & 84 & 26 \\
Ornamental & 20 & 39 & 26 \\
Cuidado personal y cosmética & 14 & 61 & 33 \\
Chimenea y horno & 12 & 52 & 30 \\
Detergente & 11 & 23 & 15 \\
Otro doméstico & 10 & 30 & 23 \\
Ambientador & 10 & 22 & 19 \\
\hline
\end{tabular}


Etnobotánica en el Alto Valle del Reno (Toscana y Emilia-Romaña, Italia)

\begin{tabular}{llll}
\hline Categorías domésticas & $\begin{array}{l}\text { Número de } \\
\text { especies }\end{array}$ & $\begin{array}{l}\text { Número de } \\
\text { citas }\end{array}$ & $\begin{array}{l}\text { Número de } \\
\text { informantes } \\
10\end{array}$ \\
Jardín & 10 & 13 & 11 \\
Objetos domésticos y escobas & 9 & 16 & 9 \\
$\begin{array}{l}\text { Repelentes o trampas } \\
\text { domésticas }\end{array}$ & 8 & 10 & \\
Tintorial & 6 & 30 & 20 \\
Ropa de cama y muebles & 3 & 13 & 13 \\
Detergente/tintorial & 2 & 6 & 5 \\
Tinta o utensilio para escribir & 2 & 5 & 5 \\
\hline
\end{tabular}

De los 151 usos diferentes registrados durante las entrevistas etnobotánicas, solamente 8 usos sobre 8 especies han sido previamente documentados en la bibliografía local como el uso de Buxus sempervirens L. para setos en el jardín, el uso de hojas de Castanea sativa Mill. para evitar que la masa de castañas de los "necci" se peguen a las piedras con las que se cocina, el uso de Lavandula angustifolia Mill. como ambientador de armarios, los cuales son usos muy comunes. Sin embargo han sido relevados un total de 143 usos novedosos domésticos no registrados previamente en la bibliografía local consultada.

En la Lámina 10 se ilustran ciertas prácticas tradicionales domésticas del AVR.

\section{Agropastoral}

En el sector agropastoral, han sido recogidas 308 citas relativas 134 usos diferentes a partir de 77 especies pertenecientes a 33 familias botánicas. Las familias más citadas han sido Fagaceae (42 citas), Urticaceae (42 citas), Salicaceae (35 citas) y Rosaceae (24 citas). Los usos agropastorales han sido clasificados en 17 categorías diferentes. El uso más importante corresponde a la alimentación animal (incluidos los forrajeros) (26 especies, 83 citas, 46 informantes), seguida de las herramientas y objetos agrícolas (26 especies, 63 citas, 26 informantes), de las prácticas de horticultura (18 especies, 27 citas y 17 informantes) y de las cuerdas y ataduras (13 especies, 27 citas, 14 informantes) (Tab. 47). 


\section{María Teresa Egea Molines}

Tab. 47. Categorías de usos agropastorales en el AVR.

En orden de importancia según el número de especies, el número de citas, y el número de informantes que las citan.

\begin{tabular}{|c|c|c|c|}
\hline Categorías agropastorales & $\begin{array}{l}\text { Número de } \\
\text { especies }\end{array}$ & $\begin{array}{l}\text { Número de } \\
\text { citas }\end{array}$ & $\begin{array}{l}\text { Número de } \\
\text { informantes }\end{array}$ \\
\hline $\begin{array}{l}\text { Alimentación animal (incluidos los } \\
\text { forrajeros) }\end{array}$ & 26 & 83 & 46 \\
\hline Herramientas y objetos agrícolas & 26 & 63 & 26 \\
\hline Horticultura & 18 & 27 & 17 \\
\hline Cuerdas y ataduras & 13 & 27 & 14 \\
\hline Vallas y delimitaciones & 9 & 22 & 14 \\
\hline Otro agropastoral & 7 & 13 & 10 \\
\hline Apicultura & 7 & 9 & 3 \\
\hline Antiparasitario & 6 & 17 & 11 \\
\hline Productos lácteos & 5 & 15 & 15 \\
\hline Avicultura & 4 & 4 & 4 \\
\hline Cría de ovejas & 3 & 9 & 6 \\
\hline Cría de ganado bovino & 3 & 5 & 5 \\
\hline Construcción agrícola (cabañas, etc...) & 3 & 4 & 4 \\
\hline Repelentes y trampas & 1 & 4 & 4 \\
\hline Cría de cerdos y productos porcinos & 1 & 2 & 2 \\
\hline Portainjertos & 1 & 2 & 2 \\
\hline Viticultura y enología & 1 & 2 & 2 \\
\hline
\end{tabular}

Las especies más citadas son Urtica dioica L. (35 citas), Castanea sativa Mill. (31 citas), Pteridium aquilinum L. Kuhn (17 citas) y Buxus sempervirens L. (12 citas).

La especie más versátil es Castanea sativa Mill. con 10 categorías diferentes de aplicación: alimentación animal, apicultura, construcción agrícola, cría de ovejas, cuerdas y ataduras, herramientas y objetos agrícolas, horticultura, otro agropastoral, vallas y delimitaciones y viticultura y enología. Aunque la especie más popular es Urtica dioica L., mencionada por 30 informantes seguida por Castanea sativa Mill. mencionada por 22 informantes), la cual se utiliza para 4 categorías diferentes: alimentación animal, antiparasitario, avicultura, horticultura.

De los 134 usos recogidos durante la investigación etnobotánica solamente 17 usos sobre 13 especies han sido documentados en la bibliografía local consultada. Los 117 usos restantes son usos novedosos y genuinos del presente estudio.

En la Fig. 46 se ilustran algunas prácticas agropastorales tradicionales del AVR. 


\section{Artesanal}

Han sido registrados un total de 85 citas sobre 44 usos artesanales de las plantas, relacionados con 31 especies diferentes pertenecientes a 18 familias. La familia botánica más importante es Salicaceae con 7 especies botánicas y 29 citas. La especie más citada y más versátil es Buxus sempervirens L. con 11 citas relativas a 4 categorías diferentes: instrumentos y utensilios para la artesanía, muebles, objetos domésticos, otro artesanal. Destaca el género Salix, ya que se emplean 5 taxones diferentes de este mismo género: Salix alba L., Salix alba var. vitellina (L.) Stokes, Salix eleagnos Scop., Salix purpurea L., Salix triandra L. para el uso de cestería y muebles, excepto Salix alba var. vitellina (L.) Stokes que también es utilizado para objetos domésticos (como la cuna de los niños).

Las categorías más importantes son los objetos domésticos como los mangos de los cuchillos, cucharones o armarios para la cocina (11 especies, 22 citas, 11 informantes) seguidos de los muebles (8 especies, 8 citas y 4 informantes) y de la cestería (7 especies, 22 citas, 10 informantes) (ver Tab. 48).

En el ámbito de la cestería es curioso notar como casi todos los informantes (9 de 10) son hombres, lo cual denota que es un sector más bien masculino.

Tab. 48. Categorías de usos artesanales en el AVR.

En orden de importancia según el número de especies, el número de citas, y el número de informantes que las citan

\begin{tabular}{llll}
\hline Categorías artesanales & $\begin{array}{l}\text { Número de } \\
\text { especies }\end{array}$ & $\begin{array}{l}\text { Número de } \\
\text { citas }\end{array}$ & $\begin{array}{l}\text { Número de } \\
\text { informantes }\end{array}$ \\
Objetos domésticos & 11 & 22 & 11 \\
Muebles & 8 & 8 & 4 \\
Cestería & 7 & 22 & 10 \\
Instrumentos y utensilios para la & 7 & 11 & 7 \\
artesanía & 3 & & \\
Tejer sillas & 3 & 9 & 7 \\
Fibra textil & 3 & 3 & 4 \\
Otro artesanal & 2 & 5 & 3 \\
Objetos personales y calzado & & & 5 \\
\hline
\end{tabular}

Solamente 5 usos han sido registrados previamente en la bibliografía local, relacionados con Buxus sempervirens L., Cytisophyllum sessilifolium (L.) O.Lang, Fagus sylvatica L., Salix alba L., Spartium junceum L., por lo que han sido registrados un total de 39 usos artesanales novedosos.

En la Fig. 47 y Fig. 48 se ilustran ciertas prácticas tradicionales artesanales del AVR. 


\section{Mágico-ritual-supersticioso}

En el sector mágico/ritual/supersticioso se incluyen los usos de las plantas relativos a las creencias paganas, a la superstición, a las festividades religiosas, así como en el folclore, en las ceremonias o en definitiva en la cultura inmaterial. Al igual que en el sector mágico/medicinal, vemos como las creencias de la cultura del AVR se basan en un sincretismo entre el paganismo y el catolicismo. Los usos de índole pagana son los adivinatorios y algunos protectores (contra las brujas, los malos espíritus, el mal ojo y algunos para proteger los campos y controlar el tiempo). Mientras que los usos de índole más religioso son las costumbres navideñas, algunos propiciatorios (como el uso del olivo bendito), y los usos relacionados con las demás fiestas católicas. En este sector las plantas están a menudo relacionadas con fechas precisas, pertenecientes al calendario litúrgico católico, como constata también Carvalho (2005) en el nordeste de Portugal, como el 30 abril, los ritos del mayo, Nochebuena, Santa Croce (3 Mayo), Domingo de Ramos, Jueves Santo, el día de San José.

Han sido registrados 104 citas sobre 35 usos relativos a 27 especies pertenecientes a 20 familias botánicas diferentes. Los usos han sido clasificados en 7 categorías diferentes.

La especie más popular es Juniperus communis L. (21 citas, 19 informantes) representa perfectamente el sincretismo de las creencias del AVR, ya que es usado tanto para alejar las brujas y el "mal de ojo" (malocchio) en diferentes formas (categoría "protector"), como para realizar un fuego sagrado para bendecir la Nochebuena (categoría "rituales navideños" de origen católico). También destaca Olea europaea L. (20 citas, 15 informantes) por representar el sincretismo que existe en las comunidades locales, ya que el ramo bendecido por el sacerdote (práctica de origen católica), el Domingo de Ramos ("ramo benedetto") es muy utilizado como propiciatorio y como protector de los campos y las casas de temporales y otros desastres climatológicos. Al mismo tiempo es muy común la práctica mágico-ritualsupersticiosa de "levare il malocchio" (quitar el mal de ojo) a través de un rito practicado por personas (por lo general mujeres) a quien se les transmite el don de generación en generación, y basado en echar aceite de oliva en un plato con agua (Fig. 16, Imagen 6.2). El "mal'occhio" es concebido como la envidia de las personas que transmiten malas energías, y hacen que una persona envidiada por otra tenga mala suerte, le sucedan sólo cosas negativas que se traducen a veces en patologías o desequilibrios anómalos en las propias personas pero también de sus animales, es por ello que a veces éstos usos pueden estar clasificados como "mágicomedicinales". La importancia de este rito contra el mal de ojo ha sido encontrada también en otras partes de Toscana, en los que el uso mágico-ritual de Juniperus communis L. y Olea europaea L. también se han puesto de manifiesto (Pieroni, 2000; Pieroni y Giusti, 2002), así como en el sur de Italia (Pieroni et al., 2004).

La mayoría de las 20 citas son mencionadas en la parte toscana del AVR (solo 3 citas de 20 han sido mencionadas en la parte boloñesa) como es normal por la importancia que tiene el olivo en la cultura toscana. La tercera especie más importantes es Ilex aquifolium L. (10 citas, 10 informantes), la cual es usada igual que Juniperus communis L. como protector y en los ritos navideños. 
Etnobotánica en el Alto Valle del Reno (Toscana y Emilia-Romaña, Italia)

A través del análisis de las categorías mágico/ritual/supersticioso, se puede observar una vez más como se mezclan las culturas boloñesa y toscana en el AVR. Los rituales del Mayo ("30 maggio" o "cantarmaggio toscano") son unas prácticas muy características de las tradiciones toscanas que encontramos sobre todo en la parte boloñesa del AVR: 6 citas sobre 10 han sido mencionadas en la parte boloñesa del AVR. De hecho estos resultados, ratifican lo que el investigador local Bill Homes asegura cuando intenta explicar que en el AVR existe una identidad cultural común a pesar de las fronteras culturales: "Basterebbe aver presenti le tradizioni della valle, dove usanze tipiche della Toscana come il maggio lirico, quello che si cantava nella notte fra il 30 aprile e il primo di maggio, o quello delle anime purganti, che rappresenta il tentativo della Chiesa di cristianizzare una tradizione sentita come potenzialmente pagana, sono ugualmente distribuite da Treppio a Badi ed in altri centri del Bolognese" (citado en Alto Reno Toscano II, 2016).

La categoría más importante es la del uso de las plantas como protectores (13 especies, 44 citas, 20 informantes) seguidas de los propiciatorios (8 especies, 18 citas, 13 informantes) y por los rituales del Mayo (5 especies, 10 citas, 7 informantes) (Tab. 49).

Tab. 49. Categorías de uso mágico/ritual/supersticioso en el AVR.

En orden de importancia según el número de especies, el número de citas, y el número de informantes que las citan.

\begin{tabular}{llll}
\hline Categorías & Número de & Número de & Número de \\
mágico/rituales/supersticioso & especies & citas & informantes \\
Protector & 13 & 44 & 20 \\
Propiciatorio & 8 & 18 & 13 \\
Rituales de Mayo & 5 & 10 & 7 \\
Rituales navideños & 3 & 25 & 22 \\
Efecto negativo & 2 & 3 & 2 \\
Adivinatorio & 2 & 2 & 2 \\
Otro mágico/ritual/supersticioso & 2 & 2 & 1 \\
\hline
\end{tabular}

Respecto a las fuentes bibliográficas consultadas de la zona, han sido recogidos 25 usos novedosos sobre la cultura y las creencias mágicas, rituales o supersticiosas.

En la Lámina 14 se ilustran ciertas prácticas tradicionales mágico-ritualessupersticiosas del AVR.

\section{Lúdico-voluptuoso}

En el sector lúdico/voluptuoso, han sido registradas 86 citas, sobre 34 usos diferentes, relativas a 22 especies y pertenecientes a 16 familias botánicas. Los usos han sido clasificados en 9 categorías diferentes (Tab. 50). Este sector recoge todos 


\section{María Teresa Egea Molines}

los usos relacionados con cualquier tipo de juego colectivo o individual, pasatiempo e incluso las plantas fumables.

Castanea sativa Mill. es la especie más utilizada en este sector (12 citas, 9 informantes) además de ser la más versátil, ya que es utilizada en categorías diferentes: decoraciones y disfraces de niños, juguetes, muñecas y sobre todo para la realización de diferentes tipos de instrumentos musicales.

Buxus sempervirens L. también es una especie importante (8 citas, 8 informantes, 1 categoría) por su popular uso del juego "fiore verde" que se realizaba entre los habitantes de la comunidad en Pascua y trataba en que si una persona decía a otra "fiore verde" esta última debía sacar del bolsillo un ramo de Buxus sempervirens L., sino pagaba una pena (como invitar algo en el bar). Otra especie muy conocida es Clematis vitalba L. por su uso difundido de fumar los ramos huecos y secos (10 citas, 10 informantes, 1 categoría).

Sambucus nigra L. (9 citas, 8 informantes) es utilizado para 3 categorías diferentes: decoraciones y disfraces para niños, fumable, juego colectivo y bromas. Y Silene vulgaris (Moench) Garcke también fue citada 8 veces por 8 informantes para juegos colectivos y bromas, y como pasatiempos.

La categoría más importante es la fumable, con 21 citas relativas a 8 especies, mencionados por 14 informantes. Las especies fumables son Clematis vitalba L., Juglans regia L., Sambucus nigra L., Solanum tuberosum L., Trifolium pratense L., Vitis vinifera L., Zea mays L. además de Ficus carica L. que es utilizado para la realización de pipas.

Tab. 50. Categorías de uso lúdico/voluptuoso en el AVR.

En orden de importancia según el número de especies, el número de citas, y el número de informantes que las citan

\begin{tabular}{llll}
\hline Categorías lúdico voluptuoso & $\begin{array}{l}\text { Número de } \\
\text { especies }\end{array}$ & $\begin{array}{l}\text { Número de } \\
\text { citas }\end{array}$ & $\begin{array}{l}\text { Número de } \\
\text { informantes }\end{array}$ \\
Fumable & 8 & 21 & 14 \\
Pasatiempos & 6 & 11 & 7 \\
$\begin{array}{l}\text { Decoraciones y disfraces } \\
\text { niños }\end{array}$ & 6 & 9 & 8 \\
Juego colectivo y bromas & 5 & & \\
Instrumentos musicales & 4 & 27 & 23 \\
Alimentos/juguetes & 2 & 11 & 10 \\
Juguetes & 1 & 3 & 2 \\
Muñecas & 1 & 2 & 2 \\
Otro lúdico & 1 & 1 & 1 \\
\hline
\end{tabular}

De los 34 usos registrados durante las entrevistas, 27 han resultado ser novedosos respecto a los usos documentados previamente en bibliografía local. Los 
7 usos registrados en las fuentes consultadas equivalen a los usos más conocidos por la población como el juego del "fiore verde" con Buxus sempervirens L., los instrumentos musicales con Castanea sativa Mill., fumar los tallos de Clematis vitalba L., los juegos colectivos y bromas a base de Sambucus nigra L. y Silene vulgaris (Moench) Garcke, o soplar las semillas de Taraxacum campylodes G.E.Haglund (s.1.) como pasatiempos.

En la Lámina 15 se ilustran ciertas prácticas tradicionales lúdico-voluptuosas del AVR.

\section{Religioso}

Los usos relacionados con la veneración de las figuras religiosas católicas, así como todos los usos relativos con las iglesias, los santuarios, y fiestas religiosas donde prevalece la componente católica, han sido clasificados a parte en el sector religioso.

Han sido registrados 38 citas sobre 24 usos religiosos a base de 19 especies pertenecientes a 13 familias botánicas. Los usos han sido clasificados en 5 categorías diferentes: rogativas, ornamento para altares e iglesias, alfombras florales, procesiones, otro religioso.

Las especies más utilizadas son Bellis perennis L. (6 citas, 6 informantes) y Rosa cv. (4 citas, 4 informantes), ambas para la realización de alfombras florales y ornamento para altares e iglesias. Respecto al uso de las plantas como ornamento de altares hemos podido comprobar observando los altares que se encuentran distribuidos por las localidades del valle que actualmente se trata de usos pasados y abandonados, ya que como se puede apreciar en las imágenes de la Fig. 51, los altares de la montaña son hoy en día adornados con plantas de plástico.

En la investigación bibliográfica no han sido relevados usos religiosos etnobotánicos sobre plantas, por lo que los 24 usos registrados durante las entrevistas de campo son novedosos.

\section{Caza y pesca}

La caza y la pesca eran un gran recurso para la alimentación familiar. Sin embargo, han sido muy pocos los usos de las plantas para estos fines.

Han sido registrados 37 citas sobre 17 usos relativos a 17 especies pertenecientes a 12 familias botánicas y relacionadas con 3 categorías diferentes: caza de pájaros, ictiotóxico, otro caza y pesca. Respecto a la caza solo han sido mencionadas especies que servían para la caza de pájaros como Cornus sanguinea L., Fagus sylvatica L., Hedera helix L., Ilex aquifolium L., Loranthus europaeus Jacq., Quercus pubescens Willd., Sorbus aria (L.) Crantz, Sorbus aucuparia L., Sorbus torminalis (L.) Crantz.

Resaltan las especies ictiotóxicas como Solanum americanum Mill., Saponaria officinalis L. y Helleborus viridis L. (s. 1.) para la pesca en los ríos, así como las cuatro especies del género Salix, Salix alba L., Salix alba var. vitellina (L.) Stokes, Salix eleagnos Scop. y Salix purpurea L. para realizar utensilios útiles para la pesca. 


\section{María Teresa Egea Molines}

Han sido encontradas muy pocas citas en la bibliografía local sobre el uso tradicional de las plantas para caza y pesca. Aunque Ilex aquifolium L. haya sido documentado por Ungarelli (1921) con empleo en caza y pesca las formas de uso eran muy distintas, ya que los informantes del AVR se ponían debajo de la especie para cazar ciertos pájaros, en cambio Ungarelli afirma que con la corteza de dicha especie se preparaba una trampa para cazar pájaros. Por esto los 17 usos recogidos en la investigación corresponden a usos novedosos sobre caza y pesca, ya que no han sido documentados previamente (Lista de Especies de uso en Caza y Pesca).

\section{Efecto nocivo}

Los conocimientos tradicionales sobre las precauciones a seguir con ciertas plantas tóxicas o nocivas por sus efectos indeseables, han sido recogidos en este sector. 12 especies fueron citadas para 12 usos o conocimientos sobre las propiedades nocivas de dichas especies, pertenecientes a 12 familias diferentes. Los usos han sido clasificados sólo en 2 categorías: 1, efecto perjudicial y 2, tóxicas y venenosas. A través del análisis de los resultados, la escasez de noticias recogidas sobre los efectos nocivos de las plantas puede ser debido a que los informantes no consideraban este conocimiento como un uso directo, por lo que ha sido evitado, o bien porque pocas personas perciben las plantas como tóxicas o perjudiciales. La especie más conocida es Atropa belladona L. (4 citas, 4 informantes), el resto son conocidas solo por un informante es decir son conocimientos raros, propios de una sola persona, como Ilex aquifolium L., Daphne laureola L. y Conium maculatum L. Algunos recuerdan que los ancianos de la comunidad les prohibían acercarse a plantas como es el caso de Sambucus ebulus L., Phytolacca americana L., Euonymus europaeus L., Elaeagnus rhamnoides (L.) A.Nelson. En los casos de los efectos nocivos, son conocimientos relativos al efecto perjudicial o negativo que podían dar ciertas plantas como comer Lactuca sativa L. provocaba acidez de estómago, no se puede cultivar plantas debajo de Ficus carica L. porque no crecen, y donde está Calluna vulgaris (L.) Hull se encuentran las víboras.

Los 12 usos registrados durante las entrevistas etnobotánicas son usos novedosos, ya no han sido documentados previamente en la bibliografía local. 
Etnobotánica en el Alto Valle del Reno (Toscana y Emilia-Romaña, Italia)

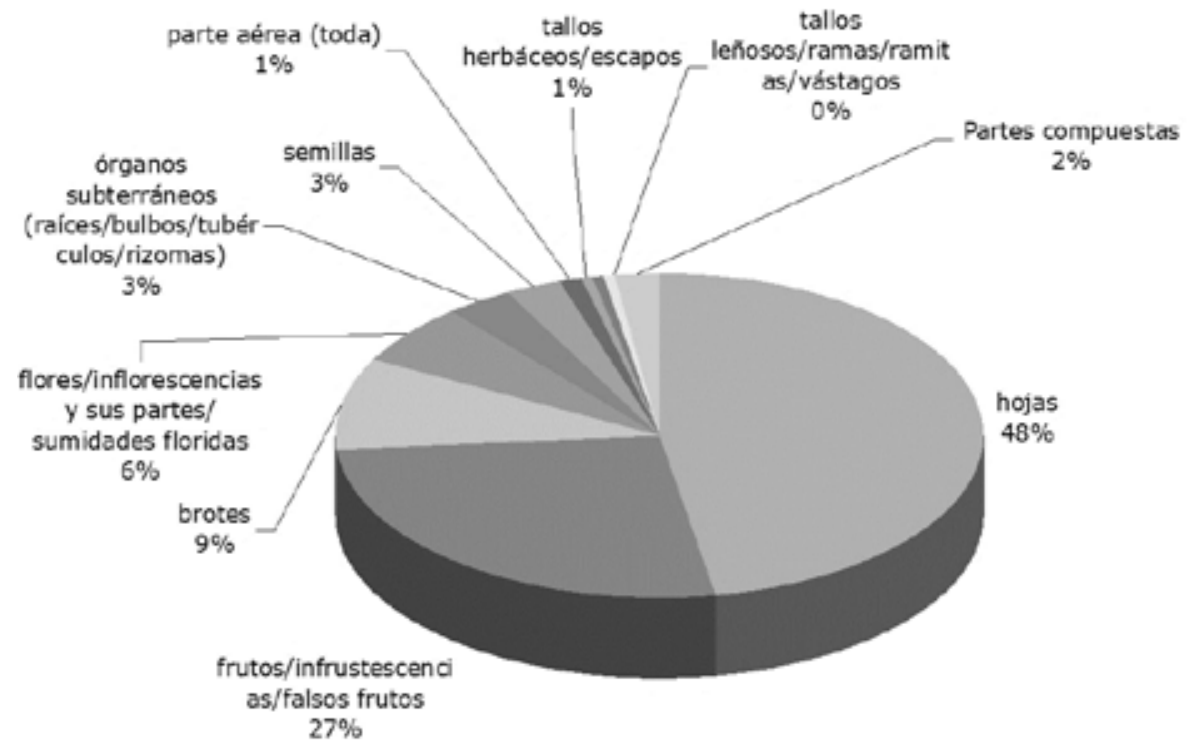

Fig. 31. Partes de las plantas más utilizadas en el AVR. Según el número de citas. 
María Teresa Egea Molines
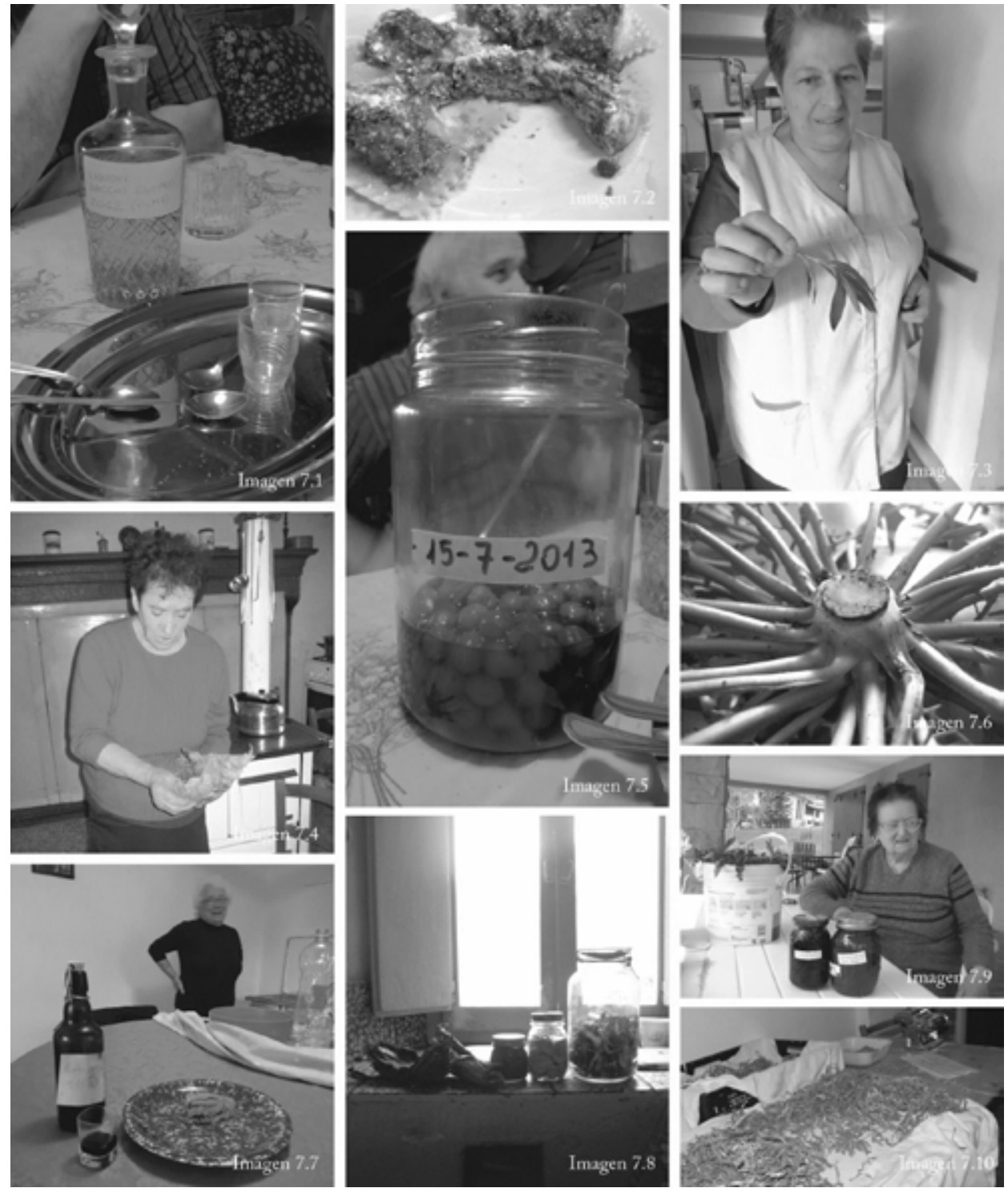

Fig. 32. Sector etnobotánico alimentario I.

Imagen 7.1. Licor casero a base de Juniperus communis L. Imagen 7.2. Ravioli relleno de Silene vulgaris (Moench) Garcke. Imagen 7.3. Cocinera local de los ravioli a base de Silene vulgaris (Moench) Garcke, con una muestra de la planta, Lentula. Imagen 7.4. Informante con las hojas de Castanea sativa Mill. secas usadas para evitar que se pegue la masa a las piedras con las que se hacen los "necci". Imagen 7.5. Conserva de Prunus cerasus L. Imagen 7.6. "Cul bianco" o Cichorium intybus L., nombre vulgar relacionado con la forma de la parte inferior de la planta ya que según el informante se debe recolectar la parte superior de la raíz y que es muy blanca. Imagen 7.7. Licor a base de frutos de Juglans regia L. "nocino" muy practicado en el 
Etnobotánica en el Alto Valle del Reno (Toscana y Emilia-Romaña, Italia)

territorio, y un bizcocho tradicional a base de Vitis vinifera L. "Zibebe" típico de Castiglione dei Pepoli y Casalecchio llamado "pinza". Imagen 7.8. Conserva de mermelada de Ficus carica L., Boletus edulis L. secos junto a las hojas secas de Castanea sativa Mill. para los "necci", en una cocina tradicional. Imagen 7.9. Mermeladas de Prunus cerasus L. y de Pyrus communis L. y Ficus carica L. , junto a un cubo de Taraxacum campylodes G.E.Haglund (s.l.). y otros "radicchi" apenas recolectados (Bivio di Provalecchio). Imagen 7.10. Elaboración de tagliatelle (pasta casera) hechas a mano con Urtica dioica L. Fotos de Teresa Egea.
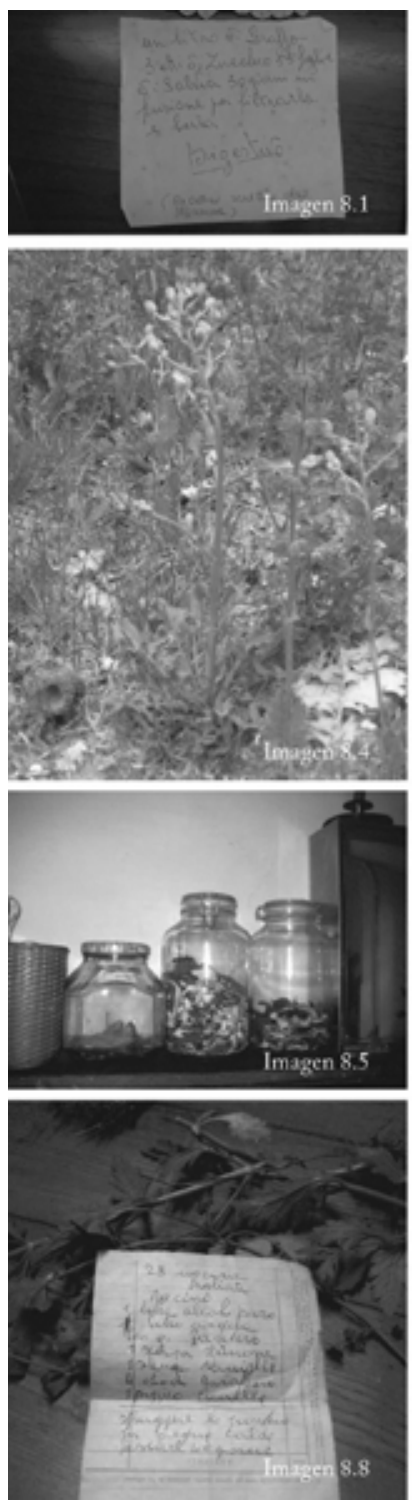
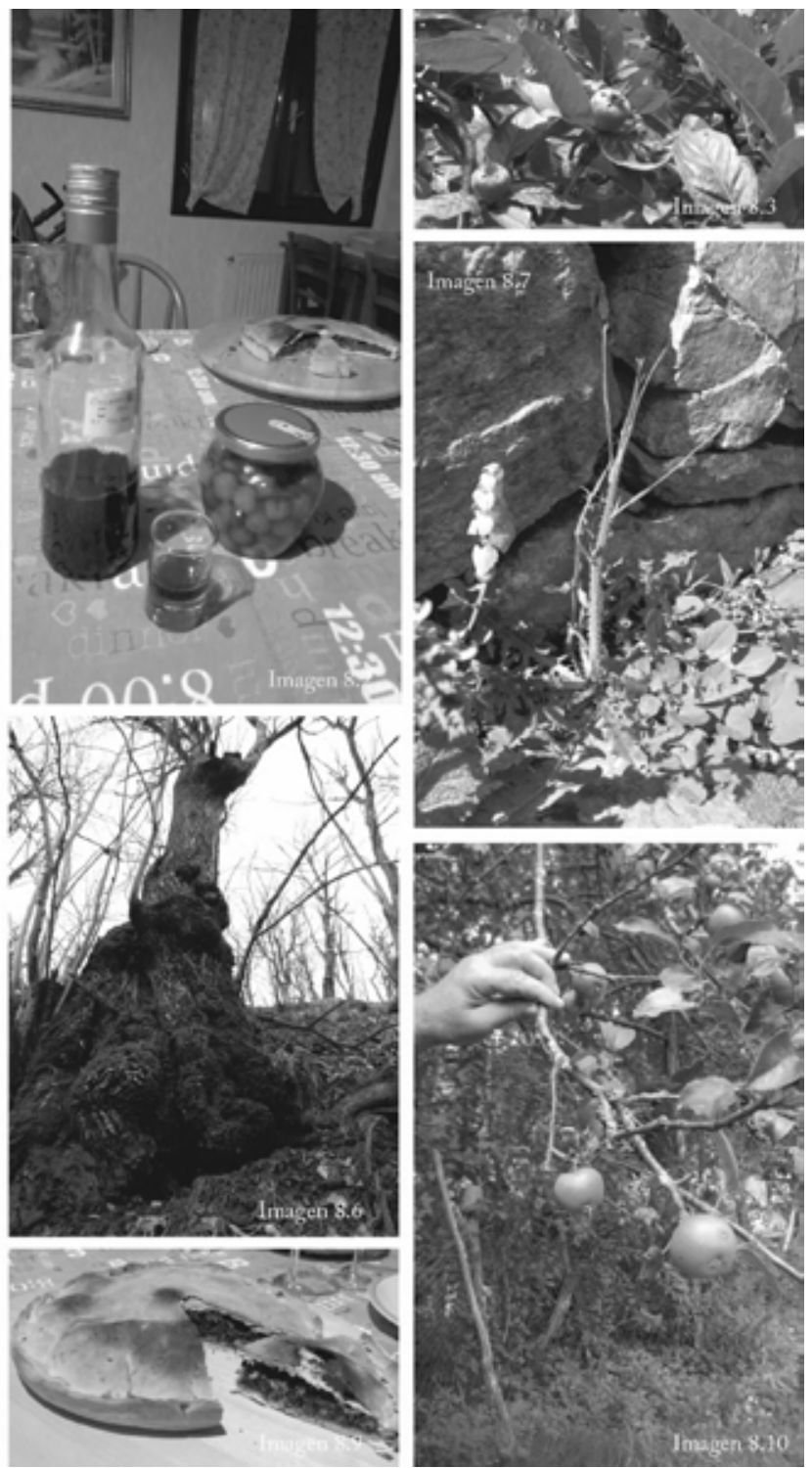

Fig. 33. Sector etnobotánico alimentario II. 


\section{María Teresa Egea Molines}

Imagen 8.1. Receta del licor a base de Salvia officinalis L. escrita por la madre de la informante y trasmitida a la hija que todavia lo practica. Imagen 8.2. Licor y conserva de frutas de Prunus cerasus L. Imagen 8.3. Fruto de Sorbus domestica L. consumidos en maduración excesiva. Imagen 8.4. Crepis vesicaria L. en flor. Imagen 8.5. Hojas de Laurus nobilis L. usados para conservar los Boletus edulis L. secos. Imagen 8.6. Castanea sativa Mill. "Pastenese" cuyas hojas se utilizan para aromatizar los "necci" a base de harina de castañas. Imagen 8.7. Chondrilla juncea L., brote joven de la inflorescencia, comida como si fueran brotes de Asparagus acutifolius L. Imagen 8.8. Receta del licor a base de frutos de Juglans regia L. "nocino", escrito por la madre de la informante y todavía practicado per esta última. Imagen 8.9. "Schiaccia alle erbe" realizada con Silene vulgaris (Moench) Garcke, Urtica dioica L., Clematis vitalba L. y Cichorium intybus L. Imagen 8.10. Malus domestica Borkh. "Antiche", Le Fabbriche. Fotos de Teresa Egea.

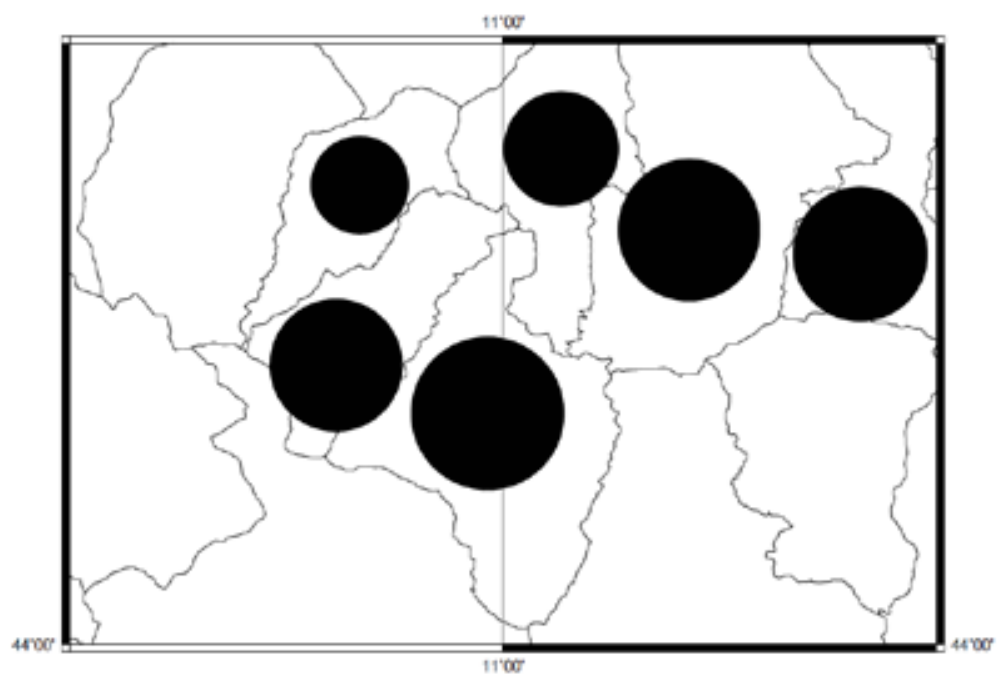

Fig. 34. Mapa del número de especies alimentarias por municipio.

La superficie del círculo es proporcional al número de especies alimentarias. En el mapa en la parte superior, de izquierda a derecha: Porretta Terme, Castel di Casio, Camugnano, Castiglione dei Pepoli, en la parte inferior, de izquierda a derecha, Granaglione, Sambuca Pistoiese. 


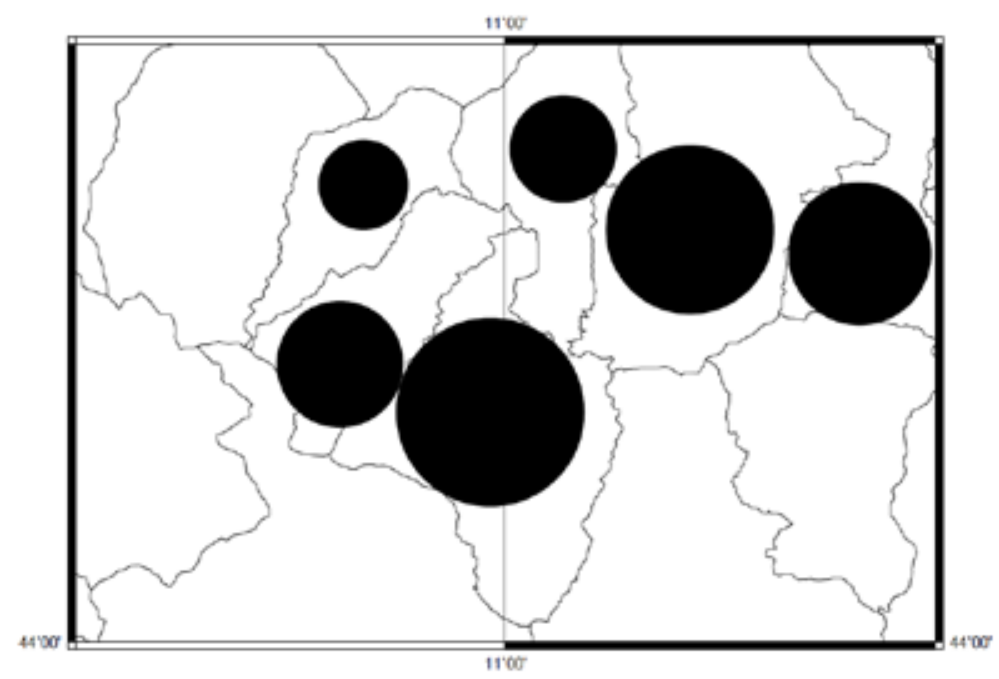

Fig. 35. Mapa del número de citas alimentarias por municipio.

La superficie del círculo es proporcional al número de citas alimentarias. En el mapa en la parte superior, de izquierda a derecha: Porretta Terme, Castel di Casio, Camugnano, Castiglione dei Pepoli, en la parte inferior, de izquierda a derecha, Granaglione, Sambuca Pistoiese. 
María Teresa Egea Molines
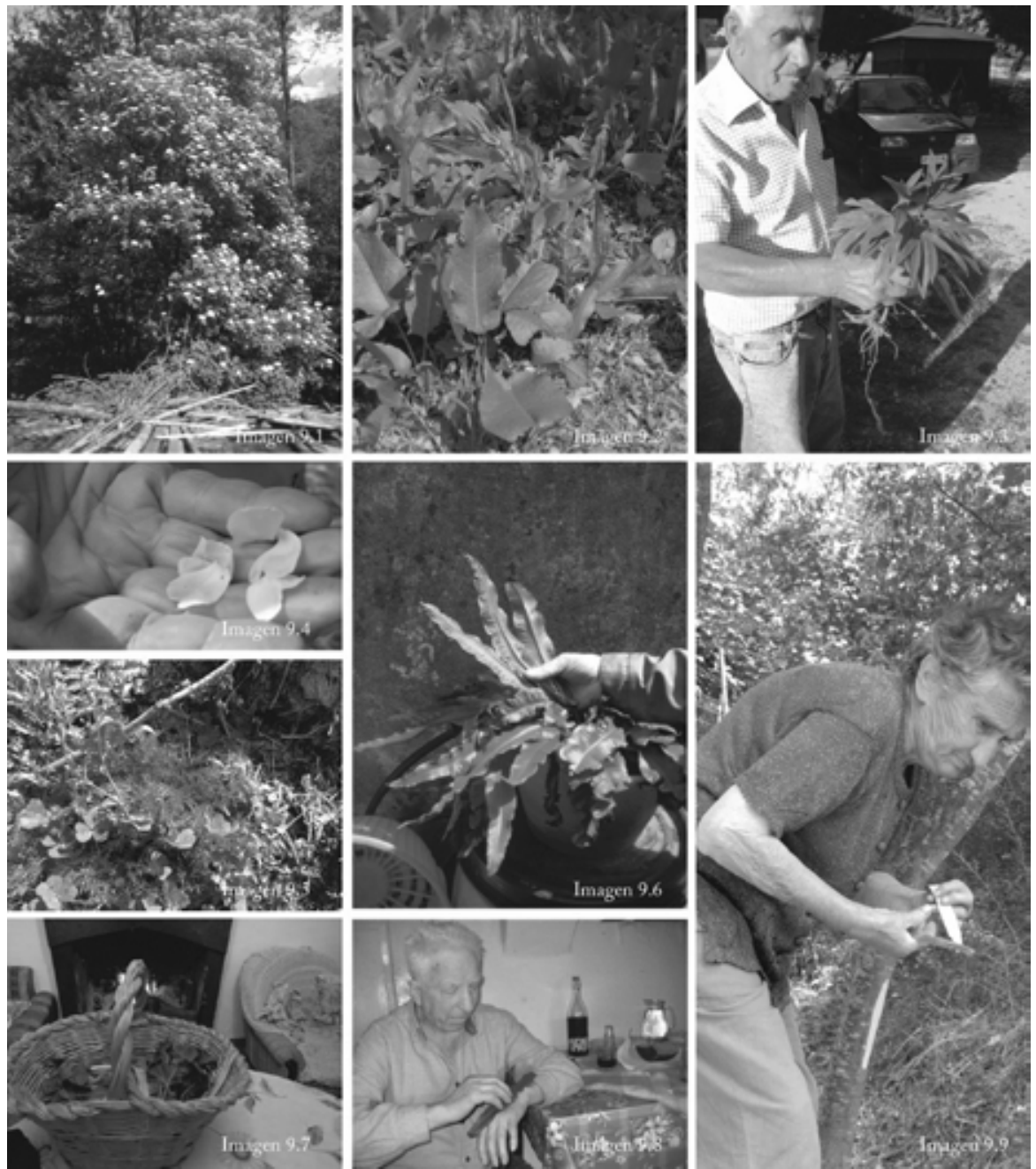

Fig. 36. Sector medicinal y veterinario.

Imagen 9.1. Sambucus nigra L. muy utilizado en la medicina tradicional. Imagen 9.2. Rumex obtusifolius L. cuyas semillas se le daban al ganado bovino en caso de diarrea. 9.3. Helleborus viridis L. cuya raiz era muy utilizada en la etnoveterinaria local. Imagen 9.4. Pétalos de Rosa canina L., utilizados como decocción breve para gripe y fiebre. Imagen 9.5. Matricaria chamomilla L. en el huerto de una informante, utilizada para diferentes afecciones. Imagen 9.6. Asplenium scolopendrium L. utilizada como cataplasma para quemaduras. Imagen 9.7. Malva sylvestris L. recolectada en el huerto de una informante, utilizada en decocción como antiinflamatorio general. Imagen 9.8. Aplicación de la hoja de Asplenium scolopendrium L. Imagen 9.9. Recolecta de la corteza de Fraxinus ornus L. o "nosgiadella" utilizada como desinfectante intestinal para las gallinas. Fotos de M.Teresa Egea. 
Etnobotánica en el Alto Valle del Reno (Toscana y Emilia-Romaña, Italia)

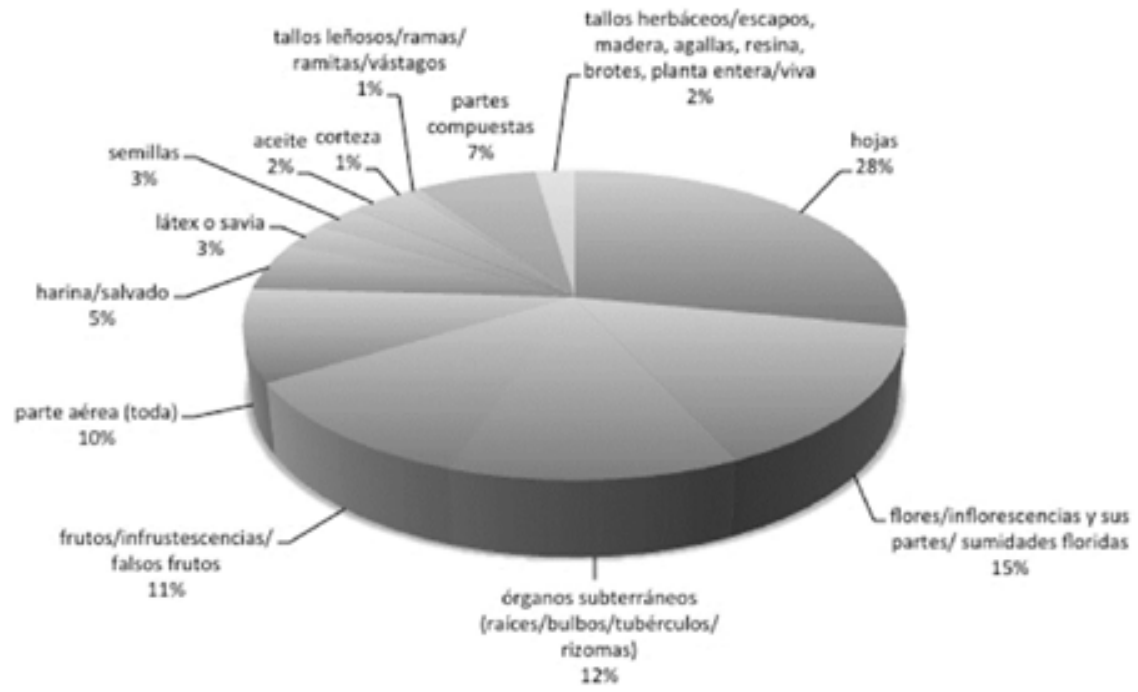

Fig. 37. Partes más utilizadas para fines medicinales. Según el número de citas.

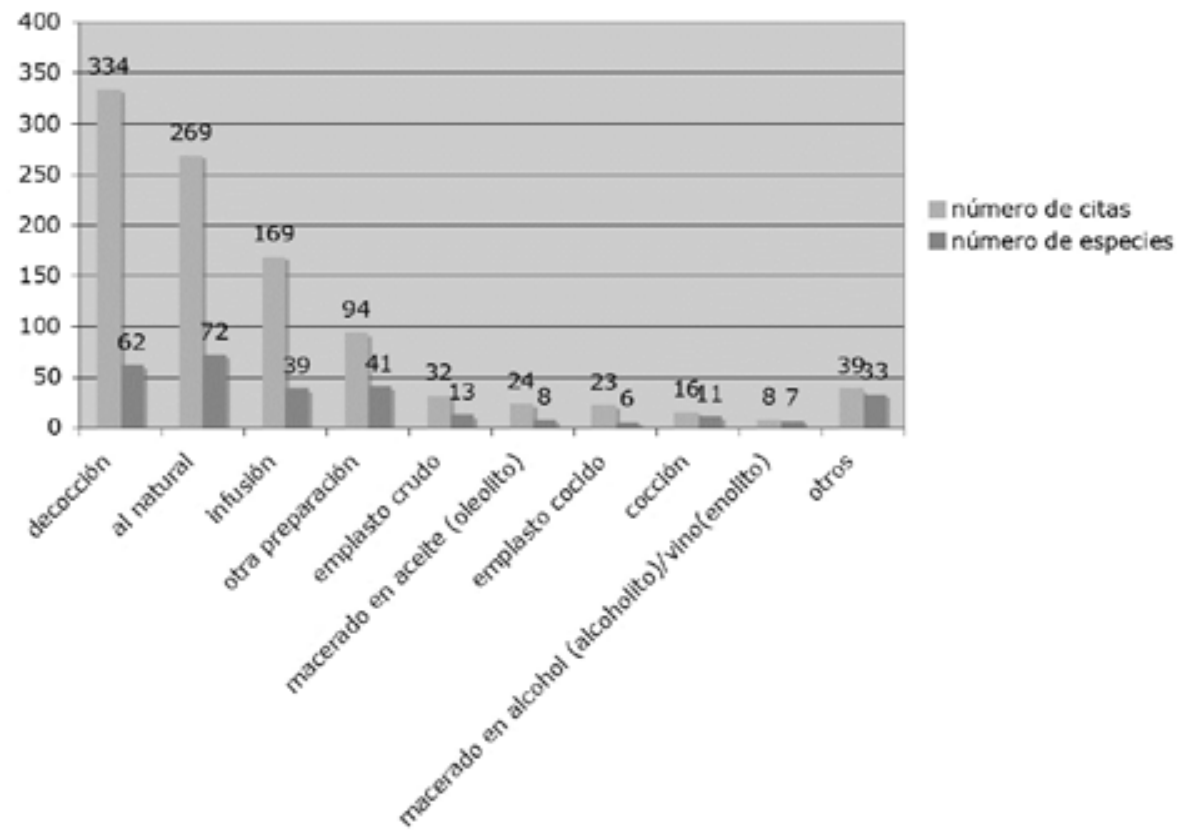

Fig. 38. Formas de preparación de los remedios con plantas. 


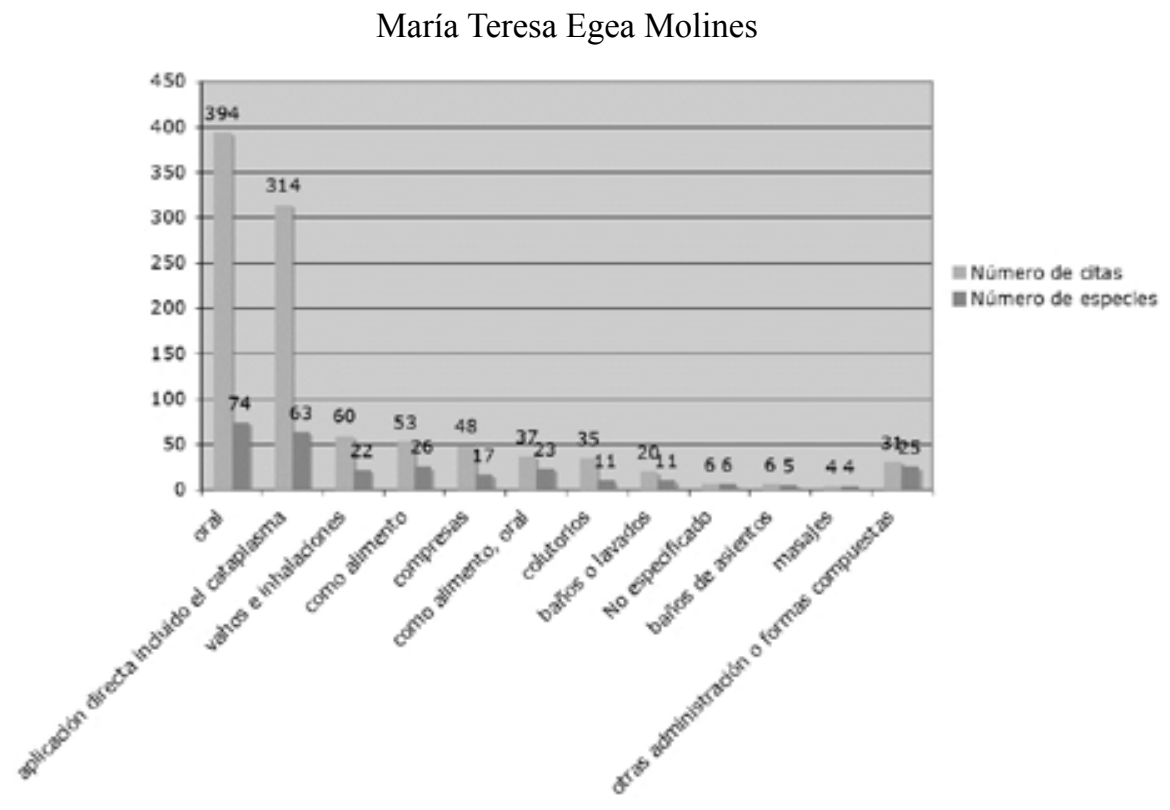

Fig. 39. Formas de administración de los remedios tradicionales con plantas.

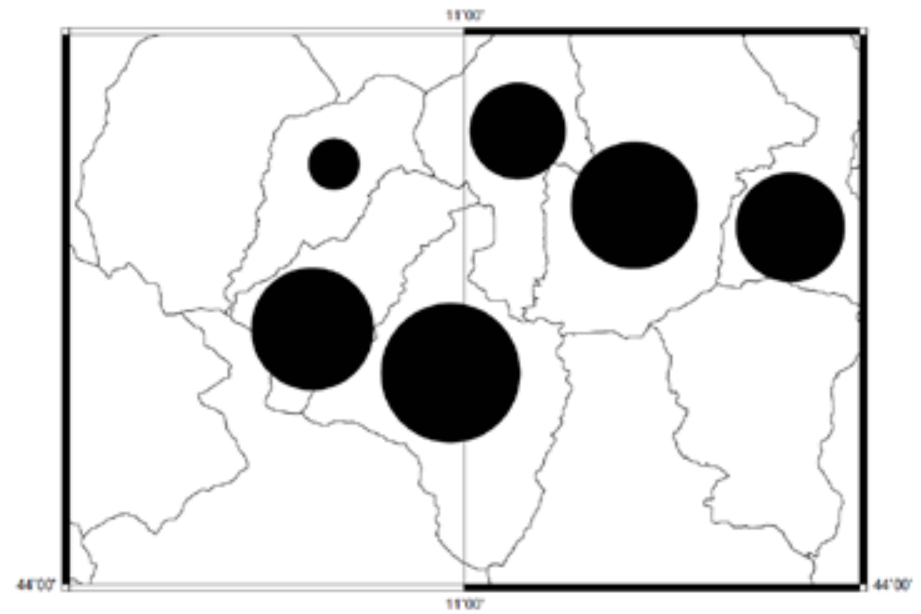

Fig. 40. Mapa del número de especies medicinales por municipio.

La superficie del círculo es proporcional al número de especies medicinales. En el mapa en la parte superior, de izquierda a derecha: Porretta Terme, Castel di Casio, Camugnano, Castiglione dei Pepoli, en la parte inferior, de izquierda a derecha, Granaglione, Sambuca Pistoiese. 
Etnobotánica en el Alto Valle del Reno (Toscana y Emilia-Romaña, Italia)

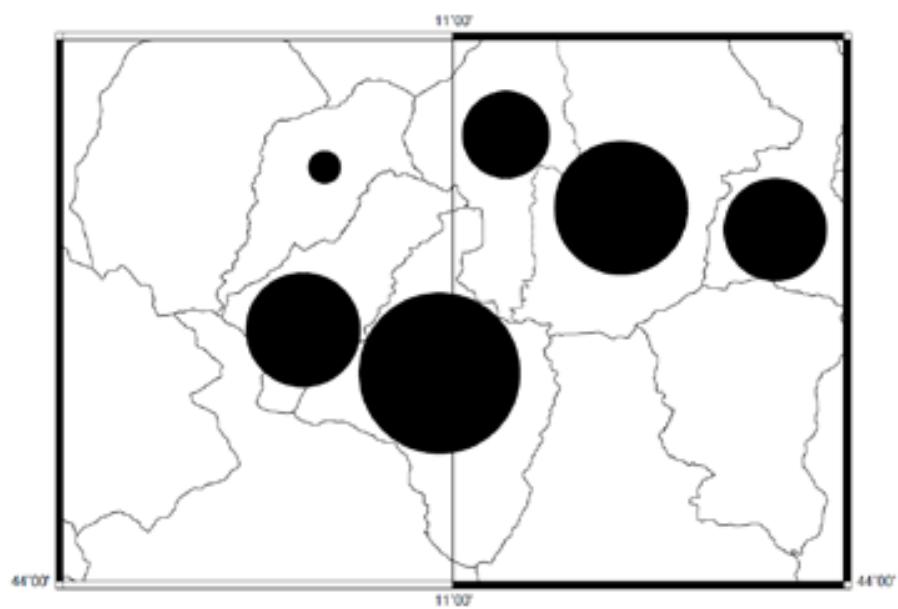

Fig. 41. Mapa del número de citas medicinales por municipio.

La superficie del círculo es proporcional al número de citas medicinales. En el mapa en la parte superior, de izquierda a derecha: Porretta Terme, Castel di Casio, Camugnano, Castiglione dei Pepoli, en la parte inferior, de izquierda a derecha, Granaglione, Sambuca Pistoiese. 


\section{María Teresa Egea Molines}
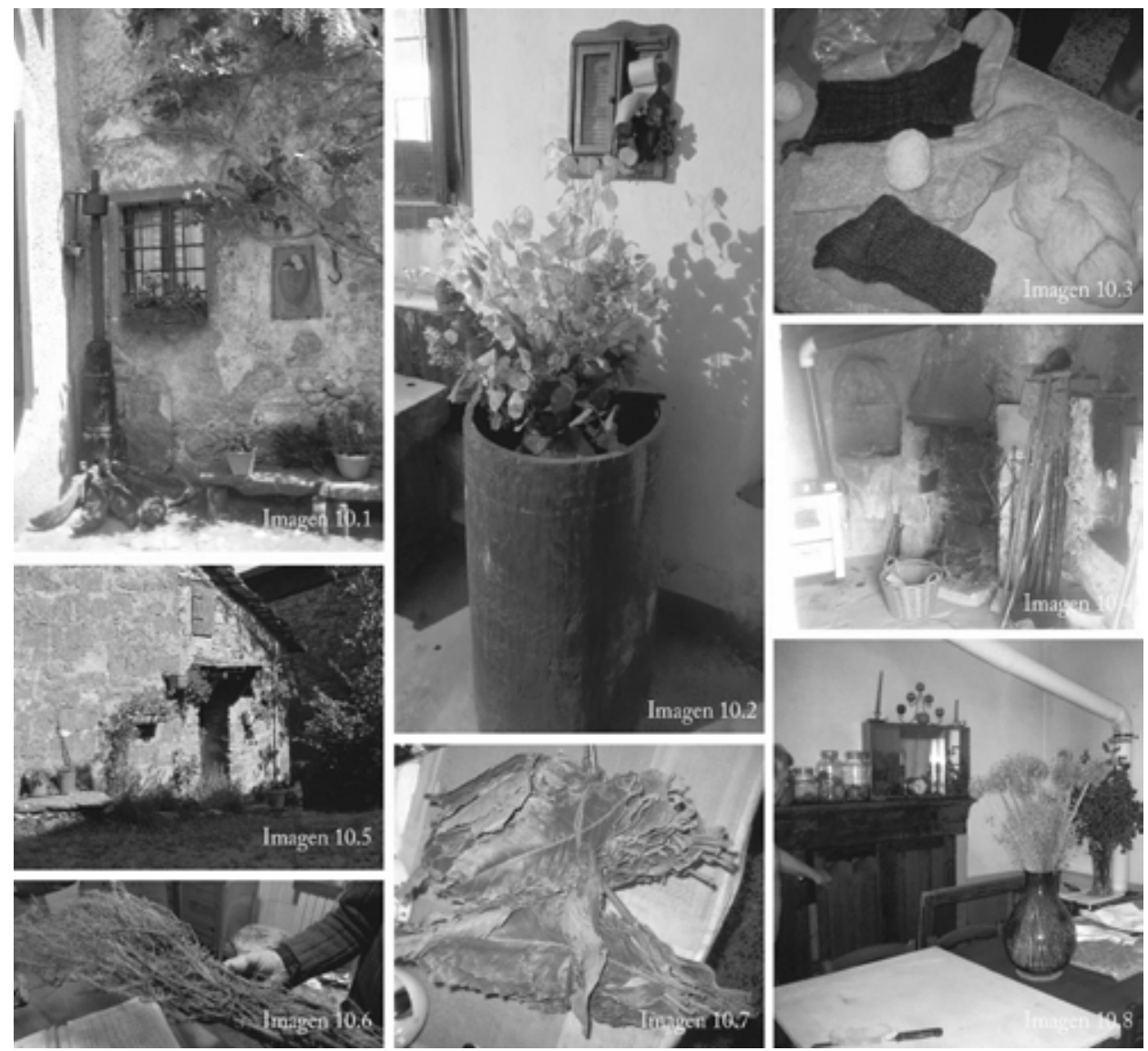

Fig. 42. Sector doméstico

Imagen 10.1. Parte del molino de agua, cuyos "brazos" eran hechos de madera de Castanea sativa Mill. y maceta alargada bajo la ventana hecho con un tronco de Castanea sativa Mill. Imagen 10.2. Semillas de Lunaria annua L. como ornamental. Imagen 10.3. Calcetines hechos a mano con la lana hilada a mano de forma tradicional, y lana teñida de beige y marrón con cáscaras de Juglans regia L. Imagen 10.4. Cocina tradicional con horno tradicional donde se realiza el pan una vez a la semana. Stagno. Imagen 10.5. Casa típica del territorio adornada con Pelargonium cv. Imagen 10.6. Escoba tradicional realizada con Erica arborea L., se utilizaba antiguamente para los establos, atada a un palo de Castanea sativa Mill. Imagen 10. 7. Hojas secas de Castanea sativa Mill. "infilzate", preparadas para la elaboración de los "necci". Imagen 10.8. Ramos de Ilex aquifolium L. y otras especies para adornar la casa. Fotos de Teresa Egea. 
Etnobotánica en el Alto Valle del Reno (Toscana y Emilia-Romaña, Italia)
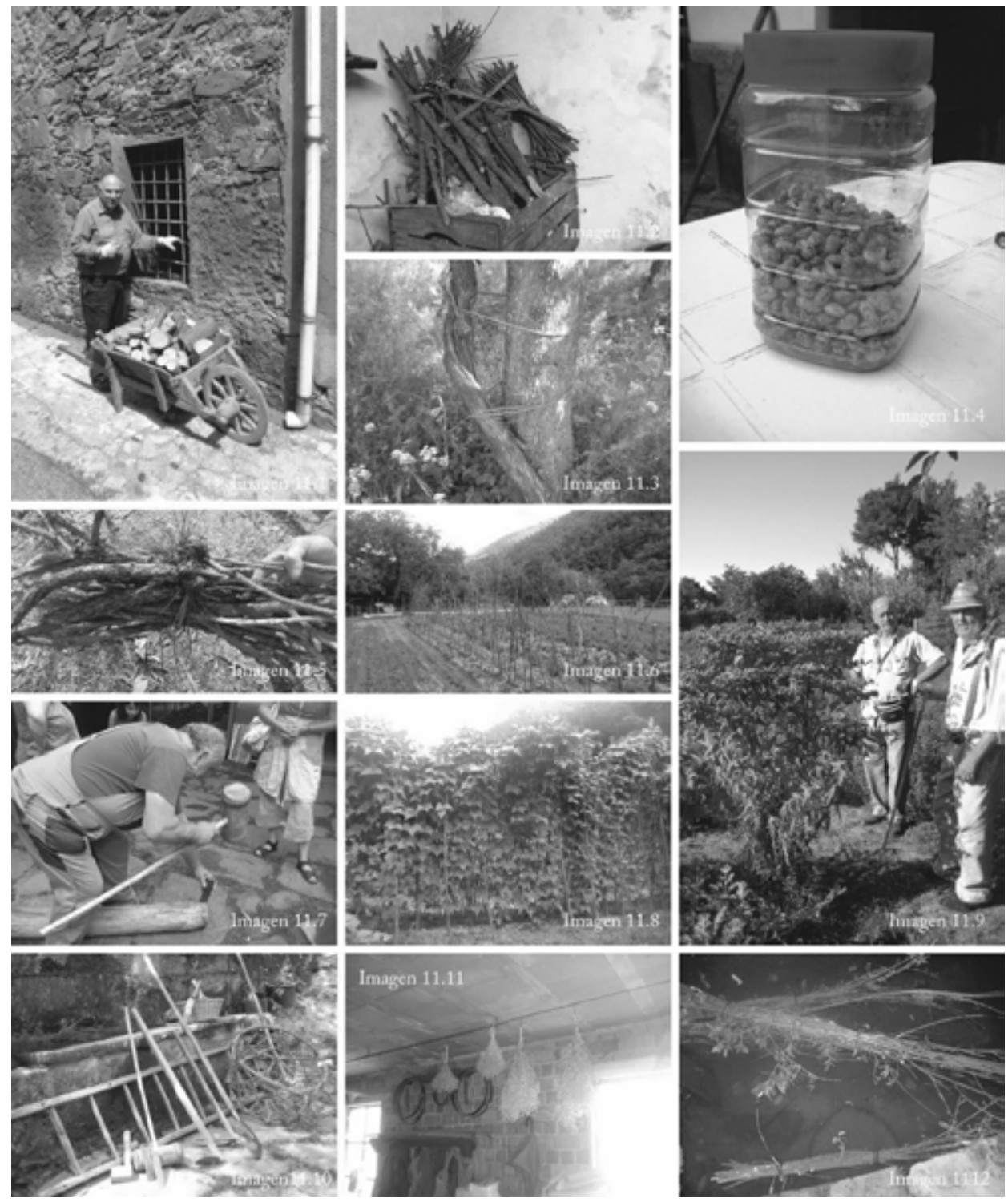

Fig. 43. Sector agropastoral.

Imagen 11.1. Carretilla de madera (especie no especificada). Imagen 11.2. Cuerdas y ataduras con Clematis vitalba L. para atar la madera pequeña de arder. Imagen 11.3. Cuerdas y ataduras con Salix alba var. vitellina (L.) Stokes 11.4. Semillas locales de Phaseolus vulgaris L. recuperadas en cada cosecha desde hace décadas. Imagen 11.5. Cytisus scoparius (L.) Link utilizado para atar la leña y transportarla. Imagen 11.6. y 11.8. Ramas de Castanea sativa Mill. como sostén de las plantas de Phaseolus vulgaris L.. Imagen 11. 7. Herramienta "mazza" hecha de Cornus mas L. con mango de Cornus sanguinea L. Imagen 11.9. Euphorbia lathyris L. plantada en el huerto como repelentes de ratas. Imagen 11. 10 Diferentes herramientas agrícolas 


\section{María Teresa Egea Molines}

realizadas con plantas locales. Imagen 11.11. Conservación de las semillas para el siguiente cultivo de ensaladas, se trata de semillas trasmitidas durante más de 20 años. Imagen 11.12 Conservación de ramas de Salix alba L. en el agua, listos para su uso como cuerdas y ataduras. Fotos de Teresa Egea.
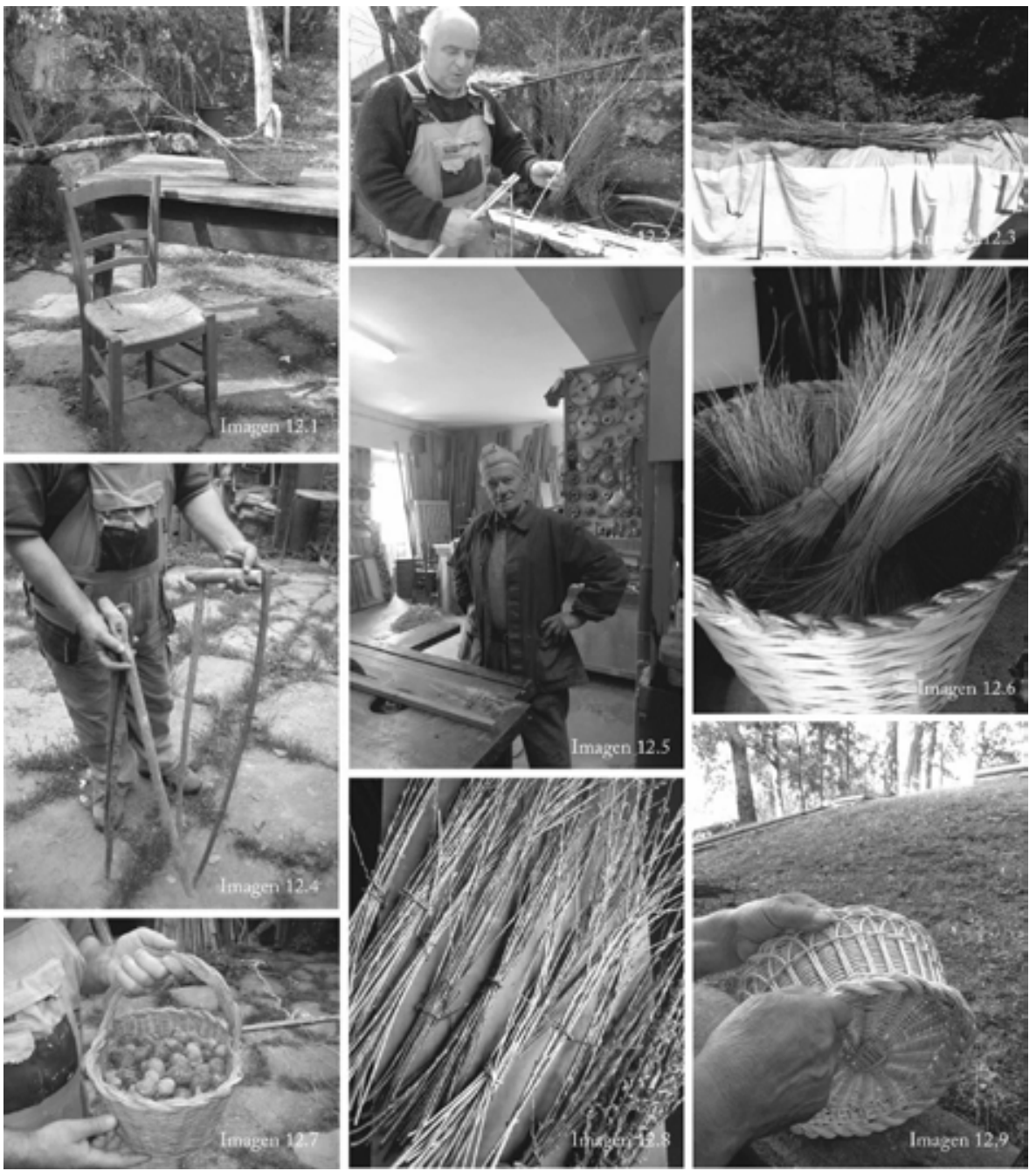

Fig. 44. Sector Artesanal

Imagen 12.1 Silla de madera de Prunus avium L. y cuerda de Carex pendula Huds. Imagen 12.2. Preparación de las ramas de Salix sp. para la realización de cestas ("sfiaccolare") con "la fiaccola" hecha de Castanea sativa Mill. Imagen 12.3. Grupo de ramos de Salix alba L. Imagen 12.4. Diferentes bastones realizados con diferentes especies Buxus sempervirens L., Cornus sanguinea L., Fraxinus ornus L. Imagen 12. 5 Carpintero tradicional que utiliza toda la madera local para sus producciones artesanales, Castelluccio, Porretta Terme. Imagen 12.6. Ramas de Cytisophyllum sessilifolium (L.) O.Lang listas para la realización de cestas. Imagen 12.7. Frutos 
de Juglans regia L. en cesto de Salix sp. antiguo. Imagen12,8. Diferentes etnoespecies de Salix sp. denominadas todas "vimini di fiume " distinguidas por su color para la realización de cestas. Imagen 12.9. Cesta realizada con ramos de Cytisophyllum sessilifolium (L.) O.Lang. Fotos de Teresa Egea.
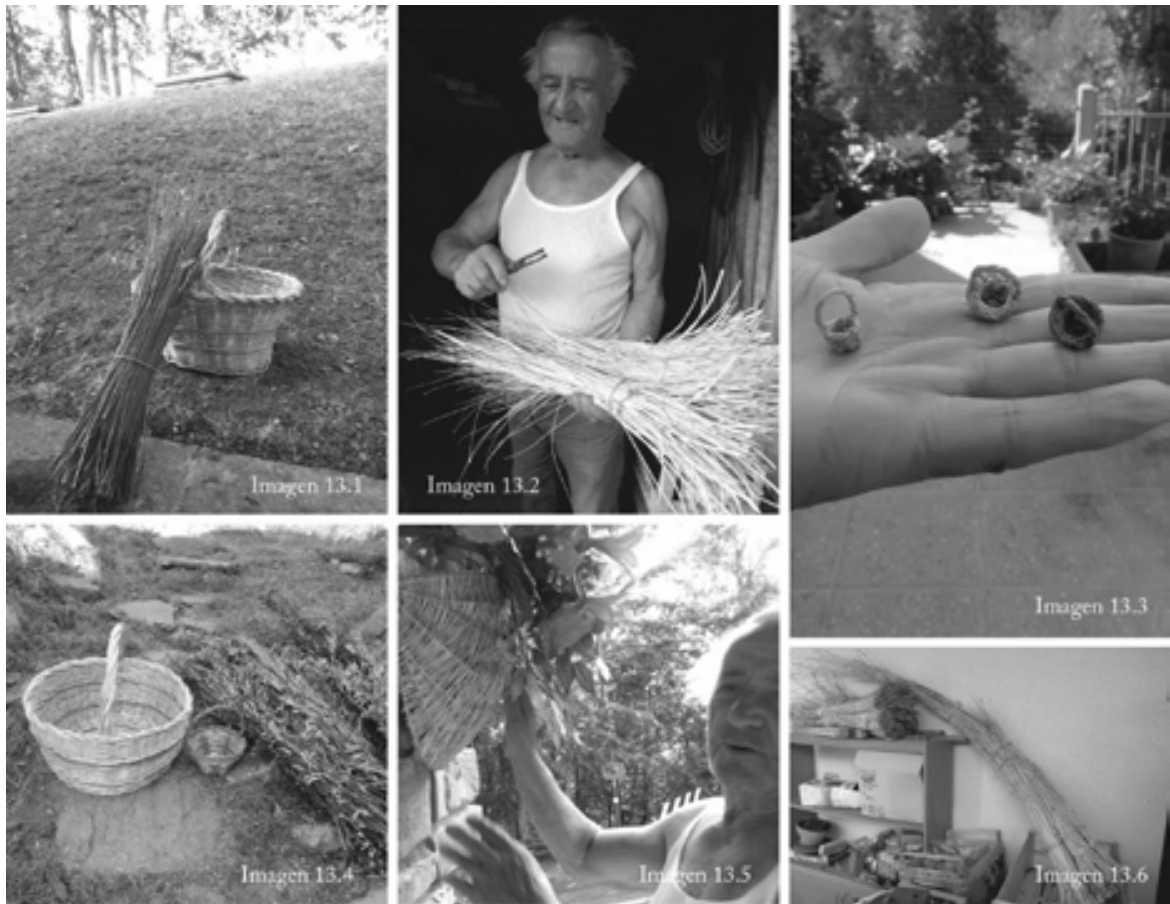

Fig. 45. Sector Artesanal II

Imagen 13.1. Ramas de Cytisophyllum sessilifolium (L.) O.Lang y cesto realizado con ellas. Imagen 13.2. Ramas de Cytisophyllum sessifolium e instrumento de Castanea sativa Mill. con el que se limpian las ramas para su uso en artesanía. Imagen 13.3. Cestos en miniatura realizados con diferentes especies de Salix sp. o la etnoespecie "vimini di fiume". Imagen 13.4. Cesto realizado con las diferentes clases de "vimini di fiume" que utilizan según el color y la flexibilidad. Imagen 13.5. Típico cesto realizado a base de Cytisophyllum sessilifolium (L.) O.Lang. Imagen 13.6. Ramas preparadas para el uso de diferentes especies de Salix sp. ("vimini di fiume"). Fotos de Teresa Egea. 
María Teresa Egea Molines
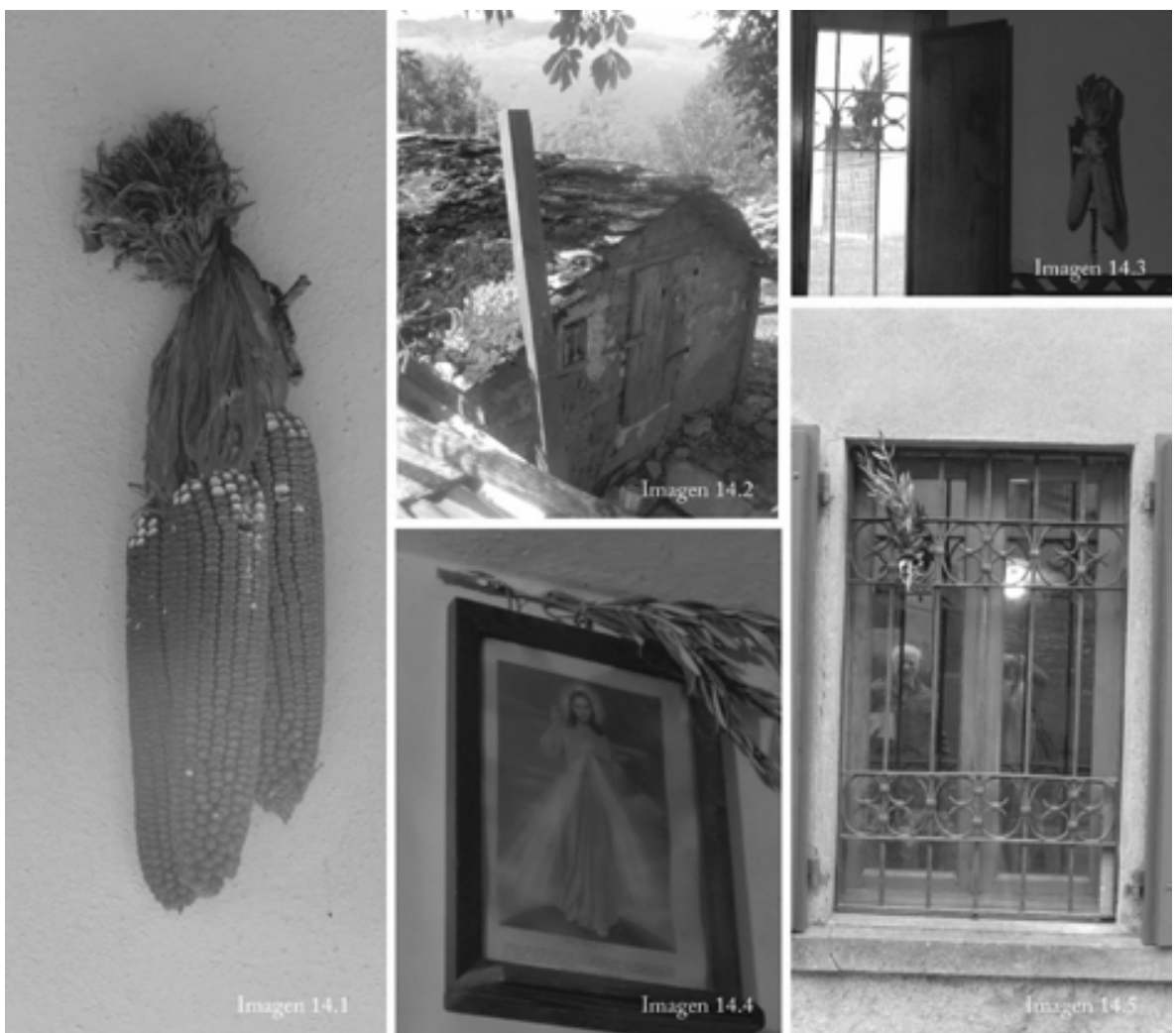

Fig. 46. Sector Mágico-ritual-supersticioso

Imagen 14.1. e Imagen 14.3. Las infrutescencias de Zea mays L. colgadas en casa traía abundancia a la casa. Imagen 14.2. Sempervivum tectorum L. se cultivaba encima de los tejados pequeños para proteger la casa, o bien encima de los gallineros como protectores de los truenos. Imagen 14.3. Las infrutescencias de Zea mays L. colgadas en casa traía abundancia a la casa (creencia pagana) y fuera de la casa, la rama de Olea europaea L. bendecido el Domingo de Ramos como bendición de la casa (creencia cristiana). Imagen 14.4. Ramo de olivo bendecido dentro de la casa, como bendición de la casa. Imagen 14.5. La rama de Olea europaea L. bendecido el Domingo de Ramos como bendición de la casa (creencia cristiana) Fotos de Teresa Egea. 
Etnobotánica en el Alto Valle del Reno (Toscana y Emilia-Romaña, Italia)
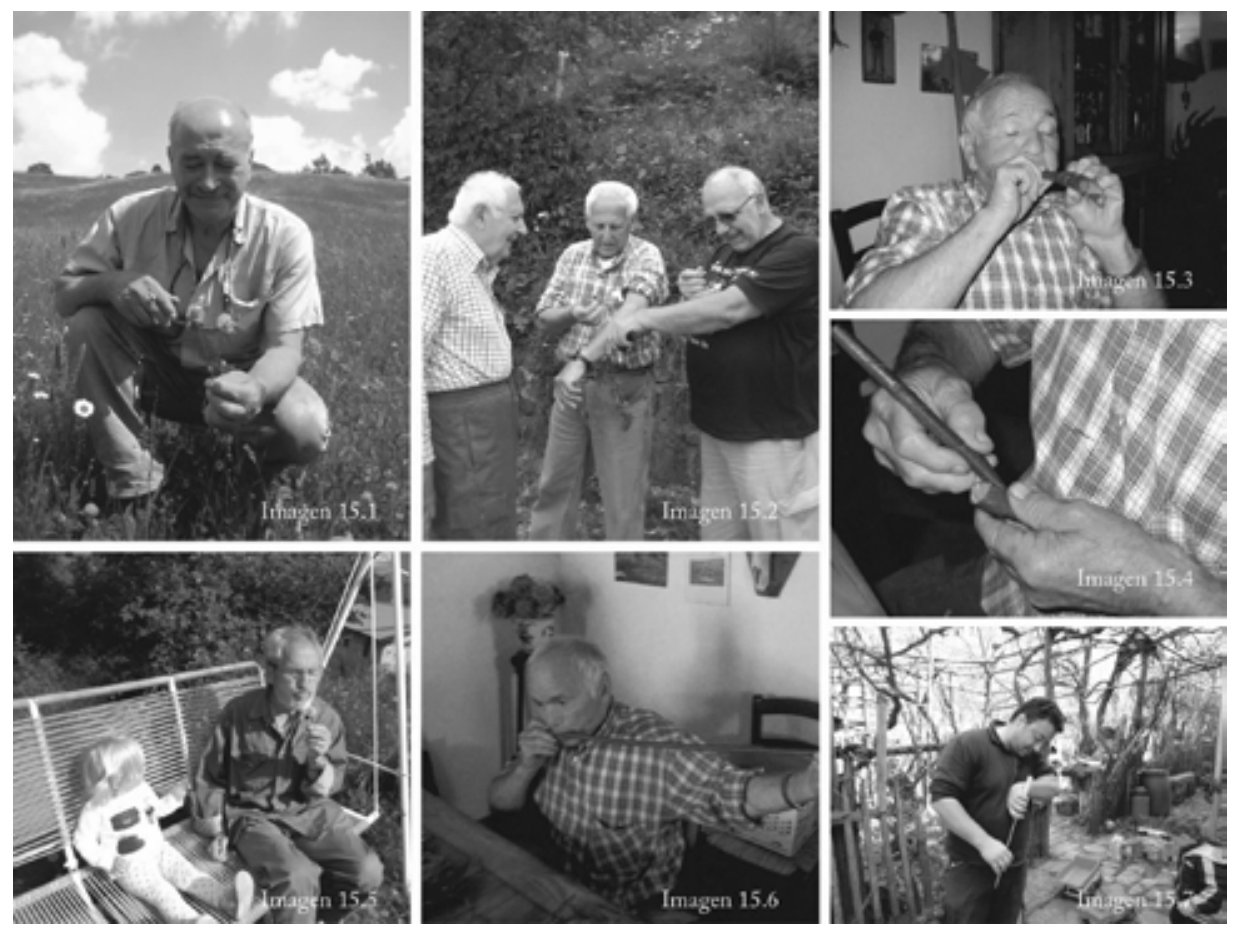

Fig. 47. Lúdico-voluptuoso.

Imagen 15.1. Las inflorescencias secas de Trifolium pratense L. se deshacian, se ponian en un papel y se hacia un cigarrillo. Imagen 15.2. Con el pistilo de Papaver rhoeas L. se jugaba a hacerse tatuajes sobre la piel. Imagen 15.3. "Il Trombo" era un instrumento realizado con la corteza de un vástago de Castanea sativa Mill. (extraída en primavera, cuando circula la savia según los informantes). Imagen 15.4. e Imagen 15.6. Realización y uso de la flauta llamada "la musetta" realizada también con la corteza de un vástago de Castanea sativa Mill. (extraída en primavera, cuando circula la savia según los informantes). Imagen 15.5. Con la infrutescencia de Taraxacum campylodes G.E.Haglund (s.l.) la gente se divertia en soplar las semillas y hacerlas volar. Imagen 15.7. Realización de un juego-broma a base de un ramo de Sambucus nigra L. denominado "schioppetti" que consiste en vaciar la parte interna de la rama, introducir una bola de papel masticado y soplar con fuerza para lanzárselo a alguien. Fotos de Teresa Egea. 
María Teresa Egea Molines
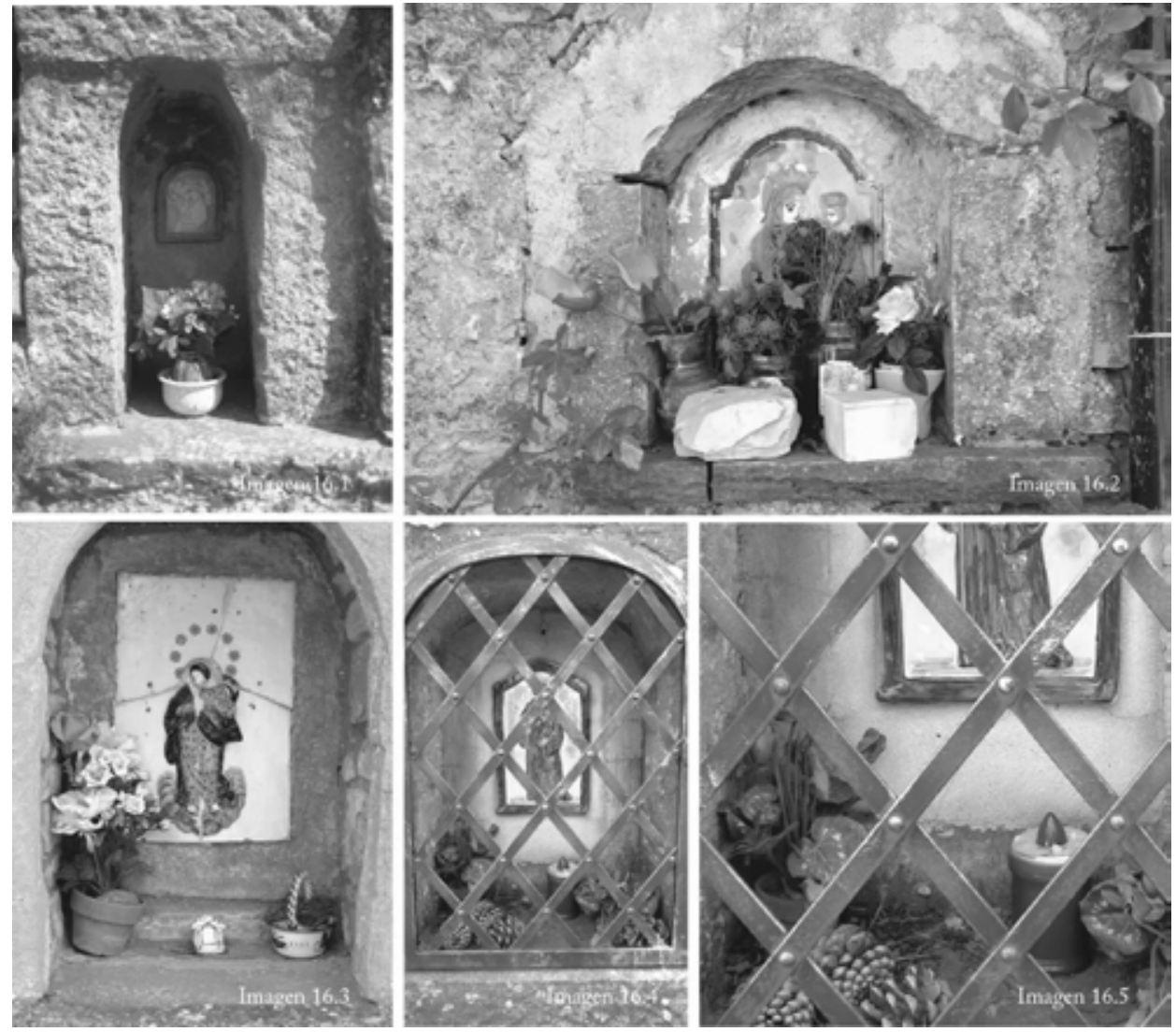

Fig. 48. Sector religioso abandonado.

Imagen 16.1, 16.2., 16.3., 16.4., 16.5. Testimonio de que los usos religioso de adornar los altares, distribuidos por todo el territorio en las aldeas de montaña con flores silvestres o con rosales, ha desaparecido del todo, ya que como se puede apreciar en las imágenes, actualmente ponen solo flores de plástico, o bien Tagetes sp., que es una especie no mencionada por los informantes, por tanto importada y que no forma parte de la cultura tradicional del AVR. Fotos de M. Teresa Egea. 



\section{Capítulo 4}

\section{Vigencia y grado de conocimiento de los usos}

Para poder afirmar o analizar si realmente los usos etnobotánicos están en peligro de desaparecer con la última generación poseedora, pocos investigadores han cuantificado el grado de conocimiento y la vigencia de los usos en detalle (lo hemos encontrado solo en Carvalho, 2005). Durante la recogida de los datos etnobotánicos siempre se ha procurado precisar el grado de conocimiento y la vigencia de los usos para cada cita mencionada por los informantes, a través de códigos específicos: (1) si el uso es actual, (2) si el uso es pasado, y por otra parte (1) si el uso es o ha sido practicado personalmente por la persona que lo menciona o bien (2) si lo ha oído decir o visto hacer a segundas o terceras personas. A través de preguntas directas o bien a través de la observación, de la forma de hablar y narrar los usos, de los tiempos verbales empleados, se han podido clasificar los usos en función de su vigencia y nivel de conocimiento con el fin de evaluar si los usos mencionados han sido abandonados o por el contrario todavía son vigentes en la comunidad.

En la Tab. 51 se presentan el índice UV y los respectivos porcentajes de los usos actuales y pasados de cada sector de uso.

Tab. 51. Vigencia de los usos etnobotánicos en el AVR.

Por sectores, por orden del \% de usos pasados, (\% usos pasados considera las citas totales de cada sector).

\begin{tabular}{llllll}
\hline $\begin{array}{l}\text { Sectores de } \\
\text { uso }\end{array}$ & $\begin{array}{l}\text { Valor de uso } \\
\text { actual } \\
\text { (UVactual) }\end{array}$ & $\begin{array}{l}\text { \% Usos actuales } \\
\text { considerando las } \\
\text { citas dentro de } \\
\text { cada sector } \\
47,7\end{array}$ & $\begin{array}{l}\text { Valor de uso } \\
\text { pasado } \\
\text { (Uvpasado) }\end{array}$ & $\begin{array}{l}\text { Usos pasados } \\
\text { considerando las } \\
\text { citas dentro de } \\
\text { cada sector }\end{array}$ & UVtotal \\
Alimentario & 6,14 & 6,73 & 52,30 & 12,88 \\
$\begin{array}{l}\text { Efecto } \\
\text { Nocivo }\end{array}$ & 0,06 & 43,75 & 0,08 & 56,25 & 0,14 \\
Agropastoral & 0,75 & 27,6 & 1,97 & 72,40 & 2,73 \\
Medicinal & 2,62 & 26,15 & 6,30 & 73,85 & 8,92 \\
Artesanal & 0,26 & 23,53 & 0,58 & 76,47 & 0,75 \\
Mágico- & 0,08 & 22,5 & 0,27 & 77,50 & 0,35 \\
medicinal & & & & & \\
\hline
\end{tabular}


Etnobotánica en el Alto Valle del Reno (Toscana y Emilia-Romaña, Italia)

\begin{tabular}{|c|c|c|c|c|c|}
\hline $\begin{array}{l}\text { Sectores de } \\
\text { uso }\end{array}$ & $\begin{array}{l}\text { Valor de uso } \\
\text { actual } \\
\text { (UVactual) }\end{array}$ & $\begin{array}{l}\text { \% Usos actuales } \\
\text { considerando las } \\
\text { citas dentro de } \\
\text { cada sector }\end{array}$ & $\begin{array}{l}\text { Valor de uso } \\
\text { pasado } \\
\text { (Uvpasado) }\end{array}$ & $\begin{array}{l}\text { \% Usos pasados } \\
\text { considerando las } \\
\text { citas dentro de } \\
\text { cada sector }\end{array}$ & UVtotal \\
\hline $\begin{array}{l}\text { Ritual- } \\
\text { supersticioso }\end{array}$ & 0,20 & 22,12 & 0,72 & 77,88 & 0,92 \\
\hline Caza y pesca & 0,07 & 21,62 & 0,26 & 78,38 & 0,33 \\
\hline Religioso & 0,03 & 21,05 & 0,31 & 78,95 & 0,34 \\
\hline Veterinario & 0,06 & 18,6 & 0,70 & 81,40 & 0,76 \\
\hline Doméstico & 0,57 & 15,84 & 3,01 & 84,16 & 3,58 \\
\hline $\begin{array}{l}\text { Lúdico- } \\
\text { voluptuoso }\end{array}$ & 0,00 & 0 & 0,76 & 100,00 & 0,76 \\
\hline Total de usos & 10,84 & 33,41 & 21,61 & 66,59 & \\
\hline
\end{tabular}

De las 3667 citas registradas sobre usos etnobotánicos, solo el 33,41\% (1225 citas) corresponden a usos actuales que todavía son practicados por los informantes, el resto $66,59 \%$ de las citas se refieren a usos pasados. Utilizando el índice UV, también vemos como son más importantes los usos pasados $(\mathrm{UV}=21,61)$ respecto a los actuales (UV=10,84), lo que índica efectivamente que gran parte de los usos tradicionales han desaparecido en la vida cotidiana del comunidad.

El sector alimentario ha mostrado ser el sector de uso con mayor número de usos actualmente practicados: vemos como los dos valores UV de los usos actuales y pasados son muy similares ( 6,14 y 6,73 respectivamente), lo cual se confirma a través del porcentaje de usos pasados que indica que el $52 \%$ de los todos los usos alimentarios citados eran realizados en el pasado, pero no se practican en la actualidad. Es curioso observar como el segundo sector con menos usos pasados es el de Efecto Nocivo, ya que son conocimientos que no deben ser practicados y que interesan a todos por el efecto nocivo o tóxico.

Respecto a los demás sectores, el sector alimentario se mantiene particularmente vivo con la mitad de los usos todavía actuales, seguramente debido a la simplicidad de las preparaciones, al hecho que se conciben como usos más seguros y sencillos en la forma de reconocer las plantas y elaborar las preparaciones culinarias, al mismo tiempo puede ser debido al hecho de que haya un redescubrimiento de las especies silvestres para usos alimentarios que se encuentran en los mercados, en los supermercados, en la televisión, o bien simplemente porque al mismo tiempo que se hacen paseos uno puede aprovechar para recolectar especies que son fácilmente reconocibles y visibles, o incluso por el hecho de que las especies en cuestión crezcan en los ambientes cercanos a las casas, y sean más accesibles.

En el resto de los sectores, la mayoría de los usos ya no se practican y son solo parte de los recuerdos. En el sector medicinal, casi el $74 \%$ de los usos son pasados (UVpasado=6,30 y UVactual=2,62), lo cual denota que la medicina familiar ha sido sustituida mayoritariamente por la medicina convencional. Esto puede ser debido a diferentes factores: los propios médicos desconfían de las prácticas medicinales 


\section{María Teresa Egea Molines}

tradicionales; el cambio epidemiológico de la sociedad rural, en la que la mayor higiene y el abandono de las prácticas agroforestales ya no hacen tan comunes los forúnculos y las heridas que antes se hacían en el campo o en el bosque y debían curarse con los recursos que tenían al alcance de la mano, como aseguran los informantes; a menudo el conocimiento etnofarmacobotánico es más específico y particular que los usos alimentarios, las plantas no siempre se encuentran alrededor de las casas y no son tan abundantes como las alimentarias. Además ciertas figuras sanitarias tradicionales (diferentes de los "tradipracticantes") que existían en la comunidad, y que sabían más que el resto de la comunidad sobre el uso de las plantas medicinales, ya no existen.

En el resto de los sectores se puede apreciar como UVpasado es siempre más importante que UVactual, demostrando que la mayoría de las plantas ya no se usan. Vemos como el doméstico contiene usos en su mayoría pasados (es decir, que ya no son practicados o usados por los informantes), ya que pertenecen a unos modos de vida muy diferentes, que ya nadie practica en la actualidad, ya que pocos cocinan con el fuego, pocos realizan las preparaciones tradicionales como los "necci" (se realizan solo en las ferias o fiestas locales como atractivo turístico) y los champús y jabones industriales han sustituido totalmente a las formas tradicionales de lavar (el cuerpo y la ropa) que implicaban mucho más tiempo en prepararse y tenían menos perfumes que los industriales.

En último lugar, los usos lúdicos $\mathrm{y}$ voluptuosos han desaparecido completamente, debido una vez más al cambio en el estilo y forma de vida, ya que los niños ya no están tanto tiempo en los campos y tienen muchas otras formas de entretenimiento como la televisión o los juegos comerciales, que han sustituido a las formas tradicionales de pasatiempos y de juegos colectivos. De la misma manera el tabaco confeccionado y comercial ha sustituido completamente las formas tradicionales de fumar.

Exceptuando los usos alimentarios, la mayoría de los usos tradicionales a base de plantas han mostrado ser datos culturales, que solamente existen y sobreviven en la memoria de la población local.

El grado del conocimiento etnobotánico se ha evaluado proporcionando en cada cita el código 1, si el uso es practicado personalmente; o bien el código 2, si el uso lo ha visto hacer u oído decir (Tab. 52). El 87,67 \% de las citas se refieren a usos conocidos profundamente, ya que son practicados $\mathrm{o}$ han sido practicados personalmente. Esto muestra la fiabilidad de los datos recogidos y un grado de conocimiento importante, ya que aunque gran parte de los usos ya no sean practicados (2442 citas, 66,59\%), el conocimiento etnobotánico todavía es profundo ya que los que los poseen los conocen en profundidad. 
Tab. 52. Grado del conocimiento de los usos etnobotánicos en el AVR.

Por sectores, por orden del $\%$ de usos directos, (\% usos directos considera los usos totales de cada sector). Directo $=$ usos practicados personalmente, indirecto $=$ usos conocidos por segundas persona.

\begin{tabular}{|c|c|c|c|c|c|}
\hline $\begin{array}{l}\text { Sectores de } \\
\text { uso }\end{array}$ & $\begin{array}{l}\text { Valor de uso } \\
\text { directo } \\
\text { (UVdirecto) }\end{array}$ & $\begin{array}{l}\% \text { Usos } \\
\text { directo } \\
\text { sobre } \\
\text { totalidad } \\
\text { de usos }\end{array}$ & $\begin{array}{l}\text { Valor de uso } \\
\text { indirecto } \\
\text { (Uvindirecto) }\end{array}$ & $\begin{array}{l}\% \text { Usos } \\
\text { indirecto } \\
\text { sobre } \\
\text { totalidad } \\
\text { de usos }\end{array}$ & $\begin{array}{l}\% \text { Usos directos } \\
\text { (considerando las } \\
\text { citas dentro de } \\
\text { cada sector) }\end{array}$ \\
\hline Caza y pesca & 0,14 & 0,44 & 0,19 & 0,57 & 43,24 \\
\hline Artesanal & 0,42 & 1,28 & 0,34 & 1,04 & 55,29 \\
\hline Nocivo & 0,10 & 0,30 & 0,04 & 0,14 & 68,75 \\
\hline Veterinario & 0,55 & 1,69 & 0,21 & 0,65 & 72,09 \\
\hline Religioso & 0,26 & 0,79 & 0,08 & 0,25 & 76,32 \\
\hline Doméstico & 2,90 & 8,94 & 0,67 & 2,07 & 81,19 \\
\hline $\begin{array}{l}\text { Mágico- } \\
\text { ritual- } \\
\text { supersticioso }\end{array}$ & 0,77 & 2,37 & 0,15 & 0,46 & 83,65 \\
\hline $\begin{array}{l}\text { Lúdico- } \\
\text { voluptuoso }\end{array}$ & 0,66 & 2,05 & 0,10 & 0,30 & 87,21 \\
\hline Medicinal & 8,09 & 24,93 & 0,83 & 2,56 & 90,67 \\
\hline Alimentario & 11,71 & 36,08 & 1,17 & 3,60 & 91,38 \\
\hline Agropastoral & 2,52 & 8,46 & 0,20 & 0,68 & 92,53 \\
\hline $\begin{array}{l}\text { Mágico- } \\
\text { medicinal }\end{array}$ & 0,34 & 1,04 & 0,02 & 0,05 & 95,00 \\
\hline Total de usos & 28,45 & 87,67 & 4,00 & 12,33 & \\
\hline
\end{tabular}

Los usos recogidos que se conocen más directamente y se practican personalmente son los alimentarios (UVdirecto $=11,71$; UVindirecto=1,17), ya que son usos fáciles de preparar a base de plantas accesibles, como ya ha sido comentado anteriormente, de hecho el porcentaje de uso con experiencia directa también es elevado $(91,38 \%)$. Los usos medicinales también son mayoritariamente practicados personalmente ya que el Valor de Uso directo es elevado (UVdirecto=8,09; UVindirecto $=0,83$ ), y el porcentaje de uso con experiencia directa es alto $(90,67 \%)$. El sector doméstico también es practicado sobre todo personalmente ya que el Valor de uso directo ocupa el tercer lugar (UVdirecto=2,90; UVindirecto=0,67); y de la misma manera el agropastoral ocupa el cuarto lugar de importancia en cuanto al UV directo (UVdirecto=2,52; UVindirecto=0,20). Vemos como los sectores más importantes (con más citas, y más especies utilizadas) incluyen sobre todo usos practicados personalmente. Esto denota una gran validez de la información recogida durante la investigación. 


\section{María Teresa Egea Molines}

Sin embargo no hay grandes diferencias entre los UV directos e indirectos en los sectores artesanal, caza y pesca, efecto nocivo, mágico-medicinal, mágico-ritualsupersticioso, veterinario y religioso, debido a que son usos que pertenecen sobre todo a un tipo de personas concretas y definidas de la población, y no generales como el alimentario, medicinal y doméstico, en los cuales toda la población estaba implicada sin diferencias de sexo o de creencias.

A pesar de que el valor de uso del sector mágico-medicinal es bastante insignificante (Uvdirecto $=0,34$ ), si consideramos el número de citas actuales dentro de cada sector, vemos cómo en éste, la mayoría de las citas son practicadas directamente (Porcentaje de Usos con experiencia directa $=95 \%$ ). Esto quiere decir que los pocos que conocen éstos usos, los practican personalmente, debido probablemente a su fácil empleo y como dicen los informantes "no se pierde nada" y el efecto puede ser positivo. En segundo lugar, el sector agropastoral también muestra un porcentaje de usos con experiencia directa muy elevado (Porcentaje de Usos con experiencia directa $=92 \%$ ) debido a la fuerte caracterización forestal y agropastoral de la comunidad.

Estos resultados vuelven a confirmar que los usos tradicionales a base de plantas para fines alimentarios y medicinales son particularmente importantes en la comunidad estudiada, ya que son usos bien conocidos por los informantes, que todavía forman parte de la tradición local etnobotánica y cultural. 



\section{Capítulo 5}

\section{Contraste bibliográfico: datos novedosos e influencia regional en el}

AVR.

A partir del estudio de los usos tradicionales documentados en la bibliografía han sido recogidos un total de 944 citas relativas a todas las especies que aparecen en el catálogo etnobotánico, es decir, sobre los usos de las plantas silvestres y cultivadas, aunque estas últimas no hayan sido el objetivo principal de la investigación. De las 944 citas, 754 citas han proporcionado informaciones sobre usos etnobotánicos sobre las especies recogidas durante el trabajo de campo, y las 190 restantes han proporcionado informaciones diversas sobre nosología, fitonímia o proverbios relativos a las especies en cuestión, los cuales han sido previamente expuestos.

De las 754 citas sobre usos etnobotánicos, 668 citas han sido referidas a usos sobre especies silvestres o cultivadas solo si son diferentes al uso común para el cual son cultivadas, es decir el objetivo principal de la investigación. En cambio, 86 citas se refieren a los usos sobre las mismas especies cultivadas con usos comunes, que han sido registrados durante la investigación de campo.

De las 668 citas sobre usos etnobotánicos que interesa la presente discusión, 244 citas coinciden con los usos registrados durante las entrevistas etnobotánicas. Sin embargo, 424 citas se refieren a usos novedosos que no han sido mencionados por los informantes, por diversas razones: puede que sean datos provenientes de otras zonas de estudio ya que UNGA21 estudia no solo el Alto Valle del Reno, sino también el resto de la provincia de Bolonia, MANG98 estudia parte del Alto Valle del Reno pero también el resto de la montaña pistoyesa del Apenino Tosco-emiliano confinante con nuestra área de estudio (desde Popiglio-Piteglio hasta Abetone, es decir los municipios de Piteglio, San Marcello Pistoiese, Cutigliano, Abetone), GRIZ03 estudia los usos alimentarios de un municipio que forma parte del Alto Valle del Reno pero confinante con nuestra área de estudio seleccionada, Grizzana Morandi, así como SANS14 que también estudio una pequeña parte de nuestra área de estudio (una parte de Camugnano),pero en gran parte el área alrededor de la ciudad de Bolonia.

El estudio etnobotánico bibliográfico local a partir de las 23 referencias bibliográficas locales ha proporcionado 668 citas sobre 188 especies de las 281 especies recogidas durante el trabajo de campo (66,90\%), pertenecientes a 63 familias botánicas (Tab. 53).

Las noticias etnobotánicas dependen del tipo de estudio realizado por la fuente bibliográfica. En la Tab. 53 se muestra el tipo de sectores de usos recogidos por 
fuente bibliográfica, así como las categorías de uso más citadas por fuente. Se puede apreciar como Ungarelli (1921), es el estudio que más informaciones ha registrado sobre la etnobotánica (256 citas, 129 especies), sobre 12 sectores de uso diferentes, de los cuales resalta el medicinal (137 citas) y el alimentario (40 citas), ya que eran los objetivos principales de su estudio, pero hay que considerar que las informaciones relativas al AVR (cuando especifica que los uso provienen del AVR, de Porretta Terme o Castiglione di Pepoli) son solo 14 citas sobre 7 especies (Primula vulgaris Huds., Helleborus viridis L. (s. 1.), Helleborus foetidus L., Anacamptis morio (L.) R.M.Bateman, Pridgeon \& M.W.Chase, Rubus idaeus L., Quercus cerris L., Carlina acaulis L. dando de estas dos últimas solo informaciones sobre la fitonímia). Le sigue Uncini Manganelli y Tomei (1998) que han registrado 129 citas sobre 62 especies de las recogidas en nuestro estudio etnobotánico, principalmente los sectores alimentarios, mágico-ritual-supersticioso, medicinal y mágico medicinal, ya que se trata de un estudio etnofarmacobotánico. Sansanelli y Tassoni (2014) han registrado 105 citas sobre 50 especies de las registradas por nuestro trabajo de campo, sobre el sector alimentario y medicinal principalmente, aunque no ha sido precisado en el estudio qué informaciones son relativas al AVR.

Con el fin de evaluar exactamente el grado de novedad de nuestra investigación no consideraremos los mencionados estudios, ya que estos pueden proporcionar noticias sobre otras áreas diferentes culturalmente a la nuestra. Sin embargo estos estudios serán de gran utilidad para evaluar la influencia que existe en la cultura etnobotánica del AVR de la cultura boloñesa y de la cultura toscana, ya que en numerosos estudios, (sobre todo lingüísticos), es un tema de gran interés.

Tab. 53. Características del conocimiento etnobotánico en la bibliografía local.

Según las referencias bibliográficas consultadas

\begin{tabular}{|c|c|c|c|c|}
\hline $\begin{array}{l}\text { Código } \\
\text { referencia } \\
\text { bibliográfica }\end{array}$ & $\begin{array}{l}\text { Número de } \\
\text { citas }\end{array}$ & $\begin{array}{l}\text { Número de } \\
\text { especies }\end{array}$ & Sectores de uso & $\begin{array}{lr}\text { Número de } \\
\text { citas por } \\
\text { sectores }\end{array}$ \\
\hline APPO10 & 1 & 1 & Lúdico/voluptuoso & 1 \\
\hline \multirow[t]{2}{*}{ BADI15 } & 8 & 8 & Alimentario & 7 \\
\hline & & & Medicinal & 1 \\
\hline \multirow[t]{2}{*}{ BAL801 } & 2 & 2 & Doméstico & 1 \\
\hline & & & Medicinal & 1 \\
\hline \multirow{2}{*}{ BAL97 } & 3 & 2 & Alimentario & 2 \\
\hline & & & Artesanal & 1 \\
\hline \multirow{2}{*}{ BENE96 } & 4 & 2 & Agropastoral & 2 \\
\hline & & & Doméstico & 2 \\
\hline \multirow{3}{*}{ BONZI00 } & 8 & 6 & Agropastoral & 1 \\
\hline & & & Doméstico & 3 \\
\hline & & & Lúdico/voluptuoso & 4 \\
\hline
\end{tabular}


María Teresa Egea Molines

\begin{tabular}{|c|c|c|c|c|}
\hline $\begin{array}{l}\text { Código } \\
\text { referencia } \\
\text { bibliográfica }\end{array}$ & $\begin{array}{l}\text { Número de } \\
\text { citas }\end{array}$ & $\begin{array}{l}\text { Número de } \\
\text { especies }\end{array}$ & Sectores de uso & $\begin{array}{lr}\text { Número de } \\
\text { citas } \\
\text { sectores }\end{array}$ \\
\hline BORR77 & 1 & 1 & Mágico/ritual/supersticioso & 1 \\
\hline CANU78 & 1 & 1 & Mágico/ritual/supersticioso & 1 \\
\hline \multirow{2}{*}{ GRIZ03 } & \multirow[t]{2}{*}{23} & \multirow[t]{2}{*}{15} & Alimentario & 22 \\
\hline & & & Medicinal & 1 \\
\hline GUC78 & 1 & 1 & Lúdico/voluptuoso & 1 \\
\hline GUC80 & 1 & 1 & Lúdico/voluptuoso & 1 \\
\hline \multirow{2}{*}{ GUC81 } & \multirow[t]{2}{*}{3} & \multirow[t]{2}{*}{3} & Lúdico/voluptuoso & 2 \\
\hline & & & Mágico/ritual/supersticioso & 1 \\
\hline \multirow{2}{*}{ GUC82 } & \multirow[t]{2}{*}{4} & \multirow[t]{2}{*}{3} & Mágico/medicinal & 1 \\
\hline & & & Mágico/ritual/supersticioso & 3 \\
\hline \multirow[t]{8}{*}{ GUC98 } & \multirow[t]{8}{*}{60} & \multirow[t]{8}{*}{32} & Agropastoral & 16 \\
\hline & & & Alimentario & 12 \\
\hline & & & Artesanal & 8 \\
\hline & & & Doméstico & 9 \\
\hline & & & Lúdico/voluptuoso & 9 \\
\hline & & & Mágico/ritual/supersticioso & 1 \\
\hline & & & Medicinal & 4 \\
\hline & & & Veterinario & 1 \\
\hline \multirow{5}{*}{ MANG98 } & \multirow[t]{5}{*}{129} & \multirow[t]{5}{*}{62} & Alimentario & 5 \\
\hline & & & Mágico/medicinal & 2 \\
\hline & & & Mágico/ritual/supersticioso & 1 \\
\hline & & & Medicinal & 120 \\
\hline & & & Veterinario & 1 \\
\hline \multirow{3}{*}{$\begin{array}{l}\text { MATT } \\
\text { MUCC01 }\end{array}$} & \multirow{3}{*}{$\begin{array}{l}2 \\
11\end{array}$} & \multirow{3}{*}{$\begin{array}{l}2 \\
9\end{array}$} & Mágico/ritual/supersticioso & 2 \\
\hline & & & Doméstico & 3 \\
\hline & & & Medicinal & 8 \\
\hline \multirow[t]{7}{*}{ POLI14 } & \multirow[t]{7}{*}{13} & \multirow[t]{7}{*}{10} & Agropastoral & 3 \\
\hline & & & Alimentario & 2 \\
\hline & & & Artesanal & 4 \\
\hline & & & Doméstico & 1 \\
\hline & & & Lúdico/voluptuoso & 1 \\
\hline & & & Mágico/ritual/supersticioso & 1 \\
\hline & & & Medicinal & 1 \\
\hline \multirow[t]{2}{*}{ SABA75 } & \multirow[t]{2}{*}{12} & 4 & Alimentario & 2 \\
\hline & & & Doméstico & 1 \\
\hline
\end{tabular}


Etnobotánica en el Alto Valle del Reno (Toscana y Emilia-Romaña, Italia)

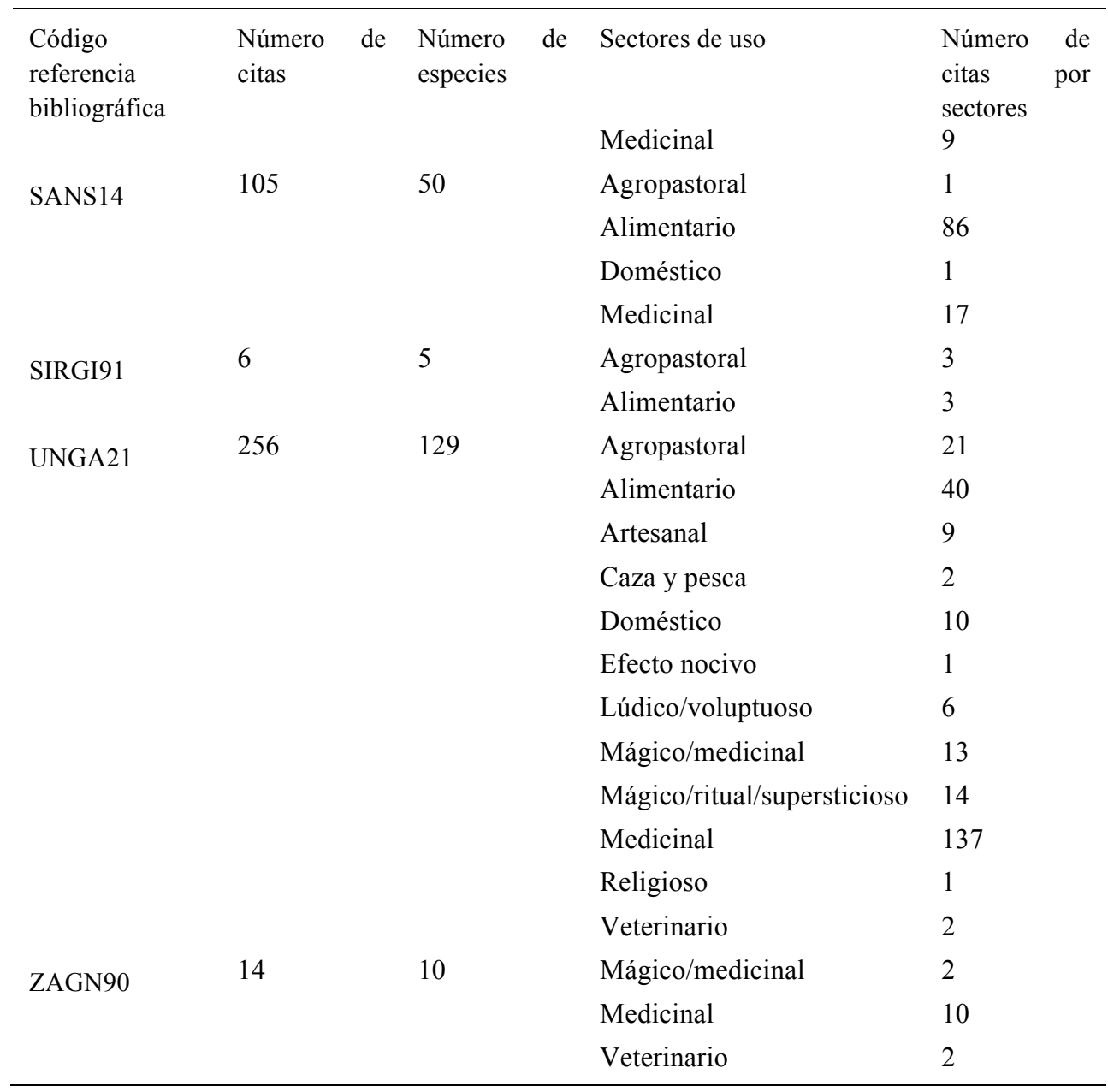

A nivel local, si no se toman en consideración las obras que han estudiado solo el AVR (incluida las citas referidas al AVR del UNGA21), 20 son las referencias bibliográficas consultadas estrictamente de la zona de estudio, las cuales han mencionado 162 citas sobre 67 especies (pertenecientes a 36 familias botánicas) de las 281 especies registradas durante las entrevistas. La obra que más usos etnobotánicos ha registrado sobre las especies recogidas en nuestro estudio es el diccionario del dialecto de Pàvana (Guccini, 1998), con 60 citas relativas a 52 especies, sobre 8 sectores de uso diferentes de los cuales curiosamente resalta el agropastoral (16 citas), el alimentario, el artesanal y el doméstico.

Los usos registrados en la bibliografía estrictamente local que no han sido mencionados por nuestros informantes (Tab. 54) son 89 citas de las 162 citas bibliográficas locales y 86 usos y 41 especies. Esto muestra la calidad del estudio de campo ya que casi la mitad de las citas bibliográficas han sido mencionadas por nuestros informantes. En cambio los usos de la bibliografía local que han sido 


\section{María Teresa Egea Molines}

mencionados por los informantes fueron 73 citas, 55 usos y 38 especies. Además los usos más repetidos en la bibliografía local y en las entrevistas conciernen las especies con mayor importancia relativa como Castanea sativa Mill. cuyos usos en la alimentación animal, como aromatizante, para la construcción agrícola, para cuerdas y ataduras, instrumentos musicales y otros usos agropastorales y domésticos han sido ampliamente documentados en la bibliografía local. Los usos de Buxus sempervirens L. también han sido documentados para jardín, juego colectivo y bromas, objetos domésticos y vallas y delimitaciones. Olea europaea L. cuyos usos en el sector mágico-ritual-supersticiosos, como su función protectora y sus propiedades para ciertas patologías del aparato digestivo han sido también documentados. Igualmente, la importante especie Taraxacum campylodes G.E.Haglund (s.1.) ha sido registrada por sus usos para ensaladas, y verdura cocida, así como por sus propiedades para el estado general. Respecto a Clematis vitalba L. han sido registrados sus usos como fumable y para la preparación de las tortillas.

Tab. 54. Usos etnobotánicos bibliográficos locales no confirmados.

Se listan los usos estrictamente locales que no han sido mencionados por los informantes durante el trabajo de campo

\begin{tabular}{|c|c|c|}
\hline Especie botánica & Categorías de uso novedosas de la bibliografía local & Citas \\
\hline & Afecciones típicas infantiles & 1 \\
\hline Allium sativum L. & Afecciones del aparato respiratorio & 1 \\
\hline \multirow{6}{*}{$\begin{array}{lrr}\text { Allium vineale L. } & & \\
\text { Anacamptis } & \text { morio } & \text { (L.) } \\
\text { R.M.Bateman, } & \text { Pridgeon } & \& \\
\text { M.W.Chase } & & \end{array}$} & Afecciones oro-faríngeas y de la cavidad oral & 1 \\
\hline & Patologías del aparato digestivo & 1 \\
\hline & Patologías del aparato urinario & 1 \\
\hline & Otro alimentario & 1 \\
\hline & Propiciatorio & 1 \\
\hline & & \\
\hline \multirow{12}{*}{$\begin{array}{l}\text { Carex pendula Huds. } \\
\text { Carpinus betulus L. } \\
\text { Castanea sativa Mill. }\end{array}$} & Construcción agrícola (cabañas, etc...) & 1 \\
\hline & Otro doméstico & 1 \\
\hline & Afecciones del aparato respiratorio & 1 \\
\hline & Alimentación animal (incluidos los forrajeros) & 1 \\
\hline & Alimentos/juguetes & 1 \\
\hline & Chimenea y horno & 1 \\
\hline & Horticultura & 2 \\
\hline & Instrumentos musicales & 1 \\
\hline & Jardín & 1 \\
\hline & Juego colectivo y bromas & 1 \\
\hline & Objetos domésticos & 2 \\
\hline & Otro agropastoral & 1 \\
\hline
\end{tabular}


Cornus sanguinea L.

Cucurbita maxima Duchesne

Erica scoparia L.

Fagus sylvatica L.

Fraxinus ornus L.

Helichrysum italicum (Roth)

G.Don

Helleborus foetidus L.

Helleborus viridis L. (s. 1.)

Juglans regia L.

Lupinus albus L.

Malus domestica Borkh.

Matricaria chamomilla L.

Olea europaea L.

Ostrya carpinifolia Scop.

Phaseolus vulgaris L.

Piper nigrum L.

Populus nigra L.
Otro mágico/medicinal 1

Afecciones típicas infantiles 1

Herramientas y objetos agrícolas 1

Objetos personales y calzado 1

Objetos agrícolas 1

Avicultura 1

Afecciones oro-faríngeas y de la cavidad oral 1

Cerdos 1

Ganado bovino 1

Otro mágico/medicinal 1

Parásitos externos 1

Patologías del aparato circulatorio 1

Parásitos externos 1

Juego colectivo y bromas 2

Otro alimentario 1

Juego colectivo y bromas 1

Dulces y golosinas 1

No especificado 1

Afecciones oftalmológicas 1

Afecciones típicas infantiles 1

Afecciones del aparato respiratorio 1

Afecciones típicas infantiles 1

Otro alimentario 1

Patologías del aparato urinario 1

Otro doméstico 1

Otro alimentario 1

Afecciones del aparato respiratorio 1

Aromatizante 1

Patologías del aparato digestivo 1

Patologías del aparato urinario 1

Chimenea y horno 1

Instrumentos musicales 1

Objetos agrícolas 1 


\begin{tabular}{|c|c|c|}
\hline Especie botánica & $\begin{array}{l}\text { Categorías de uso novedosas de la bibliografía local } \\
\text { Objetos domésticos y escobas }\end{array}$ & $\begin{array}{l}\text { Citas } \\
1\end{array}$ \\
\hline Portulaca oleracea L. & Ensalada & 1 \\
\hline \multirow[t]{2}{*}{ Primula vulgaris Huds. } & Afecciones oftalmológicas & 1 \\
\hline & Patologías del sistema nervioso & 1 \\
\hline \multirow{2}{*}{ Prunus avium (L.) L. } & Dulces y golosinas & 1 \\
\hline & No especificado & 1 \\
\hline \multirow[t]{2}{*}{ Prunus domestica L. } & Dulces y golosinas & 1 \\
\hline & No especificado & 1 \\
\hline \multirow{3}{*}{ Pyrus communis L. } & Dulces y golosinas & 1 \\
\hline & No especificado & 1 \\
\hline & Otro mágico/medicinal & 1 \\
\hline \multirow{5}{*}{$\begin{array}{l}\text { Quercus cerris L. } \\
\text { Quercus ilex L. } \\
\text { Quercus pubescens Willd. }\end{array}$} & Alimentación animal (incluidos los forrajeros) & 1 \\
\hline & Bebida & 1 \\
\hline & Bebida & 1 \\
\hline & Objetos domésticos y escobas & 1 \\
\hline & Otro agropastoral & 1 \\
\hline \multirow{3}{*}{$\begin{array}{l}\text { Robinia pseudoacacia L. } \\
\text { Salix alba L. }\end{array}$} & Objetos agrícolas & 1 \\
\hline & Instrumentos musicales & 1 \\
\hline & Objetos domésticos y escobas & 1 \\
\hline \multirow[t]{2}{*}{ Secale cereale L. } & $\begin{array}{l}\text { Afecciones ginecológicas, complicaciones } \\
\text { obstétricas, del post-parto y del puerperio } \\
\text { Objetos personales y calzado }\end{array}$ & $\begin{array}{l}1 \\
1\end{array}$ \\
\hline & Otro alimentario & 1 \\
\hline \multirow{2}{*}{$\begin{array}{l}\text { Solanum tuberosum L. } \\
\text { Spartium junceum L. }\end{array}$} & Efecto negativo & 1 \\
\hline & Cestería & 1 \\
\hline \multirow{3}{*}{ Triticum aestivum $\mathrm{L}$. } & Afecciones típicas infantiles & 1 \\
\hline & Efecto negativo & 1 \\
\hline & Juego colectivo y bromas & 1 \\
\hline \multirow{2}{*}{ Ulmus minor Mill. } & Herramientas y objetos agrícolas & 1 \\
\hline & Otro agropastoral & 1 \\
\hline \multirow[t]{2}{*}{ Vitis vinifera $L$. } & Afecciones cutáneas y tejidos subcutáneos & 1 \\
\hline & Afecciones del aparato respiratorio & 1 \\
\hline \multirow{2}{*}{ Zea mays L. } & Afecciones cutáneas y tejidos subcutáneos & 1 \\
\hline & Afecciones del aparato respiratorio & 1 \\
\hline Total citas & & 89 \\
\hline
\end{tabular}


Exceptuando el caso de Olea europaea L., las especies cuyos usos han sido más documentados en la bibliografía local coinciden con las especies con mayor importancia relativa (según los índices UV o RI), como se ha analizado al principio de la discusión sobre la importancia relativa de dichas especies, ya que al ser tan conocidas e importantes en la comunidad han sido previamente inmortalizadas en la bibliografía local.

Por otra parte si analizamos los usos registrados durante la investigación de campo, que no han sido registrados en la bibliografía (incluidos los estudios parciales) considerando las diferencias en las formas de preparación, han sido registrados 1064 usos novedosos (categorías por especies, pero teniendo en cuenta las diferencias en los modos de preparación) en forma de 2510 citas, relativas a 281 especies. Es decir los informantes han proporcionado al menos un uso novedoso sobre la totalidad de las especies. Esto también demuestra que la investigación ha sido llevada en profundidad y tiene un alto grado de genuinidad y novedad respecto a los estudios precedentes. Sólo el 8,67 \% de los usos registrados durante las entrevistas etnobotánicas han sido previamente registrados por la bibliografía local (1064 usos, de los 1165 son novedosos y solo se repiten 101 usos).

Con el fin de evaluar la influencia regional, hemos realizado una comparación transcultural con el estudio etnofarmacobotánico de la provincia de Pistoia (Uncini Manganelli y Tomei, 1998), y vemos que solo el 25,58\% de los datos (33 citas de 129) coinciden con los informantes del AVR, por lo que vemos que la influencia de la cultura pistoyesa (toscana) no es muy fuerte en la etnofarmacobotánico del AVR (Tab. 55).

Tab. 55. Influencia regional en el AVR.

\begin{tabular}{llllll}
\hline \multicolumn{2}{l}{ Referencias bibliográficas Toscana } & Citas & & Citas & Total \\
MANG98 & Biblio nuevo & 96 & Biblio repetido & 33 & 129 \\
Referencias bibliográficas Emilia-Romaña & Citas & & Citas & Total \\
GRIZ03 & Biblio nuevo & 9 & Biblio repetido & 14 & 23 \\
SANS14 & Biblio nuevo & 36 & Biblio repetido & 69 & 105 \\
UNGA21 & Biblio nuevo & 199 & Biblio repetido & 57 & 256 \\
\hline
\end{tabular}

Sin embargo comparando la proporción del conocimiento etnobotánico registrado en las referencias bibliográficas de la región Emilia-Romaña, vemos como en Sansanelli y Tassoni (2014), la mayoría de los datos etnobotánicos coinciden (el 61,75\%, 69 citas de 105) con el AVR, en GRIZ03 también el 60,86\% de los datos coinciden con el AVR (14 citas de 23). En cambio, en Ungarelli (1921) la mayoría de los usos registrados son novedosos (199 de 256), aunque puede que esto sea debido a que las dos primeras obras son recientes y ésta última es de hace de un siglo.

Aunque para analizar la influencia cultural de Emilia-Romaña y de Toscana en el AVR, necesitaríamos estudios más profundos y específicos, a partir de estos datos disponibles, parece que en el AVR predomina más una cultura emiliana que toscana, lo cual tiene sentido ya que el Reno tiene su mayor recorrido en Emilia-Romaña, aunque nazca en Toscana y parte de su recorrido inicial lo hace justo en la frontera con Toscana. 
Parte 6 Conclusiones - Conclusioni 



\section{Capítulo 1}

\section{Conclusiones}

1-Han sido documentados 4053 citas sobre 333 taxones de plantas vasculares cultivadas y silvestres pertenecientes 79 familias botánicas en el catálogo etnobotánico. La Etnoflora analizada en profundidad y relativa a las plantas silvestres y cultivadas, sólo si éstas son utilizadas para fines diferentes para los cuales son normalmente cultivadas, incluye 3667 citas sobre 1165 usos etnobotánicos relativos a 281 taxones diferentes pertenecientes a 76 familias botánicas. Han sido recogidos un total de 238 pliegos de herbario que han permitido la correcta identificación de 201 especies de las 281 especies útiles.

2-Cada informante conoce una media de $21,2 \pm 14,4$ especies y $30,2 \pm 23,5$ usos diferentes y cita las especies para un número medio de $5,1 \pm 2,4$ sectores de uso y $17,2 \pm 10,3$ categorías de uso. Pero los conocimientos tradicionales se distribuyen en la población de forma heterogénea. Aunque no haya diferencias significativas entre ambos sexos, resalta como las personas que más conocimientos etnobotánicos conservan tienen un mayor nivel de estudios y como en la parte toscana del AVR el conocimiento relativo sobre el número de especies y la diversidad de usos sea mayor que en la parte emiliana.

3-Las familias botánicas más importantes en cuanto a número de citas, número de especies que incluyen y versatilidad de usos, son Compositae y Rosaceae, tanto en la parte toscana como en la emiliana. Estas características son propias de las zonas de montaña y de carácter centroeuropeo. Resalta la familia Fagaceae por ser la familia más versátil a pesar de constituir solo 7 especies.

4-Las especies más importantes por Frecuencia Relativa de Citas, son Malva sylvestris L., Urtica dioica L., Taraxacum campylodes G.E.Haglund (s.1.), Clematis vitalba L., y considerando el índice de Valor de Uso (UV) además resalta Castanea sativa Mill., Buxus sempervirens L., Sambucus nigra L. y Triticum aestivum L. que también son las más importantes desde el punto de vista de la versatilidad de usos que se les otorga. Han sido recogidos 12 sectores de usos principales divididos en un total de 121 categorías secundarias de usos o aplicaciones de usos. Los sectores de uso más importantes y conocidos (por el índice de Valor de uso, el número de citas y el número de informantes) son el alimentario, el medicinal, el doméstico y el agropastoral. Los sectores lúdico/voluptuoso, el religioso, caza y pesca, mágico/medicinal, más propios del patrimonio inmaterial y de la cultura de antaño han sufrido una gran erosión. 
5-El alto número de nombres vernaculares recogidos (814 nombres relativos a 281 taxones) testimonia que existe todavía una cultura vernacular en el territorio. El grado de correspondencia entre la etnotaxonomía y la taxonomía botánica es del $90,79 \%$. Es decir que el 9,21\% de los nombres vernaculares presentan under differentiation. El grado de novedad de la fitonímia recogida es del 88,2\%: de los 814 nombres vernaculares, 718 no son registrados en la bibliografía.

6-La mayoría de las plantas de interés etnobotánico en el AVR son fanerófitos $(37 \%)$, seguidos de hemicriptófitos $(29 \%)$, terófitos $(15 \%)$, geófitos $(9 \%)$ y caméfitos $(6 \%)$, características de zonas de montaña y del Norte de Italia. Las plantas de interés etnobotánico más importantes son de origen europeas $(33 \%)$, cultivadas, eurimediterráneas y de amplia distribución, lo cual corresponde a la situación biogeográfica de frontera de la flora local, entre la región centroeuropea y mediterránea. Las plantas utilizadas son mayoritariamente recolectadas en lugares antropizados y modificados por la actividad humana, aunque también las plantas de ambientes más naturales como "bosques mixtos latifolios, caducifolios y de monte bajo" son importantes, sobre todo por su abundancia en el territorio.

7-La percepción ambiental del estado de las especies de interés en su condición de recurso acusa mayoritariamente al abandono de las prácticas agropastorales y a la reintroducción y protección de los animales ungulados, como los principales factores de amenaza de la etnoflora. La etnoflora está profundamente relacionada con las prácticas tradicionales y con los hábitats que derivan de esas prácticas. La percepción ambiental por parte de la población local, la gestión tradicional y la conservación de la etnoflora pueden suponer valiosas informaciones para estrategias de conservación de la biodiversidad local.

8-En el ámbito alimentario, han sido registradas 1455 citas alimentarias relativas a 142 especies botánicas, pertenecientes a 49 familias. Han sido recogidos 325 usos alimentarios diferentes, clasificados en 24 categorías. Las partes más utilizadas son las hojas $(47 \%)$ y los frutos $(27 \%)$. Las familias más utilizadas con fines alimentarios son Rosaceae (33 especies), Compositae (17 especies), Lamiaceae (7 especies) y Fagaceae (6 especies). Destaca el alto consumo de especies de las familias Fagaceae y Rosaceae con respecto a Italia, así como el escaso consumo de Brassicaceae. Se ha demostrado como la tradición fitoalimúrgica del AVR tiene más similitudes con el Norte de Italia. Las plantas más conocidas por número de citas y el número de informantes que las citan son Taraxacum campylodes G.E.Haglund (s.1.), Sonchus oleraceus (L.) L. (s.1.), Urtica dioica L., Clematis vitalba L., Silene vulgaris (Moench) Garcke, Valerianella locusta (L.) Laterr., Crepis vesicaria L, Cichorium intybus L. y Rubus ulmifolius Schott, las cuales se utilizan para una gran variedad de modalidades gastronómicas. Las categorías alimentarias más importantes en el AVR (por número de especies y número de citas) son los licores, la verdura cocida, las golosinas y masticatorias, las ensaladas y las tortillas. Las preparaciones etnogastronómicas se caracterizan por su simplicidad y las mezclas son muy poco utilizadas (solo el $14,77 \%$ de las citas). Las especies más mezcladas corresponden a la categoría etnogastronómica más importante: "radicchi". La tradición de los licores caseros a base de plantas parece una costumbre de origen más boloñés, así como las sopas de verduras y las pasta fresca rellena (como los 


\section{María Teresa Egea Molines}

"ravioli" o "tortelli"). En cambio, se nota como las frituras y las plantas aromáticas son mucho más comunes en la parte toscana.

9-El $26 \%$ de las especies alimentarias registradas en el AVR tienen un rol medicinal al mismo tiempo que alimentario (37 de las 142 especies alimentarias). De los informantes entrevistados, 37,16\% (42 de los 113 informantes totales) usan alimentos medicinales a base de plantas como prácticas comunes de salud doméstica, se trata de alimentos concebidos como una costumbre saludable capaz de prevenir y curar diferentes patologías. Las afecciones que más se tratan a través de las plantas alimentarias son las patologías del aparato digestivo (utilizan 24 especies alimentarias); las afecciones de la categoría denominada "estado general", es decir como que depurativos, antiinflamatorios generales, regenerativos, energéticos, desintoxicantes, remineralizante, reconstituyente (13 especies alimentarias) y las patologías del sistema urinario para el cual se utilizan 5 especies alimentarias.

10-En el sector medicinal, han sido recogidas 1008 citas relativas a 147 especies sobre 334 usos diferentes, clasificados en 24 categorías de usos diferentes, que corresponden a las diferentes indicaciones terapéuticas generales. Las especies medicinales registradas pertenecen a 53 familias. Compositae y Malvaceae son las familias más citadas $(15,57 \%$ y $15,17 \%$ de todas las citas medicinales), y las más conocidas entre los informantes. Compositae es la familia para la que más especies fueron mencionadas, sin embargo resalta Malvaceae por tener solo 3 especies a pesar de su gran popularidad, debido sobre todo a la popular Malva sylvestris L., que junto a Matricaria chamomilla L. constituyen una especie de "panaceas" de la medicina popular por su gran versatilidad de usos. Los usos medicinales más citados y conocidos están relacionados con afecciones cutáneas y tejidos subcutáneos, seguidas de afecciones del aparato respiratorio, de las patologías del aparato digestivo, y afecciones o síntomas del estado general de salud. El alto grado de conocimiento sobre las afecciones dermatológicas en la comunidad se demuestra también a través de los 32 términos nosológicos (dialectales) para indicar las diferentes afecciones cutáneas. Las formas de preparación de los remedios más utilizados son sencillos y de rápida preparación, sobre todo son la decocción (334 citas, 62 especies), seguidas de "al natural", es decir sin realizar ningún tipo de transformación o elaboración de la parte de la planta (269 citas, 72 especies), infusión (169 citas, 39 especies). Sólo $11,8 \%$ de las citas medicinales se refieren a mezclas de plantas y 47 especies se utilizan junto a otras. Las formas de administración más citadas son la forma oral y la aplicación directa. En los sectores mágico-medicinales y mágico-ritual-supersticioso se ponen de relieve el sincretismo que existe en la cultura local entre el paganismo y el catolicismo.

11-De las 3667 citas registradas sobre usos etnobotánicos, solo el 33,41\% (1225 citas) corresponden a usos actuales que todavía son practicados por los informantes, el $66,59 \%$ de las citas se refieren a usos pasados, lo cual se confirma utilizando el índice UV. La fiabilidad de los datos recogidos y el grado de conocimiento es importante, dado que, aunque gran parte de los usos ya no sean practicados (2442 citas, 66,59\%), el conocimiento etnobotánico todavía es profundo ya que son o han sido practicados personalmente y directamente (87,67 \% de las citas).

12-El estudio etnobotánico bibliográfico local ha proporcionado 668 citas sobre 188 especies de las 281 especies recogidas durante el trabajo de campo. Estas 
Etnobotánica en el Alto Valle del Reno (Toscana y Emilia-Romaña, Italia)

especies pertenecen a 63 familias botánicas. Han sido recogidos 248 usos alimentarios novedosos (categorías por especies) sobre las plantas alimentarias y 289 usos medicinales novedosos. Sólo el 8,67 \% de los usos registrados durante las entrevistas etnobotánicas han sido previamente documentados por estudios de diferente índole realizados precedentemente al nuestro en el área de estudio (1064 usos, de los 1165 son novedosos y solo se repiten 101 usos). Las especies etnobotánicas más documentadas en la bibliografía local corresponden a las de mayor importancia relativa: Castanea sativa Mill, Buxus sempervirens L., Olea europaea L, Taraxacum campylodes G.E.Haglund (s.1.) y Clematis vitalba L.

13- El número total de especies útiles en la parte boloñesa (529 especies) es mayor que el número de especies recogidas en la parte toscana (212 especies). El número de citas obtenidas es 1912 en la parte boloñesa y 1755 en la parte toscana. El conocimiento etnobotánico y fitoalimúrgico del AVR ha mostrado ser más rico en la parte emiliana. Las familias botánicas más importantes en la zona emiliana son Compositae, Rosaceae, Urticaceae, mientras que en la parte toscana Fagaceae y Oleaceae. Castanea sativa Mill. y Buxus sempervirens L. son mucho más importantes en cuanto al número de citas en la parte toscana mientras en la parte emiliana lo son Sonchus oleraceus (L.) L. (s.1.), Silene vulgaris (Moench) Garcke y Cichorium intybus L. Además, el Alto Valle del Reno parece presentar una mayor influencia cultural emiliana en los conocimientos tradicionales de las plantas.

14-Para concluir, a pesar del carácter cerrado y a menudo desconfiado de la comunidad debido a la historia, a la dureza de la naturaleza que lo rodea, al relativo aislamiento, y a pesar de las dificultades encontradas para realizar con rigor ésta investigación (clima, asociación del uso de las plantas silvestres a épocas de hambrunas, la edad muy avanzada de los detentores de éstos conocimientos), he conseguido recoger y documentar gran parte del conocimiento etnobotánico inherente a la cultura local y perteneciente a la tradición oral y ancestral. Al mismo tiempo, aunque se haya recogido gran parte del patrimonio cultural y natural relacionado con los usos tradicionales de las plantas, se han puesto de relieve los fenómenos de erosión que amenazan la sobrevivencia de los conocimientos (cultura inmaterial) y de las plantas relacionadas (cultura material). Las razones de esto son atribuibles al abandono de las prácticas agropastorales, a los drásticos cambios en la gestión del territorio y en las formas de vida. 


\section{Capítulo 2}

\section{Conclusioni}

1- Sono stati documentati 4053 citazioni su 333 taxa di piante vascolari coltivate e spontanee appartenenti a 79 famiglie botaniche nel catalogo etnobotànico. L'etnoflora analizzata in dettaglio e relativa alle specie spontanee o coltivate, solo se queste ultime sono usate per fini diversi da quelli per cui vengono normalmente coltivate, comprende 3667 citazioni su 1165 usi etnobotanici relativi a 281 taxa diversi appartenenti a 76 famigli botaniche. Sono stati raccolti un totale di 238 campioni di erbario, i quali hanno permesso l'identificazione corretta di 201 species delle 281 specie utili.

2- Ogni informatore conosce mediamente $21,2 \pm 14,4$ specie e $30,2 \pm 23,5$ usi diversi e cita specie in un numero medio di $5,1 \pm 2,4$ settori d'uso y $17,2 \pm 10,3$ categorie duso. Nonostante le conoscenze tradizionali sono distruibuite in maniera eterogenea all'interno della popolazione, non ci sono differenze significative rispetto al sesso degl informatori. Tuttavia si è riscontrato come la conoscenza tende ad aumentare con il grado d'istruzione e come nella parte toscana dell'AVR, le conoscenze relative sul numero de specie e la diversità di usi sia maggiore rispetto alla parte emiliana.

3- Le famiglie botaniche più importanti in quanto a numero di citazioni, numero di specie citate e versatilità di usi sono Compositae e Rosaceae, tanto nella parte toscana come nella emiliana. Queste caratteristiche sono proprie di zone di montagna e di carattere centroeuropeo. La famiglia più versatile è risultata essere quella delle Fagaceae anche se è riferita soltanto a 7 specie diverse.

4- Le specie più importanti secondo la Frecuenza Relativa di Citazioni sono Malva sylvestris L., Urtica dioica L., Taraxacum campylodes G.E.Haglund (s.1.), Clematis vitalba L., e considerando l'indice Valore d'uso si aggiungono Castanea sativa Mill., Buxus sempervirens L., Sambucus nigra L. y Triticum aestivum L., le quali sono risultate essere anche le più importanti sotto il punto di vista della versatilità degli usi. Sono stati raccolti 12 settori d'uso principali suddivisi in un totale di 121 categorie secondarie di uso (o appliacazioni d'uso). I settori d'uso più importanti e conosciuti (secondo l'indice di Valore d'uso, il numero di citazioni e il numero di informatori) sono l'alimentare, il medicinale, il domestico, l'agropastorale. I settori ludico/voluttuoso, religioso, caccia/pesca e magico/medicinale appartenenti al patrimonio immateriale e alla cultura del passato, hanno subito una grande erosione. 
5- Il numero importante di nomi vernacolari raccolti (814 nomi relativi a 281 taxoni) testimoniano l'esistenza di una cultura vernacolare nel territorio. Il grado di corrispondenza tra l'etnotaxonomia e la taxonomia botanica è del 90,79\%. Questo vuol dire che il 9,21\% dei nomi vernacolari presentano under differentiation. Il grado di novità della fitonimia raccolta è del 88,20\%: dai 814 nomi vernacolari, 718 non sono registrati nella bibliografía locale.

6- La gran maggioranza delle piante di interesse etnobotánico nell'AVR sono fanerofite $(37 \%)$, emicrittofite $(29 \%)$, terofite $(15 \%)$, geofite $(9 \%)$ e camefite $(6 \%)$, tutte caratteristiche di ambienti di montagna e del Nord Italia. Le piante di interesse etnobotanico più importanti sono di origene europea $(33 \%)$, coltivate, eurimediterranee e di amplia distribuzione, profilo che corrisponde alla situazione biogeografica di frontiera della flora locale, compresa tra la regione centroeuropea e quella mediterranea. Le piante usate sono maggioritariamente raccolte in ambienti antropizzati e modificati dall'attività umana, anche se le piante di ambienti più naturali come "boschi misti, latifoglie, caducifoglie, boschi cedui" sono importanti, soprattutto a causa della loro abbondanza nel territorio. Anche se l'obiettivo principale della ricerca sia stato lo studio etnobotanico delle piante spontanee, è stato dimostrato che le piante coltivate hanno una grande importanza nella vita delle comunità locali.

7- La percezione ambientale dello stato delle specie utili concepite come risorsa invocano principalmente l'abbandono delle pratiche agropastorali e la reintroduzione e protezione degli animali ungulati, come principale causa di minaccia dell'etnoflora. La etnoflora è profondamente collegata alle pratiche tradizionali ed agli habitat che da queste pratiche derivano. La percezione dell'ambiente da parte della popolazione locale, la gestione tradizionale e la conservazione dell'etnoflora, possono costituire rilevanti informazioni per eventuali strategie di conservazione della biodiversità locale.

8- Nell'ambito alimentare, sono stati registrate 1455 citazioni alimentari relative a 142 species botaniche, appartenenti a 49 famiglie. Sono stati raccolti 325 usi alimentari diversi, classificati in 24 categorie. Le parti più utilizzati sono le foglie $(47 \%)$ e i frutti (27\%). Le famiglie più usate a fini alimentari sono Rosaceae (33 specie), Compositae (17 specie), Lamiaceae (7 especies) e Fagaceae (6 specie). È stato evidenziato il grande consumo di specie appartenenti alle famiglie Fagaceae e Rosaceae rispetto a quanto evidenziato nel resto d'Italia, così come il ridotto consumo di Brassicaceae. Si è dimostrato come la tradizione fitoalimurgica dell'AVR abbia più somiglianze con il Nord Italia. Le piante più conosciute in quanto a numero di citazioni e numero di informatori che le citano sono Taraxacum campyloides G.E. Haglund (s.1.), Sonchus oleraceus (L.) L. (s.1.), Urtica dioica L., Clematis vitalba L., Silene vulgaris (Moench) Garcke, Valerianella locusta (L.) Laterr., Crepis vesicaria L, Cichorium intybus L. e Rubus ulmifolius Schott, le quali sono usate per una grande varietà di modalità gastronomiche. Le categorie alimentari più importanti nell'AVR (secondo il numero di specie e di citazioni) sono i liquori, la verdura cotta, gli spuntini campestri, le insalate e le frittate. Le preparazioni etnogastronomiche si caratterizzano per la loro semplicità, e le misture di piante diverse sono poco usate (solo il $14,77 \%$ delle citazioni). Le specie che con maggiore frequenza vengono usate in mistura corrispondono alla categoria 


\section{María Teresa Egea Molines}

etnogastronomica più importante:"i radicchi". La tradizioni dei liquori casalinghi a base di piante sembra essere un'abitudine di origine bolognese, così come le zuppe e minestre di verdura e la pasta fresca ripiena (i ravioli o tortelli). Invece, le fritture e le piante aromatiche sono molto più comuni nella parte toscana.

9- Il 26\% delle specie ad uso alimentare registrate nell'AVR hanno un ruolo medicinale oltre che alimentare (37 specie delle 142 specie alimentari). Il 37,16\% degli informatori intervistati (42 dei 113 informante totali) usano alimenti medicinali a base di piante come comune pratica di salute domestica, si tratta di alimenti concepiti come una salutare consuetudine in grado di prevenire e curare diverse patologie. Le affezioni che più sono trattate con le piante alimentarie sono le patologie dell'apparato digestivo (24 species alimentarie); le affezioni della categoria "stato generale", vale a dire piante utilizzate a scopo depurativo, come antinfiammatori generali, rigeneranti, energetici, disintossicanti, rimineralizzanti, ricostituenti (13 specie alimentarie) e per le patologie del sistema urinario (5 specie alimentarie).

10- Nel settore medicinale, sono state raccolte 1008 citazioni relative a 147 specie su 334 usi diversi, classificati in 24 categorie di uso diverse, e corrispondenti alle indicazioni terapeutiche generali. Le specie medicinali registrate appartengono a 53 famiglie. Compositae e Malvaceae sono le famiglie più citate (15,57\% e 15,17\% delle citazioni medicinali) e più conosciute dagli informatori. Compositae è la famiglia per la quale più specie sono state citate, tuttavia Malvaceae è rappresentata soltanto da 3 specie malgrado la sua grande popolarità, dovuto soprattutto alla rilevanza di Malva sylvestris L., che insieme a Matricaria chamomilla L. costituiscono una sorta di panacea della medicina popolare per la sua grande versatilità di usi. Gli usi medicinali più citati e conosciuti sono relativi alle affezioni dermatologiche, alle affezioni dell'apparato respiratorio, alle affezioni dell'apparato digestivo e alle affezioni o sintomi dello stato generale di salute. L'alto grado di conoscenza alle affezioni dermatologiche nella comunità è messo in evidenza con $\mathrm{i}$ 32 termini nosologici (dialettali) registrati per indicare le diverse afezzioni cutanee. Le forme di preparazione dei rimedi più usati sono semplici e veloci da preparare; soprattutto sono usati i decotti (334 citazioni, 62 specie), le preparazioni al naturale, vale dire senza nessuna trasformazione o elaborazioni della parte della piante (269 citazioni, 72 specie), infuso (169 citazioni, 39 specie). Soltanto 1'11,80\% delle citazioni medicinali sono relative a misture di diverse specie e 47 specie sono usate in combinazioni con altre. Le forme di somministrazione più citate sono la forma orale e l'applicazione diretta. Nei settori magico-medicinale e magico-ritualesuperstizioso si evidenzia il sincretismo che esiste nella cultura locale tra la paganità e il cristianesimo.

11- Dalle 3667 citazioni registrate sugli usi etnobotanici, solo il 33,41\% (1225 citazioni) corrisponde ad usi attuali, cioè ancora praticati dagli informatori, mentre il $66,59 \%$ delle citazioni sono riferite ad usi passati, dato che è confermato dagli indici UV. L'affidabilità dei dati raccolti e il grado delle conoscenze è importante, considerando che nonostante gran parte degli usi non sono praticati attualmente (2442, 66,59\%), le conoscenze etnobotaniche sono ancora profonde perché sono o sono state praticate personalmente e direttamente $(87,67 \%$ delle citazioni). 
12- Lo studio etnobotanico basato sui dati bibliografici disponibili a livello locale ha evidenziato un numero di 668 citazioni su 188 specie sulle 281 specie raccolte durante l'indagine di campo. Queste specie appartengono a 63 famiglie botaniche. Sono state raccolte 248 usi alimentari nuovi (categorie per specie) sulle piante alimentari e 289 usi medicinali nuovi. Soltanto 1'8,67\% degli usi registrati durante le interviste etnobotaniche sono stati previamente documentati da studi di diversi tipi, condotti precedentemente al nostro nell'area (1064 usi dagli 1165 sono nuovi). Le specie etnobotaniche più documentate nella bibliografía locale corrispondono a quelle che hanno una maggiore importanza relativa: Castanea sativa Mill, Buxus sempervirens L., Olea europaea L, Taraxacum campylodes G.E.Haglund (s.1.) y Clematis vitalba L.

13-Il numero totale delle specie utili nella parte bolognesa (529 specie) è maggiore di quello nella parte toscana (212 specie). Il numero di citazioni raccolte è 1912 nella parte bolognesa e 1755 nella parte toscana. In particolare, le conoscenze etnobotaniche e fitoalimurgiche dell'AVR sono più ricche nella parte emiliana. Le famiglie botaniche più importanti nella zona emiliana sono Compositae, Rosaceae, Urticaceae, invece nella parte toscana sono Fagaceae e Oleaceae. Castanea sativa Mill. e Buxus sempervirens L. sono molto più importanti nella parte toscana per quanto riguarda il numero di citazioni, invece nella parte emiliana le specie più importanti sono Sonchus oleraceus (L.) L. (s.1.), Silene vulgaris (Moench) Garcke e Cichorium intybus L. L'Alta Valle del Reno sembra presentare una maggiore influenza culturale emiliana nelle conoscenze tradizionali delle piante.

14-In conclusione, malgrado il carattere introverso e spesso diffidente mostratomi dalla comunità, dovuto alla sua storia, alla durezza della natura che lo circonda, al relativo isolamento, e malgrado le difficoltà incontrate per svolgere con rigore la presente ricerca (clima, associazione dell'uso tradizionale delle piante a periodi di casteria, l'età avanzata dei detentori delle conoscenze), sono riuscita a raccogliere e documentare gran parte delle conoscenze etnobotaniche inerenti alla cultura locale e appartenenti alla tradizione orale ed ancestrale. Contemporaneamente, anche se è stato raccolto gran parte del patrimonio culturale e naturale relativo agli usi tradizionali delle piante, devo sottolineare come siano in atto evidenti fenomeni di erosione che minacciano la sopravvivenza sia delle conoscenze (cultura immateriale) che delle piante associate (cultura materiale). Le ragioni di questo sono in parte da attribuire all'abbandono delle pratiche agropastorali ed ai drastici cambiamenti nella gestione del territorio e nei modi di vita. 
Parte 7 Bibliografía 
Etnobotánica en el Alto Valle del Reno (Toscana y Emilia-Romaña, Italia)

ABS (2016). Protocolo de Nagoya sobre Acceso y Participiación en los beneficios: $\quad$ https://www.cbd.int/abs/infokit/revised/web/factsheet-nagoya-es.pdf (última consulta: 31 enero 2016).

Adamovic, L. (1933). Die pflanzengeographische Stellung und Gliederung Italiens. Jena: Gustav Fischer.

Albuquerque U.P.; Medeiros P.M.; Sousa Araújo T.A.; Silva T.C.; Fernandes Cruz da Cunha, L.; Oliveira Júnior G.J.; Fátima Castelo Branco Rangel de Almedia, C. (2008). Bioremediation, Biodiversity and Bioavailability 2 (Special Issue 1): 2734.

Alexiades, M.N. (1996). Selected guidelines for ethnobotanical research: A field manual. Nueva York: New York Botanical Garden.

Alto Reno Toscano I (2016). Avanzi longobardi e germanici in Alto Reno e nel Pistoiese: www.kenoms3.altervista.org/altorenotoscano3/longobardismi.htm (última consulta: 16 enero 2016).

Alto Reno Toscano II (2016). Teoria dei dialetti: http://kenoms3.altervista.org/altorenotoscano3/altorenotoscano/teoriadialetti.htm (última consulta: 21 Febrero 2016).

Anónimo (s.d.) Sambuca Pistoiese, Carta degli itinerari. Montecatini Terme: Centro Naturalistico Europeo.

APG III (2009). THE ANGIOSPERM PHYLOGENY GROUP: Birgitta Bremer, Kåre Bremer, Mark W. Chase, Michael F. Fay, James L. Reveal, Douglas E. Soltis, Pamela S. Soltis and Peter F. Stevens, Arne A. Anderberg, Michael J. Moore, Richard G. Olmstead, Paula J. Rudall, Kenneth J. Sytsma, David C. Tank, Kenneth Wurdack, Jenny Q.-Y. Xiang \& Sue Zmarzty). 2009. An update of the Angiosperm Phylogeny Group classification for the orders and families of flowering plants: APG III. Botanical Journal of the Linnean Society 161: 105-121.

Appoggi, S. (2010). Piccolo dizionario di parole e modi di dire in dialetto Baignotto. Sin datos de edición.

Appoggi, S.; Bacchi, P. (2008). Baigno com'eri, tra ricordi e ricerca storica. Baigno: Grafis Polycrom.

Appoggi, S; Pritoni, A. (s.d.). Le borgate di Baigno. Baigno: Pro loco di Baigno.

ARPA (2012). Arpa. www.arpa.emr.it, (última consulta: 15- 06-2012).

Arrigoni, P.V.; Bettini, G.; Foggi, B.; Signorini M.A. (2002). Guida alla conoscenza botanica della Riserva Naturale Acquerino-Cantagallo. Carta della vegetazione. Itinerari naturalistici. Prato: Provincia di Prato y Comune di Cantagallo.

Arrigoni, P.V.; Foggi, B.; Signorini, M.A., Bettini, G.; Ricceri, C. (2005). La vegetazione della Riserva Naturale Acquerino-Cantagallo (Toscana settentrionale). Parlatorea 7: 47-69.

Atran, S. (1998). Folk Biology and the Anthropology of Science: Cognitive Universals and Cultural Particulars. Behavioral and Brain Sciences 21: 547-609.

Badi (2015). Ricettario della proloco di Badi. http://www.prolocobadi.it/mesibadesi.htm. último acceso: 15/09/2015.

Ballero, M.; Poli, F. (1997). Plants used in folk medicine of Monteleone (Northern Sardinia). Fitoterapia 69(1): 52-64. 
Balletti, P. (1979). I primi fiori. Nuèter noialtri-Storia, tradizione e ambiente dell'alta valle del Reno bolognese e pistoiese 2: 57-61.

Balletti, P. (1980a). I nostri fiori. Nuèter noialtri-Storia, tradizione e ambiente dell'alta valle del Reno bolognese e pistoiese 1: 46-50.

Balletti, P. (1980b). I nostri fiori. Nuèter noialtri-Storia, tradizione e ambiente dell'alta valle del Reno bolognese e pistoiese 2: 51-55.

Balletti, P. (1981a). I nostri fiori. Nuèter noialtri-Storia, tradizione e ambiente dell'alta valle del Reno bolognese e pistoiese 1: 36-39.

Balletti, P. (1981b). I nostri fiori. Nuèter noialtri-Storia, tradizione e ambiente dell'alta valle del Reno bolognese e pistoiese 2: 36-40.

Balletti, P. (1997). Aspetti vegetazionali e floristici della Sambuca. En: P. Balletti, P. Gioffredi (Eds.) Le valli della Sambuca. Natura, storia, ambiente. Pp. 53-60. Sambuca Pistoiese: Comune di Sambuca Pistoiese.

Balletti, P. (1998). La Nosgiadella. Nuèter noialtri-Storia, tradizione e ambiente dell'alta valle del Reno bolognese e pistoiese 48: 16 .

Balletti, P. (2001a). Storie della Sambuca, luoghi, tradizioni, personaggi di un territorio di frontiera. Pistoia y Sambuca Pistoiese: Artout-m\&m y Comune di Sambuca Pistoiese.

Balletti, P. (2001b). Dizionario toponomastico del Comune di Granaglione. Porretta Terme: Gruppo di studi Alta Valle del Reno-Nuèter.

Balletti, P.; Gioffredi, P. (1997). Le valli della Sambuca. Natura, Storia, Ambiente. Sambuca Pistoiese: Comune di Sambuca Pistoiese.

Beghelli, S. (1999). Tutela e valorizzazione del banco calcareo a lucine del Parco regionale dei Laghi di Suviana e Brasimone mediante uno studio di geologia ambientale. Tesi di laurea. Facoltà Scienze matematiche fisiche e naturali, Bologna. Bolonia: Università degli Studi di Bologna.

Bèguinot, A.; Gabelli, L. (1915). La flora alveale del Reno bolognese. Nuovo Giornale Botanico Italiano 22: 365-388, 410-476.

Beneforti, B. (1998). Piccolo dizionario dei dialetti di Badi, Bargi e Stagno. Porretta Terme: Nuèter-ricerche. In Nuèter 24: 357-388.

Benítez, G. (2009). Etnobotánica y Etnobiología del poniente granadino. Tesis Doctoral. Universidad de Granada. Granada.

Berlin, B. (1973). Folk systematics in relation to biological classification and nomenclature. Annual Review of Ecology, Evolution and Systematics 4: 259-271.

Bernard, H. R. (1988). Research methods in cultural anthropology. Newbury Park: Sage Publications.

Bernardi, G. (1940-1941). Fonetica dei dialetti dell'Alta Valle del Reno. Tesi di Laurea. Facoltà di Lettere e Filosofia, Bologna. Bolonia: Università degli Studi di Bologna.

Bernardi, M.; Zagnoni, R. (1978). Detti e proverbi. Nuèter noialtri-Storia, tradizione e ambiente dell'alta valle del Reno bolognese e pistoiese 1: 68-69.

Bernardi, M.; Zagnoni, R. (1979). Detti e proverbi. Nuèter noialtri-Storia, tradizione e ambiente dell'alta valle del Reno bolognese e pistoiese 2: 49-50.

Bernardi, M.; Zagnoni, R. (1981). Detti e proverbi. Nuèter noialtri-Storia, tradizione e ambiente dell'alta valle del Reno bolognese e pistoiese 1: 38-39. 
Etnobotánica en el Alto Valle del Reno (Toscana y Emilia-Romaña, Italia)

Bertoloni, G. (1867). Vegetazione dei monti di Porretta. Bolonia: Regia Topografia.

Biscotti, N.; Pieroni, A. (2015). The hidden Mediterranean diet: wild vegetables traditionally gathered and consumed in the Gargano area, Apulia, SE Italy. Acta Societatis Botanicorum Poloniae 84(3): 327-338.

BOE (2004). Orden SCO-190-2004, de 28 de enero, por la que se establece la lista de plantas cuya venta al público queda prohibido o restringida por razón de su toxicidad: https://www.boe.es/buscar/doc.php?id=BOE-A-2004-2225 (última consulta: 23 febrero 2016).

Boldri, G. (1991). Storia della Sambuca (998-1405). La guerra tra Bologna e Pistoia, lo Statuto del 1291. Castel di Casio: Centro Studi Editoriali Castel di Casio y Comune di Castel di Casio.

Bolognesi, L. (2003). Interventi di promozione e sostegno dell'agricoltura nei parchi attraverso l'analisi del territorio, la fornitura di servizi e la realizzazione di azioni. Relazione finale censimento aziende agricole. Progetto Esecutivo SOLE 0BO02SOLE. Camugnano: Parco Regionale dei Laghi di Suviana e Brasimone.

Bonzi, L. (2000). Piccolo dizionario del dialetto di Treppio (Porretta Terme: Nuèter-ricerche,16). Nuèter noialtri-Storia, tradizione e ambiente dell'alta valle del Reno bolognese e pistoiese 26: 145-192.

Borghi, G.P. (1989a). Un castagno per amico. En: Roda, R. (Ed.) Il castagno, tradizioni e trasformazioni. Pp. 53-55. Ferrara y Padua: Centro Etnografico ferrarese e Interbook.

Borghi, G.P. (1989b). E dai panieri le castagne vengono gettate nei sacchi: castagni e castagne nel pistoiese (da alcune esercitazioni scolastiche del 1929). En: Roda, R. (Ed.), Il castagno, tradizioni e trasformazioni. Pp. 41-52. Ferrara y Padua: Centro Etnografico ferrarese e Interbook.

Borghi, G.P. (1991). A Treppio alla ricerca di Alan Lomax e dei poeti improvvisatori. En: Anónimo. Gente e luoghi della Sambuca Pistoiese. Porretta Terme y Sambuca Pistoiese: Nuèter y Comune di Sambuca Pistoiese.

Borghi, G.P. (1997). Musa popolare e mestieri tradizionali. Porretta Terme: Gruppo di studi alta valle del Reno.

Borghi, G.P. (2000). I castelli nella tradizione popolare dell'Appennino toscoemiliano. En: Zagnoni, R.; Foschi, P.; Penoncini, E. (Eds.) I Castelli dell'Appennino nel Medioevo: atti della Giornata di studio: 11 settembre 1999. Pp. 157-170. Pistoia: Società Pistoiese di Storia Patria.

Borghi, G.P. (2002). Un antico rito popolare della settimana sana: battere il mattutino. Nuèter noialtri-Storia, tradizione e ambiente dell'alta valle del Reno bolognese e pistoiese a. 28 (56): 301-309.

Borghi, G.P. (2004). Emigrazione e mondo popolare: storie e tragedie cantate. En: Foschi, P.; Zagnoni, R. (Eds.) Migranti dell'Appennino. Pp. 39-50. Porretta Terme, Pistoia y San Marcello Pistoiese: Gruppo di studi alta Valle del Reno, Società Pistoiese di Storia Patria y Centro per 1'emigrazione "Mario Olla".

Borghi, G.P.; Zagnoni, R. (1983). La festa della Santa Croce: aspetti della religiosità popolare nella ricorrenza del 3 di maggio. Porretta Terme: Nuèter. 
Borghi, G.P.; Zagnoni, R. (1990). Attorno a casa nostra non manca mai la malva. Aspetti della medicina popolare in una ricerca nell'Alta valle del Reno. Storia e medicina popolare 8 (2,3): 19-31.

Borghi, G.P.; Zagnoni, R.; Antilope A. (2002). La Madonna del Bosco nella tradizione popolare. Porretta Terme: Nuèter.

Borri, I. (1977). Tradizioni di Badi. Porreta Terme: Nuèter.

Bracchi, R. (2003). La paterlènga, il corallo dei poveri. Nuèter noialtri-Storia, tradizione e ambiente dell'alta valle del Reno bolognese e pistoiese, a. 29 (57): 132136.

Breschi, M.; Pozzi, L. (1997). Un territorio di frontiera. Popolazione e villaggi dell'Appennino pistoiese e bolognese nell'Ottocento-preunitario. En: Anónimo. Villaggi, boschi e campi dell'Appennino dal Medioevo all'età contemporánea. Pp. 83-108. Porretta Terme y Pistoia: Gruppo Studio Alta Valle del Reno y Società Pistoiese Storia Patria.

Brousse, C. (2011). Une analyse historique et ethnobotanique des relations entre les activités humaines et la végétation prairiale. Fourrages 208: 245-251

Bruni, A.; Baller,. M.; Poli, F. (1997). Quantitative ethnopharmacological study of the Campidano Valley and Urzulei district, Sardinia, Italy. Journal of Ethnopharmacology 57: 97-124.

Bruschi, P.; Egea, T.; Ongaro, L.; Signorini, M.A. (2012). Antichi saperi sotto il cielo. IBC $X X$ http://rivista.ibc.regione.emilia-romagna.it/xw-201203/xw-201203a0010 última consulta: 16/10/2015).

Bufalari, V.; Giovannelli, P.; Franchini, G. (s.d.). Il castagno. Pistoia y Firenze: Comunità montana appennino pistoiese y Ente toscano sviluppo agricolo e forestale.

BURER (2008). Bollettino Ufficiale Regione Emilia-Romagna. Tutela del patrimonio dei razze e varietà locali di interesse agrario del territorio emilianoromagnolo. Legge Regionale 29 gennaio 2008, n.1: parte prima n.1, anno 39, n. 14.: http://demetra.regione.emilia-

romagna.it/al/monitor.php?urn=er:assemblealegislativa:legge:2008;1 (última consulta: 23 febrero 2016).

BURT (2000). Legge Regionale 6 aprile 2000, n.56. Norme per la conservazione e la tutela degli habitat naturali e seminaturali, della flora e della fauna selvatiche. Modifiche alla legge regionale 23 gennaio 1998, n.7. Modifiche alla legge regionale 11 aprile $1995, \quad$ n. 49. http://www.regione.toscana.it/documents/10180/392141/dcae9a1c7cf71b27283967b c0ab73be4_1r56del6aprile2000sir.pdf/8fc35c60-b0f0-4b6d-9009-96c7511871c1 (última consulta: 21 diciembre 2015).

Camangi, F.; Guarrera, P.M.; Camarda, P.E.; Tomei, F.; Lentini, F.; Stefani, A.; Leporatti, M.L.; Pieroni, A. (2013) Usi alimentari. En: Caneva,G.; Pieroni, A.; Guarrera P.M. (Eds). Etnobotanica. Conservazione di un patrimonio culturale come risorsa per uno sviluppo sotenibile. Pp. 43-68. Bari: Edipuglia.

Camangi, F.; Stefani, A.; Tomei, P.E. (2003). Il Casentino: tradizioni etnofarmacobotaniche nei comuni di Poppi e Bibbiena (Arezzo-Toscana). Atti della Società Toscana de Scienze Naturali, Mem. Ser. B 110: 55-69. 
Etnobotánica en el Alto Valle del Reno (Toscana y Emilia-Romaña, Italia)

Camangi, F.; Stefani, A.; Uncini Manganelli, R.E.; Tomei, P.E.; Trimarchi, S.; Oggiano, N.; Loni, A. (2007). L'uso delle erbe nella tradizione rurale della Toscana. Vol. III. Firenze: ARSIA Regione Toscana.

Camangi, F.; Uncini Manganelli, R.E.; Tomei, P.E.; Oggiano N. (2002). L'uso delle erbe nella tradizione rurale della Toscana. Vol. I-II. Firenze: ARSIA. Regione Toscana.

Camarda, I.; Guarrera, P.M. (2005). Scopi e metodologie nella ricerca etnobotanica. En: Caneva,G. (Ed.), La biologia vegetale per i beni culturali. Vol. II Conoscenza e Valorizzazione. Pp. 372-376. Firenze: Nardini editore.

Camugnano (2015).

Camugnano. http://www.comunecamugnano.gov.it/servizi/Menu/dinamica.aspx?idSezione=616\& idArea $=17951 \&$ idCat $=17953 \&$ ID $=17953 \&$ TipoElemento=categoria consulta: 2 diciembre 2015).

Canuto (1978). La zvoleda. Nuèter noialtri-Storia, tradizione e ambiente dell'alta valle del Reno bolognese e pistoiese 2: 30-31.

Carrió, E., Vallès, J. (2012). Ethnobotany of medicinal plants used in Eastern Mallorca (Balearic Islands, Mediterranean Sea). Journal of Ethnopharmacology 141: 1021-1040.

Carvalho, A.M. (2005). Etnobotánica del Parque de Montesinho. Plantas, tradición y saber popular en un territorio del Nordeste de Portugal. Tesis de Doctorado. Madrid: Universidad Autónoma de Madrid. Zara.

Castelli, M. (1992). Farmacopea popolare nell'Appennino Emiliano. Parma:

Cavazza, C. (2003). Le attivitá forestali in Appennino: notizie storiche, paesaggio, risorse, prima parte, Nuèter noialtri-Storia, tradizione e ambiente dell'alta valle del Reno bolognese e pistoiese, a. 29 (58): 300-309.

Cavazza, C. (2005). Le attivitá forestali in Appennino: notizie storiche, paesaggio, risorse, terza parte. Nuèter noialtri-Storia, tradizione e ambiente dell'alta valle del Reno bolognese e pistoiese a. 31 (61): 60-66.

CBD (1992). Convenio sobre la Diversidad Biológica. Artículo 8j. Río de Janeiro:

Naciones

Unidas:

https://www.cbd.int/convention/articles/default.shtml?a=cbd-08 (última consulta: 12 diciembre 2015).

(2015)

Centro

Etnobotanico

Toscano.

http://agronomia.di.unipi.it/wp/Orto/centro.aspx (último acceso: 15 Octubre 2015).

Chelucci, G. (1997). La montagna dei 'forastieri'. En: Balletti P., Gioffredi P. (Eds), Le valli della Sambuca. Natura, storia, ambiente. Pp. 31-38. Sambuca Pistoiese: Comune di Sambuca Pistoiese.

Ciuti, E. (1993). Evoluzione dell'attività agricola e forestale del Comune di Sambuca Pistoiese. Pistoia: Centro sperimentale per il vivaismo.

Ciuti, E. (1997). L'agricoltura com'era. En: Balletti P., Gioffredi P. (Eds.) Le valli della Sambuca. Natura, storia, ambiente Pp. 39-46. Sambuca Pistoiese: Comune di Sambuca Pistoiese.

Clément, G. (2005). Manifesto del Terzo paesaggio. Macerata: Quodlibet.

Comelli, G. (1917). Bargi e la val di Limentra. Storia e tradizioni locali con carta topografica. Bolonia: Stab. Tipografico L. Parma \& G. 


\section{María Teresa Egea Molines}

Cornara, L.; La Rocca, A.; Terrizzano, L.; Dente, F.; Mariotti, M.G. (2014). Ethnobotanical and phytomedical knowledge in the North-Western Liguarian Alps. Journal of Ethnopharmacology 155: 463-484.

Corradi, G. (2014). Piuli, baggioli, lampoline o mirtilli?. Nuèter noialtri-Storia, tradizione e ambiente dell'alta valle del Reno bolognese e pistoiese, a 40 (1): 26-27.

Daghini, R. (2005). La lavorazione della canapa a Porretta e Bologna (secoli XVI-XIX). Nuèter noialtri-Storia, tradizione e ambiente dell'alta valle del Reno bolognese e pistoiese, a. 31 (61): 98-101.

De Philippis A (1937). Classificazioni ed indici del clima in rapporto alla vegetazione forestale italiana. Nuovo Giornale Botanico Italiano 44: 1-169.

DeWalt, K. M.; DeWalt, B.R. (1998). Participant obervation. En: H. RusserlBernard (Ed.), Handbook of methods in cultural anthropology. Pp. 259-300. Walnut Creek: AltaMira Press.

Dondini, G.; Vergari, S. (2009). Natura sull'Appennino Pistoiese (Toscana settentrionale). Con itinerari escursionistici per la conoscenza di flora, fauna e ambienti naturali. Pistoia: Felici Editore.

Edwards, S.; Nebel, S.; Heinrich, M. (2005). Questionnaire surveys: Methodological and epistemological problems for field-based ethnopharmacologists. Journal of Ethnopharmacology 100: 30-36.

Egea, T.; Signorini, M.A.; Bruschi, P.; Rivera, D.; Obón, C. (2015). Spirits and liqueurs in European traditional medecine: their history and ethnobotany in Tuscany and Bologna (Italy). Journal of Ethnopharmacology 175: 241-255.

Egea, T.; Signorini, M.A.; Bruschi, P.; Rivera, D.; Obón, C. (2016). Traditional Alcoholic Beverages (TAB) in a mountain borderland between Tuscany and EmiliaRomagna (Italy): a social/cultural, environmental and nutraceutical heritage. Journal of Ethnobiology and Ethnomedicine (enviado).

Elmi, G. (1999). Studio geologico di corredo al pianto territoriale del Parco. Quadro conoscitivo. Camugnagno: Parco Regionale dei laghi di Suviana e Brasimone.

ERT (2012). La valle del Reno. http://www.emiliaromagnaturismo.it/it/pubblicazioni/miscellanea.html (última consulta: 12 diciembre 2015).

FAO (2001). Aprobación del Tratado Internacional sobre los Recursos Fitogenéticos para la Alimentación y la Agricultura y disposiciones provisionales para su aplicación http:/www.fao.org/3/contents/69fdf7a2-5405-55fb-a7d48911dadf7ba2/Y2650s01.htm\#P278 33969 (última consulta 10/12/2015).

Ferrari, E. (1997). Tracce di isoglosse e sostrato nei dialetti pavanese e sambucano. Sambuca Pistoiese: Editor desconocido.

Filipponio, L. (2007a). Vocali e consonanti a confronto. Uno studio teorico e sperimentale sui dailetti dell'Appennino bolognese. Tesi di Dottorato. Pisa: Università di Pisa.

Filipponio, L. (2007b). Lingua e storia nei dialetti della valle del Reno. Nuèterricherche 33. In Nuèter noialtri-Storia, tradizione e ambiente dell'alta valle del Reno bolognese e pistoiese (66): 353-384. 
Etnobotánica en el Alto Valle del Reno (Toscana y Emilia-Romaña, Italia)

Fioni, A. et al. (1993). Bargi, Baigno, Stagno. La vita della Chiesa nella storia di tre comunità della montagna. Porretta Terme y Camugnano: Nuèter y Parrocchie di Bargi, Baigno e Stagno.

Foggi B., Venturi E., Ferreti, G. (2007). Progetto per l'individuazione, lo studio e il monitoraggio degli Habitat e delle Specie meritevoli di conservazione della Provincia di Pistoia ai sensi della L.R. 56/2000. Habitat, specie vegetali e animali (fauna eteroterma) meritevoli di conservazione nel Comprensorio delle Tre Limentre. Pistoia: Provincia di Pistoia.

Foschi, P. et al. (1991). Gente e luoghi della Sambuca Pistoiese. Porretta Terme y Sambuca Pistoiese: Nuèter y Comune di Sambuca Pistoiese.

Fossati, F.; Bianchi, A.; Favali, M.A. (1999). Farmacopea popolare del parmense: passato e presente. Informatore Botanico Italiano 31: 171-176.

Georgescu-Roegen, N. (2003). Bioeconomia, verso un'altra economia ecologicamente e socialmente sostenibile. Torino: Bollati Boringhieri.

Gioffredi, P. (1997). Mestieri. En: Balletti P., Gioffredi P. (Eds.), Le valli della Sambuca. Natura, storia, ambiente. Pp. 61-68. Sambuca Pistoiese: Comune di Sambuca Pistoiese.

Gioffredi, P. (s.d.) Torri, storia, tradizioni, cultura. Atti degli incontri culturali dal 1996 al 2002. Pistoia y Torri: Società pistoiese di storia patria y Associazione per lo sviluppo turistico di Torri.

Gioffredi, R. (1959-1960). Osservazioni geobotaniche sulle faggete della Val di Limentra Orientale. Tesi di laurea. Facoltà di Agraria e Forestale, Firenze. Florencia: Università di Firenze.

GSAVR (1989). Sulla tradizionale coltura del castagneto nella montagna bolognese. In Il castagno. Tradizioni e trasformazioni. Quaderni del Centro Etnografico Ferrarese 30: 31-39.

Guarino, C.; Simone, L.; de, Santoro, S. (2008). Ethnobotanical study of the Sannio area, Campania, Southern Italy. Ethnobotany Research and Applications 6: 255-317.

Guarrera, P.M. (2006). Usi e tradizioni della flora italiana. Medicina popolare ed etnobotanica. Roma: Aracne Editrice.

Guarrera, P.M.; Lucia, L.M. (2007). Ethnobotanical remarks on Central and Southern Italy. Journal of Ethnobiology and Ethnomedicine. 3. DOI: 10.1186/17464269-3-23.

Guccini, F. (1978). I maggi del nostro Appennino. Porretta Terme: Nuèter.

Guccini, F. (1980). Una storia di vita, di Pàvana. Nuèter noialtri-Storia, tradizione e ambiente dell'alta valle del Reno bolognese e pistoiese 1: 58-63.

Guccini, F. (1981). Una storia di vita, di Pàvana. Nuèter noialtri-Storia, tradizione e ambiente dell'alta valle del Reno bolognese e pistoiese 2: 41- 47.

Guccini, F. (1982). Una storia di vita, di Pàvana. Nuèter noialtri-Storia, tradizione e ambiente dell'alta valle del Reno bolognese e pistoiese 1: 2-7.

Guccini, F. (1989). Cròniche épafàniche. Milán: Feltrinelli Editore.

Guccini, F. (1998). Dizionario del dialetto di Pàvana. Pàvana Pistoiese y Porretta Terme: Pro Loco Pavana y Gruppo Studi Alta Val del Reno.

Guccini, F.; Guccini, A.M. (2008). Aspetti di vita di lavoro e d'ingegno nell'appennino bolognese. Silla: Polisportiva Silla. 
Guidi, S. (2013). I frutteti della biodiversità in Emilia-Romagna. Indagini agronomiche ed etnobotaniche sulla varietà dell'agricoltura tradizionale. Bolonia: Arpa Emilia-Romagna.

Guidotti, P. (1985). Il Camugnanese, dal XII al XX secolo (capitoli per una storia). Bolonia: Ed. CLUEB.

GURI (2009). Gazzetta Ufficiale della Repubblica Italiana, Regione Toscana, Legge Regionale n.44, 31 luglio 2009, art. 13, comma 3: http://www.gazzettaufficiale.it/atto/regioni/caricaDettaglioAtto/originario?atto.dataP ubblicazioneGazzetta=2010-05-22\&atto.codiceRedazionale=009R0801 (última consulta 23 Febrero 2016).

Harshberger, J.W. (1895). Some new ideas. Philadelphia Evening Telegram, 5 dic, 1895.

Haudricourt, A.G.; Hédin, L. (1943). L'homme et les plantes cultivées. Paris: Geographie humaine, Gallimard.

Hersch, P. (1987). Investigación participativa. Una Revisión Bibliográfica. Revista de la Universidad Autónoma Estado de Morelos 16: 18-22.

Heywood, V.H. (2014). La transformación de la Etnobotánica. En: Herrera, F.; Tarifa, F.; Henández-Bermejo, E. (Eds.). ICEB 2014 VI Congreso Internacional de Etnobotánica. Etnobotánica, la riqueza de un legado. Resumenes. Pp. 15-20. Córdoba: IMGEMA, Real Jardín Botánico de Córdoba (España).

Homes, B. (1996). Le pietre dell'alta Limentra orientale. Porretta Terme: Gruppo di Studi Alta Valle del Reno.

Homes, B. (1999). Gli insediamenti della bassa Limentra orientale fra continuità e diversità. Porretta Terme: Gruppo di Studi Alta Valle del Reno.

Homes, B. (2006). Gli insediamenti ed edifici delle limentre. Porretta Terme: Gruppo di Studi Alta Valle del Reno.

Homes, B. (2011). La rocchetta Mattei di Riola: guida alla architettura e alla decorazione. Porretta Terme: Gruppo di Studi Alta Valle del Reno.

Homes, B. (2014). Cinquantadue vedute di Monte Vigese, n. 51. Porretta Terme: Nuèter-ricerche

Homes, B. (s.d.). Gli insediamenti dell'Alta Valle del Reno. Porretta Terme: Gruppo di Studi Alta Valle del Reno.

Homes, B.; Balletti, P. (1997). Acquerelli in fiore: fiori spontanei dell'Appennino tosco-emiliano. Porretta Terme: Gruppo di Studi Alta Valle del Reno.

Homes, B.; Digiuni, P.; Homes A.; Zagnoni, R.(2005). Porretta Terme forma urbis. Porretta Terme: Gruppo di Studi Alta Valle del Reno.

Homes, B.; Gioffredi, R.; Zagnoni, R.; Guccini, F. (2002). Tre viaggi lungo la Limentra occidentale. Porretta Terme: Gruppo di Studi Alta Valle del Reno.

Homes, B.; Michelini, S.; Martelli, A.; Sangiorgi, F. (2008). Le stalle-fienili ed altri edifici agricoli. Porretta Terme: Gruppo di Studi Alta Valle del Reno.

Homes, B.; Zagnoni R. (2008). Dodici disegni di Bill Homes per la Rocchetta Mattei di Riola: per celebrare il secondo centenario della nascita del Conte Cesare Mattei, 1809-2009. Porretta Terme: Gruppo di Studi Alta Valle del Reno. 
Etnobotánica en el Alto Valle del Reno (Toscana y Emilia-Romaña, Italia)

Hug, C. (1993). La Sambuca Pistoiese. Una comunità dell'Appennino al confine tra Bologna e Pistoia (1291-1991). Pistoia y Porretta Terme: Società Pistoiese di Storia Patria y Nuèter.

Hurrel, J.A. (1987). Revista Española de Antropología Americana, n. XVII. Madrid: Universidad Complutense de Madrid.

ICGM (2003). Mangia la foglia: la cucina nel bosco. Grizzana Morandi: Parco Provinciale di Montovolo.

Idolo, M.; Motti, R.; Mazzoleni, S. (2010). Ethnobotanical and phytochemical knowledge in a long-history protected area, the Abruzzo, Lazio and Molise National Park (Italian Apennines). Journal of Ethnopharmacology 127: 379-395.

ISE (2008). International Society of Ethnobiology (2006) - International Society of Ethnobiology Code of Ethics (with 2008 additions). (http://ethnobiology.net/code-of-ethics/ (última consulta: 11 febrero 2016).

Kawulich, B. (2005). La observación participante como método de recolección de datos. Forum: qualitative social research 6(2): 1-32.

Latouche, S. (2008). Breve trattato sulla decrescita serena. Torino: Bollati Boringhieri editore.

Lentini, F.; Venza, F. (2007). Wild food plants of popular use in Sicily. Journal of Ethnobiology and Ethnomedicine 3: 15.

Leonti, M.; Casu, L.; Sanna, F.; Bonsignore, L. (2009). A comparison of medicinal plant use in Sardinia and Sicily. De Materia Medica revisited Journal of Ethnopharmacology 121: 255-267.

Lepschy, A. L. (2001). The Italian Language 2 ed. Londres: Today.

Levi-Strauss, C. (1955). Tristes Trópicos. Barcelona: Ed. Paidós.

Línea Spezia-Rimini (2015). La Spezia Rimini Line. https://en.wikipedia.org/wiki/La_Spezia-Rimini_Line (última consulta: 14 diciembre 2015).

Lorenzini, D. (1910). Guida dei Bagni della Porretta e dintorni con cenni storici, biografici, archeologici e artistici, geologia paleontologia mineralogia, flora e fauna del mandamento (II edizione). Bolonia: Nicola Zanichelli.

Łuczaj L.; ZovkoKončić M.; Miličević T., Dolina K., Pandža M. (2013). Wild vegetable mixes sold in the markets of Dalmatia (southern Croatia). Journal of Ethnobiology and Ethnomedicine 9: 2. DOI: 10.1186/1746-4269-9-2.

Lustrola (2015). Lustrola. http://www.lustrola.it/docs/dizionario_lustrolese.pdf (última consulta: 13 Octubre 2015).

Maffi, L. (Ed.). (2001). On biocultural diversity: Linking language, knowledge and the environment. Washington DC: Smithsonian Books.

Malagoli, G. (1930). Fonologia del dialetto di Lizzano in Belvedere (Appennino bolognese). L'Italia dialettale 6: 125-196.

Malinowski, B. (1975). Los Argonautas del Pacífico Occidental. Barcelona: Península.

Martin, G.J. (1995). Ethnobotany: A Conservation Manual. London: Chapman \& Hall.

Mattei, A. (s.d.). Tradizioni e vecchie usanze di Monachino e Torri. (Sin localidad ni editorial). 
Mattioli, S. (1999). Macrofauna. Piano Territoriale del Parco Regionale dei Laghi di Suviana e Brasimone. Quadro conoscitivo. Camugnano: Parco Regionale dei Laghi di Suviana e Brasimone.

MATTM (1994). Ministero dell'Ambiente e della Tutela del Territorio e del Mare, Italia, Legge 14 febbraio 1994, n. 124. Ratifica ed esecuzione della convenzione sulla biodiversità, con annessi (Rio de Janeiro, 5 giugno 1992) (G.U. 23 febbraio 1994, S.O.): http://www.minambiente.it/normative/l-14-febbraio-1994n-124-ratifica-ed-esecuzione-della-convenzione-sulla-biodiversita-con (última consulta 12 diciembre, 2015).

Montemagni, S. (1984). La comunità linguistica di Treppio. Pistoia: Farestoria 2.

Motti, R.; Antignai, V.; Idolo, M. (2009). Traditional plant use in the Phlegraean Fields Regional Park (Campania, Southern Italy). Human Ecology 37: 775-782.

MPAAF (2012). Ministero delle Politiche Agricole Alimentari e Forestali. Decreto del Ministro n. 17070 del 19 novembre 2012. Osservatorio Nazionale del Paesaggio Rurale: https:/www.politicheagricole.it/flex/cm/pages/ServeBLOB.php/L/IT/IDPagina/583 2 (última consulta: 11 diciembre 2015)

Mucci, D. (s.d.). Quando i necci erano il pane. Pistoia: Provincia di Pistoia.

NAPTT (2005). Norme di Attuazione. Piano Territorale del Parco. EmiliaRomagna: Parco Regionale dei Laghi di Suviana e Brasimone. Emilia-Romagna: Parchi e Riserve dell'Emilia-Romagna.

Nebel, S.; Heinrich, M. (2009). Ta Chòrta: a comparative ethnobotanicallinguistic study of wild food plants in Graecanic area in Calabria, Southern Italy. Economic Botany 63: 78-92.

Nebel, S.; Pieroni, A.; Heinrich, M. (2006). Ta Chòrta: Wild edible greens used in the Graecanic area in Calabria, Southern Italy. Appetite 47: 333-342.

Nerattini, R. (1980). La nostra valle 35-40 anni fa. Ricostruzione dell'ambiente. (Sin localidad ni editorial).

Nerattini, R. (s.d.) Eravamo in tanti e tanto poveri. Aspetti di lavoro nell'Appennino Tosco-Emiliano agli inizi del 900. (Sin localidad ni editorial).

Nerattini, R.; Boldri, G. (2003). I Giorni dell'ira e della fede. Il Mondo di Lorenzo Magnanelli. Castel di Casio: Centro Studi Editoriali Castel di Casio.

Nerattini, R.; Borri, A.; Magni, B. (2006). Novecento Badese. Storie di donne di uomini. Badi: Proloco di Badi. Silla di Gaggio Montano: Tipolito Sillagrafica.

Nerattini, R.; Borri, A.; Magni, B.; Lorenzelli, A. (2009) Verdi riflessi blu, Badi e il suo territorio in un secolo di cartoline (1900-2000). Badi y Silla di Gaggio Montano: Proloco di Badi y Tipolito Sillagrafica.

Nerattini, R.; Ferrari, P.; Lorenzelli, S.; Chierci, S. (2010). Mostra dall'Appennino Tosco-Emiliano alla Riviera di Ponente: cestai e floricoltura nei primi del 900, storia e tradizone di una produzione artigianale. Sanremo: Istituto Internazionale di Studi Liguri, Sezione Sanremo.

Nicolas, J.P. (s.d.). Ethnobotanique appliquée. Quelques éléments de méthodes de terrain. Intervention de 1'Association "Jardins du Monde" au Laboratoire de botanique. Lille: Université de Lille. 
Etnobotánica en el Alto Valle del Reno (Toscana y Emilia-Romaña, Italia)

Nicoletti, M.; Fico, G.; Cingolani, M.L.; Savo, V.; Viegi, L.; Guarrera, P.M. (2013). En: Caneva,G.; Pieroni, A.; Guarrera P.M. (Eds). Etnobotanica. Conservazione di un patrimonio culturale come risorsa per uno sviluppo sotenibile. Pp. 43-68. Bari: Edipuglia.

Obón, C.; Rivera, D.; Alcaraz, F. (2012). Wild and cultivated plants used as food and Medicine by the Mòcheni Ethnic Minority in the Alps. Acta Horticulturae 955: 113-118.

Ogoye-Ndegwa, C.; Aagaard-Hansen, J. (2003). Traditional gathering of wild vegetable among the Luo of western Kenya - A nutritional anthropology project. Ecology and Food and Nutrition, 42: 69-89.

OMS (2013). Estrategia de la OMS sobre medicina tradicional 2014-2023. http://apps.who.int/iris/bitstream/10665/95008/1/9789243506098_spa.pdf (última consulta 10/12/2015).

Pardo-de-Santayana, M. (2003). Las plantas en la cultura tradicional de la antigua merindad de Campoo. Tesis Doctoral. Madrid: Universidad Autónoma de Madrid.

Pardo-de-Santayana, M. (2008). Estudios etnobotánicos en Campoo (Cantabria). Madrid: Ed. CSIC.

Pardo-de-Santayana, M.; Pieroni, A.; Puri, R.K. (2010). Ethnobotany in the new Europe. Environmental. People, Health and Wild Plant Resources. Nueva York: Berghah Books.

Pavari, A. (1916). Studio preliminare sulla coltura di specie forestali esotiche in Italia. Prima parte (generale). Annali del Regio Istituto Superiore Nazionale Forestale 1 (1913-15): 1-221.

Pellegrini, G.B. (1992). Il "Cisalpino” e 1'italo-romanzo. Archivio Glottologico Italiano 77: 272-296.

Pieroni, A. (1999). Gathered wild food plants in the Upper Valley of the Serchio River (Garfagnana), Central Italy. Economic Botany 53 (3): 327-341.

Pieroni, A. (2000). Medicinal plants and food medicines in the folk traditions of the upper Lucca Province, Italy. Journal of Ethnopharmacology 70: 235-273.

Pieroni, A.; Caneva, G.; Guarrera P.M.; Nicoletti, M. (2013). Introduzione. En: Caneva,G.; Pieroni, A.; Guarrera P.M. (Eds). Etnobotanica. Conservazione di un patrimonio culturale come risorsa per uno svilluppo sotenibile. Pp. 43-68. Bari: Edipuglia.

Pieroni, A.; Giusti, M.E. (2002). Ritual botanicals against the evil-eye in Tuscany Italy. Economic Botany 56 (2): 201-203.

Pieroni, A.; Giusti, M.E. (2009). Alpine ethnobotany in Italy: traditional knowledge of gastronomic and medicinal plants among the Occitans of the upper Varaita valley, Piedmont. Journal of Ethnobiology and Ethnomedicine 5: 32. DOI: 10.1186/1746-4269-5-32.

Pieroni, A.; Nebel, S.; Franco Santoro, R.; Heinrich, M. (2005). Food for two seasons: Culinary uses of non-cultivated local vegetables and mushrooms in a south Italian village. International Journal of Food Sciences and Nutrition 56 (4): 245272 . 
Pieroni, A.; Nebel, S.; Quave, C.; Münz, H.; Heinrich, M. (2002). Ethnopharmacology of liakra: traditional weedy vegetables of the Arbereshe of the Vulture area in southern Italy. Journal of Ethnopharmacology 81: 165-185.

Pieroni, A.; Quave, C.L. (2006). Functional food or food medecines? On the consumption of wild plants among Albanians and southern Italians in Lucania. En: Pieroni A., Price, LL. (Eds.) Eating and Healing: traditional food as medicine. Pp. 101-129. Nueva York: Haworth Press.

Pieroni, A.; Quave, C.L.; Santoro, R.F. (2004). Folk pharmaceutical knowledge in the territory of the Dolomiti Lucane, inland southern Italy. Journal of Ethnopharmacology 95: 373-384.

Pignatti, S. (1982). Flora d'Italia 3 vols. Bolonia: Edizioni Edagricole.

Pignatti, S. (1994). Ecologia del paesaggio. Turín: UTET.

Pignatti, S.; Bianco, P.M.; Fanelli, G.; Paglia, S.; Pietrosanti, S.; Tescarollo, P. (2001). Le piante come indicatori ambientali, Manuale tecnico-scientifico. Valle de Aosta: Centro Tematico Nazionale-Conservazione della Natura c/o ARPA Valle d'Aosta.

Pinzauti, S. (s.d.) Relazione forestale. Proposta di Piano Territoriale del Parco. Quadro conoscitivo. Camugnano: Parco Regionale dei laghi di Suviana e Brasimone.

Poli, L. (c. 2014). Glossario di Vizzero. (Manuscrito fotocopiado distribuido por el autor en Vizzero).

Ponzetta, M.P.; Cervasio, F.; Argenti, C.; Genghini, M.; Di Leo, V.; Crocetti, C.; Messeri, A. (2009). Conservazione della biodiversità e gestione faunistica nei sistemi agro-silvo-pastorali appenninici: il caso del Parco Regionale dei laghi di Suviana e Brasimone. 2 parte. Relazione finale (2 anno) CIRSEMAF, ISPRA (Informe consultado en forma de borrador).

Ponzetta, M.P.; Genghini, M.; Cervasio, F.; Di Leo, V.; Nardelli, R.; Di Prinzio M. (2007). Valutazione e controllo degli effetti della diffusione della felce (Pteridium aquilinum) sulla biodiversità e i sistemi agro-silvo-pastorali nel Parco Regionale dei Laghi di Suviana e Brasimone. Relazione finale Progetto di Ricerca. Florencia y Bolonia: Centro Interuniversitario di Ricerca sulla Selvaggina e sui Miglioramenti Ambientali a fini Faunistici, e Istituto Nazionale per la Fauna Selvatica.

Porciatti, P. (1959). Saggi di rilevamenti floristici su un pascolo del Pian della Rasa. Tesi di laurea. Facoltà di Agraria e Forestale, Firenze. Florencia: Università di Firenze.

Portéres, R. (1970). Ethnobotanique génerale. Paris: Laboratoire d'Ethnobotanique et Etnozoologie, Muséum National d'Histoire Naturelle.

PTP (2008). Quadro Conoscitivo Relazione Generale art. 26 LR 6/2005. Camugnano y Bolonia: Consorzio Parco Regionale dei Laghi di Suviana e Brasimone y Provincia di Bologna y Parchi e Riserve dell'Emilia-Romagna.

Pucci, A. (2007). La casa e le tradizioni della gente di Torri (Sambuca Pistoiese). Sambuca Pistoiese: Associazione per lo sviluppo turistico di Torri y Comune di Sambuca Pistoiese. 
Etnobotánica en el Alto Valle del Reno (Toscana y Emilia-Romaña, Italia)

Raimondo, F.M.; Lentini, F. (1990). Indagini etnobotaniche in Sicilia. I, Le piante della flora locale nella tradizione popolare delle Madonie (Palermo). Il naturalista siciliano 3-4: 77-99.

Rauty, N. (1993). Dizionario toponomastico del comune di Sambuca pistoiese. Pistoia: Società Pistoiese di Storia Patria.

RERAL (1977). Regione Emilia-Romagna Assemblea Legislativa. Legge Regionale 24 gennaio 1977, n.2, Provvedimenti per la salvaguardia della Flora regionale. Istituzione di un fonde regionale per la conservazione della natura. Disciplina della raccolta dei prodotti del sottobosco: http://demetra.regione.emiliaromagna.it/al/monitor.php?urn=er:assemblealegislativa :legge:1977;2) (última consulta: 23 febrero 2016).

Reyes-García, V.; Huanca, T.; Vadez, V.; Leonard, W.R.; Wilkie, D. (2006). Cultural, practical, and economic value of wild plants: a quantitative study in the bolivian Amazon. Economic Botany 60(1): 62-74.

Rivera, D.; Obón de Castro, C. (1998). Guía de teoría y prácticas de Etnobotánica. Murcia: DM.

Rivera, D.; Obón, C.; Alcaraz, F. (2012). Wild and cultivated plants used as food and medicine by the Cimbrian Ethnic Minority in the Alps. Acta Horticulturae 955: 31-39.

Robinns, W.; Harrington, J.P.; Freire-Marreco, B. (1916). Ethnobotany of the Twa Indians. Smithsonian Istitution Bureau of American Ethnology. Bulletin 55. Washington D.C.: Government Printing Office.

Roda, R. (1989). Il castagno. Tradizioni e trasformazioni. Ferrara y Pádua: Centro Etnografico Ferrarese e Interbook.

Ronchetti, G. (s.d.). La valle del Reno, un fiume, un territorio (depliant). Vergato: Comunità Montana Alta e Media Valle del Reno, Tipart Industrie y Grafiche Vignola.

Rossato, S.V.C.; Leitao-Filho, H.; Begossi, A. (1999). Ethnobotany of Caiçaras of the Atlantic forest coast (Brazil). Economic Botany 53: 387-395.

Sabattini, G. (1975). I mangiari di una volta. Nuèter noialtri-Storia, tradizione e ambiente dell'alta valle del Reno bolognese e pistoiese 1: 37-38.

Sambuca Pistoiese (2015) Sambuca Pistoiese. http://www.comune.sambuca.pt.it/ (última consulta: 14 diciembre 2015).

Sansanelli, S.; Tassoni, A. (2014). Wild food plants traditionally consumed in the area of Bologna (Emilia-Romagna region, Italy). Journal of Ethnobiology and Ethnomedicine 10: 69. DOI: 10.1186/1746-4269-10-69.

Savo, V.; Caneva, G.; Guarrera, P.M.; David, R. (2011). Folk phytoterapy of the Amalfi Coast (Campania, Southern Italy). Journal of Ethnopharmacology135: 376392.

Scavarelli, D. (1999). Indagini sugli invertebrati del Parco regionale dei Laghi di Suviana e Brasimone. Piano Territoriale del Parco Regionale dei Laghi di Suviana e Brasimone. Quadro conoscitivo. Camugnano: Parco Regionale dei Laghi di Suviana e Brasimone.

Signorini A. (2003). Le parlate dell'Alto Reno: Lingua o dialetto?: www.gfbv.it/3dossier/eu-min/altoreno.html (última consulta: 16 enero 2016) 
Signorini, M. A.; Lombardini, C.; Bruschi, P.; Vivona, L. (2008). Conoscenze etnobotaniche e saperi tradizionali nel territorio di San Miniato (Pisa). Atti Soc. Tosc. Sci. Nat., Mem. Ser. B., 114: 65-83.

Signorini, M. A.; Piredda, M.; Bruschi, P. (2009). Plants and traditional knowledge: An ethnobotanical investigation on Monte Ortobene (Nuoro, Sardinia). Journal of Ethnobiology and Ethnomedicine 5: 6. DOI: 10.1186/1746-4269-5-6.

Signorini, M.A.; Bruschi, P.; Camangi, F.; Guarrera P.M.; Pieroni, A.; Savo, V. (2013). Metodi della ricerca etnobotanica. En: Caneva,G.; Pieroni, A.; Guarrera P.M. (Eds). Etnobotanica. Conservazione di un patrimonio culturale come risorsa per uno svilluppo sotenibile. Pp. 43-68. Bari: Edipuglia.

Sirgi, G. (1991). Il boscaiolo.Il lavoro dell'uomo e la distruzione della foresta. Castel di Casio: Centro Studi Editoriali Castel di Casio.

Sirgi, G. (1998). La difesa del suolo nella montagna bolognese (quando si faceva). Porretta Terme: Gruppo di studi alta valle del reno - Nuèter.

Sirgi, G. (2004). L'alta montagna bolognese: bella e abbandonata. Vergato: Comunità dell'alta e media valle del Reno. Porretta Terme: Gruppo di studi alta valle del reno - Nuèter. Cinti.

Sirgi, G. (2007). La montagna che cresce. Porretta Terme: Tipografia Pisi e

Sirotti, M. (1999). Indagine sui principali aspetti botanici del Parco Regionale dei laghi di Suviana e Brasimone. Quadro conoscitivo. Camugnano: Parco Regionale dei Laghi di Suviana e Brasimone.

Sirotti, M. (2004). Censimento degli habitat di interesse comunitario nel SIC IT400020 "Laghi di Suviana e Brasimone" e nel Parco dei Laghi di Suviana e Brasimone. Camugnano: Parco Regionale dei Laghi di Suviana e Brasimone.

Sirotti, M. (2005). Censimento floristico della flora vascolare del Parco regionale dei laghi di Suviana e Brasimone. Relazione finale. Camugnano: Parco Regionale dei Laghi di Suviana e Brasimone.

Spada, C. (2010). La costruzione sociale della norma l'esperienza della valle degli elfi e la proposta deli ecovillagi. Tesi di Dottorato internazionale di ricerca. Milán: Università di Milano.

Speranza, M.; Fariselli, R.; Sirotti, M. (2001). Il parco dei Laghi di Suviana e Brasimone (Bologna) alla luce di alcuni ritrovamenti floristici. Informatore Botanico Italiano 33(1): 141-143.

Speranza, M.; Ubaldi, D.; Sirotti, M.; Pullega S. (2003). Carta della vegetazione del Parco dei Laghi di Suviana e Brasimone. Scala1:25000. Emilia-Romagna: Regione Emilia-Romagna.

Susmel L. (1964). Piano colturale della Foresta Demaniale di Collina (Pistoia). Padua: Centro Econ. Montana delle Venezie - Cedam.

Tammaro, F. (1976). Piante officinali e pratica della fitoterapia nel territorio del Gran Sasso d'Italia. Rivista Ital. Essenze, Profumi, Piante off., Aromi, Saponi, Cosmet., Aerosolo 58(11): 593-605.

Tardío, J.; Pardo-de-Santayana, M. (2008). Cultural Importance Indices: A Comparative Analysis Based on the Useful Wild Plants of Southen Cantabria (Northern Spain). Economic Botany 62(1): 24-39. 
Etnobotánica en el Alto Valle del Reno (Toscana y Emilia-Romaña, Italia)

Tardío, J.; Pascual, H.; Morales, R. (2005). Wild food Plants Traditionally Used in the Province of Madrid, Central Spain. Economic Botany 59: 122-136.

Thornthwaite, C.W. (1948). An approach toward a rational classification of climate. Geographical Review 38: 55-94.

Thornthwaite, C.W., Mather J.R. (1957). Instructions and tables for computing potential evapotranspiration and the water balance. Publications in Climatology 10(3): 1-311.

Tongco, M.D.C. (2007). Purposive Sampling as a tool for informant selection. Ethnobotany Research \& Applications 5: 147-158.

TPL (2015). The Plant list. http://www.theplantlist.org/ (última consulta: 26 diciembre 2015).

Tropicos (2015). Trópicos. http://www.tropicos.org/ (última consulta: 26 diciembre 2015).

Uncini-Manganelli, R.E.; Tomei, P.E.; (1998). Indagini etno-farmacobotaniche nel Pistoiese: l'alta val di Lima. Atti e Memorie dell'Accademia Toscana di Scienze e Lettere La Colombaria 63: 135-158.

UNESCO (2007). Convenzione UNESCO per la Salvaguardia del patrimonio culturale immateriale, ratificata dall' Italia il 27 settembre 2007 con Legge n. 167: http://www.unesco.it/ filesPATRIMONIOimmateriale/convenzionePatrImm.pdf (última consulta: 11 diciembre 2015).

Ungarelli, G. (1921). Le piante aromatiche e medicinali nei nomi, nell'uso e nella tradizione popolare bolognese. Bolonia: Tipografia L. Parma.

USDA (2015). USDA, ARS, National Genetic Resources Program. Germplasm Resources Information Network-(GRIN) (On-line database). National Germplasm Resources Laboratory,Beltsville,Maryland: https://npgsweb.arsgrin.gov/gringlobal/taxon/taxonomysearch.aspx?language=en,(ultima consulta: octubre 2015)

Vallès, J. (1996). Los nombes populares de las plantas: método y objetivo en Etnobotánica. Monografias Jardin Botánico Córdoba 3: 7-14.

Vallès, J.; Agelet, A.; Bonet, M.A.; Garnatje, T.; Muntané, J.; Parada, M.; Raja, D.; Rigat, M.; Selga, A. (2005). Algunes questions entorn de la fitonimia i els aspectes linguistics de 1'Etnobotànica. Estudis de llengua i literatura catalanes/LI. Miscel.lania Joan Veny 7: 273-293.

Venturi, E. (2006). Flora vascolare delle Valli della Limentra Orientale e della Limentrella (Province di Pistoia e Prato). Parlatorea 8: 11-46.

Vezzali, M.; Martelli, B. (2006). C'era una volta la canapa, Nuèter noialtriStoria, tradizione e ambiente dell'alta valle del Reno bolognese e pistoiese 2: 37-38.

Vitalini, S.; Iriti, M.; Puricelli, C.; Ciuchi, D.; Segale, A.; Fico, G. (2013). Traditional knowledge on medicinal and food plants used in Val San Giacomo (Sondrio, Italy) - An alpine ethnobotanical study. Journal of Ethnopharmacology 145: 517-529.

VPSRU (2013). Valutazione ambientale strategica e valutazione di incidenza. Sambuca Pistoiese: Comune di Sambuca Pistoiese, Uffici Area Urbanistica, Edilizia Privata e Residenziale Pubblica. 
María Teresa Egea Molines

Wikipedia (2015a). Castiglione dei Pepoli. https://it.wikipedia.org/wiki/Castiglione_dei_Pepoli (última consulta: 14 diciembre 2015)

Wikipedia (2015b). Camugnano. https://it.wikipedia.org/wiki/Camugnano (última consulta: 14 diciembre 2015).

Wikipedia (2015c). Castel di Casio. https://it.wikipedia.org/wiki/Castel_di_Casio. (última consulta: 14 diciembre 2015)

Wikipedia (2015d). Granaglione. https://it.wikipedia.org/wiki/Granaglione (última consulta: 14 diciembre 2015).

Wikipedia (2015e).

Porretta

Terme.

https://it.wikipedia.org/wiki/Porretta_Terme (última consulta: 14 diciembre 2015).

Wikipedia (2015f) Sambuca Pistoiese. https://it.wikipedia.org/wiki/Sambuca_Pistoiese (última consulta: 14 diciembre 2015).

Zagnoni, R. (1977). La Madonna del Faggio: una comunità e il suo santuario dal 700 al 800. n.6. Porretta Terme: Nuèter.

Zagnoni, R. (1981). L'altare di Sant'Antonio abate a Porretta. Porretta Terme: Nuèter.

Zagnoni, R. (1982). L'Altar maggiore della Chiesa parrocchiale di Porretta. n.15. Porretta Terme: Nuèter.

Zagnoni, R. (1986). Le Terme di Porretta all'inizio dell 'Ottocento. Porretta Terme: Nuèter.

Zagnoni, R. (1990). La Contea di Porretta al tramonto (1789-1797). Porretta Terme: Nuèter.

Zagnoni, R. (1991). Accademie porrettane fra Cinquecento e Settecento. Il Carrobbio Rivista di studi bolognesi 17: 325-342.

Zagnoni, R. (1992). Monasteri pistoiesi e montagna bolognese (secoli 11-13). En: Sambuca Pistoiese. Una comunità dell'Appennino al confine tra Pistoia e Bologna. Pp. 66-92. Porretta Terme: Gruppi di studi Alta Valle del Reno.

Zagnoni, R. (1993). Sant'Ilario del Gaggio o di Badi: una chiesa parrochiale, un ospitale medievale ed un oratorio fra Bolognese e Pistoiese. Nuèter-ricerche 1: 338368 .

Zagnoni, R. (1997a). I signori di Stagno: una signoria per i due versanti dell'Appennino nei secoli. 10-12. Porretta Terme: Nuèter.

Zagnoni, R. (1997b). La coltivazione del castagno nella montagna fra Bologna e Pistoia nei secoli XI-XIII. En: Villaggi, boschi e campi dell'Appennino dal Medioevo all'età moderna: atti delle giornate di studio. Pp.41-57. Pistoia: Società pistoiese di storia e patria.

Zagnoni, R. (1998). L'ospitalità gratuita lungo le strade medievali dell'Appennino bolognese e pistoiese. Porretta Terme y Pistoia: Gruppo di Studi Alta Valle del Reno y Società Pistoiese di Storia Patria.

Zagnoni, R. (2001a). Il confine appenninico: percezione e realtà dall'età antica ad oggi: atti della Giornata di studio 9 settembre 2000. Porretta Terme y Pistoia: Gruppo di Studi Alta Valle del Reno y Società Pistoiese di Storia Patria. 
Etnobotánica en el Alto Valle del Reno (Toscana y Emilia-Romaña, Italia)

Zagnoni, R. (2001b). Un confine lungo duemila anni: sintesi delle vicende del confine appenninico. Porretta Terme y Pistoia: Gruppo di Studi Alta Valle del Reno y Società Pistoiese di Storia Patria.

Zagnoni, R. (2001c) La Ferrovia Transappennina, il collegamento attraverso la montagna bolognese e pistoiese (1842-1934). Porretta Terme: Gruppo di Studi Alta Valle del Reno.

Zagnoni, R. (2003). Montovolo, montagna sacra: guida alle chiese di Santa Maria e Santa Caterina. Porretta Terme: Gruppo di Studi Alta Valle del Reno y Nuèter.

Zagnoni, R. (2004). Il Medioevo nella montagna tosco-bolognese. Uomini e strutture in una terra di confine. Porretta Terme: Gruppo di Studi Alta Valle del Reno.

Zagnoni, R. (2005). Cultura e letteratura d'Appennino: atti delle Giornate di studio, Capugnano, 13 settembre 2003. Porretta Terme y Pistoia: Gruppo di Studi Alta Valle del Reno y Società Pistoiese di Storia Patria.

Zagnoni, R. (2006). L 'abbazia di Santa Lucia di Roffeno nel Medioevo (secoli 11014): nuovi documenti. Porretta Terme y Pistoia: Gruppo di Studi Alta Valle del Reno y Società Pistoiese di Storia Patria.

Zagnoni, R. (2008a). Homo appenninicus: donne e uomini delle montagne: atti delle giornate di studio: Capugnano, 8 settembre 2007. Porretta Terme y Pistoia: Gruppo di Studi Alta Valle del Reno y Società Pistoiese di Storia Patria.

Zagnoni, R. (2008b). Sant'Ilario di Badi. La storia della chiesa ed il restauro degli affreschi cinquecenteschi. Porretta Terme: Gruppo di Studi Alta Valle del Reno.

Zagnoni, R. (2009). La città raggiunge la montagna: sintesi storica delle vie di comunicazione. Città e montagna: atti della giornata di studio (12 settembre 2009). Porretta Terme y Pistoia: Gruppo di Studi Alta Valle del Reno y Società Pistoiese di Storia Patria.

Zagnoni, R. (2013). Affreschi nella montagna bolognese. Porretta Terme y Pistoia: Gruppo di Studi Alta Valle del Reno y Società Pistoiese di Storia Patria.

Zagnoni, R.; Borghi, G.P. (2010). Pan di legno e vin di nuvoli: 1'alimentazione della montagna-bolognese. Atti delle giornate di studio (Capugnano, 13 settembre 2008). Porretta Terme: Gruppo di Studi Alta Valle del Reno.

Zagnoni, R.; Borghi, G.P.; Antilopi, A. (1996). La Madonna del Bosco: storia e tradizioni di un santuario fra Calvenzano e Vergato. Porretta Terme: Gruppo di Studi Alta Valle del Reno.

Zanini, P. (1997). Significati del confine. I limiti naturali, storici, mentali. Milán: Bruno Mondadori. 
ANNO 2007

Bracardi M., La Materia e lo Spirito. Mario Ridolfi nel paesaggio umbro

Coppi E., Purines as Transmitter Molecules. Electrophysiological Studies on Purinergic Signalling in Different Cell Systems

Mannini M., Molecular Magnetic Materials on Solid Surfaces

Natali I., The Ur-Portrait. Stephen Hero ed il processo di creazione artistica in A Portrait of the Artist as a Young Man

Petretto L., Imprenditore ed Università nello start-up di impresa. Ruoli e relazioni critiche

ANNO 2008

Bemporad F., Folding and Aggregation Studies in the Acylphosphatase-Like Family

Buono A., Esercito, istituzioni, territorio. Alloggiamenti militari e «case Herme» nello Stato di Milano (secoli XVI e XVII)

Castenasi S., La finanza di progetto tra interesse pubblico e interessi privati

Colica G., Use of Microorganisms in the Removal of Pollutants from the Wastewater

Gabbiani C., Proteins as Possible Targets for Antitumor Metal Complexes: Biophysical Studies of their Interactions

ANNO 2009

Decorosi F., Studio di ceppi batterici per il biorisanamento di suoli contaminati da Cr(VI)

Di Carlo P., I Kalasha del Hindu Kush: ricerche linguistiche e antropologiche

Di Patti F., Finite-Size Effects in Stochastic Models of Population Dynamics: Applications to Biomedicine and Biology

Inzitari M., Determinants of Mobility Disability in Older Adults: Evidence from Population-Based Epidemiologic Studies

Macrì F., Verso un nuovo diritto penale sessuale. Diritto vivente, diritto comparato e prospettive di riforma della disciplina dei reati sessuali in Italia

Pace R., Identità e diritti delle donne. Per una cittadinanza di genere nella formazione

Vignolini S., Sub-Wavelength Probing and Modification of Complex Photonic Structures

ANNO 2010

Fedi M., "Tuo lumine». L'accademia dei Risvegliati e lo spettacolo a Pistoia tra Sei e Settecento

Fondi M., Bioinformatics of genome evolution: from ancestral to modern metabolism. Phylogenomics and comparative genomics to understand microbial evolution

Marino E., An Integrated Nonlinear Wind-Waves Model for Offshore Wind Turbines

Orsi V., Crisi e Rigenerazione nella valle dell'Alto Khabur (Siria). La produzione ceramica nel passaggio dal Bronzo Antico al Bronzo Medio

Polito C., Molecular imaging in Parkinson's disease

Romano R., Smart Skin Envelope. Integrazione architettonica di tecnologie dinamiche e innovative per il risparmio energetico

ANNO 2011

Acciaioli S., Il trompe-1' $x i l$ letterario, ovvero il sorriso ironico nell'opera di Wilhelm Hauff

Bernacchioni C., Sfingolipidi bioattivi e loro ruolo nell'azione biologica di fattori di crescita e citochine

Fabbri N., Bragg spectroscopy of quantum gases: Exploring physics in one dimension

Gordillo Hervás R., La construcción religiosa de la Hélade imperial: El Panhelenion

Mugelli C., Indipendenza e professionalità del giudice in Cina

Pollastri S., Il ruolo di TAF12B e UVR3 nel ciclo circadiano dei vegetali

Salizzoni E., Paesaggi Protetti. Laboratori di sperimentazione per il paesaggio costiero euro-mediterraneo 
ANNO 2012

Evangelisti E., Structural and functional aspects of membranes: the involvement of lipid rafts in Alzheimer's disease pathogenesis. The interplay between protein oligomers and plasma membrane physicochemical features in determining cytotoxicity

Bondì D., Filosofia e storiografia nel dibattito anglo-americano sulla svolta linguistica

Petrucci F., Petri Candidi Decembrii Epistolarum iuvenilium libri octo. A cura di Federico Petrucci

Alberti M., La 'scoperta' dei disoccupati. Alle origini dell'indagine statistica sulla disoccupazione nell'Italia liberale (1893-1915)

Gualdani R., Using the Patch-Clamp technique to shed light on ion channels structure, function and pharmacology

Adessi A., Hydrogen production using Purple Non-Sulfur Bacteria (PNSB) cultivated under natural or artificial light conditions with synthetic or fermentation derived substrates

Ramalli A., Development of novel ultrasound techniques for imaging and elastography. From simulation to real-time implementation

ANNO 2013

Lunghi C., Early cross-modal interactions and adult human visual cortical plasticity revealed by binocular rivalry

Brancasi I., Architettura e illuminismo: filosofia e progetti di città nel tardo Settecento francese

Cucinotta E., Produzione poetica e storia nella prassi e nella teoria greca di età classica

Pellegrini L., Circostanze del reato: trasformazioni in atto e prospettive di riforma

Locatelli M., Mid infrared digital holography and terahertz imaging

Muniz Miranda F., Modelling of spectroscipic and structural properties using molecular dynamics

Bacci M., Dinamica molecolare e modelli al continuo per il trasporto di molecole proteiche - Coarsegrained molecular dynamics and continuum models for the transport of protein molecole

Martelli R., Characteristics of raw and cooked fillets in species of actual and potential interest for italian aquaculture: rainbow trout (oncorhynchus mykiss) and meagre (argyrosomus regius)

ANNO 2014

Lana D., A study on cholinergic signal transduction pathways involved in short term and long term memory formation in the rat hippocampus. Molecular and cellular alterations underlying memory impairments in animal models of neurodegeneration

Lopez Garcia A., Los Auditoria de Roma y el Athenaeum de Adriano

Pastorelli G., L'immagine del cane in Franz Kafka

Bussoletti A., L'età berlusconiana. Il centro-destra dai poli alla Casa della Libertà 1994-2001

Malavolti L., Single molecule magnets sublimated on conducting and magnetic substrates

Belingardi C., Comunanze urbane. Autogestione e cura dei luoghi

Guzzo E., Il tempio nel tempio. Il tombeau di Rousseau al Panthéon di Parigi

ANNO 2015

Lombardi N., MEREAFaPS: uno Studio di Farmacovigilanza Attiva e Farmacoepidemiologia in Pronto Soccorso

Baratta L., «A Marvellous and Strange Event». Racconti di nascite mostruose nell'Inghilterra della prima età moderna

Richichi I.A., La teocrazia: crisi e trasformazione di un modello politico nell'Europa del XVIII secolo

Palandri L., I giudici e l'arte. Stati Uniti ed Europa a confronto

Caselli N., Imaging and engineering optical localized modes at the nano scale

Calabrese G., Study and design of topologies and components for high power density dc-dc converters

Porzilli S., Rilevare l'architettura in legno. Protocolli metodologici per la documentazione delle architetture tradizionali lignee: $i$ casi studio dei villaggi careliani in Russia 
ANNO 2016

Martinelli S., Study of intracellular signaling pathways in Chronic Myeloproliferative Neoplasms

Abbado E., "La celeste guida”. L'oratorio musicale a Firenze: 1632-1799

Focarile P., I Mannelli di Firenze. Storia mecenatismo e identità di una famiglia fra cultura mercantile e cultura cortigiana

Nucciotti A., La dimensione normativa dell'imprenditorialità accademica. Tre casi di studio sugli investigatori principali, i loro gruppi di ricerca e i fattori di innesco dell'imprenditorialità accademica

Peruzzi P., La inutilizzabilità della prestazione

Lottini E., Magnetic Nanostructures: a promising approach towards RE-free permanent magnets

Uricchio T., Image Understanding by Socializing the Semantic Gap

ANNO 2017

Valenti R., Cerebral Small Vessel Disease and Cerebral Amyloid Angiopathy: neuroimaging markers, cognitive features and rehabilitative issues

Starnini M., L'uomo tutto intero. Biografia di Carlo Livi, psichiatra dell'Ottocento

Verardi D., La scienza e i segreti della natura a Napoli nel Rinascimento: la magia naturale di Giovan Battista Della Porta

Minicucci G., Il dolo nella bancarotta. Alla ricerca della tipicità soggettiva della fattispecie patrimoniale

Pattelli L., Imaging light transport at the femtosecond scale: a walk on the wild side of diffusion

Egea Molines M.T., Etnobotánica en el Alto Valle del Reno (Toscana y Emilia-Romaña, Italia). Etnobotanica nell'Alta Valle del Reno (Toscana ed Emilia-Romagna, Italia)

Romano I.M., Pressione turistica sul Centro Storico di Firenze - sito UNESCO. Un modello per la valutazione dell'impatto percettivo 
